NATURALIST'S GUIDE TO THE AMERICAS 
From the collection of the

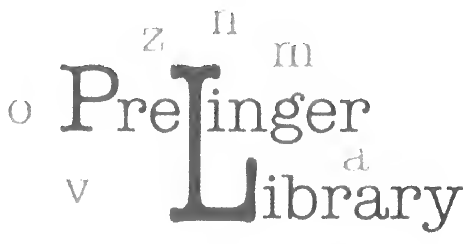
t p)

San Francisco, California 2006 


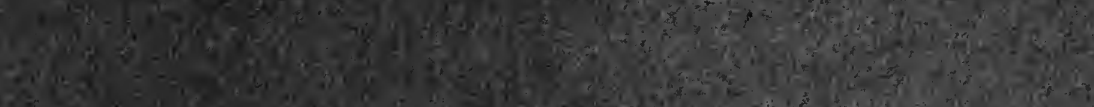

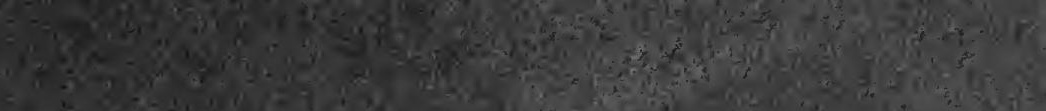

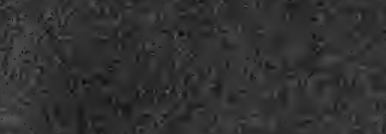

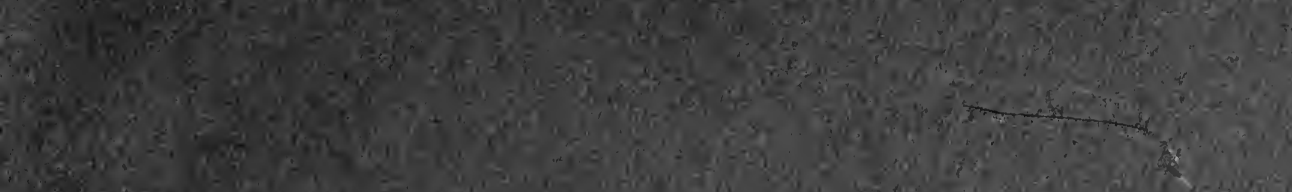
r. 



\section{THE NATURALIST'S GUIDE TO THE AMERICAS}



. 


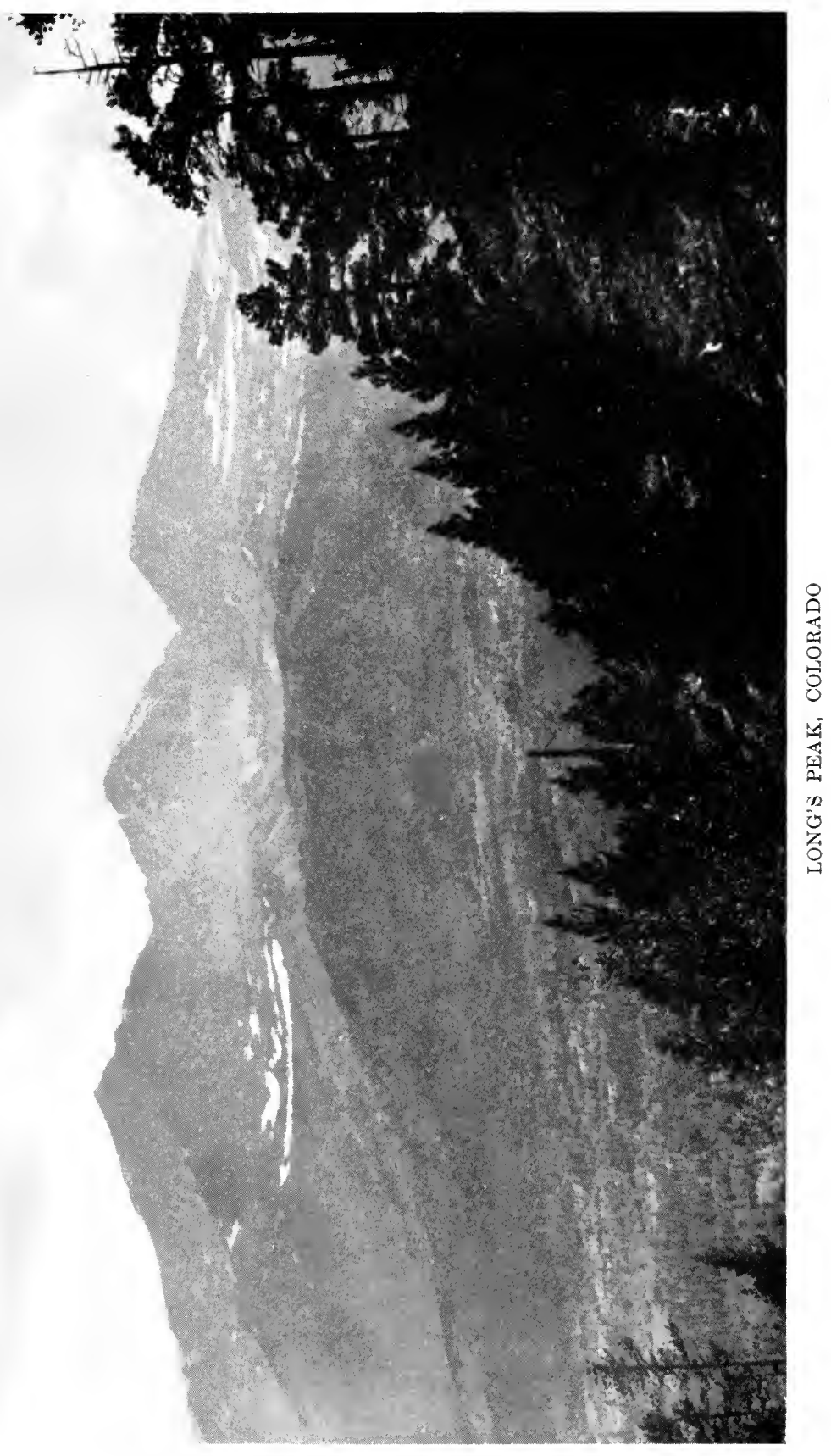




\title{
NATURALIST'S GUIDE TO THE AMERICAS
}

PREPARED BY THE

Committee on the Preservation of Natural Conditions

of The Ecological Society of America

with assistance from numerous organizations and individuals

\author{
ASSEMBLED AND EDITED BY THE CHAIRMAN \\ VICTOR E. SHELFORD \\ University of Illinois and Illinois State \\ Natural History Survey
}

\section{PUBLICATION EDITOR \\ FORREST SHREVE}

Desert Laboratory of the Carnegie Institution

ASSOCIATES AND SPECIAL EDITORS

E. LUCY BRAUN

University of Cincinnati Botany

Botany
Assembled and Edited parts on

National Parks and Monuments of the United States

LEE R. DICE

Museum of Zoology, University of Michigan Mammals

LYNDS JONES

Oberlin College

Birds
CLARENCE F. KORSTIAN

Appalachian Forest Experiment Station Forestry

A ssembled and Edited parts on

National Forests of the United States

ROBERT B. MILLER

Illinois Natural History Survey Forestry

HELEN T. GAIGE

Museum of Zoology, University of Michigan Reptiles

FRANK C. BAKER

Natural History Museum, University of Illinois Zoology

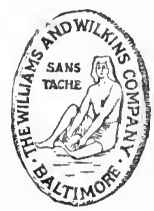

BALTIMORE

THE WILLIAMS \& WILKINS COMPANY

1926 
Copyright 1926

\section{THE WILLIAMS \& WILKINS COMPANY}

Made in United States of America

Published February, 1926

COMPOSED AND PRINTED AT THE WAVERLY PRESS

FOR

The Williams \& Wilkins Company BALTIMORE, MD., U. S. A. 


\section{CHAIRMAN'S PREFACE}

The Ecological Society of America is a national organization of approximately 500 members, the majority of whom are connected with universities, colleges, and other educational or research institutions. The membership includes a larger proportion of persons interested in the preservation of natural conditions for research in pure science and for educational work than any other of our national scientific societies. It publishes the journal Ecology, which is largely devoted to contributions on the original flora and fauna and on their conditions of existence.

In 1917 a committee was charged with the listing of all preserved and preservable areas in North America in which natural conditions persist. The original committee included about twenty-five members, scattered throughout the United States and Canada. The first work was to make the list and when this had made some progress, to urge the reservation of such important areas as demanded immediate attention. The whole problem of securing the preservation of areas, which is one of the objects of the committee work, is very complex. At the outset the committee felt the lack of any definite guides in carrying on the work. The organization which produced the Naturalist's Guide has been a growth; committee membership is limited to those willing to do some kind of work, and includes about seventy-five members. It is a committee on the preservation of nature. Its efforts are directed toward the preservation of natural areas with original flora and fauna (or as nearly so as may obtain) and the maintenance of the natural biotic balance in existing preserves.

During the preparation of the present volume the committee aimed to have two members in each state (and province of Canada). These members (1) supplied information relative to natural areas, etc. in their territory and (2) undertook to interest one local organization concerned with pure science, e.g., a state academy or natural history society, in the preservation of natural areas, commonly indicated by the appointment of a committee. This constitutes a permanent organization charged, among other things, with the keeping of the guide up to date. Other members were engaged in investigating certain topics and writing reports, in interesting pure science organizations to support the work of publication and distribution of information, and in selecting natural areas within existing public forests.

The present volume has been prepared with the aid of various institutions and organizations. The National Research Council granted $\$ 300$ in 1921-1922 which aided greatly in financing the requests for manuscripts 
and also increased the interest in the project. The American Society of Zoologists and the Botanical Society of America contributed $\$ 25.00$ each toward the classification of areas as to degree of modification from the original condition.

The establishment of coöperation with the United States Forest Service greatly reduced our financial and clerical burdens.

Acknowledgments are due the following institutions for encouraging their staff members in editing or contributing to the work: United States Forest Service; United States Biological Survey; University of Michigan Museum; University of Illinois, Department of Zoology and Natural History Survey; University of Cincinnati, Department of Botany; Oberlin College, Department of Ecology; Northwestern University, Department of Botany; New Hampshire College, Department of Zoology; and the Carnegie Institution.

The following rendered important service in reading and correcting manuscripts:

H. A. Gleason, New York Botanic Garden

H. Burrington Baker, University of Pennsylvania

A. H. Wright, Cornell University

C. C. Hamilton, University of Maryland

Vernon Bailey, U. S. Biological Survey

P. L. Ricker, U. S. Bureau of Plant Industry

A. H. Howell, U. S. Biological Survey

W. L. McAtee, U. S. Biological Survey

H. P. Loding, Mobile, Alabama

F. L. Mulford, U. S. Bureau of Plant Industry

W. L. Bray, Syracuse University

W. H. Osgood, Field Museum, Chicago

E. A. Goldman, U. S. Biological Survey

I. H. Blake, University of Maine

Samuel Eddy, James Millikin University

The associate editors did very much to improve the general character of the work, but credit should be especially given Dr. E. Lucy Braun who read the entire manuscript on states and provinces, making important general criticisms. She added greatly to the plant material and verified the scientific names. Dr. L. R. Dice made a similar careful study of the manuscript on states and provinces and contributed materially to the accounts of mammals.

Several questionnaires regarding the nomenclature to be used for the various communities and concerning the mapping of natural regions were sent out. The names of the contributors of these subjects are in connection with the lists of natural regions and maps of them.

The taxonomic nomenclature for plants in the states and provinces is mainly according to Sudworth's Check List for trees, and for other 
plants follows Britton and Brown's Illustrated Flora, Coulter and Nelson's Manual, Piper's Flora of Washington, and other state floras. Common usage has been deemed more important than adherence to supposedly universal codes of nomenclature. The nomenclature on amphibians and reptiles in the states and provinces is after L. Stejneger and T. Barbour: Checklist of North American Amphibians and Reptiles, second edition. Names of mammals are from G. S. Miller, Jr.: List of North American Recent Mammals, 1923, U. S. National Museum Bulletin 128; and those of the birds follow the American Ornithological Union check list. In the case of most animals and plants, scientific name and common name are used together the first time the name of the species appears in a state or provincial account, thereafter in the same article, the common name stands alone. The birds are an exception to this, as scientific names of species breeding or resident north of Mexico are used only in the list at the close of the volume. The common names of birds are fully as well established as the scientific ones.

The absence of data on invertebrate or lower vertebrate life is, of course, striking all through the guide. This is perhaps unavoidable. The principal users will be students of mammals, birds, or general ecology including plants. As a matter of fact, little work has been done on the invertebrates as regards ecology, excepting in aquatic work, which is seldom mentioned by the authors. As regards the Mollusca, F. C. Baker states that little work has been done except in certain states, state lists being usually systematic, and not ecologic. He has added here and there a note on invertebrate life, but little can be done at present to strengthen this side of the zoology.

The data included in the guide had been brought together in the form of manuscripts during seven years of more or less continuous effort, and when turned over to the Publication Editor, the principal task appeared to be rendering of nomenclature and organization somewhat more uniform. The extent and character of the Publication Editor's work is indicated in the second preface.

Champaign, May 7, 1924.

V. E. SHELFORD. 


\section{•}




\section{PUBLICATION EDITOR'S PREFACE}

The manuscript of the Naturalist's Guide first came to my hands in an advanced stage of preparation, after the members of the compiling committee had given several years and much hard work to the planning of its scope, the selection of contributors, and the arrangement of the material secured.

My own part of the production of the Guide has been the small one of reading the manuscript with reference to the coördination of certain features of the treatment, and the unification of typographic style. While many minor changes have been made, it has seemed best to preserve in each chapter the individuality of style and treatment of each of the various authors, chosen for their recognized familiarity with the areas which had been assigned to them. Nothing has been done by way of attempting to recast into a uniform mould all of the chapters which relate to regions of such diverse character, known with such varying degrees of completeness.

The latest work of incorporating rewritten and fresh material, as well as the final revision of the manuscript, has been in the hands of Dr. V. E. Shelford, by whom the project of such a guide was conceived, and to whom the major share of credit will belong for the hoped-for utility of this product of many hands.

Tucson, January, 1925.

Forrest Shreve. 



\section{CONTENTS}

I. Introduction. V. E. Shelford ............................. 1

II. Uses, Values, and Management of Natural Areas............... 5

A. Artistic and Literary Uses............................. $\quad 7$

1. The Value of Natural Areas to Literature and Art. S. L. WhITсомв, University of Kansas..................... 7

2. The Value of Natural Preserves to the Landscape Architect.

S. H. White, University of Illinois................... 8

B. Scientific and Practical Uses and Values................... 10

1. The Value to Silviculture of Reserved Areas of Natural Forest

Types. W. W. Ashe, United States Forest Service......... 10

2. The Value of Aquatic Preserves to Fisheries. A. S. Pearse,

University of Wisconsin......................... 11

3. The Importance to Geography of the Preservation of Natural Areas. S. S. VIsHer, Indiana University............... 12

4. The Importance of Natural Areas to Biology and Agriculture.

V. E. Shelford, University of Illinois................. 13

C. Forces Making for the Destruction or Preservation of Natural Areas.. 15

1. Forest Laws and Regulations and the Preservation of Natural

Conditions. R. B. Miller, Illinois Natural History Survey..

2. The Preservation of Natural Conditions in the National Forests.

C. F. Konstian, United States Forest Service.............

3. Permanent Sample Plots in the National Forests. C. F. KoRstian, U. S. Forest Service.........................

4. National Parks and National Monuments. E. LuCY Bradn, University of Cincinnati........................ 20

5. Museums and Nature. F. C. BAKER, University of Illinois.... 27

6. Game Preserves as Illustrated by Pennsylvania's Experience.

John M. Phillips, Pennsylvania Game Commission.........

7. The Relation of Shrubs and Trees to Wild Birds (Quoted). F.

Sмiтн, University of Illinois........................ 31

8. Grazing in the National Forests. C. F. Konstian, United States Forest Service............................

9. Fires in Relation to the Biota. R. H. WoLcotr, University of Nebraska.................................... 34

10. The Effect of Pollution on Animal Life. F. C. BAKer, University of Illinois................................. 38

D. Interests and Management............................. 42

1. Union of Interests and Management of Natural Areas. V. E.

Shelford, University of Illinois...................... 42

E. Administration of Wild Life.......................... 45

1. The Administration of Wild Life in State and National Parks

(Quoted). Chas. C. Adams, New York State College of Forestry .........................................

F. Duty of Scientific Men................................ 52

1. The Duty of Scientific Men in Conservation. H. S. Graves,

Yale University.................................

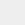

\section{7}

8

0

10

1

2

13

2


III. Original Biota of the Americas North of the Amazon. . ...........

A. Introduction. V. E. Shelford, University of Illinois.............

B. Descriptive List of North American Biota. V. E. Shelford, University of Illinois, L. JoNes, Oberlin College, and L. R. Dice, Uni-

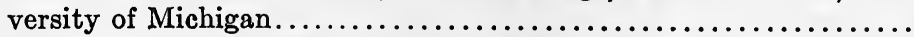

C. Life Zones. V. E. Shelford, University of Illinois, and G. T. Jones,

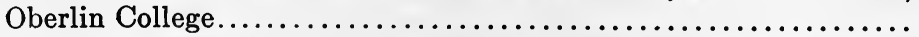

D. Descriptive list of Middle American Biota. Forrest Shreve, Desert Laboratory, and V. E. Shelford, University of Illinois...........

6. Provisional Table of Landscape Aspect and Life Zone Equivalents.

E. A. Goldman, United States Biological Survey...............

F. Bibliography. V. E. Shelford, University of Illinois............

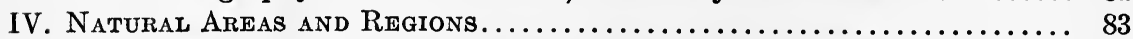

A. General Plan. V. E. Shelford, University of Illinois........... 85

B. Natural Regions and Natural Areas...................... 87

Section 1. Northern North America: Ice Covered Areas, Tundra and Northern Coniferous Forest .............................

1. Northwest Greenland. W. Elmer Ekblaw, Clark University.

2. Danish Greenland. W. Elmer Ekblaw, Clark University.....

3. The American Arctic Archipelago. W. Elmen Ekblaw, Clark University................................. 98

4. Ungava and Labrador. W. Elmer Ekblaw, Clark University. . 102

5. Newfoundland. W. Elmer Ekblaw.................... 111

6. The Mackenzie Watershed; Northern Hudson Bay Region, Upper Yukon Region, and the Arctic Islands. E. A. Preble,

U. S. Biological Survey...................... 115

7. Alaska. W. H. Osgood, Field Museum.............. 141

8. The National Forests of the Alaskan District. JoHN D.

Guthrie, United States Forest Service................ 147

Section 2. Southern Canada and the United States.................. 150

A. States, Provinces and Forest Districts, Chiefly Coniferous Forest.... 150

1. British Columbia. JoHN Davidson, University of British Columbia, P. Z. Caverhill, Provincial Forest Branch, Edward A. Preble, United States Biological Survey, and A. H. Hutchinson, University of British Columbia........

2. Washington. G. B. RIGG, University of Washington, L. R. Dice, Helen T. Gaige, University of Michigan and Horace Gon-

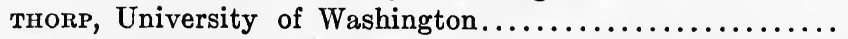

3. Oregon. Thornton T. MUnger, United States Forest Service, William E. Lawrence, Oregon Agricultural College, and Howard M. Wight, Oregon Agricultural College........... 181

4. California. H. C. Bryant, University of California.......... 193

5. National Forests of the North Pacific District (6). J. V. HoF-

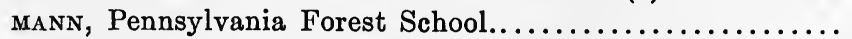
6. Eational Forests of the Northern District (1). J. A. LARSEN, Iowa State College......................... 208

7. National Forests of California. Vegetational Types. E. N.

Munns, United States Forest Service............... 216

8. National Forests of the Intermountain District (4). F. S.

BAKER and S. B. Locke, United States Forest Service....... 224

9. National Forests of the Southwestern District (3). G. A.

Pearson, United States Forest Service............... 232

10. National Forests of the Rocky Mountain District (2). C. G.

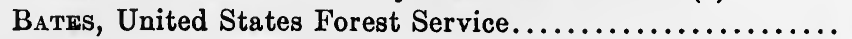
55 7 60 5 7 80 1

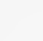

7
87
87 90

8

11


11. Idaho. R. A. Muttkowski, University of Idaho......... 249

12. Alberta. A. B. Conneld, Dominion Forestry Branch...... 253

13. Saskatchewan. John Smith Dexter, College of Porto Rico.. 258

14. Manitoba. A. B. Connell, Dominion Forestry Branch..... 263

15. Minnesota. C. O. Rosendahl, University of Minnesota..... 267

16. Wisconsin. A. S. Pearse, University of Wisconsin....... 284

17. Ontario. C. D. Howe and J. R. Dymond, University of Toronto 288

18. The Province of Quebec. G. D. Fuller, University of Chicago, and Bro. Marie-Victorin, College de Longueuil......... 293

19. New Brunswick. B. E. Claridge, University of New Brunswick 299

20. Prince Edward Island. Committee Notes............... 302

21. Nova Scotia. A. H. Mackay, Nova Scotia, Department of Education.................................. 303

22. Maine. A. O. Gross, Bowdoin College, and A. H. Norton, Portland Society of Natural History................. 305

B. States Chiefly Deciduous Forest....................... 314

1. New Hampshire. K. W. Woodward and C. F. Jackson, New Hampshire College............................. 314

2. Vermont. Geo. P. Bunns, University of Vermont.......... 316

3. Massachusetts. Anna M. Stark, Mount Holyoke College.... 318

4. Connecticut. Geo. E. Nichols, Yale University............ 326

5. Rhode Island. Marion D. Weston, Rhode Island College of

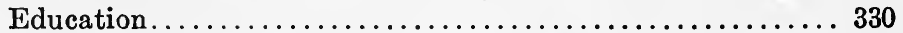

6. New York. W. L. Bray, Syracuse University............ 332

7. Pennsylvania. John W. Harshberger, University of Pennsyl-



8. West Virginia. W. E. Rumsey, West Virginia University..... 341

9. Tennessee. R. S. Maddox, Tennessee Bureau of Forestry.... 347

10. Kentucky. A. R. Middleton, University of Louisville, W. R. Jilison, F. T. McFarland and M. A. Anderson, Jr., Uni-

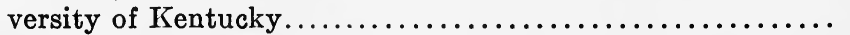

11. Ohio. E. LuCy Braun, University of Cincinnati, and Lynds Jones, Oberlin College....................... 354

12. Indiana. Wiln Scotт, Indiana University............. 372

13. Michigan. L. R. Dice, University of Michigan, Lynds Jones and Helen T. GaIge, University of Michigan.......... 377

14. National Forests of the Eastern District. E. H. FrothinghaM,

1. United States Forest Service..................... 387

C. States with Deciduous Forest, Southeastern Coniferous Forest, and

Large Swamp Areas............................... 394

1. New Jersey. T. C. Nelson, Rutgers College................ 394

2. Delaware. Frank Morton Jones.................... 398

3. Maryland. C. C. Hamilton, N. J. Agricultural Experiment Station.................................... 401

4. Virginia. Ivey F. Lewis, University of Virginia.........410

5. North Carolina. Z. P. Metcalf and B. W. Wells, North Carolina State College......................... 413

6. South Carolina. Philip Luginbill, United States Bureau of Entomology ................................. 418

7. Georgia. HENRY Fox, U. S. Bureau of Entomology........ 422

8. Florida. J. R. WAtson, University of Florida........... 427

9. Alabama. R. M. HARPer, Alabama Geological Survey, M. S. Johnson, University of Minnesota, and A. H. Howels, United States Biological Survey........................ 
10. Mississippi. Gladys Hoke, Converse College.

11. Louisiana. G. W. Goldsmith, Carnegie Institution, Lenthald Wyman, United States Forest Service, and H. H. Kopman, Louisiana Department of Conservation................ 460

12. Arkansas. JoHn T. BuchHolz, University of Arkansas...... 464 Texas. (See page 502.)

D. States Chiefly Oak Grove Savanna....................... 469

1. Illinois. T. H. Frison and R. B. Miller, Illinois Natural

History Survey............................ 469

2. Iowa. L. H. Pammex, Iowa State College............... 480

3. Missouri. A. C. Burrill, Missouri Resources Museum..... 485

4. Oklahoma. H. H. LANE, University of Kansas.............. 490 Texas. (See page 502.)

E. States Chiefly Grassland or Steppe....................... 502

1. Texas. A. R. CAHN, University of Illinois.............. 502

2. Kansas. J. W. McColloch, Kansas State Agricultural College. 515

3. Nebraska. R. H. Wolcotr, University of Nebraska.......... 519

4. Colorado. F. Ramaley and W. W. RobBins, University of Colorado..................................... 524

5. Wyoming. JoHN W. Scotr, University of Wyoming......... 529

6. Montana. M. J. Elrod, University of Montana............ 537

7. North Dakota. J. T. Sarvis, United States Bureau of Plant

Industry, and J. E. Switzer, Indiana University......... 544

8. South Dakota. E. J. Petry, South Dakota State College, and

S. S. Visher, Indiana University.................... 548

F. States Chiefly Desert and Semi-Desert................... 556

Oregon. (See under Coniferous Forest.)

California. (See under Coniferous Forest.)

1. Utah. C. F. Konstian, United States Forest Service........ 557

2. Nevada. C. F. Korstian, U. S. Forest Service............. 560

3. Arizona. G. A. Pearson, U. S. Forest Service, E. A. Goldman, United States Biological Survey, Forrest Shreve, Carnegie Institution, and Charles T. Vorhies, University of Arizona 562

4. New Mexico. A. O. Weese, University of Oklahoma......... 570

Section 3. The Tropics North of the Equator.................... 574

A. Mexico and Central America.......................... 574

1. Mexico. E. W. Nelson and E. A. Goldman, United States Biological Survey.............................. 574

2. Guatemala. Wilson Popenow, United States Department of Agriculture................................ 596

3. British Honduras. Karl P. Schmidt, Field Museum....... 600

4. Honduras. Karl P. Schmidt, Field Museum............. 601

5. The Republic of Salvador. Paur C. Standley, U.S. National Museum..................................6 602

6. Nicaragua. Lublow Griscom, American Museum of Natural History.................................... 604

7. Costa Rica. LudLow Griscom, American Museum of Natural History................................... 607

8. Panama. E. A. Goldman, United States Biological Survey, and JAMES Zetek, Custodian of the Barro Colorado Island Laboratory, United States Bureau of Entomology..........6 612

B. Northern South America........................... 623

1. Colombia. Francis W. Pennell, Academy of Natural Sciences of Philadelphia 
2. Venezuela. H. Pittrier, Caracas, Ven, and H. B. Baker, Uni-

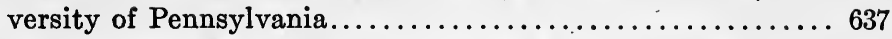

3. The Guianas. Wm. Besere, New York Zoological Society, and H. A. Gleason, New York Botanical Garden............ 649

4. Ecuador. Wilson Popenoe, U. S. Department of Agriculture, and H. E. Anthony, American Museum of Natural History. . 662

5. The Amazon Valley. Orland E. White, Brooklyn, Botanic Garden..................................... 674

C. Islands in the Atlantic and Adjacent Waters................ 681

1. Bermudas. (Committee Notes.)....................661 68 .

2. Bahamas. (Committee Notes.)...................... 682

3. Cuba. Brother Leon, Colegio de la Salle, Havana......... 682

4. Haiti and Santo Domingo. G. Kingsuer Noble, American Museum of Natural History................... 695

5. Jamaica. Forrest Shreve, Carnegie Institution..........6 698

6. Porto Rico and the Virgin Islands. N. L. Binitson, New York Botanical Garden, G. N. Wolcotr, Porto Rico Experiment Station, and others........................... 700

7. Dutch West Indies. H. B. BAKER, University of Pennsylvania. 707 D. Pacific Islands....................................... 709

1. Galapagos Islands. (Committee Notes.).............. 709

2. Philippine Islands. F. T. McLean, Rhode Island College,

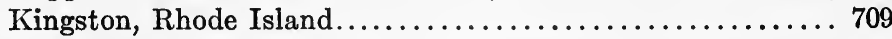

V. List of Organizations Interested in the Preservation of Natural

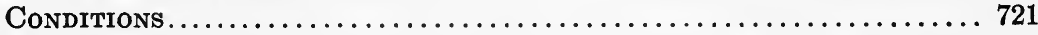

A. List of State and Territorial Representatives. W. G. Waterman,

Northwestern University......................... 723

B. Local Organizations. W. G. Waterman, Northwestern University.. 727

C. National Organizations. C. F. JACKson, New Hampshire College... 736

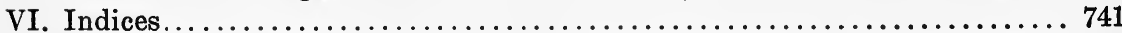

1. Index of Scientific and Common Names of Birds........... 743

2. Index to Authors and Localities...................... 759 


\footnotetext{
.
} 


\section{INTRODUCTION}




\title{
INTRODUCTION
}

\author{
By V. E. Shelford
}

Biology has been characterized by waves of interest in special fields corresponding to fads and similar phenomena in human activity generally. One of these fields of special interest is, or has been, evolution. One can hardly help agreeing with writers who state that it retarded the progress of biology (botany and zoology). This was due to the fact that it happened to turn attention to types of work that could be done in the museum and in the laboratory. The doctrine of the survival of the fittest was accepted with none but the crudest ideas of what constitutes fitness. Most backward of all was the knowledge of the environment. This, together with the ease with which morphological features could be fitted into the doctrines set forth by Darwin, led to a period of empirical speculation concerning adaptation, coloration, mimicry, etc., which contributed so little of scientific value that much of it will be quite generally ignored or forgotten in the near future.

In connection with this work observations which would show the function or fitness of the parts of features speculated about, were rare if not wanting. The uses of the structures or colors were often entirely assumed. We perhaps know less about fitness than any other biological subject. The "survival of the fittest" as usually employed means merely the survival of the survivors. There can be no adequate knowledge of fitness to environment without knowledge of environment.

Knowledge of habitats and the relations of organisms to them cannot be said to have seriously reached the ears or constituted a part of the training of more than a few of those engaged in the older lines of botany and zoology. Studies of genetics, evolution, physiology, embryology, cytology, parasitology and entomology still proceed largely or at least far too often without reference to the habitat relations of the organisms studied.

Warming, who studied the plants of the sanddunes of Denmark, discovered orderly sequences and established the fact that habitats and environment may be interpreted by putting the results of his studies into scientific order. He thus answered the epithet of a famous contemporary zoologist who closed a discussion of habitats with the words "developing hodge podge." Modern ecology has shown that the environment is orderly, proceeding in a particular direction for long periods. One of its outstanding and original features is the study and orderly interpretation of the habitats of organisms and the organisms themselves. Further experience has demonstrated what Warming indicated: That knowledge of habitats can be organized into science.

A branch of biological science which obtains its inspiration in the natural order in original habitats must depend upon the preservation of natural areas for the solution of many problems.

It was the conviction of many members of the Ecological Society soon after its organization, that the society should take steps to make available for study as much of the original biota of North America, as possible. An inventory of available areas and the extent to which they are modified is naturally one of the early steps in the preservation of suitable areas for ecological study. 
. 


\section{USES, VALUES AND MANAGEMENT OF NATURAL AREAS}


- 13 


\section{A. ARTISTIC AND LITERARY USES}

\section{THE VALUE OF NATURAL AREAS TO LITERATURE AND ART}

\section{By Selden Lincoln Whitcomb}

Some few early American poets wrote of the skylark and the nightingale. They followed the easy path of inherited literary tradition, and did not seem to realize the wealth of new natural material at their very doors. Other poets, however, very soon discovered the poetic values of the whippoorwill, the passenger pigeon, and the ruby-throated humming-bird. Freneau, poet of the American Revolution, has a well known poem on the honeysuckle. A little later Bryant's poem on the yellow violet almost marks an epoch in the poetic treatment of American flowers. Alexander Wilson may be considered, in a sense, as the last of the pioneers among the American writers on American nature. In his poetry, as well as in his letters and his American Ornithology, he has left wonderful records of his personal observations of birds, plants, and landscapes over a very large section of the region east of the Mississippi River. ${ }^{1}$

From the days of Wilson to the present time, there has been, on the part of American writers, an alert and continuous interest in the varied aspects of American nature. Perhaps no literature is richer than ours in the literary presentation of local nature. The "nature essay" is a very characteristic and practically indigenous literary type in this country. As American territory expanded, our writers accompanied or soon followed

1 For a fairly extended treatment of "Nature in Early American Literature," see the writer's article in The Sewanee Review, 1894. the pioneers of the new regions. Our literature now offers us entire volumes of nature lore from the region Where Rolls the Oregon (Dallas Lore Sharp) to that of A Florida Sketch-Book (Bradford Torrey) and from The Maine Woods (Thoreau) to The Land of Little Rain (Mary Austin). Dr. Neil E. Stevens has an interesting article in The Scientific Monthly for February, 1921, on "The Botany of the New England Poets." There is abundance of material for analogous articles-on the botany or the zoology of writers-for every section, yes, for every state of the Union.

The student of American literature welcomes any reasonable movement to preserve, in as nearly the original state as possible, as many as possible of the regions which have been observed, loved, and described by our authors. The present writer has visited the site of Thoreau's famous cabin at Walden Pond, and has followed the path of Thoreau, with Cape Cod in his hand, for miles and miles along the Cape. (Incidentally, as the writer lay on high land tracing the route from the book, an unsuspicious fox came trotting to within two yards or so of him.) Mankato, Minnesota, is a typical and beautiful prairie town and it was the western limit of Thoreau's only western trip. Mankato has a wonderful system of natural parks. The student of literature hopes that a section of prairie or woodland, known to have been visited by Thoreau, may yet be located and preserved.

Among other places of somewhat similar interest in American literary biography, in the Middle West, these may be suggested: haunts in Wisconsin, 
which inspired James Gates Percival (poet as well as geologist); places in or near Fort Gibson, Oklahoma, which stimulated the pen of Washington Irving; certain environs of Osage and Clear Lake, Iowa, which were of notable significance in the development of Hamlin Garland, etc.

Here and there in the prairie country, one finds small areas of open ground still in their natural state. This is sometimes the case with the railroad right-of-way. Here may be found plants, and, to a lesser extent, animals which seem to have passed from the neighboring regions. Such areas are especially welcome to the lover of literature. If their natural phenomena are not yet known to our literature proper, let us not destroy the opportunity for the writers of the future. The natural forest edge also-let us preserve as many sections of it as possible. Here, where the prairie meets the woods, were the original haunts of many of our familiar herbs and shrubs and birds-spring migrants: white-throated sparrow, hermit thrush, etc.; summer residents: thrasher, catbird, Bell's vireo, etc.; winter visitants: juncoes, tree sparrows, the great northern shrike, etc.

We have already destroyed much which cannot be replaced. No sane student of literature will deny the national importance of the lumber industry or of the greatest possible extension of grain producing land. But the same student is anxious to prove to himself and to the world that America is not entirely commercial in spirit. He hopes for and believes in the American artist-painters, musicians, and writers - of the near and of the distant future. For these artists and for those thousands if not millions of citizens whose lives are to be enriched by these works of pen and brush, we should preserve, all over the country, carefully selected, representative areas, as nearly in the primitive condition as is now possible.

\section{THE VALUE OF NATURAL PRE- SERVES TO THE LANDSCAPE ARCHITECT}

\section{By Stanley White}

Inasmuch as one of the chief interests of landscape architecture is the preservation of beautiful landscapes, nothing can be more evident than the importance to the profession and to those deriving benefits from its works of this movement to save various natural regions from possible injury or destruction. Landscape architects have always maintained a keen interest in such movements: as private practitioners in urging the development of organizations interested in natural preserves, and through their national professional society in formally supporting the movements in defence of our great national reservations against improper exploitation.

Frederick Law Olmsted, in speaking of our national parks, says:

The National Parks are set apart primarily in order to preserve to the people for all time the opportunity of a peculiar kind of enjoyment and recreation, not measurable in economic terms and to be obtained only from the remarkable scenery which they containscenery of these primeval types which are in most parts of the world rapidly vanishing for all eternity before the increased thoroughness of the economic use of land. In the National Parks direct economic returns, if any-are wholly secondary to the one dominant purpose of preserving essential esthetic qualities of their scenery unimpaired as a heritage to the infinite numbers of the generations to come.

One of the most notable achievements in this direction was the creation of the Boston Park system, with its rich natural and semi-natural preserves largely through the original idea and subsequently the active work of $\mathrm{Mr}$. Charles Eliot, Landscape Architect, concerning which there is an excellent account in his biography. ${ }^{1}$ Many other instances could be cited, as the design

1 Charles Eliot, Landscape Archilect, by C. W. Eliot. 
of public areas is a considerable part of the regular work of the profession.

President Emeritus Charles W. Eliot of Harvard University, at the meeting of the American Society of Landscape Architects, Boston, 1911, made the following remarks:

If I were asked to mention the most important public movement of the last twenty years, I should say it was the movement to obtain for all classes of society-indeed, for the entire population-better means of health, rational enjoyment, and real happiness. Much sympathy has been expressed in these later years for the unhappy condition of large elements of the population. Something more than economic remedies must be found for the great evils which beset modern society, and particularly for the diseases, physical and moral, which are caused by congestion of population. This profession is called upon to deal with all these problems of congestion. You must take account of the desires and hopes, tastes and purposes of the population to be relieved; and these sentiments and emotions will all be found to be closely related to that pursuit of happiness in which a free people is always engaged in accordance with their tastes and inclinations. - . The Declaration of Independence declares that all men have a right to life, liberty, and the pursuit of happiness. Now it is the pursuit of public happiness which, I think, should be the main standby of this profession in urging the public to use the landscape art, to seek its benefits, and to employ its artists.

But the preservation of natural beauty is not the only object sought in saving the untouched tracts. Not that their beauty is not a sufficient object in itself, but other factors, not less important but simply less apparent, can be justly ascribed. The training of the landscape architect begins not only with pictorial composition and practical design, but also with the study of plants, of soils, of bodies of water and of all the great natural forces and influences that have shaped and given character to the physiognomy of the land and its vegetation. Now the original sources of the literature in all these vast fields of special sciences have come from the many investigators who have utilized the natural areas not as an accessory to their mode of study but as the supreme fundamental basis of all determinations. Unlike the investigators in other than the so-called "Natural Sciences" whose laboratories are often merely specially equipped ordinary buildings, these workers must depend on all out-doors for their laboratories and particularly on the few portions of the earth's surface still remaining as an original record of the earth's history. The plea of this work is that these original tracts are so rapidly becoming modified that steps should be taken to save their destruction before too late. From the standpoint of the landscape profession their loss would be not a mere sentimental misfortune, but a real catastrophe reaching into every branch of science which contributes to the development of landscape study.

From these great sources of natural beauty comes all our inspiration; from them comes the unlimited store of fine examples teaching us the arrangement of our materials; from them comes the lesson of growth, development and natural strife that shows the way to a permanent landscape; and finally, from them comes the suggestion to the layman of the value of beauty and the desire for it in the surroundings of human habitations. It is not enough that we grow fine floral displays, wellclipped hedges and smooth lawns. We must bring to the most humble cottage in all parts of the land at least a suggestion of nature's charm, power and delicacy, the inspiration for which, unless these natural preserves are secured, will disappear for all times in spirit and in fact. 


\section{B. SCIENTIFIC AND PRACTICAL USES AND VALUES}

\section{THE VALUE TO SILVICULTURE OF RESERVED AREAS OF NATURAL FOREST TYPES}

\author{
By W. W. Ashe
}

The setting aside of vestigial units of the various forest types has three important objects in view: First, to supply the means for studying the laws which control the distribution of different species of trees. Second, to ascertain the factors which determine forest types. Third, to note the changes in such types induced by the artificial conditions which result from exploitation and silvicultural practice.

The practical silviculturist is principally concerned with the last named of these objects. It is his function to modify natural conditions, often to a profound degree, in the interest of increased yields of commercially desirable species. In this, however, he is constantly taking a chance, since his crop is a slow growing one and he is unable to wait for the results of the painstaking research, extended through the life of a stand of timber, needed to supply the accurate results under which he could proceed with complete confidence. By determining these factors of distribution and using these vestigial units as check plots, however, it may be possible for him to prevent mistakes or to rectify errors which may be made through deviating too far from the normal.

It is reasonable to suppose that each site, the biotic corollary ${ }^{1}$ of which is the forest type, bears in its natural condition (unless modified by fires) the heaviest stand which the native species are capable of producing on

${ }^{1}$ Ashe, W. W. "Forest Types of the Appalachians and White Mountains." Journal of the Elisha Mitchell Scientific Society, 37: 183-198. 1922. that site. That is, nature has already established that species or association of species which is best suited for growing under the limiting edaphic and meteorological conditions which are termed site, among the most important of such conditions being soil acidity, rate of nitrification, maximum moisture content, number and length of critically dry periods, depth of soil, and available heat units and their distribution. The species forming the type reproduce themselves, not invariably in a definite proportion, but definite within a certain latitude, the oscillation of the type, ${ }^{2}$ and utilize the full resources of the site, which is capable of producing annually (or on an average) a fixed amount of wood material (cellulose). Silviculture seeks to modify or increase this natural yield by cultural methods. There may be an attempt to concentrate increment in a few select individuals or to simplify the composition of the natural stand by eliminating from it certain of the components which are economically or silviculturally less desirable; or to replace the native species in whole or in part with other species or by a single species which is regarded as more desirable economically or silviculturally.

The problems which arise in connection with such changes can be met in two ways. They can be solved empirically for each site, as in connection with the introduction of foreign species, by experimental planting with a view to determining what species or combination of species is more advantageous than those in the original type. The establishment of final conclusions by this method may require many decades, during which time a portion of the land might not be producing to

2 Op. cit. 
its full capacity or many irreparable and costly errors may have been made. This was the method employed in testing the adaptability of certain species in the plantations on the Biltmore Estate at Asheville, N. C. For example, wild black cherry (Prunus serotina) was planted with a view to its possibly becoming a timber tree. We now know from a careful study of the forest types within which this tree attains commercial proportions that there is no site on the Biltmore Estate on which this species can be expected to attain first size or to be more, in fact, than a straggling slow growing tree.

The other method of meeting these problems is by a study of the fundamental factors which control each forest type within the type itself. Some, if not all, of these factors should be determined on sites on which the type is unmodified or least modified, for whenever it has been materially modified, especially for a long period, there has been an accompanying, though possibly slight and temporary, modification of the site.

When types formed of mixed stands are cut over it is difficult and at times impossible to determine their original composition. For these reasons it is urgently desirable that such unmodified units of the different forest types be located before the silvical conditions are altered by repeated fellings and that they be reserved for the study of their controlling factors. In a few years such vestigial units purposely reserved will be the only unmodified remnants of many of the forest types. It will be only by the setting aside now of such unmodified areas that there can be any assurance of having these plots of the various forest types available for conducting such studies.

As has been stated in a previous paper on this subject ${ }^{3}$ it is eminently undesirable that there should be a possi-

'Ashe, W. W. "Reserved areas of principal forest types as a guide in developing an American silviculture." Journal of Forestry, 20: 276-283. 1922. bility of the development of American silviculture being hampered by the failure to reserve such vestigial units of the important forest types as fields for research, and as check plots by means of which it will be possible to note the changes which take place in the same types under the stress of exploitation and silvical development. As a prerequisite for making the highest use of such reserved units and the studies which may be made in them, the areas of the different forests' types should be carefully mapped after the types have been standardized. Only this procedure will establish similarity of conditions and will permit the extension to them of the laws which are found to control on the vestigial units.

The study of the unmodified areas, in connection with those which are modified, will indicate the extent to which it will be possible to deviate from the normal and yet retain the equilibrium necessary for maintaining the factors of the locality. Such studies will determine whether it will be possible economically to replace one species by another; whether it will be advantageous to substitute a pure coniferous stand for one of mixed hardwoods, or if not, as to what proportion of the stand the conifers can occupy. The natural areas must in large measure serve as the means of developing our silviculture; their elimination from exploitation and their preservation is essential to that end.

\section{THE VALUE OF AQUATIC PRE- SERVES TO FISHERIES}

\section{By A. S. Pearse}

There are few "natural" environments for freshwater fishes in the United States. Artificially stocked streams, lakes, and ponds seldom produce such desirable fishes as are found in localities where the wilderness has not been disturbed by man. Great natural preserves like the Great Lakes and the Mississippi River should be 
kept as near their original condition as possible.

In general the larger a fish preserve is, the better. It is highly desirable to keep the environmental complexes furnished by great rivers and lakes as complete as possible. Variety of habitats is necessary because many species do not carry on their cycles of activities in the same habitat. The bass feed largely among plants, but require bare bottom for spawning. The cisco lives in the deep cool waters of lakes, but comes into shallow water on stony bottoms to breed. Many young fishes frequent shoals, even though they live elsewhere as adults.

Attempts to rear fishes in small bodies of water are often without success. In general the ecological succession in ponds eliminates the species most desirable for man. A pond left to "run" according to "nature" chokes with aquatic vegetation and becomes a swamp, populated by mud minnows, sticklebacks, and bullheads. If game fishes are desired, bare bottom is essential. Fishes confined year after year in a restricted area may be overrun by parasites. One of the trout hatcheries of the Wisconsin Conservation Commission is situated in an excellent locality and has an adequate supply of fine spring water, but is of little value because the trout are heavily infected with a parasitic copepod.

Pollution may easily destroy the value of a fish preserve. Poisons may be introduced from natural sources or from the byproducts of the industries of man. Substances which use up oxygen or produce other injurious gases may be present. Minerals may be precipitated from or dissolved in the water by substances not in themselves injurious to fishes.

If fishing is permitted in a preserve, it should not be so restricted as to catch certain fishes and allow others to increase unduly. If angling only is practised in a lake the game fishes are most often caught and undesirable species, like the carp, sucker, and dog- fish, which seldom take a hook, become too numerous. The restricted use of fyke nets or seins for the capture of the latter fishes is desirable in such a locality.

It is doubtful if the suitability of a body of water as a fish preserve can ever be judged by any single criterion. Two lakes may be of the same size and depth. The one may be "plankton poor," have a scanty bottom fauna, contain undesirable mineral constituents, lack oxygen, and have barren shores, while the other furnishes a favorable environment in all these essentials. A river may change its whole character as a habitat for fishes on account of the introduction of factory wastes, the building of a dam, or some other apparently unimportant change in a locality. Rush Lake, Wisconsin, has abundant food and shelter and furnishes excellent breeding grounds, but is so shallow that its oxygen is used up when it is covered by ice in winter, hence it contains no large fishes.

The important features for a fish preserve are: (1) sufficient size to permit variety in habitats and to lessen the dangers from contamination and rapid fluctuations in temperature, (2) adequate resources in the way of food, shelter, and breeding grounds to maintain a sufficient number of fishes to make the preserve profitable.

\section{THE IMPORTANCE TO GEOG- RAPHY OF THE PRESERVATION OF NATURAL AREAS}

\section{By Stephen Sargent Visher}

At least four of Geography's several sub-divisions will be aided by the preservation of natural areas. These are (1) Descriptive Geography, (2) Historical Geography, (3) Ecological Geography, and (4) Economic Geography.

Descriptive geography is concerned not alone with describing relief features and the cultural additions. It considers likewise the vegetation and the characteristic animals. Preserved 
areas, where natural conditions can be studied readily facilitate good geographic descriptions in two ways. First they afford examples of natural conditions. Only after type areas have been studied can a really good description of a region be written. Second, the setting aside of definite areas for preservation results indirectly in increased information about the location of typical areas, the methods of reaching them, and other significant facts concerning them. Fairly full information is gathered and made available concerning very few privately owned tracts partly because the work and expense entailed may soon have been in vain. The owner may decide to keep out even the most worthy scientists, or else the natural biota may be largely destroyed as by the cutting of the timber or otherwise altering the conditions. Thus although many nearly natural areas still remain, few geographers know just where to go, how to get there, and what they will find when they arrive.

Teachers of descriptive geography will benefit, also, from the presence of preserved areas especially near cities, for in such areas their students can learn much in a short time about natural conditions, the conditions the pioneers encountered.

This leads to the advantage to historical geography of the preservation of natural areas. The specialists who interpret the historical development of any region must have a full appreciation of conditions as they were in earlier times. Carefully preserved natural areas will aid greatly in understanding primeval conditions.

Ecological geography differs from plant and animal ecology chiefly in being more comprehensive, including both, and as the advantages to each have been discussed at length elsewhere, it is not necessary to consider the numerous advantages to this phase of geography which would result from the preservation of numerous typical natural areas. However, there are many prob- lems which special students of either plants or animals have not adequately investigated but which the geographer, with his more inclusive view wishes to study. For example, the influence of geographic factors which because of their rareness, have not been considered significant, such as the "free-air foehn," or the hurricane, need to be investigated. The native flora and fauna may show far plainer adjustments to such influences than do the recently introduced forms. Since it is probable that in the future there will be a great increase in the number of ecological studies carried on by geographers, it is advantageous to geography that many areas be preserved now before it is too late.

Economic geography with its interest in all products of commercial importance is interested in the preservation of natural areas especially because of the probability that in the future new uses will be found for native plants and animals not now very useful. If many are exterminated, as will surely result unless numerous natural areas are preserved promptly, all possibility of their ever being of economic importance will have disappeared. After a form is extinct, or practically extinct, it will be very distressing to learn that it had potentialities of great value had they been taken advantage of. Until every living form is well known, none should be allowed to become extinct. Economic geographers join with agriculturists, physicians and students of many other sorts, therefore, in advocating the setting aside of areas where the native forms can continue to live and ean be advantageously studied.

\section{THE IMPORTANCE OF NATURAL AREAS TO BIOLOGY AND AGRICULTURE}

\section{By V. E. Shelford}

Some biological subjects are of course only remotely related to habitat questions; others can hardly proceed to certain conclusions without reference 
to habitat relations. An adequate interpretation of evolutionary relations can hardly be made without knowledge of environment. This is true even if natural selection operating on characters which arise from internal causes, is assumed to be the only cause of the origin of new forms. The geneticists have rarely separated environmental effects from purely hereditary phenomena. It is safe to assume that a considerable part of the phenomena described as hereditary is some form of environmental effect. The results of genetical study can hardly have important evolutionary bearing until relations to environment have been brought into it.

The relations of physiology to ecology are more intimate under present conditions; the general physiologists are interested in and are appreciative of ecological work. The interpretation of physiological characters in connection with environmental relations is a growing field. Medical physiology is less intimately related to environmental subjects but is far from as remote as the present status of various other biological subjects.

The purpose of pointing out the relations of the various branches of biology to ecology and the study of natural habitats, and of calling attention to neglected relations is merely to indicate that present interest in the preservation of natural habitats for scientific purposes is far less than it may be expected to be in the near future. It is safe to predict that when the neglected field of habitat relations comes to attention a little more, not merely ecologists, but all biologists will require preserves of natural conditions in connection with their various scientific interests. The relations of the pure science of biology to natural conditions is believed to be much more important to future research than is generally recognized.

Agricultural problems include the development of new kinds of cultivated plants and domestic animals, and the destruction of pests of all kinds. In understanding conditions which most favor pests a knowledge of their original habitat is often very important and will save years of work on the part of investigators. For example the chinch bug was originally found on grasses in waste places along the coast of the Carolinas. Rainy, hot seasons similar to those found in the original area are favorable to the chinch bug. Knowledge of the climate and other conditions in the original habitat would have saved much useless speculation and misinterpretation. Knowledge of the original conditions under which a pest lives is usually important. Accordingly preserves of naturul conditions are important from the standpoint of insect pests and equally important for other plant and animal pests.

Domestic animals, especially sheep, have been studied in relation to climate. After thousands of years of domestication sheep still require conditions similar to those in which they are said to have originally occurred-mountain grassland-and failure to supply these conditions is one of the causes of difficulty in the sheep industry. A reservation with sheep of the wild sort in their natural conditions would have facilitated this study greatly. There are many species now in a wild state which may be utilized in the near future for domestication or crossing with domestic species and they should be preserved in their native haunts for this purpose. 


\section{FORCES MAKING FOR THE DESTRUCTION OR PRESERVA- TION OF NATURAL AREAS}

\section{FOREST LAWS AND REGULA- TIONS AND THE PRESERVATION OF NATURAL CONDITIONS}

\author{
By R. B. Miller
}

I. POSSIBILITY OF PRESERVING NATURAL CONDITIONS UNDER PUBLIC AS COMPARED WITH PRIVATE OWNERSHIP

While perhaps no state or national forest laws deal directly with the preservation of natural conditions, there are many forces working indirectly to that end. At least, natural conditions have a much better chance of being preserved under public than under private ownership, coupled as it is with the danger of changing policies, with fire, grazing and over-cutting. In fact, the failure of private initiative to properly protect its holdings is one of the main reasons given for increasing our acreage in national, state, county and municipal forests.

Since the relation of fires to plant and animal life is discussed by Wolcott (page 34) and Korstian deals with grazing on the national forests, (page 33) we may say just a word about cutting regulations and their effect upon the preservation of natural conditions. On state forests there are usually some restrictions as to the size of trees which may be cut and certain laws as to brush-disposal, leaving of seed trees or size of trees to be cut. Naturally, cutting by the shelterwood and selection methods do much less damage to soil and reproduction by too sudden exposure to the drying effects of the sun and wind than does clear cutting, which in some cases may be the wisest financial policy.
On the national forests, cutting regulations are enforced by a workable policy - the requiring of the operator to pay an additional price for his timber when he does not conform to the provisions of the timber-sale contract, with the cancelling of the agreement in extreme cases of violation of the cutting regulations.

If the purchaser of timber does not wish to follow Forest Service regulations, he has the choice of doing his logging elsewhere, probably paying more for his stumpage while he is not assured of a perpetual supply of timber for his mill as he is when he depends upon government owned timber. As Korstian $^{1}$ points out, the forester will soon be dealing almost wholly with cutover timber lands and to him the greatest value of preserving natural conditions lies in setting aside the best of these tracts, which nature has left. The chief purpose of these natural areas will be for comparison and standardization. The chance for having the greatest number of such tracts for object lessons lies in national and state ownership of timber in many typical regions.

\section{EXTENT TO WHICH FOREST LAWS MAKE POSSIBLE PERMANENT SAMPLE PLOTS}

It is generally recognized that permanent sample plots are essential to good forestry practice, serving not only as places for carrying on certain lines of research such as experiments in cut-

\footnotetext{
1 Korstian, C. F. "The preservation of natural conditions in the national forests." This volume, p. 17.
} 
ting by different methods, the study of succession after fires and the study of reproduction and growth but also as demonstration areas having a certain educational value.

Speaking of the use of school forests as research centers and the need of protection Prof. James W. Toumey, of the Yale Forests School says: "Such forests cannot perform their best service as research stations unless they are under a management which will afford the greatest protection to permanent sample plots and make it reasonably certain that investigations, once begun, can be carried through." The same may be said of private tracts.

While no special provision is made for the protection of sample plots outside of the enforcement of the usual fire laws prevalent on state forests, the setting aside of certain tracts to serve as demonstration areas is a part of the forest policy of many states and is sometimes carried on in cooperation with private owners. It stands to reason that such cooperation under state control will be a valuable aid in protecting sample plots within such demonstration forests from destruction. These demonstration forests, says Secretary Wallace, "might be established in certain "key areas," where Federal or state ownership would be of special value in protecting stream sources and giving the local people a practical demonstration of fire protection and good forest management."

Korstian $^{2}$ discusses the permanent sample plots on the National Forests (page 17) and their value to the forester, the biologist and the ecologist. He divides these into silvicultural plots, where succession and the effects of different grades of cutting and thinning can be studied; and plots which have been established in connection with range management to determine the effect of severity of grazing both upon

2 Korstian, C. F. "The preservation of natural conditions in the national forests." This volume, page 17. herbaceous, shrubby and tree reproduction.

While the Conservation Commission of Canada has ceased to function, this organization must be given great credit for the establishment of sample plots in the various provinces under the leadership of their forester, Mr. Clyde $\mathrm{N}$. Leavitt, assisted in the supervision of field parties by Dean C. D. Howe, of the Faculty of Forestry of the University of Toronto. These plots were established in cooperation with some of the provinces, lumber and paper companies and on military reservations so that they still have a good chance of being perpetuated. It can be said that the Commission went into greater detail in measuring the individual trees on these plots and recording the data than any other organization which preceded it, affording a stimulus to the provinces and private companies in sample plot work which cannot be overestimated.

On such plots, by periodically measuring and recording the increase in size of all specimens, from small saplings up to mature individuals which have been numbered and measured, figures can be obtained which will be of great value in making yield tables for pure or mixed forests, while incidental changes taking place in the life-history of the stand can be accurately studied and recorded. It is true that these plots are more or less exposed to fires and windstorms but under the frequent inspection of foresters they stand a very good chance for permanency.

III. EXTENT TO WHICH FOREST LAWS AFFECT THE ESTABLISHMENT AND MAINTENANCE OF GAME PRESERVES

While excellent fishing and game preserves have been established by private individuals, such as the Whitney tract in the Adirondacks and the various fishing clubs and game clubs both in Canada and the United States where restrictions are made regarding fires 
and poaching, with the land and streams patrolled by guards and wardens, it stands to reason that the preservation of fish and game can best be accomplished on a broad scale under state or national departments, with settled policies and greater power for law enforcement.

To what extent game protection shall be connected with forestry is an unsettled question. Foresters may object because where forests, fish and game are combined into a large department they feel that forestry is very likely to receive secondary consideration. In some of the states and Canadian provinces, however, forestry and game interests are associated under one department, either merged into a large Department of Conservation, a Department of Lands and Mines, or a Forest, Fish and Game Commission as it was for a long time in the state of New York, this, however, having been superseded by a Conservation Commission. In the province of New Brunswick, for example, all registered guides under the Department of Lands and Mines are sworn in as deputy fire wardens while foresters and scalers also report violations of the game laws of the province. New Brunswick has set aside about 600 square miles of territory on the Nepisiguit River not only to serve as an experimental area where the effects of different methods of cutting may be studied but also to serve as an immense game refuge. Game preserves have also been established by the state of Pennsylvania and it has already been demonstrated that these tracts serve as breeding grounds whence game flows over into contiguous areas. The linking up of the state game preserves with state forests is of great importance to lovers of wild life since the protection of such tracts from fire under the state forest fire laws will protect not only animals and birds but fish since it has been shown that fish have been killed in large numbers by ashes washed into streams by heavy rains.

\section{THE PRESERVATION OF NATU- RAL CONDITIONS IN THE NATIONAL FORESTS}

\author{
By C. F. Korstian
}

No fact in connection with the development of our country is more evident than the tremendous change which has taken place in the original vegetation. Many areas once covered with virgin forests are now either productive farm lands or are waste and desolate as the result of lumbering and fire. We still have left vestiges of the original growth; but even these are threatened.

It is a trait of mankind to preserve antiquities. Museums for their safekeeping and display are liberally maintained. Universities and scientific schools of today must have them for research in important fields. It is just as true of our original forest conditions, including all their biological implications, as of any other of the relics of the past, that science as well as human interest demands the preservation of these samples. They cannot be brought to the museum; they must be their own living museums. They are as necessary for the sound and progressive development of the biclogical sciences as they are for the art and science of forestry. The education of future generations demands them.

The forester will soon deal almost wholly with cutover timberlands, yet -as has been clearly pointed out by Ashe $^{1}$ and Pearson ${ }^{2}$ if the highest ideals of silviculture are to be attained the forester must not be deprived of the basic facts which Nature records in the virgin forest. The practicing forester, in the interest of the highest use to the public through increased production of the most valuable species, often profoundly changes the natural conditions and, as has been stated elsewhere in this volume, these conditions may also be readily modified by graz-

1 Ashe, W. W. "The value to silviculture of reserved areas of natural forest types." This volume, pp. 10.

2 Pearson, G. A. "Preservation of natural areas in the National Forests." Ecology, 3: 284-287. 1922. 
ing. ${ }^{3}$ Timber exploitation also has a disturbing effect on the animal life of the forest, but under proper management and control of predatory animals the forester contends that the game animals will increase. So far as the forester is concerned, the main reason for preserving natural areas is to retain a standard of accomplishment of Nature alone, to serve as a guide by which the correctness of the forester's efforts to improve on Nature may be gauged.

In addition to the justification of these natural areas as objects of research in forestry and other biological sciences, there is another valid reason for the preservation of representative natural conditions in the National Forests. This is the rapidly increasing appreciation of such areas for scenic and recreational purposes. It is the aim of the United States Forest Service in administering the National Forests to devote every tract of forest land to its highest use. It is not unduly stretching the spirit of this announced purpose to assume that it will embrace the appropriate treatment of areas which are chiefly valuable for scientific study, esthetics or recreation.

For utilitarian reasons it is evident that the Forest Service cannot be expected to satisfy every requirement with natural virgin forest conditions. The National Parks and National Monuments, on the contrary, do in many cases meet these requirements. The forests embraced in them will undoubtedly be preserved, and the opportunity is presented for establishing in them definitely located study areas, subject to the policy of administration. A study of the accompanying map (figs. 1 and 2) will show that the reserved areas are widely distributed over the country. Doubtless areas representative of widely prevailing natural conditions can be found in them. This will make it possible to limit the number of such areas within the National Forests to a scale consistent with their administrative

'Korstian, C. F. "Grazing in the National Forests." This volume, pp. 33-34. policies, selecting only such locations as will preserve and maintain typical virgin conditions, and offer a home to all forms of wild life within the forest itself and yet not interfere materially with important timber sales or other large commercial developments. Because of their diversity of conditions and types, National Forests offer to ecologists untold opportunities for study.

Within the 157 million acres of National Forests there are many areas of wilderness of rugged and diversified topography which have no great economic importance for timber or forage, but which possess high value both for recreational and scientific purposes. The Forest Service policy of best and most appropriate use includes the building of trails through these areas, partly for fire protection and partly to make them more accessible for just such purposes as those mentioned. An important step toward adequate protection of game would be the legislation-long urged by game conservationists-for the establishment, by Presidential action, of federal game refuges in the National Forests. Still another important list of areas, on which natural conditions are already being preserved, are the municipal watersheds, protected as sources of city water supply. Furthermore, because of economic inaccessibility or other such factors, vestiges of virgin forest will doubtless remain untouched indefinitely, although they may not be formally incorporated in specifically reserved areas.

With proper cooperation between the various "wild life" and "natural conditions" advocates the greater part of their needs could be adequately met without the reservation of a prohibitively large acreage. The present quota of National Parks, municipal watersheds and other forest areas which are safeguarded against exploitation and depredation are not wholly adequate. There is still need for a few more areas in each forest region which must be carefully selected to insure a proper 



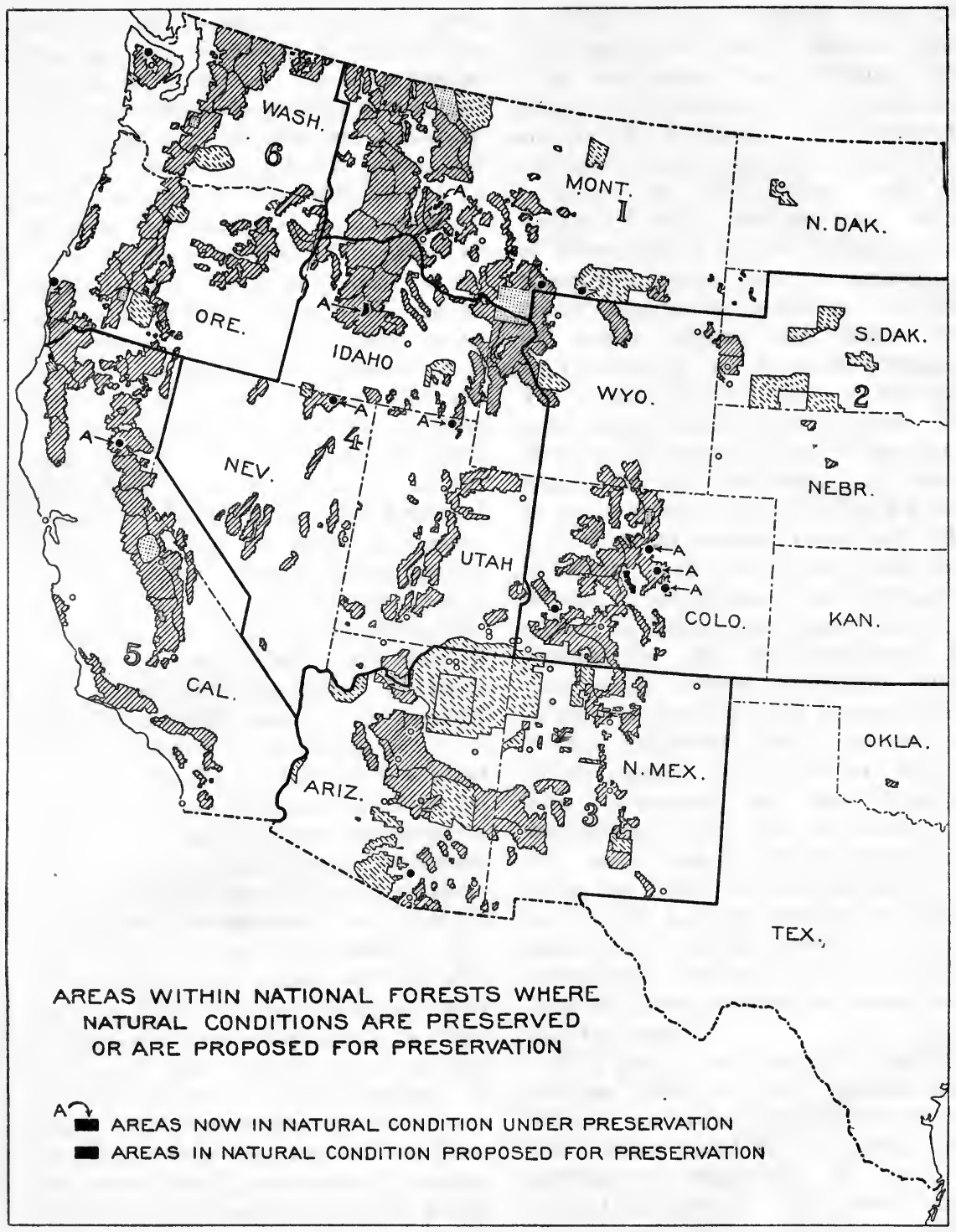

FIG. 1 




FIG. 2 

representation of all important forest types. Such areas may now be found in the National Forests. The longer their economic use and development is continued, the further will they depart from a primeval condition.

The descriptions of the National Forests in the following pages are grouped according to the eight administrative districts. The forest types vary widely between districts and also within some of these districts. The accompanying map (figs. 1 and 2) gives a general idea of the location of the National Forests and the approximate number of areas on which the forest conditions are being preserved in their natural and semi-natural states. The areas within the National Forests which are being preserved in their natural condition are chiefly those closed to grazing, timber sales, and other commercial exploitation because they possess unusual scenic features, are the sources of important municipal water supplies, or are foresters' permanent sample plots located in virgin timber as a check on some artificial cultural operation. The areas being preserved in a semi-natural condition comprise the federal and state game preserves, the majority of the permanent sample plots, experimental forests, and areas on which some forms of use are prohibited and others permitted.

It is greatly to be regretted that, on account of the prohibitive cost, the Committee found it absolutely impossible to publish the excellent maps submitted by some of the contributors. The map accompanying this paper (figs. 1 and 2) is necessarily on too small a scale to show these areas with the precision and detail of classification they deserve. Anyone desiring to visit any of the National Forest areas, whether for study or for pleasure, should communicate with the nearest District Forester at the address given on the map, who will gladly supply the desired information in much more detail than it could possibly be given here. Many of the National Forests are reached by highways, while good mountain roads are available for extensive trips into the higher portions. For the regions inaccessible by automobile, trails are available which extend throughout the mountains in such a way as to bring the greater part of them within reach. Camping equipment is often necessary and always desirable. Information regarding roads, means of transportaion and subsistence can always be secured at the office of the local Forest Supervisor or from the Forest Rangers at the ranger stations in the National Forests. Few restrictions are imposed upon naturalists in the National Forests and the local Forest Officers are always willing to give additional information as to routes and methods of travel.

\section{PERMANENT SAMPLE PLOTS IN THE NATIONAL FORESTS}

\section{By C. F. Korstian}

Within a few decades a large part of our natural wild woods will be cut over and the forest products needed in everyday life will be supplied by secondgrowth forests. It is, therefore, important to know what tree species these lands are capable of growing and how much timber they will yield. In order to answer these questions the forester must determine what kinds of trees are coming in naturally, how fast they are growing, the loss due to various causes, including natural shading out of the smaller and weaker trees, what may be expected from those which live, and whether the natural reproduction is adequate to insure satisfactory stands of valuable species of timber trees or whether it needs to be supplemented by artificial planting.

Some of the first permanent sample plots in the National Forests were established on the Coconino and Tusayan Forests by the Fort Valley Forest Experiment Station, about 16 years ago, for the purpose of obtaining basic scientific data on these questions. There are now many such plots on the National Forests throughout the West, 
and also some on the less extensive eastern Forests. In addition to these silvicultural sample plots, hundreds of permanent sample plots have been established in the National Forests in connection with the study of range management. On these are being recorded the changes occurring in the herbaceous and shrubby vegetation and timber reproduction as a result of total protection from grazing or the type of grazing management in practice.

Relatively few of the permanent sample plots on the National Forests are in virgin forest and the silviculturist cannot imagine keeping all of them in such a condition, even if they are now. A few plots, however, will be retained in natural stands as a check on the cultural operations of the forester. Such plots in the virgin forest would be valuable chiefly from the standpoint of studying the natural succession of forest vegetation and competition in its broadest sense, as between individuals, species, and associations. Thus, while permanent sample plots in the National Forests will be primarily for silvicultural purposes, there remains a huge problem which will require intensive study by the ecologist on areas left in a natural condition.

Since the silviculturist is working in part on such utilitarian problems as the effects of different methods of cutting or thinning and slash disposal on the subsequent growth of the uncut trees and on natural regeneration, the reason why his permanent sample plots must be located largely outside of virgin forests is apparent. As a matter of fact, most of these plots are on culled or cutover lands where the conditions are at most only semi-natural. In many cases the original forest type is in time re-established and in others a sub-climax replaces it. These plots, however, will ultimately prove extremely interesting to the biologist because the forester maintains a detailed record, through the periodic measurement and examination of the trees and the vegetation on the areas, of all the changes taking place between the time of the cutting of the original stand and the maturity of the subsequent crop. Protection from other disturbing factors is usually provided. These plots will give the ecologist the complete history of the successional phenomena recorded, which will enable a more exact analysis and correlation of the results by eliminating the necessity for much interpolation and speculation concerning some of the intermediate phases.

It is therefore evident that the permanent sample plots in the National Forests, although they may not all be important from the standpoint of the preservation of natural conditions, will supply the forester, the ecologist, and the biologist with much valuable scientific information which cannot be secured in any other way.

\section{NATIONAL PARKS AND NA- TIONAL MONUMENTS}

\section{Bý E. Lucy Braun}

The United States government has, by the establishment of national parks and monuments, taken a foremost position in the preservation of one of our great economic and social assetsunusual and superlative natural scenery. The establishment of Yellowstone $\mathrm{Na}$ tional Park in 1872 marked the beginning of a project which has grown to great importance, and which has become a world-wide influence in the establishment of national reservations in other parts of the world.

The first effort at conservation was made in 1832, when Congress set aside the Hot Springs Reservation, which has since (in 1921) been made a national park. From the establishment of Yellowstone to the present time, the national park system has constantly grown. It was not, however, until 1916, that the National Park Service was established as a separate bureau of the Department of the Interior. There are now under its control, 19 parks having a total area of 11,372 sq. mi., and 29 monuments with total area of about 
$1820 \mathrm{sq}$. mi. In addition to these, there are 7 national military parks and 3 monuments administered by the War Department, and 13 national monuments administered by the Department of Agriculture.

A national park is created by act of Congress, and yearly appropriations made thereafter for its upkeep and development. A national monument is set aside by presidential proclamation; no direct provision is made for its development. Small yearly appropriations are now granted by Congress for protection and maintenance of the national monuments. National monuments are often, though not always, of lesser importance and smaller area than national parks. Areas of extreme importance in remote areas are sometimes set aside as monuments and later the status changed to park. This was true of the Grand Canyon and of Zion Canyon. The desired object-preservation -is accomplished in the establishment of the monument. A number of the national monuments have been established to preserve relics of archaeological and historical interest, as Montezuma Castle and Gran Quivira; others, as Muir Woods and Rainbow Bridge, preserve natural features.

National monuments administered by the Department of Agriculture, as Mount Olympus, are situated in national forests. That is, they are reservations within national forests, where natural conditions are to be preserved.

The integrity of the national parks has been attacked time and time again. Desire of commercial exploitation of water resources for power and irrigation projects, of grazing resources, and of timber, by local interests more concerned in their own financial advancement than in the interests of the Nation, must constantly be combated.

The act of Congress in 1916 establishing the National Park Service, was a distinct step in advance. In this act is contained the following statement:

The service thus established shall promote and regulate the use of the
Federal areas known as national parks, monuments, and reservations hereinafter specified by such means and measures as conform to the fundamental purpose of the said parks, monuments, and reservations, which purpose is to conserve the scenery and the natural and historic objects and the wild life therein and to provide for the enjoyment of the same in such manner and by such means as will leave them unimpaired for the enjoyment of future generations.

As Congress still has the power to modify park boundaries, and to grant easements within the park boundaries, it behooves the citizens of the United States, to whom the parks belong, to take an interested part in all questions relating to our national parks, and to express their disapproval of any plan violating the purpose for which the parks and monuments were created.

Irrigation and water power interests have made the most insistent demands for utilization of park resources. Yellowstone, Glacier, and Yosemite have been attacked. The Sherburne irrigation reservoir at Glacier and the destruction of the Hetch Hetchy Valley in Yosemite, should be an object lesson in the results of irrigation and water power developments. The amendment of the Federal water-power act (March, 1921), which removed the national parks and monuments already established from the operation of the provisions of the waterpower act, makes difficult but not impossible, future projects of this sort. A bill now pending calls for the erection of a dam across the Yellowstone River, which will raise the level of Lake Yellowstone, thus flooding surrounding land.

Grazing concessions present a question of great importance. While damage inflicted by grazing is not as irreparable as that produced by the building of dams, it is nevertheless very serious. Natural reproduction of trees and other plants is hindered or prevented; erosion is favored. Herbaceous growth is most affected, which means that the flower display is curtailed or entirely wiped out. The fodder of native grazing 
animals, as deer and elk, may be reduced to the point where survival in periods of extreme drought or in severe winters may be difficult. And last, but not least, sanitation is affected and the water supply may be impaired. That grazing has affected the appearance of the Grand Canyon National Park is evident from the report of the Director of National Park Service for 1923. "The park floral display below the rims of the canyon is extremely varied and beautiful in successive seasons, but the lack of such display on the rims is largely due to cattle grazing." Sheep grazing is prohibited in all national parks; cattle grazing is permitted in some areas.

The national parks and monuments comprise only one-third of one per cent of the total area of our country. "Certainly as a Nation we are rich enough to preserve from spoliation such a small amount of native America intact for the enjoyment of posterity."

National parks and monuments differ radically from national forests. The parks and monuments are intended to be true preserves, where every effort should be made to maintain natural conditions. Timber cutting and grazing are not permitted except in certain instances and should be wholly prohibited. Hunting, except predatory animals, and removal of any natural object by visitors is prohibited, except that a certain amount of angling is permitted. The addition to any national park of plants or animals which are not native should not be permitted, for the addition of foreign plants or animals would certainly not be in keeping with one of the established purposes of the parks and monuments-the conserving of the wild life therein-which should be interpreted to mean native wild life. This question has been considered by the Ecological Society of America (see "Resolutions," Ecology, vol. III: 170). The national forests, on the other hand, are a valuable measure toward conservation, not complete preservation, except in limited areas. Cutting of mature timber is permitted, and thus the composition of the forest is changed. Tree planting is resorted to improve the stands, or to increase the percentage of commercially desirable trees; hunting is permitted; grazing is general, even to the point of over grazing. Outside activities in the national forests are regulated by the Forest Service. Thus, while the national forests are great conservers of our national resources, it is in our national parks and monuments that natural conditions are best maintained at present.

The national parks policy, as announced in 1918, and reaffirmed recently by Secretary Work, should maintain our parks as the preserves of wild life that they now are. Its three fundamental prnciples are: "First, that the national parks must be maintained in absolutely unimpaired form for the use of future generations as well as those of our own time; second, that they are set apart for the use, observation, health, and pleasure of the people; and third, that the national interest must dictate all decisions affecting public or private enterprise in the parks."

Following is a list of national parks and monuments, arranged in order of date of establishment. Descriptions of most of these will be found in the state accounts; the distinctive features of the less important are given here. ${ }^{1}$

\section{NATIONAL PARKS ADMINISTERED BY THE} NATIONAL PARK SERVICE

Hot Springs, Arkansas; $1832 ; 1 \frac{1}{2}$ sq. mi.; 46 hot springs.

Yellowstone, Wyoming, Montana, and Idaho; 1872; 3348 sq. mi.; Wyo., page 532 .

Sequoia, California; $1890 ; 252$ sq. mi.; Calif., page 197.

Yosemite, California; 1890; 1125 sq. mi.; Calif., page 197.

General Grant, California; 1890; 4 sq. mi.; Calif., page 197.

Mount Rainier, Washington; 1899; 324 sq. mi.; Calif., page 175 .

Crater Lake, Oregon; 1902; 249 sq. mi.; Ore., page 191.

1 All quotations from Seventh Annual Report of Director of National Park Service. 1923. 
Wind Cave, South Dakota, 1903; 17 sq. mi.; S. D., page 555.

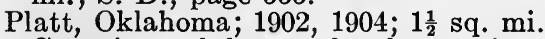
Contains sulphur and other springs of medicinal value; wooded area with wild flowers and birds.

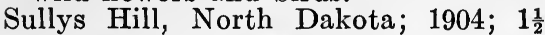
sq. mi.; N. D., page 547.

Mesa Verde, Colorado; 1906, 1913; 77 sq. mi.; Colo., page 527.

Glacier, Montana; $1910 ; 1534$ sq. mi.; Mont., page 539 .

Rocky Mountain, Colorado; 1915, 1917; $397 \frac{1}{2}$ sq. mi.; Colo., page 527.

Hawaii, Hawaiiau Islands; 1916, 1922; 186 sq. mi., in three separate areas.

Lassen Volcanic, California; 1916; 124 sq. mi.; Calif., page 198.

Mount McKinley, Alaska; 1917, 1922; 2645 sq. $\mathrm{mi}$.

Grand Canyon, Arizona; 1908, 1919; 958 sq. mi.; Ariz., page 568.

Lafayette, Maine; 1916, 1919; 8 sq. mi.; Me., page 310 .

Zion, Utah; 1909, 1918, 1919; 120 sq. mi.; includes former Mukuntuweap $\mathrm{Na}$ tional Monument; Utah, page 559.

NATIONAL MILITARY AND OTHER PARKS ADMINISTERED BY THE WAR

\section{DEPARTMENT}

Chickamauga and Chattanooga, Georgia and Tennessee; $1890 ; 6543$ acres. "Beautiful natural park. Embraces battle fields of Chickamauga and Missionary Ridge and scenes of other conflicts of the Civil War fought in the vicinity of Chattanooga during 1863."

Antietam Battle Field, Maryland; 1890; 50 acres. "Scene of one of the greatest battles of the Civil War."

Shiloh, Tennessee; 1894; 3546 acres. "Natural park embracing the battle field of Shiloh near Pittsburg Landing."

Gettysburg, Pennsylvania; 1895; 2451 acres. "Beautiful natural park. Scene of Civil War combat. Probably better marked than any other battlefield in the world."

Vicksburg, Mississippi; 1899; 1323 acres. "Beautiful natural park. Scene of the siege and surrender of Vicksburg in 1863 during the Civil War."

Lincoln's Birthplace, Kentucky; 1916; "Contains the log cabin and part of the farm where Lincoln was born."

Guilford Courthouse, North Carolina; 1917; 125 acres. "Near Greensboro. Scene of one of the great battles of the Revolution; fought in 1781."
NATIONAL MONUMENTS ADMINISTERED BY THE NATIONAL PARK SERVICE

Devils Tower, Wyoming; 1906; 1152 acres. "Remarkable natural rock tower, of volcanic origin, $1200 \mathrm{ft}$. in height."

Montezuma Castle, Arizona; 1906; 160 acres. "Prehistoric cliff-dwelling ruin . . of scenic and ethnologic interest."

El Morro, New Mexico; 1906, 1917; 240 acres. "Enormous sandstone rock eroded in form of a castle, upon which inscriptions have been placed by early Spanish explorers. Contains cliff-dweller ruins. Of great historic scenic, and ethnologic interest."

Petrified Forest, Arizona; 1906, 1911; 25,625 acres. "Abundance of petrified coniferous trees, one of which forms a small natural bridge."

Chaco Canyon, New Mexico; 1907; 20,629 acres. "Numerous cliff-dweller ruins."

Muir Woods, California; 1908, 1921; 426.43 acres. (See Calif.)

Pinnacles, California ; 1908, 1923; 2653.46 acres. (See Calif.)

Natural Bridges, Utah; 1908, 1909, 1916; 2740 acres. (See Utah.)

Lewis and Clark Cavern, Montana; 1908, 1911; 160 acres. Temporarily closed to the public. "Immense limestone cavern of great scientific interest, magnificently decorated with stalactite formations."

Tumacacori, Arizona; 1908; 10 acres. Ruin of Franciscan mission.

Navajo, Arizona; 1909, 1912; 360 acres. "Numerous pueblo or cliff-dweller ruins, in good preservation."

Shoshone Cavern, Wyoming; 1909; 210 acres. "Cavern of considerable extent, near Cody."

Gran Quivira, New Mexico; 1909, 1919; 560 acres. Early Spanish mission ruins and pueblo ruins.

Sitka, Alaska; 1910; 57 acres. "Park of great natural beauty and historic interest as scene of massacre of Russians by Indians. Contains 16 totem poles of best native workmanship.'

Rainbow Bridge, Utah; 1910; 160 acres. "Unique natural bridge of great scientific interest and symmetry. Height 309 feet above water, and span is 278 feet, in shape of rainbow."

Colorado, Colorado; 1911; 13,883 acres; "Many lofty monoliths, and is wonderful example of erosion, and of great scenic beauty and interest." 
Papago Saguaro, Arizona; 1914, 1922; 1940.43 acres. "Splendid collection of characteristic desert flora and numerous pictographs. Interesting rock formations."

Dinosaur, Utah; 1915; 80 acres. (See Utah.)

Capulin Mountain, New Mexico; 1916; 681 acres. "Cinder cone of geologically recent formation.

Verendrye, North Dakota; 1917; 253.04 acres. Includes Crowhigh Butte See N. D.

Casa Grande, Arizona; 1889, 1909, 1918; 480 acres. "These ruins are one of the most noteworthy relics of a prehistoric age and people within the limits of the United States. Discovered in ruinous condition in 1694."

Katmai, Alaska; $1918 ; 1,088,000$ acres. "Valley of Ten Thousand Smokes."

Scotts Bluff, Nebraska; 1919; 2053.83 acres. "Region of historic and scientific interest. Many famous old trails traversed by the early pioneers in the winning of the West passed over and through this monument."

Yucca House, Colorado; 1919; 9.6 acres. "Relic of prehistoric inhabitants."

Fossil Cycad, South Dakota; 1922; 320 acres. "Area containing deposits of plant fossils."

Aztec Ruin, New Mexico; 1923; 4.6 acres. "Prehistoric ruin of pueblo type containing 500 rooms."

Hovenweep, Utah-Colorado; 1923; 285.8 acres. "Four groups of prehistoric towers, pueblos and cliff dwellings."

Pipe Spring, Arizona; 1923; 40 acres. "Old stone fort and spring of pure water in desert region."

Carlsbad Cave, New Mexico; 1923; 719.22 acres. Immense cavern; see Nat. Geog. Mag., January, 1924.

NATIONAL MONUMENTS ADMINISTERED BY THE DEPARTMENT OF AGRICULTURE

Gila Cliff Dwellings, New Mexico; 1907; 160 acres. "Numerous cliff-dweller ruins of much interest and in good preservation." In Gila National Forest.

Tonto, Arizona; 1907; 640 acres; similar to Gila Cliff Dwellings. In Tonto National Forest.

Jewel Cave, South Dakota; 1908; 1280 acres. "Limestone cavern of much beauty and considerable extent, limits of which are as yet unknown." In Harney National Forest.

Wheeler, Colorado; $1908 ; 300$ acres. "Of much interest from geological standpoint as example of eccentric erosion and extinct volcanic action. Of much scenic beauty." In Cochetopa and Rio Grande National Forests.

Mount Olympus, Washington; 1909, 1912,$1915 ; 299,370$ acres. Contains many objects of great and unusual scientific interest, including many glaciers. Is summer range and breeding ground of the Olympic elk." In Olympic National Forest.

Oregon Caves, Oregon; 1909; 480 acres. "Extensive caves in limestone of much beauty; magnitude not entirely ascertained." In Siskiyou National Forest.

Devil Postpile, California; 1911; 800 acres. "Spectacular mass of hexagonal basaltic columns, like an immense pile of posts. Said to rank with famous Giant's Causeway in Ireland." In Sierra National Forest.

Walnut Canyon, Arizona; 1915; 960 acres. "Contains cliff-dwellings of much scientific and popular interest." In Coconino National Forest.

Bandelier, New Mexico; 1916; 22,075 acres. "Vast number of cliff-dweller ruins, with artificial caves, stone sculpture, and other relics of prehistoric life." In Santa Fe National Forest.

Old Kasaan, Alaska; 1916; 38.3 acres. "Abandoned Indian village in which there are numerous remarkable totem poles and other objects of historical interest." In Tongass National Forest,

Lehman Caves, Nevada; 1922; 593.03 acres. "Limestone caverns of much beauty and of scientific interest and importance." In Nevada National Forest.

Timpanogos Cave, Utah; 1922; 250 acres. Limestone cavern. In Wasatch National Forest.

Bryce Canyon, Utah; 1923; 7440 acres. "Box canyon filled with countless array of fantastically eroded pinnacles. Best exhibit of vivid coloring of earth's materials." In Powell National Forest.

Extensions of a number of parks are advocated by the Director of the $\mathrm{Na}$ tional Park Service: Crater Lake to include Diamond Lake; Yellowstone to include the Teton Country to the south; Rainier to include Ohanapecosh Hot Springs, to the southeast; and the much discussed extensions of Yosemite and Sequoia, which involve elimination of land now park territory, and inclu- 
sion of scenic areas now outside park limits.

The enlargement of Sequoia National Park by the creation of RooseveltSequoia National Park, involves not alone addition of desirable territory, but exclusion from the park boundary of parts of park territory. The addition includes some of the finest Sierra country-Mt. Whitney, the Kings and Kern Canyons and Tehipite Valley. The bill, as it now stands, retains all but a small part of the 3 southern townships whose exclusion met with so much opposition among naturalists. Most of the Sequoia groves are retained. The inclusion of the headwaters and canyons of the Kings River, one of the finest valleys of the Sierras, is meeting with strong opposition from local irrigation districts.

The proposed change in Yosemite National Park also involves the acquiring of a section of the High Sierras, and the exclusion of certain private lands (10,959.89 acres) along the western boundary. These private holdings cause administrative difficulties, because of grazing problems and the cutting of the timber. In both cases, the territory (not now privately owned) excluded from the parks comes under the control of the Forest Service.

Proposals for new parks and monuments are constantly being made. All must be investigated for availability and desirability. The area must be one of national, not merely local interest. Areas of great local interest should be taken care of as State parks. Only one national park, Lafayette, is situated east of the Mississippi River. It seems desirable that the park system be increased in this section of the country if suitable areas can be secured. Among proposals here, are Sand Dunes, ${ }^{2}$ Mississippi Valley, Appalachia, Everglades, Mount Katahdin, and Mammoth Cave. In the West, where scenic features of merit are more numerous, many propo-

2 "Report on the Proposed Sand Dunes National Park, Indiana." Stephen T. Mather, Director of the National Park Service. 1917. 113 pp. sals have been made prominent among which is the Glacier Bay region of Alaska. Many worthy areas have also been proposed as national monuments.

Proposals presented to the Sixtyeighth Congress, include the following:

Mount Katahdin (Maine).

Killdeer Mountain (North Dakota).

Roosevelt (North Dakota).

Mammoth Cave (Kentucky).

Mississippi Valley (Wisconsin, Iowa).

Utah (Utah).

Appalachia (Virginia) - to include summit of High Knob Mountain.

Wonderland (South Dakota).

Lincoln (Virginia, Kentucky, Tennessee) - to include High Pinnacle Mountain and Cumberland Gap.

Nicolet (Wisconsin)-an abandoned military reservation; 1046 acres.

Battle of Bear's Paw (Montana) -as a national monument.

Grand Coulee (Washington).

Yakima (Washington)- to include Mt. Adams and surrounding territory.

Blue Knob (Pennsylvania).

An area in a National Forest reservation in Georgia.

Many other bills to establish national parks and monuments have been presented. All such areas have been or are being investigated.

There has recently been appointed by Secretary Work, a Southern Appalachian Park Committee. This committee is "to undertake a thorough study of the Southern Appalachian Mountains for the purpose of selecting the most worthy site in that range as a national park, in order to conserve the scenery and the plant and animal life under established national park policies for the use and education of our people." They have since recommended two areas, the Shenandoah in Virginia and the Great Smokies in Tennessee and North Carolina.

The national park system will doubtless continue to expand, and to increase in value as its parks and monuments become increasingly popular as recreational areas, and as natural areas in which the study of native fauna and flora may be carried on to advantage. 


\section{LITERATURE}

Almost every periodical dealing with travel or nature contains articles on one or more of our national parks. The following are of a more general nature:

A Guide to the National Parks of America. Edited by Edward Frank Allen. Robert McBride and Co., New York, revised edition, 1918. 338 pp., map and illustrations.

The National Parks Portfolio. Robert Sterling Yard. 248 pp., 306 ill. Gov. Pr. Office.

Your National Parks. Enos A Mills.

Glimpses of our National Parks. R. S. Yard. 72 pp., 31 ill. Gov. Pr. Office. General Information regarding the National Monuments. (Contains descriptions of all national monuments administered by the Department of the Interior, the Department of Agriculture, and the War Department.) Gov. Pr. Office. (Out of print.)

Information Circulars for individual parks. Free on request to Director, National Park Service. (Available for Crater Lake, Grand Canyon, Hawaii, Hot Springs, Mesa Verde, Mount Rainier, Rocky Mountain, Sequoia and General Grant, Wind Cave, Yellowstone, and Yosemite.

Automobile Road and Trail Maps. Director, National Park Service.

Annual Reports of the Department of the Interior and of the National Park Service.

The Relation of Wild Life to the Public in National and State Parks. Charles C. Adams, Proc. 2nd Nat. Conf., State Parks, 1922.

\section{Glacier National Park}

Flora of Glacier National Park. Paul C. Standley. Contr. U. S. Natl. Herb., vol. 22, pt. 5. 1921.

Wild Animals of Glacier National Park. The Mammals. Vernon Bailey; The Birds. Florence Merriam Bailey. 210 pp., 94 fig., 37 pl., 1 map. 1918.

Origin of the Scenic Features of Glacier National Park. M. R. Campbell. 42 pp., 25 ill. 1914. Gov. Pr. Office.

Glaciers of Glacier National Park. W. C. Alden. 48 pp., 30 ill. 1914. Gov. Pr. Office.

Some Lakes of Glacier National Park. M. J. Elrod. 32 pp., 19 ill. 1912. Gov. Pr. Office.

Glacier National Park. A Popular Guide to Its Geology and Scenery.
M. R. Campbell. U. S. Geol. Surv., Bull. 600. 54 pp., 13 pl., map. 1914. Gov. Pr. Office.

Glacier National Park, Its Trails and Treasures. Mathilde Edith Holz and Katherine Isabel Bemis.

Tenting Tonight. Mary Roberts Rinehart. Houghton Mifflin Co. 1918.

\section{Yellowstone National Park}

Geological History of Yellowstone National Park. Arnold Hague. 24 pp., 10 ill. 1912. Gov. Pr. Office.

Geysers. Walter Harvey Weed. 32 pp., 23 ill. 1912. Gov. Pr. Office.

Fossil Forests of Yellowstone National Park. F. H. Knowlton. 32 pp., 15 ill. 1914. Gov. Pr. Office.

Fishes of the Yellowstone National Park. W. C. Kendall. 28 pp., 17 ill. 1915.

The Big Game Animals of Yellowstone National Park. Edmund Heller. Roosevelt Wild Life Bulletin, vol. 2, no. 4: 405-467. 1925.

The Food of Trout in Yellowstone National Park. Richard A. Muttkowski. Roosevelt Wild Life Bulletin, vol. 2, no. 4: 471-497. 1925.

The Birds of the Yellowstone National Park. Milton P. Skinner. Roosevelt Wild Life Bulletin, vol. 3, no. 1. 192 pp. 1925.

\section{Grand Canyon National Park}

The Shinumo Quadrangle, Grand Canyon district, Arizona. L. F. Noble, U. S. Geol. Surv., Bull. 549. 1914.

\section{Rocky Mountain National Park}

Geologic Story of Rocky Mountain National Park. Willis T. Lee.

Mountaineering in Rocky Mountain National Park. Roger W. Toll.

\section{Lafayette National Park}

The Sieur de Monts National Monument as a Bird Sanctuary.

The Coastal Setting, Rocks and Woods of the Sieur de Monts National Monument.

An Acadian Plant Sanctuary.

The Sieur de Monts National Monument as commemorating Acadia and early French influences of Race and Settlement in the United States.

Natural Bird Gardens on Mount Desert Island.

(All the above from Director of N. P. Service.) 
Yosemite National Park

A Yosemite Fora. Hall.

Sketch of Yosemite National Park and an Account of the Origin of Yosemite and Hetch Hetchy Valleys. F. E. Matthes. Gov. Pr. Office.

Forests of Yosemite, Sequoia, and General Grant National Parks. C. L. Hill. Gov. Pr. Office.

The Secret of the Big Trees-Yosemite, Sequoia, and General Grant National Parks. Ellsworth Huntington.

\section{Mount Rainier National Park}

Features of the Flora of Mount Rainier National Park. J. B. Flett. Gov. Pr. Office.

Forests of Mount Rainier National Park. G. F. Allen. Gov. Pr. Office. Mount Rainier and Its Glaciers. F. E. Matthes. Gov. Pr. Office.

Mount Rainier, a Record of Explorations. Edmond S. Meany. 번

Crater Lake National Park

Geological History of Crater Lake. J. S. Diller. Gov. Pr. Office.

Forests of Crater Lake National Park. J. F. Pernot. Gov. Pr. Office.

\section{MUSEUMS AND NATURE}

\section{By Frank Collins Baker}

Many well informed people have thought that the elaborate habitat groups in the modern museum can take the place of first hand contact with the animals in their natural environment. These groups are indeed wonderfully life-like, and in many cases faithfully portray the life as it may be seen in nature, and when scientifically accurate and constructed with due regard to the psychology of the museum visitor they have both a value to ecology and an interest for the visitor. But these groups, good as they are, only interpret certain phases of the life of the animals, giving the average person a birds-eye view of some of the phenomena which go to make up the every-day occupation of wild life. Such groups as the Virginia deer in the four seasons, on exhibition in the Field Museum of Natural History, give the student a good idea of the changes that take place in the form and fur of these common animals: but this simply interprets these phenomena and cannot take the place of the wild deer in their native haunts.

These museum groups, however, have a real ecological value, not only interpreting nature to those who may be fortunate enough to be able to visit the national parks and other wild places of nature, and so make these visits of more profit and pleasure, but they also give to those individuals (who unfortunately are in the majority) who cannot leave the big centers of population and enjoy wild life at first hand, a glimpse of wild animal life as it is, or more often, as it has been, before man took complete possession of the land, lake, and forest for his personal, and too often, selfish use.

The preservation of natural areas for the maintenance of wild life is emphatically desired by, and necessary for, the modern museum, for only by a study of these natural areas can these wonderful groups be made. It is becoming increasingly difficult to find places near the cities where even the smaller life can be studied for such purposes. Lakes and streams adjacent to towns and small cities (to say nothing of these near the large metropolitan cities, where almost everything is despoiled) are either heavily polluted and the fauna and flora killed or so changed by modern life of the suburbanite as to completely destroy all vestiges of original wild life. The preservation of small natural, more or less virgin, areas near small towns and cities is imperative and must be accomplished soon, or all such places will be lost forever.

The large museums of the big cities as well as the smaller museums of towns, small cities, and those connected with universities, are in a position to aid the movement for the preservation of wild life sanctuaries by the intelligent display of their material so that visitors may become interested in wild life, and thus be led to add their influence when constructive legislation is urged by the many societies fostering this subject. 
The museum habitat group has now become one of the chief features of interest in all museums, and many very good examples of this new art are scattered over the country from the Atlantic to the Pacific, notably at New York, Pittsburg, Chicago, Milwaukee, Denver, San Francisco, and other places, and the tourist may happily visit these places and later visit the native haunts of the animals exhibited. The automobile has brought the city and the wild places closer together, and one may often pass in a few hours from the museum halls to the wilds of a national or state park. The modern museum seeks to interpret the lives of wild animals for the benefit of all people, rather than to simply store up vast hordes of material for the specialist, though the latter work must be carried on also for the advancement of our knowledge of life in general. The museum is now, and always has been, the champion of the conservation of wild life.

\section{THE GAME REFUGES AND PUBLIC SHOOTING GROUNDS OF PENNSYLVANIA}

\section{By John M. Phillips}

Member of the Board of Game Commissioners of Pennsylvania, 1905 to 1924

Some 30 years ago, the thinking sportsmen of the State of Pennsylvania becoming alarmed at the rapid disappearance of wild game generally in this State, awoke suddenly to a realization of the fact that if it was to be saved for posterity immediate action was necessary to secure its protection and preservation. It was recognized that in order to attain results, a head to direct and guide the efforts of the sportsmen was necessary. After considerable agitation, in 1895, by an Act of Legislature, the Game Commission was created, empowered to collect data and to recommend legislation relating to the subject of game and wild bird preservation, and to enforce such laws as might be enacted.
The Commission was to consist of six sportsmen, appointed by the Governor, without regard to their political affiliations, as it was intended to keep the Game Commission a non-partisan body and out of politics; the Commissioners were to serve for love of the work and without remuneration.

The cause was particularly fortunate in the first Commission, as the men appointed were enthusiasts on the subject of wild game conservation; besides, they had had considerable experience in protecting birds and animals upon lands under their control. Soon after taking office, the Commissioners realized that in order to accomplish results something more than good game laws and their enforcement was necessary, for while this might take care of the game left in the State, no provision was made for increasing the supply.

Having in mind the magnificent results achieved by the Federal Government through the establishment of National Parks and Game Refuges in various parts of the United States, and the experiences of those in our State who owned private game preserves, the Commissioners, some years later, hit upon the idea of establishing in various parts of the State, refuges or sanctuaries into which game of all kinds and song and insectivorous birds could retreat and find safety when harassed by enemies. It was thought that freedom from disturbance, especially during the breeding season, in an area where predatory animals and birds could be exterminated, and where a closed season would be maintained perpetually, would result in a marked increase in the birds and animals in those sanctuaries.

A careful investigation of the subject of game propagation satisfied the Commissioners that efforts to raise in captivity our native game birds, such as wild turkey, ruffed grouse and quail had not as yet met with material success. Another point that was seriously considered was that just as the introduction of the English Sparrow and the German 
Carp had resulted disastrously to the Nation, so might the importation of foreign game birds and animals result in more injury than good to the State.

After considering all phases of the question, the idea of a game farm was abandoned, and the Commissioners turned with renewed conviction to the refuge or sanctuary idea, by which our native game birds and game could multiply without assistance from man, other than the systematic extermination of predatory forms and the absolute protection afforded by a perpetual closed season.

Happily for the purpose of the Commission, the movement for the conservation of our forests and water-supply was well under way. Our State Department of Forestry had already acquired large tracts of land, located almost without exception in our mountain counties, at the head-waters of streams, constituting a forest reserve area and recreation ground for our people, which, at the present time, aggregates over a million acres distributed over almost half of the 67 Counties of the State. The area of these forest reserves vary, ranging from 1176 acres in Wyoming County to 128,085 acres in Clinton County.

By an Act of Legislature of May 11, 1905, the Game Commission was authorized, with the consent of the Commissioner of Forestry, to establish Game Refuges or sanctuaries upon the State forest lands. The Legislature of 1907 limited the area of these Preserves to 9 mi. in circumference, while those of 1911 and 1915 increased their size and provided that the greatest transverse dimension should not exceed $10 \mathrm{mi}$. nor should the area of the preserve exceed $\frac{1}{2}$ of the total area of the tract of land of the forestry reservation upon which the preserve was located. In 1919, an Act was passed, backed by the sportsmen, authorizing the Game Commission to purchase with the surplus from the Resident Hunters License Fund, lands near our large centers of population, where the Forestry Commission did not already possess lands, for the purpose of establishing game sanctuaries and hunting grounds, similar to those on State lands. Also, an Act allowing the Game Commission to provide auxiliary game preserves of not less than 250 acres or more than 4000 acres through the consent of the owners or by lease. These auxiliary preserves may consist of farm lands.

These wild cut over and burnt over lands, although, in the main, unsuitable for agriculture, are the natural homes of the game it was desired to attract and propagate and possess the necessary summer and winter feed, streams and cover for our birds, bear, deer, squirrels, rabbits, etc. Chestnuts, beech-nuts, acorns and many other nuts, wild-grapes, haws and other fruits, are abundant, together with an almost endless variety of berries. So long as the ground remained bare feed would be plentiful, and with the coming of the snows and ice many of the birds could feed upon the buds of the beech, birch and other trees, and, if necessary, could be fed by the Preserve keepers. Besides, some of the tracts possessed waters upon which wild water-fowl might find a resting place, at least in their migratory flight.

Rather than establish a few Refuges of large dimensions, it was deemed advisable to create numerous small ones of about 3000 acres each in extent, and to locate them, as nearly as possible, in the center of the forest reserves in different counties. The purpose of so locating the sanctuaries was to make sure that the game propagated therein would first spread to the State land or land purchased with the sportsmen's funds rather than to the property of any individual or organization which might be posted to prohibit hunting. In this way, the game refuges would produce an unending supply of game which would naturally and inevitably spread to the public forest lands from which no hunter is barred.

It is thought wise to locate the refuges in sections where the game had formerly been plentiful but had been 
practically exterminated, to gain by such action the support and assistance of the hunters in that region, rather than to locate in territory containing plenty of game, thereby incurring the resentment of the hunters who would feel that their best hunting grounds has been taken away.

When the location of the Refuge has been decided upon, the first thing necessary is to exterminate the predatory species, which destroy more game than the hunters. The wildcat, weasel, fox, skunk, mink, crow, hawk, owl, and the prowling house-cat are, through the careful use of strychnine, and by other means, killed off. The next step is to guard against the danger from fire, and the brush is cleared from a strip of land 15 to $20 \mathrm{ft}$. wide around the outside of the Preserve. In some instances, where the danger from fire is pronounced, it is also crossed with fire lines, thus creating open roads where fires may be met and extinguished.

Predatory animals having been exterminated and provision made for fighting forest fires, we next surround the refuge with a single marking wire, fastened to trees or posts, about waist high on a man, the object being not to enclose the game but to define the limits of the refuge. This wire is usually nine miles long and is placed inside the fire lines surrounding the Refuge. At frequent intervals, notices printed upon muslin are tacked up along the line of wire, fastened to trees or posts, calling attention to the fact that the lands inside the wire are a State refuge for game, and asking for the coöperation of all in seeing that the game is not disturbed. The sanctity of these Preserves, in almost 15 years, has only been violated once, and then, it was claimed, by mistake, showing that our sportsmen appreciate their value.

The Refuge is now ready for the game, and if it is not already, sufficiently stocked, game of various kinds, such as deer, elk, wild turkeys, fox squirrels, etc., are purchased and placed in it. A State Game Keeper is in charge of each
Refuge. His duties are to fight fires, see that the Game is not molested, keep the Refuge free from predatory animals. on which, as an incentive, he is paid the regular bounties. In order to supplement the natural feed in the Refuges and attract and maintain wild life, he is instructed to plant walnuts, hickory nuts, mulberries, wild cherries, mountain ash, apples, wild grapes and other nut, fruit and berry producing trees and shrubbery, buckwheat and other grains. In addition to this, he plants barberries, spruces, pines, etc. for shelter and winter cover.

There are no fences around the Preserves and, as stated above, the wire is intended only as a marker, so that the game is not confined in any way, but can enter and leave the Refuge at will, it being intended to reproduce as nearly as possible the conditions under which animals and birds thrive in a wild state. Naturally, the herds and flocks intermingle at pleasure and there is no inbreeding with the consequent loss in stamina that would occur in a fenced enclosure.

Provided dogs and guns are left outside the wire, our Refuges are open to the public except during the open season for game when no person, save the officer in charge, is allowed within the wire, the purpose of this provision being to prevent the driving of deer and other game outside the Preserve onto the Forest Reserve, where it may be killed in the open season.

We now have 33 Game Refuges of about 3000 acres each with a large area surrounding them upon which men may hunt. Ten of these Refuges were purchased by the sportsmen's funds. Owing to the almost universal posting of farms against hunting and the hunter being a tenant-at-will on State lands, the forward-looking sportsmen of Pennsylvania are now asking for an increase in the Resident Hunters License Fee. This increase to be used exclusively for purchase of Game Refuges and Public Shooting Grounds, preferably in 10,000 acre tracts, scattered throughout 
the State, and to be under the absolute control of the Game Commission, for the purpose of propagating wild life and bringing back our forests and waters. The results attained have been so evident and so uniformly successful in all our Refuges as to demonstrate beyond any question the value of this idea. Our Preserves are no longer an experiment. The steady increase in the supply of game in them, on the large public hunting-grounds surrounding them, and in their neighborhood, has been remarkable. The large northern deer imported from other States and placed in these Refuges have thrived and multiplied so that localities in which they were formerly plentiful but had been exterminated are again populated with these beautiful and useful creatures of the woods.

Many stories are told regarding the instinct or sagacity of the deer, especially old bucks, in eluding their pursuers by seeking safety in these refugees. The grouse and turkeys are quick to take advantage of these sanctuaries, especially the former.

To our minds, this system of game propagation in its habitat and environment under absolutely natural conditions with protection from hunters and predatory animals, is infinitely superior to any plan which involves the breeding of game in confinement. In fact, the Pennsylvania Game Commission considers it a patriotic duty to bend all its energies and apply all its resources to the conservation and perpetuation of our native and useful wild life rather than to import from foreign countries at great expense birds and animals of doubtful values.

Through the adoption of Pennsylvania's constructive Game Refuge policy, the million acres of State Forest Reserve, on which a few years ago wild life was almost extinct, are being gradually made into the greatest hunting and recreation grounds ever contemplated for the benefit of the people of any State.

\section{THE RELATION OF OUR SHRUBS AND TREES TO OUR WILD BIRDS 1}

\section{By F. SмItн}

Anyone who pays even slight attention to the citizens of our bird world knows that they show preferences for certain kinds of surroundings. For some kinds of birds one must go to the open fields; for others, to the woodlands; while many shore and water birds must be sought along the water courses and in the swamps. A somewhat further acquaintance leads to the knowledge that birds of a given species may frequent very different kinds of situations for feeding, for nesting, and for refuge. Some species, as the robins and grackles which feed in the open fields, seek refuge and nesting sites in the woodlands and in shade trees. Still others, which may feed and nest on the ground in open fields, do not get very far from some protecting shrubbery or hedge to which they fly when disturbed.

Although certain kinds of birds are ready to adapt themselves to quite extensive changes in their surroundings, others will simply disappear when such changes occur. The cutting away of the forests of several northern states is known to have been followed by a decrease of some of the forest-loving species and an increase of those that prefer the open fields or the shrubby areas incident to new clearings. Reports on the birds of several different states are confirmatory of this statement.

When one learns the habits of all the birds which are to be found during the year in any one of our ordinary Illinois localities and then makes a list of those which are not dependent in any way on trees or shrubs for food, nesting sites,

\footnotetext{
1 From "Arbor and Bird Days," Illinois Cir. No. 83, Springfield, 1915.

W. I. McAtee states that there exists in most parts of the United States either a superstition, a conviction, or a legal requirement that roadsides be shorn of their vegetation at least once a year. So far as the effect upon birds is concerned, there can be no doubt that suppression of roadside vegetation is a potent factor in restricting their numbers. "Attracting Birds to Public and Semi-public Reservations," U. S. D. A. Bull. 715.
} 
or refuge, the list is found to be relatively short, especially if the locality is distant from a river or lake. From several locality lists available to the writer, each including from 85 to 170 species, it is evident that about 75 per cent of the species listed are in one way or another dependent on trees or shrubs. Since, of course, the same ratio may not hold for the number of individual birds found, it is desirable to ascertain, if possible, what share of the bird population of an average Illinois locality is independent in every way of trees and shrubs. Fortunately a pretty close approximation to such knowledge is obtainable from the very extensive and useful data accumulated by Prof. S. A. Forbes from the work of expert ornithological assistants in 1906, 1907 and 1909.

Two such observers, traveling in straight lines and always 30 yards apart, recorded all the birds flushed on a strip of land 50 yards wide and those that crossed the strip within 100 yards ahead. They recorded also the character of the fields traversed and the distances in each. Heavy timber in which there was little chance of a complete count was disregarded and the record was, of course, deficient for water birds. This work was carried on during all seasons of the year and was nearly equally distributed between the northern, central and southern parts of the state. The results show the numbers and kinds of birds in samples of the various sorts of environment in the state, equivalent to a strip of land fifty yards wide and over two thousand miles long. Among these results we have record of 48,558 birds from 39,940 acres. There were 9199 English sparrows and 546 birds were not positively identified. Deducting these latter two classes, we have record of the identity of 38,813 wild birds as distributed over farm lands, orchards, and shrubby areas and open woodlands. One hundred and seventy species were represented, 44 of which may be regarded as independent of trees and shrubs-able, apparently, to get along perfectly well without them.
Of these latter 24 species are birds of the open field and the others are shore birds or water birds. Of the remaining 126 species many will eventually disappear altogether, and the others will be represented in reduced numbers in localities where trees and shrubs are destroyed. About 69 per cent of the individual wild birds recorded by the foregoing observers belong to this group. These ratios correspond very closely with those from other available records based on more limited data. Fully twothirds of the wild birds of ordinary Illinois localities are in some way dependent on trees and shrubbery. The reasons for this dependence differ greatly for various species. Many, including some of the woodpeckers, are wholly dependent on trees for food, nesting sites and places of refuge. In most cases the insects associated with the trees supply the food, although to some extent the seeds, buds and even the cambium layer (in case of trees visited by the yellow-bellied sapsucker) may be eaten. Numerous other species, while getting their food from the ground or from the flying insects of the air, depend on trees or shrubbery for nesting sites or refuge or for lookout stations. Here, again, there is great diversity, since some kinds frequent mostly the upper parts of the trees, others prefer the lower parts, while still others are limited to those woods in which the ground is more or less covered with a thick undergrowth. Comparatively few species prefer the interior of the heavy forest, but many more frequent the forest margins or open woodlands, especially those with thickets. Shrubby fields and hedges are preferred by a number of species.

A large majority of the birds that pass the winter with us and of those that come from the south in the early part of the spring migration are of the thicket-and shrubbery-loving kinds. To find them we must seek them in the environment they prefer-along hedges, in neglected berry patches, in shrubby pastures, or in woods with plenty of 
under growth. When such places are all "cleaned up" the majority of the winter birds and early spring migrants disappear.

\section{GRAZING IN THE NATIONAL FORESTS}

\section{By C. F. Korstian}

The policy which governs the administration of the National Forests includes not only the insurance of a perpetual supply of timber and the preservation of a forest cover to regulate the flow of streams, but also the development of the other resources contained in the Forests for the greatest permanent good to the general public. Of all these the production and harvesting of the timber crop is the most important primary purpose defined by Congress. The forage resource, however, is of such importance in many parts of the West that its development through regulated grazing is one of the necessary functions of administration of the National Forests. Its extent is determined by the other objects of administration. The general policy therefore involves the development of the grazing resource to the extent compatible with that of the other National Forest resources and with a view to maximum production of meat and other animal products and maximum stabilization of the livestock industry.

The grazing of livestock obviously cannot be practiced without some modification of natural conditions. It may either retard or promote the development of the vegetative cover and cause either retrogression or progression, but in any case it tends to modify the types, depending chiefly upon the closeness with which the herbage is kept grazed annually and upon the time of grazing. In some instances unregulated grazing has seriously interfered with the regeneration of the forests by consuming tree reproduction along with the shrubby and associated species. Continued grazing of the range too early in the season or to too great an extent not only favors degeneration of the cover and ultimately the destruction of the vegetation, but also tends to impair the fertility of the soil by favoring erosion. These extreme adverse modifications of natural conditions, however, are the results of the abuse of the range.

Under scientific range management these abuses will be practically eliminated through the proper regulation of grazing. The writer has reviewed elsewhere $^{1}$ in some detail the consensus of opinion of range management specialists on the trend of grazing practice on the National Forests in relation to the preservation of natural conditions. The composition of the herbaceous plant associations will not, of course, be quite the same as though no grazing had occurred. The effects of grazing upon plant succession depend not only on the character and intensity of grazing, but also upon the type of vegetation. Progressive succession is favored by the system known as "deferred-and-rotation" grazing; that is, the grazing of parts of the depleted range only after the maturity of the better forage and the eventual extension of this practice in rotation to all parts of the range. This system is practiced in order to maintain the ranges at their highest producing capacity, as well as to revegetate the depleted ranges, since ordinarily by its use more ready establishment of valuable vegetation is secured than by total protection from grazing. The regulated grazing policy of the Forest Service is to keep the areas in the climax type of vegetation from the standpoint of maximum meat production consistent with the protection of watersheds and timber reproduction. This may mean occasionally a sub-climax ecological stage of the shrubby and herbaceous vegetation. Usually in the West, however, it will mean a climax ecological stage of the shrubby and herbaceous vegetation. This should offer little or no hindrance to the development of the

1 Korstian, C. F. "Grazing practice on the National Forests and its effect on natural conditions." Scientific Monthly, 13: 275-281. 1921. 
climax forest type or association since, when necessary, cut-over forest areas are closed to grazing during the regeneration period. Further, grazing has in many cases aided regeneration of the forest by improving the seed bed, trampling the seed into the soil, and lessening the competition through cropping of associated species. The aid to more rapid revegetation by properly regulated grazing has assisted in lessening erosion and in improving watershed protection.

Regulated grazing in the National Forests is further supported by the strong argument that it is beneficial in the control of forest fires. The value of grazing as a means of fire protection is realized in the utilization of the annual growth of grass which, if not so disposed of, becomes dry and inflammable and a serious fire hazard. The extensive work in forest fire prevention and suppression on the National Forests is a very important factor in promoting and maintaining climax types of forest vegetation.

In rendering the secondary uses compatible with the primary uses of the National Forests, and in harmonizing the secondary uses, it frequently becomes necessary to close areas to grazing as, for example, watersheds which comprise important sources of municipal water supply; recreational areas and those of unusual scenic attractiveness, such as the National Monuments; areas on which the forage on the range is needed for important game animals; and some forest areas in the course of regeneration. Many of the areas shown on the map of the National Forests (figs. 1 and 2) are in a semi-natural condition and fall within this category.

\section{FIRES IN RELATION TO THE BIOTA}

\section{By R. H. WolcotT}

For a long time previous to the development of ecology as a science fires have been recognized as an important ecological factor. Many scattered references to their effects upon animal and plant life are found in all kinds of literature, but few of these are based upon exact data or represent the results of continued observations.

A very full discussion of forest fires as to their kind, occurrence, causes, and methods of prevention will be found in Chapter VII of Graves' Principles of Handling Woodlands or in Chapter XV of R. C. Hawley's The Practice of Silviculture. At the end of these chapters there is given a very excellent bibliography on forest fires so that an enumeration of these points seems out of place here.

The damage caused by forest fires on this continent is enormous. Plummer ${ }^{1}$ makes the statement that

Forest fires in the United States have caused an annual loss of about seventy human lives, the destruction of trees worth at the very least $\$ 25,000,000$ and the loss of stock, crops, buildings and other improvements to the amount of many millions more. To these must be added enormous losses from the destruction of young tree growth, deterioration of the soil, damage to water courses and adjacent property by low water and flood, interruption of business and depreciation of property.

When to the loss by forest fires is added the loss from prairie and other fires it is seen that the total loss to this continent from fires up to the present time amounts to several billions of dollars.

As to the injuries due to fires, we may mention first, the destruction of the plants themselves with whatever loss that entails; second, the destruction of the humus in the soil with the resulting loss of fertility; third, the destruction of lumber or other valuable products; and fourth, the accumulation of dry material which may serve to feed succeeding fires. In many of the forested parts of the country the debris which has accumulated from one fire after another has resulted in the periodical burning over of areas for long periods of time.

1 Plummer, Fred G. Forest Fires, Bull. 117, U. S. Forest Service, Washington, 1912. 
There are certain benefits which may be attributed to fires including: first, favorable effects upon certain plants which find a greater abundance of nutrients in burned over tracts, such as blueberries and huckleberries; second, the improvement of forage by the removal of the stiff stems of the previous year's growth, permitting grazing animals to get at the young and succulent herbage; and third, improvement of reproduction by burning off grass or heavy leaf litter, thus giving a better chance for the germination of tree seeds.

Even "light burning" which has been advocated by some in order to keep the forest floor clean of litter, as a safeguard against more serious fires, upon investigation has been shown to bring about injury due to removal of nitrogen from the soil, change in soil texture, increased evaporation, and the scarring of trees, which paves the way for the attacks of fungi and wood-boring insects. It is decidedly a question if fires can serve any useful purpose in forestry, while on the other hand they constitute an ever-present menace.

The relation of fires to plant succession is obvious, but varies according to many conditions. If the fire has been such that the destruction of the vegetative cover is complete there may occur stages in its replacement corresponding to a complete succession beginning with the pioneer plants, but these are much condensed if the soil is not destroyed. This is most often observed after a general and a very destructive forest fire. In the destruction of bogs the soil may be largely consumed.

Invasion from the adjacent areas may occur and if the vegetation of these is similar to that destroyed the result may be the reëstablishment of the former conditions in a relatively short time. But actually it must be understood that any replacement takes many years. If the destruction is not complete and roots and seeds remain from which to develop a new growth, the invaders from surrounding areas may take possession at first, but these are gradually replaced by the species which were destroyed until finally the vegetation assumes the character which it possessed before the fire. In the case of forests, these invaders serve to protect the more tender forest vegetation until it has become established, when they are replaced by it.

If the fire affects only the secondary species such as herbs and shrubs in a forest in any plant formation then the succession operates only within those forms, and as a result the stages are short and not well defined.

It is possible for the fire to do so little damage, especially in grassland, as to destroy none of the members of the formation and give rise to no succession.

It has been remarked by others that succession after fires usually operates within water-content groups, due to the fact that the alterations of the soil are slight, except on slopes where the burning of the vegetation allows erosion to occur. Grasslands are replaced in most cases by grasslands and forest usually by forest.

The immediate effect of fires upon animal life, as well as upon plant life, is always destructive. Only those forms escape that are of large size and have effective means of rapid locomotion. Before the advancing flames is driven a horde of larger animals which under the influence of terror lose all fear of man and even invade towns and cities, while the smaller and weaker forms perish if exposed to the fire. Aquatic animals are not exempt from destruction for it is stated that in the great Miramichi fire in New Brunswick in 1825 fish in the streams were killed in such numbers as to be afterward found in heaps on the river banks.

The completeness of this destruction of animal life varies with the character of the fire. Since fires usually occur when the soil is dry, earthworms and moisture-loving forms will have retreated below the level affected or will have resorted to wet places where the fire is less severe. The numerous forms, especially insects, which live in the sur- 
face stratum will be affected in proportion as this stratum is involved, while those that hide beneath the trash which litters the ground are almost sure to be destroyed. In less severe fires, however, many species and numerous individuals escape by being hidden within and beneath fallen logs, where neither the flames, the heat, nor the poisonous gases generated in the fire reaches them. In the case of surface fires these three agencies (heat, etc.) destroy many forms in the forest canopy above but also spare many, especially if these are protected by being in the crevices of the bark, beneath it, or in cavities within the trees.

Fires also affect animal life by removing the cover behind which they find concealment, by destroying their nests and young, or the animals themselves in early stages of development, and by eliminating their food supply. At the same time a limited number of forms that live upon dead organic matter may find their opportunity in the halfdestroyed remains of animals killed by the fire.

Succession operates among animals, as among plants, and corresponding invasion occurs. The succession is very short in the case of grassland, where the original conditions are more speedily restored, but in the case of woodland the succession is more extended and occurs by several stages. First, in forest regions, animals of open ground may invade the burned area, later those resorting to thickets find congenial surroundings, and last the forest forms themselves return. Here again, however, certain of the original species may have disappeared never to return. For a short time after a forest fire a fauna flourishes, the existence of which is due to the presence of dead standing timber. This includes wood-boring insects and the predaceous forms which prey upon them. Woodpeckers find now both food and nesting places in the dead trees, while raptorial birds find the devastated area a favorable hunting ground.

Not only is animal succession after a fire dependent upon plant succession, but in certain respects the latter is affected by the former. For instance forest-dwelling mammals such as squirrels, and also certain woodland birds, which feed upon the seeds of coniferous trees, being excluded, the cones within the area which have escaped destruction may open and reproduction begin by means of the seeds which they have enclosed and protected, whereas in the undisturbed forest these would have been found opened, and the seeds eaten by the animals. In other cases seeds buried by rodents are the only ones left.

To one interested in the conservation of wild life, forest and prairie fires are sources of profound regret, not alone because of the destruction of life, but also because of the fact that the areas burned over are rendered incapable for some time of supporting an abundant and varied fauna and flora. To the ecologist fires mean the destruction of the evidence upon which may be based conclusions as to the history of the past succession of both plant and animal life, and the creation of new conditions, which, though they present many interesting problems, do not yield data of general or fundamental value in the determination of the principles of ecology.

Fires due to natural causes are unavoidable and unpreventable but these may be limited by constant watchfulness especially on the part of fire wardens. Those which are incendiary can only be reduced in number by the faithful cooperation of all the members of a community in the detection and bringing to punishment of the persons responsible for them. Those due to carelessness, which constitute by far the largest number, can be avoided in the degree to which the public generally is aroused to a realization of the damage resulting from fires and educated to the need of legislation and of care on the part of every individual.

It is absolutely essential, if bird and game refuges and all tracts set aside for 
wild life conservation or for ecological study are to fulfil the aims of those who have established them, that fires be entirely prevented. Aside from the actual loss of game animals which attends a fire of any extent, if even a small fire occur during the breeding season, there is the destruction of nesting birds, their eggs and young, the removal of the grassy or shrubby "cover" upon which they depend for concealment, and the elimination of the carpet of decaying leaves and rotting fallen logs which create conditions favorable for the development of a myriad of insects and lower forms upon which birds and other higher animals depend more or less directly for food. Those who resort to these preserves to satisfy their love of nature or for scientific investigation neither need nor desire the construction of roads, paths, and clearings within the tract, and such areas should be free from the intrusions of all others and carefully safeguarded from the danger of fires.

For the pleasure-loving public generally which desires opportunity for field sports and games, picnicking, etc., numerous and well distributed parks should be provided. The National Government is doing a service of inestimable value to our citizens and of far greater significance to future generations in the establishment of large national parks so situated as to include and preserve areas of great scenic interest. The states should supplement this effort by the establishment of state parks so disposed as to be accessible to the greatest number of people. Cities have long since come to appreciate the economic and social value of parks and every progressive community has a system of public parks with carefully devised plans for future expansion. Interest in birds, wild flowers, and all wild life is aroused and rapidly increasing and all such parks, whether national, state, county or municipal should offer opportunities for the exercise of that interest. All parks should, therefore, contain a certain proportion of wild land, which may well include hill slopes, ravines, creek valleys, and other tracts difficult to cultivate. This part should be left in a strictly natural state, with the native vegetation, shrubbery, fallen leaves, rotting $\operatorname{logs}$, etc., undisturbed. With proper care in landscaping, such areas could be made very attractive, and would furnish a refuge and breeding place for birds which are most valuable in the destruction of tree pests. The more open portions of parks should never be burned over and the greatest care should be taken that fires made for the burning of refuse or by picnickers be kept at a safe distance from growing forests. Liberal posting of notices and constant watchfulness on the part of attendants in local parks and by fire wardens in the state and national parks will be necessary to reduce the number of fires to the minimum.

Earnest and continued efforts should be made by all persons and associations interested to educate the public generally, and especially campers and hunters, in regard to the destructive results of fires and the necessity of always extinguishing camp fires before leaving them. The Boy Scout organizations can do effective work here. In any region, where there are extensive areas of public lands or lands in a wild state, wise and effective legislation is necessary, including the enactment of proper regulations, the posting of notices and the development of an efficient fire warden service.

All citizens should be urged to limit the burning over of land and to discourage unnecessary burning off of roadsides, waste areas, groves, and woodlands, because of the injury done to bird life and the damage to the soil due to the destruction of humus and consequent exposure to drying. It is sometimes necessary to burn over grassland to destroy pests but in very many cases at least the result may be more perfectly attained by ploughing. From the standpoint of the farmer it would be well if every bit of the land not under cultivation were occupied by grassland, shrubbery, or woodland. 
While the burning over of land may be the only practical method of cleaning it under some circumstances, it should be recognized that this involves a reduction in the future fertility of the soil and is a method to be avoided so far as possible. Unless scattering of brush is necessary to prevent drying out of the soil or to favor reproduction it should be collected in piles and burned in the late fall or winter. Railroads in timbered country, operators of portable saw mills and men using power logging should be induced to adopt such safeguards as would prevent the occurrence of fires or restrict the damage caused by those which may occur from their negligence. If necessary the aid of the law should be invoked to these ends.

In conclusion, attention should be called to the desirability of careful investigations on the precise changes in the ecological conditions due to fires in various types of habitat; to the need of exact quantitative as well as qualitative studies on succession in such habitats; and especially to the almost untouched field afforded by studies upon the fauna in these tracts. Every student of ecology who has available for study a burned over area has in it an opportunity which should not be neglected.

\section{THE EFFECT OF POLLUTION ON ANIMAL LIFE ${ }^{1}$}

\section{By Frank Collins Baker}

Stream 'pollution may be broadly divided into two main divisions: contamination by organic sewage from cities and towns and by chemical wastes from factories and mines. Both are inimical to life but the latter is especially fatal to animal life, causing wide stretches of otherwise fertile streams to become veritable deserts. Organic sewage, in a crude or highly concentrated form, is also very injurious, effectually eliminating most forms of life from the polluted body of water.

1 The greater part of this topic is condensed from a paper read before the Illinois State Academy of Science, and published in Vol. XIII, of the Transactions of that Society, pp. 271-279, 1920.
The importance and seriousness of the problem of stream pollution in its effect on the life of the rivers and streams into which the contaminating material is discharged has not, until very recently, been given the attention the subject demands. The diminishing fish supply, and in many places the very objectionable physical character of the polluted waters, have caused the authorities of several states to pass laws governing the discharge of these wastes into streams and the establishment of penalties for disregarding these laws. New York and Massachusetts have led in the framing of these laws and other states are following the good example set by these two older commonwealths, where the conditions seem to have reached a maximum of harmfulness (see Ward, 1918, 1919).

During recent years stream pollution has enormously increased and the problems arising from this condition have been investigated by many biologists and sanitary engineers. The former have studied the problem from the viewpoint of its effect on the useful animal life, especially fishes and river mussels, and this phase probably bears as close a relation to human welfare as any other. Of course, from the standpoint of health, the polution problem is of paramount importance because of its bearing on such diseases as typhoid fever which may be caused by a polluted water supply.

Perhaps the worst effect of chemical pollution is to be found in the streams of western Pennsylvania, where mine water heavily loaded with oil or acid water from coal mines is permitted to flow into the rivers and streams of this part of the state. Studies by Ortmann (1909) show that whole stretches of the Allegheny, Ohio, and Monongahela rivers have been made into deserts, as far as the animal life is concerned, by the large amount of poisonous substances discharged into these streams by the mines, oil industries, and chemical and other factories that border these rivers. In the Susquehanna 
River the same condition prevails in many places (Leighton, 1904). Such pollution causes a complete extermination of the fauna (and largely of the chlorophyl-bearing flora) and leaves the stream in such condition that restocking by either natural or artificial means is practically impossible, and if attempted is a waste of money.

Pollution by sewage, when the polluting material is of small percentage as compared with the pure water of the stream (as 200 to 1), causes little inconvenience to the animal life and is doubtless of some benefit because of the additional food material that is added (Forbes and Richardson, 1919, p. 146). But the streams seldom remain long in this innoxious condition, the sewage becoming more and more concentrated and less diluted until the whole stream may be supersaturated with noxious substances, the amount of oxygen in saturation reduced, and the biota finally driven out or killed.

Pollution is worst and usually most deadly to animal life during periods of low water and in winter when the amount of water in the stream is small and the decomposing organic material has less water to deprive of its dissolved oxygen. During times of floods the putrescent material is also carried down stream for many miles and contaminates areas not previously affected.

While all clean-water forms of animal life are more or less affected by sewage pollution, the decomposition of the organic matter abstracting dissolved oxygen from the water and rendering it unsuitable for aquatic life, the fish, river mussels, and crayfish are particularly affected, most fish being especially sensitive to contaminated water. Some fish (as the brook silversides, Labidesthes sicculus) are notably sensitive, while others (as the black bullhead, Ameiurus melas) will endure water that is badly polluted (Shelford, 1918, p. 27; Wells, 1918, pp. 562-567). Young fish are relatively more sensitive than adult fish. It is noteworthy that the more resistant species of fish are inhabitants of sluggish bodies of water, as ponds and shallow lakes, while the least resistant species live in running streams. It seems to be a question of the amount of oxygen necessary for the well being of the fish.

The ill effect of sewage pollution is most marked on the bottom of bodies of water, where a sludge is formed, often of great thickness (as much as $10 \mathrm{ft}$. in several cases), consisting of a mass of soft, black, sediment, with a high content of organic matter, in which only a few organisms, normally inhabitants of polluted streams, can live (e.g., septic Protozoa and Rotifera, foul-water algae, and slime-worms, Tubificidae). This effect on the bottom is perhaps the most serious phase of stream pollution because the septic condition of this area continues in operation long after the original source of contamination ceases to operate. This sludge formation renders the bottom unfit for clean-water life upon which many fish depend for food. The time necessary for the recovery of the normal biota of such a stream will in most cases be of long duration, and in the case of a stream polluted with wastes from mines and chemical manufacturies, there may never be a return to the original condition.

In the case of the Genesee River at Rochester, N. Y., we have a striking example of the history of a polluted stream and its effect on one group of the animal life. Previous to the stage of great pollution there is a varied fauna of mollusks very numerous in individuals. In the course of 11 years the gill-bearing species are forced out and after a lapse of 14 years all molluscan life ceases to live in this part of the river. Seven years later the greater amount of sewage is diverted to another outlet. Two years after this change we find that the mollusks have returned in as great numbers as before the maximum stage of pollution. The significance of all this lies in the fact of the early return of this life, and 
strikingly indicates that streams may become restocked with life in a short period after pollution has ceased to be of an unfavorable character. At the present time the sturgeon, which formerly resorted to the river to feed and breed, and had been driven out by the polluted condition of the stream, has returned, which is another indication of improved conditions. It is quite probable that the large fall in the river, some 60 feet in height, has had a marked effect in the return of these favorable conditions.

A study of the Salt Fork of the Big Vermilion River, indicates that all clean water life, including mussels and crayfishes, has been excluded from this stream for a distance of fourteen miles, and a normal fauna of these animals is not encountered until a distance of twenty miles has been traversed. The shallowness of this stream has evidently provided a sufficient supply of dissolved oxygen and it is apparent that in a deeper stream the ill effects of sewage pollution would be experienced for a much greater distance.

Ecological reports from different states show that wherever towns, cities, mines, or manufacturing plants are located near a stream, that body of water sooner or later becomes polluted. Little definite work has been done to bring together all of the data concerning river and stream pollution. That which is available indicates a truly alarming condition of affairs.

In South Carolina the fertilizer factories discharge wastes of many kinds, including sulphuric acid, into the streams, and oil-burning steamers permit oil to run into the water of harbors and bays. The State is taking action against this practise.

In Idaho and Montana mine water pollutes some of the streams. In West Virginia, as in Pennsylvania, the lower parts of the streams are polluted by refuse from coal mines, pulp and paper mills, chemical plants, and sewage from cities and towns. In Ohio, large streams are polluted by sewage and mine wastes. Iowa and Missouri streams are reported as badly polluted. In Arkansas, in the Poteau River, fish are being killed by mine wastes charged with iron salts, whose rapid oxidation suffocates the fish. In Minnesota, the large streams are polluted by sewage from the large cities. In Wisconsin, sewage is polluting Lake Winnebago from which the water supply of Oshkosh is derived. Manufacturing wastes from match factories and paper mills also pollute the waters of the Fox River.

These examples might be indefinitely extended. The survey of present conditions indicates that wherever stream pollution occurs the clean-water animals are sooner or later driven out or killed. Such a condition seriously affects our food and game fishes, which form so large a part of the meat of our population, and the situation demands immediate attention and early remedy. It is a matter of great satisfaction to scientific men that the authorities are awakened to the seriousness of such conditions and that in many cases they are providing remedial measures.

LIST OF REFERENCES IN THE TEXT

Baker, Frank Collins

1920. Animal Life and Sewage in the Genessee River, New York. American Naturalist, LIV, pp. 152-161.

1922. The Molluscan Fauna of the Big Vermilion River, Illinois. With Special Reference to its Modification as the Result of Pollution by Sewage and Manufacturing Wastes. Illinois Biological Monographs, VII, pp. 1-126, $6 \mathrm{pl}$.

Forbes, S. A., and Richardson, R. A.

1913. Studies on the Biology of the Upper Illinois River. Bull. Ill. State Lab. Nat. Hist., IX, pp. 481-574.

1919. Some recent changes in Illinois River Biology. Bull. Ill. Nat. Hist. Survey, XIII, pp. 137-156.

Leighton, Marshall O.

1904. Quality of Water in the Susquehanna River Drainage Basin. Water Supply and Irrigation Paper, No. 108, U. S. Geol. Surv., pp. 1-76. 
Ortmann, Arnold E.

1909. The Destruction of the Freshwater Fauna in Western Pennsylvania. Proc. Amer. Phil. Soc., XLVIII, pp. 90-110.

Shelford, Victor E.

1918. Ways and Means of Measuring the Dangers of Pollution to Fisheries. Bull. Ill. Nat. Hist. Surv., XIII, pp. 23-42.

Ward, Henry B.

1918. The Elimination of Stream Pollution in New York State. Trans. Amer. Fisheries Soc., XLVIII, pp. 1-25.

1919. Stream Pollution in New York State. A Preliminary In- vestigation of the Problem from the Standpoint of a Biologist. Report to N. Y. Conservation Commission, pp. 1-79.

Whipple, George C.

1913. Report on the Sewage Disposal System of Rochester, N. Y. By Edwin A. Fisher, City Engineer. pp. 179-200.

Wilson, Charles B., and Clark H. Walton, 1912. The Mussel Fauna of the Maumee River. Bureau of Fisheries, Document No. 757.

1912. The Mussel Fauna of the Kankakee River. Bureau of Fisheries, Document No. 758. 


\section{INTERESTS AND MANAGEMENT}

\section{UNION OF INTERESTS AND MANAGEMENT OF NATURAL AREAS}

\section{By V. E. Shelford}

With the growth of population, the destruction of forest and other original types of vegetation, and the modification of streams and lakes progresses rapidly. We have no royalty or nobility whose hunting and fishing preserves are being withheld from exploitation. Many more reserves are needed, but each year it becomes more difficult to secure them. Such reserves as are already created are continuously threatened with partial exploitation.

Probably the only effective way to retain all the features of existing reserves and secure an adequate number of new ones is to create and maintain a public interest in each reserve as well as in reserves in general. The public's knowledge of the uses of preserves is scanty. The interests which may combine in one reserve have been too little emphasized and may be classified as follows :

\section{A. INTERESTS IN PRIMEVAL AREAS}

\section{Scientific interests}

1. Biology. There is a growing tendency to make use of reserves of original character as a check on various laboratory operations, and in the study of ecology, as well as in the older taxonomic and natural history work.

2. Forestry. Natural areas will be valuable to foresters as object lessons, for comparison and standardization of forestry practice. They will serve as a standard of accomplishment of Nature alone and as a guide by which the correctness of the foresters' efforts to improve on Nature may be gauged.
Permanent sample plots, corresponding to the "quadrats" of the ecologist, are left in their original conditions for comparison with adjacent plots variously treated, so that changes in the composition, growth, and history of natural forest stands, as compared with modified stands, may be noted. On some of the National Forests a number of permanent plots are also maintained for the study of herbaceous vegetation and principles of range management in order to compare conditions on grazed and ungrazed areas.

3. Geography. Geographers require a knowledge of original vegetation and animals to interpret existing cultures, to generalize on various climatic and economic questions.

4. History. Historians require information similar to that sought by the geographer, in the interpretation of historical facts, and especially in interpreting the events of pioneer days.

\section{Literary and artistic interest}

1. Many pieces of literature cannot be interpreted without a knowledge of the original vegetation. Bryant's poem "The Prairies" is an example. Not a few teachers of literature make use of preserves.

2. Many artists who are students of nature use natural subjects.

\section{Recreational interests}

1. Sportsmen desire to increase the amount of game and in many states certain areas are set aside as game sanctuaries. In Pennsylvania a game sanctuary has a single wire stretched around it and is kept carefully guarded by wardens. No hunting is allowed inside the wire. The game is allowed 
to reproduce unmolested and overflows into the surrounding territory where hunting is permitted. The game in the area is not likely to become very much more numerous under such conditions than it was originally with its natural enemies, such as wolves, etc., roaming about. Thus perhaps within the sanctuary the conditions of balance of animal life is as nearly like the original one as could be hoped.

2. Ornithologists are interested in areas which afford protected nesting places for birds.

3. Wild flower lovers desire to see the flowers preserved and accordingly are interested in natural areas, which may act as seeding centers.

B. INTERESTS IN MODIFIED AREAS

("SECOND GROWTH" OF ALL KINDS)

1. Camping and related recreation.

2. Hunting.

3. Forestry operations leading to the production of lumber and other forest products.

4. Bird and game refuges.

5. Scientific study of succession of organisms with the development of a new biota (e.g., natural reforestation).

\section{ECONOMIC INTERESTS}

There are often watersheds which supply water to cities and water for irrigation purposes which will always be maintained and are available for scientific study, sample plots, bird preserves and perhaps game sanctuaries. Forestry practice retains some of the natural features. It is often possible for several interested groups to combine and make a strong plea for the setting aside of areas bounded by natural topographic features as preserves of natural conditions to serve all the eight or more purposes enumerated. The diversity of interest is an asset which makes the creation of preserves a far less hopeless task than many of those interested think.

\section{Management of preserves}

1. Subdivision. Areas should be subdivided into (a) public park, always open to the public but kept as nearly natural as possible, (b) tree growing areas which if large enough may serve for hunting and fishing, (c) natural areas which will serve for the study of biology, geography, history and art and as wild life sanctuaries.

The accompanying plan (fig. 1) shows a 60 acre tract designed primarily for a preserve of natural conditions. The entire tract is surrounded by a drive to prevent fires. The drive margin is set with native shrubs such as grow at the edges of woods, etc., designed to attract a maximum number of birds. The front portion adjacent to the public highway containing about 14 acres, is a public forest park with 3 circular driveways within which fires may be built. Behind is the preserve and this is an area (with the keeper's house at the center) surrounding it, designed for silviculture, the chief object of which is the demonstration of farm woodlot: forestry. This is open to the public with some restrictions. The central area is a preserve open only to those with special interests and designed as a game sanctuary, center of seeding, for wild flowers, a bird sanctuary, etc. Larger tracts may be similarly divided following topographic features (fig. 2) and even small city parts may maintain natural areas.

2. Rotation and policing. Natural parks are most easily obtained when the recreational interests support the project strongly. Two natural parks in two different states illustrate this point. The movement to secure them in each case was started by artists and nature lovers and only when the recreational possibilities were realized by politicians was the project pushed through the legislature. No plans of management were suggested and the parks were practically turned over to hotel and amusement concessionaires and naturalists now maintain that the 
original beauty will soon be ruined. Granting that most reserved areas must serve either for tree growing or recreation, or both, all proposed legislation should provide for management. This includes subdivision, coupled with a complete scheme of rotation of natural areas.

There should be a resident officer charged with caring for and guarding the park and instructing the public in the prevention of fires.

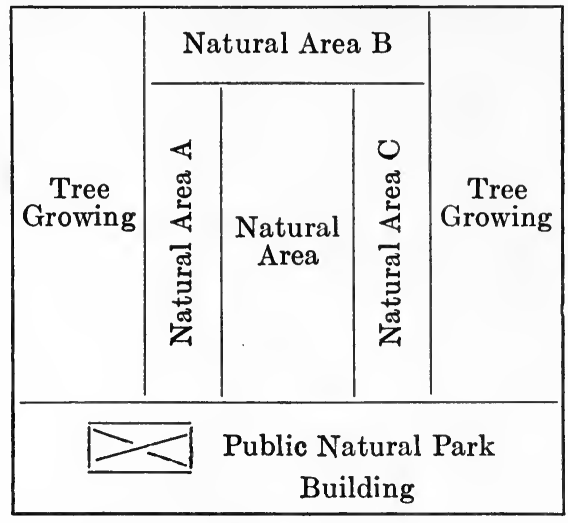

Plan for Park Subdivision into Tree Growing, Recreational and

Natural Areas

$A$, Open to the public for the year 1920, closed in 1921 and 1922.

B, Open 1921, closed 1922 and 1923.

C, Open 1922, closed 1923 and 1924. 


\section{E. ADMINISTRATION OF WILD LIFE}

\section{THE ADMINISTRATION OF WILD LIFE IN STATE AND NATIONAL PARKS 1}

\section{By Chas. C. Adams}

The administrative aspect of the wild life in our parks is a large and important subject. The problem of properly caring for and using wild life to the best advantage in our parks is becoming increasingly more serious and difficult. With the increasing number of park visitors new problems are coming up all the time. By decreasing the congestion-by enlarging the parksor by temporarily closing other parts as intensive use threatens to wear them out-recovery can be secured, but the general drift, with increasing population, is always to encroach upon the wilderness. Thus we see that to maintain park wildernesses can only be accomplished by a struggle, and the eternal vigilance needed to preserve our liberty is the same price which must be paid for the free wild nature of the wilderness. The wilderness, like the forest, was once a great hindrance to our civilization, but now the tide has turned and wildernesses and forests must be maintained, even at much expense, because human society needs them. Not infrequently have I talked with enthusiastic friends of our parks, who feel that in this struggle the odds are so much against the parks and their wild life, that there is perhaps no use to continue what they feel to be a losing fight. But it seems to me that this is only another aspect of that constant struggle for any high ideal-the only kind worth striving for; this is not at

1 Extracted from "The Relation of Wild Life to the Public in National and State Parks." Proceedings of the Second National Conference of State Parks. 1922, pp. 129-147, 1923. Revised edition, Roosevelt Wild Life Bull., Vol. 2, pp. 371-402. 1925. all a peculiar feature of our park problems.

European experience furnishes us with a number of examples of the value of wild areas because so little of the original conditions now remain there. But in spite of the unfavorable conditions the appreciation of these original conditions has not yet died out. This is worthy of special mention because of the fear one hears expressed that this is a hopeless cause. In several European countries there are active organizations, endowments devoted to this cause, and even governmental bureaus devoted exclusively to it (cf. Ahrens, 1921; Conwentz, 1909).

Some of the main administrative problems concerned with wild life are, the maintenance of this resource, including all protective aspects of vegetation and its animals, the formulation of policies, the education of the public on wild life, and the perpetuation of its ideals.

\section{MAINTENANCE}

The maintenance of wild life in the park, in a normal, healthy state, is a relatively new art in America. This involves proper protection, by rules, rangers or police, and by all educational devices available. But this protection is not all a question of restrictions, for there is the productive and constructive aspect. Favorable conditions must be maintained, so that the animals will breed normally. If fishing is permitted, the maintenance of the stock in the streams must be looked after continuously, and the supply maintained. Careful supervision of all this must be given and definite policies followed or great blunders will be made, and much damage will be done. A competent park official should supervise all this fish work. 
At present, administrators are in a difficult position because of the lack of definite ideas, policies, and public sentiment to support definite programs, and the frequent changes of officials favor a lack of cuntinuity in policies; and furthermore, with such a wobbling policy little is learned from experience.

\section{EDUCATION OF PARK OFFICIALS}

At present parks suffer to a large degree because they are necessarily in the hands of administrators who, because of their lack of special training, we must consider as amateurs. We have had no profession for this line of work, and some who have had the most training are feared to a corresponding degree, because of preconceived, formal ideals, which they with almost religious zeal slip into the wilderness parks. The ideal of a wilderness park is beyond their ken, because their approach has been from another angle. These persons are welcomed in formal city parks but in our large National and State parks they are liable to be a menace. In the training of such men there has been no adequate recognition of the wild life problems.

Another source of difficulty is the lack of trained rangers, and nature guides in our parks. These men are needed not only with a special familiarity with a special subject matter, but as well with the ideals of parks. Until very recently we have had no provision for such a training in our educational system, and not until adequate provision has been made can we expect the detailed work in the parks to be wholly satisfactory. A whole technical staff is needed for our parks, but this fact must be generally appreciated before men will devote themselves to it, and the public appreciate it fully enough to provide for it in the appropriations.

\section{NEED OF FORMULATING POLICIES}

At present our parks are in great need of definitely formulated policies, even if they are of a provisional nature (cf. Waugh, '18). A broad, general policy is not enough; it should be comprehensive but as well, it should be worked out in as much detail as is possible, so that in time we will have for our National Parks, a manual corresponding to the Use Book of the Forest Service. Each State Park or park administration should have a similar policy, which should be published and made a part of the educational data available to the public. It will then be available for criticism and improvement. Of course, as many park executives are without adequate help, are liable to political interference, and their tenure short, they are frequently liable to neglect the formulation of these policies, and depend solely upon the laws establishing these parks. Without general policies we can not expect detailed, well-worked-out plans for wild life. Today we have no such published program for the wild life of our National Parks, not even for the fish, which might be expected to precede that of other kinds of animals. The attitude of the U. S. Fish Commission, in the early days, had no conception whatever of the Yellowstone as a wilderness park, with the fish life maintained as nature left it and for this reason the Commission was favorable to stocking the waters with a variety of exotic fish, and of stocking the streams thoroughly above all falls uninhabited by fish, and likewise the isolated lakes. The idea that forests with big game animals should be maintained as a wilderness, and that there was an advantage in natural wild waters was beyond their conception. The attitude of the present U. S. Bureau of Fisheries, and of the Park Service itself has improved somewhat, but still it has in the main adhered to the older policies and standards of making angling available everywhere, rather than to maintaining a wild preserve. I have no doubt that this has come about or grown up without much deliberation, and certainly not after considering the 
value, in the remote future, of large areas for the educational and scientific value of true wilderness waters. Some of the same persons who are very eager to maintain a wilderness forest about their homes have never realized that others are equally interested in an aquatic wilderness untouched by man.

\section{THE WILDERNESS POLICY}

The Council of the American Association for the Advancement of Science, at the Toronto meeting, December, 1921, passed the following resolutions, which have a very direct bearing on the policy of our National and State Parks in maintaining their native plants and animals in natural conditions. These resolutions read (Science, N. S., Vol. 55, p. 63, 1922):

Whereas, One of the primary duties of the National Park Service is to pass on to future generations for scientific study and education, natural areas on which the native flora and fauna may be found undisturbed by outside agencies; and

Whereas, the planting of non-native trees, shrubs or other plants, the stocking of waters with non-native fish, or the liberating of game animals not native to the region, impairs or destroys the natural conditions and native wilderness of the parks;

Be It Resolved, That the American Association for the Advancement of Science strongly opposes the introduction of non-native plants and animals into the national parks and all other unessential interference with natural conditions, and urges the National Park Service to prohibit all such introduction and interferences.

If parks are to be managed so as to pass them on to future generations unharmed, they must in the main remain wild. No one can safely assume that he is able to tell how valuable these regions, when properly stocked, will become in the future. When once a plant or an animal becomes extinct it is beyond human power to restore it.

Although there are considerable areas of the National Forests which are likely to remain virgin wilderness this is not a sufficient guarantee that we will have all that we need. The chances are that in the near future foresters will, with increasing emphasis, strive to retain valuable examples of representative virgin forests within our National Forests and State Forests, in a virgin condition for special study. These areas will also act as preserves for many animals but they will not necessarily provide for the larger animals unless they coincide, as they well might, with wild life preserves. Some foresters have already observed the need of the forest "wilderness" as a part of the recreational policy of the National Forests (Leopold, 1921), and others for the purpose of teaching and investigation (Ashe, 1922), and if such areas give complete protection to both plants and animals great progress will be made. The grazing of domestic animals must be restricted or excluded from such preserve areas or the herbaceous vegetation will soon be greatly modified (Korstian, 1921). The experiences in the National Forests clearly show just what will certainly happen in our National Parks if they are not strictly guarded, from the wilderness point of view. These experiences also clearly show the great caution that must be exerted even with the present customary grazing in our National Parks. No doubt this should now be under the closest supervision of a forage ecologist. The same ideas apply even to living and dead trees, that at any time may be cut in these parks. At present we have only one official park forester in any of these great National Parks, and very few connected with State Parks and not all of these are fully alert to the value of virgin forests. European experience (Conwentz, 1909, pp. 118, 131), has clearly shown that clear cutting of the forests is very harmful to many kinds of native plants, and this is equally true for many animals, for we know that the vegetation exerts a powerful influence upon most forest animals. (Cf. Pearson, 1922.)

In certain State Parks commercial 
forest management is conducted, and this is very desirable under certain circumstances, which properly limits the commercial forests and the preserves, and provides for a corresponding management. At present great caution will be needed not to confuse the management of these two types of forests. A proper balance should be secured and then the income from the commercial forest might well be made a source of revenue for the maintenance of the whole park. In time the preserves themselves may find it necessary to charge a small fee for their use, and a forest park with funds from the timber and from a fee or license for the use of the preserve, might secure enough revenue to do much more constructive work than one depending solely upon taxation and gifts. This possibility is so important that it deserves more attention than it has received in the past. The new Allegany State Park in New York was planned upon such a program.

The time has come when we must begin an educational campaign for large endowments for the educational and scientific work in our National and State Parks. Of course, much can be done by cooperation with various individuals, the colleges, universities, and scientific societies, particularly with some of the State universities, especially if urgent requests are made to them for cooperation. They are likely to respond best when sought. But it is likely to take some time for these institutions to become acquainted with this phase of work, as most of them, even today, have but a faint realization of outdoor biological problems, and their application to parks. Fortunately there are a few marked exceptions.

The parks need these funds primarily for three purposes:

1. They need a technical scientific staff to solve their own scientific problems as much as they need lawyers and engineers. The need exists-but it is only slightly realized-and in the main only those who are taking a broad view of the situation are aware of the conditions.

2. They need an educational staff to build up their local museum-library, as nature guides, and to supplement and aid in the training of rangerswho should also be trained men. This staff should be the mainstay for popular lectures, lantern and moving picture lecturers who will arouse intelligent appreciation of the resources of the parks.

In general, the scientific and educational staffs must be distinct because the two kinds of work can not be done at the same time and the staff can not be expected to divide its attention successfully. An executive does not expect his lawyers or engineers to drop their work at any moment and give a popular talk or to conduct other extraneous work, and the same applies to the scientific staff.

The educational and scientific staff should be large enough to include certain men who could devote their whole time to the practical and technical problems that demand immediate attention, closely related to the administrative, rather than to the educational aspects of park work. The only reason for advocating this as a distinct group is that in practice it is rarely that sufficient funds can be obtained to secure men who are versatile enough to cover so large a field; it is therefore safer to plan for a larger staff.

It is generally difficult in administrative circles to appreciate that firstclass research men can only rarely be secured, who are willing to have their work continually interrupted by all sorts of administrative breaks. These men must, to get the results, be protected from such interruptions.

3. The wild life of the parks requires constant, all-year-round attention. A great number of our parks will become more and more patronized the year 'round when the people are educated to it. With this increasing patronage there will constantly develop new problems for solution and supervi- 
sion. It is only such a staff that can be expected to present, in the best popular form, the natural history resources of the parks. These popular accounts must be presented from many angles of approach, if a large public is reached to advantage. It is a common error to assume that there is only one popular form of approach; a multiple approach should be carefully cultivated by different types of students and authors.

There are certain problems of administration that must first be solved as scientific problems, and then executed under technical supervision, such as care of fish, game, birds, mosquito control and the management of the forests. These are examples of the problems, which, with increasing use, the natural resources will require. This is a kind of supervision which the average executive can not be expected to know, and yet these are just the points that a special staff will know about, and their advice and help are thus necessary.

In concluding these remarks on the need of endowments it is important to emphasize that wild life is a more or less elusive subject for the public and the administrator to understand, and cannot be understood merely by inspection-it must be known intimately, and therefore great damage can be done before it is realized.

The real difficulty is that wild life suffers just as the human animal does in our democratic system of environment. As Walter Lippmann has recently said: "For the troubles of the press, like the troubles of representative government, be it territorial or functional, . . go back to a common source: to the failure of selfgoverning people to transcend their casual experience and their prejudice, by inventing, creating, and organizing a machinery of knowledge.

\section{SUMMARY}

In concluding this discussion, I wish to summarize my main points as follows:

1. We will derive benefit from wild life in our parks in a direct relation to what we devote to them. We need to recall that they are living organisms and respond readily to fair treatment.

2. In general, wild life can only prosper with the parks as a whole.

3. Wild life is a very valuable resource in any wild park and is generally so recognized by the public.

4. The National Parks should remain a virgin wilderness for educational and scientific purposes.

5. State parks should retain wilderness areas, as well as contain commercial forests, depending somewhat on local conditions.

6. In relating the wild life to the public a variety of experimental popular publications is advocated. Technical reports are needed for Park officials. We need a distinctive park literature.

7. Field excursions conducted by trained guides are advocated, to develop trails and a trail literature.

8. A museum-library, devoted exclusively to the particular park, should be equipped for exhibits, lectures, demonstrations, lantern slides and moving pictures, to arouse interest primarily in the local park. This should be the headquarters for the guide service.

9. A local zoological garden of the park animals only should stimulate interest in those in the park.

10. The maintenance of a virgin wilderness park is very difficult, but not a hopeless problem, if proper public sentiment is developed in its behalf.

11. The education and training of park officials of all kinds is urgently emphasized. As a means to this end park policies should be formulated and published with a full explanation of park ideals.

12. The far-reaching importance of preserving original habitat conditions for plants and animals from an educational aesthetic and scientific standpoint is strongly emphasized. The value of State Parks in this plan is very important.

13. To develop public appreciation and utilization of parks, large endow- 
ments are needed to supplement public support. The greatest progress is made where public and private aid is combined with high and practical idealism. A movement should be started for endowments for educational and scientific work in both National and State Parks.

14. Park endowments are perhaps one of the best means of developing a technical staff for our parks. The preservation of wild life requires such supervision by specialists.

15. The wild life problem suffers from the major defects of our democratic system of control, and its welfare depends fundamentally upon improvements in this.

REFERENCES TO LITERATURE

Adams, Charles C.

1908: The Ecological Succession of Birds. The Auk, Vol. 25, pp. 109-153.

1908a. Some of the Advantages of an Ecological Organization of a Natural History Museum. Proc. Assoc. Museums, Vol. 1, pp. 170-177.

1910. The Relation of Field Excursions to the Activities of Local Museums. Proc. Amer. Assoc. Museums, Vol. 4, pp. 112-124.

1913. "The Value and Method of Ecological Surveys." Guide to the Study of Animal Ecology, pp. 23-35. N. Y.

1919. An Ecological Survey of the Palisades Interstate Park. Empire Forester, N. Y. State College of Forestry, Syracuse, Vol. 5, pp. 12-18.

1920. The Relation of Natural History and Ecology to Public Forest Parks. N. Y. State College of Forestry, Syracuse, Bull. No. 10 , pp. 11-14.

1921. Delights of the Wild Forest Trail. State Service (Magazine), Vol. 5, pp. 100-103.

1921a. Suggestions for the Management of Forest Wild Life in the Allegany State Park, New York. Roosevelt Wild Life Bull., Vol. 1, pp. 62-74.

Adams, Charles C., Hankinson, T. L., and Kendall, W. C.

1919. A Preliminary Report on a Fish Cultural Policy for the Palisades Interstate Park. Trans. Amer. Fish Soc., Vol. 48, pp. 193- 04.
Ahrens, Theodor G.

1921. Aims and Status of Plant and Animal Preserve Work in Europe, with Special Reference to Germany including a List of the Most Important Publications on These Preserves. Roosevelt Wild Life Buill., Vol. 1, pp. 83-94.

Ashe, W. W.

1922. Reserved Areas of Principal Forest Types as a Guide in Developing an American Silviculture. Jour. Forestry, Vol. 20, pp. 276-283.

Brown, Edward F.

1920. Social Aspects of Park Administration. N.Y. State College of Forestry, Syracuse, Bull. No. 10, pp. 47-66.

1920a. Camping Facilities in the Palisades Interstate Park. N. Y. State College of Forestry, Syracuse, Bull. No. 10, pp. 67-79.

Buxton, Edward North

1884. Epping Forest. Pp. 1-147. London.

Conwentz, H.

1909. The Care of Natural Monuments with Special Reference to Great Britain and Germany. Pp. 1-185. Cambridge, England.

Graves, C. Edward

1919. A Plan for a Nature Library. Litrary Journal, Vol. 44, pp. 707-710.

Grinnell, Joseph

1914. Bird Life as a Community Asset. Calif. Fish and Game, Vol. 1, pp. 1-3.

Grinnell, Joseph, and Storer, Tracy I.

1916. Animal Life as an Asset of National Parks. Science, N. S., Vol. 44, pp. 375-380.

Hahn, Walter L.

1913. The Future of the North American Fauna. Pop. Sci. Monthly, Vol. 83, pp. 169-177.

Haddon, A. C.

1903. The Saving of Vanishing Data. Pop. Sci. Monthly, Vol. 62, pp. 222-229.

Heller, Edmund

1925. The Big Game Animals "." of Yellowstone National Park. Roosevelt Wild Life Bull., Vol. 3, pp. 405-467.

Jessup, Elon 붕

1919. The Strangest Camp in the World. Outing, Vol. 75, pp. 155-160. 
Korstian, Clarence F.

1921. Grazing Practice on the National Forests and its Effect on Natural Conditions. Sci.

Leopold, Aldo Monthly, Vol. 13, pp. 275-281.

1921. The Wilderness and its Place in Forest Recreational Policy. Jour. Forestry, Vol. 19, pp. 718-721.

Mills, Enos A.

1920. The Adventures of a Nature

Pearson, G. A. Guide. Pp. 1-271. New York.

1922. Preservation of Natural Areas in the National Forests.

Safford, W. E. Ecology, Vol. 3, pp. 284-287.

1919. Natural History of Paradise Key and the Near-by Everglades of Florida. Smithsonian Report for 1917, pp. 377-434.

Shelford, Victor E.

1920. Preserves of Natural Conditions. Trans. Ill. State Acad Sci., Vol. 13, pp. 37-58.

Silloway, P. M.

1920. Guide to the Summer Birds of the Bear Mountain and Harriman Park Sections of the Palisades Interstate Park. N. Y. State College of Forestry, Syracuse, Bull. No. 11, pp. 1-105. 1920a. The Palisades Interstate Park: A Study in Recreational Forestry. The N. Y. State College of Forestry, Syracuse, Bull. No. 10, pp. 15-45.

Skinner, M. P.

1925. The Birds of Yellowstone National Park. Roosevelt Wild Life Bull., Vol. 3, pp. 1-189.

Smith, Harlan I.

1914. Handbook of the Rocky Mountains Park Museum, Dept. of Interior, Canada, Dominion Parks Branch. Pp. 1-126.

Sumner, Francis B.

1920. The Need for a More Serious Effort to Rescue a Few Fragments of Vanishing Nature. Sci. Monthly, Vol. 10, pp. 236248.

1921. The Responsibility of the Biologist in the Matter of Preserving Natural Conditions. Science, N. S., Vol. 54, pp. 39-43.

Waugh, Frank A.

1918. A National Park Policy. Sci. Monthly, Vol. 6, pp. 305-318.

1922. What is a Forest? Jour. Forestry, Vol. 20, pp. 209-214. 


\section{F. DUTY OF SCIENTIFIC MEN}

\section{THE DUTY OF SCIENTIFIC MEN IN CONSERVATION}

\section{By H. S. Graves}

The conservation movement of a few years ago crystallized and brought to public attention a great principle, one so far reaching that its real significance and scope are even today not generally grasped. Regardless of how the term may be defined, the problem of conservation involves the whole question of the relation of our natural resources to the economic life and upbuilding of the country. We have to do not merely with the prevention of waste and economical use of our resources, but also with the problem of how these resources may render their highest service in building up local communities, maintaining our industries, and contributing to a strong civilization.

We can point to considerable progress in certain features of conservation during the past decade. Scientific men have conducted research of great value that already is resulting in new uses of various raw materials, in more economical methods of handling them, and in improved methods of perpetuating those resources which are renewable; engineers are giving more attention than formerly to the problem of preventing unnecessary losses in the exploitation of raw resources; the more far-sighted leaders of industry have an increasing appreciation of the relation of natural resources to the permanence of their own enterprises. And yet, the conservation principle is making very slow headway, when viewed from the larger aspects of the economic needs of the country. The loss through unnecessary waste is still appalling, uneconomic methods in the use and de- velopment of various of the resources continue, and the interests of industries and communities are already in many cases jeopardized by the depletion of local sources of raw material.

Among the obstacles to the more rapid application of the principles of conservation are ignorance and indifference on the part of those engaged in developing natural resources, unwillingness to change old methods, and selfishness of individuals who are willing to sacrifice even the interests of their own industry to immediate gains. But there are also obstacles of an economic and public character, that are retarding progress. These relate to the character of ownership and control of natural resources, to the existing organization of certain of the industries to problems of transportation, and in some cases to questions of taxation and the relation of the public to industry.

Scientific research furnishes the foundation of conservation. Education will solve the problem of ignorance and indifference. The economic and political obstacles, however, can usually be overcome only through action by the public. Thus it is that those who are engaged in promoting the principles of conservation in their respective fields are urging legislation in the federal Congress and in state legislatures, seeking public aid for private owners of resources and for the industries, public cooperation in marketing and distribution, public action in road building and other transportation problems, and in some instances public control over the basic resources themselves, over their exploitation, or over the distribution of their products.

The efforts in conservation today are scattered among a large number of 
institutions, organizations, and individuals. There is a lack of unified purpose and direction in the movement. Workers in separate fields fail to give adequate consideration to the bearing of the problems of other resources upon their own. Oftentimes there is an actual conflict of interests in the use and development of two or more resources that is not being adjusted and is leading to public injury. In the field of public policy many proposals are being made, each perhaps with a good purpose, which are not in harmony as to principle and often are in conflict, with resulting confusion to the public and frequent failure to secure the legislation requested.

Today there is no central agency, governmental or otherwise, that is considering our natural resources as a whole in their relation to our economic, industrial, and social development. There is no leadership in conservation in its larger aspects, that defines objectives, assembles and interprets the basic data regarding our resources, works out the principles of harmonizing conflicting interests in resource development; that furnishes, in short, the economic background for conservation and the principles that must underlie the public action necessary to make our natural resources render their best service, and there is no agency equipped to organize the educational work that should be introduced into our colleges and schools aside from popular education in conservation.

It must be clear to every student of the natural resource problem that there is an undertaking in conservation of great magnitude awaiting leadership and organized effort. There is an opportunity and, in my opinion, a duty for the great national organizations of scientific men to join hands in assuming this leadership. They are in a position to bring into harmony the objectives, the policies, and the efforts of those working in the several branches of natural resources. Under their guidance and inspiration there could be assembled the available information regarding our natural resources, and the interpretation of the problems of conservation from the broad viewpoint of the relation of all resources to our national development. The scientific organization would thus be able to contribute to the formulation of public policies, and to aid in bringing about their adoption, and finally it would be possible for them through existing agencies to carry out an educational plan for the introduction of appropriate studies in conservation in our schools and colleges, and to forward a far-reaching campaign of popular education.

The appointment of conservation committees by the National Academy of Sciences, the National Research Council, and the American Association for the Advancement of Science, and the meeting of these committees for the consideration of joint action, should prove to be the first step in a new leadership that will give power to the conservation movement, with the promise of very large achievement.

In my opinion a very great responsibility rests upon scientific men. We have an opportunity to organize the intellectual forces of the country in a movement that will have a profound influence upon the future well-being of the country. Our action may determine the direction of that movement, and whether it will be effective or lag behind for lack of leadership. A great public interest depends upon our foresight and vision, upon our ability to plan with wisdom. 


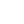




\section{ORIGINAL BIOTA OF THE AMERICAS NORTH OF THE AMAZON}




\title{
A. INTRODUCTION
}

\author{
By V. E. Shelford
}

The early naturalist travellers described the regions which they visited in terms of the vegetation landscape aspect. Brehm and others wrote on tundra, steppe, desert coniferous forest, etc., and described the behavior characteristics and mode of life of their larger animals. Of the Arctic fox Brehm says: "Of the slyness and ingenuity, the calculating craft, the never failing presence of mind of his congeners he evinces hardly a trace. His disposition is bold and forward, his manner officious, his behavior foolish." Many other naturalists made observations of this type relative to the animals of natural vegetation landscape aspect regions.

With the acceptance of evolutionary doctrine attention turned to the seeking of facts which supported doctrines of origin, migration, modification, and adaptation, and naturalistic observations relative to behavior, mode of life, etc., of animals received little attention from travellers, naturalists, and collectors. The description of vegetation in relation to climate, etc., however, received a less serious check. In recognizing natural regions these landscape aspects still serve as a general guide in modern ecology but the limits of areas may be made on the basis of climax communities whenever investigations have demonstrated the facts. A climax community may occur only locally, for example within the coniferous forest of southeastern United States, which is commonly regarded as giving way to a deciduous climax. In this case there are two landscape aspects and only one climatic climax. The nature of the climax communities has been determined only for a few regions in temperate latitude. Accordingly landscape aspect must serve as the chief guide and plant ecologists of necessity approach the subject of plant geography from the standpoint of the landscape aspects and physiological characters of the plants of the larger plant communities. Animal ecologists recognize the value of such a viewpoint as applied to animals, but so far they have made little progress with it largely because little investigation has been done. As a rule zoogeographical discussions have proceeded along the line of refinements of Wallace's faunistic ideas, of tracing paths of migration for particular groups of species or genera, etc. The point of view of those using life zones based largely on temperature is largely descriptive, but has been related to faunistic (i.e., evolutionary) work rather than physiology. They have made few or no attempts to find differences in physiological life histories, habits, etc., between animals in different regions, or similarities of those in like regions. The ideas of modern ecological geography are known to but few zoological investigators.

The ecology of animal communities which is the basis of modern animal ecology has received little attention. While much zoological work is referred to as "ecology," especially among economic entomologists, analysis shows that it is largely the ecology of particular species and individuals (autecology). In other words it is a continuation of the old natural history under the new name. Where community studies are made, too often only a part of the animals are considered so that we find such misnomers as "Insect Associations," etc. 'Though the essential principles were recognized by a few early zoologists (Mobius, 1877 
and 1880) there is nothing in zoological literature representing the essence of modern synecology as do Clements' two works on plants. (Succession, 1916, and Plant Indicators, 1920.) Clements has for some time recognized the importance of considering animals in plant ecology. Plant ecologists in general are prone to describe formations and associations, often without giving a comprehensive idea of the nature of an area as an animal habitat. For example the combination grassland and streamside and grove forest of the Mississippi Valley which, on account of animal movement, seems best named savanna, was referred to in several manuscripts as deciduous forest and prairie without any statement as to arrangement and relative area of the two. Many of the original large and small animals of this region, characteristically divided their time (usually seasonally) between the two plant communities or lived at the shrubby border between them. Plant ecologists appear to have recognized the symbiotic relation of plants and animals in communities only to a small degree. Animal ecologists have of course not contributed their share of knowledge for reasons already noted. Movement of animals from one small plant community to another may be as important to the general biota as is number of dominants or at least secondary considerations concerning plants in communities.

While faunistic zones agree with vegetation in some cases, those who use life zones often divide regions with similar climate and uniform vegetation into two or more zones because the species are different, though physiological relations may be supposed to be similar (Chaprnan, 1917). It may be said that floristic and faunistic geography including life zone work rests on a background of evolution and migration, while ecological plant and animal geography have a similar relation to (climatic) conditions and physiology.

No one doubts that the life zones as used mainly by zoologists are a correct representation of certain facts of relationship, and are worthy of scientific recognition. They do, however, violate two important principles or methods of modern ecology. In the first place they fail to separate the local communities determined by soil, water, etc., from the extensive communities which are commonly regarded as determined by climate. Life zone index organisms are as likely to belong to local areas such as stream margins or other early stages in succession as otherwise. Second, the life zones sometimes divide a uniform climax association into two or three parts as in the case with deciduous forest and mixed prairie. In much of the United States life zones are separated by east and west lines and plant communities by north and south lines. To the north in Canada the two appear to be in better agreement. In the Rocky Mountains they are sometimes in agreement and sometimes not. In the tropics most of the life zone studies have been carried on in mountainous regions. While the work is largely descriptive, the expression of the viewpoint is found in Chapman's introduction, in which he states that "To determine the boundaries of zones and faunas as they are manifest by birds and mammals is our first aim . . and trust that we may throw some light on laws governing the origin of species. . . ."This is not the object of modern ecology, which is on the contrary concerned with symbiosis (sense broad) succession, climax types, and physiological relations to the physical environment and its rhythmic phenomena, etc.

However, it is true that the life zones pointed out by investigators in Central and South America do consist of one or more landscape aspect areas. The investigators along this line possess an excellent knowledge of the landscape aspect types. Accordingly, a measure of agreement has been reached for the tropics; though starting from two quite different viewpoints, it is evident that agreement cannot be general. Parallel 
tables have been developed to show the relations of the two kinds of regions.

\section{NORTH AMERICA NORTH OF MEXICO}

The accompanying maps (figs. 1, 2, and 3) show the more important extensive habitats drawn so far as practicable on the basis of dominant landscape aspect conditions. In differentiating the areas, plants, animals, and climate were considered.

\section{a. Plants and animals}

From the standpoint of the larger animals the following are of much importance and should tend to outweigh minor botanical considerations:

Is the forest evergreen or do the leaves fall, thus accentuating the severity of adverse seasons?

Are grasses or other plants present which afford dry food in cold or dry seasons?

Is the vegetation of such height and density as to afford shelter for larger animals, or is it short-stemmed and inconspicuous, or scattered and nonshade producing?

\section{b. Climate}

The most important question about climate is probably the character of the annual march of rainfall, of temperature, and of other factors.

The accompanying maps ${ }^{1}$ are very generalized. Figure 1 is based largely on Shreve's map for the United States, on the maps of Schimper and of Hardy on Koppen's Classification of climate, and Bartholomew's Atlas. The descriptions of vegetation are modifications of Shreve's. Some modifications of the plant regions have been made because of facts about animals. For instance, an area like the Snake River Plains which once supported herds of bison should hardly be called desert.

1 Submitted to the members of the committee. Suggestions by B. E. Livingston, F. Shreve, W. E. Lawrence, H. C. Cowles, G. B. Rigg, G. E. Nichols, C. D. Howe, E. N. Transeau, J. W. Harshberger G. P. Burns, C. O. Rosendahl, E. Lucy Braun, R. M. Harper (botanists) and J.' R. Watson, W. G. Van Name, A. S. Pearse (zoologists) were adopted and are as represented in figure 3 and those parts of the United States shown in figure 4 . 


\title{
B. DESCRIPTIVE LIST OF NORTH AMERICAN BIOTA (SOUTH TO CENTRAL MEXICO)
}

\author{
By V. E. Shelford, L. Jones and L. R. Dice
}

1. ARCTIC TUNDRA, OR BARREN GROUND BIOTA (ARCTIC TUNDRA OF CLEMENTS)

Extensive areas in the northern part of the continent have long cold winters and little rainfall. In the more northern localities the ground thaws only at the surface and a growth of herbaceous plants springs up in the summer. There are dense growths of grass, many miniature shrubs, shown in black on the map, considerable areas of high tundra, especially in Alaska. Large areas of perpetual snow are included.

It supports muskoxen (Ovibos moschatus subspp.), barren ground caribou (Rangifer spp.), arctic hare (Lepus arcticus group), arctic fox (Alopex spp.). The chief local conditions are swamps and ponds, which support hordes of mosquitoes.

The breeding birds ${ }^{1}$ include the following: willow ptarmigan, rock ptarmigan, white gyrfalcon, gray gyrfalcon, gyrfalcon, black gyrfalcon, snowy owl, horned lark, pallid horned lark, Greenland redpoll, hoary redpoll, greater redpoll, snow bunting, Lapland longspur, Alaska longspur, Smith's longspur, Alaska yellow wagtail, and pipit.

Breeding birds whose habitat is limited to the presence of water, generally a local condition, include the following: yellow-billed loon, Pacific loon, red-throated loon, pomarine jaeger, parasitic jaeger, long-tailed jaeger, red-breasted merganser, old-squaw, Harlequin duck, Steller's eider, spectacled eider, King eider, Pacific eider, scoter, white winged scoter, snow goose, white-fronted goose, whistling swan,

1 English names conform strictly to the A. O. U. Check-list, unless otherwise specifically noted. red phalarope, northern phalarope, long-billed dowitcher, stilt sandpiper, knot, purple sandpiper, pectoral sandpiper, white-rumped sandpiper, Baird's sandpiper, least sandpiper, red-backed sandpiper, semipalmated sandpiper, western sandpiper, sanderling, Hudsonian godwit, yellow-legs, buffbreasted sandpiper, Hudsonian curlew, Eskimo curlew, black-bellied plover, golden plover, Pacific golden plover, semipalmated plover, turnstone, ruddy turnstone, and black turnstone.

1a. ALPINE STEPPE OR HIGH TUNDRA (PARAMOS OF PENNELL) (APLINE SUMMITS, SHREVE) (APLINE MEADOW CLIMAX, CLEMENTS)

Sedge, grass, and herb covered areas in high mountains. The large mammals include bighorn sheep (Ovis canadensis subspp.), and Rocky Mountain goat (Oreamnos americanus subspp.). Rosy finches and white-tailed ptarmigan are characteristic birds.

\section{NORTHERN CONIFEROUS FOREST BIOTA}

(NORTHERN MESOPHYTIC EVERGREEN FOREST, SHREVE)

"This extensive region is characterized throughout by a pure or nearly pure stand of needle-leaved evergreen trees, among which deciduous trees are often present either as minor components of the forest or else as trees of lower stature. Virgin stands of this forest range from 60 to $125 \mathrm{ft}$. in height and vary from open park-like formations to heavy forest with a completely shaded floor. The heaviest stands are almost devoid of shrubby undergrowth, but the more open ones are accompanied by deciduous shrubs and under-trees. In 


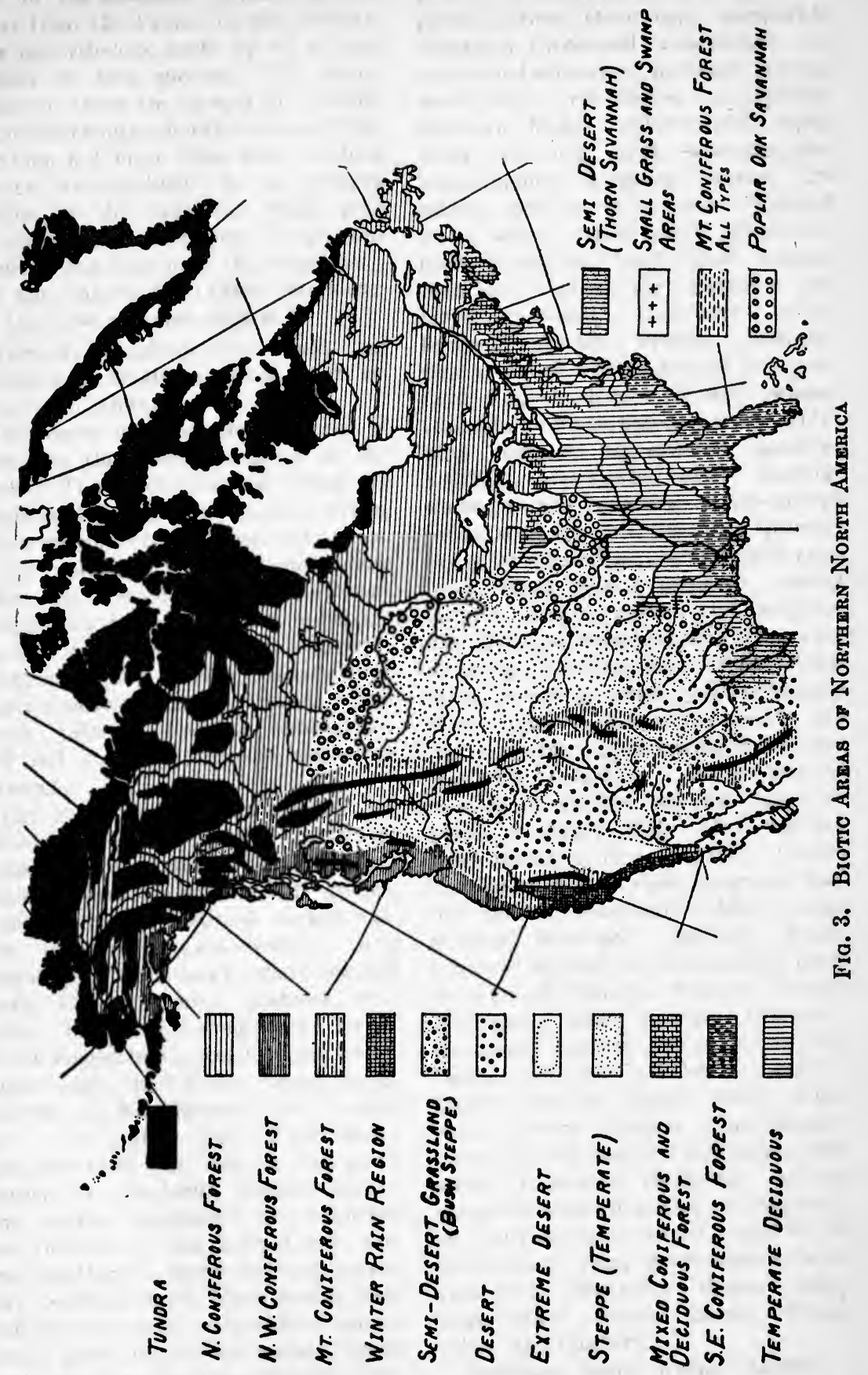




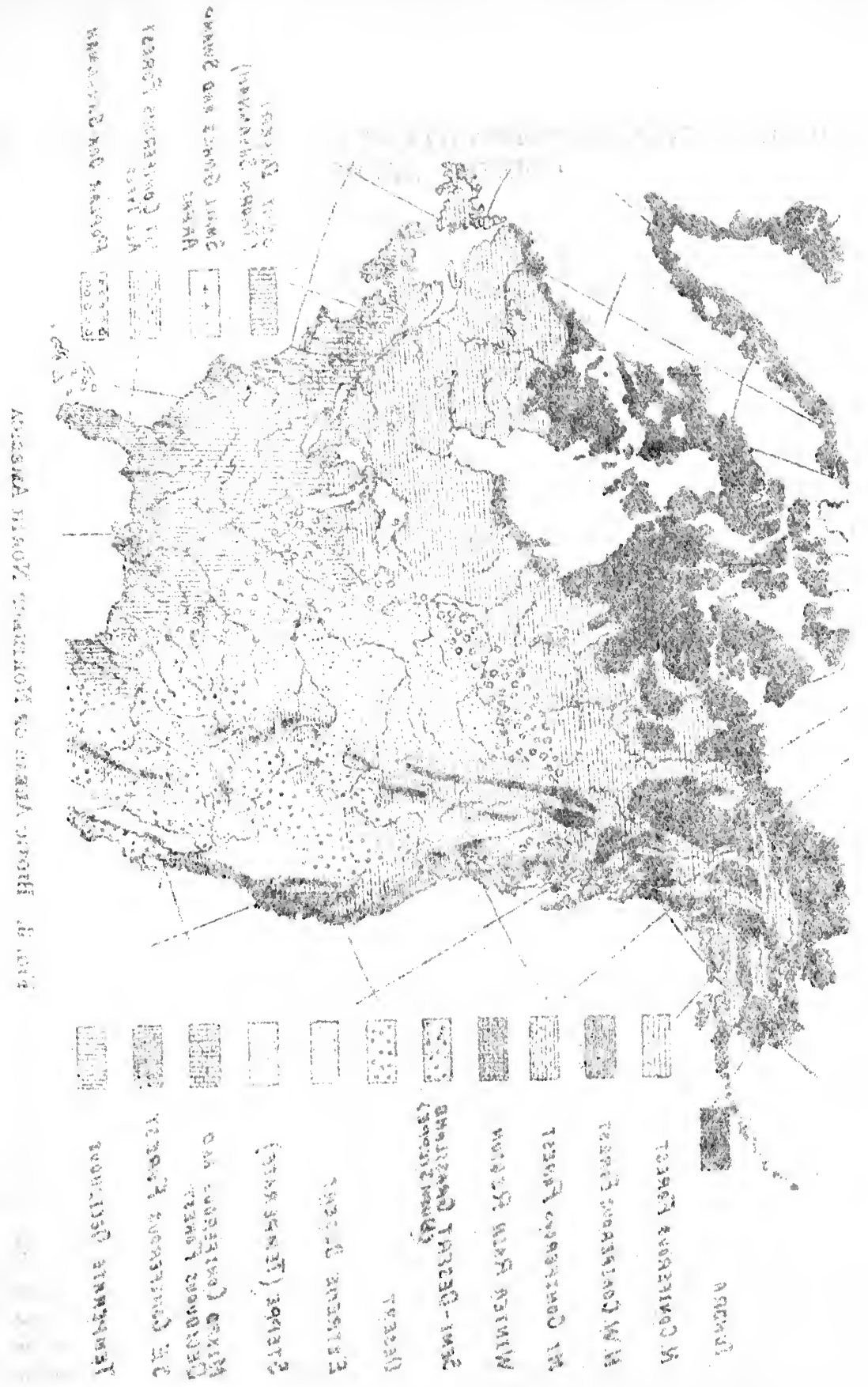


spite of the essential identity of this forest from the Pacific to the Atlantic it is nevertheless made up of a large number of tree species. Very many extensive areas are formed by a single species and many others by an admixture in which not more than three or four species are involved. In the eastern portion of the area the white pine ( $P$. strobus), the hemlock (Tsuga canadensis), the jack pine ( $P$. divaricata), and the balsam fir (Abies balsamea), are the most common species."

Northern localities with cold wet winters and usually as much as $50 \mathrm{in.}$ of snow in winter.

The open marshes and margins of lakes are the favorite haunts of the moose. The chief local conditions are ponds and marshes of various types, which are important to migratory birds.

The mammals include the moose (Alces spp.), woodland caribou (Rangifer spp.), elk (Cervus canadensis subspp.), black bear (Ursus americanus group), wolverine (Gulo luscus), Canada lynx (Lynx canadensis group), Canada woodchuck (Marmota monax canadensis), and red squirrel (Sciurus hudsonicus subspp.).

The breeding birds include the following: Hudsonian spruce partridge, Canada spruce partridge, Canada ruffed grouse, Nova Scotia ruffed grouse, passenger pigeon (extinct), turkey vulture (southern), swallow-tailed kite (formerly), marsh hawk, sharp-shinned hawk, Cooper's hawk, goshawk, redtailed hawk, red-shouldered hawk, broad-winged hawk, rough-legged hawk, golden eagle, duck hawk, pigeon hawk, sparrow hawk, long-eared owl, barred owl, great gray owl, Richardson's owl, saw-whet owl, screech owl, great horned owl (eastern), western horned owl (central, northerly), arctic horned owl (northern), pale horned owl (central, southerly), Newfoundland horned owl (Newfoundland, Nova Scotia, Labrador), hawk owl, yellow-billed cuckoo (south part), black-billed cuckoo (south part), northern hairy woodpecker, Newfoundland woodpecker, downy wood- pecker, Newfoundland downy woodpecker, Arctic three-toed woodpecker, American three-toed woodpecker, yellow-bellied sapsucker, northern pileated woodpecker, red-headed woodpecker, northern flicker, whippoorwill, nighthawk, chimney swift, ruby-throated hummingbird, kingbird, crested flycatcher, phoebe, olive-sided flycatcher, wood pewee, yellow-bellied flycatcher, least flycatcher, black-billed magpie, blue jay, Canada jay, Labrador jay, crow, cowbird, Baltimore oriole, bronzed grackle, evening grosbeak, pine grosbeak, Newfoundland pine grosbeak, purple finch, crossbill, white-winged crossbill, white-throated sparrow, chipping sparrow, clay-colored sparrow, goldfinch, pine siskin, Harris' sparrow, white-crowned sparrow, slate-colored junco, song sparrow, Lincoln's sparrow, fox sparrow, towhee, rose-breasted grosbeak, black-headed grosbeak, scarlet tanager, purple martin, cliff swallow, barn swallow, Bohemian waxwing, cedar waxwing, red-eyed vireo, Philadelphia vireo, warbling vireo, yellow-throated vireo, blue-headed vireo, black and white warbler, golden-winged warbler, Nashville warbler, orange-crowned warbler, Tennessee warbler, northern parula warbler, Cape May warbler, black-throated blue warbler, Cairn's warbler, myrtle warbler, magnolia warbler, chestnut-sided warbler, bay-breasted warbler, black-poll warbler, Blackburnian warbler, black-throated green warbler, Kirtland's warbler (central Michigan), pine warbler, oven-bird, mourning warbler, Wilson's warbler, Canada warbler, redstart, catbird, brown thrasher, house wren, winter wren, brown creeper, white-breasted nuthatch, red-breasted nuthatch, chickadee, Hudsonian chickadee, Acadian chickadee (eastern), golden-crowned kinglet, ruby-crowned kinglet, wood thrush (south part): veery, gray-checked thrush (western), Bicknell's thrush (east), olive-backed thrush, hermit thrush, robin, and bluebird.

Breeding birds whose habitat is generally limited to the pre-forest or 
other early stages of succession include the following: tree sparrow, field sparrow, swamp sparrow, indigo bunting, northern shrike, white-rumped shrike, migrant shrike, yellow warbler, pine warbler, palm warbler, and yellow palm warbler.

Breeding birds preferring a moist habitat, generally near a stream or swamp, include the following: tree swallow, bank swallow, rough-winged swallow, northern water-thrush, Grinnell's waterthrush, Connecticut warbler, and northern yellow-throat.

Breeding birds whose habitat is limited to the presence of water, generally a local condition, include the following: bald eagle, osprey, belted kingfisher, and northern raven.

2a. MOUNTAIN CONIFEROUS FOREST (MONTANE FOREST CLIMAX, THE ROCKY MOUNTAIN MONTANE FOREST, THE SIERRAN MONTANE FOREST, CLEMENTS, (HUDSONIAN AND CANADIAN ZONES)

In the western half of the area the yellow pine (Pinus ponderosa), the lodgepole pine ( $P$. murrayana), and the red fir (Pseudotsuga mucronata) are the trees which dominate the most extensive stands.

In the montane forests are found such characteristic mammals as the yellowbellied marmot (Marmota flaviventris subspp.), red squirrel (Subgenus Tamiasciurus), deer-mouse (Peromyscus spp.), red-backed vole (Evotomys), chipmunk (Eutamias), and flying-squirrel (Glaucomys sabrinus subspp.).

The breeding birds include the following: dusky grouse (Utah and south), Richardson's grouse (Wyoming and north), Alaska spruce grouse (Mt. McKinley range), Franklin's grouse (Idaho and north), gray ruffed grouse (Utah and north), band-tailed pigeon (Utah and south), sharp-shinned hawk, Cooper's hawk, western goshawk, western red-tail, golden eagle, pigeon hawk, Richardson's pigeon hawk, desert sparrow hawk (lower mountains), longeared owl, Richardson's owl, saw-whet owl, MacFarlane's screech owl (west mountain slope), Rocky Mountain screech owl (east mountain slope), flammulated screech owl (Colorado and south), dusky horned owl, hawk owl, Rocky Mountain pygmy owl, Rocky Mountain hairy woodpecker, Batchelder's woodpecker (British Columbia and south), Nelson's downy woodpecker (Alberta and north), Arctic three-toed woodpecker, Alaska threetoed woodpecker (northerly), Alpine three-toed woodpecker (southerly), rednaped sapsucker, Williamson's sapsucker, northern pileated woodpecker, Lewis' woodpecker, red-shafter flicker, Stephens' whippoorwill (Arizona and south), western nighthawk, black swift, white-throated swift, black-chinned hummingbird, Rivoli's hummingbird (Arizona and south), blue-throated hummingbird (Arizona and south), broad-tailed hummingbird (Idaho and south), rufous hummingbird, calliope hummingbird, white-eared hummingbird (Arizona and south), broad-billed hummingbird (Arizona and south), sulphur-bellied flycatcher (Arizona and south) olivaceous flycatcher (Arizona and south), olive-sided flycatcher (Arizona and south), Coues' flycatcher, western wood pewee, western flycatcher, Hammond's flycatcher, Wright's flycatcher, gray flycatcher (Arizona and south). buff-breasted flycatcher (Arizona and south), magpie, longcrested jay (Wyoming and south), black-headed jay (Wyoming and north), Rocky Mountain jay, western crow, Clarke's nutcracker, pinyon jay, western evening grosbeak, Rocky Mountain pine grosbeak, Cassin's purple finch, crossbill, white-winged crossbill, pine siskin, white-crowned sparrow, Gambel's sparrow, western chipping sparrow, whitewinged junco (Rocky Mountain region), Shufeldt's junco (northerly), Montana junco (northerly), pinksided junco (southerly), Ridgway's junco (Wyoming, Colorado, Arizona, New Mexico), Arizona junco (Arizona and south), red-backed junco (Arizona and south), gray-headed junco (Wyoming and south), mountain song sparrow, 
Lincoln's sparrow, slate-colored fox sparrow, Arctic towhee, green-tailed towhee, black-headed grosbeak, Lazuli bunting, western tanager, hepatic tanager (Arizona and south), purple martin, cliff swallow, barn swallow, Bohemian waxwing (northerly), cedar waxwing (southerly), red-eyed vireo, (low elevations), western warbling vireo, Cassin's vireo (north and west), plumbeous vireo (east and south), Virginia's warbler (southern), orange-crowned warbler, Tennessee warbler, olive warbler, Hoover's warbler, Audubon's warbler, black-fronted warbler, Grace's warbler, black-throated gray warbler, Townsend's warbler, Macgillivray's warbler, long-tailed chat, pileolated warbler, redstart, painted redstart, redfaced warbler (Arizona and south), catbird, rock wren, western house wren, western winter wren, Rocky Mountain creeper, Rocky Mountain nuthatch, redbreasted nuthatch, pygmy nuthatch, gray titmouse, long-tailed chickadee, Mexican chickadee, mountain chickadee, Hudsonian chickadee, chestnut-backed chickadee, lead-colored bush-tit, western golden-crowned kinglet, ruby-crowned kinglet, Townsend's solitaire, willow thrush, olive-backed thrush, Audubon's hermit thrush, western robin, northern varied thrush, western bluebird, azure bluebird, chestnut-backed bluebird, mountain bluebird.

Breeding birds whose habitat is generally limited to the preforest or other early stages of succession include the following: pale goldfinch, western tree sparrow, northern shrike (northerly), white-rumped shrike (low elevations), and yellow warbler.

Breeding birds preferring a moist habitat, generally near a stream or swamp, include the following: tree swallow, northern violet-green swallow, bank swallow, rough-winged swallow, Grinnell water-thrush, and western yellow-throat.

Breeding birds whose habitat is limited to the presence of water, generally a local condition, include the following: nothern bald eagle, duck hawk, osprey, and dipper.
3. NORTHWESTERN MOIST CONIFEROUS FOREST BIOTA (NORTHWESTERN HYDROPHYTIC EVERGREEN FOREST, SHREVE) (INCLUDES THE LARCH-PINE FOREST AND THE CEDAR-HEMLOCK FOREST; CLEMENTS), (THE COAST FOREST CLIMaX, CLEMENTS)

The climate is mild with some rain in all seasons but especially in winter.

This is "a well-marked type of forest characterized by density of stand and by the size of its trees, which commonly reach 100 to $125 \mathrm{ft}$. in height and are often in excess of this. The floor of the forest is heavily shaded and supports relatively few deciduous under-trees, although there is usually a rich growth of shrubs and of ferns, mosses, and other herbaceous plants. The trees which characterize this area are the Douglas fir (Pseudotsuga mucronata), redwood (Sequoia sempervirens), western hemlock (Tsuga heterophylla), canoe cedar (Thuja plicata), grand fir (Abies grandis) and others."

The mammals include the elk (Cervus canadensis occidentalis), black bear (Ursus americanus group), bob cat (Lynx fasciatus group), and blacktailed deer (Odocoileus columbianus subspp.).

The breeding birds include the following: mountain quail, California quail, sooty grouse, Oregon ruffed grouse, band-tailed pigeon, dusky mourning dove, marsh hawk, sharp-shinned hawk, Cooper hawk, western goshawk, western red-tailed hawk, Alaska red-tail (Southeast Alaska), golden eagle, Peale's falcon, black pigeon hawk, sparrow hawk, spotted owl, saw-whet owl (except Queen Charlotte), island saw-whet owl (except Queen Charlotte), Kennicott's screech owl (Oregon and north), Brewster's screech owl (Oregon and south), dusky horned owl, Vancouver pygmy owl (Vancouver Islands), coast pygmy owl (Washington and south), California pygmy owl (Montery, etc.), California cuckoo (Washington and south), Harris' woodpecker (north), white-breasted woodpecker (south), Sitka hairy woodpecker (Southeast Al- 
aska), Gairdner's woodpecker (British Columbia and south), Valdez downy woodpecker (British Columbia and north), red-breasted woodpecker (California), northern red-breasted sapsucker (California and north), western pileated woodpecker, California woodpecker (Oregon and south), northwestern flicker, Pacific nighthawk, black swift, Vaux's swift, white-throated swift, rufous hummingbird, Allen's hummingbird, olivesided flycatcher, western flycatcher, Traill's flycatcher, Hammond's flycatcher, Steller's jay (Washington and north), coast jay (Oregon and south), California jay (south), Oregon jay, western crow (Washington and south), northwestern crow (Washington and north), Bullock's oriole, Brewer's blackbird, western evening grosbeak, Kadiak pine grosbeak, California purple finch, crossbill, pine siskin, Oregon vesper sparrow, Nuttall's sparrow (British Columbia and north), golden-crowned sparrow (British Columbia and north), western chipping sparrow, Oregon junco, Point Pinos junco (Monterey district), rusty song sparrow (Washington and north), sooty song sparrow (Alaska coast), San Diego song sparrow (Monterey region), mendocino song sparrow (Oregon to San Francisco), Forbush's sparrow (Alaska coast), sooty fox sparrow (British Columbia and Washington), Kadiak fox sparrow (Cross Sound and north), Townsend's fox sparrow (Cross Sound and south), Oregon towhee (British Columbia, Washington, Oregon), San Francisco towhee (California), black headed grosbeak, western martin, cliff swallow, barn swallow, western warbling vireo, Cassin's vireo, Anthony's vireo, Calaveras warbler, lutescent warbler, Alaska yellow warbler (Vancouver Islands and north), California yellow warbler (Washington and south), Audubon's warbler, Townsend's warbler (northerly), hermit warbler (southerly), Macgillivray's warbler, golden pileolated warbler, rock wren (Oregon to Vancouver Islands), western house wren, western winter wren, California creeper, slender-billed nuthatch, red-breasted nuthatch, Oregon chickadee, chestnutbacked chickadee (Sonoma County, California and north), California chickadee (Sonoma and Marin Counties), Barlow's chickadee (Monterey region), bush-tit, coast wren-tit (Oregon to Humboldt Bay, California), ruddy wrentit (Humboldt County and south), western golden-crowned kinglet, sitka kinglet (British Columbia and north), Townsend's solitaire, russet-backed thrush, Alaska hermit thrush, dwarf hermit thrush, Monterey hermit thrush, western robin, varied thrush, northern varied thrush, western bluebird, mountain bluebird.

Breeding birds whose habitat is generally limited to the preforest or other early stages of succession include the following: western meadowlark, willow goldfinch, and western tree sparrow (north).

Breeding birds preferring a moist habitat, generally near a stream or swamp, include the following: northwestern red-wing, bicolored red-wing, tree swallow, northern violet-green swallow, bank swallow, rough-winged swallow, and Pacific yellow-throat (British Columbia and south).

Breeding birds whose habitat is limited to the presence of water, generally local condition, include the following: northwestern coast heron (Washington and north), California heron (Washington and south), spotted sandpiper, bald eagle, northern bald eagle (north), osprey, northern belted kingfisher, northern raven, and dipper.

\section{XEROPHYTIC CONIFEROUS FOREST} BIOTA (NOT INDICATED ON THE MAP) (WESTERN XEROPHYTIC EVERGREEN FOREST, SHREVE) (THE WOODLAND CLIMAX : PINE JUNIPER FORMATION, CLEMENTS) (INCLUDES PINYON CEDAR WOODLAND; OAK-CEDAR WOODLAND; PINEOAK WOODLAND IN PART, CLEMENTS)

This type lies between the northern coniferous forest and the desert and semi-desert areas in the United States and northern Mexico. It does not cover an extensive area. 
It is "an open forest of low stature, the trees seldom exceeding $40 \mathrm{ft}$. in height. The needle-leaved and scale-leaved evergreens are the dominant trees, but the forest is everywhere accompanied by shrubbery and by some succulent or semi-succulent plants, and is carpeted in many localities by an open growth of perennial grasses. Along the Mexican boundary this forest merges into the encinal, or evergreen oak type. The dominant species of the Xerophytic Evergreen Forest vary from state to state but are in almost all cases either junipers or pinyons."

Among the characteristic mammals are the woodrats (Neotoma spp.), deermice (Peromyscus spp.), and cottontail rabbit (Sylvilagus audubonii subspp.).

The breeding birds include the following: white-checked goose, plumed quail (Ventura County and north), San Pedro quail (San Ber. and San Gab. Mountains), Sierra grouse, band-tailed pigeon, western mourning dove, California vulture (Santa Clara County, south), turkey vulture, sharp-shinned hawk, Cooper's hawk, western goshawk, western red-tailed hawk, golden eagle, desert sparrow hawk, spotted owl, Pasadena screech owl, Pacific horned owl, pygmy owl, Sierra woodpecker, Cabanis woodpecker, Nuttall's woodpecker, white-headed woodpecker, Sierra three-toed woodpecker, red-naped sapsucker, red-breasted sapsucker, Williamson's sapsucker, northern pileated woodpecker, Lewis' woodpecker, redshafted flicker, western nighthawk, black swift, white-throated swift, blackchinned hummingbird, broad-tailed hummingbird, rufous hummingbird, calliope hummingbird, ash-throated flycatcher, olive-sided flycatcher, western wood pewee, Hammond's flycatcher, Wright's flycatcher, gray flycatcher, blue-fronted jay, California jay, gray jay, Clark's nutcracker, pinyon jay, tricolored blackbird, Bullock's oriole, Brewer's blackbird, western evening grosbeak, California pine grosbeak, Cassin's purple finch, Mexican crossbill, green-backed goldfinch, pine siskin, white-crowned sparrow, Thurber's junco, western chipping sparrow, black-chinned sparrow, mountain song sparrow, Lincoln's sparrow, thick-billed fox sparrow (northerly), Stephens ${ }^{2}$ fox sparrow (southerly), spurred towhee, greentailed towhee, black-headed grosbeak, Lazule bunting, western tanager, western martin, western warbling vireo, Cassin's vireo, gray vireo (Cajon Pass and south), Calaveras warbler, hermit warbler, lutescent warbler, Audubon's warbler, black-throated gray warbler, Townsend's warbler, Macgillivray's warbler, golden pileolated warbler, California thrasher, rock wren, dotted canyon wren, western house wren, western winter wren, Sierra creeper, slender-billed nuthatch, red-breasted nuthatch, pygmy nuthatch, gray titmouse, mountain chickadee, lead-colered bush-tit, western golden-crowned kinglet, ruby-crowned kinglet, Townsend's solitaire, Sierra hermit thrush, western robin, western bluebird, mountain bluebird.

Breeding birds whose habitat is generally limited to the preforest or other early stages of succession include the western vesper sparrow and the California yellow warbler.

Breeding birds whose habitat is limited to the presence of water, generally a local condition, include the following: merganser, hooded merganser, wood duck, Harlequin duck, spotted sandpiper, and dipper.

\section{POPLAR GROVE SAVANNA Biota ("PARK STEPPE" OF HARDY)}

A narrow strip skirting the coniferous forest on the west and south in Minnesota, Wisconsin, Manitoba, Saskatchewan and Alberta. It consists of groves of poplar or low shrubs, the former with characteristic forest edge lying in a mesophytic prairie. In some localities the grassland forms islands. The mammals include forest bison (Bison bison athabascae), mule deer (Odocoileus hemionus), skunk (Mephitis hudsonica), raccoon (Procyon $l$. lotor), and red fox (Vulpes fulva). 


\section{DECIDUOUS FOREST BIOTA}

Occupies areas with rainfall throughout the year, especially in spring.

"The extensive area chiefly east of the Mississippi and south of the Great Lakes, which was formerly occupied by an almost unbroken forest of a score or more of deciduous trees. A few prairies occur in the southern portion of the area and evergreen needle-leaved trees occupy bluffs and shallow soil in the mountains. The commonest trees are species of oak (Quercus), hickory (Hicoria), chestnut (Castanea), beech (Fagus), maple (Acer), walnut (Juglans), tulip (Liriodendron), and ash (Fraxinus)."

The mammals include the Virginia deer (Odocoileus virginianus subspp.), black bear (Ursus a. americanus), bobcat (Lynx r. ruffus), gray fox (Urocyon c. cinereoargenteus), red fox (Vulpes fulva), opossum (Didelphis v. virginiana), cottontail rabbit (Sylvilagus floridanus subspp.), and gray squirrel (Sciurus carolinensis subspp.).

Breeding birds include the following: ruffed grouse, wild turkey, passenger pigeon (extinct), mourning dove, turkey vulture, black vulture (south), swallowtailed kite, white-tailed kite, Mississippi kite (south), marsh hawk, sharpshinned hawk, Cooper's hawk, red-tailed hawk, red-shouldered hawk, broadwinged hawk, pigeon hawk, sparrow hawk, barn owl, long-eared owl, barred owl, saw-whet owl, screech owl, great horned owl, Carolina paroquet (formerly), yellow-billed cuckoo, blackbilled cuckoo, ivory-billed woodpecker (south), hairy woodpecker (north), southern hairy woodpecker (south), southern downy woodpecker (south), downy woodpecker (north), red-cockaded woodpecker, pileated woodpecker (south), northern pileated woodpecker (north), red-headed woodpecker, redbellied woodpecker, flicker (south), northern flicker (north), Chuck-will'swidow (south), whip-poor-will, nighthawk, chimney swift, ruby-throated hummingbird, kingbird, crested flycatcher, phoebe, wood pewee, Acadian flycatcher, blue jay, crow, fish crow (southeastern), cowbird, orchard oriole, Baltimore oriole, purple grackle (Atlantic Coast south), chipping sparrow, Bachman's sparrow, song sparrow, towhee, cardinal, rose-breasted grosbeak, blue grosbeak (south), painted bunting (south), scarlet tanager, summer tanager (southerly), purple martin, cliff swallow, cedar waxwing, red-eyed vireo, warbling vireo, yellow-throated vireo, whiteeyed vireo, black and white warbler, worm-eating warbler, Bachman's warbler (south), blue-winged warbler, golden-winged warbler, parula warbler (south), northern parula warbler (north) pine warbler, oven-bird, Kentucky warbler, yellow-breasted chat, redstart, mockingbird, catbird, brown thrasher, Carolina wren, Bewick's wren, house wren, white-breasted nuthatch, brownheaded nuthatch (south), tufted titmouse, chickadee, Carolina chickadee (south), blue-gray gnatcatcher, wood thrush, robin, southern robin, and bluebird.

Breeding birds whose habitat is generally limited to pre-forest or other early stages of succession include the following: upland plover, killdeer, bob-white, goldfinch, vesper sparrow, field sparrow, indigo bunting, loggerhead shrike (south), migrant shrike (north), yellowthroated warbler, and prairie warbler.

Breeding birds preferring a moist habitat, generally near a stream or swamp, include the following: boattailed grackle (southeast), swamp sparrow, tree swallow, bank swallow, roughwinged swallow, prothonotary warbler, Swainson's warbler (south), sycamore warbler, Louisiana water-thrush, Maryland yellow-throat, northern yellowthroat, hooded warbler, and shortbilled marsh wren.

Breeding birds whose habitat is limited to the presence of water, generally a local condition, include the following: merganser, wood duck, great blue heron, egret (south), snowy egret (south), little blue heron (south), green heron, black-crowned night heron, yellow-crowned night heron (south), sand- 
hill crane, king rail, Virginia rail, sora, yellow rail, black rail, purple gallinule (south), Florida gallinule, coot, woodcock, Wilson's snipe, solitary sandpiper, spotted sandpiper, piping plover, duck hawk, osprey northern raven, redwinged blackbird, and long-billed marsh wren.

7. OAK GROVE SAVANNA BIOTA (PARK STEPPE OF HARDY IN PART; GRASSLANDDECIDUOUS FOREST TRANSITION, SHREVE; SUBCLIMAX PRAIRIE, CLEMENTS)

An area with little rainfall in winter and late summer and heavy rainfall in June.

The rather ill-defined belt in which the Deciduous Forest emerges from the flood-plains and river margins and occupies a portion of the upland. On the western edge of the belt there is a high percentage of grassland, while in the eastern portion the deciduous forest becomes nearly continuous. The principal trees of this region are the bur, white, and black oaks (Quercus macrocarpa, Q. alba, Q. velutina); the principal grasses, beard grass (Andropogen furcatus), Indian grass (Sorghastrum nutans), and dropseed (Sporobolus cryptandrus).

The forest edge is a very important habitat for a few mammals, birds and many insects ranging eastward. The Franklin ground-squirrel (Citellus franklinii), and many birds and insects are restricted to it. Steppe animals invaded the grass covered areas while the wooded parts supported the Virginia deer (Odocoileus virginanus macrourus), elk (Cervus c. canadensis), raccoon (Procyon l. lotor), gray squirrel (Sciurus carolinensis leucotis), and cottontail rabbit (Sylvilagus floridanus mearnsii).

The species that occur in the deciduous forest are, for the most part, also found in the oak grove savannas. But a few species that are confined to the southeastern part and the northeastern part of the deciduous forest do not find their way into the oak grove savannas. The oak grove savanna thus become a westward extension of the decidunua forest like arms into the grasslands. Breeding birds that occur in the oak grove savannas are as follows: upland plover, turkey vulture, black vulture, swallow-tailed kite, Mississippi kite, sharp-shinned hawk, Cooper's hawk, red-tailed hawk, red-shouldered hawk, broad-winged hawk, bald eagle, duck hawk, sparrow hawk, great horned owl, barn owl, long-eared owl, barred owl, saw-whet owl, screech owl, Carolina paroquet (formerly), yellow-billed cuckoo, black-billed cuckoo, hairy woodpecker, downy woodpecker, yellowbellied sapsucker, red-headed woodpecker, red-bellied woodpecker, northern flicker, whip-poor-will, nighthawk, chimney swift, ruby-throated hummingbird, kingbird, Arkansas kingbird (west), crested flycatcher, wood pewee, yellow-bellied flycatcher (north), Acadian flycatcher, least flycatcher, blue jay, raven, crow, cowbird, orchard oriole, Baltimore oriole, bronzed grackle; goldfinch, vesper sparrow, chipping sparrow, field sparrow, song sparrow, towhee, cardinal, rose-breasted grosbeak, painted bunting (south), scarlet tanager, summer tanager, purple martin, cliff swallow, barn swallow, cedar waxwing, loggerhead shrike (south), white-rumped shrike, red-eyed vireo, warbling vireo, yellow-throated vireo, black and white warbler (occasionally), worm-eating warbler, bluewinged warbler (occasionally), cerulean warbler, chestnut-sided warbler (occasionally), prairie warbler, oven-bird, yellow-breasted chat, redstart (north), mockingbird, catbird, brown thrasher, Carolina wren, Bewick's wren, brown creeper, white-breasted nuthatch, tufted titmouse, chickadee, blue-gray gnatcatcher, woodthrush, veery (east), willow thrush, robin, and bluebird.

Breeding birds whose habitat is generally limited to the pre-forest or other early stages of succession include the following: prairie chicken, bobwhite, short-eared owl, prairie horned lark, bobolink, meadowlark, grasshopper sparrow, Henslow's sparrow, lark sparrow, dickcissel, and indigo bunting. 
Breeding birds preferring a moist habitat, generally near a stream or swamp, include the following: green heron, black-crowned night heron, sandhill crane, king rail, Virginia rail, sora, yellow rail, black rail, purple gallinule (south), Florida gallinule, marbled godwit (north), spotted sandpiper, marsh hawk, osprey, belted kingfisher, phoebe, Traill's flycatcher, savanna sparrow, Nelson's sparrow, swamp sparrow, tree swallow, bank swallow, rough-winged swallow, prothonotary warbler, Swainson's warbler (south), yellow warbler, sycamore warbler, Louisiana waterthrush, Maryland yellow-throat, hooded warbler, short-billed marsh wren.

Breeding birds whose habitat is limited to the presence of water, generally a local condition, include the following: bittern, least bittern, great blue heron, snowy egret, little blue heron, yellow-headed blackbird, red-winged blackbird, and long-billed marsh wren.

\section{SOUTHEASTERN CONIFEROUS FOREST} (SOUTHEASTERN MESOPHYTIC EVERGREEN FOREST, SHREVE) (PROBABLY INCLUDES THE SOUTHEASTERN EVERGREEN-DECIDUOUS TRANSITION, SHREVE)

Copious rain in summer. Frequent fires an important environmental factor. The coastal plain forest is of evergreen needle-leaved trees, with a subordinate admixture of evergreen broad-leaved and deciduous species. "Extensive areas of this forest are pure stands of longleaf pine (Pinus palustris), or Cuban pine ( $P$. caribaea) in open formation, with a clear floor nearly devoid of shrubs and carpeted with grasses and herbaceous plants." The mammals are in part similar to those of the deciduous forest, which is probably the climax type over most of the region. For a list of mammals and reptiles see account of Alabama.

Breeding birds include the following: wild turkey, passenger pigeon (extinct), mourning dove, ground dove, black vulture, swallow-tailed kite, Mississippi kite, Cooper's hawk, Florida redshouldered hawk, red-tailed hawk, broad winged hawk, sparrow hawk, barn owl,
Florida barred owl, Florida screech owl, great horned owl, Carolina paroquet, yellow-billed cuckoo, southern hairy woodpecker, southern downy woodpecker, red-cockaded woodpecker, pileated woodpecker, red-headed woodpecker, red-bellied woodpecker, chuckwill's widow, flicker, Florida nighthawk, chimney swift, ruby-throated hummingbird, kingbird, crested flycatcher, wood pewee, blue jay, southern crow, fish crow, cowbird, orchard oriole, Baltimore oriole, purple grackle, pinewoods sparrow, Bachman's sparrow, chipping sparrow, Alabama towhee, cardinal, blue grosbeak, summer tanager, purple martin, red-eyed vireo, warbling vireo, yellow-throated vireo, white-eyed vireo, black and white warbler, black-throated green warbler, pine warbler, Florida yellow-throat, yellow-breasted chat, Kentucky warbler, mockingbird, catbird, brown thrasher, Carolina wren, Bewick's wren, Florida white-breasted nuthatch, brown-headed nuthatch, tufted titmouse, Carolina chickadee, blue-gray gnatcatcher, wood thrush, southern robin and bluebird.

Breeding birds whose habitat is generally limited to the pre-forest or other early stages of succession include the following: bob-white, goldfinch, loggerhead shrike, and prairie warbler.

Breeding birds preferring a moist habitat, generally near a stream or swamp include the following: indigo bunting, prothonotary warbler, Swainson's warbler, sycamore warbler, Louisiana water-thrush, and hooded warbler.

Breeding bird whose habitat is limited to the presence of water, generally a local condition, is the bald eagle.

\section{GRASSLAND BIOTA (GRASSLAND, SHREVE) (GRASSLAND ClIMAX, CLE- ments) (INClUdes TRUE PRAIRIE; MIXED PRAIRIE; SHORT-GRASS PLAINS; BUNCH-GRASS PRAIRIE OF THE NORTH- WEST, CLEMENTS)}

Areas with rain chiefly in spring and early summer. Dry season late in summer. Winters cold and dry.

The vast plains area, covered by a 
more or less closed sod of perennial grasses, distributed as follows:

Tall grass prairie west to central Dakotas, eastern third of Nebraska and central Kansas; tall and short grasses forming sod in all of grassland north of central Kansas and Colorado, west to Rockies, except in sand or where overgrazed. South of this is mostly scattered grass steppe; west of it mostly bunch-grass steppe. Bunch-grass occurs regularly in sand. A scattering representation of desert forms is present, particularly in the "bad lands," shrubs are locally present, in portions of the area (bush steppe) and the evergreen forests advance from the west onto hills and rocky soil, while the Deciduous Forest encroaches from the east through the valleys of the largest streams. A number of species of herbaceous perennials are found in all parts of the Grassland, being chiefly Composities. The leading grasses are the gramas (Bouteloua), buffalo grass (Bulbilis dactyloides), and prairie grass (Koeleria cristata).

The mammals included immense herds of bison, large herds of pronghorn antelope (Antilocapra americana), wolf (Canis spp.), coyote (Canis spp.), white-tailed jackrabbit (Lepus townsendii subspp.), kit fox (Vulpes velox), and "towns" of prairie-dogs (Cynomys).

Breeding birds include the following: upland plover, killdeer, bob-white, Florida bob-white (Florida prairies), prairie chicken, lesser prairie chicken, prairie sharp-tailed grouse, western mourning dove, turkey vulture, marsh hawk, Swainson's hawk, ferruginous rough-leg, prairie falcon, duck hawk, sparrow hawk, desert sparrow hawk, burrowing owl, poor-will, western nighthawk, Sennett's nighthawk, scissor-tailed flycatcher, kingbird, Arkansas kingbird, phoebe, Say's phoebe, prairie horned lark, desert horned lark, dusky horned lark, magpie, cowbird, meadowlark, western meadowlark, southern meadowlark, Bullock's oriole, Brewer's blackbird, goldfinch, chestnut-collared longspur, McCown's longspur, vesper sparrow, western vesper sparrow, Oregon vesper sparrow, savanna sparrow, western savanna sparrow, Baird's sparrow, grasshopper sparrow, western grasshopper sparrow, Florida grasshopper sparrow, Henslow's sparrow, western Henslow's sparrow, Leconte's sparrow, Nelson's sparrow, lark sparrow, western lark sparrow, western field sparrow, western chipping sparrow, clay-colored sparrow, Brewer's sparrow, song sparrow, Dakota song sparrow, dickcissel, lark bunting, purple martin, cliff swallow, barn swallow, white-rumped shrike, migrant shrike, Sprague's pipit, western house wren, robin, western robin, and bluebird.

Breeding birds preferring a moist habitat, generally near a stream, include the following: tree swallow, bank swallow, rough-winged swallow, Maryland yellow-throat, western yellowthroat, northern yellow-throat, and short-billed marsh wren.

Breeding birds whose habitat is limited to the presence of water, generally a local condition, include the following: sandhill crane, Wilson's phalarope, avocet, Wilson's snipe, marbled godwit, solitary sandpiper, western willet, spotted sandpiper, and long-billed curlew, prairie marsh wren.

10. TEMPERATE DESERT-GRASSLAND BIOTA (INCLUDES DESERT-GRASS LAND TRANSITION, SHREVE; DESERT PLAINS, CLEMENTS; THE NORTHERNMOST EXTENSION OF THE GREAT BASIN MICROPHYLL DESERT, SHREVE)

A region intermediate in character between the grassland and the deserts of Texas, New Mexico, Arizona and Idaho.

An open carpet of perennial grasses and ephemeral or root-perennial herbaceous plants, with a more or less sparing representation of succulent and semi-succulent forms. The leading Grassland plants (in southern localities) are the gramas (Bouteloua) and galleta grass (Hilaria), and the chief desert plants are palmilla, amole, and a small group of cacti. 
The Snake River plain with sagebrush among which grasses grow up in spring and with local areas of grass, is included here.

The mammals originally included bison, pronghorn antelope, badger (Taxidea taxus subspp.), ground-squirrels (Citellus spp.), black-tailed jackrabbit (Lepus californicus group), pocket-mouse (Perognathus), and kangaroo-rat (Dipodumys).

Breeding birds include the following: sage hen, western mourning dove, turkey vulture, marsh hawk, Swainson's hawk, ferruginous rough-leg, prairie falcon, desert sparrow hawk, short-eared owl, MacFarlane's screech owl, burrowing owl, California cuckoo, Sierra woodpecker, Batchelder's woodpecker, redshafted flicker, poor-will, western nighthawk, black-chinned hummingbird, broad-tailed hummingbird, kingbird, Arkansas kingbird, Say's phoebe, western wood pewee, western flycatcher, desert horned lark, magpie, Woodhouse's jay, western crow, cowbird, western meadowlark, Bullock's oriole, Brewer's blackbird, house finch, green-backed goldfinch, western vesper sparrow, $\mathrm{Ne}$ vada savanna sparrow, western grasshopper sparrow, western lark sparrow, western chipping sparrow, Brewer's sparrow, desert sparrow, sage sparrow, Merill's song sparrow, spurred towhee, black-headed grosbeak, lazuli bunting, purple martin, cliff swallow, barn swallow, California shrike, yellow warbler, long-tailed chat, and sage thrasher.

Breeding birds preferring a moist habitat, generally near a stream or swamp, include the following: raven, bobolink, northern violet-green swallow, bank swallow, western yellow-throat, and tule wren.

11. EXTREME DESERT (CALIFORNIA MICROPHYLL DESERT, SHREVE) (THE WESTERN DESERT SCRUB IN PART, CLEMENTS)

"An extremely low and open stand of microphyllous (small-leafed) shrubs, chiefly evergreen but partly deciduous; very poor in grasses and in succulent plants. The dominant plants are creosote bush (Covillea tridentata), and sand bur (Franseria dumosa)."

Mammals, small burrowing forms and diurnal reptiles are present.

For list of mammals see account of Mexico (Sonoran District) page 592.

Breeding birds ${ }^{2}$ include the following: Gambel's quail, western mourning dove, desert sparrow hawk, prairie falcon, road-runner, Texas woodpecker, Gila woodpecker, poor-will, western nighthawk, Texas nighthawk, Costa hummingbird, Say's phoebe, vermilion flycatcher, Sonora horned lark, western raven, Sonora red-winged blackbird, western meadowlark, Scott's oriole, California purple finch, black-throated sparrow, desert song sparrow, Abert's towhee, western blue grosbeak, phainopepla, white-rumped shrike, least vireo, Lucy's warbler, western mockingbird, Bendire's thrasher, Leconte's thrasher, crissal thrasher, cactus wren, rock wren, verdin, and plumbeous gnatcatcher.

12. SAgEBRUSH DESERT BIOTA (GREAT BASIN MICROPHYLL DESERT, SHREVE) (THE SAgEbRUSH ClimaX, AND INCLUDES THE BASIN SAGEBRUSH AND POSSIBLy THE COASTAL SAGEBRUSH, CLEMENTS)

(The northern portion is classed under * 10 on account of desert grassland animals present.)

"An open stand of shrubs, sometimes nearly closed; varying from place to place in stature; usually poor in grasses and succulents. The dominant plant is sagebrush (Artemisia tridentata), locally accompanied by other forms."

Among characteristic mammals are the pronghorn antelope (Antilocapra americana), black-tailed jackrabbit (Lepus californicus subspp.), pygmy rabbit (Brachylagus idahoensis), cottontail rabbits (Sylvilagus spp.), ground-squirrels

${ }^{2}$ Aquatic birds have been omitted from the desert list because of the extreme scarcity of their habitat in such regions. Many of these birds do not nest on the ground but in the thinly forested areas along streams, in canyons, among the rocks, in mesquite or cacti. No effort is made to distinguish ground nesting birds from others. 
(Citellus spp.), kangaroo-rats (Didodomys spp.), and pocket-mice (Perognathus spp.).

Breeding birds include the following: upland plover, killdeer, Columbian sharp-tailed grouse, sage hen, western mourning dove, turkey vulture, sharpshinned hawk, Cooper's hawk, western red-tail, red-bellied hawk, Swainson's hawk, ferruginous rough-leg, prairie falcon, Richardson's pigeon hawk, desert sparrow hawk, short-eared owl, spotted owl, burrowing owl, California cuckoo, Sierra woodpecker, Batchelder's woodpecker, red-shafted flicker, poorwill, western nighthawk, black-chinned hummingbird, broad-tailed hummingbird, kingbird, Arkansas kingbird, cassin kingbird, ash-throated flycatcher, Say's phoebe, western wood pewee, western flycatcher, Traill's flycatcher, desert horned lark, dusky horned lark, blackbilled magpie, woodhouse jay, raven, western crow, bobolink, cowbird, yellowheaded blackbird, San Diego red-wing, Nevada red-wing, western meadowlark, Bullock's oriole, Brewer's blackbird, house finch, green-backed goldfinch, western vesper sparrow, western savanna sparrow, western grasshopper sparrow, western lark sparrow, western chipping sparrow, desert sparrow, sage sparrow, mountain song sparrow, Nevada towhee, black-headed grosbeak, lazuli bunting, western tanager, purple martin, cliff swallow, barn swallow, white-rumped shrike, western warbling vireo, yellow warbler, long-tailed chat, sage thrasher, western mockingbird, rock wren, canyon wren, western house wren, lead-colored bush-tit, western gnatcatcher, western robin, and western bluebird.

Breeding birds preferring a moist habitat, generally near a stream or swamp, include the following: spotted sandpiper, long-billed curlew, snowy plover, marsh hawk, belted kingfisher, tree swallow, bank swallow, northern violet-green swallow, rough-winged swallow, western yellow-throat, and western marsh wren.
13. EASTERN (RIO GRANDE) SUCCULENT DESERT BIOTA (TEXAS SUCCULENT DESERT, SHREVE) (EASTERN DESERT SCRUB, CLEMENTS)

"A mixed stand of microphyllous shrubs and succulent and semi-succulent plants. The shrubs are either evergreen (Covillea) or deciduous (Acacia, Flourensia). The stem-succulents comprise many species of cacti, chiefly low in growth; the commonest leaf-succulent is lechuguilla (Agave lechuguilla); the semisucculents include sotol (Dasylirion texanum), amole, and palmilla (Yucca)."

For list of mammals see Texas account, page 502.

Breeding birds include the following: killdeer, snowy plover, Texas bob-white, Arizona scaled quail, western mourning dove, white-winged dove, Mexican ground dove, Inca dove, black vulture, turkey vulture, white-tailed kite, Harris' hawk, western red-tail, Texas redshouldered hawk, zone-tailed hawk, Swainson's hawk, Mexican black hawk, Mexican goshawk, prairie falcon, Aplomado falcon, desert sparrow hawk, Audubon's caracara, spotted owl, Sahaura screech owl, flammulated screech owl, western horned owl, burrowing owl, road-runner, California cuckoo, Texas woodpecker, cactus woodpecker, Stephens' poor-will, Texas nighthawk, broad-tailed hummingbird, Cassin's kingbird, ash-throated flycatcher, dwarf cowbird, Rio Grande meadowlark, thickbilled red-wing, Scott's oriole, Bullock's oriole, housefinch, Arkansas goldfinch western lark sparrow, desert sparrow, rufous-winged sparrow, Scott's sparrow, Arizona pyrrhuloxia, western blue grosbeak, varied bunting, barn swallow, phainopepla, white-rumped shrike, blackcapped vireo, Stephens' vireo, least vireo, Sonora yellow warbler, western yellowthroat, long-tailed chat, western mockingbird, curve-billed thrasher, crissal thrasher, cactus wren, canyon wren, Texas wren, Sennett's titmouse, verdin, and plumbeous gnatcatcher.

Breeding birds preferring a moist habitat, generally near a stream or 
swamp, include the following: marsh hawk, duck hawk, white-necked raven, rough-winged swallow, and bank swallow.

14. WESTERN SMALL TREE AND SUCCULENT DESERT BIOTA (ARIZONA SUCCULENT DESERT, SHREVE) (WESTERN DESERT SCRUB, IN PART, CLEMENTS)

"A mixed stand of microphyllous shrubs or small trees, either evergreen or deciduous, and of succulent forms, chiefly the stem-succulent cacti. The leading shrubs are creosote bush and cat-claw (Acacia); the commonest small trees are palo verde (Parkinsonia) and palo fierro (Olneya). The succulents comprise large columnar forms (Carnegiea), branching aborescent forms (Opuntia), and many smaller types."

Mammals include the black-tailed deer (Ododoileus), black-tailed jackrabbit (Lepus californicus group), cottontail rabbit (Sylvilagus audubonii group), coyotes (Canis spp.), badger (Taxidea), and many species of rodents.

Breeding birds include the following: killdeer, snowy plover, masked bobwhite, Gambel's quail, western mourning dove, white-winged dove, Mexican ground dove, Inca dove, turkey vulture, Harris' hawk, western red-tail, zonetailed hawk, Swainson's hawk, Mexican black hawk, Mexican goshawk, prairie falcon, Aplomado falcon, desert sparrow hawk, Audubon's caracara, Arizona spotted owl, Mexican screech owl, spotted screech owl, western horned owl, burrowing owl, road-runner, California cuckoo, Chihuahua woodpecker, cactus woodpecker, Gila woodpecker, gilded flicker, Stephens' poor-will, Texas nighthawk, Costa hummingbird, broad-billed hummingbird, Arizona crested flycatcher, ash-throated flycatcher, olivaceous flycatcher, buff-breasted flycatcher, vermilion flycatcher, beardless flycatcher, scorched horned lark, bronzed cowbird, Sonora red-wing, Rio Grande meadowlark, Scott's oriole, orchard oriole, house finch, Arkansas goldfinch, .western lark sparrow, desert sparrow, botteri sparrow, rufous-winged sparrow, Scott's sparrow, desert song sparrow, Arizona cardinal, Arizona pyrrhuloxia, western blue grosbeak, beautiful bunting, Mexican cliff swallow, barn swallow, phainopepla, whiterumped shrike, Stephens' vireo, least vireo, Lucy's warbler, Sonora yellow warbler, western yellow-throat, western mockingbird, Palmer's thrasher, Bendire's thrasher, Leconte's thrasher, crissal thrasher, cactus wren, Baird's wren, verdin, and plumbeous gnatcatcher.

Breeding birds preferring a moist habitat, generally near a stream or swamp, include the following: marsh hawk, duck hawk, white-necked raven, rough-winged swallow, and bank swallow.

\section{MESQUITE SEMI-DESERT BIOTA}

(TEXAS SEMI-DESERT, SHREVE)

"An open or closed stand of small trees and shrubs, chiefly deciduous, with local areas of grassland and a representation of succulents. The dominant tree is mesquite (Prosopis glandulosa); the principal shrub, huisache (Acacia farnesiana)."

Mammals include white-tailed deer (Odocoileus texanus), wolf (Canis rufus), opossum (Didelphis marsupialis texensis), peccary (Tayassu), and armadillo (Dasypus novemcinctus texanus).

Breeding birds include the following: killdeer, Mexican jacana, chestnutbellied scaled quail, Attwater's prairie chicken, Rio Grande turkey, chachalaca, red-billed pigeon, western mourning dove, white-winged dove, Mexican ground dove, Inca dove, white-fronted dove, black vulture, turkey vulture, Harris' hawk, western red-tail, zonetailed hawk, Swainson's hawk, Sennet's white-tailed hawk, Mexican black hawk, Mexican goshawk, prairie falcon, Aplomado falcon, desert sparrow hawk, Audubon's caracara, spotted owl, Texas screech owl, burrowing owl, groovebilled ani, road-runner, California cuckoo, coppery-tailed trogon, Texas 
kingfisher, Texas woodpecker, cactus woodpecker, golden-fronted woodpecker, Stephens' poor-will, Merril's parauque, Texas nighthawk, Reiffer's hummingbird, buff-bellied hummingbird, Couch's kingbird, scissor-tailed flycatcher, Mexican crested flycatcher, Derby flycatcher, vermilion flycatcher, beardless flycatcher, Texas horned lark, green jay, white-necked raven, red-eyed cowbird, Vera Cruz red-wing, Rio Grande meadowlark, Audubon's oriole, Sennett's oriole, Bullock's oriole, greattailed grackle, house finch, Arkansas goldfinch, Texas seaside sparrow, western lark sparrow, black-throated sparrow, botteri sparrow, Cassin's sparrow, Texas sparrow, gray-tailed cardinal, Texas pyrrhuloxia, western blue grosbeak, varied bunting, painted bunting, Sharpe's seedeater, lesser cliff swallow, gray-breasted martin, rough-winged swallow, phainopepla, white-rumped shrike, small white-eyed vireo, Texas vireo, Sennett's warbler, Florida yellowthroat, Rio Grande yellow-throat, western mockingbird, Sennett's thrasher, curve-billed thrasher, cactus wren, lomita wren, black-crested tit-mouse, verdin, and plumbeous gnatcatcher.

Breeding birds preferring a moist habitat, generally near a stream or swamp, include the following: snowy plover, Wilson's plover, and marsh hawk.

16. BROAD THICK-LEAVED EVERGREEN SEMI-DESERT BIOTA (WINTER RAIN REGION) (PACIFIC SEMI-DESERT, SHREVE; CALIFORNIA CHAPARRAL, AND WOODLANDS OF MEDITERRANEAN TYPE, HARDY ; COASTAL CHAPARRAL AND PINEOAK WOODLAND IN PART, CLEMENTS)

"A region of great topographic diversity in which the vegetation varies locally from encinal (open oak forest, chiefly evergreen), through chaparral (a closed scrub of evergreen shrubs), to desert (ephemeral herbaceous plants, small perennials, local succulents). . . . The principal chaparral plants are chamiso (Adenostoma fasciculatum) and species of manzanita (Arctostaphylos)."
The mammals include black-tailed deer (Odocoileus columbianus scaphiotus), coyote (Canis ochropus), and blacktailed jackrabbit (Lepus californicus subspp.).

\section{MAGNOLIA, Bay, holLy, "haM- MOCKS' (TEMPERATE RAIN FOREST)}

Various correspondents contend that there is no forest of this type in the Americas. Various others have mapped the areas in the states adjacent to the Gulf of Mexico, especially Florida, as of this type. Pittier is inclined to consider some of the South American forests in high altitude as coming under Schimper's definition. From diagrams of the distribution of temperature and rainfall in the Australian and Asiatic areas commonly called temperate rain forest localities, there is evidently no climatic reason why this type should not occur in some localities in the southern states. The botanical objections to considering the magnolia, bay, holly "hammocks" temperate rain forest seems to be the sclerophyll character of the leaves. This may be another case where more consideration of the animals and lower plants should be allowed to dictate. So far as the animals living under the forest cover are concerned the failure of the leaves to fall is more important than the character of their covering. For lists of animals see under the Florida account, page 427 .

\section{TROPICAL HAMMOCKS (SUBTROPICAL RAIN FOREST)}

Some small areas in southeastern Florida have sufficient rainfall correctly distributed to give a tropical rain forest. Some areas of this type have reached a climax which may be considered as a less luxuriant type of rain forest. Their small size does not permit them to afford shelter to the larger tropical animals but the biota is generally taxonomically related to the biota of the West Indies. 
For lists of animals and further dis- The swamps composed of evergreen cussion see the Florida account page 427. and deciduous trees in great variety, the bald cypress and tupelo gum being

19. LOCAL AND EDAPHIC BIOTA

All the waters, sand areas, rock slides, the commonest species. The marshes are widely varying areas of grasses, sedges, and immersed aquatic plants. etc., belong here but swamps and Mangrove swamps border shores in marshes cover most extensive areas. southern Florida. 


\section{LIFE ZONES}

\section{By V. E. Shelford and G. T. Jones}

In this book an attempt has been made to use natural features: climate, landscape aspects, and the characteristic plants in designating and describing areas. Various authors of local accounts use "ife zones" to designate areas. Without a glossary the names do not suggest the landscape aspect types. It is necessary in such a work that natural features be used in order that the traveler may identify his location. The characteristic plants were substituted by the compilers for "life zones" wherever mentioned by contributors in temperate America. This was done in accord with the table below.

\section{Approximate correspondence of Vegetation and Merriam's Life Zones}

(Prepared by George T. Jones)

\section{Vegetation type}

I. Tundra and Alpine Summits

A. Arctic Tundra

B. Paramos or Alpine Meadow

II. Coniferous Forest
A. Northern Coniferous Forest
B. Mountain Coniferous Forest

1. Rocky Mountain Forest

2. Sierran Sub-alpine Forest

3. Rocky Mountain Montane Forest

4. Sierran Montane Forest

\section{Larch-Pine For- est of North- west}

\section{Northwest Moist Coniferous Forest}

III. Eastern Forests
A. Mixed Coniferous and Deciduous
B. Temperate Deciduous
C. Southeast Coniferous Forest

D. Gulf Coast Forest
Composition

Merriam's Life Zone

\section{Lichens and herbs}

Sedges, grasses and herbs, dwarf willows

Red, black and white spruces, balsam fir

Engelmann spruce and alpine fir

Mountain hemlock, firs, white-bark pine

Western yellow pine, Douglas fir, white fir, lodgepole pine

Sugar pine, western yellow pine, incense cedar, white fir, Douglas fir

Western white pine, western larch, western hemlock, Engelmann spruce, giant cedar

Redwood, douglas fir, western hemlock, giant cedar, Sitka spruce

Beech, birch, maple, hemlock, white pine

Beech, maple, oaks, hickories, tulip tree, sassafras

Longleaf pine, loblolly pine, slash pine, magnolia, live oak, bald cypress

Southeast Coniferous Forest with undergrowth of Palmetto
Arctic-Alpine Zone

Arctic-Alpine Zone

Hudsonian and Canadian

Hudsonian and upper Canadian

Hudsonian and upper Canadian

Canadian and upper Transition

Canadian and Transition

Canadian and Transition

Canadian and Humid Transition

Alleghanian

Carolinian

Austroriparian

Sabalian or Gulf Strip 
IV. Temperate Rain Forest

V. Sub-tropical Rain Forest

VI. Poplar Savanna

VII. Oak Savanna

VIII. Rocky Mountain Forest Margin

A. Chaparral

B. Woodland

IX. California region of various vegetation with Summer drouth and Winter Rain

A. Chaparral

B. Woodland

C. Coastal sagebrush or "chaparral"

D. Bunch-grass plains in X. Grassland valleys (cultivated)

A. Prairie

B. Steppe (Brush-grassland in part)

XI. Bush-Steppe

1. Semi-desert Northwest

2. Semi-desert Southwest

XII. Temperate Desert

XIII. Subtropical Desert

A. California Microphyll Desert

B. Succulent Desert

XIV. Thorn Savanna
"Hammock" Country, Florida

Very rare frost, south tip of Florida

Mixture of poplars and tall grasses

Mixture of oaks and tall grasses

Brush, as dwarf oak (Quercus undulatus) and Mountain mahogany (Sercocarpus parvifolius)

Pinyons and junipers

Brush, as Manzanita and Buck brush

Evergreen oaks, junipers, etc.

"Old Man" (Artemisia californica) and Salvia

Tall grass in bunches

Largely included in Savanna VI and VII

Grasses in open sod. Bare ground between plants, or rather short grasses forming sod

Mixed grass and sagebrush

Mixed Grass and desert shrub

Sagebrush-Atriplexrabbit brush

Creosote bush and Sandbur

Cacti, mesquite, etc.

Thorn bushes and grass
Sabalian Zone

Tropical Zone

Transition and Alleghanian

Alleghanian, Carolinian and Austroriparian

Arid Transition

Upper Sonoran

Arid Transition

Upper Sonoran

UTper Sonoran

Upper and Lower Sonoran

Arid Transition and Upper Sonoran

Upper Sonoran

Upper Sonoran

Upper Sonoran

Lower Sonoran

Lower Sonoran

Lower Sonoran
The maps of Southern North America and Northern South America are the results of the circulation of three preliminary maps. The earlier maps were criticized by T. Barbour, L. Griscom, G. K. Noble, A. G. Ruthven and others. A much larger scale map was then planned with the aid of Dr. W. H. Osgood, drawn and circulated. Most of the contributors of tropical accounts made important suggestions and $\mathrm{Mr}$. E. P. Killip of the National Museum added his knowledge of several countries.

Florida may be used to illustrate difficulties in mapping the vegetation of areas. It is covered largely by long- leaf pine, and is commonly mapped as coniferous forest. Detailed study shows, however, that on well-developed soils in stable physiographic situations such as the highest terraces of flood plains, other types occur which indicate future dominants. Thus Professor Watson shows northwestern Florida to be deciduous forest, much of central Florida to be temperate rainforest (evergreen), southeastern Florida to be tropical rainforest, and the remaining parts are represented according to present dominants because neither the knowledge nor conditions make possible prediction of the coming type. 


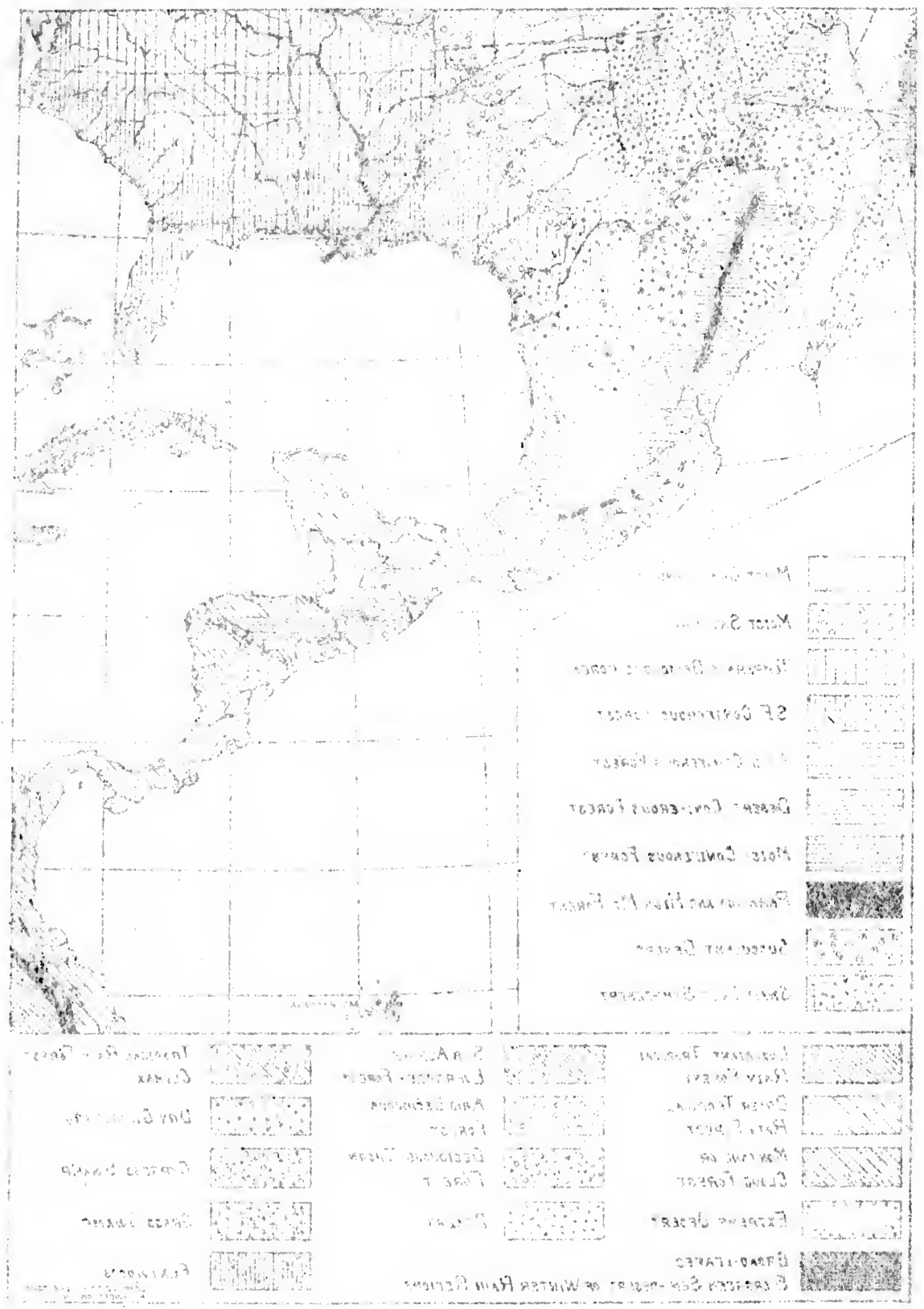

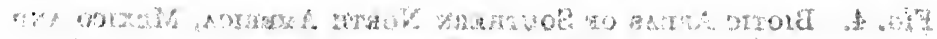

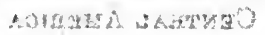






Fig. 4. Biotic Areas of Southern North America, Mexico and Central America 


\title{
D. DESCRIPTIVE LIST OF MIDDLE AMERICAN BIOTA (CENTRAL MEXICO TO THE AMAZON)
}

\author{
By Forrest Shreve and V. E. Shelford
}

(Names in parenthesis are synonyms used in published works or in the manuscripts submitted)

1. LUXURIANT TROPICAL RAIN-FOREST BIOTA (RAIN-FOREST; LOWLAND TROPICAL FOREST; HEAVY FOREST; HEAVY HUMID FOREST)

This forest occupies regions with uniform mean monthly temperature and a heavy and well distributed rainfall. The forest is composed of a great number of different species and genera of trees of different stature and of shrubs and vines. The dominant trees are evergreen, or nearly so, and their leaves are relatively small and thick, while those of the subordinate trees are broad and thin.

The animal life is also represented by a vast number of species. Termites which build nests on trees, leaf carrying ants, military ants and gaudy butterflies characterize the insect population. Frogs and lizards are numerous. The snakes include some of the constrictors and poisonous coraline and crotaline species. Most of the birds are of common neotropical types, many being large, grotesque or gaudy. Monkeys are most numerous here-many rarely coming to the ground. Cats large and small, squirrels, and opossums are plentiful, Arboreal anteaters and sloths are characteristic. Tapirs are nearly always present.

\section{DRIER TROPICAL RAIN-FOREST BIOTA (LOWLAND RAIN-FOREST)}

This type of forest is similar to the luxuriant tropical Rain-Forest, but is not so heavy, the trees are not usually so tall nor so numerous in species, and the abundance of epiphytes and lianas depends upon local conditions, tending to be less numerous than in the Luxuriant Tropical Rain-Forest. The animal life is similar to that of the luxuriant forest but poorer in species and with many species different.

\section{ARID DECIDUOUS FOREST BIOTA \\ (MONSOON FOREST; SEMI- DECIDUOUS FOREST)}

This forest is similar to the drier rain forest in the wet season, but exhibits partial leaf fall in the dry season. It is rich in epiphytes of bromeliad type, but relatively poor in lianas. The shrubs are chiefly evergreen.

The monkeys, opossums, and arboreal anteaters drop out or become much less numerous than in the tropical rain forest. Peccaries, forest rabbits, foxes, and deer are more numerous. It must be borne in mind, however, that trees adjacent to streams often retain their leaves and that monkeys, tapirs, etc., ordinarily found in rain forest may occur here. In general, however, the species in the deciduous forest proper are quite different in the case of animals.

4. DECIDUOUS THORN FOREST BIOTA (XEROPHYLOUS FOREST; THORN FOREST; CAATINGA)

Deciduous Thorn Forest occupies some of the more arid portions of South America. It consists of a more or less close stand of large shrubs, small trees and succulents. The majority of the dominant plants are leafless in the dry 
season. The animal life is scanty, armadillos, forest rabbits, and foxes being dominant mammalian types.

\section{5. gRASSLAND BIOTA (PRAIRIES; llanos; CAMPOS; PAMPAS; PAJONALES)}

The diverse grassland areas of tropical America are alike in the tall coarse, character of the grasses and in the occurrence with them of numerous shrubs and perennial herbaceous plants. In some localities the vegetation is low and open, as on the limestone mesas of Venezuela; in others it is more luxuriant and more nearly perennial in its activity. Only restricted areas of grassland are without trees. Little distinction can be made between the animal life of the Grassland and Savanna due to the lack of information, particularly as to the smaller forms.

\section{SAVANNA BIOTA (ARID GRASSLAND; GALLERY SAVANNA)}

The Savannas are tropical grasslands occupied by greater or less numbers of trees or shrubs, growing singly or in groups, and being chiefly deciduous except in the case of the palms. The grasses vary in density and stature, up to $1 \mathrm{~m}$. in height.

The Savannas of South America are characterized by two or three species of savanna deer and brocket, tayra, skunks, savanna foxes, peccaries, etc. Monkeys live in groves of trees in some localities and may move from grove to grove through bushes when they occur.

\section{SEMI-DESERT BIOTA}

The principal area of Semi-desert is in the lower valley of the Rio Grande and in the Mexican state of Tamaulipasothers occurring on the coast of South America. Thorny deciduous shrubs and small trees make up the principal part of the open vegetation together with evergreen shrubs, cacti, scattered bunch grasses, and herbaceous plants of seasonal activity.
Rats, mice, and ground-squirrels are the dominant animals, though peccaries, deer, and coyotes also occur.

\section{DESERT BIOTA}

The Desert areas of Tropical America are chiefly in northern Mexico and on the Pacific Coast of South America. They are alike in the low stature and open stand of the vegetation and in the restriction of its activity to the rainy seasons. They differ in the density of their shrubbery and in the relative abundance of succulent and non-succulent plants. There are both deciduous and evergreen shrubs; grasses are of local occurrence.

The Deserts are characterized by numerous reptiles, usually diurnal and conspicuous and numerous nocturnal rodents, particularly small ones able to hide. Jack-rabbits and coyotes are common except in extreme deserts.

The following birds breed in the Mexican Plateau desert: Mearn's quail, Merriam's turkey, chachalaca, black vulture, zone-tailed hawk, Sennett's white-tailed hawk, Mexican black hawk, Mexican goshawk, flammulated screech owl prairie falcon, Aplomado falcon, Audubon's caracara, Mexican screech owl, burrowing owl, ferruginous pygmy owl, thick-billed parrot, grooved-billed ani, road-runner, California cuckoo, cactus woodpecker, Arizona woodpecker, ant-eating woodpecker, Stephen's poorwill, Texas nighthawk, Rivoli hummingbird, blue-throated hummingbird, black-chinned hummingbird, Lucifer hummingbird, white-eared hummingbird, broad-billed hummingbird, scissortailed flycatcher, Cassin's kingbird, Derby, flycatcher, sulphur-bellied flycatcher, Mexican crested flycatcher, ashthroated flycatcher, Coues' flycatcher, gray flycatcher, buff-breasted flycatcher, vermilion flycatcher, scorched horned lark, blue-eared jay, Arizona jay, whitenecked raven, San Diego red-wing, Scott's oriole, Arkansas goldfinch, Worthen's sparrow, black-chinned sparrow, desert sparrow, Cassin's sparrow, Scott's sparrow, canyon towhee, Abert's towhee, western blue grosbeak, hepatic tanager, Cooper's tanager, Mexican cliff swallow, phainopepla, Stephen's vireo, least vireo, gray vireo, olive warbler, Sonora yellow warbler, black-fronted warbler, long- 


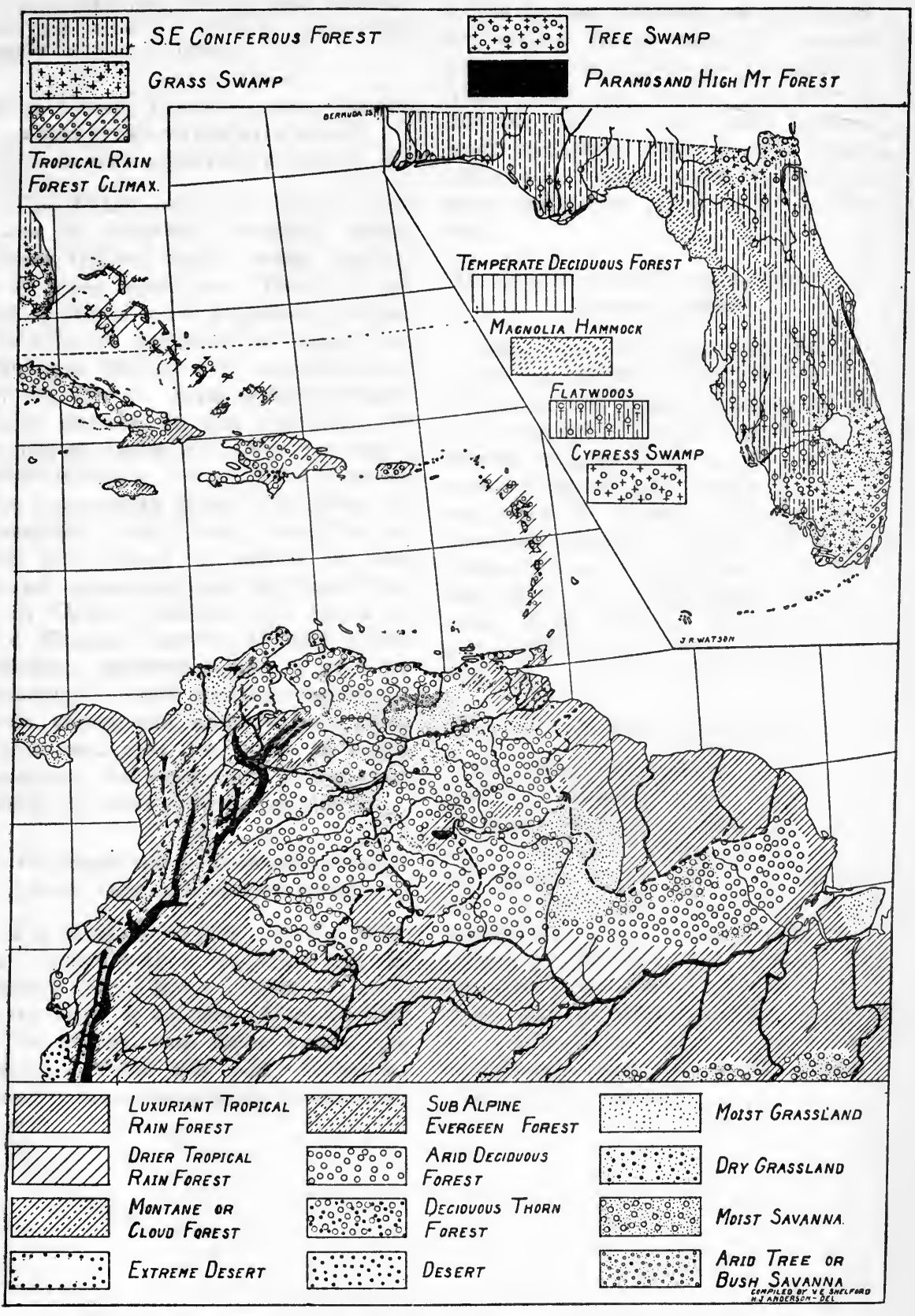

Fig. 5. Biotic Areas of Florida and Northern South America 


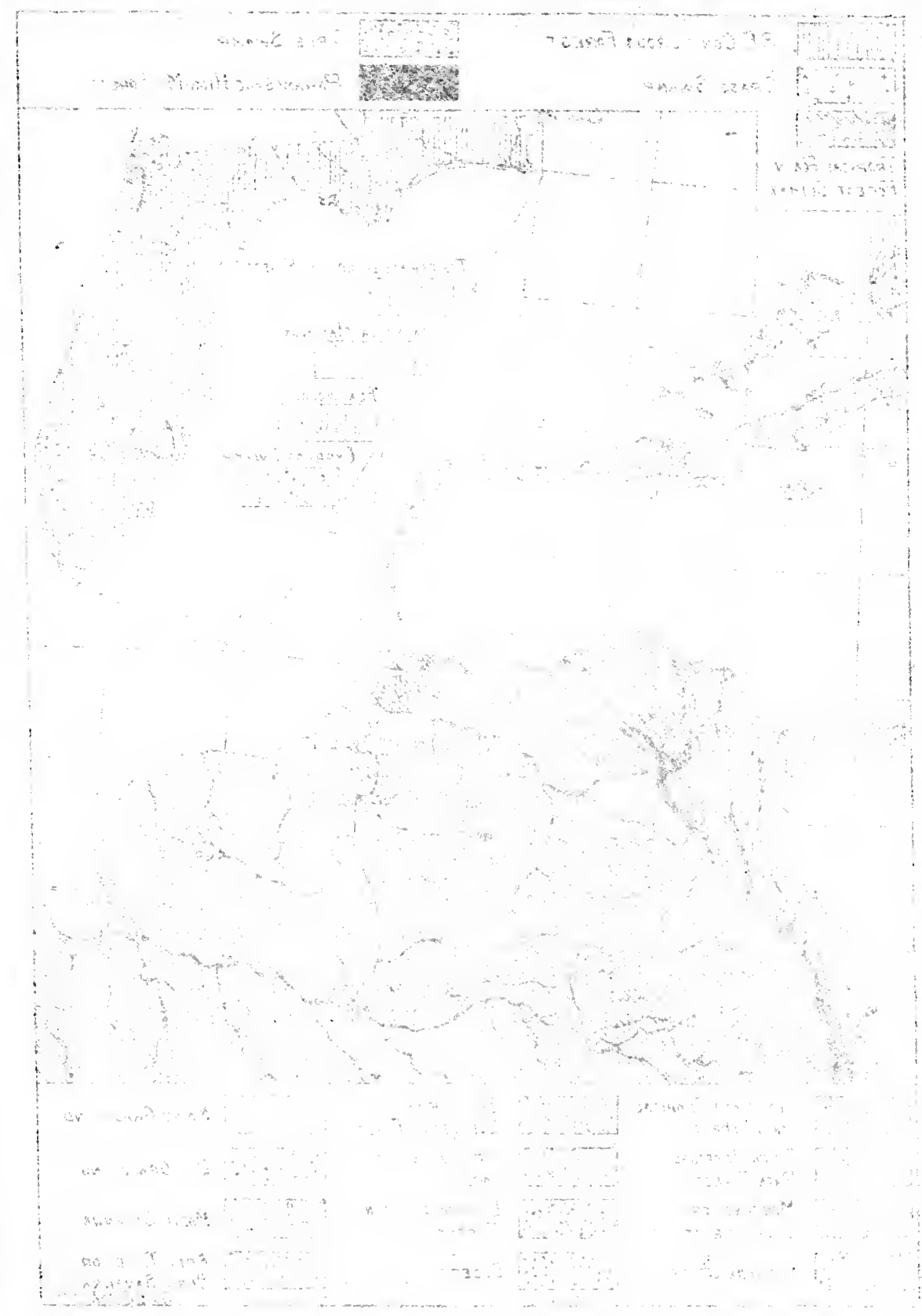

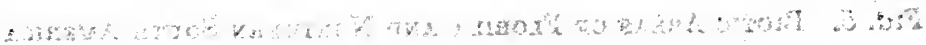


tailed chat, western mockingbird, Palmer's thrasher, Bendire's thrasher, crissal thrasher, white-throated wren, bridled titmouse, lead-colored bush-tit, Lloyd's bush-tit, verdin, plumbeous gnatcatcher.-L. Jones.

\section{MONTANE FORESTS BIOTA (CLOUD FOREST; TEMPERATE RAIN FOREST; LOWER MOUNTAIN FOREST)}

This forest occurs at various elevations in tropical mountains where clouds, fog, and heavy rainfall produce very moist conditions. The trees are not so tall as in the Luxuriant Tropical Rain-Forest, but in other respects the Montaine Forests rival the luxuriance of the former. Ferns form a conspicuous element in the vegetation as epiphytes, lianes and terrestrial plants, while tree ferns are conspicuous among the subordinate trees. The trees are evergreen, mostly with small leaves; but solid stands of conifers are also found, depending upon soil conditions.

In Central America the fauna of the Montane forest is in part highly peculiar. Endemic genera of birds are numerous. North American temperate zone plants and animals here reach their limit also. In parts of South American the conspicuous animals are about the same as in the rain forest.

\section{SUBALPINE EVERGREEN FOREST} BIOTA (UPPER MONTANE FOREST)

The mountains rising above $9000 \mathrm{ft}$. are clothed with a temperate and deciduous broad-leaved forest of evergreen trees or conifers. Monkeys and other tropical rain forest species are excluded from this belt. Numerous small rodents characterize it, however.

\section{ANDINE BUSHLAND BIOTA (AN- DINE BRUSHWOOD)}

The Andine Bushlands are just below timber-line, being frequently broken by small areas of grassland (paramillos). Tree shrubs and dwarfed trees form a low but compact stand, which becomes lower and more open at still higher altitudes. Deer, wild-cats, wolves, bear, and forest rabbit occur in this belt.

12. ANDINE MEAdOW BIOTA (PARAMOS; ALPINE MEADOW)

Lying above the uppermost shrubby vegetation, chiefly over $12,000 \mathrm{ft}$. elevation, are the Andine Meadows, which are composed of grasses, sedges, many species of composites, notably of the genus Espeletia, and scattering representatives of various genera of temperate relationship. Plants with hoary tomentum are conspicuous in this vegetation, as are also areas of sphagnum. Deer, wild-cats, forest rabbit, and numerous small rodents occur in this belt.

\section{MANGROVE SWAMP BIOTA}

The Mangrove Swamps of tropical America consist of nearly pure stands of Rhizophora mangle, Avicennia nitida or $A$. tomentosa, occupying the coast, the shallow saline or brackish waters of bays and lagoons. The interlocking prop-roots of these trees make the Mangrove Swamps very difficult to penetrate from either land or water. There are characteristic insects, birds, etc., but the fauna of the swamps varies in different regions on account of their wide geographical range. 


\title{
E. PROVISIONAL TABLE OF LANDSCAPE ASPECTS AND LIFE ZONE EQUIVALENTS
}

\author{
By E. A. Goldman
}

Mangrove Swamps (Tropical Zone as a whole, but as mangrove swamps are not dependent upon rainfall, they occur within the arid or humid divisions of the Lower Tropical section).

Flood Plain Forest (low altitudes) -Lower Tropical Zone.

Luxuriant Tropical Rain ForestHumid Lower Tropical Zone.

Drier Tropical Rain Forest-Humid Lower Tropical Zone.

Montane or Cloud Forest-Humid Upper Tropical Zone. It includes conifers and oaks in Central America.

Subalpine Evergreen ForestTemperate Zone. (In Central America.)

Ecuador and British Honduras, ranging in altitudes from 6000 to $7000 \mathrm{ft}$. in the former country and to 1000 to 4000 ft. in the latter.

The areas in British Honduras extending from 1000 to $4000 \mathrm{ft}$. altitude would be within the Lower Tropical Zone, associated with an immense number of tropical species. Areas at 6000 to $7000 \mathrm{ft}$. altitude in Ecuador would probably be assigned to Sub-tropical or Upper Tropical.

Partially Deciduous Forest-Arid Lower Tropical Zone.

Deciduous Thorn Forest-Arid Lower Tropical Zone. In Mexico and in Panama this can not satisfactorily be separated from the preceding, as the regions are coastal plains crossed by streams; and along the streams the vegetation may be only partially deciduous, or near the water line evergreen, while it is completely deciduous away from the water. (Shrub) Desert-Sonora and Lower California. Lower Austral Zone. Semi Desert-Lower Austral Zone. Extreme Desert-Lower Austral Zone. Desert District Vizcaino. Gallery Savanna-Arid Lower Tropical Zone. A mixture of monsoon forest and savanna. Arid sometimes corresponds to the Lower Tropical Zone.

Grassland, Dry Grassland-Arid Lower Tropical Zone.

Andine bushland ParamillosParamo Zone. 


\section{F. BIBLIOGRAPHY}

By V. E. Shelford

Adams, C. C.

1920 Zoogeography of Northeasternmost South America (after Chapman). Geog. Rev.,10:101107.

Brehn, A. E.

1890 North Pole to Equator, London Batholomew, J. G.

1917 Advanced Atlas of Physical and Political Geography (Oxford Press).

Clements, F. E.

1916 Plant Succession. Carnegie Inst. of Wash., Pub. 242.

1920 Plant Indicators, Carn. Inst. Wash. Pub. 290.

Chapman, F. M.

1917 Distribution of Bird Life in Colombia. Bull. Am. Mus. Nat. Hist., 36: 1-729.

Goldman, E. A.

1920 Mammals of Panama. Smithsonian Misc. Coll., Vol. 69, No. 50: 1-309.

Hall, H. M., and Grinnell, J.

1919 Life Zone Indicators in California. Proc. Cal. Am. Sci., 9: 37-67.

Hardy, M. E.

1920 The Geography of Plants. (Oxford Press)

1913 An introduction to Plant Geography. (Oxford Press.)

Livingston, B. E. and Shreve, F.

1921 Distribution of Vegetation in the U. S. as related to Climatic Conditions. Carnegie Inst. of Wash., Pub. 284.
Mobius, $\mathbf{K}$.

1880 The Oyster and Oyster Culture.

U. S. Com. Fisheries Report 1880 (Part VIII): 683-751.

Merriam, C. H.

1898 Life Zone and Crop Zones. U.S. Dept. Agr. Bur. Biol. Surv., Bull. 10.

Sanders, E. M.

1921 The Natural Regions of Mexico. Geog. Rev., 11: 212-26.

Schimper, A. W.

1903 (Translation by W. R. Fisher. Plant Geography on a Physiological Basis. Oxford.

Shreve, F.

1917 A Map of the Vegetation of the United States. Geog. Rev. 3: 119-125.

Ward, R. DeC.

1919 A New Classification of Climates

(Koppen's). Geog. Rev., 8: 188-199.

Van Dyke

1919 Distribution of Insects in Western North America. Ann. Ent. Soc. of America, 12: 1-12.

Shelford, V. E.

1911 Physiological Animal Geography. Jour. Morph., 22: 551-618.

Strohl, J.

1921 Physiologische Gesichtpunkte in der Tiergeographi. Vierteljahresschrift der Naturforsch. Ges., Zur. 46: 1-22. 
IV. NATURAL AREAS AND REGIONS 



\title{
A. GENERAL PLAN
}

\author{
By V. E. Shelford
}

The primary object of this volume is to locate natural areas so as to make them available to naturalists. Everyone who learns the location of a natural area through this volume should realize the moral obligation to keep the area as it is. Using an area described in this book to satisfy one's selfish desires for possession is a violation of a trust placed in the nature-loving public.

Convenience of treatment divided the territory covered into three sections: (1) Northern tundra and icecovered regions; (2) Temperate America including the southern tier of Canadian provinces and the whole of the United States; (3) Tropical America, including the areas between the southern boundaries of the United States and the Amazon River and adjacent islands. In the first and last divisions the greatest latitude was permitted the authors and no attempt to map or classify areas was made. The meagre character of the available knowledge forbade attempting anything of the kind. The name of the person preparing the account for each territory stands at its head as the one responsible for the completeness and accuracy.

The materials on the States and southern tier of Canadian provinces are divided into (1) a general account of biotic conditions of the territory, and (2) specific descriptions of natural areas.

The general account describes the territory as it was before modified by civilization. General physiographic features are described and geographic and local plant and animal communities briefly outlined. The names of Merriam's life zones are used only in parentheses following the names of the plants commonly used to designate them. The original conditions of the biota are then contrasted with the present modified condition; the communities and conspicuous plants and animals which have been destroyed are enumerated. Some authors have enumerated polluted and unpolluted waters.

In specific descriptions, the existing natural areas are in part arranged according to the natural subdivision recognized in the general account. All preserved areas and areas available for study, in natural condition, preserved areas in a semi-natural condition, such as forest preserves, bird and game sanctuaries, and second growth areas undergoing succession, are as a rule included and properly designated in so far as they were known to the authors.

The National Forest were treated separately by members of the United States Forest Service. The National Parks and Monuments are included in the state accounts.

\section{ABBREVIATION AND SYMBOLS}

a. In locations of areas which appear abbreviated, words in brackets have been omitted:

[From] Chicago, [Ill. go] $12 \mathrm{mi}$. west [via] C. B. \& Q. R. R. or La Grange Electric, to Riverside [and walk] (W) $\frac{1}{2}$ mi. N. W. [From] Riverside, Ill.

b. Modification of areas. As compared with their condition at the time of the discovery by America by Europeans in the fifteenth century all areas have doubtless suffered considerable modification. The degree of modification varies greatly in the various natural reservations, and in those areas avail- 
able for study and proposed for preservation. It was the opinion of the committee, that to publish an extensive list without at least an estimate of the degree of modification would give an entirely erroneous idea of what is available for scientific study and of desirable policies relative to the improvement and maintenance of existing preserves and the acquirement of more.

The conditions of the vegetation are indicated by capital letters. The original conditions are indicated by $\mathrm{A}$, and degrees of modification by C, D, etc.

The conditions of the fauna are indicated by Arabic numerals. The orig. inal natural conditions are indicated by 1 (one) and degrees of modification by other figures, $2,3,4$, etc.; 10 would indicate a cultivated field, though the plan is only carried to H8, e.g., single trees in parks or pastures.
Symbols, etc.

* (in front of the name of an area): Preserved-that is, areas held in a natural state as parks, forest preserves, etc.

** Preserved for scientific purposes

$p$ (in front of the name of an area) indicates that it is proposed for preservation.

Areas not designated by either of these symbols are available for study.

$\ddagger$ Hotel or boarding-house facilities.

|| Hotel or boarding-house during tourist season only.

† Especially important; should be preserved unmodified.

$\S$ Camp outfit desirable; necessary.

Figures in $\mathrm{ft}$. indicate elevation above sea level.

Letters in parentheses indicate desirable means of reaching the area as follows: (w) on foot; (a) by automobile; (h) horseback; (c) canoe. 


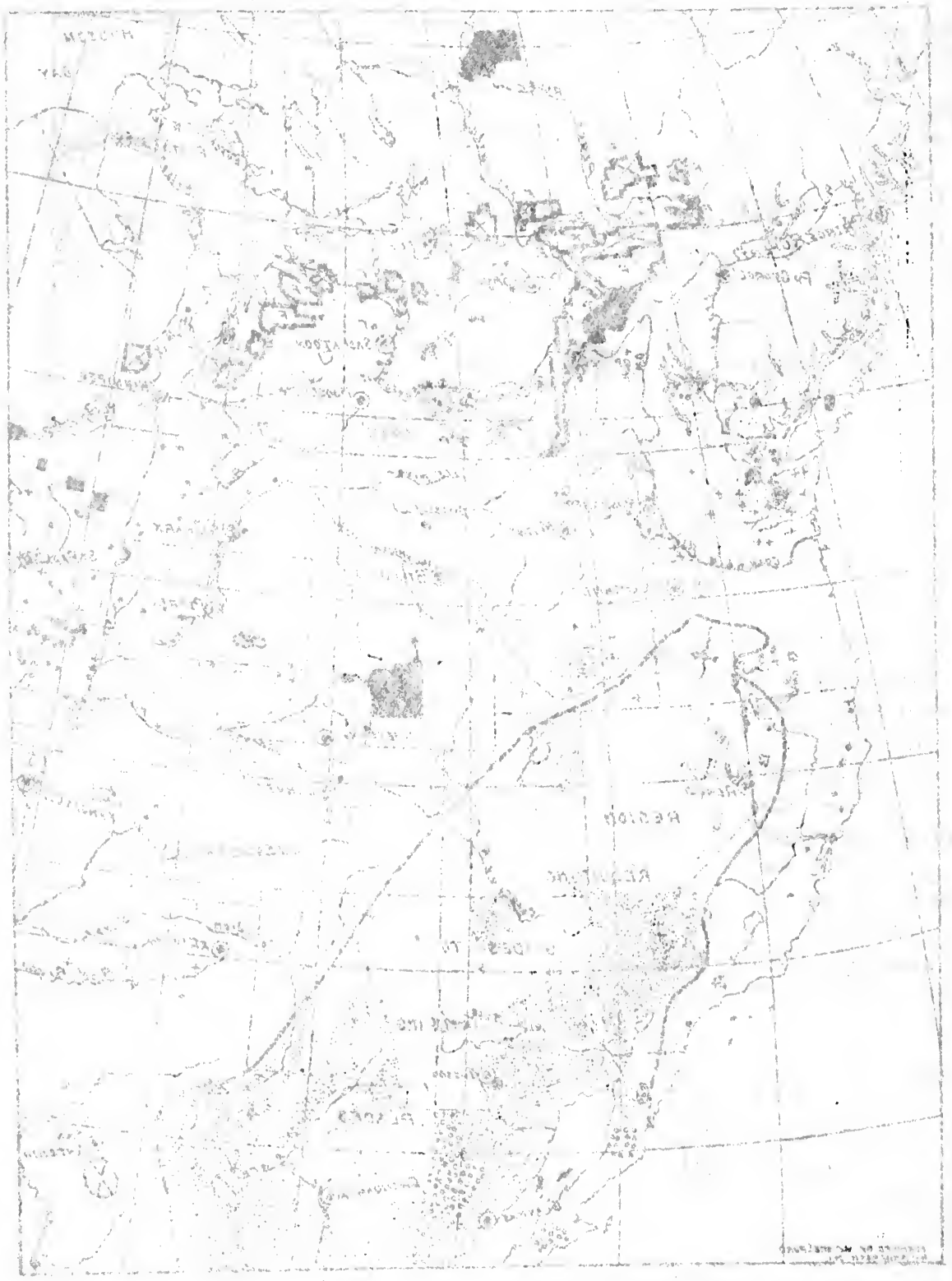






Fig. 6. Preserved and Available Areas in Western North America 


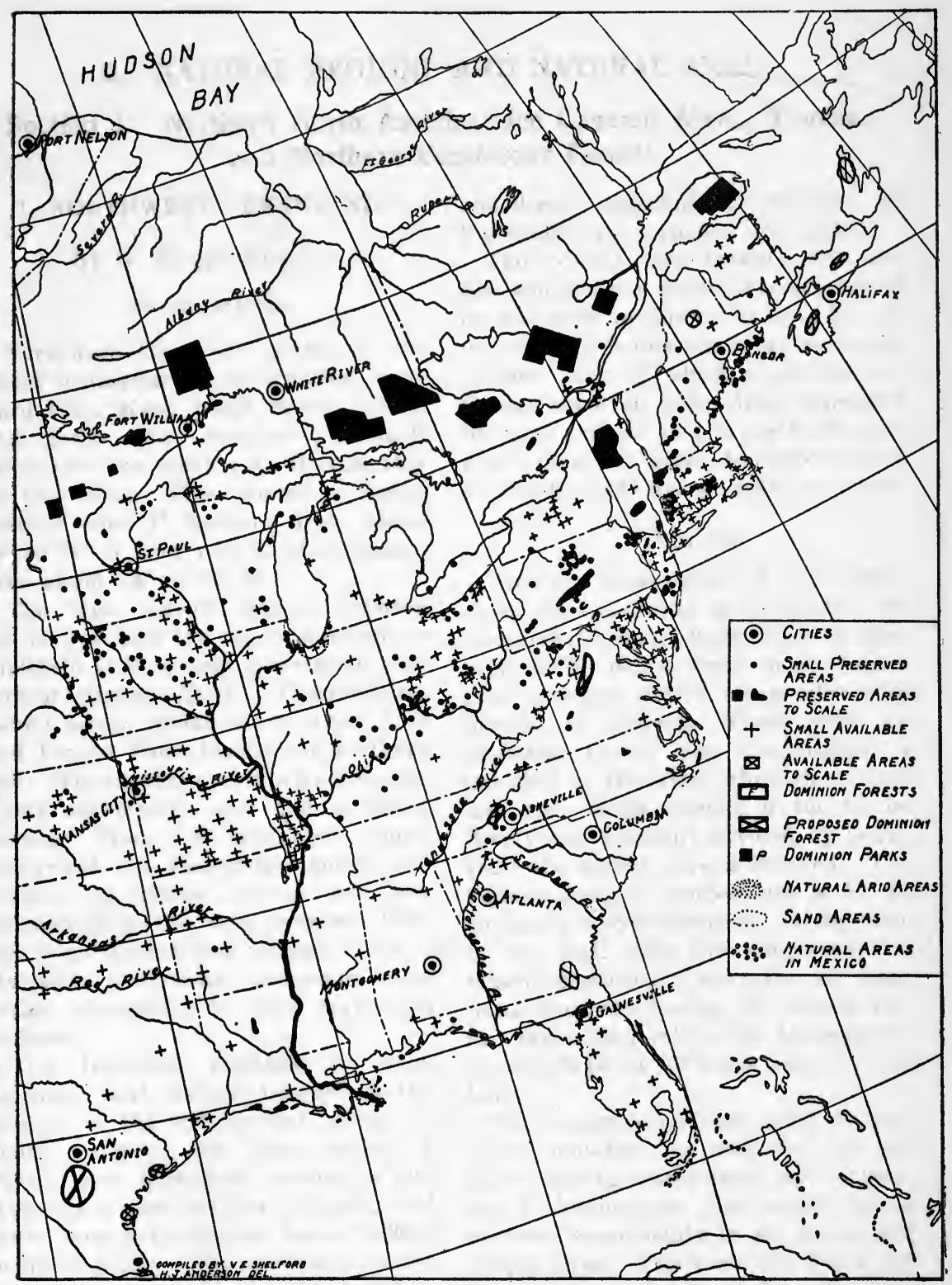

Fig. 7. Preserved and Available Areas in Eastmrn North Amgrica 


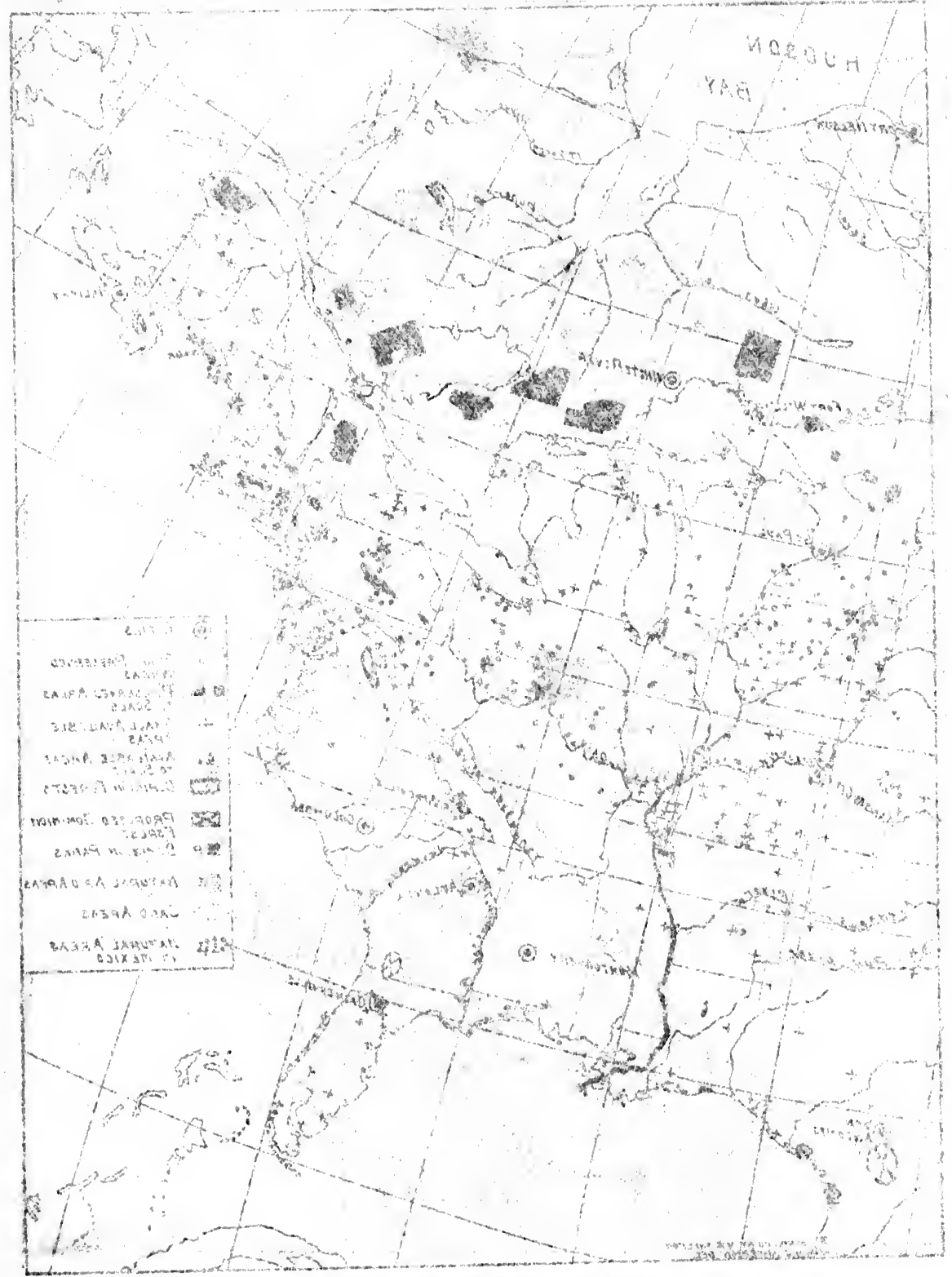

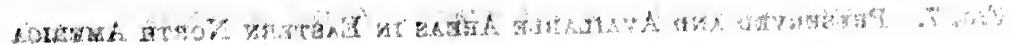




\section{B. NATURAL REGIONS AND NATURAL AREAS}

\section{Section 1. Northern North America; Ice Covered Areas, Tundra, and Northern Coniferous Forest ${ }^{1}$}

\section{NORTHWEST GREENLAND}

\section{By W. Elmer Ekblaw}

\section{PHYSIOGRAPHY}

Northwest Greenland embraces the broad peninsular region fronting westward upon Kane Basin, Smith Sound, and Baffin Bay, between Humboldt Glacier on the north and Melville Bay on the south. This peninsular region extends over $3^{\circ}$ latitude, from about $76^{\circ}$ to $79^{\circ} \mathrm{N}$. and over $8^{\circ}$ of longitude, from about $64^{\circ}$ to $72^{\circ} \mathrm{W}$.

The high narrow plateau between the ice-cap and the sea is bisected by Inglefield Gulf, a deep indentation with several tributary fjords. Wolstenholme Sound again bisects the southern half and Foulke Fjord bisects the northern half. The northern portion from Foulke Fjord northward, and the southern portion from Wolstenholme Sound southward are Laurentian gneiss and granite, in places capped by later sedimentaries; the area between Wolstenholme Sound and Foulke Fjord is Huronian sandstones, limestones, and shales, intersected by dark traps and diabases.

The Huronian coastline is much indented, with narrow beaches at the mouths of the valleys and along the gentler slopes; the land-surface is varied, with high sharp mountains and deep canyon-like valleys in places, and lower, rounded hills and broad valleys in other places. The Laurentian coast line is smoother, with very few beaches; the land-surface is more uniformly high

1 This section was not edited as the others were. All accounts were read by Messrs. Preble and Ekblaw and a part by Dr. Osgood. F. C. Baker read the zoology of the entire section. and deeply dissected. Everywhere the topography is comparatively rugged.

The coastal belt between the icecap and the sea which becomes free of ice and snow in summer is from 2 to 40 mi. wide. It is intersected by numerous glaciers, most of which reach the sea, though some do not. Areas separated by these glaciers vary in size from small tracts of a few acres, to large regions several hundred square miles in extent.

\section{CLIMATE}

With the large extent of open water along the coast even in midwinter, the temperature rarely drops down to more than $50^{\circ} \mathrm{F}$. below zero, much higher than extreme winter temperatures in Siberia or Canada. Even with an extensive ice-lay the temperature is modified by the water, through crevices and open pools, though if the ice be deeply and generally covered by heavy snow the temperature is lowered. The highest summer temperature is $55^{\circ}$ to $60^{\circ}$ above zero Fahrenheit. Along some of the high cliffs the temperature is raised adiabatically when the air drops down from the ice-cap, so that in certain favorable localities the temperature never falls below $40^{\circ}$ below zero Fahrenheit.

The temperature rises high enough about mid-June to melt the ice and snow; melting ceases about mid-August. By mid-September the sea-ice begins to form permanently in the fjords and deeper bays. The bays and fjords are generally occupied throughout the summer by drifting fields of ice; rarely are they free of icebergs.

Snow falls in every month of the year, but the first snows of summer 
that do not melt are those of late August or early September. The depth of snow, even after a winter's accumulation, is rarely over 2 or $3 \mathrm{ft}$., because the relative humidity is frequently so low that a great deal of snow evaporates even in the coldest weather. When the snow begins melting in June under the continuous sunlight, every canyon and valley holds a roaring torrential mountain stream which flows with heavy volume until melting ceases. Rain rarely falls; yet when the chinook comes down off the ice-cap, rain may fall even in January. The region is one of general low humidity.

The winds are cyclonic in character. The heaviest storms come from the southwest with destructive on-shore winds. In the bays and fjords the winds invariably blow down to the sea from the ice-cap, no matter what the wind may be above the plateau. Sudden winds sometimes sweep down off the plateau or from the ice-cap and drive the shore-ice out to sea even in mid-winter.

The period of continuous night begins about mid-October and ends about mid-February. Continuous sunlight begins about mid-April and lasts until mid-August. Between mid-February and mid-April the days lengthen and the nights shorten; between mid-August and mid-October the days shorten and the nights lengthen. The night is rarely so dark as to stop traveling or sledging entirely, and throughout the moon-lighted periods during which the moonlight is continuous, all activities can be carried on without difficulty. During the period of continuous sunshine, noon and midnight do not differ greatly in temperature or intensity of light. The air is always fresh and clean.

\section{BIOTA}

Because of the short growing season and the long dry cold period no trees or shrubs grow in the homeland of the Polar Eskimo. The tallest tree is the Arctic willow, a scant three inches in height. Over a hundred species of vascular plants grow in the region. The sedges, blue grasses, and similar grassy plants grow luxuriantly. Two are particularly abundant-Poa pratensis and Alopecurus alpinus. On some of the talus slopes manured by nesting birds, the mat of grasses is thick and heavy. Mushrooms are common and lichens clothe the rocks. Flowering plants, though small and relatively inconspicuous, grow in dense mats on favorable slopes where the sun shines warmly, and moisture is ample.

Due in large measure to the rich carbon dioxide content of the water and the continuous sunlight, the plankton development in the sea is incredibly rich throughout the summer, and the heavy growths of laminaria and other sea weeds on every shoal ledge are particularly luxuriant.

The bird life is incredibly abundant, not in species but in individuals. Of the land birds the ptarmigan and snowbunting are the most common. Shorebirds, ravens, snowy owls and falcons are rather numerous. The redpolls, wheat-ear, and Lapland longspur all nest in the area. The ptarmigan, ravens, and snowy owls are permanent residents. Of the sea-birds the dovekies are the most numerous. They nest in suitable slopes of easy gradient along the entire coast in such numbers that they cover the sea when feeding and darken the sky when in flight. Almost as numerous as the dovekies are the murres, that nest on the ledges of the steeper shore cliffs along the coast. The old squaw is common, the red-throated loon frequents the inland pools, and the merganser and greenwinged teal are occasionally seen along the coast. The eider duck frequents the coast in thousands, and the black brant is common. Kittiwakes, guillemots, gulls, jaegers and the fulmars are numerous. All the seabirds find an abundant supply of food in the small life of the cold, well-lighted waters off the shore.

Animal life on land is relatively scarce. 
The muskox (Ovibos moschatus wardi) is extinct along the Greenland shores of Smith Sound though still common in Ellesmereland, Grantland, and westward. The caribou (Rangifer groelandicus), though still fairly abundant, is generally restricted to a few isolated areas not readily accessible. The fact seems fairly well established that the caribou migrate across the ice-cap to Northwest Greenland from the east coast and the regions to the north. The Arctic hare (Lepus groenlandicus) is widely distributed and common. The blue fox and the white fox (Alopex groenlandicus) are abundant in the bird-cliff localities where they feed upon both the eggs and the birds. They are color phases of one species, both occasionally being littered by the same dam. The Arctic wolf (Canis tundrarum is almost extinct, and the lemming and the ermine do not frequent this part of the Greenland Coast. T e muskox, caribou and hare feed upon the willows, grasses, and small herbs; the wolf and fox feed upon the muskox and the caribou.

The sea animals, because of the ample supply of food, are very numerous. Four species of seal-the ringed seal, the bearded seal, the hooded seal, and the harp seal-are all rather common, though the ringed seal is by far the most abundant. The walrus frequents the coast during the whole year, especially when the mussel-shoals furnish good feeding grounds. The narwhal and the white whale are numerous. The killer whale and the bowhead, and occasionally the right whale, visit the coast. The sleeper shark feeds over the deeper bottom. Fish are few. Salmon are caught along shore and in some of the inland lakes.

Mollusks are particularly abundant and number upwards of 72 species. These are all marine, no land or fresh water species having been reported from this part of Greenland. These are all of Arctic forms, including Buccinum, Astarte, and Saxicava as leading types.

The polar bear (Thalarctos m. mari- timus), an animal of both land and sea, is as much at home out on the open sea among the icebergs as along the shore. He avoids all habitations of man, particularly when there are dogs about. Keen of scent and of all perceptions, as well as of intelligence, the polar bear is certainly the most superb animal of the North, though not nearly so dangerous as the walrus.

\section{NOTES}

Northwest Greenland is accessible almost every year between July 20 and September 10 . The outermost capes and islands may be reached by ships as early as July 1, but the innermost bays and fjords do not open up before August 1.

The plant life may best be studied from Etah on Foulke Fjord; Kañgerd luksuah deep within Inglefield Gulf; Keatek on Northumberland Island at the mouth of Inglefield Gulf; and at Umanak on North Star Bay, in Wolstenholme Sound.

Of these places Umanak is probably best, though because of the very localized occurrence of many species, a comp'ete collection is impossible from any one point. For a critical study of the Arctic Drabae in the field, Umanak is unexcelled, since nearly every species of far northern distribution is found there in abundance. For a study of the immigration of American species, Etah is probably most favorably situated. It is interesting that at Etah, Pedicularis hirsuta and Pedicularis capitata are abundant; but Pedicularis lanata is entirely lacking; at Lifeboat Cove only $5 \mathrm{mi}$. north, Pedicularis hirsuta and Pedicularis lanata are numerous, but Pedicularis capitata is quite absent. The carices may be best studied at Kangerdluksuah.

The sea-animals may be best studied from Akpat on Saunders Island or from Keatek on Northumberland Island. The land animals may be best studied from Etah. Umanak affords the most favorable base for the ornithologist to study both land- and sea-birds; 
but Etah is better for the study of the dovekies, the eider, the ptarmigan, and the snow-bunting. Foulke Fjord, Inglefield Gulf, and its tributaries, and Wolstenholme Sound all offer fascinating fields for dredging the bottom life of the sea.

The entire region offers an interesting field for the physiographer, but two tracts are particularly promising; the shores of Grenville Bay, a tributary of Wolstenholme Sound, for a comparative study of glacier forms and phenomena; and Prudhoe Land, lying north of Etah, for a study of the possible relationships between the oscillation of the sea level, as shown by coastal terraces, the recession and advance of glaciers as indicated by serial terminal moraine, and the development of the drainage systems. A careful study of these two areas might throw much light on the phenomena and history of glaciation.

\section{ROUTES OF TRAVEL}

Except in rare years of exceptionally heavy ice-lay, the Northwest Greenland may readily be reached by well-built ships with dependable motive power. The route lies across the lower reaches of Baffin Bay from the Labrador Coast to the vicinity of Sukkertoppen, or Godthaab, Greenland, and thence northward fairly close into shore to avoid the heavy pack which occupies the middle portion of Baffin Bay, as far as Upernivik; thence the route must be determined by the situation of the middle pack-if it lies off-shore the course may be laid northward inshore to Cape Seddon, thence northwestward to Cape York and thence along the coast around Conical Rock, and Northward; if the ice lies inshore the course must be laid out beyond the pack.

The ice is generally not open enough for navigation in those far northern waters before mid-July, though the mid-western Danish Greenland coast is accessible even in early May. The southern portion of the west-Greenland coast is almost continuously barred by the heavy ice that comes out of the Arctic Ocean, drifts down along the east coast, and swings around Cape Farewell, then sweeps up along the west coast for some 500 to $600 \mathrm{mi}$.

By mid-September the ice is again freezing thick and heavy in the bays and fjords and along the shores of Northwest Greeland, so that a ship may find herself frozen in for the winter if she remains beyond that time. Navigation is frequently open along the midwest Danish Greenland coast until mid-November.

Northwest Greenland constitutes a readily accessible, fruitful field for study of far arctic life and habitats, and will richly repay further research.

\section{DANISH GREENLAND}

\section{By W. Elmer Ekblaw}

\section{INTRODUCTION}

Greenland, the earth's largest island, lies just to the northeast of the North American continent, of which it is a detached part. North and south it extends from $60^{\circ} \mathrm{N}$. at Cape Farewell, to $83^{\circ} 37^{\circ} \mathrm{N}$. at Cape Bridgeman, about $24^{\circ}$ of latitude, or $1650 \mathrm{mi}$. East and west it is roughly $650 \mathrm{mi}$. wide over its northern three-fifth of extent; its southern two-fifth gradually narrows to a point at Cape Farewell.

The area of Greenland is 850,000 sq. mi., of which about three-fourths is occupied by the ice-cap, a frozen desert of age-old ice, thousands of feet thick; while the other one-fourth is comprised in the narrow coastal belt which becomes generally free of ice and snow every summer, so that the terrain itself is there exposed.

The north coast is washed by Kane Basin, Kennedy Channel, Hall Basin, and Robeson Channel, constituting the straits between Ellesmereland and Greenland, and the ice-bound Arctic Ocean; the east coast is washed by the Arctic Ocean, the Greenland Sea, Denmark Strait, and the Atlantic Ocean, in all of which the cold Greenland current 
with its continuous sheet of ice- floes and bergs sweeps the Greenland coast; and the west by Davis Strait, Baffin Bay, and Smith Sound-a branch of the Greenland current sweeps around Cape Farewell and northward as far as the Arctic Circle. All these waters are studded with bergs from the glaciers and covered with vast fields of pan-ice from the multitudinous fjords and bays of the coast.

\section{GEOLOGY}

The portion of Greenland lying south of the seventieth parallel, so far as known, is composed of pre-Cambrian granites, gneisses, and schists-of which the gneisses are most widely distributed-with later intrusives, both acidic and basic, and a few isolated areas of sedimentaries of doubtful geologic age.

Along both the mid-eastern and midwestern coasts are widespread areas of Tertiary basalt, which have locally preserved from erosion the fossiliferous Tertiary and Cretaceous sedimentaries of the west coast, and the Tertiary sedimentaries of the east coast. This belt of basalts separates the pre-Cambrian area of the south from the northern extent of similar gneisses, granites, and schists.

This northern area of pre-Cambrian rocks, like the southern, is the northeastward extension of the old Canadian shield, and though locally affected by tectonic disturbances at various periods, is generally quite similar throughout its extent. It slopes toward the north and west. Along its northern and northwestern boundaries it is overlapped by Paleozoic sedimentaries from the Cambrian to the Carboniferous, some of the formations being richly fossiliferous.

\section{PHYSIOGRAPHY}

\section{Outline}

Throughout its entire length of thousands of miles, the coast-line of Greenland is almost a continuous series of long, deep, narrow fjords and bays separated by long, narrow, peninsulas and headlands, and bordered by innumerable skerries, islets, and islandsprobably the most extensive development of fjords and skerries in the world.

Generally, these fjords and the sounds between the islets are bordered by such high steep cliffs that landing upon them is impossible, but in some localities the shore is a low, sloping foreland that in most places leads rapidly up to steep slopes or cliffs. Many of the fjords are so narrow and cliff-walled as to be veritable canyons, into which the sun can shine only when they open out toward it.

A barrier of ice lies along most of the coast of Greenland. The heavy ice of the Arctic Ocean is swept along the north and east shores of the island and even around Cape Farewell, and northward hundreds of miles along the west coast. This Arctic ice-pack is of heavy solid fields and floes, and numerous great bergs. The Smith Sound Region becomes relatively open in summer. Baffin Bay holds three great fields known as the south pack, the middle pack, and the north pack respectively, which bear in upon the Greenland shore whenever the wind so drives them.

For ten months of the year, from September first to July first, practically the entire coast of Greenland is inaccessible because of the ice that freezes over the sea throughout the entire extent of the coast. Only for a few hundred miles along the mid-west coast, from Godthaab northward to Proven, is the open season longer, but here it sometimes begins in May and continues to November. The entire east coast, except for a small extent about Sermilik Fjord, at the mouth of which is situated the Eskimo village, Angmagssalik, is often icebound even in summer. From Cape Farewell northward almost to Godthaab, and from Upernivik northward to Cape York, the coast is more or less icebound also, much of the summer. The Smith Sound region is relatively free of ice for the two summer months, and some of the outermost headlands like Cape Alexander are free of ice throughout the year. 
Four kinds of ice form the barrier to the coast-the Great Ice from the Arctic Ocean; the West Ice from the Arctic Archipelago; the Winter Ice formed in the fjords, bays and sounds of the Greenland coast itself; and the ice-bergs, the discharge of the glaciers debouching upon the sea from the ice-cap.

\section{Relief}

Greenland considered as a whole, is essentially a plateau, the elevated surface of an old peneplain, with two central points of maximum elevation, from which the ice-cap slopes away on all sides. The northern center of elevation, over $9000 \mathrm{ft}$., lies on the seventythird parallel, approximately half-way between the east and west coasts; the southern center, $7500 \mathrm{ft}$., is an elongated divide half-way between the coasts, from $64 \mathrm{~N}$. to $68 \mathrm{~N}$. latitude. Both the northern and the southern portion of the plateau tilt toward the north, so that the southern slopes are steeper and shorter than the northern slopes. The northern slope of the northern block extends roughly over ten degrees latitude. Isolated peaks, and tracts of considerable size, rise above the general level of the interior plateau, and along the coast at several points, cordilleran areas rise far above the average marginal elevation.

Because the general level of the coastal belt of ice-free land is very high, except along the northern shore, and deeply dissected, the scenery along most of the coast is exceedingly wild and picturesque. Precipitous cliffs and headlands rise sheer out of the sea thousands of feet to form the entrances and walls of fjords and bays and gulfs of exceeding grandeur. Deep cleft-like valleys; low narrow forelands; small deltas at the mouths of streams; majestic snowcapped peaks and domes rising above the plateaus; picturesque, rocky skerries and islets innumerable; satin-white glaciers discharging colossal bergs into the skyblue sea in summer-these are the elements of a landscape that surpasses in wild beauty the most scenic spots of the rest of the world.

The coastal belt is generally rugged and rough with steep slopes of angular scree, or precipitous cliffs with narrow ledges. At places, even where the relief is highest, broad valleys, probably carved out by active glaciers when the ice mantle was more extended than at present, lie between the table-lands of the headlands, and along considerable stretches of coast, forelands of varying width lie between the sea and the higher lands behind.

\section{Drainage}

Though Greenland is a large land, it has no streams of any size, and such streams as there are, are frozen for almost ten months of the year. In the short summer every gulch and valley bears a torrential rushing streamlet, fed by the rapidly melting snows of the coastal land-belt, and by the marginal ice of the ice-cap. The ice-cap does not melt very far back from its edge, generally not within the $4500 \mathrm{ft}$. elevation in the northern part, and the 6000 ft. contour in the southern part; as a consequence no great rivers are formed.

The many brooks and smaller streamlets are turbulent and impassable after the summer melting begins, and the freshets sweep before them great volumes of detritus. Those streams that have their sources in the ice-cap, and flow considerable distances across the coastal border-land, often augmented by tributaries from local neve on the marginal plateau-tracts, or from snowbeds along the valley, may become riverlike in volume and burden of material carried, and sweep torrentially seaward the sand, gravel, and boulders that fall or roll into their currents.

\section{The Ice-cap}

The ice-cap, the dominant feature of the Greenland landscape, as well as the dominant factor in the environmental complex, is the largest remnant of the great mantle of ice that lay over the northern part of the northern hemi- 
sphere during the maximum development of the Pleistocene glaciation. Here the balance between precipitation and refrigeration on the one hand, and evaporation and melting and run-off on the other, is so nice that in the centuries that the ice-cap has been under observation, little change in its extent or volume has been noticed.

The interior of the ice-cap is relatively level, conforming to the general slope and elevation of the plateau on which it lies, but cast into drifts and domes like sand-dunes by the prevailing winds. Thus the highest places on the ice-cap are the two centers of elevation, on the seventy-third paralel and the sixtyfifth parallel. The ice-cap in the interior portion is composed of thousands of feet of thicknesses of ice in the lower strata, and of recrystallized snow near the surface. The surface snow of the interior portion of the ice-cap does not melt and become running water, and then freeze to ice, but recrystallizes slowly into ice.

Along the margin of the ice-cap, where the ice annually melts, and forms water that either freezes again, or runs off the surface in the thousands of brooks and streamlets that flow turbulently and torrentially to the sea in the short summer season, the surface is exceedingly broken and rough, and isolated peaks and tracts of bare rock, called "nunataks" project from the ice. The very edge of the ice itself may be a perpendicular wall, revealing the stratification of the ice-mass; a gentle slope that spreads out over the plateau on the bed of a valley; or it may be concealed under some of the local neve of the outer headlands.

Glaciers, varying in width from a few hundred feet to hundreds of miles, move forward from the ice-cap itself along every valley and cleft. Some of these glaciers reach the sea and discharge vast and numerous ice-bergs; others move so slowly that they melt back as fast as they advance, and so do not yield any bergs; others do not reach the sea at all, and melt away back from the coast, the so-called "dead" glaciers

\section{Climate}

The climate of Greenland is characteristically arctic not only because of the high latitude, but also because of the pronounced influence of the extensive inland ice-cap and the iceburdened waters that border the entire island. The great masses of ice tend to lower the temperature in both summer and winter, but along the coast the tempering influence of open leads and pools of water in relative proximity to most of the coast modifies the rigor of the climate in winter and makes it more equable in summer.

The seasonal variations in temperature are not so wide as in a great unglaciated land mass like Siberia, but sudden fluctuations due to varying winds, and to the combined effect of wind-direction and topography, are as great in range as anywhere in the world.

\section{Winds}

Whenever the wind blows off the icefields and the cold waters from the north. west, or east, the temperature falls; whenever it blows from the south and southwest off the warm waters of the Gulf Stream the temperature rises fast. Whenever the "fohn," that wind peculiar to certain alpine or plateau regionslike Alpine Europe or the western part of the United States-begins to come down off the plateau heights of Greenland, the temperature rises incredibly fast and suddenly; and since both the east and west coasts of the island are topographically favorable to the development of the "fohn," its characteristic occurrence is frequent and effective. The "fohn" may continue for only a few hours, but it may prevail for several days. Under the influence of this warm, drying wind, the temperature may rise as much as $80^{\circ}$ in a day, or as much as $45^{\circ}$ in an hour, sometimes evaporating several inches of snow during its continuance.

\section{Temperature}

The mean temperature in southern Greenland is only a half degree above 
freezing; at Umanak, about halfway between the southernmost and northernmost points, it is $11^{\circ}$ below, and along the northern coast it is probably $35^{\circ}$ below freezing. The mean winter temperature is successively lower along the coast as the latitude increases, but this is not true of the mean temperature of summer. Due to increasing effect of the continuous sunlight the mid-west Greenland coast in summer has a higher mean temperature than Cape Farewell; thus Holsteinsborg, lying along the coast in latitude $76^{\circ} \mathrm{N}$. has a mean summer temperature of $45^{\circ}$ while Nanortalik, on the sixtieth parallel, $7^{\circ}$ farther south, has a mean summer temperature of $42^{\circ}$.

The lowest temperature reported from the neighborhood of Cape Farewell is $-20^{\circ}$; from the mid-west coast, $-45^{\circ}$; and from the northern portion, $-70^{\circ}$; the highest temperature reported from the southern portion is $75^{\circ}$; from the mid-west coast, $70^{\circ}$; and from the northernmost portion, $65^{\circ}$. From year to year the temperature in any period may vary widely; for instance the highest temperature for February, 1891, at Upernivik, in $72^{\circ} 54^{\prime}$ was $-4^{\circ}$; for February, 1892, $57^{\circ}$; for February, 1894, $2^{\circ}$; and for February, $1895,60^{\circ}$.

The average number of days below freezing increases from north to south successively-at Cape Farewell 208; at the sixty-fifth parallel, 244, at the seventieth parallel, 257; at the seventyfifth parallel, 300. Except in the southernmost portions and at the heads of the deep fjords between the sixtyfifth and the seventieth parallels, frost is likely even in midsummer.

\section{Precipitation}

The precipitation varies considerably in character and amount. The northern portion has a relatively small precipitation, almost all of which falls as snow, rain being very exceptional; snow falls every month of the year. Along the western coast the precipitation decreases from Cape Farewell northward.
At Cape Farewell with about one hundred days of precipitation, it is over 45 in. annually; at the sixty-fifth parallel it is 27 in. in one hundred seventy days of precipitation; at the seventieth parallel it is $10 \mathrm{in}$. in one hundred days; and thence decreases slowly northward. The precipitation is heaviest in summer, next in fall, then in spring, and least in winter. Snow constitutes about half the precipitation in the southern portion, about two-thirds in latitude $73^{\circ} \mathrm{N}$. Fog is rather common, especially along the coast in summer. In some localities along the southern coast almost a third of the days are foggy.

\section{Pressure}

The mean barometer for the southern point of Greenland is $754.7 \mathrm{~mm}$; f for the mid-western part $759 \mathrm{~mm}$. The pressure may vary greatly and rapidly. At Ivigtuk along the southern coast, the lowest barometer is $709.2 \mathrm{~mm}$.; the highest is $758.8 \mathrm{~mm}$. The average windvelocities are small and calm weather is frequent. In summer the prevailing winds along the west coast are southerlies and westerlies; in winter easterlies prevail. In the fjords the winds usually blow strong from the ice-cap to the sea, even though at right angles to the direction of the wind on the plateau above. Except along the southernmost stretches of coast the southerly winds bring the worst storms, from seven to ten a year; in the southern portion the north and west winds bring storms, as many as twenty a year.

The inner reaches of the fjords differ from the coastal headlands and the skerries in having a higher summer temperature and lower winter temperature; the humidity is considerably less, so that bright, clear weather often prevails while the coast is cloudy or foggy; the days are more often calm; and the snow melts away earlier.

\section{Day and night}

One of the most important factors in the climate of Greenland is the suc- 
cession of day and night. This factor is equally important in the character, distribution, and development of the plant and animal life. Since all except the southernmost point of the island lies within the Arctic Circle, nearly its whole extent has periods of continuous sunshine and continuous night. The period without sunlight is six weeks long in latitude $70^{\circ} \mathrm{N}$.; thirteen weeks in latitude $75^{\circ} \mathrm{N}$.; and eighteen weeks in $80^{\circ} \mathrm{N}$. The period of continuous sunlight is slightly longer. The sudden development of the plant life, and the rich life of the sea are in considerable measure due, to this period of continuous light.

\section{BIOTA}

\section{Plant life}

The plant life of Greenland includes some 400 species of vascular plants, 600 mosses, 700 fungi, 300 lichens, 500 algae, and 600 diatoms. More of the lower species will doubtless be discovered, but the list of vascular plants is probably almost complete. The long stretch of Greenland coast, through varying physiographic and climatic conditions, would suggest a richer flora than that represented by only a few more than 400 species, even with the rigorous arctic climate; but the flora is quite post-glacial in origin, and since Greenland is an island swept almost exclusively by polar currents, and having its nearest point of approach to other lands at its northern extremity, where conditions for plant migration are most unfavorable, the immigration of plants since the dispersal of the ice-sheet has been exceedingly slow.

The flora of Greenland offers some interesting problems in distribution and immigration. Some species are highly localized. Some are European in relationship, some are American, and a very few are endemic. Some are circumpolar high latitude species, some are from the Canadian zone. How have they come to Greenland, and how have they established themselves? The answer has been only partially given, and many a controversy has raged over the solution of these problems.

Fifty families of vascular plants are represented in the Greenland flora, of which the Cyperaceae, Graminae, Caryophyllaceae, Cruciferae, and Compositae are the largest. The genera richest in species are Carex, Saxifraga, Pedicularis, and Draba. Many of the genera are represented by one species, the average ratio of genera to species being 2:5. The southernmost part of the island about Cape Farewell has a flora of almost 300 species; the Smith Sound region almost $20^{\circ}$ farther north and within $15^{\circ}$ of the pole, has almost 150 species.

The entire island is beyond the northern limit of true trees, and though isolated small tracts far within the land near the head of the fjords of the southern west coast may bear a tree-like growth of birch, willow, alder, and conifers, the entire land is unforested. Even well developed shrubbery is rare. Generally all tree-growth and shrubbery are dwarfed to creeping or prostrate form-alder, willow, juniper, vaccinium, and birch. Even the arctic and alpine forms are pauperate or dwarfed as the northern reaches of the coast are approached.

The "Feldmark" is the most widely distributed type of vegetation, the first to appear on moraines from which the ice has retreated, or wherever new land appears to afford opportunity for new plant growth. In this association the plants are so far apart that the spaces between are much larger than the spaces occupied. The struggle is not among one another, but against the rigorous conditions. Among the plants taking their place thus as pioneers are the arctic poppy, a number of the saxifrages and cresses, dryas, some of the cinquefoils, a number of the cresses, and a few others.

Where the soil is relatively dry the heath-association covers the terrain. It is composed of the small shrubsjunipers, Vaccinium, Salix, Betula, Cassiope, Empetrum, Dryas, Rhododendron, 
and others, and numerous herbs, grasses, and sedges. Potentilla, Draba, Pyrola, Arnica, Pedicularis, Campanula, Antennaria, Festuca, Poa, Carex, and numerous others belong in this group.

In the moister, damper places a moorvegetation frequently establishes itself, with wet-soil grasses, sedges, cottongrasses, and rushes, forming hummocky turf with mosses, and liverworts growing all over the soil between. Here grow Montia, several species of Ranunculus, Oxyria, Tofieldia, Lucopodium, Equisetum, and othèrs.

Though almost no high trees or heavy growth of shrubbery are found, the land seems rich in plant growth during the short summer, and wherever a plant can establish itself on cliff or slope or rocky ledge, one is usually found.

The plant life of the sea is well developed, and Laminaria, Agarum, Alaria, and others form a rather rich seagrowth wherever conditions permit. The cold seas with their high content of gases support an incredibly rich plankton life, so dense at times during the continuous summer sunshine as to color the water. It is from this abundant plankton life that the multitudinous bird and animal life of the Greenland seas derive their ultimate sustenance.

\section{Animal life}

Three thousand species of animal life have been reported from Greenland and its adjacent waters of which all except a very few are lower forms. Of the higher forms 30 are mammals; 150 are birds, and 100 are fish.

The land mammals are the muskox, confined to the northern and northeastern coasts; the caribou, which, though once distributed throughout the coastal lands, is. now rather limited to certain favorable stretches of coast; the arctic hare, common along the entire coast; the lemming, occupying approximately the same range as the muskox; these 4 are herbivores, feeding upon the low, hard vegetation. The carnivores are 3 in number-the arctic wolf, now almost extinct except in the northernmost tracts; the polar fox, both white and blue phases, rather common among the whole coast, particularly where the seabirds nest most numerrously; and the ermine, restricted to the range of the lemming, upon which it feeds.

The polar bear, frequenting the whole coast, may be classed as both landanimal and sea-animal, since he is equally at home on both, and may bear his young either on land, or in snowdrift burrows beside the grounded bergs. $\mathrm{He}$ is generally carnivorous, feeding chiefly upon the seals that he catches on the ice or in the sea, but he may, in times of hunger, feed upon berries where they are available.

The land-birds nesting in Greenland are Reinhardt's ptarmigan, common on every hillside; the Lapland longspur, frequenting the willow and alder copses; the snow-bunting, ubiquitous as to habitat; the Greenland wheat-ear, at home on the drier, rockier, sunnier hillsides; the American pipit; the redpolls (Acanthis hornemanni hornemanni and Acanthis linaria rostrata); the snowy owl, most common about the haunts of the lemming; the raven, the gyrfalcon, and the peregrine falcon, frequenting the bird-cliffs and the coastal heights. The ptarmigan, the owl, the raven, may and often do, remain all year, even in the northernmost parts of Greenland, even through the long, dark night.

The gray sea-eagle nests along the coast; like the polar bear, he frequents both land and sea, and though preying largely on the inland salmon, often captures young seals and sea-birds.

No reptiles are found. Only two freshwater fish are common-Salmo alpinus L., and Gasterosteus aculeatus $L$.

Insects are not numerous, considered as a group. Four hundred species are known, of which many have been introduced. Coleoptera are represented by about 40 species; Hymenoptera, by about 70 species, including two bumblebees; Lepidoptera, by 50 species, mostly moths; and the Diptera by about 200 species. Mosquitoes are numerous and 
swarm over both coasts as far north as $75^{\circ} \mathrm{N}$. Culex nigripes and Simulium viltatum swarm over the copses, moors, and moss-grown slopes and flats; in a few localities the tiny Ceratopogon sordidellus is a plague. Six species of fleas are found. Pediculus capitis, Pediculus corporis, and Phthirius pubis are probably native, while Pulex irritans and Cimex lectularius have been introduced. The fur-clad Eskimos are a paradise for parasites.

The marine fauna is relatively richer than the land life, and it is largely from these marine fields that the Eskimos in large part garner their sustenancetheir food from the flesh, their clothing from the skins and furs, and their fuel from the blubber of the large sea animals.

Twenty-two species of mammals frequent the Greenland coastal waters, not including the polar bear. Of these the walrus and the seals are most important. The walrus is found all along the coast, but is abundant only in a few restricted localities. Five species of seal-the bearded seal (Erignathus barbatus), the ringed seal (Phoca foetida), the harbor seal (Phoca vitulina), the harp seal (Phoca cristata), and the hooded seal (Cystophora cristata)-frequent the coast, the 3 latter being most common along the southern coast, the two former along the northern shores. Of the whale and porpoise families sixteen species are found in considerable numbers; the right whale (Balaena glacialis), and the Greenland whale or bowhead (Balaena mysticetus), are still seen along the coast, but are practically extinct; the humpbacked whale (Megaptera nodosa), once fairly common, is no longer seen; the bottlenose whale, (Hyperodon rostratus) is a rather frequent visitor. The killer whale (Orca gladiator) is common; the narwhal (Monodon monoceras) is numerous, and the beluga (Delphinapterus leucas) migrates up and down the coast in huge schools, often of many thousands.

Though 150 birds have been recorded from Greenland, only 52 are known to nest on the island. Of these, 41 species are shore-birds or sea-birds, frequenting either the coastal waters or the sea, or less frequently the pools of the interior. The loons, eiders, phalaropes, oldsquaws, snow-geese, and mergansers are often found in these inland pools; and the sandpipers, knots, plovers, sanderlings, turnstones, and others of the shore-bird group frequent the valleys and lowlands as well as the coastal forelands. The barnacle goose and the black brent are locally common.

But the wealth of bird-life for which the Greenland coasts are famous is made up chiefly of the sea-birds. Most numerous of these are the dovekies (Alle alle), which nest along the northwestern coasts in incredible numbers; the murres (Uria troille troille, and Uria lomvia lomvia) populating nearly all the high, precipitous forelands; and the guillemots (Cepphus grylle and $C$. mandiii), the latter most common northward, the former abundant southward. The cormorant (Phalacrocorax carbo) is found locally along the western coast from $73^{\circ} \mathrm{N}$. southward; the puffins, (Fratercula arctica arctica and $F$. a. naumanni), are fairly common; and the razor-billed auk is locally abundant.

The gulls are numerous-the glaucous gull, the ivory gull, the black-backed gull, the herring gull, Kumliens gull, the kittiwake, and Sabine's gull, are all native to the coast. The Arctic tern is common along most of the coast. The fulmars are likewise common. The jaegers are all found along the Greenland coast.

The fish fauna is relatively rich in the south Greenland waters. The sleeping shark is generally common; the cod and rock-cod are found off the southern coast; the halibut, dab, and the related "hellefisk" (Reinhardtius hippoglossoides Walb) are also common along the southern portion of the coast. The sculpin is found everywhere. The caplin, as on the coast of the Labrador, fills the coastal waters early in summer.

The lower forms of sea-life are locally so numerous in the ice-free, sunlighted 
summer seas as to color the water. They furnish food to the myriads of bird-life, fish, and sea-animals.

THE DANISH ARCTIC SCIENTIFIC STATION AND THE PORSILD NATURE RESERVE

Morten P. Porsild, Danish geographer and naturalist, with more than usual vision and determination, has secured governmental support for a scientific station and base for exploration, at Godhavn on Disko Island. This station, of which he is director, is well equipped with library, laboratory, and study supplies, the most advantageously located base for Arctic research in the world. Here investigators from all lands are welcome; here young explorers are trained in the Arctic technique; and here Science finds its well-guarded Arctic frontier.

Porsild has also established a preserve which includes the areas watered by the warm springs of Disko Island, where an exceptionally rich and varied flora and an unusual invertebrate fauna are preserved from destruction. This preserve, like the warm spring area itself, is unique. It is the northernmost station of many plants, like some of the orchis family, and a number of invertebrates, among them two species of earthworms.

\section{ROUTES OF TRAVEL}

Greenland is maintained by the Danish Government as a trade monopoly for the Danish Royal Trading Company, and stern restrictions are imposed upon visitors to the country, discouraging travel to the land.

The mid-west Greenland coast is readily accessible by means of the Danish vessels that ply back and forth from Copenhagen in the summer months-from May to October. Less frequently, vessels visit the northwestern coast, and the southern coasts. Occasionally, a vessel from America goes to Greenland for a cargo of cryolite, to fish in the southern waters, or to take an expedition to the Far North.

The monopoly maintained by the Danish government and the restrictions imposed upon travelers are wise, and beneficial to the Eskimo, who are cared for in a most paternal and unselfish manner by the Danish authorities; as a consequence, the Eskimo population of Danish Greenland has doubled in the last century. The Danes, by virtue of their kindly administration of the affairs of these primitive people, deserve an undisputed right to the land.

\section{THE AMERICAN ARCTIC ARCHIPELAGO}

\section{By W. Elmer Ekblaw}

\section{INTRODUCTION}

The American Arctic Archipelago comprises that island group or polynia lying to the northward of the American continent, of which it forms a part in that it lies on the same portion of the earth's continental shelf. It does not include Greenland. Possible islands northwestward in the Arctic Ocean, as yet undiscovered, may be included. North and South it extends from the south end of Baffin Land in latitude $62^{\circ} \mathrm{N}$. to the north end of Ellesmere Land in latitude $82^{\circ} \mathrm{N}$., a latitudinal extent of $20^{\circ}$, or $1400 \mathrm{mi}$. It is widest in the south where it extends from the sixtieth to the one hundred twentyfifth meridian, west longitude. It forms a rough triangle with its east side almost due north and south from the northeast point of Ellesmere Land to the southeast corner of Baffin Land, and its apex at the westernmost cape of Banks Land.

\section{GEOLOGY}

The geology of the entire archipelago is only imperfectly known, and merely a general statement of the areal distribution of the outcropping formations may be made.

The southeastern portion of the triangle, and most of the eastern coasts throughout, are pre-Cambrian, with scattered patches of sedimentaries, mostly Silurian. The Silurian limestones, in many places fossiliferous, are dominant over the southern portion of the western corner, principally on 
Victoria Island, Prince of Wales Island, North Somerset Island, and northwest part of Baffin Land.

On Banks Land and in the Parry Islands in the northwest part of the archipelago, the Carboniferous is the chief formation comprising the terrane. The Devonian, so far as known, is restricted to the northwest corner of North Devon, and the west part of Ellesmere Land. Triassic formations constitute the dominant outcrops in the Sverdrup Islands and, if the so-called Cape Rawson series are included with the Triassic, in a belt across the north part of Ellesmere Land. A few scattered Tertiary deposits have thus far been noted.

\section{PHYSIOGRAPHY}

\section{Outline}

The Arctic Archipelago is made up of numerous large and small islands, separated by sounds and straits of varying size. The land surface exceeds considerably the water surface of the area. The larger islands, like Baffin Land and Victoria Land, and Ellesmere Land, are cut by a number of deep bays and, in general, the coast lines of all are rather irregular. All are continuously bordered by heavy ice for ten months of the year, and many of the sounds and straits are always unnavigable, because of heavy ice, or heavy ice and rapid currents. Some are open for the passage of a ship some years, closed others. Navigation is always hazardous and doubtful.

\section{Relief}

The relief is highest at the north, in the north part of Ellesmere Land and gradually decreases southward and southwestward, being generally lowest toward the southwest corner of the area. The United States and Grant Mountains in Ellesmere Land rise high and sharp, probably $9000 \mathrm{ft}$. or even more. Ellesmere Land and Axel Heiberg land are both high and rugged lands, and the eastern part of Baffin Land is relatively high. Westward the topography be- comes gradually smoother and more mature. The shores of the eastern islands are generally steep and high, but cut by valleys, and bordered by forelands, both of which are wider and flatter toward the south. The general contour of the islands becomes more rounded and subdued toward the west; the hills are not so high nor so steep, and the valleys are wider and flatter.

Relic ice-caps with projecting glaciers, some of which reach the sea and discharge icebergs, occupy considerable portions of the Ellesmere Land, North Devon, and Baffin Land plateaus. Practically the entire area of the Archipelago was probably heavily covered during the Pleistocene glaciation, though most of the evidence has in places been obliterated.

\section{Drainage}

Throughout the archipelago the drainage has been profoundly modified by the morainal deposits of the glacial period. In the western portion the drainage has been fairly well restored, or an adequate new system developed, but in the eastern portions the drainage is still undeveloped. A number of large lakes lie in the interior of Baffin Land; Lake Hazen in the north part of Ellesmere Land is a considerable body of water; and smaller lakes are found on most of the islands. Many lakes have probably not yet been discovered or mapped. No large rivers are found in any of the islands, though in the melting season many of the streams are swollen by the freshets to turbulent, riverlike torrents.

\section{CLIMATE}

The climate of the Arctic Archipelago can be described only in a general way. The few definite data available are so scattered in point of time and locality, that they can be used only as general indices of the character of the climate.

The entire archipelago is a region of long, cold winter, and very short summer, beginning with mid-June and ending with the first of September. The climate in winter is almost con- 
tinental since all the water is frozen over and its modifying effect is negligible; but in summer the climate is arctic-oceanic, and even with twentyfour hour sunlight during the summer months, the temperature does not rise high because of the depressing chill off the cold shore waters with their masses of ice. In northern Ellesmere Land the lowest winter temperature is probably $-70^{\circ}$; the highest temperature in the interior dales and valleys sheltered from the sea-winds, probably rises to $+70^{\circ}$. In the southern portion the temperature does not often drop below $-40^{\circ}$, while the interior summer temperatures do not rise far above $+75^{\circ}$.

The precipitation is uniformly light. The rains of summer in the southern portion and the summer snows of the northern part are relatively light. The snowfall over the entire group is not heavy for the entire winter, but the accumulation remains until late May or June, and then the melting furnishes ample moisture for the rapid growth of the vegetation through the short, sunlighted summer. The western coast, facing the prevalent winds receive the maximum precipitation. The first frost comes late in August in the southern portion, earlier in the same month in the northern portion. The ground is frozen throughout the year, except for a thin surface layer a few inches thick that opens up for the short summer. Because of the effect of the twenty-four hour sunlight, and the protracted insolation, the "summer" period is approximately the same throughout the whole north and south extent of the archipelago.

\section{BIOTA}

\section{Plant life}

The plant life of the Arctic Archipelago has never been thoroughly investigated. The collections are few, far scattered, and incomplete. From none of the islands, except Ellesmere Land perhaps, has even an approach been made to an exhaustive and representative collection.
The character of the vegetation is similar to that of Western Greenland, though in the lower, flatter western portions of the archipelago, the bog and moor, or tundra, vegetation spreads over much greater areas, and the "Feldmark" is relatively more restricted. There are no trees, and few shrubs of any size, most of the vegetation being confined to creeping or dwarfed shrubs and vascular plants-particularly grasses and sedges.

The paucity of the flora of the Silurian siliceous limestone areas is characteristic, and seems due principally to the lack of fine particles in the detritus resulting from the disintegration of the limestone. There is no true soil; even in the flatter expanses of the Silurian the limestone is riven by frost into sharp angular fragments that do not afford proper foothold for plants or for the absorption and capillary retention of the necessary water supply. The purer or more argillaceous limestones of the other sedimentaries give rise to a more favorable soil, and on this, as on the soil derived from the pre-Cambrian, the vegetation is abundant and more generally distributed, apparently little affected by the composition of the soil.

The flora, so far as known, is made up of slightly more than 200 species, representing 31 families, of which the largest are the Graminae, Cyperaceae, Cruciferae, and Compositae, in the order named. The genera richest in species are Carex with 12, Saxifraga with 12, Salix with 10, and Pedicularis with 7. Sixtytwo species are distributed throughout the archipelago; 18 species extend over the southern portion; 35 are confined to the south-western islands; 28 species are decidedly western in origin and range; and 23 are distinctively eastern. The proportion of monocotyledonae increases northward. The distribution of these genera and species over the archipelago raises interesting questions of origin, migration, and relationship which have been the cause of much controversy, involving the extent and continuity of the Pleistocene glaciation; former land 
connections now submerged, among the islands themselves and with the mainland, Asia, and Europe; variations of the climate in the past; the rise of endemic species, and modifications of immigrants; and the effect of transporting agencies.

In the warmer, drier niches of the rockier slopes where sufficient soil has accumulated, small heath-growths of Campanula uniflora, Pyrola rotundifolia, Arnica alpina, Antennaria alpina, Festuca alpina, Trisetum spicatum, Carex incurva, Potentilla Vahliana, and Calamagrostis purpurascens are set among a basic growth of Cassiope tetragona and Dryas integrifolia, which are distributed over all the drier tracts.

The seepage-swales along the mossgrown streamlets of ice-cold water from melting streamlets are well carpeted with grasses, sedges, Luะula and Juncus, with here and there patches of whitefurred Eriophorum and timothy-like Alopecurus alpinus. In these seepageswales the drier margins have scattered beds of Rhododendron lapponicum, Saxifraga oppositifolia, Oxyria digyna, Cerastium alpinum, the several species of Draba, Ranunculus nivalis, and Melandrium affine.

Silene acaulis, Braya purpurascens, Papaver radicatum, Poa, Salix arctica, Potentilla nivea, Statice maritima, Erigeron compositus, Taraxacum, Lesquerella arctica, and Stellaria longipes, grow over the windswept, gravely reaches, not too dry.

The grass- and sedge-grown moors with an "undergrowth" of moss and marchantia, hold scattered plants of Pedicularis hirsuta, Eriophorum Polystachium, Ranunculus sulfureus, Cardamine bellidofolia, Equisetum arvense, Eutrema edwardsii, Ranunculus hyperboreus and R. pygmaeus, Tofieldia palustris, and many other moisture-loving plants.

Cystopteris fragilis, Woodsia, and Aspidium fragrans are among the ferns of the archipelago. Hippuris vulgaris, Dupontia fischeri, Pleuropogon sabinei, Batrachium paucistamineus, and several carices grow in the pools or long the margins.

These are but part of the species that go to make up the vegetation of the islands.

\section{Animal life}

Except for the mammals and the birds, the animal life of the archipelago is most imperfectly known. The lower forms have been relatively neglected by the explorers and investigators who have collected in the polynia.

The muskox (Ovibos moschatus) finds on the more remote lands of these islands, notably in Banks Land, Axel Heiberg Land, and Ellesmere Land, his last extensive range. Here the last large herds have thus far been preserved; on the broad valley-pastures and slopes of Ellesmere Land, several thousand still persist, finding there food and safety from slaughter.

The barren-ground caribou (Rangifer spp.) ranges over the southern islands, while in Axel Heiberg Land and in Ellesmere Land a small species, Rangifer pearyi finds its home. These small northern caribou do not gather in large herds, nor do they migrate extensively.

Along all the coastal stretches and far out upon the frozen reaches of the Arctic Sea the polar bear (Thalarctos), the arctic wolf (Canis tundrarum), and the polar fox (Alopex spp.) wander restlessly about, still relatively numerous. The Arctic hare (Lepus arcticus group) is rather widely distributed. The lemmings (Lemmus and Dicrostonyx) and the weasel (Mustela $a$. arctica) frequent the grassgrown plains and moors.

The sea-life is relatively abundant. Walrus, ring-seal, bearded seal, harp seal, hooded seal, and harbor seal are found in the sounds and off the islands. Narwhal and beluga are common. In places, several species of whale are found. The Big Finner, the Little Finner, the Humpback, the Right whale, the Greenland whale, and the Killer are found locally.

The bird-life is numerous, but little 
is definitely known about the distribution and northern habits of some of the species.

The pipit and the horned lark are common among the southern islands. The lapland longspur, the snow-bunting, and the redpolls are widely distributed. The northern raven, the snowy owl, Reinhardt's ptarmigan, the duck hawk and the gyrfalcon are rather common throughout the archipelago.

The Greenland and American eiders are common toward the east, the Pacific and Steller's eiders toward the west, and the king-eider is found in small numbers throughout the polynia. The Hutchin's goose, the blue goose, the Canada goose, the swans, and the snow geese probably nest on the islands bordering Hudson Bay on the north. The hooded merganser, the greenwinged teal, the old squaws, and casually, other ducks, frequent these islands. The black-throated loon toward the west, and the red-throated loon throughout the archipelago, are rather common.

Shorebirds are numerous. At least two species of phalaropes breed in the islands. A number of the sandpipers and the plovers, the sanderlings and turnstones, all these frequent the low, flat valleys, the damp plateaus, with myriad pools and ponds, and the broad, shingly shore-land. Even the little brown crane is found on the southern islands.

The sea-birds are numerous. Fulmars, terns, kittiwakes, Sabine's gull, Ross's gull, the herring gull, the great black-backed gull, the glaucous gull, and the ivory gull nest in the archipelago. Three jaegers course over the islands and the sounds. The dovekies are found in the North. Brunnick's murre, Mandt's guillemot, the puffin, and the razor-billed auk are other representatives of the sea-bird group.

Both the plant-life and the animallife of the archipelago are relatively little known. These islands offer a fascinating field for exploration and study.
ROUTES OF TRAVEL

The arctic archipelago is generally difficult of approach. The entire eastern coast from Hudson Strait to the Arctic Ocean is more or less barred by ice, and accessible only with favorable ice-conditions, winds, and tides. A rare fur-trading ship or whaler may afford passage, but generally a special ship is necessary for transportation to the region.

The south side of the archipelago is more easily accessible in summer by way of Hudson Bay. The west side is even more difficult of approach than the east side. A special ship must be engaged for the trip, unless a whaler or furtrader happens to be bound for those far arctic waters.

\section{UNGAVA AND LABRADOR}

\section{By W. Elmer Ekblaw}

\section{INTRODUCTION}

Because the great peninsula of Labrador and Ungava offers to the naturalist one of the most promising fields for exploration and study, considerable attention to the geography of the area is well worth while.

It comprises a great triangular, peninsular territory forming the major northeastern portion of the North American Continent. This triangle, broken only by Ungava Bay, is bounded roughly on the west by James Bay and Hudson Bay; on the northeast by Ungava Bay, Hudson Strait, and the Atlantic Ocean; on the south by the Rupert River and its tributaries to Lake Mistassini, the Saguenay and its tributaries to the St. Lawrence, and the St. Lawrence River and Gulf, and the straits of Belle Isle. Only that portion lying north of the 52nd parallel is included within this account, and in general it does not include any of the territory drained by the rivers that flow into the St. Lawrence system. 


\section{GEOLOGY}

Over the greater part of the Labrador Peninsula, probably nine-tenths the area, the Laurentian gneisses and schists form the country rock. These consist of highly metamorphosed and foliated clastic and igneous rocks of great geologic age, all, with a few exceptions, Pre-Cambrian. More or less interfolded with these aged Laurentian rocks are several widely separated areas of Huronian clastic and volcanic rocks, and many basic eruptives-schists, conglomerates, breccias, and others. Resting unconformably upon these aged Laurentian and Huronian rocks, sandstones, argillites, shales, and limestones, of doubtful age, with bedded traps and other basic or volcanic rocks, may constitute an early Cambrian deposition.

In the long period between the folding of the Laurentian and Huronian rocks and the submergence when these sediments were laid down, the peninsula was profoundly sculptured and denuded to the fundamental basic form and physiography it has today-the great central plateau, the lake and valley basins, and the fjords and inlets.

In relatively recent geologic times this old original land surface has been considerably modified by glaciation throughout its entire extent except the highest mountain areas along the northeastern coast of the peninsula. The central nevé from which this glaciation proceeded, moved progressively northward in three distinct successive periods of ice accumulation, with intervening periods of diminished glaciation. The earliest ice-flow radiated from a central gathering-ground between the 50th and 51st parallels near the center of the peninsula; the second from a point to the northwest beyond the 54th parallel; and the latest from a center about a hundred miles inland from the east coast of Hudson Bay, between the 55th and 56th parallels.

In the areas of these central nevé the rocks and boulders rest upon rocks of the same kind and evidently have not been transported far. As the distance from these central areas of nevé increases, the sculpturing by the ice becomes more distinct; but in general the amounts of erosion and change wrought upon the general surfaces have not been so great as is generally thought. Though the ice certainly did erode in one place and deposit in another to reduce the surface to a general uniform level over the most of the plateau, the evidence does not show that it ever trenched or plucked out such deep depressions as it apparently did farther south along the peripheral edges and lobes of the ice-sheet.

\section{PHYSIOGRAPHY}

\section{Outline}

The west coast of the peninsula, running nearly due north and south for $800 \mathrm{mi}$. is remarkably straight and unbroken by any deep indentations, though bordered by numbers of long groups of low narrow islands paralleling the shoreline; the south side of the area covered in this report corresponds roughly to the divide between the rivers flowing into the St. Lawrence and those emptying westward, eastward, and northward to Hudson Bay, Ungava Bay, and the Atlantic. The Atlantic coast is exceedingly irregular, cut by many deep, narrow fjords and bays, of which Hamilton Inlet, the southernmost, is the largest and deepest; and bordered by islets and skerries innumerable. The coast of Hudson Strait and Ungava Bay are relatively regular, bordered by many islets. The passages between the islets and the mainland, and between the islets themselves are locally designated as "tickles."

\section{Relief}

The Labrador peninsula is a gently undulating plateau which rises abruptly within a short distance from the coast line to a general elevation of about $2000 \mathrm{ft}$., and which slopes rather gently westward, northward, and eastward to 
the rim of the plateau, from a central crest lying approximately along the 53rd parallel between the 65th and 70th meridians, west longitude. The plateau is bordered in the northeastern portion, along the Atlantic seaboard by ranges of sharp, unglaciated mountains, beginning about latitude $55^{\circ} \mathrm{N}$. and extending northward to Cape Chidley, with maximum altitudes of $6000 \mathrm{ft}$. inland from Saglek Bay; but elsewhere the rim of the plateau does not rise above the general level of the plateau.

The entire inland area of the plateau is comparatively level, traversed only by low, rounded, roughly parallel ridges of crystalline rocks, so that except for a very few places, there is not in the entire plateau area $200,000 \mathrm{sq}$. mi., a difference of level of more than $400 \mathrm{ft}$. The general surface is further modified by low moraines extending in a general way the same direction as the slope of the country, yet appreciably modifying the preglacial drainage system of the terrain.

\section{Soil}

Most of the soil of the peninsula is a boulder-studded, infertile, glacial till, derived from the Archean rocks. Over wide areas it is very sandy. The soil along the river valleys has been modified and enriched by redeposition and with a consequent heavier growth of vegetation. The richest soils bearing the best development of vegetation are the alluvial-topped soils along the coast and the inlets, and the areas of limestone and shale outcrops of the supposed early Cambrian rocks.

\section{Drainage}

As a consequence of the damming of the valleys and basins of the streams of the Labrador plateau by the masses of glacial till and moraines, the whole area is dotted with myriads of lakes and pools, that occupy at least a fourth of the entire area. They vary in size from small narrow ponds to large extensive lakes hundreds of square miles in area, most of them relatively shallow, some deep. In addition to the great lake areas, large portions of the plateau are occupied by damp, boggy, tundra with defective drainage, almost lakelike in character.

A perfect network of streams connects these lakes and ponds, all interlocking so closely that no great distances separate the headwaters; and since above the rapids near the coast, the streams and lakes are generally navigable by canoes, water travel is relatively easy throughout the plateau, with few portages more than 2 or $3 \mathrm{mi}$. long.

Three principal watersheds comprise the peninsular north of the Height of Land. The eastern is drained principally by the tributaries of Hamilton Inlet-the northern is drained by the Koksoak, the largest and longest river of Labrador, the George, the Whale, and the Leaf; the western, the most extensive of the peninsula, is drained by the Nastapoka to the north, the Little Whale and the Great Whale about the middle, and the Big and East Main to the south.

The water in the pools, lakes, and streams is remarkably clear, quite different from the dark-brown waters of the Laurentian basin. Because the summer season is short, the swamps and tundra from which most of the streams and lakes drain their water are thawed only to a depth of 12 to 18 in., and vegetable decomposition, particularly of the sphagnum mosses, is negligible.

\section{CLIMATE}

The climate of the plateau of Labrador is generally and distinctly Arctic. Except at the heads of the deeper fjords and inlets of the southern portion of the east coast, where the diurnal range of temperature is from $45^{\circ}$ to $90^{\circ}$, and the average temperature in summer is above $50^{\circ}$, the temperatures for the year are characteristically sub-Arctic.

Though situated in the same latitude as some of the most pleasant and most productive lands of Europe, Labrador is chilled by the cold waters of the Greenland current along its eastern shore, and by the prevailing westerly 
winds which come off the cold expanses of Hudson Bay, and the frigid, icebound islands of the Arctic Archipelago, instead of being warmed by the balmy winds that blow off the temperate Gulf Stream, as in northwestern Europe.

\section{Temperature}

The temperature depends greatly on the direction of the winds. During the summer the prevailing winds in the interior are southerly and southwesterly, bringing higher temperature and cloudy skies, often with drizzling rain. The prevailing westerly and northwesterly winds of winter are accompanied by lower temperatures and clear skies. The northerly and northeasterly winds accompany heavy storms of rain and snow, with damp, chilly weather. Clear, pleasant weather usually comes with easterly and southeasterly winds, though fogs along the coast are then most common.

The temperature in the interior, even in the southern part of the area, rarely rises above $80^{\circ}$ during the middle of the day, on more than a few days during the warm season. The summer temperature of the Atlantic coast region is considerably lower than inland, or along the western coast. The lowest winter temperatures inland are $-55^{\circ}$; along the coast $-45^{\circ}$, at the head of Ungava Bay; and at the mouth of Hamilton Inlet $-40^{\circ}$.

The interior plateau has but two seasons, winter from mid-September to mid-June, and summer-rather springfrom mid-June to mid-September. The summer season begins almost simultaneously throughout the interior, with a suddenness that is surprising. In the first two weeks of June the snow disappears, the ice melts off all the lakes except the larger, the temperature rises rapidly every day, the trees and shrubs burst into leaf and early bloom, and the birds arrive to mate, and to begin nesting almost immediately. Until the first of July frosts are likely to occur every night and flurries of snow may come even later. Summer ends about the middle of September when the first fall snow falls and the ice forms in the small lakes. From early in October the snow remains permanently, and all the smaller lakes are solidly frozen.

\section{Precipitation}

The precipitation over the interior is relatively light. The summer precipitation is fairly constant though very light, with few days without drizzles or thunder-showers. The winter snowfall varies from 3 to $6 \mathrm{ft}$., of which the most is brought by the north and notheast winds. Three-fourths of the winter season is clear and crisp with brisk northwest winds blowing.

\section{BIOTA}

Plant life

The vegetation along the coast of the Labrador Peninsula is distinctly tundra, with no trace of forests except at the heads of the deeper inlets, while the interior is more or less forested according to the latitude and topography.

The tundra of the coast is almost continuous over the islands, capes, promontories, and forelands, being broken only by ledges of outcropping rock with no soil covering; pools and lakes; the low depressions which form moors; the high rocky summits of the coastal mountains where broken masses of rock (typical "Felsenmeer") constitute the surface; and scattered moist sunny slopes and protected niches where the same plants as those of the less favored localities attain a most luxuriant growth.

In these coastal tundras, the essential element is the sphagnum moss which grows in all the damper portions. Arctic grasse, sedges, rushes, and cotton-grasses form turfy patches where conditions are favorable. Northern Saliceae and Ericaceae are the common shrubs, all low-growing-Empetrum nigrum, Vaccinium uliginosum and $V$. Vitis-Idaea, Betula nana, Rubus chamaemorus and R. arctica, Ledum, Loiseluria, Bryanthus-that grow in the tundra and tundra moor. Viola palustris, Diapensia lapponica, Cerastium, 
Draba, Saxifraga, Papaver, Epilobium, Drosera, Pinguicula, Silene, Pedicularis, and numerous other arctic vascular plants constitute the more prominent flowers. On the drier slopes Linnaea borealis, Rhododendron lapponicum, $P y$ rola grandiflora, Campanula, Arnica, Antennaria, Festuca, Trisetum, and Calamagrostis characterize an almost heath-like association of plants.

The interior plateau as a whole is quite different from the coastal belt, though large areas within the limit of the plateau are composed of similar tundra and tundra-moor vegetation.

The forest is practically continuous over the southernmost edge of the area described in this report, only the summits of the highest, rockiest hills being bare; but from the 53rd parallel northward, all the higher hills are treeless, the size and number of barren areas rapidly increase, and the trees themselves grow smaller. In latitude $55^{\circ}$ $\mathrm{N}$. more than half the surface is without trees, forested areas being found only in narrow belts along the streams and lakes, and in moist, sheltered recesses among the hills. The northern limit of trees extends from the mouth of the Nastapoka River on Hudson Bay, to the mouth of Leaf River on Ungava Bay, thence along the south shore of Ungava Bay to the mouth of the George River, thence along the foothills of the Atlantic coast range to Hebron, just north of Cape Mugford and south of Saglek Bay.

The arborescent flora comprises the following species:

1. Black spruce (Picea mariana), the most widely distributed and abundant tree of Labrador, extends to the northern limit of trees and constitutes ninetenths of the forest. It flourishes on the sandy soils of the Archean complex and grows equally as well on the dry hills of the southern portion as in the boggy land between the ridges. Farther north it grows rank and slim in the valleys, but on the uplands where it forms open glades, it spreads out like the white spruce.
2. Balsam fir (Abies balsamea) is a more southerly tree than the black spruce. It grows only along the edges of the waterways and the shores of the larger lakes. Its northern limit is the Great Whale River, and then roughly eastward across the plateau to Hamilton Inlet.

3. White spruce (Picea alba) is distributed throughout the wooded area but is not so abundant. It is confined to the scattered areas of rearranged drift of the river valleys, the marine deposits of the coast, and to the heavier soils of the interior. Its size and number are thus more dependent upon the soil factor than upon the climate, latitude, or altitude. Its northern limit approximates the forest limit.

4. Tamarack (Larix laricina), the largest and the hardiest tree of the subarctic forest belt, grows everywhere over the Labrador Peninsula, next in abundance to black spruce. It frequents all the cold bogs; and even to the northern limit of the forest, where the black spruce is a mere shrub, the tamarack retains its arboreal form and size, though somewhat diminished.

5. Banksian pine (Pinus divaricata) occupies the southwestern portion of the Labrador Peninsula, south of the Great Whale River and west of a line that roughly corresponds with the seventy-first meridian. It grows on dry sandy ridges and hills, where it is often combined with black spruce to form the second growth on fire-swept reaches.

6. Canoe birch (Betula papyrifera) grows commonly over the southern portion of the peninsula but is rare and small toward the north. Its northern limit lies to the south of the forest limit, though scattered groups of the trees are found even in the valley of the Koksoak river a few miles above its mouth.

7. Aspen (Populust remuloides) is found in clumps in the original coniferous forest, and in company with white birch, as second growth in many burned-over areas. It seems most abundant and widely distributed in the western portion 
of the peninsula on the undisturbed original till of the drift ridges. Its northern limit approximates the fiftyfourth parallel.

8. Balsam poplar (Populus balsamifera) grows farther north than the aspen but it thrives only on the heavy clay soil of the river valleys or that derived from limestone and shale rocks. Its extreme northern limit is near the head of Ungava Bay, thence southeastward to the mouth of Hamilton Inlet, and southwestward to Bishop Roggan river on the shore of Hudson Bay.

At least one-half of the original forest cover has been burned off, and a secondary growth of black spruce, Banksian pine, aspen, and white birch replaces the former forest. In many places only blackened stumps and small second growth extend for miles over the plateau and up the river valleys, with here and there a large thrifty tract of the original forest to indicate the character of the former pristine forest covering.

Throughout the forest belt, the lowlands fringing the streams are covered over with thickets of low willows and alders. Toward the semi-barrens northward, these fringes of shrubbery become wider, and with dwarf birch occupy much of the open glades. The willows and birches grow on the hillsides above the tree-line up to the "Felsenmeer" and its patches of Sphagnum-or Cladonia-tundra, and form low thickets through which it is difficult to pass. North of the tree-limit similar thickets of Arctic willow, birch, and alder grow over the lower reaches, but on the hills they attain only a carpet-like form. Ledum and Kalmia in tangled masses form the undergrowth of the southern forest region, but die out in the semibarrens. Sphagnum is the ground carpet of the southern regions, being replaced by Cladonia to the north, a rich growth everywhere throughout the semi-barrens and barren regions.

The semi-barrens and barren mountain-tops and northern tracts are either areas of "Felsenmeer" with little vegeta- tion, or tundra or tundra-moor vegetation such as is found along the coast. Over 450 species of vascular plants have been reported, including about 35 Compositae, 30 Ericaceae, 30 Cruciferae, 30 Rosaceae, 30 Cyperaceae, 30 Gramineae, 25 Caryophyllace; 20 Saliceae, 20 Saxifragaceae, 20 Ranunculaceae, and 15 Scrophulariaceae.

During the short summer season the open places of the peninsula become dotted with the blossoms of berrybearing shrubs and flowering plants. Nearly all vernal in character, they burst into bloom abruptly, just as breaks the summer. Their flowering and growing season is brief, and they hasten through their vegetative and reproductive processes in a rapid, continuous succession by which the aspect of the landscape seems of ten to change over night. Grassy, sedgy, swales are dotted with the plants of the moor; gravelly, clayey slopes become colored with the heath-plants in every warm sheltered nook; and every niche and ledge among the rocks bears a flower, or a bit of fern, or sedge, or grass. The subarctic landscape during the all too brief summer is far from monotonous.

\section{ANIMAL LIFE}

\section{Mammals}

Of the land-mammals the barrenground caribou is the most significant form in the whole fauna of the peninsula. The woodland caribou once abundant, and the chief reliance for food of the Nascaupee and Montaignais Indians, has been almost exterminated, with the result that a large portion of these tribes has perished from starvation.

The barren-ground caribou ranges immense herds over the barren and semi-barren grounds. These animals spend the summer season on the barren highlands near the coast where the strong winds reduce the number of flies and mosquitoes that plague all life. In the autumn they migrate inland and southward into the semibarrens of the lower lands, and 're- 
turn to the high barrens in April and May.

Three distinct herds browse over the north part of the peninsula. One, on the Atlantic coast occupies in summer the mountainous area between the 56th and 59th parallels, and migrates almost as a unit southwestward toward the semi-barrens of the inland valleys and forested lowlands beyond Lake Michikimau. Hundreds are killed by the Indians while crossing the George River about $100 \mathrm{mi}$. below the lake. The spring migration is more desultory in small bands. Another of the herds frequents in summer the point of the peninsula between Ungava Bay and the Atlantic, and migrates to the point west of Ungava Bay and Hudson Strait, crossing the lower regions of Koksoak River. The third herd winters about Clearwater Lake, and migrates northward for summer pasturage to the highlands along the divide of the northwestern part of the peninsula.

With irregular periodicity the caribou remain on the barrens throughout the winter, not migrating back to the forested inland valleys and lake shore tracts. Whenever this happens the Indians are likely to face stress and starvation and death.

With diminution in number of the Indian hunters, there is a corresponding increase in the number of furbearing animals. Of these the most abundant are the pine marten (Martes) ranging through the forested regions, but not found on the semi-barrens of the highlands, or north of the tree-limit; the wolverine (Gulo) common throughout the entire extent of Labrador to its northernmost point; the otter (Lutra) common throughout the wooded regions and ranging northward into the barren grounds; the beaver (Castor), numerous throughout the forested lands, and ranging into the semi-barrens wherever the food-supply permits; the weasel (Mustela), distributed throughout the wooded regions; the mink (Mustela vison), rare even in the southernmost portion of the peninsula; the red fox
(Vulpes) and its variant color phases, relatively abundant throughout the peninsula; and the arctic fox (Alopex) both blue and white forms - found most abundantly in the barren ground to the north, and ranging farther south along the coast to the 52 nd parallel.

The arctic hare (Lepus arcticus) is confined to the barren and semi-barren lands, but the common rabbit (Lepus americanus) is found in great numbers throughout the wooded regions, except that periodically it is almost exterminated by an epidemic infection that rages through the species. This rabbit is an essential element in the Labrador fauna, for many of the carnivoran species depend upon it for their basic food supply. The Canada lynx (Lynx canadensis), the gray wolf, and many of the fur-bearing carnivores find the rabbit the ultimate source of sustenance. It is said that whenever the rabbits die from disease, the lynx faces such difficult food conditions that it does not breed during the shortage of rabbits. The gray wolf (Canis lycaon) preys chiefly upon the caribou (Rangifer spp.), and since the woodland form has become almost extinct, the range of the gray wolf has been largely limited to the barrens and semi-barrens, the haunts of the barren-ground caribou. The arctic wolf (Canis tundrarum) is rare, and found only in the barrens and along the coast.

Three species of bears are found in Labrador, the barren-ground bear, the black bear, and the polar bear. The barren-ground bear (Ursus sp.), as its name implies, is northerly in its range, and is very rare. The black bear (Ursus americanus group) is common throughout the wooded country, frequenting the coast when the great shoals of caplin are swept in on the beaches; the rapids and falls of the streams when the salmon and other fish are "shoaling;" and the burnt-over areas in the fall when the berries are ripe. The polar bear (Thalarctos) is common along all the coast of Labrador, but most abundant in the northern portion where it finds seals in 
abundance. It frequents the ice-fields and bergs, and rarely travels inland except in winter when the fjord and inlets are frozen over. The polar bear is essentially a shore-loving animal, spending much of its time at sea.

The smaller mammals that frequent the northern barrens and semi-barrens include the Labrador deer-mouse (Peromyscus) common as far south as the 52nd parallel, particularly about buildings and huts; the small and large yellow-faced Phenacomys of rather far northern distribution; the Ungava redbacked mouse (Euvotomys ungava) restricted to these northern barren and semi-barren areas; the small Labrador vole (Microtus); two species of lemming (Lemmus and Dicrostonyx), most common about the grassy, sedgy moors and bogs; and the Labrador shrew (So$r e x)$, found from Fort Chimo 'south.

The small mammals that are of more southern range, found principa llyin the wooded lands are as follows: the porcupine (Erethizon), ranging northward into the semi-barrens; the northern red squirrel (Sciurus hudsonicus) of the same range; the Labrador flying squirrel (Glaucomys sabrinus makkovikensis), rare even in the southernmost portions; the large Labrador vole common throughout the wooded regions and penetrating into the semi-barrens; the Labrador rock vole and Labrador jumping mouse (Zapus), rare along the coast; the Hamilton Inlet red-backed mouse and the northern jumping mouse, common in the woodlands to the edge of the semi-barrens; the Labrador muskrat (Ondatra) becoming progressively less numerous from the heavily-wooded tracts in the south to the semi-barrens as far north as Fort Chimo, where it is very rare; and the little brown bat and Say's bat (Myotis L. Lucifugus and $M$. subulatus), that may occasionally be found in the extreme southern portion.

In the waters off the coast the walrus is found along the whole coast, its former usual range, but now it is common only along the northern reaches. Six species of seal frequent the coast; the harbor seal, common to the coast and low parts of the rivers all around Labrador, and plentiful in a number of northern freshwater lakes in which they breed and rear their young, and from which apparently they never go, having acquired a freshwater habit; the ringed seal and harpseal, common along the whole coast; the bearded seal, the gray seal, and the hooded seal, everywhere and always rare. The white porpoise or beluga, and the narwhal, are fairly common. The humpbacked, the little-piked, the finback, the sulphur bottom, the killer, and the bottle-nosed whales are locally relatively common; while the right whale, the bowhead, the Pollock whale, and the sperm whale are rare. The porpoises and dolphins are common.

\section{Birds}

The bird life of Labrador, both inland and coastal, is numerous and varied, the number of species of the seabirds being relatively small, though the number of individuals in many cases is incredibly large; while of the land birds the number of species is relatively large, the number of individuals relatively small.

Of the sea-birds, two species once common, the great auk and the Labrador duck, have been quite exterminated. The puffin, the black, guillemot, and the Mandt's guillemot, the common murre and the Brunnich's murre, and the razor-billed auk, are common summer residents in the waters off the coasts, and the dovekies are numerous during the winter. The skuas, and jaegers, many gulls and terns, petrels and shearwaters, fulmars, gannets and cormorants frequent the coast. The mergansers and many species of ducks and geeseincluding the eiders, brant, and the whistling swan-populate the coastal inlets, fjords, and lagoons.

Along the shores, the fast vanishing curlew may still be found, though the oyster-catcher has been exterminated; the sandpipers, the phalaropes, the plovers, the ruddy turnstone, the sand- 
erling, and the godwit, all help to make the coastal skerries and lowlands along the inlets interesting and lively:

On the inland plateau the loons, the grebes, the coots, and the Canada geese nest in numbers about the lakes and pools, a few herons and rails, harlequin ducks, and sandpipers frequent the shores of the streams and ponds, sometimes nesting. In the woods and timber lands of the interior the northern ranging species of woodpeckers-hairy, downy, black-backed, three-toed, and the yellow-shafted flicker; the Canada blue jay, and the Labrador jay; the yellow-bellied fly-catcher, the raven, the pine grosbeak, the white-winged crossbill; the tree sparrow, the waxwing, the warblers-Tennessee, yellow, myrtle magnolia, black-poll, black-capped yellow, the water-thrush, and rarely, a few others; the northern shrike; the Hudsonian chickadee; the kinglets; the live-backed and hermit thrushes; the American robin; the ruffed grouse and the Canada grouse; and transient or casual visitors of other species; all these form the interior woodland avifauna.

In the more open glades and on the barrens and semi-barrens, the willow ptarmigan and Reinhardt's ptarmigan are common, the latter migrating northward about mid-April to the northern barrens, and the islands to the north of Labrador; the yellow-legs, Wilson's snipe, and the inland sandpipers are found on the moorlands; the cow-birds and rusty blackbirds frequent the shrubby fringes of the open places; the red-polls, the longspur, the savannah sparrow, Lincoln's sparrow, the whitesparrow, the white-crowned and whitethroated sparrow, the junco, the pipit, and the horned lark, flit about the semi-barrens, and the shrub-carpeted stretches of the barrens; while the snowbunting commonly, and the rare wheatwar, occasionally, make their home among the rocky ledges and Felsenmeer of the whole region of barrens and semibarrens. The gyrfalcon, the duck hawk, the bald eagle, and the American gos- hawk course over the plateau; the osprey frequents the waters of the southern portion; the kingfisher darts along the wooded streams; a number of owlsshort-eared, saw-whet, dusky, horned, and American hawk owls-prey on the small life; and the snowy owl sweeps down over the plateau in winter, coming from the high-arctic lands to the north.

\section{Insects}

About 300 species of insects are known from Labrador. The diptera, many circumpolar in distribution, and an almost intolerable feature of the short Labrador summer, include two species of botfly that infest the caribou; deerflies and horseflies of 10 or 12 species of which the larvae are aquatic or subaquatic and of which the adult flies are the torment of the larger land life of the peninsula; mosquitoes, beyond credible enumeration, that rise in cloudlike swarms from the moors and tundra and hover about the woodlands equally densely; the minute midges, that help to make human existence during summer almost worthless in the woods; and a few other species "that do not bite."

The hymenoptera number less than 30 species, of which 11 or 12 are leafeaters or saw-flies; two are ants, confined to the southernmost wooded valleys; two are wasps; and 5 are bumble bees. The bumblebees are far northern species.

One hundred and fifteen species of lepidoptera have been listed; 18 butterflies, including 4 small Fritillaries; Argynnis atlantis; Papilio turnus; Pontia napi v. frigida; 4 Eurymus; Eugonia $j$-album; Oeneis norma $v$. semidea; Agriades aquilo; and Lycaena ladon. Two species of skippers, Pamphila comma and Hesperia centaureae, have been collected. Of the moths the Arctiidae include 4 species; the Noctuidae, 40 species; the Geometridae, 20 species; the Lipariidae one species; the Hepialidae, two species; the Pyralidae, 8 species; the Crambidae, 6 species; the Tortricidae, 20 species; the Tineidae, 
10 species; and the Trichoptera (caddisflies) 5 species.

The Hemiptera include only 4 species; the Orthoptera number one. Eight Ondonata (dragon-flies) have been found in Labrador; one Ephemeris, or May-fly; 3 Piecopterids; several Thysanura or spingtails; and the snow-flea; all these have been recorded. Sixty species of beetles and 11 spiders have been described from the peninsula.

\section{Fish}

The inland waters of Labrador are well stocked with fish. The sturgeon is common in many streams; the northern sucker and the red sucker are common throughout the peninsula in all the lakes and streams; the whitefish is everywhere abundant; the Atlantic salmon enter all the streams opening on the Atlantic and Hudson Straits watersheds; the Great Lake trout, the brook trout, and the pike are found in most of the streams; the ling, an important fish for the Indians because it will take bait freely during the winter months when other fish can not be caught and food is scarce, is abundant in all the deeper lakes.

The most important fish of the coastal salt-water is the cod, which comes to the coast to feed on the immense schools of caplin that run inshore to feed. The cod comes to the Labrador coast about June twentieth, and moves northward along the coast at the rate of about a degree of latitude a week, but from August to September they are spread along the entire coast. The smaller cod begin leaving the coast about the first of October, but the larger remain until well into November.

The mackerel left the Labrador coast about the middle of the nineteenth century and is rarely found there now. The herring is again abundant after a long period of relative absence. The halibut, dab, and rock-cod are common. The sleeper shark is abundant in all the inlets and near the coast, a scavenger of the sea-floor.

Crustacea of many species frequent the Labrador coast. Crabs, lobsters, shrimps, amphipods, isopods, copepods, and barnacles are numerous. The molluscan fauna is distinctly Arctic, largely of circumpolar species, both lacustrine and littoral. Land molluscs are rare. The plankton life, seasonally, is exceedingly rich.

\section{CONCLUSION}

The Labrador is relatively unexplored. It offers one of the most promising fields for the explorer and the pioneer naturalist. The coast may be readily visited during the summer months by mail-steamers from St. Johns and by fishing vessels from Gloucester, Provincetown, and the Atlantic coastal fishing towns, where the cod-fleets have their bases. The interior may be traversed only by well-organized and well-equipped expeditions with experienced guides and leaders.

\section{NEWFOUNDLAND}

\section{By W. Elmer Ekblaw}

\section{INTRODUCTION}

Newfoundland, an island of some $42,000 \mathrm{sq}$. mi. off the mouth of the Gulf of St. Lawrence, lies between the parallels of $46^{\circ} 36^{\prime} 50^{\prime \prime}$ and $51^{\circ} 39^{\prime}$ north latitude, and between the meridians $53^{\circ} 37^{\prime}$ and $59^{\circ} 24^{\prime} 50^{\prime \prime}$ west longitude. It forms an equilateral triangle, the distances between Cape Bauld at the north angle, Cape Spear at the southeast angle, and Cape Ray at the southwest angle, being each approximately $320 \mathrm{mi}$.

\section{GEOLOGY}

Except for a belt composed of the highest portion of the Long Range Hills, the entire island has been glaciated. Possibly two-thirds of the area is occupied by Laurentian granites and gneisses, with considerable tracts of serpentine; Huronian gneisses and schists predominate in the eastern portion; considerable belts of Carboniferous sandstones and shales and scattered tracts of Silurian and Devonian 
limestones are found along the western coast and in a few places over the plateau. The distribution of the soils resulting from the disintegration of these different rocks influences to a considerable degree the flora and vegetation of the island.

\section{PHYSIOGRAPHY}

\section{Outline}

The northwest coast of the island, paralleling the fold known as the Long Range, is fairly regular; the south coast is much more broken by bays and fjords, particularly toward the east end; and the northeast coast is exceedingly broken and irregular throughout its entire extent, like the west coast of Norway, or Greenland. These bays and fjords occupy the valleys and lowlands of a peninsular continuation of the eastern Canadian coast prior to the post-glacial submergence which left Newfoundland an island. Numerous islets and islands occupy the bays and gulfs. Avalon Peninsula, almost detached from the main island by Trinity Bay and Placentia Bay, is connected only by a narrow isthmus.

\section{Relief}

The relief, like the shore line, is an expression of the geologic structure of the terrain, the ridges and valleys paralleling the direction of the folds, N.N.E. to S.S.W. Seen from the sea, the coast rises steep, 200 to $300 \mathrm{ft}$. or even more, like a broad rocky wall, bleak and apparently barren, to a plateau dissected to form a rugged hilly landscape.

Back of this dissected coastal belt, the plateau is extensive and undulating, with parallel ranges of hills and mountains, of which the Long Range along the west coast, with heights of $2000 \mathrm{ft}$. or more, is the most important. Avalon peninsula is rather rugged and rough, but the highest hills here are not over $1200 \mathrm{ft}$. in height. Throughout the region of the interior rolling plateau, scattered sharp peaks called "tolts," serve to identify the various localities of the island.

\section{Drainage}

Consequent upon the disturbance of the original drainage system by the general glaciation of the area, Newfoundland is characterized by innumerable lakes, pools, ponds, and marshes, of such extent that one-third the island is thus occupied by small bodies of water, lying along the flood plains of the streams, in hollows along the slopes of the valleys, in depressions between the moraines and ridges, and even in hollows in the tops of the hills.

Three rivers of considerable sizethe Humber running west into the Bay of I'slands; and the Gander and Exploits running northeast into the Hamilton Sound and Notre Dame Bay respectively-and a number of smaller streams drain the island; but because of $\mathrm{nu}$ merous falls and rapids, and shallow riffles they are unnavigable except for canoes. Extensive bogs occupy much of the valley areas and the plateau slopes and levels.

\section{CLIMATE}

The climate of Newfoundland does not merit designation as an oceanic climate, but it is so modified by the waters bathing its shores that it is distinctly more equable and uniform than that of the neighboring mainland. The temperature rarely falls below zero even in mid-winter, and rarely rises above $80^{\circ}$ in summer. The mean temperature for the year, except in the extreme northern portion where it is lower, is from $40^{\circ}$ to $45^{\circ}$. The average precipitation, about evenly divided between rain and snow, is less than 60 in.

The average barometer is 29.37 in. The storms are mildly cyclonic, with winds varying with the seasons in general direction and velocity. Winter sets in late in November and continues until mid-April. During this period 
a general covering of snow keeps the frost from penetrating deep. The first frosts are rather early in places-as early as mid-August-and spring is often tardy, particularly when the icefloes and ice-bergs have accumulated unduly off the coast. July in Newfoundland is like May in New York.

The north, east, and south coasts are chilly and damp and foggy, because of the meeting of the cold GreenlandLabrador current with the warm air and water of the Gulf stream. There where the warm, moisture-laden air off the Gulf stream encounters the chill air off the cold waters of the Greenland current, with its fleets of floes and bergs, the vapor is condensed into clouds and fogs and mists that characterize the region. The interior and the west coast, however, have a pleasant, relatively mild and equable climate, generally clear and invigorating.

\section{BIOTA}

\section{Plant life}

The vegetation of the island varies with the topography of the soil, and the drainage. The greater part of the island has been heavily forested, the dominant type of forest being coniferous, with interspersed areas of deciduous woods-but great tracts have been destroyed by fire.

The white pine, once abundant over the island, has been almost all cut, surviving only in isolated groves where it has been intentionally preserved, or in small tracts remote or difficult of access. The most abundant coniferous tree is black spruce, though the balsam fir or spruce is also common; the tamarack is abundant in the bog or tundra; and white spruce and cedar (low-growing juniper) are widely distributed. Arborvitae, rather common in New Brunswick and Nova Scotia, is absent.

Scattered about among the coniferous woods are large tracts of rather pure growths of deciduous trees, balsam, poplar, aspen, white and red maple, birch, elm, mountain ash, alder and a few others. In places, particularly on the burned tracts, these are also scattered promiscuously among the new stands of coniferous trees.

As a rule the forests are found in belts from two to $10 \mathrm{mi}$. wide along the streams and about the shores of the lakes. The most extensive areas of timber left standing are in the basins of the Exploits, Gander, and Humber Rivers. It is estimated that the acreage of marketable timber left standing in Newfoundland is $6,500,000$, of which no small portion is well established second growth on cut-over or fire-swept areas.

The forests rarely extend above the $1000 \mathrm{ft}$. elevation and generally cease considerably lower. The crests and the rolling tops of the hills are bare of trees, in many places quite destitute of vegetation-the soccalled barrens; in others, where the soil and moisture are more favorable the barrens are covered with scrub willow, alder, and birch and low evergreens. Thus from east to west, Newfoundland is a succession of parallel barren ridges, and forested valleys.

On the plateaus and in the valleys where the drainage is incomplete, lie extensive bogs; some of them are forested with black spruce, tamarack, willow, and alder as dominant trees, and Labrador tea, dwarf birch, andromeda, kalmia and other low shrubs forming a rather dense undergrowth on the wet floor of sphagnum, sedge, and cotton grass; others are shrubby; but many of them are open, grassy, and sedgy moors, with a wealth of flowering plants and ferns.

The vascular plants of Newfoundland are many and varied, comprising over 1000 species, some of general distribution, others confined to certain limited types of soil, or physiographic divisions. Berry-bearing plants-Rubus, Vaccinium Empetrum, and Viburnum-are numerous. Flowering plants, both shrubs, and herbs, and ferns grow in profusion, except in the driest, windswept portions of the barrens. Grasses, sedges and mosses carpet the wet open places. Reindeer moss (Cladonia) clothes the 
rockier slopes and crests, particularly in the northwest part.

The flora seems to possess definite affinity with the sub-alpine life of Labrador, and with the flora of New England and New Jersey, but forms related to those of New Brunswick, Quebec, and Nova Scotia, are relatively few, probably due to a barrier of unfavorable soils prior to the postglacial submergence of the connecting lands.

\section{Animal life}

The most important feature of the fauna of Newfoundland is the woodland caribou, which migrates in March from the valleys and the more wooded portions of the southern half of the island, to the Cladonia-covered barrens of the northwest, there to bear its young in May and June, and to browse through the summer until the first heavy frosts of October, when it again moves southward. The large herds of this animal thus moving annually back and forth over the island are the dominant feature in the animal life of the land, as the cod is of the sea.

The gray wolf (Canis lycaon), now very scarce, and the black bear (Ursus americanus group), frequent the interior. The red fox and its variants are common. Beaver, otter, weasel, arctic hare, muskrat and bats abound. No reptiles are indigenous. Frogs have been introduced and thrive well. The moose and porcupine of the neighboring Canadian coast are absent. Salmon and trout, but no pike or pickerel, or other predaceous fish, are found in the inland streams or lakes.

Bird life, both on land and sea, is rich and varied. Over 300 species have been recorded-eagles, hawks, owls, woodpeckers, swallows, king fishers, fly catchers, thrushes, warblers, ravens, jays, sparrows, and others inland; golden plover, sandpipers, curlews and other shore-birds, but no woodcock; ducks, geese, loons, coot and others frequent the many lakes and the coast; dovekies, gannets, gulls, guillemots, puffins, murres, and razorbill auks are abundant in the waters that wash the shore; on the lower lands the willow ptarmigan is one of the most distinctive birds and on the uplands, the rock ptarmigan. The great auk once frequented the shores and the outlying islands but has been extinct these many years.

Insect life is abundant. Mosquitoes and deerflies are apparently omnipresent throughout much of the summer. Gay butterflies flit over the open vales and barrens; moths of many species frequent both open and woodland.

And in the sea adjacent to Newfoundland, particularly on the Grand Banks to the south and southeast, the aquatic fauna is one of the richest in the world. In this meeting ground of the Greenland current with the Gulf Stream, both bearing heavy loads of pelagic algae and other minute forms, sea life is most abundant. Echinoderms, molluscs, annelids, and coelenterates innumerable, feed upon this rich plankton growth, and in turn yield sustenance to the fish and larger forms.

About the first of June the caplin, a small fish, appears on the banks in incredible millions, and preying upon them appear the cod. When the caplin disappear, the squid comes to take its place as cod-food, and when the squid leaves the herring appear, thus furnishing the cod with an abundance of food until mid-October, when it too leaves. Lobsters are abundant in the off-shore waters. Mackerel once frequented the coast in large numbers but disappeared about the middle of the nineteenth century, and have not returned.

In spring thousands of harp and a few hooded seal float south from the Arctic regions on pan-ice borne by the Greenland Current, to bear their young on the floes. They are killed by hundreds of thousands, both young and old, during the month of April. Hundreds of whales are also killed annually, many of them sulphur-bottoms, finbacks, and humpbacks. The white whale, or beluga, one of the porpoises, is occasionally 
common. The narwhal once abundant along the coast is now disappearing. The killer whale is abundant, as are the grampus and porpoise.

\section{ROUTES OF TRAVEL}

Newfoundland is readily accessible as a field for study, either by the InterColonial Railway or by steamers from America and Europe. The island itself is difficult of traverse, particularly toward the northwest, because of the bogs, rocky hills, and barrens, without roads or even trails. The rivers are navigable only by canoes. Most parts of the island are accessible only by boat from the sea; the southern half may be studied fairly well from the main railway and the spurs built out from it. Mosquitoes and deerflies are so annoying as to hinder field work and special precautions for comfort and relief are necessary.

6. THE MACKENZIE WATERSHED; NORTHERN HUDSON BAY REGION, UPPER YUKON REGION, AND THE ARCTIC ISLANDS

\section{By Edward A. Preble}

\section{GENERAL CONDITIONS}

\section{General topography of the entire region}

The region treated in the present sketch includes a vast area in the northern interior of North America, between latitude $50^{\circ}$ and $78^{\circ} \mathrm{N}$., and extending from longitude $85^{\circ}$ west to $115^{\circ}$ at the south, and from $80^{\circ}$ west to $141^{\circ}$ at the north. The Arctic Ocean washes its northern shores and islands; Hudson Bay marks its eastern limit, and its western border includes the headwaters of streams which enter the Pacific from middle British Columbia to Bering Sea. Its physiography is very much varied. At the south grassy plains, interspersed with small patches and tongues of forest, are succeeded as one goes northward by a forest that is almost unbroken save by the rivers and the lakes, which are numerous and sometimes very large. Because of differences in geology, the lakes are more numerous in the eastern portion. North of the great forest lies a large area which for climatic reasons is treeless, but still has a rich and varied flora. The southern and eastern parts of the region are rolling, with only a few hilly areas. At the extreme northwest, however, it includes the northern part of the Rocky Mountain chain, here lower than farther south, and its foothill ranges. These are forested on their lower slopes but hold large alpine areas, the flora and fauna of which have close affinities with the treeless Arctic.

North and northeast of the continental portion of the region, alove briefly described, lies the Arctic Archipelago, including a number of large islands similar in topography, flora, and fauna to the treeless part of the mainland.

The region is exceptionally wellwatered, mainly by the great Mackenzie, which ranks second in size of basin, and third in actual volume, among North American rivers. Northwestwardly, the region includes areas watered by streams which enter the Pacific Ocean and Bering Sea, this lying, of course, west of the Continental divide.

For transportation, the naturalist must depend largely on boats of some kind, supplemented by dog sled if it is desired to enter the region before the opening of navigation, or if the freezeup should overtake him en route. To reach the northward flowing streams several rail routes are possible. For most direct access to the lower Athabaska and the Mackenzie, the Alberta and Great Waterways Railway, running north-northeastward from Edmonton, Alberta, takes one to navigable water on the lower Clearwater. From here steamboat travel, interrupted only at one point, the $16-\mathrm{mi}$. Smith portage, is afforded to the mouth of the Mackenzie. From many points on this 1500-mi. route a great number of canoe routes lead to all parts of the immense region now treated, to thousands of lakes, streams, and mountains unknown except to the wandering native. Alternative railroad lines leading to the north 
are the Athabaska Landing branch of the Canadian Northern, running $100 \mathrm{mi}$. northward from Edmonton, and the E. D. and B. C. railway running to Peace River by way of Lesser Slave Lake. The latter line affords access to the Mackenzie by way of the lower Peace and Slave River, or to the upper tributaries of Peace River, in the interior of northern British Columbia. Another route to the latter section is by canoe northward from various points on the Canadian National railway, which crosses central British Columbia from the head of Fraser River to the Pacific in about latitude $54^{\circ}$.

\section{Climate of entire region}

The climate of a region of such magnitude as the one under discussion is so varied that it seems best to take up this subject in the account of the various areas. In general it may be said that the winters are long and cold, and the summers short and comparatively warm. There is a very wide yearly range of temperature especially over the Continental portion of the region, the greatly increased number of hours of sunlight enjoyed in summers in high latitudes making up in a measure for the increase in latitude. This enables the smaller shrubs and other plants to complete their reproductive processes within a comparatively short time.

\section{Original biotic divisions}

A. Poplar forest and savanna of southern portion (Canadian Zone). This division occupies most of a broad strip extending north-northwestward from Edmonton, passing west of Athabaska (on the river), thence, including the basin of Lesser Slave Lake, on to Peace River, northward down its valley on either side, and northward nearly to Great Slave Lake. In a modified form, it stretches westward to include much of the Peace River valley, in northeastern British Columbia.

This is the region of transition from the grassy and treeless Great Plains to the great northern Forest. Its principal tree is the aspen poplar (Populus tremuloides) which forms groves of greater or lesser extent on the slopes of the rolling hills. In low areas where the drainage is imperfect, mossy swamps or muskegs where the black spruce (Picea mariana) is dominant are frequent. Farther north these become more numerous and become a dominant feature.

Originally this area was the habitat of the bison (Bison b. athabascae) and the elk (Cervus canadensis), but the latter is long since extirpated here, and the bison remains only in small numbers near its northern part. Other mammals presumably here were the moose (Alces americanus), Franklin ground squirrel (Citellus franklinii), thirteen-lined ground-squirrel (C. tridecemlineatus) (these two not north of Athabaska River), Saskatchewan pocket-gopher (Thomomys talpoides) (southerly), northern plains skunk (Mephitis hudsonica), and several mice and voles. Birds are numerous; a few notable breeders include the sharp-tailed grouse, upland plover, and the western solitary sandpiper.

The only reptile, the northern garter snake (Thamnophis sirtalis parietalis), which enters any part of the region is confined mainly to the savannas of this subdivision. Scarcely less strictly confined to it are the western toad ( $B u f o$ lentiginosus woodhousei), and the leopard frog (Rana pipiens). The northern wood frog (Rana cantabrigensis latiremis) and the northern chorophilus (Chorophilus septentrionalis) also are found in it, but extend their ranges far beyond-to the limit of trees.

B. Transcontinental coniferous area. 1. Southern heavy timber (Canadian Zone): Covering most of the region under discussion is the great transcontinental conifer forest. Its principal trees are the white and black spruces (Picea alba and P. mariana), whose ranges are coextensive with its limits, and the canoe birch (Betula papyrifera), tamarack (Larix laricina), aspen and 
balsam poplars (Populus tremuloides and $P$. balsamifera), Banksian pine (Pinus divaricata) (replaced in British Columbia and Yukon by lodge-pole pine (Pinus contorta)), and balsam fir (Abies balsamea), which are common in the southern part of the belt, and which terminate, counting from the north, in about the order given. With these are associated, generally in the form of undergrowth, a variety of shrubs, some of which, also, have a continuous distribution through the forest zone, while others are more or less restricted in range. Some of the more conspicuous of these are the following: creeping juniper (Juniperus sabina), low juniper ( $J$. nana), a large variety of willows (Salix), one (S. bebbiana) attaining the dignity of a tree, but most being creeping shrubs or low bushes, sweet gale (Myrica gale), two hazels (Corylus americana and $C$. rostrata) (southerly), dwarf birches (Betula glandulosa and B. nana), alders (Alnus), several currants and gooseberies (Ribes), red raspberry (Rubus strigosus), shrubby cinquefoil (Dasiphora fruticosa), wild rose (Rosa acicularis), service berry (Amelanchier alnifolia), cherries (Prunus pennsylvanica and $P$. virginiana) crowberry (Empetrum nigrum), silverberry (Elaeagnus argentea) buffalo berry (Lepargyrea canadensis), dwarf cornel (Cornus canadensis), red-osier cornel (Cornus stolonifera), Labrador tea (Ledum groenlandicum), swamp laurel (Kalmia glauca), wild rosemary (Andromeda polifolia), leatherleaf (Chamaedaphne calyculata), red bearberry (Arctostaphylos uvaursi), mountain cranberry (Vitisidaea vitisidaea), small cranberry (Oxycoccus oxycoccus), bog blueberry (Vaccinium uliginosum), cranberry tree (Vivurnum americanum) (southerly), few-flowered viburnum (V. pauciflorum), and snowberry (Symphoricarpos racemosus) (southerly). With these are associated a great variety of herbaceous plants, many of which bear flowers of great beauty, a number of ferns, and a great variety of mosses and lichens.

The more common and characteristic mammals of the great forest include the following: 1

Eastern moose (Alces americanus)

Eastern woodland caribou (Rangifer caribou)

Wood bison (Bison bison athabascae)

Canadian woodchuck (Marmota monax canadensis)

Liard River chipmunk (Eutamias borealis)

Hudson Bay red squirrel (Sciurus hudsonicus)

Hudson Bay flying squirrel (Glaucomys sabrinus)

Arctic white-footed mouse (Peromyscus m. borealis)

Mackenzie phenacomys (Phenacomys mackenzii)

Athabaska red-backed mouse (Evotomys gapperi athabascae)

Northern lemming vole (Synaptomys borealis)

Drummond vole (Microtus drummondi)

Chestnut-cheeked vole (Microtus xanthognathus)

Northwest muskrat (Fiber zibethicus spatulatus)

Canadian beaver (Castor canadensis)

Hudson Bay jumping mouse (Zapus hudsonius)

Canada porcupine (Erethizon dorsatum)

Hudson Bay snowshoe hare (Lepus americanus)

Canada lynx (Lynx canadensis)

Gray wolf (Canis occidentalis)

British Columbia red fox (Vulpes alascensis abietorum)

Black bear (Ursus americanus)

Canadian otter (Lutra canadensis)

Western mink (Lutreola vison energumenos)

Richardson weasel (Mustela cicognanii richardsoni)

Least weasel (Mustela rixosa)

Alaska marten (Martes americana actuosa)

Fisher (Martes pennantii)

Hudson Bay wolverene (Gulo luscus)

Common eastern shrew (Sorex personatus)

Richardson shrew (Sorex richardsoni)

Marsh shrew (Neosorex palustris)

Alaska microsores (Microsorex eximius)

Little brown bat (Myotis lucifugus)

Hoary bat (Nycteris cinereus)

Among birds the following may be noted:

Horned grebe

Loon

1 These lists do not include certain West Coast and Rocky Mountain species occurring in British Columbia and Yukon, and which are listed under those subdivisions. 
Pacific loon

Herring gull

California gull

Short-billed gull

Bonaparte gull

Common tern

American merganser

Mallard

Baldpate

Green-winged teal

Pintail

Lesser scaup duck

Ring-necked duck

American golden-eye

Bufflehead

Canada goose

Little brown crane

Sora rail

Yellow rail

American coot

Wilson snipe

Greater yellowlegs

Yellowlegs

Western solitary sandpiper

Spotted sandpiper

Hudsonian spruce grouse

Gray ruffed grouse

Sharp-tailed grouse

Marsh hawk

Sharp-skinned hawk

Goshawk

Western red-tailed hawk

Golden eagle

Bald eagle

Duck hawk

Pigeon hawk

American sparrow hawk

American osprey

Long-eared owl

Short-eared owl

Great gray owl

Richardson owl

Arctic horned owl

American hawk owl

Belted kingfisher

Northern hairy woodpecker

Nelson downy woodpecker

Arctic three-toed woodpecker

Banded-backed three-toed woodpecker

Yellow-bellied sapsucker

Northern flicker

Nighthawk

Kingbird

Phoebe

Olive-sided flycatcher

Western wood pewee

Alder flycatcher

Least flycatcher

Canada jay

Northern raven

Crow

Cowbird

Northern redwing

Rusty blackbird

Bronzed grackle

Eastern pine grosbeak
White-winged crossbill

Redpoll

Western Savanna sparrow

Intermediate sparrow

White-throated sparrow

Western chipping sparrow

Slate-colored junco

Lincoln sparrow

Swamp sparrow

Fox sparrow

Louisiana tanager

Cliff swallow

Tree swallow

Bank swallow

Bohemian waxwing

Northern shrike

Red-eyed vireo

Western warbling viree

Blue-headed vireo

Black and white warbler

Orange-crowned warbler

Tennessee warbler

Yellow warbler

Myrtle warbler

Magnolia warbler

Bay-breasted warbler

Black-poll warbler

Palm warbler

Ovenbird

Grinnell water-thrush

Wilson warbler

Redstart

Red-breasted nuthatch

Long-tailed chickadee

Hudsonian chickadee

Golden-crowned kinglet

Ruby-crowned kinglet

Olive-backed thrush

Eastern hermit thrush

Robin

2. Northern stunted timber (Hudsonian Zone): Included in the great coniferous forest and bordered on the north by the Barren Grounds, there is a strip of country from 100 to $200 \mathrm{mi}$. wide, which is covered by forest somewhat stunted and dwarfed (Hudsonian Zone). In some places, where areas of fertile soil, usually the valleys of northwardflowing rivers, impinge closely on more exposed areas of rocky ground, the transition from one type to another is wellmarked, while in others the change is more gradual.

In the Mackenzie region this belt has no strictly characteristic mammals, though the range of a red-backed vole (Evotomys dawsoni) is practically confined within its limits. Most of the woodland mammals necessarily have 
their northern limit within it. Such comprise the following: Rangifer caribou, Alces, Sciuropterus, Sciurus, Castor, Evotomys, Fiber, Erethizon, Lepus americanus, Lynx, Lutra, Lutreola, Mustela, and others. Among birds, the pigeon hawk, great gray owl, hawk owl, pine grosbeak, Harris sparrow, tree sparrow and gray-cheeked thrush breed principally within it. Its trees are not peculiar, though the Banksian pine (Pinus divaricata) and balsam poplar (Populus balsamifera) barely enter its borders. Its shrubs are mainly species that overlap from the adjoining zones. Among those which seem to reach their greatest perfection in the belt of stunted trees may be mentioned Empetrum nigrum, Ledum palustre, Vaccinium uliginosum, Vitisidaea vitisidaea, Oxycoccus oxycoccus, Arctous alpina, and Betula nana.

On the southwest shores of Hudson Bay this zone occupies a strip about 200 mi. in width. Thence its southern boundary extends inland, passing through Athabaska Lake, and then bending northward crosses Great Slave Lake just east of the mouth of Slave River. Practically all of the northern shore of Great Slave Lake lies within its limits. Beyond here its lower boundary is very uncertain. It is bounded by a strip of well wooded country, probably only a few miles in width, extending northward along the Mackenzie. This southern influence ceases to be effective near the mouth of Bear River, and the southern limit of the zone may be considered to cross the Mackenzie near latitude $65^{\circ}$. Thence it bends southward, following the western border of the Canadian strip. Here, as on the eastern side, the position of the boundary is unknown, but because of the great altitude of most of the country west of the Mackenzie and north of the Liard the southern heavy timber (Canadian Zone) can not extend far from the river and the stunted timber (Hudsonian) must cover nearly the entire area, exclusive of the alpine summits of the mountains. A large area to the south of the Liard, including most of the country drained by its southern tributaries, and practically all the country about its headwaters in northeastern British Columbia and southeastern Yukon below the timberline, are also in this class. The latter area will be considered more fully later.

\section{Barren grounds (Arctic Zone).} North of the Trans-continental Forest lies an immense area usually called the Barren Grounds, from its treeless condition, which results from a summer so short that reproduction can not be effected. This condition, however, does not prevent the perpetuation of many species of shrubby and herbaceous plants and a rich insect fauna, which together support a great variety of vertebrate life.

Shrubby plants are common, Rhododendron lapponicum, Cassiope tetragona, Dryas integrifolia, and several dwarf willows being perhaps the most characteristic. Many other less strictly representative plants also are abundant. The area is further characterized by the presence of certain mammals, as the lemmings of the genera Lemmus and Dicrostonyx, the Arctic fox (Alopex lagopus innuitus), musk-ox (Ovibos moschatus), Barren Ground caribou (Rangifer arcticus), and Arctic hare (Lepus arcticus canus). Most of the birds which characterize this area are migratory, spending only the breeding season within its boundaries. They comprise, among the Anatidae, the various species of the genus Chen, the brent geese, and one or two genera of maritime ducks; and among the Limicolae, the genera Lobipes, Phalaropus, Macrorhamphus, Pisobia and related genera, Crocethia, Tryngites, Numenius (hudsonicus and borealis), Squatarola, Pluvialis and Arenaria. The Gallinae are represented by willow and rock ptarmigans, the Raptores by the gyrfalcons, and the Passeres by the Snowflakes, Lapland and painted longspurs and the pipits.

D. Local conditions. 1. The larger rivers, the Athabaska, Peace, Slave, Mackenzie, and Liard, have a moder- 
ately swift current and are usually muddy, especially in spring and at times of high water, when the clay banks are cut down by the flood. Their courses are characterized by a series of long alternating curves, with cut banks on the concave sides, and gravel bars opposite. Spruce trees usually line the high banks, and willows, alders and poplars the lower younger shores. Many islands usually wooded, occur.

2. Lakes are numerous especially in the area of primitive rocks, and are of course bordered by rocky and sandy shores, and contain many islands. The principal ones form a more or less connected system, part of a series extending from Lake Superior to the Arctic Sea. These lie along the junction of the primitive or granitic and the newer limestone formations, usually heading in the primitive belt and outletting in the limestone district. They are of irregular shape, usually sending long arms eastward into the primitive formation and north and south along the junction of the two systems, though in some cases the southern arms have been filled by the sediment-bearing streams which enter them. In addition to the large lakes thousands of smaller ones are scattered over the entire region.

3. Marshes are numerous and in several cases very extensive. The more important of these will receive detailed attention in the proper places.

4. Fire-swept areas are all too common. In the case of coniferous woods, a growth of deciduous woods usually succeeds.

\section{PRESENT BIOTA}

Apart from the general reduction in numbers of the game and fur bearing animals, and the game birds, due to partial settlement, the changes in the fauna of the wooded parts of the region are mainly chargeable to fire, which has profoundly changed large areas. Some sections have been reburned, sometimes repeatedly, and in such the forest covering may be entirely destroyed, and grassy prairie may succeed. Coniferous areas which are burned usually change to the deciduous type, and this change in type of forest is of course accompanied by the ingression of certain birds and mammals which were originally absent. The most conspicuous mammalian examples are the mule deer (Odocoileus hemionus), which, within the past century, has extended its range northward for several hundred miles. The coyote also (Canis latrans), aided perhaps by partial settlement within its former habitat, has effected an extension of its range even more notable. Among birds, it is certain that the rose-breasted grosbeak (Hedymeles ludoviciana), has traveled northwestward upwards of 500 mi., and there is reason to suspect that several other species of small birds have entered the region of the lower Athabaska within historic times. This ingression, probably caused in part at least, by the changes referred to, has not been accompanied by the loss of any species excepting the elk (Cervus canadensis), although many mammals, notably the larger game animals and especially the fur-bearers, have suffered great reduction in numbers, and two others, the northern bison (Bison $b$. athabascae), and the musk-ox (Ovibos moschatus), have had their ranges greatly reduced. These reductions and losses, however, it should be emphasized, can not be charged to changes in the character of the forest cover, but are rather in line with the usual reduction of the large animals which follow partial settlement and the exploitation of the natural resources of a region.

Along the Arctic coast of Alaska and Canada, the presence of whaling and trading ships has resulted in great diminution of the game animals. Since about 1896, when the whalers begun to winter at Herschel Island and Baillie Island, and a few years later at Langton Bay and in Coronation Gulf, the effect has been serious. These vessels depend largely on the game resources of the country for subsistence, hiring the natives as hunters. This has resulted in the practical extermination of the 
caribou along the entire coast of northern Alaska and Yukon, and great reduction in their numbers east to the region of the Coppermine. During the same period the musk-ox has been extirpated from most of its former range from Coronation Gulf westward.

\section{NATURAL DRAINAGE AREAS AND} PHYSIOGRAPHIC REGIONS

\section{The Mackenzie and Upper Yukon Basins}

In any description of northern North America from the standpoint of the traveler one must be guided in his method of treatment by its waterways, which now, and which probably will for many years to come, afford almost the only means available for visiting its most interesting sections. Thus considered, the valley of the Mackenzie is by far the largest and most important of the natural divisions. Broadened to include certain areas not actually drained by this great river system, but which can most readily be reached by its help, it comprises a vast region in the northern part of Canada, with an area of nearly 700,000 sq. mi., bounded roughly as follows: On the north by the Arctic Ocean; on the east by the valleys of the Great Fish, Thelon, Telzoa, and Churchill rivers; on the south by the Churchill and Saskatchewan valleys; and on the west by the main range of the Rocky Mountains.

For convenience of reference the Mackenzie basin may be divided into several areas: The Athabaska Valley; the basin of Athabaska Lake; the Peace River Valley, including the Slave; the basin of Great Slave Lake; the Mackenzie Valley proper; the basin of Great Bear Lake; the region to the north of that body of water, and drained by the Anderson and smaller rivers which enter the Arctic Ocean, and the Liard River Valley. The areas will be considered in the order given. These accounts will be followed by a description of northeastern British Columbia and Yukon, comprising the drainage areas of the
Upper Liard and Yukon rivers, and of the Stikine and other rivers which reach the Pacific in middle British Columbia.

A. The Athabaska Valley. The Athabaska River rises in the Rocky Mountains near Mount Brown, at an altitude of about $5700 \mathrm{ft}$., and pursues a northeasterly and northerly course for nearly $600 \mathrm{mi}$. to Athabaska Lake, falling in this distance some $5000 \mathrm{ft}$., and being interrupted by several series of rapids. In the first $300 \mathrm{mi}$. of its course it falls about $4000 \mathrm{ft}$., and receives in succession Baptiste River from the west, the McLeod and Pembina from the south, and the Lesser Slave from the west. Below its confluence with the last-named stream the Athabaska turns southeastward for some $50 \mathrm{mi}$. and then resumes its northerly course. In the course of the next 150 mi. it receives in succession La Biche River, Quito or Calling River; Big Mouth Brook; Pelican River; and House River. Just below the mouth of the last river the Athabaska strikes a range of low hills, and in forcing a passage through them is deflected eastward, and for a distance of about $75 \mathrm{mi}$. contains many rapids, falling in this distance some $400 \mathrm{ft}$. At the lower end of this stretch it receives the waters of Clearwater River, its principal tributary below Lesser Slave River. The Clearwater rises on the height of land between the Churchill and the Athabaska, and 30 or $40 \mathrm{mi}$. above its mouth it is joined by the Pembina, a stream of about equal volume.

The country drained by the Athabaska is mainly a rolling plain, and with the exception of a few areas of semiprairie land is well wooded with a forest composed mainly of spruce, fir, pine, tamarack, poplar, birch, and willow. A large part of its surface is occupied by mossy swamps, called muskegs, and hundreds of lakes, of which Lesser Slave, $70 \mathrm{mi}$. in length is by far the largest, occupy its shallow valleys.

The country lying between the Athabaska and Peace rivers, and drained in part by the latter stream, may be best characterized by quoting in part the 
account by McConnell, who examined it in the summer of 1889:

The country between the Peace and Athabasca rivers north of Lesser Slave Lake, comprising an area of about 44,000 sq. mi.,. . . may be described as a gently undulating wooded plain, diversified with numerous shallow lakes, muskegs and marshes. Small prairie patches, manifestly due to forest fires, occur north of the west end of Lesser Slave Lake, at several points along the Loon and Wabiscaw rivers, - but their total area is relatively insignificant.

The rolling plains between Peace River and the Athabasca are relieved by several high ridges or plateaus, all of which owe their origin to a differential denudation of the soft rocks on which the plains are based. Of these Marten Mountain is situated northeast of ILesser Slave Lake, above which it rises to the height of about $1000 \mathrm{ft}$. The Buffalo Head Hills commence abruptly about $50 \mathrm{mi}$. above the mouth of the Loon River, with an elevation of about 2500 ft. above the Sea, and running in a south-southwesterly direction die away opposite the mouth of Battle River, while Birch Mountain extends for nearly $90 \mathrm{mi}$. along the lower part of the Athabasca, from which it is separated by a plain 15 to $20 \mathrm{mi}$. wide. Among the smaller elevations are Trout Mountain, which is situated north of the Wabiscaw River, and the Thickwood Hills, which lie south of Birch Mountain. The uplands of the district, like the lowlands, are all wooded, and are dotted everywhere with lakes and marshes. (Ann. Rept. Geol. Surv. Canada, V, pp. 6D, 7D, 1893.)

Climatology: The climate of the Athabaska Valley in common with most of the country included in the Mackenzie basin, is characterized by a wide range of temperature. In winter the mercury frequently reaches $-40^{\circ}$, while summer temperatures of between $80^{\circ}$ and $90^{\circ}$ are not infrequent. Its western portion is subject to Chinook winds, which periodically temper the climate.

Of vital interest to the traveler, who must depend so largely on water transportation, are data on the freezing and breaking up of the rivers. In all northern rivers navigation is interrupted, before the actual closing of the stream, by drift ice. This is mainly ice which has formed in the eddies and which, by a slight rise of water, the usual result of its formation, or from the accumulation of snow upon it, becomes detached and descends the current, continually adding to its own volume. This continues until the increasing cold causes the mass to jam and become solidly cemented. After the breaking up of the rivers in spring the ice, of course, continues to run for a longer or shorter period.

The following table shows the dates of the opening and closing of the Athabaska at Fort McMurray during a series of years:

Table showing condition of Athabaska at Fort McMurray

\begin{tabular}{|c|c|c|c|}
\hline YEAR & $\begin{array}{c}\text { RIVER } \\
\text { OPENED }\end{array}$ & ICE DRIFTING & RIVER CLOSED \\
\hline 1878 & Apr. 18 & Oct. 27 & \\
\hline 1879 & & Oct. & Nov. 1 \\
\hline 1880 & May 2 & Nov. 14 & \\
\hline 1881 & Apr. 21 & Oct. 14 & Nov. 12 \\
\hline 188 & Apr. 24 & Nov. 1 & Nov. \\
\hline 1883 & Apr. 25 & Oct. 30 & Nov. 10 \\
\hline 1884 & Apr. 27 & Oct. 18 & Oct. 28 \\
\hline 1885 & Apr. 9 & Oct. 23 & Nov. 13 \\
\hline 1886 & Apr. 16 & Nov. 4 & Nov. 14 \\
\hline 1887 & Apr. 27 & Oct. 22 & Oct. 24 \\
\hline 1888 & May 4 & Nov. 3 & Nov. 9 \\
\hline
\end{tabular}

B. Athabaska Lake Region. Athabaska Lake is long and narrow and lies in a general easterly and westerly direction. Its greatest length is about 195 mi.; greatest width, $35 \mathrm{mi}$.; and area, approximately $2850 \mathrm{sq}$. mi. Its elevation above the sea is about $690 \mathrm{ft}$.

The principal tributary of Athabaska Lake is the river of the same name, just described. Its capacity for deposition is so great that, assisted by the Peace, it has filled up a large portion of what was originally the western part of Athabaska Lake, and has isolated several good-sized sheets of water, the largest of which, Lake Claire, is some $35 \mathrm{mi}$. in length.

The north shore of Athabaska Lake is mainly rocky and sparsely wooded, and is broken by the mouths of a number of insignificant streams, which help to drain the unexplored country to the 
northward. On its southern side, whose shores are mainly low and sandy, Athabaska Lake receives the waters of William, Grand Rapid, and several smaller rivers.

Black River, draining a very large area of rocky, sparsely wooded country, flows into the extreme eastern end of Athabaska Lake. Black Lake, the principal expansion in its lower portion, receives the waters of Chipman and Cree Rivers.

The climate of Athabaska Lake is not radically different from that of other parts of the Mackenzie region which are practically removed from the influence of the warm Pacific winds. Though it lies at a low altitude, the proximity of the lake to the Barren Grounds, from which winds are frequent, keeps its average temperature rather low. An occasional warm west wind slightly tempers the winter climate. The Peace and Athabaska break up at their mouths about the 1st of May, but the neighboring part of the lake usually does not open until about the middle of May, and the eastern part probably not before June. The lake usually closes at Fort Chipewyan some time in November.

C. The Peace River Valley. Peace River is the largest of the affluents of the Athabaska-Mackenzie system, and being in fact much larger than the Athabaska, may be considered the main river. It rises on the western side of the Rocky Mountains and is already a a good-sized stream when it breaks through that range.

From the confluence of the Finlay and the Parsnip, the Peace flows in a general easterly direction for some $300 \mathrm{mi}$. to its junction with the Smoky, falling in this distance a little less than $800 \mathrm{ft}$. The country through which it flows east of the mountains may be considered as a plateau, in which it has excavated a rather deep valley. Back from the river the country is mainly level or rolling, and is thinly wooded.

Smoky River is the largest tributary of the Peace. Its principal branches rise on the eastern slope of the Rocky
Mountains, and it drains a large extent of thinly wooded and prairie country.

Below the mouth of the Smoky, the Peace turns and pursues a winding though general northerly course nearly to Fort Vermilion. It is bordered at first by steep sandstone cliffs, but its valley gradually becomes wider and shallower. Extensive plains, comparatively level and clothed with grass or a sparse growth of poplars, border it on both sides. North of Fort Vermilion this character of country is said to extend to the valleys of Hay and Buffalo rivers.

Between Fort Vermilion and the Peace-Athabaska Delta the Peace is very broad and contains many wooded islands. Vermilion Falls, a formidable rapid, interrupts navigation a short distance above the mouth of Red River, and another, usually called the "Little Rapid," occurs at some distance below.

The Quatre Fourches, an offshoot of the Peace, connects that stream with Athabaska Lake, and few miles below, Rocher River also joins the Peace. These streams traverse the Peace-Athabaska Delta, and their currents run to or from Peace River, being dependent on the relative heights of the water in Peace River and Athabaska Lake. The delta is a vast marsh, partially wooded with poplars and willows and studded with hundreds of reedy lakes. This marsh is one of the most important breeding areas of waterfowl in North America, and is also one of the principal resting and feeding places for migratory wildfowl on their semi-annual journeys. Of the breeding birds, the following may be noted: Holboells grebe, horned grebe, black tern, American merganser, mallard, baldpate, green-winged teal, shoveler, pintail, canvasback, lesser scaup, ringneck, American goldeneye, bufflehead, Canada goose, little brown crane, sora, Wilson snipe, yellowlegs, alder flycatcher, yellow-headed blackbird, northern redwing, rusty grackle, Leconte's sparrow, Nelson's sparrow, Lincoln's sparrow, swamp sparrow, Alaska yellow warbler, Grinnell's water 
thrush, redstart, and olive-backed thrush.

Below the delta the combined stream, here called the Slave, turns abruptly northward and flows for a distance of about $70 \mathrm{mi}$. in a general northerly direction to the Smith Rapids. It is a broad, rather deep stream with a moderate current, and its low banks are well wooded. In latitude $60^{\circ}$ it cuts through "a gneissic spur from the Luarentian district to the east," forming the Smith Rapids, some $16 \mathrm{mi}$. in length. Below here it flows in a rather irregular manner for about 175 mi. in a general northwesterly direction to Great Slave Lake. In this stretch it has an average width of about half a mile, and its banks are high at first, but gradually diminish. The country bordering it is level and mainly well wooded, but to the west are extensive tracts of prairie, especially in the region of Salt River, its principal tributary. Slave River enters Great Slave Lake through an extensive delta, in forming which it has silted up an extensive arm of the lake. Its breeding birds are practically the same as those of the Athabaska delta.

The Peace River Valley, as here considered, exhibits the greatest diversity of climatic conditions at the same season of any of the regions now under discussion. Its extreme upper portion, lying at a comparatively low altitude and near the Pacific, has a relatively mild winter climate, while its lower part at the same season is surrounded by almost Arctic conditions. Its middle part, just east of the mountains, seems to be characterized by violent extremes of temperature.

Preserved areas: Wood Buffalo Park: An area lying west of Slave River, partly in Alberta and partly in Mackenzie, known by this name, was set aside in December, 1922, as a Preserve for the resident herds of the northern race, known as the wood buffalo, which now constitute the only wild specimens of this race in existence. This area, which includes the entire ranges of the two aggregations of herds, covers an area of about 10,000 sq. mi. It covers that part of the primitive range of this northern race, formerly much more wide-spread, on which it has been able longest to maintain itself against the persecution attendant on the partial settlement of the country, and which therefore may be considered as the most favorable portion of that range under modern conditions. It contains considerable wooded and swampy country, but is mainly characterized by its areas of meadow and prairie and sparsely-wooded glades. The number of the animals now remaining is not definitely known, but probably numbers several hundred. Many moose, a few woodland caribou, and many fur-bearers, besides grouse, ducks, and the usual birds of the country, abound on this area. These may still be hunted by the natives.

The buffalo has been protected on this area for about 20 years, but the establishment of this preserve, with its attendant warden service, should ensure the continued increase of these unique herds, which under the inadequate protection which has heretofore been possible, have not increased as they should.

Slave River Preserve: This area, which contains about 2200 sq. mi., includes a broad strip of country bordering the lower part of Slave River, and adjoining the Wood Buffalo Park for some distance. The country is mostly low and swampy, and comprises the delta of Slave River and the area between that and the Taltson, and is the breeding ground of thousands of geese, ducks, rails, cranes, and other water birds, and is also the resort in spring and autumn of vast numbers of the same and other species, where they linger to rest and feed while on their migrations to and from their more northern breeding grounds. Natives only are allowed to hunt on this area.

D. Great Slave Lake. Great Slave Lake is said by McConnell to have a superficial area, including islands, of about 10,400 sq. mi., and thus to rank fifth among the great lakes of the 
continent. $^{2}$ It has a total length of nearly $300 \mathrm{mi}$., and is over $60 \mathrm{mi}$. wide in its broadest part. Its shore lines have remained unexplored, especially as regards its eastern arm, until recent years. Maps issued in 1923 by the Topographical Surveys branch show details of this portion, excepting a few comparatively short stretches.

The eastern part of the lake is much deeper than the western part, and its water is very clear, as is also that of the northern arm. The main or western part of the lake, which receives the sediment-laden flood of Slave River, never becomes so clear, although it is fairly so at its outlet. Its southern shores are very low; its northern borders higher. It has few islands, and the rocks on its shores are largely limestone.

Great Slave Lake lies wholly within the forested region, though some of its eastern affluents drain large areas of treeless country. Its southwestern shores are well wooded, while the northern shores, exposed for most of the year to cold winds from the north and watered by colder streams, are poorly wooded. The soil conditions are more favorable on the southern side of the lake, exerting a marked influence on the foresting. In general it divides the southern heavy timber from the northern stunted forest.

On the Eastern Arm of the lake, however, the conditions in this respect are more nearly uniform. Several streams, the courses of some of which are practically unknown, enter this arm on the southern side. Hoarfrost River, draining Walmsley Lake, and Lockhart River, carrying the waters of Mackay, Aylmer, Clinton-Colden, and Artillery lakes, which lie almost wholly in the Barren Grounds, fall into this arm near its eastern extremity. The country bordering its northern shore is rocky and sparsely wooded, and contains a great many lakes.

The Northern Arm of Great Slave Lake

2 It is exceeded in size by Superior $(31,500)$, Huron $(23,000)$, Michigan $(22,300)$, and Great Bear $(11,400)$. [McConnell.] lies along the junction of the primitive and the newer formations. Its eastern shore, therefore, is mainly composed of granite, while its western border is of limestone. Yellowknife River enters this arm on its eastern side. At the head of the Northern Arm, in an expansion named Lake Marian, or Lac du Brochet, Grandin River discharges its waters. To the westward of the Northern Arm and north of the main body of Great Slave Lake lies a low, broad plateau, dotted with many lakes and muskegs. It contains no rivers of consequence and is mainly rather thinly wooded, though a number of large prairies occur in the western part, north of the outlet of Great Slave Lake.

The country south of the main part of Great Slave Lake is mainly flat and swampy. Eagle Mountain, a low, isolated range, lies a short distance south of the extreme western end of the lake. The principal stream is Hay River, which rises close to the height of land between the Nelson and the Peace, far to the southwest. The region drained by it is practically unknown, but is reported to be low and swampy and mainly well wooded, though it contains much grassy prairie, Hay River being said to mark the northern limit of this character of country.

Ice forms in the bays and along the shores of Great Slave Lake in late October, and the whole lake, though kept open later by the violent winds, is usually closed by mid-November. The ice, which attains a thickness of 6 or $8 \mathrm{ft}$., usually breaks up in the main or western part about the first of July, but sometimes remains in the eastern part until late July.

Yellow Knife Preserve: An immense area estimated to contain 70,000 sq. mi., extending from Great Bear Lake and the Coppermile River, south to Great Slave Lake and Marten Lake, and thus including much of the hunting grounds of the Yellow Knife and the Dogrib Indians, is now closed to hunting by others than natives. Its principal large game are the moose and caribou. Formerly 
large numbers of musk oxen inhabited the northern and eastern part of this area, but few, if any, of this notable species now remain. Large numbers of a few species of geese and ducks breed within this area, but it does not abound in large marshy tracts which form the favorite nesting places of waterfowl.

$E$. The Mackenzie Valley proper. The Mackenzie (taken in a restricted sense as comprehending only that part of the river known under this name) has a course of over $900 \mathrm{mi}$. from Great Slave Lake to the Arctic Sea. It averages over a mile in width and is usually deep, with a current of from 2 to $6 \mathrm{mi}$. an hour. Its general course is to the northwest. It is bordered mainly by sandy or gravelly beaches and occupies a narrow, comparatively shallow valley, through which it flows in a succession of gentle curves. Many low islands, usually well wooded, occur throughout its course. Its rocks are chiefly Devonian.

Issuing from Great Slave Lake, the Mackenzie first follows a general westerly course for nearly $300 \mathrm{mi}$. The tributaries which it receives in this stretch, with the exception of the Liard, are of minor importance. The Horn Mountains, a long low ridge lie at some distance north of the middle of the stretch. To the southward occur other lower ranges, the principal one being Trout Mountain. These mountains are very imperfectly known, but they are too low to support a fauna and flora differing appreciably from that of the surrounding country. A large part of the country bordering this part of the Mackenzie is swampy, and it is all well wooded. Nearly all the species of trees of the great subarctic forest are represented.

A short distance north of latitude $62^{\circ}$ the Mackenzie strikes a spur of the Rocky Mountain system, the Nahanni Mountains, is deflected toward the north, and for some distance flows close to their bases. At the point where the Mackenzie first approaches them the nearest peaks are from 200 to $2500 \mathrm{ft}$. in height and are sparsely wooded to their summits. Farther back they rise much higher, and above an altitude of $2500 \mathrm{ft}$. are treeless. In early summer these mountains are capped with snow, but this disappears entirely beneath the almost continuous sunlight of midsummer.

Near this point the fauna receives an infusion of Rocky Mountain types. Among mammals, these include a chipmunk (Eutamias borealis caniceps) common in northern British Columbia and southern Yukon. The Rocky Mountain shrew (Sorex obscurus) also occurs, but has reached also the middle Athabaska and Great Slave Lake, farther south. The white mountain sheep (Ovis dalli) occurs in the Nahanni Mountains at some distance back from the river and also farther north, but is not found near the Mackenzie. Among birds the blue grouse (Dendragapus obscurus), and the Townsend solitaire (Myadestes townsendi) seem to reach their northeastern limit on the mountains near the mouth of the North Nahanni. The northern varied thrush (Ixoreus naevius meruloides) also reaches the Mackenzie near this point, and follows its valley to the delta.

Continuing northward, the Mackenzie is bordered on the west by a broad expanse of mountain country, mainly unexplored. A few low spurs of the same system eross the river and appear in the form of isolated peaks or disconnected ranges to the eastward of its valley. The principal western tributaries between latitude $62^{\circ}$ and $65^{\circ}$ are the Red Rock and Gravel rivers. In the same interval the Mackenzie received several small streams which drain the country east of the river. One of the largest of these is the Blackwater Mount Clark, which is visible from the river at some distance below the mouth of this stream, has an estimated altitude of $3500 \mathrm{ft}$., and is the highest of the mountains east of the Mackenzie. The most conspicuous landmark in the immediate valley is Roche Trempe-l'eau, a limestone mass which rises abruptly from the water's edge a short distance north of latitude $63^{\circ}$. Bear River, the principal eastern tributary of the 
Mackenzie, joins it just south of latitude $65^{\circ}$. Below its mouth, on the north side of the Mackenzie, is Bear Rock, 1400 $\mathrm{ft}$. in height.

Below here the Mackenzie resumes its general northwesterly course. Wolverene Rock, $100 \mathrm{mi}$. below Bear Rock, is formed, like that eminence, by an uplight of the Devonian limestone, and is about $1000 \mathrm{ft}$. in height. Twentyfive miles below here a rocky ridge crosses the river, forming the Sans Sault Rapid. The next important feature in the valley of the Mackenzie is the defile called the "Ramparts." Here the river contracts from a width of $2 \mathrm{mi}$. to about $500 \mathrm{yds}$., and flows for about $7 \mathrm{mi}$. between precipitous limestone cliffs, which in places rise to a height of $250 \mathrm{ft}$.

Below Sans Sault Rapid the Mackenzie recedes from the mountains, and they are not again visible until the delta is reached. Hareskin River enters the Mackenzie from the east a short distance north of the Ramparts. It drains a large extent of rocky wooded country between Great Bear Lake and the Mackenzie. For a long distance below here the Mackenzie maintains a general northwesterly course. In about latitude $67^{\circ} 40^{\prime}$ it turns rather abruptly at right angles, and for about $50 \mathrm{mi}$. follows a course considerably south of west. It is here bordered, especially on the north, by high clay banks, through which several good-sized streams cut their way. The river then turns northward again and maintains a northwesterly direction to the delta. The defile called the "Narrows" or "Lower Ramparts" is encountered near $67^{\circ} 40^{\prime}$, and at its lower end Arctic Red River, from the south, discharges its muddy waters. As far as known the country bordering this part of the Mackenzie on both sides is rolling, well watered, and fairly well wooded. A few miles below Arctic Red River the high banks of the Mackenzie gradually become lower and the river spreads out into the delta.

The Mackenzie Delta occupies a triangular area nearly $100 \mathrm{mi}$. in length and $50 \mathrm{mi}$. broad at its widest part. To the westward of the delta lies a range of high hills, the northern extremity of the Rocky Mountains. They rise to a height of from 1200 to $1500 \mathrm{ft}$., and their lower slopes only are wooded. The Caribou Mountains, apparently a continuation of the ridge which crosses the Mackenzie at the Lower Ramparts, lie to the eastward of the delta. They rise to a height of 700 to $800 \mathrm{ft}$. and are less rugged than the mountains west of the delta.

Climatology: The climate of the Mackenzie Valley is fairly indicated by the tables of temperature which follow. They were taken in 1900, which seems to have been a year of about average conditions.

Summaries of temperatures taken at Fort Simpson, Mackenzie, during the year 1900

\begin{tabular}{|c|c|c|c|c|c|}
\hline \multirow[b]{2}{*}{ MONTH } & \multirow[b]{2}{*}{ 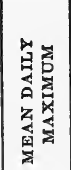 } & \multirow[b]{2}{*}{ 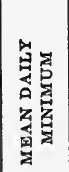 } & \multicolumn{2}{|c|}{ EXTREMES } & \multirow{2}{*}{ 甭 } \\
\hline & & & 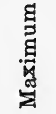 & ב્ּ & \\
\hline January ........... & -16.2 & -335 & 50 & -51.0 & -24.8 \\
\hline February .......... & -9.2 & -33.5 & 140 & -50.5 & -214 \\
\hline March............. & 12.8 & -174 & 390 & -500 & -23 \\
\hline April............. & 41.2 & 178 & 600 & 5.0 & 295 \\
\hline May............ & 52.6 & 35.2 & 66.0 & 270 & 43.9 \\
\hline June............ & 69.3 & 453 & 800 & 27.0 & 57.3 \\
\hline July $\ldots \ldots \ldots \ldots \ldots$ & 69.4 & 45.7 & 79.5 & 31.5 & 57.6 \\
\hline 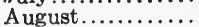 & 65.0 & 44.1 & 78.0 & 27.0 & 54.5 \\
\hline September........... & 56.8 & 34.7 & 710 & 23.0 & 45.7 \\
\hline October.............. & 29.0 & 19.2 & 40.0 & 3.0 & 24.1 \\
\hline November......... & 5.4 & -8.7 & 23.0 & -29.0 & -1.7 \\
\hline December........... & -7.3 & -20.1 & 13.0 & -48.0 & -13.7 \\
\hline Year & & & 80.0 & -51.0 & 20.7 \\
\hline
\end{tabular}

The temperatures of the extreme upper Mackenzie are undoubtedly slightly lower than those recorded for Fort Simpson, but comparable data are not at hand.

Comparable figures for points in the valley of the lower Mackenzie and for Herschel Island show that the winter climate of the upper and lower Mackenzie varies but slightly, while the summer climate is considerably cooler to the northward.

As has been stated, the warm winds 
from the Pacific sometimes exert a decided though temporary influence on the climate of the Mackenzie, and the Liard, opening early, disrupts the Mackenzie ice below the confluence. The removal of the icy covering of an immense river and the blending with its flood of the waters of a warmer tributary necessarily affect conditions along its banks. The ice in the Liard, having broken its bonds, is forced against that of the Mackenzie, through which it opens a passage, and urged on by the immense pressure behind it breaks its way seaward, occasionally becoming dammed and raising the level of the water until the increased pressure again clears a channel. At Fort Simpson, near latitude $62^{\circ}$, the ice continues to drift in quantity for some days after its disruption. About ten days, on the average, after the Mackenzie opens at this point, or about the time that the breaking ice has reached latitude $65^{\circ}$, the upper Mackenzie opens and the channel is filled again with floating ice. Sometimes a third consignment of floes, from the "Little Lake" or from Great Slave Lake, fills its current.

Records of the opening and closing of the Mackenzie at Fort Simpson, kept between 1876 and 1906 (but not continuously) show that the river usually broke up between May 5 and 10 (extreme dates April 29 and May 14), and closed usually about November 20 (extreme dates November 17 and November 28). At the mouth of Bear River the Mackenzie usually opens between May 15 and 20 (extreme dates May 9 and May 28), and closes about November 10 (extreme dates November 2 and November 18).

Seasonal phenomena in Mackenzie Valley, 1903-1904: Following is a brief account of the progress of the seasons and attendant phenomena as observed by the writer from October 1, 1903, to July, 1904. The first three weeks in October were spent in ascending the Mackenzie from Fort Norman, at the mouth of Bear River, to Fort Simpson, at the mouth of the Liard. The fact that these notes were taken while the party was traveling detracts but little from their value, since the conditions in different parts of this stretch of river were nearly uniform at that time. The period from October 20, 1903, to June 1, 1904, was spent at Fort Simpson, and the month of June in descending the Mackenzie to its delta.

When the Mackenzie was reached, on September 30,1903, by descending Bear River, a marked contrast was noted between the conditions left behind at Great Bear Lake and those encountered on the Mackenzie. The temperature was considerably higher, and several species of small birds which had practically disappeared from Great Bear Lake were common. The high mountains to the west of the Mackenzie were covered with snow.

During the first few days of October, as we were ascending the Mackenzie, the weather was mostly fine, with southerly winds part of the time. The nights were frosty and ice formed on still water. The blue flowers of a gentian (apparently Gentiana acuta), the latest flowers observed, were seen on October 3. During the night of October 7 (above Blackwater River) a little snow fell, but it disappeared during the following day. On the night of October 12 (above Fort Wrigley) 4 in. of snow fell, and on the night of October 14 another fall of snow occurred. Some ice was seen drifting on the west side of the Mackenzie on October 15 (above mouth Nahanni River). ${ }^{3}$ On the following day the drifting ice had greatly increased in quantity, and on October 17 our progress by canoe was arrested. At this time the last of the tree sparrows and a few other hardy species left for the South.

Fort Simpson: The Liard was partially closed at its mouth on October 21 , but broke away once or twice before it finally set fast. The weather from October 21 to 25 was considerably milder than it had been during the previous

3 It should be noted that the appearance of drifting ice at this early date was almost unprecedented. 
week, and on the 26th and 27th it became still warmer and the ice practically ceased running. On October 28, however, the weather became colder and the ice again appeared. From this date it continued to run and the snow steadily accumulated. The thermometer did not rise above the freezing point, and consequently there was no thawing, except to a very slight extent in sheltered spots directly exposed to the sun. While the river remained open its expanse of ice-laden water added greatly to the intensity of the cold. From the same cause the trees and shrubs were nightly loaded with ice crystals. On the night of November 7 the minimum temperature recorded was $-10^{\circ}$, and on the night of November 15 a temperature of $-27^{\circ}$ was registered.

During the night of November 18 the river finally set fast. In this process the drifting ice accumulates until it has so filled the river that it jams in some place where it has partially bridged the channel. Against this barrier the oncoming floes, laden with saturated snow, are pushed by the current, and becoming lodged in all possible positions are almost instantly cemented together by the intense cold. This process continues upstream, usually without interruption, until the whole river is closed.

During November and December the cold steadily increased in intensity and the snow gradually accumulated. When no thaw occurs the snow remains so light and powdery that it does not settle appreciably. On the shortest days the sun rose in the southeast about 9.30 a.m. and, after describing a low arc over the tree tops, set about 2.30 p.m. Even at midday its heat was scarcely appreciable. After the middle of December the thermometer scarcely ever rose above zero. From January 1 to March 12, 1904, it rose above zero on only eight occasions. The lowest temperature recorded was $-54^{\circ}$, on January 20 and 21. During the third week in January the average daily maximum was $-30^{\circ}$; the average daily minimum $-45^{\circ}$.
A grave which was dug on February 26, 1904, afforded an opportunity to ascertain the depth to which frost had penetrated. The location was a sandy knoll somewhat sheltered on the north by a thick growth of young trees and open to the south. Snow lay to a depth of about $3 \mathrm{ft}$. The frost had reached a depth of only 20 in., but the excavation was not carried to a sufficient depth to reach the permanently frozen substratum.

On March 26 the temperature first rose above the freezing point and from that date did not descend below zero. When the spring thaw set in the snow had attained a depth of nearly $4 \mathrm{ft}$.

The progress of the season at Fort Simpson from March to June, 1904, as indicated by the temperatures of successive weeks, is shown in the following table:

Temperatures of successive weeks, spring of 1904, at Fort Simpson, Mackenzie River

\begin{tabular}{|c|c|c|c|c|}
\hline & 最舅 & 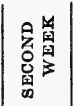 & 量罩 & 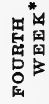 \\
\hline Average of daily maxima: & & & & \\
\hline 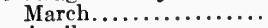 & -2.8 & -2.7 & 9.5 & 30.7 \\
\hline 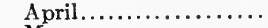 & 39.4 & 42.7 & 46.4 & 57.9 \\
\hline $\operatorname{May} \ldots \ldots \ldots \ldots \ldots \ldots$ & 46.0 & 50.8 & 59.7 & 53.2 \\
\hline June............... & 62.1 & 63.1 & 60.0 & 70.4 \\
\hline A verage of daily minima: & & & & \\
\hline 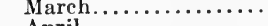 & -25.4 & -26.8 & -16.0 & $\begin{array}{r}3.3 \\
33.5\end{array}$ \\
\hline 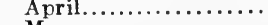 & 11.8 & 23.4 & 23.4 & 33.5 \\
\hline 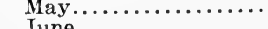 & 30.6 & 33.2 & $\begin{array}{l}38.8 \\
43.8\end{array}$ & $\begin{array}{l}34.5 \\
48.6\end{array}$ \\
\hline June......... & 39.7 & 44.4 & 43.8 & \\
\hline
\end{tabular}

* The "fourth week" includes the last nine or ten days of the month.

On March 19 a flock of white-winged crossbills, evidently migrants, was seen. On March 28 the first hawk owl of the spring was observed, and snow fleas (Achorutes) appeared. About the same time several species of small birds, which had been seen rarely during the winter, appeared in larger numbers. On March 30 the buds and catkins on the willows and alders imparted a brown tinge to the hillsides where these shrubs were common. On the same date snow buntings, which had been absent since the middle of December, reap- 
peared. On April 2 many small grayish moths were seen in the woods. On April 17 a mourning-cloak butterfly (Euvanessa) was seen. By April 18 the snow had nearly disappeared from the fields. Mosquitoes (Culex annulatus) first appeared on April 20, and were biting on April 24, but did not become troublesome until over a month later. The sap of the white birches began to flow freely on April 20. On April 23 a small space of open water was seen near the mouth of the Liard. Frogs (Rana cantabrigensis latiremis) were first observed on April 28.

On April 29 Liard River broke up. Its advancing flood first opened a channel nearly straight across the Mackenzie, forcing the ice with irresistible power up on the opposite bank in immense piles. At the same time a mound 60 or $70 \mathrm{ft}$. in height was formed at the mouth of one of the channels of the Liard, several immense cracks opened in the white expanse before the post, and the huge sheets were soon broken up. The stupendous amount of force exerted by the river upon the broad expanse of ice, $5 \mathrm{ft}$. in thickness, as with a grinding roar it folds and crushes the mighty sheets like cardboard, reducing them to powder and forcing them aloft in great mounds, impresses the beholder, who is likewise occupied in considering the possibility of the river being dammed sufficiently to overflow the ground on which he stands. Such a catastrophe has destroyed more than one post on the Mackenzie in years past.

At this time a few ducks appeared in open places on the river. On May 6 a small quantity of snow fell. The leaves of Ribes oxyacanthoides began to appear on May 8. By this time the river was nearly clear of ice below the mouth of the Liard, but above its mouth the ice in the Mackenzie was still intact. On May 10 large sheets of the Mackenzie ice broke away and floated down, but the river did not open from above until May 13. The water then rose and became filled with ice, but on the following day was nearly clear again and had fallen. On May 10 the leaves on aspens and birches were half an inch in length. About the middle of May blue violets (Viola albertina) blossomed. The weather continued warm and vegetation advanced steadily. On May 18 Virburnum pauciflorum and Populus balsamifera put forth their leaves, and mountain cranberry (Vitisidaea) was in flower. Birds were now coming fast and additional species were noted daily, but on May 21 the weather turned cold and stormy. This had the effect of retarding the advance of vegetation and the tide of bird migration. On May 22 Ribes oxycanthoides and Calypso bulbosa were in flower. The weather remained cold and stormy during the remainder of the month and the conditions of vegetation and of bird migration remained almost at a standstill. On May 29 several inches of snow fell: Mackenzie below Fort Simpson: On June 1, 1904, I left Fort Simpson, and spent the remainder of the month descending the Mackenzie, my rate of travel keeping pace in general with the advance of spring. The weather during the first few days of June was favorable and vegetation made good progess. On June 2, a few miles below Fort Simpson, the leaves of the tamaracks were just coming out. All along the river more or less ice still lay on the banks, but a few miles above Fort Norman the quantity was astounding. Many of the stranded cakes were upward of 20 ft. in thickness. On June 17, below Fort Norman, a small quantity of snow fell. On June 21, at Fort Good Hope, the leaves on most of the trees were about half grown. On the same date the sun was visible at midnight from a low hill near the post, and many birds were in full song at that hour. For the next three weeks, north of this point, the sun was continually above the horizon. Vegetation now advanced rather faster than our rate of travel northward, but was not at its height when we reached the delta of the Mackenzie on June 30.

Preserved areas: Peel River Preserve: 
This recently established preserve, on which natives only are allowed to hunt, includes a rather long and narrow area lying between Arctic Red River and the Peel River divide north to the Mackenzie delta, being entirely in the Mackenzie district. It contains about $3300 \mathrm{sq}$. mi. Its principal game animal is the moose. Many ducks of several species nest here, but the area is not especially notable as a wild fowl resort.

F. The Basin of Great Bear Lake. A short account of Great Bear Lake may begin with a portion of the description by Richardson, who examined most of its shore line in 1825 and 1826 . He says:

Great Bear Lake is an extensive sheet of water, of a very irregular shape, being formed by the union of five arms or bays in a common center. The greatest diameter of the lake, measuring about $150 \mathrm{mi}$., runs from the bottom of Dease Bay, which receives the principal feeding stream, to the bottom of Keith Bay, from whence the Bear Lake River issues, and has a direction of N.E. to S.W. The transverse diameter has a direction from N.W. by W. to S.E. by $\mathrm{E}$., and is upwards of $120 \mathrm{mi}$. in length. The light bluish-coloured water of Great Bear Lake is everywhere transparent, and is particularly clear near some primitive mountains, which exist in M'Tavish Bay. A piece of white rag, let down there, did not disappear until it descended fifteen fathoms. The depth of water, in the center of the lake, was not ascertained; but it is known to be very considerable. Near the shore, in M'Tavish Bay, forty-five fathoms of line did not reach the bottom. (Narr. Second Exp'd to Polar Sea, Appendix, p. ii, 1828.)

Great Bear Lake, according to the Canadian Geological Survey, has an area of approximately 11,400 sq. mi. and lies $391 \mathrm{ft}$. above the level of the sea. Its shores, with the exception of parts of MacTavish Bay, are rather low. Its southern and western shores are well wooded, while its northern and eastern borders are more thinly forested. The immediate shores are mainly of sand or gravel and are usually devoid of trees, but are well clothed with willows and various ericaceous shrubs and herbaceous plants. In most places along the south shore this treeless stretch is only a few hundred yards in width, and in the bays the forest extends to the water's edge. In the vicinity of Leith Point, however, a treeless area stretches from near MacTavish Bay to McVicar Bay, and extends inland for several miles. On this area the faunal and floral conditions are practically those of the Barren Grounds.

The junction between the primitive or granitic rocks and the limestone formation crosses Great Bear Lake near its eastern extremity. To the eastward of the dividing line the shores are higher, especially around MacTavish Bay, where the mountains approach closely to the shore. The Grizzly Bear Mountain, which occupies the peninsula between Keith and McVicar bays, is upwards of $900 \mathrm{ft}$. high and several hundred feet of its upper portion are devoid of trees. On the opposite side of the lake, between Smith and Keith bays, a broad peninsula is occupied by the Scented Grass Hills, of about the same height and similar in structure to the Grizzly Bear Mountain. The mountains which border MacTavish Bay are so rocky that it is difficult to trace the limit of timber on their sides.

The northern shores of Great Bear Lake are described as mainly low and thinly forested, although the country at some distance inland is better wooded.

The tributaries of Great Bear Lake are comparatively few in number. Dease River, which discharges into the northeastern extremity of the lake, is probably the best known of its feeders. It rises on the treeless height of land between Dease Bay and the lower Coppermine. Several important streams enter the lake from the north. Several others, draining a very large extent of country to the southward, enter MacTavish and McVicar bays. The latter receives also the waters of a chain of large lakes lying north of Marten Lake (which discharges into Great Slave Lake). The country drained by the 
southern tributaries is very rough and rocky, though fairly well wooded, and is traversed in various directions by ranges of low mountains.

G. Region north of Great Bear Lake. North of Great Bear Lake lies an area of considerable size bounded on the west by the Mackenzie, on the east by the lower Coppermine and Coronation Gulf, and on the north by the Arctic Ocean, into which flow most of its rivers. Its southern portion is sparsely wooded; its barren northern part receives narrow tongues of forest along the northward flowing rivers. Its fauna and flora, therefore, are those of the northern stunted forest and the Barren Grounds, about equally divided. Its surface is mainly rolling with some ranges of low hills, and many lakes. Its climate is essentially Arctic.

H. The Liard River Valley. The Liard River has its sources west of the Rocky Mountains, one of its branches rising within $150 \mathrm{mi}$. of the Pacific.

In its upper portion the Liard bears a strong superficial resemblance to the upper Peace, being formed by large north and south trending branches which unite west of the mountains and, like the Peace, cut eastward through the main range of the Rocky Mountains. Fort Nelson River, entering the Liard from the south, is its principal branch east of the mountains. It rises near the headwaters of Pine River (north), and pursues a very tortuous northerly course to the Liard. Below the junction the Liard flows northerly and then northeasterly, still being bordered on the western side by spurs of the Rocky Mountain range. The country east of the lower Liard is mainly low and swampy in character. The valley of the lower Liard is heavily wooded, the largest tree being the balsam poplar (Populusbalsamifera), which here attains perfection of habit, and from which the river is said to take its name. The other forest trees also are those common to the whole region.

The upper reaches of the Liard are most readily reached from the Pacific side, by ascending the Stikine, and crossing the low height of land.

The climate of the Liard River Valley, like that of the Peace, varies widely in the different sections. The upper part of the river, lying west of the main divide, enjoys a climate much tempered by the warm Pacific winds. The upper Nelson River also, the principal tributary of the Liard east of the mountains, lies far to the southward and sufficiently near the Pacific to come within its modifying influence. Unfortunately no exact data regarding the temperature of the upper Liard or the Nelson are at hand; hence the conditions there can not be compared directly with those on its lower course. The average temperature conditions on the lower Liard may be fairly represented by those taken at Fort Simpson in 1900 . The warm westerly winds which reach the valley of the Liard extend their influence as far as its mouth and have been known to cause a pronounced thaw there even in January, the coldest month. This modifying influence is apparent in the character and progress of vegetation, the migration of birds, and in other phenomena. It is especially manifest, however, in its relation to the breaking up of the river and the attendant effect on the conditions along the banks. Furthermore, the disruption of the Liard ice starts that in the Mackenzie also, which thus opens considerably earlier than would be the case were it not affected by its warmer tributary. This, of course, has its natural effect in accelerating the progress of vegetation on the banks of the Mackenzie below the Liard.

At Fort Liard, the river freezes up between the last of October and the middle of November and usually opens about the first of May.

I. Northeastern British Columbia and Yukon. Reference has already been made to the fact that both Peace and Liard rivers rise west of the main ranges of the Rocky Mountains which farther south form a strict watershed, but which are here traversed by these great streams. There results a large area in 
British Columbia which faunally and florally resembles the Mackenzie Basin, but which naturally has derived many of its species from the Pacific slope and the Rocky Mountains. Northwestwardly this area extends to include the valley of the Upper Yukon, whose upper branches interlock with those of the Liard.

The valleys of the Parsnip and the Finlay, which unite to form the Peace, lie in the valley referred to in another account as the Rocky Mountain Trench, which extends in a general north-northwest direction from near the northern boundary of the United States to Yukon Territory. This great valley was plainly formed at a time when the drainage of the region was very different from the present system. The various northward and southward flowing streams which now occupy it are long and comparatively slow-flowing, so that one may travel from latitude $49^{\circ}$ northward to the Yukon without encountering any. extraordinary differences in altitude. Most of the side tributaries of these streams, however, are comparatively short and swift. Farther north the ancient valley holds tributaries of the Liard and the Yukon.

To the west of these rivers lies an elevated region which besides forming a nursery for these eastward-flowing rivers, gives rise to several others entering the Pacific. The mountains of this area comprise many single mountain masses and short ranges disposed in irregular systems, and the numerous streams which drain them flow in all directions. The principal ones on the upper courses occupy broad valleys through which they meander over shallow gravelly beds, but lower down they cut canyons as they approach the main rivers, which occupy deep valleys, sometimes gorge-like in character. This region, lying between the Rocky Mountains and the coast ranges, is considered by Dawson (1891) to be an ancient plateau which has been dissected by glacial action into a region traversed by broad level valleys flanked by moun- tains which are often steep and craggy. It is evident to the most casual observer that these wide flat valleys must have been excavated by some more formidable forces than the comparatively small and shallow streams which now meander through them.

The trees and shrubs of this region are largely those common to the great transcontinental conifer forest, enumerated on earlier pages. The lodge-pole pine here replaces the Banksian pine, however, and certain other trees and shrubs characteristic of the coast region or of the Rocky Mountains are present. Some of these will be noted in the descriptions of the various topographic features. These may best be considered under the several river valleys.

Stikine River Valley: The Stikine River rises in a large irregular mountain mass in about latitude $57^{\circ}$ from which flow also head tributaries of the Finlay, flowing to Peace River and the Arctic, and the Skeena, flowing to the Pacific. Disregarding its smaller head feeders, the Stikine may be considered as rising from a string of three lakes, from which it flows eastward, or directly away from its final destination. Traversing valleys flanked by high mountains it is soon joined by numbers of small branches, and in the first one hundred miles of its course has attained a considerable size, has turned a half-circle northward and westward, and is now started fairly toward its final goal. Here it joins the Ispatseeza which has risen near the same place and has flowed northward and eastward. These streams are of about equal size and divide honors as the head tributary. From their junction the combined river turns to the westward, and receives in succession the Ketatsil or Pitman from the east, the Kilicho from the north, the Klappan from the south, the Tanzilla from the north, and the Klastline or Second South Fork and the Mestua, or First South Fork, from the south. The northerly streams mentioned take their rise close to tributaries of the Liard, while those from the south rise in ranges which 
give birth also to branches of the Nass, the Skeena, and the Finlay.

A typical valley, that of the Upper Ispatseeza, may be described in some detail. It varies from a mile or less to several miles in width. Long stretches, perfectly level, having a gravelly soil covered with a good growth of grass, are frequent, and these often succeed each other as terraces, with altitudinal differences of only a few feet, or may alternate with gently undulating meadows clothed with patches of willows and dwarf birches, or with stunted white spruces, which merge gradually into the fairly well grown forest which covers the sides of the bordering mountains.

These valleys though largely treeless correspond to the stunted forest belt of the Mackenzie and most of their woody plants are the same. With them are found also certain Rocky Mountain plants, including the large blue larkspur (Delphinium menziesii), western anemone (Pulsatilla occidentalis), and the yellow paint brush (Castilleja pallida). Mammals more or less characteristic of these broad valleys are the Osborn caribou (Rangifer osborni), the hoary marmot (Marmota caligata oxytona), the Yukon ground squirrel (Citellus plesius), and the British Columbia lemming (Lemmus helvolus). The most characteristic birds are the willow ptarmigan (Lagopus lagopus) which breeds almost entirely on these brushy meadows, the golden-crowned sparrow (Zonotrichia coronata), and the western tree sparrow (Spizella monticola ochracea).

In these valleys, usually at the sources of streams, sometimes in the forest, and sometimes above the timberline, lakes of clear water occur. About these nest Barrow's goldeneye.

Bordering the valleys a zone of spruce usually covers the lower slopes of the mountains, which are treeless above an altitude of about $5000 \mathrm{ft}$. The summits of the mountains are usually rocky, sometimes craggy and precipitous, but hold many gently sloping meadows and hanging valleys, well-watered and sup- porting an alpine flora of great beauty. The fauna of the peaks include the mountain sheep (Ovis $d$. stonei) and the mountain goat (Oreamnos m. columbianus) which usually, but not invariably, choose different mountains, the hoary marmot, the white-tailed and rock ptarmigan, the pipit, the Alaska horned lark, and the Hepburn rosy finch.

Below the level of these broad valley meadows, where the streams cut their way down to the deeper canyons of the main valleys, the trees are those of the main transcontinental forest, with an infusion of west coast types. Populus trichocarpa replaces Populus balsamifera, and the red-berried elder is occasional in the damper situations. The plants, however, are virtually the same as those of the great interior forest as far down the Stikine as the Little Canyon, below which the flora and fauna changes abruptly to that characteristic of the coast region, elsewhere considered. In these lower valleys and the adjacent slopes up to about $2000 \mathrm{ft}$. (Canadian Zone), certain birds of the Athabaska-Mackenzie region are common, including gray ruffed grouse, yellow-bellied sapsucker, eastern nighthawk, Say's phoebe, alder flycatcher, rusty grackle, Gambel's sparrow, western chipping sparrow, junco, cliff swallow, barn swallow, western warbling vireo, Tennessee warbler, redstart, olivebacked thrush, hermit thrush, with many others. With these are found the following which are mainly confined to the Rocky Mountain region: Hammond flycatcher, Wright flycatcher, violetgreen swallow, Macgillivray warbler, Myadestes townsendi, and Ixoreus naevius meruloides.

Yukon: Yukon, stretching through nearly ten degrees of latitude, and extending from the Arctic Ocean nearly the Pacific, lies between Mackenzie, British Columbia, and Alaska, and sends rivers of considerable size to all of these adjacent regions. 'Its affinities are close to Alaska, owing to its contributions to the Yukon, Alaska's main waterway. 
All of the main head tributaries of this great stream, the Stewart, Pelly, Lewes, and White, together with the Porcupine, rise either within Yukon's borders, or close to them, and drain about fourfifths of its territory. Most of the area remaining contributes to the Liard and Peel.

As might be inferred from the foregoing discussion of its drainage, the Yukon River affords the principal means of access to most parts of Yukon Territory. From Skagway, at the head of navigation on Lynn Canal, the White Pass and Yukon Railway takes one to Whitehorse at the head of steamboat navigation on the Yukon, which may, of course, be easily descended with or without power. From their junctions with the Yukon, the Pelly, Stewart, and many smaller streams may be ascended by small power boats or by tracking well toward the main divide, affording access to alpine areas of large extent. The Frances Lake region, which is drained by Frances River and other tributaries of the Liard, may be reached by canoe from the upper Pelly, or from the Dease Lake region of British Columbia.

Faunally and florally, Yukon has close affinities with both Mackenzie and Alaska. Comparison of lists of plants of the three sections show very few differences. Their mammal and bird faunas are also strikingly alike.

Of the large game animals of Yukon the mountain sheep, found on both the eastern (Mackenzie) and the western slopes of the main Rocky Mountain range, here generally referred to as the Mackenzie Mountains, as well as in many of the ranges to the westward, from southern Yukon north to the Arctic watershed, is probably the most interesting. This animal (Ovis dalli), is found in its typical form in many of the ranges of northern Yukon. To the south it gradually becomes darker, finally merging into the dark race named Ovis stone $i$ of northern British Columbia. Moose, caribou, black and grizzly bears, and (in extreme southeastern Yukon) moun- tain goats, are also found in some numbers.

Most of the small mammals show affinities with both Mackenzie and British Columbia, in varying degrees. The chestnut-cheeked meadow mouse (Microtus xanthognathus), the Hudson Bay jumping mouse (Zapus hudsonius), the Rocky Mountain shrew (Sorex obscurus), and the Yukon chipmunk (Eutamias b. caniceps) are found in both the Mackenzie and Yukon regions. The British Columbia wood rat (Neotoma c. saxamans) is a Rocky Mountain type, extending northward from British Columbia into southern Yukon.

The avifauna of Yukon, especially as regards the smaller land birds, shows close affinities with the Mackenzie Valley. Conspicuous are the following species, most of which probably have a breeding range which is continuous from Mackenzie to Yukon by way of the low valleys tributary to the upper Liard and thus including northeastern British Columbia. A partial list follows: Colaptes a. borealis, Chordeiles virginianus, Empidonax trailli alnorum, Euphagus carolinus, Passerculus sandwichensis alaudinus, Zonotrichia leucophrys gambeli, Junco hyemalis, Petrochelidon lunifrons, Hirundo erythrogaster, Tachycineta bicolor, Vermivora celata orestera, $V$. peregrina, Dendroica aestiva rubiginosa, $D$. coronata, D. striata, Seiurus aurocapillus, S. noveboracensis notabilis, Wilsonia pusilla, Sitta canadensis, Penthestes atricapillus septentrionalis, Hylocichla aliciae, $H$. ustulata swainsoni, $H$. a. pallasi, and Ixoreus n. meruloides. Species which extend northward from western British Columbia include the following: Selasphorus rufus, Pica $p$. hudsonica, Dendroica townsendi, Empidonax hammondi, Zonotrichia coronata, and Tachycineta thalassina lepida. Most of these reach the upper Yukon (Canadian Zone) only.

\section{The Barren Grounds (Arctic Zone)}

Under this heading will be considered the great area lying to the north and northeast of Great Bear and Great 
Slave lakes. It is watered by the Anderson, Coppermine, Great Fish, Thelon or Ark-i-linik, and many smaller rivers. With the exception of Great Fish River all those named are wooded to some extent on their upper portions, but by far the greater part of the area drained by them is treeless. It may be well to trace the northern boundary of the great transcontinental forest from the western shore of Hudson Bay to the mouth of the Mackenzie.

Starting from the mouth of Churchill River, Hudson Bay, the tree line follows the shore closely for a few miles and then curves gently inland. Thence it extends northwesterly, crossing Nueltin, or Island Lake; Ennadai Lake on Kazan River; and Boyd Lake on the Dubawnt. Just north of $60^{\circ}$ on Artillery Lake is the next point where we have a definite dividing line. Between the Dubawnt and Artillery Lake is the valley of the upper Thelon, or Ark-i-linik, along whose banks the forest extends in a narrow line far into the general treeless area. This northward extending tongue of forest will be more fully described beyond.

From Artillery Lake the line extends northwestward to Point Lake, curving toward the southwest in the interval and crossing Lake Mackay south of latitude $64^{\circ}$. From Point Lake, whose shores are practically devoid of trees, nearly to latitude $67^{\circ}$, the banks of the Coppermine are so thinly wooded that the river may be taken as the approximate boundary of the woods. Spruces occur on the Coppermine as far north as the mouth of Kendall River, but are absent from the summit of the divide between there and Great Bear Lake and reappear on lower Dease River. The north shore of Great Bear Lake is thinly wooded and tongues of timber follow the northward-flowing rivers well into the Barren Grounds, on the Wilmot Horton to latitude $69^{\circ}$. The tree line crosses the Anderson north of the same parallel, and thence extends northwest to the mouth of the Mackenzie, probably dipping to the south in the interval, as is usually the case in the areas between rivers. West of the timbered delta of the Mackenzie a considerable area of treeless country occurs.

In general the surface of the Barren Grounds may be described as rolling. The greater part of its area lies within the region of the primitive rocks, and many low granitic hills, some of them with precipitous cliffs, are found. Thousand of lakes, many of considerable extent, and abounding in lake trout, dot its surface. There are vast areas of grassy plains and gentle slopes, on which, during the short summer, the bright flowers of a profusion of shrubby and herbaceous plants lend their beauty to the landscape, and prove the appellation "Barren Grounds" to be a misnomer, though in many parts, from the nature of the soil, there is little plant life. Alders (Alnus alnobetula) occur in a more or less dwarfed condition in favorable places well into the treeless area, and several species of willows, some of which here attain a height of 5 or $6 \mathrm{ft}$., border some of the streams as far north as the Arctic Ocean. These are the only trees which occur even in a dwarfed state on the Barren Grounds proper.

The northward extension of the coniferous forest along the banks of northward-flowing rivers has already been referred to. The most remarkable example of this phenomenon is found on the Thelon, or Ark-i-linik, a stream tributary to Hudson Bay. From a point near latitude $62 \frac{1}{2}^{\circ}$, which is as far south as the river has been explored, and is within the main area of the Barren Grounds, a more or less continuous belt of spruce borders the river as far north as latitude $64 \frac{1}{2}^{\circ}$, a distance of over $200 \mathrm{mi}$. by the river. A few species of woodland-breeding birds follow these extensions of the forest to their limits.

Climatology: No tables of temperature taken throughout the year at any point in the Barren Grounds are available. The winters are, of course, very long and the summers short, with the intervening seasons practically wanting. 
Winter sets in soon after the 1st of September and persists until May, with only a short season of spring. During the short summer the progress of vegetation is very rapid, but the seeds and berries are scarcely ripened before winter again asserts its sway.

Owing to the great thickness of their icy covering, some of the lakes of the Barren Grounds are not clear of ice in backward seasons until July, or even August, when new ice has usually begun to form in still water. They generally break up in late June or early July. The rivers, having the advantage of a current, open earlier than the lakes.

During a residence of about five years at Fort Anderson, on Anderson River, MacFarlane observed the river to set fast on two occasions as early as September 10 , though once it remained open until October 10. In 1857 the Anderson broke up at the mouth of the Lockhart on June 12. At Fort Anderson the dates of the opening of the river were as follows: 1861, about May 15; 1862, May $19 ; 1863$, May $30 ; 1864$, May 31 ; 1865, June 2. During the last days of June, 1864, MacFarlane found nearly all the lakes on the Barren Grounds still covered with ice, though the rivers were open.

In 1821, when Franklin's party started to descend the Coppermine on July 1, the lakes on its upper course were still covered with ice. Apparently the river had opened only a short time before. In 1849 Doctor Rae noted the breaking up of the same river near its mouth on June 28. At this time the leaves of the dwarf birches were out, and the leaf buds of the willows had begun to develop. The lower part of the river remained blocked with ice until July 13.

Preserved areas: Backs River Preserve: This great area containing upwards of 65,000 sq. mi., includes most of the valley of Backs River and north to the Arctic Coast, from Bathurst Inlet east to Backs Inlet. Its natives, chiefly Eskimo, retain the sole right to hunt. This area is the breeding ground of great numbers of the Barren Ground caribou, some of which remain in winter, though many migrate southward at that season. Many musk oxen also are found here, this being the only one of the several preserves recently established which harbors this notable species in any numbers.

\section{The region northwest of Hudson Bay}

This section of country has already been described, in effect, in the account of the Barren Grounds of the Mackenzie region. Its rivers excepting those emptying into Chesterfield Inlet, are not readily navigable. Those parts bordering on Hudson Bay can be reached, of course, most readily by means of that great inland sea, which is itself reached either by way of Hudson Strait, or by means of the several rivers, navigable by canoes only, which enter it from the south and southwest. Railroads, branches of the Canadian National, now take the traveler several hundred miles nearer Hudson Bay than formerly, and as projected will ultimately reach its shores, but at present the journey must be completed by canoe or dog-sled. The waters of Hudson Bay, furthermore, are scarcely nagivable by means of the frail canoes by which the passage of these rapid and shallow streams must be effected, so that access to the region is very difficult. Parts of the country draining into northwestern Hudson Bay, however, can be reached by canoe from Great Slave Lake, though the shortness of the season of open water makes such a journey a very hurried one.

\section{The Arctic Islands (Arctic Zone)}

The Arctic Islands, lying to the northward of the continent of North America, are closely related faunally and florally to the neighboring mainland. Being more northerly and surrounded by an ocean which is frozen over from 6 to 9 months of the year, it follows that both animal and vegetable life include fewer species. They are of course treeless, and their shrubs comprise only a few creeping species, some indeed, the same that inhabit more favorable habitats to 
the southward, but which here, in deference to the influence of the chilling winds and hard-packed snow against which they must struggle, cling closely to their parent earth.

The mammalian inhabitants of the Arctic Islands are few in number. The musk-ox (Ovibos moschatus) occurs only on certain ones, the reasons for its choice being in many cases difficult or impossible of explanation. Its habitat includes the peninsulas and islands northward from the eastern part of its main continental range northeastward to northern Greenland. Another island area comprises Banks Land, the adjacent part of Victoria Island, and the southern part of Melville Island, this aggregate area being isolated from the remainder of its present range. The only other ruminant is the Barren Ground caribou (Rangifer arsticus and related forms), which inhabits practically all the islands, forsaking some of them in winter, but being a year-long inhabitant of most of the area in question. The other land mammals include the polar bear (Thalarctos maritimus), Aretic fox (Alopex lagopus innuitus), Arctic weasel (Mustela arctica), an occasional wolverene (Gulo luscus), the Arctic hare (Lepus arcticus), pied lemming (Dicrostonyx), and the brown lemming (Lemmus). All these are either circumpolar species, or close relatives of such.

The birds of the Arctic Islands are more numerous in species, including most of the genera already listed as breeding on the continental Barren Grounds, and a few which are practically confined as breeders to these uttermost insular lands.

Most of the Arctic Islands are accessible only by sea-going vessels, and can be reached practicably only by way of Baffin Bay and Lancaster Sound, and its various connecting channels. In this category may be included all the islands and peninsulas lying to the north and east of McClintock Channel and McClure Strait, and the northern and eastern shores of Victoria Land and Banks Land. The southern and western shores of these latter insular masses may be reached in ordinary seasons from the west by way of the Arctic Ocean, and Dolphin and Union Strait. The reason for this strict division is the drift ice that usually chokes the western entrance to McClure Strait, which prevented the accomplishment of the Northwest passage when it was first attempted in 1819, and has since almost invariably forbidden the passage of vessels in either direction. In winter and early spring, by Eskimo methods of traveling, these islands are accessible from the west and south, but this method is seldom practicable for expeditions having for their main objective the collecting of natural history specimens.

Plants. Excluding the ferns, grasses, and sedges, the plants of the Arctic Islands include the following:

Tofieldia palustris

Salix arctica

Salix glauca

Salix richardsonii

Salix alaxensis

Salix reticulata

Polygonum viv parum

Oxyria digyna

Silene acaulis

Lychnis apetala

Lychnis affinis

Stellaria longipes

Stellaria humifusa

Cerastium alpinum

Helianthus peploides

Alsine verna rubella

Caltha palustris radicans

Anemone richardsonii

Ranunculus hyperboreus

Ranunculus pygmaeus

Ranunculus sulphureus

Ranunculus nivalis

Ranunculus affinis

Ranunculus sabinii

Papaver nudicaule

Draba alpina

Draba nivalis

Draba fladnizensis

Draba hirta

Braya purpurascens

Eutrema edwardsii

Hesperis pallasii

Cardamine digitata

Cardamine pratensis

Parrya arctica

Chrysosplenium tetrandrum

Saxifraga rivularis

Saxifraga cernua

Saxifraga hirculus

Saxifraga nivalis

Saxifraga hieraciifolia 
Saxifraga decipiens groenlandica

Saxifraga tricuspidata

Saxifraga aizoides

Saxifraga flagellaris

Saxifraga oppositifolia

Dryas octopetala

Dryas integrifolia

Potentilla pulchella

Potentilla nivea

Potentilla rubricaulis

Potentilla vahliana

Potentilla emarginata

Rubus chamaemorus

Lupinus arcticus

Astragalus alpinus

Astragalus aboriginorum

Oxytropis campestris

Oxytropis nigrescens

Oxytropis arctobia

Hedysarum mackenzii

Hedysarum alpinum

Empetrum nigrum

Epilobium latifolium

Epilobium angustifolium

Hippuris vulgaris

Pyrola grandiflora

Ledum palustre

Rhododendron lapponicum

Loiseleuria procumbens

Cassiope tetragona

Arctostaphylos alpina

Vaccinium uliginosum microphylla

Primula borealis

Androsace chamaejasme

Androsace septentrionalis

Statice armeria sibirica

Phlox richardsonii

Polemonium boreale

Mertensia maritima

Castilleja pallida

Pedicularis lapponica

Pedicularis hirsuta

Pedicularis sudetica

Pedicularis arctica

Pedicularis lanata

Pedicularis capitata

Campanula uniflora

Erigeron uniflorus

Erigeron compositus

Artennaria alpina

Matricaria inodora grandiflora

Chrysanthemum integrifolium

Petasites frigida

Arnica alpina

Senecio palustris

Senecio frigidus

Taraxacum ceratophorum

Crepis nana

Preserved areas. Within the area here classed under the term Arctic Islands, two preserved areas have recently been created by the Canadian Government. These cover the entire areas of Banks Island and Victoria Island respectively.
Like the areas established at the same time in the Mackenzie Basin and along Backs River, hunting and trapping by natives is allowed, but the areas are closed against hunting by white men. This will exclude sportsmen but will still allow the natives to make legitimate use of the game, a vital necessity since the areas in question comprise the hereditary hunting grounds of either Indians or Eskimo, who are almost entirely dependent on the chase for their subsistence, clothing, and equipment.

Banks Island: Banks Island contains an area of about $26,000 \mathrm{sq}$. mi. It was formerly the home of large numbers of musk oxen, but these are believed to be now extirpated. Many caribou are still found, while the Arctic fox is the only fur bearer of importance. The island is also the breeding ground of large numbers of geese, principally snow geese, several species of the more northerlybreeding ducks, large numbers of shorebirds of several species, and ptarmigan.

Victoria Island: The principal large game of Victoria Island is the caribou. The muskox appears not to have inhabited the island, at least within historic times, excepting limited areas near its northern shores where it is still found. Victoria Island has an area of over 74,000 sq. mi., and like Banks Island is the summer home of great numbers of geese, ducks, and shorebirds.

\section{BIBLIOGRAPHY}

The following list includes a few of the more important titles referring to northern North America, excluding Alaska, Greenland, eastern Franklin, and the Ungava Peninsula, with special reference to topography and natural history. In titles by the author here listed $(1902,1908)$, may be found fuller lists of publications relating to most of the areas therein treated.

1795. Hearne, Samuel. A Journey from Prince of Wales's Fort in Hudson's Bay to the Northern Ocean. Undertaken by Order of the Hudson's Bay Company, for the Discovery of Copper 
Mines, a North West Passage, etc., in the years 1769, 1770, 1771 and 1772 . 4to, pp. i-xliv, 1-45s. London, 1795. There is also a Dublin edition, 8vo, 1796, and another London edition, 1807.

Contains, scattered throughout the narrative, many notes on the mammals and birds of the region; Chapter X, pp. 358 458 , treats exclusively of the natural history of the Barren Grounds, and the Great Slave Lake and Hudson Bay regions.

1801 Mackenzie, Alexander. Voyages from Montreal, on the River St. Laurence, through the Continent of North America, to the Frozen and Pacific Oceans; in the years 1789 and 1793. With a preliminary account of the rise, progress and present state of the Fur Trade of that country. 4to, pp. 412. London.

Mackenzie was the first traveler to descend the Mackenzie River; and the first to cross the continent north of Mexico, which he accomplished by ascending the Peace and descending the rivers west of the divide. His narratives of these voyages contain many notes on natural history.

1826 Parry, William EDWard; AND Ross, James Clark. Journal of a Third Voyage for the Discovery of a Northwest Passage from the Atlantic to the Pacific; performed in the years 1924-25, in His Majesty's Ships Hecla and Fury, under the orders of Captain William Edward Parry. 4to, pp. i-xxvii, 1-186; 1-151. (Appendix on Zoology, Ross, pp. 1-151.)

The zoological appendix refers mainly to the natural history of Port Bowen, where the expedition wintered, and other points about Prince Regent Inlet. A few notes on natural history occur in the narrative.

1829 Richardson, J. Fauna BorealiAmericana. Part First. Quadrupeds. 4to, pp. i-xlvi, 1-300. London.

This work, in which the material accumulated on the first two journeys of Franklin and the early voyages of Ross and Parry is elaborated, contains a great deal of informa- tion on the mammals of the Athabaska and Mackenzie region.

1831 Swainson, W., and Richardson, J. Fauna Boreali-Americana. Part Second. The Birds. 4to, pp. i-lxvi, 1-524. London.

This publication was for many years the standard work on the birds of British America.

1875 Petrot, E. Geographie de L'A thabaskaw-Mackenzie et des Grands Lacs du Bassin Arctique. Bulletin de la Societe de Geographie. Pp. 5-42 (July); pp. 126-183 (August); pp. 242-290 (September); with a map of the region from Great Slave Lake northward.

A geographical and general description of the region, based mainly on the explorations of the author, for many years a missionary in the Mackenzie region. Traveling mainly on snowshoes, he visited many remote districts never before explored. The present account and map may be considered the official announcement of some of his geographical discoveries.

1888 Greely, Adolphus W. Report on the Proceedings of the United States Expedition to Lady Franklin Bay, Grinnell Land. [Report of International Polar Expedition.] 2 vols.; pp. 545, 738. Washington.

This expedition left the United States in the Proteus in the summer of 1881 and returned in 1884. Headquarters were established at Fort Conger. In Appendix 129 (Vol. II, pp. 1-10) and App. 131 (Vol. II, pp. 19-37, are given the reports on mammals and birds, respectively. In connection with the notes recorded on this expedition, many recorded by other northern expeditions are given. This is particularly true in the case of birds (Vol. II, pp. 30-37) where the principal notes made by several Arctic observers are summarized in tabular form.

1890 Macfarlane, Roderick Ross. Land and Sea Birds nesting within the Arctic Circle in the Lower Mackenzie District. Transaction 39, Historical and Scientific Society of Manitoba, season 1888-9 (1890).

An annotated list of the birds observed and taken in the Anderson River region, from 
April, 1862, to June, 1865, inclusive; annotations mainly in reference to nesting habits, nests, and eggs.

1893 WICKHAM, H. F. Report on an Entomological Reconnaissance of Southern Alaska and adjacent portions of British Columbia. Bulletin from the Laboratories of Natural History, Univ. of Iowa, Vol. 2, No. 3, pp. 202-233 with 2 maps.

Comparison of the lists of Coleoptera of the Little Canyon, and Glenora, on the Stikine, with those found at the mouth of the river, and at Fort Simpson on the Mackenzie and other interior points.

1900 Osgood, W. H., AND Bishop, L. B. Results of a Biological Reconnaissance of the Yukon River Region (North American Fauna No. 19,100 pages). General Account of the Region; Annotated List of Mammals, by Wilfred H. Osgood; Annotated List of Birds, by Louis B. Bishop.

Relates to a natural history expedition made along the Yukon in 1899.

1902 Preble, Edward A. A Biological Investigation of the Hudson Bay Region (North American Fauna No. 22, 140 pages).

Annotated lists of the mammals, birds, and reptiles and batrachians of the country bordering Hudson Bay on the west and northwest. Account of a natural history expedition conducted in 1900. Bibliography.

1908 Preble, Edward A. A Biological Investigation of the AthabaskaMackenzie Region (North American Fauna, No. 27, 574 pages).

Topographic and historic description of the region, with special reference to its natural history. Annotated lists of mammals, birds, reptiles, and amphibians, fishes, and trees and shrubs; extensive bibliography. Bibliography.

1922 HoLm, Theodor. Contributions to the Morphology, Synonymy, and Geographical Distribution of Arctic Plants. Report of the Canadian Arctic Expedition, 1913-18, part B, vol. 5 , pp. 4B$139 \mathrm{~B}$.

Includes list of species found in Arctic North America with distribution indicated.
1922 Swarth, H. S. Birds and mammals of the Stikine River region of northern British Columbia and southeastern Alaska. Univ. of Calif. Pub. in Zool., Vol. 24, No. 2, pp. 125-314.

Results of a somewhat intensive study of the fauna of the Stikine Valley from its mouth to Telegraph Creek, including discussion of zoogeography.

1923 Dall, William H. Land and Fresh water Mollusks. Harriman Alaska Expedition, Vol. XIII.

List of land and fresh water mollusks of Mackenzie, Alaska, and whole northern part of British America.

\section{ALASKA}

By W. H. Osgood

\section{GENERAL}

Alaska has an area of 590,000 sq. mi. or about one-fifth that of the United States. The main part of it lies between the same parallels of latitude as the Scandinavian Peninsula. Its shores are washed on the north by the Arctic Ocean on the west by Bering Sea, and on the south by the Pacific. Its coastline is very long and much indented, and there are many outlying islands. It is largely a mountainous region, although flatlands of considerable area are found on its northern coast and about the deltas and in parts of the valleys of its larger rivers. In general, the mountains are in two series, northerly extensions of the main continental systems. The Pacific or Coast system follows the coast and curves southward to include the Aleutian Islands. The Rocky Mountain system, continuous from Canadian territory, is parallel in general trend with the coast system but separated from it by a wide plateau through which course Alaska's two greatest rivers, the Yukon and the Kuskokwim.

Notwithstanding its great area and its complex topographic features, including the highest mountains in North America, the greatest glaciers, and some of the largest rivers and forests, 
it is easily divisible into a few general regions in which biological conditions are broadly similar. At least four primary divisions are necessary: (1) the humid and relatively warm southeastern or Sitkan region; (2) the intermediate glacial region lying next to the coast just northwestward; (3) the wooded plateau and mountains of theinterior, and (4) the treeless coast of the Arctic and Bering Sea.

\section{REGIONAL ACCOUNTS}

\section{Southeastern region}

A. Topography. This is the so-called panhandle of Alaska extending from the British Columbian boundary to the vicinity of Lynn Canal and including a narrow strip of wholly mountainous coast and numerous adjacent islands, some of considerable size and also mountainous. The mainland is only $20 \mathrm{mi}$. in average width and is much dissected by long fjords bounded on either side by mountains rising sheer from the water. These fjords and smaller channels are very deep and usually navigable for large vessels. The mountains rise to heights from 5000 to $8000 \mathrm{ft}$. with timberlines from 2000 to $3000 \mathrm{ft}$., the higher elevations mostly to the northward. One large navigable river, the Stikine, breaks through the mountain wall. In the northern part of the region, another river of considerable size is the Taku, but although other streams are numerous, they are all of small size. At the head of some of the inlets and on the higher slopes are glaciers of some size, although small as compared to those found farther north. The evergreen forests, snow-crowned mountains and narrow waterways combine to make the region exceedingly picturesque. The islands of the Alexander Archipelago lie close to the mainland and are similar to it in character, but the relief is generally lower and in many cases the mountains are fully timbered. Some of the islands are quite large, Prince of Wales, the largest, being about $140 \mathrm{mi}$. long and $40 \mathrm{mi}$. wide.

$B$. Climate. The climate of south- eastern Alaska is relatively mild and, in general, is similar to that of the Puget Sound region. In ordinary winters but little snow falls, and severe cold is almost unknown. At Sitka, the mean for February, the coldest month, is $33^{\circ}$ and for August, the warmest, it is $57.2^{\circ}$. The region is subject to much rain and cloudy weather. At Sitka and Juneau, the annual precipitation is about $90 \mathrm{in}$. and at stations farther southeast, annual rainfall may be as much as $130 \mathrm{in.}$ The greatest fall is during the months from September to January and the pleasantest months as well as the warmest are May, June and July. The rains are usually of the soft gentle variety but often continuous for many days and nights at a time.

C. Original biota. Vegetation: Although the region has been inhabited for many years and has been exploited to some extent, its general biological conditions are not greatly changed. The forests are so vast that the consumption of lumber for local purposes has had little effect and no great amount of exporting has yet taken place. This is partly due to the bringing of over 1000 sq. mi. under federal control in the Tongass National Forest. The entire region below an altitude of $2000 \mathrm{ft}$. is heavily grown with coniferous forest. This consists of the giant cedar (Thuja), which is generally distributed; the yellow cedar (Chamaecyparis), mostly scattered except in a few fine stands; the Sitka Spruce (Picea sitchensis), common throughout; the western hemlock (Tsuga heterophylla), very abundant; the yew (Taxus vrevifolia), locally abundant; and the mountain hemlock (Tsuga mertensiana), scarce and local. The important timber tree, the Douglas Spruce (Pseudotsuga), does not occur, its northern limit being reached in British Columbia. Underbrush and herbaceous plants are everywhere very luxuriant, The principal shrubs are Alnus, Ribes, Vaccinium, Viburnum, Menziezia, Gaultheria, and Echinopanax. At higher elevations on the mountains is an alpine flora. 
Animals: A characteristic large mammal is the Sitka deer, generally distributed and very abundant except where reduced by market hunting. Other mammals are brown and black bears, timber wolves, beaver, otters, mink, red squirrels, voles, white-footed mice and shrews. The mountain goat is common on the heights of the mountains of the mainland, but not on the islands. Moose, caribou, mountain sheep, and typical grizzly bears do not occur in this part of Alaska. The sea otter, formerly abundant, is now practically extinct and is the only important element of the fauna of which this can be said. A conspicuous and characteristic bird is the Alaskan bald eagle, recently much reduced in numbers through a bounty directed against it. Water birds, loons, gulls, ducks, and shorebirds are well represented, and among common land birds are the rufous hummingbird, the varied thrush, sooty grouse, Steller's jay, northern raven, pine siskin, rusty song sparrow, and golden-crowned sparrow. Ptarmigan occur in the mainland mountains but only rarely on the islands. Fish are abundant in the waters, and besides several varieties of salmon, there are important fisheries of halibut, herring, candlefish and others. Marine invertebrates abound and in much greater variety than in similar latitudes on the Atlantic coast.

D. Travel conditions. Southeastern Alaska is easily reached by comfortable steamers from Seattle, operating on regular schedules and calling at the ports of Ketchikan, Juneau and Skagway from which connections are often possible with small steamers running to various points among the islands. Independent excursions are made best with power launches or with canoes as sailing is impractical on account of tidal currents. There are no roads and few trails, so all but foot travel is by water.

\section{Glacial coast region}

A. Topography. This region embraces the coast and seaward slopes of the mountains from Lynn Canal to the
Kenai Peninsula. The dominating feature is found in the numerous live glaciers debouching directly into the sea, and numbering nearly 200 , including some of very large size, as the Malaspina Glacier which has an ice area of some 1200 sq. mi. with a front of not less than $60 \mathrm{mi}$. Behind these glaciers and the plain of some $20 \mathrm{mi}$. width on which they lie, rise some of the highest peaks on the continent, Mt. St. Elias (about 18,000 ft.) and Mt. Logan (about 19,500 ft.), being the best known. The eastern coast is mostly icebound and forbidding, but there are harbors and settlements in Yakutat Bay and at Katalla where there is petroleum in Controller Bay. The Copper River, a very large and important stream, has its delta in the western part where the higher mountains recede from the coast. Beyond this is Prince William Sound, an irregular bay of great beauty with several large islands guarding its entrance and the Kenai Peninsula forming its western boundary.

B. Climate. In this region, which also has a relatively equable but colder climate, there is a greater precipitation and more cloudy weather even than in southeastern Alaska. Cold mists or steady downpours are the rule, and bright fine weather is not long sustained at any season. At stations about Prince William Sound, the annual rainfall is from 130 to 190 in. In summer, the temperature is moderate, usually ranging from $40^{\circ}$ to $70^{\circ}$ and scarcely reaching a maximum of $90^{\circ}$; while in winter, the recorded minimum is $0^{\circ}$.

C. Biota. The biological features of this region are mainly negative and it is to some extent connectant between the southeastern region and the Arctic region. Some of the southern forms of life do not continue into it and others which were found in the south on the mountains, are here found coming to the coast.

Vegetation: At altitudes below $1500 \mathrm{ft}$. where soil conditions permit, there is heavy forest growth largely consisting of Sitka Spruce (Picea sitchensis), but also including giant cedar (Thuja), 
and considerable quantities of Alpine hemlock (Tsuga mertensiana). Alders, willows, and cottonwoods also occur and the Devil's Club (Echinopanax) and some of the Salmon berries and other small shrubs persist in diminishing numbers as one proceeds westward. In the eastern part of the region, these forests grow in close juxtaposition to the glaciers and are frequently uprooted and displaced by the slow moving ice. About Prince William Sound, there is considerable good forest consisting mainly. of Sitka Spruce and Alpine Hemlock. Non-arborescent alpine vegetation occupies its usual place above the coniferous, but in much of the heights among the great glaciers there are vast areas without the slightest vegetable growth, only rocks and ice fields.

Animals: The Sitka deer does not extend to the glacial region nor do any of the large game animals of the interior. The only important large mammals are the mountain goat, the great brown bear, and the black and glacier bears. The last is peculiar to the region but is possibly not a true species but only a color phase of the black bear. Small mammals are principally the red squirrel, meadow voles (Microtus), red-backed voles (Evotomys) and shrews (Sorex). Birds include some Arctic types of waterbirds, as murrelets, puffins, etc. Land birds include sooty grouse, ptarmigan, Steller's jay, northern raven, goldencrowned sparrow, and representative subspecies of the song sparrow and fox sparrow. There are no reptiles nor amphibians.

D. Travel Conditions. Regular steamers from Seattle touch at Yakutat, Katulla, Cordova and various points in Prince William Sound. A railroad runs inward from Cordova to mines on the Copper River and a government trail for pack horses leads to the interior from Valdez. The government railroad to the interior has its terminus at Seward on the south side of the Kenai Peninsula.

\section{Interior region}

A. Topographu. This region embraces the vast territory lying beyond the coast barrier ranges, being too irregular for exact measurement but probably covering at least two-thirds of the total area of Alaska. It comprises mountain, plateau and valley. The great Yukon River with its important tributaries, the Tanana and the Koyukuk, course through it and three other large rivers, the Copper, the Sushitna and the Kuskokwim belong mainly to it. Between the rivers are more or less defined mountain ranges, the most important being the so-called Alaskan Range in which Mt. McKinley rises to the height of 20,464 ft. North of the Yukon is another range, the Endicott Mountains, bordering on the Arctic Region, while east of the Copper River is the group known as the Nutzotin Mountains. Elsewhere there are many lower lessdefined ranges and much rolling or broken relief. The principal extensive areas of relatively flat surface are found in the central Copper River valley, the south side of the Tanana River along the base of the Alaskan Range, and about the great bend of the Yukon where it touches the Arctic Circle in the region of the Yukon Flats. In other parts, level land is easily found but not in great uninterrupted areas. In all this region there are scarcely any large lakes although countless ponds and small swamps are found. The large lakes, Iliamna and Clark are too near the edge of the region to be classified as properly belonging to it.

B. Climate. The climate of the interior is relatively dry with great annual extremes of temperature-a long cold winter and a short hot summer. The annual precipitation may be no more than 12 in. and as much as 25 in. is exceptional. Much of this is in showers coming principally in August and September. Snowfall during the winter is not heavy and February, one of the coldest months, is also one of those of least precipitation. The summer climate is delightful, although in certain seasons there may be two or three weeks when it is very hot. Official records, however, indicate that temperatures above $90^{\circ}$ are very rare. From Octo- 
ber to May, there is no month in which temperatures below zero are not recorded. The minimum recorded is $-80^{\circ}$, and temperatures from $-40^{\circ}$ to $-60^{\circ}$ are frequent. For the month of January, the mean for a typical northerly interior station is about $-30^{\circ}$. For the same station the mean for July would be about $65^{\circ}$.

C. Biota. Practically the whole region is in virgin condition. About the small settlements and the few larger towns, the timber has been cut, but in comparison with the whole, these areas are infinitesimal. The game and especially the fur-bearing animals, as beaver and marton, have been much reduced in some parts, but is not seriously threatened while federal regulations are enforced.

Vegetation: Along all watercourses in the interior, there is practically continuous forest consisting of a very small number of species of trees, none of which grow to large size. The principal conifer is the white spruce (Picea canadensis) which is generally distributed, sometimes in pure stands, but frequently associated with deciduous trees which nearly or quite equal the conifers in numbers. The black spruce (Picea mariana) is abundant, but confined mainly to swampy ground. These are the only conifers in the entire region, except the larch (Larix) which has been recorded at a few stations. The balsam poplar (Populus balsamifera) and the aspen (Populus tremuloides) are the common deciduous trees, but the paper birch (Betula papyrifera) is numerous. Alders and willows also are abundant. This forest usually extends only a short distance away from the water courses and the small divides are but sparsely timbered and especially to the northward the timber is restricted to a thin line of trees on the actual banks of the rivers. In the mountains, timber ascends to $1500 \mathrm{ft}$. or more in central Alaska and gradually drops down as it goes northward until finally itdwindles to its limit at practical sea-level. The areas above timber have Alpine floras including plants not found in the lowlands and these areas gradually merge with the Arctic tundra.

Animals: Large mammals include the moose, caribou, white mountain sheep, grizzly bear, black bear, lynx, gray wolf, red fox, marten, mink, weasel, wolverine. Small mammals are mostly Palaearctic types, as voles (Microtus, Evotomys, Synaptomys), lemmings (Lemmus) and ground squirrels (Citellus). The number of species is small, but individuals are often excessively abundant. The birds, likewise, are largely of genera and frequently of species which have a transcontinental range from Labrador to Alaska. They include as breeders the common ducks, geese and shorebirds which pass through the United States as migrants. Northern forms of the ruffed grouse and the Canada grouse are generally distributed and smaller birds include Canada jay, three-toed woodpecker, pine siskin, slate-colored junco, fox sparrow, hermit thrush, and robin. The fauna is almost entirely distinct from that of the coast region although in one place (Cook Inlet), the interior fauna extends to the coast.

D. Travel conditions. The interior is accessible by regular rail and steamship transportation from three principal points. From Skagway, there is rail connection with navigable waters of the upper Yukon in Canadian territory whence the whole Yukon system can be traversed. From Cordova, by rail, and from Valdez, by government trail, the Copper River valley is reached. From Seward on the Kenai Peninsula there is rail connection with Fairbanks and the Tanana Valley.

Flat-bottomed river steamers ply on the Yukon and at least to certain points on its larger tributaries. Canoe travel is largely practiced, and for downstream work, rafts and roughly made wooden boats are successful. There are some trails, but no roads, and overland travel in summer is done with horses or on foot with Indian packers who are available in some places. Winter travel is by dog sled and, aside from other considera- 
tions, this method is preferred for convenience, economy and speed.

\section{Arctic coast region}

A. Topography. This is the treeless coast region of northern and western Alaska, including the Alaska Peninsula and the Aleutian Islands which, at least biologically, belong with it. For practical purposes, it may be defined on the east and south by the irregular line formed by the extreme limit of tree growth, but its general conditions extend, with interruptions, throughout much of the interior region in the elevated areas above timber and in scattered parts of the interior lowlands which, for local reasons, are without trees. It is flat or slightly rolling ground, including the deltas of the Yukon, Kuskokwim, Kobuk and some other rivers of fair size. Elsewhere it is traversed by small meandering streams and dotted with lagoons and small ponds. Its average width is scarcely more than $100 \mathrm{mi}$., but in the north it is continuous with treeless mountains which lie between it and the timbered interior. The Alaska Peninsula and Aleutian Islands consist largely of volcanic mountains.

B. Climate. From the Arctic coast at Point Barrow to the Aleutian Islands, there is considerable range in climatic conditions. The Arctic coast proper is not so warm in summer and not so cold in winter as the interior forested region. The maximum for July and August is about $65^{\circ}$ and the minimum for January and February is about $-55^{\circ}$. Nevertheless, nearly every month in the year may be subject to light frost, and in early June or late August frost is usual. Temperatures on the coast of Bering Sea average somewhat higher, and on the Alaska Peninsula and the Aleutian Islands they never go to extremes. Nevertheless, the means for the four warmest months, effective in controlling the distribution of life, are substantially the same at Unalaska in the Aleutian Islands and at St. Michael on the central coast of Bering Sea.

The precipitation on the Arctic coast is the least of any part of Alaska, averaging only 6 to 8 in. per annum, almost comparable to that of a desert region. The Bering Sea coast has more, 20 to 30 in., and the Aleutian Islands still more, perhaps 80 in., and more rainy days (250) than any other part of the territory.

C. Biota. Vegetation: Although entirely non-arborescent and including relatively few species, the vegetation is profuse. It forms a thick continuous mat over the surface of the ground, including depauperate willows, Vaccinium, Cassiope, Ledum, Arctos, Dryas, and Empetrum. With these are mixed a few grasses and sedges and various mosses and lichens. There are many saxifrages and bright flowered poppies and buttercups.

Animals: The animals are strictly Arctic types. Mammals include the Arctic fox, wolverine, weasel, polar bear, barren-ground caribou, lemming, Arctic hare, walrus, and various seals. The birds comprise many migrating shorebirds, ducks and geese, including the eider ducks. Ptarmigan are generally distributed, and small land birds are reduced to few species, as snow bunting, redpolls, and longspurs. The invertebrate marine fauna is Arctic in character, but quite varied and embraces at least 200 species.

D. Travel conditions. Regular steamers during the summer season from June to September run to Unalaska and Nome. Yukon River steamers also come to the coast at St. Michael, but the Arctic coast northward is reached only by chartered vessel or by special arrangement with a trading or whaling ship or with the government revenue cutter which makes one trip per annum to Point Barrow. 


\section{THE NATIONAL FORESTS OF THE ALASKAN DISTRICT}

\section{By John D. Guthrie}

Although there are over $20,000,000$ acres of National Forest land within the Alaskan District, it is at present divided between only two National Forests, the Tongass and the Chugach.

\section{*tongass national forest}

Area $15,443,000$ acres of coniferous forest, in southeastern Alaska, consisting of a bewildering assortment of islands, surrounded by channels, straits, canals and bays. These islands vary from those containing thousands of acres, whose interiors have never been explored, much less surveyed and mapped, such as Prince of Wales, Baranoff, Chicagof, down to mere green specks projecting above high tide. Generally speaking, the land rises abruptly from the water's edge up to elevations of several thousand feet, timber line being approximately at $2000 \mathrm{ft}$. and the heaviest stands of timber being found near sea level. The country is characterized by a very heavy rainfall but with general climatic conditions similar to the Puget Sound region. The forest consists of approximately $60 \%$ western hemlock (Tsuga heterophylla), 20\% Sitka spruce (Picea sitchensis), the other $20 \%$ being made up of western red cedar, (Thuja plicata), yellow cypress (Chamaecyparis nootkatensis), some lodgepole pine (Pinuscontorta) and a small amount of cottonwood and white birch (Betula, alaskana). There are glacier-fed lakes on these islands, the outlets of which drop in many cases almost precipitously into the sea. The higher peaks are usually snow covered from about October until May; the lower elevations in the forest, however, have a comparatively light snowfall. Navigation is open throughout the year. The conditions prevailing on the Tongass Forest, located as it is in extreme southeastern Alaska, must not be confused with conditions to be found elsewhere within Alaska. The region is one of great interest to the ecologist, to scientists generally, and to travelers. Copper mines, canneries (salmon, shrimp, crab, etc.), lumbering operations, whaling stations, totem poles, water power plants, marble quarries, are abundant and are of extreme interest in addition to the very large number of readily accessible glaciers as well as the interesting relics of the Russian occupation and of the earlier Indian inhabitants. The surface conditions of the Tongass region are characterized by abundant rock, with little or no soil but a vast amount of moss and very heavy undergrowth, with a very dense stand of coniferous forest with swamps or muskegs on bench lands. Magnificent scenery characterizes this entire "pan handle" of Alaska.

The forest is reached by regular boat lines from Seattle and Prince Rupert and has a number of thriving towns in which comfortable hotel accommodations can be found. Supervisor's headquarters at Ketchikan. $\ddagger$

\section{*CHUGACH NATIONAL FOREST}

Area 5,129,544 acres, lying in the Prince William Sound, Cook Inlet and Kenai Peninsula. This forest has not the timber resources of the Tongass and is broken up into several distinct units. Its forest types are practically the same as found on the Tongass although the climatic conditions are somewhat different. The rainfall, however, is somewhat less. On the northern edge of the Chugach are found several species which do not occur on the Tongass namely, white spruce (Picea canadensis), black spruce (Picea mariana) and white birch, species characteristic of the great interior basins of Alaska. Scenically, the Chugach is characterized by tremendous mountain masses, glaciers, large rivers, many lakes and especially on the Kenai Peninsula abundant big game.

The Chugach Forest is reached by regular steamers from either Seattle or Prince Rupert and its principal towns are Cordova, $\ddagger$ Seward $\ddagger$ and Anchorage. $\ddagger$ 
The new government railroad also traverses a portion of the Forest. Supervisor's headquarters at Cordova. $\neq$

\section{*MOUNT MCKINLEY NATIONAL PARK}

Situated in South Central Alaska. Reached from the Cook Inlet country. Area 2200 sq. mi. A snow-clad mountain $20,300 \mathrm{ft}$. high, rising from a rolling plateau peopled with caribou and mountain sheep. Glaciers on southern and eastern slopes. North and west sides drop abruptly to grassy valleys only $3000 \mathrm{ft}$. in altitude. Park created principally to prutect wild animals.

The park includes treeless plateaus rich in mosses and grasses, and fertile valleys rich in flowers.

For more complete information apply to director of National Park Service, Washington, D. C., or to Chamber of Commerce, Seattle, Wash.-G. B. Rigg.

\section{*THE KATMAI NATIONAL MONUMENT}

More than a million acres at the base of the Alaska peninsula, largely devasted by the eruption of 1912 , presenting unparalleled opportunity for study of colonization of volcanic areas by plants and animals $(a)$ the invasion of ordinary pumice plains at air temperature, (b) colonization of hot deposits aruund fumaroles.

Around the devasted areas are many square miles of undisturbed country.

The reservation is located at the geographical edge of the forest. Such animals as the moose, elk, lynx and wolf reach the edge of their range in this district. The northern end of the park is heavily covered with a forest dominated by white spruce (Picea canadensis), with alder, birch, poplar and willow as subordinate trees. Beyond the forest is typical tundra.

It is a lake country with several large and very deep lakes and many small ponds and swamps. These are the breeding grounds of innumerable waterfowl such as ducks, geese, swans, gulls, cormorants, and so forth. The lakes are among the most famous spawning grounds for sockeye salmon in the world.

Reached at present either from Kodiak, $100 \mathrm{mi}$. southeast, or from Naknek, 75 mi. northwest.

At present it is necessary to outfit one's own expedition, which involves considerable expense. The whole country can, however, be made readily accessible by the construction of about $60 \mathrm{mi}$. of automobile road from Geographic Harbor, whichlies in the middle of the reservation at the head of Amalik Bay.-Robert F. Griggs.

\section{AVAILABLE AREAS}

The Copper River Valley (available). Including Arctican and Alpine lands, ice fields, lakes, ponds, streams, conifer forest, inland from the rivers. One finds active and decadent glacier tongues, new made lands and all stages of incoming vegetation from that to the fully established conditions. Most of the large game is gone. Lake Klutina region has splendid beaver colonies. We put a canoe over 20 beaver dams in one-half day. The Copper Valley is easily reached from Cordova by the Copper River and Northwestern Railway. This line runs along the coastal plain $30 \mathrm{mi}$. east from Cordova, follows the river north with frequent crossings to Chitina and then a branch river of the same name to the east $60 \mathrm{mi}$. to Kennicott. Stops can be made almost anywhere.-Henry B. Ward.

Glacier Bay $\dagger$. Many-branched fjord $60 \mathrm{mi}$. long, surrounded by lofty icecovered mountains. Nine tidewater glaciers discharging icebergs (the Muir being the largest) and hundreds of others. Extensive areas laid bare by retreat of ice, the history of which is accurately known; every stage in plant succession from pioneers through alder thicket to spruce-hemlock forest; also areas of very old forest which antedate last glacial advance. Valuable relics (stumps, trunks, lower vegetation) of interglacial forest exposed by erosion of gravels. Subarctic fauna well developed: goat, bear, ptarmigan; abundant salmon in streams. See John Muir: Travels in Alaska.

Juneauf $\mathbb{1}, 70 \mathrm{mi}$. west, gas-boat.William S. Cooper.

Holkham Bay. Typical narrow fiord, with two branches, Endicott Arm and Tracy Arm, each $25 \mathrm{mi}$. long and terminated by glaciers discharging icebergs. Mountains $600 \mathrm{ft}$. high immediately 
adjacent; many fine waterfalls. Ford's Terror, a branch of Endicott Arm, five miles long, a quarter-mile wide, with entrance $300 \mathrm{ft}$. wide; at its head a glacier, recently tidal, now ending on land, also several fine cataracts. Shores of lower bay densely clothed with spruce-hemlock forest; upper portions, especially Ford's Terror, show all successional stages. See John Muir: Travels in Alaska, chapter on "Sum Dum Bay."

Juneauł T, $45 \mathrm{mi}$. south, gas-boat.William S. Cooper.

Knyg Lake. Lake, $1 \frac{1}{2} \mathrm{mi}$. long, $\frac{1}{2} \mathrm{mi}$. wide, draining into Stikine River by outlet stream $3 \mathrm{mi}$. long; surrounded by cliffs $3000 \mathrm{ft}$. high, with several waterfalls; a glacier enters upper end and discharges very large icebergs. All stages in plant succession following glacial retreat; fine display of wild flowers around lower end in early summer. Along outlet stream may be seen all stages of flood-plain succession, from willow-cottonwood, through alder thicket to spruce-hemlock forest.

Wrangell $\ddagger$ T, $25 \mathrm{mi}$. up Stikine River, gas-boat and row-boat.-William $S$. Cooper.

\section{BIBLIOGRAPHY}

Cooper, W. S. The recent ecological history of Glacier Bay, Alaska. I. The interglacial forests of Glacier Bay. Ecology, Vol. 4, pp. 93-128, 1923. II. The present vegetation cycle, Ecology, Vol. 4, pp. 223-245. III. Permanent quadrants at Glacier Bay: An initial report upon a longstudy period. Ecology, Vol. 4, pp. 355-365, 1923. (The first paper cites papers dealing with the geology of the Glacier Bay region.)

Dice, L. R. The land vertebrate communities of Interior Alaska. Univ. of Mich., occ. papers Mus. Zool., no. 86,1920 .

Osgood, W. H. 1909 Biological investigations in Aiaska and Yukon Territory (North American Fauna No. 30, 96 pages). I. East Central Alaska; II. The Ogilvie Range, Yukon; III. The MacMillan River, Yukon. With special reference to explorations made in 1903 and 1904. 


\section{Section 2. Southern Canada and the United States}

\section{A. States, Provinces and Forest Districts, Chiefly Coniferous Forest}

Few or none of the states or provinces are covered exclusively by coniferous forest, and classification is accordingly difficult on any basis. Several types of coniferous forest are included; northern, northwestern mesophytic, southwestern xerophytic, and the montane of the Rockies, Sierras, and Cascades. In addition to coniferous forests Idaho, Oregon, and California include a desert, sage brush, semi-desert, grassland, and considerable areas above timber line; Washington and British Columbia, sagebrush, semi-desert, and grassland, and large areas above timber line; Alberta, Saskatchewan, Manitoba, and Minnesota include popular savanna, and steppe; Ontario, deciduous forest and tundra; Quebec, tundra. The state, national, provincial, and dominion forests included in this section are almost entirely coniferous.-V. E. S.

\section{BRITISH COLUMBIA ${ }^{3}$}

By John Davidson, P. Z. Caverhill, Edward A. Preble and A. H. Hutchinson

\section{General Conditions (P. Z. C.)}

\section{A. TOPOGRAPHY}

British Columbia occupies the northcentral portion of the Pacific slope of North America, which is regarded as the greatest forest region of the continent and the greatest coniferous forest of the world. The Province is a quadrangle about $760 \mathrm{mi}$. long and $470 \mathrm{mi}$. wide. It extends from the 49th to the 60th parallels of latitude and from the crest of the Rocky Mountains westward to

1 Where there was no coöperation between the authors their names are given in the order of the receipt of their manuscripts and parts written by each are indicated in the body of the text. the Pacific. Its eastern boundary follows the axis of the Rockies north from $49^{\circ}$ to $54^{\circ}$, and from there to latitude $60^{\circ}$ it follows longitude $120^{\circ}$. On the west between latitudes $55^{\circ}$ and $60^{\circ}$ it is shut off from the Coast by the long narrow strip sometimes called the "Pan-handle" of Alaska.

The topography is prevailingly mountainous except in the northeast corner, which includes a triangular area of the eastern foot-hills and the great plains east of the Rocky Mountains. The main physiographic features are the series of parallel mountain ranges and intermontane trenches or valleys which extend with a general northwest trend along both the east and west sides of the Province, separated by a central belt of plateau and minor mountain ranges.

The Rocky Mountains on the east are the northern end of the Cordilleran belt which forms the backbone of the continent from Mexico to Alaska. It consists of the upturned edges of the strata underlying the Great Plains on the east, chiefly alluvial and carboniferous limestone. In the southern half of the Province the average height of the peaks is around $8000 \mathrm{ft}$., and the higher peaks range from 10,000 to $13,500 \mathrm{ft}$.; northward the mountains become progressively lower. The average width of the range is $60 \mathrm{mi}$.

Along the western base of the Rockies is the Rocky Mountain trench, a large $\mathrm{U}$-shaped trough from 2 to $15 \mathrm{mi}$. wide, extending $900 \mathrm{mi}$. through the whole length of the Province.

Forming the western rim of the trench is the Columbia system of mountains extending from the United States boundary north to the Fraser River, latitude $53^{\circ} 45^{\prime}$, with an average width of $80 \mathrm{mi}$. 




Fig. 8. Grasslands of British Colombia 


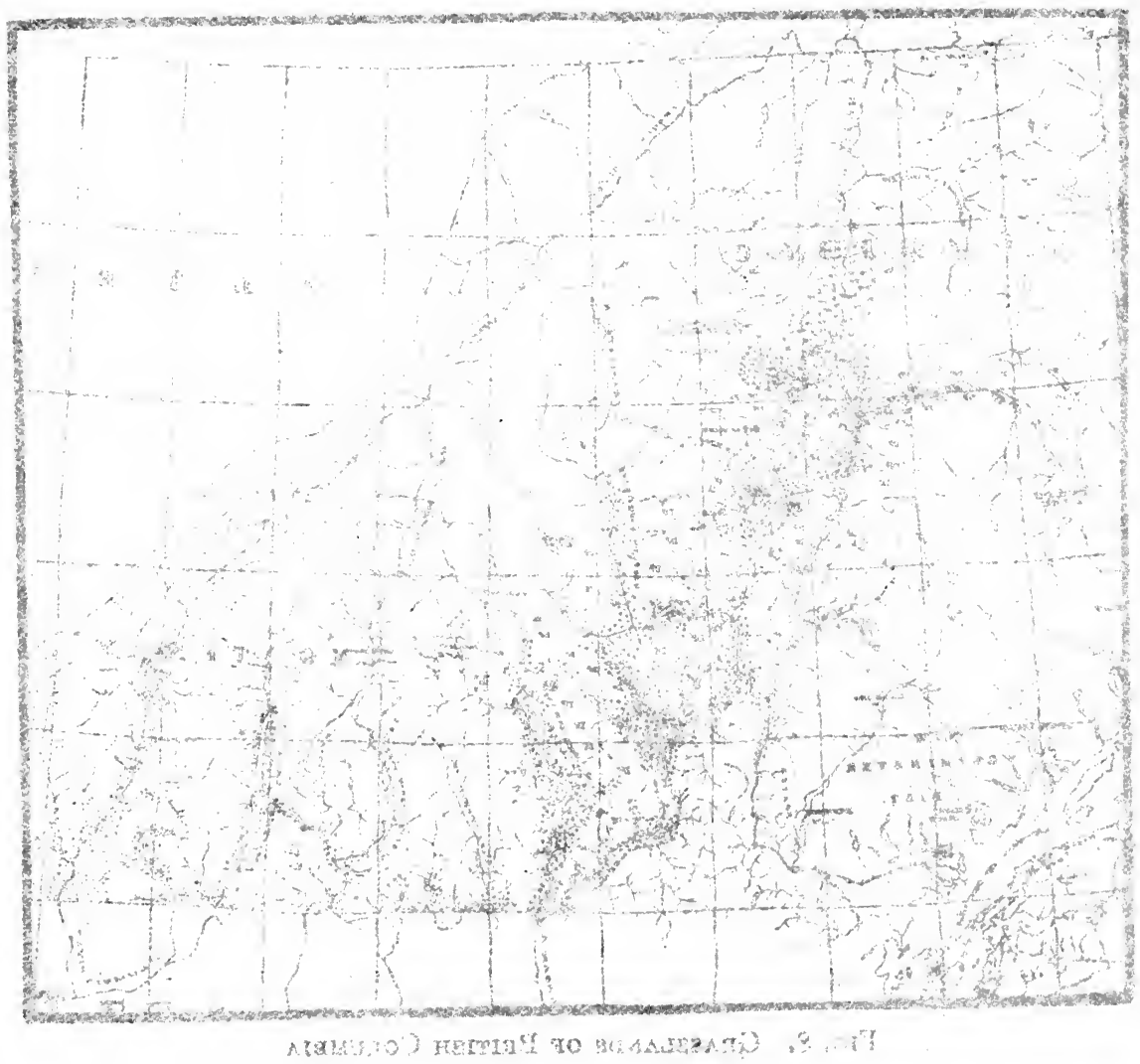


In the south it includes the Purcell and the Selkirk Trenches, each of which is threaded by large rivers and lakes North of these are the Cariboo Range, the Peace and the Stikine Mountains. Geologically the Columbia system represents an earlier upheaval and is formed of an entirely different series of rocks than the Rockies. The average height is almost that of the Rockies.

Within the Rocky Mountain Trench is found the headwaters of most of our important river systems. The Kootenay, Columbia, Fraser; the Parsnip, and Finlay, which unite to form the Peace; and the Kachika and Frances, which form (with the Dease) the Liard, either rise in or flow for some distance through this trench. These streams are mostly glacier-fed and therefore subject to rapid variations in run-off, while their tributaries flowing from the steęper side-valleys are turbulent mountain torrents. These systems, therefore, are not important for log transportation except when diverted and used in conjunction with $\log$ flumes. In the lower courses, however, numerous lake expansions become of prime importance for transportation.

The central regions of the plateau and low mountains, $200 \mathrm{mi}$. wide, merge into the Columbia and Rocky Mountain systems on the east and Coast Mountains on the west. Originally it was a tableland elevated about $3500 \mathrm{ft}$. above sealevel, but it has been so dissected and eroded that from the valley-bottoms it now appears mountainous. Much of the soil is composed of disintegrated lava, which once overflowed large areas, and glacial drift. This plateau is largely drained by the central portion of the Fraser River system. The Skeena and Stikine Rivers drain the northern section, while the south-eastern section is drained by the Okanagan and Kettle Rivers. The characteristic topography is of two types: First, the deep-cut Ushaped valleys with elevation ranging from, 1000 to $2000 \mathrm{ft}$. above sea-level and occupying one-third of the area; second, the rolling upland plateau, 3500 to 5000 ft. in elevation, dissected with V-shaped valleys where the rivers debouch from the uplands into the main valleys. The plateau is generally found covered with glacial drift, while the valleys show distinct evidence of glaciation. The fauna and flora of the greater part of this region resembles closely that of the interior of Canada to the eastward and is discussed in connection with that area. (See pp. 288, 293.)

The coast range forms a barrier between the Interior Plateau and the ocean, 6000 to $7000 \mathrm{ft}$. high and averaging about 100 mi. in width. The mountains are composed of massive crystalline rocks of an ancient period. Lying to the west of the Mainland is a partially submerged mountain range-the Island Range or insular system-now represented by an archipelago of islands, of which Vancouver and Queen Charlotte are the largest. Between this system and the Mainland is the deep submerged Coastal Trench.

The Coastal Trench, like the Rocky Mountain Trench, extends the entire length of the Province. It was formerly a land trench and still appears as such south from Puget Sound. Pre-glacial submergence, however, sunk the main trench and the lower reaches of its tributary valleys far below sea-level, thus forming that remarkable system of straits and fiords which penetrate into the very heart of the Coast Range and which characterizes the British Columbia Coast. Twelve per cent of productive timber area of the Province, containing 65 per cent of the standing timber, is tributary to this trench, which becomes of the greatest economic importance because these submerged valleys form navigable sheltered waterways for the transportation of this timber to mills. Eighty per cent of the timber cut of the Province is derived from timber tributary to the Coast Trench.

During the glacial period the whole Province, except the highest peaks, was covered by a continuous ice-sheet. The 
glaciation and subsequent stream erosion has considerably modified the topography. Valleys were enlarged and lowered, soil deposited, and lakes formed -all matters of importance to forestry, agriculture, and transportation today. The soil is largely formed of these deposits of glacial drift. It is estimated that of the total area about 47 per cent is suitable for agriculture, grazing or the production of timber, while 53 per cent is above merchantable timber-line, is water surface or swamp land, or is incapable of growing timber of any commercial value on account of ruggedness.

\section{B. Climate}

The chief factors for consideration in relation to climate area: Influence of Japan Current; the 11 degrees of latitude through which the Province extends; the extremes of altitude from sea level to 13,500 feet (Mount Robson).

The principal topographic features have a general trend at right angles to the prevailing winds. Warm moistureladen air-currents sweep inland from across the Japan Current, to be chilled as they ascend the western slope of the mountain ranges and are forced to deposit their moisture. As they cross the summit to the warm eastern slope they become comparatively dry, to be again chilled as they cross the next range. The result is alternating wet and dry belts, the wet belts occurring again and again on the main Rockies, while the Interior plateau and the east slope of the Selkirks are comparatively dry. These winds also moderate extremes of temperature. The main climatic regions are as below:

Lower Coast Belt. Characterized by mild, even temperature and a variation of only $30^{\circ}$ between summer and winter mean. The summer isotherm on which the region is situated would pass through Quebec, Edinburgh, and Southern Norway; the winter through New York and London. The precipitation averages 60 to 70 in., of which one third occurs during the summer season; the record of bright sunshine averaging about 2000 hours per year.

North Coast Belt. Averages'some $5^{\circ}$ lower in mean temperature throughout the year and has an increased precipitation, this being 110 in., one-quarter of which falls during the summer season. A part of the winter precipitation falls in the form of snow.

Interior Plateau or Dry Belt. Characterized by greater variations of temperature and a relatively limited precipitation. Typical Stations show:

\begin{tabular}{|c|c|c|c|}
\hline BTATION & 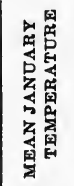 & 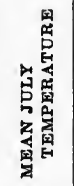 & 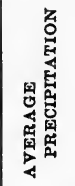 \\
\hline & degrees & degrees & inches \\
\hline Penticton. & 26 & 67 & 11 \\
\hline Kamloops......... & 22 & 69 & 11 \\
\hline 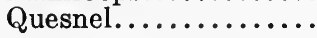 & 14 & 62 & 15 \\
\hline
\end{tabular}

This region is on the same isotherm as Toronto and Central Europe, Warsaw, during January; New York or Paris during July. The record of bright sunshine is 200 and $2200 \mathrm{hrs}$.

Second Wet Belt. This has relatively the same temperature range as the Dry Belt, but greater precipitation.

\begin{tabular}{|c|c|c|c|}
\hline BTATION & 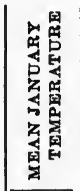 & 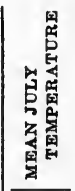 & 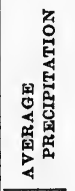 \\
\hline & degrees & degrees & inches \\
\hline Nelson. & 25 & 66 & 27 \\
\hline Revelstoke. & 20 & 64 & 43 \\
\hline Barkerville........... & 18 & 57 & 35 \\
\hline Glacier.............. & 14 & 52 & 60 \\
\hline
\end{tabular}

The first two stations are valley stations and the last two hill stations; the elevation of Barkerville being $4180 \mathrm{ft}$. and Glacier $3778 \mathrm{ft}$.

Second or Columbia Dry Belt. This 
forms the western rim of the Rocky Mountain Trench:

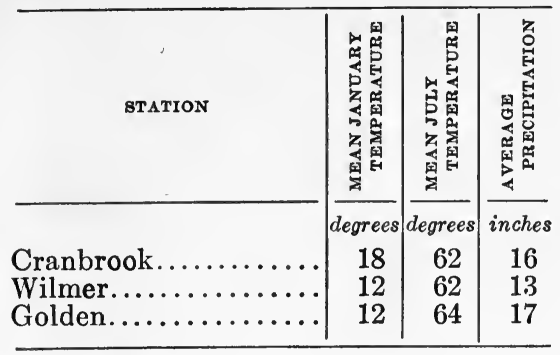

Great Northern Belt. This is subject to greater extremes, but less data are available. Liard varies from $40^{\circ}$ to $50^{\circ}$ below zero during extreme winter weather to $90^{\circ}$ and above, during the summer. These periods, however, are of short duration, and generally it may be stated that this region is in the same isotherm as Quebec or Central European Russia during January and that of Edinburgh or Christiana, Norway, during summer. The precipitation is from 16 to 20 in., nearly half of which falls during the growing season.

\section{Original Biota}

\section{A. NORTHWESTERN MOIST CONIFEROUS FOREST (COAST FORESTS)}

\section{General}

The coast forests are characterized by the giant size of the trees. These tower 200 to $300 \mathrm{ft}$. high and often reach 25 to $30 \mathrm{ft}$. in girth. The underbrush consists chiefly of salal (Gaultheria shallon), in drier situations, especially in Douglas fir (Pseudotsuga taxifolia), with devilclub (Echinopanax horridum), and salmon berry (Rubus spectabilis) in the lower and wetter situations.-P.Z. C.

Here the humid atmosphere favors a luxuriant growth of ferns including sword fern (Polystichum munitum), maiden hair fern (Adiantum pedatum), oak fern (Phegopteris dryopteris), the latter often carpeting large areas of the forest floor; while the western polypody (Polypodium vulgare, var. occidentale), clothes the large trunks and branches of the soft maples (Acer macrophyllum). The combined effect of thcse ferns, to- gether with an abundance of mosses and lichens hanging in festoons from the branches, is to impart to the coast forest a close resemblance to a tropical jungle.

Near the margin of such an environment the cascara tree (Rhamnus purshiana), is found at its best. The bark of this tree is the Cascara Sagrada of commerce, and in recent years British Columbia has been called on to furnish a very large proportion of the world's needs of this valuable medicine.-J. $D$.

Mammals and birds ${ }^{2} E$. A. P. The mammals include the coast long-tailed shrew (Sorex obscurus longicauda); Rhoads deer-mouse (Peromyscus maniculatus macrophinus) northerly; Bangs deer-mouse (P. m. oreas) southerly; Wrangell lemming-vole (Synaptomys borealis wrangeli) northerly; Wrangell red-backed vole (Evotomys wrangeli) northerly; coast red-backed vole (Evotomys caurinus) southerly; long-tailed vole (Microtus mordax macrurus), Sitka deer (Odocoileus columbianus sitkensis); elk (Cervus canadensis roosevelti) southerly; black bear (Ursus americanus). The so-called white bear (Ursus kermodei) from Gribble Island, is probably only an instance of albinism. Several forms of brown and grizzly bears (Ursus chelidonias, $U$. atnarko, U. quakiutl, $U$. warburtoni, and $U$. pervagor) are described from the coast forests, but their ranges are, not well defined. The northwest wolf (Canis occidentalis gigas), preys on the deer. The northwest coast skunk (Mephitis o. spissigrada), and the Pacific raccoon (Procyon psora pacifica), and the British Columbia Seweelek (Apoldontia $v$. columbiana), extend only a short distance northward along the coast; while the British Columbia mink (Mustela v. energumenos), and the northwest marten (Martes a. caurina) range farther north and into the interior.

Birds more or less characteristic of the crast forests include the following: silka grouse, red-breasted sapsucker, Oregon junco, lutescent warbler, Stellers jay, Townsend's warbler, piliolated warbler, chestnut-backed chickadee, russet-backed thrush, varied thrush.

\footnotetext{
2 See page 181 (Oregon) for note on Molluscs.
} 
The northwest painted turtle (Chrysemys marginiata belli), and the northwest garter snake (Thamnophis sirtalis concinnus), inhabit southeastern British Columbia near the coast.

\section{Forest types (P.Z.C.)}

The climatic factors previously described largely determine the main forest types, of which a brief description follows:

a. Lou'er coast or Douglas fir-cedar type. This is the prevalent type at the lower altitude in southern, eastern, and central portions of Vancouver Island and along the Mainland and adjacent islands to Knight Inlet. In general it may be said that this type occurs in sections where the annual precipitation is less than 75 in., reaching its best development when precipitation is between 50 and 60 in. The type extends from sea-level up to $2000 \mathrm{ft}$. and occasionally to $3000 \mathrm{ft}$. This is one of our chief commercial types. Stands of $50,000 \mathrm{ft}$. B.M. per acre extend over large areas and sometimes stands reach 200,000 or even $300,000 \mathrm{ft}$. B.M. per acre. Typical stands show in south and east Vancouver Island: Douglas fir 70\%; giant cedar (Thuja plicata) $17 \%$; western hemlock (Tsuga heterophylla) 6\%; and white fir or "balsam" (Abies amabilis) $2 \%$. Other species, including western white pine (Pinus monticola), Sitkaspruce, etc., $5 \%$.

b. Giant cedar-hemlock type. This type occupies a zone immediately above or just north of the lower coast type. The mean temperature is slightly lower and rainfall heavier, ranging from 90 to 100 in., where optimum growth is obtained. This type centres around Broughton Island, Smith and Seymour Inlets, but also extends down the Coast where it forms a belt above the Douglas fir-cedar type up to an elevation of sometimes $4000 \mathrm{ft}$. Commercially giant cedar is the most important species and forms the principal part of the stand. Associated therewith are western hemlock, white fir, sitka spruce and yellow cypress (Chamaecyparis nootkatensis). The species run in percentages:
Giant cedar $60 \%$; western hemlock $22 \%$; white fir $11 \%$; sitka spruce (Picea sitchensis) $4 \%$; others $3 \%$ at Seymour Inlet; while typical stands on slopes at Capilano give $31,000 \mathrm{ft}$. per acre; giant cedar $57 \%$; western hemlock $17 \%$; white fir $9 \%$; Douglas fir $8 \%$; yellow cedar (Chamaecyparis nootkatensis) $8 \%$; and western white pine (Pinus monticola) $1 \%$.

c. Western hemlock-sitka spruce type. This type centres on Queen Charlotte Islands where Sitka spruce attains its maximum growth. On the Mainland the type occupies the lower slopes of the North Coast and especially the valleybottoms, being found in isolated stands at the head of inlets as far south as Vancouver.

The temperature averages $5^{\circ}$ colder than in the Douglas fir type and rainfall varies from 45 to 120 in. On the Queen Charlottes, where the best spruce is found, the rainfall averages 52 in. In this type hemlock represents 25 to $40 \%$ of the stand. Sitka spruce averages about $30 \%$, associated species being giant cedar, yellow cypress and white fir, except on Queen Charlotte Islands where white fir is not found.

d. Hemlock-white fir type. This type occupies the more exposed sites and higher altitudes. It is the prevailing type on Vancouver Island around Quatsino Sound and generally extends in a belt along western slopes just below the sub-alpine type reaching an elevation of $4000 \mathrm{ft}$. on the lower coast. The species are chiefly western hemlock and white fir. Associated with these, however, are Sitka spruce, giant cedar and lodgepole pine (Pinus contorta). Typical stands of this type run at Quatsino Sound: hemlock 50\%; white fir $23 \%$; giant cedar $17 \%$; sitka spruce $10 \%$. At Kitimat, at an elevation of $1700 \mathrm{ft}$ : hemlock $60 \%$; white fir $39 \%$; the stand averaging 2,000 to $15,000 \mathrm{ft}$. B.M. per acre. On the Naas River this is the prevailing type. Species represented are: hemlock $45 \%$ or over; white fir 15 to $20 \%$; sitka spruce 15 to $30 \%$, giant cedar 2 to $15 \%$. Stands average 15,000 to $20,000 \mathrm{ft}$. per acre, reaching 40,000 to $50,000 \mathrm{ft}$. per acre. 
Above the hemlock-white fir type and below cold timber-line is the sub-alpine type of no commercial value, the species consisting of mountain hemlock ( $T$ suga Mertensiana), alpine fir (Abies lasiocarpa), lodgepole pine, and with some spruce and western hemlock. As a rule a considerable portion of this type is treeless and tundra in character, the soil being wet and covered with a thick growth of moss.

B. TEMPERATE SEMI-DESERT BROKEN AND BUSH COVERED GRASSLAND (DRYBELT) (J. D.)

\section{General}

The semi-desert regions of British Columbia are characterized by the scarcity or absence of trees and the predominance of sagebrush (Artemisia tridentata and $A$. frigida); rayless golden rod (Bigelovia dracunculoides); balsam root (Balsamorhiza sagittata); and other white-pubescent xerophytic plants. (For a discussion of grasses, etc., see page 156.)

There are three main drybelt regions: (1) the Columbia-Kootenay semi-arid area, in the valley between the Rocky Mountains and the Purcell Range, comprising the Windermere Valley and the region to the south; (2) the OkanaganSimilkameen area; between the Gold Range and the Cascade or Coast Range; (3) The Fraser area including the Thompson Valley, extending north through the Interior plateau to latitude $53^{\circ}$. In each of these areas may be found noteworthy variations in the flora which may be summarized by selecting two characteristic drybelt genera Purshia tridentata (locally known as "Greasewood"), and Opuntia polyacantha, (Cactus) and noting their distribution:

\begin{tabular}{c|c|c}
\hline areas & PUrshia & opuntia \\
\hline $\begin{array}{c}\text { Kolumbia. } \\
\text { Kootenay ..... }\end{array}$ & Present & Absent \\
$\begin{array}{c}\text { 2. Okanagan- } \\
\text { Similkameen.... }\end{array}$ & Present & Present \\
$\begin{array}{c}\text { 3. Fraser- } \\
\text { Thompson...... }\end{array}$ & Absent & Present \\
\hline
\end{tabular}

As Purshia is one of the characteristic members of the Sonoran life zone, it is interesting to note its presence in the southern valleys which ultimately drain into the Columbia River.

Taken as a whole, the semi-desert flora is found only in the valleys and adjacent benches; although Artemisia tridentata is most frequently given as the characteristic sage brush, Artemisia frigida is the species most widely distributed in the drybelt regions of this Province. Where Artemisia tridentata is found, the Cactus (Opuntia polyacantha var. borealis) is usually very prolific. Associated with these may be found large clumps of milkweed (Asclepias speciosa), and stickweed (Mentzelia laevicaulis).

The flora of such a region in spring and early summer differs greatly from that found later in the year. For a short season after the melting of the winter's snow, when the soil is warm and moist, the desert region is ablaze with many annuals and perennials which send up their flowers and hurry through with the production and dispersal of seeds before the soil becomes hot and dry. Spring flowers include the yellow fritillary (Fritillaria pudica); Mariposa lily (Calochortus macrocarpus); Menzies Phacelia (Phacelia Menziesii); balsam root (Balsamorhiza sagittata); clematis ( $C$. ligusticifolia); bitter-root (Lewisia rediviva). The fritillary, Mariposa lily, balsam-root, and bitter-root grow in such abundance that the bulbs or roots are dug and used as food by the Indians of these regions.

In the numerous gulches caused by erosion, may be found thickets of Juneberry (Amelanchier alnifolia), mountain maple (Acer glabrum), and sumach (Rhus glabra).

Mammals, birds, and reptiles (E.A.P.). Mammals of the sagebrush area include a pocket gopher (Thomomys fuscus), Lord's pocket mouse (Perognathus lordi), and western white-tailed jackrabbit (Lepus townsendii townsendii). These enter British Columbia only in this area.

Birds found almost exclusively in this 
area include: Sage grouse, Arkansas kingbird, western lark sparrow, Brewer sparrow, Lazuli bunting, poorwill and rock wren.

According to Fannin, the western spadefoot toad (Scaphiopus hammondii) is found in southern British Columbia. The northwestern rattlesnake (Crotalus oreganus) also inhabits its sagebrush areas.

\section{Grasslands (A. H. H.)}

The natural grasslands of British Columbia are limited to the Dry Belt areas; where the precipitation is abundant, particularly in the coast region, the tree growth is so dense that grasses are eliminated, because of insufficient sunlight. The principal natural grasslands or grazing areas are: The Fraser valley, and the plateau neighboring thereon from its confluence with the Nicola River northward to its confluence with the Quesnel River, particularly in the regions about the Nicola, Bridge, Thompson, and Chilcotin basins; the Okanagan and Similkameen basins from the United States border northward toward the extremity of Okanagan Lake; the lowlands bordering the southern part of the Kettle River. In the valleys of the southern parts of the Arrow and Kootenay Lakes, to a limited extent; and the Columbia basin northward to Lake Windermere particularly in the region of the St. Mary's River.

Natural grasslands occur to a comparatively limited extent along the southeastern coast of Vancouver Island. In addition, undoubtedly, there are large unexplored areas, particularly in the north; the regions mentioned constitute the better known and more generally used grazing lands of the Province.

Although one kind of grazing area merges into another, several rather distinct types of grasslands may be distinguished, namely: the open grassland including those areas where grasses predominate (indicated on fig. 1 by the mark " $O$ "), also those areas where the sagebrush is predominant and the wooded grasslands including those areas where western yellow pine (indicated by " $\mathrm{X}$ "), jack pine (indicated by "P"), poplars and willows (indicated by "W"); Douglas fir (indicated by " $\mathrm{D}$ "); or oaks (indicated by "T"); are the respective dominant tree forms associated with the forage plants of the region.

Open grasslands may be classified as: first, those where grasses predominate, and second, those where sagebrush is predominant. The two types are not strictly separable by any hard and fast line; ordinarily however the latter occupies the comparatively level lowlands particularly where the yearly precipitation is very low-ordinarily not exceeding $3.5 \mathrm{in}$. , and where the temperature is high-the average summer temperature approximating $70^{\circ} \mathrm{F}$.; in contrast, the open grassland dominated by grasses is found on the slopes where there is more available water, due to seepage; where the yearly precipitation may be greater, from 3 to $10 \mathrm{in}$. , and where the temperature may be considerably lower.

The so-called "meadows" may also be included among the open grasslands. They occur in the undrained basins where water stands at least during the earlier part of the growing season. Although included under grasslands, sedges are the dominant forage plant belonging to this plant association.

Many of the plants found in the sagebrush areas have stout rootstocks in which food is stored during the early growing season in provision for the dry summer months and they obtain sufficient water by means of an extensive root system which penetrates the soil to a great depth and not infrequently to the lowest water level. Most conspicuous among the number are the sagebrush (Artemisia frigida); balsamroot or wild sunflower (Balsamorhiza sagittata); and southward from Dog Lake "Greasewood" (Purshia tridentata). The broad leaves of the balsamroot afford good forage until the latter part of June. These plants are not 
only drought resistant but also, because of their underground food supply and deep roots, are able to withstand the ravages of over-grazing and fires. When conditions are adverse they are often the sole survivors.

Annual plants which grow early in the spring and which produce large quantities of seeds early in the season are also associated with the sagebrush, namely; stickseed (Lappula occidentalis and $L$. echinata); fleabane or wild aster (Erigeron linearis, or $E$. caespitosus and $E$. peucophyllus); tumbling mustard (Sisymbrium altissimum, S. incisum var. Hartwegianum); everlasting (Antennaria microphylla).

Grasses even in the sagebrush areas constitute the most stable forage; they are mostly of the tufted, perennial deep rooted varieties such as: Tufted wheat grass, or bunch grass (Agropyron biflorum and $A$. tenerum); big bunch grass (Agropyron spicatum); shining spike grass (Koeleria cristata), tufted (Festuca hallii, and $F$. ovina); needle grass, (Stipa viridula and S. comata); triple awned grass (Aristida purpurea), and little blue grass (Poa Sandbergi).

On the open grazing lands where grasses predominate the forms enumerated above make up the greater proportion of the covers; associated with them are short-awned brome grass (Bromus marginatus); tall bunch grass (Agropyron caninum and $A$. richardsonii), and tufted lyme or wild rye (Elymus condensatus); also annual leguminous plants; lupine (Lupinus argenteus); hairy milk vetch (Astragalus stenophyllus), and other plants of little or no forage value as wild geranium or cranebill (Geranium viscosissimum); woolly plantain (Plantago purshii) and rushes (Juncus spp.).

Many of the plants named above as belonging to the open grasslands are also found in the yellow pine grasslands, especially in the more open stands; to this list may be added a number of the grasses known as "Pine Grass" such as narrow-leaved pine grass (Calamagrostis Suksdorfii), shining spike grass
(Koeleria cristata); tall wheat grass (Agropyron occidentale); spear grass (Poa glauca) little blue grass (Poa sandbergii), and Nevada spear grass (Poa nevadensis). Many of these grasses, in contrast with the bunch grasses characteristic of the open grasslands, have creeping rootstocks sending up a number of shoots from buds which appear at intervals along the rootstock. Because of this character the grass cover has a matted appearance. The possession of these budding rootstocks make the production of seeds less imperative in order that the grass may be maintained.

Leguminous plants, of considerable forage value, are also more abundant: Milk vetch (Astragalus campestris); bird-foot clover (Hosackia denticulata); and so-called loco-weed (Oxytropis monticola), are among the most common.

Poisonous plants, however, are more numerous also; for instance poison camas (Zygademus venenosus); larkspur (Delphinium bicolor); lupines (I. argenteus). It is doubtful however, whether Oxytropis may justly be called Locoweed in this region since evidence is wanting to prove that it has poisoned stock while grazing on British Columbia grasslands.

The plants growing on the Douglas fir grassland areas include those already indicated as belonging to the forage plants of wooded regions. The bunch grasses become still less conspicuous and the pine grasses more predominant. To the list may be added another wheat grass (Agropyron caninum); fescue grass (Festuca ovina, and $F$. octiflora); melick or sweet grass (Melica striata); brome grass (Bromus Pumpellianus), also such legumes as milk vetches (Astragalus americanus), and peavine (Lathyrus Nuttallii, and $L$. ochroleucus).

With jack pines are found plants whose palatability and food value are generally lower especially where the stand is closed as the result of frequent burns: Pine grass and shining spike grass are the chief forms, while in more open 
stands needle grass (Stipa spp.), is of common occurrence.

The cottonwood grassland plants do not differ essentially from those of the Douglas fir or jack pine grasslands, when the region is arid. In the transition region, however, the common pine grass gives place to marsh pine grass (Calamagrostis canadensis), and the following become conspicuous forms; foul meadow grass (Poa triflora), short awned brome grass (Bromus marginatus), and wheat grass (Agropyron caninum). In the same region leguminous forage plants are abundant and grow to great size. In the "Pea-vine Country" masses of pea-vine associated with milk vetches grow to a height of $5 \mathrm{ft}$. or more.

There is abundant evidence that the grasses, at least of the dry belt regions, are pioneer forms; that they constitute the first cover of the soil; that they precede trees in the succession of plant associations. In the wooded regions bordering upon open grasslands, areas are common where the undeveloped soil of a recently formed ridge is covered with grasses while the surrounding country is wooded. It is also significant that in British Columbia the largest open grassland areas are located upon the most recent geological formations (Miocene).

\section{Dry Belt and mountain forests}

1. Yellow pine. On the slopes of the benches, which rise to an altitude of 2000 or $3000 \mathrm{ft}$. one may see a gradual transition from the semi-desert to the plateau flora, passing through the western yellow pine zone to Douglas fir, lodgepole pine and in places Engelmann spruce. Red cedar-(Juniperus scopulorum) and buckbush (Ceanothus velutinus and $C$. sanguineus) and the shrubby Pentstemon ( $P$. scoulerii) are sometimes found in great masses at approximately $2500 \mathrm{ft}$. altitude.-J. D.

The western yellow pine (Pinus ponderosa) type is found in almost pure stands on lower benches within its range, but mixed with Douglas fir as it approaches the upper limit at 3000 ft. These species come much lower down on northern slopes to where soilmoisture is more readily available. The commercial stands in this type average 5000 to $10,000 \mathrm{ft}$. per acre; occasionally more. As a type western yellow pine in British Columbia is confined to dry, well-drained sites where the precipitation is from 10 to $15 \mathrm{in}$. and in a belt between 1500 and $3000 \mathrm{ft}$. in elevation.-P. Z. C.

2. Mixed forest. In the Kootenay district western larch (Larix occidentalis) is a common tree in mixture with Douglas fir, the Douglas fir-western larch forming a type between the western yellow pine on the one hand and the spruce-lodgepole on the other in the same relation as the Douglas fir type in the Dry Belt. Apparently climatic requirements are about the same as described for the latter.-P. Z. C.

3. Montane forest. On the open parklike slopes, at an altitude of from 3000 feet to $6000 \mathrm{ft}$. within the dry belt area, may be seen a most gorgeous array of color; yellows contributed by millions of Dog-tooth lilies (Erythronium grandiflorum), balsam-root, Arnica ( $A$. cordifolia), tiger lilies (Lilium parviflorum); stonecrop (Sedum stenopetalum); fleabane (Erigeron aureus); blues by tall "forget-me-nots" (Lappula floribunda); larkspur (Delphinum bicolor); Jacob's ladder (Polemonium humile); Pentstemon $(P$. confertus var. coerulea purpureus), Brodieas (B. Douglasii), reds by Indian paint-brush (Castilleja spp), columbine (Aquilegia formosa); whites by tall specimens of cow-parsnip (Heracleum lanatum); death camas ( $Z y$ gadenus venenosus); Indian Tatuan (Claytonia lanceolata); Spiraea (S. lucida), with many other colored flowers in profusion. The field botanist who visits the semi-desert regions of British Columbia in the months of May and June will reap a rich harvest in the great variety of species to be obtained then.-J. D.

4. Subalpine forest and meadow. The timber line subalpine forest here consists of mountain meadows interspersed 
with stunted tree growth of lodgepole pine, white-bark pine (Pinus albicaulis) and alpine fir. Among the grasses are Agrostis humilis, Phleum alpinum, Danthonia intermedia, Trisetum spicatum, Koeleria cristata, and several species of Fescues, while in the moister meadows and swales Valeriana sitchensis, Castillejas, Senecios and other herbaceous plants occur.-P. Z. C.

\section{NORTHERN AND MOUNTAIN CONIFEROUS FOREST}

\section{Second Wet Belt}

The forests in the second wet belt resemble those on the coast and we have the same transition in types. Giant cedar and hemlock ranging from almost pure cedar on the river-bottoms, where the water-table is near the surface, to a mixture of cedar and western hemlock on the lower mountain slopes, and finally changing into hemlock-spruce (here Engelmann)-cedar type on the higher benches or into the subalpine (or spruce-lodgepole) type, which occurs on the mountains at an elevation of 4000 and $6000 \mathrm{ft}$. Stands in the Second Wet Belt will reach 20,000 to $30,000 \mathrm{ft}$. B.M. per acre over considerable areas. Much, however, depends on the age of the stand and defect, which is sometimes conspicuous, especially in cedar and hemlock throughout the type.

\section{Northern sub-arctic or spruce-pine type}

This is a continuation of the great forest area that sweeps across Canada, lying between the tundra on the one hand and the plains or the pine-hardwood forests on the south.

In British Columbia pine is represented by lodgepole. In the north both white spruce (Picea canadensis) and black spruce (Picea mariana) occur, but farther south they are replaced by the Engelmann spruce. This type occupies the northern plateau, spreads over the Rocky Mountains, and out across the foot hills to the north-east corner of the Province, where it joins the sub-arctic forests of Alberta. Extending northward along the mountains it forms a belt, just below the sub-alpine type, usually occuring between the 4000 and $6000 \mathrm{ft}$. contours. The type has been greatly modified by fire and in many cases converted into pure lodgepole pine, which acts as an intermediary or nurse crop for the spruce which subsequently comes in under the pine. Islands of black spruce swamp are frequently encountered or stands of pure cottonwood on southern exposures. The average stand per acre in mature forest is from 5000 to $10,000 \mathrm{ft}$., occasionally reaching 20,000 $\mathrm{ft}$. or over near the lower limits of its range.

Typical cruises show. Elk River, elevation 4500 to $6000 \mathrm{ft}$., average stand $20,000 \mathrm{ft}$. per acre: Engelmann spruce $75 \%$; lodgepole pine $15 \%$; alpine fir $10 \%$; Douglas fir $2 \%$. Clearwater River, plateau 4000 to $6000 \mathrm{ft}$. above sea-level; average stand $8500 \mathrm{ft}$. per acre: spruce $65 \%$; balsam $20 \%$; lodgepole pine $5 \%$. While stands in Northern British Columbia, elevation 1000 to $2000 \mathrm{ft}$. will run: spruce $70 \%$; lodgepole pine $25 \%$; fir $5 \%$. This type is of great commercial importance from the standpoint of pulpmanufacturing.-P. Z. C.

Fauna (E. A.P.). The northern part of the area covered with this type of forest is considered in the discussion of the transcontinental coniferous forest of central Canada of which it forms a part.

The commoner and more characteristic mammals of its southern portion include the following: Dusky shrew (Sorex obscurus obscurus); Rocky Mountain marsh shrew (Neosorex palustris navigator); northwestern bat (Myotis longicrus); black and grizzly bears of several races (distribution not worked out); northwest marten (Martes a. caurina); British Columbia mink (Mustela $v$. energumenos); Bonaparte weasel (Mustela cicognanii cicognanii); northern deer mouse (Peromyscus $m$. borealis); western bushy-tailed wood rat (Neotoma c. occidentalis); heather vole (Phenacomys intermedius intermedius); British 
Columbia red-backed vole (Evotomys g. saturatus); Rocky Mountain vole (Microtus mordax mordax); British Columbia muskrat (Fiber z. osoyoosensis); Rocky Mountain jumping-mouse ('Zapus princeps); Okanagan marmot (Marmota c. okanagana) ; northern mantled groundsquirrel (Callospermophilus l. tescorum); Canadian mountain chipmunk (Eutamias amoenus ludibundus); Streator's red squirrel (Sciurus $h$. streatori); British Columbia snowshoe hare (Lepus a. columbiensis); Rocky Mountain pika (Ochotona princeps); bighorn sheep (Ovis canadensis); Rocky Mountain goat (Oreamnos montanus); mule deer (Odocoileus hemionus); mountain caribou (Rangifer montanus). Some of the more notable of the birds are the following: dusky grouse, Franklin's grouse, Canada ruffed grouse, red-necked sapsucker, western piliated woodpecker, Rocky Mountain jay, Clark's nutcracker, longtailed chickadee, Louisiana tanager, red-eyed vivio, Audubon's warbler, mountain chickadee, Hudsonian chickadee, willow thrush, olive-brcked thrush, and mountain bluebird.

\section{ALPINE REGIONS}

Alpine conditions are to be found on most of the British Columbia mountains above an altitude of $5500 \mathrm{ft}$., especially on those mountains situated within the "wet belts" where the precipitation ensures an abundant snowfall during winter.

At an altitude of $4500 \mathrm{ft}$., is found moist meadow-like land containing much humus, and abounding in ericaceous shrubs such as White Rhododendron (R. albiflorum); red heather (Phyllodoce empetriformis); creamy yellow heather ( $P$. glanduliflorus); white heather (Cassiope Mertensiana); copper-bush (Cladothamnus pyroloflorus), blue-berries (Vaccinium, various species). Much of the moist land is carpeted with the beautiful alpine Spiraea (Eriogynia pectinata) so frequently mistaken for a saxifrage, associated with marsh marigold (Caltha leptosepala); globe flower (Trollius albiflorus), and numerous saxifragaceous plants. In this zone small subalpine lakes are abundant. These are frequently stocked with yellow water lilies (Nuphar polysepalum); while spongy Sphagnum areas in the vicinity have mountain laurel (Kalmia polifolia); gentians (G. sceptrum); grass of Parnassus (Parnassia palustris); deer cabbage, and bogbean (Menyanthes crista-galli and $M$. trifoliata). This subalpine association ranges, according to locality, from $4000 \mathrm{ft}$. altitude to approximately $6000 \mathrm{ft}$. At the former elevation the supply of moisture is maintained by seepage from the melting snow in the adjacent wooded slopes; at the latter elevation, seepage is from the snowfields or glaciers on the exposed mountain sides, timber line ranging in the "wet belts" from $5500 \mathrm{ft}$. to approximately $6500 \mathrm{ft}$. altitude. Here, the last trees are alpine fir, white bark pine (Pinus albicaulis), and mountain hemlock, all of which are low and stunted, forming dense tangle thickets from 1 to $3 \mathrm{ft}$. high, the older trees often spreading over a large area, due chiefly to the great weight of snow which buries them for the greater part of the year. The snowfall during the winter, at that altitude varies from 30 to $50 \mathrm{ft}$. in depth.

The soil of the Arctic Alpine belt (Arctic-alpine zone) contains little humus, and is largely composed of silt from the weathered rocks. The type of vegetation varies in accordance with this soil, whether formed from rocks of sedimentary or volcanic origin; the latter, as a rule, producing the greatest variety of species.

The characteristic plants of this belt are moss campion (Silene acaulis); northern wormwood (Artemisia norvegica var. pacifica); silky phacelia ( $P$. serica); Douglas' Phlox (P. Douglasii); crowberry (Empetrum nigrum); creeping Azalea (Loiseleuria procumbens); bluegreen gentian (Gentiana glauca); western Anemone (A.occidentalis); Tolmie's saxifrage ( $S$. Tolmiea), often growing within a few feet of glaciers, and many other low growing tufted flowering plants. 
Between this Alpine belt and the subalpine vegetation is found a great variety of habitats bearing different associations of plants. On Rock slides are stone crop (Sedum divergens); juniper (J. communis); lupine ( $L$. arcticus); Jacob's ladder (Polemonium confertum). Cold gravelly creek banks bear great masses of dark crimson Mimulus ( $M$. Lewisii), while sand bars or islands in the middle of shallow streams are covered with the golden yellow alpine Mimulus (M. alpinus); butter-bur (Petasites frigidus); or fireweed (Epilobium latifolium).

Alpine slopes are bedecked with lupines, Indian paint-brush, of all shades from pale pink to fiery scarlet, mountain heliotrope (Valeriana sitchensis), louseworts (Pedicularis bracteosa, and others), columbines, alpine speedwell (Veronica alpina), numerous tall sedges, and rushes, but compartively few species of grasses.

To see the vegetation of alpine regions in British Columbia as above described one should visit them sometime between the latter part of July and the end of August. (J.D.)

Mammals and birds (E. A. P.). The hoary marmots (Marmota c. okanagana and $M . c$. cascadensis), races of a species which farther north ranges down to sea level, are confined in southern British Columbia practically to the treeless mountain summits. Rangifer montanus and Ovis canadensis are also generally found there.

Birds breeding on the Alpine summits include the following: Rock ptarmigan, white-tailed ptarmigan, pallid horned lark, Hepburn's rosy finch, and pipit.

\section{E. LOCAL OR EDAPHIC COMMUNITIES}

$$
\text { (J. D. AND E. A. P.) }
$$

\section{Muskeg and peatbogs}

The principal muskeg and bog areas are to be found in the northern parts of the Province, especially in the Liard and Peace River basins, others occur at various points along the Grand Trunk Railway system in central British Co- lumbia, Prince Rupert, Queen Charlotte Islands, the northern part of Vancouver Island, and in the southwest part of the mainland.

In the north-eastern regions tamarack (Larix laricina), and black spruce encroach on these areas, whereas in the southern and western bog areas these are replaced by the coast form of lodgepole pine (Pinus contorta) which is also found on rocky bluffs and on well drained sandy soil along the coast.

Excellent opportunities for the study of bog evolution are found within a few miles of Vancouver, B. C., where one may find every transition from the open lake to the mature bog. The margin flora of yellow water lilies, cat-tails (Typha latifolia); bogbean (Menyanthes trifoliata); cinquefoil (Comarum palustre), is followed by a floating Sphagnum layer with approximately ten or twelve feet of water or liquid muck underneath. On this sphagnum layer the bog flora develops somewhat in the following order: Sedges and rushes, clumps of sweet gale (Myrica gale), and Spiraea (S. Douglasii), followed by the usual western bog association: Labrador tea (Ledum groenlandicum), mountain or bog laurel (Kalmia polifolia), and cranberry (Vaccinium Oxycoccus). Into this ericaceous association the lodgepole pine encroaches, and sometimes succeeds in establishing a dense stand of low stunted trees, often badly affected by mistletoe (Arceuthobium americanum), and lodgepole pine blister rust.

One interesting feature is the frequent occurrence of stranded or isolated pioneers, water lilies which have survived for ages, cut off from their confreres in the lakes, and separated from them by several hundreds of yards of bog. These stranded lilies have successfully competed with the Sphagnum and ericaceous shrubs by sending up their leaves on long petioles thus monopolizing the light over an area 6 or 8 $\mathrm{ft}$. in diameter. This results in a kind of "pot-hole" in the bog, and in some places, where the water lilies have succumbed, these "pot-holes" take the 
unwary traveller by surprise. Tests made in the vicinity of these isolated pioneers, showed a depth of $22 \mathrm{ft}$. of muck with blue clay underlying.

In the spring, the bogs are ablaze with the flowers of the laurel and Labrador tea, the latter being considered by apiarists as a useful bee plant. Later in the year such bogs yield great crops of cranberries, blueberries (Vaccinium canadensis, $V$. uliginosum being the most common species here), and cloud berries (Rubus chamœmorus).

Although bog land is generally classified as agricultural land, little has been done in this Province to raise crops suited for cultivation on this type of soil. Promising results have been obtained by ranchers on Queen Charlotte Islands where experimental plantations of spearmint and peppermint have yielded luxuriant crops, but the absence of an oil distillation outfit to handle the crop hinders the development of what might prove a profitable industry.

Mammals and birds. While the peat bogs, usually referred to in the north as muskegs, offer advantageous habitats for many species of mammals and birds, no species inhabit them to the exclusion of other areas. The moose finds in the willow thickets which border many of them a favorite food, and the bears feast in autumn on the berries which grow in their drier parts. Within its range the Dall lemming-vole (Synaptomys borealis dalli) is perhaps as characteristic as any species. Long-tailed shrews (Sorex obscurus and S.personatus) also find congenial homes in such bogs.

The birds which especially favor muskegs as breeding places include the lesser yellow legs, and in south-central British Columbia the greater yellow legs; Holboell's grebe northerly; piedbilled grebe southerly; and the Virginia rail southerly. In places where ponds of sufficient size occur the loon often nests on their borders.

\section{Seashores}

It has been estimated that British Columbia has approximately $7000 \mathrm{mi}$. of coast line, most of this is rocky but there are a few good stretches of beautiful sandy sea-shore the most noteworthy being found near Barkley Sound on the west coast of Vancouver Island, at Qualicum on the east coast, and at Savary Island. Smaller beaches are scattered here and there along the coast but from an ecological point of view, the above offer the best facilities for the study of the sandy sea-shore vegetation.

A. Sand areas. Sand-dune regions, such as occur on the eastern part of the continent, are rare here; but where they do exist, Lyme grass (Elymus mollis), and the large headed sedge (Carex macrocephala), associated with sea purslane (Arenaria peploides var. major), and sea pea-vine (Lathyrus maritimus) are the pioneers; lupine (L. littoralis); wormwood (Artemisia canadensis); and sand-bur (Franseria bipinnatifida), often take a conspicuous place in the sandy sea-shore association.

Amongst the noteworthy pants of the Sandy Sea-Shores here, may be found the beautiful sand Convolvulus (Convolvulus soldanella); the yellow and pink Abronias ( $A$. latifolia, and umbellata), with their sweet scented flowers. The Abronias frequently have large mangellike roots whose food store is protected by cells containing needle shaped crystals or raphides. When a small portion of the root is chewed, these raphides painlessly pierce the mucous membranes of the mouth and produce the same numbness or loss of sensation as is produced by several members of the Araceæ which possess similar raphides.

A species of broom-rape (Orobanche fasciculata) is often found parasitic on the roots of the wormwood. This is also found on roots of Artemisia on sand hills in the interior of British Columbia.

b. Rocky shores. The Madrona tree (Arbutus Menziesii) reaches its northern limit in this Province and many beautiful specimens may be seen on the margin of the sand dune areas, as well as on the rocky bluffs of the southern part of the mainland and on the adjacent islands. 
These rocky bluffs near the sea generally have their ledges covered with a layer of mossy soil which supports a wealth of spring flowering species mostly annuals and bulbous plants, including banks of lobelia-like Collinsia ( $C$. grandiflora); sea-blush (Valerianella congesta); Bongard's saxifrage (Saxifraga Bongardi); and other saxifrages, white dog-tooth lilies, Indian camas (Camassia quamash); (Brodiea grandiflora), brown fritillary, (Fritillaria lanceolata); wild onions (Allium cernuum and $A$. acuminatum) and where sufficient soil has accumulated in crevices or pockets in the rocks are found flowering shrubs such as flowering currant (Ribes sanguineum); mock orange (Philadelphus Lewisii), Saskatoon (Amelanchier alnifolia); barberries (Berberis aquifolium and B. nervosa), manzanita (Arctostaphylos tomentosa); with flowering trees such as western dogwood (Cornus Nuttallii); and wild cherry (Prunus emarginata), so that although much of the coast line is rocky it is by no means barren, especially in spring when all the above species come into flower. Later on, however, the ledges become brown and dried up, and the visitor to this Province in the summer or autumn gets no conception of the floral wealth of the land adjacent to the sea.

Mammals and birds (E. A. P.). The only mammals which are especially characteristic of the shores are the seals and sea lions, listed under marine mammals, which have their young on rocky ledges just above the surf, usually on islands.

The more common sea birds which breed on cliffs include the following: tufted puffin; horned puffin; rhinoceros auklet; California murre; and violetgreen cormorant.

During migration many species of shore birds and plovers use the beaches as migration routes, and a few hardy species spend the winter there.

\section{Salt marshes}

On the south west coast of British Columbia may be seen some very fine salt marshes probably the best on the Pacific Coast, if not on this continent. In area they extend over many square miles and may be seen in all stages from their origin at the edge of the water, where eel grass, ditch grass (Ruppia maritima); samphire or glasswort (Salicornia ambigua) and sea blite (Suæda maritima) are the pioneers, until they "come under the plow" and become fertile agricultural land.

As the salt marsh develops one finds the usual association of halophytes: sea milkwort (Glaux maritima); sea plantain (Plantago maritima). In most of the salt marshes here dodder (Cuscuta salina) may be found primarily attacking Salicornia but spreading to other members of this association.

Later on, salt grass (Distichlis spicata), makes its appearance, and aids greatly in retaining the accumulated silt. It is quite a common occurrence to see cattle and even horses grazing on salt marshes, and the owners of the stock consider salt grass good fodder. Naturally, as a result of grazing, many weeds are introduced and we soon find, yarrow (Achillea millefolium); velvet grass or Yorkshire fog (Holcus lanatus); and other weeds overrunning the grazed areas.

Through the growth of countless generations of halophytic plants the soil becomes very rich in humus, forming a kind of peat and, by ditching and dyking, parts of this land have been separated from the main marsh areas and cultivated. On this reclaimed land farmers have to contend with the same weeds as prevail on newly reclaimed bogs, namely lesser sorrel (Rumex acetosella), and several species of smart weed (Polygonum) together with the dainty little mud-button (Cotula coronopifolia). The abundant rainfall during the winter soon leaches out the salt, and in a short time good crops can be raised on this rich, dark brown silt.

\section{Marine areas}

The marine flora along the coast of the Gulf of Georgia - between Vancouver 
Island and the mainland-differs in many respects from that found on the West Coast of Vancouver Island, and on the northern part of the mainland. The Gulf receives great quantities of fresh water from many rivers draining the western slopes of the Coast Range. The mighty Fraser River, which drains the largest river basin in the Interior of British Columbia, debouches here, carrying thousands of tons of sand and silt, discoloring the sea water for miles, and leaving a deposit of fine silty mud on the adjacent sea-shores. This muddy deposit is absent from the shores of the west coast of Vancouver Island and northern mainland; these shores, facing the Ocean, are frequently lashed by the full force of gales and storms of the Pacific.

The rocky parts of the coast abound with a great variety of brown and red seaweeds, giant kelps occasionally occupying large areas. The most conspicuous kelp in these waters is the "Sea-pear" (Nereocystis luetkeana) whose huge thalli, each with a large pear-shaped float attached to a stipe often more than forty feet in length, may be seen in great profusion. This kelp, and Macrocystis which is not so abundant here, was collected on a commercial scale during the period of the "world war," and prepared as a fertilizer to overcome the shortage of potash for agricultural purposes.

In shallow brackish bays, the intertidal area is often covered with eel grass (Zostera marina); while on rocky shores, this is replaced by its larger relative false eel grass (Phyllospadix scouleri). The sheltered waters of the Gulf, the diminished salinity, and the deposition of beds of silt in bays and at the estuaries of rivers, are all conducive to the building up of salt marshes with their characteristic halophytic flora.

Marine mammals ( $E . A . P$.$) . The$ sea otter (Latax lutris) formerly common along the entire coast is now nearly extirpated. The fur seal (Callorhinus alascanus), which breeds only on the Pribilof Islands, Alaska, is found in migration along the entire coast, but is not known to land. The spotted harbor seal (Phoca richardii) is rather common and breeds in certain favorable places. The southern sea lion (Zalophus californianus) barely enters our southern coast waters, while the northern sea lion (Eumetopias jubata) breeds in considerable colonies in many places along the coast.

The cetaceans known to inhabit the coast waters include the killer whale (Orcinus rectipinna); Pacific right whale (Balaena seiboldii); California gray whale (Rhachianectes glaucus); Pacific humpback whale (Megaptera versabilis); Davidson's finback whale (Balaenoptera davidsoni); Pacific sulphur-bottom whale (Balaenoptera sulfureus); Pacific finback whale (Balaenoptera velifera); sperm whale (Physeter macrocephalus); Pacific blackfish (Globiocephala scammoni), and common porpoise (Phocaena phocaena).

\section{Present Biota (E. A. P.)}

Data regarding changes in the distribution of British Columbia birds and mammals within historic times concern mainly the larger game and predatory mammals. These may be given under species.

The moose (Alces americanus), within the past 50 years has made a notable addition to its range, extending westward and southwestward several hundred miles. In the Stikine region it has moved its frontier from the region of Dease Lake to the mouths of the Stikine and Taku rivers. Farther south it has reached the vicinity of Chilcotin River and $83 \mathrm{mi}$. House only during recent years.

The elk or wapiti (Cervus canadensis occidentalis) originally ranged over that portion of the Province east of the Rocky Mountains north nearly to Liard River. Here it is now entirely extirpated. In southern British Columbia also, where it formerly ranged practically across the Province, it has suffered great loss in range, and is now confined mostly to the Kootenay District and to Vancouver Island. 
The caribou (Rangifer montanus and related forms) originally occupied suitable areas, including the barren summits and more sparsely wooded elevated sections, and excepting the humid coast region, practically over the entire Province. Excessive pursuit has practically extirpated it from most of its range in the southern half of the Province, but it remains in numbers in most of the country drained by the Stikine and Peace rivers, and northward. A few still persist, apparently, on Graham Island, the largest of the Queen Charlotte group, which furnishes a number of examples of mammalian distribution which are difficult to understand.

The mule deer (Odocoileus hemionus) confined to the dry interior forests, has extended its range northward several hundred miles during recent years, being now frequently seen in the Skeena and Peace River, and occasionally in the upper Stikine valleys.

The mountain goat is found in suitable places practically all over British Columbia, barring the islands, on which, excepting Pitt Island, it was never known.

The coyote (C'anis lestes) originally found only in the southern part of the Province, has pushed northward through the central valleys nearly to the northern boundary within the past 25 years.

\section{Areas Available for Biological STUDY}

\section{A. PROVincial forests (P. Z. C.)}

The officials of both the Dominion and Provincial Forest Branches encourage proper use of the forest and are always prepared to give advice on how best to reach any locality, equipment necessary, etc., to anyone entering any region. Definite boundaries have not been established for the forests.

*Coast Forest South. Area 23,000,000 acres. A region of mountain and forest intersected by deep sheltered fjords. Game is plentiful in woods.

Vancouver, $\ddagger$ C.N.R., G.N.R.

Headquarters, District Forester.

Victoria $\ddagger$ (80 mi. south west) C.P.R.
*Provincial Headquarters. Forest Service, Auto service to most points Vancouver Island, south, Nanaimo $\ddagger 40$ mi. west C.P.R.

Supervisor, Nanaimo, headquarters for Vancouver Island.

${ }^{*}$ North Coast. Area 22,000,000 acres. Interesting region of coniferous forests, mountains and inlets. Here Sitka spruce reaches its best development.

Prince Rupert. ‡ C.N.R., U.S.S. Co.

Headquarters, District Forester.

Gasoline launches available to visit many interesting spots or for more extended cruises along the Coast.

${ }^{*}$ East Kootenay Area. Area 7,500,000 acres. Embraces southern end of main Rocky Mountains and Rocky Mountain Trench. Altitude 3000 to $9000 \mathrm{ft}$. Vegetation zone changes from Dry Belt types to Alpine type as we ascend the mountains. Western larch attains its best development here.

Cranbrook, $\ddagger$ C.P.R.

Headquarters, District Forester.

Outfits may be obtained at Cranbrook for visiting any section of district.

*West Kootenay Area. Area 7,950,000 acres. A region of lakes and mountains. Very interesting since it embraces changes from Dry to Wet Belt vegetation. Lakes abound in fish and forest in game.

Nelson, $\ddagger$ C.P.R. \& G.N.R.

Headquarters, District Forester.

*Okanagan. Area 6,000,000 acres.

The typical Dry Belt region.

Vernon, $\ddagger$ C.P.R.

Headquarters, District Forester.

Penticton, C.P.R., K.V.R., Princeton, $\ddagger$ K.V.R., G.N.R., Merrit, $\ddagger$ C.P.R.

*Thompson Region. The area embraces northern border of Dry Belt and the western slope of Gold Range.

Kamloops, ‡ C.P.R., C.N.R.

Headquarters, Dominion Forest Branch for British Columbia, and District Forester.

*Big Bend. Central part of Rocky Mountain Trench and Selkirk Mountains, a region of rigid mountains and steep wooded slopes and especially noted for its bear hunting. 
*Revelstoke. ‡ C.P.R.

Outfitting points for trips into adjoining district which can be made readily with pack animals.

*Cariboo. Area 14,000,000 acres, Central section of Interior plateau. Good hunting and fishing. Forests have suffered extremely from fires-original Douglas fir has been converted into lodgepole pine.

Williams Lake, $\ddagger$ P.G.E. Railway.

Headquarters, District Forester.

Quesnel, $\ddagger$ P.G.E. Railway, outfitting point for prospectors and others.

*Northern. The great northern hinterland, including the valleys of Parsnip, Peace, Nelson, Liard rivers, has been scarcely explored except by prospectors and trappers, and offers an attractive opportunity for naturalists.

*Prince George. $\quad$ †.N.R. Railway.

Headquarters, District Forester.

Outfitting point for parties going further north.

\section{B. DOMINION FORESTS (P. Z. C. AND} D. G. CAMERON)

The Dominion Government owns and controls what is known as the Railway Belt. This Belt was granted to the Dominion by the Province to aid in the building of the Canadian Pacific Railway through British Columbia, the title of conveyance being executed in 1883 . It includes the land within $20 \mathrm{mi}$. on each side of the Canadian Pacific Railway from the Alberta Boundary to a western limit bounded by the Meslilloet River and the North Arm of Burrard Inlet. To compensate for lands within this Belt which the Province had disposed of prior to the transfer the Dominion Government was also granted some $3 \frac{1}{2}$ million acres which was selected by them in 1907 in a block comprising $73 \frac{1}{2}$ sq. mi. adjoining the Alberta Boundary in the Peace River Valley.

As the Railway Belt stretches east and west across the Province it is subject to all the changes in forest types as described for the Province, that is, The Coast or Wet Belt, Dry Belt, The Second Wet Belt and the Rocky Moun- tain section. Of the 16,700 sq. mi. in the Belt it is estimated that 10,000 is forest land but only 3000 bears timber of commercial quantity which is estimated at 22 billion feet.

- A number of small forest reserves have been created on the headwaters of the streams throughout the Dry Belt. These reserves including the Yoho and Glacier parks by the same names are representative of the Rocky Mountain District.

The reserves of the drybelt district are: Larch Hills, Mount Ida, Fly Hill, Martin Mountain, Monte Hills, Niskonlith, Long Lake, Tranquille, Nicola, Arrowstone, and Hat Creek cover about $1 \frac{3}{4}$ million acres. They serve more as watershed protection than for the production of timber, although some 82 sq. mi. is held under timber berth within these reserves. The timber types on the reserves are typical of those of the Dry Belt and the Lodgepole Pine resulting from burn on the higher mountains.

The timber conditions on these forest reserves are similar to those described in detail in the book entitled "The Forests of British Columbia," published by the Conservation Commission of Canada, 1918, authors-H. N. Whitford and R. D. Craig. See particularly pages 63 to 68 . The bulk of the forest reserve area is in the Dry Belt proper where the timber on the lower slopes is western yellow pine and Douglas fir. The plateau areas above are largely covered by lodgepole pine. This lodgepole type is temporary as a result of forest fires. The climax type will be Engelmann spruce and Alpine fir. There is, of course, an altitudinal progression toward these types, the yellow pine merging into the Douglas fir and the latter into the Engelmann spruce as altitude increases. The timber line type is pure Alpine fir.

The reserves bordering on Shuswap Lake are in a transition area between the Dry Belt proper and the interior Wet Belt of the Columbia valley. The south and southwestern slopes exhibit Dry Belt characteristics and the opposite 
slopes verge to Wet Belt species. The climax forest growth in the lower elevations is Douglas fir, western larch ( $L$. occidentalis), western white pine, giant cedar, western hemlock. Higher up there is Engelmann spruce, Alpine fir and white bark pine. The westerly reserves have been largely fire swept, particularly on the elevated plateaus. Fair stands of Douglas fir and yellow pine remain on the lower slopes. The summits of the Fly Hills and Niskonlith Forest Reserves have large areas of the original climax type spruce-alpine fir forests. The Fly Hills particularly is very accessible by Forest Service trails. The Larch Hills Reserve has also large areas of second growth and mature mixed forest.

These reserves are readily accessible from any point along the line of the Canadian Pacific Railway, but particularly as follows:

Larch Hills Reserve-Sicamous

$\left.\begin{array}{l}\text { Mount Ida } \\ \text { Fly Hills }\end{array}\right\}$ Salmon Arm

Niskonlith-east side Chase, west side Kamloops

Martin Mountain

Monte Hills

Long Lake

Tranquille

Nicola

Hat Creek Ashcroft

Arrowstone

The administrative headquarters of the reserves is at Kamloops where the Forest Supervisor is located, while New Westminster is the headquarters of the Timber Branch for the coast section.

\section{PARKS}

${ }^{*} M t$. Robson Park. (A3.) About 409,600 acres of alpine peaks ranging up to $13,000 \mathrm{ft}$. in the Rocky Mountains of British Columbia. Lower slopes clad with sub-alpine forests and associated flora, grading upwards through alpine belt to regions of perpetual snow. Open country with talus slopes, ravines and canyons.

Mt. Robson Station, British Columbia (G. T. P. R.), near Yellow Head Pass.John Davidson.
* Strathcona Park. (A 3.) Area 530,566 acres. Situated in the center of Vancouver Island, a provincial Park Reserve; comprising mountain ranges up to between 6000 and $7000 \mathrm{ft}$. altitude. Slopes under $5000 \mathrm{ft}$. altitude timbered with northwestern and subalpine trees; subalpine plateaus, ravines and canyons. Buttle Lake, a large freshwater Lake, drains the central part of the Park, flows north and east to Campbell Lake, thence via Campbell River to the East Coast of the Island.

Campbell River, B.C., $30 \mathrm{mi}$. walk. Good trail through western mesophytic forest. Camp outfit necessary.-John Davidson.

*Yoho Park, B. C. Dominion Park Reserve 560 sq. mi. of peaks and passes in the Canadian Rockies, with characteristic northwestern arctic-alpine flora on mountain slopes and meadows. Canyons, glaciers, fossil-beds $2000 \mathrm{ft}$. thick. Deer, big-horn sheep and Rocky Mountain goats.

Passes 6000 to $7000 \mathrm{ft}$. altitude.

Peaks up to $11,000 \mathrm{ft}$.

Field, $\ddagger(4060 \mathrm{ft}$.) or Yoho Park, B.C. (C. P. R.). Coaches and saddle ponies for hire.-John Davidson, and Dominion Park Branch.

*Glacier Park, B. C. (A3.) Dominion Park Reserve of 460 sq. mi. of mountains and valleys in the heart of the Selkirk Range. Peaks up to $10,808 \mathrm{ft}$. Northwestern mountain forest, subalpine meadows with rich flora. Glaciers, caves.

Glacier, B. C. (C. P. R.) $\$ 4086 \mathrm{ft}$. Ponies and alpine guides to hire.John Davidson, and Dominion Park Branch.

*Revelstoke Park, B. C. (A2 I.) Dominion Park Reserve of 9559 sq. mi. of coniferous and northwestern mountain forest. Rainbow, Dolly Varden, cut-throat, gray and "Nipigon" trout in streams in vicinity. Rocky and glacial situations.

Revelstoke (C. P. R.), (1492 ft. altitude) $18 \mathrm{mi}$. (a). Pack horses for hire.John Davidson.

*Stanley Park. (B3.) Near City of 
Vancouver, B. C., Dominion Militia Reserve, 1000 acres of northwestern, mesophytic, semi-natural, coniferous forest; cedar, fir and hemlock formation with great variety of thallophytes and bryophytes. Marsh and pond with natural hygrophytic and hydrophytic flora.

Vancouver, B. C. Electric Car $1 \mathrm{mi}$. west.-John Davidson.

*Garibaldi Park. (A3.) Provincial Park Reserve of approximately 360 sq. mi. of mountains of volcanic origin (to $9000 \mathrm{ft}$.). Several young lakes of which Garibaldi Lake $3 \frac{1}{4} \mathrm{mi}$. long by $1 \frac{1}{2} \mathrm{mi}$. wide is the largest. Many torrential and swift creeks, splendid facilities to study the movement and action of several large glaciers.

Extensive subalpine slopes and meadows, rich and varied arctic-alpine flora, great variety of habitats and corresponding plant associations.

Grizzly bear, iimber wolves, goats, marmots, grouse ptarmigan.

Vancouver, B. C., $45 \mathrm{mi}$. north, steamer to Squamish, P. G. E. R. R. to Brew Station, walk $10 \mathrm{mi}$. mountain trail to good camping grounds on Black Tusk Meadows (5100 ft.). Mountaineering outfit desirable.-John Davidson.

Savary Island. (A3.) Five and onehalf miles by approximately one mile of lowland coniferous forest and semidesert flora, broad-leaved evergreen forest, sand dunes at west, and sandy and rocky bluffs at east end. Beautiful illustration of succession, in transition from sandy sea-shore to luxuriant mesophytic forest. Many western saprophytic and parasitic spermatophytes (Monotropaceæ, Orobanchaceæ, and Loranthaceæ!. 'Marine Littoral (Zostera).

Vancouver, B. C., by steamer $82 \mathrm{mi}$. north to Savary Island. Hotel accommodation during season.-John Davidson, and $R$. S. Sherman.

\section{BIBLIOGRAPHY}

Whitford, H. N., and Craig, Roland D. Forests of British Columbia. Commission of Conservation, Canada. Ottawa, 1918. (A book of $409 \mathrm{pp}$. with pictures and distribution maps.)

\section{WASHINGTON}

By Geo. B. RigG

(ACCOUNTS OF ANIMALS BY L. R. DICE, HELEN T. GAIGE, AND HORACE GUNTHORP)

\section{General Description}

\section{A. PHYSIOGRAPHIC REGIONS}

The State of Washington has a great variety of conditions as to topography and climate, resulting in a great diversity of plant and animal communities. The state is divided north and south by the Cascade Mountains. They form a general elevation $100 \mathrm{mi}$. wide in places, and throughout much of their extent they are $5000 \mathrm{ft}$. or more in elevation. In or near this range are 5 notable moun. tains: Rainier (14,526 ft.), Adams (12,470 ft.), Baker $(10,827$ ft.), Glacier Peak $(10,436 \mathrm{ft}$.$) and St. Helens (9750 ft.).$ The area of perpetual snow is extensive on all of these and glaciers are numerous on most of them. At the south side of the state along the Columbia River, the lowlands of western Washington are continuous with those of eastern Washington.

A good many places in the Cascades are accessible by train, stage and private conveyance. Other portions are accessible only by horse trail, while still others can be reached only by rather strenuous trips on foot.

East of the mountains the region tends to be semi-arid, while on the west the conditions are much more humid. West of the mountains the climate tends to be equable, while on the east side the differences between the summer temperatures and those of the winter are greater. East of the mountains there are elevated plains of considerable area, the soil of which is in some places of volcanic ash and in other places is of basaltic origin. West of the mountains the characteristic soil is largely glacial till or gravelly outwash. The Blue Mountains in the southeastern portion of the state have an elevation of $5000 \mathrm{ft}$. The northeastern portion of the state is also somewhat mountainous. 
The Pacific Ocean borders the state on the west, forming in many places, long, straight beaches of sand behind which sand dunes are often extensive. Such dune areas are found in the vicinity of Willapa Bay and Grays Harbor. These dune regions may be reached from Aberdeen, Hoquiam, South Bend or Ilwaco.

The mouth of the Columbia River forms a broad navigable indentation between Washington and Oregon. A little north of this river is Willapa Bay which forms an extensive harbor, largely enclosed by a long peninsula of sand extending north from the rocks at the north side of the mouth of the Columbia River. There are extensive sand dunes on this peninsula. Grays Harbor, also enclosed partially by sandy peninsulas, lies to the north of Willapa Bay.

In some places, notably toward the north the coast of this state is rocky. There is a considerable extent of rocky coast in the vicinity of Cape Flattery.

The most extensive indentation of the coast is that formed by Puget Sound and the Strait of Juan de Fuca. This indentation begins with the Strait, which forms the northern boundary of the state for about $100 \mathrm{mi}$. and is extended by the Sound, which continues south about 80 mi. The shores of Puget Sound as well as those of the numerous islands that it contains are very irregular. High bluffs of glacial till and of rock are common along these shores, though in some places there are sandy beaches and in others salt marshes are common.

The Olympic peninsula lies between Puget Sound and the Pacific Ocean. It is largely mountainous. Mount Olympus (8150 ft.) has extensive glaciers. The peninsula contains several large lakes.

The San Juan Islands lying between the Strait of Juan de Fuca and the Gulf of Georgia are so attractive from the standpoint of their natural features as to deserve special mention. The rain fall in these islands is scanty-usually about 20 inches-contrasting with an average of about 34 inches in Seattle and over 100 at Cape Flattery and other points on the west coast of the state. There are considerable exposures of bare rock on these islands, and the soil where present is usually thin. There is glacial till in some depressions and on some slopes, especially on north slopes. Lime is abundant at several places on San Juan Island. Some of the smaller islands of the group are flat topped and extremely dry. Mount Constitution (2500 ft.) is situated on Orcas Island and is the highest point in the islands. It commands a view of the whole group of the San Juan Islands as well as of some of the mainland and Vancouver Island.

\section{B. LAND AND FRESHWATER PLANT AND} ANIMAL COMMUNITIES

The plant communities of the state, considered in the larger sense, may be grouped under seven heads. In preparing the following account of them free use has been made of the chapter on Zonal Distribution of Washington Plants in Piper's Flora of Washington. The names of the Merriam life zones are used in parentheses. (The section on sagebrush vegetation was written by Ellis B. Harris.)

\section{Northwestern moist coniferous forest (see also British Columbia, page 153, and Oregon, page 181)}

A. Plants. ${ }^{1}$ The great luxuriant forests of Douglas fir (Humid Transition zone), are continuous over all of western Washington that is not included in the following belts. Characteristic trees in addition to the Douglas fir, which often forms $90 \%$ of the forest, are giant cedar western hemlock (Tsuga heterophylla), red alder (Alnus oregona), broadleaf maple (Acer macrophyllum), and vine maple (A. circinatum). Large areas of virgin forest are still found in this belt. They are extremely damp and their

\footnotetext{
1 Scientific names of plants and animals mentioned in the British Columbia account do not occur here. (See page 150.)
} 
undergrowth is luxuriant. The ground is in many places covered with fallen, partially decayed tree trunks overgrown with mosses, lichens and liverworts. Ferns and large-leaved herbs are common. This zone is composed largely of evergreens. The large trees are mostly evergreen conifers, the number of deciduous trees being relatively small. Broad-leaved evergreens are common. The madrona (Arbutus menziesii) is a tree. Among the shrubs are salal, two species of Oregon grape (Berberis nervosa and $B$. aquifolium), the sticky balm (Ceanothus velutinus), the rhododendron (Rhododendron californicum), a manzanita and Kinnikinnick (A. uva-ursi). Many herbs such as wild ginger (Asarum caudatum) and others remain green all winter.

B. Animals. ${ }^{1}$ The notable mammals are the shrews (Sorex trowbridgii), Bendire water shrew (Neosorex bendirii), black bear, bob-cat, deer-mouse, chipmunk (Eutamias townsendii), Douglas squirrel, silver-gray squirrel (Sciurus griseus), flying-squirrel (Glaucomys sabrinus oregonensis), sewellel (Aplodontia rufa), Washington hare (Lepus washingtonii), black-tailed deer, and wolf (Canis gigas).-L. R. D.

In this forest salamanders abound (Triturus torosus, Ambystoma macrodactylum, A. paroticum, Dicamptodon ensatus, Rhyacotriton olympicus, Plethodon intermedius, $P$. vandykei, and Ensatina eschscholtzii) and the tree-frog (Hyla regilla.) The two frogs, Rana aurora and $R$. pretiosa, are common, as also is the western toad. The discoglossoid toad (Ascaphus truei) is numerous locally in streams. Of snakes the garter-snakes (Thamnophis sirtalis concinnus and T.o. ordinoides) are common; the lizard (Gerrhonotus principis) is fairly numerous, especially in clearings.

Seven rather distinct associations are obvious in this area.

a. Uplands, characterized by salal, Oregon grape (Berberis nervosa), the Scouler willow (Salix scouleriana), red huckle berry (Vaccinium parvifolium), thimble berry (Rubus parviflorus), redflowered currant (Ribes sanguineum), sword fern and bracken fern (Pteris aquiliana).

$b$. Bottom lands in which are found grand fir broadleaf maple, Oregon ash (Fraxinus oregona), cottonwood (Populus trichocarpa), western dogwood (Cornus occidentalis), crab apple (Pyrus rivularis), vine maple, devil's club (Fatsia horrida), salmon berry and red-berried elder (Sambucus callicarpa).

$c$. Gravelly prairies (see also Oregon account) on which are found scattered oaks (Quercus garryana) mixed with Douglas fir at the borders of the areas. Western yellow pine is also found. These areas are found between Tacoma and Olympia and southward. In spring and early summer they are carpeted with flowers among which are violets, lupines, dog-tooth violet (Erythronium giganteum) shooting star (Dodecatheon latifolium), and many others. In late summer these areas are dry and appear very barren.

$d$. Sphagnum bogs, whose surface is composed mainly of living sphagnum, which is underlaid with soft, partially decayed organic matter. They occur in undrained places frequently bordering swamps or lakes. Their most characteristic flora is Labrador tea, swamp laurel (Kalmia polifolia), cranberry (Vaccinum) sundew (Drosera rotundifolia) and cotton grass (Eriophorum russeolum). Sweet gale is common on the borders of these bogs in the interior, and the wax myrtle (Myrica californica) is found around those near the coast. Dwarf birch (Betula glandulosa) also occurs around these bogs in the vicinity of Seattle and elsewhere. The bunchberry and crow-berry are found in some. In the later stages of succession these bogs are invaded by trees, usually stunted. The western hemlock is usually the first invader and grows best in them, though almost pure stands of western white pine or of lodgepole pine are found in some. Cedar is common. Douglas fir invades these bogs last and grows most poorly in them. Deciduous trees are rare in these bogs, though the aspen (Populus tremuloides), the crab apple (Pyrus rivularis) and some willows are common in the very wet 
zone (marginal ditch), found around nearly all sphägnum bogs.

$e$. Salt marshes are common along the shores of Puget Sound and elsewhere along salt water. Many of them are located near the mouths of streams or behind high sea beaches. Nearly all of them are inundated by salt water at extreme high tide, and many of them are under water at even ordinary high tides. Glass-wort and saltgrass are the most abundant species. The former is commonly infested with dodder (Cuscuta squamigera). Other species frequently found in these marshes are seaside atriplex (Atriplix littoralis), a fleshy composite (Jaumea carnosa), black slat wort (Glaux maritima), and seaside arrow grass (Triglochin maritima). The higher sea beaches fronting many of these marshes commonly have a characteristic seaside flora which does not extend much into the salt marsh proper. Among the plants occurring on these beaches are the beach pea (Lathyrus maritimus), sand spurry (Tissa marina), sand-bur and a hog-fennel (Lomatium nudicaule).

$f$. Sand dunes are abundant on the ocean coast but do not occur on Puget Sound. They shift rapidly, overwhelming forests, many of which are almost pure stands of lodgepole pine. Among the plants characteristic of these dunes and other shifting sand along the shore are two abronias (Abronia acutalata, and shaggy pea (Lathurus littoralis), a lupine (Lupinus littoralis), a sedge (Carex macropcephala), Glehnia littoralis and many others.

$g$. There may also be distinguished a coastal strip of forest in which Sitka spruce largely replaces Douglas fir. Lodgepole pine is also common in places, especially around sand dunes and bogs. Among the other plants characteristic of this strip are fool's huckleberry, a currant and the single beauty (Moneses uniflora).

\section{Arid coniferous forest (western yeilow pine forest)}

a. Plants. These forests occupy the lower portion of the eastern slope of the Cascades, the lower levels of the Blue mountains, and nearly all of the northern portion of eastern Washington, including considerable portions of Okanogan, Ferry, Stevens and Pend Oreille counties. Western yellow pine is the dominant tree, though some Douglas fir occurs. Among its shrubs are nine bark (Opulaster pauciflorus), buck brush (Ceanothus sanguineus) and rose (Rosa gymnocarpa). In the higher altitudes huckleberry (Vaccinium macrophyllum) and pine grass are common in these forests.

b. Animals. The mammals of the yellow pine forests of eastern Washington are to a considerable extent an admixture of elements from the montane forests and from the bunch grass. Among the more conspicuous forms are the coyote (Canis lestes), deer-mouse, pocket-gopher, ground-squirrel (Citellus), chipmunk (Eutamias), goldenmantled ground-squirrel (Callospermophilus), and pine squirrel.-

In the yellow pine forests of the eastern part of the state the bull-snake (Pituophis catenifer catenifer) and the racer both occur while garter-snakes are found chiefly along streams and the rattle-snake (Crotalus oreganus) chiefly in rocky places.

\section{Mixed mountain forest (Canadian Zone)}

This ecotone type extends upward from the dense mesophytic coniferous forest to about $6000 \mathrm{ft}$. This belt is poorly defined, since few species are confined to it alone. It forms a continuous area in the Olympics and the Cascades and is also found adjacent to the subalpine belt where it occurs in eastern Washington, as well as in a considerably area in Ferry County. Among the trees found in this belt in western Washington are western white pine lodgepole pine (murrayana), grand fir, western hemlock, Douglas fir, silver fir (Abies amabalis) and noble fir (A. nobilis), while in eastern Washington. Engelmann spruce and western larch replace the last two species. Among the 
shrubs of this belt are blue huckleberry (Vaccinum ovalifolium), fool's huckleberry (Menziesia ferruginea), mountain box (Pachistima myrsinites), blackberry (Rubus nivalis), and dwarf cornel or bunch-berry, (Cornus canadensis). Among the herbs are Clintonia ( $C$. uniflora), fairy-bells (Disporum oreganum) and two species of wood-sorrel (Oxalis oregana and O. trillifolia).

Mammals. The following species of mammals occur more or less generally in the montane forests over the state: raccoon (Procyon psora pacifica), marten (Martes americana group), black bear, cougar (Felis concolor group), bob-cat (Lynx fasciatus group), Cascade redfox (Vulpes cascadensis, in Cascades), yellow-haired porcupine (Erethizon epixanthum), deer-mouse (Peromyscus maniculatus group), woodrat (Neotoma cinerea occidentális), red-backed vole (Evotomys), jumping-mouse (Zapus), chipmunk (Eutamias townsendii), snowshoe hare (Lepus bairdii group), black-tailed deer (Odocoileus columbianus), and elk (Cervus canadensis occidentalis). In the Cascade and Olympic mountains the Douglas squirrel (Sciurus douglasii) is common, while in the mountains of eastern Washington it is replaced by the pine squirrel (Sciurus hudsonicus richardsonii). - L. R. D.

Among the characteristic reptiles and amphibians of the montane forests in the eastern parts of the state are the rubber-snake (Charina bottae), the racer (Coluber constrictor mormon), and especially along streams the garter-snake (Thamnophis ordinoides ordinoides), the western toad (Bufo boreas boreas) and the western frog (Rana pretiosa).

\section{Subalpine forest (Hudsonian Zone)}

The Hudsonian Zone is characterized by alpine trees tending to become prostrate at their extreme limits: This is found largely in the Cascades and the Olympics, though there is a considerable area of it in the Blue Mountains in the southeastern corner of the state, and a line of it in the extreme northeastern corner in the Kaniksu National Forest. There are also five isolated patches of it on mountain peaks of the northeastern portion of the state (Bonaparte, Tonk, Baldy, Calispell, and Chewaiah). The trees found in it are alpine fir, Alaska cedar, Chamaecyparis-nootkatensis, mountain hemlock, white-bark pine. Among the shrubs of this zone are a juniper (Juniperus communis siberica), the white rhododendron, a currant, and the western mountain ash. Bear grass is conspicuous and abundant in places.

\section{Alpine meadow (Arctic Zone)}

a. Plants. This belt is sharply defined and is similar in conditions and to a certain extent in species to the arctic meadows of the extreme northern regions of North America, many of the species found in this belt in Washington being common at or near sea level in western and northern Alaska. This belt is confined to the higher portions of the Cascades and the Olympics, and is not continuous, consisting largely of isolated patches. Among the plants charateristic of this region are a low bush huckle berry (Vaccinum deliciosum) producing delicious fruit in late summer, a buttercup (Ranunculus suksdorfii), a marsh marigold, a shooting star (Dodecatheon jefferyi), a pasque flower (Pulsatilla occidentalis), two lupines (Lupinus subalpinus and $L$. Lyallii), a painted cup (Castilleja oreopola), a cinquefoil (Potentilla flabellifolia), red heather, white heather, a blue gentian (Gentiana caly$\cos a$ ), a crimson monkey flower (Minulus lewisii), several arnicas (Arnica spp.), a saxifrage, partridge foot (Lutkea pectinata) and three grasses (Festuca viridula, Poa arctica, and Argosteris rossae).

b. Animals. Alpine summits. Characteristic mammals of the treeless alpine summits of the Cascade Mountains are the hoary marmot (Marmota caligata cascadensis), pika (Ochotona princeps brunnescens), bighorn sheep (Ovis canadensis californiana), and 
Rocky Mountain goat (Oreamnos americanus). The extensive talus slopes are the habitat of the marmot and pika. The marmot (Marmota olympus) is also found in the higher altitudes of the Olympic Mountains.

\section{BUNCH GRASS PRAIRIE}

(The bunch grass community with the western yellow pine community makes up Merriam's Arid Transition Zone.)

a. Plants. The bunch grass area is quite extensive and is bordered above by the western yellow pine forest and below by the sagebrush area. It occupies portions of Okanogan, Douglas, Lincoln, Spokane, Adams, Whitman, Walla Walla, Columbia, Garfield and Asotin counties. It is grass covered and mostly treeless. Willows (Salix spp.), haw (Crataegus brevispina), aspen and cottonwood (Populus trichocarpa) are the principal trees and are found mostly along streams and around springs. Undershrubs are snowberry (Symphoricarpos racemosus), roses (Rosa nutkana and $R$. pisocarpa), gooseberries (Ribes inerma and $R$. irriguum) and a low birch (Betula microphylla). Bunch grass (Agropyron spicatum) is the most characteristic plant of this community. Other plants are June grass (Poa sandbergii), lupines (Lupinus ornatus, $L$. sericeus and $L$. wyethii), sunflowers (Helianthella douglasii and Balsamorhiza sagittata), and Indian paint brush (Castilleja miniota). The vegetation in this area is frequently more luxuriant on north slopes than on south.

b. Animals. Some of the characteristic forms of the bunch-grass of eastern Washington are the coyote, mountain weasel (Mustela arizonensis), skunk (Mephitis occidentalis major), badger (Taxidea taxus neglecta), pocket-mouse (Perognathus), pocket-gopher, groundsquirrels, and white-tailed jackrabbit (Lepus townsendii). In the willow and cottonwood timber along the streams occur a number of other forms, such as the shrew (Sorex vagrans dobsoni), mink (Mustela vison energumenos), harvest-mouse (Reithrodontomys megalotis nigrescens), deer-mouse, muskrat (Ondatra zibethica osoyoosensis), and beaver (Castor)-L.R.D.

The bull-snake is the most conspicuous reptile of the bunch grass areas. Here also occur the racer and the skink (Eumeces skiltonianus). The gartersnake (Thamnophis o. ordinoides) the western toad, the leopard-frog (Rana pipiens), the western tree-frog (Hyla regilla), and the pond-turtle (Chrysemys bellii bellii) occur chiefly along streams. -H. T. G.

7. Sagebrush semi desert (see also in British Columbia and Oregon accounts) (Upper Sonoran Zone)

a. Plants. This community is almost wholly included within a line surrounding the Columbia basin below an elevation varying from 1200 to $1700 \mathrm{ft}$. depending upon slope and precipitation. Where the elevation exceeds $1700 \mathrm{ft}$. or the rainfall about 12 in. sagebrush gives way to bunch grass. The annual precipitation of this basin, as is typical of such districts, is low, ranging from 6 to 12 in.

Sagebrush is the most conspicuous plant of the area, though according to Piper, there are frequently found rabbit brush, hop sage (Grayia spinosa), antelope brush (Kunzia tridentata), and in alkaline situations, greasewood. There also occur frequent and characteristic patches of prickly pear (Opuntia polycantha). The sagebrush often reaches a height of from 8 to $12 \mathrm{ft}$., and becomes a veritable thicket, though in some localities it does not become more than a few inches high. The appearance of an extensive sagebrush plain is that of a desert waste. Another feature of the sagebrush district is the occurrence here and there of dunes of drifting sand. In some places these dunes practically wipe out all forms of vegetation as they march on their age-long journey. In their march, however, they are closely followed by the ever-present sagebrush. Álong the coulees, on the hills which 
reach an elevation too great to be irrigated, on the basalt stab lands and along the bluffs bordering the Columbia river are extensive tracts which must remain permanently sagebrush.

b. Animals. In the sagebrush of the Columbia River basin occur such typical forms as the coyote, badger, pocketmouse, kangaroo-rat (Dipodomys ordii columbianus), ground-squirrel, blacktailed jackrabbit (Lepus californicus wallawalla), and cottontail rabbit. In the willows along the smaller streams are found the shrew, harvest-mouse, deer-mouse, muskrat, beaver and other riparian species. $-L$. $R$. D.

In the sagebrush occur the rattlesnake, bull-snake, racer, two small lizards (Scelopors occidentalis occidentalis and $S$. graciosus gracilis), the horned toad (Phrynosoma d. douglassii) and spadefoot toad (Scaphiopus hammondii). Along streams occur the garter-snake and the leopard-frog.

\section{MARINE VEGETATION}

The bladder kelp (Nereocystisluetkeana) forms the most conspicuous feature of the marine vegetation of Puget Sound. The huge size of the individual plants, the fact that the bladder-like float is always at the surface of the water, and the fact that it forms such dense beds covering large areas, bring it to the attention of every observer who crosses the waters of Puget Sound. A good bed may be seen at Lincoln Beach, Seattle, and another at Point Defiance, Tacoma. Especially good beds are found in the vicinity of the Puget Sound Biological Station (Friday Harbor) and at other points in the San Juan Islands.

Another kelp (Macrocystis pyrifera) forms beds of considerable size near Neah Bay and Cape Flattery. The sea palm (Postelsia palmaeformis) grows in the same region, forming dense clusters in the littoral zone on rocks that are exposed to violent waves. Pterygophora californica, a perennial kelp with thick, stout stems, grows in the same region and is commonly washed up on the beaches. The feather boa kelp (Egregia menziesii) is also common in this region and also around San Juan Island.

Leaf-like kelps of the following genera are common in the waters of Puget Sound: Laminaria, Cymathaere, Agarum Alaria and Costaria. Several other kelps are also found in certain places. Rockweed (Fucus sp.) is common along many of the rocky shores.

The sea lettuce (Ulva sp.) and other green algae are also common in the littoral zone. Red algae, both filamentous and thalloid, are found in the littoral zone and are also commonly dredged at the Biological Station at Friday Harbor. Many of the filamentous forms are unusually beautiful. Some blue-green algae (e.g. Nostoc) are also found. Mineral-encrusted red algae (Ampiroa and Corallina) are abundant in some places.

Three species of seed plants are found in salt water along the shores of this state, especially in Puget Sound. Eelgrass forms dense growths in shallow waters, and two species of sea basketgrass (Phyllospadix scouleri and $P$. torreyi) grow on rocks exposed to wave action.

\section{Pollution}

In general the waters of the Pacific Ocean, the Strait of Juan de Fuca, and Puget Sound, where they border the State of Washington, are not badly polluted. There is considerable pollution, however, in the vicinity of the salmon canneries during the summer. The sewage from some of the cities (e.g. Seattle) is also discharged into the Sound. At times oil from boats covers the surface of the water in places, and there is more or less of general refuse near cities and along lines of travel of boats. Fortunately the sea gulls act as scavengers and take care of a good deal of the refuse.

Many of the fresh water lakes are practically free from pollution, though those in or near the cities are commonly more or less polluted. For example, Green Lake in Seattle is badly polluted, 
but measures have now been taken to stop pollution and improve conditions by running pure water through the lake. Some small lakes are badly polluted with saw mill waste.

Mountain streams in their upper courses are mostly unpolluted except occasional instances where concentrator water or other material from mines is allowed to run into a small stream. In their lower courses many of them receive the sewage from the towns along their banks, and considerable refuse is also thrown into them. The amount of this sewage, however, is small relative to the volume of flow in the rivers and the pollution is so soon taken care of that the water supply for some of the towns is taken from the rivers. The Skykomish River is an illustration of the conditions mentioned.

\section{National Park}

\section{* mount rainier national park (A3)}

Area 207,360 acres. Elevation of summit 14,526 ft. Has 28 glaciers, 6 of which appear to originate at the very summit of the mountain. The glaciers and snow fields give rise to numerous precipitous mountain streams. Fairly dense forest, mostly coniferous, up to $4000 \mathrm{ft}$. Among the conifers are Douglas fir, western red cedar, hemlock, grand fir, silver fir, noble fir, and western white pine. Among the deciduous trees are maple, alder, and cottonwood. Gradual decrease in density of forest up to $5000 \mathrm{ft}$. At and above that elevation the trees are scattered and stunted. Many rocky ridges and pumice fields above timber line. Large meadows above forests, characterized by rich subalpine flower gardens, containing heathers, daisies, anemones, columbines, Erythroniums, larkspurs, lupines and other flowers. The park has $150 \mathrm{mi}$. of trail including one encircling the mountain.

Tacoma Seattle. Distance by auto road from Tacoma 58 miles, from Seattle 88 miles. Daily stages from both places to south side of mountain. Tacoma Eastern R. R. from Tacoma to
Ashford. Stage from Ashford (6 mi.) to south side of park. Guides and pack animals also available.

Auto road to north side of mountain from Enumclaw. North side also reached by trail from Fairfax (R. R station). Pack animals available at Fairfax. Automobile road from Fairfax up the Carbon River extending several miles within the park.

\section{State Parks and Reserved Park Sites}

\section{A. PARKS}

1. ${ }^{*}$ Chuckanut State Park. (B4.) A tract of 20 acres situated $6 \mathrm{mi}$. south of Bellingham on Chuckanut Drive. It fronts on salt water, part of the shore being sandy beach and part rocky. It has some virgin timber, mostly fir, with some alder. Bellingham $\ddagger$ $6 \mathrm{mi}$. south (a).

2. Jackson State Park. (D4.) A half acre not in a state of nature, preserved for historical reasons. Toledo. Also reached from Winlock $\ddagger$, which is on Nor. Pacific Ry. 5 mi. s.e. (a).

3. *Moran State Park. (B3.) A tract of 2600 acres on the south side of Mount Constitution on Orcas Island in San Juan County. The elevation of the summit of the mountain is $2400 \mathrm{ft}$. and the park extends almost to the summit. This park includes some fine stands of Douglas fir and of western hemlock, as well as some lodgepole pine. Practically all has been burned over within the last 25 years, and in places a pure stand of lodgepole pine has occupied the burns. The large firs and hemlocks were not killed by these fires. Some untimbered rather xerophytic areas in this park will be valued by naturalists on account of their flora of ferns, Selaginella and other plants. The park includes a lake $1 \frac{1}{4} \mathrm{mi}$. long and $\frac{1}{3} \mathrm{mi}$. wide. Deer are numerous. A careful estimate puts the number in the park and the 2000 acre game preserve adjoining it, at 1500 .

Seattle $\neq$, $75 \mathrm{mi}$. north by Steamer; 5 mi. north (h) or (w) from Olgał or East Sound $\ddagger$.

It is hoped and expected that the 
State Parks committee may secure also the tract including the summit of the mountain, a sphagnum bog and some water-front on salt water.

4. *Deception Pass State Park. (D3.) This comprises 2000 acres lying on both sides of Deception Pass. The park includes four islands-two in the pass and two east of it. There is a very strong tide through the pass and it changes suddenly. It is passable for small boats at slack tide only. Large beds of bladder kelp occur in the tideways around the pass. There are several fine sandy beaches and numerous rocky cliffs with sparse timber and other vegetation in the crevices. The timber of this park is mostly fir, of the stunted and distorted sort commonly found in poor soil in exposed situations along salt water.

Seattle $\ddagger, 70 \mathrm{mi}$. north (or Everett $\ddagger 50$ mi. north) Great Northern Ry. 14 mi. south (a) from Anacortesł. Ferry service across the pass.

5. ${ }^{*}$ Crawford State Park. (A4.) A tract of 40 acres including the entrance to Gardner Cave. The cave is extensive and is not fully explored. The park is hilly and is in the western yellow pine zone.

Spokane $\ddagger$, $40 \mathrm{mi}$. n.e. to Newport $\ddagger$, thence $50 \mathrm{mi}$. n. to Metaline Falls $\ddagger$ from which the park is $6 \mathrm{mi}$. n.e. by trail.

6. Money Creek Park. (D4.) A tract of 18 acres near the Skykomish River among the Cascade mountains. It is on the Cascade Scenic Highway, and is privately owned. Heavily timbered, tall, beautiful Douglas firs and some fine cedar, plenty of vine maple; devil's club and other plants of rich coniferous forest.

Everett $\ddagger 50$ mi. east by Gr. Nor. Ry. or stage, 1 mi.s.e. (w) or (a) from Miller Riverł.

7. *Lewis and Clark State Park. (A4.) An area of 520 acres of virgin coniferous timber with the undergrowth practically undisturbed. The smaller animals are also practically undisturbed. The tract is nearly level and has a small stream flowing through it. On Pacific Highway between Chehalis and Toledo (12 mi. north of Chehalis). Chehalis is $50 \mathrm{mi}$. by rail or auto south of Tacoma.

\section{B. RESERVED PARK SITES}

The following park sites have been selected, although formal reservation has not, in all cases, been made. These areas are of interest at present, mainly to automobile tourists only. Local inquiries will be necessary in most cases in order to find them.

*Clarke County. (B4.) Five acres, located just north of Amboy. Portland, Oregon $\ddagger 30 \mathrm{mi}$. north Nor. Pac-Ry. to Woodland $\ddagger$ Wash., thence 15 mi. east (a).

Grays Harbor County. (B4.) (Section 36, township 19 north, range 7 west.) South and east of the county road. Montesanoł or Satsopł.

*Five acres bordering on Boone Street, Aberdeen. On Westport, Highway Aberdeen $\ddagger$, or Hoquiam $\ddagger$.

*King County. (B4.) Five acres on the Sunset Highway, east of Issaquah.

*Five acres bordering road on east side of tract. Vashon Island. Seattle $\ddagger 15$ mi. southwest by stage and ferry to Vashon Heightsł.

3.92 acres, on south side of main traveled highway from Seattleł to North

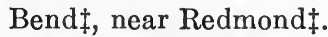

Mason County. (B4.) Located east of the state road and including all tide lands in front of lot 1 . On Olympic Highway. Lilliwaupł.

*Three acres bordering on Hood Canal and on the Navy Yard Highway. Unionł.

Okanogan County. (B4.) Located in lot 3, on Whitestone Lake. Sixteen miles s.w. of Orovilleł.

*Pierce County. (B4.) Section 36, township 18 north, range 3 east. A strip of land lying on each side of the county road (now National Park Highway). Twenty-five miles south of Tacomał.

Spokane County. (B4.) Section 16, township 24 north, range 45 east; on a county road and creek. On paved highway $22 \mathrm{mi}$. from Spokaneł. 
IV. Bird and Game Sanctuaries

\section{A. FEDERAL}

All islands on the west coast of the state from Cape Flattery to the mouth of the Columbia River are federal bird reservations. The birds on these islands are mostly sea birds. No game birds nest on these islands.

\section{B. STATE}

A game preserve one mi. wide is established all around Lake Washington. This closes an area of about 75 sq. mi. Mercer Island in the lake is also closed to hunting. The island is about $6 \mathrm{mi}$. long and two miles wide. There are deer on the island. Lake Washington is over $20 \mathrm{mi}$. long and has an irregular shore line.

\section{COUNTIES}

\section{King County}

a. Foss River Valley. (B2.) Snoqualmie National Forest, virgin except trails. Skykomish $\ddagger$ (w), Tonga (w).

b. Lake Dorothy. (A1.) Closed to fishing. It is about two $\mathrm{mi}$. long and $\frac{3}{4}$ mi. wide. It is in the Cascade mountains south of Skykomish. Inquire at office of King County Game Commission, Court House, Seattle, for method of reaching the lake.

\section{Chelan County.}

a. Four areas aggregating 151,000 acres on which no mammals or birds can be killed for an indefinite period, and no grazing permits can be issued. Set aside by county Game Commissioner with assistance of forest officials.

\section{Other Preserved Areas}

\section{A. SPOKANE $\ddagger$}

1. ${ }^{*} U p$ River Park. (B3.) Area 464 acres. Situated along both sides of Spokane River. On north side, rugged hills whose southern slopes are barren except scattering western yellow pine. Many vernal plants such as Ranunculus glaberrimus, Olsynium grandiflorum,
Frittilaria pudica, Tellima tenella, and Draba verna; later Balsamorhiza sagittata, Sedum douglasii, Piperia sp., and various lupines and composites are found. This park is characteristic of the semi-arid region in which Spokane is situated.-Ellis B. Harris.

2. *Hangman Park. (B3.) Area 294 acres. Situated in a deep canyon in Hangman Creek valley. Bordered on both sides by high, sandy hills or rocky cliffs. More moist than Up River Park because subirrigated from the creek. Has much the same flora as Up River Park, but has also willows, dogwoods (Cornus stolonifera and C. occidentalis), alder, elderberry roses (Rosa nutkana and R. pisocarpa). The park is in a totally wild state and is likely to remain so for several years.-Ellis B. Harris.

3. *Indian Canyon Park. (B3.) Is in a deep gorge. Besides the plants mentioned in the preceding descriptions it has also Philadelphus lewisii, Berberis aquifolium, $B$. repens, Holodiscus discolor, Spiraea mensiesii, S. corymbosa, Opulaster pauciflorus, amelanchier florida, A. cusickii, Rubus pauciflorus, $R$. leucodermis, Arctostaphylos uvuursi, Vagnera amplexicaulis, V. stellata, and Veratrum californicum.-Ellis $B$. Harris.

4. *Mount Spokane. (B4.) A tract of 220 acres, including the summit of the mountain and a $60 \mathrm{ft}$. roadway from its base. The conifers on this tract include grand fir, alpine fir, Engelmann spruce, western larch, western white pine, lodgepole pine, giant cedar, Rocky Mountain juniper (Juniperus scopulorum), and Pacific yew (Taxus brevifolia). The orchids include Cypripedium parvifolium, Corallorhiza striata, and Peramium decipiens. Many of the plants listed under the city parks of Spokane are also found on this tract.-Ellis $B$. Harris.

\section{B. TACOMA}

1. *Point Defiance Park. (B3.) Area over 600 acres. Largely coniferous forest with some deciduous trees. 
Broad-leaved evergreens, native shrubs, flowers, ferns, and mosses, marine water front. Good kelp bed (Nereocystis) easily accessible by rowboat.

2. *Spanaway Park. (B4.) Area 477 acres. Borders on Spanaway Lake, about 20 miles south of the city. Prairie vegetation. Oak trees. Reached by electric car.

3. *Green River Water Shed. (B3.) A tract 27 miles long and 13 miles wide along the Green River in King County. Hunting and fishing prohibited. Confer with city officials of Tacoma before visiting.

4. *Little Nisqually Watershed. (B3.) Area 24,000 acres. Located in Pierce County.

5. *Lake Cushman Power Site. (B3.) Area 7500 acres. Situated at Lake Cushman, Mason County. Part of it will be flooded, but the rest will be left in a state of nature.

\section{c. BELLINGHAM $\ddagger$}

1. *Whatcom Falls Park. (B4.) Area about 100 acres. Coniferous forest with ravine and creek.

2. *Cornwall Park. (B4.) Area 150 acres. Coniferous trees, natural waterfall, ravine and meandering creek.

3. *F'airhaven Park. (B4.) Area 10 acres. Coniferous trees, ravine and small creek.

\section{SEATTLE $\ddagger$}

1. ${ }^{*}$ Roosevelt Park. Area 50 acres. A deep ravine with some level, higher land on each side. Fir, hemlock and cedar predominate. Alder, maple and yew also found. Undergrowth of salal, Oregon grape and huckleberry. Flowers, ferns and mosses abundant. Some liverworts. Situated $\frac{3}{4}$ mile north of campus of University of Washington. Trails.

2. *Schmitz Park. (B4.) Area 45 acres. Native forest with dense undergrowth. Ravines and brook. Natural vegetation undisturbed. Trails.

3. *Seward Park. (B4.) Area 193 acres. Consists of a peninsula extend- ing into Lake Washington. Native forest with dense undergrowth. Trails.

4. *Lincoln Beach Park. (B4.) Area 2.8 acres. Consists of about 500 feet of water front on Puget Sound and a wooded ravine extending up the steep slope to the street car line. Abundance of marine algae accessible at low tide. Good kelp bed (Nereocystis) about 100 ft. from shore.

5. ${ }^{*}$ Cedar River Watershed. (C2.) A tract $25 \mathrm{mi}$. long and $8 \mathrm{mi}$. wide including the Cedar River, its valley and Cedar Lake, located in King County. Hunting and fishing prohibited. Logging has been carried on, but much natural vegetation is still undisturbed. Confer with city authorities before visiting.

6. ${ }^{*}$ The Skagit Power Site. (C2.) When the upper dam is completed the Skagit River as far back as the Canadian boundary (some $25 \mathrm{mi}$. or more) will become a lake. This will be an opportunity to study the colonization of plants at a new water level. The entire drainage basin tributary to this power site is about 1200 sq. mi., the northern portion of it being in Canada.

\section{E. KITSAP LODGE (C2)}

Area 70 acres. Located in Kitsap County. Owned by the Mountaineers. Coniferous forest with some deciduous trees. Hills, ravines and stream. Soil of hills very gravelly, supporting xerophytic vegetation. Pine trees, rhododendron, manzanita, kinnikinnick, mountain box, flowers, ferns, and mosses. Confer with officers of the Mountaineers in Seattle in regard to visiting. .

\section{*F. BUNCH GRASS VEgETATION (B4)}

Area 3 acres. On the farm of the Washington State College, Pullman $\ddagger$. Splendidly representative of the conditions that are rapidly disappearing from Eastern Washington. F. L. Pickett.

$$
\text { *G. guinault lake area (A3) }
$$

Seven thousand acres bordering on Lake Quinault in the Olympic peninsula. 
It includes about three-fourths of the shore line of the lake (though the lake itself is a part of the Quinault Indian Reservation) and extends to the mountain summits on the north and east. It lies entirely in the Olympic National Forest, except that 40 acres of privately owned land is included. It has been set aside by the district forester as a recreation area whose scenic features are not to be disturbed. It is under the supervision of the United States Forest Service. A summer cottage area has been established along the lake where a limited amount of cutting is permitted under supervision.

A large part of the 7000 acres is covered with virgin forest, much of it very dense and consisting largely of enormous trees of Douglas fir. There is also some cedar. Ferns and other undergrowth are abundant, and lichens and moss cover many of the tree trunks and branches profusely. The original animal communities are practically undisturbed. Deer, bear, cougars and bob-cats are common.

Tacoma $\ddagger$, 60 mi. west, Nort. Pac. Ry. to Hoquiam $\ddagger$, State $35 \mathrm{mi}$. north from there to Olson $\ddagger$, on Lake Quinault. Roads (a) to some parts. Trails (w) or (h) to some others. Guides usually available.

\section{Marine preserve}

A marine preserve was created by the 1923 legislature of the State of Washington. It is composed entirely of the shores of certain islands and the waters lying between these islands. It comprises San Juan County and also Cypress Island which is in Skagit County. The act provides that with the exception of bladder kelp (Nereocystis Luetkena) and of articles used for food, there shall be no collecting of plants or animals below the high tide line, except by permission of the director of the Puget Sound Biological Station. The object is to prevent the depletion of the plants and animals of the sea in the region about the Station. The reason for excepting the bladder kelp is that it often interferes with fish traps. The station has 485 acres of land mostly cutover timber land which is held as a wild life preserve. One mile northeast from Friday Harbor, Wash.-G. B. R.

\section{Other Areas that Should be Preserved}

1. Wooded area. (H8.) Area 3 acres; deciduous trees; includes a flooded plain; has typical vegetation of a stream margin of the region. Much frequented by birds. Walla Walla.-H. S. Brode.

2. Steppe area. (B3.) Of 160 acres or more in Walla Walla County. Hills and river; cottonwood and willow; native grass land. Prescottf, Waitsburgł.-Lee R. Dice.

3. Area along Snake River. (C3.) In Walla Walla County; area two square miles or more, extends one mile along the river, including the river bank, and south two miles; includes river valley, high basaltic cliff, canyon walls, and a good area of bunch grass on top of hill. Utilized at present for grazing only. Lyon's Ferry. Lee R. Dice.

4. Sage Brush. (C3.) An area of one square mile about two miles east of Wallula $\ddagger$ and extending north from the Walla Walla River. Typical sagebrush. Area should include a small portion of the Walla Walla River in order to preserve the native willow conditions along the stream. Walla Wallał, Walla Walla County, $30 \mathrm{mi}$. west via O. W. Ry. to Wallula.-Lee. R. Dice.

5. A forested area of about 50 acres around Baker Lake in Whatcom County. Coniferous and deciduous trees; flood plains; talus slopes and swamps; mountains, canyons and lake shore; beaver, deer. Seattle. Great Northern Ry. $100 \mathrm{mi}$. NE. to Concrete $\ddagger$, thence $20 \mathrm{mi}$. north by trail (w) or (h).-H. B. Ward.

6. A sphagnum bog (cranberry marsh), including a bog lake. One hundred and sixty acres should be preserved. This includes about 50 acres of typical sphagnum bog with lake in center; includes also about 30 acres of hard hack 
swamp, some logged off land and a large portion of Graham Lake which borders the bog. Bog flora: Labrador tea, swamp laurel, cranberry, sundew, lodgepole pine. Seattle $\ddagger$, 20 miles N. E., N.P.R.R., 1 mi. south (w) Maltby $\ddagger$.

7. Salt Marsh. (B4.) Central portion covered with such salt marsh plants as Salicornia, Atriplex, Distichlis, Triglochin and Glaux. Dodder is parasitic on several of these. Along each shore is a gravelly, wave-built ridge with a flora of Gaertneria, Lomatium and grasses. Vegetation not likely to be disturbed at present. There are numerous other salt marshes in the region. One outside of the city could be obtained much cheaper, but no others seen show all of the plant communities found in and around this one. Situated in the City of Seattle between Fort Lawton and the West Point Light house.

8. Wooded ravines on the campus of the University of Washington, Seattle. (B4.) About 10 acres of forest. Conifers, deciduous trees, broadleaf evergreens, native flowers, ferns (7 species), mosses, liverworts.

9. Swamp and ravine on the south side of Liberty Lake in Spokane County. This includes very characteristic swamp and ravine vegetation. The ravine is deep, and has a mountain stream in it. - Ellis B. Harris.

\section{Literature List Botany}

1. Allen. Forests of Mount Rainier National Park, 1916, 32 pages, including 27 illustrations, 20 cents. Contains descriptions of the forest cover and of the principal species.

2. Document 190, Sixty-second Congress, second session, Washington, D. C., 1912. Contains several papers on kelps of this region.

3. Flett. Features of the flora of Mount Rainier National Park. 1916, 48 pages, including 40 illustrations, 25 cents. Contains descriptions of the flowers, trees and shrubs in the park.

4. Frye and Rigg. Northwest Flora, University Book Store, Seattle. (Out of print, but may be consulted at libraries.)

5. Frye, Rigg and Crandall. The size of kelps on the Pacific Coast of North America. Bot. Gaz. Vol. 60 , pp. 473-482, 1915.
6. Hotson. Sphagnum as a Surgical Dressing. Northwest Division Red Cross. Copies of this may be had free, from Prof. Hotson, Univ. of Wash., Seattle.

7. Piper and Beattie. Flora of the Northwest Coast. State College, Pullman, Wash.

8. Publications of the Puget Sound Biological Station, Friday Harbor, Wash. Dr. T. C. Frye, Director, Univ. of Wash., Seattle. Many of the papers in these volumes deal with plants and animals of the Puget Sound region.

9. Report 100, U. S. Dept. of Agriculture. Contains papers on kelp of the West Coast and Alaska.

10. Weaver. A study of the root systems of prairie plants of southeastern Washington. Pl. World, Vol. 14, pp. 227. 1915.

\section{Fauna}

Bovard, J. F., and Osterud, H. L. Partial list of the animals yielding embryological material at the Puget Sound Biological Station. Publ. Puget Sound Biol. Sta., 2: 127-137. 1918.

Bush, Mildred. Key to the Echinoderms of Friday Harbor, Washington. Publ. Puget Sound Biol. Sta., 2: 17-44, 58 figs. 1918.

Dawson, William Leon, and Bowles, John Hooper. The birds of Washington. 2 vols., 997 pp., numerous illust. Seattle, 1909.

Dice, Lee Raymond. The Mammals of Southeastern Washington. Jour. Mamm., 1: 10-22, pls. 1-2. 1919.

Johnson, Herbert Perlin. The Polychaeta of the Puget Sound region. Proc. Bost. Soc. Nat. Hist., 29: 381-437. 1901.

Jordan, David Starr, and Starks, Edward Chapin. The fishes of Puget Sound. Proc. Calif. Acad. Sci., 2nd' ser., 5: 785-855, pls. 74-104. 1896.

Kincaid, Trevor. An annotated list of Puget Sound fishes. Dept. of Fisheries, State of Wash., 51 pp., 114 figs. 1919.

Oldroyd, Ida S. The marine shells of Puget Sound and vicinity. Publ. Puget Sound Biol. Sta., 4:1, illus. 1924.

Taylor, Walter P. A distributional and ecological study of Mount Rainier, Washington. Ecology, 3: 214-236, 4 figs. 1922.

Way, Evelyn. Brachyura and crab-like Anomura of Friday Harbor, Washington. Publ. Puget Sound Biol. Sta., 1: 349-382, 28 figs. 1917. 


\section{OREGON'}

By Thornton T. Munger, William E. Lawrence and Howard M.

\section{WIGHT}

I. GENERAL CONDITIONS (T. T. M.)

\section{Topography}

The state borders on the Pacific Ocean, it is traversed by coast ranges of mountains near the ocean, and by a much higher range, the Cascade Range, farther inland, between which is a troughlike series of valleys of low altitude and less humidity than the westward slopes of each range. East of the Cascade Range is a plateau of arid or semi-arid condition intersected by deep canyons on which are scattered detached mountain masses. The altitudes in Oregon range from sea level on the west to $11,253 \mathrm{ft}$. on $\mathrm{Mt}$. Hood. The prevailing altitude of most of eastern Oregon is over $3500 \mathrm{ft}$.

The ocean strip has salt marshes, and sand dunes; the interior has every type of flood plain, valley floor, ravine, canyon, swamp, hillside and bluff; the high mountains have talus slopes, old and fresh moraines, alpine meadows and wastes, mountain meadows or bogs, recent and old lava flows, waterfalls, natural lakes and uncontaminated streams; and the Eastern Oregon plateau has deserts, alkali and fresh lakes and swamps, and mountains and valleys of every description.

Soils. There is a wide range in soils over the state. Pure sand on the dunes of the Coast and Columbia River, great areas of loess in eastern Oregon, glacial deposits in the mountains, river deposits, peats, and of special interest, great areas of fresh volcanic ash and pumice which blanket parts of the Cascade Range and eastern Oregon, together with lava flows upon which soil formation has hardly started.

\section{Climate}

Precipitation. West of the Coast Range and on the western slopes of the

1 Where there was no cuöperation between the authors their names stand in the order of the receipt of their manuscripts and the authorship of the different parts is indicated.
Cascades the annual precipitation is over 100 in. The valleys between the Coast and Cascade Ranges have about 40 in. per year, well distributed except during a two months' summer drought. East of the Cascade Range the climate is dry, ranging as low as 7 in. and averaging perhaps 20 in.

Temperature. West of the Cascade Range the climate is very equable, extreme heat and cold being rare. The diurnal range is small. It is an insular climate. Along the ocean strip a minimum winter temperature as cold as $20^{\circ} \mathrm{F}$. is uncommon. East of the Cascade Range the climate is continental and extremes of both heat and cold are experienced. Cold nights (frosts at the higher altitudes) are the rule throughout the year. Much cloudy weather is usual west of the Cascades while clear skies and considerable wind are the rule east of the mountains. On the mountains an alpine climate prevails.

\section{Original biota}

A. Plant ${ }^{2}$ communties (W. E. L.). A summary of the plant associations of western Oregon follows:

Douglas fir forest (Hygrophytic coniferous forest)

Spruce forest (Hygrophytic coniferous forest)

Cedar-hemlock forest (Hygrophytic coniferous forest)

Redwood forest

Siskiyou chaparral

Hill prairie (or grassland)

Valley prairie (or grassland)

The Cascade Range of Mountains extending from the California line to the Columbia river, divides the state of Oregon into an eastern dry and a western humid section. This long mountain range serves as an effective barrier to the moisture laden winds from the ocean. The natural flora of the two sections, therefore, differs in the principal species of plants and the landscape aspect.

Western Oregon. Western Oregon is characterized by a moister climate due to the Cascade barrier. The Coast Range

${ }^{2}$ Scientific names of plants mentioned in British Columbia and Washington do not occur here. 
in the western half also serves as a secondary barrier, producing a still more humid coastal strip. In southwestern Oregon the Cascade and Coast ranges merge into the Siskiyou mountains. This region is somewhat drier. The Willamette, Umpqua, and Rogue River valleys are the principal low areas between the two mountain ranges. Elsewhere the western part of Oregon is broken into numerous mountain peaks and ridges with small and often long, narrow valleys between.

The bulk of the mountain and foothill area is covered by a heavy forest of Douglas fir (Pseudotsuga mucronata). Western cedar (Thuja plicata), and western hemlock Tsuga heterophylla may replace the Douglas fir on the moister slopes and in the $\mathrm{v}$-shaped valleys. The lowland white fir (Abies grandis) on the low lands, the noble fir (Abies nobilis) silver fir (Abies amabilis), and mountain hemlock (Tsuga mertensiana) on the higher elevations, and Sitka spruce (Picea sitchensis) near the coast may occur as conspicuous associates if not occasional dominants in the Douglas fir forest. The Sitka spruce characterizes the moist coastal strip along the northern half of the state, while the Port Orford Cedar, Chamaecyparis lawsoniana is an important Coastal species in the southwestern part of Oregon. A small stand of very fine redwood (Sequoia sempervirens) is found in the fog belt in the extreme southwestern corner of the state. Elsewhere the lodgepole pine (Pinus contorta) occupies the sandy coastal area.

In the drier mountains of southwestern Oregon, the western yellow pine, Douglas fir, and incense cedar (Libocedrus decurrens) make. up the coniferous forest.

A dense undergrowth occurs throughout much of the humid coniferous forest in western Oregon. Salal, vine maple (Acer circinatum), salmon berry (Rubus spectabilis), Devil's club (Fatsia horrida) and other shrubs often grow so profusely that it is difficult to travel on foot. Along the forested streams in the northern part of western Oregon numerous species of deciduous shrubs and trees are always seen. Oregon ash (Fraxinus oregona), broadleaf maple (Acer macrophyllum), choke cherry (Prunus demissa), western flowering dogwood, and alders (Alnus oregona) are common. Willows, black cottonwood (Populus trichocarpa), hazel (Corylus californica), chittim or cascara (Rhamnus purshiana), and Oregon grape (Berberis aquifolium) are more common along the more open streams.

The original forest was composed of Douglas fir, but in the more mature stands western cedar and western hemlock will take the place of Douglas fir. Extensive lumbering operations, and great fires in the past have destroyed large stands of this one time magnificient and valuable timber. It is a real fight to preserve these forests from fire, and the United States Forest Service is doing a great work in preserving the remainder of this wonderful national asset. Oregon has more standing merchantable timber than any other state in the Union, and it behooves every citizen to assume personal responsibility for his part in the prevention of fire and to further reforestation.

Fires have probably been recurrent for an indefinite period in the past so that the bulk of the forest has probably always been composed of the Douglas fir. Under normal conditions these burned areas will reforest. On the west slope of the Coast mountains and elsewhere are large areas that are not reforesting. These old burns are covered by a dense growth of the bracken fern (Pteris aquilinum pubescens) and the accompanying herbaceous flora. The bracken fern is also common on burns and cut over lands that are restocking. However in the latter situations the fern is quickly overtopped by the vine maple, service berry (Amelanchier florida), thimble berry (Rubus parviflorus), red flowering currant (Ribes sanguineum), blue elder berry (Sambucus glauca), ocean spray (Holodiscus discolor) and young Douglas fir. 
Wherever this western mesophytic coniferous forest borders on the prairie it is bounded by the Garry or Oregon oak (Quercus garryana), in the northern part of the state and by the black oak (Quercus californica), madrona and manzanita in the southern portion.

The Willamette valley is the largest of the important valley sections in western Oregon. It differs from the Umpqua and Rogue river valleys chiefly in its size and the more northerly location. It is therefore a cooler valley. A study of the floras of these valleys shows that the southern floras extend northward into the Rogue and Umpqua valleys, while the northern plants may be found southward into these sections. Intercepting transverse mountain divides serve in part as climatic barriers to the northward and southward migration of plants. These intercepting ranges are neither high enough nor com. plete enough to serve as effective barriers in themselves. Their true significance seems to be in the alteration of the temperature and moisture conditions, which in turn controls the character of the vegetation. The numerous smaller valleys take on the character of the larger valleys. The Coos Bay, and Tillamook sections are more humid, whereas the Hood River Valley which drains into the Columbia on the north is more like the Willamette Valley.

The floor of the Rogue river valley was originally a sagebrush desert surrounded by grassland. The prairie may be seen on the higher ground and lower slopes. Between the hill-prairie and the forest is a zone of chaparral. There may be a question regarding the occurrence of typical chaparral, in Oregon. The name Siskiyou chaparral may be used to distinguish the brush lands of Southwestern Oregon from chaparral of California and elsewhere in the Southwest. However, at present, there is much ground occupied by manzanita (Arctostaphylos spp.), antelope bush (Purshia tridentata), young madrona, scrub oaks, and young yellow pine.

In the Umpqua valley and corre- sponding situations the black oak is intermixed with the Garry or Oregon oak and replaces it to some extent on the exposed hill slopes. Alder, broadleaf maple, service berry, chinquapin (Castanopsis chrysophylla), Oregon or Coos Bay myrtle (Umbellularia californica), and black cottonwood are characteristic hardwoods. The Oregon or Coos Bay myrtle is found more abundantly in the coast sections of southern Oregon.

There are two types of prairie in the Willamette, Umpqua, and other northern valleys in western Oregon-hill prairie and valley prairie. These are not always distinct. The hill slopes are drier early in the season. At present weedy bromes and fescues are the dominant hill prairie grasses. The grasses of the valley are almost all introduced. One of the original grasses (Deschampsia caespitosa) may still be seen along the roadside places.

Eastern Oregon. The eastern section is a high plateau that rises rapidly from the Columbia river southward to 4000 and $5000 \mathrm{ft}$. in altitude on the interior high desert. Deep canyons are cut through the plateau and in the mountains. Rising above the plateaus are numerous buttes and mountain ranges varying in altitude from a few hundred feet above the plateau to over $9000 \mathrm{ft}$., above sea level in the Blue Mountains.

All of the area lies in the Cool Zone of Livingston and Shreve, ${ }^{3}$ so that the character of the flora is determined by this and the low average rainfall, which is especially true during the growing season. Local differences are affected chiefly by slope exposure and altitude.

The eastern plant communities may be given as follows:

Sagebrush desert, or (Great Basin Microphyll desert)

Bunch grass prairie, or grassland

Juniper forest, or (Xerophytic Coniferous forest)

Yellow pine forest, or (Xerophytic Coniferous forest)

Mesophytic coniferous forest

${ }^{3}$ Livingston, B. E., and Shreve, Forrest. "The distribution of vegetation in the United States, as related to climate conditions." Carnegie Inst. Publ. 284; 
Sub-Alpine forest

Alpine meadow

The largest single area is known locally as the "high desert." This area is characterized by the sagebrush and the rabbit brush (Chrysothamnus spp.) on the slopes and well drained bottom lands. Extensive alkaline lake beds, river bottoms, and poorly drained flats are characterized by the dominance of the greasewood (Sarcobatus vermiculatus) and saltgrass (Distichlis spicata). Sage brush may be associated with the above plants in the transition zone. Originally the western wheat grass (Agropyron spicatum) and other bunch grasses grew abundantly throughout the entire desert area. The overstocking of this sagebrush desert has largely destroyed the grass as an abundant associate plant. The main desert area lies south of the Blue Mountains and east of the Cascade timbered slopes. It extends northward to the bunchgrass prairie on the upper reaches and down the river canyons to the Columbia. Extensive desert lands also lie along the Columbia in Gilliam and Umatilla counties and in Baker county. The sagebrush desert is called the Great Basin Microphyll desert by Livingston and Shreve although it extends beyond the physiographic limits of the Great Basin. Lava outcrops as "rim rock" in frequent places where erosion has cut through the great lava outpourings. Along streams and under the rim rock may be found various herbs and shrubs that require more soil moisture. Conspicuous among these plants are the western choke cherry (Prunus demissa), service berry (Amelanchier), squaw currant (Ribes cereum), golden currant (Ribes aureum), mock orange (Philadelphus lewisii), willows and others. Within the area of the desert plateau and in Klamath County are large lakes and marshes, which range from fresh to alkaline. The lake borders and marshes of the fresher waters are characterized by the tule (Scirpus validus), cattail (Typha latifolia), water hemlock (Cicuta occidentalis) and others.
Between the high desert and the timbered area on the south slope of the Blue Mountains and other similar climatic situations is a transition belt of western juniper (Juniperus occidentalis), mountain mahogany (Cercocarpus ledifolius), and antelope bush.

Perhaps the largest juniper forest in the world is found as a transition between the sagebrush desert on the south and the bunchgrass prairie on the north, and lying between the Cascade and Blue Mountains. Sagebrush and also antelope bush, are abundantly associated with the juniper. Originally the western wheat grass and other grasses were abundantly found in this area.

The present wheat growing sections of eastern Oregon were originally bunchgrass prairie. It lies mainly on the high rolling lands to the north of the Blue Mountains. Small remnants of this one time extensive prairie may be seen in protected places. Western wheat grass is the dominant grass. More or less abundantly associated with it are the prairie June grass (Koeleria cristata), and other species of Agropyron, lupines, prairie sunflower (Balsamorrhiza sagittata), geranium, and others. Stream borders are characterized by the alder (Alnus tenuifolia), hawthorn (Crataegus brevispina), snowberry, symphoricarpos and clematis.

Within the Blue Mountains proper and on isolated peaks and small chains, where the altitude may be responsible for the supply of sufficient moisture, the slopes are timbered. Western yellow pine is the dominant tree throughout all of the lower mountain slopes. The same may be said for the east slope of the Cascade Range and the Mountains of Klamath county. Yellow pine may be intermixed with sugar pine (Pinus lambertiana) and a few other scattered conifers to the south and with western larch (Larix occidentalis), and Douglas fir to the north. Western white pine, lodgepole pine, Engelmann spruce, white fir, alpine fir (Abies lasiocarpa), and other conifers are found in increasing abundance with the rise in altitude 
and the corresponding increase in moisture.

The yellow pine forest is the semidesert or xerophytic coniferous forest. The forest floor is characterized by snow bush (Ceanothus velutinus), antelope bush, manzanita, and Idaho fescue (Festuca idahoense).

It is well known that the herbaceous and shrubby vegetation varies with the type of forest. On account of the large territorial area and the varying climatic and soil conditions, it is impossible to accurately picture the smaller vegetation that accompanies the larger. The mesophytic coniferous forest is the habitat of the following: Snowbush, thimble berry, huckleberries (Vaccinium), naked rose (Rosa gymnocarpa), twin berry (Lonicera involucrata), Prince's pine (Chimaphila umbellata), twin flower (Linnaea americana), columbine (Aquilegia formosa), false bugbane (Trautvetteria grandis) and species of currants and gooseberries.

Alpine meadows in both the Blue and Cascade Mountains may be found at or near timber line on the gentle slopes and valleys. But the rocky ridges and peaks are more or less covered with scattered white bark pine (Pinus albicaulis), mountain hemlock, and various shrubs. Following the recession of snow, alpine erythroniums, and anemones may be found.

B. Animal communities illustrated by mammals (H. M. W.). The divide of the Cascade Mountains separates Oregon into two areas, Western and Eastern Oregon. Western Oregon is again cut by the Coast Range Mountains leaving the big valleys of the Willamette, the Umpqua and Rogue Rivers, lying between the two ranges.

The areas of Western Oregon recognized in this paper are, the Moist coniferous forests of two slopes of the Coast Range Mountains; the Valley prairie areas of the Willamette, Umpqua and the Rogue River, the Hill prairie areas comprising the foothills of the two mountain ranges rising out of the valleys; and the moist coniferous forests situated throughout the west slope of the Cascade Mountains.

The areas of Eastern Oregon considered are, the Semi-desert coniferous forests of the Eastern slope of the Cascades; the Coniferous forests of the Blue Mountains; the Bunch grass prairie lying between the Blue Mountains and the Cascades in the North, and drained by the Deschutes, John Day and Umatilla rivers; and the big Sage brush desert lying south of the Blue Mountains and Bunch grass prairie.

The flora of Oregon is not as greatly changed from its original condition as is its fauna. Few mammals ${ }^{4}$ have been entirely exterminated, but the distribution of many has become restricted, and the numbers of nearly all show evidence of decrease. Within the great coniferous forests of Oregon and throughout the arid section of the Sagebrush desert in the southeastern corner of the state, and extending into Idaho and Nevada, the biota has been remarkably well preserved.

The west slope of the Coast Range Mountains. Luxuriant open valleys within this stand of timber furnished forage for thousands of western wapiti or elk (Cervus c. occidentalis). The black-tailed deer (Odocoileus columbianus) fed within the jungles of Salal, which carpeted this virgin forest. The black bear stripped the huckleberry, and the chittim (Cascara) berries, and caught the fish from the numerous streams which drain the west slope into the Pacific Ocean. These streams were followed by the western raccoon (Procyon psora pacifica), the Pacific mink, the Pacific otter (Lutra canadensis pacifica). The Pacific beaver (Castor canadensis pacifica) were abundant as were in some sections, the Oregon coast muskrat (Fiber zibethica occipitalis). The Puget Sound skunk and the spotted skunk (Spilogale phenax latifrons) were present. The hillsides were pentrated by the mountain beaver (Aplodontia rufa pacifica).

4 Scientific names of mammals mentioned in British Columbia and Washington do not occur in Oregon account. 
Throughout the entire area the cougar (Felis 0 . oregonensis) preyed upon the young elk and deer. The Douglas pinesquirrel (Sciurus douglassii), the fuscus bushy-tailed woodrat (Neotoma cinerea fusca) and the deer-mouse (Peromyscus maniculatus rubidus), were constantly pursued by the bobcat (Lynx fasciatus pallescens) the Pacific fisher (mustela pennonti pasific) and the Pacific marten. This area is also inhabited by the Bachman flying-squirrel (glaucomys sabrinus oregonensis). The bald eagle and the band-tailed pigeon nested within this region, while the coast wren built its home in no other place.

All of these species are still present in varying degrees of abundance. The elk is no longer, however, a game animal and the bear are becoming limited.

The east slope of the Coast Range Mountains. The East slope of the Coast Range Mountains, characterized by the Douglas fir, meets the Hill prairie area in its foothills rising out of the valleys on the eastern side.

The fauna of the west slope is quite generally carried to the east slope, and while several species are now mapped for the west side, a more detailed study might show that their range could be extended.

The western bushy-tailed woodrat was found throughout this area. The California skunk (Mephitis occidentalis) probably extended his range well into the valleys of the east slope, as did the timber wolf (Canis gigas) as he pursued both the black-tailed deer and the western white-tailed deer (Odocoileus leucurus).

The Hill Prairie area. The Hill Prairie area was characterized by open grass land and Oregon oak which covered the foothills on either side of the Willamette Valley. These groves of Garry oak afford a natural home for the beautiful silver-gray squirrel (Sciurus griseus griseus) which, however, extends its range far back into the coniferous forest on both sides of the valley and in the southern section to the Coast. Especially numerous in this area were the Douglas ground squirrel (Citellus beecheyi douglasii), the white-tailed deer formerly bedded among these hills, and the sooty grouse were numerous.

The Valley Prairie area. This was the original home of the western whitetailed deer. The main streams and their many tributaries wooded by Douglas fir, maple, oak, willow and numerous shrubs, afforded an ideal home for the mink, otter, raccoon and skunk. Especially numerous were the beaver of this area, feeding upon the cottonwood and willow which grew close to the water's edge. The Puget Sound muskrat found an ideal habitat in the numerous sloughs caused by the annual flooding. Along these streams the abundant thornbearing shrubs formed an excellent location for the dusky-footed woodrat (Neotoma fuscipes) to build its nest. The wild rose, Spiraea, and snowberry associations afforded covers for the Pacific Coast brush rabbit (Sylvilagus bachmani ubericolor) and the California black-tailed jackrabbit (Lepus californicus) fed upon the luxuriant vegetation of the open grass land. In the wooded areas of this section were found the silver gray and Douglas pine-squirrels and Bachman flying-squirrel. The gray fox (Urocyon californicus townsendi) and the coyote made their dens within the foothills and sought their prey throughout the valleys, as did the cougar and bobcat. The covers along the streams of service berry, red-twigged dogwood, hawthorn, and numerous other fruit and seed bearing shrubs, furnished feeding grounds for the Oregon ruffed grouse. The numerous sloughs and streams furnished natural breeding conditions for many duck and shore birds.

Probably no section of Oregon has lost a greater share of its abundant wild life than the Willamette valley. This has been brought about through rather intensive grazing and cultivation, but factors of greater importance have been the rifle and trap.

The wolf, coyote, and white-tailed deer have practically disappeared. The beaver, under protection showed indica- 
tions of reestablishing themselves in their old haunts, but the open trapping season of 1923 and 1924 has reduced their numbers to such an extent that their extermination seems imminent.

The introduction of the ring-necked pheasant and bob-white (quail) has replaced the other game birds which have become too scarce to any longer be considered game.

The west slope of the Cascades. This great area lies entirely within the moist coniferous forest. It is composed largely of magnificent stands of Douglas fir. At higher altitudes are found areas of lodge pole pine, noble fir and Englemann spruce. Interspersed among these trees are beautiful mountain meadows filled with a luxuriant growth of flowering plants. The highest sections of the timbered areas are marked by the presence of the mountain hemlock and whitebark pine, above which the bare mountain peaks rise.

About the numerous rock tumbles could be heard the cry of the little cony, or pika (Ochotona), and within these tumbles the western bushy-tailed woodrat, mountain beaver, Apoldontia rufa, and the yellow-bellied marmot (Marmota flaviventris) whistled from his mound. The black bear extended throughout the area while the grizzly remained in the south.

The Cascade flying-squirrel (Sciuropterus alpinus fuliginosus) and the Cascade tree squirrel (Sciurus douglasii cascadensis) were typical of the west slope, while the silver gray squirrel was present in the lower elevations.

Both the Washington snowshoe hare (Lepus w. washingtonii) in the north and the Oregon snowshoe hare (Lepus $w$. klamathensis) in the south were pursued by the timber wolf, the coyote, and the Cascade fox (Vulpes cascadensis). The bobcat and the Canada lynx (Lynx canadensis) reluctantly shared their hunting area with the marten, fisher (Mustela pennanti) and the wolverine (Gulo luscus). The cougar ranged freely from the side of the divide to the other in pursuit of the deer. Below, the otter and mink shared the stream with the beaver; the former probably the first to enjoy the excellent fishing of the Cascade streams. The porcupine, more at home on the eastern slope, nevertheless frequented the western slope as well, and in the south the basserisk or ringtail cat (Bassariscus astutus oregonus) made his home. The pacific elk crossed the valley and entered the valleys of the west slope of the Cascades.

The mountain chicadee, red-breasted nuthatch, mountain blue-bird and Oregon jay are found breeding at an elevation of 3700 to $6000 \mathrm{ft}$. From this elevation to timber line is the breeding area of Clarke nutcracker, the arctic threetoed woodpecker and the alpine threetoed woodpecker.

Above timber line the Hepburn rosy finch has been observed, feeding its young at an elevation of 9000 to $10,000 \mathrm{ft}$.

The eastern slope of the Cascade Mountains. The eastern slope of the Cascades lies within the semi-desert coniferous forest. The predominant tree of this area is the western yellow pine which extends throughout the entire length of this slope of the Cascades and follows the higher cliffs of the rivers well into the floor of the plateau below.

Many of the western forms were present on this eastern slope but of very great interest is the rather marked tendency of the black-tailed deer to remain on the western slope and of the mule deer to remain on the eastern slope of the Cascades.

Among those animals present upon both sides of the divide are the bobcat, Canada lynx, coyote, wolf, porcupine, pika, gray fox, mink, beaver, wolverine, fisher, marten, otter, basserisk, and snowshoe hare.

The porcupine was exceptionally abundant within the yellow pine forests of the eastern slope, and the limit of the badger's (Taxidea taxus neglecta) western distribution is here reached. In the north occurred the Cascade skunk (Mephitis occidentalis notata). The two jackrabbits of eastern Oregon, the western white-tailed and the Wash- 
ington black-tailed (Lepus californicus wallawalla) probably made the limit of their westward distribution in the lower areas of the east slope of the Cascades. The black bear was present throughout this area, while the grizzly bear inhabited the southern section only. The bobcat, coyote and cougar were present in large numbers, and while the Canada lynx occurred here, its abundance is uncertain. Undoubtedly the prong horn antelope (Antilocapra americana) made this the limit of its westward migrations.

The bunchgrass prairies. This was the typical coyote and sharp-tailed grouse country. The many rivers which drained the interior of this area coupled with the rugged foothill country of the Cascade and Blue Mountain ranges, transformed this otherwise monotonous country of bunchgrass prairie into a rugged and interesting area.

In the south it overlapped and intermingled with the sagebrush country in such a way as to make any definite southern boundary impossible.

While there was a marked difference between this bunchgrass prairie and the forests of the eastern slope of the Cascades, nevertheless the fauna of each was very similar; however, due to the difference in the animals upon which they preyed, their habits varied considerably. The following were present throughout the range mentioned: antelope, mule deer, coyote, cougar, Cascade skunk, mink, otter, beaver, and the Rocky Mountain muskrat (Fiber $z$ osoyoosensis). The black bear, cougar and both lynxes inhabited the timbered areas. The badger was numerous within the big fertile areas, now turned into wheat ranches, where he dug for the plentiful pocket-gophers, mice, and ground-squirrels. The most numerous animals were the jackrabbits, the more common at that time being the whitetailed.

The Blue Mountains. The Blue Mountains are a rather extensive range massed in the north-eastern section of the state. It was the home of the mule deer, the marten (Martes pennantii pacifica), the fisher, the wolverine, the coyote, the grizzly and black bears, and Great Basin skunk.(Mephitis occidentalis major) were probably common mammals within this section, while the pika (Ochotona schisticeps jewetti) is typical of the talus slopes.

The sagebrush desert. The sagebrush desert of eastern Oregon comprises that area extending from the Blue Mountains and bunch grass prairie to the California and Nevada line and lying between Idaho in the east and the Cascade Mountains in the west.

This big area affords a great variety in types of conditions. It possesses mountains, deeply worn and treeless gulches, rolling sagebrush plains, lakes, swamps, and timbered areas.

It is the home of several animals that have with difficulty survived, among which the most interesting, owing to its present pending extinction, is the pronghorn antelope, which originally numbered into the thousands and moved in immense bands instead of the few flocks of today.

The bighorn sheep (Ovis) was a very abundant animal and probably before being molested ranged considerably throughout the higher areas. The mule deer inhabited this entire area, as did both the white-tailed and black-tailed jackrabbits, the badger, the bobcat, cougar, Great Basin skunk, and spotted skunk (Spilogale gracilis saxatalis).

Within the hills were found the pallidbellied marmot (Marmota flaviventris avara), the western bushy-tailed woodrat, the Washington cottontail rabbit (Sylvilagus nuttallii) and the Idaho pigmy rabbit (Brachylagus idahoensis).

The lakes and streams were the homes and hunting grounds of the otter, mink, beaver and Nevada muskrat (Ondatra $z$. mergens). The cougar probably preyed upon the jackrabbits, deer, and antelope, and the bobcats and coyotes pursued the jackrabbits and smaller game throughout this area. The grizzly and 
black bear were both inhabitants of this country and the American bison (Bison bison) penetrated well into its interior from the east.

The Great Sagebrush Desert was and is today a paradise for birds and bird lovers. Birds too abundant to attempt any enumeration nested within and around the many lakes and marshes of this section. The number of species and individuals found in this area are beyond all comprehension of the average nature student. Among those of special interest are the egret, white-faced glossy ibis, black-necked stilt, white pelican, sandhill crane, and many species of duck; grebes, gulls, terns, herons, bitterns, cranes, sandpipers and other shore birds.

A discussion of the mammals of Oregon would not be complete without mention of the islands lying within the Pacific and off the coast of Oregon. Some of these islands are notable as breeding grounds for thousands of sea birds. It furnished also a resting place for the Pribilof fur seal, and was the breeding grounds of the Steller sea lion and the harbor seal.

Mention should be made particularly of the south-western section of Oregon, comprising the Rogue River Valley and its surrounding hills and mountains. It is apparently the meeting grounds of species from the east and west and the north and south. Present knowledge will not permit an accurate statement regarding this area.

Mollusca (F. C. B.). Binney divided the United States into regions and gave the name Pacific Province to that territory lying between the Cascade and the Sierra Nevada mountains on the east and the Pacific Ocean on the west. The great majority of the land snails are peculiar to this region and are largely distinct, even as to genera, from those of eastern North America. Of about 100 species 65 per cent are peculiar to this region. The region is further divided into the Oregonian W. Mesophytic coniferous forest extending from
Humboldt Bay northward to Alaska, and containing some 15 peculiar species. The dominant groups are Ephiphragmophora, Glyptostona, Binneya, Hemphillia, Ariolimax, Hesperarion. There are features of vertical distribution which coincide with distribution of vegetation, subalpine, alpine, arctic, etc.

\section{iI. present biota (see "NAtional FORESTS OF THE PACIFIC DISTRICT")}

Hofmann's account of forests of District 6

Most of western Oregon was originally all timbered with northwestern coniferous type of forest. Patches of deciduous forest occurred here and there. In the valleys a considerable acreage of the original forest has been cut and the land cleared. In western Oregon there still remains in practically its virgin forested condition an enormous area, about half of which is in the National Forests. Here the plant life is practically undisturbed except as fires have increased in severity since the advent of man. The animal life has been somewhat affected by the proximity to settlement and hunters, but not fundamentally changed. In Eastern Oregon the semi-desert coniferous forest occupied originally only a small percentage of that part of the state and was confined to the east slope of the Cascades and to such independent mountain groups as the Blue Mountains. It is still practically in its virgin condition as the area logged is small, though affected so far as its lesser vegetation and fauna are concerned by man through fires, hunters and stock grazing. There is here a large acreage of sagebrush desert, some alkali country and a variety of plant and animal communities about such local formations as springs, lakes, swamps, hot low altitude canyons and cold high altitude mesas.-T. T. $M$.

The forests have encroached upon the original prairie lands throughout western Oregon. This is due to the stopping of extensive prairie fires since 
the advent of the white man. The prairie areas were burned by the Indian as a part of his system of hunting the larger game animals.

Except as specifically mentioned the flora as described in this paper is today much the same as originally found by the early settlers. However, it has not been practicable to discuss all of the floristic changes in the state due to settlement. -W. E. L.

\section{NATURAL AREAS}

\section{Federal Preserves (T. T. M.)}

A large part of the state is likely to remain in its present virgin condition for many years to come. The virgin forest both east and west of the Cascades is being cut relatively slowly, and much of the desert and semi-arid country will remain in its natural state for an indefinite time. It may be said that every type of natural condition that originally occurred in the state is still to be found. In certain types, definite steps to preserve natural conditions are now desirable. Certain areas are now adequately safeguarded, such as the Bull Run division of the Mount Hood National Forest, and Crater Lake National Park; and there may easily be segregated for preservation by administrative action as much more of the National Forests as it may be deemed best to leave in a natural condition.

There are in Oregon 13,178,023 acres of National Forest land distributed over the mountainous timbered portions of the state. Most of these lands are in their natural condition, except in so far as accidental fires, stock grazing and the slight occupancy of man have changed them. They are subject to timber cutting, as the economic demand requires, except that where conditions of such scientific interest exist that they should be left in their natural condition action can readily be secured to preserve such areas. Several such areas have already been preserved when timber sales were being made in the neigh- borhood, primarily because of their aesthetic or recreational value. Furthermore, at least half the National Forest acreage of the state is so inaccessible on the high mountains that commercial exploitation (except for stock grazing) is practically out of the question. It seems assured, therefore, that every set of natural conditions which occurs within the timbered portions of the state may be perpetuated under Government control on the National Forests.

\section{Federal game and bird refuges in. Oregon}

*Cold Springs of 2520 acres, created in 1909 on a Reclamation Service project to protect waterfowl.

* Klamath Lake of 81,619 acres in Klamath County created in 1908 on a Reclamation Service project to protect waterfowl, pelicans, gulls, waders and shorebirds.

*Lake Malheur of 88,960 acres in Harney County created in 1908 on federal land to protect waterfowl and marsh birds. This is recognized as one of the most remarkable places in the United States for study of water and marsh bird life.

*Three Arch Rocks off the coast of northwestern Oregon reserved in 1907 as a breeding place for seabirds and regarded as a very wonderful place for ornithologists' study.

${ }^{*} A$ dune region on the Oregon coast. (In the Sinslaw National Forest.) Sand dunes border the ocean continuously for a distance of about $50 \mathrm{mi}$. from Marshfield on Coos Bay northward. The area of most active dunes is from one to four miles wide, and the transition is gradual through less active dunes to the very old inactive ones now covered with forest. On the newer dunes the following plants were found: A rush that holds small areas of sand by means of its abundant rhizomes and roots, a wild strawberry, a beach pea, and scattered willows and lodge pole pine. The willows grow fast enough to keep their tips above the incoming sand, and the pines live even when almost 
covered. Sand loving plants observed in the vicinity of Marshfield are: Polygonum paronycia, Abronia latifolia, Cakile californica, Fragaria chiloensis, Lupinus littoralis, Glehnia littoralis, Godetia quadrivulnera, Gaertneria bipinnatifida, Anaphalis occidentalis, Arctostaphylos uva-ursi.

Dunes which represent a stage intermediate between the very young active stage and the very old inactive stage are usually occupied by lodgepole pine (Pinus contorta), Douglas fir (Pseudotsuga taxifolia), manzanita (Arctostaphylos tomentosa), rhododendron (Rhododendron californicum), salal (Gaultheria shallon), kinnikinnick (Arctostaphylos uva-ursi), common brake (Pteris aquilina), mosses (Polytrichum juniperinum, Hylocomnium splendens).

The forest that covers the very old dunes is the ordinary coniferous forest of the region. The following trees make up the forest in the vicinity of Marshfield: Douglas fir, western hemlock, Sitka spruce (Picea sitchensis), lowland white fir (Abies grandis), western red cedar, and Port Orford cedar (Chamaecyparis Lawsoniana). Undergrowth includes Myrica californica, Ribes sanguineum, and Gaultheria shallon.

Plants occurring in dune meadows in the vicinity of Marshfield are: Lycopodium inundatum, Eriophorum chamissonis, Carex pausa, C. mirata, C. magnifica, C. Hindsii, Juncus falcatus, $J$. oreganus, Hookera pulchella, Hydostylus brachypus, Spiranthes stricta, Ranunculus flammula unalaskensis, Argentina (Potentilla) anserina, Hosackia parviflora, Trifolium fimbriatum, Viola adunca, Gentiana sceptrum, Mimulus Langsdorfi, Plantago maritima, Orthocarpus castilleoides, Aster Douglasii.

Sphagnum bogs occur in or adjacent to the dune area at Florence, Westlake, Clear Lake, and Houser. Their flora comprises peat mosses (Sphagnum spp.), Labrador tea (Ledum columbianum and L. groenlandicum), sundew (Drosera rotundifolia), cotton grass (Eriophorum $s p$.), buck bean (Menyanthes trifoliata).
The government had put in large areas of grass on the dunes near the mouth of the Siuslaw River about 1917 in an effort to keep the sand from blowing into the river. Some of this grass still flourishes, but much of it has been blown out and the sand still blows into the river. The Forest Service has stopped the grazing and the sand movement has been slowed up.

Near Florence, Glenada, Clear Lake, West Lake, Houser, and Marshfield on the S. P. R. R.-G. B. Rigg and T. T. Munger.

*Summit and upper slopes of Strawberry Butte. (Malheur National Forest, Grant County.) Shows typical altitudinal succession in Blue Mountains of Oregon. Forest of western yellow pine, Douglas fir and spruce, with species of Abie near top, alpine meadows, and scattered white-bark pine, characteristic rock and alpine flora as well as flora of the lower forest. See sonnet by C. H. Sholes on "The White-bark pine" in Mazama, vol. 3, p. 30, March, 1907. The mountain has been grazed but not over grazed. Characteristic Blue Mountain fauna.

Take John Day Highway east from Prairie to Blue Mountain Hot Springs.W. E. L.

*Crater Lake National Park (A3). This area of about 249 sq. mi. lies on the summit of the Cascade Range, about the wonderful lake of that name. It is surrounded by National Forest lands. It is covered chiefly with the type of forest characteristic of the upper slopes in the Cascades. A few exposed peaks have alpine conditions. Much of the Park is in its absolutely virgin condition and is likely to remain so. Trapping. timber cutting, hunting and grazing of stock are forbidden.

It may be reached during the summer months by stage from Medford or Klamath Falls, Ore.-T. T. M.

\section{State reserves and available natural areas}

*Reed College Reserve. One-half sq. mi. deciduous and northwestern conif- 
erous forest with ravine, canyons, hills, swamps, marshes, ponds, plains. Original vegetation and animals. Located in Mulnomah Co., Portland, Ore.-H. B. Torrey.

Rock Creek Forest. A long stretch of Douglas fir forest. Along Rock Creek, a branch of the North Umpqua River in the central part of Douglas County, northeast of Hoaglin.-W.G. Van Name.

Spencer Creek Forest. A long stretch of unlogged forest, with quite large trees in many places. Along the highway between Klamath Falls and Ashland (Klamath and Jackson Counties), from Spencer Creek (some miles west of Klamath Falls) to Pinehurst.-W. G. Van Name.

Juniper Forest. (Deschutes County.) Typical mature juniper forest with sagebrush, and antelope bush as the desert underscrub. About $10 \mathrm{mi}$. northeast of Bend, and lying to the east of the Bend-Powell Butte road.-W. E. L.

High Desert and Sagebrush Desert. (Lake County.) Large area of typical sagebrush desert lying east of Butte; has been grazed for many years. The traveler ant hills are common, other animals are the jackrabbit and other desert associates.

On road between Burns and Silver Lake via Wagontire mountain, no water except at distant ranch wells.W. E. L.

Yellow Pine Forest and Forest Floor Vegetation. (Northern Lake County.) (Deschutes National Forest.) Typical yellow pine forest with undisturbed shrub associations also shows lodgepole pine areas. Location almost anywhere around China Hat or north of it or on Sand Spring road. About $30 \mathrm{mi}$. north of Fort Rock.-W. $E$. $L$.

Fort Rock Crater. A large amphitheatre shaped volcanic cylinder the south side of which is open allowing typical desert vegetation and rock border vegetation to come in. Has been grazed. Situated about two mi. north of town of Fort Rock in Lake County.$W . E . L$.

Forest and Desert Tension Areas. (Lake County.) Typical desert and forest border shows succession from sagebrush to yellow pine and Cercocarpus. About one mi. south of town of Silver Lake just outside of the Fremont National Forest.-W. E. $L$.

Sycan Marsh. (Lake County.) Typical central Oregon marsh of Typha, Scirpus, etc., shows succession from marsh to meadow to desert to scrub to forest of yellow pine, also Cercocarpus and Juniperus. About $20 \mathrm{mi}$. south of town of Silver Lake.-W. $E . L$.

Silver Creek Falls and mountain stream, glens and canyons in Marion County, Ore. There are four beautiful falls ranging from 65 to $180 \mathrm{ft}$. high on north and south forks of Silver Creek. Typical mesophytic canon and stream flora to the hill top. Douglas fir forest.

About $32 \mathrm{mi}$. east of Salem via Silverton. See "Silver Creek Falls as seen by the Mazamas" by W. P. Hardesty in Mazama, vol. 4: 32-33, December, 1915. -W.E.L.

Climax Forest in Clatsop County. Typical climax forest of cedar-hemlock -Douglas fir-Thuja-Tsuga-Pseudotsuga, undisturbed, situated on Inland Double Loop Highway about $15 \mathrm{mi}$. southeast of Astoria, Clatsop County, Ore.-W. E. L.

Clear Lake and Big Spring, formed by the filling in of lower end of valley by a lava flow submerging the forest. Tree trunks are still standing on the lake bottom. Lake surrounded by a typical Douglas fir forest of the Cascades.

About two mi. from Fish Lake on the Santiam Road over the Cascade Mountains.-W. $E . L$.

"Hanging Valley." A beautiful mountain valley on north slope of Mt. Jefferson. Shows typical mountain meadow and forest border, with groups of trees throughout the park. Located in Santiam National Forest. Hanging Valley is partially protected by the United States Forest Service.

Reached by pack trail about $24 \mathrm{mi}$. from Detroit.-W. $E$. $L$.

Mary's Peak in western Benton County, Ore. Highest peak in the Coast Range, typical coast range sub-climax forest of Douglas fir and Noble fir. Shows forest edge succession from alpine prairie, protected and exposed slopes. The alpine meadow has been grazed for a long time and timber cutting is in progress, altitude ranges from 570 to 4097 ft. Pure mountain streams.

Take autos for $12 \mathrm{mi}$. south of Philomath, thence trail west to base of peak. -W.E.L.

Lost Falls in Coast Range of Coos County, Ore. Typical primitive Coast forest of fir and cedar along Lost River. See Scientific American, vol. 130, page 1, 4 figs., January 4, 1919, for further information and reference to Cape Horn Falls on the Coquille River, where grows the myrtle and the "Toe Head Falls" on Camas Creek, all in Coos County, Ore. $-W . E . L$. 
Sphagnum bog and typical sub-climax forest. In Lincoln County south of Yaquina Bay and about one-half mi. from the ocean; typical sphagnum bog and lodgepole pine forest with salal, huckleberries and rhododendron, shows succession from water level to subclimax forest.

Take ferry from Newport to South Beach, walk down railroad for about one mi. -W. E. L.

Sand dunes. The sand dunes of Coos County are the most extensive. See "The sand dunes of Coos Bay, Oregon" by H. D. House, Plant World, 17: 238243, August, 1914.-W. E. L.

State game and bird refuges in Oregon (T. T. M.)

Multnomah County Pheasant Reservation of 80,640 acres in Multnomah and Clackamas counties.

Deschutes Game Reservation of 829,440 acres in Crook and Lake counties.

Steens Mt. Game Reservation of 414,720 acres in Harney County.

Sturgeon Lakes Game Reservation of 22,000 acres in Multnomah and Columbia Counties.

Grass $M t$. Reservation of 34,560 acres in Lane County.

Umatilla Bird Reservation of 500 acres in Umatilla County.

\section{Antelope reserve}

(From information furnished by Mr. George Orr, Jordan Valley, Ore.)

"The estimated number of antelope in this locality, at present, is about 300 ." The land is owned by the United States government. "The sheep are crowding out the antelope very fast. It is also reported that there is a band of about 30 bighorn sheep in this locality."

Note: This is in a section little frequented by man. The traveler almost never goes in this section. The automobile is the best method of travel on account of the great distance. Gasoline and other supplies should be procured at Jordan Valley.

"Southeastern end of Malheur County, Ore., south of Jordan ,Valley, Ore." W. E. L.

\section{Antelope reserve no. 2}

"Northeast of Jordan Valley, Ore., near the Cow Lakes." This is about $15 \mathrm{mi}$. from Jordan Valley. The land and antelope are "owned by Sam Scott, postmaster at Jordan Valley, Ore." I believe Mr. Orr said this man was doing all he could to preserve this band of antelope.-W.E.L.

\section{CALIFORNIA}

By H. C. Bryant

I. GENERAL FEATURES AND ORIGINAL BIOTA

\section{Physiographic regions}

California is a state of unusual climatic and topographic diversity. The northern two-thirds of the state is characterized by mountains on the coast and mountains near the eastern border. These come together in the extreme northern part of the state and again in the southern third of the state enclosing a great central valley which opens to the west centrally through San Francisco Bay to the Pacific Ocean. Southeast of this wall lie the Mohave and Colorado deserts and those arid portions which require the use of such guides to watering places as have been published by the Department of Interior. The west coast of the southern third of the state is a plain with low hills; this leads back to a series of mountain ranges some $50 \mathrm{mi}$. east of the coast. The paths across these mountains lie to the east of Los Angeles.

\section{GEOGRAPHIC AND LOCAL PLANT AND}

\section{ANIMAL COMMUNITIES}

\section{Vegetation}

The vegetation is very diversified. The moist Pacific Coast coniferous forest which is a luxuriant growth of conifers with deciduous trees beneath extends southward to a short distance south of San Francisco along the western portion of the Coast Range. The Great Central Valley (Sacramento-San Joaquin) was originally grass land, probably similar to the Russian steppes. The southern coastal plain is characterized by a type of vegetation similar to that in the region of the Mediterranean, which is called broad-leafed Schlerophyll forest. In central California the foothill country appears to have been a scattered tree savanna, the trees being live oaks. In the higher portions the evergreen oaks and associated 
trees (broadleaf sclerophyll) originally occurred in rather dense stands. Farther south this type of vegetation is found at a higher altitude. About San Diego the country is commonly classed as semi-desert. Farther back the live oaks occur at higher altitudes. The southeastern desert portion of California includes the Mohave and Colorado deserts, the former including Death Valley. Here are some of the most arid areas in the West, characterized by moving sand dunes, almost barren tracts covered largely with creosote bush (Covillea tridentata) and with only occasional watering places.

Characteristic trees of the various timber belts of the Sierra are as follows:'

1. Foothill belt, 500 to $3000 \mathrm{ft}$.: digger pine (Pinus sabiniana), blue oak (Quercus douglasii), interior live oak (Quercus wislizenii).

2. Main timber belt, 3000 to $6500 \mathrm{ft}$.: yellow pine (Pinus ponderosa), black oak (Quercus kelloggii), sugar pine (Pinus lambertiana), white fir (Abies concolor), incense cedar (Libocedrus decurrens), big tree (Sequoia gigantea).

3. Upper portion of main timber belt, 6500 to $9000 \mathrm{ft}$.: red fir (Abies magnifica), tamarac pine (Pinus murrayana), Jeffrey pine (Pinus jeffreyi).

4. Timber-line belt, 9000 to $11,000 \mathrm{ft}$ : white-bark pine (Pinus albicaulis), Sierra juniper (Juniperus occidentalis), mountain hemlock ( $T$ suga mertensiana), tamarac pine, foxtail pine (Pinus balfouriana).

The southern and eastern portion of California is geographically separated from the northern two-thirds by differences in climate and location of mountains. This area includes the semidesert low country south of Bakersfield, the Mohave Desert, and Death Valley, and the Colorado Desert (including Coachella Valley and Imperial Valley) and the low mountains which separate the two areas. These mountains are characterized by the broad leaf sclerophyll type of vegetation in the upper

1 From Jepson, W. L., 1909, The Trees of California (Cuuningham, Curtis and Welch, S. F.), $228 \mathrm{pp}$. reach of the western slopes and conifers on their highest peaks. Numerous valleys, very nearly enclosed, with a flat floor covered with scattered live oaks and characterized by grasslands, are common in the foothills. The east slope of the mountains is quite different in the character of the vegetation and these differences have been used by Shreve to suggest the inadequacy of the theory of temperature control and distribution.

\section{Fauna, especially larger vertebrates ${ }^{2}$}

The broken topography, lofty elevations, and the long coast line extending from the latitude of Sitka, to the lower latitudes of Lower California, constitute some of the important factors which lead to great diversification locally in temperature and humidity. Within the single state of California the effects of this climatic diversity on the animal life are abundantly illustrated. Terrestrial vertebrate animals at home within the boundaries of the state are representative of the life of the far North and of that of portions of Mexico. Marine life, of both cold and warm waters, is also abundantly represented. The result is a very large number of species and higher groups in proportion to the size of the area. Within this state alone there have been detected up to 1915 a total of 361 species of mammals, 539 of birds, 76 of reptiles, and 24 species of amphibians. It may be stated with confidence that no other state in the Union, or even a contiguous pair of states, possesses so many species as California, unless Texas proves more prolific than present knowledge indicates.

Dr. Grinnell states that the plants, most of the birds and some of the mammals which are found restricted to the chaparral belt "are of relatively ancient origin and that they are quite certainly indigenous." $\mathrm{He}$ continues:

Among these are to be counted the huge grizzly bear of California, now exterminated, and the nearly extinct condor. Of the smaller mammals peculiar to the same belt we may mention the diminutive brush rabbit, the parasitic white-footed mouse, . . . and cer-

2 From Grinnell, Joseph, 1915, "The vertebrate fauna of the Pacific Coast,"' (pp. 104-112) in Nature and Science on the Pacific Coast (Paul Elder \& Co., S. F.), 302 pp. 
tain species of 5-toed kangaroo rats. Of the birds, we must call particular attention to the California thrasher, - . the California brown towhee, the California bush-tit, the rufouscrowned sparrow, the Bell sparrow, the California jay, and the wren-tit.

Birds and mammals in the northern coast belt are, relatively to adjacent districts, more plentiful in individuals than they are in species. Of the more interesting kinds may be mentioned the Columbian black-tailed deer, . . . the Roosevelt elk. . . . The strange rodent called Aplodontia or mountain beaver, which lives in burrows in wet hillsides overgrown with rank clumps of sword fern; the peculiar shrewmole; . . the varied thrush, . . south even to the Humboldt redwoods and in winter generally over west-central and southern California; and the diminutive western winter wren whose creaking song greets one from dense tangles in ravine bottoms or from mossy logs in the deepest shade of the redwoods. There are, in addition, a number of other mammals and birds, of more or less wide general range elsewhere, though presenting local species or subspecies in different parts of the humid coast belt.

While reptiles are very few in species and individuals in the coast belt, amphibians are correspondingly numerous in both respects, and include some species of exclusively Pacific distribution. The big, slug-eating salamander (Chrondrotus) is one of these.

The author calls attention to the fact that the mammals are nearly all of nocturnal habits whereas the reptiles are more active during daylight hours. This accounts for the fact that the reptiles are the most conspicuous of the vertebrates on the desert. Few reptiles can be seen abroad during the cool days of the midwinter season on the western deserts, but by April they appear in considerable numbers. Of the poisonous reptiles found on the deserts of the Southwest, only the rattlesnakes occur in California. Several lizards are common, including the chuckwalla (Sauromalus), the fleet-footed lizards (Sceloporus) and the whiptails (Cnemidophorus). Of these, the chuckwalla ( $S$. ater) of black and orange coloring is the largest, attaining a length of $15 \mathrm{in}$. and having a proportionately stout body. The desert tortoise (Gopherus agassizii) is found excavating its burrows in sandy places and wandering about over the great stretches of the Mohave. That there is a sufficient food supply for the numerous reptiles of the deserts is accounted for by the fact that nearly all parts of the southwestern deserts are visited at irregular intervals by heavy rains followed by luxuriant growths of herbs which produce an abundance of seeds. These seeds, lasting over periods of drouth, support great numbers of insects and rodents, and these in turn furnish the food supply of the reptiles.

Notwithstanding that reptiles are more conspicuous, due to their daylight habits, Grinnell believes that individually, mammals outnumber the combined birds and reptile population on many parts of the Mohave and Colorado deserts. Among these the seed-gathering rodents, Dipodomys and Perognathus, known as the kangaroo-rats and pocket-mice are the commonest. The deer-mice, the carnivorous grasshoppermice (Onychomys) and the desert woodrats are other night-roaming rodents. Three species, the antelope groundsquirrel (Ammospermophilus leucurus), the round-tailed ground-squirrel (Citellus tereticaudus), and the desert jackrabbit (Lepus californicus deserticola), are found abroad during the early morning and evening hours of daylight. Two carnivorous mammals are present: the big-eared kit fox (Vulpes arsipus) and a species of coyote (Canis ochropus estor), small and pale in color. There are also quite a large number of different kinds of bats which feed upon the abundant insect life of these deserts.

Birds of the deserts

are few in individuals save on the bottomlands along such streams as the Gila, Colorado and Mohave. Here, where the deciduous mesquite, cottonwood and willow furnish directly or indirectly abundance of food and shelter, birds are plentiful. . . The tit-mouse-like verdin, Abert towhee and crissal thrasher are resident the year through, while the Lucy warbler, plumbeous gnatcatcher, Cooper tanager, whitewinged dove, Sonora yellow warbler, and a score of other species are but 
summer visitants. Out on the desert proper, far from water, one may find here and there a pair of Say phoebes nesting in some rocky ravine or mine tunnel; rock wrens associate with the chuckwallas in the bare broken rock masses; cactus wrens build their conspicuous covered nests in clumps of the most prickly cactus.

The Le Conte thrasher which, owing to his wary nature and sand-toned color was formerly "considered the rarest of southwestern birds," is heard in the cool morning hours on the desert, while pairs of ravens and several species of woodpeckers are also to be noted.

Very few typical animals of the chaparral belt extend their range above an elevation of $4000 \mathrm{ft}$. in the Sierras. At this altitude one finds blue-fronted jays, western robins, the sierra junco and several species of woodpeckers. In the red fir forests above elevations of $7000 \mathrm{ft}$. will be found ruby-crowned and golden-crowned kinglets, nuthatches of three species, two species of sapsuckers, the Townsend solitaire and near timberline, the famous Clarke nutcracker. Characteristic mammals include certain species of chipmunks (Eutamias), the Sierra red squirrel (Sciurus douglasii albolimbatus), Sierra marmot (Marmota flaviventris subsp.), porcupine (Erethizon epixanthum) and bushy-tailed wood-rat (Neotoma cinerea subsp.).

Above timberline, at about $10,000 \mathrm{ft}$. altitude and for some 1000 or $2000 \mathrm{ft}$. farther, plant life of dwarfed types continues, and here the rosy finch and rabbit-like cony find their permanent abode. They, with other similarly restricted species characterize the Alpine-Arctic Zone.

\section{PRESENT BIOTIC CONDITIONS}

Much of the Pacific Coast mesophytic forest of which the redwood (Sequoia sempervirens) is the characteristic tree, is still in its natural state though there has been much cutting. As the redwood stump sprouts, a second growth rapidly appears.

The great central valleys which were once steppe or grassland areas are now largely under cultivation. Much is now irrigated farm land and the remainder is heavily grazed.

The great chaparral belt of the foothills of the Sierras is little disturbed except for areas cleared for fruit land and the modification due to extensive grazing.

There has been extensive lumbering in the main forest belt, inroads having been made especially on the sugar pine and western yellow pine, the trees of greatest commercial value. Most of the mountain districts have been grazed by cattle and many mountain meadows have been modified due to extensive grazing of sheep. Exotic forage plants are to be found in unlooked for places. Perhaps the least modified areas in the northern part of the state are to be found in Del Norte County and in eastern Siskiyou and western Modoc counties in the area known as the "lava beds" or "devils garden." Even these areas are frequented by hunters and cattlemen.

The streams of the southern and eastern portions of the Sierras and of southern California have been diverted for irrigation purposes. Pollution of many streams by sawdust and mine refuse and to some extent by sewerage is only partly checked by laws. As a consequence the fauna of some of them is quite completely changed.

The Pacific slope of southern California is largely under cultivation and fauna and flora greatly modified. The deserts of the southwest are cultivated wherever water is available. However, large areas of the desert are still unmodified except as the result of grazing.

The grizzly bear, burro deer, Columbian sharp-tailed grouse, and trumpeter swan are now extinct in California and the elk, pronghorn antelope and bighorn sheep are candidates for extinction. The sturgeon has practically disappeared from streams, and many game species are greatly reduced in numbers.

There has been extensive planting of exotic plants and trees in southern 
California. Perhaps the most conspicuous trees are various species of Eucalyptus and Acacia from Australia and the pepper tree (Schoenus molle) from South America. A wide variety of forage plants have been introduced and many of them are now considered weed pests, for example Johnson grass (Sorghum halapense) and Bermuda grass (Cynodon dactylon).

Among exotic vertebrates now thoroughly acclimated are three species of rats, the house mouse, Tennessee opossum, English sparrow, and ring-necked pheasant, the latter purposely introduced as a game bird. The opossum introduced by accident in both southern and central California is already becoming a serious pest. Many attempted introductions of game species have proved failures.

In the streams and lakes are to be found many introduced species of fishes, including two kinds of black bass, the striped bass, calico bass, crappie, ringed perch, blue-gilled sunfish, shad, carp, two kinds of catfish and four kinds of trout-eastern brook, mackinaw, lock leven and brown. Topminnows have been widely distributed in recent years as a means of controlling mosquitos. Many predatory insects have been introduced as controls on insect pests of citrus groves. The accidentally introduced Argentine ant is proving one of the worst of pests.

The areas within the national parks probably come nearest to being preserved in a natural state for no hunting is allowed, grazing and flower picking is restricted and there is but a slight amount of timber cut.

The National Forests of the State furnish considerable protection to fauna and flora. (See accounts in National Forests of California, page 216.)

IV. NATURAL AREAS

\section{Middle Eastern California}

*Yosemite National Park (B2 I). Area, 1125 sq. mi.; elevations 2000 to $13,090 \mathrm{ft}$.; includes granite-walled Yo- semite Valley of world-famed beauty; lofty cliffs; romantic vistas; many waterfalls of extraordinary height; glacial evidences; ravines, canyons, mountains; coniferous and mountain forest, chaparral; three groves of big trees (Sequoia gigantea), including the Mariposa Grove. Mule deer and black bear commonly seen. Includes type locality of Yosemite toad (Bufo canorus), Mt. Lyell salamander (Hydromantes platycephala), Yosemite pocket gopher (Thomomys alpinus awahnee), Yosemite vole (Microtus montanus yosemite), Yosenite cony, Yosemite mole, High Sierra bat, Yosemite fox sparrow.

$190 \mathrm{mi}$. east of San Francisco by Big Oak Flat Road and $225 \mathrm{mi}$. east of San Francisco by Wawona Road. Southern Pacific R. R. or Sante Fe R. R. to Merced; Yosemite R. R. to El Portal and Yosemite Transportation Company stages to Yosemite Valley.-W. $F$. Bade.

*Devil Post Pile National Monument (B2). Area of 800 acres at the upper end of the San Joaquin canyon containing a spectacular mass of hexagonal basaltic columns like an immense pile of posts. Administered by the United States Forest Service. Madera County, Southern Pacific R. R. to Laws thence by stage to Mammoth, thence by trail. Also reached by trail from Yosemite Valley.-E. N. Munns.

* Sequoia National Park (B2). Created 1890. Area, 252 sq. mi. 12,000 sequoia trees over $10 \mathrm{ft}$. in diameter, some 25 to $36 \mathrm{ft}$. in diameter; towering mountain ranges; steep precipices; cave of considerable size.

72 mi. east of Visalia, California, Southern Pacific R. R. Good automobile roads.

*General Grant National Park (B2). Area, 4 sq. mi. Created to preserve the celebrated General Grant Tree, 35 $\mathrm{ft}$. in diameter-6 $\mathrm{mi}$. from Sequoia National Park.

$71 \mathrm{mi}$. east of Fresno, California, Southern Pacific R. R.

$49 \mathrm{mi}$. east of Visalia, California, Southern Pacific R. R. 
*Lassen Volcanic National Park (B2). Area, 124 sq. mi. Only active volcano in United States proper-Lassen Peak 10,465 ft.; Cinder Cone $6879 \mathrm{ft}$.; Hot Springs; mud geysers. Lakes, streams, forests of western yellow and white pine and lodgepole pine.

Southern Pacific R. R. to Red Bluff or Western Pacific R. R. to Paxton.

\section{West Central California}

*Pinnacles National Monument (B2). Area, 2080 acres; mountain coniferous forest, chaparral; waterfall, mountainous and rocky conditions; caves, spring, excellent canyon. Deer present. Included in State Game Refuge $3 \mathrm{~B}$.

Entrance via Hollister, California, $91 \mathrm{mi}$. south of San Francisco, or Soledad, Monterey Co., $140 \mathrm{mi}$. south of San Francisco.-Eliot Blackwelder.

*Mount Diablo State Park (B2). Mountain $4000 \mathrm{ft}$. high giving a commanding view of the entire center of the state, embracing mountains, rivers, valleys, bays and cities. 320 acres have been set aside; the purchase of 4000 more is contemplated. Typical sample of California foothill country including groves of live oak, California laurel, chaparral, and so forth. The region and fauna little disturbed by civilizing influences save that deer and other larger mammals are less abundant than under original conditions.

West base of mountain reached by branch of San Francisco-Sacramento R. R. at Walwood, or by Southern Pacific Railroad at Walnut Creek. San Francisco $35 \mathrm{mi}$. west. Reached by auto over paved roads.-E. N. Munns.

Spring Valley Water Company Properties (C3). Typical humid coast flora and fauna, including redwoods; modified by storage reservoirs and predatory mammal control with some grazing. No hunting allowed.

San Mateo County. $30 \mathrm{mi}$. south of San Francisco. Southern Pacific R. R. or over good roads.

Redwood Preserves. ${ }^{3}$ (The Redwood

3 Information from N. B. Drury, Sec., Save the Redwoods League, July, 1923, Annual Report of the League for 1922 and publicity material issued by the League in July, 1923.
Belt is a strip of forest which averages $20 \mathrm{mi}$. in width and extends some 450 mi. from Monterey County, California, to just above the Oregon line.)

*California State Redwood Park (B2). An area of 2500 acres of redwood in the region known as "The Big Basin." In addition to the redwood forest, scattered areas surrounding the park have been purchased by the state and set aside by the National Government, making a total of some 9000 acres in the entire reservation. Facilities have been provided for campers in the park, and a central dining hall and cabins have been erected which are run as a hotel. As far as possible, the park is to be maintained in a state of nature. Santa Cruz County.

$33 \mathrm{mi}$. southwest of San Jose on highway. Stages from Boulder Creek, $11 \mathrm{mi}$.

$25 \mathrm{mi}$. northwest of Santa Cruz on highway.

*Muir Woods National Monument (B2). Area, 295 acres. Virgin stand of Sequoia sempervirens and associated vegetation. The whole Mt. Tamalpais region is a game refuge and all life is protected inside the monument.

Marin County. $8 \mathrm{mi}$. north of San Francisco; reached by Northwestern Pacific R. R. and Mt. Tamalpais R. R.

*Armstrong Grove. An area of 419 acres of Sequoia sempervirens, located near Guerneville and owned and administered by Sonoma County. A caretaker is in charge and all life is preserved.

Guerneville, $3 \mathrm{mi}$. south on county road. Guerneville reached by Northwestern Pacific R. R. from San Francisco.

*Bohemian Grove (B2). A stand of redwoods preserved and owned by the Bohemian Club of California.

Sonoma County. $85 \mathrm{mi}$. north of San Francisco on N. W. P. R. R.

*Edward R. Hickey Memorial Grove (B2). An area of 40 acres of redwoods. Mendocino County.

On State Highway, north of Willits. N. W. P. R. R.

*Humboldt State Redwood Park (B2) An area of 2216 acres of virgin redwood in Humboldt County bordering the 
State Highway for $14 \mathrm{mi}$. between Miranda and Dyerville in the basin of the South Fork of the Eel River. The park is administered by the State Board of Forestry. Camp facilities are provided at various points.

$230 \mathrm{mi}$. north of San Francisco. Reached either by automobile via the main State Highway to Eureka, or via Northwestern Pacific Railroad to South Fork Station or to Eureka, and thence to the park by automobile.

*Humboldt County Pioneer Memorial (B2). An area of 166 acres of giant erdwoods on the California State Highway near Orick, Humboldt Co. Some of the largest trees in the redwood belt are found in this tract; these with the massive firs, maples, spruce, and oaks, together with the giant ferns and other undergrowth, make it an area of unusual beauty. It is still in a primeval state and the deed stipulates that it shall be kept in a natural condition. The grove is crossed by Prairie Creek which adds to the beauty of the grove and its advantages from a park and recreational standpoint.

About $60 \mathrm{mi}$. north of Eureka on the California State Highway.

\section{PROPOSED AREAS}

\section{Proposed Redwood National Park}

1. It is hoped that eventually a Redwood National Park, consisting of a tract of primeval forest possessing the scenic features most characteristic of the region, will be established in the northern limit of the redwood belt (Del Norte County). It should be truly representative of the redwoods in their maturity, and should be of adequate size-probably not less than 20,000 acres, should be accessible, and should present adequate opportunities for recreation. In accordance with a resolution passed by Congress in 1920 , surveys have been made and the problem studied extensively. The groves along the approach to this national park will be preserved through private donation and through state and county appropriations, ultimately making a "Highway of the Giants," extending from their southernmost limit to their northernmost, and connecting the various groves and parks.
2. The redwood region of Humboldt and Del Norte Counties (along and near the Trinidad-Crescent City Highways).

In view of the efforts being made to save areas of the coast redwoods and of the good information that is available regarding them from other sources, attention is called merely to the importance, from an ecological point of view, of preserving not only areas of pure stands of redwoods (to which the efforts of the Save the Redwoods League will doubtless be chiefly directed), bui also of the several very different types of mixed forest of redwoods and other trees, and especially of the covering forest (largely Sitka spruce and lowland white fir) which intervenes between the redwood belt and the ocean shore, and is necessary to protect the redwoods from the ocean winds unless hills intervene. Along the old Trinidad-Crescent City Highway, much of the forest is of the mixed type and contains magnificent examples of Douglas firs, hemlocks and white firs. Firs 250 to $260 \mathrm{ft}$. high are common in these forests.

The forest consists in some places of almost pure Sitka spruce, sometimes of large size and great height. Much of it has already been destroyed. It is easily killed by fire and exposure to wind and sun. Prompt efforts should be made for the permanent protection of some of this tract of spruce and lowland fir.

There are magnificent stands of Sitka spruce in the vicinity of Requa, Del Norte County, and Orick, Humboldt County (some of them are probably 280 ft. tall). The finest lowland white fir along the highway is in two rather small tracts of mixed redwood forest between Orick and Trinidad. There is little forest anywhere in the United States more worth saving from a scientific and aesthetic point of view than some of the tracts along this highway and in its immediate vicinity, especially from the Del Norte-Humboldt County line to near Orick, although so far as the redwoods themselves are concerned, better stands can be found elsewhere, especially near Smith River and South Fork.

3. Monterey Coniferous Forest. Northwestern coniferous forest, sand areas, ravines, canyons, sand and rocky shores, and marshes. Fine stand of Monterey pine and coast redwood. Monterey cypress along the shore line.

Monterey County. Pacific Grove or Monterey, California, 3 to $10 \mathrm{mi}$. north. -Prof. Lynds Jones, Oberlin College, Oberlin, Ohio. 


\section{Northeastern California}

*The McArthur Burney Falls Park (B2). An area of 160 acres in Shasta County, including original forests of pine with various species of game present. Includes Burney Falls and Burney Creek, the falls being $187 \mathrm{ft}$. high. Five mi. from the highway between Redding and Alturas.

Redding $75 \mathrm{mi}$. southwest. - Stephen Mather, Memorandum on State Parks.

\section{Southwestern California}

*Torrey Pines Park (B3). An area of about 700 acres in San Diego Co. including the rare Torrey pines (Pinus torreyana) and an association of typical semi-desert vegetation. Owned by the city of San Diego and set aside as a wild life reservation. Important as the habitat of the mainland group of Torrey pines, a prostrate form of Arctostaphylos, and other shrubs of botanical interest and of certain birds and small animals.-Guy Fleming.

San Diego $22 \mathrm{mi}$. south on State Highway.

Los Angeles Summer Camp (B3). Los Angeles County has purchased property with Jeffrey pine and piñon timber west of Cajon Pass, San Bernardino County for summer camp ground. It will be kept in a seminatural state. For further particulars, address County Forester, Los Angeles, California.-H. C. Bryant.

Mt. Pisgah Lava Field. A very irregular area covering about 15 sq. mi. An old lava field, or rather a series of fields of varying ages, but without evidences of very recent volcanic activity. Is extremely rugged and difficult of passage; crossed by jagged ridges and yawning fissures; sand has drifted in from the surrounding desert and become deposited in the cracks and depressions affording soil for the support of scattered shrubs and annuals for a mile or more from its nearest border. Area for observation of white-footed mice, by Scripps Institution.

San Bernardino County. Adjacent to (south of) the main line of Santa Fe
R. R. at Lavic and Pisgah stations. Ludlow $12 \mathrm{mi}$. east. $-F$. B. Sumner (see Journal of Mammalogy, vol. II).

\section{Southeastern California}

Lankershim Semi-Desert. Twelve acres semi-desert, San Fernando Valley in Los Angeles County, with cacti and level plain and with sand areas. Mammals: pocket-mice, kangaroo-rats and grasshopper mice; such birds as: blacktailed gnatcatcher, cactus wren, Bell sparrow, and rufous sparrow.

Lankershim, California, is $6 \mathrm{mi}$. northwest direction from Hollywood.

Near "Toluca," on Santa Monica Quadrangle, U. S. G. S.-J. Grinnell.

Tujunga Wash. Five square miles of semi-desert, chaparral and cacti, flood wash, and sand area. Few spots of wild desert left in the rapidly developing San Fernando Valley.

Los Angeles County. Burbank, California, $5 \mathrm{mi}$. northwest; north of Newhall Division of S. P. R. R. $-J . E$. Law.

Los Angeles Live Oak. Two acres of deciduous forest, chaparral, mountain ravine, and canyon; a narrow strip between Los Angeles River and steep slope of mountains just south containing a magnificent grove of gigantic live oak, fern-filled, well-wooded, steep canyon.

Los Angeles County. Los Angeles, adjacent to Griffith Park.-J. E. Law. Big Prospector Meadow. An area of 500 acres of steppe, $10,500 \mathrm{ft}$. altitude, sagebrush, alpine meadow on the mountain top. Threatened by sheep; almost tramped out now. Home of Merrill horned lark, sage grouse, sage thrasher, Brewer sparrow, short-tailed meadow mouse, and white-tailed jackrabbit.

Inyo County in White Mountains. Laws, California, $13 \mathrm{mi}$. northeast. Shown on U. S. G. S. map of "Bishop" Quadrangle.-J. Grinnell.

Oro Grande Rock Area. Consisting of hills, covered with large masses of igneous rock of pale buff and pinkish hues, interspersed with sand and gravel. The vegetation is of the usual type of the western Mohave desert region. Selected as a trapping station for whitefooted mice, as control for Pisgah Lava Field (see above), the object being to test the alleged effect of color of background upon color of these rodents. Altitude $2700 \mathrm{ft}$.

Barstow $31 \mathrm{mi}$. north, San Bernardino $50 \mathrm{mi}$. south on Santa Fe R. R. San Bernardino County.-F. B. Sumner.

Kelso Desert. Hundreds of square 
miles of creosote bush desert showing a scattered stand under extreme arid conditions, the brush supporting two species of grasshoppers that are common in autumn; scorpions and lizards numerous; horned rattler present. Providence Mountains $10 \mathrm{mi}$. southeast with mountain sheep present. Kelso, California, immediate environs; Salt Lake Route Railway; water station with a restaurant for railroad men and probability of lodgings among the few residents. Convenient points for study of Mohave Desert.-V. E. Shelford.

Desert Moving Dunes. An area of 25 sq. mi. of desert moving dunes just south of the L. A. \& S. L. R. R., between Flynn and Kerrens. Kelso, California; $5 \mathrm{mi}$. west to Flynn, California.-V. $E$. Shelford.

Mohave Yucca Forest. An area of about $720 \mathrm{sq}$. mi. including one of the finest of tree yucca forests and the unsettled parts of the Tehachapi Mountains, Antelope Valley, and the Sierra de la Liebre, the pine-clad slopes of Mt. Frazier, and finally, the arid desert at the mouth of Jawbone Canyon. The fauna includes a few antelope (1914), black-tailed deer, black bear, cougar, and bighorn sheep together with the smaller mammals, birds, and reptiles, commonly associated with these animals. The geological features are interesting. The San Francisco earthquake rift with springs and lakes along it, runs through Fort Tejon, Elizabeth Lake, and Palmdale. There are important fossil beds at Ricardo, in Red Rock Canyon.

Los Angeles and Kern counties. Tehachapi, adjacent to the mountains. S. F.\& S.P.R.R. Mohave-Inyo R.R. gives access to northeastern portions in the regions of Jawbone Canyon and El Paso Mountains. Saugus, Southern Pacific, adjacent to the southern portion. Bakersfield-Los Angeles Highway crosses through Tejon Pass near the base of Mt. Frazier.-Chas. L. Camp (1922).

\section{California's game sanctuaries}

California is assured a perpetual supply of game by having set aside areas where no hunting is allowed and where game is allowed to breed unmolested. The state is responsible for the creation of most of them, the Federal Government for others. Certain areas known as Game Refuges have been set aside by legislative enactment. Others known as State Game Preserves have been created by the Fish and Game Commission after the owner of the property has ceded all hunting privileges to the state for a period of not less than ten years. The Federal Government has set aside three Bird Reservations and protects all of the wild life within the $\mathrm{Na}$ tional Parks and National Monuments. As a consequence, game is now absolutely protected on nearly $3,000,000$ acres within the State of California, an area roughly equivalent to three per cent of the total area of the state. On these areas fishing is allowed.

Game refuges (C3)

\begin{tabular}{|c|c|c|c|}
\hline NAME & COUNTY & AREA & 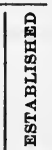 \\
\hline & & acres & \\
\hline $1 \mathrm{~A}$ & Siskiyou & 22,540 & 1917 \\
\hline $1 \mathrm{~B}$ & Modoc & 83,060 & 1917 \\
\hline $1 \mathrm{C}$ & Modoc & 21,760 & 1917 \\
\hline $1 \mathrm{D}$ & Trinity & 82,560 & 1915 \\
\hline $1 \mathrm{E}$ & Shasta & 37,760 & 1917 \\
\hline $1 \mathrm{~F}$ & Lassen & 46,720 & 1917 \\
\hline $1 \mathrm{G}$ & Tehama & 33,920 & 1917 \\
\hline $1 \mathrm{H}$ & Plumas & 37,760 & 1917 \\
\hline & $\begin{array}{l}\text { El Dorado, Cala- } \\
\text { veras }\end{array}$ & & \\
\hline $1 \mathrm{~J}$ & Amador & 58,320 & 1917 \\
\hline $1 \mathrm{~K}$ & Fresno & 34,240 & 1917 \\
\hline $1 \mathrm{~L}$ & Tulare and Kern & 35,520 & 1917 \\
\hline $2 \mathrm{~A}$ & Mern & $\begin{array}{l}01,920 \\
35,200\end{array}$ & 1917 \\
\hline $3 \mathrm{~A}$ & $\begin{array}{l}\text { and Butte } \\
\text { Santa Cruz }\end{array}$ & 4,480 & 1915 \\
\hline $3 \mathrm{~B}$ & San Banitoand Mon & 14,080 & 1909 \\
\hline $3 \mathrm{C}$ & Santa Barbara & 41,600 & 1917 \\
\hline $3 \mathrm{D}$ & Ventura & 125,760 & 1917 \\
\hline $3 \mathrm{E}$ & Santa Clara & 3,600 & 1919 \\
\hline $3 \mathrm{~F}$ & Contra Costa & 10,240 & 1921 \\
\hline $4 \mathrm{~A}$ & Los Angeles & 293,120 & 1915 \\
\hline $4 \mathrm{~B}$ & Los Angeles & 325,120 & 1915 \\
\hline $4 \bar{C}$ & Orange & 99,840 & 1913 \\
\hline $\begin{array}{l}4 \mathrm{D} \\
4 \mathrm{E}\end{array}$ & Riverside & $\begin{array}{l}69,120 \\
51,840\end{array}$ & $\begin{array}{l}1917 \\
1917\end{array}$ \\
\hline $4 \mathrm{~F}$ & Los Angeles and & 46,080 & 1919 \\
\hline Mount & $\begin{array}{l}\text { Kern } \\
\text { Marin }\end{array}$ & 28,000 & 1917 \\
\hline Lake Merritt & Alomeda County & & 1869 \\
\hline & $\begin{array}{l}\text { Alamealand) } \\
\text { (Oaklo }\end{array}$ & & \\
\hline & & $1,792,000$ & \\
\hline
\end{tabular}

State game preserves (G7)

\begin{tabular}{|c|c|c|c|}
\hline No. 5 & Monterey and San & 8,570 & 1916 \\
\hline $\begin{array}{l}\text { No. } 6 \\
\text { No. } 7\end{array}$ & $\left.\begin{array}{l}\text { Santa Barbara } \\
\text { Santa Barbara }\end{array}\right\}$ & 42,000 & 1918 \\
\hline & & 50,570 & \\
\hline
\end{tabular}

Federal bird reservations (H8)

\begin{tabular}{l|l|r|r}
\hline $\begin{array}{l}\text { Klamath } \\
\text { Lake } \\
\text { Clear Lake } \\
\begin{array}{c}\text { Farallon } \\
\text { Islands }\end{array}\end{array}$ & $\begin{array}{l}\text { Sodoc } \\
\text { Pacific Ocean, near } \\
\text { San Francisco }\end{array}$ & $1,600^{\circ}$ & 1911 \\
\hline & & $24,400^{\circ}$ & 1908 \\
\hline
\end{tabular}

- Approximate. -H. C. Bryant. 


\section{BIBLIOGRAPHY}

Grinnell, J.

1908. The Biota of the San Bernardino Mountains. Univ. Calif. Publ., vol. 5, pp. 1-170, pls. 1-24.

1913. A Distributional List of the Mammals of California. Proc. Calif. Acad. Sci., 4th ser., vol. 3 , pp. 265-390, pls. 15, 16.

1914. An account of the Mammals and Birds of the Lower Colorado Valley, with Especial Reference to the Distributional Problems Presented. Univ. Calif. Publ. Zool., vol. 12, pp. 51-294, pls. $3-13$, 9 figs. in text.

1914. Barriers to Distribution as Regards Birds and Mammals. American Naturalist, vol. xlviii, April, 1914.

1915. A Distributional List of the Birds of California. Pac. Coast Avifauna (Cooper Ornithological Club), no. 11, 217 pp., 3 pls. (maps).

1917. Field Tests of Theories Concerning Distributional Control. American Naturalist, vol. li, Feb., 1917.

Grinnell, J., and Storer, T. I.

1924. Animal Life in the Yosemite. An account of the mammals, birds, reptiles and amphibians in a cross section of the Sierra Nevada. (Univ. Calif. Press), 750 pp., 12 colored pls., 48 Hall, H. M. pls., 2 maps, 65 figs. in text.

1902. A Botanical Survey of San Jacinto Mountain. Univ. Calif. Publ. Bot., vol. 1, pp. 1-140, pls. 1-14.

Hall, H. M., and Grinnell, J.

1919. Life-zone Indicators in California. Proc. Calif. Acad. Sci., 4th ser., vol. ix, no. 2 , pp. 37-67, June, 1919.

Jepson, Willis Linn

1909. The Trees of California. (Cunningham, Curtis \& Welch, San Francisco), 228 pp., 125 figs. in text.

Merriam, C. Hart

1898. Life Zones and Crop Zones of the United States. U. S. Dept. Agric., Div. Biol. Surv., Bull. no. 10,79 pp., 1 map (colored).

1899. Results of a Biological Survey of Mount Shasta, California. U. S. Dept. Agric., Div. Biol. Surv., N. Amer. Fauna, no. 16,179 pp., 5 pls., 46 figs. in text.
Smiley, F. J.

1921. A report upon the boreal flora of the Sierra Nevada of California. Univ. Calif. Publ. Bot. 9, pp. 1-423, pls. 1-7.

1915. Nature and Science on the Pacific Coast. Edited under auspices of the Pacific Coast Comm. of the A. A. A. S. (Paul Elder \& Co., San Francisco), 302 pp., 19 figs. in text, 29 pls., 14 maps.

\section{NATIONAL FORESTS OF THE NORTH PACIFIC DISTRICT (6)}

\section{By J. V. HofmanN}

The National Forests of Oregon and Washington include large areas of mountainous country and some of the most gigantic forests of the world. The total National Forest area covers nearly $52,000,000$ acres of which about $15,000,000$ are in Oregon, and 10,000,000 acres in Washington. ${ }^{1}$

The wide variety of conditions existing in these forests affords a mecca for the nature lover and scientist alike. These regions provide fertile fields for the pursuit of studies in biology, geology and any of the botanical sciences.

The preservation of natural conditions in the Pacific Northwest for purely ecological or biological purposes, or for keeping intact some of the forest formations that exist at the present time and which will not be reproduced under forest management, can best be served by considering the region as a whole.

The present economic conditions are such that there will undoubtedly be regions left untouched in this section for several decades, and large areas of types will be preserved without any special effort. This will apply to this region more than to various other sections because the National Forest land covers practically all the types and conditions of the region, and portions of these forests will be left untouched until the lumber industry advances to the stage where the last areas of the present mature stands of timber are

1 The national forest areas mentioned in this and the following accounts are as of July 1, 1923 . 
logged. For these reasons types that are included in such forests need not be designated at the present time because the future development of these large bodies of timber can not be foreseen, and the selection of the areas should be made in accordance with conditions at the time any special type is being cut. Conditions arise under which areas can be set aside very easily during the progress of logging without any special effort or inconvenience to the operators or any great financial sacrifice by the Government.

To consider the different types of the Pacific Northwest, it appears best to divide the region into its natural areas or types. This would divide Washington and Oregon into three distinct areas; namely, the Eastern Oregon or Blue Mountain division, the Cascade Mountain division and the Coast division including the Olympic Peninsula. The range of elevation in each division divides it again into forest types. The species in the Coast and Cascade divisions are similar at similar elevations and form the following types:

1. Lower slope type, sea level to about $3500 \mathrm{ft}$. forms the Douglas fir-hemlockcedar type, including Douglas fir; western red cedar; western hemlock, sitka spruce, in the coast region; sugar pine in southern Oregon; Port Orford cedar, in southwestern Oregon; western yellow pine, in the Willamette Valley and the east side of the Cascade Mountains; western white pine, lowland white fir, lodgepole pine, in isolated occurrence; western larch, on the east side of the Cascade Mountains, and Alaska cedar in northern Washington. Minor hardwood species are scattered throughout the region.

2. Upper slope type, 3500 to $4500 \mathrm{ft}$., forms the true fir type including noble fir, silver fir, Englemann spruce, white fir, Douglas fir, western hemlock, western red cedar, lodgepole pine, western yellow pine, western white pine, Alaska cedar in northern Washington, and sugar pine, knobcone pine, and Shasta red fir in southern Oregon.
3. Subalpine type, $4500 \mathrm{ft}$. to timber line at 5000 to $6000 \mathrm{ft}$., including mountain hemlock, alpine fir, white-bark pine, dwarf juniper, Rocky Mountain juniper, western juniper, lodgepole pine, white fir, noble fir, silver fir, Englemann spruce, western white pine, Shasta red fir in southern Oregon, and Alaska cedar in northern Washington.

The Blue Mountain group of forests consists largely of western yellow pine and includes also Douglas fir, western hemlock, white fir, lodgepole pine, and western larch.

The conditions included within each of these regions are so similar that any convenient locality may be selected to preserve a representative area of the general type of vegetation. The selection of any area for ecological or scientific purposesshould contain the optimum conditions for the type of vegetation concerned, consequently such mixtures as occur in eastern Washington, where the loogepole pine, western larch, western white pine, Douglas fir, white fir and other species are in mixture, would not be representative of any one species. The same condition prevails in southern Oregon where the sugar pine, knobcone pine, and the Shasta red fir occur in mixture with the typical species of Oregon. In other words, areas should be selected in the region in which the species develops not necessarily to its optimum growth, but at least the average or better, and where it forms the greatest per cent of the stand.

At present there are no areas in the western yellow pine type of Oregon and Washington that are more permanently preserved than that they are a part of a National Forest. The large areas of yellow pine within the National Forests gives adequate assurance of the preservation of the western yellow pine type for a long time to come. The only factor concerned is grazing, and there are extensive ungrazed areas on which studies may be made where natural conditions are desired.

The Cascade forests vary in elevation from $100 \mathrm{ft}$. to timber line at between 
5000 and $6000 \mathrm{ft}$. Vegetation does not extend far above timber line, although at the higher elevations the beautiful mountain meadows occur among the scattered stands of the subalpine species. The next lower zone is occupied by the noble and silver firs, some alpine fir and mountain hemlock, below which occurs the Douglas fir forest, which is the predominating forest of the region. The Douglas fir forest varies from a pure stand to a mixture with western hemlock, western red cedar, lowland white fir, and some other minor species. In these various zones of the Cascade Mountains the greater per cent of the area is in its natural condition. All stages of the forest may be found in various localities.

Where the forest has been reburned several times the large huckleberry fields occur, and where two or more fires have occurred at varying intervals, or in patches, the mixed succession forest occurs, and on areas where single forest fires have destroyed mature forests the typical succession forest consisting of the species of the original forest is present.

The Olympic Peninsula is of special interest because it contains some of the largest Douglas fir in mixture with Sitka spruce, western hemlock and western red cedar. This is probably the best region for preserving some of the largest timber of the Pacific Northwest. At present, very little logging is being done in regions that would destroy the last remnants of this type, and it will probably be a long time before this area is opened up for general logging. It would be difficult at this time to designate any special area that would be suitable for preservation because the development of the peninsula is uncertain, and during the process of cutting it will be more feasible to determine what areas should be selected.

The situation on the southwestern coast of Oregon is somewhat different. In this region the Port Orford cedar occurs in a very limited range. The Port Orford cedar is at present the most valuable individual tree of the entire region, and it is being cut in regions where logging was not considered even a few years ago. The selective logging, by which Port Orford cedar is being cut, is threatening the extinction of this species. This calls for action if this type of forest is to be preserved. Fortunately, some of the best stands of Port Orford cedar are included in the Siskiyou National Forest on the Sixes River watershed. This region possibly may be cut, at least in part, in the near future, and some definite action should be taken to preserve a part of this type of forest. The Port Orford cedar merits attention and preservation equally as much as the redwoods. It appears that this species is a remnant of the forests of the bygone ages. The Port Orford cedar is re-producing very well, and various age classes may be found. The area mentioned ranges from sea level to about $2000 \mathrm{ft}$. and is located from 10 to $15 \mathrm{mi}$. from Port Orford, Oregon. The Port Orford cedar is the only species of this region that is in immediate danger of being exploited to the point that will leave none of the mature forests.

In the Cascade Mountains there are at present several areas that are permanently preserved, and no doubt there will be future selections for various purposes that will add to these areas. Areas already preserved are: The Crater Lake National Park, The Rainier National Park, The Bull Run WaterShed on the Oregon National Forest which supplies the water for the eity of Portland, The Sultan River WaterShed on the Snoqualmie National Forest which supplies the water to the city of Everett, and the game preserve on the Stilaguamish River above Silverton, Washington on the Snoqualmie National Forest and a similar preserve around Lake Chelan on the Chelan National Forest. There is also a reservation surrounding the Government Mineral Springs in the Wind River Valley on the Columbia National Forest.

Areas that are set aside for such purposes as these are usually left intact. Such areas are also valuable for the 
study of natural conditions, for scientific research, and for biological purposes. There are other mineral springs, natural camp sites, recreation grounds, and other localities that will undoubtedly be set aside in the near future. This selection of areas is distributed along the Cascade Range and includes practically all of the types of vegetation of the region.

The sagebrush region in eastern Oregon and Washington may not receive attention, although no doubt there always will be sections available for study if left as it is. It includes the region on the east side of the Cascade Mountains. This is a border type between the forest and desert and is an interesting type from both ecological and biological standpoints.

Wild animal life abounds throughout this northwestern region and varies very little in the different sections. The black bear and grizzly bear are found throughout the region. Timber wolf and coyote are found throughout the region, especially on the east side of the Cascades. Deer are plentiful throughout the region, and elk are also found. Bands of elk are known at present around Mt. St. Helens in Northern Washington; on the Siskiyou National Forest; in the Southern Cascades of Oregon, and in the Olympic Peninsula. Cougar, fox, marten, fisher, and numerous smaller animals are found throughout these forests. Good fishing is found in all of the streams, many of them being restocked periodically.

\section{NATIONAL FORESTS}

Cascade National Forest (Oregon). The Cascade National Forest has an area of $1,022,312$ acres. It ranges in elevation from $1000 \mathrm{ft}$. along the McKenzie River to over $10,000 \mathrm{ft}$. where the boundary reaches the Three Sisters Mountains. These three peaks are covered with perpetual snow, and the melting snow from the Cascade Range feeds the many scenic waterfalls and cascades from which the forest derives its name. Most noted among the falls are the Salt Creek Falls with a perpendicular drop of over $275 \mathrm{ft}$., and the McKenzie Falls.

The forest consists of a dense stand of Douglas fir estimated to contain 20 billion board feet of merchantable timber. The higher ridges contain the upper slope and the alpine species.

The headquarters of the forest are at Eugene on the Southern Pacific Railway. The southern part of the forest is reached on the branch to Oak Ridge, and the northern part of the forest is reached over the McKenzie Highway.

Chelan National Forest (Washington). The Chelan Forest covers an area of $1,997,988$ acres and ranges in elevation from about 3000 to nearly $7000 \mathrm{ft}$. This forest includes the famous Lake Chelan which is a rival of the world famed Lake Brienz of Switzerland. This forest contains western yellow pine on dry soil at lower altitudes good stands of Douglas fir at the lower elevation, and has the typical upper slope and subalpine types at the higher, also the beautiful mountain meadows near timber line.

An area around Lake Chelan has been set aside as a game preserve and this area harbors the mountain goat and sheep as well as deer, bear and other game.

The headquarters are at Okanogan $\ddagger$ and the forest is accessible by stage and boat on Lake Chelan.

Columbia National Forest (Washington). Includes an area of 785,224 acres. It lies in the southcentral part of the state and includes the Cascade Range. The elevation varies from 100 to over $12,000 \mathrm{ft}$. at Mt. Adams.

The forest includes Mt. Adams and Mt. St. Helens; the latter is the youngest of the glacier peaks of the Cascade Range. The range in elevation makes it possible for all forest types to be found on the Columbia Forest. In the lowlands are the heavy, mature stands of Douglas fir and associated species. On the higher slopes is the upper slope type of true firs, above which is the true subalpine type which adjoins the mountain meadows at timber line. 
On the Columbia National Forest the Wind River Forest Experiment Station is located in the Wind River Valley, eleven miles from Carson on the S. P. \& S. Ry. This Station is the headquarters for research on the forests of the Pacific Northwest.

The headquarters of the Columbia Forest are at Portland, \pm and the forest is reached by the S. P. \& S. Ry. to points along the Columbia River.

Colville National Forest (Washington). The Colville Forest covers an area of 754,737 acres and ranges in elevation from 950 to over $7000 \mathrm{ft}$. Within the Colville Forest are the Kettle Falls at which point the Columbia River falls nearly $100 \mathrm{ft}$.

The forest type ranges from the Douglas fir type in the lower elevation to the subalpine type and mountain meadows. It also includes large areas of lodgepole pine forests.

The headquarters are at Republic from which point the forest is reached by stage.

Crater National Forest (Oregon). The Crater Forest is divided into two separate tracts aggregating 852,158 acres. The larger tract includes the southern slope of the Umpqua Range of mountains and the other is in the Siskiyou Mountains. The elevation ranges from 1500 ft. to over $9000 \mathrm{ft}$. on Mt. McLoughlin.

On the Crater Forest the traveller will see 5 forest types: western yellow pine, lodgepole pine, Douglas fir, white fir, and the alpine species.

Within the Crater Forest lies Crater National Park which includes Crater Lake.

The headquarters of the forest are at Medford, $\ddagger$ and the Cascade division of the forest is reached over the highway to Crater Lake. The Siskiyou division is also accessible by auto road from Medford.

Deschutes National Forest (Oregon). The Deschutes National Forest is located entirely on the east side of the Cascade Range in central Oregon. It includes $1,283,808$ acres and ranges from about $4000 \mathrm{ft}$. in elevation to over
$10,000 \mathrm{ft}$. The boundary of the Deschutes joins the Cascade and includes a part of the Three Sisters. This forest contains Mt. Jefferson which is one of the picturesque peaks of the Cascade Range and, due to its almost perpendicular summit, is a peak that is of special interest to mountain climbers.

The forest is typical western yellow pine and lodgepole with some of the subalpine species.

The headquarters are at Bend $\ddagger$ which is reached by a branch of the O. S. L. R. R.

Fremont National Forest (Oregon). The Fremont National Forest is located in south central Oregon and is on the east side of the Cascade Range. It is a typical western yellow pine forest. It includes 849,526 acres and ranges in elevation from 4200 to $7000 \mathrm{ft}$.

The headquarters are at Lakeview $\ddagger$ which is reached by stage from Bend or Klamath Falls.

Malheur National Forest (Oregon). The Malheur Forest is one of the group of forests located in the Blue Mountain region of Eastern Oregon. It has a total area of $1,043,777$ acres. Its elevation ranges from 200 to $8000 \mathrm{ft}$. The forest surrounds Strawberry Mountain which is one of the highest peaks in the Blue Mountains.

The forest is like all of the Blue Mountain group of forests and contains western yellow pine on the south slopes and white fir, larch and Douglas fir on the north slopes. Areas of lodgepole pine also occur in places that have been burned several times.

The headquarters are at John Day $\ddagger$ which is reached by stage from Burns. $\ddagger$

Ochoco National Forest (Oregon). The Ochoco Forest is another of the Blue Mountain group. It contains 717,994 acres and ranges in elevation from 3000 to $7400 \mathrm{ft}$. It is a typical western yellow pine forest with the white fir-larchDouglas fir type on the north slopes.

The supervisor's headquarters are at Prineville $\ddagger$ which is reached by the O. S. L. R. R.

Olympic National Forest (Washington). 
The Olympic Forest covers an area of $1,535,503$ acres and ranges in elevation from near sea level to over $8000 \mathrm{ft}$. at Mt. Olympus. The Olympic Forest contains some of the heaviest stands of Douglas fir, Sitka spruce and western hemlock of any of the north Pacific forests. Almost pure stands of Sitka spruce may be found, and large areas of western hemlock, as well as Douglas fir. On the higher altitudes are the upper slope types merging into the subalpine types and mountain meadows. Within the forest are found Quiniault and Crescent lakes.

The headquarters are at Olympiał and the forest may be reached by stage or by boat on Puget Sound.

Oregon National Forest (Oregon). The Oregon Forest includes the famous Columbia Gorge on the Oregon side and is traversed by the Columbia Highway which makes it very accessible from Portland. $\ddagger$ It contains 1,053,820 acres and ranges in elevation from about 100 ft. at Cascade Locks to over $11,000 \mathrm{ft}$. at the summit of Mt. Hood.

The Eagle Creek Camp Ground along the Columbia Highway is a large camp site maintained by the Forest Service.

The Oregon Forest contains heavy stands of Douglas fir in the lower altitudes and includes some of the best upper slope types of the true firs, and also the subalpine stands.

The headquarters are at Portland $\ddagger$ and the forest is reached principally by stage, although the north end is very accessible by the O. W. R. \& N. R. R. and Columbia River boats.

Rainier National Forest (Washington). The Rainier Forest covers an area of $1,316,517$ acres. It is located in southcentral Washington along the Cascade Range, and the elevation varies from $200 \mathrm{ft}$. to over $14,000 \mathrm{ft}$. on Mt. Rainier.

On the Rainier may be found all of the forest types from the heavy timber types of the lowlands to the subalpine species and the extensive mountain meadows.

The headquarters are at Tacoma $\ddagger$ and the forest is reached over the Tacoma \&
Eastern R. R. to Morton or by stage line to various points.

Santiam National Forest (Oregon). The Santiam Forest covers an area of 607,097 acres and ranges in elevation from 1500 to over $10,000 \mathrm{ft}$. on Mt. Jefferson. The lower slopes are covered by heavy Douglas fir forests, and there are also large areas of the upper slope types.

The headquarters of the forest are at Albany $\ddagger$ on the S. P. R. R., and a branchline to Detroit $\ddagger$ takes one into the heart of the forest.

Siskiyou National Forest (Oregon). The Siskiyou Forest is one of the coast forests in southwestern Oregon and northwestern California covering an area of $1,346,901$ acres. It ranges in elevation from sea level to about $6000 \mathrm{ft}$. On this forest are a variety of types changing from the Port Orford cedar of the northern and the redwoods of the southern lowlands, to the Douglas' firhemlock types at the higher elevations. On this forest are located the Oregon Caves which are the most beautiful caves in the western United States. These caves are reached by stage from Grants Passł.

The headquarters of the forest are at Grants Pass $\ddagger$ from which point any part of the forest may be reached by stage.

Siuslaw National Forest (Oregon). The Siuslaw is another of the coast forests, covering an area of 545,750 acres. It ranges in elevation from sea level to about $4000 \mathrm{ft}$.

On the Siuslaw Forest the Douglas fir produces very heavy timber, and some of the best young stands of this species may be found there.

The headquarters of the forest are at Eugene+, from which point the forest may be reached by stage.

Snoqualmie National Forest (Washington). The Snoqualmie Forest includes 693,733 acres. It is located in the central part of the state along the Cascade Mountains and varies in elevation from $300 \mathrm{ft}$. in the foot hills to over $10,000 \mathrm{ft}$. Some of the most scenic areas of the Cascades may be found within the forest because of its perpendicular canyons and picturesque mountain peaks. 
All of the types of forest typical of the Cascade Range may be found. The Sunset Highway is the main channel of travel from the Puget Sound region to Spokane and makes this forest accessible. Along the Highway is the Denny Creek Camp ground.

The headquarters are at Seattle $\ddagger$ from which point the forest is accessible by stage or over the N. P. R. R. to Darrington or Monte Cristo, also points on the main line of the G. N. R. R.

Umatilla National Forest (Oregon and Washington). The Umatilla is another of the Blue Mountain group which covers an area of 1,228,793 acres and ranges in elevation from 3000 to $7000 \mathrm{ft}$. This is a typical western yellow pine forest.

The headquarters are at Pendleton, Oregon $\ddagger$ and the forest is accessible by stage from this point.

Umpqua National Forest (Oregon). The Umpqua Forest is one of the west side forests in the Cascade Range and includes 1,229,060 acres. The elevation ranges from about 1000 to nearly $9000 \mathrm{ft}$. on the summit of Diamond Peak.

This is one of the heaviest timbered forests and contains large, untouched tracts of mature Douglas fir.

The headquarters are at Roseburg $\ddagger$ and the forest may be reached by stage.

Wallowa National Forest (Oregon). The Wallowa is one of the Blue Mountain group comprising 957,419 acres. The forest contains some of the finest scenery in Oregon along the Snake and Imnaha Rivers. The elevation ranges from 1000 $\mathrm{ft}$. in the canyons to nearly $10,000 \mathrm{ft}$. in the peaks.

The timber is typical of the Blue Mountain group of western yellow pine forests.

The headquarters are at Wallowa $\ddagger$ and the forest is reached from there by stage.

Washington National Forest (Washington). The Washington Forest includes and area of 1,461,193 acres. It covers the Cascade Range along the Canadian boundary and ranges in elevation from 500 to over $10,000 \mathrm{ft}$. on the summit of Mt. Baker. The rugged country and the wide range in elevation makes possible all of the forest types and combines them with the scenic beauty of the country.

The headquarters are at Bellingham $\ddagger$ and the forest is reached by stage.

Wenatchee National Forest (Washington). The Wenatchee Forest includes an area of 818,334 acres. The elevation varies from about $1000 \mathrm{ft}$. to over 10,000 ft. on Glacier Peak, consequently all of the forest types and mountain meadows are included within the forest.

Three transcontinental railroads, the G. N., the C. M. \& St. P., and the N. P. cross the forest, and the remainder of the forest is accessible by stage.

The headquarters are at Wenatchee. $\ddagger$

Whitman National Forest (Oregon). The Whitman Forest completes the Blue Mountain group. It contains an area of $1,313,523$ acres and ranges in elevation from about 3000 to over $8000 \mathrm{ft}$.

On the high plateaus are some of the best western yellow pine forests of the Blue Mountain region, and the north slopes contain the typical white fir-larchDouglas fir type.

The headquarters are at Baker $\ddagger$ and the forest is accessible by stage.

\section{NATIONAL FORESTS OF THE NORTHERN DISTRICT (1)}

\section{By J. A. LARSEN}

In Montana and Idaho north of the Salmon River, the natural forest types fall into altitudinal belts, the boundaries of which vary according to aspect, degree of slope and drainage courses. The same forest type does not always occupy corresponding elevations east and west of the main mountain chains or principal divides. It is therefore necessary to treat this subject according to the different topographic divisions, as follows: (1) The section west of the Bitterroot mountains in Washington and Idaho; (2) Flathead and Bitterroot valleys lying between the Bitterroot Divide and the Continental range; (3) the Montana section of the Great Plains culminating in the high Yellowstone Plateau and the main Rocky mountains.

The lower forest line borders on the 
prairies in each of these sections, at $2000 \mathrm{ft}$. in altitude on the western, at $3000 \mathrm{ft}$. in the central and 4000 to $4500 \mathrm{ft}$. in the eastern section. The high points along the Bitterroot range and in southwestern Montana reach $8000 \mathrm{ft}$. while the principal high ridges vary between 6000 and $7000 \mathrm{ft}$. Ridge elevations in the northern Rockies on the Flathead National Forest and in Glacier National Park vary between 8000 and $9000 \mathrm{ft}$. in altitude, the peaks frequently rise to 10,000 and $11,000 \mathrm{ft}$. and have permanent glaciers. This is also true of the forests bordering the Yellowstone Park on the northeast and east. Topography in western Montana and northern Idaho is characterized by very steep canyon slopes and easier grades at the higher levels, indicating a recent uplift. Elsewhere the general slopes from mountain tops to creek bottoms are more regular and uniform. The southeastern Montana forests center around remnants of an old tableland which rises 1000 to $3000 \mathrm{ft}$. above the rolling plains.

Aside from the occasional grassland and upper barrens six broad natural forests types exist. These are in their order of altitudinal occurrence, beginning with the lowest; western yellow pine; cedar-hemlock-grand fir-white pine in Idaho; replaced by Douglas fir-western larch in western Montana; Douglas-firlodgepole pine in central and eastern Montana; isolated bodies of Englemann spruce in northwestern Montana; and subalpine forests of mountain hemlockwhite bark pine, alpine fir and lodgepole pine.

\section{GRASSLANDS AND PRAIRIES}

The prairies or natural grasslands occur generally below $2000 \mathrm{ft}$. elevation in Idaho, below $3000 \mathrm{ft}$. in western Montana and below $4000 \mathrm{ft}$. in central Montana. The vegetative communities on different parts of the Palouse plain in Idaho have been well described by Piper $^{1}$ and by Weaver. ${ }^{2}$ For description

\footnotetext{
1 Piper, Chas. V. "Flora of the State of Washington." Contributions U.S. National Herbarium, XI: 38-40. 1906.
}

of plant communities in Montana see Harshberger's Phytogeography of the United States. The air temperature over the prairies in summer averages higher than for the lowest forest type. The mean annual temperature for the former in Washington-Idaho is $49.7^{\circ}$ and that for the western yellow pine type $47.3^{\circ}$. At the same time the prairies show greater extremes of air temperature, lower snowfall, and lower relative humidity than the western yellow pine forests. Precipitation in the western yellow pine type varies between 15 and 22 in. per year while that for the prairies averages below $15 \mathrm{in}$. The total snowfall on the prairies is 17 in. while in the western yellow pine type it is $52 \mathrm{in}$.

\section{FOREST TYPES}

\section{Yellow pine type (Transition Zone)}

Western yellow pine (Pinus ponderosa) grows in pure stands at the lower elevation border of the forest: from $1000 \mathrm{ft}$. altitude up to $4500 \mathrm{ft}$. in the Clearwater drainage; from 2000 to $4000 \mathrm{ft}$. in North Idaho generally; and from 3000 to 4000 ft. in western Montana. In central Montana the elevations are generally too high for the development of this species. The characteristic open stands, the clear trunks and sparse undergrowth give this forest a park-like appearance. There is more air movement, more sunlight, more heat and less precipitation in yellow pine forests than in the other forest types and therefore more evaporation. These conditions, combined with scant humus and litter, result in a soil poor in loam and water-holding capacity. There is invariably more rock and gravel in the soil which causes it to heat by day and cool at night in much greater degree than in other forest types. Deer, coyotes, squirrels, ground squirrels, pocket gophers, rabbits, pack rats and pheasants are found in this type. ${ }^{3}$

2 Weaver, J. E. "A study of the Vegetation of Southeastern Washington and Adjacent Idaho." Univ. of Nebr. Studies, 17, No. 1, 1917.

3 For some of the more common plants see: Larsen, J. A., "Association of Trees, Shrubs and other Vegetation in the Northern Idaho Forests." Ecology 4: 63-67, 1923 . 
It is not possible to give with any degree of certainty a distinct bird life for the various forest types since most of the birds inhabit several types. A list of these is given under the cedar-hemlock-grand fir type.

Western yellow pine, Pinus ponderosa scopulorum, is the only coniferous tree occurring in southeastern Montana on the Sioux and Custer National Forests. This type represents outposts of the Black Hills Yellow Pine type.

The western yellow pine occurs in largest bodies on the following National Forests:

\begin{tabular}{|c|c|c|}
\hline $\begin{array}{l}\text { NATIONAL } \\
\text { FOREST }\end{array}$ & $\begin{array}{l}\text { SUPERVISOR'S } \\
\text { HEADQUARTERS }\end{array}$ & RAILROAD \\
\hline $\begin{array}{l}\text { Bitterroot } \\
\text { Missoula } \\
\text { Kootenai } \\
\text { Selway } \\
\text { Nexperze } \\
\text { Sioux }\end{array}$ & $\begin{array}{l}\text { Missoula, Mont. } \\
\text { Missoula, Mont. } \\
\text { Libby, Mont. } \\
\text { Kooskia, Mont. } \\
\text { Grangeville, Mont. } \\
\text { Miles City, Mont. }\end{array}$ & $\begin{array}{l}\text { N. P. } \\
\text { N. P. } \\
\text { G. } \mathrm{N} . \\
\text { N. P. } \\
\text { N. P. } \\
\text { N. P. }\end{array}$ \\
\hline
\end{tabular}

Cedar-hemlock grand fir-western white pine type

The Thuja plicata-Tsuga heterophyllaAbies grandis-Pinus monticola type occurs chiefly in northern Idaho between 2000 and $4500 \mathrm{ft}$. elevation. This type is not necessarily confined to higher elevations than the western yellow pine but marks a region of much heavier rainfall. Air temperatures are lower than those observed in the western yellow pine forests. The cedar-hemlock-white pine forests have a mean annual air temperature of $42.4^{\circ}$ and an annual precipitation up to $40 \mathrm{in}$. Snowfall, which is 112 in. per year is also much heavier and the humidity greater here than in the western yellow pine type. This type is found on more protected slopes and aspects over broken topography where the extremes of climate are tempered by greater precipitation and cloudiness, and where the texture and moisture holding qualities of the soil are improved and maintained by a dense stand, deep shade and rapid accumulation of humus. This type of forest, therefore, shows a wealth of herbaceous species, shrubs and conifers.
The fauna is also rich in species of birds and of fur-bearing mammals. The following birds and animals have been observed: Woodpeckers (pileated, flicker, red-headed, hairy, downy, and sapsucker), screech owl and great horned owl, mourning dove, swallow, kingbird, ruby-throated humming bird, bronzed grackle, junco, winter wren, chickadee, songsparrow, vesper sparrow, ruffed grouse, occasional quail, pine grosbeak, American crossbill, varied thrush, Steller's jay, and Canada jay. ${ }^{4}$

Among the important animals may be mentioned the mule and white-tailed deer (Odocoileus hemionus and O. sp.), elk (Cervus canadensis occidentalis), black bear (Ursus americanus), cougar (Felis concolor group), lynx and bob-cat (Lynx spp.), coyote and timber wolf (Canis spp.), skunk (Mephitis), weasel (Mustela), porcupine (Erethizon), pine squirrel (Sciurus hudsonicus richardsoni), snowshoe hare (Lepus bairdii), flying squirrel (Glaucomys sabrinus subspp.), pack rat (Neotoma cinerea subspp.), jumping-mouse (Zapus), beaver (Castor), muskrat (Ondatra zibethica osoyoosensis), mink (Mustela vison energumenos), and rarely otter (Lutra) occur along the streams.

Forest fires have been frequent and destructive in this type of forest and have greatly limited the distribution of the species, which are moistureloving, tolerant of shade and less fire resistant than larch and Douglas fir. Because of prolific seeding and the ease with which lodgepole pine and western white pine reproduces on burns these species, particularly the latter, are much in evidence. In fact the Idaho forests are known for areas of stately virgin forests of almost pure white pine. These trees reach 180 and $200 \mathrm{ft}$. in height and are found up to 50 and occasionally $60 \mathrm{in}$. in diameter. The highest cut on record is one million board feet of lumber on 10 acres. This type, therefore, marks the greatest activity of the lumbering industry in the Inland Empire. Virgin stands

\footnotetext{
${ }^{4}$ I am indebted to Ranger G. Kempff for help in preparing the list of birds.
} 
of this species are rapidly yielding to lumbering and not a few to fire.

The cedar-hemlock-grand-fir-white pine type occurs on the following National Forests in Idaho:

\begin{tabular}{|c|c|c|}
\hline $\begin{array}{l}\text { NATIONAL } \\
\text { FOREST }\end{array}$ & $\begin{array}{l}\text { SUPERVISOR's } \\
\text { HEADQUARTERS }\end{array}$ & RAILROAD \\
\hline Kaniksu & Sandpoint, & G. N. \\
\hline Pend O'Reille & Sandpoint, & G. N. \\
\hline Couer d'Alene & $\begin{array}{l}\text { Couer d'Alene, } \\
\text { Idaho }\end{array}$ & $\begin{array}{l}\text { C. M. \& St. P., } \\
\text { N. P., G. N. }\end{array}$ \\
\hline St. Joe & $\begin{array}{l}\text { Couer d'Alene, } \\
\text { Idaho }\end{array}$ & C. M. \& St. P., \\
\hline Clearwater & Orofino, Idaho & N.P. via Spo- \\
\hline
\end{tabular}

\section{Douglas fir-western larch type}

This type prevails in Flathead and Bitterroot valleys in western Montana. The larch (Larix occidentalis) is really not a climax species but since it is so prevalent everywhere, having gained by repeated fires, its name has become linked with Douglas fir in the designation of this association. These species are of much less commercial value and have therefore been less exploited than western yellow pine and western white pine. The larch grows on moist soils from the lower edge of the forest up to an altitude of $5000 \mathrm{ft}$. Douglas fir has a much wider altitudinal range. The mean annual air temperature in this type is $40.9^{\circ} \mathrm{F}$., and the annual precipitation is 18 to 25 in., snowfall 70 in. and over. Bird and animal life is similar to that of the cedar-hemlock-grand fir type but less varied and not so plentiful.

The Douglas fir-western larch type occurs on the following National Forests:

\begin{tabular}{|c|c|c|}
\hline $\begin{array}{l}\text { NATIONAL } \\
\text { FOREST }\end{array}$ & $\begin{array}{l}\text { SUPERVISOR'S } \\
\text { HEADQUARTERS }\end{array}$ & RAILROAD \\
\hline Kootenai & Libby, Mont. & G. N. \\
\hline Blackfeet & Kalispell, Mont. & G. N. \\
\hline Flathead & Kalispell, Mont. & G. N. \\
\hline Cabinet & Thompson Falls, & N. P. \\
\hline Lolo & Missoula, Mont. & N. P., C. M. \& \\
\hline Missoula & Missoula, Mont. & N. $_{\text {St. }}$ P. C. M. \& \\
\hline
\end{tabular}

\section{THE ENGELMANN SPRUCE TYPE}

This is characterized by Picea Englemanii. Solid areas of this type are relatively rare in Montana and northern Idaho. This species is not plentiful around the headwaters of the Clearwater drainage nor generally in Montana. It is confined to the cool northern aspects and canyons where the snow is deep and lingers late in summer, particularly in northeastern Montana on the Blackfeet and Kootenai National Forests. Individuals or grouped specimens line all the principal mountain streams. There is also considerable spruce at higher elevations on the forests surrounding Yellowstone Park. Repeated forest fires in the past have no doubt greatly restricted the spruce type. This forest has not been exploited. Bird and animal life is much the same as that noted in the Cedar-Hemlock-Grand fir type. Grizzly bear and moose (Alces) should be added for northwestern Montana.

The Engelmann spruce type may be studied in the following National forests :

\begin{tabular}{|c|c|c|}
\hline $\begin{array}{l}\text { NATIONAL } \\
\text { FOREST }\end{array}$ & $\begin{array}{l}\text { SUPERVISOR'S } \\
\text { HEADQUARTERS }\end{array}$ & RAILROAD \\
\hline $\begin{array}{l}\text { Pend O'Reille } \\
\text { Kootenai } \\
\text { Blackfeet } \\
\text { Flathead }\end{array}$ & $\begin{array}{l}\text { Sandpoint, Idaho } \\
\text { Libby, Mont. } \\
\text { Kalispell, Mont. } \\
\text { Kalispell, Mont. }\end{array}$ & $\begin{array}{l}\text { G. N. } \\
\text { G. N. } \\
\text { G. N. } \\
\text { G. N. }\end{array}$ \\
\hline
\end{tabular}

(Also Glacier National Park, Belton, Montana.)

\section{Douglas fir-Lodgepole Pine Type}

Douglas fir (Pseudotsuga taxifolia) and Lodgepole pine (Pinus contorta) occur on all of the National forests in Montana and northern Idaho. It is however in the higher forests of central and southern Montana, where climatic conditions are unsuitable for the previously described types, that these two species occur in greatest abundance. These species are invariably found at the lower tree line at $2000 \mathrm{ft}$. in Idaho, $3000 \mathrm{ft}$. in western Montana and $4000 \mathrm{ft}$. in central and southern Montana. In Idaho this type attains an elevation from 7000 to $8000 \mathrm{ft}$.

Repeated fires greatly increase the proportion of lodgepole pine, often 
resulting in dense impenetrable thickets which show very slow growth. This forest is composed of trees of small diameter and has a low volume production compared with the Idaho forests, thereby reflecting the lesser annual precipitation in Montana than in Idaho. This type grows under a mean annual air temperature ranging from $35^{\circ}$ to $40^{\circ}$ and annual precipitation of 20 in., while the snowfall is about $150 \mathrm{in.}$ The flora and fauna are quite similar to those found in the Douglas fir-western larch type. Since this type embraces the major portions of the forests of central and southern Montana there is quite a local demand for the timber for mines, railroads and for building material, but there is no immediate danger of excessive cutting such as would eliminate natural virgin areas. Grazing is very important in this part of the state, especially on the open grasslands at lower elevations.

The Douglas fir-lodgepole pine type occurs on most of the National Forests in northern Idaho and Montana but may be studied to best advantage on the following:

\begin{tabular}{|c|c|c|}
\hline $\begin{array}{l}\text { NATIONAL } \\
\text { FOREST }\end{array}$ & $\begin{array}{l}\text { SUPERVISOR'S } \\
\text { HEADQUARTERS }\end{array}$ & RAILROAD \\
\hline Deerlodge & Anaconda, Mont. & C.M.\& St. \\
\hline $\begin{array}{l}\text { Helena } \\
\text { Jefferson } \\
\text { Madison } \\
\text { Beartooth } \\
\text { Gallatin }\end{array}$ & $\begin{array}{l}\text { Helena, Mont. } \\
\text { Helena, Mont. } \\
\text { Sheridan, Mont. } \\
\text { Billings } \\
\text { Bozeman }\end{array}$ & $\begin{array}{l}\text { N. P. } \\
\text { N. P. } \\
\text { N. P. } \\
\text { N. P. } \\
\text { N. P. }\end{array}$ \\
\hline
\end{tabular}

\section{SUBALPINE FORESTS}

Above $5500 \mathrm{ft}$. in altitude in Idaho most of the forest trees mentioned in the cedar-hemlock-grand fir type give way to mountain hemlock (Tsuga mertensiana), whitebark pine (Pinus albicaulis), alpine fir (Abies lasiocarpa); Douglas fir and lodgepole pine continue upward above $5500 \mathrm{ft}$. Engelmann spruce usually lines the water courses on north aspects. Alpine fir is more generally distributed but prefers northern and eastern aspects. Mountain hemlock is the climax species on the broad ridge tops in the Clearwater basin while white- bark pine and lodgepole pine are most abundant on the upper sunny aspects.

At these elevations the summer is short but warm and much clear weather prevails. The mean annual air temperature at Roosevelt in the Thunder Mountains of Idaho at $7000 \mathrm{ft}$. averages $36.4^{\circ}$; the annual precipitation is $26.5 \mathrm{in}$.

Wherever the mountain hemlock holds sway on high ridges, as in the Clearwater drainage, Engelmann spruce is largely wanting. Perhaps the dry summer winds coming from the Snake River desert limits it to the more northern and eastern forests. In the subalpine forest to the east of the Bitterroot range, limber pine (Pinus flexilis) replaces whitebark pine (Pinus albicaulis).

In this type or belt the vegetation. varies greatly according to soil moisture and aspect. The fauna does not differ greatly from that of the cedar-hemlockgrand-fir type. Blue grouse, fool hen, grosbeak, hawk are found, in addition.

This type of forest may be studied to advantage on the following National forests:

\begin{tabular}{|c|c|c|}
\hline $\begin{array}{l}\text { NATIONAL } \\
\text { FOREST }\end{array}$ & $\begin{array}{l}\text { SUPERVISOR'S } \\
\text { HEADQUARTERS }\end{array}$ & RAILROAD \\
\hline $\begin{array}{l}\text { Clearwater } \\
\text { Selway } \\
\text { Bitterroot } \\
\text { Lolo }\end{array}$ & $\begin{array}{l}\text { Orofino, Idaho } \\
\text { Kooskia, Idaho } \\
\text { Hamilton } \\
\text { Missoula }\end{array}$ & $\begin{array}{l}\text { N. P. } \\
\text { N. P. } \\
\text { N. P. } \\
\text { N. P. }\end{array}$ \\
\hline
\end{tabular}

ALPINE FORESTS AND BARRENS

Points above $8000 \mathrm{ft}$. elevation represent alpine conditions. Such areas are marked by permanent glaciers and barrens and are found in the northern section of the main Rocky mountains, and on the Beartooth National Forest. The forest at these high elevations is represented by more or less dwarfed Engelmann spruce and Lyall larch (Larix Lyallii), the latter not occurring east of the main Continental Divide in northern Montana. The alpine flora of the Yellowstone National Park has been listed by F. Tweedy. This list shows several species also found in similar situations in Europe and Asia. The 
highest weather station from which records are available is Yellowstone Park, $7733 \mathrm{ft}$. which shows a mean annual air temperature of $31.4^{\circ}$, an annual precipitation of 24.5 in. and an average snowfall of $178 \mathrm{in}$.

The alpine conditions may be studied on the following National Forests:

\begin{tabular}{l|l|l}
\hline \multicolumn{1}{c|}{ NATIONAL FOREST } & $\begin{array}{c}\text { SUPERvisor's } \\
\text { HEADQUARTERS }\end{array}$ & $\begin{array}{l}\text { RAIL- } \\
\text { ROAD }\end{array}$ \\
\cline { 2 - 3 } $\begin{array}{l}\text { Flathead } \\
\text { Glacier National Park } \\
\text { Beartooth }\end{array}$ & $\begin{array}{l}\text { Kalispell, Mont. } \\
\text { Kalispell, Mont. } \\
\text { Billings, Mont. }\end{array}$ & $\begin{array}{l}\text { G. N. N. } \\
\text { N. P. }\end{array}$ \\
\hline
\end{tabular}

In different places within these forest areas are smaller units of considerable interest for study of characteristic flora and fauna under natural conditions. The Yellowstone and Glacier National Parks offer a great variety of typical conditions from low prairie to alpine and glaciers with a great variety of lakes and streams. These two parks contain typical forests of western yellow pine, Douglas fir, Engelmann spruce, whitebark pine, limber pine, lodgepole pine and juniper. The fauna within these two parks is rich, embracing many species of bear, goat, sheep, elk, moose, and fur-bearing mammals, as well as birds, and fishes. ${ }^{5}$

The future may demand the preservation of additional natural areas within Montana and northern Idaho. Areas are desirable for the study of the hydrophytic and mesophytic forests of western white pine, western red cedar, western hemlock and grand fir in Idaho. For this purpose three areas are listed in northern Idaho in the Priest Lake region, one of which, the Roosevelt Grove of Giant cedar, has already been preserved. The other two represent some of the best and oldest stands of the rapidly vanishing western white pine and associates.

In addition to these three areas which lie outside the National Parks another area of western white pine occurs in the Capt. Mullan park near Coeur d'Alene

\footnotetext{
5 For Glacier National Park, see: Wild Animals of Glacier National Park; U. S. Department of the Interior, National Park Service (1918); and Flora of Glacier National Park; Contr. U. S. Nat. Herb. 22: Pt. 5 (1921).
}

and a mesophytic formation is represented by the Heyburn park on Coeur d'Alene Lake. The Rocky Mountain National Monument near Helena should also prove valuable. Some action will be needed to have this last one preserved.

The area near Anaconda where the trees and vegetation for many miles around have been killed by smelter fumes is listed; also an area in western yellow pine representative of the Black Hills type in the Custer National Forest in southeastern Montana.

The region generally is rich in alpine and subalpine conditions. These abound within the two national parks. There are listed a few places at high elevations lying in the Clearwater National Forest along the Lolo trail because it is doubtful whether similar areas can be found within the parks. These are flat alpine meadows like the one near Cook Mountain. The old mountain hemlock stands and the heavy burns of 1910 and 1919 may also be studied along the Lolo Trail and near Cook Mountain in the Clearwater National Forest. Alpine larch occurs on the Kootenai-Priest River Divide in northern Idaho. Alpine larch occurs also within Glacier National Park but mountain hemlock may be seen to best advantage and best development along the Bitterroot Divide and the Clearwater Mountains in Idaho.

In Carbon County, Montana, are typical high altitude forests, timberline conditions, glacial lakes and glaciers. One of these glaciers has numerous grasshoppers imbedded in the ice. Elevations 5000 to $10,000 \mathrm{ft}$., precipitous.

The burned areas near Cook Mountain and the older burns near Upper Priest Lake, will probably remain undisturbed for many years, and the alpine areas will remain in a natural state indefinitely.

NATURAL AREAS

\section{Roosevelt Grove of Giant Red Cedar}

†Coniferous Forests, Northwestern. In Bonner Co., northern Idaho, within Kaniksu National Forest. About 100 
acres on Forks of Granite Creek. Typical hydrophytic forest of western red cedar up to $12 \mathrm{ft}$. in diameter said to be over 1000 years old. Characteristic flora of mosses, lycopods, ferns, evergreens. $4000 \mathrm{ft}$.

Priest River $\ddagger$ G. N. Ry. Coolin $\ddagger$ (auto), motor boat to Reeder Creek, trail (h) 12 mi.

\section{Priest Lake}

$\dagger$ Fresh Water Lake surrounded by northwestern coniferous forests. Fresh water vegetation, swamps, marshes and ponds. In Bonner Co., Idaho, within the Kaniksu National Forest. On government land a strip along this lake will be preserved or at least cut very sparingly.

Priest River $\ddagger$, G. N. Ry. Coolin $\ddagger$ on Priest Lake (a). Motor boats and Evinrudes. See more particularly "The Thoroughfare."

"The Thoroughfare" Priest Lake, Idaho

†Coniferous Forest, Northwestern. About 640 acres in Bonner County, northern Idaho, within Kaniksu National Forest in Secs. 4 and 9 T. 62 and Sec. 33 T. 63 N. R. 4 W. Boise M. along "Thoroughfare," a channel which connects upper and lower Priest Lake; typical mesophytic mature forest of western white pine, western red cedar, western hemlock, western larch, lowland grand fir, alpine fir, Engelmann spruce, with characteristic northern Idaho vegetation of shrubs, grasses, evergreens and annuals. $2300 \mathrm{ft}$. Recommendation to preserve in a natural state will be made by the U. S. Forest Service.

Priest River $\ddagger$ G. N. Ry. Coolin $\ddagger 25$ miles by auto; motor boat on lake $20 \mathrm{mi}$. to Forest Lodge hotel $\ddagger$ close by area.

\section{Grove of Virgin White Pine Forest ${ }^{6}$}

†Coniferous Forest, Northwestern. 120 acres in Bonner Co., Idaho, in Sec. $22 \mathrm{~T}$. 64 N. R. 5 W. B. Mer. within Kaniksu National Forest in northern Idaho,

6 Name tentatively given; not yet approved; will be recommended as such; name for E. C. Rogers, deceased, one of the first Forest Research men in this region. $-J . A . L$. north of upper Priest Lake. Typical mesophytic virgin forest of western white pine, western red cedar, western hemlock, grand fir, alpine fir, western larch, Engelmann spruce, and characteristic northern Idaho vegetation. $3000 \mathrm{ft}$.

Priest River $\ddagger$ G. N. Ry. Coolin $\ddagger$ (a); motor boat to Forest Lodge; to area (h) $20 \mathrm{mi}$.

\section{Mullan Park}

Coniferous Forest, Northwestern. About 50 acres in Kootenai Co., Idaho, Sec. 6, T. 49 N., R. 1 W. within Coeur d'Alene National Forest. Burns summit $20 \mathrm{mi}$. from Coeur d'Alene, $40 \mathrm{mi}$. from Wallace on Yellowstone Trail. Typical forest of western white pine, Douglas fir, western larch, some western red cedar, western hemlock, characteristic vegetation. $3000 \mathrm{ft}$.

Coeur d'Alene $\ddagger$ N. P. Ry. (a) $20 \mathrm{mi}$.

Wallace $\ddagger$ N. P. (a) $40 \mathrm{mi}$.

\section{Heyburn Park (Idaho)}

Coniferous Forest, Northwestern. In Kootenai Co., Idaho, on southern end of Coeur d'Alene Lake about 2 sections. Typical mesophytic forest of western larch, Douglas fir, some western yellow pine, riverside and hillside flora. 2000$3000 \mathrm{ft}$.

Coeur d'Alene $\ddagger$ N. P. Ry. and C. M. \& St. P. Ry. via Spokane.

Steamer to hotel \|| in park.

\section{"Montana State Game Preserve"}

\section{(Northern Rockies)}

Coniferous Forest Prairie and Aspen. In Lewis and Clark Co., Mont., within Lewis and Clark National Forest and Montana State Game Preserve. Also valuable for study of forest succession after fires. Forests of Douglas fir, lodgepole pine, Engelmann spruce, western yellow pine, aspen, zerophytic prairie, open range and forest border. Fauna-elk, deer, moose, grizzly bear, black bear, beaver, otter, mink, marten, muskrat, squirrels, gophers. 5000$10,000 \mathrm{ft}$. 
Great Falls $\ddagger$ G. N. Ry. local to Choteauf, $20 \mathrm{mi}$. (a) to Allen's hotelt $5 \mathrm{mi}$. from game preserve.

\section{"Rocky Mountain National Monument" (near Helena, Mont.)}

Coniferous Forest, Northwestern. In Teton Co., in T. 12 and 13 N., R. 3 W., Montana P. Meridian, within Helena National Forest, Montana, along Hauser Lake and the upper Missouri River. Typical xerophytic forest, Douglas fir, western yellow pine and lodgepole pine and xerophytic vegetation. Principally limestone rock which in places is jagged and pinnacled with sheer cliffs. $4500 \mathrm{ft}$.

Helenał. N. P. Ry. and C. M. \& St. P. Ry. Electric to lake, $18-20 \mathrm{mi}$.

Recommendation made for a preserve by U. S. Forest Service, and by Montana Legislature. See Substitute for House Bill No. 3 introduced by committee on Federal Relations, 1921. Proclamation pending. Depends also upon purchase of additional land by government.

\section{Beartooth National Forest (Mont.)}

Ice Caves and Glaciers Timberline Lakes. In Carbon Co., Mont., within Beartooth National Forest. The ice caves are on Pryor Mountain division, the glaciers on the main part of the forest. Typical high altitude forests; vegetation and fauna not much different from Yellowstone National Park. Interesting from standpoint of small glaciers, glacial lakes, timberline conditions. $5000-11,000 \mathrm{ft}$.

Billings $\ddagger$, N. P. Ry. Burlington Ry. Local train to Bridger for Pryor Mountain.

Local train to Redlodge for main part of forest $(h) \S$.

\section{Along Lolo Trail}

Coniferous Forest, Northwestern, heavily burned. In Clearwater Co., Idaho, within Clearwater National Forest. Typical single and double burn by two of the worst forest fires known in the Northwest, 1910 and 1919. One may observe the effects of the 1910 fire alone, both fires or only the 1919 fire. Excellent chance for study of succession of forest vegetation and influence of fire on site.

Elev. 5000-7000 ft., mountainous.

Missoula, Mont. $\ddagger$ N. P. Ry., C. M. \& St. P. Ry. 35 miles; to Lolo Hot Springs (a) Lolo Trail to Cook Mountain $30 \mathrm{mi}$. (h)**.

Alpine Meadow. In Clearwater Co., Idaho, within Clearwater National Forest along Lolo Trail. Typical hydrophytic alpine meadow; alpine and subalpine vegetation, and fauna at $6575 \mathrm{ft}$. level.

Missoula, Mont., N. P. Ry., C. M. St. P. Ry. Lolo Hot Springs $35 \mathrm{mi} . \|$. Cook Mountain $30 \mathrm{mi}$. (h)**.

Subalpine Forest, Northwestern. In Clearwater Co., Idaho, within Clearwater National Forest along Lolo Trail near Cook Mountain. Typical subalpine forest of mountain hemlock, very old climax stand, and characteristic subalpine vegetation; xerophytic, mesophytic and hydrophytic. $7000 \mathrm{ft}$.

Missoula $\ddagger$, N. P. Ry. and C. M. \& St. P. Ry. Lolo Hot Springs, (a) $35 \mathrm{mi}$. (h)**.

\section{Smelter Fume Damage}

Coniferous Forest, Northwestern. In Deerlodge Co., Mont., within Deerlodge National Forest. Typical mesophytic lodgepole pine forest. Excellent opportunity to observe effect of smelter fumes on forest and vegetation.

Anaconda $\ddagger$, Mont., N. P. Ry., C. M. \& St. P. Ry., (a) 5 to $10 \mathrm{mi}$.

\section{Alpine Forest, Northwestern}

Alpine Larch, Larix Lyallii. In Bonner County, northern Idaho, within Kaniksu National Forest. About 200 acres of alpine larch, mature trees and reproduction on summit of divide between Kootenai and Priest Rivers at Roman Nose Lookout. Subalpine flora of alpine fir, Engelmann spruce, whitebark pine, heather, sedges and grasses. 6000-7000 ft. Precipitous. 
Priest River $\ddagger$ G. N. Ry. $25 \mathrm{mi}$. to Coolin $\ddagger 12 \mathrm{mi}$. by trail to Lookout (h)§.

\section{Old Burns}

Coniferous Forest, Northwestern. In Bonner Co., Idaho, north end of upper Priest Lake in Kaniksu National Forest.

About one township of forestland burned over at different times now showing succession of vegetation and amount of restocking of the forest trees after the fires. Flora shows great variety of evergreens, deciduous shrubs and annuals, mosses, lichens, lycopods. 3000 $4000 \mathrm{ft}$.

Priest Riverł. G. N. Ry. Coolin $\ddagger$, motor boat to Forest Lodgeł. Evinrudes.

\section{Priest River Experimental Forest}

Subalpine Meadow. In Bonner Co., northern Idaho, within Kaniksu National Forest. About 45,000 acres on west slopes of Selkirk Range. Typical subalpine meadow, and associated vegetation, the result of repeated fires. Forest extending from 2300 to $6000 \mathrm{ft}$. elevation. Subalpine meadow and forest of alpine fir, whitebark pine, and Engelmann spruce. $6000 \mathrm{ft}$.

Priest River $\ddagger$, G. N. Ry., (a) $15 \mathrm{mi}$. to Priest River Forest Experiment Station\&.

\section{NATIONAL FORESTS OF CALI- FORNIA. VEGETATIONAL TYPES}

\section{By E. N. MunNs}

The vegetation of California is probably more diverse than that to be found in any other state, ranging from the deserts of the southeastern part to the rich mesophytic forests of redwood and spruce along the northwest coast through various kinds of brushland growths, woodlands, pine, fir and subalpine forests. Because of the range in latitude, the forests have different altitudinal levels, and the lower tree limit of $6500 \mathrm{ft}$. near the Mexican boundary is reduced to 1000 near the Oregon line. "Deserts" occur in the northeast at elevations of $3000 \mathrm{ft}$. while in the south, they run below sea-level; the optimum of the redwood region is reached but a few feet above sea-level along the northwest coast.

Such a bewildering complexity of plant life is due to the great variation in climate brought about by latitude, altitude and topography. The state is characterized by a wet cold winter and a hot dry summer, the winter storms usually descending down the Pacific Coast, the farther south the path of the storm, the heavier the precipitation. Conversely, during the summer, the farther north the storm crosses the coast-line, the hotter and drier is the summer, the convectional thunderstorm is common in the high mountains during the summer. The southern part of the state receives less precipitation than the northern, and having a greater insolation, is much warmer. The storm clouds passing over the region deposit most of their moisture on the mountains, leaving the bulk of it on the seaward slopes, the inland slopes and high plateaus receiving comparatively very little moisture. Precipitation increases with altitude to an optimum in the Sierras and then tapers off, but because of lower temperatures, snow banks last longer giving the appearance of greater moisture. Along the northern coast, summer fogs are frequent and result in a rather even temperature and a general high atmospheric moisture.

The principal vegetative types of the state include the desert, grassland, chaparral, oak and juniper woodlands, western yellow pine, mixed conifer, fir, alpine, Douglas fir, and redwood forests. In addition, there are minor types such as the Torrey pine, localized on the southern coast, the Monterey pine of the central coast, and the big cone spruce of the southern mountains. These types are all influenced by the climate, and altitudinal limits vary greatly with soil and exposure. 


\section{DESERT (LOWER SONORAN)}

The desert region embraces the eastern side of the major mountain masses in the south and includes the local deserts of the Colorado River, Mojave Desert and Death Valley. Vegetation is scanty or absent and is usually simple. The Yucca and palm are the largest plants, with the cacti and creosote bush as typical. Rainfall varies from practically nothing to $10 \mathrm{in}$., with temperatures from $20^{\circ}$ to $132^{\circ}$, the summer maximum running well above $100^{\circ}$. Evaporation is tremendous and winds blow more or less constantly. The humidity often remains around 5 per cent during the summer season.

The fauna of the desert region excluding reptiles is as scanty as the vegetation but includes the desert coyote, the Kit fox, Arizona fox, Arizona skunk, grasshopper mouse, desert jack-rabbit, Arizona cottontail, desert bighorn sheep and burro deer. Bird life is represented by the Gambel partridge, white-winged dove, elf owl, cactus woodpecker, western nighthawk, Abert towhee, hooded oriole, LeConte thrasher, cactus wren.

\section{GRASSLAND (SONORAN)}

The former grassland region of California is now practically under cultivation except for those areas too rough or dry for agriculture. Over-grazing has resulted in the practical extermination of the native grasses which formerly covered the plains of the Sacramento and San Joaquin River valleys which form a trough between the Coast Ranges and the Sierras proper. Rainfall varies from 10 to $20 \mathrm{in}$. with no rain for 3 to 7 months during the summer. The temperature varies between an average summer maximum of $90^{\circ}$ and an average winter minimum of about $40^{\circ}$.

In the grassland region, the demands of agriculture have forced the animal life to inhabit other life zones, or caused them to change their mode of life or to disappear. The most typical of the larger animals are the dwarf elk, San Joaquin fox, Valley coyote, Fisher ground squirrel, San Joaquin jack and cottontail rabbits. Bird life includes the prairie falcon, the Swainson hawk, ferruginous rough-leg, towhee, yellow warbler, road-runner, burrowing owl, Texas nighthawk, crow, bicolored blackbird and San Joaquin wren.

\section{CHAPARRAL (UPPER SONORAN)}

The chaparral is found as a climax type with a great variety of sub-types below the lower limit of the forests. It forms a practical cover for all areas where tree growth is unable to exist, or in the forest belt where poor soil conditions make local "islands." On the poorer sites, chamise or greasewood (Adenostema fasciculatum) takes full possession, giving way under better conditions of soil or climate to the scrub oaks (Quercus dumosa, Q. wislizenii), ceanothi (Ceanothus cuneatus, C. cordulatus and $C$. divericatus) and manzanitas (Arctostaphyllos patula, A. manzanita and $A$. glauca). Along the coast, under the influence of fogs, chaparral growth becomes ranker, and stands where the brush reaches $30 \mathrm{ft}$. or more are not uncommon. Here other species enter the stand, which still retains its brushy characteristic. On moister sites, tree growth such as the laurel (Umbellularia Californica), madroña (Arbutus menziesii) and the woodland oaks, enters the stands. In the transition to grassland, the digger pine (Pinus sabiniana) is found, while in the transition to forest, the Coulter pine (Pinus coulteri) occurs in southern California and the knobcone pine (Pinus attenuata) in the north. In the moister and cooler canyons, of southern California, the big cone spruce (Pseudotsuga macrocarpa) occurs as a pure type. None of these trees are of commercial value except the Coulter pine, because of the lack of large stands, of large size, or of good form. Along the streams is a forest of alder (Alnus rhombifolia), sycamore (Platanus californica) and poplar (Populus fremontii).

As a type, the chaparral is of little economic value except as a soil cover in preventing erosion and retarding floods. 
In this field it is of primary importance and to protect the watersheds of southern California, large areas of chaparral are included in three National Forests. Most of species sprout readily and there is little danger of the stands being obliterated. Some grazing occurs in the chaparral and the larger stems are cut locally for fuel.

In the chaparral region proper, which may extend from sea-level to $7000 \mathrm{ft}$. in southern California, the precipitation varies from 10 to 25 in. annually, most of it being received in the period from December to March, inclusive. Snow falls occasionally but seldom lasts. The temperature extremes vary from $10^{\circ}$ to $120^{\circ}$, the mean summer maximum temperature being about $85^{\circ}$, with a mean minimum temperature for the winter of about $35^{\circ}$. The mean annual temperature is around $50^{\circ}$.

The mammals of the chaparral region include the California ring-tailed cat (Bassariscus astutus raptor), California raccoon (Procyon psora), California weasel (Mustela xanthogenys), California spotted skunk (Spilogale phenax), California jackrabbit (Lepus californicas), brush rabbit (Sylvilagus bachmani group), and wood rat (Neotoma spp.). Among the bird life in this region are the owl, sparrow, hawk, California towhee, spurred towhee, black-headed grosbeak, titmouse, grasshopper sparrow, several song sparrows, while many birds of the transition zone and from farther north, winter in this belt.

\section{WOODLAND (UPPER SONORAN)}

The woodland types include the oaks and the juniper. The oaks are characteristic of the better sites and moister soils in the valley region and the rolling hills in the grassland and chaparral belt along the coast where the precipitation ranges from 10 to $20 \mathrm{in}$. and the maximum temperatures in summer do not exceed $110^{\circ}$ but average about $85^{\circ}$. In this belt, the mean temperatures do not fall low enough to preclude growth the year round. Three species of oaks are usually found (Quercus douglasii, Quercus lobata and Quercus agrifolia). Because of their presence near the agricultural and urban population, these oaks, which reach heights of $60 \mathrm{ft}$. and diameters of 36 in. are being rapidly cut for firewood and it is but a question of time till the old stands are completely cut out. Many places which once boasted extensive areas of this type can now show only scattered trees and pasture land. City parks in various places will preserve some usually ragged and open remnants of a once continuous woodland.

The juniper woodland is found in the northeastern part of the state with a similar rainfall, but lower winter and summer temperatures on the lava soils. The juniper (Juniperus occidentalis and Juniperus utahensis) merges into pure western yellow pine on better soils and at higher elevations, while at lower elevations and on poorer soils this type merges into the Nevada desert. The stands are more or less open and are now being cut for fence posts and pencil stocks. Along with this juniper woodland type on the edge of the desert region is also the pinyon pine (Pinus monophylla) which in places forms extensive stands. It is not now being exploited commercially except locally and many stands will remain in a virgin condition for a long time.

In the woodland type, bird life is similar to that of the chaparral and grassland and many mammals use one locality as their home while foraging over the adjacent region. The California jay, red-shafted flicker, Lewis woodpecker, road-runner, cuckoo, screech owl, California thrasher, western mockingbird, western bluebird, and California towhee are often seen in this belt.

\section{YELLOW PINE (TRANSITION)}

The western yellow pine (Pinus ponderosa) and Jeffrey pine (Pinus jeffreyi) form extensive forests at the lower elevations in the Sierra and Coast Mountains and on the extensive plateau lands of the lava flows of the northeastern part of the state. At the lower limits $-7000 \mathrm{ft}$. in the extreme south and $1000 \mathrm{ft}$. in the 
north-the yellow pine forest merges with the chaparral growth, and at the upper limit, mingles with the firs and cedars in a complex coniferous forest. The yellow pine type covers a greater area than any other in the state and furnishes a large amount of the pine lumber manufactured. The forests are utilized as far as desirable as a summer pasture for sheep and cattle. The precipitation varies from 18 to 30 in. Temperatures in summer reach a maximum of $95^{\circ} \mathrm{F}$. with an average summer maximum of $85^{\circ} \mathrm{F}$. and an average winter minimum of $30^{\circ} \mathrm{F}$. The average annual temperature is about $45^{\circ} \mathrm{F}$. The period of rest ranges from two weeks to four months, and up to 30 per cent of the precipitation occurs as rain.

\section{MIXED CONIFEROUS TYPE (TRANSITION)}

The yellow pine type merges gradually at higher elevations into a mixed coniferous type which includes the western yellow pine as a dominant member but with the sugar pine (Pinus lambertiana) as its companion. With these white fir (Abies concolor), Douglas fir (Pseudotsuga taxifolia) and incense cedar (Litocedrus decurrens) are also found. In scattered groves, occurs also the big tree (Sequoia gigantea) famous because of its tremendous size. In the central part of the Sierras, the pines, cedar and Sequoia reach their optimum development, and the forest, without the gloom that usually characterizes dense forests, are light and airy, and offer excellent recreational possibilities. The bulk of this type, as the preceding, lies inside the boundaries of the National Forests. In addition, several National parks are maintained in this type, chief of which is the Yosemite.

These pine forests include the really valuable commercial pine forests of the state and are being exploited to the utmost. On private lands, natural conditions are quite often badly upset through destructive lumbering and fire, and too often become brushfields until succession can reëstablish a forest. On government lands, exploitation is possi- ble, but under restrictions that do not permit the destruction of the stand through careful marking of trees for cutting, fire protection, and supervised lumbering. All of this forest area is not accessible now for logging so that small patches will exist for a long time in a virgin condition, but these areas are quite often not typical stands, and are being grazed by both sheep and cattle. The Forest Service is now setting aside small areas of timber which will not be cut or touched in so far as is possible, to serve as miniature virgin forests, as demonstration and experimental areas. Several have already been established and more will be set aside from time to time. In addition, the National Parks maintain natural conditions in forest types typical of those being lumbered.

Precipitation varies from 30 to $70 \mathrm{in}$. mostly coming as snow, which remains on the ground from November to April or May. The mean annual temperature is around $45^{\circ}$ with a mean summer temperature of $65^{\circ}$. In this belt, which runs up to an average elevation of $6000 \mathrm{ft}$., is the zone of maximum precipitation in the Sierra region.

DOUGLAS FIR (TRANSITION OR CANADIAN)

The Douglas fir type is characterized by almost pure stands of the Douglas fir (Pseudotsuga taxifolia) associated with the white fir (Abies concolor) incense cedar (Libocedrus decurrens), and occasionally with other species. The Douglas fir forms rather dense pure stands in the northern part of the state particularly along the coast range at elevations from 1000 to $4000 \mathrm{ft}$. In the Sierras proper it is a tree of the mixed forest. Pure stands are confined to north slopes, and cool moist bottom lands, and the coast ranges. The average monthly temperatures do not vary greatly from winter to midsummer. The precipitation is heavy, occurring mainly as rain, though some areas receive considerable snow. Atmospheric moisture is high and often forms fogs. The average summer temperature 
is about $80^{\circ}$ and the average winter temperature is around $30^{\circ}$.

Cutting is not extensive because of the rather poor quality of the timber. Grazing is not an important factor. Fire is the only seriously damaging agent.

\section{FAUNA OF THE YELLOW PINE AND DOUGLAS FIR FORESTS}

(TRANSITION ZONE)

In the yellow pine and Douglas fir forests the fauna is so intermingled that it is impossible to separate out those species characteristic of one locality. This region is the home of the black and grizzly bears, mountain coyote (Canis lestes), mountain weasel (Mustela arizonensis), pine marten (Martes caurina), Pacific raccoon (Pyocyon psora), California gray fox (Urocyon cinereoargen. teus group), bushy-tailed wood rat (Neotoma cinerea subspp.). Douglas ground squirrel (Citellus beecheyi group), many chipmunks (Eutamias), Sierra flying squirrel (Glaucomys sabrinus group), mule deer (Odocoileus hemionus), black-tailed deer (O. columbianus subspp.). Bird life in this region includes the western red-tailed hawk, golden eagle, Pacific horned owl, spotted owl, California woodpecker, nighthawk, Sierra woodpecker, Lewis woodpecker, flicker, blue-fronted jay, western and mountain bluebird, Sierra cross-bill, sierra junco, tree swallow, dipper, mountain chickadee, mountain quail and Sabine ruffed grouse.

\section{FIR TYPE (CANADIAN)}

Altitudinally, the true fir type is just above the mixed coniferous. It includes the forests of white fir (Abies concolor) and red fir (Abies magnifica), both pure and in mixture. The altitudinal limits vary widely with the latitude, but average from 6000 to $8000 \mathrm{ft}$. The stands are often dense and few annuals or grasses prevail except in meadows where heavy grazing by sheep and cattle is permitted. The stands, because of their relative inaccessibility, and low value for commercial lumber, are not being exploited to any extent and probably will not be for some time to come.

The precipitation is chiefly in the form of snow, and varies between 30 and 50 in. annually. Average minimum temperatures during the winter do not exceed $25^{\circ}$, and the mean summer temperature is not over $65^{\circ}$, the average annual temperature is not above $40^{\circ}$. Because of low temperature and depth of snowfall, the snow lasts till late in the summer season. The growing season is from June to October.

In the fir type are found the mountain weasel, Cascade red fox and high Sierra red fox (Vulpes cascadensis and $V$. necator), Pacific fisher, bob-cat (Lynx rufus californicus), bushy-tailed woodrat (Neotoma cinerea subspp.), alpine chipmunk (Eutamias alpinus), goldenmantled ground squirrel (Callospermophilus chrysodeirus), yellow-haired porcupine, chickadee. In this region is also the Sierra sooty grouse, the goshawk, Sierra nighthawk, Hammond flycatcher, Lincoln sparrow, and varied thrush.

\section{SUBALPINE (HUDSONIAN)}

The sub-alpine forests include a variety of species at elevations where the growing season is short and temperatures are not excessive even in summer. Included in this forest are the mountain hemlock (Tsuga mertensiana), white bark pine (Pinus albicaulis), foxtail pine (Pinus balfouriana), western white pine (Pinus monticola) and lodgepole pine (Pinus contorta). The forests are not extensive, and are utilized to some extent by grazing. No lumbering of consequence will be carried on in this region because of the relatively poor quality and inaccessibility of the stands. The trees of this zone exist chiefly only on the higher mountainpeaks and ridges.

Climatic conditions are usually severe; the minimum temperature during the winter is not known, but probably is not below that of the fir type, while the precipitation is probably not over 30 or $40 \mathrm{in}$. annually, practically all coming 
in the form of snow. The average summer temperature is about $53^{\circ}$, maximum temperatures do not exceed $70^{\circ}$, while the average maximum is probably not over $63^{\circ}$. The daily range is slight, not over $30^{\circ}$, and frosts occur throughout the summer.

This high mountain country is the home of the wolverine (Gulo luscus luteus), Belding ground-squirrel (Citellus beldingi), alpine chipmunk, pika (Ochotona) and the rare Sierra sheep (Ovis canadensis sierrae). In addition to the visitors from the lower zones, occur also the Arctic three-toed woodpecker, Clark nutcracker, western evening grosbeak, pine grosbeak, whitecrowned sparrow and Sierra hermit thrush.

\section{REDWOOD TYPE (HUMID TRANSITION)}

The redwood region is restricted to the coastal area of northern California and is characterized by the coast redwood (Sequoia sempervirens), and the Sitka spruce (Picea sitchensis). Douglas fir, white fir, and the prickle-cone pine (Pinus muricata) are found in certain areas. The redwood is rapidly being exploited. All of the forests are privately owned, though there are small areas being set aside as parks in which the type will be preserved in its virgin condition. As redwood sprouts readily, there is little chance of the area remaining unforested. Some of the region after being cut over has been badly burned, but a dense undergrowth soon springs up and forest reappears.

In the redwoods, the annual march of the temperature is even, the average annual temperature being about $50^{\circ}$ with a heavy rainfall during the six coldest months of the year. Freezing temperatures are unusual, and though snows are occasional the snow seldom lies long on the ground. Fogs are heavy and frequent and keep the forests more or less moist throughout the year.

The redwood region, because of its very humid climate, has a characteristic fauna of its own, differing from the Sierra transition. Many of the Sierra species are found in this belt and many similar species occur as sub-species. Native to this region is the Columbia black-tailed deer (Odocoileus columbianus), redwood chipmunk (Eutamias townsendii ochrogenys) (redwood brush rabbit (Sylvilagus bachmani ubericolor), redwood weasel (Mustela xanthogeny munda), redwood gray fox (Urocyon californicus sequoiensis), and coast flying-squirrel (Glaucomys sabrinus stephensi). Among the bird life are the Harris woodpecker, dusky horned owl, California pigmy owl, varied thrush, northwest flicker, red-breasted sapsucker, and coast jay.

The National Forests of California are chiefly in the pine and fir region of the state and include practically every vegetational type except the redwood, though there are large private holdings within the exterior boundaries of the National Forests.

The tremendous increase in the utilization of the forest lands of the state and of the National Forests in the past few years should be emphasized as indicating the necessity for at once setting aside some natural areas. The individual descriptions of the National Forests follow.

\section{NATURAL AREAS}

\section{Angeles National Forest}

1. Area-826,331 acres.

2. Present condition-approximately one-fifth of total area has been burned within the last 20 years. Large numbers of campers and recreationists use the forest annually. Some portions of the area are inaccessible and will probably remain so for many years. The Forest Service will probably set aside between 600 and 1000 acres in the timber type as an experimental area.

3. Succession is shown to good advantage.

4. Very little grazing except in the higher elevations and that by cattle.

5. Forest types include low and high chaparral, western yellow pine, Jeffrey 
pine, mixed conifers, lodgepole pine, pinyon and desert.

6. Two game refuges in the Forest cover practically the entire area. Predatory animal work carried on by the Biological Survey. The chief wild mammals are deer, cougar, wild-cat, fox.

7. Elevation from 500 to $11,500 \mathrm{ft}$.average elevation $6000 \mathrm{ft}$.

8. Supervisor's office at Los Angelesł is $15 \mathrm{mi}$. from Forest. Other important towns are Pasadenał, $8 \mathrm{mi}$.; Pomonał, 8 mi.; San Bernardino $\neq$, 6 mi.

\section{California National Forest}

1. Area-818,459 acres.

2. Present condition-much of area natural state. Area to be set aside by the Forest service about 1200 acres.

3. Forest heavily grazed, especially by sheep.

4. Types-low and high chaparral, yellow pine, mixed conifers, fir.

5. Small game refuge on forest. Deer very abundant, cougar, coyote, fox, bear.

6. Elevation from 1200 to $8000 \mathrm{ft}$.average elevation about $5500 \mathrm{ft}$.

7. Distance from Willows $\ddagger, 30 \mathrm{mi}$.

\section{Cleveland National Forest}

1. Area-549,271 acres.

2. Present condition-many recreationists visiting forest annually and in increasing numbers. Most of the forest readily accessible to large centers of population. About 600 acres to be set aside as experimental forest.

3. Slight amount of grazing-cattle, sheep and horses.

4. Types-low and high chaparral, yellow pine, mixed coniferous forest.

5. Three game refuges on the Forest cover approximately one-tenth the area. Deer plentiful.

6. Elevation from 200 to $10,500 \mathrm{ft}$.average about $4000 \mathrm{ft}$.

7. Distance from San Diegoł, about $8 \mathrm{mi}$; from Riversideł, $12 \mathrm{mi}$.

\section{Eldorado National Forest}

1. Area-552,918 acres.

2. Forest being heavily cut; it is doubtful if any experimental areas will be set aside on the Forest.

3. Moderate grazing by sheep and cattle.

4. Forest types-yellow and sugar pine, sugar pine and fir, mixed fir, subalpine.

5. Small game refuge on the Forest.

6. Elevation from $3000-9000 \mathrm{ft}$.average $6200 \mathrm{ft}$.

7. Distance from Placervilleł, $12 \mathrm{mi}$.

\section{Klamath National Forest}

1. Area-1,533,980 acres.

2. The forest has been very little known and is practically inaccessible. No forest activities at the present time. 1000 or more acres will be set aside as an experimental area.

3. Grazing to a moderate degree by sheep and cattle.

4. Types-Douglas fir, yellow pine, mixed conifers, brushfields.

5. Small game refuge on the forest.

6. Elevation ranges from 500 to 7500 ft. - average $4000 \mathrm{ft}$.

7. Distance from Yrekał, $6 \mathrm{mi}$.

\section{Lassen National Forest}

1. Area-943,197 acres.

2. Present condition-semi-natural state, large cutting operations now in progress. Small areas will be set aside as experimental areas.

3 . Forest is heavily grazed by sheep.

4. Important types-yellow pine, mixed conifers, lodgepole pine.

5. Elevation ranges from 2500 to $10,000 \mathrm{ft}$. , average elevation about $4500 \mathrm{ft}$.

6. Distance from Red Bluff, $25 \mathrm{mi}$.

\section{Modoc National Forest}

1. Area-1,461,599 acres.

2. Present condition-semi-natural, some cutting now in progress; heavy grazing.

3. Forest grazed by sheep, cattle and horses.

4. Types-sagebrush, desert, pinyon, juniper, western yellow pine and mixed conifers. 
5. Elevation from 3500 to $8000 \mathrm{ft}$., average elevation $6500 \mathrm{ft}$.

6. Distance from Alturas $\ddagger, 10 \mathrm{mi}$.

\section{Plumas National Forest}

1. Area-1,153,044 acres.

2. Present condition-semi-natural; forest being very heavily cut. Several areas will be set aside for experimental purposes.

3. Moderate amount of grazing by cattle and sheep.

4. Types include brushfields, western yellow pine, yellow and sugar pine, mixed conifers, fir.

5. Elevation from 3000 to $8000 \mathrm{ft}$.average elevation $4500 \mathrm{ft}$.

6. Distance from Quincy $\ddagger$ $3 \mathrm{mi}$.

\section{Santa Barbara National Forest}

1. Area-2,017,398 acres.

2. Present condition-semi-natural; area has been badly burned in the last ten years-approximately one-fourth of area has been burned since 1910 .

3. Area is grazed by sheep, cattle and goats to a moderate amount.

4. Forest types include chaparral, western yellow pine, Jeffrey pine, mixed conifers.

5. Wild animals include deer, cougar, wild-cat, coyote.

6. Elevation ranges from 500 to 8000 $\mathrm{ft}$.- -average elevation about $4000 \mathrm{ft}$.

7. Distance from Santa Barbaraf, $4 \mathrm{mi}$.

\section{Sequoia National Forest}

1. Area-1,879,779 acres.

2. Area very largely natural, relatively inaccessible. Includes within its boundaries National Parks and Monuments.

3. Forest grazed, by sheep and cattle.

4. The important types are sugar pine and yellow pine, sugar pine and fir, and fir.

5. Elevation from 300 to $15,000 \mathrm{ft}$.average elevation about $7000 \mathrm{ft}$.

6. Distance from Porterville $\ddagger$, $30 \mathrm{mi}$.

\section{Shasta National Forest}

1. Area-849,656 acres.

2. Present condition-forest badly burned and heavily cut. Some areas will be withdrawn for experimental purposes, probably 2000 acres in all.

3. Forest grazed by sheep and cattle; in places heavily.

4. Types-brushfields, western yellow pine, mixed conifers, fir, alpine.

5. Elevation from 2500 to $14,500 \mathrm{ft}$.; average elevation $4000 \mathrm{ft}$.

6. Distance from Sisson $\ddagger 5$ mi.

\section{Sierra National Forest}

1. Area-1,493,400 acres.

2. Forest in a semi-natural condition; much of the area obligated to timber operators and being logged at a rapid rate. Some areas to be preserved for experimental purposes.

3. Grazing to a moderate amount by sheep and cattle.

4. Important types are sugar and yellow pine, sugar pine and fir, and fir.

5. Range in elevation about 3000 to $10,000 \mathrm{ft}$.- -average elevation $6500 \mathrm{ft}$.

6. Distance from Fresnof, $40 \mathrm{mi}$. Supervisor's headquarters at Northfork $\ddagger$.

\section{Stanislaus National Forest}

1. Area-810,802 acres.

2. Forest being rapidly cut over or obligated to timber operators. Areas to be set aside for experimental purposes.

3. Moderate amount of grazing by cattle, sheep and horses.

4. Types-yellow and sugar pine, sugar pine and fir, and fir.

5. Range in elevation from 3000 to $10,000 \mathrm{ft}$.- average $6000 \mathrm{ft}$.

6. Distance from Sonora $\ddagger$, about 12 mi., Stockton $50 \mathrm{mi}$.

\section{Tahoe National Forest}

1. Area-512,748 acres.

2. Present condition-very badly cut and burned over. Some areas will be withdrawn for experimental purposes.

3. Heavy grazing by cattle and sheep. 
4. Important types-yellow pine, yellow and sugar pine, Jeffrey pine, red fir, and sugar pine and fir.

5. Elevation from 3000 to $8000 \mathrm{ft}$.average $4500 \mathrm{ft}$.

6. Distance from Nevada City $\ddagger 10 \mathrm{mi}$.

\section{Trinity National Forest}

1. Area-1,409,490 acres.

2. Present condition-practically inaccessible. Experimental area will be established.

3. Forest heavily grazed by sheep, and to moderate extent by cattle.

4. Important types include yellow pine, mixed conifers.

5. Elevation from 2500 to $7500 \mathrm{ft}$.average $4000 \mathrm{ft}$.

6. Distance from Redding $\ddagger$, $30 \mathrm{mi}$. Supervisor's headquarters at Weavervilleł.

\section{NATIONAL FORESTS OF THE INTERMOUNTAIN DISTRICT (4)}

\section{By F. S. BAKer and S. B. Locke}

The national forests of the Intermountain Region (Utah, Nevada and Southern Idaho) cover practically all the forested land which bears tree growth other than pinyon (Pinus edulis), juniper (Juniperus utahensis and $J$. monosperma), within the states of Utah, Nevada and the portion of Idaho south of the Salmon River. The only notable exception in western Idaho is where considerable areas of western yellow pine (Pinus ponderosa and Pinus ponderosa scopulorum) timber land are held in private ownership. Ecologically, however, this area contains nothing not found within the national forests adjoining. These forests lie within an area of varying climatic conditions and present very different appearances in different portions. In every region there is a typical altitudinal zonation of forest types on the mountains, but within the Intermountain Region the zonation is quite variable from north to south, while in many places it is further modified by the fact that the high plains of the Snake River valley further modify the lower lying altitudinal types on account of the topography.

In western and southwestern Idaho the plains are covered with sagebrush (Artemisia tridentata) and present nearly unmodified ecological conditions, and will do so for a great many years to come as irrigation at best is only a local possibility and vast areas of this land will remain in a virgin condition. Winter grazing of sheep is practiced to a certain extent and has modified the herbaceous vegetation (to that degree).

The lower slopes of the foothills are usually covered with grasses, largely 6 weeks grass (Bromus tectorum) which is in itself evidence of greatly modified vegetational conditions. It is safe to say that the flora and fauna in this zone have been very greatly modified by grazing and fires.

This grassy belt extends into the yellow pine type which in the mountain valleys usually extends directly to the agricultural lands, although in the main Snake River valley it is separated by the grass land on the foothills mentioned above. At elevations almost as low as where the yellow pine first appears, Douglas fir (Pseudotsuga taxifolia), is found on north slopes. As altitude increases the Douglas fir increases in proportion to the yellow pine, becoming more extensive on the north slopes than on the flats, finally occupying all the ground except rugged knobs and ridge tops. This occurs at fairly high elevations, however, where the potential Douglas fir type is covered very largely with the temporary lodgepole pine type (Pinus murrayana) which has come in as a result of fires.

Still higher, lodgepole pine, alpine fir (Abies lasiocarpa), and Engelmann spruce (Picea engelmannii) predominate. Through all the timber types, fairly natural conditions exist, except around the outermost edges of the National forests, and around mining camps. Grazing is and has been generally moderate and the herbaceous flora 
is only moderately affected. Absolutely virgin conditions in this respect can be found on the more remote parts of the Idaho, Salmon, and Challis National Forests. Hunting and trapping have gone on for many decades and game conditions are consequently below normal. The same is true of fishing.

The foregoing description applies to the region west of the Sawtooth Range and along the Salmon River eastward as far as Salmon City. To the west of the Salmon Mountains in the region covered by the greater part of the Salmon, Challis, and Lemhi National Forests the western yellow pine type disappears, its place being taken by a grass formation. Farther eastward the Snake River plains become more and more elevated and carry their sagebrush formation directly to the lodgepole pine and aspen (Populus tremuloides) types in the mountains, virtually crowding out the grass type which appears farther west. In the Targhee National Forest of Idaho as well as in the Teton and Wyoming National Forests of Wyoming, virgin stands of lodgepole pine characterize the mountains. These extend to the lowest slopes of the mountains. The higher elevations are covered with stands of alpine fir and Engelmann spruce, the same being true indeed of all the forests throughout this region. Very little cutting has been done in any of these and grazing is generally light to moderate. In the Teton National forest especially in the neighborhood of the Yellowstone National Park game conditions are practically unaffected by the activities of man. In the Caribou National Forest a change begins to appear. The timber types become broken and scattered, interspersed with large areas of open country and the aspen begins to assume a prominent place. The valleys between the ranges are high, so that lodgepole pine and aspen extend to the foot of the mountains. The higher summits and northern slopes bear stands of alpine fir and Engelmann spruce. Conditions are similar on the Cache National Forest in
Utah, although here in main valleys become lower and a brush type made up largely of mountain mahogany (Cercocarpus parvifolius), dwarf oak (Quercus utahensis), skunk-bush (Rhus trilobata) and chokecherry (Prunus demissa), is found between the lower parts of the lodgepole pine and Douglas fir types and the agricultural valleys. Farther south this brush belt becomes wider, and is largely dominated by scrub oak (Quercus utahensis). Lodgepole pine is less prominent and aspen becomes more conspicuous. South of the headwaters of the Provo River on the Uinta National Forest lodgepole pine drops out entirely. On the Manti National Forest the altitudinal succession of types is extended by the appearance of a well developed pinyon-juniper type below the brush belt and above the agricultural valleys, making the succession; sagebrush (largely under cultivation), pinyon-juniper, brush, aspen-Douglas fir, and lastly spruce-fir. On the higher elevations are many open grassy meadows. Eastward from the Wasatch and Uinta National Forests, on the Uinta Mountains conditions again become somewhat different. On the Ashley and parts of the Uinta National Forest, lodgepole pine is prominent at high elevations. Toward the east end of the Ashley National Forest at lower elevations, adjoining the sagebrush, the western yellow pine type reappears. Southward from the Manti National Forest in Utah, the Fishlake and Fillmore National Forests present similar aspects. On the Powell and Dixie National Forests, the western yellow pine again reappears taking the place of the brush type farther north. The pinyon-juniper type is very well developed at the lower elevations. The Kaibab National Forest in northern Arizona consists of a plateau covered primarily with western yellow pine encircled by an escarpment bearing an open stand of pinyon and juniper. On the National Forests of Nevada the pinyon-juniper and brush types are common and the arborescent flora is 
generally scattering, both as to numbers and species. Throughout Utah and Nevada the wild life is decidedly below normal and herbaceous vegetation has been considerably affected by grazing in many places by decided over-grazing.

NATURAL AREAS

\section{Ashley National Forest (Utah and Wyoming)}

The Ashley Forest (980,135 acres) is located upon the east end of the Uinta Range and consists of a broad mountain range with a high barren east and west backbone. The whole central part is in a nearly virgin condition due to light grazing that results from very dense timber and the high barren alpine region. The leading types in order of extent are: Lodgepole pine $45 \%$, Engelmann spruce $14 \%$, barren $13 \%$, grass $6 \%$, western yellow pine $5 \%$, sagebrush $5 \%$.

Deer, elk, and bighorn sheep range in the northeastern part of the Forest. At high elevations there are many glacial lakes of considerable interest from a geological standpoint. The streams in the high mountains contain a pure stock of native trout.

Vernal, Utah $\ddagger$. Supervisor's headquarters.

\section{Boise National Forest (Idaho)}

The Boise Forest (1,062,698 acres) lies in central Idaho upon a granite uplift deeply cut by canyons. It is largely a virgin Forest. Grazing is general although not heavy. Timber cutting is mostly around the edges and in the vicinity of several mining camps on the Forest. The chief types are: subalpine $37 \%$, Douglas fir $24 \%$, western yellow pine $19 \%$, grass $10 \%$, lodgepole pine $4 \%$.

The game preserve in the northeastern part of the Forest on the South Fork of the Payette River is well stocked with deer, mountain goat, and elk.

Boiseł. O. S. L. R. R. Supervisor's headquarters.

\section{Bridger National Forest (Wyoming)}

The Bridger Forest (698,325 acres) lies upon the west slope of the Wind River Range, which is high and rugged and is largely virgin. At the south tip of the Forest and also at the north end are State Game Preserves. Grazing is general. Timber cutting is very limited.

There are considerable numbers of big game such as bighorn sheep, elk, and grizzly bear well distributed over the Forest. Geologically this area is very interesting, containing fully 500 lakes formed principally by glacial action. At the head of the streams rising in the Wind River Range there are a few living glaciers.

Kemmererł. O. S. L. R. R. Supervisor's headquarters.

\section{Cache National Forest (Utah and Idaho)}

The Cache Forest (770,131 acres) lies mainly on the north extension of the Wasatch Mountains with minor divisions upon other small north and south ranges in northern Utah and southern Idaho. The Forest has an absolutely protected area of about $15 \mathrm{sq}$. $\mathrm{mi}$. in the lower part of Logan Canyon. The Forest is completely grazed, except for about $25 \mathrm{sq}$. mi. in the Pocatello Division where grazing is prohibited upon the Pocatello municipal watershed; and is all cut over except for a small area at the north end now under sale. In this Forest are three 5-acre permanent sample plots one of which is to be maintained in its natural condition except that grazing is not restricted. The south end of the Forest is within a State Game Preserve. The major types are: brush $34 \%$, sage $20 \%$, aspen $18 \%$, Douglas fir $11 \%$, subalpine $5 \%$, lodgepole pine $4 \%$, Engelmann spruce $3 \%$, juniper $3 \%$. The northern limit of the range of Abies concolor is on this Forest.

Logan, Utahł. O. S. L. R. R. and U. I. C. R. R. Supervisor's headquarters. 
Caribou National Forest (Idaho and Wyoming)

The Caribou Forest (703,858 acres) lies upon a series of mountain ranges of moderate elevation in eastern Idaho. Timber bodies are not extensive and are largely limited to north slopes. Cutting has been general especially toward the south end of the Forest. Grazing is general throughout the Forest. The major types in order of abundance are: sagebrush $29 \%$, aspen $26 \%$, lodgepole pine $14 \%$, brush $11 \%$, Douglas fir $10 \%$, grass $9 \%$.

Montpelier, Idahoł. O. S. L. R. R. Supervisor's headquarters.

\section{Challis National Forest (Idaho)}

The Challis Forest $(1,253,856$ acres) is located upon a broken mountainous uplift marked by high rugged major ridges, which are barren and rocky. There is a state game preserve on the Middle Fork of Salmon River and one area in the north part of the Forest is protected from grazing by domestic stock in order to furnish fall and winter game range. A larger area adjoining is virtually ungrazed because of the density of the timber. High ridges are barren and not grazed. Timber cutting is unrestricted, but is limited so far chiefly to one area around Bonanza. The major types in order of abundance are: lodgepole pine $50 \%$, subalpine $28 \%$, Douglas fir $7 \%$, sagebrush $6 \%$.

Inaccessible parts of this Forest contain many deer, mountain goats, and bighorn sheep. There are abundant spawning grounds for migratory fish within the Forest, several species coming from the Pacific Ocean to these grounds.

Challisł. Supervisor's headquarters.

\section{Dixie National Forest (Arizona, Nevada and Utah)}

The Dixie Forest (795,000 acres) lies in southern Utah upon two uplifts, the Markagunt Plateau and the Pine Mountains, both largely composed of igneous rocks in their higher forested parts. Small isolated units occur in Arizona and Nevada. Grazing is unrestricted and fairly heavy, the only ungrazed parts are the extensive lava beds of the Sevier Forest proper. Much of the timber in the upper mountains is virgin. Cutting is nowhere prohibited. The entire Dixie division is a game preserve together with a small area in the north part of the Sevier division. On the Dixie division the main types are: pinyon-juniper $57 \%$, brush $25 \%$, western yellow pine $9 \%$, sage $7 \%$. On the Sevier division they are: western yellow pine $39 \%$, pinyon-juniper $19 \%$, brush $9 \%$, Engelmann spruce 8\%, barren $8 \%$.

Navajo or Duck Lake is interesting, since it discharges through sinks and is probably a solution lake. Occasionally the water becomes sufficiently low that the sinks are exposed.

Cedar City, Utah $\ddagger$. Supervisor's headquarters.

\section{Fillmore National Forest (Utah)}

The Fillmore Forest (701,696 acres) lies upon the Tushar Range (high, volcanic) and the Pahavnt Plateau (lower, sedimentary). It is not exceptionally well forested and is all cutover to some degree, except three virgin areas, two in Beaver Creek drainage and one in Chalk Creek drainage. The major types in order are: pinyonjuniper $35 \%$, Douglas fir $26 \%$, brush $19 \%$, Engelmann spruce $8 \%$, sage $5 \%$.

Richfield‡. D. \& R. G. R. R. Supervisor's headquarters.

\section{Fishlake National Forest (Utah)}

The Fishlake Forest $(665,275$ acres) lies upon the Fishlake Plateau and a part of the Sevier Plateau in central Utah. The Forest has been heavily culled and grazing is general throughout its area. There are no permanently protected areas on the Forest, although there is one area of virgin timber on Thousand Lake Mountain. A small area at Fish Lake has almost complete protection from grazing. Nearly the 
whole forest lies within a State Game Preserve, and in the lower Salina Canyon watershed a small herd of elk has been introduced. Fish Lake has a remarkable growth of vegetation and accompaning water life. It has a large production of trout maintained principally by fish cultural activities. The major types of vegetation are pinyon-juniper $31 \%$, brush $23 \%$, aspen $15 \%$, sage $9 \%$, grass $7 \%$, Engelmann spruce $7 \%$.

Richfield‡. D. \& R. G. R. R. Supervisor's headquarters.

\section{Humboldt National Forest (Nevada)}

The Humboldt Forest (1,332,450 acres) is located upon three widely separate mountain ranges in Nevada. Many portions are slightly forested, but represent interesting conditions. There is one limited area with absolute permanent protection near Jarbidge, but a more general policy is now in effect on the Santa Rosa division whereby periodic protection is practiced to secure aspen reproduction and range revegetation. Elsewhere, grazing is generally heavy. Cutting is limited in extent. Upon the Ruby Division of this Forest, is an unexplored cave of apparently large dimensions. The major types are: grass $48 \%$, aspen $12 \%$, pinyon-juniper $10 \%$, sage $7 \%$, subalpine $3 \%$, barren $3 \%$.

Elkoł. So. Pac. R. R. Supervisor's headquarters.

\section{Idaho National Forest (Idaho)}

The Idaho Forest (1,864,321 acres) lies upon a deeply eroded broad granite uplift characterized by deep canyons and a generally level horizon seen in looking across the ridgetops. On account of its general inaccessibility it will remain virgin for a long time. Although grazing is unrestricted about $\frac{1}{3}$ of the area is virtually ungrazed due to inaccessibility. There is almost no logging done upon the Forest. Forest fires are frequent and there are many burned over areas. The major types in order of abundance are (excluding Thuinder Mountain region): lodgepole pine $54 \%$, western yellow pine $15 \%$, Engelmann spruce $13 \%$, subalpine $11 \%$.

A few specimens of the western red cedar (Thuya plicata) are found along the main tributaries to the Salmon River.

McCall‡. O. S. L. R. R. Supervisor's headquarters.

\section{Kaibab National Forest (Arizona)}

This Forest $(752,217$ acres) is located upon the Kaibab Plateau just north of the Grand Canyon. The entire National Forest is a National Game Preserve and faunal conditions are not greatly disturbed, although predatory animals are hunted diligently. It is the home of the Kaibab squirrel. The grazing of game and domestic stock is general and heavy and the herbaceous cover is not generally in a virgin state. The grazing of domestic stock has been greatly restricted. Game animals are heavily overgrazing certain forage classes and action has been necessary to reduce the number of deer to the capacity of the range. The timber is virgin. Cuttings are small at present, but the whole area is open to sale. All natural conditions as represented within this Forest are found also within the Grand Canyon National Park under complete protection. The major types are western yellow pine $32 \%$, barren $33 \%$, pinyonjuniper $20 \%$, grass $7 \%$.

Kanab, Utah. Supervisor's headquarters. The Forest may be reached from the south with a pack outfit by crossing the Colorado River and gorge at the town of Grand Canyon (A. T. \& S. F. R. R.), or by automobile from Flagstaff, Arizona, crossing the river at Lees Ferry. It may also be reached from the north by way of Marysvale or Cedar City, Utah. For description of the Kaibab Forest, see Hough, Emerson.-The President's Forest. Saturday Evening Post, January 14 and 21, 1922. 


\section{La Sal National Forest (Colorado and Utah)}

The La Sal Forest (538,717 acres) lies upon two isolated mountain masses in southeast Utah. They are generally poorly timbered, although local bodies of considerable extent may be found. Three areas (unforested) are being protected from grazing as a measure of watershed protection upon overgrazed range. There are also two areas of considerable extent in the Abajo Mountains inaccessible to stock together with local areas of cliff and slide rock in many parts of the Forest. The major types are: brush $45 \%$, pinyon-juniper $32 \%$, western yellow pine $16 \%$, Engelmann spruce $3 \%$.

Moab, Utahł. Supervisor's headquarters.

\section{Lemhi National Forest (Idaho)}

The Lemhi Forest (1,109,779 acres) is located mainly upon the Lost River Mountains of south central Idaho, high rugged narrow ranges. Natural conditions obtain in many places on account of natural obstacles. Considerable areas in both the Lost River and Lemhi Ranges are inaccessible to stock (about 60 sq. mi. in three main areas). Elsewhere, grazing is general. Timber cutting is very local, largely in the vicinity of Mackay. The Big Lost River State Game Preserve covers the southwest portion of the Forest. The major types are: grass $34 \%$, subalpine $24 \%$, Douglas fir $19 \%$, barren $16 \%$, lodgepole pine $6 \%$.

One of the few remaining bands of antelope range on the Lost River and Pahsimroi River.

Mackeył. O. S. L. R. R. Supervisor's headquarters.

\section{Manti National Forest (Utah)}

The Manti Forest $(778,651$ acres) is located upon a plateau of sedimentary rocks (Wasatch Plateau) in central Utah. The whole Forest has been cut over with the exception of a few scattered areas rather difficult of access located mostly in the heads of tributaries of Huntington Canyon. Grazing is general and heavy. The only inaccessible areas being the "breaks" of cliffs and talus slopes on the east edge. Such areas are usually barren or covered with the pinyon-juniper type. There are a number of permanent sample plots established by the Forest Service on this Forest in the aspen type. They are not absolutely protected, as normal grazing is allowed upon them. Cutting, however, is prohibited. The major types are: aspen $26 \%$, sage $17 \%$, brush $16 \%$, grass $14 \%$, Engelmann spruce $11 \%$, pinyon-juniper $11 \%$. Fish and game are rare.

Ephraim‡. D. \& R. G. R. R. Supervisor's headquarters.

\section{Minidoka National Forest (Utah and Idaho)}

The Minidoka Forest (590,485 acres) lies in southern Idaho and northern Utah upon a number of small mountain ranges. It is not heavily timbered. It is generally grazed. There are practically no areas of virgin timber, the whole Forest being cut over. The chief types are: sage $65 \%$, aspen $15 \%$, pinyonjuniper $15 \%$, Douglas fir $4 \%$.

Burley, Idahoł. O. S. L: R. R. Supervisor's headquarters.

\section{Nevada National Forest (Nevada)}

The Nevada Forest (1,175,355 acres) is located upon several mountains ranges in east central Nevada. These ranges are generally poorly timbered, although locally there are considerable bodies of several types. A considerable area upon the rocky range crests and in localities without water which are inaccessible to stock and are ungrazed so that botanically, these areas are natural. Tree growth is rare on these sites. There have been extensive cuttings upon this Forest, but in the higher country there are still many limited areas representing natural timber conditions. The major types are: pinyonjuniper $55 \%$, sage $27 \%$ subalpine $6 \%$, Engelmann spruce $5 \%$. 
Elyț. Nev. Nor. R. R. Supervisor's headquarters.

\section{Payette National Forest (Idaho)}

The Payette Forest $(1,202,451$ acres) lies upon an extensive granite uplift in central Idaho. There is no general structural trend to the ridges which are products of erosion. The canyons are steep sided and frequently very rocky. Much of the Forest lies in a country difficult of access and is practically virgin in every respect. There are practically no areas closed to stock or inaccessible to them, although grazing is very light on the Middle Fork of the Salmon River and will probably be entirely stopped within a few years, the State having established a game preserve there. Timber cutting is light. The major types in order of abundance are: western yellow pine $29 \%$, Douglas fir $20 \%$, subalpine $20 \%$, lodgepole pine $16 \%$, brush $8 \%$, grass $6 \%$.

Permanent sample plots in the yellow pine type have been established by the Forest Service on this Forest. These plots are grazed, and are to be cut over under different methods (check plots reserved). Abies grandis and Larix occidentalis find their southern limits on this Forest.

There are extensive game areas within the Payette Forest where deer, bighorn sheep and mountain goats are abundant. There is a great variety of fish and considerable numbers of migratory species spawn within the boundaries of the Forest. In some of the inaccessible regions practically virgin conditions are found in the streams. The introduction of various fish species will, within a few years bring about an adjustment of the native species.

Emmettł. O. S. L. R. R. Supervisor's headquarters.

\section{Powell National Forest (Utah)}

The Powell Forest (about 1,046,000 acres) lies upon the Aquarius, Sevier and Paunsagunt Plateaus, which bear on their tops, stands of spruce, fir, and pine, breaking off into pine and juniper slopes. Grazing is heavy and general, except where the topography is locally precipitous. Little logging has been done in the yellow pine type. Forest conditions are essentially virgin. The major types (Powell Division only) run: western yellow pine $28 \%$, Engelmann spruce $27 \%$, pinyon-juniper $27 \%$, aspen $8 \%$, grass $7 \%$.

Widtsoeł. Supervisor's headquarters.

\section{Salmon National Forest (Idaho)}

The Salmon Forest $(1,620,265$ acres) lies in central Idaho upon several mountain ranges. It is generally rough and in the higher and more remote sections natural conditions are generally found. There are no completely protected areas on the Forest. Grazing is general, but a large area on the Middle Fork of the Salmon River and the northwest corner of the Forest is too rocky and steep to be accessible to domestic stock, while an area near Salmon City is protected on account of the municipal watershed and a small area in the north end (Ditch Creek) is preserved from grazing as a huckleberry patch. A State Game Preserve occupies a part of the area inaccessible to domestic stock and about two townships of the accessible area adjoining. Cut-over areas are small. The major types are: lodgepole pine $37 \%$, Douglas fir $31 \%$, western yellow pine $10 \%$, sage $6 \%$, subalpine $6 \%$. The southeastern limits of western yellow pine in Idaho are found on this Forest.

Salmonf. Gilmore and Pittsburg R. R. Supervisor's headquarters.

\section{Sawtooth National Forest (Idaho)}

The Sawtooth Forest (1,159,339 acres) consists of a broken mountainous country characterized by main ridges of great height and ruggedness. The types in order of extent are grass $41 \%$, Douglas fir $23 \%$, brush $8 \%$, barren $8 \%$, lodgepole pine $6 \%$, subalpine $6 \%$, aspen $2 \%$, western yellow pine $2 \%$, miscellaneous small types making up the balance. Graz- 
ing is general all over the Forest except in areas around the Redfish and Alturas Lakes region where there is full protection. This preserved area is covered largely with virgin lodgepole pine. Interesting experiments in fish stocking and fish food productions are being undertaken. Logging is permitted except in this region. Cut-over areas are limited largely to the Wood River drainage.

Haileył. O. S. L. R. R. Supervisor's headquarters.

\section{Targhee National Forest (Idaho and Wyoming)}

The Targhee Forest (1,357,297 acres) lies largely upon a lava plateau in eastern Idaho and western Wyoming. The Forest consists principally of lodgepole pine. The whole Forest is naturally ecologically similar to the Yellowstone National Park adjoining. Grazing is general but not heavy. Both cut-over and virgin areas of timber are well represented. The major forest types in order of importance are: lodgepole pine $34 \%$, grass $21 \%$, Douglas fir $15 \%$, brush (incl. sage) $14 \%$, subalpine $8 \%$.

St. Anthony, Idahoł. O. S. L. R. R. Supervisor's headquarters.

\section{Teton National Forest (Wyoming)}

The Teton Forest $(1,880,825$ acres) is located in a mountainous country immediately to the south of Yellowstone National Park. The Forest as a whole is slightly used. It contains large areas of virgin lodgepole pine type which is slightly grazed and although there are no protected areas there are large areas in a natural condition. The Grand Teton peak, $13,747 \mathrm{ft}$. high, extends far above timberline. There is a great deal of game on this Forest and the north part above the latitude of Jackson Lake is a State Game Preserve. The major types are: lodgepole pine $29 \%$, grass $21 \%$, barren (high rocky) $21 \%$, subalpine $16 \%$, brush $5 \%$, Engelmann spruce $5 \%$.

Jackson $\ddagger$. Supervisor's headquarters.

\section{Toyabe National Forest (Nevada)}

The Toyabe Forest (1,883,837 acres) lies upon several mountain ranges in central Nevada. These are generally poorly timbered. Grazing is unrestricted. There are, however, certain high rocky areas inaccessible to domestic stock used primarily by mountain sheep and deer. Cutting has been heavy locally (in the vicinity of old mining camps), but most of the Forest is virgin as to timber. The major types are: pinyon-juniper $51 \%$, brush $36 \%$, aspen $10 \%$, subalpine $3 \%$.

Austin $\ddagger$. Nevada Cent. R. R. Supervisor's headquarters.

\section{Wasatch National Forest (Utah)}

The Wasitch Forest (609,576 acres) lies mainly upon the Wasatch and Uinta Mountain Ranges of central Utah, although two minor divisions lie farther west upon small isolated ranges. Nearly the whole Forest has been cut over and is generally grazed. Several watersheds near Salt Lake City are closed to grazing. There is also a State Game Preserve in this region. In the most easterly part of the Forest is a considerable area (about 35 sq. mi.) of virgin lodgepole pine forest. The major types in order of abundance are: lodgepole pine $23 \%$, barren $13 \%$, subalpine $11 \%$, brush $11 \%$, grass $11 \%$, sage $10 \%$, aspen $8 \%$, Douglas fir $6 \%$, pinyonjuniper $4 \%$, Engelmann spruce $3 \%$. The northern limit of Pinus ponderosa scopolorum in Utah is on this Forest.

Salt Lake Citył. D. \& R. G. R. R., O. S. L. R. R. and W. Pac. R. R. Supervisor's headquarters.

\section{Weiser National Forest (Idaho)}

The Weiser Forest (566,002 acres) is located in western Idaho upon a mountainous highland which becomes very rugged in the northwestern part. Two burns (Sec. 3 and 4, T. 21 N., R. 1 W. and Sec. 8 and 9, T. 20 N., R. 1 W., Boise Mer.) of about one sq. mi. each are protected from grazing. In the 
northwest corner about three townships lie in a State Game Preserve. Grazing is general. Timber cutting is very localized and the greater part of the Forest is virgin. The major types are: western yellow pine $30 \%$, grass $24 \%$, Douglas fir $17 \%$, larch-fir $12 \%$, subalpine $10 \%$.

Weiserł. O. S. L. R. R. Supervisor's headquarters.

\section{Wyoming National Forest (Wyoming)}

The Wyoming Forest (966,954 acres) lies upon a mountain range of a plateaulike character, becoming more rugged northward. This Forest contains large areas of lodgepole pine which are being widely cut over at the present time. The Swift Creek watershed near Afton is closed to sheep, however, as a protection to the Afton water supply. At the north end of the Forest in high mountainous country is a game refuge. Grazing is general and timber cutting is not restricted on any areas. The major types in order of abundance are: brush $25 \%$, lodgepole pine $21 \%$, Douglas fir $15 \%$, aspen $9 \%$, sage $8 \%$, grass $6 \%$.

Kemmerer, Wyoming‡. O. S. L. R. R. Supervisor's headquarters.

\section{NATIONAL FORESTS OF THE SOUTHWESTERN DISTRICT (3)}

\section{By G. A. Pearson}

The National Forests of Arizona and New Mexico cover about 22 million acres and comprise approximately $65 \%$ of the forest area in the two States. They are situated in high mountain regions ranging from 2000 to $13,000 \mathrm{ft}$. in altitude. Although the forest boundaries occasionally take in desert and brush lands down to $2000 \mathrm{ft}$. in elevation, the true forests, as distinguished from brush and woodland, rarely occur below $7000 \mathrm{ft}$. The upper altitudinal limit of tree growth is around $11,500 \mathrm{ft}$. Four distinct forest associations or forest types are recognized. They are, in order of altitudinal occurrence, beginning with the lowest, the woodlands, the yellow pine type, the Douglas fir type and the Engelmann spruce type. The altitudinal limits vary with soil, climate, aspect and other local conditions. Other factors being equal, any given forest type occurs roughly 1000 $\mathrm{ft}$. higher on southerly than on northerly aspects. Since the same forest type varies but little on different $\mathrm{Na}$ tional Forests in the Southwest, the following descriptions will apply in a general way over the entire region.

\section{WOODLANDS (UPPER SONORAN ZONE)}

Woodland areas are not, strictly speaking, classed as forests because the trees do not attain saw timber size. The woodlands occur mostly between the altitudinal limits of 5000 and 7000 $\mathrm{ft}$., though in some localities they extend above or below these extremes. The average annual precipitation seldom exceeds $17 \mathrm{in}$. and falls as low as $12 \mathrm{in}$. Mean annual temperatures range from $50^{\circ}$ to $55^{\circ}$.

Two distinct types of woodland occur. In the one most commonly encountered, the dominant trees are the junipers (Juniperus monosperma, J. utahensis, $J$. pachyphloea and $J$. scopulorum), and the piñon, (Pinus edulis). In southern Arizona, notably the Coronado National Forest, is a woodland composed mainly of oaks, (Quercus emoryi and $Q$. arizonica).

Woodland stands are usually open and the space between the trees is generally occupied by short grasses. Cutting for fuel and posts removes most of the mature and overmature trees, but provision is always made for seed trees to restock cut-over areas. Because of the accessibility of the woodlands to settled communities and the demand for their wood and grazing resources, it is probable that they will be exploited to the limit of their capacity. The piñon jay, scaled partridge, Woodhouse's jay, wild turkey, whitetailed deer (Odocoileus), mule deer (Odocoileus hemionus group), coyote (Canis sp.), rock squirrel (Otospermophilus), prairie dog (Cynomys), cotton- 
tail rabbit (Sylvilagus audubonii group), and black-tailed jackrabbit (Lepus californicus group) and woodrat (Neotoma sp.) inhabit this zone, but are not confined to it.

\section{yELLOW PINE TYPE (TRANSITION ZONE)}

Western yellow pine (Pinus ponderosa scopulorum) forms stately forests on the tablelands and lower mountain slopes between altitudes of 7000 and $8500 \mathrm{ft}$. The parklike character of the stands, the ease with which travel is accomplished, the delightful summer climate and the wealth of plant and animal life, give these forests a peculiar charm. The mean annual precipitation totals between 20 and 25 in. and the mean annual temperature is around $45^{\circ}$. Grasses dominate the herbaceous vegetation, but brilliant flowered plants lend color to the landscape during the summer rainy period of July and August. Birds are represented by the pigmy nuthatch, long-crested jay, western robin, chestnut-backed bluebird, Mearns quail and wild turkey. Among the characteristic mammals are Abert squirrel (Sciurus aberti group), white-tailed deer, mule deer, coyote, wolf (Canis mexicanus), and black bear (Ursus americanus group). Since this forest is the main source of saw timber in the Southwest, natural conditions will be disturbed by lumbering, though not to the extent of destroying forest conditions. Extensive areas exist which, because of the lack of transportation facilities, will probably remain unexploited for fifty years. Grazing interferes with the normal development of herbaceous vegetation, but this in turn aids in the control of fires which otherwise would endanger the forest itself.

\section{DOUGLAS FIR TYPE (CANAdian ZONE)}

Douglas fir (Pseudotsuga taxifolia), associated with white fir (Abies concolor), limber pine (Pinus flexilis), and several minor species, forms dense stands on cool slopes between altitudes of 8000 and $10,000 \mathrm{ft}$. Undergrowth is usually light and consists mainly of shrubs and broad-leaved herbs. Natural reproduction of forest trees is usually abundant. Extensive areas in this forest type have been burned over and have grown up to aspen. In many cases the aspen thickets are being invaded by conifers which will eventually replace the aspen. The mean annual temperature is about four degrees lower, and the precipitation about five inches higher than in the yellow pine type. Cutting is progressing rapidly in certain localities; in others rugged topography or distance from lines of transportation will bar the lumberman for many years to come. Grazing is less intensive than in the Yellow Pine type. Characteristic birds and mammals are the Clarke nutcracker, blue grouse, wild turkey, porcupine (Erethizon epixanthum), red fox (Vulpes fulva group), and spruce squirrel (Sciurus fremonti group).

\section{ENGELMANN SPRUCE TYPE (UPPER CANADIAN AND LOWER HUD- SONIAN ZONES)}

The densest forests of this region are composed of Engelmann spruce (Picea engelmanni), associated in varying degrees with alpine fir (Abies lasiocarpa), corkbark fir (Abies arizonica), and bristle-cone pine (Pinus aristata). As in the Douglas fir type, extensive areas have been burned and have grown up to aspen which will eventually give way to the conifers. Since the highest slopes are above the range of aspen, burns in such situations remain bare until restocked by coniferous trees. Exploitation has been limited usually to the removal of ties and poles. Much of this forest will remain undisturbed by cutting for an indefinite period because of the difficulties encountered in transporting the timber to market. The Engelmann spruce type extends to the upper limit of tree growth which is encountered at around 11,500 $\mathrm{ft}$. Precipitation is little, if any, higher than in the Douglas fir type, but the temperature is lower. Snow lies on north exposures until July. Undergrowth is usually sparse, 
but forest reproduction is often dense. The fauna is very similar to that of the Douglas fir type.

\section{ALPINE ZONE}

This term is applied to the areas lying above the upper limit of normal tree growth, which is not, strictly speaking, a forest type. Engelmann spruce, bristlecone pine and alpine fir, where present, assume a bushy or trailing posture. The trailing juniper (Juniperus communis) is characteristic. Some of the grasses and other herbs whose usual habitat is several thousand feet below, occur here in a dwarfed form. This is the home of the ptarmigan, the pipit, the marmot (Marmota flaviventris group) and the pika (Ochotona).

\section{PARKS}

Within all of the forest types are treeless areas known as parks, prairies and mountain meadows. The parks and prairies occur mainly within the yellow pine forests, and their existence is attributed to various causes. They are occupied by grama grass (Bouteloua) or bunch grass (Muhlenbergia), or in some cases by shrubs such as sagebrush (Artemisiatridentata) or shadscale (Atriplex canescens). The term mountain meadow as usually understood applies to wet valleys or other comparatively flat lands in the high mountains. They bear a luxuriant growth of grasses, sedges, and often of showy flowering plants such as the iris and gentian.

\section{FOREST RESEARCH}

A research organization is maintained by the Forest Service for the purpose of solving problems in forest and range management. Forest research is concentrated to a large extent at the Southwestern Forest Experiment Station located near Flagstaff, Arizona, but studies are being conducted on a number of National Forests. Permanent stations for the study of range problems are maintained on the Santa Rita Range
Reserve near Tucson, Arizona, and the Jornado Range Reserve near Las Cruces, New Mexico. So-called permanent sample plots for the study of forest reproduction and growth are being maintained on several National Forests. They vary in size from 5 to 480 acres. On all but one of these plots, cutting has removed from 40 to $75 \%$ of the original stand of timber, and all are subject to further cutting in from 50 to 75 years. Some of the plots are fenced against all grazing, but present plans do not contemplate exclusion of grazing more than from 20 to 25 years, or until natural restocking is completed. In short, the purpose of the sample plots is not to create natural conditions, but rather to demonstrate various methods of forest management. Similar plots are maintained for the study of herbaceous vegetation and methods of range management. Further information regarding these plots can be obtained from the District Forester, Albuquerque, New Mexico.

The present administration of $\mathrm{Na}$ tional Forests, though safeguarding against devastation, does not insure the preservation of any areas in a natural state. Extensive tracts, because of inaccessibility, will remain relatively free from industrial development for many years, but this status cannot be regarded as permanent. From the forester's point of view, as well as that of the botanist and zoologist, the reservation of typical forest areas under distinct provisions for keeping them in a natural state is desirable.

The Forest Service invites scientific workers to avail themselves of the opportunities for research afforded by the National Forests. It is possible in summer to travel by automobile over considerable portions of all the Forests. Sections which are inaccessible by automobile can usually be reached by wagon roads or trails. Camping equipment is often necessary and always desirable. Information regarding roads, means of transportation and subsistence can always be secured at the office of the local Forest Supervisor. 
NATURAL AREAS

\section{Apache National Forest (Arizona)}

Area 1,185,512 acres, mainly coniferous forest representing the woodland, yellow pine, Douglas fir and Engelmann spruce types, almost entirely in the virgin state. The topography varies from level tablelands to rugged peaks, and altitudes range from 4000 to $12,000 \mathrm{ft}$.

Holbrook $\ddagger$, $100 \mathrm{mi}$. north, A. T. \& S. F. R. R.; auto stage to Springervilleł, Supervisor's headquarters.

\section{Carson National Forest (New Mexico)}

Area 869,320 acres. All of the coniferous forest types of the Southwest are represented; altitudes 5000 to $13,000 \mathrm{ft}$.; fine streams, numerous prehistoric ruins.

Taosł, Supervisor's headquarters. Reached by way of Santa Fe and Taos Junction, D. \&. R. G. R. R.; auto stage, 25 mi. to Taos.

\section{Coconino National Forest (Arizona)}

Area 1,637,052 acres, mainly coniferous forest representing all the forest types. Altitudes range from $3000 \mathrm{ft}$. on the Verde River to $12,700 \mathrm{ft}$. on the San Francisco Mountains. The topography is mostly level or gently rolling mesas intersected by occasional deep canyons and dotted by volcanic cones. Prehistoric ruins occur in several localities. This Forest and the Tusayan which adjoins it on the west, are the scene of the most extensive lumbering operations in the Southwest. Five permanent sample plots, three fenced.

Flagstaff $\ddagger$, A. T. \& S. F. R. R., Supervisor's headquarters.

\section{Coronado National Forest, Arizona and New Mexico)}

Area 1,430,043 acres. This Forest is made up of several "islands" rising out of the desert. Altitudes range from 3000 to $9000 \mathrm{ft}$., and vegetation zones from the scrub and woodland to the Douglas fir forest. Emory oak and Arizona oak attain their best development here. Desert mountain sheep have been reported in the woodlands.
Tucson, Arizona $\ddagger$ E. P. \&. S. W. and S. P. railroads, Supervisor's headquarters.

\section{Crook National Forest (Arizona)}

Area 889,939 acres. This Forest consists of four small units or separate mountain masses which rise to a sufficient height above the desert to support coniferous forests. The forest types range from the woodland to Engelmann spruce. Altitudes range from about 4000 to $10,500 \mathrm{ft}$.

Safford , A. E. R. R., Supervisor's headquarters.

\section{Datil National Forest (New Mexico)}

Area 2,641,521 acres, coniferous forest, woodland to spruce type; altitudes 4000 to $10,000 \mathrm{ft}$.; little cutting. A large portion of the timbered area will probably remain inaccessible for many years. Ten game refuges, averaging 21,000 acres each are located within this Forest.

Magdalena $\ddagger$ Supervisor's headquarters, A. T. \&. S. F. R. R.

\section{Gila National Forest (New Mexico)}

Area 1,596,296 acres; coniferous forest, woodland to spruce; altitudes 5000 to $11,000 \mathrm{ft} . ;$ little cutting; large areas relatively inaccessible. Two permanent sample plots; four small game refuges.

Silver City + , Supervisor's headquarters, A. T. \& S. F. R. R.

\section{Lincoln National Forest (New Mexico)}

Area 1,123,868 acres; desert, scrub and coniferous forest, the latter representing all forest types, including the alpine above $11,000 \mathrm{ft}$. The forest is made up of several small mountain masses rising abruptly out of the desert. A fine summer resort is located in the heart of the fir forest at Cloudcroft $\ddagger, 9000 \mathrm{ft}$. Desert Mountain sheep have been reported on this Forest.

Alamogordoł, Supervisor's headquarters, E. P. \&. S. W. R. R. 
Manzano National Forest (New Mexico)

Area 702,208 acres. Coniferous forest, including woodland, yellow pine, Douglas fir and Engelmann spruce, up to $11,000 \mathrm{ft}$.; small lumbering operations.

Albuquerque $\ddagger$, Supervisor's headquarters, A. T. \& S. F. R. R.

\section{Prescott National Forest (Arizona)}

Area 1,447,024 acres, coniferous forest with some oak woodland. Only the forest types below the Engelmann spruce are represented. Altitudes range from 2000 to $8000 \mathrm{ft}$.

Prescott $\ddagger$, A. T. \& S. F. R. R., Supervisor's headquarters.

\section{Santa Fe National Forest (New Mexico)}

Area 1,364,585 acres. Coniferous forest, including all forest types to timber line; altitudes 6000 to $13,000 \mathrm{ft}$.; very rugged topography, well watered; six small sample plots. Famous prehistoric ruins of Rito de los Frijoles near Santa Fe.

Santa Fe $\ddagger$, Supervisor's headquarters, A. T. \& S. F. and D. \& R. G. Railroads.

\section{Sitgreaves National Forest (Arizona)}

Area 631,474 acres, mainly virgin western yellow pine, though small areas of Douglas fir may be found. Altitudes range between 5000 and $9000 \mathrm{ft}$. The topography is characterized by high, comparatively level tablelands dissected by deep, precipitous canyons.

Holbrook $\ddagger$ A. T. \& S. F. R. R. Supervisor's headquarters, $35 \mathrm{mi}$. by automobile stage.

\section{Tonto National Forest (Arizona)}

Area 2,112,888 acres. Relatively small areas bear a true forest, the greater portion being desert brush or woodland, which are included because of their watershed value. The famous Roosevelt Dam and Reservoir and the Natural Bridge are located on this Forest. Roosevelt Lake is a game preserve.

Roosevelt $\ddagger$, $38 \mathrm{mi}$. from Globe, A. E.
R. R., and $60 \mathrm{mi}$. from Phoenix, A. E. and A. T. \& S. F. R. R., reached from either place by automobile stage. Supervisor's headquarters, Phoenix.

\section{Tusayan National Forest (Arizona)}

Area 1,289,351 acres. This Forest is generally similar to the Coconino which it adjoins on the west. To the north lies the Grand Canyon National Park. One permanent sample plot.

Williams $\ddagger$ A. T. \& S. F. R. R., Supervisor's headquarters.

\section{Jornado Range Reserve (New Mexico)}

Area about 200,000 acres; desert plains and foothill country, ranging from 4000 to $7000 \mathrm{ft}$. in altitude. No forest occurs within the reserve. The prevailing vegetation includes grama grasses, tobosa (Hilaria mutica), drop seed (Sporobolus), creosote bush (Covillea tridentata) and mesquite (Prosopis glandulosa). The area is maintained for the purpose of carrying on experiments and demonstrations in range management.

Las Cruces $\ddagger$, headquarters of Grazing Examiner in charge; A. T. \& S. F. R. R.

\section{Santa Rita Range Reserve (Arizona)}

About 49 sq. mi. of desert and semidesert, fenced against cattle from 1903 to 1915. Since the latter year it has been handled by the Forest Service as an experimental range for livestock. Much research work has been done on the succession of natural types of vegetation. Altitudes 3000 to $5000 \mathrm{ft}$.

Tucson $\ddagger$ S. P. R. R., headquarters of Grazing Examiner in charge.

\section{Sample plots within National Forests (Arizona)}

Coconino and Tusayan National Forests. Sample plots S-1 to S-6 inclusive. The areas vary from 120 to 480 acres. All are in pure yellow pine stands at altitudes around $7000 \mathrm{ft}$. All but plot S-6 have been cut, removing 40 to $70 \%$ of the timber. Topography: gently rolling; soil clay loam derived from basalt. 
Within each area are several plots of from 4 to 12 acres on which all trees are numbered and located on a map. Diameter and height measurements are made every 5 years. Progress of reproduction is checked annually. A few of these small plots are fenced against all grazing, but this condition will be maintained only until reproduction is established. All but S-6 are subject to future cutting in 50 to 75 years. Established 1909-1913.

Flagstaff $\ddagger$, A. T. \& S. F. R. R., 10 to $30 \mathrm{mi}$. Detailed information at Southwestern Forest Experiment Station.-G. A. Pearson.

\section{Sample plots wilhin National Forests (New Mexico)}

Datil National Forest. Sample plots S1A, S1B, S2A. Area about 10 acres each. S1A and S1B are in a canyon at about $8300 \mathrm{ft}$. elevation. The composition is western yellow pine, Douglas fir and limber pine. Plot S2A is comparatively level, pure western yellow pine. All plots logged and established 1910; all are grazed. Trees numbered and mapped, diameters and heights measured every 5 years.

Magdalenaf, A. T. \& S. F. R. R., Supervisor's headquarters.

Gila National Forest. Sample plots S1A and S2B. Area 6 acres each, practically pure western yellow pine, about $70 \%$ cut. Plots established 1911 . Trees measured every 5 years. Both plots are grazed.

Silver City $\ddagger$ A. T. \& S. F. R. R., Supervisor's headquarters.
Santa Fe National Forest. Sample plots, Pecos S1A and S1B and Jemez S1A and S2A and S3A. Area 6 acres each; western yellow pine with varying mixture of Douglas fir and limber pine. Altitudes around $7500 \mathrm{ft}$. All plots cut, removing 60 to $70 \%$, and all grazed. Established 1911.

Santa Fe , A. T. \& S. F. and D. \& R. G., Supervisor's headquarters.G. A. Pearson.

\section{NATIONAL FORESTS OF THE ROCKY MOUNTAIN DISTRICT (2)}

\section{By C. G. Bates}

There are 26 National forests in this district, Colorado having 15, Wyoming 5, South Dakota 2, Nebraska 1, Michigan 1 and Minnesota 2.

Owing to the extremely diverse climatic conditions found in going from South Dakota to the Rocky mountains, from the southern border of Coloradoto Minnesota, and from the western to the eastern slope of the Rockies it has been thought best to give a detailed account of each forest rather than to attempt a general description for the entire district.

For the sake of brevity and to avoid monotony, a tabulation is given below showing the name and area of the forest, the supervisor's headquarters and the directions for reaching it. Under each description there is given a brief account of the plant and animal life, the special physiographic features and the natural areas reserved or suitable for reservation.

\begin{tabular}{l|l|l|l}
\hline NATIONAL FOREST & HEADQUARTERS TOWN & DIRECTIONS FOR REACHING HeAdQUARTERs & $\begin{array}{c}\text { ACREAGE } \\
\text { OF THE } \\
\text { FOREST }\end{array}$ \\
\hline
\end{tabular}

Colorado (15)

\begin{tabular}{|c|c|c|c|}
\hline Arapaho & $\begin{array}{l}\text { Hot Sulphur } \\
\text { Springs }\end{array}$ & D. \& S. L. R. R. from Denver & 634,284 \\
\hline Cochetopa & Salida & D. \& R. G. W. R. R. & 907,000 \\
\hline Colorado & Ft. Collins & $\begin{array}{l}\text { C. \& S. R. R. and U. P. R. R. from } \\
\text { Denver or Cheyenne }\end{array}$ & 853,641 \\
\hline $\begin{array}{l}\text { Grand Mesa } \\
\text { Gunnison }\end{array}$ & $\begin{array}{l}\text { Grand Junction } \\
\text { Gunnison }\end{array}$ & $\begin{array}{l}\text { D. \& R. G. W. R. R. } \\
\text { D. \& R. G. W. R. R. (narrow gauge } \\
\text { from Grand Junction or Salida) }\end{array}$ & $\begin{array}{l}660,823 \\
905,382\end{array}$ \\
\hline
\end{tabular}




\begin{tabular}{l|l|l|c}
\hline NATIONAL FORESTS & HEADQUARTERS TOWN & DIRECTIONS FOR REACHING HEADQUARTERS & $\begin{array}{c}\text { ACREAGE } \\
\text { OF THE } \\
\text { FOREST }\end{array}$ \\
\hline
\end{tabular}

Colorado (15)

\begin{tabular}{|c|c|c|c|}
\hline Holy Cross & Glenwood & D. \& R. G. W. R. R. & $1,171,921$ \\
\hline Leadville & Leadville & $\begin{array}{l}\text { D. \& R. G. W. R. R. and C. \& S. } \\
\text { R. R. }\end{array}$ & 930,568 \\
\hline Montezuma & Mancos & $\begin{array}{l}\text { R. G. S. R. R. from Durango or } \\
\text { Montrose }\end{array}$ & 697,742 \\
\hline Pike & $\begin{array}{l}\text { Colorado } \\
\text { Springs }\end{array}$ & $\begin{array}{l}\text { R. I.; D. \& R. G. W. R. R. ; Sante Fe; } \\
\text { C. \& S. R. R. }\end{array}$ & $1,093,073$ \\
\hline Rio Grande & Monte Vista & D. \& R. G. W. R. R. & $1,135,728$ \\
\hline Koutt & $\begin{array}{l}\text { Steamboat } \\
\text { Springs }\end{array}$ & D.\& s. L. K. K. Irom venver & \\
\hline San Isabel & Pueblo & $\begin{array}{l}\text { D. \& R. G. W. R. R.; Sante Fe; } \\
\text { M. P. R. R. }\end{array}$ & 599,096 \\
\hline San Juan & Durango & $\begin{array}{l}\text { D. \& R. G. W. R. R. from Alamosa } \\
\text { or Denver and R. G. So. Ry. from } \\
\text { Montrose }\end{array}$ & $1,240,141$ \\
\hline Uncompahgre & Delta & $\begin{array}{l}\text { D. \& R. G. W. R. R. (narrow gauge } \\
\text { from Grand Junction or Salida) }\end{array}$ & 778,291 \\
\hline White River & $\begin{array}{l}\text { Glenwood } \\
\text { Springs }\end{array}$ & D.\& R. G. W. R. R. & 845,104 \\
\hline
\end{tabular}

Wyoming (5)

\begin{tabular}{|c|c|c|c|}
\hline $\begin{array}{l}\text { Bighorn } \\
\text { Hayden }\end{array}$ & $\begin{array}{l}\text { Sheridan } \\
\text { Encampment }\end{array}$ & $\begin{array}{l}\text { C. B. \& Q. R. R. } \\
\text { U. P. R. R. branch or stage from } \\
\text { Walcott, Wyoming }\end{array}$ & $\begin{array}{r}1,124,617 \\
394,011\end{array}$ \\
\hline $\begin{array}{l}\text { Medicine Bow } \\
\text { Shoshone }\end{array}$ & $\begin{array}{l}\text { Laramie } \\
\text { Cody }\end{array}$ & U. P. R. R. & $\begin{array}{r}477,701 \\
1,583,489\end{array}$ \\
\hline Washakie & Lander & C. \& N.W. R. R. & 852,315 \\
\hline
\end{tabular}

South Dakota (2).

\begin{tabular}{l|l|l|l}
\hline Black Hills & Deadwood & C. B. \& Q. and C. \& N. W. R. R. & 620,556 \\
Harney & Custer & C. B. \& Q. Ry. & 508,514 \\
\hline
\end{tabular}

Minnesota (2)

\begin{tabular}{|c|c|c|c|}
\hline $\begin{array}{l}\text { Superior } \\
\text { Minnesota }\end{array}$ & $\begin{array}{l}\text { Ely } \\
\text { Cass Lake }\end{array}$ & $\begin{array}{l}\text { D. \& I. R. R. from Duluth } \\
\text { G. N. R. R.; Soo Line }\end{array}$ & $\begin{array}{l}857,339 \\
190,602\end{array}$ \\
\hline \multicolumn{4}{|c|}{ Michigan } \\
\hline Michigan & East Tawas & D. \& M. R. R. & 123,647 \\
\hline \multicolumn{4}{|c|}{ Nebraska } \\
\hline Nebraska & Halsey or Nenzil & C. B. \& Q. or C. \& N. W. R. R. & 205,944 \\
\hline
\end{tabular}

NATURAL AREAS

Arapaho National Forest (Colorado)

The forest forms the headwaters of the Colorado River and also North Platte River, with numerous small lakes at heads' of streams.

514,653 acres of lodgepole pine (Pinus contorta) and Engelmann spruce (Picea engelmannii); small amount of Douglas fir (Pseudotsuga tarifolia); two small isolated areas of Western yellow pine (Pinus ponderosa Scopulorum); numerous open un-timbered land above areas of aspen. There are 120,202 acres timber-line, and sagebrush. 
Deer, elk, and black bear are found over a large portion of the forest. Cougar occur in small numbers and bighorn sheep occasionally. Trout are found in most streams and lakes.

Fraser, D. \& S. L. R. R., is center of lodgepole pine and Engelmann spruce areas and several sawmill operations. Ranger at Idlewild R. S., $5 \mathrm{mi}$. SE. Small hotel at Fraser.

Grand Lake is one of largest in state; reached by stage from Granby, $20 \mathrm{mi}$., or from Estes Park. Summer resort; ample accommodations. Center for number small mountain lakes and peaks.

Monarch Lake, $20 \mathrm{mi}$. from Granby by auto road or $12 \mathrm{mi}$. from Tabernash by trail.

Plots $20 \mathrm{ft}$. square have been fenced against grazing to study effect of grazing on forage species. One is near Gilsonite R. S., auto from Granby and two more near Hot Sulphur Springs, walk.

Winter range of deer and elk near Hot Sulphur Springs. Williams Fork State Game Refuge (1923) lies back of this and extends to timber-line. 400 deer and 400 elk in vicinity.

\section{Cochetopa National Forest (Colorado)}

Contains extensive areas of lodgepole pine in northern portion, which is the southern limit of lodgepole pine; Engelmann spruce at high elevations; mixed stands of Douglas fir and yellow pine at lower altitudes. Extensive burns in spruce type on Saguache, Mineral and Spring Creek drainages, 1893. Typical burns may be seen at Marshall Pass (D. \& R. G. W. narrow-gauge) as well as anywhere. Burns also in the lodgepole pine type during the last 35 or 40 years; probably entire type has followed fires which occurred in the last 200 years, and original type on northerly slopes in present lodgepole pine stands was largely Douglas fir.

Bighorn sheep range, an area of 3200 acres, lies between the cattle range on Spring and Mineral Creeks and the high sheep range, so rough and inaccessible that it is not grazed by domestic stock. Reached by few miles on foot, snow- shoes, or horseback from Cathedral after 40-mile stage from Gunnison. (D. \& R. G. W. R. R.) Ranger at Cathedral entire year.

Poncha Pass State Game Refuge (1923) lies near Salida and is bounded on the north by the transcontinental autohighway over Monarch Pass. Similarly the Cochetopa State Game Refuge (1923) may be reached from Salida or Saguache over the Cochetopa Pass highway, the area lying to the south of this road and east of the Continental Divide. Both highways are main routes of travel to Gunnison and the west.

Sargents (D. \& R. G. W. R. R. from Salida) is in the center of the lodgepole pine forest. Eight sample plots have been established in this vicinity, 7 of which are $\frac{1}{4}$ acre and one 1 acre in area. Designed to show the results of thinnings in lodgepole pine timber which matures at mine-prop size. For further details of location see ranger stationed either at Sargent's or at Long Branch ranger station $3 \mathrm{mi}$. distant.

Sample plot of $\frac{1}{2}$ acre on overgrazed range badly infested with pingue ( $H y$ menoxys). The original grama-grass type has been largely replaced by pingue. Grazing has been excluded from the sample area by fence to determine whether grama grass will recover and dominate the pingue. Reached from Moffat (D. \& R. G. W. R. R.) by an 18mi. stage trip to Saguache, thence 17 $\mathrm{mi}$. by auto to the area. Ranger at Carnero R. S. can be reached by phone from Saguache.

\section{Colorado National Forest (Colorado)}

The Forest covers portions of the North and South Platte watersheds and bounds the Rocky Mt. Nat. Park on 3 sides. Forests of lodgepole pine, Engelmann spruce and alpine fir (Abies lasiocaria) cover large areas in the higher elevations. The type in the foothills embraces yellow pine, with an admixture of Douglas fir. About $20 \%$ burned and cut-over.

The Colorado State Game Refuge (1921) covers a large part of the Forest. 
Portions of the area are accessible by auto from Boulder, Loveland, Longmont, Lyons, Ft. Collins and other R. R. points. The NW. portion may be approached via mail stage from Laramie, Wyo. (U. P. R. R.) to Glendevey P. O., $55 \mathrm{mi}$., thence about 10 miles to Refuge. Rangers at Boulder, Bellvue (near Ft. Collins) and 2 miles from Glendevey. At west edge of Refuge in Boulder district are Arapaho, Isabel and St. Vrain glaciers.

Trail End. A licensed game preserve of 200 acres for the propogation of western animals. Reached by auto from Ft. Collins, 43 mi., or Tie Siding Wyo. (U. P. R. R.) $33 \mathrm{mi}$.

West Lakes. A reserve of 2560 acres containing lakes which are used by State for trout-spawning purposes. Reached via stage from Ft. Collins to Log Cabin, thence $7 \mathrm{mi}$. west.

Proposed Red Rock Lake botanical area, of about 20 acres, should be fenced to exclude stock and perpetuate the great variety of plants to be found in a restricted area. Reached by auto stage, Boulder to Ward, thence distant $2 \frac{1}{2} \mathrm{mi}$.

\section{Grand Mesa National Forest (Colorado)}

Grand Mesa, which forms the main unit of the Forest, is a table-like mountain with a top area of $53 \mathrm{sq}$. mi. and a perimeter of $60 \mathrm{mi}$. The sides are abrupt and rise over $6000 \mathrm{ft}$. above the floor of the valley, the top being comparatively level meadow-land interspersed with groves of spruce and fir. The mountain owes its existence to a huge lava flow which capped the soft sedimentary formations. Erosion has exposed large cross-sections of the underlying strata, making over 100 lakes just under the volcanic rim or on top of the mesa.

The flora and fauna characteristic of the altitudinal zones can be very conveniently studied as good roads have been built from the floor of the Colorado and Gunnison Rivers to the top of Grand Mesa, and a range in altitude from $4500 \mathrm{ft}$. to 10,500 can be traversed in less than three hours. The characteristic vegetation of the desert extends to the base of the Grand Mesa; from there up timber is present from the pinyon type up through the oak and aspen to the spruce-balsam. The aspen and spruce belts are rich in plant growth and elk, deer and bear are plentiful, besides a variety of smaller mammals. Beaver are found in every stream upon the Mesa; bird life is abundant; the lily-pad lakes furnish nesting places for waterfowl.

Forty lakes have been made accessible to automobiles.

Hotels have been built at three principal groups. Horses, boats and private cabins are available. Grand Mesa reached by 25 -mi. stage from Delta, $56 \mathrm{mi}$. from Grand Junction and 28 mi. from Debeque. (All on D. \& R. G. W. R. R.)

\section{Gunnison National Forest (Colorado)}

The forest consists of $43 \%$ productive timberland, $19 \%$ woodland, chiefly aspen, $6 \%$ brushland, $14 \%$ grass or sagebrush, $1 \%$ burn not restocking, $17 \%$ barren and above timber-line. It is further characterized by extensive burns and large areas of lodgepole pine.

Crater Lake, an unstocked freshwater lake lies near the summit of Mt. Gunnison at an elevation of approximately 10,500 ft. Area 40 acres. Surrounded on the east, south and west by dense stands of Engelmann spruce and alpine fir. Approached by saddle and pack $17 \mathrm{mi}$. from Paonia, Colo. (D. \& R. G. W. R. R. from Delta) where are good accommodations and ranger. Four miles from end of pack trip to Lake.

Storm Range Game Refuge is an area of $21 \mathrm{sq}$. mi. from which grazing is excluded by Forest Service policy. Mostly barren of timber, on a high mesa, bounded on three sides by high cliffs. Forage on the mesa is of alpine type. Reached by horse or on foot, $6 \mathrm{mi}$. from Baldwin, Colo. (C. \& S. R. R. from Gunnison) where there is a ranger.

Gunnison State Game Refuge (1923) a large area to the north of Sapinero and west of Crested Butte, may be 
reached from either of these towns or from Gunnison.

About 100 acres permanent sample plots in lodgepole pine illustrating reproduction after clear-cutting and various degrees of thinning, established in 1911. Reached from Pitkin (D. \& R. G. W. R. R.) or from Gunnison (a), thence one mi. S.W. ranger at Pitkinf.

\section{Holy Cross National Forest (Colorado)}

The greater part of this forest was burned over in connection with early settlement and mining operations. It is characterized by extensive areas of rugged mountainous country, supporting scattered bodies of Engelmann spruce and lodgepole pine. Douglas fir and an occasional yellow pine occur along the lower reaches of several streams.

Two Elk and Battle Mountain Game Protection Area. 7680 acres closed to grazing of domestic stock and used by game animals for winter range, mainly on south slopes along Eagle River Canyon adjoining an extremely rugged range country. Reached by leaving D. \& R. G. train at Minturn or Red Cliff, whence Eagle River Canyon may be traversed by auto in a few miles. Ranger at Red Cliff, hotels at either place.

Woody Game Refuge. An area of 11,600 acres in high country between Roaring Fork and Frying Pan Rivers, characterized by scattered stands of Engelmann spruce with open grassy parks. Not used for grazing domestic stock and has become a sanctuary for game animals during the summer. Reached from Aspen (D. \& R. G. W. R. R. from Glenwood) $10 \mathrm{mi}$. by saddle horse. Hotel and ranger at Aspen.

Capitol Peak Game Refuge. (By Colo. statute, 1923, this area included in Snowmass State Game Refuge.) An area of 12,120 acres, including Avalanch. Comprises extremely rough high mountains between Crystal River and Roaring Fork. Serves the same purpose as the Woody Refuge. Reached (h) from either Aspen or Carbondale (D. \& R. G. W. R. R.) distance $15 \mathrm{mi}$. Ranger at Carbondale.

Permanent sample plots of 3 acres established 1914 in heavy spruce forest, illustrating different weights of cutting with resultant growth and reproduction. No virgin area retained. Two other plots established 1924. Both areas reached from Red Cliff (D. \& R. G. W. R. R.) (h) about $7 \mathrm{mi}$. up Wearyman Creek. Ranger at Red Cliff $\ddagger$.

\section{Leadville National F'orest (Colorado)}

Approximately 2590 acres have been burned and 1590 cut-over. Extensive areas of lodgepole pine and Engelmann spruce at high elevations, Douglas fir and yellow pine remnants on border of Arkansas valley.

Gore Range, 12,000 acres (higher portions on east side) is of special interest because so rugged and precipitous that along its higher portion no cattle or domestic sheep graze, and it is almost inaccessible even on foot. Deer, elk, and bighorn sheep; small, clear lakes; abundant trout. Reached from Dillon (C. \& S. Ry.) by horse, finally reverting to foot travel. Ranger $1 \frac{1}{2} \mathrm{mi}$. south of Dillon. Hotel at Dillon

Twin Lakes, 2000 acres. Two freshwater lakes joined by narrow neck at an altitude of 9000 are set back in rugged mountains with spruce and pine timber along their shores. Reached by Ocean-to-Ocean highway, $20 \mathrm{mi}$. by auto from Leadville, or $9 \mathrm{mi}$. by stage from Granite (D. \& R. G. W. R. R.).

Proposed Game Preserve. 189,000 acres in Buffalo Peaks and adjoining country down to Arkansas River. All forest types; comparatively low; parts free of snow year round; small portion above timberline; mountain grasses, herbs and shrubs; ideal summer and winter range. Adjacent to Buena Vista (D. \& R. G. W. R. R.) Hotel and ranger.

\section{Montezuma National Forest (Colorado)}

Most of the southern and western parts of the forest support yellow pine 
timber. The north and east parts support mixed Engelmann spruce and alpine fir timber. About $10 \%$ burned over and many burned areas support aspen.

There are a few deer and elk and many bear and also a few bighorn sheep.

Silver Creek Watershed for town of Rico is closed to grazing. Area $6 \mathrm{sq}$. mi. Timber growth consists of aspen, Engelmann spruce and alpine fir.

\section{Pike National Forest (Colorado)}

Practically all parts of the Forest, including some areas above timberline are accessible by good auto roads, and during summer fair accommodations may be had at nearly all towns and resorts.

The land is $78 \%$ timbered, $2 \%$ aspen, $1 \%$ brush lands (oak), $2 \%$ grassland, $5 \%$ burns not restocking and $12 \%$ barren and grassland above timber-line. Elevations below $9000 \mathrm{ft}$., characterized by open stands of western yellow pine and Douglas fir. Limber pine occurs on the ridge crests and exposed sites. From $9000 \mathrm{ft}$. to timber-line, Engelmann spruce is the principal species, with a mixture of Douglas fir and limber pine at the lower elevations, and on the exposed ridges, bristle-cone pine (Pinus aristata). The spruce forms stands with an unusually light mixture of alpine fir. In the north half of the Forest, lodgepole pine occurs, the southern limits of lodgepole east of the Continental Divide being near the South Platte River.

Successful elk plants were made in 1916 in the vicinity of Idaho Springs and Pikes Peak.

Sample plots 4 acres in extent established 1920 for study of thinning in a 40-year Douglas fir sapling stand through commercial sales of Christmas trees, to shorten the rotation for tie and saw-timber production. Accessible (a) from Denver or Sedalia; $8 \mathrm{mi}$. from Sedalia over Decker Springs road. Auto service and fair accommodations at Sedalia.

Grazing-Planting-Erosion Sample Plots, involves 30 acres of fenced land from which grazing is excluded with similar area adjacent and unfenced and subject to usual grazing by cattle and horses. Planted and unplanted areas both within and without enclosure. Vegetation quadrats for the study of effects of erosion are established on each plot. Forest type is essentially yellow pine. Vegetation characterized by mountain mahogony, deer bush and grama grass. Reached from Denver via C. \& S. Ry. to South Platte. Thence two mi. SW. via old abandoned wood road. Local residents familiar.

Planted areas of several thousand acres in vicinity of Pikes Peak, Cascade and Monument, some dating from 1909, illustrate possibilities of artificial reforestation. Forest Service Nursery for production of tree stock at Monument. Leave any local train between Denver and Colorado Springs; or auto from Colorado Springs.

The Denver Mountain Parks State Game Refuge, 500,000 acres, ranging in elevation from 6000 to $14,000 \mathrm{ft}$. Vegetative types very diverse. Accessible from Denver (a).

Pikes Peak State Game Refuge, 129,000 acres, covers a range of from 6250 to $14,000 \mathrm{ft}$. Deer, elk, bighorn sheep, beaver, coyote, bear, cougar, ptarmigan, and grouse are found. Accessible from Colo. Springs and Manitou by rail and (a). Towns on all sides, Rangers at Colo. Springs and Cascade.

Watershed, City of Colorado Springs and Town of Manitou. This area includes some 60,000 acres, closed to grazing, and mostly within the game preserve described above. One of the most readily accessible spots of the United States in which to gain an intimate knowledge of practically all forms of plant and animal life characteristic of the region. Within the area are the Fremont Forest Experiment Station of the U. S. Forest Service, and the Alpine Laboratory of the Carnegie Institution.

The City of Denver Watershed, con- 
sists of Lake Cheesman and 10,000 acres of land. The area is fenced to exclude stock and owned by the City of Denver. Forests of yellow pine and Douglas fir. Accessible (a) from Denver, via Sedalia-Decker Springs Road. Fair accommodations at Decker's.

\section{Rio Grande National Forest (Colorado)}

This is an enormous basin forming the headwaters of the Rio Grande river and including vegetative types from practically desert at the edge of the San Luis Valley to vast areas of almost perpetual snow-fields and alpine meadows above the line of spruce timber. A very large part of the area is used for grazing, especially of sheep, which winter on ranches in the Valley. The yellow pine type is sparsely represented in the foothills, while lodgepole pine is entirely absent. A peculiar feature of the forest is the occurrence of blue spruce (Picea pungens) in mixture with Douglas fir, far removed from the usual streambed habitat.

Pole Mtn. Bighorn Sheep Breeding Ground. About 3000 acres closed to sheep-grazing to permit development of bighorn sheep. Reached by pack trip of about $50 \mathrm{mi}$. from Creede (D. \& R. G. W.).

Elk Mountain and Goose Creek Elk Ranges. These two separate areas cover about 10,000 acres, and are closed to grazing of domestic stock. Several hundred elk range here. Both are reached from Wagon Wheel Gap. (D. \& R. G. W.) by saddle horse, about 15 mi. Summer hotel only at Wagon Wheel Gap.

Wheeler National Monument. An area of 400 acres containing unusual "toad-stools" and other peculiar erosion forms of interest to geologists. Reached by saddle-horse from Creede (D. \& R. G. W. R. R.) about $15 \mathrm{mi}$.

Wagon Wheel Gap Streamflow Experimental Area. The two watersheds which have been under study since 1910 comprise 400 acres. After preliminary study one was denuded in 1919-20 to determine the effect of forest removal on streamflow. This will also present excellent opportunity for the study of plant succession. Only limited sheep grazing is to be permitted on denuded watershed; none on other. Expected visitors may usually be cared for at Station headquarters, $2 \mathrm{mi}$. from Wagon Wheel Gap. (D. \& R. G. W.) Ref: "First Results in Streamflow Experiment, Wagon Wheel Gap. Colo., Carlos G. Bates, Jour. Forestry, Vol. XIX, No. 4, pp. 402 to 408.

\section{Routt National Forest (Colorado)}

Comprises a forest of which the lower portions, once occupied by Douglas fir, have been so badly ravaged by fire as to result in extensive stands of aspen. Large areas at higher elevations are covered by lodgepole pine and Engelmann spruce which has been little exploited. The herbaceous and shrubby vegetation is very diverse and characteristic of western slope conditions.

Deer, bear, elk and bighorn sheep occur in unusual numbers, owing to the undeveloped nature of the country. Elk winter within a few miles of Steamboat Springs. Whitefish are found in all branches of Bear River.

\section{San 1sabel National Forest (Colorado)}

The accessible timber was cut in the early days. Fires have left scars over the entire forest. A large part of the Sangre de Cristo Range contains virgin timber types, as well as remarkable alpine lakes and rugged scenery.

Most lakes are stocked with fish. Good accommodations can be found at various towns adjacent and several summer hotels located within the Forest. The D. \& R. G. W. R. R. passes along the north end, with branches into Wet Mountain Valley and on the west and south sides into San Luis Valley. Rangers at Wetmore, Rye, Gardner, Westcliffe, Mirage and La Veta.

Reserved areas: City of Florence Watershed, 8000 acres on Newlin Creek, 
extending from yellow pine to Engelmann spruce. Grazing is limited upon the area. Reached by auto from Florence. (D. \& R. G. W. R. R.) $10 \mathrm{mi}$.

Spanish Peaks State Game Refuge. Contains 75,416 acres, extending from the foothills type up to the Spanish Peaks elevation $13,600 \mathrm{ft}$. Game is also being protected upon the Sangre de Cristo Grant just west of the Refuge; large herd of bison under enclosure. Reached from La Veta by auto.. Summer hotels within the Refuge.

City of Trinidad Watershed. 10,000 acres on North Fork of the Purgatory, and within the Spanish Peaks Game Refuge. Heavy fires occurred in early days. Wild turkeys are found. Grazing limited. Reached from La Veta (a) $25 \mathrm{mi}$. Summer hotel $5 \mathrm{mi}$. from watershed.

\section{San Juan National Forest (Colorado)}

The forest is $5 \%$ burned and $5 \%$ cutover. The pine timber near Pagosa Springs has for years been the center of an important lumber industry.

Animals consist of deer, bear, bighorn sheep; grouse are fairly plentiful; native trout in nearly all streams.

The Needle Mountains are very rough and inaccessible. The summits of four of the peaks are over 14,000 ft. in elevation, while $6000 \mathrm{ft}$. below Animas River rushes through a canyon which separates the West Needles from the main group. A large portion of these mountains is above timber-line. The area is so broken that domestic stock cannot be profitably grazed on it, and the timber, consisting principally of Engelmann spruce, may be preserved in its natural condition without sacrifice or expense. Reached from Needleton, a station 35 mi. north of Durango on Silverton branch of D. \& R. G. W. All arrangements should be completed before leaving Durango.

The Durango Reservoir Grant, 3050 acres of natural forest land is approximately $32 \mathrm{mi}$. northeast of Durango on the headwaters of the Florida River. This area can be reached only by saddle horse or on foot, this inaccessibility comprising its principal virtue for purposes of nature study. Information should be obtained and arrangements made at Durango.

\section{Uncompahgre National Forest (Colorado)}

The larger part of the forest is on the Uncompahgre Plateau, which rises gently to the south from the Uncompahgre-Gunnison valley, then breaks off more abruptly to the San MiguelDolores valley on the south.

The plateau changes gradually from a pinyon-juniper or desert type on the north edge to a fair yellow pine forest with increasing elevation, then through Douglas fir to very excellent spruce. The fir forest, however, is represented only by remnants and occupied largely by aspen. A striking characteristic of the middle-lower zone, especially on the south escarpment, is the prevalence of oak-brush.

The Ouray Mountain Sheep and Elk Refuge (1923) covers 40 sq. mi. Several hundred mountain sheep are fed by the people of Ouray each winter. Arrangements made to plant elk during 1922-23. Ouray (D. \& R. G. W. R. R.) from Montrose, is in center of area. Travel from Ouray by horseback; stables, hotels, ranger.

\section{White River National Forest (Colorado)}

The forest is $1 \%$ cut-over and $5 \%$ burned. There is a heavy belt of Engelmann spruce under rim of flattops, with some lodgepole pine at lower elevations. Small bodies of Douglas fir are found in gulches and a body of yellow pine on South Derby Mesa.

The following game refuges are such only by exclusion of domestic stock:

Elk range of about 5000 acres around Sleepy Cat Peak. Elk on this range throughout the summer. Reached via Yampa, also from Meeker, inland town, $45 \mathrm{mi}$. from Rifle (D. \& R. G. W. R. R.) 
daily stage or Craig (D. \& S. L. Ry.) tri-weekly stage.

Deer refuge areas, in Trapper's Lake region, four of about 1000 acres each. Black-tailed deer during July, August and September. Best seen July 15 to August 15. Best areas west of Trapper's Lake. Reached by saddle and pack, $30 \mathrm{mi}$. from Yampa (D. \& S. L. Ry.). Outfit at Yampa; hotel, ranger.

Mountain sheep refuge of about 2000 acres on Sheep Mountain. Bighorn sheep can be easily seen throughout summer. Big open country surrounded by rim rock. Can be connected with trip to deer refuges. Outfit at Yampa.

\section{Bighorn National Forest (Wyoming)}

This forest covers the Bighorn Mountains in north central Wyoming. The lower portions of the uplift are mainly sedimentary rocks, while the upper belongs to the Archean.

The forest on the slopes up to $7500 \mathrm{ft}$. is western yellow pine, Douglas fir, limber pine and some juniper in mixed stands. The upper portions are covered with extensive bodies of lodgepole pine and Engelmann spruce. Open grass and sagebrush parks are extensive and are grazed by domestic stock. Grassy meadows and willow thickets are frequent.

Game animals are elk, deer, bighorn sheep, black and grizzly bear. Original elk herd reinforced by artificial stocking in 1912; have increased so that they are again plentiful on north end of Forest. Bighorn sheep scarce; only few bands remain around the peaks in central part of Forest. A few grizzly bear on the north end. Fur-bearing animals include coyote, beaver, lynx, fox, marten, and weasel. Wolf and cougar are scarce.

Winter Elk Range on Horse Creek in Tongue River Canyon. Includes approximately 1600 acres. Domestic stock is excluded by natural barriers and fencing. 500 elk use it as a winter feedingground. Reached by (a) from Sheridan to Dayton, $25 \mathrm{mi}$. thence $8 \mathrm{mi}$. (w) or (h).

\section{Hayden National Forest (Wyoming)}

The Forest lies astride the Sierra Madre Range in southern Wyoming, extending a few miles into Colorado. The formation is almost wholly granitic.

It is estimated that lodgepole pine occupies 135,000 acres, Engelmann spruce 30,000 acres and aspen 100,000 acres of this forest, the last on the west slope. During the mining boom most of the north end was burned and cutover. A large part of this area is restocking naturally with lodgepole pine. On Big Creek watershed some virgin lodgepole is to be found.

Native trout in streams on west side of the Forest. Elk and black-tail deer are present but not abundant. Bighorn sheep not seen in recent years. Antelope present on sheep range north of Forest. Black bear, coyotes, bobcats, cougar, beaver, marten, mink and fox are fairly abundant. Sheep and cattle graze almost the entire Forest.

In 1924 small fenced areas have been set aside to determine effect of grazing on the forage types and on progress of pine reproduction. Obtain details of location from Supervisor.

Between the Hayden and Medicine Bow Forest lies the broad and beautiful valley of the North Platte, abandoned ages ago when that stream found a new channel well back in the mountains to the east. The remarkable situation can best be viewed on the Rocky Mt. highway from Laramia, by which Encampment may also be reached.

\section{Medicine Bow National Forest (Wyoming)}

Nearly this entire area is accessible to stock and is grazed by cattle and sheep. $85 \%$ of entire area is timberproducing, and of this $95 \%$ is lodgepole forest, mostly virgin though this Forest has been center of tie-producing region for many years. $9 \%$ of area has been burned within 30 to 50 years and bears dense stands lodgepole reproduction. Forpark is center of tie industry, on C. W. \& E. Ry. from Laramie, which reaches other points within Forest. 
Cinnabar Park Range Rotation Area. A semi-permanent fenced area of 160 acres in which for several years the development of the forage plants by natural reseeding has been assisted by careful study of the proper season for grazing. A dry grassy park at $9600 \mathrm{ft}$. surrounded by timber. Reached by stage from Albany (C. W. \& E. Ry.) to Holmes, where Forest Ranger will furnish accommodations and directions.

Foxpark Permanent Sample Plots, an area of 5 acres in lodgepole forest on which various methods of cutting were practiced in 1909, one-fourth also being left in virgin condition. Permanently fenced. Presents interesting reproduction study. On outskirts of Foxpark where ranger and fair accommodations may be had. Within a mile are also thinning experiments in lodgepole sapling stands.

\section{Shoshone National Forests (Wyoming)}

The elevation is 7000 to $13,000 \mathrm{ft}$.; rock formations are granite, limestone and conglomerate. Extensive areas of open grassland, mountain meadows, lodgepole pine, Engelmann spruce, limber pine and Douglas fir forests.

Common animals are elk, deer, bighorn sheep, pronghorn antelope, moose, bear (grizzly and black), cougar, coyote, lynx, and bobcat. Very large areas are closed to or inaccessible to domestic stock. Practically all points of interest are reached from Cody but a number may be approached from the Yellowstone National Park, which adjoins on the west.

Hoodoo State Game Preserve, 120,000 acres, used as summer range for deer, elk and bison. Reached from Cody; 15 miles auto to Two Dot ranch, thence $30 \mathrm{mi}$. by horse or wagon to Painter Ranch or Sunlight R. S., thence by pack outfit up North Fork Shoshone River. Can also be reached by pack outfit from Cooke, Montana or through Yellowstone Park.

Shoshone Game Preserve. 500,000 acres of summer and winter range for elk and deer. (Elk Fork is main winter elk range.) Accessible from Cody via auto. Good auto road to Wapiti, Canyon Cr. R. S., Wapiti R. S., Holm Lodge and Pahaska Tepee. From these places pack outfit is necessary. Also reached from Cody to Valley by fair auto road and pack outfit from that place.

Carter Mountain Game Preserve, 150,000 acres of summer and winter range for elk, deer, and bighorn sheep. From Cody by auto and pack outfit via Valley, Wyoming, Belknap R. S., South Fork R. S. and Ishawooa.

U. S. Bird Refuge, 10,000 acres, including Shoshone Reservoir and a narrow fringe of shore. Reached from Cody (a) $9 \mathrm{mi}$.

\section{Washakie National Forest (Wyoming)}

Two blocks of land east of Continental Divide at headwaters of Popo Agie and Wind Rivers, the latter forming a large basin.

The prevailing forest type is lodgepole pine, yellow pine being only poorly developed at low elevations, the Douglas fir forest represented by remnants only, while at high elevations are large bodies of spruce almost wholly inaccessible. Very large lodgepole cutting operations on Wind River, using river for transport to the railroad.

There are no reserves of interest but three trios of sample plots have been established in lodgepole cutting areas, to show effects of thinning. Near Sheridan Creek and Dunoir ranger stations $20 \mathrm{mi}$. (a) from Dubois, $100 \mathrm{mi}$. from Riverton, $100 \mathrm{mi}$. from Lander. Dubois is on Rocky Mt. Highway to southern entrance of Yellowstone.

\section{Black Hills and Harney National Forests (South Dakota)}

An isolated range of mountains approximately $100 \mathrm{mi}$. long by $60 \mathrm{mi}$. wide, rising to $7000 \mathrm{ft}$., surrounded by semi-arid plains. Intensely interesting geological structure. Within a range of a few miles one may pass from fossiliferous sedimentary deposits through gypsum, limestone, sandstone, conglomerate, quartzite, porphyries, 
schists, and slates to the igneous granite core of the Black Hills uplift. Nearly all parts of Forests are accessible by auto from towns on the two railroads and good accommodations may be had. Rancers scattered throughout the Hills

Western yellow pine constitutes $95 \%$ of the forest. Has a habit of growth resembling lodgepole pine in the character and density of stands. Forest $50 \%$ cut-over and $15 \%$ burned. Meeting ground of eastern and western floral and faunal species.

Mt. Roosevelt State Game Refuge of approximately 50,000 acres is easily reached from Deadwood. Affords abundant food for deer, elk, and game birds, good cover and also open feeding grounds. Contains the beautiful Spearfish Canyon summer resort, where the game is seen by tourists. Beaver colonies are numerous in Canyon and other fur-bearing animals present (muskrat, mink, marten, skunk), are all protected.

Several small permanent sample plots representing natural and thinned yellow pine 25 to 200 years old, in vicinity of Nemo, Merritt and Benchmark, furnish examples of forestry practice. All reached most quickly by auto from Deadwood.

The So. Dakota State Park represents one of the best State Forest properties and game preserves in the country. A portion has been fenced as a game preserve in which are herds of deer, elk, buffalo and antelope; an attempt is being made to stock it with moose. Topography and forest cover similar to rest of Black Hills region: a well timbered and very picturesque locality developed by the State for recreational purposes as well as a game preserve. An extension of its boundaries takes in Harney Peak and the Sylvan Lake region, the latter purchased by the State and run as a summer resort. Reached from C. \& N. W. R. R. at Fairburn, or C. B. \& Q. R. R. at Custer. Most accessible from Custer. Excellent hotel facilities at State Park lodge and at Sylvan I ake\|.
Custer Federal Game Sanctuary, an area of 30,000 acres around Harney Peak and Sylvan Lake. Practically entire area covered by virgin forest. Most of it inaccessible to lumber operations owing to the roughness of the country.

Wind Cave National Monument, approximately 11,000 acres, adjoins Harney Forest on the southeast corner. Principal feature is Wind Cave, containing over $100 \mathrm{mi}$. of cavern. The park contains bison, elk, pronghorn antelope and deer. Very little timber, most of the area being prairie. Nearest town Hot Springs, good hotel accommodation (Branch lines of C. B. \& and C. \& N. W. R. R., from Minnekahta and Buffalo Gap, respectively). Auto roads to Cave from Hot Springs, passenger bus twice daily in the summer months.

Jewel Cave National Monument. Limestone caves of large extent; undeveloped. Forests of western yellow pine and an occasional limber pine. Reached (a) from Custer over passable road.

\section{Nebraska National Forest (Nebraska)}

The two divisions are the Bessey and the Niobrara. The Bessey Division is in very rough sandhills with scant vegetation. Niobrara Division more rolling with better soil and vegetation.

There are some native hardwoods, also yellow pine and red cedar; largely grassland. 10,000 acres have been artificially afforested, principally with jack and western yellow pines.

Small number of native deer on Bessey Division. Prairie chickens, sharp-tailed grouse, and quail. Entire Forest set aside as a State Bird and Game refuge.

The following reserves in Nebraska have no connection with the National Forest:

Niobrara Game Preserve, 20,000 acres, along scenic Niobrara River, $4 \mathrm{mi}$. east of Valentine, a city of 2000 population on C. \& N. W. R. R. Preserve formerly Fort Niobrara, U. S. Biological Survey protecting native birds and animals and breeding herds of elk and bison numbering about fifty of each. 
Native yellow pine and hardwood timber in canyons; balance grass-covered sandhills and tableland.

Scottsbluff National Monument, approximately 1900 acres. Central attraction is mountain $4667 \mathrm{ft}$. above the sea and $800 \mathrm{ft}$. above the river. Most of area is of rugged nature. "The bad lands" consist of twisted and corrugated rocks of the White River period, several hundred acres lying between the mountain and the river. Fossils of the Eocene and Oligocene are quite abundant. Historically the mountain has great interest. Reached from Scottsbluff (C. B. \& Q. Ry. from Sterling or Alliance or Gering) (U. P. R. R. from No. Platte) approximately $2 \mathrm{mi}$.

Fontenelle Forest, about 2000 acres, $5 \mathrm{mi}$. south of Omaha. Native hardwood timberland, oaks, hickory, elm, sycamore, etc. About the only native hardwood forest being preserved in its natural state for use of nature lovers and citizens of the state. A rich field for botanists and also has interesting archeological history. Fontenelle Forest Association, Omaha, owner. Reached (a) or trolley from Omaha.

\section{Minnesota National Forest (Minnesota)}

The characteristics of the area are best shown by the following typical reserves:

Star Island Game Refuge, 1200 acres (entire island). Lake Helen about 200 acres in extent, lies within this island. Virgin stand of timber, chiefly white and Norway pine, with some jack pine and hardwoods. Reached from Cass Lake by motor boat.

Ten sections of virgin forest, comprising the shore line of Cass Lake, Pike Bay and connecting lakes. A virgin stand of timber 200 years old, to be cut only as it dies or is blown down; consists of chiefly white and Norway pine, some jack pine and hardwoods, and swamp species.

Itasca State Park (Game Refuge) 20,000 acres, a virgin stand of timber, chiefly white and Norway pine, some jack pine and hardwoods. Lake Itasca is the accepted source of the Mississippi
River. Reached from Arago by bus from Park Rapids (G. N. Ry.) or Bemidji (G. N. R., Soo Line and N. P.).

\section{Superior National Forest (Minnesota)}

Ely, centrally located for western half of Forest. Grand Marais, port on Lake Superior (east or Lake Superior entrance), good accommodations, no railroad-on North Shore Drive (auto road). Forest ranger. Travel after leaving railroad mainly by boat, canoe or launch, or by auto and boat. Boats necessary for all or parts of every trip. $80 \%$ burned, $10 \%$ cut-over.

Characterized by a network of thousands of lakes and streams, mixed coniferous and broad-leaved forests, swamps and rock ridges. The forest consists of white, Norway and jack pines, white and black spruce, tamarack, cedar, birch, poplar and maples. Game Refuges.

Superior Game Preserve covers a large part of the Forest and extends beyond its boundaries, with acreage of $1,290,000$. Principal game animals are moose, caribou, white tailed deer, black bear, snowshoe hare, red, gray, and flying squirrels, and grouse (ruffed, pin-tailed, spruce hens). Fur-bearing animals are marten, fisher, weasel, muskrat, mink, wolf (timber), coyote, red fox, beaver, lynx, and bobcat. Principal fish are pike, pickerel, bass, and trout (lake and brook).

\section{Michigan National Forest (Michigan)}

An extensive area, mostly of sand "plains" 100 to $200 \mathrm{ft}$. above Lake level, once bearing excellent forests of Norway pine (Pinus resinosa) and some white pine (Pinus strobus).

It has been cut-over and repeatedly burned in past years so that there remains only a few scattered clumps of Norway pine, largely failing to reproduce, but with much of the ground occupied by jack pine (Pinus divaricata) and scrub oak. Ecologically most interesting for observations of vegetational succession following establishment of forests by planting. 


\section{IDAHO}

\section{By R. A. MuttKowski}

\section{GENERAL FEATURES AND ORIGINAL BIOTA}

\section{Physiographic regions}

Idaho might be compared to a chair, the back and seat of which consist of mountain ranges along the eastern border. The area between the upper and lower rung of the chair is occupied by a great plateau, the Snake River Plains.

In the northern panhandle the mountains are relatively low, chiefly of the round top type. Toward the middle of the state, the "seat of the chair," the mountains grow very rugged and precipitous.

Throughout the state the bases of the mountains lie in volcanic lava, upon which are heaped the aeolian soils. This is seen in the Snake River Plain which is a built-up plain formed by outpouring sheets of tertiary lava interbedded with accumulated sediments of the tertiary Lake Payette, which two processes of upbuilding were contemporaneous within the basin, out of which this plain was formed. Through this plain the Snake River eroded a canyon, and finally drained this geologic lake. Except for the extreme southeastern part.

\section{Plant and animal communities}

All of the original types of communities are still available for study. Originally, two-fifths of Idaho comprised the forests and mountains, two-fifths the arid plains, and one-fifth the fertile prairies. These proportions have changed somewhat in regard to the extent of the forests and the arid plains, due to lumbering, grazing, irrigation and reclamation.

a. Forests. There are two types of forests in Idaho, the western whitc pine forests of the north (see page 210) extending from the Canadian boundary to the Clearwater Preserve: and the western yellow pine forests in the central and southern parts of the state. In central and southern Idaho especially the forests were interspersed with great fertile prairies, called Camas Prairies, by the early travellers, from their continuous Camas blue.

In the montane forests of the northern part of the state are found characteristically the black bear (Ursus americanus group), grizzly bear, wolverine (Gulo luscus), marten (Martes americana group), fisher (Martes pennanti group), weasel (Mustela sp.), marsh shrew (Neosorex), masked shrew (Sorex personatus group), red-backed vole (Evotomys), mountain lemming-vole (Phenacomys orophilus), chipmunks (Eutamias spp.), pine squirrel (Sciurus hudsonicus richardsoni), flying squirrel (Glaucomys sabrinus group), yellow-haired porcupine (Erethizon epixanthum group), snowshoe hare (Lepus bairdii), moose (alces americana group), and blacktailed deer (Odocoileus).-L. R. D.

Among the reptiles and amphibians occurring in the Montane are the rubbersnake (Charina bottae), a garter-snake (Thamnophis), the western frog (Rana pretiosa), the western toad (Bufo $b$. boreas), and a salamander (Ambystoma macrodactylum).-H. T. G.

Idaho and Utah are filled with small mountain ranges which are for the most part isolated by stretches of arid territory. Each range usually contains a group of species peculiar to itself and in many cases certain species are apparently confined to some one of these ranges. The genus Oreohelix here reaches its greatest development in species. While little study has been given to the ecological features of distribution, a good idea of the distribution of the genus Oreohelix among the mountain ranges may be obtained from the paper by Henderson and Daniels, Proc. Acad. Nat. Sci. Phil., 1916, pp. 315-339.-F'. C. B.

b. Yellow pine forests. (See page 209.)

c. Alpine tundra. The central peaks carry snow and ice fields the year round. The vegetation is typically alpine. 
The principal mammals of the Alpine summits above timberline are the Rockly Mountain goat (Oreamnos americanus subsp.), bighorn sheep (Ovis canadensis group), hoary marmot (Marmota caligata group), and pika (Ochotona).

d. Prairies. (See under Oregon.)

e. Sagcbrush semi desert. The great sagebrush region of Idaho is traversed by the Snake river. It is a lava desert, with great extinct craters, solidified lava flows, canyons, crevices, caves with ice, super-chilled springs.

They have as characteristic mammals the coyote (Canis lestes), grasshoppermouse (Onychomys leucogaster subspp.), pocket-mouse (Perognathus), kangaroorat (Dipodomys), ground-squirrel (Citellus spp.), sage chipmunk (Eutemias minimus pictus), pigmy rabbit (Brachylagus idahoensis), white-tailed jackrabbit (Lepus townsendii), black-tailed jackrabbit (Lepus californicus group), cottontail rabbit (Sylvilagus muttallii group), and pronghorn antelope (Antilocapra americana).-L. R. D.

Reptiles include the collar lizard (Crotaphytus collaris baileyi), the leopard-lizard (Crotophytus wislizenii), the swifts (Sceloporus graciosus gracilis and $S$. occidentalis biseriatus), the rattle-snakes (Crotolus oreganus and $C$. confluentus), the bull-snake (Pituophis $C$. catenifer), the racer (Coluber constrictor mormon), and the horned toad (Phyrnosoma $d$. douglassii and $P$. platyrhinos). $-H . T . G$.

In the mountains there are innumerable small lakes, cascades, and falls. Along these streams there are springs both hot and cold, notably so in the central and southern regions. Larger lakes are Payette, Coeur d'Alene, Pend Oreille, Priest and Bose. Idaho grows higher from north to south, with an elevation of about $1800 \mathrm{ft}$., in the north to about $5000 \mathrm{ft}$., in the south. The only "low" spot is at Lewiston (westcentral, near the Washington boundary), lying in a canyon of $700 \mathrm{ft}$. elevation. The Snake River Plains also slope down from east to west, so that Idaho slopes down from southeast to northwest, from 5000 to $1800 \mathrm{ft}$.

f. Aquatic communities. The aquatic communities present perhaps the greatest variety of all. In the mountains there are innumerable alpine lakes which form the headwaters of precipitous creeks. The creeks have dug deep canyons, through which they tumble in rapids, falls, cascades, with occasional placid stretches. Such lakes and streams are most numerous in the Salmon River and Clearwater River drainage. Swamps are found in a number of the valleys throughout Idaho, although none of them occupy more than a few square miles of area.

The fresh water mollusca are abundant, especially in the northern part of Idaho, in Lake Pend Oreille, and the rivers and streams flowing into and from this lake. Nearly all are related to those of eastern North America, and include the genera Lymnaea, Planorbis, Rhysa, Amnicola, Valvata, Fluminicola, Ferrissia, Hydrobia, Pisidium, Sphaerium. Only a few Naiades are found nor are the Pleuroceridae abundant, as both of these groups are in the central part of the United States. A few species are peculiar to the region. For the ecological distribution of the Lymnaediae, see Baker, Monograph of Lymnaediae, 1911.-F. C. B.

\section{I1. PRESENT BIOTIC CONDITIONS}

Except for the American bison and perhaps the prong-horned antelope, the original biota of Idaho are found in at least a part of Idaho, chiefly in the mountain fastnesses and the Snake River Desert.

Along the border of Washington and in the central valleys of northern Idaho three factors have tended to alter the biota, or at least to diminish their extent. These are, first, the great fires which from time to time have swept over millions of acres and left barren wastes which are slow in reforesting themselves. The second factor was the discovery of gold and other precious 
ores. This, with its need for clearings for the settlements, timber for buildings, fuel, and the mines, has thinned the forests, while the sewage from the settlements, the wastes from the mines and the fumes of the smelters polluted land and stream and killed plant and animal life for miles around. Lumbering has been the third factor in the withdrawal of the biota in the north. In the wake of cutting has followed agriculture which has still further restricted the natural areas. In the same areas in central and southern Idaho irrigation and reclamation have gone hand in hand and turned many arid sage-brush prairies into fertile farms and orchards.

\section{POLLUTION}

On the whole Idaho streams have suffered relatively a slight pollution. There are streams, notably in the mining regions of the north, east and southwest, that receive considerable waste and refuse from the mines. Thus, the Coeur d'Alene and Clearwater Rivers of northern Idaho, before they pass into Washington, receive both sewage and mine refuse from the small cities along the lower stretches of the streams.

\section{NATURAL AREAS}

\section{Idaho State Game Preserves}

The Idaho State Game Preserves are 7 in number and cover an area of over 2000 sq. mi. or approximately 1,500,000 acres. In these preserves all game animals are protected. Hunting is prohibited except by the game wardens and duly authorized persons.

*Preserve on South Fork of Payette River. (B2.) About 456 sq. mi.292,000 acres. Located in northern portion of the Boise National Forest at the base of the Saw tooth Range. All hunting, trapping, and killing of any species of game and birds is forbidden.

Game animals protected: bear, lynx, wolverine, fox, otter, beaver, marten, mink, and fisher.
Predatory animals permitted to be destroyed by game wardens: mountain lion, timber wolf, coyote, wild cat.

*Black Lake Game Preserve. (A3.) About 350 sq. mi. $-225,000$ acres. Located in north portion of Snake River Section of the Nez Perce National Forest. Since it is very inaccessible, this promises to continue as a permanent preserve. All animals protected here. Beaver, otter, marten, fisher, fox, mink, wolverine.

Predatory animals; cougar, bear, lynx, wolf, coyote, and wild cat may be destroyed by game wardens only.

*Lewiston Orchards Preserve. (C3.) About 19 sq. mi.-12,000 acres. Located in Nez Perce, and covering the depression in which the Lewiston Orchards lie.

In this preserve birds of all kinds are protected, including game birds, water fowl, and song birds.

*Big Lost River Game Preserve. (B2.) About 432 sq. mi. $-290,000$ acres. Located in north and northeastern portion of Sawtooth National Forest.

Birds include grouse, wild geese, wild ducks, pheasant, partridges, quail, prairie chicken, sage hen, swan, snipe, plover, eagle, mourning dove, hawks, crow, and magpy.

Mammals include: deer, elk, caribou, moose, mountain goat, bighorn sheep, pronghorn antelope, beaver, otter, marten, fisher, fox, and mink, cougar, black bear, lynx, wolverine, wolf, coyote, wild cat, rabbits, badger, weasel, and skunk.

*Selway State Game Preserve. (A2.) About 725 sq. mi. 460,000 acres. Located in northern part of Selway National Forest.

*Big Creek Game Preserve. (B2.) About 192 sq. mi.-125,000 acres. Located in Salmon National Forest.

*Pocatello Game Preserve. (B2.) 49.5 sq. mi. $-61,680$ acres. Located southeast of Pocatello in Cache National Forest.

Owyhee County. (Cl.) (B1.) An available Game Preserve, of about 5000 sq. mi.

This county constitutes the southwestern corner of Idaho, comprising 
nearly 8000 sq. mi. It has recently been much mentioned as a possible game preserve, especially for antelopes. Oregon Short Line to Nampa, a spur to Silver City, then by wagon road to Riddle, near the Indian Reservation, or by road along Bruneau River.

\section{Springs}

Idaho has literally hundreds of thousands of springs.

Thousand Springs Valley. (B4.) Lie in East Fork Basin of East Fork of Salmon River. Innumerable hot and cold springs here. There are several "Warm Springs Creek." On road from Ketchum to Stanley, then Salmon River Highway to Springs.

Guyer Hot Springs. (D5.) Huge mineral springs, and Warm Springs Creek near Ketchum Springs commercialized. Piped to houses for heat. Oregon Short Line R. R. to Ketchum. Scenery here marvelous, the "saw teeth" of the Sawtooth Range conspicuous.

Hailey Hot Springs. (D5.) Near Hailey, Blaine County. Somewhat commercialized. Piped to Hailey for heat.

Hot Springs in Elmore County. (B4.) Within $8 \mathrm{mi}$. northeast of Mountain Home. $103^{\circ}$ to $167^{\circ} \mathrm{F}$. Mud spring northwest of Mountain Home. Fairly large. Also natural cave of considerable size. Near good auto roads. $-E . F$. Mason.

South Fork of Boise River between Pine and Featherbille has half a dozen large hot springs along road (D4). One piped for a large outdoor bathing pool. Fish spring flows hot from small islet in Boise River.

Soda Springs and Vicinity. (B5.) Originally famous for its Soda springs, has been commercialized to a large extent. The region "was a miniature Yellowstone Park."

Lava Hot Springs.

County, a state. (B5.) In Bannock Short Line R. R.

\section{Caves}

Among other attractions, Idaho has a large number of caves. Unfortunately, very little is known of most of them, as they have been little explored. A number of caves are found in Caribou County, in Franklin County (perpetual ice), Elmore County. Gooding County (perpetual ice), and Valley of the Moon in Blaine County.

\section{Sand dunes}

Sand dunes covering considerable area are found in Freemont County north of St. Anthony. These adjoin some old lava fields and craters, and are intermingled with good grazing prairie. At least 20 sq. mi. Local roads from St. Anthony north.

\section{Lava flows}

a. The Sinks. (B4.) The lava flow in the region of the Snake River Desert has produced a phenomenon called the "Sinks" where considerable streams appear from the surface and continue their way underground to the Snake River miles away. Located in Butte County some miles below and east of the Howe at the edge of Snake River desert. There the Big Lost River and Little Lost River disappear into the ground, to reappear at intervals. Further up the Birch Creek Sinks can be found. These streams here go under the lava to the depth of hundreds of feet and emerge finally as gigantic springs on the sides and bottom of the Snake River Canyon $60 \mathrm{mi}$. away. Reached best from Arco on the Oregon Short Line, then by auto road through Howe to the various sinks.

b. Lava Fields. (B2.) Fields of rolling or broken lava are found in a number of places in southern Idaho; in Freemont, Minidoka, Bingham, Owyhee, Bonneville Counties.

c. Craters. (A3.) May be found in most of the southern counties, also in the central counties northward to Idaho County.

d. Buffalo Hump. (A3.) A Ione butte in the middle of Idaho County, active in 1866, with lava flow accompanied by tremors. Active in AugustSeptember, 1881. Reached from Grangeville, then by road to Concord. e. Snake River Desert. (B3.) (B2.) About 3400 sq. mi. Available. Occupies middle center of Idaho, particularly the region north of the Snake River extending from Wood River northeast past the Sinks of the Big Lost River.

Lava fields partly covered with sagebrush, with patches of small trees. Sagebrush fauna most abundant. Big Lost River, Little Lost River, Camas Creek and Birth Creek enter the desert in the north, but soon become lost in the "sinks;" these are fissured areas where shallow lakes form in spring, which later disappear. According to geologists there is a subterranean bed in which the streams flow hundreds of miles southwest and west and reappear as gigantic springs from the north wall of the Snake River Canyon, in the $18 \mathrm{mi}$. between 
Shoshone Falls and Bliss. Smaller streams than those mentioned also disappear.

A particular feature are the crevices which interline the lava fields in the desert, from two to fifty feet wide, from thirty to hundreds of feet in depth, and extending for long distances. In the larger crevices there is a distinct fauna of snakes, lizards, insects, and other animals.

Between Blackfoot and Big Lost River there is a Juniper forest of $175 \mathrm{sq}$. mi. From Arco south a belt $15 \mathrm{mi}$. wide and 50 long, at least 800 sq. miles of pine and fir, extends to Cinder Buttes. Smaller patches at many points. Area adjoining forest with bunch grass, not sagebrush, forming splendid pasture land.

Sand dunes occur in a great many places and great stretches of recent flows of lava in many parts of Plains.

f. Big Butte, $5600 \mathrm{ft}$., and Pillar Butte, $5300 \mathrm{ft}$., are famous land-marks on the plains and rise directly from rolling plain. Big Butte is unscalable. Approach from many points. Short trips inward easily arranged by automobile, but better with pack-horses. (See "Valley of the Moon.")

"The latest evidence shows molten rocks in recent historical times, perhaps not over one hundred years ago. It came up through volcanic cones, out of which highly liquid lava in vast quantities flowed away in all directions where it hardened in a horizontal position. There are scores of vents, cones, and craters within this area, Big, Middle, and East Buttes being conspicuous examples."-Russell.

\section{6. "Valley of the Moon"}

$\dagger$ About 100 sq. mi. a proposed National Monument. Comprises a portion of the western end of the Snake River Desert, named "Valley of the Moon," especially the northwest region known as the "Craters," because of its marked resemblance to the conventional astronomers pictures of the moonscape.

Topography of barren lava fields, canyons, hills, craters. Area is exceedingly rough, in places utterly depressing through its somber coloration, in others startling, through the brilliant blues and vermilions. One crater known as Echo crater $700 \mathrm{ft}$. deep. Close by 63 craters can be seen from one spot. An extinct volcanic and lava flow. Ice caves plentiful, icy springs, and short streams.

A dwarf bear of special interest. Pines, some sagebrush, and a nearly white "pigmy buckwheat."

This region has never been explored and was virtually rediscovered by $R$. W.
Limbert, of Boise. After a trip into the desert in 1917 he made several expeditions. Reported that in Summer, 1921, an expedition of the National Geographic Society entered the desert. It is proposed to create a national monument of the whole or a portion of this area.

Approach from many points: from the south from a number of towns between Idaho Falls and Minidoka on the Oregon Short Line R. R. west from Shoshone to Hailey, north from Arco. The highway from Hailey to Arco passes within four miles of the lava fields, where some of the craters can be seen. $-R$. A. M., after R. W. Limbert.

\section{REFERENCES}

Bancroft,H. H. History of Washington, Idaho, and Montana. In Vol. 10 of Collected works, Idaho, pp. 393$588,1889$.

Bailey, F. M. Handbook of the Birds of the Western United States. Houghton, Mifflin Co., 1921, pp. 590, 33 plates, 601 text figures.

Fountain, Paul. The Eleven Eaglets of the West. New York (Dutton \& Co.). 1906. Snake or "Mad" River, pp. 91-99. Idaho, pp. 125-153. Description of journey made in late seventies.

Rees, John E. Idaho: Chronology, Numenclature, Bibliography, pp. 125. Published by the author, Salmon, Idaho.

Merriman, C. H., and Stejineger, L. Biological Reconnoissance of South Central Idaho. W. A. Fauna, no. 5, 1891.

Limbert, R. W. The Valley of the Moon, in Nat. Geogr. Mag., 1924.

\section{ALBERTA}

\section{By A. B. Connell}

\section{GENERAL}

The Province of Alberta, the westernmost of the prairie provinces of Canada, extends from the Montana boundary north to the 60th parallel of north latitude. The 110th meridian of longitude forms the eastern boundary and the province extends west from this line to the crest of the Rocky Mountains in the south and to the 120th meridian in the north. The area is approximately 260,000 sq. mi. 


\section{PHYSIOGRAPHY}

The province may be divided into four physiographic regions.

1. The Rocky Mountain region: In the south of the province the mountains occupy a narrow zone some $25 \mathrm{mi}$. in width extending from the front ranges westward to the British Columbia boundary upon the Continental divide. The mountains trend sharply to the northwest until the 120th meridian is reached near the 54th parallel of latitude. At this point the provincial boundary turns northward and the Rockies continue northwesterly into British Columbia. The montane region of Alberta broadens to the north with a decrease in elevation. The higher peaks reach an elevation of over 11,000 $\mathrm{ft}$. The passes vary from $7000 \mathrm{ft}$. at the South Kootenay pass in the south to $3700 \mathrm{ft}$. at the Yellowhead pass in the north.

2. The Foothill region: The foothills are extremely narrow or almost lacking near the International boundary in the south. As they follow the mountains northward, however, they broaden out forming an extensive area of low rolling ridges with a general northwest and southeast trend.

3. The Alberta plateau: The Cretaceous plains extend eastward from the foothills forming a high shelf-like plateau which sinks gradually from an elevation of $3500 \mathrm{ft}$. in the southwest to $1500 \mathrm{ft}$. in the northeast. Along the eastern boundary of the province south of the North Saskatchewan River the elevation averages $2000 \mathrm{ft}$. The larger rivers have cut broad and deep valleys in crossing the plateau eastward from the mountains. The valley of the Peace River in the north of the province is in places upwards of $700 \mathrm{ft}$. in depth and over two miles in width from rim to rim.

4. The northeastern portion of the province: This is occupied by a comparatively low flat plain having an average elevation of $800 \mathrm{ft}$. above sea level. The western portion of Lake
Athabaska and the lower course of the Peace River lie within this area.

\section{BIOTIC CONDITIONS}

The vegetation of Alberta may be divided broadly into five climatic formations.

1. The Alpine belt extends along the higher mountains above timber line. Climatic conditions are severe with low temperatures, a short growing season, high and dry winter winds and low atmospheric pressure. The climatic cli$\max$ is meadow-like and characterized by heaths and saxifrages.

2. The Montane belt occupies the slopes of the mountains from timber line to the eastern border of the foothills. The precipitation varies between 20 and 30 in. and occurs mainly in the spring and summer. The climatic cli$\max$ is a xeromesophytic coniferous forest characterized by Engelmann spruce (Picea Engelmannii), western larch (Larix Lyallii), lodgepole pine (Pinus murrayana), white spruce (Picea canadensis) and Douglas fir (Pseudotsuga mucronata). Limber pine (Pinus flexilis) and whitebark pine (Pinus albicaulis) are found on the upper slopes of the higher foothills and outer ranges in the south.

Engelmann spruce gives place to the white spruce toward the north. Western larch occurs well up to timber line south of the Crow's Nest pass. Lodgepole pine in pure stands is very extensive.

3. The great plains in the south of the province are occupied by a xerophytic grassland climax which is an extension northwards of the mixed Prairie Association of Montana. The precipitation is in the neighborhood of 15 in., mainly in the summer. The winters are dry with little snow and marked by many "Chinook winds." This condition extends north from the Montana boundary to and beyond the Red Deer River. Buffalo grass, grama grass and wire grass are present, together with tumble weed and sage brush. (The northern 
portion of the grassland becomes a more mesophytic turf grass prairie association in which wheat grass, wild rye and red top are dominant.-G. D. Fuller.)

4. A transition belt of poplar-savanna fringes the northern border of the grassland region. This belt extends from the foothills eastward across the south central portion of the province to the Saskatchewan boundary. The south boundary of this region runs eastward from a point a short distance south of the town of Red Deer on the C. P. railway between Calgary and Edmonton. The north boundary extends from Whitecourt west of Edmonton northeasterly to the great bend of the Athabasca river some ten miles north of the town of Athabasca, thence southeasterly south of Lake La Biche to the Saskatchewan boundary line a few miles north of the Saskatchewan river. This region has a width north and south of from 100 to $150 \mathrm{mi}$. The characteristic trees are the aspen and balsam poplar. (In the south the trees become smaller and the small aspens in turn give way to willows from 3 to $12 \mathrm{ft}$. in height. This aspen and willow scrub occurs continuously over considerable areas but more frequently exists as scattered clumps and groves in the rather mesophytic prairie.-G. D. F.)

Northwards the trees become more dense and as the southern boundary of the northern coniferous forest is approached more or less dense forests of poplar occur with occasional large areas of meadow and prairie land.

5. The northern coniferous forest extends from the transition region northward to the northern boundaries of the province. The climax is a nesophytic coniferous type. The precipitation is not high but the summers are short and cool and the saturation deficit low. The predominant trees are the white spruce, balsam (Abies balsamea), poplar, paper birch (Betula papyrifera), jack pine (Pinus banksiana), and tamarack (Larix laricina). An interesting condition occurs along the southwestern border of the coniferous forest where it approaches the foothills of the Rockies in the region of the Peace River Valley. Large areas of open prairie land are found here together with a preponderance of poplar in the surrounding forested areas. Some of these openings, such as that known as Grande Prairie, contain upwards of 1000 sq. mi.

The fauna of the province has been modified considerably in the south but comparatively little in the north. Bison (Bison bison), once very plentiful, are extinct in the southern portion of the province with the exception of a large herd in the Buffalo Park Reserve near Wainwright. Several herds of wild wood bison (Bison bison athabascae), however, are still in existence in northern Alberta and have been reported west and south of Fort Smith. Pronghorn antelope (Antilocapra americana) are in existence on some of the smaller preserves. Coyotes are numerous on the open plains. In the northern forest fur-bearing animals and moose (Alces americana) are plentiful. Bighorn sheep (Ovis canadensis), goats (Oreamnos montanus group), grizzly and black bear are found in the mountains. ${ }^{1}$

\section{PRESERVED NATURAL AREAS}

\section{*Rocky Mountain National Park (A2)}

Area 2750 sq. mi. This area extends along the eastern slopes of the Rockies from the Kananaskis Lakes on the south to the Clearwater river on the north. It includes the Sawback, Vermillion, Palliser, Goat and Kananaskis ranges. The peaks range from 9000 to $12,000 \mathrm{ft}$. in altitude. The forest is of the Rocky Mountain coniferous type. Bison, deer, elk, bear, sheep, and goat are found. The main line of the C. P. R. R. west from Calgary traverses the Park. Banff $\ddagger$ is the central outfitting point. Guides, ponies and camp equipment can be obtained there.

\footnotetext{
1 For further information on the fauna of the forested part of the province, see under MacKenzie
} Watershed, page 116, 


\section{*Jasper National Park (A2)}

Area 4400 sq. mi. Eastern slope of the Rocky Mountains. Extends from the Brazeau River on the south north to the Smoky river divide and from the Continental divide on the west to the foothills on the east. The main transcontinental line of the Canadian $\mathrm{Na}$ tional Railway passes through the park.

Jasper is the central outfitting point. Good hotel accommodation, camp equipment and supplies can be obtained there. C. N. R. R. from Edmonton. For information and maps write Superintendent, Jasper Park, Jasper, Alberta.

\section{*Waterton Lake National Park (A2)}

Area 423 sq. mi. Adjoins Glacier National Park at extreme southwestern extremity of the province. Eastern slope of the Rocky Mountains. Reached from Cardston $\ddagger$ on the C. P. Ry. 20 mi. by motor.

\section{*Buffalo Park (A2)}

Area 150 sq. mi. Located in the plains in the eastern portion of the province. Poplar-savanna with much open rolling grassland. The largest herd of bison in Canada is located here. One mi. from Wainwright $\ddagger$ on the C. N. Ry. east from Edmonton.

\section{*Rocky Mountains Forest Reserve}

Area 12,000 sq. mi. This Dominion Forest extends along the entire eastern slope of the Rockies from Waterton Lake National Park in the south to the 54th meridian in the north. The eastern boundary coincides approximately with the eastern limits of the foothills. Both the Rocky Mountains National Park and Jasper National Park are within the boundaries of this forest. The southern portion of the forest south of the main line of the C. P. Ry. is easily accessible from any point along the MacLeod branch of the C. P. Ry. south from Calgary, notably High River, Nanton and Claresholm. Along the Crow's Nest branch Pincher Creek and Coleman are excellent outfitting centers. There is hotel accommodation at all of these points and wagon or motor roads lead to the forest. Travel by wagon along the outskirts of the forest in the south is quite feasible. The interior trails are usually open for pack and saddle animals only. North of the main line of the C. P. Ry. travel is generally by means of pack ponies only. A branch of the C. N. Ry. from Red Deer penetrates the forest along the valley of the Saskatchewan river to Brazeau. Rocky Mountain House is the most suitable outfitting center in this part. The Coal Spur branch of the C. N. Ry. from the main line near Edson enters the northern part of the reserve. The portion of the reserve lying north of the main line of the $\mathrm{C}$. N. Ry. may be easily reached with pack ponies from Entrance. In this case supplies should be taken from Edmonton and ponies obtained locally. The forest is administered by the Dominion Forestry Branch from Calgary. Supervisors' offices are located at Pincher Creek, Rocky Mountain House and Entrance.

\section{*Lesser Slave Forest Reserve (A2)}

Area 4000 sq. mi. The Lesser Slave Reserve lies northwest from Edmonton. It is upon the Alberta plateau beyond the foothill zone. It is a rough residual elevation rising some $2000 \mathrm{ft}$. above the general level of the plains to elevations of $4000 \mathrm{ft}$. or more. It is underlain by soft shale and heavily mantled with drift. The northern coniferous forest extends over these hills. There is a considerable amount of lodgepole pine with scattered areas of muskeg in the depressions. The bulk of the area is well drained and supports an association of spruce and poplar. Lesser Slave Lake at the northern base of this highland supports a considerable fishing industry. Camp outfit required. Outfit at Edmonton. C. P. Ry. to Sawridge. Pack trails over which pack animals can be taken extend into the hills from this point. A detached portion of this forest lies northeast of the lake and 
may be reached from Sawridge whence a pack trail runs north to Wabiscaw. Hotel at Sawridge. The Forest is administered by the Dominion Forestry Branch from Calgary.

\section{*Cooking Lake Forest Reserve (B3)}

Area 40 sq. mi. The Cooking Lake Forest is a small area of wasteland 20 mi. east from Edmonton. It is accessible by motor from Edmonton and is a popular resort.

\section{${ }^{*}$ Cypress Hills Forest Reserve (C3)}

Area 50 sq. mi. This area lies in the southeastern portion of the province upon the boundary between Alberta and Saskatchewan. It is a rough elevated tract rising to a considerable elevation above the surrounding plains. The hills are covered with a forest of lodgepole pine and surrounded by the short grass plains. This is the most easterly point reached by the lodgepole pine in western Canada. The hills are 20 mi. south of Walsh on the C. P. Ry. and southeast from Medicine Hat which is the nearest large outfitting center. They may be reached by motor and camp outfit is desirable.

\section{*Foremost Antelope Reserve (A3)}

Area 9 sq. mi. A small area in the short grass plains of southeastern Alberta. The topography is rough and the soil sandy in places. Sagebrush is common. Both pronghorn antelope and bison are reported on this area. The altitude is $2900 \mathrm{ft}$. The reserve lies west of the Cypress Hills and is $3 \mathrm{mi}$. north of Nemiskam on the C. P. Ry. Hotel at Foremost $10 \mathrm{mi}$. west. Roads are good and the reserve is easily reached by automobile.

\section{*Elk Island Park (A3)}

This small area of 16 sq. mi. lies northeast from Edmonton and adjoins the Cooking Lake Forest on the north. Spruce swamps and bogs are frequent with poplar on the higher ground. Bison, beaver, elk, deer, moose and pronghorn antelope are reported here.
Altitude $2196 \mathrm{ft}$. Lamont $\ddagger$ on the C. N. Ry. $30 \mathrm{mi}$. from Edmonton is close to the Park. Hotel accommodation and equipment may be obtained there.

\section{*Buffalo Lake Bird Sanctuary (B3)}

Area 51 sq. mi. Altitude $2536 \mathrm{ft}$. Located close to Bashaw $\ddagger$ on the C. N. Ry. between Calgary and Edmonton.

\section{*Pakoiwki Lake Bird Sanctuary}

Area 44 sq. mi. Altitude 2893 ft. Located in southeastern Alberta 8 mi. southeast from Etzikom $\ddagger$ on the C. P. Ry. Pronghorn antelope is reported here.

\section{*Birch Lake Bird Sanctuary}

Area 15 sq. mi. Altitude $2228 \mathrm{ft}$. Located two mi. from Innisfree $\ddagger$ on the C. N. Ry. east from Edmonton.

* Lac La Biche Bird Sanctuary (B3)

Area 92 sq. mi. Altitude 1788 ft. Lac La Bicheł station on C. P. Ry. northeast from Edmonton.

\section{* Ministik Lake Bird Sanctuary}

Area 25 sq. mi. Located $25 \mathrm{mi}$. southeast from Edmonton near Tofield $\ddagger$ on the C. N. Ry. Reserve $12 \mathrm{mi}$. distant may be reached (a).§

\section{*Miquelon Lake Bird Sanctuary}

Area 11 sq. mi. Altitude 2427 ft. Located $14 \mathrm{mi}$. north from Camrose. $\ddagger$ on the C. N. Ry. May be reached (a).

\section{*Many Islands Lake Bird Sanctuary (B3)}

Area 21 sq. mi. Altitude 2448 ft. Located in the plains of southeastern Alberta $12 \mathrm{mi}$. north of Walsh $\ddagger$ on the C. P. Ry.

\section{Proposed Forest Reservations}

Proposed Athabasca Forest Reserve. (B2.) Area 7000 sq. mi. This area forms an extension of the Rocky Mountains Forest upon the north. It lies between the present boundary of the Forest and the Grande Prairie settlements to the north and the Lesser Slave Forest to the northeast. The average elevation is over $2000 \mathrm{ft}$. The surface 
is undulating. The forest cover is fairly open with many patches of prairie and meadow land. The forest is an extension of the Rocky Mountains coniferous forest but is mingled to a certain extent with the Northern Coniferous forest which extends southwards from the Lesser Slave Lake region. May be reached from Edson $\ddagger$ or Entrance on the C. N. Ry. west from Edmonton**(h).

Proposed Embarras Forest Reserve. (B2.) Area 700 sq. mi. A proposed extension to the Rocky Mountains Forest in the Coal Spur district south of Edson on the main line of the C. N. Ry. west of Edmonton. Rocky Mountain coniferous forest. Outfit at Edson. $\ddagger$

Proposed Lac La Biche Forest Reserve. (B2.) Area 1400 sq. mi. This area lies northeast from Lac $\mathrm{La}$ Biche and is traversed by the A. \& G. W. Ry. from Edmonton to McMurray. The country is rolling with an average elevation of $1800 \mathrm{ft}$. Northern coniferous forest. Good hotel at Lac La Biche. Camp outfit and pack ponies required.

Proposed Pelican Mountain Forest Reserve. (B2.) Area 700 sq. mi. Situated at the east end of the north block of the Lesser Slave Forest. A rough highland reaching elevations of $3000 \mathrm{ft}$. Northern coniferous forest. May be reached by pack trail from Athabasca $\ddagger$ or by canoe by means of the Athabasca and Pelican rivers. The canoe route is very interesting and not difficult with the exception of the portage at Pelican Settlement.

Proposed Peace River Forest Reserve. (B2.) Area approximately $1000 \mathrm{sq}$. mi. This tract is in three blocks which lie immediately south of the Peace River at the western boundary of Alberta. The country is a high rolling plateau averaging $2500 \mathrm{ft}$. in elevation. Northern coniferous forest. May be reached from Spirit River $\ddagger$ on the Grande Prairie branch of the C. P. Ry. from Edmonton** (h) or (c). Also by boat up the Peace River from Peace River Crossing $\ddagger$.

Proposed Clear Hills Forest Reserve. (A2.) This is a large area comprising over $1000 \mathrm{sq}$. mi. lying north of the Peace River at the western boundary of the Province. The hills form a rough rolling elevation rising to $3500 \mathrm{ft}$. Northern coniferous forest with patches of open country. Peace River Crossing $\ddagger$ C. P. Ry. from Edmonton. Pack ponies and camp outfit required. Trails are rough and poor. Little travel in this region.

Proposed Wapiti River Forest Reserve. (B2.) Area $200 \mathrm{sq}$. mi. A small area of northern coniferous forest at the junc- tion of the Wapiti and Smoky Rivers and south of the Grande Prairie settlement. Four miles south of the town of Grande Prairie $\ddagger$ on the C. P. Ry. north from Edmonton. The northern boundary of the area may be reached by (w) or (a), but the interior is accessible with pack ponies only.

\section{Available areas}

North of the Athabasca River and Lac La Biche Alberta is very thinly settled with the exception of the Peace River settlements west from Peace River Crossing. $\ddagger$ The bulk of this immense area is little travelled except along the main waterways.

Lake Athabasca is easily reached from Edmonton to McMurray over the A. \& G. W. Ry. and thence by boat down the river to Fort Chip'ewyan. The country about the western end of Lake Athabasca is very low and marshy. It is one of the notable localities for waterfowl in the north. The eastern portion of the lake lies within the boundaries of the Laurentian plateau.

The Peace River is reached from Edmonton via C. P. Ry. to Peace River Crossing‡. Regular steamboat service down the river to Fort Vermilion, Lake Athabasca and Fort Smith on the Slave river. Hay River may be reached with pack ponies north from Vermilion. Fort Vermilion may also be reached from Athabasca by way of the Wabisca and Loon rivers.

\section{SASKATCHEWAN}

\section{By John Smith Dexter}

Saskatchewan, the middle one of the three "Prairie Provinces" of Canada, lies between the 49 th and the 60 th parallels of latitude, and between approximately the $102 \mathrm{nd}$ and the $110 \mathrm{th}$ meridians west of Greenwich. It is more than $750 \mathrm{mi}$. from north to south; and along the southern boundary, its width from east to west is some $388 \mathrm{mi}$.

The surface is comparatively level, though gently rolling. The altitude is markedly higher in the southwest corner, where the Province approaches the foothills of the Rockies. In that region (the Cypress Hills) its highest elevation is $4243 \mathrm{ft}$. Wood Mountain, $150 \mathrm{mi}$. farther east, reaches $3371 \mathrm{ft}$. The average elevation in the southwest part of the province is above $3000 \mathrm{ft}$., 
and this region is a portion of the Missouri Coteau.

At the southeastern corner of the province, and north along the eastern boundary to the 52nd parallel, the average elevation is $1700 \mathrm{ft}$., and ascends to about $2500 \mathrm{ft}$. in the Porcupine Hills between the 52nd and 53d parallels. From this point the descent is fairly rapid until a low point of $870 \mathrm{ft}$. is reached where the Saskatchewan River crosses the boundary. North of this point, the ascent is gradual to about $1250 \mathrm{ft}$. at the northeast corner. Lake Athabasca, in the northwest corner, has a level of $700 \mathrm{ft}$., the lowest point in the province. Numerous hills of glacial origin occur in various parts of the province, and rise in some cases nearly a thousand feet above the surrounding territory.

The chief rivers drain into Hudson Bay. The Qu'Appelle, running eastward at about $50^{\circ} 30^{\prime}$ north latitude, is a tributary of the Assiniboine River which joins the Red at Winnipeg. The Saskatchewan has two great branches which rise in the Rocky Mountains west of Alberta. The Churchill River, crossing the Province still farther north, drains a great part of the northern forest, and has its source in central Alberta. Among the lesser rivers, two of special interest are (1) Frenchman River, arising in the Cypress Hills, which empties into the Gulf of Mexico, via the Missouri; and (2) Clearwater, a strong tributary of the Athabasca, that drains to the Arctic Ocean.

The direction of the isothermal lines shows markedly the influences of the Rocky Mts., and of Hudson Bay, for they have a well-defined dip from northeast to southwest. The range of temperature is great, occasionally reaching above $90^{\circ}$ in summer, and below $-50^{\circ}$ in winter.

The annual rainfall in the southwest is from 10 to $13 \mathrm{in}$. in the forested northern half, it is frequently more than $20 \mathrm{in}$.

South of a line drawn across the Province from $52^{\circ} 30^{\prime}$ on the western boundary to $51^{\circ} 45^{\prime}$ on the eastern, the vegetation is typically that of the prairies, with few trees or none, and with grasses predominating. (In its western part, a continuation of the plains of Alberta, page 254; toward the east, passes into the true prairie. North of this line, a belt perhaps 50 to $75 \mathrm{mi}$. wide is called "the park country," and in this belt, dense thickets of aspen and willow are interspersed with typical grassy plains.) (The transition zone of poplar-savanna; see Alberta, page 255, and Manitoba, page 263.)

The forested area includes the rest of the Province (for description, see northern coniferous forest of Alberta, page 255, and Manitoba, page 264). North of a line drawn through the southwest extremities of Athabasca, Cree, Reindeer Lakes, the forest becomes thin, and at the extreme northeast corner of the Province, almost vanishes into the Barren Grounds (see Manitoba, page 264).

Aside from considerable collecting of plants, insects, and birds in the prairie region, a very little collecting of birds in the north by numerous naturalists, and some work on life histories of insects by Prof. A. E. Cameron of the University of Saskatchewan, the province is virgin territory to the naturalist. As for bird life, the southwest corner has been described by F. M. Chapman in Camps and Cruises, and by A. C. Bent in the $A u k$ for 1907 and 1908. P. A. Taverner of the Victoria Museum, Ottawa, Mr. H. H. Mitchell, Provincial Naturalist, Regina, Sask. and others, have collected birds in many parts of the prairies. Still earlier work in this field is well digested in Macoun's Catalogue of Canadian Birds. Cap't, Angus Buchanan, whose book on his 1914 trip through northern Saskatchewan has been published by John Lane, collected birds as he travelled, and his collection has been described by J. H. Fleming in the Canadian Field-Naturalist.

A rich hunting-ground for the naturalist is offered in the prairie pools. At Saskatoon, within 5-minute walk of the biological laboratories of the University, 
the evanescent pools still standing in May from the melted snows of April swarm with all sorts of invertebrates. There are various tiny turbellarians, some of which are filled with Zoochlorellae. Especially abundant are the small crustacea ns. including Branchipus, Lepidurus, Estheria, and countless daphnids. Some of the pools are tinged red by myriads of Canthocamptus sp. and by the huge Diaptomus shoshone.

Forest reserves and game sanctuaries have been set aside to a fairly satisfying extent. These regions are almost untouched by civilization, except in the form of local forest fires. They cannot be advantageously studied without a full camp equipment. They are, naturally, located on land ill-suited to agriculture in regions of hills or of marshes or both, and all of them have abundant supplies of water in the form of sloughs or lakes. (For information regarding animals of the northern part of the province see index account of Mackenzie Watershed page 116, and Seton's Life Histories of Northern Animals (Scribner's).)

\section{NATURAL AREAS}

\section{The Forest Reserves}

The Dominion Government has set aside in Saskatchewan, Forest Reserves totalling in area some $9000 \mathrm{sq}$. mi. In the following descriptions, the areas are only approximately estimated in most cases. Two parallel lines, thus \|, indicate "camp outfit necessary."

${ }^{*}$ Cypress Hills, No. 1. (A4, 1.) 54 sq. mi. (Described with *Cypress Hills, No. 2. $3200-3700 \mathrm{ft}$.)

Maple Creek $\ddagger$, on the C. P. R., with Post Office, stores, is $25 \mathrm{mi}$. (a) .

Cypress Hills, No. 2. (A4.) 18 sq. mi. The two Cypress Hills Reserves are rather-inaccessible, being in the arid sandhills of southwestern Sask. Lodgepole pine, white spruce, birch, aspen, black poplars make up the forest. Small cacti occur. Antelope, cougar, elk, lynx, and timber wolves are found, though not abundantly. The first two named, are found nowhere else in the
Province save in this corner. Hawks, coyote, beaver, ground-squirrel, badger, rabbit, prairie chicken, and waterfowl are common. $3200-3700 \mathrm{ft}$.

Maple Creek $\ddagger$, on the C. P. R., with Post Office, stores, is $15 \mathrm{mi}$. (a) $\S$.

*Moose Mountain. (B2.) 156 sq. mi. Poplars, willows, birch, box elders and ash are the principal trees. Hawks, weasel, coyote, beaver, owls, and waterfowl, are the chief animals. Large game are rare. $2000 \mathrm{ft}$.

Carlyle $\ddagger$, on the C. P. R., with Post Office, stores§, is $12 \mathrm{mi}$. (a).

*Beaver Hills. (B2.) ** 99 sq. mi. Poplars and willows are the chief trees. Large game are rare. "Moose Mountain and Beaver Hills are two small Reserves with much slough land. . . Both have the usual history-stripped of timber and overrun by fire, and now carrying a reproduction of poplar, mostly immature." (1915 Report of Canadian Commission of Conservation) $1800 \mathrm{ft}$.

Ituna $\ddagger$, on the G. T. P., with Post Office and stores, is 6 miles (a).

*Elbow. (B2.) 115 sq. mi. In two parts, one along the west shore of the South Saskatchewan River at the "Elbow;" the other among the head waters of the Qu'Appelle River, ten miles further east. $1800 \mathrm{ft}$.

Elbow $\ddagger$, on the C. P. R., with Post Office and stores, is two mi. (a).

*Dundurn. (B2.) 63 sq. mi. Sandy soil, drifting in some localities. $1750 \mathrm{ft}$.

Dundurn $\ddagger$, on the C. N. R., with Post Office and stores, is $5 \mathrm{mi}$. (a). $\S$

*Duck Mountain, No. 2. (B2.) 81 sq. mi. A rolling country on the eastern boundary line of the Province. Jack pine, tamarack, balsam fir, black spruce, white spruce, aspen, balsam poplar, and birch are common. Skunk, coyote. weasel, muskrat, beaver, ground-squirrel, moose, deer, and bear, are characteristic of the fauna. 1400-2500 ft.

Kamsack $\ddagger$, on the C. N. R., with Post Office and stores, is $8 \mathrm{mi}$. (a) $\$$.

Porcupine, No. 2. (A4.) 3220 sq. $\mathrm{mi}$. This is another large area of waste land, very similar to that of the Duck 
Mountain Reserve, and with a similar fauna and flora. Its eastern end has been set aside as a Game Preserve. 1000-2500 ft.

Hudson Bay Junction $\ddagger$, on the C. N. R., with Post Office and stores, is $3 \mathrm{mi}$. distant by wagon; (h), or (w) §.

*Pasquia Hills. (A4.) 2592 sq. mi. Similar in character to the last two described. All three contain elevations of land rising to approximately $2500 \mathrm{ft}$., which with Riding Mountain and Turtle Mountain in Manitoba, make up a range, of which Pembina Mountain at the boundary of Manitoba, Minnesota, and North Dakota, is the southern member. 900-2500 ft.

Hudson Bay Junction $\ddagger$, on the C. N. R., with Post Office and stores, is two mi. distant (h) or (w), over a muskeg trail§.

*Manitou Lake. (B2.) 180 sq. mi. On the western border of the Province, south and west of the alkali lake of the same name. It lies in the so-called "park country" in which prairie and aspen associations alternate. Coyote, ground-squirrel, and crane, abound. The Reserve contains many small lakes, many without outlet. $2000 \mathrm{ft}$.

Yonker, on the G. T. P., with Post Office and stores, but no hotel, is onehalf mi. (a) from the Reserve§.

${ }^{*}$ Keppel. (B2.)** Some 85 sq. mi. in three small patches of brush-covered country in the prairies south of Battleford. Hawks, ground-squirrel, and coyote are plentiful. $1700 \mathrm{ft}$.

Perduef, on the C. P. R., with Post Office and stores, is seven miles (a) from the Reserve.

*The Pines. (B2.) 165 sq. mi. A particularly interesting Reserve, being readily accessible and on the very boundary between park country and dense northern forest. It is heavily forested on its northern parts with spruce-aspen associations, while in the southern portion aspen thickets alternate with typical prairie grass-lands. It touches both the north and south branches of the Saskatchewan River, and contains numerous sloughs and lakes. $1500 \mathrm{ft}$.

Duck Lakeł, on the C. N. R, with Post Office and stores, is $6 \mathrm{mi}$. (a)§.

*Nisbet. (B2.) 150 sq. mi. A reserve of irregular outline, north of the North Saskatchewan River at Prince Albert, which is two miles distant by auto. There is a good deal of spruce bog, and the forest is extremely dense. The winter wrens and Canada jay ("whiskey jack") are common, and the pine siskin, ruby-crowned kinglet and olive-sided flycatcher are not rare.

Prince Albert, which may be reached by various branches of the C. N. R., is one of the chief commercial centers of the Province.

*Steep Creek. (B2.) 7 sq. mi. A spruce bog $16 \mathrm{mi}$. distant (a) east from Prince Albert, and situated on the south shore of the North Saskatchewan.§

* Fort a la Corne. (A4, 1.) 506 sq. mi. At the juncture of the two main branches of the Saskatchewan, and lying chiefly on the north shore. Not notably different in character from the Nisbet Reserve at Prince Albert. $1200 \mathrm{ft}$.

(a), $30 \mathrm{mi}$. from Prince Albert, or 20 mi. from Kinistino $\ddagger$, on the C. N. R., where there are stores and Post Office§.

*Big River. (A4.) 1250 sq. mi. A large tract of densely forested land, with much spruce-poplar vegetation, and a good deal of large game, as well as water-fowl in abundance. Some areas have been forested, some have been burned over, but much is still primitive. $1600 \mathrm{ft}$.

Big Riverf, on the C. N. R., with Post Office and stores, is one-half mi. by road from the Reserve§.

*Sturgeon River. (A4.) 708 sq. mi. A little-known tract, (a) by a 30-mi. ride either from Prince Albert, or from Canwood $\ddagger$ (C. N. R., Post Office, stores). This Reserve is heavily forested and its sand hills rise to a height of over $2300 \mathrm{ft}$. The Sturgeon River is a tributary of the North Saskatchewan. Waskesiu Lake, in the northeast corner of the Reserve is more than fifteen miles long, and is 
more than five miles broad at its widest place. $1600-2300 \mathrm{ft} . \S$.

\section{Bird Sanctuaries in Saskatchewan}

Cabri Lake. Covers $3 \frac{1}{2}$ sq. mi. of prairie, sagebrush, cactus, and alkali area with a ravine and rocky situations, lake and spring. Altitude $2300 \mathrm{ft}$. Located $5 \mathrm{mi}$. South of Mantario, $\ddagger$ Saskatchewan on the Canadian National Railroad.\$-Canadian National Parks J. B. H. L. H.

Crane Lake. Covers 23 sq. mi. of lake and islands with prairie, sagebrush and cactus, marshes. Located 5 mi. east of Piopot $\ddagger$ Station on the Canadian Pacific Railroad.\$-Canadian National Parks, J. B. H. - L. H.

Lenore Lake. Includes $37 \frac{1}{2}$ sq. mi. of lake, shore and islands, deciduous forest, prairie and swamp. Altitude $1865 \mathrm{ft}$. Located $18 \mathrm{mi}$. north of Humboldt $\ddagger$ on the Canadian National Railway. \&Canadian National Parks, J. B. H.L. $H$.

*Last Mountains Lake. Embraces 92 sq. mi. of lake with marshes, shores, and some prairie. Located $10 \mathrm{mi}$. west of Govan $\ddagger$ on the Canadian Pacific Railway. This is probably the first bird sanctuary in North America. It was reserved in 1887.\$-Canadian National Parks, J. B. H. L. H.

Quill Lake. Covers 250 sq. mi. of shore, water and islands. Deciduous forest, prairie, marsh. Located at Quill Lakef Station on the Canadian National $8 \mathrm{mi}$. north of Wynyard $\ddagger$ on the Canadian Pacific.\$-Canadian National Parks, J.B.H.-L.H.

Big Stick Lake. Includes 20 sq. mi. of prairie, sage brush, sand areas, marshes with antelope present. Altitude 2500 ft. Located $20 \mathrm{mi}$. north of Maple Creek on the Canadian Pacific Railroad.\$-Canadian National Parks, J. B. H. - L. $H$.

White Bear Lake. This is $3 \mathrm{sq}$. mi. of steppe, semi-desert, sage brush, and cactus, with some ravines. Valuable duck breeding ground. Altitude 2050 ft., located $5 \mathrm{mi}$. south of Elrose.Canadian National Parks, J. B. H.L. $H$.

Chapin Lake. Includes 73 sq. mi. of which 18 are water, prairie, sagebrush, and cactus, sand areas, shore, marsh, and lake. Located at Chapin, Canadian Pacific Railway. The lake is strongly alkaline. §-Canadian National Parks, $J$. B. H. $-L . H$.

Redberry Lake. Embraces $30 \frac{1}{2}$ sq. mi. chiefly water, but with deciduous forest, prairie, marsh, and shore. Altitude is $1700 \mathrm{ft}$. Located at Redberry Station, Canadian National Railway.
No hotels available.**-Canadian $\mathrm{Na}$ tional Parks, J. B. H.-L. H.

Basin Lake. Includes $28 \mathrm{sq}$. mi. of water and island, deciduous forest, prairie, some marsh. Altitude $1865 \mathrm{ft}$. Is $24 \mathrm{mi}$. northwest of Humboldt $\ddagger$ on the Canadian National Railway.\$-Canadian National Parks, J. B.H.-L. H.

Johnston Lake. Covers $125 \mathrm{sq}$. $\mathrm{mi}$. with prairie, sagebrush, cactus, marsh and the lake. Altitude $2189 \mathrm{ft}$. Located 2 mi. north of Expanse $\ddagger$ on the Canadian Pacific Railway, $25 \mathrm{mi}$. south of Moose Jaw, Canadian Pacific Railway, can be reached from Moose Jaw by automobile. $\$$ -Canadian National Parks, J. B. H.L. $H$.

Game preserves set aside by the provincial Government

The Provincial Government has set aside as Game Preserves the three following areas:

The water and shores of the north and south branches of the Saskatchewan River from the Alberta boundary to the point where the two branches unite at Fort a la Corne.

The water and shores of Wascana Lake, in the city of Regina, Sask.

The Isle of Bays, a small rocky island in Lake Johnston, $25 \mathrm{mi}$. south of Moose Jaw, Sask. (See account of Lake Johnston Bird Sanctuary.) On this island, white pelicans, double-crested cormorants, and other birds breed.-John Smith Dexter.

\section{Miscellaneous areas not elsewhere described}

The Churchill River Basin. Includes $1000 \mathrm{mi}$. of river, wet spruce forest, and broad, marshy hay-meadows. Birds abundant, including grebes, ducks, cranes, rails, herons, pelicans, cormorants, gulls, terns, snipe, etc. Bear, moose, and smaller mammals abound, with muskrat and porcupine prominent among them. The breeding season for birds begins in May. Ducks hatch in June and July. In spite of many forest fires in various portions of it, the country could hardly be more primitive. Altitude, $1200-1500 \mathrm{ft}$.

The region may be entered by the Canadian National Railway to Big River Sask., Prince Albert Sask., or 
The Pas, Man. Camp outfit necessary, but may be obtained at any of the three towns named. Indian guides are advisable, Cree Indians being probably preferable to Chipewyan. (The Anglican or Catholic Missionaries are excellent advisers with reference to the selection of a guide.)-John Smith Dexter.

\section{MANITOBA}

\section{By A. B. Connell}

\section{GENERAL}

The province of Manitoba is the easternmost of the three prairie provinces of Canada. It extends from the northern boundary of Minnesota and North Dakota north to.the 60th parallel of latitude a distance of $750 \mathrm{mi}$. The west boundary follows the 102nd meridian of longitude. The Ontario boundary on the east runs northwards near the 95th meridian for a distance of 275 mi. and then swings northeast to the shore of Hudson Bay. The width of the province in the south is approximately $300 \mathrm{mi}$.

\section{PHYSIOGRAPHY}

Manitoba is divided into four distinct physiographic regions.

1. The Cretaceous plains, entering the Province from the west, terminate abruptly in an escarpment which extends from the Pembina Mountain upon the International boundary northwesterly to the Porcupine Hills. The surface of this region is rolling and the elevation averages $1400 \mathrm{ft}$. above sea level. The line of the escarpment is marked by a series of drift-covered elevations rising in places to $2500 \mathrm{ft}$. The most important of these are the Duck and Riding Mountains. The Cretaceous plains occupy the southwestern portion of the Province.

2. A relatively narrow structural plain of undisturbed Paleozoic strata extends eastwards from the line of the escarprent to Lake Winnipeg. This plain has an average elevation of $800 \mathrm{ft}$. above sea level. It is upwards of $100 \mathrm{mi}$. in width east and west and extends from the international boundary north beyond the Saskatchewan river. The Winnipeg system of lakes, the residue of the glacial Lake Agassiz, occupies a portion of this area. Soils are deep and drainage in the northern part is poor.

3. East and north of Lake Winnipeg the Laurentian Peneplain stretches to within $100 \mathrm{mi}$. of Hudson Bay. The surface is rolling and the soils thin. The rocks are of a disorganized crystalline character. The elevation is generally less than $1000 \mathrm{ft}$. especially in the valleys of the Nelson and Churchill rivers. The region is one of low relief, disorganized drainage and innumerable lakes. The general slope of the plains from the Rocky Mountains to Hudson Bay seems to be continuous across this Laurentian section of Northern Manitoba.

4. A level plain underlain by limestone borders the shore of Hudson Bay in the vicinity of York Factory.

\section{BIOTA}

The vegetation of the Province may be separated into four climatic formations.

\section{The Prairies}

The extreme southwestern portion of the Province is characterized by a grassland formation composed of tall, deeprooted mesophytic grasses. Typical flood plain forests of ash, Manitoba maple, poplar and willow occur along the stream courses. Alkali sloughs are frequent.

Antelope (Antilocapra americana) and bison (Bison bison), once plentiful, are now extinct. The region is well developed agriculturally.

\section{The transition zone of grassland and deciduous forest (poplar-savanna)}

This condition covers an area varying in width from 50 to over $100 \mathrm{mi}$. It extends eastwards from the prairie country to the vicinity of South Junction on the C. N. R. near the south boundary 
of the province. Thence the boundary with the northern coniferous forest follows roughly a line north through Molson on the C. P. R. to Ft. Alexander at the mouth of the Winnipeg river. From this point the line crosses Lake Winnipeg to Washow Bay on the west shore and continues north and west around the north of Lake St. Martin to the foot of Lake Winnipegosis. Crossing Winnipegosis near Red Deer Point the base of the Porcupine highland is reached near Norva on the C. N. R. The trees are mainly aspen and balsam poplar. Scrub white oak is sometimes found. This area together with the prairies is the agricultural section of the Province and contains the bulk of the population.

\section{The Northern Coniferous Forest}

North of the transitional area the northern coniferous forest formation appears and occupies the northern part of the province practically to Hudson Bay. The climax trees are the white spruce (Picea canadensis), black spruce (Picia mariana), balsam (Abies balsamia), paper birch (Betula papyrifera), aspen (Populus tremuloides), and balsam poplar (Populus balsamifera). Along the southern border flood plains are characterized by the green ash (Fraxinus lanceolata), Manitoba maple, American elm (Ulmus americana), and willows. Jack pine (Pinus divaricata), is found on sand plains and areas of poor soils. Larch (Larix laricina), and black spruce occur in the swamps. Outlying areas of this forest occur along the Manitoba escarpment upon the Riding, Duck, and Porcupine Mountains. These areas have been incorporated into forest reserves and are easily accessible.

The characteristic mammals of the northern forest are the moose (Alces americana), black and cinnamon bear (Ursus americanus), timber wolf (Canis occidentalis), red fox (Vulpes fulva), beaver (Castor canadensis), muskrat (Ondatra zibethica), mink (Mustela vison group), lynx (Lynx canadensis), otter (Lutra canadensis), - fisher (Martes pen- nanti), marten (Martes americana), snowshoe hare (Lepus americanus), red squirrel (Sciurus hudsonicus), skunk (Mephitis hudsonica), and weasel (Mustela cicognanii). For further information see Seton's Life Histories of Northern Animals (Scribner's). Waterfowl are still plentiful in the valley of the lower Saskatchewan river and in the level plain about the Winnipeg system of lakes. Hawks, owls, and partridge are numerous. Deer are not numerous except along the south border of the forest country. Whitefish and lake trout occur in most of the larger lakes. Sturgeon are fairly plentiful. Pike, pickerel, and suckers abound.

\section{Tundras}

The extreme northern portion of the province extends beyond the coniferous forest into the Arctic tundra. The barren ground caribou (Rangifer) are plentiful, ranging south to Reindeer, South Indian and Split lakes.

\section{NATURAL AREAS}

*Riding Mountain Forest Reserve. (B2.) Area 1000 sq. mi. A rolling drift-covered plateau. The sharply dissected eastern slopes rise steeply from the Agassiz plain at $900 \mathrm{ft}$. to elevations of $2500 \mathrm{ft}$. The western slopes fall gently to the level of the Cretaceous plain at $1400 \mathrm{ft}$. The elevation is covered by northern coniferous forest and is surrounded at the base by poplar savanna. In addition to the climax trees mountain maple (Acer spicatum), hazel (Corylus americana), alder, pin cherry (Prunus pennsylvanica) and mountain ash (Sorbus sp.) are found as an understory usually in the poplar and spruce association. Glacial potholes and poorly drained depressions are occupied by sphagnum swamps. Meadows and sloughs are frequent. Elk are present in this area in addition to moose, deer, and bear. Natural conditions have been interfered with to some extent by fire and lumbering.

The reserve is administered by the Dominion Forestry Branch with office 
at Dauphin. There have been set aside $1161 \mathrm{sq}$. mi. as a game preserve by the Manitoba provincial government.

Dauphinł. Canadian National Railway from Winnipeg§. Outskirts of reserve can be reached by motor car, interior by wagon. Flies are bad in June and July normally.

*Duck Mountain Forest Reserve. (B2.) Area 1500 sq. mi. This elevation is similar to the Riding Mountain from which it is separated by a broad valley upon the south. Elevations reach approximately $2500 \mathrm{ft}$. Eastern slopes are steep and sharply dissected while the western slope is long and gentle. The plateau is covered by northern coniferous forest and is surrounded by poplar savanna. Elk, moose, and deer are present. Madge lake in the west of the reserve is a popular summer resort. 432 sq. mi. have been established by the Provincial Government as a game preserve. Wagon trails have been opened through the reserve and the outskirts can be reached by motor car. Administration is by the Dominion Forestry Branch from the Dauphin office. C. N. R. from Winnipeg§.

*Porcupine Forest Reserve.

Area 1000 sq. mi. The Porcupine hills extend across the western boundary of Manitoba from Saskatchewan just south of the 53rd parallel of latitude. They are separated from the Duck Mountain on the south by a broad valley $20 \mathrm{mi}$. in width through which the Preeceville branch of the C. N. R. runs. The Prince Albert branch of the C. N. R. skirts their eastern base from Swan river to Westgate.

The highland is similar to the Duck and Riding Mountains but is higher and rougher. The eastern slopes rise steeply some $2000 \mathrm{ft}$. from the level of the Agassiz plain, to a total elevation of nearly $3000 \mathrm{ft}$. Westward in Saskatchewan the fall is gentle. The plateau is underlain by soft shales and is heavily mantled with drift. A series of beach lines can be traced around the eastern base. The area lies upon the southwestern border of the northern conif- erous forest. The forest extends without a break from the north and east over these hills but ends abruptly upon the south slopes. where it gives way to poplar savanna. The deep well drained soils of the upland are occupied by a typical climax association of spruce, balsam fir, poplar and white birch. Muskegs are not extensive. Lumbering and fires have interfered to some extent with natural conditions.

Bison which formerly ranged into these hills are now extinct. Woodland caribou and elk have been noted. Moose and deer are plentiful.

Swan River $\ddagger$ is the nearest outfitting center. C. N. R. from Winnipeg. Wagon trails extend to the boundary of the reserve from Bowsman and Birch river. Interior accessible (h) only. No hotel accommodation at flag stops upon the railway between Bowsman and Hudson Bay Junction. Administration by Dominion Forestry Branch.

*Spruce Woods Forest Reserve. (C3.) 108 sq. mi., southwestern Manitoba. An area of sand dunes and light soils surrounded by developed agricultural lands. Scattered natural spruce. Some artificial plantations. Game Preserve.

Reached from Carberry, C. P. R. (a). The Canadian National railway crosses the tract. Administered by Dominion Forestry Branch, Customs Building, Winnipeg.

*Turtle Mountain Forest Reserve. (B3.) Area 100 sq. mi. Located on the International Boundary in southwestern Manitoba. A low rolling drift-covered upland surrounded by agricultural prairie land. Covered with small poplar with many areas of typical mesophytic prairie. Sloughs and ponds are numerous. Game Preserve. Administered by Federal Forestry Branch, Winnipeg. Reached from Waukopa or Adepha, C. N. R. Boisevain or Deloraine nearest outfitting center§. Accessible by wagon.

*Cedar Lake and Winnipegosis Game Preserves. (A2.) Area 3600 sq. mi. 
These two adjacent areas are in northern Manitoba extending from the head of Lake Winnipegosis north to the Hudson Bay railway. The tract lies upon the level plain of Paleozoic limestones which stretches from the Manitoba escarpment to Lake Winnipeg. The soils are stratified lake clays mainly with scattered areas of drift deposits. The elevation averages $800 \mathrm{ft}$. The Saskatchewan river flows through Cedar lake in the southern part of the preserve.

The tract is typical of the northern coniferous forest formation as modified by a low terrain and lack of drainage. Open muskegs and black spruce and tamarack swamps occupy the bulk of the area. Upon ridges and well drained areas the climax association of white spruce, balsam fir, birch and poplar appears but is greatly restricted in extent and has often suffered from fire. The lakes are shallow and surrounded by broad zones of carex and willow. They are filling rapidly. An opportunity is offered upon this area for studying the successional relationships of drained and undrained swamps and flood plains. The area has been slightly modified by fire but not by lumbering. Occasional woodland caribou are found here. Moose are fairly plentiful. Deer few. Wolves, foxes, mink, muskrat and beaver are numerous. Ducks, geese and other waterfowl are exceptionally plentiful especially during the fall. White fish, lake trout, sturgeon, pike and pickerel are caught in the lakes.

The Pas on the Canadian National railway $400 \mathrm{mi}$. north of Winnipeg is the most convenient outfitting center. Cedar or Moose lake can be reached down the Saskatchewan river by steamboat, (c). They may also be reached from Winnipeg by steamer to Grand Rapids over Lake Winnipeg§. Take supplies from Winnipeg or The Pas for duration of trip. Maps can be obtained from the Game Branch at Winnipeg or Natural Resources Intelligence Branch at Ottawa.

Birch Island Game Preserve. (A3.) Area 57 sq. mi. An island in Lake
Winnipegosis underlain by limestone. Northern coniferous forest. Outfit at Winnipegosis, C. N. R. (c).§

Red Deer Point Game Preserve. (A3.) Area 39 sq. mi. In Lake Winnipegosis $15 \mathrm{mi}$. north of Winnipegosis, C. N. R. $\S$ (c). Northern coniferous forest.

Peonan Point Game Preserve. (A3.) Area 72 sq. mi. Northern end of Lake Manitoba. Northern coniferous forest Outfit at Winnipeg. C. N. Ry. Gypsumville branch, to Fairford.§ (c).

Lake St. Martin Game Preserve. (A3.) Area $240 \mathrm{sq}$. mi. Northern coniferous forest. Much muskeg. Outfit at Winnipeg. C. N. Ry. to Fairford. This area has also been set aside as a proposed forest reserve.

Grindstone Point Game Preserve. (A3.) Area $42 \mathrm{sq}$. mi. Southern part of Lake Winnipeg. Drift underlain by undisturbed limestones. Northern coniferous forest. Outfit at Winnipeg. Steamer from Selkirk. (c).§

Dog Head Point Game Preserve. (A3.) Area 225 sq. mi. Narrows of Lake Winnipeg. Level limestone strata overlain by drift and lake clays. Northern coniferous forest. Much muskeg. Outfit at Winnipeg. Steamer from Selkirk. $\$$ (c). This is also a proposed forest reserve.

Reindeer Island Game Preserve. (A3) Area 65 sq. mi. Island in Lake Winnipeg. Northern coniferous forest. Outfit at Winnipeg. Steamer from Selkirk. § (c).

Whitemouth Proposed Forest Reserve. (A2.) Area 200 sq. mi. Southeastern Manitoba. Northern coniferous forest. Large proportion is muskeg. Outfit in Winnipeg. Go to Bedford or Sandilands on C. N. Ry. § Wagon (c).

Manigotagan Proposed Forest Reserve. (A2.) Area 2000 sq. mi. This area lies east of Lake Winnipeg between the Wanipigou River on the north and the English River on the south. It extends eastwards to the Ontario boundary and is within the Laurentian area of eastern Manitoba. The country is rolling and rocky with thin soils. Lakes and streams are numerous. The forest is of the northern coniferous type with considerable muskeg and burn.

C. P. Ry. from Winnipeg to Lac du Bonnet; also by steamboat from Selkirk to Manigotagon. Outfit at Winnipeg. Camp outfit and canoes required. Small hotel at Lac du Bonnet.

\section{Available areas}

The settled area of Manitoba is restricted largely to the south. Northern Manitoba, comprising the bulk of the province, is still very largely in a virgin 


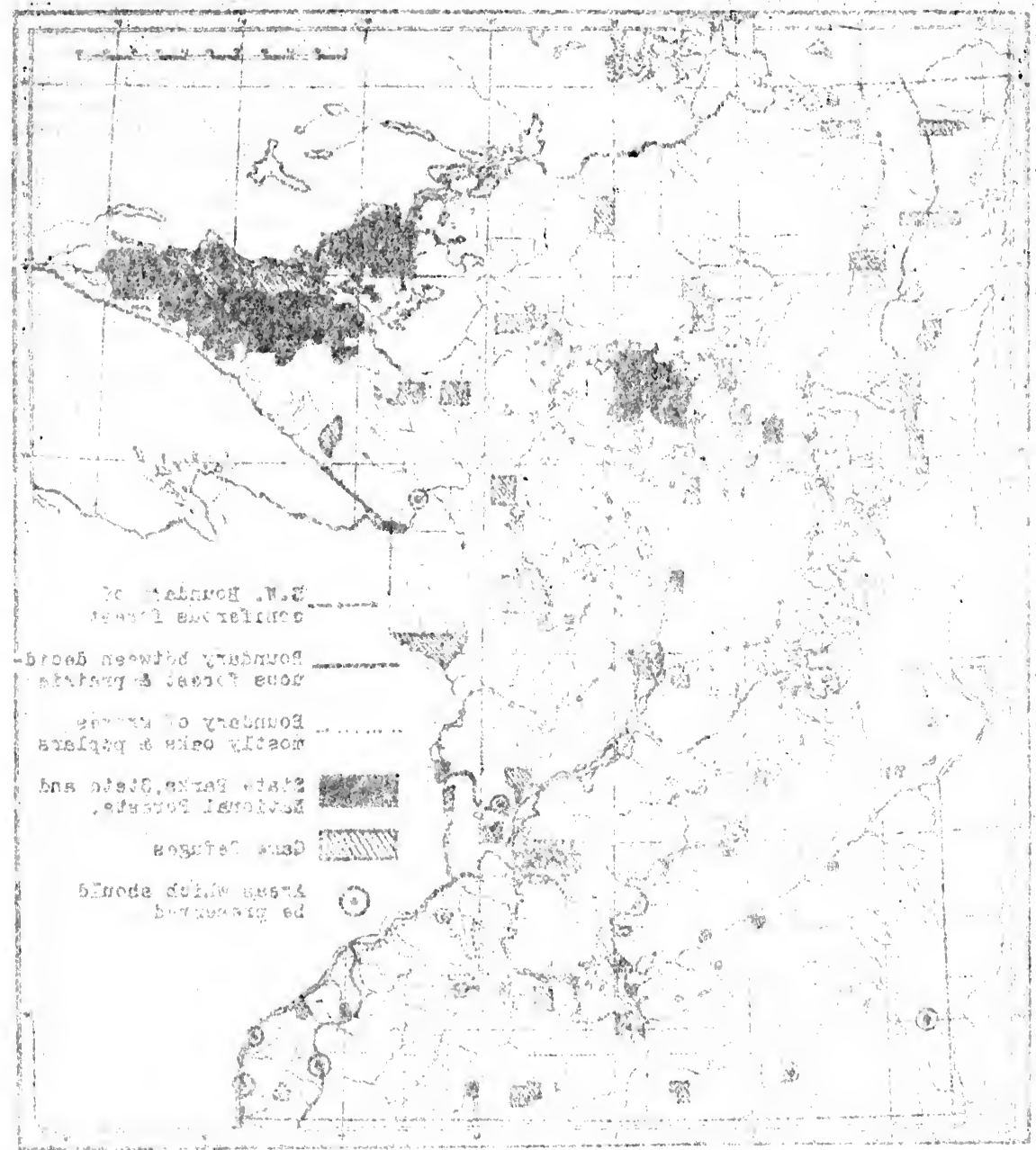

nTo

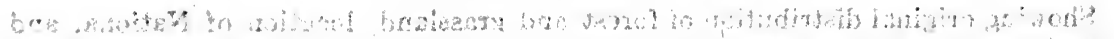

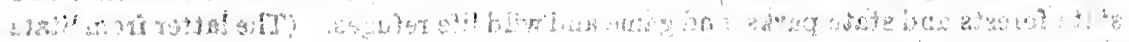

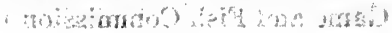




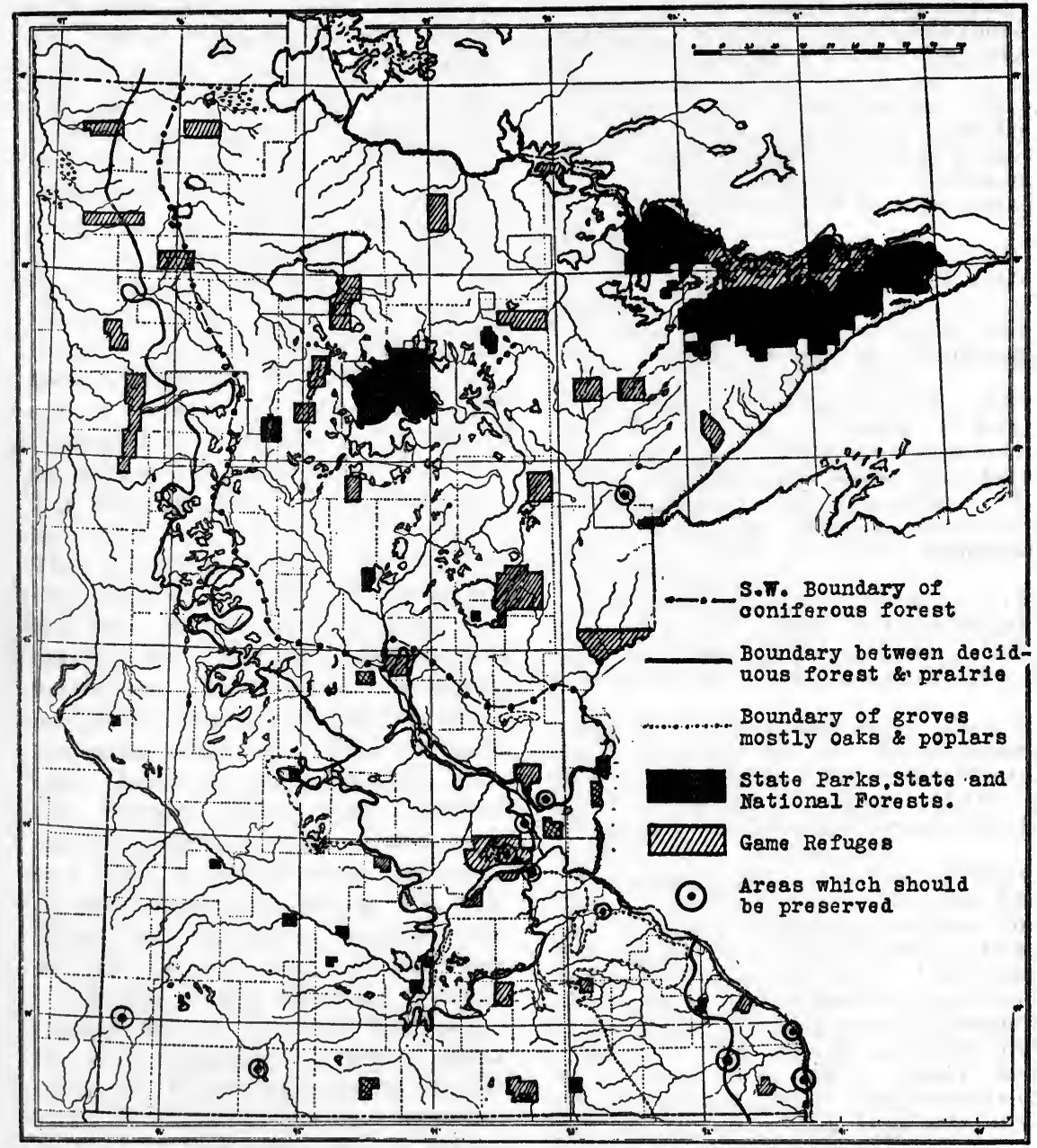

Fig. 9. Map of Minnesota

Showing original distribution of forest and grassland; location of National and state forests and state parks, and game and wild life refuges. (The latter from State Game and Fish Commission.) 
condition. It lies mainly within the boundaries of the Laurentian plateau and is covered with the northern coniferous forest. Travel is by canoe in summer and dog team in winter. The Pas, a town of 2000 people, is the usual outfitting center for travel in the north. Hotel accommodations are good and camp equipment, canoes and supplies can be obtained there. C. N. R. from Winnipeg. The Hudson Bay Railway has been completed from The Pas to within $90 \mathrm{mi}$. of Port Nelson on Hudson Bay. Regular boat service is available from The Pas up the Saskatchewan River to Cumberland House and Sturgeon Lake. Thence the Churchill River can be reached easily (c). Northeastern Manitoba is generally reached by steamer from Winnipeg to Norway House at the north of Lake Winnipeg. From here the old Hudson Bay canoe route runs to York Factory on Hudson Bay by way of the Hayes River.

\section{MINNESOTA}

\section{By Carl Otto Rosendahl}

\section{GENERAL FEATURES}

\section{Physiography}

The whole state of Minnesota with the exception of the extreme southeastern corner has been heavily glaciated and a typical glacial topography is therefore characteristic of most of the state. The glacial soil or drift varies from a few feet to $300 \mathrm{ft}$. in thickness and occurs mainly as unmodified till plains or ground moraines, as gravelly and sandy outwash plains, and as terminal moraines. The generally level surface of the main body of the state is due to the predominance of the two first mentioned types of drift. The four corners of the state, drained each in its own direction from the central portion, exhibit considerable variations from the typical sheet of till which covers the rest.

The southeast corner is characterized by a broken and hilly surface where high uplands alternate with numerous deeply eroded valleys running in various directions. These valleys have been cut in the generally level strata to a depth of 300 to $500 \mathrm{ft}$. through the bygone ages and have undergone very little subsequent disturbance by the glacial period. Both the glaciated and unglaciated portions of this part of the state are overlaid with a sheet of loess, varying in thickness from a few inches to $30 \mathrm{ft}$. or more. In general this deposit shows the greatest depth on the uplands - but in some valleys, where subsequent erosion has not been too extensive, a depth of twenty feet is not uncommon. From some areas the loess has been completely washed away.

The northeast corner of the state is rough and rugged and may be said to be semi-mountainous in places. Elevations of 1200 to $1500 \mathrm{ft}$. above Lake Superior are attained in the Sawteeth, Mesabi, and Giant's Ranges. This part of the state was heavily glaciated and much of the area is covered with an uneven deposit of drift. In the region north and east of Vermillion Lake the rocks for the most part are bare or only thinly mantled with soil formed in situ.

In the northwest part of Minnesota, embracing part of the Red River Valley of the North, the surface is very flat and even. Over this part of the state once stood glacial Lake Agassiz and the level nature of the land is due to lacustrine deposits laid down evenly and to a considerable depth over the till sheet.

The southwest corner has a gently rolling to flat surface but the plain is interrupted by a height of land known as the Coteau des Prairies, running from northwest to southeast and rising 400 to $500 \mathrm{ft}$. above the general level. Near the extreme corner occur large outcrops of quartzite rocks.

Extensive moraines, marking either the limits of advance of the various ice sheets or places where they rested in their retreats, form belts of low hills, isolated knobs, or ranges which rise above the general plain. These moraines are found in many parts of the state but the most extensive are those which occur in the west-central portion through Kandiyohi, Pope, Douglas, Otter Tail and Becker counties, the region of the upper Mississippi River and the region surrounding Minneapolis 
and St. Paul. They give to these portions of the state a rolling or even hilly aspect.

A very striking feature of the Minnesota landscape is the numerous glacial lakes estimated to number about 10,000 and ranging in size from a few acres in area to large bodies of water 15 to 35 mi. in expanse. Together with the streams and rivers these lakes give Minnesota a greater fresh water area than any other state in the Union, amounting to approximately 5637 sq. mi., without including Lake Superior. These lakes can be divided into three classes as follows, depending upon the nature of the topography of the region in which they are situated:

1. Lakes of morainic till areas.

2. Lakes of modified drift areas.

3. Lakes of bare rock areas.

The first class is the most numerous embracing about three-fourths of the total number. The most remarkable of these areas is that of the Leaf Hills of Becker and Otter Tail counties where nearly half of the surface is covered by water. This area extends in a southerly direction to Douglas, Carver, Hennepin and Le Sueur counties and northward to Clearwater, Beltrami, and Itasca counties. The second class embraces the largest lakes of the state including Red, Mille Lacs, Leech, Winnibigoshish, and Cass Lakes. They are for the most part shallow and are situated on extensive outwash plains or otherwise modified drift. The third class embraces the lakes of rocky basins and are mostly confined to the northeast corner of the state which was subjected to the severest glaciation. These lakes are very numerous. They are usually long and narrow with tortuous and bold shores. Many are of considerable depth and they are frequently connected by swift flowing streams.

\section{Drainage systems and elevations}

It is a remarkable fact that the state of Minnesota, although possessing no great elevation above sea-level, gives rise to three of the great drainage systems of the North American continent. Within its borders arise the Mississippi River system, draining about 45,000 sq. $\mathrm{mi}$. of the area of the state; the St. Lawrence system, arising in the northeast and draining approximately 8500 sq. mi.; the Red River of the North system, arising in the northwest and draining $15,000 \mathrm{sq}$. mi. The remaining area of the state is drained by four other rivers which reach the three main systems beyond the borders of the state. Approximately 4730 sq. mi. of the southwestern and south-central parts are drained by the Rock, the Des Moines, and Cedar Rivers into the Mississippi; and $10,300 \mathrm{sq}$. mi. of the northeastern part by the Rainy River into the Hudson Bay outlet.

\section{Relative elevations of different parts of the state}

The lowest part of the state is the land bordering on Lake Superior whose elevation is $602 \mathrm{ft}$. Where the Mississippi River leaves the state it has an elevation of $620 \mathrm{ft}$. and the lowlands bordering the main stream and its tributaries in this region rise only a few feet above that level. The flat land adjoining the Red River of the North where it enters Manitoba is approximately $770 \mathrm{ft}$. The highest elevation in the state is attained in the Mesabi Range north of Lake Superior which rises 2200 $\mathrm{ft}$. above sea level. It is thus seen that the lowest and the highest elevations are in close proximity to each other.

\section{Geographic and local plant and animal communities}

Minnesota occupies a strategic position in a biological sense since diagonally across it from northwest to southeast runs the dividing line between the coniferous forest type (Canadian Zone of the Boreal Region) on the one hand and the grassland and deciduous forest (Transition Zone of the Austral Region), on the other. The northeastern part of the state is occupied by the Coniferous Forest Formation which originally ex- 
tended in a somewhat irregular line from about longitude $96^{\circ} \mathrm{W}$., near the northwest corner, to about latitude $45^{\circ} 45^{\prime} \mathrm{N}$. on the eastern border. All of the southwestern part, and including the Red River valley of the North, belongs to the Grassland Formation, all of which was originally treeless except for fringes of forest along certain lake shores and stream borders. Between these two great formations stretched a belt of varying width of deciduous forest which might properly be designated the Deciduous Forest Formation since it is fairly sharply marked out from the other two. Originally the state had about 31,800 sq. mi. of prairie and $52,200 \mathrm{sq}$. mi. of forest.

The nature and extent of the five main vegetation areas of Minnesota are determined mainly by climatic factors. It is probable, however, that the original border line between the forest and the grassland was to some extent determined by prairie fires periodically started by the Sioux Indians, partly to increase the extent of their hunting grounds, and partly to keep back their woods enemies the Ojibwas or Chippewa Indians.

The five plant formations, deciduous forest, coniferous forest, oak grove savanna, poplar savanna and grassland or steppe, although in the main well delimited naturally showed considerably overlapping along their borders. Thus in the coniferous forest area numerous outposts of hardwood timber, mostly hard maple, oak and elm occurred and in the southeast irregular tongues of the prairie extend into the deciduous forest formation. Similarly in the southwest and the west hardwood timber formed scattered groves out on the prairie, and followed up along some of the main river valleys like the Minnesota, the Cedar, the Des Moines and the Rock. In each of the five areas the climax stages, of development had probably been reached and each one was characterized by a goodly host of important species.

1. Coniferous forest. Thus in the coniferous forest area the principal species of trees were white pine (Pinus strobus), Norway pine (Pinus resinosa), Jack pine (Pinus banksiana), white spruce (Picea canadensis), black spruce (Picea mariana), tamarack (Larix laricina), balsam fir (Abies balsamea), white cedar (Thyja occidentalis), together with some intermixture of paper birch (Betula papyrifera), aspen (Populus tremuloides), red oak (Quercus rubra), bur oak (Quercus macrocarpa), black ash (Fraxinus nigra), green ash (Fraxinus lanceolata), yellow birch (Betula lutea) and mountain ash (Pyrus americana). The characteristic shrubs are: yew (Taxus canadensis), juniper (Juniperus communis), willow (Salix discolor, S. lucida, S. balsamifera, S. candida), beaked hazel (Corylus rostrata), dwarf birch (Betula pumila var. glandulifera), hoary alder (Alnus incana), meadow sweet (Spiraea salicifolia), red raspberry (Rubus idaeus aculeatissimus), pin cherry (Prunus pennsylvanica), choke cherry (Prunus virginiana), wild rose (Rosa acicularis), northern gooseberry (Ribes oxyacanthoides), wild black currant (Ribes floridum), leatherwood (Dirca palustris), mountain maple (Acer spicatum), red osier dogwood (Cornus stolonifera), Labrador tea (Ledum groenlandicum), leather leaf (Chamaedaphne calyculata), bearberry (Arctostaphylos Uva-ursi), trailing arbutus (Epigaea repens), wintergreen (Gaultheria procumbens), bog rosemary (Andromeda polifolia), blueberry (Vaccinium pennsylvanicum, $V$. canadense), cranberry (Vaccinium Oxycoccus, $V$. macrocarpon), pipsissewa (Chimapbila umbellata), snowberry (Symphoricarpos racemosus), bush honeysuckle (Diervilla Lonicera), mountain fly honeysuckle (Lonicera caerulea), swamp fly honeysuckle (Lonicera oblongifolia), red berried elder (Sambucus racemosa), downy arrow-wood (Viburnum pubescens), highbush cranberry (Viburnum americanum).

The predominant herbaceous plants of the coniferous forest of the state aside from numerous species of grasses, sedges and rushes, are bracken fern (Pteris aquilina), shield fern (Aspidium spin- 
ulosum, A. cristatum), beech fern (Phegopteris Dryopteris), club moss (Lycopodium obscurum, L. clavatum, $L$. annolinum, L. complanatum), horsetail (Equisetum pratense, E. sylvaticum), Clintonia (Clintonia borealis), false lily-of-the-valley (Maianthemum canadense), lady's slipper (Cypripedium hirsutum, C. parviflorum C. acaule), rein orchis (Habenaria hyperborea, H. obtusata, H. dilatata, H. Hookeri, H. orbiculata), coral root (Corallorrhiza trifida, C. maculata), ladies' tresses (Spiranthes gracilis S. cernua), Hepatica (Hepatica triloba), northern strawberry (Fragaria americana), running swamp blackberry (Rubus triflorus), sundew (Drosera rotundifolia), pitcher plant (Sarracenia purpurea), dwarf cornel (Cornus canadensis), wild sarsaparilla (Aralia nudicaulis), shin leaf (Pyrola secunda, $P$. minor, $P$. chlorantha, $P$. asarifolia, $P$. americana), lungwort (Mertensia paniculata), twin flower (Linnaea borealis), bedstraw (Galium trifidum, G. boreale, G. triflorum), Aster (Aster macrophyllus, A. puniceus, A. junceus, etc.), goldenrod (Solidago juncea, S. bicolor, S. nemoralis etc.) and sweet coltsfoot (Petasites palmatus, P. sagittatus).

Within this formation soil factors determined largely the plant communities. On the clayey moraines, which constitute the best soil of the region, were developed either pure stands of white pine or mixed communities of white pine with a few species of deciduous trees like hard maple, bur oak, red oak and occasionally basswood. Where the soil is gravelly or sandy occurred forests of Norway pine, while over all the sandy barrens Jack pine held undisputed sway. All the low areas which had reached the tree stage of their succession, were either muskegs with Sphagnum and heath undergrowth or characteristic tamarack and spruce swamps.

In a similar way the distribution of the shrubby and herbaceous undergrowth was largely determined by soil and moisture conditions except in the case of a few species like the dwarf cornel, twin flower, wild sarsaparilla, the northern strawberry and the running swamp blackberry, all of which seem to grow equally well in the spruce-tamarack swamps, and in the pine forests of the moraines and gravelly outwash plains.

A study of the fauna of the different parts of Minnesota reveals a rather striking correlation in regard to the distribution of its various elements and the principal vegetation areas. Aside from a number of adaptable and wide ranging species, belonging to several of the major classes of the animal kingdom, there are numerous forms which are mainly and in some cases wholly confined to the principal plant formations.

Within the coniferous forest area there occurred originally the following species of mammals: Canada lynx (Lynx canadensis), wolverine (Gulo luscus), marten (Martes americana), fisher (Martes pennanti), least weasel (Mustela rixosa), short-tailed weasel (Mustela cicognanii), skunk (Mephitis mephitis), woodland caribou (Rangifer caribou) moose (Alces americana), northern, Virginia deer (Odocoileus virginianus borealis), long-tailed chipmunk (Eutamias minimus neglectus), Canada woodchuck (Marmota monax canadensis), deer-mouse (Peromyscus maniculatus gracilis), Canada porcupine (Erithizon dorsatum), snowshoe hare (Lepus americanus phaeonotus).

The following northern birds occurred as permanent residents of the coniferous formation although straying further south as winter visitants: Canada spruce partridge, Richardson's owl, Arctic three-toed woodpecker, American three-toed woodpecker, Canada jay northern raven, purple finch, red crossbill, pine siskin, and Hudsonian chickadee.

Most of the following species are mainly summer residents of the northern wooded area of the state: Loon or great northern diver, herring gull, redbreasted merganser, golden-eye, northern hairy woodpecker, Nelson's downy woodpecker, northern pileated woodpecker, white-winged crossbill, white- 
throated sparrow, slate colored junco, Bohemian waxwing, Philadelphia vireo, blue-headed vireo, northern parula warbler, Tennessee warbler, pine warbler, myrtle warbler, mourning warbler, magnolia warbler, black-throated blue warbler, Blackburnian warbler, palm warbler, Grinnell's water-thrush, Connecticut warbler, Wilson's warbler, Canada warbler, Louisiana waterthrush, olive-backed thrush, hermit thrush, winter wren, brown creeper, red-breasted nuthatch, Hudsonian chickadee, and golden-crowned kinglet.

A considerable number of animal species were not so strictly confined to the Coniferous area but ranged farther southward and westward into the adjoining deciduous forest formation. Of these the principal ones were: elk (Cervus canadensis), northern flyingsquirrel (Glaucomys sabrinus), Minnesota red squirrel (Sciurus hudsonicus minnesota), red-backed vole (Evotomys gapperi), bog-lemming (Synaptomys cooperi), black bear (Ursus americanus), eastern cougar (Felis couguar), red fox (Vulpes fulva), timber wolf (Canis nubilus), short-tailed weasel (Mustela cicognanii), marsh shrew (Neosorex palustris), Canada beaver (Castor canadensis), and the muskrat (Ondatra zibethica).

Among the more notable fishes of this region might be mentioned the following: Lake sturgeon (Acipenser rubicundus), common whitefish (Coregonus clupeiformis), lake herring (Argyrosomus artedi), tullibee (Argyrasomus tulbibee), Great Lake trout (Cristimover namaycush), brook trout (Salvelinus fontinalis), muskallunge (Lucius masquinongy).

2. Deciduous forest. The deciduous forest formation, interposed between the coniferous forest and the western grassland formed an almost continuous belt from the southeastern to northwestern corner of the state except for an irregular tongue of prairie extending from middle northern Iowa northeastward almost to the Mississippi river through Freeborn, Mower, Steele, Dodge,
Rice, Dakota and part of Goodhue counties. The portion of this formation stretching northward from the big bend of the Minnesota River as far as Otter Tail County was named the "Big Woods" by the early explorers and was a hardwood forest of imposing proportions. Along the $45^{\circ}$ parallel of latitude it was nearly $100 \mathrm{mi}$. in width but from the $46^{\circ}$ parallel northwestward it narrowed down to an average width of about $25 \mathrm{mi}$. with frequent deep indentations of the prairie formation.

The dominant trees of this forest were hard maple (Acer saccharum), slippery elm (Ulmus fulva), white elm (Ulmus americana), basswood (Tilia americana), bur oak (Quercus macrocarpa), red oak (Quercus rubra) and ironwood (Ostrya virginiana). Other species occurring less typically were coarse toothed aspen (Populus grandidentata), black cherry (Prunus serotina), green ash, black ash, hackberry (Celtis occidentalis), pignut hickory (Carya cordiformis) and butternut (Juglans cinerea).

The characteristic shrubs of this formation were: prickly gooseberry (Ribes Cynosbati), Missouri gooseberry (Ribes gracile), thorn apple (Crataegus punctata), choke cherry, juneberry (Amelanchier canadensis), prickly ash (Xanthoxylum americanum), stag-horn sumac (Rhus typhina), alternate-leaved dogwood (Cornus alternifolia), roundleaved dogwood (Cornus circinata), black haw (Viburnum lentaga) and honeysuckle (Lonicera dioica). A few climbers occurred in this forest such as bitter sweet (Celastrus scandens), wild grapevine (Vitis vulpina), Virginia creeper (Psedera quinquefolia) and moonseed (Menispermum canadense).

In the southeastern corner of the state along the Mississippi River and the lower portions of its tributaries existed originally a deciduous forest of very similar nature to the "Big Woods." This forest, being rather sharply separated from the latter by the above mentioned extension of the prairie formation differed in some important respects and 
was very interesting as marking the northern limits of some of the characteristic species of the Ohio-KentuckyTennessee forest. Prominent among these are honey locust (Gleditsia tria canthos), black oak (Quercus velutina), shell-bark hickory (Carya ovata), river birch (Betula nigra), chinquapin oak (Quercus prinoides) and black maple (Acer saccharum var. nigrum). A few other species, occurring typically in this southeastern hardwood forest of the state, had migrated up the main Mississippi Valley and had established outposts as far northwestward as the vicinity of Minneapolis. These are: black walnut (Juglans nigra), swamp white oak (Quercus bicolor), Kentucky coffee tree (Gymnocladus dioica), wild crab apple (Pyrus ioensis), red mulberry (Morus rubra), and lastly the white oak (Quercus alba) which apparently found congenial conditions in the sour soil of the red Wisconsin drift and penetrated as far as the eastern shores of Lake Mille Lacs.

A few shrubs and vines also occurred in this forest which did not reach the Big Woods. They were witch hazel (Hamamelis virginiana), Sullivant's honeysuckle (Lonicera Sullivantii), button bush (Cephalanthus occidentalis), and blue grape (Vitis bicolor)

The herbaceous undergrowth of the deciduous forest formation was so rich and varied that only a few of the more striking and characteristic species can be enumerated here. In the rich soil of densely shaded slopes occurred Virginia grape fern (Botrychium virginianum), interrupted fern (Osmunda claytoniana), maiden-hair fern (Adiantum pedatum), Jack-in-the-pulpit (Arisaema triphyllum), bellwort (Uvularia grandiflora), Solomon's seal (Polygonatum commutatum), false Solomon's seal (Smilacina racemosa), wake robin (Trillium cernuum, T. declinatum), showy orchis (Orchis spectabilis), wild ginger (Asarum canadense), Hepatica (Hepatica acutiloba), baneberry (Actaea rubra, A. alba), blue cohosh (Caulophyllum thalictroides), May apple (Podophyllum peltatum), bloodroot (Sanguinaria canadensis), Dutchman's breeches (Dicentra Cucullaria), mitrewort (Mitella diphylla), ginseng, (Panax quinquefolia), wild spikenard (Aralia racemosa) and Greek valerian (Polemonium reptans).

On the rich wooded bottomlands and in the lower portions of ravines abounded ostrich fern (Onoclea struthiopteris), shield fern (Aspidium spinulosum), lady fern (Asplenium augustum), green dragon (Arisaema dracontium), dog's-tooth violet (Erythronium albidum), water leaf (Hydrophyllum virginianum), touch-me-not (Impatiens pallida, I. biflora), golden glow (Rudbeckia laciniata) and others. In the upland portions of the forests the species more commonly met with are yellow lady's slipper (Cypripedium pubescens), rattlesnake plantain (Epipactis pubescens), rein orchis (Habenaria bracteata), columbine (Aquilegia canadensis), enthanter's nightshade (Circaea lutetiana), snakeroot (Sanicula marilandica S. gregaria), shin leaf (Pyrola elliptica), lopseed (Phryma leptostachya).

The deciduous forest formation in Minnesota is embraced within the Alleghanian Faunal area and as is the case with many plant species a considerable number of animals reached the northwestern limits of their range in this formation. Some of the typical species are: southern flying squirrel (Glaucomys volans), fox squirrel (Sciurus niger rufiventer), gray squirrel (Sciurus carolinensis hypophaeus), rufescent woodchuck (Marmota monax rufescens), Mearns cottontail rabbit (Sylvilagus floridanus mearnsii), long-tailed weasel (Mustela longicauda spadix), Wisconsin gray fox (Urocoyon cinereoargenteus ocythous), prairie mole (Scalopus aquaticus machrinus). Some species like the raccoon (Procyon lotor) and the eastern red fox (Vulpes fulva), although most typical of this area, ranged considerably beyond the hardwood forest, while others belonging to the coniferous and prairie areas were, and are, fairly common in parts of the hardwoed forest. Representatives of this class are the 
coyote (Canis latrans), mink (Mustela vison letifera), otter (Lutra canadensis), wild cat (Lynx rufus), Hudsonian skunk (Mephitis hudsonicus), badger (Taxidea taxus), Missouri Valley mole (Scalopus aquaticus machrinoides).

Since the area of Minnesota under discussion lies mainly within the path of the great mid-continental spring and fall migrations and furthermore because of the great numbers of fresh water lakes and streams, it is obvious that numerous species and vast hordes of birds frequented the region for longer or shorter periods. To enumerate only a small portion of the species which originally were encountered would require too much space in this brief survey and it must suffice to list only such as are more or less permanent or summer residents of the main natural areas already outlined. Accordingly the avian fauna more strictly limited to the southeastern deciduous forest area embraced the following species: Red-bellied woodpecker, field sparrow, prothonotary warbler, blue-winged warbler, and Louisiana water-thrush. The egret (Herodias egretta) and snowy egret (Egretta candidissima candidissima) have both been recorded from the extreme southeastern corner of the state. Among species which ranged somewhat farther north (up to Lat. $46^{\circ} \mathrm{N}$.) are to be mentioned the king rail and the Florida gallinule.

Fishes of southeastern Minnesota; mainly occurring in the Mississippi River and its principal tributaries: Spoonhill (Polyodon spathulata), shovel nosed sturgeon (Scaphirhynchus platorynchus), gar pike (Lepiosteus osseus), great cat fish (Ameiurus lacustris), common buffalo fish (Ictichus cyprinella), carp sucker (Carpioides carpio), eel (Anguilla chrysypa), hickory shad (Dorosonia cepedianum). Many other species also abound in this area but they range much farther northward and westward.

Of the large classes of animals the Reptilia show the smallest representation in the Minnesota fauna. A few species like the garter-snake (Thamnophis s. sirtalis and T. radix), the snapping turtle (Chelydra serpentina), and the painted turtle (Chrysemys marginata bellii) range pretty well over the entire state. The southeastern and southern parts have in addition the timber rattler (Crotalus horridus), bull-snake (Pituophis sayi), blue racer (Coluber c. constrictor), water-snake (Natrix s. sipedon), hog-nose (Heterodon contortrix), blacksnake (Elaphe o. obsoleta), fox-snake (E. vulpina), red-bellied snake (Storeria occipitomaculata) and possibly a few other species. Records on the occurrence and the distribution of reptiles of the state are largely wanting.

3. Oak grove and (4) poplar savanna. The latter is poorly developed except in the two extreme northwestern counties, hence the two are treated together. (See map, unshaded portion.) With the exception of narrow strips of timber along the streams or on the north slopes of protected bluffs or in the ravines leading down into the main river valleys all of western and southwestern Minnesota is typical prairie and steppe or dry grassland.

$a$. Where timber occurred it was made up of the following species of trees: American elm, slippery elm, bur oak, cottonwood (Populus deltoides), hackberry, ironwood, box elder (Acer negundo), silver maple (Acer sacchariuum), basswood, green ash and willow (Salix amygdaloides). Occurring with the trees or more often along the borders of thickets were found the following shrubs: wild plum (Prunus americana), choke cherry, black haw, downy arrowwood, burning bush (Evonymus atropurpureus), red osier dogwood, June berry (Amelanchier oblongifolia), smooth rose (Rosa blanda), shining willow (Salix lucida), heart-leaved willow, buffalo berry (Shepherdia argentea) and wolfberry (Symphoricarpos occidentalis).

Most of these trees and shrubs are typically eastern and are an important constituent of the deciduous forest formation already described. They succeeded in penetrating the prairie region 
only along the principal water courses where sufficient moisture was present the year around for them to maintain a foothold.

The characteristic grassland vegetation of this savanna region may best be considered under a few sub-headings as follows:

(a) High Rolling Grassland Flora: The principal species of this association were: slender wheat grass (Agropyron tenerum), awned wheat grass ( $A$. caninum), western wheat grass (A. Smithii), rye grass (Elymus canadensis), crested hair grass (Koeleria cristata), porcupine grass (Stipa spartea), forked beard grass (Andropogon furcatus), brown beardgrass (A. scoparius), Indian grass (Sorghastrum nutans), purple love-grass (Eragrostis pectinacea), Pursh's lovegrass (Eragrostis Purshii), switch grass (Panicum virgatum), hairy mesquite grass (Bouteloua hirsuta), grama grass (B. oligostachya), tall grama grass ( $B$. curtipendula), buffalo grass (Buchloe dactyloides), sedges (Carex pennsylvanica C. Sestucacea), blue-eyed grass (Sisyrinchium campestre), yellow star grass (Hypoxis hirsuta), Pasque flower (Anemone patens var. Wolfgangiana), Anemone (Anemone cylindrica), prairie larkspur (Delphinium Penardi), prairie crowfoot (Ranunculus rhomboideus), prairie rose (Rosa arkansana), tall cinquefoil (Potentilla arguta), alum root (Heuchera hispida), ground plum (Astragalus caryocarpus), milk vetch (Astragalus canadensis), prairie apple (Psoralea escunlenta), prairie clover (Petalostemum purpureum, $P$. candidum, $P$. villosum), lead plant (Amorpha canescens), ticktrefoil (Desmodium canadense), prairie violet (Viola pedatifida), birdsfoot violet (Viola pedata), flowering spurge (Euphorbia corollata), Phlox (Phlox pilosa), ground cherry (Physalis longifolia), puccoon (Lithospermum canescens), lady's tobacco (Antennaria plantaginifolia), ox-eye (Heliopsis scabra), sunflower (Helianthus scaberrimus), blazing star (Liatris scariosa), golden-rods (Solidago missouriensis, $S$. nemoralis, $S$. rigida, S. canadensis), Asters (Aster multiflorus, A. commutatus, A. azureus).

(b) The prairie meadow: In these situations occurred a limited number of species, mostly grasses, demanding a moister habitat than that of the high rolling prairie. The characteristic plants were: holy grass (Hierochloë odorata), Scribner's panicum (Panicum Scribnerianum), red top (Agrostis alba), Canada blue grass (Poa compressa), fowl meadow grass (Poa triflora), tall marsh grass (Spartina cynosuroides) and wild onion (Allium canadense).

(c) Wet meadow and marsh flora: In the wet meadows, marshes and sloughs flourished sedges, rushes, and bulrushes, together with a considerable number of other hydrophytic species and shallow water forms of which the principal ones were: arrowhead (Sagittaria latifolia), cat-tail (Typha latifolia), bur-reed (Sparganium eurycarpum), reed (Phragmites communis), sedges (Carex vulpinoidea, C. gravida, C. cephaloidea), bulrushes (Scirpus fluviatiiis, S. polyphullus, S. americanus, etc.), spike-rush (Eleocharis palustris, $E$. acicularis), yellow water crowfoot (Ranunculus delphinifolius), white water crowfoot ( $R$. aquatilis), water persicaria (Polygonum amphibium), yellow water cress (Radicula palustris), swamp milkweed (Asclepias incarnata), water hemlock (Cicuta maculata), water parsnip (Sium cicutaefolium), tufted loosestrife (Lysimachia thrysiflora), mare's tail (Hippurus vulgaris), begger-ticks (Bidens frondosa), and stick-tight (Bidens cernua).

(d) Fauna of the Savannas: Forest animals frequenting small groves, open spaces, and stream skirting forest: elk, mule deer (Odocoilus hemionus) (extreme western part only, now wanting), raccoon, chipmunk, skunk, red fox.

Forest edge (thicket) species.

Franklin ground squirrel (Citellus franklinii), jumping-mouse (Zapus hudsonius), rose-breasted grosbeak, yellow warbler, indigo bunting, yellow-billed cuckoo, house wren, mourning dove, 
song sparrow, migrant shrike, catbird, goldfinch, and many insects.

Mesophytic grassland species.

Prairie chicken, prairie jumpingmouse (Zapus hudsonius campestris), badger (occasionally).

4. Grassland or Steppe. For a short distance east of the western border, especially in the S.W. over what is known as the Coteau des prairies and to a lesser extent on dry slopes and along the bluffs of the river valleys the flora assumed a more typical western aspect since it was in these habitats that many of representatives of the great plains flora found congenial surroundings. Here flourished beardtongues (Pentstemon grandiflorus, $P$. albidus, $P$. gracilis), puccoons (Lithospermum canescens, L. Gmelini, $L$. augustifolium), purple avens (Geum triflorum), several milk vetches (Astragalus adsurgens, A. lotiflorus, A. missouriensis, $A$. flexuosus), loco weed (Oxytropis Lambertii), evening primroses (Oenthera serrulata, Oe. pallida, Oe. rhombipetala), yellow flax (linum rigidum, $L$. sulcatum), blazing stars (Liatris scariosa, L. cylindracaea, $L$. punctata), cone flowers (Lepachys pinnata, L. columnaris, Brauneria purpurea), numerous wormwoods (Artemisia longifolia, A.dracunculoides, A. frigida), golden aster (Chrysopsis villosa) and several others.

The pronghorn antelope (Antilocapra americana) was a characteristic form; vast herds of Bison (Bison bison) exceeded in size the eastward extension; ground-squirrel (Citellus richardsonii), pocket-gopher (Geomys bursarius), badger, white-tailed jackrabbit (Lepus townsendii campanius). Even the grizzly bear is reported to have extended as far east as the Red River in the region of the Pembina Hills. Other species which were common throughout the greater extent of this area were: prairie red fox (Vulpes regalis), coyote (Canis latrans), badger, pocket-gopher, whitetailed jackrabbit (Lepus townsendii companius).

The avian fauna of the prairie region in the early days was even more impressive than the mammalian. The innumerable lakes, ponds, sloughs, and marshes offered ideal feeding and nesting grounds to a large number of water birds. No less than 25 species of ducks are known to have occurred and 17 of these used to breed in the state. Most of these occurred in greatest abundance in the prairie region. Four species of geese, the snow goose, the blue goose, the white-fronted goose and the Canada goose, used to be very common and the whistling and trumpeter swans alighted on the lakes and streams in great numbers during their migrations.

Among the bird species more strictly confined to the grassland region of Minnesota should be mentioned the western grebe, eared grebe, Swainsons hawk, burrowing owl, Arkansas kingbird, Brewers blackbird, chestnut-collared longspur, McCown's longspur, Baird's sparrow, lark bunting and Spragues pipit, while the following had a somewhat more extended range: Forster's tern, Franklin's gull, blackcrowned night heron, Kirider's Hawk, prairie chicken and prairie sharp-tailed grouse.

For notes on Mollusca see under Wisconsin.

\section{PRESENT BIOTIC CONDITIONS}

Most of the original prairie area of Minnesota has been converted into farm lands and only such portions as are either too low and swampy or too alkaline or in other ways unsuited for growing crops have remained undisturbed. Of the original prairie vegetation there are only remnants to be found along old highways, along the railroad rights-of-way, and on tracts of untillable soil. Fortunately several of the smaller state parks are located in this part of the state and help to preserve original conditions.

The fauna inhabiting the prairie part of the state has suffered the greatest destruction, many noteworthy species having completely disappeared long ago. Of the birds which once were common 
over the area but now are rare or absent Roberts (2) cites the following species: whooping crane, marbled godwit, western willet, upland, black-bellied, and golden plover, prairie chicken and prairie sharp-tailed grouse.

In the forested portion of Minnesota the disturbance of natural conditions incident to settlement has been much less severe. This is due partly to the rough nature of the topography or to other causes which retard or wholly prevent agricultural development. Probably half the area originally covered by deciduous forest is still woodland. In the coniferous region, although most of the primitive forest has either been cut or burned, a comparatively small per cent of the land has been transformed into farms. Over large tracts natural reforestation is going on and wherever it has been possible to prevent forest fires promising forests are well under way. It is fortunate for the fauna of Minnesota that so large a portion of the northern part of the state is unsuited, both physiographically and climatically, to agricultural development for it will insure, with proper and adequate protection and sufficient sanctuaries, the perpetuation of most of the wild species native to the region. Most of the natural preserves are located in the forested area of the state, but even where no definite tracts are set aside the wild species are far better able to maintain a foothold than in the open country. In the rugged, wooded counties of the southeast corner the coyotes are apparently nearly as numerous as when the country was first settled.

\section{POLLUTION}

Pollution of waters in Minnesota is a factor of importance only along the main rivers since the principal cities of the state are located on these streams. The Mississippi River below Minneapolis and St. Paul is heavily polluted with sewage, which undoubtedly affects the biota for many miles below. Several towns of considerable size are situated on the upper Mississippi but the effects of pollution are not serious at Minneapolis, as shown by the fact that the city obtains its water supply from this stream. Minnesota lakes are in general remarkably free from sewage pollution but occasionally some of the smaller ones late in the season become heavily infested with certain forms especially of the Cyanophyceae (1).

\section{NATURAL PRESERVES AND STATE PARKS} OF MINNESOTA

\section{Preserves within the coniferous forest area}

* Superior National Forest†. A large, irregular tract of approximately $1,268,538$ acres in St. Louis, Lake, and Cook Counties and an almost equally extensive area on the Canadian side of the International Boundary.

Rough glacial topography with extensive out-croppings of underlying igneus rocks of various kinds. Lakes exceedingly numerous; many of them of large size and with many rocky and forested islands; shore frequently precipitous, rising in sheer ledges $100 \mathrm{ft}$. or more from the water's edge. Rivers and streams numerous, in some places sluggish, in others turbulent, with long rapids; beautiful waterfalls.

Eastern coniferous forest consisting mainly of white and Norway pines, black and white spruce, white cedar, balsam, and tamarack. The principal deciduous trees are: white birch, aspen, balsam poplar, elm, ash, willows, hard and red maples, mountain ash, and occasional oaks. These species occur mostly scattered throughout the coniferous forest except on burnt-over tracts where nearly pure stands of birch or poplar have developed. On account of the rocky nature of the substratum the lichen and moss flora is profusely developed.

Fauna abundant and varied. There are perhaps more moose in the Lake Superior forest than in any other area of equal size on the North American continent. Caribou occurs. Other species which are common are Virginia deer, coyote, timber wolf, black bear, beaver, 
red fox, mink, marten, lynx, porcupine, and snowshoe hare, ruffed grouse, spruce grouse, and many species of water fowl are abundant. Many species of fish, including muskallonge, lake trout, pike and brook trout.

The rough nature of the country and the scarcity of roads and trails make the region difficult of access. These factors together with the uninterrupted protection provided by law make this a game sanctuary of unusual character and importance.

Streams clear, alternately rapid and sluggish. Lakes clear, with rocky shores and bottoms, some of great depth. 1300-2100 ft., rugged.

Elył. $10 \mathrm{mi}$. east from Ely; Duluth and Iron Range R. R. Accessible only by trail or canoe.**

St. Louis, Lake and Cook Counties, Minnesota.-C. O. R.

*Burntside State Forest $\dagger$ (B2.) An area comprising 20,000 acres of rocky glacial topography, situated near Burntside Lake, St. Louis County. The country is wild and of great natural beauty. Within this State Forest are 43 connected lakes, with numerous streams and swamps. Mostly eastern coniferous forest, embracing white, Norway, and jack pines, together with white cedar, black and white spruce, tamarack, and balsam fir. There are scattered patches of deciduous forest made up largely of birch, black ash, poplar, basswood, and balsam poplar. Blueberries are exceedingly abundant. Some portions of the forest are burnt, but there are beautiful stands of Norway pine.

The fauna is varied and very abundant, embracing such species as Virginia deer, moose, timber wolf, beaver, red fox, porcupine, coyote, mink, marten, beaver, and snowshoe hare. Aquatic birds are very common.

Streams clear, sluggish; lakes clear, rocky shores and bottoms. 1300-1400 ft., rugged.

(a) Elył. 10 mi. S. W.; Duluth and Iron Range R. R. 3 mi. North of (W) Robinson, St. Louis County. ${ }^{* *-C}$ - O. R.
*Scenic State Park†. (B3.) A recently acquired area comprising 1920 acres, situated in Itasca County. It is situated north of the west end of the Iron Range in a region of glacial topography abounding in lakes and streams; clayey and sandy moraines alternating with till plains.

Northeastern coniferous forest consisting of Norway, white, and jack pines, the first named species being the most abundant, frequently occurring in pure stands; other conifers are tamarack, white cedar or arbor vitae and black spruce, confined to the swamps; white spruce and balsam fir; scattered tracts of deciduous forest, mostly along streams in which the principal species are birch, elm, black and green ash, aspen, balsam poplar, basswood, and willows; in some places sugar maple occurs; representatives of the heath family are common, including Labrador tea, blueberries, cranberries, leatherleaf, wintergreen, swamp laurel, and others.

The park is situated in a thinly settled part of the state and the fauna is rich, numbering such species as Virginia deer, black bear, coyote, beaver, mink, porcupine, marten, red squirrel, snowshoe hare, and skunk.

Many kinds of aquatic birds inhabit the lakes and streams and ruffed grouse is plentiful in the forest throughout.

Streams clear, moderate. Lakes clear and cool. 1300-1400 ft. rolling.

Grand Rapids + 25 mi. N. E. Great Northern R. R, $4 \frac{1}{2} \mathrm{mi}$.

East of Bigfork, Minneapolis and Rainy River R. R.-C. O. R.

*Jay Cooke State Park†. (B3.) An area of approximately 3200 acres of extremely rugged territory along the St. Louis River, where it drops to the level of Lake Superior. In this area the river descends in rushing rapids and water falls over $300 \mathrm{ft}$., cutting through the folded and broken strata of slate rock. The park lies within the northern coniferous area, but owing to the extremely rugged and precipitous nature of the river valley, the tree growth is of 
a scattered and interrupted nature. White and Norway pines occur on the rocky ledges, together with such deciduous species as green ash, mountain ash, choke cherry, pin cherry, poplars, alders, and willows. Vacciniums, ledum, bearberry, and other heaths are abundant over the rocky substratum.

The fauna includes Virginia deer, mink, marten, timber wolf, snowshoe hare, and red squirrel.

Streams swift to torrential, clear, 800-1200 ft. precipitous.

(a) Duluth + 10 mi. south. N. P. Great Northern and Soo Line R. R. $\frac{1}{2}$ mi. east from (w) Thompson.

Carleton County, Minn.-C. O. R.

*Minnesota National Forest $\dagger$ (B2.) A large tract of 322,560 acres embracing the Chippewa, Cass Lake and Winnebagoshish Indian Reservations. It is situated in northern Cass and southern Itasca counties and extends from Cass Lake on the west, south to Leech Lake and eastward to beyond Winnebagoshish Lake; glacial topography, consisting of undulating till and modified drift and extensive outwash plains. Northern coniferous forest made up largely of white, Norway, and jack pines, tamarack, and spruce; scattered areas of deciduous forest in which birch, poplar, elm, ash, red oak, balsam, poplar, and sugar maple predominate. There are large cut-over areas, but also extensive tracts of original forest. The largest and finest stands of Norway pine still to be found in the state occur in this forest. Second-growth timber on cutover areas made up principally of birch, poplar, jack pine, norway pine, hazel, pin cherry, and scrub oaks. Muskegs and spruce-tamarack swamps numerous and of great extent. Over $50 \%$ of the tamarack killed by the ravages of the saw fly; the dead trees for the greater part still standing. Marshes, streams, lakes, and ponds numerous.

Fauna varied and abundant, including Virginia deer, black bear, beaver, timber wolf, coyote, fox, mink, marten, skunk, porcupine, snowshoe hare, and squirrels, together with a great variety of water fowl and fish.

Lakes young, clear; streams clear, moderate. 1300-1400 ft.; rolling.

Cass Lake +12 mi. E. Great Northern R. R. Around Schley; Camping outfit necessary. Cass and Itasca Counties.-C. O. R.

*Itasca State Park†. (H8.) This state park embraces approximately 30,000 acres, at the headwaters of the Mississippi River. It is a region of rough, glacial topography, made up of terminal moraines of several lobes of the late Wisconsin drift, gravelly outwash plains; low, swampy areas, and numerous lakes and ponds. The park lies within the northern coniferous area of Minnesota but there are considerable patches of deciduous forest as well as a considerable admixture of birch, aspen, basswood, elm, and maple in many places throughout the coniferous forest. The principal hardwood trees are white birch, white elm, green and black ash, bur oak, red and sugar maple.

The climax forest on the clayey moraines, in some places not touched by the lumberman, is made up almost wholly of Norway and white pine. On the gravelly outwash plains, it consists almost exclusively of jack pine, with either a few scattered trees, or occasional small patches of Norway pine. The climax forest of the swamps is mostly a mixture of tamarack and black spruce. The balsam fir occurs abundantly and in various situations. Often it is found in the mixed evergreen, deciduous forest, on clayey moraines; at times it grows with ash and elm in low or swampy areas, or it may form almost solid patches of second growth on cut-over areas.

Considerable areas of the park were cut over thirty years ago and these are now found in various stages of reforestation. On the gravelly and sandy outwash plains occur dense stands of young jack pine; on the more gravelly moraines, jack pine and Norway pine; while on the 
typical clay moraines, the birch, aspen, and balsam fir are the chief constituents of the new forest. Young trees of Norway and white pine are scattered throughout this formation, but are not abundant, nor have they over-topped the other trees. Springs and streams are common throughout the park and there is considerable variation both in the temperature and the chemical nature of the waters they contain. Some of the lakes are fed largely from springs and their waters are very rich in mineral content.

The fauna of the Park is abundant and varied. Streams pure and clear. 1500-1750 ft., rolling.

(a) Park Rapids + 30 mi. north. Great Northern R. R. $\frac{1}{2} \mathrm{mi}$. south of Itasca P. O. Douglas Lodge, in Park Clearwater County.-C. O. R.

*Pillsbury State Forest $\dagger$. A tract of land comprising 1000 acres situated near the west shores of Gull Lake in Cass County, Glacial topography consisting of rolling, high moraines, alternating with more or less level tracts and swampy areas; mostly clayey and gravelly soil. Originally covered for the most part by eastern coniferous forests in which Norway, white and jack pines predominated; swamps mostly tamarack and spruce. Second growth consists mostly of poplar, birch, scrub oak, willows, hazel and dogwood. Reforestation with the three above mentioned species of pine is being carried out by the State Forest Service.

The fauna embraces Virginia deer, black bear, coyote, fox, muskrat, mink, woodchuck, snowshoe hare, squirrel, porcupine, skunk, and numerous species of small rodents; aquatic birds numerous.

1200-1400 ft., rolling.

(a) Brainerd +12 mi. N. W. N. P. and Soo Line R. R. 6-8 mi. S. W. from (a) Hubert. Cass County, Minn.-C. O. R.

*Spirit Island Federal Game Reserve. (A4.) A small rocky island situated in Lake Mille Lacs, near its southern end. It is about one acre in extent and is made up entirely of large, granite and gneiss boulders, without any filling of gravel and sand. It rises about $15 \mathrm{ft}$. above the lake level and is the nesting place of a colony of common terns, called locally "gulls," and a considerable number of purple martens. Various species of waterfowl, inhabiting the lake frequent the place but apparently not for nesting purposes.

$1300 \mathrm{ft}$.

(a) Waukon $4 \mathrm{mi}$. West. Soo Line R. R. $5 \mathrm{mi}$. north of Cove. (c) Mille Lacs County, Minnesota.-C. O. R.

\section{Preserves of the deciduous forest and prairie areas}

*Inter-state State Park†. (B4.) About 720 acres on both sides of the St. Croix River at the Dalles. The region is of great interest geologically since it represents an extensive outcrop of Keweenawan rock. The river has cut through this barrier and rushes between vertical ledges of rock, towering a hundred feet and more over the level of the stream. On the west side of the river, there is an extensive area of pot holes, ranging in size from a few inches in diameter and depth to large cisterns up to $30 \mathrm{ft}$. in diameter and 50 or more ft. deep.

Forest formation composed of two species of pine with many elements of the northern coniferous forest, and various species of oak, elm, ash, birch, and maple together with a few other deciduous trees like butternut, basswood, aspen, cherry, and willows. Vegetation on the exposed trap rock is of xerophytic nature and is largely composed of lichens, mosses, a few pteridophytes and of typical xerophytic Angiosperms like Opuntia and Sedum.

Along the heavily forested hillside on the Wisconsin side are numerous springs and marshy places where skunk cabbage, calla lily, water hemlock, saxifrage and chrysosplenium together with other hydrophytes and mesophytes abound.

Because of the proximity of the park to the villages of Taylors Falls and St. 
Croix Falls, the fauna is of necessity limited.

Streams swift, clear. Springs numerous, cold.

700-950 ft., precipitous.

St. Paul and Minneapolis $55 \mathrm{mi}$. N. E. N. P. and Soo Line R. R.

Outskirts of (W) Taylors Falls village.

$\frac{1}{4}$ mi. south from (W) St.' Croix Falls, Chicago County, Minnesota. Polk County, Wisconsin.-C. O. R.

*Ft. Snelling Military Reservation†. (B4.) Approximately 1000 acres at the confluence of the Mississippi and Minnesota Rivers. Glacial topography. A large part of this area is made up of a sandy, slightly undulating outwash plain. On the higher portions of this plain is found a typical prairie vegetation while in the lower places occur copses of oak, aspen, cherry, hazel, plum, and dogwood, alternating with moist meadows, willow thickets, and a few shallow ponds. On the northeast the Reservation is bounded by the Mississippi River gorge which is excavated to a depth of about $100 \mathrm{ft}$., and is of comparatively recent origin. The narrow flood-plains support a mixed forest of elm, soft maple, cottonwood, ash, and hackberry. The slopes, where not too precipitous, and the upland immediately back are covered by a mixed deciduous forest of oak, elm, sugar maple, and basswood. This forest is gradually invading the prairie and in this invasion the bur oak and northern pin oak, together with hazel form the skirmish line. Along the edge of the gorge are numerous springs. On the south and southeast, the Reservation is bounded by the ancient Minnesota River gorge. The slopes are rounded and except where cut by ravines, are mostly covered with a prairie vegetation. The ravines are mostly wooded and in some of these are clear, cool, fast flowing streams.

The flood plains of the Minnesota River are extensive and are covered with wide stretches of Scirpus americanus, Phragmites, wild rice, and other tall grasses and sedges. Many species of birds nest on these bottom lands.

The fauna of the mixed forest and the upland portions of the Reservation consists mostly of the red and the gray squirrel, the striped ground-squirrel, the cottontail rabbit, woodchuck, quail, ruffed grouse, and various species of summer visiting birds.

The reservation is under Federal control but the proximity to the two large cities of Minneapolis and St. Paul makes it difficult to prevent poaching, and the extensive picking of flowers. Many species of spring flowers are becoming rare on the Reservation.

Mississippi River moderate, usually clear, but polluted with Minneapolis sewage; Minnesota River usually sluggish, but given to frequent flooding in early summer; muddy.

Rivers and flood plains $700 \mathrm{ft}$.Upland. $800-850 \mathrm{ft}$.

(a) Minneapolis $\ddagger$ (7 mi. south).

(a) St. Paulf (7 mi. southwest).

Snelling-Minnehaha Electric R. R. through (w) Reservation.

Hennepin County.-C. O. R.

*Fort Ridgeley State Park. (C3.) This park embraces 160 acres and is located in the Minnesota River valley near the northwest corner of Nicollet County. It marks the battlefield of the first engagement of the Indian uprising of 1862 . Here are located the stone buildings which were the agency post and most important structures of frontier days: nearby are the sites of the early trading points, the Indian stone church, Birch Coulee battlefield, Brown's Castle, and several monuments.

Glacial topography flat till plain above, bordered on the southwest by river valley $175 \mathrm{ft}$. deep; coolees with swift streams descending from the uplands; bluffs with terraces and rock outcrops below; river bottoms and flood plains.

Deciduous climax forest in the river valley of which the principal species are white and slippery elm, basswood, silver and sugar maple, box-elder, 
butternut, bitternut, hickory, hackberry, black cherry, ironwood, cottonwood, and willows. In the coolees occur wild plum, sumach, hazel, dogwood, bur and scarlet oaks.

Streams clear, rapid; river mostly sluggish and muddy; springs cold.

800 to $1000 \mathrm{ft}$.

Sleepy Eye $10 \mathrm{mi}$. north.

Chicago and Northwestern R. R. at Ft. Ridgeley.

Nicollet County.-C. O. R.

*Alexander Ramsey State Park. (C3.) About 100 acres at the junction of Ramsey Creek with the Redwood River on the south side of the Minnesota River valley in Redwood County. The park includes $\frac{1}{2} \mathrm{mi}$. of river gorge below the falls together with the tributary gorge of Ramsey Creek. There are precipitous granite cliffs on both sides of the streams and on these the red cedar is very common.

In the bottoms of the gorges there is a dense deciduous forest made up principally of white and slippery elms, box elder, basswood, ironwood, Kentucky coffee tree, hackberry, and sugar maple.

Streams clear, rapid. 820 to $1000 \mathrm{ft}$.

(a) Redwood Falls, 1 mi. north. Chicago and Northwestern R. R. About $1 \mathrm{mi}$. southwest from North Redwood. Redwood County, Minn.C. O.R.

*Horace Austin State Park. (B3.) A tract of fifty acres adjoining the city of Austin. Situated in the valley of the Cedar River and embracing many heavily wooded islands. Glacial till with exposures of Cretaceous clays in which Angiospermous and Gymnospermous fossils occur. Underneath the Cretaceous are exposures of Devonian shales and sandstones.

Deciduous forest in the river valley, made up principally of elm, basswood, bur and scarlet oak, ash, poplar, black cherry, crab apple, soft maple, sugar maple and red cedar.

Historical records show that in 1840 , the fauna embraced, Virginia deer, elk, black bear, and bison, but these have long since disappeared and at present it consists principally of squirrels, cottontail rabbit, woodchuck, ground squirrel, and other small rodents.

Streams somewhat polluted, moderate; $1150-1225 \mathrm{ft}$.

(w) Austinł. Chicago, Milwaukee, and St. Paul R. R.

Mower County.-C.O.R.

*Minneopa State Park. (B3.) A tract of land originally comprising 60 acres, but recently increased to 114 acres; located at the confluence of Minneopa Creek with the Minnesota River. The name is contracted from Sioux words-Minne-hinhe-nopa-which mean water falling twice, or two waterfalls, according to Upham (4). Rolling upland, precipitous river bluffs, gorges, and flat river bottoms.

The park is situated at the south end of the "Big Woods," which extended northward over $100 \mathrm{mi}$. from this point. Borders of the upland prairie with heavy deciduous forest in the creek and river valleys consisting of white elm, basswood, ironwood, bur oak, slippery elm, black ash, box elder, sugar maple and white ash.

The fauna is somewhat varied, embracing coyote, red fox, raccoon (all three rare), muskrat, gray and red and fox squirrels, cottontail rabbit, woodchuck, skunk, and several species of ground-squirrel.

800 to $900 \mathrm{ft}$.

(a) Mankato +, 4 mi. W. Northwestern R. R.

Chicago, Milwaukee, and St. Paul R. R. at (w) Minneopa.

Blue Earth County, Minn.-C. O. R.

*Whitewater State Park†. (B4.)

This park is located in the western part of Winona County between the towns of St. Charles and Elba and when completed will embrace 2560 acres. It lies in the valley of the Whitewater River, near the border of the driftless area, and is therefore of great interest both geologically and biologically. Extremely rugged topography; upland areas covered with loess; deeply eroded river valley with steep, heavily wooded 
slopes, and alluvial bottom lands. In many. places there are extensive exposures of paleozoic rocks.

The deciduous climax forest consists of white, red, and buroaks, shell bark hickory, bitternut hickory, aspen, coarsetoothed poplar, and black cherry. The fauna is varied for a country which has been settled for so many years, including coyote, raccoon, red fox, bobcat, red and gray and fox squirrels, flying-squirrel, mink, skunk, woodchuck, cottontail rabbit, weasel, and ground-squirrel.

Streams clear, swift; springs numerous and some of great volume. 850$1100 \mathrm{ft}$.

St. Charles +10 mi. north. Chicago and Northwestern R. R.

$2 \mathrm{mi}$. southwest from Elba. Winona County.-C.O.R.

*Sibley State Park†. (B4.) One of the recent state acquisitions, embraces about 400 acres located north of Lake Andrew within the Monongalia Game Refuge of Kandioyhi County. Glacial topography, embracing terminal moraines, moderately to very rolling and hilly, with lakes, ponds and streams, making this park one of the most beautiful and picturesque places in the state. Situated near the western border of the "Big Woods" of Minnesota with virgin timber clothing the rugged moraines; climax forest made up principally of white elm, slippery elm, sugar maple, basswood, bur oak and red oak.

The fauna includes, although in some cases rare, such species as red and gray squirrels, raccoon, skunk, woodchuck, cottontail rabbit, white-tailed jackrabbit, red fox, and coyote.

Lakes and streams clear, moderate: 1500-1700 ft.

Wilmar + 12 mi. N. E. Gt. Northern R. R. about $5 \mathrm{mi}$. west from New London, Gt. Northern R. R. Kandioyhi County.-C.O.R.

In addition to the larger parks and preserves described in the foregoing pages, there are several smaller ones ranging in size from 2 to 50 acres scattered throughout the state wherein natural conditions are safeguarded in the same degree as in the case of those of more pretentious area. They should properly be included in the list, but it is hardly necessary to accord them as full descriptions.

*Sleepy Eye State Park. (C3.) Surrounding Sleepy Eye Lake, estimated 50 acres in extent; glacial topography mixed deciduous forest. Located at Sleepy Eye, Ch. \& N. Wn. R. R. Brown County, Minnesota.

Toqua Lakes State Park. Approximately 23 acres in area; level ground moraine; in prairie region of state; deciduous forest along lake shore. Graceville, Gt. Northern, Ch. Mil. \& St. Paul. R. R. Bigstone County.

*Travers De Sioux. (D5.) About 2.5 acres. Minnesota River Valley; glacial topography; deciduous forest. St. Peter. Ch. \& N. W. R. R. Nicollet County.

*Camp Release State Park. (D5.) A monument site, commemorating the release of white prisoners from captivity among the Sioux Indians in 1862. Bordering the Minnesota River valley on the south. About $1 \mathrm{mi}$. S. W. from Montevidio. Chi. Mil. \& St. Paul. R. R. Lac Qui Parle County.

3. Areas already proposed or under consideration for State Parks or Preserves

$p$ Mille Lacs State Park. Mille Lacs County. Mature hardw ood forest; coniferous forest; one of the finest regions of the state.

pCamden Hills State Park. Hilly country; springs; origin of Redwood River; mixed deciduous forest. Lynd, Lincoln, County.

pLake Benton Park. North shore of Lake Benton; in prairie region; mixed deciduous forest along lake shore. Lake Benton, Lincoln County.

pLake Sarah Park. In region of terminal moraines, hilly to rolling prairie region; mixed deciduous forest along streams and lake shores. Slayton, Murray County.

$p$ Worthington State Park. On the edge of terminal moraines, level to rolling; lakes and streams; deciduous forest limited to lake shores and along streams. Worthington, Nobles County.

pPipestone State Park. Marking the locality of the famous "Pipestone quarry 
where the ancient arrow maker made his arrowheads of sandstone." Extensive outcropping of red quartzite; waterfalls; small lakes. Pipestone, Pipestone County.

Wild Life and Game Refuges. In addition to the State Parks, Minnesota has set aside thousands of acres in various parts of the state as Wild Life and Game Refuges. These differ from the State Parks in that they embrace land which for the most part is privately owned and is to some extent under. cultivation.

Natural conditions are therefore not preserved to the same degree as in the State Parks especially so far as vegetation is concerned.

Four of these refuges, however, are absolute wild-life sanctuaries because all wild life within their boundaries is completely protected by law at all times. These refuges are indicated on the accompanying map as cross-shaded areas enclosed by heavy black outlines.

Their location and extent are as follows:

*Ramsey County Wild-Life Refuge. (G7.) 5000 acres, glacial topography, terminal moraines of Wisconsin drift, embracing groves of mixed hardwood forest, tamarack swamps, meadows, lakes, ponds, and streams. Located in N.W. Ramsey County. $10 \mathrm{mi}$. north of St. Paul.

*St. Croix River Wild-Life Refuge. (G7.) Embraces 3000 acres of river valley and river gorge, splendid mixed hardwood forest with scattered white pines, numerous cold springs and streams. One of the richest regions of the state for wild flowers as well as Pteridophytes and Bryophytes. N.E. Washington County. $5 \mathrm{mi}$. north of Stillwater.

*Martin County Wild-Life Refuge. (G7.) Embraces 760 acres of undulating or rolling glacial till, numerous lakes and streams; deciduous hardwood forest mostly along streams and lakes. S.E. Martin County, near Fairmont.

*Morrison County Wild-Life Refuge. No. 2. (G7.) Embraces 1060 acres. Glacial topography. Moderately to considerably rolling, low and swampy areas alternating with moraines. Mixed hardwood forest, near the border of continuous coniferous forest. S.W. Morrison County. About $10 \mathrm{mi}$. S.W. of Little Falls.

The remaining Refuges of the state afford uninterrupted protection for all game animals as there are no open seasons within their limits.

The unprotected mammals and outlawed birds. however, may be hunted and killed at any time and this permits of more or less shooting and disturbance. Within this type of refuge, therefore, there is not the complete freedom from annoyance which obtains in the other refuges and State Parks.

Because of the fact that these refuges are comparatively numerous and of each of considerable area they are of great importance to the wild life of the state. On the accompanying map they are indicated by parallel-line shading within heavy black outlines.

Areas which should be added to the various classes of State Preserves on account of their biologic and geologic interest.

Minnesota River Valley, near Savage. An area of about 300 acres, embracing heavily wooded north-facing bluffs, with ravines and clear streams; wet peaty meadows with Cypripedium candidum, Cypripedium hirsutum, Cypripedium parviflorum and Sarracenia purpurea in great profusion.

Minneapolis $10 \mathrm{mi}$. south. $\frac{1}{2}-1 \mathrm{mi}$. from Savage. Omaha R. R. and Electric Southern R. R. Dakota County.

Purgatory Swamp. Covering an estimated area of 200 acres. Typical tamarack swamp with a few ridges covered with hardwood forest; contains many elements of the coniferous forest more particularly the northern swamps.

Minneapolis $15 \mathrm{mi}$. west. $\frac{1}{2} \mathrm{mi}$. north of Clear Springs Station on Minnetonka Electric R. R.

${ }^{*}$ Crystal Lake. Approximately 40 acres. Glacial topography. Swamps, lakes and streams; deciduous forest; mostly elm, oak, maple and basswood, with a rich herbaceous flora.

Minneapolis $5 \mathrm{mi}$. north. One mile from Robbinsdale. Mpls. \& Robbinsdale Electric R. R. Hennepin County.

Moore Lake. An estimated area of 400 acres including a shallow, grassy, lake about $\frac{1}{2} \mathrm{mi}$. long. Shifting sand dunes along west shore, in some places moving into the lake; typical dune vegetation. Many species of birds nesting in the reeds of the lake.

About $3 \mathrm{mi}$. north of Minneapolis.

Cannon River valley. An area of approximately 600 acres of river valley at the junction of Belle Creek with the Cannon River. Heavily forested north slope, forested river and creek bottoms; great profusion of spring flowers in early May, and a great many species of song birds.

Redwing $12 \mathrm{mi}$. northwest. One to two mi. southeast of Welch. Ch. \& Gt. Nor. R. R. Goohue County.

Hemlock Grove. An area of 280 acres in southern St. Louis County; Rough 
glacial topography. Northeastern coniferous forest in which the dominant species is the hemlock (Tsuga canadensis). This is an isolated grove, marking the northwest limited of the species and situated about $60 \mathrm{mi}$. northwest of the hemlock forests of Wisconsin.

Floodwood $8 \mathrm{mi}$. southeast. Gt. Nor. R. R. 2 mi. northeast of Paupores Station.

Gwinn's Bluff. One of the most picturesque bluffs of S.E. Winona County rising nearly $500 \mathrm{ft}$. over the Mississippi River, flowing along its N.E. base, and situated within the driftless area. The lower slopes of the bluff are covered with a dense hardwood forest; along a stream at the north end of the bluff occurs the witch-hazel, and this spot marks the northwestern limit of the species; nearby is an isolated outpost of Claytonia Chamissoi which occurs typically in the Rocky Mts. and Alaska. The summit of the bluff is composed of dolomite and in the crevices and on upper ledges of this formation occurs a patch of white cedar or arbor vitae which must be regarded as a relic since the nearest station in Minnesota is situated fully $160 \mathrm{mi}$. farther north.

Winona $18 \mathrm{mi}$. S.E. Chi. Milwaukee, \& St. Paul R. R.

About $2 \mathrm{mi}$. below (a) Richmond. Winona County.

Jack Pine Grove. About 40 acres, situated on a sandy north-facing hillside in the Root River Valley, about $3 \mathrm{mi}$. west of Rushford.

An isolated grove of typical jackpine situated on the border of the Driftless Area, containing in addition to the pine many elements of the northern jack pine forest. Obviously a relic.

Rushford, Chi. Mill. \& St. Paul R. R. Fillmore County.

Heron Lake. A shallow inland lake in the prairie region of S.W. Minnesota. About $12 \mathrm{mi}$. long, very shallow in the northern portion, and filled with tall grasses, rushes, sedges, cat-tails and other aquatic plants. Shores with mixed deciduous forest, marshy places with willows. One of the famous nesting places for aquatic birds in Minnesota. Among the species which are still common and nesting among the reeds and grasses in early summer are: The American and least bittern, red-winged and yellow-headed blackbird, coot, mallard, pintail, redhead, Florida gallinule, piedbilled grebe, Franklin's gull, Wilson's phalarope, Sora rail, Virginia rail, blue-winged teal, black tern, Forster's tern, swamp sparrow, and prairie marsh wren. Heron Lake, Chi. St. Paul, Minn. \& Omaha R. R.
Jackson County.

Hell Hollow. A place of great geologic interest embracing an area of about 400 acres of precipitous river bluffs along the west side of the Mississippi River, near the southeast corner of the state. Lower slopes heavily clothed with a mixed hardwood forest; upper slopes with perpendicular dolomite ledges in the crevices of which grow red cedar and white pine. In a recently eroded ravine are exposed successively almost down to the river level the Cambrian strata of shale, various sandstones, and magnesium limestone.

About $2 \mathrm{mi}$. N. of Reno. Chi., Milwaukee, and St. Paul R. R. Houston County.

Winnishiek Bottoms. An area of bottom lands extending along the Mississippi River, a distance of over $300 \mathrm{mi}$. from Wabasha, Minn., to Rock Island, Ill. Izaak Walton League Monthly, Vol. 1 No. 2, pp. 1, 25, 29, August, 1923. Vol. 1, No. 11, pp. 1, 600-601, 623, July, 1923. See Illinois Account.-P. $L$. Ricker.

\section{BIBLIOGRAPHY}

1. Nelson, N. P. B. Observations on Some Algae Which Cause "Water Bloom." Minn. Bot. Studies, 3: 56. 1903.

2. Roberts, T. S. Review of the Ornithology of Minnesota. Research Publications of the University of Minnesota 7: No.2. 1919.

3. Upham, Warren. Catalogue of the Flora of Minnesota. Geological and Natural History Survey of Minnesota, Part 4 of Annual Report. 1883.

4. Upham, Warren. Minnesota Geographic Names. Minn. Hist. Soc. Coll. 17: 1920.

5. Winchell, N. H. Geological and $\mathrm{Na}$ tural History Survey of Minnesota. 1-6: 1875-1901.

6. Legislative Manual of Minnesota. 1921.

\section{WISCONSIN}

\section{By A. S. Pearse}

\section{GENERAL FEATURES AND ORIGINAL} BIOTA

Wisconsin is essentially a plain, though there are highlands in the north and west. All except the southwestern quarter of the state is covered with glacial deposits, which rest upon Precambrian, Cambrian, and Silurian 
rocks. There are many beautiful lakes throughout the glaciated areas. The greater part of the state was formerly covered by coniferous forests; portions of the southern half by oak and maple, interspersed with swamps and prairies. The mean annual temperatures now vary from $39^{\circ}$ in the north to over $47^{\circ}$ in the south, the average being $43^{\circ}$. The mean annual precipitation is about 36 in. ranging from 28 to $44 \mathrm{in}$. in various parts of the state.

In days gone by the beaver, Virginia deer, timber wolf, wolverine, red squirrel, porcupine, black bear, ruffed grouse, barred owl, and fox snake were common in the northern coniferous forests. Further south, the hardwoods were populated by Virginia deer, gray and fox squirrels, chipmunk, cottontail rabbit, red fox, etc. The sloughs along the Mississippi and Fox Rivers and the swamps along lakes and rivers throughout the state were resorts for water fowl, mink, and muskrat. In the sandy areas as far north as the middle of the state lizards ran about among cactus and other xerophytic plants. On the prairies in the southwest were herds of bison, with prairie chickens and ground-squirrels. In northern waters the muskellonge and lake trout were more or less characteristic fishes. The mud-puppy (Necturus maculosus) and painted turtle (Chrysemys marginata bellii) ranged throughout the state. For further information on animals see accounts of Minnesota, Illinois, and Michigan.

The northern coniferous forests have been largely cut and burned over, but retain many of their original characteristics and in some places are primeval. 159,000 acres of this land, which is chiefly in Oneida and Vilas Counties, is under state supervision as forest reserves. Here Virginia deer, and in some places even beaver, are quite common. Away from settlements the porcupine and black bear are found. Ruffed grouse are protected and in many localities are common. In the south the hardwood forests have generally been replaced by farms and dairies.
The cottontail rabbit, ground-squirrel, and quail remain fairly common. The opossum is rare in the southeastern corner of the state, and the wood turtle occurs in sandy areas in the west. The cardinal is rather uncommon on the southern border, except on the Mississippi bottoms, where it occurs in considerable numbers.

The lakes in the south have been more or less "fished out," though carp, buffalo, and other fishes are usually abundant. The Northern lakes continue to furnish many game fishes, such as pickerel, bass, and sunfish. Certain of the deeper inland lakes and the Great Lakes contain ciscoes. The rock sturgeon is very rare but the little hackleback continues to flourish in the Mississippi and certain of its tributaries.

\section{Mollusca}

It has been observed that ecologically the fresh water molluscan fauna is divisible into groups which contain characteristic species or varieties. Thus, the lakes have one assemblage of species; the large rivers, as the Mississippi, another; the medium sized rivers, as the Wisconsin and St. Croix, another; the very small rivers, as the Fox and Red Cedar in Wisconsin, another, while the small swales and pools have still another. In most cases, species inhabiting several of these diverse habitats differ varietally and the general character of a stream may be predicted by the form of a species which has been collected from it. This appears to be a law of ecology which has been observed in several places, as in Ohio, Kentucky, Wisconsin, Michigan, Illinois, and Indiana. It is probably widespread, and when other localities are carefully studied it may perhaps be found to apply universally. The Mollusca are admirably adapted to reflect the character of the environment, but little attempt has been made in most states to study the mollusk fauna from this standpoint. Most of the published lists are distinctly systematic. A full discussion of this subject will be found 
in Baker's Monograph of the Mollusca of Wisconsin, now in preparation.F. C. Baker.

\section{NATURAL AREAS}

*Pattison Park. (A3.) An area of 660 acres, containing a falls in the Black River, $165 \mathrm{ft}$. high. Covered with a mixed forest of hardwoods and pine. Most of the area was cut over years ago, but has grown up in a fair way at the present time. Soil clay-loam. Located $12 \mathrm{mi}$. south of the city of Superior, Douglas County, C. M. \& St. P. R. R.

* Brule Park and Forest Lands. (B3.) Area 4221 acres, all cut over about 25 years ago, but has since grown up to poplar, mixed hardwoods and some pine. Sandy land. Portions of these lands adjoin the river, others lay back but along the valley. Located along the Brule river valley, in the vicinity of the village of Brule, Douglas County. N. P. R. R.

*Vilas and Oneida Counties. (A3.) State Land Area. (C2.) 200,000 to 300,000 acres in the lake region of these counties. Larger portion cut over. Some virgin timber, mixed hardwoods, hemlock and pine. Many lakes stocked with regulation game fish and streams containing trout. Land varies from lean sands to fertile loams. Country level to rolling. Population sparse. Lands most accessible from the village of Woodruff in Oneida County. C. \& N. W. R. R.

*Coniferous Forest on Lake Muskalonge. (A4.) 27 acres of original white pine on lake shore, with sandy shore, lake, many birds. Preserved by C. G. Pearse, Milwaukee. Located in Vilas Co., $1620 \mathrm{ft}$. Sayner, $6 \mathrm{mi}$. east. C. M. \& ST. P.

*Nelson-Dewey Park. (B2.) At the junction of the Wisconsin and Mississippi rivers. An area of 1651 acres bluff land covered with mixed hardwoods, oak, walnut, soft maple, etc. Portions of this area have been farmed, balance partially cut over. Located $4 \mathrm{mi}$. north of Wyalusing, in Grant County. C. B. \& Q. R. R.
*Interstate Park. (B2.) 580 acres along the St. Croix river. Large fish hatchery being established at this point. Rough, rocky land, with mixed forest of hardwoods and white pine. Small lake formed by back water from the river on this area contains carp in some quantities, also a limited supply of game fish. Large springs rise on portions of this park. These supply the trout hatchery with exceptionally fine water. Area has been partially cut over in years gone by. Located one-half mile from the village of St. Croix Falls in Polk County. C. B. \& Q. R. R.

*Bird islands. (A3.) Islands of unknown area. Nesting site of gulls and mergansers. Strawberry, Hat and Jack Islands. Located $40 \mathrm{mi}$. north of Sturgeon Bay, Wis. Lake boats.

*Peninsular Park. (A3.) 3190 acres of mixed farm and forest land. On the Green Bay shore. Bluffs rise $250 \mathrm{ft}$. above the bay. Forest type of mixed hardwood, hemlock and pine. Many of the old farm areas have been planted to coniferous trees. Located near the village of Fish Creek, Door County. Stage from Sturgeon Bay, or lake boats.

${ }^{*}$ Neil Coniferous Forest. (A3.) 6 acres coniferous forest with ravines, hills, swamps and springs. Located in Neil County; Neil, Wis., $9 \mathrm{mi}$.

*Idlewild Refuge. (B4.) Area of approximately 1200 acres in the bottoms of the Mississippi river. Covered with bottom land type of timber, soft maple, ash, river birch, etc. Near Fountain City, Buffalo County. C:B.\& Q. R. R.

*Perrot Park. An area of 910 acres along the Mississippi bluff land, practically all cut over. Predominating species-oak. Presented to the state by John A. Latsch of Winona, Minnesota. Location adjoins village of Trempealeau in Trempealeau County. C. \& N. W. R. R.

*Fox River Wild Rice Fields. (A3.) $70 \mathrm{sq}$. mi. deciduous forest, deciduous savanna, some evergreen, birch, marsh, bogs, with hill, bluff, shore, sand, and rocky and glacial topography, swamp, pond, lake, river, spring. Winnebago 
County, on Lake Beaut des Morts, Winnecone, Poygan and the Fox and Wolf Rivers, including Rush Lake, Lake Winnebago, Lake Beaut des Morts, 65 sq. mi. of water and marsh of which 20 is estimated to be marsh. Rush Lake is a shallow lake $67 \mathrm{sq}$. mi. in area. Lake Beaut des Morts 3 sq. mi. Lake Winnebago 12 by $30 \mathrm{mi}$. Few places offer as good opportunities in study of aquatic marsh and bog life in this vicinity. The marsh will probably always remain about the same unless drained. Located in Winnebago County, Oshkosh, Wis., 8-20 mi. C. M. \& ST. P. R. R.-C. B. Terrell.

*Sheboygan Preserve. (B4.) 6000 acres deciduous and coniferous forest, glacial topography swamps, deer present. Boreal fauna, a cedar swamp far south. Should be preserved by the state. Located near Sheboygan, Wis., 1 mi., C. \& N. W. R. R., C. M. \& ST. P. R. R.

*Milwaukee Tamarack Swamp. (A4.) 10 acres, owned by the Wild Life Protective Society. Located in Milwaukee County, $600 \mathrm{ft}$; Milwaukee, $3 \mathrm{mi}$.

*Swamp on Green Lake. (B2.) 80 acres sand area, swamp, marsh, pond, river, waterbirds and muskrats. Preserved by Norton Bros., Green Lake, Wis. On shore of Green Lake, $815 \mathrm{ft}$.; Green Lake, 6 mi. north, C. \& N. W.

*Devils Lake Park. (B3.) An area of 1113 acres rough rocky land. Devils Lake $1 \frac{1}{4} \mathrm{mi}$. long, $\frac{1}{2} \mathrm{mi}$. wide, maximum depth 50 feet. Contains pike, bass, pickerel, suckers, etc. Land well wooded, oak predominating, with white pine in the rockier areas. Located 3 mi. south of Baraboo, Sauk County. C. \& N. W. R. R.

*Devils Lake Forest. (B3.) $\frac{1}{2}$ sq. mi. deciduous forest, sand area, talus slope, loose deposit, hills, bluffs, shores, sandy and rocky glacial topography, lake and spring. Located near Devils Lake, Sauk County. Baraboo, Wis., $4 \mathrm{mi}$. Eliot Blackwelder.

*Okauchee County Lake. (B2.) 50 acres hill, shore, glacial topography; swamp, lake, river, spring. Beautiful lake with swampy shores on one side, good hills on the other. Well wooded and entirely natural. Abundant with life, both plant and animal. Should be made a state game farm. Located in Waukesha County, 1 mi. south of Okauchee, Wis., C. M. \& ST. P. R. R.-A.R. Cahn.

*Bark River. (C3.) 8 acres level plain with shore, marsh and river. Gift to the state. Located near Bark River. Waukesha County. $850 \mathrm{ft}$. Delafield, $\frac{1}{2}$ mi. east. C. M. \& ST. P.

*Pabst Forest Preserve. (F6.) 1000 acres broadleaved and evergreen woods, hill, shore, glacial topography. Particularly good swamp, lakes, Genesee river. Owned by Mr. Gus Pabst, who is using it as a fancy game preserve. Well kept. No fishing, no hunting. Swamp and lake areas very important and unimproved. Located in Waukesha County, $850 \mathrm{ft}$. Oconomowoc $6 \mathrm{mi}$.A. R. Cahn.

*Pabst Swamp Preserve. (B2.) 30 acres sand area with some gravel. Level plain, shore, sandy and glacial topography, swamp, pond, lake. Mud Lake and Aunt Polly's Washtub, about $10 \mathrm{ft}$. deep, with neither inlet nor outlet. Good for botanical studies. Abundant micro-fauna; ideal bird breeding ground. Good place for state game park. Now owned by Mr. Fred Pabst, and is protected. Located in Waukesha County, Oconomowoc, Wis., 2 mi. north. C. M, \& ST. P. R. R.

\section{REFERENCES}

Juday, C.

1914. The inland lakes of Wisconsin. The hydrography and morphometry of the lakes. Wis. Geol. \& Nat. Hist. Surv. Bull.

Martin, L. 27: $x v-137$.

1916. The physical geography of Wisconsin. Wis. Geol. \& Nat. Hist. Surv., Bull. 36: xxii-549.

Wisconsin Conservation Commission issues pamphlets describing the state parks. 


\section{ONTARIO}

By C. D. Howe and J. R. Dymond ${ }^{1}$

\section{GENERAL CONDITIONS}

The greater portion of the province is very thinly inhabited. More than one half its area has no permanent population and has been only roughly explored. Over $80 \%$ of the population is confined to an area of 30,000 sq. mi., which may be found south of a line drawn from the southern end of Georgian Bay on Lake Huron to the city of Ottawa.

\section{Topography and climate}

The greater portion of the Province drains into Hudson Bay. Although extensive agricultural areas are being developed in the northern region, most of the agricultural and populated portion at present belongs to the St. Lawrence drainage basin. The agricultural areas are for the most part underlain by limestones and shales, which have been largely covered with glacial drift. There are, also, sedimentary rocks in a band from 25 to $100 \mathrm{mi}$. wide around James Bay. The remaining portion of the province consists chiefly of crystalline rocks in much of the area so near the surface, that it will probably remain for all time as forested land. The physiography of the vast forested area is that of a partially dissected peneplain. It has a general elevation of 1,000 to $1,500 \mathrm{ft}$. with a relief which is usually less than $300 \mathrm{ft}$.

It extends through $15^{\circ}$ of latitude in a north-south direction and through $21^{\circ}$ of longitude in an east-west direction, it displays considerable variation in climate. The precipitation is equally distributed as to seasons and ranges from 20 to 40 in. while the growing season varies from 150 days in the Niagara Peninsula to 60 days in the Hudson Bay region.

\footnotetext{
1 I am indebted to Mr. J. H. Fleming for advice and assistance in the preparation of the faunal
accounts.
}

\section{ORIGINAL BIOTA}

\section{Deciduous and mixed forest}

The character of the forest varies with the climate. The district lying between Lake Huron and Lake Erie has the hardwood flora of the Ohio valley, and the northern part of the province has a coniferous forest flora.

a. Plants. The basis of the southern forest, which has now almost entirely made way for agriculture, was maple (Acer saccharum), oak, elm, chestnut (Castanea dentata) and hickory, with tulip (Liriodendron tulipifera), black walnut (Juglans nigra), hackberry (Celtis occidentalis), sassafras (Sassafras variifolium), as secondary species. This area is represented in practically virgin condition by Rondeau Park.

A line drawn from the most western point of Lake Ontario to the southern most point of Lake Huron marks the northern boundary of the southern hardwood forest. Outliers of this type, however, may be found as far north as Toronto on Lake Ontario and as Goderich on Lake Huron. Northward and eastward of these points to the line mentioned in the first paragraph, the forest is chiefly represented by farm woodlots and at the present time they consist of hardwoods, mostly maple, elm, beech, basswood (Tilia americana), hop horn-beam (Ostrya virginiana), with northern white cedar (Thuja occidentalis) swamps in the depressions.

Along the southern border of the crystalline rock, sugar maple comprises about $50 \%$ and beech $25 \%$ of the hardwood forest; basswood $10 \%$, yellow birch (Betula lutea) 6\%, hemlock (Tsuga canadensis) $3 \%$, white ash (Fraxinus americana), balsam fir (Abies balsamea), American elm (Ulmus americana) each about $1 \%$. As one goes northward, the beech and basswood drop out, and then the maple, yellow birch making up the deficiency until it becomes dominant. The hardwood forest occupies the deeper glacial drift soils, which for the most part are very stony loams, and it usually caps the low!ridges. 


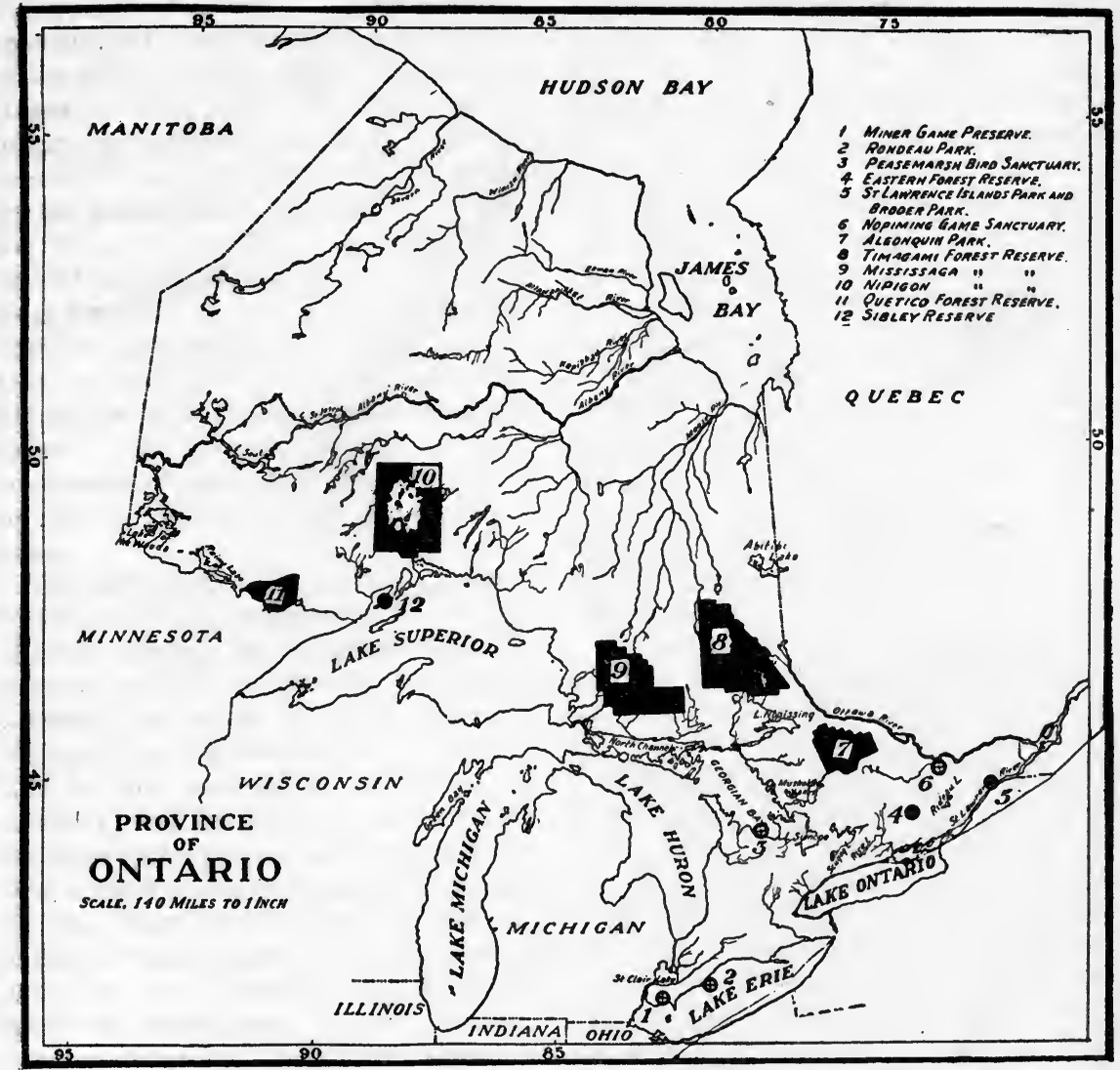

Fig. 10. Map of the Province of Ontario Showing the Location of Forest and Game Reserves 


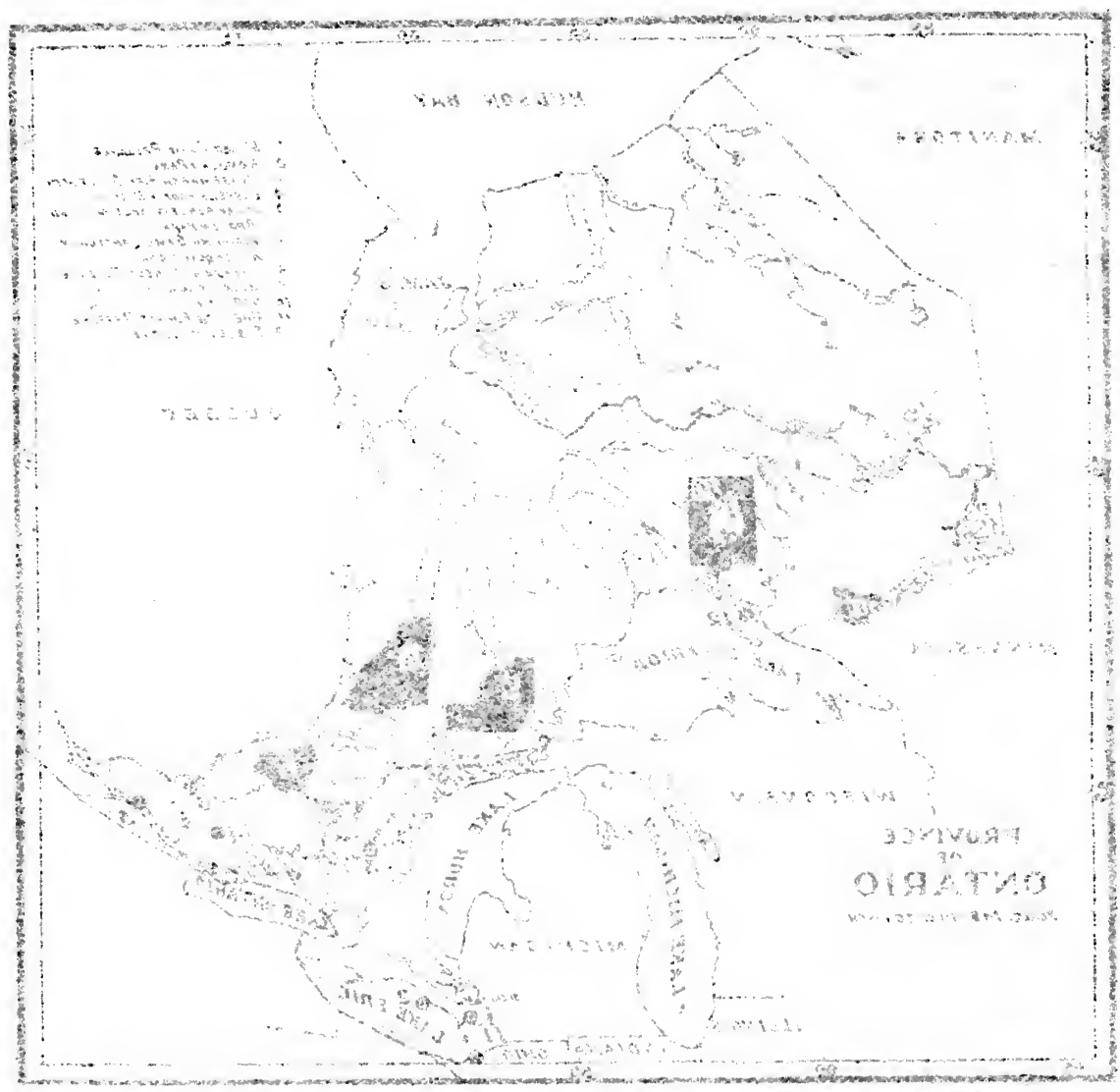

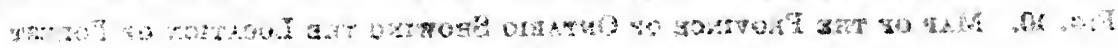




In the southern portion of Ontario, exclusive of the Niagara peninsula, the pure hardwood forest probably occupied about one quarter of the original forested area. A pine forest, consisting of white pine (Pinus strobus) and red pine (Pinus resinosa), mostly the former, was the most widely distributed type. It occupied two situations: one, the extensive outcrops of sandy soils deposited in glacial lakes that at one time or other occupied much of the region, and the other, the granitic ridges of thin soil. This pine forest originally occupied about $60 \%$ of the area and it has now been largely replaced by the poplar-birch associations following forest fires. It is probable that on not more than one-fifth of the area thus occupied is the pine reproducing itself in potentially commercial quantities, so that it will be a very long time before the pine forest will be re-established. The Eastern Forest Reserve represents to perfection the conditions on the repeatedly burned areas of this type.

The remaining $15 \%$ of the original forested area of southern Ontario, as defined above, was represented by various mixed hardwood coniferous associations, of which there were at least four well marked kinds. One was due to the increasing occurrence of hemlock, and the other to the intrusion of white pine in the hardwood stands. The former was particularly noticeable in the Georgian Bay district and the latter is still noticeable in the present northern and western distributional areas of white pine. In the northern portion of the area designated as southern Ontario there was some admixture of balsam fir and spruce (P. canadensis and $P$. mariana) among the hardwoods, but probably never as extensive as the hemlock and pine mixtures. The fourth mixed association is the ordinary black ash-white cedar-balsam fir swamp.

The three types described above, namely, the pure hardwood, the pine, and the mixed forest can all be found in Algonquin Park, where the mixed type occupies about $55 \%$ of the area; the hardwood forest, in which yellow birch is dominant and of fine quality and the sugar maple subordinate and of poor quality, 20\%; the poplar-birch association, representing the old pineries, $20 \%$. Beautiful illustrations of pure hardwood stands and mixed stands in practically virgin condition are to be found within easy reach of Headquarters (Algonquin Park Station) on the Canadian National Railway. The railway from Parry Sound to Ottawa cuts through the southwestern portion of the Park and the railway (also Canadian National) from North Bay to Ottawa traverses the northern and eastern portions. The former passes through the less undisturbed forests of the Park, while the latter route displays more of the present condition of the old pineries.

Forest conditions essentially as described above are to be found extending westward along Lake Huron to the Sault in a strip about $50 \mathrm{mi}$. back from the shore. They appear again west of Lake Superior in a strip of about the same distance north of the international boundary line.

b. Animals (J.R. D.). The larger animals of the southern faunal region as described above have long been exterminated and there remain only the smaller forms such as muskrat (Ondatra z. zibethica), woodchuck (Marmota monax rufescens), raccoon (Procyon $l$. lotor), skunk (Mephitis mephitis group), mink (Mustela vison group), weasel (Mustela n. noveboracensis), red squirrel (Sciurus hudsonicus group), gray squirrel (Sciurus carolinensis group) and chipmunk (Tamias striatus group). As Fleming ${ }^{2}$ has pointed out the cottontail rabbit (Sylvilagus floridanus mearnsii) was probably not indigenous to Ontario, but since its appearance here more than fifty years ago, has spread over the whole southwestern peninsula of the province. The European hare (Lepus europaeus) introduced in $1912^{3}$ has also become

\footnotetext{
2 Ottawa Naturalist, vol. XXII, pp. 158-159, 1908.

3 Canadian Field-Naturalist, vol. XXXVI, pp. 142-143, 1922.
} 
distributed over much the same territory as the cottontail rabbit although it has not yet spread quite as far north or east as that species. The Virginia deer (Odocoileus virginianus borealis) formerly occupied this whole area but has long been exterminated except where given sanctuary protection as in Rondeau Park and in a few isolated areas unsuitable for agriculture. The elk (Cervus canadensis) inhabited the extreme southwestern part of this area originally, although it is perhaps one hundred and fifty years since this deer occurred wild in Ontario. The bob-cat (Lynx r. rufus) is now nearly, if not quite extinct in the province; it formerly occurred in the more southern parts of this area. Some typical birds of the region are bob-white, mourning dove, yellow- and black-billed cuckoos, bobolink, meadow-lark, Baltimore oriole, towhee, catbird and wood thrush. The extreme southwestern portion of the province, especially a strip along Lake Erie is often considered as belonging to the Carolinian Zone of Merriam. Rondeau Park has been set aside to preserve the original forest which still stands there. Of the birds we have in this small area a few species of distinctly southern aspect, including the yellowbreasted chat, mockingbird, Carolina wren, cardinal, red-bellied woodpecker, orchard oriole and barn owl. The wild turkey was an original inhabitant of this zone.

\section{Coniferous forest}

The vast area north of the Great Lakes and of a line extending along the French River, through Lake Nipissing west to the Ottawa River, is usually called northern Ontario, and it represents for the most part the present commercial forest area of the province.

a. Plants. North of the French River-Lake Nipissing line to the height of land the forest becomes more prevailingly coniferous, with spruce and balsam fir growing in importance. To be sure, there are scattered patches of beech, maple and yellow birch in pure stand or in mixture on the northern slopes of hills or in protected valleys nearly or quite to the James Bay-St. Lawrence water parting, but north of these points the trees are of inferior or stunted growth. White and red pine are found in commercial stands to the height of land, especially to the westward. Such stands at their northern limit and varying in age from 150 to 250 years can be seen in the Timagami Forest Reserve within a short distance from the Timagami railway station. While there are frequent jack pine stands in the northern portion of southern Ontario, the outcrops of gravelly sand plains are more extensive in northern Ontario and consequently such stands form a large portion of the forest.

The prevailing broad-leaved species in northern Ontario are poplar ( $P$. tremuloides and $P$. balsamifera) and paper birch. Their distribution has been greatly extended through the agency of forest fires, but these species are undoubtedly subordinate but constant components of the climax forest. Paper birch apparently outnumbers the poplar until the height of land is reached. They occur on the heavier and better drained soils.

It is probable that the greater portion of the area now under review, that is from the French River-Lake Nipissing line to the height of land, was originally occupied by mixed associations, chiefly spruce, balsam fir, white pine and paper birch, with the conifers predominating. One is impressed with the numerical abundance of balsam fir in the understory, but it enters only sparsely into the dominant crown cover.

The southern portion of the James Bay drainage area is deeply covered with stratified and unstratified glacial deposits, the greater portion of which is silt loam and clay, so it is popularly designated as the Clay Belt. It stretches in Ontario from the Quebec boundary westward to near Lake Nipigon. In the eastern portion, it begins with the water parting, but at its western limit the southern border is about 
$50 \mathrm{mi}$. from the height of land. The Clay Belt covers an area of nearly 25,000 sq. mi.- one half the size of the State of New York.

A recent survey of approximately three million acres in the Clay Belt in those portions of the Abitibi-Mattagami drainage basins lying north of the National Transcontinental Railway indicates that approximately 60 per cent of the land area is covered with a black spruce forest about equally divided between muskegs and poorly drained upland soils. The remaining 40 per cent is again approximately equally distributed between the mixed associations and burned areas. Since the latter are on the best drained areas, it may be assumed that they originally were of the mixed association character. Another point of evidence in this direction is that the older burns show coniferous reproduction beneath the poplar stands. The mixed associations are composed of white spruce, balsam fir, black spruce, balsam poplar, aspen and paper birch. Usually the conifers form over half the stand.

The National Transcontinental Railway passes through the central portion of the Clay Belt throughout its entire length, traveling east from Winnipeg, it is first encountered near Paska station, about $\mathbf{4 7 5} \mathrm{mi}$. east of that city.

Little is known about the forest conditions in the northwestern portion of the Province in districts not traversed by railways. It seems evident, however, that the proportion of jack pine increases as one goes westward, and, also, that the mixed associations are of more frequent occurrence.

It may be said in this connection that as our knowledge of northern Ontario increases, some revision will be necessary in the conception of the pure coniferous forest as the climax type. The forest of this character is apparently found only in the swamps and on the poorly drained areas, and such areas do not dominate the topography until the James Bay coastal plain is reached. b. Animals (J. R. D.). This conifer- ous forest of the north is the home of the moose. North and west of Lake Huron and Lake Superior the moose is still common but south of the French River it is rare except in sanctuaries and even these is much less common than farther. north. The woodland caribou which until comparatively recently wintered as far south as the north shore of Lake Superior has now largely abandoned this area except in the extreme north. The white-tailed deer has been steadily extending his range until today he is found far beyond the National Transcontinental Railway. His centre of abundance, however, is much farther south. In this part of Ontario we still have the black bear (Ursus americanus), timber wolf (Canis lycaon), Canada lynx (Lynx canadensis), fisher (Martes pennanti), marten (Martes americana), porcupine (Erethizon dorsatum), beaver (Castor canadensis), otter (Lutra canadensis), snowshoe hare (Lepus americanus), muskrat (Ondatra zibethica), mink weasel (Mustela vison group), woodchuck (Marmota monax canadensis), red squirrel (Sciurus hudsonicus), eastern chipmunk (Tamias striatus lysteri), and in the western part of the area the western chipmunk (Eutamias minimus group). The larger animals of this list are naturally commoner in the more inaccessible and more thinly settled districts of the north. The wolverine (Gulo luscus) was never abundant even in northern Ontario and is now to be found only in the extreme north. Among the characteristic birds of this area may be mentioned the whitethroated sparrow, olive backed thrush, northern pileated woodpecker, spruce grouse, and Canada jay.

\section{NATURAL AREAS}

*Point Pelee. (C4.) Federal Bird Sanctuary, in which duck shooting only, is allowed for a short season. Size, about 7 by $4 \mathrm{mi}$. The basal 2 by 4 mi. drained and cropped. Remainder mostly marsh near the base, a narrow strip of sand at each side for $3 \mathrm{mi}$. 
varying to $\frac{1}{2} \mathrm{mi}$. at the widest on the west side; the final narrow $2 \mathrm{mi}$. all sand. All of the dry area, except a small cultivated area is covered with forest, in which are many original trees; in Auvorg Forest is maple, walnut, oak (many species), ash, elm, and conifers, red cedar and white pine. Along the east sand strip are many willows, but most of that area is swept by wind and water, and is bare.

Cottontail rabbit and red squirrel common; Chipmunk gone; several mice, shrews, and moles (Scalopus) occur, which are very rare elsewhere in Ontario.

Leamington Ont., $4 \mathrm{mi}$. N. W. of base of Point. L. E. \& D. R. Ry., and Electric line from Windsor.-W. E. Saunders.

*Algonquin Park. (A2.) Located in east-central portion of Ontario. Low rounded hills and ridges, a dissected peneplain; lakes, rivers, peat bogs and marshes. About 1,700,000 acres; transition, mixed forest type, yellow birch, sugar maple, paper birch, red spruce, balsam fir, white pine and red pine; all stages of succession after fire. Beaver, Virginia deer, moose, otter, mink, marten, fisher, muskrat. Fish and game preserve; bird sanctuary. Pembroke, Ontario. $106 \mathrm{mi}$. east. Grand Trunk Ry. Official headquarters and hotel, Algonquin Park, Ontario.C. D. $H$.

*Quetico Park. (A1.) Located in western Ontario, a continuation in Canada of the Superior National Forest in Minnesota. Low hills and ridges, abundant lakes, ponds and peat bogs. About 1,000,000 acres. Northern coniferous forest; pine, spruce, balsam fir. All stages of succession after fire. Beaver, Virginia deer, moose. Fish and game preserve; bird sanctuary. Windigo Station on the Canadian Northern Ry. $12 \mathrm{mi} .-C . D . H$.

*Rondeau Park. (B3.) Located in southern Ontario, Kent Co., on Lake Erie. Sand dunes, swamps and marshes. About 5000 acres. A remnant of virgin forest, southern hardwood type. Game preserve and bird sanctuary. Ridge- town, Lake Erie and Detroit River Ry. $12 \mathrm{mi} .-C . D . H$.

*Nipigon Forest Reserve. (A1.) The Nipigon Forest Reserve comprises 7297 sq. mi. of northern coniferous forest surrounding lake Nipigon, $80 \mathrm{mi}$. north of Lake Superior. Located on Laurentian plateau. Lake Nipigon (1769 sq. mi. including the islands; $852 \mathrm{ft}$. above sea level) occupies a central depression. Many smaller lakes between the rounded rocky elevations are characteristic of Laurentian country; numerous rivers, usually swift, often with rapids and falls in their courses enter the lake; virgin forest of spruce, balsam fir, poplar, birch with occasional areas of jack pine and tamarack; moose, Virginia deer, caribou (occasionally in winter), black bear, wolverine, fisher, marten, beaver; whitefish, ciscoes (lake herrings), lake trout, speckled trout, pike perch, pike, and sturgeon; the wood frog (Rana cantabrigensis), mink frog (Rana septentrionalis).

Canadian National Railway to village of Orient Bay, Ont., where accommodation, including canoes, guides and equipment may be had.-J.R.D.

*Rondeau Park. (B3.) An area of 8 sq. mi. lying between Rondeau Harbour and Lake Erie contains finest piece of the original deciduous forest of southern Ontario including magnificent specimens of species now rare elsewhere such as black walnut, butternut, and sycamore.

Walk from Ridgetown on Michigan Central and Pere Marquette railways.

*Nopiming Game Sanctuary. (C3(b).) A small wild-life sanctuary near the town of Arnprior, Ontario. Comprises about 2000 acres of land, situated on south shore of Ottawa River between Madawaska and Mississippi rivers, its southern boundary being the Grand Trunk Railway right-of-way. About onethird is cleared farm land, remainder bush and swamp, bush second-growth mixed hardwoods and softwoods. Two small streams run through swampy "beaver meadows." Ruffed grouse, ducks, beaver.

Walk from Arnprior. 
Miner Game Preserve. (C4.) Consists of farm of Mr. Jack Miner, Kingsville, Essex County, Ontario, 200 acres and a surrounding protective zone of approximately 2000 acres. Visited each spring by about 4500 Canada geese during migration, also about 500 pond and river ducks, and several hundred whistling swans. Cleared farm land containing two large artificial ponds. For study and photography of geese and dqcks should be visited between April 10 and 25. Windsor, Essex and Lake Shore Electric Railway from Windsor, Ont.

Pearsemarsh Bird Sanctuary. (C4.) The farm of Miss Edith L. Marsh, situated on Georgian Bay in Grey County, Ontario. Consists of about 300 acres of upland with orchard, good arable farmland and rough pasture, also some areas of swamp and bush (birch, northern white cedar, hemlock, etc.). Bird and other wild life has been protected for many years.

\section{*Timagami Forest Reserve. (A1.)} An area of about $6000 \mathrm{sq}$. mi. to the west of lake Temiskaming and the upper Montreal River in the Province of Ontario. The most important single feature is lake Timagami in the southern part of the area. The lake (965 ft. above sea level) is about $30 \mathrm{mi}$. long from north to south and slightly less from east to west. The whole area is full of smaller lakes from $12 \mathrm{mi}$. in length down. The timber is red and white pine, spruce and balsam fir, with considerable patches of poplar; tamarack is reestablishing itself in places. Moose, black bear, wolf, Virginia deer, beaver are common; lake trout, speckled trout, black bass, pike-perch and pike abound. The reserve is most easily entered by the lake since Timagami Station on the Temiskaming and Northern Ontario Railway (from Toronto) is at the head of the northeastern arm of the lake. There is a Hudson Bay Co. post on Bear Island in the centre of lake Timagami, as well as a small hotel and several large permanent summer camps. Two vessels run daily during the summer from Timagami to the Post and the camps. Supplies are obtainable either at Timagami or the Post. Gowganda, a moribund mining centre lies in the northern half of the reserve.

*Sibley Reserve. (A4.) An area of 70 sq. mi. on the point of Thunder Cape, Lake Superior. Preserved principally to keep the promontory of Thunder Cape covered with timber, typical Laurentian plateau forest. (See Nipigon Reserves.)

*St. Lawrence Islands Park. (C3.) Consists of 13 islands and one mainland reservation, 140 acres in all, among the Thousand Islands of the St. Lawrence river, equipped for use of summer campers and visitors as places for outdoor recreation; more like town parks than natural areas.

*Broder Park. (C3.) 20 acres, an island in the St. Lawrence river opposite Morrisburg, near above park; well wooded. Grand Trunk Railway from Montreal or Toronto to Morrisburg.

\section{BIBLIOGRAPHY}

C. D. Howe. Life Zones. The Natural History of the Toronto Region, Ont., Canada, the Canadian Institute, Toronto, 1913.

P. A. Taverner. Faunas of Canada in the Canada Yearbook, 1915, has also been drawn upon especially in connection with bird lists.

\section{THE PROVINCE OF QUEBEC}

\section{By Geo. D. Fuller and Brother}

\section{MARIE-VICTORIN}

\section{GENERAL CONDITIONS}

\section{Topography}

The province of Quebec comprises an area of approximately $700,000 \mathrm{sq}$. mi. extending from the Gulf of St. Lawrence to Hudson Bay and James Bay. It lies between $45^{\circ}$ and $62^{\circ} 40^{\prime} \mathrm{N}$ and $57^{\circ}$ and $79^{\circ} 30^{\prime} \mathrm{W}$. Of its entire area $16,000 \mathrm{sq}$. $\mathrm{mi}$. are water comprising the surface of numerous small lakes which form a network through the northern part of the province.

The main physiographic divisions of the province are the St. Lawrence plain in the southwest, the Appalachian highlands in the southeast, whose hills 
reach the magnitude of low mountains in the extreme east and west, and the Laurentian highlands covering the greater part of the vast region north of the St. Lawrence River. These rise abruptly a short distance north of this stream, reach an altitude of about 1000 $\mathrm{ft}$. at the height of land and slope gradually to the north where they include vast lowlands about James and Hudson Bays. Much of this northern region is quite unexplored and nowhere has it more than a sparse population.

The St. Lawrence plain is underlain with limestones, possesses deep rich soils of clay and clay loam, modified in places by glacial drift, and is the most fertile part of the province where settlement began with the coming of the earliest French colonists. It skirts the north shore of the St. Lawrence and Ottawa rivers as a narrow strip of plain bordering the uplifted edge of the Laurentian peneplain between the cities of Quebec and Ottawa. South of the St. Lawrence it comprises all of the province lying west of a line running from the city of Quebec to Lake Champlain and marking the limits of the Appalachian highlands. It ranges from $100 \mathrm{ft}$. above the sea along the river to $400 \mathrm{ft}$. along the edge of the Appalachians. It presents to the eye a level surface interrupted by the Monteregian Hills, a double line of eight isolated peaks. These are composed of igneous rocks and stretch at intervals of 10 to $20 \mathrm{mi}$. from Mount Royal at Montreal to Shefford Mountain some $50 \mathrm{mi}$. to the east, varying in their elevation above the plain from $650 \mathrm{ft}$. for Mt. Royal to $1300 \mathrm{ft}$. for Yamaska, Shefford and Brome. The rugged slopes of these hills preserve the remnants of the deciduous forests which originally covered the plain.

The Appalachian range enters the province from Vermont and New Hampshire at a point just east of Lake Champlain and extends to the Gaspé Peninsula varying much in altitude. The eastern portion is known as the Notre Dame Mountains which reach a maximum altitude of $2800 \mathrm{ft}$. in Mt. Orford while under the name of Shickshock Mountains the peaks attain a height of $4000 \mathrm{ft}$. in Gaspé. Within this region the topography varies from plains with gently rolling hills of low elevation to rugged mountains. Only the tops of the higher mountains have escaped glaciation and the soils are mostly morainic varying much in texture and fertility. Less than one-fourth of this region is suited to agriculture in any form but it includes approximately 20,000,000 acres of forest.

The Laurentian highlands begin a short distance north of the St. Lawrence River and extend northward a distance of at least $500 \mathrm{mi}$. It seems doubtful whether the northern part of the Labrador peninsula, now a part of the province of Quebec, should be regarded as a portion of this physiographic unit. The surface characteristics of this northern region so far as they are known seem to be similar to those of the Laurentian highlands and together the two occupy $90 \%$ of the area of the province. On the whole it is a region of low relief and immature drainage. Granite and other crystalline rocks present surfaces planed and swept bare of soil by the ice sheets and remain as a vast expanse of low rounded hills that reach a maximum elevation of about $2000 \mathrm{ft}$. along the height of land some $300 \mathrm{mi}$. north of the St. Lawrence River. These rocks are well seen along the great cleft occupied by the Saguenay River where granitic cliffs rise perpendicularly from the water's edge to the level of the surrounding upland from 1000 to $1800 \mathrm{ft}$. above. The immaturity of the drainage is shown in the chains of innumerable lakes and in the great expanses of swamp and muskeg. As James and Hudson Bay are approached the elevation gradually decreases and great areas of muskeg and tundra occur at levels little above that of the waters of the bays. The only soils suited to agriculture are in the narrower valleys and their limited area together with the rigorous climate makes the region as a whole destined to remain permanently forested in so far 
as forest fires and the woodman's axe will permit.

The Canadian National Railways runs northwestward from the city of Quebec and passes over the height of land at Monet, $308 \mathrm{mi}$. from Quebec, at an altitude of $1454 \mathrm{ft}$. It affords an excellent opportunity of studying a section of the highlands.

\section{Climate}

The rainfall ranges from 25 to 45 in. throughout the portion of the province for which records are available. The distinctly continental characteristics of the western portion give way to those that are largely oceanic along the Gulf of St. Lawrence. In the south the temperatures range from a summer maximum of $95^{\circ} \mathrm{F}$. to a winter minimum of $-30^{\circ} \mathrm{F}$., with a growing season of 120 days. There are all gradations between this and a growing season of 60 days in the north.

\section{Vegetation}

The forests of the St. Lawrence plain were similar to those of eastern Ontario (q.v.). They were of the mixed hardwood type in which maple (Acer saccharum) and beech (Fagus grandifolia) with a mixture of hemlock (Tsuga canadensis) and yellow birch (Betula lutea) dominated the climax areas. In the western portion of the area red and burr oak (Quercus rubra and $Q$. macrocarpa) and hickory (Carya cordiformis) formed a portion of the stand and some modified remnants of such forests are to bè seen on the Island of Montreal. As in eastern Ontario white and red pine (Pinus strobus and $P$. resinosa) were found on the sandy areas mixed with the hardwoods.

At present farm crops have replaced the forests except on the rugged slopes of the Monteregian Hills and on the low swampy lands too wet for cultivation and too low to be readily drained. In many of these areas grey birch (Betula populifolia) as a pioneer is forming second-growth forests on areas originally occupied by arbor vitae (Thuja occidentalis) and ashes (Fraxinus americana and $F$. nigra). Farm wood lots of modified hardwoods are fairly abundant and include "sugar bushes" or groves of sugar maples used for the production of maple sugar. This industry reaches its greatest development in the adjacent Appalachian region.

The Eastern Townships, as the eastern portion of the Appalachian highlands is commonly designated, were settled early in the nineteenth century by English speaking people from United States and Great Britain. They originally possessed a forest similar to that of the St. Lawrence plain except for a smaller portion of pine and oak and an increasing amount of spruce as the Maine boundary was neared. Hardwood stands occupied all the better soils. These consisted of maples (Acer saccharum, A. saccharinum and A. rubrum), basswood (Tilia americana), ashes (Fraxinus americana and $F$. nigra), birches (Betula lutea and B. papyrifera) and beech together with hemlock and, upon swampy areas, arbor vitae and tamarack. Much of the area has been cleared for farming and almost all the coniferous timber has been cut but considerable areas of hardwood remain, more particularly the stands of maple which give the large yields of maple sugar harvested from the region between the counties of Brome and Beauce.

East of a line drawn southward from the city of Quebec the hemlock largely disappears and spruces (Picea canadensis and $P$. rubra) together with balsam fir (Abies balsamea) become increasingly abundant, forming immediately west and north of the Maine boundary $60 \%$ of the forest stands. Nearer to the St. Lawrence River arbor vitae becomes increasingly abundant occupying much of the flat low-lying areas in the counties from Kamouraska to Gaspé. The hardwoods, however, persist in decreasing abundance to Gaspé. The flat tops and higher mountains in Gaspé give considerable areas of subalpine and alpine forest, scrub and fell-field. This is still untouched and largely unvisited. 
It is estimated that $70 \%$ of the Appalachian area must eventually remain in forest or waste land. Over 5000 sq. mi. of this area are included in the Quebec Forest Reserves.

The region north of the St. Lawrence River may conveniently be divided into two main forest regions, the northern and the Laurentian. The former comprises the Hudson Bay and Labrador basins and the latter the St. Lawrence basin. Most of the province north of the 55th parallel is essentially treeless tundra and fell-field while in a zone some $100 \mathrm{mi}$. broad about Hudson and James Bays the forests are largely limited to the better drained lands along the rivers, The northern forests are estimated at some 250,000 sq. mi. in area of which perhaps one-sixth has some merchantable timber in the form of fuel and pulp wood. Here coniferous and deciduous types mingle. Black spruce (Picea mariana) and tamarack are the principal conifers with jack pine (Pinus divaricata) on some of the poorer sandy but better drained soils. Aspen and white birch form stands of deciduous forest of the low stature or mingle with the conifers. Through much of the area the tamarack was almost exterminated in 1885 and 1900 by attacks of the larch saw-fly. Since those years of destruction some recovery has been made.

As the highlands are reached the trees increase in size and arbor vitae and white spruce and balsam popular (Populus balsamifera) become more abundant.

These forests are all upon public lands and little has been cut but extensive and destructive fires have occurred.

The Laurentian forests are the best and the most valuable in the province not less than $160,000 \mathrm{sq}$. mi. of which are within the Quebec Forests Reervses. Much of this area, however, has been leased to the lumber companies and has been cut over. Destructive and extensive fires have also occurred but it is estimated that $75 \%$ of this area is capable of yielding merchantable timber.
This forest is composed principally of white and black spruce mixed with balsam fir. With these trees are mingled in varying degrees of abundance the aspen and balsam popular (Populus tremuloides and $P$. balsamifera) and the white birch (Betula papyrifera). Here too are large bogs or muskegs with few small trees. The southern portion of this area has the best forests of the province, the spruces being mixed with white and red pine and arbor vitae and as the St. Lawrence River is approached by a mixture of such hardwoods as yellow birch, ash and maple.

The Quebec Forest Reserves are largely within this Laurentian region. They comprise $168,000 \mathrm{sq}$. mi. of which 110,000 are in the Saugenay and Labrador Reserve. Other large units are the Ottawa Reserve with 27,000 sq. mi. in the basin of the Ottawa River containing much of the remaining white pine and the St. Maurice Reserve, $21,000 \mathrm{sq}$. mi., with some of the best spruce and mixed forests.

\section{Mammals of the Gaspe Peninsula, Quebec (Extracted from article by George G. Goodwin)}

The Gaspé Peninsula is in the extreme eastern part of Quebec, south of the St. Lawrence, and is bounded by the bay of Chaleur on the south. It has an area of about $11,000 \mathrm{sq}$. mi. and lies entirely within the Canadian zone. The peninsula is covered largely with primeval forest and is almost roadless, except along the shores. No roads pass from north to south on account of the chain of Shickshock Mountains, which are far too rugged to be crossed. There is a fringe of settlements along the north coast which depend for livelihood mainly on fishing in the summer and lumbering in the winter. Most of the inhabitants cultivate a few fields and do a little farming, using oxen and old-time farm implements. Only the coast region, for a maximum depth of $10 \mathrm{mi}$., has opened up to settlement.

The north shore is particularly strik- 
ing on account of the greater number of huge bowlders scattered about. The bowlders are probably derived from the north shore of the St. Lawrence and transported hither by ice. These bowlders were not found at altitudes much above sea level.

The following species were recorded in 1923: star-nosed mole (Condylura cristata), the rocky condition of the land in the mountains was not suitable for this mole, which seems to prefer soft soil and marshy ground; masked shrew (Sorex personatus personatus), were well distributed throughout the forested area; smoky shrew (Sorex fumeus umbrosus); Gaspé gray shrew (Sorex gaspensis); water shrew (Neosorex palustris acadicus) appear to be uncommon in this region and very local; of the small series taken, all were trapped on the same stream within $\frac{1}{2} \mathrm{mi}$. of each other; Hoy's shrew (Microsorex hoyi); short-tailed shrew (Blarina brevicauda brevicauda); little brown bat (Myotis lucifugus lucifugus); black bear (Ursus americanus americanus); red fox (Vulpes sp.); raccoon (Procyon lotor lotor); pine marten (Martes americana americana), sparingly distributed through the timbered mountain region; fisher (Martes pennanti pennanti); short tailed weasel (Mustela cicognanii cicognanii); mink (Mustela vison vison); Canada skunk (Mephitis mephitis); Canada otter (Lutra canadensis canadensis); Canada lynx (Lynx canadensis canadensis); dusky white-footed mouse (Peromyscus maniculatus abietorum); redbacked vole (Evotomys gapperi gapperi); meadow vole (Microtus pennsylvanicus fontigenus); was fairly numerous in the fields and swampy places near the river at Ste. Anne, but was rare in the forest. Two were taken in traps set on a small mountain stream in the dark forest at the foot of Mount Albert. On the bare summit of the mountain, $3660 \mathrm{ft}$. in elevation, runways were abundant in the wet and mossy grassland which surrounded the small lakes; rock vole (Microtus chrotorrhinus chrotorrhinus); muskrat (Ondatra zibethica zibethica). The Hudson Bay jumping mouse (Zapus hudsonius hudsonius) was found to be fairly common and specimens were taken in the open grass country and in the clearings along the coast. The woodland jumping-mouse (Napaeozapus insignis insignis) was only taken in the forested country and most of the specimens were caught in traps set in tall dead grass along the banks of small mountain streams. Canada porcupine (Erethizon dorsatum dorsatum); Canada woodchuck (Marmota monax canadensis) were commonest in the open country along the coast. One woodchuck was seen in the forest near the foot of Mount Albert; striped chipmunk (Tamias striatus lysteri), not taken in the cold mountain regions or in the damp spruce forests; red squirrel (Sciurus hudsonicus gymnicus); northern flying-squirrel (Ġlaucomys sabrinus sabrinus); Canada beaver (Castor canadensis canadensis); snowshoe hare (Lepus americanus struthopus); northern white-tailed deer (Odocoileus virginianus borealis); there are a few moose (Alces americana americana) on the head-waters of the Ste. Anne River, traces of which were seen in the swampy places at the foot of Mount Albert; woodland caribou (Rangifer caribou caribou). For animals of western Quebec see Ontario account.

\section{GUIDE TO AREAS AVAILABLE FOR STUDY}

1. *Laurentide National Park. (A1.) An area of 3271 sq. mi., located in the Counties of Montmorency and Charlevoix and distant $40 \mathrm{mi}$. from Quebec City. It contains many lakes and streams and is largely covered with coniferous and mixed coniferous and deciduous forests. It is intended to demonstrate intelligent forestry as well a a well preserved forests. It offers the flora of a typical glaciated Laurentian area and within it some important tree species such as Quercus rubra and Acer saccharum reach their northern limits. The streams teem with fish. 
It abounds in large game such as deer, moose, caribou and American elk. It may be reached from Quebec by the Canadian National Ry.-Bro. M.-V.

2. *Gaspé Park (Provincial). (A1.) This consists of an area of approximately $2500 \mathrm{sq}$. mi. and comprsies the greater part of the elevated area of the Gaspé Peninsula. The vegetation ranges from the mixed conifer-deciduous forest through various types of scrub to alpine fell-field.

The chief features of the Gaspé Peninsula which at once attract the botanist are the high, calcareous cliffs of the coast which begin on the north in eastern Matane County and extend with only slight interruption along the south side of the St. Lawrence to Percé. These cliffs with their talus slopes and high crests often reach a height of 1500 to $1800 \mathrm{ft}$. and are bleak and wind-swept and essentially without direct sunshine, consequently they harbor a large number of alpine and Arctic species.

The next striking feature is the Shickshock Mountain range, a system of rather complex minor ranges, most of which are quite unexplored and unmapped. These extend from western Matane County through the northcentral and northern portions of the Peninsula to the Madeleine River; beyond this point the mountains become less conspicuous and gradually merge into the foot hills and sea-cliffs. The striking feature about the mountains is the fact that their upper levels were quite unglaciated, with the result that there we find a very large proportion of the plants indentical with or related to species otherwise known only in the Cordilleran or Pacific slope regions of North America.

The third feature is the rivers, which beginning with the Little Cascapedia on the south, and the Ste. Anne des Monts on the north and extending eastward to the tip of the Peninsula, share with the Shickshock Mtr. the distinctly Cordilleran flora which is otherwise unknown in eastern America. To a large extent this flora has been derived from the Shickshock Mts., but certain species like Dryas Drummondii characterize the river gravels, but are unknown in the high alpine areas. The region may be reached by Can. Nat. Ry. from Quebec to Matane on the west or Percé on the east. During the summer there are boats from Quebec every two weeks. Guides are necessary. \&G. D. F.

3. St. Maurice Valley. (A1.) St. Maurice Valley, an area of 16,000 sq. mi. within the Forest Reserve mixed deciduous and evergreen forests with some swamps and many lakes. The fauna includes moose, deer, bear, hares, grouse, squirrels, beaver, muskrat, foxes and wolves. Altitude approximately 1500 ft. From Montreal or Quebec take the Canadian National Railway to Latuque. There is a hotel at Latuque; a guide is usually needed\$. The area must be reached by canoe from the railroad station.-Nevin M. Fenneman, Elwood Wilson.

4. *Great Bird Rocks Group. (A1.) 7 acres and some small rocks located near Magdalene Islands in the Gulf of St. Lawrence. There is very little vegetation. The rocky shores present a marine fauna. Water birds are plentiful. A camping outfit would be needed, also permission from the Canadian National Parks, Department of Interior, and from the Department of Marine. The area has to be reached by special boat transportation from Percé or other towns on the main land.-J. B. H., L. H.

5. Anticosti Island. (A1.) An island over $100 \mathrm{mi}$. long in the Gulf of St. Lawrence held as private property and as a game reserve. It is practically uninhabited. On it is a northern bog (Hochmoor formation) on limestone overlain with clay. It abounds in northern forms. It is accessible by steamer from Quebec.-Bro. M.-V.

6. Sixteen Island Lake. (A1.) This is a typical Laurentian lake surrounded by forest. It is $60 \mathrm{mi}$. from Montreal and is accessible by the Can. Nat. Ry.Bro. M.-V.

7. *Bonaventure Island. (A2.) A small island covered with eastern coniferous forest with cliffs, rocky shores, etc. The cliffs are Canadian Government bird preserves.

Located in the Gulf of St. Lawrence in Gaspé County, $3 \mathrm{mi}$. from Percé where a hotel is located, or $12 \mathrm{mi}$. northeast of Cape Cove, Quebec. It may be reached 
over the Canadian National or the Quebec Oriental.-J. B. H., L. H.

8. ${ }^{*}$ Percé Rock. (A4.) Area of 2 acres in the Gulf of St. Lawrence with only scant vegetation, with rocks and cliffs and sea-coastal fauna. The nearest railroad station is Cape Cove, QueLoc, reached by the Canadian National and the Quebec Oriental Railroads. Hotel is at Percé, $9 \mathrm{mi}$. distant by bus.J. B. H., L. H.

9. Caughnawaga Indian Reservation. (C4.) This contains an area untouched by cultivation, but grazed, and showing a typical development of the genus Crataegus. A variety of wind-beaten forms are to be seen and many endemic varieties. It is $10 \mathrm{mi}$. from Montreal bordering the Lachine Rapids. It is accessible from Montreal by rail and from Lachine by ferry.-Bro. M.-V .

10. St. Lawrence Island. (A4.) A small island of boulder clay, flooded in the spring. It shows typical hydrophytic argillaceous vegetation with interesting zonation. The vegetation is subject to injury from the mechanical action of ice. It is about $3 \mathrm{mi}$. from Montreal and is accessible by row-boat from Longueuil.-Bro. M. $-V$.

11. Pine barren forest. (C4.) This is a stand of Pinus divaricata on sand dunes with Comptonia sweet fern, Cyperus Houghtonii, Panicum Xanthophysum and other unusual forms. This is a rare feature in the north.

This is accessible from the monastery of La Trappe, near the village of Oka, which is reached by boat from Lachine. -Bro. M.-V.

12. Peat bog. (A4.) This bog in Chambly County, near St. Hubert, is. of the hochmoor type and is two mi. in length. It was worked for peat in the seventies and several stages in peat formation can be observed. It is distant $7 \mathrm{mi}$. from Montreal and is easily reached by the Grand Trunk Ry.-Bro. M. $-V$.

13. Magdalen Islands. (C4.) These contain several sq. mi. of sand dunes located at the eastern extremity of Grande-Entrée. The region is unglaciated and has untouched associations of dune and aquatic vegetation. There are many endemic forms.-Bro. $M .-V$.

\section{BIBLIOGRAPHY}

Bent. Life histories of American Birds, Vol. 2, p. 37.

Clarke. Seventh Annual Report of the Conservation Com. of Canada, 1915, p. 108.

Clarke. The Heart of Gaspé.
Toverner. Cormorants in Relation to Salmon, Bull. of the Geol. Surv.

Toverner. Canadian Field Naturalist, vol. xxxii, p. 21 , no. 2 .

Townsend. Canadian Field Naturalist, vol. xxxiv, nos. 4 and 5.

\section{NEW BRUNSWICK}

\section{By B. E. Claridge}

\section{GENERAL FEATURES}

\section{Topography}

For the most part, the surface of New Brunswick is a gently undulating upland with average elevations which vary in different sections from several hundred to approximately a thousand feet. The main characteristic of the topography is the even slope of the hills to the complete network of drainage liner. Relative elevations, on the average, are not great with the exception that in the north and northwest, dividing the Tobique, Restigouche and Nepisguit watersheds, are numerous ranges of high hills with altitudes which in the majority of cases are from 1200 to $2000 \mathrm{ft}$. These ranges include some higher individual peaks separated by narrow gorge-like valleys in many situations. Bald Mountain or Sagamook rises here to a height of $2600 \mathrm{ft}$. which is the maximum for the province. Along the Gulf of St. Lawrence Coast-the Bay of Chaleur and Miramichi Bay,-the land is comparatively low; the coast of the Bay of Fundy is rocky and bold. The east coast for nearly $20 \mathrm{mi}$. inland is somewhat flat with numerous marshes.

\section{Geology}

The uplands of New Brunswick form a part of the northern zone of the older Appalachians with similar rock formations to those found in many parts of northeastern United States. In the northwestern part of the Province the Silurian rocks, slates, and shales are prevalent, while to the south and west of this tract the Pre-cambrian rock series predominate and include large scattered granite masses. A narrow area in the northeast which grows wider 
to the southward is underlain by Carboniferous sandstone, shale, dolomite, etc. This region extends from the Bay of Chaleur along the east coast well into Nova Scotia. The Cambrian and Silurian formations are distinctive of the region which borders the Bay of Fundy.

\section{Physiography and soils}

In a rough manner the province may be divided into four physiographic units which may be termed the Northern Pateau, the Central Highlands, the Eastern Plain, and the Southern Highlands. The region known as the Northern Plateau and the watershed of the Restigouche river and its branches coincide almost exactly. The Central Highlands include the watersheds of the Tobique and Nepisguit rivers together with a short stretch of the watershed of the St. John above the fork of this river with the Tobique. The east coast from the mouth of the Nepigsuit to Nova Scotia and the greater portion of the large central area drained by the Miramichi River make up a unit which in some situations is flat and in others is low and rolling. For the want of a better name this may be known as the Eastern Plain. Along the Bay of Fundy the land again becomes relatively high and hilly for about 40 mi. inland and forms the Southern Highlands.

The great continental ice sheets left in a marked manner their imprint both upon the topography and the soils of this region. The glacial accumulations were laid down in no regular way; as a result the soils show a diversified composition and due to this, different properties. By far the greater proportion of the soil is of glacial origin. With such soils, however, are often intermingled rather large included areas of local sands, residual clays, and clayey loams.

\section{Flora}

Despite the fact that the province lies at the northern edge of the transition belt between the deciduous and coniferous types of tree vegetation, there is a comparatively great diversity of species. The predominant trees of the vast forests are black spruce (Picea mariana), red spruce (Picea rubra), white spruce (Picea canadensis), balsam fir (Abies balsamea), white pine (Pinus strobus), beech (Fagus grandifolia), sugar maple (Acer saccharum), yellow birch (Betula lutea), and paper birch (Betula papyrifera). The climax type of tree growth in the region is a mixed forest of spruce, fir, beech, maple, and birch. The bryophytes, on the whole, are well represented as are also many of the herbaceous flowering plants. Thus far little has been done in regard to the study of the botany of the region, so that the extent and range of the plant species is not completely known. This fact, together with the exceptional opportunity for study in the vast evergreen and hardwood forests, marshes, barrens, tundra formations, and muskegs should be an inducement for much more work in the future. In a very few localities-not all of which have been definitely located-are patches of virgin timber containing some good examples of old growth spruce, fir, beech, maple, and birch.

\section{Fauna}

The term "the Sportsman's Paradise" has long been applied to New Brunswick. It was not far in the past that the numerous species of game and fur-bearing animals ranged practically the entire province. Yet, to give an example, there are more moose (Alces americanus) here to the square mile than in any other part of the continent of North America, in spite of years of constant attack by large numbers of visiting and native hunters who have greatly reduced the numbers of these magnificent animals. Other mammals still continue to be somewhat plentiful although the woodland caribou (Rangifer caribou) which were formerly found in large herds on some of the northern barrens have almost disappeared. Great numbers 
were shot and the remainder except for a few small scattered herds have emigrated to Quebec. The black bear (Ursus americanus) is of frequent occurrence; numbers are trapped each year. Throughout the entire region the Virginia deer (Odocoileus virginianus borealis) is plentiful and forms a good portion of the food supply of many of the backwoods families. Among the smaller animals, the beaver (Castor canadensis group), red fox (Vulpes fulva), marten (Martes americana), fisher (Martes pennanti), otter (Lutra canadensis), weasel (Mustela cicognanii), Canada lynx (Lynx canadensis), and bobcat (Lynx rufus) are still more or less abundant in certain parts of the province. Birds are those of eastern coniferous forest.

\section{Fish}

New Brunswick can reasonably be proud of her rivers with the different species of fish that they support. Practically all of these bodies of water contain game fish in large numbers while the Bay of Fundy and other bordering salt water bodies furnish a large supply of food fish for domestic consumption. The principal fish of the fresh water streams and rivers are the speckled trout and the salmon; the lakes contain trout, some bass, and numerous smaller species. The sea fisheries are located on the north shore, the Bay of Fundy, and on the islands at the mouth of the latter body of water. Haddock, herring, cod, smelt, shad, and mackerel comprise a few of the many kinds taken from the sea and the tidewater portions of the larger rivers. The lobster industry is also a considerable one.

\section{PRESENT BIOTIC CONDITIONS}

The comparative isolation of New Brunswick, together with a lack of density of population has done much to prevent the complete destruction of many areas and the extinction of a numerous and diverse animal life. Thus far the necessity for the preservation of areas in order to conserve the vegetation and animal life has not been given the attention that it at no far distant date will demand. Attempts along this line are hampered to a certain extent by local opinion which feels that reservations will hinder progress and development in the locality.

The lack of specific information makes it difficult to give an exact statement as to the presence of all of the remaining natural forest areas. Some natural or virgin stands of deciduous tree species are to be found in small areas scattered over a good part of the province. There are according to the information already gathered in the progress of the New Brunswick Forest Survey some isolated patches of virgin coniferous forest in inaccessible parts of the north. Obviously it is of importance that wherever possible these areas should be set aside in their present condition.

The animal life has fared well considering the vigorous hunting and trapping to which it has been subjected. An occurrence that should be viewed with regret is the practical disappearance of the caribou from the north central barrens. They will never return except as a few well-protected herds. Furthermore, the number of fisher, beaver, and marten have in the past few years been noticeably less and further steps in more conservative and workable trapping laws are needed. In spite of the above there are few regions in the East which have an animal life so numerous and well represented as this province.

Naturally enough those areas which offer the best opportunity for the study of either the flora or the fauna lie in the most unsettled and wildest districts which are located in the north and central regions. They are for the most part accessible only by tote road or by canoe; any naturalist who is going in for the first time will do well to engage the services of a competent guide. Of course there are areas of untouched marsh and barren in many localities. These are likely to remain so, and consequently they do not need immediate attention as regards reservation. 
Under a condition of sparse settlement, few manufactories, and complete drainage, pollution is a negligible quan. tity. Thus far no important records of pollution can be found for the province.

\section{NATURAL AREAS}

\section{Northern Mixed Forest in Northum- berland County (A2)}

This tract contains approximately 100 sq. mi. of virgin forest lying between the watersheds of the Lower Branch of the Nepisguit river and the Northwest Branch of the Miramichi River.

The growth is almost the typical climax forest type of the region with a large percentage of balsam fir, maple, white or paper birch, and yellow birch. Occurring as scattered individuals are a few large spruce.

The topography of this tract is rough and for this reason has never been logged. The growth is the result of a fire which occurred in 1825 .

Virginia deer, moose, red fox, black bear, and marten inhabit this area in rather large numbers. The Lower South Branch of the Nepisguit contains some good trout, but the country is rather rough. The elevation ranges from 900 to $1500 \mathrm{ft}$.

As might naturally be expected the tract is somewhat inaccessible and the greater part of the journey to it must be made by tote road (h) and (c). Fredericton to Plaster Rock (poor hotel accommodations) by the Canadian $\mathrm{Pa}$ cific R. R., 120 mi.; by wagon to Nictau, $20 \mathrm{mi}$.; tote road from Nictau to Nepisguit Lakes, $15 \mathrm{mi}$; to Freeze Lake on the Lower South Branch, $10 \mathrm{mi}$. Travellers should be outfitted for camping out from Nictau to the destination.

It is possible to go by canoe up the Tobique to Nictau Lake and from this lake to the Nepisguit Lakes with a portage of about $3 \mathrm{mi}$.

\section{The Bathurst Forest Experimental Plot (C3)}

An area of 500 acres has been laid out for a period of 25 years as an experi- mental plot for the study of the different kinds of cuttings, planting, thinnings, etc., commonly followed in forestry work. This contiguous tract, the largest sample plot in Canada, is located near Bathurst Mines in Gloucester County. The growth consists of a cutover coniferous forest type of spruce and fir with a few scattered hardwoods.

The various kinds of experimental work being conducted here is of interest mainly to foresters, but in time should be of general interest from the intensiveness and the rcope of the undertaking.

Occasionally Virginia deer, red fox, and perhaps beaver may be found on this area. Elevation $300-400 \mathrm{ft}$.

The best route for visitors to follow is from Fredericton to Bathurst; branch line with speeder only from Bathurst to Bathurst Mines and the Grand Falls of the Nepisguit, $14 \mathrm{mi}$. Accommodations may possibly be secured from families residing in the vicinity of the nonoperating Bathurst Mines, or from workers at the power station at the Grand Falls. The plot is approximately one mi. northwest of the village.

\section{PRINCE EDWARD ISLAND}

\section{Committee Notes}

"The original forests of Prince Edward Island conform essentially to those of Nova Scotia and New Brunswick, as regards species, but their distribution is different. The trees indigenous to the ilsand are the following:

Acer saccharum
Acer rubum
Acer pennsylvanicum
Prunus serotina
Prunus pennsylvanica
Fraxinus nigra
Fraxinus americana
Ulmus americana
Betula papyrifera
Betula populifolia
Betula lutea
Fagus americana
Quercus rubra
Populus tremuloides

Acer saccharum

Acer rubum

Acer pennsylvanicum

Prunus serotina

Prunus pennsylvanica

Fraxinus nigra

Fraxinus americana

Ulmus americana

Betula papyrifera

Betula populifolia

Fagus americana

Populus tremuloides 
Populus balsamifera

Pinus strobus

Pınus resinosa

Picea alba

Picea nigra

Picea rubra

Abies balsamea

Tsuga canadensis

Larix americana

Thuja occidentalis

"Sugar maples and beeches, which grow on the ridges and more elevated parts of the mainland of Nova Scotia and New Brunswick are found throughout Prince Edward Island on the general level only a few feet above the sae. Finer specimens of Abies balsamea, Picea alba, P. nigra, P. rubra are found here than on the mainland, while the presence of Thuja occidentalis in isolated patches at the north end of the island is remarkable". ${ }^{1}$ - From Harshberger, Phytogeography of North America, p. 361 .

\section{NOVA SCOTIA}

\section{By A. H. Mackay}

\section{GENERAL CONDITIONS}

The Atlantic Provinces of Canada are three-the peninsula of Nova Scotia running out into the Atlantic Ocean, Prince Edward Island, lying to the rear in the Gulf of St. Lawrence, and New Brunswick, through which Nova Scotia has land connection with the State of Maine to the south and the Province of Quebec to the west. Nova Scotia has an area of $21,068 \mathrm{sq}$. mi. with $1000 \mathrm{mi}$. of sea coast. The population is 533,000 .

Nova Scotia extends northeast and southwest about $370 \mathrm{mi}$. with a breadth of from 60 to $100 \mathrm{mi}$.- the northeastern quarter consisting of the island of Cape Breton. It is the crest of a submerged elevation lying sub-parallel to the Atlantic American coast, and is connected with the land system of the continent (New Brunrwick) by an isthmus near its center about $20 \mathrm{mi}$. wide. The

1 Macoun, John. "The forests of Canada." Proceedings and Transactions Royal Society of Canada, XII (1894): 7-8, Sect. IV. $-E$. L. B. mainland area is deeply cleft by the Mines Basin and Cobequid Bay; and the Island of Cape Breton is almost divided into two by an inland salt water sea, known as Bras d'Or Lakes. The high lands of the island are in the northwest part where the elevated axis rises to a plateau about $1200 \mathrm{ft}$. in height with higher peaks towards Cape North.

North of Minas Basin the Cobequid range runs due east and west in the mainland, and south of the Basin on each side of the Cornwallis and Annapolis Valleys, and St. Mary's Bay run the interrupted Triassic North Mountains, and the older South Mountains in the axis of the peninsula. The Atlantic slope has been deeply eroded by glacial action, exposing Lower Cambrian. Further back the Silurian, Devonian and Carboniferous strata remain, with some Triassic in the northwest along the Bay of Fundy which at one time communicated with the Gulf of St. Lawrence where the Triassic is highly developed in Prince Edward Island. The Atlantic slope has been heavily scored by glacial action. Lakes and streams abound, although there can be no great rivers when no watershed is $100 \mathrm{mi}$. from the sea; the majority averaging $50 \mathrm{mi}$.

\section{ORIGINAL BIOTA}

The vegetation of southern low lands of Nova Scotia is deciduous forest climax and that of the northern and higher areas is largely coniferous.

The fauna was originally very similar to that of New Brunswick and Eastern Quebec (pages 299 and 293).

\section{PRESENT BIOTA}

The forests have been too carelessly exploited hitherto; and this condition is now giving rise to serious thoughts of forest conservation, and the preservation of game and of territory exhibiting the natural conditions of the country without modification by man.

Of the $13,000,000$ acres of land no more than 100,000 remain ungranted by the Government; and the ungranted territory is probably all practically barren 
land at present. Reservations to be made for public natural parks and game preserves may now have to be repurchased from private owners by the Provincial Government.

\section{NATURAL AREAS}

A central location in the southwest of the province including the region where the counties of Annapolis, Digby, Yarmouth, Shelburne and Queens meetterritory still in a more or less natural condition on the watershed of a country not well adapted to agriculture, and abounding in lakes and small streams.

The lake region of Queens County nearby, where similar conditions prevail with more water area.

A central region at the confluence of the counties of Annapolis, Kings and Luenburg, not very far removed to the northeast.

Near the center of the province, a similar area at the confluence of the counties of Colchester, Pictou, Antigonish and Halifax.

Cape Breton Island, northern portions of Inverness and Victoria counties (B2), an area $30 \mathrm{mi}$. broad by about 70 long, with its high glacier planed plateau, 1000 to $1200 \mathrm{ft}$. above the sea, showing the greatest range of ecological conditions from the base to the summits, of any other portion of the province, is also being suggested. The most of the region is unsuited to agriculture, and is now the best natural reservation of large game in the Province. It has many square miles of deciduous and coniferous forest, alpine meadows, sand areas, flood plains, talus slope, gravel slides, bogs, waterfalls, mountains, ravines, hills, bluffs, shores, sandy and rocky; glacial striations, swamps, marshes, ponds, lakes and rivers. It is splendidly described in 218 pages with illustration3, by Dr. Geo. E. Nichols in Volume 22, pages 249-467 of the Transactions of the Connecticut Academy of Arts and Sciences, June, 1918.

${ }^{*}$ Wild Geese and Water Fowl Reservation. The Nova Scotia "Forest and Game Act, 1921," creates probably the only thing approaching a "territorial reservation" for water fowl which appear to go no furthers outh for wintering purposes. The territory includes three deep neighboring indentation (bays) on the Atlantic coast-one in Queens County, one between Queens and Shelburne County and the other wholly in Shelburne County.

Lepreau Hochmoor. Fine example of hochmoor. Lepreau, N. B. Shore Line Ry.-F. W. Ganong.

Sable Island in the Atlantic. About $150 \mathrm{mi}$. from Halifax, Nova Scotia, is now a sand dune island about $20 \mathrm{mi}$. long and less than one mi. broad, containing a brackish pond in which a fresh water sponge has been found. The island has a light-house and lifesaving station. Attempts have been made to grow trees and grasses, etc., to bind the sand which rises in some places to nearly $100 \mathrm{ft}$. in height. But the island has diminished very considerably within historic times. A very complete historical and ecological description is given of this most interesting island by Harold St. John in the Proceedings of the Boston Society of Natural History, Vol. 36, No. 1, pp. 1-103, Plates, 1, 2. (Cont. Gray. Herb., Harvard University, New Series, No. LXII.)

Guysboro Heath. Heath of unknown area. Will probably remain for the next hundred years. In Guysboro and part of Antigonish Counties.-C. $J$. Connolly.

Minas Basin Salt Marsh. Area of salt marsh in Minas Basin, between the mouths of the Gaspereau and Cornwallis Rivers, including sand areas, flood plain, lakes, rivers, and marshes. Located in warm area, at the southern end of Annapolis Valley, with waters of the basin to the northwest, and mountains to the southeast. Very high tides of the basin render it an attractive area for plant study. Located in Kings County, $7 \frac{1}{2} \mathrm{mi}$. from Wolfville, N. S.H. G. Perry.

The Ellenwood and Agards Lake Region. Deciduous and eastern forest, sand areas, flood plains, swamps, marshes, ponds, rivers, springs. Located in Yarmouth County, which has a flora in many ways more typical of Massachusetts than that of the northern part of the United States. Lakes are suitable natural preserves for both plants and animals. Located in Yarmouth County, $12 \mathrm{mi}$. from Yarmouth, N. S.-H. G. Perry. 


\section{MAINE}

\section{By A. O. Gross AND A. H. Norton}

\section{GENERAL ACCOUNT (A. H. N.)}

\section{Introduction}

Maine is the most northeastern state of the Union, situated approximately half way from the equator to the north pole. The mean annual temperature is about $42^{\circ}$; the mean winter temperature about $19^{\circ}$ and the mean for summer about $62^{\circ} \mathrm{F}$. The mean annual precipitation is in the vicinity of $42 \mathrm{in}$. The coast of Maine from Kittery Point on the southwest to West Quoddy Head on the east is about $230 \mathrm{mi}$. when measured in a straight line, but by reason of the many and deep indentations, and the very numerous islands it has been determined that $1319 \mathrm{mi}$. of ocean bathe its shores.

\section{The sea}

The tides of the coast have a most important bearing on the life of its shores and the adjacent waters.

Their range (rise and fall), increases from west to east from mean tide of $8.7 \mathrm{ft}$. and spring tide of $9.9 \mathrm{ft}$. at Kittery to $18.2 \mathrm{ft}$. (mean) and $20.7 \mathrm{ft}$. (spring) at Eastport.

The tides also have a dominating influence on the coastal currents, which flow according to the general trend of the bays or channel ways landward on the flood, and seaward on the ebb. Beyond the coastal currents, an offshore current from the Bay of Fundy flows to the westward certainly as far west as the region off Penobscot Bay.

The constant circulation of coastal and offshore waters thus maintained is highly favorable to an abundance and great variety of marine and its dependent terrestrial life, bringing into the bays hordes of free swimming organisms; in winter it prevents in a large measure the outer parts at least from becoming icebound.

With the exception of certain tidal portions of the Kennebec and Penobscot
Rivers, the muddy shores just below low water mark bear an abundance of eelgrass (Zostera marina), which is of great importance as a refuge and a home for many marine animals, and as food for many water birds. The rocky shores from the half tide mark down to moderate depths bear an abundance and variety of algae contributing further to the security and sustenance of animais.

Among those animals which through their edible qualities and plentitude are known to contribute in an important degree to the sustenance of fishes, birds and mammals may be mentioned, several Asteroides (of least importance), Ophiurians of several species, sea urchins, one species, but great in numbers, and several Holothurians, many species and great numbers of Annulates ("clam worms"), the great class of Crustaceans, ranging from the minute Copepods to the commercially important lobster, a group rich in species and with a surpassing wealth of individuals, ranging the waters from their surface to the bottom in all depths. Mollusks occur in great variety and number.

Among the marine fishes, which number about a hundred species, several are of great importance through their abundance and excellent qualities; cod, haddock, hake, and pollack are the chief of the larger; mackerel, herring, and menhaden among the smaller sea fishes, with eels, shad, alewives, smelts, and flounders along shore or running into the rivers. Though these are of chief importance directly to man, many other species contribute materially to the needs of the great family of the ocean.

With this vast variety and inexhaustible supply of food, and the comparative freedom from ice, the coast of Maine is a major winter resort for hordes of the hardier species of seafowl, forced southward from the icebound regions of the North.

Murres, razor-bills, dovekies, and kittiwakes find conditions they desire among the currents and eddies off the coast or about the mouths of the bays. 
Eider ducks, in vast beds, a few harlequins, black guillemots, scoters in small numbers, with the ubiquitous old-squaw, find suitable winter resorts about the outermost islands and ledges where they come to feed by day, at night seeking security on the open ocean, where the wildest storms fail to daunt them.

In the waters of the harbors and inner bays, wherever open water is to be found, grebes of two species, loons, cormorants, whistlers, buffleheads, and red-breasted mergansers find feeding grounds suited to their needs. Along the shore of the inner waters, and sheltered pools of the outer islands black ducks winter in vast numbers.

Some of the outermost ledges and islands harbor large bands of purple sandpipers throughout the cold months.

Everywhere from the inner harbors to the outermost ledges, the garrulous old-squaw congregates in numbers, ranging from a few pairs to several or many hundreds.

Herring gulls are to be found in open water, while the great black-backed gull is common about the outer waters and shores.

Though today the great gatherings of eider ducks and other species of waterfowl which are to be met with at certain of the outermost ledges or shoals fringing the very outposts of the bays, seem large, they are but a vestige of the hordes which formerly were forced by numbers to feed throughout the outer bays.

Several species of whales follow the schools of schizopods and gregarious surface fishes well into the bays; these are now greatly reduced in numbers. Two or three species of porpoises or dolphins are common, and formerly the harbor seal (Phoca vitulina) abounded all along the coast from the mouth of the Saco River to Little Machias Harbor, giving their name freely to the nomenclature of the coast, in Sea Rocks, Seal Ledges, Seal Islands, Seal Coves and Seal Harbors. Today these animals are reduced to a few colonies. It has been indicated that the coast of Maine also affords summer homes to a considerable variety of sea birds, some of them in numerous large colonies.

\section{The shores and islands}

The coast between Kittery Point and Cape Elizabeth, about $40 \mathrm{mi}$. in length, is chiefly low with sand dunes and beaches. These beaches of ten form barriers behind which creeks bordered with large salt marshes are sheltered. This part of the coast is but little broken by rocky points or islands. Eastward from Cape Elizabeth but two of these sand dune-beach salt marsh areas of noteworthy size are to be found. These are the Popham-Small Point beach, trending southwestward from the mouth of the Kennebec River, and the MileLittle River beach trending in the same general direction from the western entrance to Sheepscot Bay.

Resuming the coast line at Cape Elizabeth, where the sandy beaches disappear except as noted, the shores become rocky and are indented by a continuous series of bays, the latter well studded with rock-bound islands. Proceeding eastward the ruggedness increases slightly, to become pronounced as the entrance to Penebscot Bay is approached from the west. Here the cliffs of the historic Georges Islands and Monhegan are of sufficient height and wildness to afford nesting places for northern ravens. Entering the bay from the west, and proceeding about half way to its head, the Camden Hills or "Mountains" rise from a narrow platform close by the sea. The maximum height is reached by Mount Megunticook in an elevation of $1380 \mathrm{ft}$.; $25 \mathrm{mi}$. to the southward the isolated group of the Matinicus Islands, lying slightly beyond the confines of the Bay are to be seen as low outposts of the land. About $25 \mathrm{mi}$. across the Bay to the eastward, Bluehill Mountain, another seaside elevation, reaches a height of $940 \mathrm{ft}$.; about 35 mi. from Megunticook, to the eastward is Mount Desert Island with its group of hills or mountains which reach their 
greatest height in Green Mountain, (now Cadillac Mountain), which has an elevation of $1532 \mathrm{ft}$.

Eastward the coast line has now become especially jagged, with numerous long narrow bays and hosts of islands with bold shores, often with high sea cliffs on the southern and eastern sides.

Seguin Island off the mouth of the Kennebec River, was formerly well covered with spruce and fir, but for a long time has been nearly destitute of trees, through destruction by the sprucebud worm. The Georges islands and Monhegan about $20 \mathrm{mi}$. eastward from Seguin (already mentioned), are rather large, very rugged, and well clothed with a spruce forest. Though the forests of the Georges islands are probably second growth, they are now old and present very natural conditions. These islands and their small satellites afford breeding grounds for herons, gulls, terns, petrels, black guillemots, ravens and ospreys.

The Matinicus group of eight islands form the outermost group of the state, being about $15 \mathrm{mi}$. from the nearest point of the mainland. Two of these are still clothed with goodly sized forests, chiefly of spruce, while another has recently lost a similar forest growth, probably through the ravages of the spruce bud worm (Tortrix). These outer islands, when once denuded of the last vestiges of the descendants of their primitive forests, seldom or never are reforested owing to the grazing of sheep, and the strong winds which sweep them at all seasons of the year. In this group are to be found such northern plants as Polygonum allocarpum, seabeach sandwort (Arenaria peploides), roseroot (Sedum roseum), crow-berry (Empetrum nigrum), broom crow-berry (Corema Conradii) and sea lungwort (Mertensia maritima). Their principal birds are black guillemots, gulls, terns, petrels, and formerly a few puffins and eider ducks. Mount Desert Island is the largest island of the state. It is remarkable for its collection of moun- tains or great hills, its lakes and deep vales, its great fjord extending $3 \mathrm{mi}$. inland between the mountains. It contains the Lafayette National Park.

Great Wass Island, Roques Island and Cross Island, to the eastward, with a few small satellites terminates the series of islands ranging along the southern border of the state. Some of these Islands are destitute of trees, part having been treeless from the beginning of our history, while others have become so through the work of man or destructive insects within recent times. Though composed chiefly of rocks they are usually covered with glacial gravel and often with beds of dry peat as much as $3 \mathrm{ft}$. deep.

These treeless islands are the natural breeding places of terns, which occupy them, sharing these places with spotted sandpipers and savannah sparrows. By far the greater number are well clothed with red and white spruce (Picea rubra and $P$. canadensis), with balsam fir (Abies balsamea). By this means a belt of decidedly coniferous forest life is carried southwestward to Cape Elizabeth. Following this insular spruce belt to that cape, such birds as olive-sided flycatchers, red crossbills, juncos, white-throated sparrows, myrtle and magnolia warblers, with golden crowned kinglets are to be found breeding.

On the other hand a narrow belt of deciduous forest species follows the shores of the mainland eastward to the Kennebec River, with red pine (Pinus resinosa), red cedar (Juniperus virginiana), chestnut (Castanea dentata), red and white oak (Quercus rubra and Q. alba), white hickory (Carya alba), and black or sour gum (Nyssa sylvatica) as characteristic or frequent species, with such birds as whippoorwills, field sparrows, towhees, indigo birds, brown thrashers and catbirds. Arms of this belt are carried well up the river valleys.

\section{The interior}

Starting again at Kittery Point and proceeding northward to the foothills 
of the White Mountains which appear at Acton and Shapleigh, about $35 \mathrm{mi}$. inland, and eastward to the shore of Sebago Lake, upwards of $45 \mathrm{mi}$. from Kittery, is a sand plain area broken by valleys, small lakes, cool bogs and with an occasional elevation of noteworthy altitude. Mount Agamenticus (673 ft.) is the most striking example of the latter.

This area is in contrast with much of the rest of the state through the preponderance of deciduous forest. Most striking are the large areas of oaks of several species, and pitch pine (Pinus rigida), which here attains superior development. Here also, southern white cedar (Chamaecyparis thyoides) occurs in considerable quantities, and red cedar is frequent.

Besides the red and white oaks, which are of wider distribution in the state, there are in this area scarlet oak (Quercus coccinea), black oak (Q. velutina), and bear or black scrub oak $(Q$. ilicifolia) in greater or less abundance. The scrub oak occupies large tracts on the plains. Chestnut oak (Q. prinus) is also found in a single locality. Sassafras, black or sour gum, poison sumach (Rhus vernix), and smooth winterberry (Ilex laevigata) are of frequent occurrence.

An interesting feature of this transition extension is the frequency of cool bogs, occasionally bringing together such a combination as sphagnum, spruce, creeping snowberry (Chiogenes hispidula), growing with southern white cedar and smooth winterberry.

Starting at the western boundary of the state, to the northward of the sand plains a spur of the Appalachian highlands appear as foothills rising to a height of $1000 \mathrm{ft}$. at Acton and Shapleigh, about $35 \mathrm{mi}$. northerly from Kittery Point. These elevations increase in height and in numbers to the northward, the range trending in a general northeasterly direction, and culminate in the Grafton Mountains, a group just south of the Rangley Lakes. Speckled Mountain or Mount Matalluck, chief of the group is said to be the second mountain of the state in height.
Its summit is flat with a good depth of soil and a growth of straight spruces about $30 \mathrm{ft}$. tall. Below this crown on the steep sides is an alpine belt, devoid of trees except a few mats of scattered spruce and fir sprawling over rocks, and various alpine Plants. Matalluck throws out an arm at the southwest known as Mahoosic Mountain, between these is a deep notch through which Mahoosic Brook flows, for nearly a mile buried, often $30 \mathrm{ft}$. beneath gigantic boulders which have fallen from the mountainsides above. Its icy waters are contributed to the Androscoggin through the medium of two other streams. Ice is said to be found in the bottom of this notch throughout the summer.

The sides of Matalluck are very steep, and on the east is another notch, Grafton Notch, through which passes the turn pike to the foot of the Rangley Lakes, between Matalluck and Saddleback, the latter but slightly less in height than its brother.

To the northeastward the mountains become scattered, appearing at various places as more or less isolated peaks. Some of these have alpine summits thrust above the spruce forests. Among the best known are:

A group clustered about Moosehead Lake including Squaw Mountain, and Mount Kineo, two of the conspicuous highlands of the region.

About 110 mi. northeast of the Grafton Mountains, Mount Ktaadn rises to an elevation of $5273 \mathrm{ft}$. It is the highest mountain of the state, and when viewed from a distance seems to stand alone in a vast wilderness, but when approached it is found to be flanked by a worthy assemblage of lesser elevations or foothills. It is well to the eastward of the Appalachian highlands of western Maine, rising from a relatively low plateau embraced between the West and East branches of the Penobscot River.

Its summit is about $9 \mathrm{mi}$. long, with a vast alpine plateau or "Tableland."

Ktaadn, together with about 90,000 acres of the surrounding region, has been established as a State Game Preserve. 
The lakes and ponds of Maine are very numerous. According to Kendall (Proc. Portland Soc. N. H.) "there are about 2000 lakes from 100 acres to 120 sq. mi. in area," ranging from Moosehead Lake, the largest, with a length of about 35 mi. and an area of $117.4 \mathrm{sq}$. mi. to ponds of very small size. A map of the state shows the numerous lakes scattered closely and apparently in hopeless confusion. They fall, however, into perfect systems, or basins, which take their names from the river by which they ultimately reach the ocean.

The principal lake of the Presumpscot River Basin is Sebago, the second lake of the state in size. It has an area of $44.80 \mathrm{sq}$. mi., an elevation of $262 \mathrm{ft}$. and depth of $316 \mathrm{ft}$.; hence its bottom ss in part below the level of the sea. Its waters are remarkably pure and are used as the water supply of the city of Portland and several other towns. It is controlled in a large part by the Portland Water District, whose trustees take every precaution to preserve its purity and natural conditions. It receives the waters of several other lakes, one of which, Long Lake or Long Pond has a length of about $10 \mathrm{mi}$. and is largely environed with lofty hills.

The Androscoggin system finds its principal waters in the Rángeley chain of Lakes, resting close to the western border of the state and near the crown of the Appalachian spur. Mooseluckmaguntic Lake is the largest of this chain. A charr formerly abounded in the Rángeley lakes, but through excessive netting at the spawning season and the introduction of landlocked salmon it has been exterminated in these waters.

The Kennebec System has its extreme headwaters along the northern flank of the Appalachian spur.

After leaving Moosehead lake the Kennebec River passes for a distance of about $25 \mathrm{mi}$. over a rocky bed with numerous cataracts, falling nearly 450 ft. It reaches tide water at Augusta, and $22 \mathrm{mi}$. below that place enters Merrymeeting Bay. This Bay with its great body of tidal fresh water affords conditions for an abundant and unique flora, and an exceptional feeding ground for waterfowl.

The Penebscot River Basin has its source to the northward of the Appalachian spur, the headwaters of its West Branch being very near the northwestern boundary of the state. It is fed by a host of lakes.

The St. John Basin lies to the northward of the Penobscot baisn, draining all of the remainder of northern Maine through its several arms, including the Woolastock or main St. John and the Allegash.

The lakes of this region are very numerous and many are of considerable size, as Chamberlain (area 17.48 sq. mi., elevation $946 \mathrm{ft}$.), originally an Allegash or St. John Lake, but now through the agency of the Telos Canal considered as belonging to the Penobscot system; Eagle, Churchill, Long and Chemquassabamticook of the Allegash, with Portage and the Eagle chain of the Fish River.

With its great assemblage of lakes, their shallow lagoons, swamps, and streamlets, some swift, others sluggish, reaching into every valley and to every hillside, the state is adapted to those plants and animals requiring a cool moist atmosphere; hence Maine is preeminently a state of evergreen forests, which are composed of black red and white spruce, balsam fir, and arbor vitae in the lower levels, and pine and hemlock on its minor hills. The denser forests of arbor vitae and spruce are highly favorable to the growth of Bryophytes (mosses and liverworts), which carpet the ground and enshroud every fallen tree trunk and stump. Pine and hemlock are less favorable to these humble plants and beneath their less dense shade relatively few of the smaller plants of any description are found.

In these moist evergreen forests wood warblers find the conditions best suited to their needs and are represented by numerous species, together with many of the smaller 10-primaried Passeres, 
Canada jays, spruce grouse, owls and woodpeckers of several species. The lakes and lagoons are highly favorable for summer homes for bitterns several species of ducks, grebes and loons.

Among the mammals of these evergreen forests and waters are the Moose (Alces americanus), formerly abundant, but now reduced below the danger line of abundance. Canada lynx (Lynx canadensis), fisher (Martes pennanti), marten (Martes americana), mink (Musela vison), porcupine (Erethizon dorsatum), beaver (Castor canadensis), red squirrel (Sciurus hudsonicus gymnicus), and snowshoe hare (Lepus americanus virginianus), Martens and fishers have become very rare; beaver, though once threatened with extermination, are again increasing through perpetual protection and their great success in reproduction.

Caribou (Rangifer caribou) in some numbers were formerly found from the Appalachian Spur throughout the Penobscot Basin to tide water at Bangor, and east of the Penobscot to the coast. These animals have all been eliminated from the state.

Deer (Odocoileus virginianus borealis), black bear (Ursus americanus), bobcat (Lynx rufus), weasel (Mustela cicognanii), wolf (Canislycaon), red fox (Vulpes fulva, raccoon (Procyon lotor), muskrat (Ondatra zibethica), formerly abundant, ranged the entire state. The wolf has long since been exterminated, while the other species hold the greater part of their range in more or less reduced numbers.

The inland waters of the state formerly abounded in fish, especially such choice game fish as salmon, togue, and brook trout. Salmon and trout are of very general distribution but the togue is more restricted. Through the practice of experimenting in the introduction of every popular fish that has been available for many years, natural fishing conditions are to be found only in the more distant lakes and in the streams far from civilization.
II. NATURAL AREAS (A. O. G.)

\section{Shores and islands}

*Lafayette National Park (Mt. Desert Island). (B2.) Mt. Desert Island is the largest island on the coast of Maine. It is about $15 \mathrm{mi}$. long by $12 \mathrm{mi}$. wide. A range of granite mountains, $1532 \mathrm{ft}$. at the highest point, runs through the southern part of the island. The slopes have for the most part been swept bare by the ice, the predominant soil being a brown, stony, glacial till.

The Lafayette National Park includes approximately 6000 acres, covering most of the mountain summits which form the backbone of the island, most of the gaps, and extending north and south part way down the ridges. Much of the island outside of the park is still in its natural condition and likely to remain so for a considerable length of time. Within the park there are representatives of all the associations of vegetation found on the island. Much of the park has been burned at one time or another but there are still bodies of virgin forest, notably spruce, white pine, northern hardwoods, and pitch pine $(1,2,3$, and 5 below).

The flora of the Lafayette National Park is of northern relationship, but southern species are well represented. Five principal forest associations can be distinguished. (1) Spruce: red spruce, white spruce, with small amounts of balsam fir and scattering paper birch (Betula papyrifera); (2) white pine: some nearly pure stands, but mostly in mixture with red spruce, balsam fir, arbor vitae (Thuja occidentalis), red pine, red oak, paper birch, grey birch (Betula populifolia) and aspen (Populus tremuloides and $P$. grandidentata); (3) spruce and northern hardwoods: red spruce, beech (Fagus grandifolia), yellow birch (Betula lutea) and sugar maple (Acer saccharum); (4) white cedar or arbor vitae swamp; (5) pitch pine in pure stands with stratal societies of huckleberry (Gaylussacia baccata) and bearberry (Arctostaphylos uva-ursi), similar 
to the New Jersey pine barrens; in some places under the pitch pine Corema Conradii and Hudsonia ericoides. There are also bogs with black spruce, Labrador tea (Ledum groendlandicum), leatherleaf (Chamaedaphne calyculata) and other typical bog plants; and salt marshes. Along parts of the shore are beds of crowberry. The scrub oak grows abundantly on a single mountain, Robinson, on the west side of Somes Sound, and is unknown elsewhere on the island.

The Weir Mitchell station of the Harpsweli Laboratory is open for workers on any problem and allows perfect liberty to carry on whatever piece of research one may wish.

Bar Harbor, on the Maine Central Railroad (ferry), and Eastern Steamship Company, is $1 \frac{1}{2} \mathrm{mi}$., (w) (a), from the nearest point of the park. Hotels are open from June 1 to October 30; board and lodging is procurable during the remaining months. Seal Harbor, on Eastern Steamship line and connected with Bar Harbor by motor stage during the summer, is two mi. from the nearest part of the park; it has summer accommodations. Northeast Harbor, Eastern Steamship line, is $1 \frac{1}{2}$ mi. from the park. Southwest Harbor west of Somes Sound, is two mi. from the western part of the park. The park and rest of the island are easily accessible by a well marked system of trails. Information can be obtained from the park headquarters at Bar Harbor, and good maps are procurable.-Barrington Moore.

${ }^{*}$ Hancock County Forest (Mt. Desert Island). (B3.) 10 acres of deciduousconiferous forest with mountain, ravine, shore, rocky and glacial situations. Located in Hancock County, $5 \mathrm{mi}$. southwest of Bar Harbor. Maine Central Railroad (ferry) to Bar Harbor, road and trail to Sieur de Mont' Nationäl Monument.-J. M. Briscoe.

Shore and Island Bird Reservations. The following 19 reservations have been listed and described by A. H. Norton of the Portland Society of Natural History, Portland, Maine.
1. *Old Man Island. (A2.) In the town of Cutler, Washington County. About 10 acres. An outside island, with rocky precipitous shores, except on the south or seaward side, rising to a height of about $40 \mathrm{ft}$. It is covered with stunted white spruce and balsam fir and beneath these is a dense mat of brambles. A washed out trap dike separates the island, forming a chasm about $5 \mathrm{ft}$. wide, which is bridged by fallen trees. During the spring tides the water flows through the chasm, making for a short period two islands. It is the breeding ground of herring gulls, eider ducks, black-crowned night herons, and probably ravens. Leased and protected by the National Association of Audubon Societies as a breeding place for birds. $12 \mathrm{mi}$. southeast of Machias, which is reached by the Maine Central Railroad.

2. *Brothers Islands. (C3.) Two islands connected (except at high tide). About 50 acres; turf-covered masses of granite with sea cliffs on the south side about $60 \mathrm{ft}$. high; fine examples of glacial action are shown on the bar which connects these islands. Sheep are pastured, but herring gulls and Leach's petrels breed, and the island is guarded by the National Association of Audubon Societies. It is located in the entrance to Machias Bay, and is $11 \mathrm{mi}$. south (by boat) from Machias.

3. *Pulpit Rock. (A2.) A twoparted pinnacle of rock, $20 \mathrm{ft}$. above high water mark. Herring gulls and black guillemots breed and cormorants roost. Guarded as above. One mi. west of Brothers Islands.

4. ${ }^{*}$ Cone Island. (C3.) A low, rather marshy island of about 40 acres, close to Nash Island Light, and pastured by sheep. It supports a large colony of herring gulls, and is guarded like the above-named islands. About $11 \mathrm{mi}$. south of Addison, Washington County.

5. *Petit Manan Point. (B3.) Maintained as a private game preserve; deer, foxes, hares and wild fowl. Steuben, Washington County, $15 \mathrm{mi}$. from Cherryfield, Hancock County. 
6. *Little Duck Island. (B2.) An island of about 30 acres, partly covered with spruce and fir. Well out at sea, with rocky shores and a difficult landing. Large numbers of herring gulls, blackcrowned night herons, black guillemots and Leach's petrels breed here. The island is owned by B. W. Arnold, of Albany, New York, who has dedicated it to the use of the birds. It is guarded by the Audubon Society. $18 \mathrm{mi}$. south of Bar Harbor.

7. *Great Duck 1sland. (C3.) Two mi. long, with a U. S. Light House at its southern end; sheep are pastured. Covered with turf and spruce forest; very large colonies of herring gulls and Leach's petrels and some black guillemots breed here. Guarded by the National Association of Audubon Societies. Located $1 \mathrm{mi}$. south of Little Duck Island.

8. *Matinicus Islands. (C3.) A group of 8 islands about $20 \mathrm{mi}$. southeast of Rockland, Knox County. Matinicus is the center of the group, and seat of a prosperous fishing hamlet. (See general account.)

9. *Nomans Land. (C3.) A turf-covered, granite island of about 30 acres, pastured by sheep. It is the home of a large colony of herring gulls, and is guarded by the National Association of Audubon Societies. Located one mi. northeast of Matinicus.

10. *Ten Pound Island. (C3.) Contains 15 acres of turf-covered granite; pastured by sheep. There is a large colony of herring gulls, guarded as above described. Located one-half mi. south of Matinicus.

11. *Matinicus Rock. (A2.) A mass of granite with practically no soil, about 35 acres in extent, and $60 \mathrm{ft}$. above high water mark; during the heaviest southeast gales it is occasionally completely washed by gigantic waves. It is owned by the U. S. Light House Board, and occupied as a light and fog signal station. Occupied by thousands of Arctic terns and a few black guillemots and puffins. Guarded like the above mentioned islands. Located five mi. south of Matinicus.
12. *Metinic. (G7.) Two mi. long, containing 2 farms with fields, pastures and a tract of spruce timber. On the south end is a colony of common and Arctic terns. Located $15 \mathrm{mi}$. south of Rockland.

13. *Mettinic Green Island. (C3.) Contains 20 acres of grassland. Occupied by a very large colony of herring gulls and a few black guillemots. Located one-half mi. south of Metinic.

(Both the south end of Metinic and Metinic Green Island are owned by Woodbury Snow of Rockland, who acts as warden for the National Association of Audubon Societies in protecting the birds that breed on these places.)

14. *Eastern and Western Egg Rocks. (A2.) Two small islands, consisting of masses of turf-covered granite, each about 5 acres in area; uninhabited. Colonies of black guillemots, herring gulls, laughing gulls, common and Arctic terns breed here. Guarded by the National Association of Audubon Societies. Located about $15 \mathrm{mi}$. southeast of Damariscotta, in Lincoln County.

15. *Back Cove. (C3.) An arm of the sea, on the north side of the city of Portland, Cumberland County. It is nearly circular, and about a mile across. The water is very shallow and at low tide large areas of clam flats and mussel beds are exposed. The margins of the cove are filled with thatch, and the shallow water contains much eelgrass. It is the resort of thousands of waterfowl from early September to early May.

16. *Breakwater and Ram Island Farms. (G7.) A privately owned area, operated as two farms, with farm lands and woodlands. On Cape Elizabeth, about $8 \mathrm{mi}$. south of Portland.

17. *Prout's Neck. (G7.) About 100 acres of sea beach, rocky, wooded headland and fresh water pond. Scarborough, Cumberland County.

18. *Stratton and Bluff Islands. (B2.) Two islands about 50 acres in area, without trees. Large colonies of common terns and a few roseate and Arctic terns breed here. Guarded by the National Association of Audubon Socie- 
ties. One mi. south of Prout's Neck.

19. *Hogback and Birch 1slands. (B2.) Two small islands in Moosehead Lake, with a small growth of trees, chiefly pine; uninhabited by man. Occupied by colonies of herring gulls and numbers of ducks. Guarded as above.

Scarborough Salt Marshes. (B2.) About 600 acres of typical salt marsh. Vegetation chiefly thatch (Spartina glabra), black grass (Juncus gerardi) and various sedges. In the upper portions of the Nonesuch Marsh there are areas of wild rice (Zizania aquatica) and other important plant communities. Bitterns, green herons, red-winged blackbirds, sharp-tailed sparrows and probably many other birds breed. It is a rendevous for thousands of ducks in the spring and autumn, and during the open season is frequented by hunters. A part or all of this marsh should be preserved as a reservation, as it is the largest and most typical salt marsh located on the Maine coast. Located along the Scarborough and Nonesuch rivers about $10 \mathrm{mi}$. south of Portland. It is traversed by the Maine Central Railroad, the nearest station being Scarborough.-A. O. Gross.

The Knox Arboretum. (H8.) 60 acres in a semi-natural state, consisting of acres of open fields and 55 acres of forest, containing about 700 varieties of trees, shrubs and other plants, including many rare species, which are being continually added. Wild life, especially birds, protected. Bounded by unpolluted rivers, their lower portions tidal, the St. George on the south and west and the Oyster on the east. The soils are sand and sandy loam on the higher land, clay along the rivers. Owned by the Knox Academy of Arts and Sciences, Thomaston; two mi. west of that place by electric railway.-J. A. Tolman.

Owl's Head. (C3.) Tip of Owl's Head peninsula, about 1700 acres owned by the national government, the point being occupied by a light house. The shores are mostly ledges, and the inland area is mostly wooded with spruce in a semi-natural condition, although there are some fields and open ground. The area offers great possibilities as a bird and mammal sanctuary. Located one mi. from Owl's Head Postoffice $(4 \mathrm{mi}$. (a) from Rockland).-J. A. Tolman.

\section{The interior}

Speckled Mountain Region. (B3.) About 100 sq. mi. of the dissected and glaciated upland lying in an elbow of the Androscoggin River, south of the Rangeley Lakes. The country rock is composed of crystalline schists injected with granites. The topography of the valleys is modified by deposits of glacial gravels. Mountain streams and two ponds occur in the region. Speckled Mountain is about $4300 \mathrm{ft}$. high, and the lowest altitude of the region is approximately $700 \mathrm{ft}$. The forests are mixed deciduous and coniferous, representing wild conditions. Where cut a secondgrowth is appearing. Small mammals are mostly characteristic of the coniferous forest. The region lies about $10 \mathrm{mi}$. northwest (a)** of Bethel, Maine, which is on the Grand Trunk Railroad, and where supplies may be obtained.Manton Copeland and $P$. W. Meserve.

Mount Ktaadn. (B2.) Mount Ktaadn Game Preserve and proposed state park. About 90,000 acres located in the heart of the northeastern coniferous forest. Mount Ktaadn (5273 ft.) rises abruptly from the lowlands. (See general account.) Located about $20 \mathrm{mi}$. west of Staceyville, which is reached by the Bangor and Aroostook Railroad. Trail to the mountain from Staceyville by way of Ktaadn Lake and Chimney Pond.

\section{LITERATURE}

Many authors.

1890-date. Entomological Papers from the Maine Agric. Exp. Sta.

Churchill, J. R.

1901. A Botanical Excursion to Mt. Katahdin. Rhodora, 3, 147165.

Dutcher, B. H.

1903. Mammals of Mt. Katahdin, Maine. Proc. Biol. Soc.Wash., XVI, 63-71.

Fernald, M. L.

1892. The Portland Catalogue of Maine Plants. Proc. Port. Hamlin, C. E. Soc. N.H., II, 41-72 and suppl.

1881. Observations upon the Physical Geography and Geology of Mount Ktaadn and the Adjacent District. Bull. Mus. Comp. Zool., VII, 189-223.

Harvey, L. H.

1903. An Ecological Excursion to Mt. Ktaadn. Rhodora, 5, 41-52.

A Study of the Physiographic Ecology of Mount Ktaadn, Maine. Univ. of Me. Studies, 5.

Hill, A. F.

1919. Vascular Flora of the Penobscot Bay Region. Proc. Port. Soc. $N$. H., III, 199-304. 
Knight, O. W.

1897. A List of the Birds of Maine. Univ. of Me. Bul. 3 .

Rand, E. L., and Redfield, J. H.

1894. Flora of Mount Desert, Maine. Smith, E. S. C., and Avery, M. H.

1922. A Bibliography for Mount
Ktaadn. Appalachia, XV. 334-340.

Revised and extended, 1924. Appalachia XVIII, 59, 70.

Tarr, R. S.

1900. Glaciation of Mount Ktaad n Maine. Bul. Geol. Soc. Am., 11, 433-448.

\section{B. States, Chiefly Deciduous Forest}

Nearly all these states here included contain some coniferous forest either on the high mountains, or in their northern reaches; or mixed coniferous and deciduous forest on rock outcrops and shallow soil, or on low lands where hemlock and white pine are sometimes found. The states north of the Ohio River include small areas of prairie in the form of local patches in dried up marshes, on west sloping river bluffs and similar situations.

\section{NEW HAMPSHIRE}

By K. W. Woodward and C. F. Jackson

\section{GENERAL CONDITIONS}

\section{Physiographic regions}

New Hampshire is difficult to describe briefly in its physical aspect. Perhaps the most striking single feature is the White Mountain region, but even this is not isolated. It is merely the culmination of a series of elevated ridges. There are high points on all sides of it.

While the Connecticut River is the largest and longest stream in the state its valley is a comparatively narrow one. The Merrimac River has a wider watershed even though it is only about half as long. In addition to these two principal streams, portions of the basins of the Androscoggin, Saco, and Salmon Falls Rivers are included in the eastern portion of the state although all three streams receive most of their waters from Maine.

This diversity of conditions gives throughout the comparatively limited area of the state a great variety of topography. No one of the 10 counties is exclusively valley, mountain or hill country. Each has all three kinds.

\section{Plan and Animal communities}

a. Plant communities. While there are in each county level valley floors susceptible of easy tillage the general character of the state is hilly. Twothirds of the land surface is either too steep or too rocky to be cultivated cheaply. Hence the dominant plant communities are forest types. In the valleys and the comparatively low southeastern section white pine is the most valuable tree species and probably the most abundant numerically. Above the white pine region, on the hills and lower mountain slopes this species (Pinus strobus) gives way to the northern hardwood zone in which beech, birch (two or three species) and sugar maple are the characteristic species. The higher mountains are covered with stands of spruce (Picea rubra) and balsam fir (Abies balsamea). Timber line occurs at about $4500 \mathrm{ft}$. above sealevel.

The distribution of these three main forest types is as follows:

White pine, sea-level to $1000 \mathrm{ft}$; northern hardwoods 1000 to $2500 \mathrm{ft}$.; red spruce 2500 to $4500 \mathrm{ft}$.; treeless 4500 ft. to top.

b. Animal communities. Except for the animals peculiar to the alpine summits there is very little difference in the fauna. For the most part the vertebrates found in one part of the state occur in every other part so far as man's activities permit. Invertebrates are naturally more localized.

\section{PRESENT BIOTIC CONDITIONS}

There is little difference between the present flora and fauna of this area and that of pre-colonial New Hampshire. The invertebrates are characteristic of 
a northern hardwood or white pine and spruce forest.

In the mountain streams there occur commonly spirogyra and blue green algae associations together with the fresh water sponge (Heteromeyemia ryderi), cadis fly larvae (Hydropsyche sp.), and in the shelter of stones and eddies numerous species of Neuroptera. Of the terrestrial invertebrates, the chief groups, as in all localities, consist of insects and spiders. Of the former the only distinctive species is the White Mountain butterfly (Oeneis semidea), which seldom ventures below tree line at $4500 \mathrm{ft}$.

The area is not especially prolific in vertebrate species. The dominant fish of this region and in fact the only species in many sections is the brook trout (Salvelinus fontinalis). Along the margin of the streams and ponds are found large colonies of the bullfrog (Rana catesbeiana), pickerel frog (Rana palustris), and occasionally spotted salamanders (Ambystoma maculatum).

In the drier localities toads (Bufo americanus and (Bufo fowleri)) and wood frog (Rana sylvatica), occur in varying abundance.

Reptiles are very scarce. The common garter snake (Thamnophis sirtalis sirtalis), black snake (Coluber constrictor constrictor), and the red bellied snake (Storeria occipito-maculata) being the most common. Wood tortoises (Clemmys insculpta) are occasionally met with but other species of turtles, snakes and lizards are seldom found.

Birds form the usual grouping of a transitional forest area. In the mixed white pine and hardwood forests are to be found associations of ruffed grouse (Bonasa umbellus), chickadee (Parus atricapillus), junco (Junco hyemalis), with numerous species of thrushes, warblers, and sparrows during the spring and summer. As one ascends the ridges and enters into the red spruce forest at 2500 to $4500 \mathrm{ft}$., bird life is much less abundant being represented by scattered groups of Canadian spruce grouse (Dendragapus canadensis), white- crowned sparrow (Zonotrichia leucophrys), yellow warbler (Dendroica aest$i v a)$, and various species of sparrows and finches.

During the winter months the red spruce region is almost devoid of bird life except the spruce grouse, chickadee and junco, even the latter being rather irregular in their occurrence.

The early colonial history of New Hampshire mammals was one of almost complete extermination. With the settling of the country and the clearing of vast forest areas, the cougar (Felis couguar), Lynx (Lynx canadensis), bobcat (Lynx rufus), black bear (Ursus americanus), woodland caribou (Rangifer caribou), and the moose (Alces americanus), were killed off or driven farther north into Maine and New Brunswick. Few records are available concerning the smaller species although the Virginia deer (Odocoileus virginianus borealis), and gray squirrel (Sciurus carolinensis leucotis), seem to have followed the settlement of the country rather than to have suffered as a result oi such changes. Later, due to the stress of economic conditions, farms and upland pastures were abandoned, the country being rapidly conquered by a second growth which furnished excellent protection for a great variety of mammals. Virginia deer, snowshoe hare (Lepus americanus virginianus), and gray squirrel, owing to the depleted predatory animals, became more numerous than ever before in the history of the state.

At the present time predatory animals are returning to their former abundance. The raccoon (Procyon lotor), red fox (Vulpes fulva), bob-cat and Canada lynx are more numerous today than since colonial times While the black bear, mink (Mustela vison), pine marten (Martes americanus), and fisher (Martes pennantii), are increasing at a much slower rate.

Undoubtedly as the second growth gradually approaches the climax of its development there will be found through the red spruce and white pine forests all species which formerly occurred here 
with the exception of the timber wolf (Canis lycoon), moose, and caribou.

\section{Changes since settlement}

At present man's clearing and lumbering operations only show in a minor degree. They have changed, somewhat, the composition of the forest types and reduced temporarily the number of larger vertebrates. All large streams of the state are more or less polluted by sewage and waste from factories.

\section{PRESERVED AREAS}

\section{Plains and foothill regions}

1. Old growth white pine and hemlock, 50 acres belonging to New Hampshire College, Durham, Strafford County. 50 to $80 \mathrm{ft}$. above sea-level. Red squirrels, ruffed grouse and deer are common. Five minutes walk from B. \& M. Railroad Station at Durham.

2. Old growth white pine, Sutton, Merrimac County. Area, 5 acres. Too small to have a characteristic fauna. $500 \mathrm{ft}$. above sea level. Bradford B. $\&$ M. Railway, 5 mi. north. Administered by town and Society for the Protection of N. H. Forests.

3. Old growth white pine, Conway, Carroll County. The 10 acres owned by S. P. N. H. F. is merely a part of a $100-$ acre tract. $800 \mathrm{ft}$. above sea level. Red squirrels, partridge and deer common. 10 minutes walk (east) from North Conway station on B. \&. M. Railway.

\section{Northern hardwood and spruce regions}

1. White Mountain National Forest. See account in National Forests of the Eastern District.

2. *The Crawford Notch State Forest. 6000 acres. Is an integral part of the White Mountain National Forest (B4) and handled in the same way although under different management. The Black Mountain State Forest, Benton, Grafton County, is also merely a portion of the White Mountain area.

3. *Mount Monadnock State Forest. (B4.) 1000 acres on the summit of Mt.
Monadnock, Jaffrey, Cheshire County. 3000 to $5000 \mathrm{ft}$. above sea level. All of it has been logged over but dense second growth forests of spruce and hardwoods exist. The old fauna has largely returned. East Jaffrey, $5 \mathrm{mi}$. west, B. \& M. Railway.

4. ${ }^{*} M t$. Kearsarge. (B4.) State Forest, on the 800 acres in Warner Merrimac County, is of the same general character. 3000 to $4000 \mathrm{ft}$. above sea level. Potter Place, $10 \mathrm{mi}$. north, B. \& M. Railway.

5. ${ }^{*}$ Mt. Cardigan State Forest. (B4.) 700 acres on Orange and Alexander, Grafton County, have been cut and burnt over for the most part. $3000 \mathrm{ft}$. above sea level. Graiton, $7 \mathrm{mi}$. S.W., B. \&. M. Railway.

6. ${ }^{*} M t$. Sunapee State Forest. 656 acres in Newbury, Merrimac County. Is similar in character to the State Forests on Monadnock and Kearsarge. 3000 to $4000 \mathrm{ft}$. above sea level. Mt. Sunapee, 5 mi. north, B. \& M. Railway.

7. The Rhododendron Reservation. 300 acres, in Fitzwilliam, Cheshire County, controlled by the Appalachian Mountain Club is an area of cutover mixed northern hardwoods and conifers mainly notable for possessing much rhododendron. 500 to $1000 \mathrm{ft}$. above sea level. Fitzwilliam on the B. \&. M. Railway is 5 mi. south

\section{VERMONT}

\section{By Geo. P. Burns}

The State of Vermont consists of a series of mountain ranges and valleys running north and south. Only a few of the mountain tops are above the timber-line. The lower mountains and all the mountain slopes were originally covered with a dense forest growth made up chiefly of spruce, fir, white pine, maple, ash, birch, elm, cedar and beech.

In the early forests lived the black bear, raccoon, weasel, mink, otter, timber wolf, red fox, lynx and beaver in great abundance; while elk, moose and Virginia deer were commonly seen. Among the birds were the bald and 
golden eagle, several varieties of hawks and owls, meadow lark, crow, blue jay, and vireo. A complete statement of early conditions in Vermont is to be found in Thompson's Vermont, 1853.

As Vermont was one of the first territories settled, the pioneers at an early date occupied the lower slopes of the mountains and then pushed up the mountain slopes clearing farms on the more gentle slopes and later on the steeper slopes and "alpine meadows." As drainage was improved they also moved down to the lower lands along the rivers.

Due to this occupation by man only the higher mountain tops escaped the work of the ax and these are the only places left in Vermont which are today preserved in their "natural conditions." However the changing commercial conditions have made the cultivation of many of the hill farms unprofitable. Many have been abandoned for the more fertile lands in the valleys or those of western states.

Vermont, then, represents a state which is gradually going back to natural conditions in her mountainous regions. The abandoned upland farms are being reforested partly by natural reproduction and partly by artificial planting. An old cellar hole and a decrepit orchard are not uncommon sights in spruce or hardwood forests which now occupy thousands of acres of the state.

The forest areas of the state are being purchased by four classes of owners: by the lumber companies for purely commercial purposes; by the cities as a protection for water supplies; by the outing clubs and by the State. Added to these are the University of Vermont which owns the top of Mt. Mansfield, the highest mountain in the state, which has been little disturbed in either flora or fauna and Middlebury College which owns the Battell Forest, a large tract of land, part of which is a commercial forest and the remainder is to be preserved in its natural conditions.

There are 12 or 13 State forests. Some of this land is not suitable for tree growth for commercial purposes. The state forests contain hundreds of beautiful lakes of all sizes to which many tourist come every summer for their vacations. The state policy encourages this movement but attempts to so guard the permits that our native flora and fauna are adequately protected. The state legislature passed a law protecting many of our rare plants. This was necessary because a number of nursery men were coming to the state and taking rare plants in large numbers. If unprotected many of the tourists would not hesitate to take the last specimen of a rare plant.

Where soil and topography are suitable the State is planting softwoods for commercial purposes.

The problem of Vermont, then, seems to be one of a return to natural conditions rather than the preservation of such conditions. There seems to be a growing sentiment in the state in favor of the movement to repair the damage which unintentionally has resulted from the conditions existing in the past. The younger states should profit by this example and wherever possible preserve their natural conditions.

The principal areas in Vermont which, in all probability, will be kept in their natural conditions, or allowed to return to their natural conditions are the State Forests, the forests recently purchased by cities to protect their water supplies, the game preserves and the lands owned by the Universities of the State.

\section{NATURAL AREAS}

\section{State Forests}

The principal State Forests are as follows:

*Downer State Forest. A tract of 800 acres located in the Green Mountains in a natural spruce area. Sharon, Vermont. Walk or drive $5 \mathrm{mi}$. north to forest. Accommodations for an indefinite stay in a very comfortable farm house located in the center of the forest. 
*L. R. Jones State Forest. Plainfield, via Vermont Central, drive or (w) $12 \mathrm{mi}$. A suitable cabin for camping out.

${ }^{*}$ Hapgood State Forest. 900 acres, Manchester via Rutland R. R., stage $12 \mathrm{mi}$. into the mountains. No accommodations.

*Crouching Lion State Forest. 1200 acres. Burlington via Rutland R. R., or Central Vermont R. R., stage $20 \mathrm{mi}$., walk $5 \mathrm{mi}$. into mountains, forest lodge for camping.

*Mansfield State Forest. (C3.) 5000 acres. Deciduous forest and coniferous mountain forest. Burlington via Rutland R. R., or Central Vermont R. R., bus $18 \mathrm{mi}$., walk $7 \mathrm{mi}$. to top of Mansfield. Hotel accommodations during the summer season.

*Putnam State Forest. 1100 acres. Montpelier via the Vermont Central R. R., bus to Worcester, walk $5 \mathrm{mi}$. to forest. No accommodations.

*Proctor-Piper State Forest. 400 acres. Cavendish via the Vermont Central R. R., walk $3 \mathrm{mi}$. to forest. Ample accommodations at small hotel at base of mountain.

${ }^{*}$ West Rutland State Forest. 3500 acres. West Rutland via Rutland $R$. R. or Delaware and Hudson R. R., drive $9 \mathrm{mi}$. No accommodations.

*West River Valley State Forest. Townshend via Central Vermont R. R., walk $6 \mathrm{mi}$. to forest. No accommodations on the mountain but excellent farm boarding near the base. A forest in the center of a vast spruce region.

*George Aitken State Forest. 850 acres. Woodstock via Woodstock R. R., drive $12 \mathrm{mi}$. to Mendon, walk $4 \mathrm{mi}$. to forest. No accommodations.

\section{University forests}

\section{*Middlebury College Tract. (C3.)} The Battell Forests. 30,000 acres. Deciduous, eastern coniferous and mountain forests; ravines, rocky and glacial situations. Middlebury via Rutland R. R., bus $13 \mathrm{mi}$. to center of tract. Excellent hotel [Breadloaf Inn] accommodations during the summer season.
*University of Vermont Tract. The top of Mount Mansfield bordering the Mansfield State Forest. Burlington via Rutland R. R. and Central Vermont or Waterbury via Central Vermont R. R., trolley to Stowe thence walk or drive $12 \mathrm{mi}$. to top of the mountain. Hotel accommodations during the season.

\section{State Game Preserve}

Mouth of Lamoille River on Lake Champlain. Landing place for wild duck and geese. Grand Isle via Rutland R. R., bus $5 \mathrm{mi}$. No accommodations.

\section{City Forests}

The largest near Rutland. Rutland via Rutland R. R., walk or bus, 8 mi. to forest. All houses and other buildings have been removed and camping is not encouraged.

\section{The Green Mountain Trail}

This trail has been built by the Green Mountain Club and runs almost the entire length of the Green Mountains. It begins at the Massachusetts line and is completed as far as Johnson. It passes through many of the State Forests and the University of Vermont and Middlebury College tracts. Camps, hotels and many farm boarding houses are located at convenient places. A camp outfit is necessary but it is not necessary to carry a heavy load of supplies as they can be purchased at intervals along the line. "The Long Trail follows dashing trout brooks, goes around lovely blue lakelets in the mountain areas, traverses wooded ridges with frequent outlooks and goes over the tops of 30 mountain peaks."

\section{MASSACHUSETTS}

\section{By Anna M. Starr}

\section{PHYSIOGRAPHY}

The State of Massachusetts presents a perfect illustrative section across the Appalachian Mountain system in an area where it culminates in variety and 
complexity, about midway between Newfoundland and Alabama. The rocks now at the surface, show by their structure, that they can have attained their present condition only under the weight of a great mass of superincumbent material, and as the surface shows steeply dipping and truncated layers, it is evident that erosion cut the mass down towards sea level and almost reached it, for the region was worn down to a peneplain, with elevations surviving, called "monadnocks" from the name of the mountain just over the border in New Hampshire. The chief monadnocks are Mount Wachusett, the Watatics, Mount Grace, Brush Mountain, and Asnebumskit Hill.

This plain was then raised as a whole, without folding, but by broad warping and tilting; so that in the northwestern part of the state it stood about $2000 \mathrm{ft}$. above the sea. As a result of this uplift the streams cut deep trenches. In the soft sandstone of the Connecticut Valley and the soluble limestones of the Housatonic Valley these trenches were widened into broad valleys, the beginnings of new transient peneplains.

Thus erosion has marked out the broad topographic divisions of the State, which are also the broad geologic divisions. These divisions are:

1. The Cambrian and Ordovician limestone valley of the Housatonic, in which steep schist ridges rise from Greylock to Canaan Mountain.

2. The broad Archean-Silurian upland of eastern Berkshire County, running through Hoosac Mountain and the "hill towns"-Peru, Washington, and Becket.

3. The Devonian-Triassic valley of the Connecticut in which there are sharp trap ranges, illustrated by the Mount Tom and Mount Holyoke Ranges.

4. The central upland, or Worcester County plateau, made up of alternate broad bands of Carboniferous granite and narrower bands of folded schists.

5. The bordering slope that descends gradually eastward and southeastward from the irregular escarpment bounding the central upland. The rocks of this division, which is about equal in area to the first four combined, present a greater diversity in kind and structure than those of any other division. The whole complex has been several times folded and faulted and has been deeply eroded, so that in parts of the area rocks of presumed Archean age are exposed.

6. The Coastal Plain, which includes the Cape Cod peninsula and the islands south of the mainland.

\section{Soil cover}

Massachusetts is almost wholly covered by Quaternary glacial drift, forming the only mineral soil. In a few places only are there accumulations of preglacial soil. The rocks are too hard and the period since the ice-age too short for the addition of much soil from weathering in post-glacial tin es.

During the Pleistocene Period the country was covered with ice and accumulated rock material, perhaps a mile thick. When the ice relted the material was left as a thin veneer; thin because the rock origin was hard. The layer was thicker in valleys.

The ice cut deep flutings in the hard Holyoke diabase, forn ed drun lins first in the Connecticut Valley, a secrind zone about $8 \mathrm{mi}$. wide that exterds north and south across the State, parting on Wachusett, a third zone through Groton and Marlboro, and a fourth zone along the coast, and formed bowlder trains that can be followed from many ledges of rock. Well-defined terminal moraines mark the places where the ice ren ained stationary $f \circ r$ son e tin e.

Many broad sand areas, sor e of them underlain by laminated clays, mark the sites of lakes, which were fed by the glacial waters and wholly or partly dammed back by the ice.

On the elevation of the land and the recession of the waters, the strears began to cut into the Pleistocene deposits, producing steep scarps and broad alluvial terraces. These terraces were not forested and were therefore sought 
out by the first settlers. They are still the chief agricultural regions of the State. The loam formed by deposition at high water periods is $8 \mathrm{ft}$. thick in many places and forms one of the most fertile soils in Massachusetts.

\section{Waters}

Practically all of the streams are unpolluted in the upper parts of their courses. Lower down, most are contaminated by factories. In the mountains they are beautifully clear and generally pure, so that they are used freely for drinking by campers. Besides there are innumerable springs, so that one is seldom far from good water.

\section{BIOTA}

Livingston and Shreve place Massachusetts in the deciduous-forest area of the United States, with the exception of a narrow zone on the west, a projection from the north into the state just west of the middle, and the northeastern corner, where they find extensions of the northeastern evergreen deciduous transition forest.

The deciduous forest is the usual climax formation of the region, whose dominant trees are species of beech, maple, hemlock, chestnut, oak, ash, basswood, and birch. The notable shrubs are mountain laurel, witch hazel, dogwood and viburnum. The undergrowth is rich in spring herbs, such as red trillium (Trillium erectum), twisted stalk (Streptopus roseus), bellworts (Uvularia and Oakesia), and bishop's cap (Mitella diphylla); in small sclerophylls belonging to the Ericaceae, as trailing arbutus (Epigæa repens), wintergreen (Gaultheria procumbens), prince's pine (Chimaphila umbellata and $C$. maculata), and shin-leaf (Pyrola spp); and in ferns and lycopodiums.

The mountains and bogs have many northern forms, and the coastal regions southern ones. The balsam-fir (Abies balsamea) and red spruce (Picea rubra) are examples of northern forms found only on the mountains, while southern forms are the American holly, which grows on the Elizabeth Islands, the tulip-tree, noted in a few places only, and the flowering dogwood, common everywhere. Merriam mentions the same fact with reference to animals, stating that "the Southern mole and cottontail-rabbit meet the Northern Star-nosed and Brewer's moles and varying hare; and the Southern bobwhite, Baltimore oriole, blue bird, cat bird, chewink, thrasher and wood thrush live in or near the haunts of the bobolink, solitary vireo and the hermit and Wilson's thrushes."

Few virgin forests are left, but sheltered ravines may closely resemble the original forest. Regions that had worked up to the climax have generally been cut over many times or burned at intervals, so that associations that have returned to pioneer conditions are common, illustrated by acres of poplars and gray birches. On cut-over, southfacing slopes usually the oak-hickory association is in evidence, while trap cliffs and sand hills display a white pine stage.

The fauna of Massachusetts originally included a good many Mammalia now lacking, though the number still remaining is always surprising to a visitor from states more recently settled, but more intensively cultivated. When Emmons $^{1}$ wrote his report in 1840 , the moose (Alces americana), the cougar (Felis couguar), and the beaver (Castor canadensis), had already disappeared. The gray fox (Urocyon cinereoargenteus), the Canada lynx (Lynx canadensis), the black squirrel (Sciurus carolinensis leucotis), and probably the wolf (Canis lysaon) were rare. The black bear (Ursus americanus), formerly abundant on the Hoosic Mountains, was still found, several specimens being taken every year, but it is now extinct. The fisher (Martes pennanti), marten (Martes americana), weasel (Mustela noveboracensis), have all been eliminated.

The mammals listed by Emmons that

1 Emmons, Ebenezer. A Report on the Quadrupeds of Massachusetts, published by order of the Legislature, by the Commissioners on the Zoological and Botanical Survey of the State. 1840. 
are included in the Fauna of New England by Glover M. Allen² as now present are the star-nosed mole (Condylura cristata), raccoon (Procyon lotor), red fox (Vulpes fulva), bob-cat (Lynx rufus), mink (Mustela vison mink), otter (Lutra canadensis), skunk (Mephitis nigra), muskrat (Ondatra zibethica), cottontail rabbit (Sylvilagus transitionalis), snowshoe hare (Lepus americanus), woodchuck (Marmota monax preblorum), gray squirrel (Sciurus carolinensis leucotis), red squirrel (S. hudsonicus), chipmunk (Tamias striatus lysteri), flying-squirrel (Glaucomys sabrinus macrotis), deer mouse (Peromyscus leucopus noveboracensis), porcupine (Erethizon dorsatum), deer (Odocoileus virginianus borealis), short-tailed shrew (Blarina brevicauda), hairy-tailed mole (Parascalops breweri), besides the forms inhabiting the coastal waters. The deer are protected except during a short open season, and are numerous enough to be of interest to hunters, and to be a cause of worry to farmers and orchardmen.

Wild turkeys were formerly common over the entire state, the last record being Mt. Tom, winter of 1850-1851. Heath hen was common, now found only on Martha's Veneyard. Wild pigeons were also common.-C. W. Johnson.

\section{PRESERVED AREAS}

There are 7 State Parks in Massachusetts, where they are called Reservations. The land was bought by the State and is maintained by the counties under the direction of special commissioners appointed by the Governor. In addition Massachusetts has 16 State Forests, including the "Province Lands," controlled by the Department of Conservation, Division of Forestry, Metropolitan Parks owned by the State, two Demonstration Forests for the study of forestry, fish and game farms. Three Reservations are held by the Appalachian Mountain Club. (6 or 7 small areas held by the Trustees of Public Reservations.)

2 Allen, Glover M. "Fauna of New England," Occasional Papers of the Boston Society of Natural History. VII. 1904.
The areas described begin with the western boundary of the State and pass eastward.

*Mt. Everet State Reservation.

815 acres of mountain-forest in the town of Mt. Washington, in the southern part of Berkshire County. Northeastern evergreen-deciduous-transition forest. There is a good road from the town to Lake Undine, and a road practically completed from the lake to the top. Waters unpolluted. Good boarding houses at the foot of the mountain. About $2800 \mathrm{ft}$., the second highest mountain in the State.

From Great Barrington, 6 mi.; N. Y., N. H. \& H. R. R.-H. C. Joynor, Gt. Barrington.

*Mt. Greylock State Reservation.

in spots.) Comprising 8600 acres in the northern part of Berkshire County, including mountains, ravines, bluffs, gravel slides, rocky and glacial situations; for the most part wooded, with many varieties of trees both deciduous and conifer showing succession from pioneer conditions on rocky upland to mature forest. Fauna includes small animals and deer. Automobiles can go to the top. Good trails make walking easy. Greylock Summit House furnishes meals and limited accommodations. Camping is permitted and places are assigned by the superintendent. Mr. Rockwell of Pittsfield will furnish information concerning the park. Elevation 800 to $3600 \mathrm{ft}$. Sharp.

From Williamstown $3 \frac{1}{2} \mathrm{mi}$., North Adams $7 \mathrm{mi}$., both on the Nickle Plate R. R.

*October Mountain State Forest. (B2.) 11,000 acres of mountains and plateaus, in the town of Washington, mostly cut over and once cultivated; now abandoned; to be reforested. About one-third consists of woodland, 60-70 years old, reverting to natural conditions. Restocked by the former owners with moose and deer. Average elevation $1900 \mathrm{ft}$., highest $2300 \mathrm{ft}$.

From Pittsfield, 8 mi. south. Partly from a newspaper article by Allen Chamberlain. 
*Arthur Warton Swann State Forest. (C3 (b).) 986 acres in Monterey and Great Barrington; two-thirds forested; joins Bear Mountain Forest on the south. Elevation 1200-2100 ft.

Great Barrington near the base of the mountain.

* Bear Mountain State Forest. (B2.) 5174 acres in Great Barrington and Monterey; eastern mountain-forest of hardwoods and conifers. Elevation 1200-2000 ft.

From Great Barrington about $3 \mathrm{mi}$. east.-State Division of Forestry.

*Savoy Mountain State Forest. (H8 in part.) 3999 acres in Savoy; half covered with a natural growth of hardwoods and spruce of fair size. The rest has been cut over and is being reforested. Elevation 1900-2500 ft.

From North Adanis, 6 mi. south, B. and A. R. R.-State Division of Forestry.

*Mohawk Trail State Forest. (A3 or B3.) 3260 acres, along the Mohawk Trail in Charlemont, Florida, Hawley and Savoy; covered with hardwoods and hemlock in original condition on very steep slopes, too steep and rocky to have been cut over. Succession on rocky upland. Elevation 600-2000 ft. Precipitous.

From Greenfield $16 \mathrm{mi}$. west (a) to Charlemont which is on the Trail. Or North Adams, at west end of the Trail. Nickle Plate R. R.-State Division of Forestry.

*Deer Hill State Reservation. (B4.) 259 acres in Cummington; of undeveloped timber, mainly hardwoods and spruce; not used by the public. Administered by Mr. Clarence E. Hodgkins, Northampton. Elevation $900 \mathrm{ft}$.

From Northampton $23 \mathrm{mi}$. N. W. (a).

*Tolland State Forest. 2925 acres in two tracts in Tolland and Granville. Second growth, chiefly of hardwoods and pine. Hubbard River and Otis Reservoir unpolluted. Elevation 600$1600 \mathrm{ft}$.

From Westfield, B. and A. R. R. 17 mi. (a).-State Division of Forestry.

*Colerain or Christian Hill State Forest. (D4.) 796 acres in Heath and
Colerain. Second growth, chiefly of pine and spruce, once pasture-land. Elevation 1640-1740 ft.

From Greenfield on Nickle Plate R. R. $10 \mathrm{mi}$. N. W. (a).-State Division of Forestry.

*Conway State Forest. (H8.). 666 acres, in Conway. Second growth of hardwoods and conifers, partly planted. Elevation 800-1380 ft.

From Northampton, about $12 \mathrm{mi}$. (a) N. W.

*Mt. Tom State Reservation.

1679 acres in Easthampton and Holyoke. A trap rock formation covered with a forest of hardwoods, pine, hemlock and some spruce, which has been cut in the past on the gentle slopes, but preserves some natural conditions, especially in ravines and on cliffs. Small animals and occasionally deer are seen. There are $15 \mathrm{mi}$. of improved roads and 40 to 50 mi. of paths. Springs abound. There are twenty or more beautifully cleared spots for camps. A road to Goat's Peak gives a wonderfully fine view of the Connecticut Valley, ranging from Hartford to Greenfield. The Chairman of the Mt. Tom Reservation at Northampton will furnish information about the park. Elevation $1200 \mathrm{ft}$. Precipitous.

From Holyoke about $4 \mathrm{mi}$. by trolley or automobile. Mt. Tom House at the top can be reached by cable cars; it furnishes refreshment and amusement, but not lodging.-R. T. Fisher and Division of Forestry.

*Mt. Sugarloaf State Reservation. (B4.) 89 acres in Deerfield, overlooking the Connecticut Valley; a red sandstone formation (Sugarloaf Arkose), covered with forest. There is a mountain house at the summit, $600 \mathrm{ft}$. above the river, reached by a path, or by a wagon road up the gentle slope on the north side. Information can be obtained from Mr. Eugene Blake, Chairman of the Franklin County Commissioners at Greenfield. 200-700 ft. Precipitous.

Northampton, $6 \mathrm{mi}$. north, B. and M. R. R. to South Deerfield; then 1 mi. east.

*Mt. Toby State Demonstration Forest. (C2.) In Sunderland; a conglom- 
erate formation, oi 756 acres, held by the Massachusetts Agricultural College to afford illustrations of timber-growing. The policy of the present administration is to keep about 50 acres of the Roaring Brook ravine untouched, so that it will revert to virgin-forest conditions. About 200 acres of the rocky slopes are too steep to have been cut over and show the natural state. There are springs, brooks, picturesque waterfalls, and one pond of 2 to 3 acres in size. Waters unpolluted. Small animals and deer present. $400-1200 \mathrm{ft}$. Sharp.

From Northampton 8-9 mi. north (a).

From Holyoke $20 \mathrm{mi}$. north (a) or trolley.-L. R. Grose.

*Wendell State Forest. (G7.) 2224 acres in Wendell and Montague. Mostly cut-over land reverting to natural form.

Deciduous forest. $1100 \mathrm{ft}$.

Reached from Greenfield.

*Erving State Forest. (G7.) 1595 acres in Erving, Northfield and Warwick. Second growth of conifers and hardwoods.

Reached from Northfield.

*Mt. Grace State Forest. (A2.) 1004 acres in Warwick. For the most part forested with a natural growth of pine and hardwoods. Noted for beautiful scenery. Greatest elevation $1600 \mathrm{ft}$. Rolling.

From Athol $4 \mathrm{mi}$. N. W. Accommodation can be had at Mt. Grace Inn or at Mrs. Ladd's.-Division of Forestry.

${ }^{*}$ Harvard Forest. Three separate tracts in Petersham; 2000 acres of eastern deciduous and conifer forest, with ravines, hills, rocky and glacial situations, swamps and ponds; including 4 or 5 acres of original forest, and about 40 acres of original sphagnum bog with ericaceous plants and black spruce. Deer present. Used for experiment and demonstration in forestry.

From Athol 9 mi. south.-R. T. Fisher.

*Otter River State Forest. 1721 acres in Winchendon, Royalston and Templeton; recently cut over, being replanted to white, red and scotch pine. A few swamps present. $500-900 \mathrm{ft}$.

From Athol 12 mi. east. Fitchburg

\section{R. R.-L. R. Grose and Division of Forestry.}

*Wachusett Mountain State Reservation. (B2, A in spots.) 1500 acres in Princeton and Westminster; covered with eastern deciduous-and mountain-conifer forest, undisturbed on small areas of ledge; includes mountain, bluff, rocky and glacial situations. There is a good macadam road to the top of the mountain, and plenty of dirt roads around the mountain, built as fire lines. There is a small hotel on the summit, where meals can be obtained; open from the first of June to the middle of October. Mr. John T. Burnett, Chairman of the Reservation, Princeton, Mass., will furnish information. $2000 \mathrm{ft}$. Sharp.

From Worcester, 8 mi. north.-R. T'. Fisher and Division of Forestry.

*Purgatory Chasm State Reservation. (D5.) In Sutton, of 80 acres, of which 60 are fairly well wooded, the rest cut over. The chasm itself is nearly a quarter of a mile long, lies between great ledges, and averages $40 \mathrm{ft}$. in width, and between 40 and $80 \mathrm{ft}$. in depth. Large trees grow in and about the chasm, some growing in between ledges or boulders at the top or on the sides of the cliffs. By careful climbing one can go through the chasm its entire length. Good example of rock ravine.

From Worcester 4 or $5 \mathrm{mi}$.

A. E. Seagrave, Secretary of the Purgatory Chasm State Reservation, Uxbridge, Mass. and Division of Forestry.

*Harold Parker State Forest (G7.) In Andover, North Andover, and North Reading, comprising 1223 acres, generally covered with second-growth hardwoods. Barberry abundant. 100-200 ft. Rolling.

From Lowell or Lawrence a few miles-Division of Forestry.

* Miles Standish State Forest.

In Carver and Plymouth, of 7464 acres of flat and slightly rolling ground, covered with scrub growth of oak and pitch pine. There are no marshes, but twelve beautiful, clear ponds of varying size, in their natural condition, ap- 
parently fed by underground springs, with shores and bottoms of white sand. Camping permitted. $200-300 \mathrm{ft}$.

From Plymouth about $3 \mathrm{mi}$.-Division of Forestry.

*Sandwich State Forest. (G7.) In Bourne and Sandwich, of 673 acres of very sandy land, for the most part burned over and grown up to scrub oak and pitch pine. 100-200 ft. Slightly rolling.

From Boston $56 \mathrm{mi}$. south, N. Y., N. H. and H. R. R.

*Martha's Vineyard State Reservation. In Edgartown, 601 acres of scrub growth, controlled by the Department of Conservation. The heath hen is endemic.

*Province Lands. In Provincetown, at the tip of Cape Cod. 3900 acres of eastern conifer forest, sandy shore, swamps, and sand dunes. The Massachusetts Forestry Association is doing a good deal of planting on the dunes as an experiment in reclamation of unprofitable land, but many acres will probably remain for a long time in a natural condition.

\section{Small Public Reservations}

These reservations are gifts, held in trust by a corporation, named Trustees of Public Reservations, whose purpose it is to acquire and maintain for the public, beautiful and historical places within the Commonwealth. All are heavily wooded with the exception of Governor Hutchinson's Field.

Monument Mountain Reservation. 260 acres in Great Barrington.

Pine Knoll, 6 acres in Sheffield.

Petticoat Hill, 50 acres in Williamsburg.

Rocky Narrows, 21 acres in Sherborn.

Mount Ann Park, 50 acres in Gloucester.

Virginia Wood, 139 acres in Stoneham. Systematic work in forestry carried on by the Metropolitan Park Commission. Now part of Middlesex County Reservation.

Governor Hutchinson's Field. 10 acres in Milton. Some work in forestry carried on.

\section{Reservations of the Appalachian Mountain Club}

The Club owns 16 parcels of land, 3 of them in Massachusetts, managed by a board of Trustees of Real Estate. They are held in trust for the public.

Parsons Reservation. (C3.) 40 acres on Mt. Grace in Warwick; upon an eminence locally known as Bennett's Knob. The view includes Wachusett, Greylock, and other mountains in Massachusetts; the Monadnocks just over the line in New Hampshire; the Green Mountains in Vermont; and the Adirondacks in New York. The reservation is largely wooded, with a mixed growth of good quality and middle age. $1490 \mathrm{ft}$. Sharp.

From Athol about $13 \mathrm{mi}$. N.W.-H. N. Shepard, Chairman.

Carlisle Pines Reservation. (F6.) 20 acres in the town of Carlisle. This reservation is notable for its 100 great white pines, $2 \frac{1}{2}$ to $3 \frac{1}{2} \mathrm{ft}$. in diameter and 100 to $120 \mathrm{ft}$. tall, as large and as fine as New England can produce. The hardwood trees have been cut to give prominence to the big pines, and to render possible the growth of others, and especially to deprive the gypsy moth of food. Elevation $200 \mathrm{ft}$.

From Boston about $20 \mathrm{mi}$. N. W.H. N. Shepard.

Gilson Hill Reservation. In Billerica, includes about 9 acres upon the summit of the hill, and about 15 acres in the connecting wood-roads. It is one of the best view-points in Middlesex County, commanding Wachusett, the Monadnocks, Joe English Hill, and a broad sweep eastward to the sea. At the foot of the hill is a spring, near which an early settler, Gilson, built his home.

From Boston about $25 \mathrm{mi}$. N. W. $-H$. $N$. Shepard.

Moose Hill Sanctuary, Sharon, Mass. 19 mi. from Boston, on the N. Y. N. H. \& H. Railroad. Located mi. west of Sharon station. A tract of 235 acres for bird and flower protection and supervised jointly by the Massachusetts Audubon Society and the Society for the Protection of native New England plants. (Bibliography: S. P. N. E. P. Leaflet $32: 1920$.)

\section{Areas proposed (Massachusetts)}

1. 3 acres sand area with bogs, sandy, rocky shore, and dunes. Located in Essex County, $5 \mathrm{mi}$. from Ipswich, Mass. Preserved privately by R. T. Crane.-Laetitia H. Snow.

2. Plum Island. A narrow island, about $8 \mathrm{mi}$. long, lying parallel to the coast, near Ipswich, Mass. $-R$. $T$. Fisher. 
3. Elizabeth Islands. South of Buzzards Bay.

(a) Naushon. Primeval forest. Overgrazed by deer and sheep, so not a fit home for ground-nesting birds. Owned by the Forbes family.

(b) Wepecket Islands and Little Pine Island, recommended as a bird sanctuary, as they are the mating ground of at least two species of terns. Owned by the Forbes family.

(c). Penikese Island, owned by the state, and formerly used for a leper colony; now likely to be sold; a breeding ground of common and roseate terns.

(d) Gull Islands; a breeding ground of common and roseate terns. $-E$. $H$. Forbush.

4. Martha's Vineyard. (a) The south side of Martha's Vineyard should be protected as a breeding place for least terns. It is one of the few localities in which these birds remain in the east; and with its ponds, beaches, etc., offers exactly the conditions these birds need. The least tern in the northeast is very near extinction. The land around the ponds is now owned largely by gunners who have gunning stands at the ponds.

(b) The Squibnocket region at the west end of the Vineyard should be protected as a bird reservation, because of the number and variety of birds that breed there.

(c) One of the ponds at east end of the Vineyard should be made a reservation. -E. H. Forbush.

5. Muskeget Island. A small island lying northwest of Nantucket and a part of Nantucket County, controlled by the town of Nantucket, which employs a warden. It would make a splendid reservation for sea-birds. It was formerly a great breeding place for gulls and terns. The laughing-gulls are apparently encroaching on the breeding grounds of the terns, and are increasing while the terns are decreasing. $-E$. $H$. Forbush.

6. Cape Cod. (a) Monomoy Island, the southeast extension of Cape Cod, south of Chatham, would make an excellent reservation for sea-birds. There are three species of terns that breed in this region. The best place for the reservation would be the south end, if something could be done to protect the birds from cats, skunks, and foxes which readily travel the whole length of the point of land, no longer an island.

(b) North Beach near Chatham, formerly the habitat of terns, now almost eliminated by cats and skunks.

(c) South Beach near Chatham, where three species of terns form a colony of 8000-10,000.

(d) An island in the harbor of Nausett Beach, where terns breed.

(e) Long Point on the bay side of Cape Cod, together with some of the woods farther back from the shore, where the night herons breed in numbers.

(f) A peninsula at Truro.

(g) An island at Hyannis.

(h) A large section of land at Sandy Neck, Barnstable, recommended for reservations for the study of bird-life. -R. T. Fisher and E. H. Forbush.

7. A rock ravine, called Orient Springs (D5) in Pelham, about $3 \mathrm{mi}$. east of Amherst. Two branches of a clear brook have cut a gorge in the hills, forming picturesque cliffs, where many liverworts, mosses and ferns grow. Some steep slopes and uplands have a good stand of white pine and hemlock. It is owned by the street railway company and is used as a picnic ground. It is within reach of Mt. Holyoke, Amherst, and Massachusetts Agricultural Colleges. Succession in a rock ravine.Anna M. Starr.

8. A white pine grove at Boxford, owned by Prof. George H. Palmer of Harvard. The pink lady-slipper grows here in unusual abundance. It is about $25 \mathrm{mi}$. north of Boston, within reach of Bradford Academy, Wellesley College and Harvard University.-Helen $W$. Farrell, Bradford Academy.

9. Congamond Bog. (B4.) On the borderland between Massachusetts and Connecticut. It is a splendid example of natural bog vegetation, interesting to both ecologists and systematists, and should be preserved for study. It is 
within reach (a) of Yale University and the Connecticut Valley Colleges.-Anna M. Starr.

10. An island in the Connecticut River near Holyoke (B4), covered with cottonwoods, willows, silver maple and other flood plain vegetation, might well be preserved for the study of the development of an island. It is of recent formation and has never been cut.Anna M. Starr.

\section{CONNECTICUT}

\section{By George E. Nichols}

For an area comparatively small in size ( $5000 \mathrm{sq}$. mi.) the State of Connecticut presents a remarkable diversity of natural and semi-natural conditions. Physiographically the state comprises three north-south provinces: an eastern and a western highland and a central lowland. In the highlands the topography is rugged, the land being greatly dissected by stream erosion, and on nearly every hand the surface deposits of glacial material are interspersed with outcrops of bare rock, mostly granites, gneisses, and schists. In the central lowland, except for the trap ridges which form a prominent feature, the surface contours are more gentle and the underlying sandstones and shales for the most part are covered over by a mantle of glacial debris, sometimes to a depth of $200 \mathrm{ft}$. In certain parts of western Connecticut, limestone and dolomite are the prevailing rocks, but elsewhere calcareous rocks are practically absent. On the south Connecticut is bounded by Long Island Sound. In proceeding from the Sound northward the general level of the land surface gradually rises, and in the northwestern part of the State hills more than $2000 \mathrm{ft}$. in elevation are encountered. Both the maximum and the average elevations in the Eastern Highland are lower than in the western, while the general surface level of the Lowland in northern Connecticut is scarcely $200 \mathrm{ft}$. above sea level. There are upwards of 1000 lakes and ponds in the state, while permanent springs are everywhere abundant. Of the several rivers only one, the Connecticut, is to any extent navigable.

The type of vegetation favored by climate here is a mesophytic forest, and in former days the greater part of the state was heavily wooded. For the most part the forest comprised a mixture of deciduous and evergreen trees. Conspicuous among the deciduous species were the chestnut (Castanea dentata), various oaks and hickories, tulip (Liriodendron tulipifera), sugar maple (Acer saccharum), and beech (Fagus grandifolia); among the evergreens the hemlock (Tsuga canadensis) and white pine (Pinus strobus), and, at the higher elevations northwestward, the red spruce (Picea rubra). The nature of the original vegetation, as of that today, however, varied greatly with differences in physiography, and forests of the sort just described were best developed on the better, well-drained soils. In addition to these, there were forests of pitch pine (Pinus rigida) on the sand plains, forests of red maple (Acer rubrum), elm (Ulmus americana), and black ash (Fraxinus nigra) or of southern white cedar (Chamaecyparis thyoides) in the swamps, forests of cottonwood (Populus deltoides), elm, silver maple (Acer saccharinum) and the like along the streams; and there were many areas that were not forested at all. Lakes and ponds, as today, were occupied by communities of herbaceous aquatic plants, and salt marshes and sandy beaches by communities made up largely of grass.

Practically all the original forest growth in Connecticut has been wiped out by the inroads of civilization, and at the present time only a few small and for the most part inferior patches of near-primeval growth remain. Even today, however, nearly $50 \%$ of the area of the state is occupied by woodland of one sort or another, a remarkable condition for a section of the country so long settled and having so large a population. This apparent incongruity of conditions is to be explained by two facts, namely, 
that most of the land is poorly adapted to agriculture and that the bulk of the population centers in and about the towns and cities. The Central Lowland, being more generally suited to agriculture, has been more thoroughly cleared of its natural vegetation than the Highlands and it is in these latter regions, particularly northward, that the wildest parts of the state today are situated. The second-growth forests of today probably differ from the original forests, so far as their composition is concerned, chiefly in the greater abundance of oaks, hickories and other trees which are capable of sprout reproduction, and in the lesser abundance of white pine and hemlock, which have suffered most heavily from the influence of lumbering and fire. Twenty-five years ago chestnut ranked as the premier forest tree of the state, comprising nearly $60 \%$ of the standing timber, but this tree has now nearly vanished, due to the ravages of the chestnut blight. Another outstanding feature of the woody vegetation today is the groves of cedar (Juniperus virginiana) and gray birch (Betula populifolia) which have preempted abandoned farmlands on every hand.

The flora of the state is rich and varied, comprising some 2000 species of ferns and flowering plants, in addition to which there is a wealth of mosses, algae and other lower forms. The fauna is correspondingly varied, the larger mammals of the present day including the Virginia deer (Odocoileus virginianus borealis), red fox (Vulpes fulva), raccoon (Procyon lotor), porcupine (Erethizon dorsatum), skunk (Mephitis nigra), cottontail rabbit (Sylvilagus transitionalis), woodchuck (Marmota monax preblorum), muskrat (Ondatra zibethica), mink (Mustela vison mink), otter (Lutra canadensis), and probably the bobcat (Lynx rufus). The timber wolf (Canis lycaon), black bear (Ursus americanus), and beaver (Castor canadensis), formerly native, have long since been exterminated along with certain of the birds, notably the wild turkey. Both flora and fauna have been aug- mented by the introduction of many non-native species. Thus, fully $25 \%$ of the flowering plants now growing wild in the state have been introduced, while the English sparrow and the European starling are among the common birds.

From various of the remarks above it is quite obvious that the preservation of natural conditions, so far as this means the preservation of the original forests, is no longer possible, save in the case of a few small patches. The last great opportunity of this sort was lost in 1912, when the sole surviving large stand of indisputably primeval timber, situated in the town of Colebrook, was cut down. The best that can be done now, aside from rescuing the few scattered vestiges of original forest that still remain, is to preserve areas of good second-growth woodland. So far as other types of plant community are concerned, it is still possible to set aside areas in which the primitive conditions may be perpetuated for future generations, and indeed many of these communities seem in little danger of extinction.

The setting aside of natural areas in the form of parks has long since been undertaken by various of the.cities and towns of the State. West Rock Park, New Haven, for example, includes some 200 acres of trap ridge, mostly in natural woodland and probably destined to be preserved with but little change. Hubbard Park, Meriden, is another notable example of a city park of this same sort. Various areas have also been set aside by individuals, and notably by the White Memorial Foundation of Litchfield. By far the most promising development in this direction, however, has been undertaken by the State Park Commission which, beginning in 1913, has established 28 State Parks, ranging in size from one to more than 1700 acres. These parks are designed fundamentally for purposes of public recreation, and for the preservation of places of natural beauty or historic association. An outline is given below of various features of vegetation included in the State Parks, so far as these seem to be 
of interest in the present connection. ${ }^{1}$ Following this outline is an annotated list of certain areas in the state which, in the opinion of the writer, are especially worthy of preservation as examples of natural forest vegetation.

\section{NATURAL AREAS}

a. Areas already included in Public Preserves, and where it is probable that natural conditions will be wholly or largely retained

1. *Kent Northern Hardwood Forest. (C3.) In Macedonia Brook State Park. Park about 1700 acres in area, partly good second-growth northern hardwoods. Certain selected areas of woodland should be preserved in natural condition. 600-1400 ft., rugged.

Kent $\ddagger$, about $4 \mathrm{mi}$. northwest, N. Y. N. H. \& H. R. R. -G. E. N.

2. *Kent Falls Ravine Forest.

In Kent Falls State Park. Several acres of dense old hemlock and characteristic ravine vegetation. About 500 ft., rugged.

North Kent, 2 mi. northeast; N. Y. N. H. \& H. R. R. -G. E. N.

3. *Millington Gorge Hemlock Forest. (C3.) In Devil's Hop Yard State Park. A remarkably fine stand of old hemlock and hardwoods, several acres in extent. Rocky cascade. About $200 \mathrm{ft}$., rugged.

Millington, about $1 \frac{1}{2} \mathrm{mi}$. southeast; (Colchester $\ddagger$, 8 mi. south, N. Y. N. H. \& H. R. R.). - G. E. N.

4. ${ }^{*}$ West Rock Forest-Complex. (C3.) In New Haven City Park System. A trap ridge, 205 acres under Park supervision, largely in natural conditions: second-growth hardwood forest types; all successional intergradations between rock-face and inferior maple-beechhemlock climax; cliff and talus vegetation; fair example of wooded rock ravine. Representative series of natural vegetation-types, if left "unimproved." 20$400 \mathrm{ft}$., rolling to precipitous.

\footnotetext{
1 The organization of this fine system of State Parks is due very largely to the efforts of the field secretary of the State Park Commission, Mr. Albert M. Turner, from whose reports these notes are largely taken.
}

New Haven $\ddagger$, $3 \mathrm{mi}$. northwest, N. Y. N. H. \& H. R. R. and trolley.-G.E.N.

5. *Hanging Hills Forest-Complex. (C3.) In Meriden City Park System. Several hundred acres essentially similar in physiography and vegetation to West Rock area. 200-600 ft.

Merident, about two mi. north; N. Y. N. H. \& H. R. R. and trolley.-G. E. N. 6. *Pomfret Ravine Forest. (C3.) In Mashomoquet Brook State Park. A deep gorge, about 12 acres, containing a good stand of old hemlock. $500 \mathrm{ft}$. Putmant, about $5 \frac{1}{2} \mathrm{mi}$. west; N. Y. N. H. \& H. R. R. -G. E. N.

7. *Pomfret Hardwood Forest. (C3.) In Sap Tree Run State Park. Several acres of excellent forest, mixed hardwoods especially sugar maple. $500 \mathrm{ft}$., sharp to rolling.

Putman $\ddagger$, 1 mi. west, N. Y. N. H. \& H. R. R.-G.E. N.

8. *North Haven Pine Barrens. (C3.) Adjoining and partly included in Wharton Brook State Park. About 12 acres, young but typical pitch pine barren. $50 \mathrm{ft}$. , flat, sandy.

Wallingford $\ddagger$ about $3 \mathrm{mi}$. south; N. Y. N. H. \& H. R. R. and trolley.G. E.N.

\section{9. *Hammonasset Littoral Association-} Complex. (C3.) In Hammonasset State Park. About 550 acres, including good sea beach, low dunes, salt and brackish marshes with characteristic vegetation. Sea level; flat.

Clinton $\ddagger$, $3 \mathrm{mi}$. west or Madison $\ddagger$, 3 mi. east. N. Y. N. H. \& H. R. R.G. E. N.

10. *Westport Littoral AssociationComplex. (C3.) In Sherwood Island State Park. About 50 acres, including beach, low dune, and salt marsh with characteristic vegetation. Sea level; flat.

Greens Farms, 1 mi. south, N. Y. N. H. \& H. R. R. and trolley.-G. E. N.

11. *Quinebaug White Pine Forest. (C3.) In Quinebaug Pines State Park. Several acres of fine old white pine, with excellent reproduction of all ages.

Putman $\ddagger$, $1 \frac{1}{2}$ mi. south; N. Y. N. H. \& H. R. R.-G. E. N. 


\section{b. Areas privately owned}

11. Cornwall Pinest. (C3.) 10 acres, magnificent stand of near-virgin white pine, with hemlock and hardwoods. Calhoun estate; likely to be preserved.

Cornwall (Cornwall Bridge $\ddagger$, $4 \mathrm{mi}$. northeast; N. Y. N. H. \& H. R. R.).G. E.N.

12. Bantam Lake Forest-Complex†. (C4.) Several hundred acres of land, included in much larger holdings of the White Memorial Foundation of Litchfield. A wide range of conditions is represented, including excellent secondgrowth forest of pine, hemlock, and hardwoods; deciduous swamp forests; and transition from lake to swampforest. $900-1100 \mathrm{ft}$., flat to rolling. Likely to be preserved.

Litchfield $\ddagger$, 2-3 mi. south; N. Y. N. H. \&. H. R. R.-G.E.N.

13. Simsbury Pines†. (C3.) 25 acres or more, mixed forest of white pine, hardwoods, and hemlock, fine secondgrowth to near-virgin; sandy upland, with some swamp. $200-300 \mathrm{ft}$.; rolling.

Simsbury $\ddagger$ N N. Y. N. H. \& H. R. R.G. E. N.

14. Uncasville Hardwood Forest $\dagger$. (C3.) About 10 acres, fine near-virgin forest of hardwood and hemlock, with typical undergrowth. 100-250 ft.; rolling to sharp.

Uncasville; New London $; 7$ mi. north; N. Y. N. H. \& H. R. R. and trolley.G. E. N.

15. Sage's Ravine Forest $\dagger$ (C4.) Wild mountain ravine, perhaps 100 acres, with typical ravine vegetation and essentially virgin forest of hemlock and hardwoods. $800-1200 \mathrm{ft}$. , at stream level, with precipitious slopes.

Salisbury $\ddagger ; 5$ mi. north; Central N. E. R. R.-G.E.N.

16. Hop Brook Ravine Forest. (D4.) 25 acres, partly a rocky gorge with nearvirgin growth of hemlock. Whittemore estate; likely to be preserved. $500 \mathrm{ft}$., rugged.

Naugatuck $\ddagger$, Union City, about one mi. northwest; N. Y. N. H. \& H. R. R. and trolley.-G. E. N.
17. Windsor Flood Plain Forest $\dagger$. (B2.) Island, about 15 acres, situated in Connecticut River at mouth of Farmington; of comparatively recent alluvial origin. Fine forest of (mainly) cottonwood, essentially virgin, together with various stages of succession. $60 \mathrm{ft}$.; level.

Windsor $\ddagger$, one mi. southeast; N. Y. N. H. \& H. R. R. and trolley.-G. E. N.

18. Middletown Flood Plain Forest. (B2.) Island in Connecticut River, perhaps 10 acres, forested with cottonwood, silver maple, and willow.

Middletown $\ddagger, \frac{1}{2}$ mi. north; N. Y. N. H. \& H. R. R.-G. E. N.

19. Bingham Pond Bog and Spruce Forest $\dagger$. (B2.) About 25 acres on Mt. Riga. Shallow pond with fine marginal cassandra-spruce-tamarack bog; adjoining forest of large red spruce contains many boreal plants. $1900 \mathrm{ft}$. ; level.

Salisbury $\ddagger$, $5 \mathrm{mi}$. northwest, or Lakeville $\ddagger$ mi. north; Central N. E. R. R. -G. E. N.

20. Canaan Mountain Spruce Swamp $\dagger$. (C3.) About 5 acres mixed swamp forest, predominantly red spruce with mountain ash and other boreal associates, near-virgin. $1500 \mathrm{ft}$.

Norfolk $\ddagger, 3 \frac{1}{2}$ mi. east; Central N. E. R. R.-G. E. N.

21. Ayer Hill Cedar Swamp. (C3.) 400 acres flat swampy land, mainly Chamaecyparis thyoides, some apparently primeval, with undergrowth of Rhododendron maximum. Partly private; partly Indian reservation. $120 \mathrm{ft}$.

Norwich $\ddagger$ $7 \mathrm{mi}$. southeast; N. Y. N. H. \& H. R. R. and trolley.-G. E. N.

22. Mansfield Cedar Swamp $\dagger$. 20 ares of near-virgin Chamaecyparis, Tsuga, and Nyssa sylvatica; swamp surrounded by sandy second-growth pine land. $500 \mathrm{ft}$.; fairly level.

South Willington, $3 \mathrm{mi}$. southeast; N. Y. N. H. \& H. R. R.-G. E. $N$.

23. Darien Sweet Gum Swamp†.

5 acres, sandy swamp, well-wooded with large gum (Liquidambar styraciflua), practically northern limit, swamp oaks (Quercus bicolor, Q. palustris) and red maple. $25 \mathrm{ft}$; flat. 
Darien, $\frac{1}{2}$ "mi. west (South Norwalk $\ddagger, 4$ mi. west); N. Y. N. H. \& H. R. R. and trolley.-G. E. N.

\section{BIBLIOGRAPHY}

Nichols, George E. "The vegetation of Connecticut." Torreya, 13: 89-12; 199-215 (1913); 14: 167-194 (1914); Bull Torr. Bot. Club, 42: 169-217 (1915) ; 43: 235-264 (1916); 47: 89-117 (1920); 47: 511-548 (1920).

Connecticut State Park and Forrest Commission guide to Connecticut state parks and forests. Hartford (1924).

\section{RHODE ISLAND}

\section{By Marion D. Weston}

The state is small and its original biota very similar to that of Connecticut and Massachusetts. It was thought unnecessary to provide a general account as has been done for the other states.V.E.S.

Preserved areas in natural or seminatural condition in Rhode Island are managed in one of the following ways: the Providence City Park Commission, the Metropolitan Park Commission, the Providence City Water Works Department, the Public Parks Association, the Rhode Island Historical Society or the Secretary of State.

Of the 52 parks and playgrounds owned by the city of Providence only four are in a sufficiently natural condition to be of interest in this survey.

With few exceptions the parks controlled by the Metropolitan Park Commission are included in this report.

The City Water Works Department has the management of far more land than all the other agencies combined. Since this land will probably remain in its natural condition the protection or wild life, both plant and animal, may in the end be more complete here than in any of the other areas.

The preserved areas which owe their existence to historical associations are managed by the Rhode Island Historical Society or by the Secretary of State. From the ecological point of view the
Great Swamp Battlefield is the most interesting area in the state.

\section{SOURCES OF MATERIAL}

Much of the material in this report has been taken directly from the Providence Magazine, August, 1916.

Other statistics were obtained from the office of the Metropolitan Park Commission the report of the Auditor of the City of Providence for the year 1921 and the Soil Survey of Rhode Island, Washington. Many individuals interested in certain areas have given much information.

\section{NATURAL AREAS}

*Lincoln Woods. (C3.) About 458 acres of rocky woodland; glaciated ledges and glacial boulders, making the land too rocky for cultivation; mixture of hard woods; north shore of Olney Pond (artificial). Vegetation in natural condition throughout the park. Special map. Miami stony loam. 200-280 ft. Met. Park Com.

Providence, $5 \mathrm{mi}$. north, Woonsocket Electric; Quinsnicket Station.

*Ten Mile River Reservation. (B3.) about 104 acres of wooded stream bank and meadows; stream sluggish, winding, not polluted. Conditions natural. Warwick stony loam. 40-60 ft. Met. Park Com.

Pawtucket, $3 \frac{1}{2}$ mi. west, Slater Park Electric.

*Seekonk River Reservation. (B3.) About 19 acres of "bluff bordering river," which is really an estuary. Norfolk coarse sand. 20-40 ft. Met. Park. Com.

Pawtucket, one mi. south, Ingraham's Corner Electric.

* Barrington Parkway. (C3.) About 116 acres; "chain of picturesque tracts" $2 \frac{1}{2}$ miles ong, "overlooking Providence Harbor." Norfolk coarse sand, Warwick sandy loam and Miami stony loam. 20-100 ft. Met. Park Com.

Providence, $1 \frac{1}{2} \mathrm{mi}$. east; East Providence Electric.

*Haines Memorial Park. About 104 acres running back from east 
shore of Bullock's Cove; wooded shore; scattered red cedars. Warwick sandy loam. $20 \mathrm{ft}$. flat. Met. Park Com.

Providence, $6 \frac{1}{2}$ mi. southeast, Providence, Warren and Bristol R. R. Crescent Park, $1 \frac{1}{2}$ mi. east.

*Davis Park. (H8.) About 40 acres; old estate; conditions semi-natural; plateau with deep ravines, wide floodplain with meandering brook (intermittent). Oak stand on steep slope. Warwick sandy loam and Norfolk coarse sand.) 20-60 ft. Prov. City Park Com.

Providence, one mi. west, Chalkstone Ave. Electric.

*Blackstone Park. (B3.) About 7 acres along west shore of Seekonk River (estuary); wooded bluff; mixed stand of hardwood, undergrowth of Mountain Laurel. Estuary badly polluted. Norfolk coarse sand. 40-60 ft. Prov. City Park Com.

Providence, two mi. east, Swan Point electric.

*Roger Williams Park. (H8.) About 431 acres; chain of lakes (partly artificial); scattered oak stands, many introduced trees; chart of trees published by Museum. Certain sections remain in entirely natural condition. Norfolk coarse sand, a little Warwick sandy loam. 40-60 ft. rolling. City Park Com.

Providence, $3 \frac{1}{2}$ mi. south, Broad St. Electric.

*Mashapaug Pond. (C3.) About 55 acres; east shore steep; mixed hard wood stand. Norfolk coarse sand. 20-40 ft. Met. Park Com.

Providence, $2 \frac{1}{2} \mathrm{mi}$. south, Reservoir Ave. Electric.

${ }^{*}$ Edgewood Beach. (B4.) About 19 acres on the west shore of Narragansett Bay; bathing beach. Norfolk coarse sand, Warwick sandy loam. $40 \mathrm{ft}$. City of Cranston. Met. Park Com.

Providence, $3 \frac{1}{2}$ mi. south, Washington Park via Eddy St. Electric.

*Shellhouse Cove Reservation. (B4.) About $39 \frac{1}{2}$ acres on west shore of Narragansett Bay; Norfolk coarse sand. Met. Park Com.

Providence, $4 \frac{1}{2} \mathrm{mi}$. south, Pawtuxet Electric.
*Pawtuxet River Area. (C4.) About 75 acres of flood plain; river meandering. Warwick sandy loam. Met. Park Com. City of Cranston.

Providence, $4 \frac{1}{2} \mathrm{mi}$. south, Pawtuxet Electric.

*Narragansett Parkway. (B4.) About 33 acres west shore of Narragansett Bay; sandy shore; portion of Rock Island composed of ledge; (Outwash plain and ice escarpment facing Narrangansett Bay). $40 \mathrm{ft}$. Norfolk coarse sand. Met. Park Com. Town of Warwick.

Providence, $5 \frac{1}{2}$ mi. south, Pawtuxet Electric. One mi. south from Pawtuxet.

*Neutaconkanut Hill Park. (C3.) About 69 acres; glaciated hill, steep southern face, gradual northern slope; mixed hard wood stands. Miami stony loam. $260 \mathrm{ft}$. Prov. City Park Com.

Providence, $3 \frac{1}{2}$ mi. west, Plainfield St. Electric.

*Round Rocks. (A4.) 4 acres; "enormous glacial boulders;" scrub oak. Gloucester stony loam. $360 \mathrm{ft}$. Town of Johnston. Pub. Park Association.

Providence, $8 \mathrm{mi}$. west, Thornton and Hughesdale Electric. 1 $\frac{1}{2} \mathrm{mi}$. west from Hughesdale.

*Meshanticut Park and Parkway. (B2.) About 28 acres; small lake; wooded shore. Alton stony loam. $60-80$ ft. City of Cranston. Met. Park Com.

Providence, $5 \frac{1}{2}$ mi. southwest, Meshanticut Park Electric.

*Scituate Reservoir. (B3.) About 10,000 acres will be preserved about the new Scituate Reservoir; this land extends from Barden Reservoir along the valley of the Ponaganset River to the point where it unites with the Moswansicut River to form the Pawtuxet River and down the Pawtuxet to the town of Kent; on the north the area extends north of North Scituate to Moswansicut Pond. Gloucester stony loam, Alton stony loam; 300-500 ft. Prov. Water Works Dept.

Providence, $8 \frac{3}{4} \mathrm{mi}$. southwest, North Scituate Electric.

${ }^{*}$ Great Swamp Fight Battlefield. (A4.) About 4 acres; typical cedar swamp vege- 
tation; many bog plants not usually found north of New Jersey. "Scene of Indian Fight, King Phillips War," marked by monument.

Wickford Junction, $11 \mathrm{mi}$. southwest, N. Y. N. H. \& H. R.R. Two mi. north from Kenyon. R. I. Historical Society.

* Fort Neck. (B4.) 19 acres along northeast shore of Charlestown Pond; boggy areas along pond; scattered red cedars; shrubs along brooks; flat. Alton stony loam, Warwick sandy loam. 20 ft. Controlled by Secretary of State. Westerly, 11 mi. east, N. Y. N. H. \& H. R. R. 6 mi. south from Wood River Junction.

\section{NEW YORK}

\section{By William L. Bray}

\section{GENERAL CONDITIONS-THE PHYSIO-} GRAPHIC UNITS OR COMPLEXES AND THEIR ASSOCIATION TYPES

In this connection one should have in mind a picture of the orographic features of the State: highlands, such as the Adirondacks, Catskills, Shawnugunks, Hudson Highlands, Allegheny plateau, and their dissections; river valleys and their tributary erosion channels, gorges, etc.; lake basin lands, sand plains, wet lands of sea coast, and inland bog and swampland. It is quite essential for one considering the physiography of New York State and its attendant natural life conditions to take account of conditions created by glacial agencynotably deeply cut channels (Finger Lakes), the extensive wearing down of highlands and filling of lowlands, piling up of morainic debris, drumlins, etc., and the consequent blocking of drainage channels or creation of water-filled basins, thus resulting in a myriad of lakes.

It will be recognized that physiographic features exercise a determining influence upon the character of the native vegetation and its associated animal life.

Conditions of rainfall and humidity in this state are such that the natural expression of plant life is in the form of a final, relatively stable, high forest, but local conditions of physiography modify this theoretical condition so that, regarded as a whole, the State presents a mosaic of vegetation aspectsfilling lakes, marsh land, wet meadows, swamp forest, bogs, pine heaths, spruce slopes, virgin forest, etc., with their associated animal life. It further adds to the interest in and appreciation of our wild life conditions to observe that, because of the effects which the vegetation especially exerts upon the land and of the natural cause of erosion and filling and leveling these various mosaic patterns of vegetation are not staticpermanent-but tend to follow a course of evolution toward the final climax or stable type of plant society-the high forest. For this reason, it becomes desirable in suggesting areas for reservation to have in mind those which may be subjects of study through a course of years to determine phenomena and causes of this evolution of natural plant and animal communities.

Original vegetation, a complex of forest types predominating: Some open prairies with groves (Erie County); marsh lands (coast of Long Island, Montezuma marshes); swamp forest, bogs (Ontario basin and especially in the Adirondacks), sand plains with pure stands of white pine (Albany-Schenectady Plattsburg, Black River pine plains near Carthage); mountain summit vegetation above timber line (related to Arctic-Alpine).

Climax forest cover heavy and of large growth embracing the following zonal types: (1) Sweet gum (Liquidambar styraciflua), oaks, hickories, chestnut (Castanea dentata), and tulip tree (Liriodendron tulipifera), of the lower Hudson and adjacent Long Island and Staten Island with occasional yellow pine (Pinus echinata); (Carolinian); (2) Oak, hickory, chestnut, tulip tree of middle Hudson, Delaware, and Susquehanna drainage, and the Ontario basin (Carolinian related); (3) Suga maple (Acer saccharum), beech (Fagu 
grandifolia), yellow birch (Betula lutea), white pine (Pinus strobus), hemlock (Tsuga canadensis), type of the Allegheny Plateau (Allegheny Transition); (4) Species of 3 plus red spruce (Picea rubra) and some upland balsam (Abies balsamea) of the Adirondacks from 1000 to $2500 \mathrm{ft}$. (Canadian Transition); (5) Red spruce, balsam, paper birch (Betula papyrifera), mountain ash (Pyrus americana) of Adirondacks 2500 to $2500 \mathrm{ft}$. (Canadian). Generally much modified by human agency, but in Ádirondacks, approximately as original. In general the present secondary forests tend to repeat original types. The mammalian fauna included bison (Bison bison), at least as far east as the salt licks at Syracuse, moose (Alces americana) "over the entire state," but "extinct since the early sixties," caribou (Rangifer caribou) probably in the Adirondacks, elk (Cervus canadensis) "throughout the state, extinct since early part of the nineteenth century," Virginia deer (Odocoileus virginianus) still abundant, northeastern cougar (Felis couguar), bob-cat (Lynx rufus), Canada lynx (Lynx canadensis), timber wolf (Canis lycaon), black bear (Ursus americanus), wolverine (Gulo luscus), marten (Martes americana), fisher (Martes pennanti), and southern representatives, such as the opossum (Didelphis virginiana) and southern flying squirrel (Glaucomys volans).

\section{NATURAL AREAS}

\section{Areas of biological interest}

New York State has a large number of parks, reserves, and memorial tracts of varying character, among which the following are subject to treatment as preserved natural areas.

1. The Adirondack Park. (A2.) The central portion of the Adirondack Mountain region embracing $3,313,564$, acres of which $49 \%$ is State land. A diversified and geologically very old mountain region of much worn, rounded summits with extreme elevation of $5344 \mathrm{ft}$. (Mt. Marcy) and in general from 1500 to $2000 \mathrm{ft}$. Pronounced glacial effects seen in modification of ancient drainage (filling of streamways and creation of large numbers of glacial lakes, e.g., the Fulton Chain). The Adirondack Park, being one of the great recreation grounds of America and within easy reach of at least one-fifth of its population, is annually penetrated to the remotest points by tourists, campers, hunters, and anglers. Hence, very little, if any, of it may be said to be wholly unmodified. Nevertheless, the state lands within it and some of the privately owned and club lands have been preserved in approximately natural condition.

The vegetation complex embraces: Approximately natural areas of (1) upland forest $(a)$ of sugar maple, beech, yellow birch, white pine, hemlock, and red spruce (Canadian Transition zone), (b), of red spruce, white spruce, balsam, paper birch and mountain ash (Canadian zone); (2) mountain summits with dwarf red spruce, white spruce, balsam fir and paper birch (Canadian zone species) and numerous alpine plants, as Diapensia lapponica, Lapland rose bay (Rododendron lapponicum), crowberry (Empetrum nigrum), bearberry willow (Salix Uva-ursi) (Arctic-Alpine zone); (3) bogs with sphagnum-sedge, heath-shrub, and bog forest cover of black spruce (Picea mariana), tamarack (Larix laricina) and arbor vitae (Thuja occidentalis).

\section{References:}

Bray, Wm. L. Development of the Vegetation of New York. State Tenical Publ. 3: N. Y. State Coll. Forestry, 1915.

Miller, Gerritt S., Jr. N. Y. Mammals, Bull. N. Y. State Mus., vol. 6, No. 29: 1899.

Eaton, E. H. Birds of New York, 2 vols., Univ. State of New York, Albany.

Streams are generally free from pollution, and the game fish of these and the lakes are maintained by stocking from state hatcheries (e.g., Old Forge, Saranac Inn station). 


\section{References:}

Bray, Wm. L. Op. cit.

Harshberger, J. W. The Plant Formations of the Adirondacks. Torrey, 5:187-194, 1907.

Numerous State Conservation Commission and State Museum Publications.

\section{2. *The Catskill Park. (A2.) This} reservation embraces 576,120 acres occupying the central portion of the Catskill Mountains. Of this tract the State owns 116,364 acres. This is the main section of the Catskill uplift, having elevations around 1000 to 4204 $\mathrm{ft}$. (Slide Mountain). It is a region of rounded contours and broad valleys, of no glacial lakes, and with rapidly flowing unpolluted streams.

Original biota at elevations 2000 to $3500 \mathrm{ft}$. similar to beech, sugar maple, hemlock type (Canadian Transition) of Adirondacks 1000 to $2500 \mathrm{ft}$. Plant cover much modified in age and conifer content by human agency. Large predatory and game animals, except bear and deer exterminated.

On the Hudson River side, the oak (including chestnut oak), hickory, chest-. nut, tulip tree forest of the Hudson Valley (Carolinian) extends up the southeasterly, facing valleys (coves) nearly to the heart of the highlands. From 1000 to about $3000 \mathrm{ft}$., sugar maple, beech, yellow birch, white pine, and hemlock (Allegheny Transition) forest predominates, while above 3000 $\mathrm{ft}$. the addition of red spruce, balsam fir and similar numerous northerly forest floor species indicate its relation with the Canadian Transition zone of the lower Adirondacks. Commercial soft woods have been largely cut out, so that the mountain slopes and summits are covered with secondary hardwood forest, reproductions of spruce, balsam fir and dwarf white birch, or burns with fire weed, blueberry, popple, and fire cherry. The valleys are in farms and pastures. There are many acres of approximately typical climax forest with its characteristic forest floor species.
Deer not uncommon, black bear rare, foxes, skunks, squirrels (red and gray), and raccoons common. Abundant bird fauna, including species of sprucebalsam fir (Canadian) zone. Smaller streams not much polluted, stocked with trout. Traversed by State highways. Go from Arkville, D. and H. R. R., to Phonecia, $21 \mathrm{mi}$. and Tannersville, 35 mi.; by $D$. and H. from Kingston to Phonecia, $27 \mathrm{mi}$.; by Catskill Mountain and Incline Railway from Catskillon-the-Hudson to Haines Falls, $20 \mathrm{mi}$. Hotels numerous; favorable camping sites throughout the region.

In charge of the State Conservation Commission, Albany, N. Y.

\section{References:}

Harshberger, J. W. Plant Formations of the Catskills. Plant World, 8: 276-281, 1905.

Mearns, E. A., Notes on the Mammals of the Catskill Mts., etc., Proc. U. S. Nat. Mus. 21:341-360, 1898.

Pettis, C. R., Catskill Highways. Recreation Circular No. 4. State Conservation Commission Publication.

3. *Palisades Interstate Park. (D3.) Secondary (sprout) forest, lakes, and marsh; about 36,000 acres of the Hudson Highlands, including the Palisades of the Hudson, lying on the west bank of the Hudson between Ft. Lee, New Jersey and Fort Montgomery, New York. Mountain-like upland with numerous peaks from 1200 to $1400 \mathrm{ft}$. elevation, series of upland lakes, broad valleys, and fresh streams.

Original forest cover of oaks (including chestnut oak), hickories, chestnut (very abundant originally, now greatly depleted by chestnut blight), tulip tree, and at lower levels occasional sweet gum (lower Transition to Carolinian zone). Present forest vegetation much modified but retaining original types by sprout reproduction. Mountain laurel (Kalmia latifolia) on the slopes. Great laurel (Rhododendron maximum) about interior lake at $1000 \mathrm{ft}$. elevation. Deer occa- 
sional; opossum, red fox, and common smaller mammals. Summer bird fauna abundant and varied, including ruffed grouse, yellow-breasted chat, whippoorwill, black duck, bald eagle, Cooper's hawk, turkey vulture, cardinal and Maryland yellow-throat (predominantly Carolinian); 108 species listed by Silliman during two seasons.

Elevation from Hudson tide water to $1314 \mathrm{ft}$. (Bear Mountain.) Reached by West Shore and O. \& W. R. R.'s from Englewood, New Jersey, to Iona Island near Bear Mountain, $40 \mathrm{mi}$; by boat from New York City to Bear Mountain landing, $45 \mathrm{mi}$., by the Erie R. R. to Tuxedo, 40 mi., from New York City.

Special facilities for camping, maintenance, and transportation provided by the Palisades Interstate Park Commission, address 90 Wall St., New York City.

\section{References:}

Publications of the Palisades Interstate Park Commission. Bull. 10, N. Y. S. Coll. Forestry and Recreational Studies in Palisades Interstate Park, 1920.

Silloway, P. M. Guide to Summer Birds: Bull. No. 11, N. Y. S. Coll. Forestry, 1920.

\section{4. *Allegheny State Park.} Modified Allegheny Plateau forest; about 6500 acres in southern New York (Cattaraugus County) adjacent to Allegheny River and embracing finest type of deeply eroded Allegheny Plateau highlands.

Original forest cover of sugar maple, beech, yellow birch, and notable occurrence of best white pine, hemlock, and cucumber tree (Magnolia acuminata), oaks, hickories, and tulip tree at lower elevations. Original mammalian fauna embraced large game animals (deer and probably moose and wapiti) (Miller, New York Mammals); bear, panther, wild cat, lynx, and many smaller mammals.

Forest cover much modified, depleted upland type, and mostly hardwood species but with areas of natural climax forest conditions (except for depletion of pine and hemlock); black bear and deer still occur, the former scarce. Birds characteristic of southern New York uplands abundant; ruffed grouse, native; pheasants introduced and hunted under close restrictions. Small streams and brooks of the uplands unpolluted.

Elevation about 1400 to $2376 \mathrm{ft}$.

Reached from Salamanca via Penna. R. R. to Tunesassa, $15 \mathrm{mi}$. Special camping facilities provided by the Allegheny Park Commission, local member, Hon. Albert Faucher, Salamanca, N. Y.

Publications of informational character by the Commission.

5. *Letchworth Park. (D3.) Modified stream, gorge and bluff vegetation. About 1000 acres both sides of Genesee River at Portage Gorge, near Portage, New York. Typical mixed forest (Transition) of oaks, maple, beech, white pine, and hemlock: north facing crest of gorge with paper birch here out of its usual range. More level areas much modified by park improvements. No large mammals; smaller mammalian and bird fauna characteristic of Allegheny Plateau region of New York, moderately polluted stream, but not to extent of eliminating game fish, elevation, $850 \mathrm{ft}$. (below falls) to $1400 \mathrm{ft}$.; deeply cut gorge.

From Rochester $50 \mathrm{mi}$. southwest to Portage via Penna. R. R., hotel (Letchworth Inn).-Park Commissioner, Letchworth Park, N. Y.

6. ${ }^{*}$ Enfield Falls Reservation. (D4.) Deep gorge habitat of Cayuga Lake Basin; 387 acres of gorge and bluffs with waterfalls, five miles southwest of Ithaca, New York. Remnant of approximately natural conditions favorable for field study and employed for this purpose by naturalists at Cornell University, $6 \mathrm{mi}$. Elevation 450 to $1000 \mathrm{ft}$.Professor James G. Needham, Ithaca, N. $Y$.

7. *Clark Reservation. (D4.) Hart's tongue fern (Scolopendrium vulgare) habitat. About 100 acres adjacent to and including Green Lake (a glacial cataract plunge basin); modified forest 
cover of the maple-beech-birch type (Allegheny Transition) with well preserved forest floor vegetation, especially rich in ferns. Features of outstanding interest, a series of glacial drainage channels and pot-holes of cooler summer temperature with colonies of hart's tongue fern. One of the main areas for study by staff and students of natural history departments at Syracuse University.

Go from Syracuse $6 \mathrm{mi}$. southeast via D. L. \&. W. R. R., or Syracuse Suburban electric to Jamesville and walk one mile. Walk from University campus $4 \mathrm{mi}$. Elevation 550 to $800 \mathrm{ft}$.-William $L$. Bray, Syracuse Univ., Syracuse, N.Y.

\section{Reference:}

Hunter, Mabel R. The Present Status of Scolopendrium in New York State. Amer. Jour. Bot., 9: 28-36. 1922.

8. *McLean Bogs. (A4.) Bog plant associations related to peat and marl deposits. 100 acres occupying glacial moraine area located about $15 \mathrm{mi}$. northeast of Ithaca and one mi. east of the village of McLean, a good example of the Central New York type of bogs occupying shallow glacial basins in a limestone region; small mammal and bird fauna characteristic of. Allegheny Plateau region; used as a biological field station by Cornell University, a member of whose biological faculty is by special provision made custodian of the preserve. Elevation, $1000 \mathrm{ft}$.

Go $15 \mathrm{mi}$. northeast of Ithaca via Lehigh Valley R. R. to McLean, walk one mi. east-Prof. James G. Needham, Cornell University, custodian.

\section{Reference:}

Needham, James G. McLean Bog. Science Monthly, 12: 246-252, 1920.

\section{Spring Lake Marl Ponds. (A4.)} Peat Bogs, and Swamps. An area of several hundred acres, comprising a series of small lakes or ponds surrounded by numerous bogs, swamps, and prairies,
Ontario Basin topography, $20 \mathrm{mi}$. north of Cayuga Lake. Good botanical collecting ground, especially rich in orchids (25 species listed). Typical Central New York bogs and swamps associated with marl deposits. Elevation $400 \mathrm{ft}$.

Walk of about $8 \mathrm{mi}$. from Savannah or Port Byron on the N. Y. Central and Rochester-Syracuse electric.-Profs. $K$. M. Wiegand and A. M. Wright, Cornell University, Ithaca, N. Y.

\section{Reference:}

Metcalf, F. P., and Griscom, L. Rhodora, 19:28-37 and 48-55, 1917.

10 West Junius Bogs and Marl Ponds. (A4.) 100 to 300 acres lying $6 \mathrm{mi}$. north of Geneva. "Affords excellent examples of marl springs, marl moor and marl ponds as contrasted with peat bogs and ponds." Flora very rich containing many rare plants. Elevation, $400 \mathrm{ft}$.Prof. K. M. Wiegand, Cornell University.

\section{References:}

Rowlee, W. W., Relation of Marl Ponds and Peat Bogs. Mem. Brooklyn Bot. Garden, 1: 410-414, f. 1-3, 1918.

11. Bergen Swamp. (A4.) 100 to 200 acres of typical bog and swamp vegetation, $20 \mathrm{mi}$. southwest of Rochester between the West Shore R. R. and Black Creek; "one of a succession of swamps which occupy a depression extending from the Genesee River to the Niagara River: 100 acres of open bog and swamp--a marl bed covered with grasslike plants, chiefly sedges, with patches of sphagnum and a few dwarf cedars (Thuja) and tamaracks. The surrounding belt of land is covered with a dense jungle of cedar (Thuja) and tamarack; one of the choicest locations for field excursions from the University of Rochester and by the naturalists of the Rochester Academy of Science." Elevation 550 to $600 \mathrm{ft}$.

Go from Rochester via West Shore R. R. $20 \mathrm{mi}$. southwest to Byron on the New York Central to Bergen.-Prof. W. D. Merrill, Univ. of Rochester. 
Reference:

Beckwith, Florence, and Macauley, Mary E. Plants of Monroe County, New York. Proc. Rochester Acad. Sci., 3:1896. Extracted and repaged pp. 1-150. Subsequent supplements by Baxter, etc.

See also State Botanists' Report, 1918.

12. Montezuma Marshes. (A4.) Cattail marsh. Several thousand acres of low marsh land lying along the west side of Cayuga Lake Outlet, immediately northwest of the village of Cayuga, a unique and widely known region of cattail marsh merging on slightly higher land into marsh meadow and swamp forest. Marl, muck and peat deposits indicating typical hydrarch sequence of vegetation. Small marsh mammals (e.g., muskrat), marsh birds, feeding ground for migrating ducks. Elevation $375 \mathrm{ft}$.

Reached by N. Y. Central (Auburn Branch) Syracuse to Cayuga, $37 \mathrm{mi}$., by Lehigh Valley, Ithaca to Cayuga 40 mi., and by R. S. \& E. Electric to Montezuma.-Prof. E. H. Eaton, Hobart College, Geneva, N. Y.

13. The Hempstead Plains. (A4.) A flat treeless area of about 50 sq. mi. in the central part of Nassau Co., rapidly encroached upon by truck farming, suburban extension, etc., so that by 1907 only 10 sq. mi. remained in a natural state. From 1907 to 1918 further encroachments had reduced the area by at least one-tenth. (Harper). Several hundred acres should still be available for reservation. Typical prairie similar in aspect to parts of the Great Plains. Some portions resembling pine heath with pitch pine, gray birch, black jack oak, black huckleberry, sweet fern and scrub oak. Characteristic prairie species are broom beard grass, forked beard grass, Indian grass, cat-gut (Cracca Virginiana), savory-leaved aster, wild indigo, star grass, etc. The area is traversed by streams with adjacent wet lands with marsh grass (Dulichium arundinaceum), cinnamon fern, sensitive fern, royal fern, marsh shield fern, white beaked rush, etc.

Elevation 40 to $60 \mathrm{ft}$.

Go by Long Island R. R. to Garden City $20 \mathrm{mi}$. from Pennsylvania Station, New York City.-Dr. R. M. Harper, College Point, N. Y.

\section{References:}

Harper, R. M. Vegetation of the Hempstead Plains, Mem. Torr. Bot. Club, 17:262-286, 1918; also Bull. Amer. Geogr. Soc., 43:351-360, 1911.

14. Albany-Schenectady Sand Plains. (A4.) Pine heath vegetation. Selected areas of several hundred acres, available for preservation. Originally white pine forest. Present, vegetation a secondary succession of pitch pine, gray birch, heath shrubs, sweet fern, scrub oak, broom grass, etc. Typical sand barren or pine heath associations. Original animal biota radically modified and depleted. Area rapidly encroached upon by cultivation and suburban extension. Elevation 250 to $300 \mathrm{ft}$.

Reached by New York Central from Albany to Karner, $8 \mathrm{mi}$. or by Interurban electric line.-Homer D. House, State Botanist, Albany, N. Y.

\section{References:}

Bray, W. L. Development of the Vegetation of New York State. Bull. N. Y. State College of Forestry, Tech. Pub., No. 3, 1915.

15. Plattsburg Sand Plain. (A4.) Similar in topography, structure and vegetation to the preceding. Original plant cover white pine forest. Much modified and subject to complete elimination as a natural biotic area by extension of cultivation and military usage. (w) two or $3 \mathrm{mi}$. from Plattsburg. Elevation $250 \mathrm{ft}$.

\section{Reference:}

Bray, Wm. L. Op. cit.

16. Sodus Bay Yellow Lotus Colony. (A4.) Lake Ontario. A well preserved 
almost pure stand of native species (Nelumbo' lutea) at nearly the northerly limit of its range. The only considerable colony of this species in New York State, so far as known. In State-owned waters and subject to reservation and protection by the Conservation Commission.

Reached by Northern Central R. R. from Newark on N. Y. Central R. R. to Sodus Point, about $18 \mathrm{mi}$ - -Dr. Homer D. House, State Botanist, Albany, N. Y., $M r$. Alfred C. Weed, Field Museum, Chicago, Ill.

\section{References:}

17th Report of State Botanist, 1918. (Photograph).

Numerous State parks, monuments, and protected water shed areas of minor consequence as natural areas not listed here. Many other larger or smaller areas either within State parks (Red Horse Chain of Lakes, Mt. Marcy, Grasse River Bog, Bean Pond Bog in the Adirondacks) or not specifically set aside (Gardiners Island and Jones' Beach, L. I.) might well be included in the suggested natural areas for New York State.

\section{Other reserved areas by Stephen Mather}

*Mohansic Lake Reservation consists of 1100 acres in the town of Yorktown, Westchester County.

${ }^{*}$ Watlins Glen is a reservation of 103 acres in the village of Watkins and the town of Dix, at the head of Seneca Lake, containing a picturesque rock-walled glen about $3 \mathrm{mi}$. long with many waterfalls and cascades.

*Chittenango Falls is one of the picturesque waterfall and gorge features of Central New York. Gorge and hillside vegetation. Rare hart's tongue fern. The spot is easily reached by a good State highway from Cazenovia to Chittenango.

*The John Boyd Thatcher Park comprises 350 acres, lying on the crest of the Helderberg escarpment in the towns of Guilderland and New Scotland, in
Albany county, cliffs, forest, small streams and a beautiful lake. Go D. $\&$ H. R. R. from Albany about $20 \mathrm{mi}$. to Meadow dale.

Jones' Beach, Long Island, New York. Character: Ocean beach, sand dunes, salt marshes and tidal flats and creeks. Reservation should include as much as possible of the beach (which has dunes on the land side) and also areas of the salt marsh and the adjacent tidal flats. The area is especially adapted for preserving the fauna and flora of such localities and as a reservation for shore birds.

On south shore of Long Island, accessible by motor boat from adjacent points on main island, especially Freeport, L. I.

Gardiner's Island, Long Island N. Y. Island in Peconic Bay, over $3 \mathrm{mi}$. in greatest length; Main island; fine woods, chiefly of oaks; breeding colony of fish hawks; colonies of terns, and skimmers breed on the detached islands.

Reached by motor boat from Greenport and Sag Harbor.-John T. Nichols.

Carman's River, Long Island, N. Y. Character: Harwood forest bordering a fresh-water running into Great South Bay near Brookhaven; forest of oak, pepperidge, etc.; ducks and other water fowl. River for a couple of miles beginning a little south of Yaphank, and including the adjacent woods, but would not have to be wide. Reached by long Island R. R. to Yaphank Station.George P. Engelhardt.

\section{PENNSYLVANIA}

\section{Bx John W. HARshberger}

\section{GENERAL CONDITIONS AND ORIGINAL BIOTA}

Topographically the state of Pennsylvania is divided into five regions: (1) south eastern coastal plain, a narrow area; (2) the Piedmont or scattered hills bounded on the west and northwest by the Kittatinny or North Mountain; (3) a middle region of symmetrical mountains; (4) a western table land; and (5) a northwestern table land. The 
coastal plain consists of low lands along the Delaware and Schuylkill rivers. Sweet gum and willow oak are characteristic trees and the muskrat is common. The Piedmont, the central mountain mass and the Alleghany plateau were originally and are covered with deciduous forest of black, white and red oak, chestnut, tulip tree, ashes, hickories and black walnut. Dogwood, honeysuckle, spice bush and laurel are important undergrowth shrubs, while bloodroot, mayapple, Indian turnip, hepatica, arbutus (Epigaea repens) are abundant herbaceous plants of the forest floor.

The valleys of the several large rivers possess characteristic plants. Hemlock is common in some parts on the lower ground, while the high mountain tops have groves of table mountain pine. The celebrated Lear Meadows of the mountain district support the pitcherplant, orchids, etc.

The northern plateau is continuous with the Catskill mountain plateau, reaching in the Pocono region, an elevation of $2200 \mathrm{ft}$. (Rhododendron canadense), creeping snowberry (Chiogenes hispidula) plants which are characteristic of the mountains farther north occur.

Originally the fauna included the elk, Virginia deer, black bear, cougar, timber wolf, beaver, opossum, porcupine, raccoon, gray squirrel, woodchuck, red fox, gray fox (Urocyon cinereoargenteus), and skunk (Mephitis nigra). The birds included the wild turkey, turkey vulture, whippoorwill, wood and hermit thrushes, song sparrow, and red-headed woodpecker. Occasionally marine whales and porpoises have come up the Delaware River to the shores of the state.

\section{PRESENT CONDITION OF THE BIOTA}

The original forests have been almost entirely removed and much that is now nearly natural is really second growth. The wapiti is extinct and the number of other game animals greatly reduced. All the larger streams are polluted. Those which drain the coal regions have suffered from acid mine seepage. So much fine coal has been introduced into the Susquehanna that it is dredged in some places for fuel purposes.

\section{NATURAL AREAS}

Pocono Plateau Region. (C4.) Here are located celebrated mountain resorts, many of them at $2000 \mathrm{ft}$. above sea level comprising forest, lakes and mountain streams and R. R.

Deciduous Forest near Broadhead Creek Valley. (C4.) $20 \mathrm{sq}$. mi. of a wild tangle of deciduous forest on mountain and in valley; much laurel.

Reading Municipal Forest and Tree Nursery. (H8.) Canadensis, Monroe Co., $\mathrm{Pa}$. It has been preserved by the city of Reading 1,000,000 coniferous and broad-leaf trees planted.

Antietam Lake, Berks County. Two mi. east of Reading, Pa., endangered by grazing. $-J . W . H$.

Nockamixon Rocks, or Delaware Palisades. The sheer cliffs of red shale, 300 ft. high, facing the Delaware River, are covered with an interesting forest of such trees as sugar maple, cherry birch, linden (Tilia americana), slippery elm, and such shrubs as Hydrangea arborescens, nine-bark, bladder nut, red-berried elder and others. Mosses and ferns abound and on a steep slope near the top the local Sedum roseum.

Kintnersville and Upper Black Eddy, Fa.-J.W. H.

Playwicky Oak. (D5.) This historic tree which marks one of the points of the Penn purchase.

One mi. north of Wrightstown, Bucks County, Pa.-J.W.H.

Rock Hill Marsh. (C3.) This marsh which is noted for the growth of the buck bean (Menyanthes trifoliata) out of its range should be perserved by the purchase of 2 acres of marsh. Rock Hill, Bucks Co., Pa.-J. W. H.

Tohickon Creek Forest. (D5.) Along Tohickon Creek which has in some places precipitous banks covered with deciduous and hemlock forest.

Bucks Co., 5 mi. south of Doylestown, Pa.-J.W. H.

Rock Hill, Bucks Co., Pa. (C3.) There should be preserved 10 acres of rocky hill slope as a means of preserving the climbing fumitory (Adlumia fungosa) and other rare plants.

Rock Hill Station, Bucks County, Pa. -J.W.H.

*Wissahickon Creek Forest. (D5.) Part of Fairmount Park of Philadelphia. Along Wissahickon Creek are found mixed deciduous hemlock forests interspersed with open country which was 
once farmland. Adequate roads and walks have been provided.

Wissahickon Valley $6 \mathrm{mi}$. north of Philadelphia.-J. W. H.

Delaware River Tidal Marsh.

The tidal marshes of the Delaware river are worthy of preservation because frequented by birds and because of their botanical interest. There are the feeding grounds of the shad and other food fishes.

Eddington, Pa., Bucks Co., Pa.J.W. H.

Painter Arboretum. (H8.) This arboretum was founded by Jacob and Minshall Painter about 80 years ago; it comprises about 100 acres. Here they planted many rare trees, now grown to maturity. The rare trees included cedar of Lebanon (Cedrus Libani). Gordonia pubescens, redwood (Sequoia sempervirens), big tree (Sequoia gigantea), varnish tree (Koelreuteria paniculata), and bald cypress (Taxodium distichum) with well-developed knees.

Delaware County, one mi. west of Lima.- J. W. H.

Pink Hill. (CD.) Along Dismal Run is a serpentine outcrop on which grown black jack oak (Quercus marilandica), postoak (Q. stellata), Phlox subulata, Cerastium ol longifolium, etc. This hill slope of 10 acres should be preserved. See Harshberger, John W.: "The Flora of the Serpentine Barrens of S. E. Penna.," Science, new ser. XVIII: 339343, September 11, 1903; Pennell, F. W.: "Flora of the Conowingo Barrens of $\mathrm{S}$. E. Penna.' Proc. Acad. Nat. Sci. Phila., 1910: 541-584; 1912: 520-539.

One mi. north of Lima, Delaware County.-J.W.H.

Crum Creek Deciduous Forest. (C3.) 8000 acres or more of the valley and valley slopes of Crum Creek. The water of this creek furnishes the drinking water of nearby towns as supplied by the Springfield Water Co. There is some of the finest forest in eastern Pennsylvania with hemlock groves prominent. The herbaceous flora is also rich in such forms as blue cohosh (Caulophyllum thalictroides), wild ginger (Asarum canadense), green violet (Hybanthus concolor), etc. The principal area which should be preserved by the state lies 2 miles east of Media, Delaware County, Pa., 20 to 30 minutes by trolley from Phila. See Harshberger, John W.: "A Phytogeographic Sketch of Extreme Southeastern Penna.," Bull. Torr Bot. Club, 31: 125159, March, 1904.

Delaware County, Pa., between Swarthmore and West Chester Turnpike.-J. W. H.

Forest and River Shore on Lower Sus- quehanna. (C3.) See Porter, Thos. C.: "The Flora of the Lower Susquehanna,; Bull. Torr. Club, 25: 485-494, September, 1898.

York Furnace in the Counties of Lancaster and York. Reached from Columbia and Safe Harbor.-J. W. H.

Deciduous Forest. (C3.) Located in a narrow defile or gorge of the South Valley Hills Philadelphia and Norristown. Here Gulph Creek breaks its way by water gap through hills composed of Octoraro Schist. See Harshberger, John W.: "Slope Exposure and the Distribution of Plants in Eastern Penna." Bull. Geog.Soc. Phila., XVII:43-61, Apr., 1919. Gulph, Pa. Between Philadelphia and Norristown P. \& W. Electric.-J. W. H.

Mixed Forest on Slate hills. (C3.) Here under oaks and other trees grown the rare box-huckleberry (Gaylusaccia brachycera), known to grow in only in a relatively few other localities in the world. See Coville F. V.: "The Threatened Extinction of the Box Huckleberry, Gaylusaccia brachycera," Science, new ser. L: 30-34, July 11, 1919.

South of New Bloomfield, Perry Co., Pa.-J.W. H.

Coniferous and Deciduous Forest. (B3.) Located on a mountain plateau 2000 feet in elevation; lake plants, deciduous and coniferous forest. Eaglesmere is a noted resort.

Eaglesmere.-J. $W . H$.

Black Forest. (C2.) There are 3000 sq. mi. of coniferous (hemlock) and hardwood forest covering a hilly country.

In several counties (Cameron, Clinton, Elk, Lycoming, McKean, Potter, Tioga and Warren) near Renova, Pa. $-J . W . H$.

Center County Barrens. (C3.) Here are 10 acres of coniferous and mountain forest with sandy pine barrens without a counterpart anywhere in the western Pennsylvania or western New York.

7 or 8 mi. southwest of State College in Center County.-J. W. H.

Clarion River deciduous and coniferous forest. (H8.) Along the Clarion River. Here 2000 acres have been planted to 100,000 white pine trees. There is some primeval forest of oak, chestnut, maple, ash and white pine.

Foxburg, Clarion Co., Pa.

Cook Tract. (B3.) Ảbout 7600 acres of which 4000 are covered with forest primeval. The ground rises 300 to 500 $\mathrm{ft}$. above the river and is covered with fine white pine, hemlock and cherry. The purchase of the tract has been advocated by the Pennsylvania Forestry Association and the Wild Life League.

Clarion, Forest and Jefferson County Cooksburg.-J. W. H. 



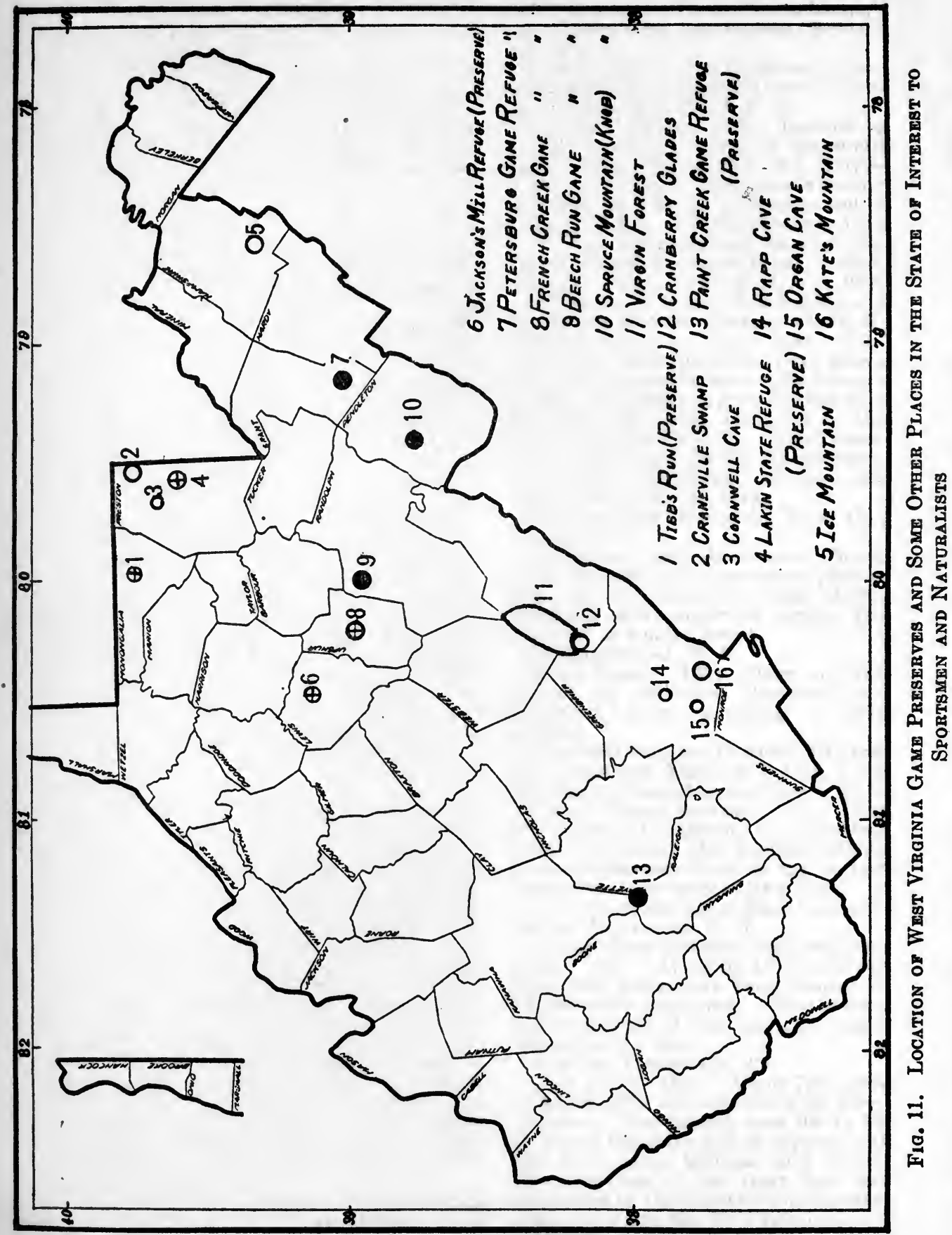


Tamarack Sphagnum Bog in Pymatuning Swamp. (C3.) There are about 100 acres that should be preserved at once, for each year sees more of the Tamarack cut off. Here grow pitcher plant (Sarracenia purpurea), Lonicera altissima and many more plants described by Dachnowski, Alfred, in Peat Deposits of Ohio, 1912: 33 . It should be purchased by State Dept. of Forestry.

About two mi. west of Hartstown.O. E. Jennings.

*Presque Isle Sand Dunes and Deciduous Forest. (B2.) A tract of unknown area is located on Lake Erie. Here is a series of successions on sand in inland lake regions. Part of the island has been turned over to the City of Erie for a water park and still more recently some of it for a state fish hatchery. For the latter purpose, the large inland ponds are being dredged out and connected by artificial canals. The park should be preserved in its natural state by the nation, as it is under control of the War Department, Erie, Pa.-J. $W . H$.

Sheffield (Warren County) Areas. South Sheffield Wood. (C3.) Contains a few scattered large white pines, the largest apparently about $140 \mathrm{ft}$. high or more, and $4 \mathrm{ft}$. or more in diameter. The wood was largely hemlock with red oaks, maples, some red birch, cherry and tulip trees, quite similar in size and character to that described below. Located south of Sheffield.-Willard $G$. Van Name.

North Sheffield Wood. (C3.) Large tract of old woods on hills N. and N. E. of town south of $4 \mathrm{mi}$. creek. Tract begins practically in sight of W. part of town. Very dense stand of hemlock in some places. Usual height of hardwood trees in this tract 80 to $85 \mathrm{ft}$., some hemlocks $100 \mathrm{ft}$. or a little over, but majority 90 to $95 \mathrm{ft}$. Almost no pines. Few trees of large diameter. Name.

Sheffield, Warren Co.-Willard G. Van

\section{WEST VIRGINIA}

\section{By W. E. Rumsey}

\section{GENERAL CONDITIONS}

The mere mention of the name West Virginia brings to mind a state irregular in outline, uneven in surface, and of great natural resources. At least $85 \%$ of its area consists of hills and mountains. The only broad valleys are those of the Ohio, the Kanawha, the Potomac, and the Shenandoah rivers. The eleva- tion ranges from 260 to $4860 \mathrm{ft}$. A clearer idea of the general surface features of the state can be conveyed by dividing it into three parts, namely, the Ohio Valley Section, the Mountain Region, and the Potomac Area. The first division includes about half of the State, sloping westward from the Allegheny Mountains to the Ohio River and constituting the northeastern continuation of the tableland of the Cumberland Mountains. In all places this plateau is dissected by narrow valleys so that it is recognizable as such only in a general view from high elevations. This area varies in altitude from $500 \mathrm{ft}$. at the mouth of the Big Sandy River, to 1500 $\mathrm{ft}$. on the hill tops nearest the mountains. The Allegheny Region may be said to begin at the $1500-\mathrm{ft}$. elevation near the eastern border of Monongalia County at the north and lies east of a line drawn from this place in a southwesterly direction to the eastern extremity of Kentucky. This is but an arbitrary division for the hilly area of the Ohio Valley Section and the Mountain Region pass almost imperceptibly into each other. In the eastward rise from the $1500-\mathrm{ft}$. level there are thousands of mountain tops arranged irregularly and deeply cleft, followed by long undulating ridge after ridge to the crest of the Alleghenies-the highest point of which is Spruce Mountain in Pendleton County, $4860 \mathrm{ft}$. high. From this summit the portion of the mountain region to the east is of greater uniformity. The ranges extend in a northeastern and southwestern direction with much regularity and each successive eastward ridge is less elevated than the preceding one. The $1500-\mathrm{ft}$. level, which may be taken as the eastern edge of this area, is reached in Grant County. The remainder of the State constitutes the Potomac section which is commonly known as the Eastern Panhandle. Its elevation runs from $260 \mathrm{ft}$, at the eastern border, near Harpers Ferry, to the $1500 \mathrm{ft}$. level mentioned above.

While there are no natural lakes in West Virginia its many rivers, numer- 
ous ever-flowing smaller streams, and thousands of never-failing springs place it among the best watered states. The entire drainage of the State, except a small area in the eastern part of Monroe County, is through two river systemsthe Ohio and the Potomac. Thirtythree of the 38 principal rivers in West Virginia have their sources within the borders of the State and many of these rise near each other in the Allegheny Mountains. There are many rapids, cascades, and waterfalls in practically all these streams until they reach the lower levels in the Ohio or Potomac regions.

\section{PRESENT AND ORIGINAL BIOTA}

Among the original timber trees that are rapidly being removed from the forests of West Virginia are the white pine, red spruce, and tulip or yellow polar, all of which were at one time abundant in certain sections of the State. The white pine was formerly common in parts of Greenbrier, Mercer, Pendleton, Pocahontas, Raleigh, and Tucker counties; and sparsely distributed in all the counties east of the Allegheny Mountains. West of the mountains it is found in Doddridge, Gilmer, Jackson, Monongalia, Preston, Ritchie, Taylor, Wetzel, and Wirt Counties. White pine is at present too scarce in the State to attract the attention of lumbermen. The red spruce is confined to the high elevations of the Allegheny Mountains and plateaus where it once formed the greater part of vast forests. Now only comparatively small areas of virgin spruce timber remain owing to lumbering and the forest fires that follow in its wake. The tulip tree is rapidly being converted into lumber as well as the virgin stands of white pine and spruce. At one time the tulip was abundant throughout the western and central portions of the State below the spruce belt, but rare in the eastern section. Some of the other trees and plants are discussed in the account of natural areas given elsewhere in this article.

When the sound of the settler's ax began to ring in the forests of what is now West Virginia many big game and carnivorous animals roamed through this region, but with the advent of civilization practically all of these have disappeared from the confines of the State. History records that large herds of bison were found in the Ohio and the Great Kanawha valleys. While going down the Ohio River by boat in 1765 Colonel Crogan saw a vast herd of these animals crossing the river at the point where the village of Letart, Mason County, now stands. The last bison killed in the State, as far as known, was at Valley Head, Randolph County, in 1825. The elk is another of the big game animals that formerly thrived in the higher mountain regions. There is an account of 3 elk having been killed in the Canaan Valley (Tucker County) about 1843 and the last record of these animals was in 1845 when a herd of seven was observed near Durbin, Pocahontas County. In an effort to re-establish the elk in the wilds of the Allegheny mountains of West Virginia, the Allegheny and Cheat Mountain Clubs introduced 65 of these animals into Pocahontas County-15 from Iowa in 1912 and 50 from the Yellowstone National Park in 1913. These elk were placed in a fenced area of 100 acres composed of forest and pasture lands. Subsequently about half of the animals escaped and formed a wild herd which later divided into two groups, one of which is still in the wilds of Pocohontas County while the other one has moved north into Pencleton County. It is not definitely known to what extent these two wild herds have increased or diminished since their escape from the inclosure. The future of these animals depends upon the continuation of conditions suited to their habits and needs, and upon their protection through the enforcement of our game laws. The beaver at one time constructed dams and built homes in West Virginia, but until a few months ago it was supposed to have been exterminated here by civilization and trappers as none of its work had been 
reported for many years. During the autumn of 1922 a report became current that beavers were building a dam on North Fork River in Hampshire County. A. B. Brooks, Chief Game Protector, inspected this locality about February 8 , and judges from the amount of cutting that there must be a colony of good size. In one place there were 15 willows gnawed down, all of their branches and parts of their trunks cut up and hauled off. The trees were from 8 to 16 in. in diameter, and all had been cut during the past three or four months. Where this colony of beavers came from is yet unknown. The porcupine, too, was undoubtedly more or less common in the higher mountain areas, but it has not been seen in this range for many years. The last record of the animal in the State was the presence of its tracks in the snow observed by C. L. Brooks in Morgan County in 1913.1 The panther or cougar is extinct notwithstanding an occasional report to the contrary. The Canadian lynx no doubt lived in the Alleghenies of the State for it is known to have inhabited these mountains in the southern part of Pennsylvania. Along with the other wild life mentioned the gray or timber wolf is now extinct in West Virginia. What is considered as the last one of this species here was killed in Randolph County by Stofer Hamrick in January, 1900. The marten a former inhabitant of the State has disappeared and the otter has not been seen for many years. The simple mention of the passenger pigeon reminds one of the past.

Owing to the many streams that rise within its borders West Virginia has been rightly named the "Birthplace of Rivers." These numerous streams of crystal, sparkling water heading among the mountain peaks and ridges wending their way through the highland forests amid unsurpassed scenic beauty as cascades, rapids, riffles, and mirrorlike pools make a fisherman's paradise.

\footnotetext{
1 Since this article was written a porcupine was seen in Preston County by a hunter, Charles Cox, during November, 1923.
}

Here the native speckled trout is yet plentiful and a week's vacation in these places where civilization has not penetrated, where the hoot-owl calls the watches of the night and the veery sings by day one forgets the cares of business and professional life and in the arms of nature the flush and vigor of youth is renewed. While fish is becoming less abundant in the lower reaches of the streams the restocking of some of the waters of the State, which has been going on for some time, will tend to keep up the supply. In addition to the wild life already mentioned the smaller game animals are yet present but greatly reduced in numbers. The black bear, Virginia deer, and wild turkey are also found in limited numbers in the mountain section. Ruffed grouse is yet plentiful in certain areas of the State.

\section{POLLUTION}

Although the headwater streams still retain their pure sparkling waters practically all of them in their lower reaches have become polluted by coal mines, tanneries, pulp and paper mills, chemical plants, and sewage from cities and towns located along their banks. Perhaps the least polluted river in West Virginia is the Great Cacapon, which has its source in the southern extremity of Hardy County and flows in a northeasterly direction through Hardy, Hampshire, and Morgan Counties, emptying into the Potomac near Great Cacapon village. Up to the present time very little has been done to check the pollution of the streams in the State other than by prohibiting the dumping of sawdust into the water. May the activities of the few people of this generation who are striving for the preservation of natural conditions in the different states and provinces of America bring about the establishment and maintenance of many such desirable and important sanctuaries. Speed the day when man shall be disenthralled from his enslaving selfishness and think more about the future of his race and nation; then the 
wanton destruction of plant and animal life will cease and the denuded mountains shall again be clothed with their forest verdure where wild life always abounds and the crystal-like streams flow regularly in their onward rush to the sea.

\section{NATURAL AREAS}

*Monongahela National Forest and Shenandoah National Forest ( $V a$. and $W$. Va.). See account in "National Forests of the Eastern District."

*Spruce Mountain. The highest mountain in West Virginia is located in the western part of Pendleton County within the Monongahela Area of the National Forest and is known as Spruce Mountain (or Spruce Knob). It consists of a flat-topped mountain $18 \mathrm{mi}$. long the crest of which varies in width from one-fourth to one-half mile. The ridge contains scattered growths of the original red spruce, and several species of deciduous trees. Black huckleberry, red raspberry, dwarf cornel, Hooker's orchis and other plants are found along the slopes. Aside from the animals common in other parts of the State there are found representatives of the coniferous forest fauna among which are bob-cat (Lynx rufus), snowshoe hare, smoky shrew, starnosed mole, red-backed vole, and Canadian deer-mouse. Among the birds not commonly found elsewhere in the State are the red-breasted nut-hatch, Canadian warbler, veery and olivebacked thrush. $4860 \mathrm{ft}$.; level.

Cumberland, Md., 14 mi. east, B. \& O. to Green Spring, $50 \mathrm{mi}$. south on branch line to Petersburg, $25 \mathrm{mi}$. south (a), dirt road to Franklin, 20 mi. west (a), dirt road to Circleville, at base of mountain.-A. B. Brooks.

Gauley River Virgin Forest. ${ }^{2}$ An area of virgin forest of about 50,000 acres is the largest tract of undisturbed timber land in West Virginia at this time (1922), and is located principally in Pocahontas County at the headwaters of the Gauley,

\footnotetext{
2 Available after the region has been cut over.
}

the Williams, and the Elk Rivers. Practically one-half of this wooded region, a rough mountainous country, is covered with mountain coniferous forest, chiefly red spruce and hemlock, and the balance deciduous forest; such as yellow and sweet birch, sugar maple, tulip tree and various species of oak. This virgin forest tract is being rapidly reduced in size by lumbering operations, but it will take about 20 years at the present rate of logging to complete the cutting. As with other high elevations in the State many plants of a more northern range are found here. Among the animals are Virginia deer, black bear, bob-cat, red and gray fox, raccoon, red and gray squirrels, and many other smaller mammals. Many birds belonging to the coniferous forest fauna nest in the mountains of this region. 2000 to $4800 \mathrm{ft}$.; level.

Clarksburg, 70 mi. south, B. \& O. R. R. to Holly Junction, $30 \mathrm{mi}$. east, W. Va. \& M. R. R. to Webster Springs; 25 mi. east by wagon road up Elk River or south $5 \mathrm{mi}$. across mountain to the Gauley River and east $25 \mathrm{mi}$. up this stream.-A. B. Brooks.

Kate's Mountain. Kate's Mountain lies just south of White Sulphur Springs, Greenbrier County. It has an area of about $40 \mathrm{sq}$. $\mathrm{mi}$. and is in the form of a mountain ridge with abrupt margins on the east, west and north. Deciduous forest covers it in the main, with small tracts of mountain coniferous forest on the higher elevations such as are found in the Appalachian region. Owing to lumbering operations and forest fires much of this territory is not in its original natural condition. This area is of special interest to the botanist on account of a species of clover (Trifolium Virginicum), that grows on the mountain side. This rare and indigenous clover has not been recorded elsewhere in the United States. It is a small inconspicuous plant occurring only in restricted areas and therefore hard to find. Another interesting plant, Clematis ovata, closely associated with this clover has here its northern limit. Owing to the overlapping of plants of a more northern and southern habitat on and about Kate's Mountain the place has added value to the naturalist. $3000 \mathrm{ft}$.; level. 
White Sulphur Springs, or Dry Fork Village, C. \&. O. R. R., at north end of mountain.-C. L. Brooks.

Ice Mountain. Ice Mountain on the North Fork of Cacapon River, Hamp. shire County, is an area of about 100 acres, extending from the east bank of the river to the top of the mountain. Here the mountain slope is covered with a loose talus of sandstone boulders, within which an immense quantity of ice is formed each winter. Over a small portion of this tract, at the foot of the mountain, ice persists throughout the summer, affecting the vegetation. While the elevation is only $1000 \mathrm{ft}$. the plants are such as are found in other parts only at altitudes of $4000 \mathrm{ft}$. or over, e.g., twin flower (Linnaea borealis), dwarf cornel (Cornus canadensis) and oak fern (Phegopteris dryopteris). The line of demarkation between the plants of adjacent territory and those of the ice area is distinctly visible, making a study easy.

The forest is composed chiefly of red cedar, hemlock, oak, birch, chestnut, and maple. In the forest are red and gray fox, raccoon, opossum, red and gray squirrels, chipmunk, Virginia deer and black bear. The bird life is characterized by the wild turkey, ruffed grouse, turkey vulture, and a large number of song birds. $1000 \mathrm{ft}$.; level.

Cumberland, $M d$. 14 mi. east, B. \& O. R. R. to Green Spring, $40 \mathrm{mi}$. south, branch line to Moorefield, W. Va. 30 mi. northeast (a); or Winchester, Va. 30 mi. west (a) improved and dirt roads to Capon Bridge, W. Va.; $10 \mathrm{mi}$. west (a) and (w).-A. B. Brooks.

Cranberry Glades. (Available.) The southwestern portion of Pocahontas County is a high mountainous region originally covered with mountain coniferous forests and deciduous forests where game of many kinds was plentiful. A large portion of this tract has now been greatly changed by fire and lumbering. These forest areas are of great importance for stabilization of stream flow.

Near the head of the Cranberry River, on the southwestern border of the territory mentioned, are the Cranberry Glades. This swampy area consists of one glade containing from 300 to 400 acres. This tract and its environs are teeming with a variety of plant and animal life. Among the former are ground hemlock (Taxus canadensis), northern rattlesnake plantain (Epipactis repens var. ophioides), rose pogonia (Pogonia ophioglossoides), horned bladderwort (Utricularia cornuta), sphagum moss (Sphagnum girgensohnii) and cranberry (Vaccinium macrocarpon and $V$. oxycoccos). Such animals as the masked shrew (Sorex personatus), the smoky shrew (Sorex fumerus), the red-backed mouse (Evotomys gapperi), and the yellow-checked meadow mouse (Microtus chrotorrhinus) are found in and about the glade. In the forest are Virginia deer, black bear bob-cat (Lynx rufus), red and grav fox, raccoon, gray squirrel, and red squirrel. The bird life during nesting time is marvelous. Such species as the alder flycatcher, olive sided flycatcher, swamp sparrow are among those that nest in the trees and shrubs and the grasses and sedges of this glade, while the cairn's warbler, mourning warbler, mountain solitary vireo, olive backed thrush, and other species have their habitat in the surrounding forest. Glade $3100 \mathrm{ft}$. Level with surrounding mountains arising from 1000 to $1500 \mathrm{ft}$. above it.

Grafton, $59 \mathrm{mi}$. southeast, B. \&. O. and W. M. R. R. to Elkins, 95 mi. south, W. M. and C. \& O. R. R. to Seebert: or Ronceverte, $40 \mathrm{mi}$. northeast, C. \& O. R. R. to Seebert, W. Va., $14 \mathrm{mi}$. west to the Glades**_-9 miles (a) or wagon, remaining $5 \mathrm{mi}$. (h) or (w). $-A$. $B$. Brooks.

Cranesville Swamp. (Available.) This is an area of about 560 acres near Cranesville, Preston County, on the West Virginia-Maryland border. Plants and animals that belong to the northern flora and fauna are found here, and the place is frequently visited by naturalists.

Originally this tract was covered with mountain coniferous forest consisting of red spruce, white pine, hemlock, and tamarack. At present these trees are to be found only here and there. The deciduous forest growth contains such trees as chestnut, mountain ash (Pyrus americana), oak, hard maple, and aspen. In and about the swamp are found gold thread (Coptis trifolia), dwarf cornel (Cornus candensis), purple fringed orchis (Habenaria fimbriata), and two species of Cranberry (Vaccinium macrocarpon and $V$. oxycoccos). Among the animals are the snowshoe hare, cottontail rabbit, gray squirrel, red squirrel, raccoon, and red and gray fox. The northern water thrush, veery, Canadian warbler, Nashville warbler, and great blue heron are among the birds found in this locality. $2500 \mathrm{ft}$.; level.

Terra Alta, $10 \mathrm{mi}$. north (a) over dirt road to Cranesville, $\frac{1}{2} \mathrm{mi}$. southeast.W. E. Rumsey.

French Creek. A tract of about 1000 
acres lying within the basin of French Creek on Little Bush Run in Upshur County is a privately owned preserve. This area is in a farming community, hilly, with excellent water and good grazing land. The plants and animals of this locality are typical of the hilly region which lies between the ridges of the Alleghenies and the Ohio River. This territory has perhaps contributed $\rightarrow$ re to the flora and fauna of the State than has any other area of equal size. The orchid family, for example, is well represented in this locality. The following species occur here only, or are very rare in the state: crane fly orchis (Tipularia unifolia), green adder's mouth (Microstylis unifolia), nodding pogonia (Pogonia trianthophora), whorled pogonia (Pogonia verticillata), fringeless purple orchis (Habenaria peramoena).

Besides these rare orchids the following are also found in this neighborhood: small green wood orchis (Habenaria clavellata), ragged orchis (H. lacera), smaller purple fronged orchis ( $H$. psycodes), moccasin flower (Cypripedium acaule), yellow lady's slipper (C. parviflorum), showy orchis (Orchis spectabilis), slender ladies' tresses (Spiranthes gracilis), nodding ladies' tresses ( $S$. cernua), rattlesnake plantain (Epipactis pubescens), twayblade (Liparis liliifolia), coral root (Corallorhiza odontorhiza), and putty-root (Aplectrum spicatum). Among the rare plants of other families that occur along Little Bush Run are adder's tongue fern (Ophioglossum vulgatum), leek (Allium tricoccum) and fox grape (Vitis labrusca). Of the many butterflies found here Vanessa $j$-album and Tachyris ilaire have no other West Virginia record and the latter is recorded as occurring in "Florida and throughout tropical America." 1500 to $1700 \mathrm{ft}$.; level.

Clarksburg, $40 \mathrm{mi}$. south to Buckhannon, or Grafton, $47 \mathrm{mi}$. south to Buckhannon, 10 mi. south (a) to French Creek village, W. Va., within the area.A. B. Brooks.

Tibb's run. An area of about 250 acres near the head waters of Tibb's Run in Monongalia County is a game and fish preserve. This tract is owned by the West Virginia Utilities Co. By means of a dam on this property a lakelike body of water of about 15 acres, surrounded by wooded slopes and ridges, has been formed. The woodland is of second-growth deciduous forest interspersed with hemlock and pitch pine. Adjoining this tract is an additional area of about 250 acres posted as a game preserve. $1250 \mathrm{ft}$.; level.
Morgantown, W. Va., $6 \mathrm{mi}$. east (a) over improved and dirt roads. $-W . E$. Rumsey.

Jackson's Mill Refuge. This preserve is located in Lewis County on the West Fork River and consists of about 2000 acres. A part of this tract is owned by by the State. The area is made up of bottom land and hills more than half of which is cleared and used for agricultural purposes. The wood lots scattered over the tract are made up of second-growth deciduous forest. The quail, cottontail rabbit and gray squirrel are common. Bird life is abundant. 1000 to $1300 \mathrm{ft}$; ; level. Clarksburg, W. Va., 16 mi. south by trolley. $-A$. $B$. Brooks.

Beech Run Game Refuge. A rough mountainous tract of 2000 acreas on the left fork of the Buckhannon River in Randolph County has been set aside as a State game preserve. The property is privately owned and has been cut over but it has good second-growth timber. The forest now consists of hardwood with a sprinkling of hemlock and spruce. Among the animals found with the area are black bear, Virginia deer, red and gray fox, raccoon, gray squirrel, wild turkey, and ruffed grouse. 1000 to 2500 ft.; level.

Clarksburg, $40 \mathrm{mi}$. south to Buckhannon, B. \& O.: $30 \mathrm{mi}$. south to Alexander, $10 \mathrm{mi}$. northeast by lumber road to mouth of Beech Creek, $2 \mathrm{mi}$. (w). $-A$. $B$. Brooks.

Petersburg Game Refuge. Located in Grant County, near Petersburg on the South Branch of the Potomac River. It is a privately owned area of 2000 acres composed of rough ridges and ravines covered by a deciduous forest with a scattering of scrub pine. Much of the territory has been cut over. Such game as wild turkey, ruffed grouse, quail, and gray squirrel are found. 1000 to 2800 ft.; level.

Cumberland, Md., 14 mi. east B. \& O. to Green Spring, $50 \mathrm{mi}$. south on branch road to Petersburg, W. Va., 2 mi. south (w).-A. B. Brooks.

Lakin State Refuge. A privately owned tract of 4000 acres in Preston County under the supervision of the State Game and Fish Commission. The wooded areas consist of a scrubby deciduous growth. 2500 to $2800 \mathrm{ft}$.; rolling.

Terra Alta, W. Va. Preserve reaches to the town limits on the northeast.A. B. Brooks.

Paint Creek Game Refuge. An area of about 10,000 acres in Kanawha, Fayette, and Raleigh counties, between Cabin 
Creek and Paint Creek, tributaries of the Great Kanawha River, is a privately owned game preserve. The surface of this tract is rough with high ridges and narrow valleys covered with deciduous forest. 800 to $3000 \mathrm{ft}$.; level.

Charleston, W. Va., 15 mi. southeast to Cabin Creek Junction, C. \& O., $20 \mathrm{mi}$. south on branch line to Republic, within the area.-A. B. Brooks.

Caves of West Virginia. (Available.) There are many caves in West Virginia, the most important of which are near the Cheat and the Greenbrier rivers. They are all of limestone formation and are privately owned. In some of them there are exceptionally good specimens of stalactites and stalagmites available for study. Great numbers of the little brown bat (Myotis lucifugus) pass the winter in some of the caves and some are inhabited by the wood rat, (Neotoma pennsylvanica). Three of the largest and most accessible caves are described here for the benefit of those interested in natural subterranean chambers.

Rapp Cave is near Frankford, Greenbrier County, to the $2200 \mathrm{ft}$. level. Its surface opening is only about $3 \mathrm{ft}$. high, but within a few yards one finds large, rough rooms. It has not been explored to any great extent, but is known to contain excellent stalactites and stalagmites.

Organ Cave is near Ronceverte, Greenbrier County at the $2000 \mathrm{ft}$. level. The natural opening is sufficiently high to permit one to enter easily into the long one-roomed cavern which is about threequarters of a mile in extent. Not much water seeps through the roof of this cave but a considerable stream flows through it. This is the only West Virginia cave lighted with electricity.

Cornwell Cave is near Masontown, Preston County, along the Cheat River at the $900 \mathrm{ft}$. level. To enter this cave one is compelled to crawl a distance of $45 \mathrm{ft}$. as the passage-way is less than $3 \mathrm{ft}$. high. Beyond this low hall-way the cavern opens into a succession of large rooms, through one of which a small stream flows. This cave extends into the mountain for a distance of about onehalf mile. 900 to $2200 \mathrm{ft}$.; level.

Ronceverte, 5 mi. north, Branch C. \& O. R. R. to Lewisburg, $10 \mathrm{mi}$. north (a) over dirt road to Frankford, W. Va.; one mi. northwest to Rapp cave. Ronceverte, $4 \mathrm{mi}$. southeast (a) over dirt roads to Organ cave. Terra Alta, $12 \mathrm{mi}$. southwest, B. \& O. R. R. to M. \& K. Junction, 35 mi. northwest, to Masontown, W. Va.; or Morgantown, $14 \mathrm{mi}$., Branch B. \& O. southeast to Masontown, 5 mi. east (a) over dirt roads and half mile $(w)$ to Cornwell cave. $-A$. J. Dadisman.

\section{TENNESSEE}

\section{By R. S. MADDOX}

\section{PHYSIOGRAPHIC FEATURES}

(1) The Unaka Mountains and the Great Smoky Mountains (a portion of the Appalachian system), rise to an elevation of about $6000 \mathrm{ft}$., and alon. the summits of the main ridge runs the boundary line between North Carolina and Tennessee; the portions lying between Mt. Guyot and Clingmans Dome including both these and Le Conte are compelling in rugged grandeur. (2) The East Tennessee Valley is a broad fertile valley lying between the foot of the Unakas on the East and the Cumberlands on the west; it is drained by the Tennessee River which flows in a southwesterly direction until it reaches northern Alabama, turning there in a more westerly direction to the northern part of that state finally turning northward between the West Tennessee Plateau and the Highland Rim Section of Tennessee. (3) The Cumberland Plateau is a broad elevation on with average elevation of $2000 \mathrm{ft}$. This plateau might be termed the big coal bearing section of the state. ${ }^{1}$ (4) The Highland $\mathrm{Rim}$ receives its name from its being a fairly broad belt surrounding the depression in the middle of the state known as the Great Central Basin. (5) The Great Central Basin or blue-grass section of Tennessee is a fertile limestone area with limestone strata lying very close to the surface and frequently outcropping. (6) The Plateau of western Tennessee lies between the Mississippi and Tennessee rivers with an elevation ranging from about 120 to $500 \mathrm{ft}$. The Cumberland River drains a portion of the Cumberland Plateau, a portion of the Highland Rim and a portion of the Great Central Basin, flowing in a general southwesterly direction until directly after leaving Nashville, thence turning northwesterly into the Ohio River.

1 Vol. 6, No. 3, Resources of Tennessee, State Geological Survey. 
The original vegetation constituted practically a vast wilderness of hardwood forests. There occur, however, some of the coniferous species as follows: bald cypress in the swamp lands and along the sluggish streams of the West Tennessee Plateau; short-leaf pine on the southern part of this plateau: in the Highland Rim, scrub pine $(P$. Virginiana) and short leaf pine; in the Cumberland Plateau white pine, shortleaf pine, scrub pine and hemlock; in the Unaka Range white pine (at its foot), shortleaf pine, hemlock, red spruce, Fraser fir and pitch pine; in the East Tennessee Valley scrub pine, short leaf pine and white pine; in the Great Central Basin, red cedar (Juniperus virginiana). Red cedar was found originally in almost all sections of the state, but was most abundant in the Great Central Basin.

In the hardwood forests of the West Tennessee Plateau, the principal species were red oak, black oak, post oak, white oak, scarlet oak, hickory, sweet gum, tupelo gum, black gum, sycamore and yellow poplar. On the Highland Rim, the chief trees were red oak, black oak, blackjack oak, post oak, red maple, chestnut, poplar, hickory and white oak. In the Great Central Basin, yellow poplar, black oak, burr oak, red oak, walnut, hickory, white oak, sugar maple, hackberry, elm, American elm, and bass wood were the chief trees; in the Cumberland Plateau were chestnut, yellow poplar, white oak, black oak, red oak, scarlet oak, walnut, bass wood, buckeye. In the East Tennessee Valley were found chestnut, yellow poplar, white oak, black oak, walnut, hickory. In the Unaka Range, chestnut, black cherry, cucumber tree, white oak, black oak, yellow poplar, sugar maple, black birch and beech were found. Mountain laurel and rhododendron abound in some localities of the Highland Rim, Cumberlands and Unakas. The forests which are replacing the original are in type the same as the original.

The original mammals included the blaok bear (Ursus emericanus), Virginia deer (Odocoileus virginianus), cougar, grey fox, red fox, opossum, bob-cat, raccoon, gray squirrel, fox squirrel, flying-squirrel, muskrat, beaver, mink, and otter.

The cougar, originally in the Unakas, is now extinct. The birds of the state are said to number about 275 species. ${ }^{2}$ Among these are included the golden eagle and the bald eagle. It is claimed that there are not more than four pairs of the bald eagle now in the state and possibly one pair of golden eagle. The bald eagle has its home in the woodlands at Reelfoot Lake; here also the golden eagle is an occasional visitor. The golden eagle is said to nest and rear its young in the Unaka Range, in Monroe County, Tennessee. The wild turkey and pheasant which once abounded in all sections of the state, have become very rare.

The streams abounded in fish consisting largely, of yellow cat, channel or blue cat, buffalo, eastern brook trout, black bass, sucker, red horse and perch.

\section{NATURAL AREAS}

*Reelfoot Lake, State Game Preserve. (B3.) This body of water is very irregular in the contour of its banks and is about $15 \mathrm{mi}$. long and probably $5 \mathrm{mi}$. wide in its widest place. It was formed by an earthquake in 1812. The lake abounds in black bass, perch and crappie. Reelfoot Lake can be reached by automobile from Union City, situated on both the N. C. \& St. L. Ry. and the Mobile and Ohio Ry. The distance from Union City to the lake is about $20 \mathrm{mi}$. The lake may be reached also from stations along the Illinois Central between Dyersburg and Rieves or from stations along the C. M. \& C. Ry. which passes on the west side of the Lake. (Nelson, Wilbur A.: "Reelfont-an Earthquake Lake in Tennessee." Nat. Geog. Mag., 45: 95-114, January, 1924.)

There are no state parks. The state however, owns a total of about 30,000 acres of land exclusive of Reel-

\footnotetext{
2 Preliminary list of birds in Tenn., by A. F. Ganier (Nashville, Tenn.).
} 
foot Lake on which state institutions are maintained. On one of these tracts (the Brushy Mountain in Morgan County) the state coal mines are situated; on another tract (The Herbert Domain, mostly in Bledsoe County) is situated a branch of the State Training and Agricultural School for boys (Colored Department). The State Penitentiary and other state institutions are maintained on the lesser tracts.

Portions of two National Forests, the Cherokee and the Unaka, are located in the eastern part of Tennessee. (See National Forests of the Eastern District.)

Along the channels of the Hatchie River and the prongs of the Obion River in West Tennessee there are still standing a number of virgin cypress trees.

So far as ultimate state forests are concerned the two tracts, Herbert Domain and Brushy Mountain, would form two excellent nuclei. The Brushy Mountain tract in particular, has many of the biggest and oldest poplars and chestnuts yet remaining in the state.

Near Chattanooga, Tennessee, is the Chicamauga Park. Chattanooga is the logical terminus from which to reach this park.

\section{KENTUCKY}

By A. R. Middleton, W. R. Jillson, Frank T. McFarland and W. A. Anderson, Jr.

\section{GENERAL ACCOUNT}

\section{Climate}

Kentucky extends $400 \mathrm{mi}$. in an eastwest direction, from the Cumberland Mountains of its eastern border, to the lowlands of the Mississippi River at the west. Some differences in temperature and rainfall are evident in different parts of the state. The mean annual temperature is $56^{\circ}$, slightly lower in the east, higher in the west. The mean summer temperature of the western section, $75^{\circ}$ to $80^{\circ}$, is $5^{\circ}$ higher than that of the eastern plateau section. The temperature range is about $140^{\circ}$, from $-28^{\circ}$ to over $100^{\circ}$. Rainfall is heaviest in the Cumber- land River basin (45 to 51 in.) and lightest in the Licking Rivèr basin (37 to 48 in.). This is fairly evenly distributed throughout the year; March and July are months of heaviest precipitation; September and October are the driest months. The Bluegrass Region is more subject to droughts than the other parts of the state; here a minimum rainfall of 26.5 inches is recorded.

\section{Topography and biota (F. T. M. and} W. A. A., Jr.)

Kentucky may be divided into five well defined physiographic areas.

1. That portion of the state lying east of a line beginning at Portsmouth, Ohio, and extending southwestwardly to about Monticello, Ky., is very mountainous. It is a part of the maturely dissected Allegheny and Cumberland Plateaus. The vegetation on the more mesophytic slopes, is a characteristic beech-maplechestnut-hemlock formation ( $F^{\prime}$ agus grandifolia, Acer saccharum, Castanea dentata, Tsuga canadensis). Among the predominant trees of this mountainous section are: beech, sugar maple, chestnut, hemlock, tulip tree (Liriodendron tulipifera), bigleaf magnolia (Magnolia macrophylla), cucumber tree (Magnolia acuminata), umbrella tree (Magnolia tripetala), is very mesophytic areas; red oak (Quercus rubra), chestnut oak (Quercus prinus), Spanish oak (Q. falcata), white oak (Q. alba), shingle oak (Q. imbricaria), walnut (Juglans nigra) and sourwood (Oxydendron arboreum) on slopes and shaly uplands; scrub pine (Pinus virginiana), pitch pine (Pinus rigida) and yellow pine (Pinus echinata) on sandstone summits. Some of the shrubs and herbaceous plants are: Rhododendron maximum, mountain laurel (Kalmia latifolia), oilnut (Pyrularia pubera), several species of blueberry (Vaccinium spp.) and huckleberry (Gaylussacia spp.), and in the southern part, muscadine grape (Vitis rotundifolia); bird-foot violet (Viola pedata), Clintonia umbellata, climbing fern (Lygodium palmatum), wintergreen 
(Gaultheria procumbens) and trailing arbutus (Epigaea repens).

In this region are red fox (Vulpes fulva), skunk (Mephitis nigra), gray squirrel, and a great variety of birds, including both northern and southern species. Rattlesnakes are numerous. The larger mammals which formerly inhabited this area-black bear (Ursus americanus), cougar (Felis couguar), bob-cat (Lynx rufus), Virginia deer (Odocoileus virginianus)-are now extinct with the exception of black bear.

2 . The second region which is quite well defined is one underlain by limestones of the Cincinnatian Series. It is a region of low relief, rolling to hilly, and lies about $500 \mathrm{ft}$. lower than the mountain section to the east. In this is the so-called Bluegrass Region of Kentucky. The boundary of this region begins near Maysville and extends to Stanford in Boyle County and then circles around to near Louisville. The fertile Bluegrass Region was originally entirely forested. Several forest types could be distinguished: (1) bur oak (Quercus macrocarpa), chinquapin oak (Q. muhlenbergii), white oak ( $Q$. alba), shellbark hickory (Carya ovata), black walnut (Juglans nigra); (2) tulip tree, beech, white oak, red oak, hickory; (3) white oak, sweet gum (Liquidambar styraciflua), red maple (Ace rubrum); and (4) on the best soils, sugar maple, blue ash (Fraxinus quadrangulata), black walnut, pignut hickory (Carya glabra), mulberry (Morus ruhra), Kentucky coffee tree (Gymnocladus dioica). Chestnut, hemlock and pines, so plentiful in the inountainous section to the east, are absent here. Little of this forest now remains. The remnants are open forests of blue ash, bur oak, chinquapin oak, black walnut and sugar maple. Grasses now carpet the floor of grazed forests, the most important being Kentucky blue grass (Poa pratensis) and orchard grass (Dactylis glomerata). The little red fox is quite common in the hillier portions of the region, especially near Falmouth.

3. A region lying to the west of these two regions and extending west to the Tennessee River is underlain by limestones of Mississippian age. In this area, there is found an open region specially in the lower portion which is known as the barrens. This was originally covered with prairie grasses and low and stunted trees of black jack oak (Quercus marilandica), post oak ( $Q$. stellata), and black oak (Q. velutina). Since the cessation of prairie fires and of grazing by bison, a forest of small and poorly developed trees has grown up, made up of the following species: black jack oak, Spanish oak, red ce?ar (Juniperus virginiana), black gum (Nyssa sylvatica), sweet gum and sugar maple.

4. West of the Tennessee River one finds a region belonging to the Quaternary age, and the country is generally more or less rolling. The forest of this region is made up of shingle oak, red oak, overcup oak (Quercus lyrata), and scattered beech and sugar maple on the richer lands. The smaller plants are: Bidens aristosa, Helenium tenuifolium, Hedeoma pulegioides, Solidago spp., Aster spp., Vernonia fasciculata, Vernonia missurica, Ambrosia tridentata, and Silphium.

5. The alluvial land of the Mississippi River bottoms constitutes the fifth distinct area of the state. Here are typical sloughs, small lakes, aud swamps. In these the principal trees are sugar berry (Celtis mississippiensis), water locust (Gleditsia aquatica), willow oak (Quercus Phellos), bald cypress (Taxodium distichum) and cottonwood (Populus deltoides). The chief herbaceous plants are: American lotus (Nelumbo lutea), white water lily (Castalia odorata), spatterdock (Nymphaea advena) and false loosestrife (Ludvigia sp.). The wood duck is found to breed in this region.

\section{Present biota $(W . R . J .)^{1}$}

There are no large regions in Kentucky remaining today in which the fauna and

1 Primeval Tracts of Kentucky, by W. R. Jillson. Reprint from Pan-American Geologist, Vol. XLI, April, 1924. 
flora are in their natural condition. There are, however, widely separated and restricted areas in which natural conditions nearly obtain. The flora of these regions simulates the original condition, but the fauna in most instances is either greatly reduced in number and species, or reduced and otherwise altered by additions of new groups. The principal areas which approach a natural condition are:

1. A few swamps and lowlands bordering the Mississippi River in the "Purchase Region."

2. A few recently discovered or undiscovered caves in central, southern, and eastern Kentucky.

3. The topmost craggy ridges of the Pine and Cumberland Mountains.

4. A few timber tracts in Harlan, Perry, Leslie, Knott, Breathitt, Pike, and Martin Counties. These tracts are for the most part small.

5. A few dissociated but geologically contiguous dells, coves, and hollows along the outcrop of the Pottsville Conglomerate (Pennsylvanian) in eastern Kentucky and on the western edge of the eastern coal field.

6. A very few hollows in the vicinity of outcrops of the Cypress sandstone (Mississippian) in western Kentucky, notably in Grayson and Breckenridge Counties.

7. Widely scattered throughout the State, notably in Elliott, Pulaski, Rockcastle, Laurel, Edmonson and Clinton counties, there are restricted areas in the box canyons of entrenched streams which simulate natural conditions. These canyons were in the beginning too small to permit extensive lumbering and the timber now found in them is not much different from what it was originally. The streams in many cases occupy the entire floors of the canyons, especially at high water, and do not allow cultivation. Streams on which such conditions occur are the headwaters of the Little Sandy in Elliott County, headwaters of the Cumberland River, headwaters of the Rockcastle River in Rockcastle County, and streams in
Powell, Wolfe, Lee, Jackson, Laurel, Pulaski, and Whitley Counties, and on Nolan River and Deer Creek in Grayson and Edmonson Counties and Ill Will Creek in Clinton County. The greatest change in all of this region, and in fact in the state generally, has been the removal of the larger native forest trees and the extinction of certain species in the local fauna.

8. Original aquatic biologic conditions of western Kentucky in the Mississippi River bottoms, and in some portions of the western Kentucky coal field adjoining the Ohio River, simulate original conditions.

9. The caves still retain their natural fauna and flora.

\section{Location of unpolluted waters}

Unpolluted waters really do not occur in Kentucky due to the fact that the state is almost entirely inhabited. However, if the term "unpolluted" refers to such waters as are in a nearly natural condition with only mountain farms affecting their drainage basins, the following may be listed:

1. Head of the Middle and South Forks of the Kentucky River.

2. Head of Green River, in Knott County.

3. Head of Johns Creek in Pike County.

4. Head of Beaver Creek in Knott County.

Besides these which are really in a class by themselves, there are hundreds of small creeks and branches in Kentucky which are unpolluted by city, manufacturing or mining drainage. Instances of this sort of stream which is always short and small, can be found in almost every county of the state. The water strictly speaking, however, is not unpolluted since it is sometimes used for watering animals.

5. Kentucky caverns. Kentucky is famous for its cavernous regions which afford not only the largest of caves, Mammoth Cave (D5) in Edmonson County, but also a very large number of caves distributed over a wide area of 
central and southern Kentucky. This is the region where the Mississippian limestone is exposed or close to the surface. It includes certain areas within the Bluegrass Region. West of the Bluegrass Region, Mammoth Cave, Colossal Cavern and Hidden River or Horse Cave are the largest and best known. The fauna of Mammoth Cave includes twenty-eight species, among which are blind fish, salamanders, crayfish, crickets and beetles. The caves of the Bluegrass Region are smaller and not so well known. Several Boone's caves, in Highbridge limestone, have considerable local interest. In the plateau section of eastern Kentucky, a few caves occur in the Mississippian limestone. Among these are Oligonung in Carter County, and the small caves at Natural Bridge. The best known caves of this section are on the western margin and are not real caves but rock shelters or rock houses hollowed out beneath resistant conglomerate sandstones of the basal Pennsylvanian. Such is the "cave" at Torrent, one of the finest of these overhangs. A waterfall $160 \mathrm{ft}$. in height drops over this during wet seasons. There are no caves in Kentucky west of the Cumberland River.

6. Natural bridges. Several natural bridges of different types occur within the state. The sandstone bridges of the western margin of the Allegheny Plateau are represented by the one at Natural Bridge, Powell County, a picturesque bridge at the plateau summit.

\section{References:}

Garman, H. 1913. The Woody Plants of Kentucky. Ky. Agr. Exp. Sta. of the State University. Bull. 169.

Miller, A. M. 1919. The Geology of Kentucky: a classified compend of State Reports and other publications, with critical comment based on original investigation. (Contains chapters on the "Physical Regions of Kentucky" and on "Natural Features and Phenomena of Geologic and Scenic Interest," and extensive bibliography.) Dept. of Geology and Forestry of Kentucky, Series 5, Bull. 2.

Jillson, W. R. 1924. Kentucky State Parks. Ky. Geol. Survey, Frankfort, Ky. Also Primeval Tracts of Kentucky, Pan-American Geologist, Vol. XLI, ap. 1924.

\section{NATURAL AREAS (A. R. M.)}

Kentucky. At the present Kentucky has no completed state parks, but tracts of land for State Park purposes have been given to the Commonwealth near Pineville, Harrodsburg, Elkton, Craborchard Springs and elsewhere. These are proposed State Parks and will be considered by the State Legislature in 1926. The Mammoth Cave (D5), in Edmondson County is being proposed as a National Park. The place where Stephen G. Foster wrote the Old Kentucky Home near Bardstown and Lincoln's birthplace at Hodgenville in Larue County are respectively State and national shrines. The State expects the next Legislature to make appropriations to establish several parks, the last General Assembly having created a State Park Commission of which the State Geologist is the chairman.

Natural Bridge. (A4.) Area of virgin forest, mixed deciduous and evergreen; very beautiful. Limestone on the lower slopes and cliffs of sandstone on the upper slopes. Cliffs and flat summits. Beech-hemlock climax below, chestnut, white pine higher up on east and north slopes. Pine on south slopes, pine barren summits. Small sphagnum swamps, caves, rockhouses, sandstone natural bridge, mountain streams, flat alluvial valley. $760-1180 \mathrm{ft}$.; dissected area of the Allegheny Plateau.

Winchester!̣, $27 \mathrm{mi}$. southeast, Lexington and Eastern R. R.; at Natural Bridge Station, Powell County, Ky.E. Lucy Braun.

*The Lloyd Library Forest Reservation. (A4.) This consists of two tracts of about twenty acres each that have never been touched with the ax. It represents 
the natural woods as it existed originally in the Blue Grass region of Kentucky. The trees are mostly beech, maple, walnut, oak, tulip and other trees. Lying on the crest of the ridge they are not subject to wash and the soil is the accumulation of the humus of ages. Trees that blow over or fall down are not removed and the rotting logs are characteristic of a primeval forest.

Crittenden, Grant County, Kentucky on So. R. R. and Dixie Highway.Chas. A. Shull.

*University of Kentucky Zoological Experiment Station. (D4.) Tract cut over a number of years ago (480 acres). Now second-growth of a larger number of the species that were less valuable at the time the hardwood timber was cut. Series of ridges with narrow valleys, watered by a number of small springs and branches. The wild life is being protected so far as possible and every opportunity afforded for investigation of the native plants and animals; also instruction in summer.

Quicksand, Tenn.-Thomas Cooper.

Berea College Forest Reserve and Adjacent Territory. (A3.) This tract includes a territory $10 \mathrm{mi}$. in length north and south and $6 \mathrm{mi}$. in width. East of Berea about $6 \mathrm{mi}$. and southeast of Richmond some $16 \mathrm{mi}$., Madison, Rockcastle and Jackson Counties.

Woolper Creek Glacial Moraine.

(D5.) (Split Rock.) A deposit of glacial conglomerate locally called "Split Rock." Woolper Creek has cut through this mass and there are now two sections, the upper "Split Rock" and the lower a cliff of conglomerate $185 \mathrm{ft}$. high paralleling the channel of the creek on the south side. $^{2}$

The interesting part of this area lies on the south side of Woolper Creek between the Ohio River and the Bellevue and Petersburg Road. The distance along the creek is about a mile, the width varying from one-eighth to onehalf mile.

A meadow of possibly 50 acres is flanked on both sides by ravines in which

2 See page 216, "Geology of Kentucky," Prof. A. M. Miller, published by the Department of Geology and Forestry, Frankfort, Ky., 1919. a large number of ferns are found. These ravines are steep and the sides are covered with second-growth timber. There is a large variety of wild flowers in the ravines, along the base of the cliffs, etc.

The best way to reach this locality is (a) from Cincinnati, crossing the river at Anderson's Ferry to Constance, then to Hebron, Bullitsville, Gainesville, Petersburg, turning south along the Ohio River a distance of about $3 \mathrm{mi}$.; crossing Woolper Creek on iron bridge, a total distance from Cincinnati of $30 \mathrm{mi}$.Morten Carlisle.

Middle Creek Glacial Moraine. (B3.) A large area of glacial gravel and conglomerate probably higher than "Split Rock" but not so precipitous.

Part of the area is cultivated, but numerous wooded ravines have outcropping conglomerate with a very interesting flora, columbine, ferns, hepatica, etc. This is a well-watered section, the conglomerate resting on sedimentary strata permits the rainfall to percolate to the strata whence it emerges in numerous springs. Highest parts about $800 \mathrm{ft}$. above sea level.

Area about $3 \mathrm{mi}$. by one $\mathrm{mi}$. in dimensions, but broken up by occasional cultivated fields. On Middle Creek, Boone County, Ky., about $6 \mathrm{mi}$. west of Burlington, the county seat. Distance about $25 \mathrm{mi}$. from Cincinnati.

Reached (a) from Cincinnati through Covington, Erlanger, Florence, Burlington, automobile may be driven on a side dirt road for short distance into this region.-Morten Carlisle.

The Hillman Land and Iron Company Reservation. (A3.) This area comprises 65,000 acres in Lyon and Trigg Counties, Ky., nearly all of which is in virgin timber and which is already set aside as a game preserve. There are at least 150 deer and 18 or 20 droves of wild turkeys on this preserve.

Lyon and Trigg Counties, Ky.-C. J. Meredith.

"Tight Holler" Forest. (A3.) A virgin forest occupying a branch of Mill Creek or Middle Fork of Red River known as "Tight Holler"; extends from head of ravine about $3 \mathrm{mi}$. down. Bordered by high sandstone cliffs which completely hem in the valley, making entrance to its head impossible except in one place. Forest of hemlock, tulip tree, magnolias ( $M$. macrophylla, $M$. tripetala, $M$. acuminata); dense rhododendron and mountain laurel thickets. Rich rock flora of north and south facing cliffs and dry and wet cliffs. Clear small permanent stream. Fauna said to include black bear and probably all of the 
animals native to this section. $800-$ $1300 \mathrm{ft}$.; abrupt.

Torrent $\ddagger$ (B3.) $3 \frac{1}{2} \mathrm{mi}$. north, Lexington and Eastern R. R.; Glencairn, north to Mill Creek, east to lower end of "Tight Holler" (w). Or, Torrent, 5 mi. north, L. \& E. R. R.; Campton Jct.; east, about $15 \mathrm{mi}$. on narrow gage to Pine Ridge; the one mile across upland to faint trail leading into head of "Tight Holler." Wolfe County, Ky. $-E$. L. Braun.

\section{OHIO}

\section{By E. Lucy Bradn and}

\section{Lynds Jones (Birds)}

\section{LOCATION AND EXTENT}

The area of Ohio is 41,240 sq. mi. It extends from about $38^{\circ} 30^{\prime} \mathrm{N}$. latitude at the most southerly bend of the Ohio River, nearly to $42^{\circ} \mathrm{N}$. in the northeast corner; and from $80^{\circ} 30^{\prime}$ to $84^{\circ} 45^{\prime}$ west longitude. The Ohio River forms the entire southern and part of the eastern boundary; Lake Erie, most of the northern boundary. These natural boundaries are to some extent biological barriers.

\section{CLIMATE}

The climate is fairly uniform over the entire state. As Ohio lies in the path of most of the cyclonic storm areas which pass across the country from west to east, its temperature, precipitation, sunshine and cloudiness, are largely affected by the passage of "highs" and "lows." Slight differences in temperature in a north-south direction may be noted. Lake Erie has a decided influence on the temperature of a narrow belt near the lake, increasing the length of the period between the last killing frost of spring and the first killing frost of autumn from one to two months. The mean annual temperature for the period from 1883 to 1910 is $50.7^{\circ} \mathrm{F}$. The mean temperature for July is about $73^{\circ}$; for January, about $28^{\circ}$. The extreme annual range of temperature for the state is about $150^{\circ}$.

The average annual precipitation for the state is about 39 in., fairly evenly distributed through the year. Extremes of 20.2 in. in 1856 and 50.33 in 1890 are recorded. The river counties of the southeastern part of the state and the northeast corner have the highest rainfall-averaging 40 in. or more; the western lake counties and the upper Maumee basin have the lowest-34 in. or less.

\section{PHYSICAL FEATURES}

Altitude. The altitudinal range in Ohio is scarcely more than $1100 \mathrm{ft}$. The lowest land in the state, in the southwest corner, is $420 \mathrm{ft}$.; the highest, in Logan County near Bellefontaine, is $1540 \mathrm{ft}$. The eastern and southeastern part, and the west central counties, contain most of the highest land, a considerable area lying between 1000 and $1500 \mathrm{ft}$.

Drainage. About five-sevenths of the state lies in the drainage basin of the Ohio, the remainder in the St. Lawrence basin. The divide between the two drainage basins is well north of the center of the state, and in its eastern half approaches close to Lake Erie. The headwaters of the larger northflowing and south-flowing streams are very close together. Most of the state is fairly well drained; swamps are neither extensive nor numerous, and natural lakes are few. Streams have cut their valleys in a former plateau, and valleys are everywhere narrow, and bottomlands not extensive.

Glaciation. The surface features of about three-fourths of Ohio have been modified by glaciation. In addition to the lacustrine deposits of glacial Lake Maumee, in the northwest part of the state, three glacial deposits are exposed-the Late Wisconsin, the Early Wisconsin, and the Illinoian. The Illinoian drift is covered with a deposit of loess.

Of the unglaciated part of Ohio, all except a small area in Brown and Adams Counties along the Ohio River, is included in the "hill country."

\section{PHYSIOGRAPHIC PROVINCES}

The western half or more of Ohio is underlain by limestones and shales, 


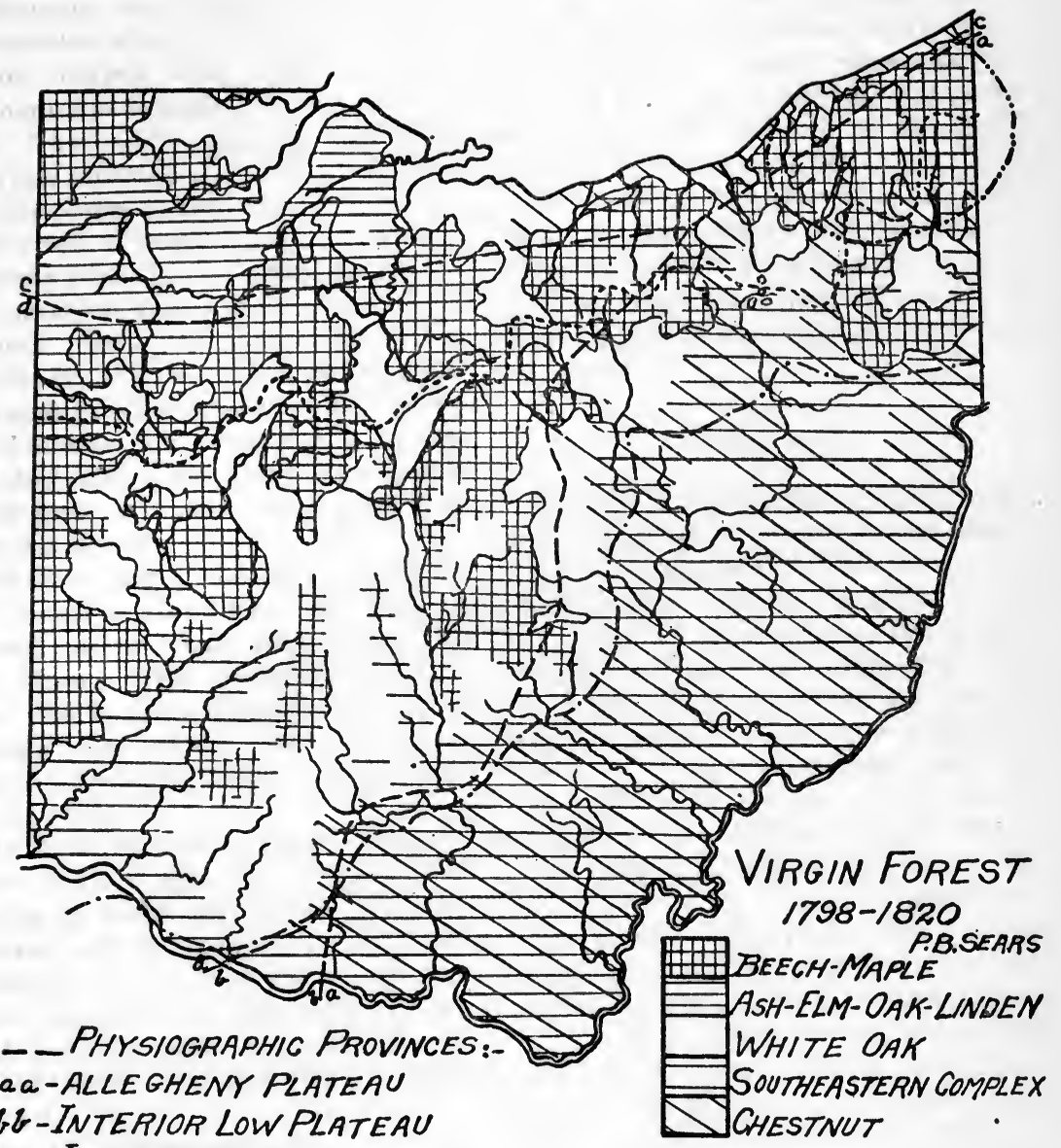

$\left.\begin{array}{l}\text { cc-LAKE SECTION, } \\ \text { dd-TENL PLAINS, }\end{array}\right\}$ TENTRALOWLAND

. SOUTHERN BOUNDARY OF GLACIATION

WATERSHED

SMALL AREA INCLUDED IN NORTHEASTERN EVERGREEN-DECIDUOUS

TRANSITION FOREST (SHREVE); REMAINDER=DECIDUOUS FOREST.

Fig. 12. Map of Ohio Indicating Physiographic Boundaries and

Vegetational Areas 

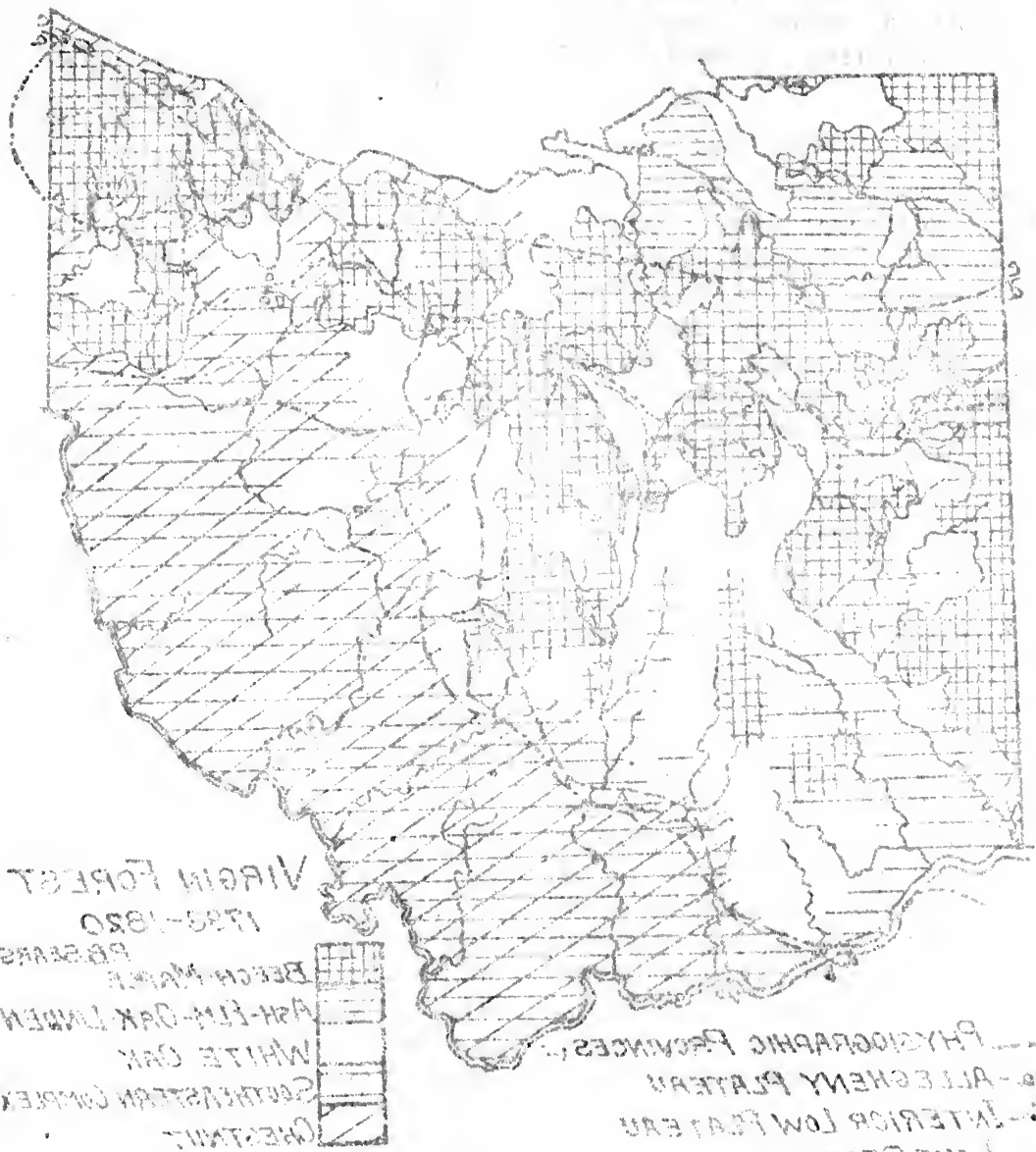

Aft

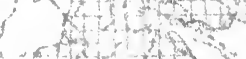

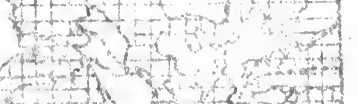

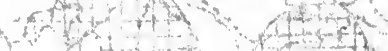
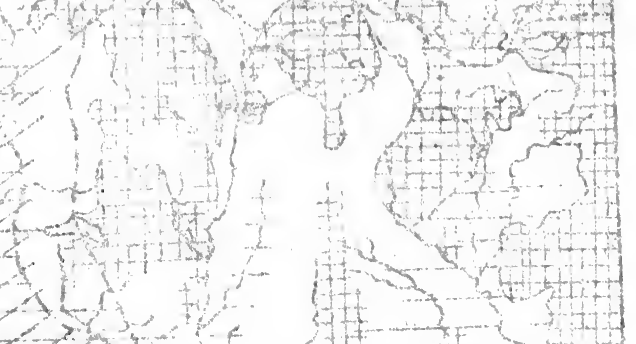

$1+$

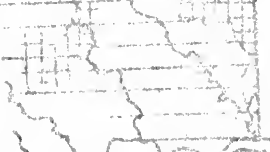

$x+$
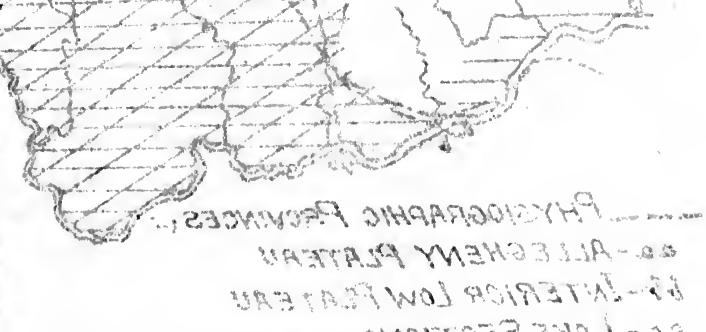

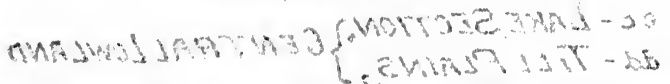

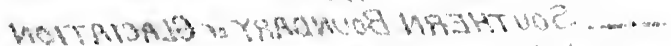

घ

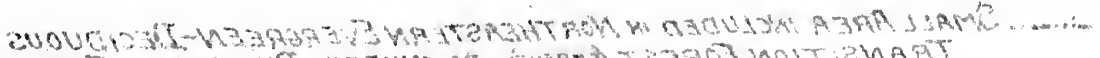

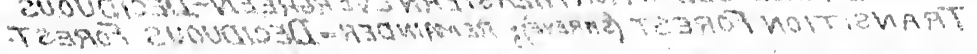

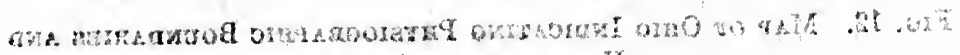

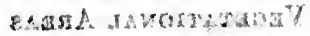


and covered with a mantle of drift. Level areas and gentle slopes are the rule. In the eastern part of the state, the sandstones and conglomerates of the Mississippian and Pennsylvanian series have resisted erosion and given rise to a more rugged topography. Several physiographic boundary lines cross the state. The most prominent of these is the one separating the "hill country" from the plains to the west.

The "hill country" is a part of the Allegheny Plateau. It includes a glaciated northern part and an unglaciated southern part. Adjoining the hill country, in Adams and Brown counties, is a small area belonging to the Interior Low Plateau. The topography is less bold than that of the Allegheny Plateau to the east, but more hilly than that to the northwest.

The remainder of the state belongs to the Central Lowland Province. This is divided into the Lake Section and the Till Plains. The boundary between these two is approximately the shoreline of glacial Lake Naumee, and separates the level lake plains from the rolling till plains.

The Lake Section extends along the shore of Lake Erie as a narrow belt varying in width from about $10 \mathrm{mi}$. in the east to 20 at Sandusky and 50 at the western boundary of the state. Part of it is a succession of lake beaches, with sandy soil; the large area in the westthe old lake bed-is very flat and poorly drained.

The Till Plains occupy all of western Ohio except the northern part. The area occupied by the Wisconsin drift is level to rolling; it is crossed by a series of terminal moraines. The topography of the Illinoian drift area, except near the largest streams, is peculiar. The land is level and poorly drained; the streams have cut narrow though sometimes deep valleys, but have left extensive undissected areas of drift.

\section{SOILS}

Twenty-six soil types are recognized in Ohio, and classified as residual, glacial, loess, terrace, and alluvial soils. Soils of the Allegheny Plateau, whether glacial or residual, are usually sandy; those of the Till Plains, calcareous, though poor surface drainage has in many places resulted in an acid surface and calcareous subsoil. The Interior Low Plateau has a residual limestone soil. The soils of much of the Lake Section are characteristically black (Clyde Series), and this color, together with the poor drainage, has given rise to the name "Great Black Swamp." Artificial drainage has converted the Great Black Swamp of pioneer days into fertile farm land.

\section{PLANT LIFE}

The whole of Ohio lies in the Deciduous Forest Area except a very small part in northeastern Ohio, correlated with a higher annual precipitation (40 in.) and the shortest growing season in the state (134 days). Except for the few small prairie areas of the western part, the whole state was originally covered with one of the finest hardwood forests of the country. Accounts of pioneer days and early travels (Stage Coach Journey across Ohio in 1834) give us a fair idea of the grandeur and magnitude of this forest. Most of the deciduous trees and many of the conifers of eastern United States occur within its limits. Over 2000 species of vascular plants have been recorded from Ohio. In the western half of the state, only a small part of the forest remainsisolated areas, pasture woodlots-from which to reconstruct the picture. Ohio is primarily an agricultural state, and this level and rolling land is preeminently suited to agriculture. The forests of the hill country have more largely escaped the ax, and while few absolutely virgin areas remain, much of the land is forested and will probably remain so.

The early surveyors noted the trees at section corners, and from these records, Dr. Paul B. Sears has reconstructed a map showing the virgin forest 
cover of Ohio (see figure 12). Well defined vegetation regions, correlated with topographic features and soil types, are discernible.

On the Allegheny Plateau, are mixed coniferous and deciduous forests. The most important deciduous trees are oaks (Quercus prinus, Q. rubra, Q. coccinea, Q. alba, Q. velutina), chestnut (Castanea dentata), hickories (Carya alba, C. ovata, C. glabra), birch (Betula lutea), basswood (Tilia americana), black gum (Nyssa sylvatica), with sugar maple (Acer saccharum) and beech (Fagus grandifolia) only on lower slopes of ravines; red maple (Acer rubrum) here is a small tree of the undergrowth. Among the conifers are scrub, pitch, and short-leaf pine (Pinus virginiana, $P$. rigida, $P$. echinata), and in the north white pine (Pinus strobus), red cedar (Juniperus virginiana), arbor vitae (Thuja occidentalis), yew (Taxus canadensis), and in mesophytic locations, hemlock (Tsuga canadensis). Ericaceous plants are abundant throughout the hill country, but almost lacking elsewhere in the state. The large admixture of conifers in the forests, and the important ericaceous element, will distinguish the vegetation of the Allegheny Plateau from that of the remainder of the state.

The Lake Section of the Central Lowland Province includes the lake shore, with its strand and dune vegetation, and coastal marshes; the beach ridges, very low and inconspicuous, and clothed with a mesophytic beech-maple forest; the intervening low and poorly drained belts, where red maple mingles with beech in the forest; and the large level poorly drained areas-the old lake bed-of northwest Ohio, originally covered with enormous tracts of swamp forest (Great Black Swamp) and open oak forests (oak openings). Evergreens occur locally in the region.

On the Till Plains, are hardwood forests of oaks, maples, hickories, walnut, beech, and elm; and occasional small prairies. The one most characteristic and abundant tree of all this area is the white oak. By this charac- teristic and the almost complete absence of conifers, except red cedar, the vegetation of the Till Plains is readily distinguished from that of the Allegheny Plateau.

The Interior Low Plateau is not well marked vegetationally. White oak is much less abundant than on the Till Plains; conifers are not prominent, as on the Allegheny Plateau.

\section{ANIMAL LIFE}

In the trackless forest of pioneer days, many of the larger mammals abounded. Timber wolves (Canis lycaon) howled in the forests close to settlements, and cougars (Felis couguar) roamed at will about 60 years ago. Bison disappeared from Ohio about 1800. Other larger mammals recorded from Ohio are Canada lynx (Lynx canadensis), bobcat (Lynx rufus), red and gray fox (Vulpes fulva and Urocyon cinereoargenteus), fisher or pekan (Martes pennanti), black bear (Ursus americanus), Virginia deer (Odocoileus virginianus), elk (Cervus canadensis), beaver (Castor canadensis), and opossum (Didelphis virginiana). Of these only red fox and opossum remain. The smaller mammals were more numerous, and included least weasel (Mustela allegheniensis), common weasel (Mustela noveboracensis), mink (Mustela vison mink), skunk (Mephitis nigra), raccoon (Procyon lotor), five species of bats, moles, bob-tailed shrew (Blarina brevicauda), southern flyingsquirrel (Glaucomys volans), red, grey, and fox squirrel (Sciurus hudsonicus loquax, S. carolinensis leucotis, and S. niger rufiventer), chipmunk (Tamias striatus), striped ground-squirrel (Citellus tridecemlineatus), woodchuck (Marmota monax), deer-mouse (Peromyscus leucopus noveboracensis), meadow vole (Microtus pennsylvanicus), muskrat (Ondatra zibethica), porcupine (Erethizon dorsatum), and cottontail rabbit (Sylvilagus floridanus mearnsii). A large proportion of the species originally recorded still occur. Faunal distribution is not so much influenced by the natural 
topographic divisions as is vegetation. Most of the animals range throughout the state; a few, however, are more restricted. The woodrat (Neotoma pennsylvanica), partial to caves and common throughout the entire Allegheny region, occurs in Ohio only in the Allegheny Plateau section; the southern snowshoe hare (Lepus americanus virginianus), only in the northeastern part of the state. The porcupine is occasionally seen in the extreme northeastern part of the state; the badger (Taxidea taxus) has appeared recently in the extreme northwestern part. The prairie mole (Scalopus aquaticus machrinus), common throughout western Ohio, is replaced in the northeast part of the state by the hairy-tailed mole (Parascalops breweri). Both occur in the region about Columbus. The deermouse (Peromyscus maniculatus bairdii) of the sand dune area along Lake Erie is a slightly different variety from that found elsewhere throughout the state. In the small prairies of western Ohio, the striped ground-squirrel is found; this is extending its range eastward in cleared land, and is now found at Columbus.

Bird life is abundant throughout the state; about 300 species are found.

\section{Birds (L.J.)}

The breeding birds of the swampy and marshy areas are: Pied-billed grebe, black tern, double-crested cormorant, mallard (rare), black, blue winged teal, bittern, least bittern, green heron, sandhill crane, king rail, Virginia rail, yellow rail, sora, Florida gallinule, coot, marsh hawk, red-winged blackbird, swamp sparrow, short-billed marsh wren, long billed marsh wren.

Birds breeding along the lake shore on the sand and islands: Piping plover, spotted sandpiper, common tern.

Birds breeding on the original prairie of the northwestern part of the state, and in other grassy areas: Lesser scaup duck, upland plover, killdeer, prairie chicken, prairie horned lark, bobolink, meadowlark, vesper sparrow, grasshoppersparrow, Henslow's sparrow, lark sparrow, song sparrow, dickcissel.

Bird breeding in brushy tangles, flood plains, etc.: Bob-white, goldfinch, white-throated sparrow (rarely), field sparrow, indigo bunting, migrant shrike, yellow warbler, prairie warbler, northern yellow-throat, mockingbird, catbird, brown thrasher.

Birds breeding in the deciduous woods: Wood duck, great blue heron, ruffed grouse, woodcock, wild turkey, passenger pigeon, mourning dove, turkey vulture, swallow-tailed kite, sharpshinned hawk, Cooper hawk, red-tailed hawk, red-shouldered hawk, broadwinged hawk, bald eagle, pigeon hawk, sparrow hawk, osprey, barn owl, longeared owl, barred owl, saw-whet owl, great horned owl, screech owl, yellowbilled cuckoo, black-billed cuckoo, hairy woodpecker, downy woodpecker, northern pileated woodpecker, red-headed woodpecker, red-bellied woodpecker, northern flicker, whippoorwill, nighthawk, ruby-throated hummingbird, kingbird, crested flycatcher, phoebe, wood pewee, Acadian flycatcher, blue jay, crow, cowbird, orchard oriole, Baltimore oriole, bronzed grackle, goldfinch, chipping sparrow, field sparrow, song sparrow, towhee, cardinal, rosebreasted grosbeak, scarlet tanager, summer tanager, cedar waxwing, redeyed vireo, warbling vireo, yellowthroated vireo, white-eyed vireo, black and white warbler, prothonotary warbler, worm-eating warbler, bluewinged warbler, golden-winged warbler, yellow warbler, cerulean warbler, blackthroated green warbler (rarely), ovenbird, Louisiana water-thrush, Kentucky warbler, northern yellow-throat, yellowbreasted chat, hooded warbler, redstart, Carolina wren, Bewick's wren, house wren, brown creeper, white-breasted nuthatch, tufted titmouse, chickadee, Carolina chickadee, blue-gray gnatcatcher, wood thrush, Wilson's thrush, robin, bluebird.

Breeding in banks, bird houses, etc.: Belted kingfisher, purple martin, 
bank swallow, rough-winged swallow, barn swallow, cliff swallow, phoebe.

\section{General}

The reptiles are represented by 36 species, only three of which are poisonous: The banded rattlesnake (Crotalus horridus) of hilly or mountainous sections; the prairie rattlesnake (Sistrurus catinatus) found in swampy ground and prairies of western Ohio; and the copper head (Agcistodon mokasen) along streams, especially in the eastern half of the state.

Of amphibians, 25 species are recorded, including toads, tree toads, frogs and salamanders.

Seventy species of fish are recorded from the Scioto River and its tributaries in Franklin County; 37 species from Portage Lakes (30 of these also from the Scioto River). Certain of the fishes are confined to the Ohio drainage system, others to the Lake Erie drainage system; some are common to both. There is also a difference in the fish fauna of the lakes of the two drainage systems. Some species of glaciated and non-glaciated sections of the state are different. H-ion concentration in streams is also a factor in fish distribution.

The insect fauna of Ohio is rich in species and in numbers of individuals. The range of phytophagous species is in general, though not always, coincident with that of the food plant. While there are no such sharp limits in distribution as are found in some of the western states, the different physiographic regions of the state show general differences in the insect fauna. In some instances there are insects characteristic of and limited to a region. This is especially true of the Lake shore, to which some species are sharply limited, and of the Allegheny Plateau, which has in general a rich and characteristic insect fauna. It is noteworthy, that in the state, many plant-feeding species are restricted to the Allegheny Plateau, although the food plant has a much broader range. Other insects are dependent upon particular habitats found only in one region; thus the wet sandstone moss and liverwort covered cliffs of the Allegheny Plateau are the only known locality for the rare moth, Epimartyria auricrinella. Southwestern Ohio shows a mingling of elements derived from the east and from the west and southwest; it lacks many of the species characteristic of the Allegheny Plateau, but marks the eastern and northern limit of other species.

\section{INFLUENCE OF PHYSICAL FACTORS ON DISTRIBUTION}

As Ohio lies at the southern edge of glacial advance, much of its life, both animal and plant, has been determined through post-glacial migrations. Two great recognized pathways of postglacial migration-the Appalachian Plateau and the Mississippi-Ohio Valley -enter its borders. The geographic location, just north of the rather indefinite boundary between warm temperate and cool temperate (about $40^{\circ} \mathrm{N}$. latitude); and at the eastern edge of the deciduous forest-prairie transition, brings about a mingling of plants and animals from the north and south, the east and west. This mingling is evident in the relationships of fauna and flora. The migratory pathway of birds, both water fowl and song birds, summering farther north, crosses Ohio, so that the number of species of birds in spring and fall is enormously increased by these transients.

Barriers, such as Lake Erie, the Ohio River, and the Erie-Ohio divide, have interfered with migrations, not only in proportion to the inability of migrants to cross them, but in other less obvious instances. The watersheds are barriers only for some exclusively aquatic animals. They frequently form sharp limits for distribution of species of crayfish-some of which are limited to specific streams. The southern mocking bird, while abundant in northern Kentucky opposite Cincinnati, is rarely seen north of the Ohio River at this place. The absence of pronounced barriers, either physical or climatic, is partly 
responsible for the somewhat uniform flora and fauna of the entire state.

\section{LOCATION OF UNPOLLUTED WATERS}

Contributed by Division of Fish and Game, Ohio Department of Agriculture, A. C. Baxter, Chief.

Lakes. None of the state-owned lakes are polluted, with the exception of Summit Lake, which is surrounded by the city of Akron and which is badly polluted. All others are in excellent condition, and as far as the fish faunas are concerned are practically in their original condition.

Streams. The headwaters of the Muskingum above Zanesville and most of the streams of the central and western parts of the state, beginning with the Scioto are in good condition and many of the larger tributaries in this region are free from any serious pollution. The eastern and southeastern sections of the state, being concerned with coal mining and manufacture of steel and iron products, are in bad condition, many of the streams being barren or nearly so.

The headwaters of the Muskingum above Zanesville and the region between the Scioto and the Big Miami are probably the best in the state as far as freedom from pollution is concerned.

\section{LITERATURE}

The citations given below represent only a fraction of the works dealing with the biota of Ohio. They are placed here either because of their comprehensive nature, or historical value in reconstructing the picture of Ohio life.

Bownocker, J. A. 1909. A Geological Map of Ohio. (Scale, $8 \mathrm{mi}$. to 1 in.; "shows counties, towns, townships and cities, railroads, traction lines, canals (including some of those abandoned), streams, lakes and reservoirs, railroad or river shipping coal mines, salt works, portland cement works, gypsum mines, oil and gas producing territory, some of the glacial geology, and the areal geology. • " )

Brayton, A. W. 1882. Report on the Mammalia of Ohio. Rept. Geol. Surv. Ohio, IV, Pt. I: 1-185.
Coffey, George N., Rice, Thomas D., and party. 1915. Reconnaissance Soil Survey of Ohio. U. S. Dept. Agr. Bur. Soils.

Cope, E. D. 1872. Zoological Sketch of Ohio.

Howe, Henry. 1896. Historical Collections of Ohio. In two volumes. (Arranged by counties; contains many notes concerning fertility of soil, forests, and wild animals of pioneer days. Includes "A Stage Coach Journey across Ohio in 1834"; II: 193-197.)

Dawson. Birds of Ohio.

Jones, Lynds. 1903. The Birds of Ohio. Ohio Acad. Science, Sp. Paper, 6.

Jordon, David L. 1882 . Report on the Fishes of Ohio. Rept. Geol. Surv. of Ohio, IV; Pt. I : 735-1002.

Morse, Max. 1904. Batrachians and Reptiles of Ohio. Ohio Acad. Sci., Sp. Paper no. 9.

Osburn, Raymond C. 1901. Fishes of Ohio. Ohio Acad. Science, Sp. Paper no. 4.

Schaffner, John H. 1914. Catalog of Ohio Vascular Plants. (Includes distribution) Ohio Biol. Surv., Bull. 2.

Smith, J. Warren. 1912. The Climate of Ohio. Ohio Agr. Exp. Sta., Bull. 235.

Smith, W. H. 1882. Report on the Reptiles and Amphibians of Ohio. Rept. Geol. Surv. Ohio, IV; Pt. I: 629-734.

Sterki, V. 1907. A preliminary catalogue of the land and fresh-water moluscs of Ohio. Ohio Acad. Science, Sp. Paper no. 12.

Wheaton, J. M. 1882. Report on the Birds of Ohio. Rept. Geol. Surv. Ohio, IV; Pt. I : 187-628.

\section{CAVES}

Caves occur in Ohio in the Silurian (Niagara limestone), the Devonian (Columbus limestone), and the Mississippian (Berea sandstone and Black Hand conglomerate). The caves in the Berea sandstone and Black Hand conglomerate are not solution caverns, but overhangs or peculiarly weathered crevices and joints in cliffs; they are never large, but some are very picturesque.

\section{Descriptions of caves}

Hocking County Caves. The Black Hand conglomerate reaches its best development in the Sugar Grove region of Hocking County, and here forms high cliffs. "When first quarried this stone is very friable, but on exposure it becomes hard and durable. Thus it often hap- 
pens that the exposed top of a cliff becomes much harder than the protected portion which weathers away more rapidly, forming an overhang. The 'caves,' as they are popularly called, so formed are very numerous and some of them are very extensive, when the method of their formation is considered." The following are most important:

*Ash Cave. A semi-circular cavern nearly $700 \mathrm{ft}$. long with an overhang of about $60 \mathrm{ft}$., and height of $84 \mathrm{ft}$.

*Old Man's Cave. Smaller than Ash Cave; the dryest of the large caves; sand which covers floor is perfectly air-dry, very fine and dusty.

Cave in Cantwell Cliffs. "Almost hemispherical with a narrow ledge half way up where one finds acoustic properties that are little short of marvelous."

*Rock House. The formation of this cave is due to the crumbling of rock "back along the moisture-laden joint planes till the soft interior was exposed and in turn crumbled along a joint plane parallel to the face of the cliff until there has been formed a corridor about $200 \mathrm{ft}$. long which runs along behind a series of six columns, the remains of the original face of the cliff, which supports the vaulted roof."

Rock Bridge. A natural bridge similar in formation to the caves; water passes through joint above the falls, and goes underneath the overhanging ledge, leaving the crest of the former falls as a bridge.

Cedar Falls Cave.

Saltpetre Cave.

Dead Man's Cave.

\section{Reference:}

Griggs, Robert F. 1914. A botanical Survey of the Sugar Grove Region. Ohio Biol. Surv. Bull. 3.

Howe, Henry. 1896. Historical Collections of Ohio, I: 929.

Map: Laurelville quadrangle.

Elyria Caves. In Crystal Park, in Elyria. (1) Cave at foot of West Branch a water-fall undercut in Berea sandstone; overhang $50-60 \mathrm{ft}$.; two chambers with small hole between. Water coming through roof depositing iron, and calcite in crust and stalactites. (2) Elyria Shelter Cave-abandoned water-fall.

Elyria, Loraine County.-Geo

Hubbard.

\section{References:}

Howe, Henry. Historical Collections of Ohio, II: 124.

Map: Oberlin quadrangle.
Bellevue Caves. Many solution caverns in Columbus limestone, perhaps $\frac{1}{4} \mathrm{mi}$. in length; scores of sink holes communicate with small underground passages. Nearly all surface drainage of this locality goes down through the sink holes, and some emerges in Castalia, Blue Hole, Miller's Pond, Green Spring, etc.

Bellevue, 2-3 mi. south; Huron County.-Geo. D. Hubbard.

Map: Bellevue, Siam quadrangles.

Dublin Caves. North of Dublin toward Rathbone there are many sink holes in Columbus limestone through some of which one can enter small subterranean passages.-Ohio Geol. Surv. Bull. 14.

Put-in-Bay Caves. "Near the center of Put-In-Bay Island is a subterranean cavern [in White Dolomite, Silurian] that is quite an object of interest. It is $200 \mathrm{ft}$. long, $150 \mathrm{ft}$. wide, and has an average height of $7 \mathrm{ft}$. At the farther end is a lake whose pure, limpid waters are ice cold and said to be $50 \mathrm{ft}$. deep in one place and to extend under the rocks to regions and depths unknown."

\section{References:}

Howe, Henry. 1896. Historical Collections of Ohio, II: 368 .

Cottingham, Kenneth. 1919. The Origin of the Caves at Fut-in-Bay, Ohio. Ohio Jour. Sci., 20: 38-42.

Map: Put-in-Bay quadrangle.

Reames Cave. Also called Mount Tabor Cave. Cave in Columbus limestone; $1800 \mathrm{ft}$. long; general form that of a Y, with the entrance at the base of the letter, and the fork $1100 \mathrm{ft}$. from it. Maximum width of galleries $50 \mathrm{ft}$.; maximum height $25 \mathrm{ft}$. Deposits on walls and roof are of calcium carbonate and iron oxide. Many stalactites and stalagmites, varying in size from a few inches to 4 or $5 \mathrm{ft}$. long. Surface opening formed in 1897.

West Liberty $\ddagger$ (Big Four and Ohio Electric), 3.5 mi. S.E.; Champaign County, Ohio.

\section{Reference:}

Hills, Thomas M. 1916. Reames Cave. Ohio Jour. Sci., 16: 209-215. Map: Mechanicsburgh quadrangle.

Bainbridge, Rocky Fork, or Paint Creek Caves. Caves in Niagara limestone; dome-shaped chambers connected by narrow slit-like crevices; several inaccessible, owing to small apertures. Some moist, with dripping water; deep pools; stalactites, etc. (See Paint Creek Caves and Gorge Area.) 
Dry Cave, about $300 \mathrm{ft}$. long, set with stalactite and stalagmite formations; perfectly dry.

Wet Cave, so-called from a spring of cold water some $600 \mathrm{ft}$. from its mouth; a series of chambers.

Dancing Cave, a very large chamber.

Marble Cave, one of the most beautiful of the group; a number of chambers all of good size.

\section{Reference:}

Howe. 1896. Historical Collections of Ohio, I: 920-922.

Map: Bainbridge quadrangle.

\section{DESCRIPTIONS OF AREAS}

Descriptions of preserves and proposed areas are grouped according to physiographic provinces. Within these provinces, the arrangement is geographical -from north to south and from east to west. Any group of areas located within a defined region-as the Sugar Grove Region and the Cincinnati Region-is placed under the regional heading; with this is a brief description of the region as a whole; the descriptions of included areas are correspondingly shortened. Since the topographic mapping of Ohio has been completed, the name of the quadrangle in which the area lies, is given.

\section{Allegheny Plateau Section of the Appalachian Plateaus Province}

Conneaut Creek Hemlock Forest. (B4.) A privately owned farm on which is a magnificent stand of virgin hemlock. Trees over $100 \mathrm{ft}$. in height and as much as $4 \mathrm{ft}$. in diameter. Banks of Conneaut Creek, which borders tract, 50-75 ft. high. $700 \mathrm{ft}$.

North Kingsville, 5 mi. east. Ashtabula County.

North Conneaut, $2 \frac{1}{2} \mathrm{mi}$. south (w, a). -J. S. Houser.

\section{Reference:}

Soil Survey of Ashtabula Area. U. S. Dept. Agr., Bur. Soils; in coöperation with Ohio Agr. Exp. Sta.

Map: Conneaut quadrangle.

Little Mountain White Pine Frorest. (F6.) About 40 acres of virgin white pine timber. Usual Ohio birds and animals, and in addition the pileated northern woodpecker. No streams of any consequence. Fine grove on a hill extending about $200 \mathrm{ft}$., above surrounding country. $1100-1260 \mathrm{ft}$.

Mentor $\ddagger$, 4 mi. S.E. (w, a); or Willoughby, $8 \mathrm{mi}$. east. Lake County, Geauga Co.-J. S. Houser.

Map: Mentor quadrangle.

*Portage Lakes Park. (B2.) State Park. The Portage Lakes consist of a chain of lakes and reservoirs extending southward about $10 \mathrm{mi}$. from Akron. Twelve larger lakes, and many smaller ones of the "kettle hole" type. Reservoirs completed in 1840 . Water area 1600 acres; marsh land 300 acres; embankments and islands 79 acres. Average depth, $9 \mathrm{ft}$. Summit Lake badly polluted; other lakes not polluted or scarcely so. The construction dates back far enough so that conditions of natural stability have long ago been reached in the lakes and reservoirs. Natural lakes were present in most of these bodies of water before the level was raised. A generation ago all of these bodies of water are said to have been exceedingly productive of game and food fishes and though somewhat less productive at the present time, they are still among the best in the state. Conditions are still fairly natural as may be shown by the number of species in the lakes, most of them present in abundance. Forty species of fish are recorded, all but two native. The Fish and Game Division maintains an inland fish hatchery of 20 acres on the island at New Reservoir. $1000 \mathrm{ft}$.

Akronł, south on Ohio Canal; this part of canal included in dedication of Portage Lakes for park purposes. Summit County.-Raymond C. Osburn, Division of Fish and Game.

\section{Reference:}

Osburn, Raymond C. 1921. Report on Fish Conditions in the Portage Lakes, near Akron, Ohio. Division 
of Fish and Game, Ohio Dept. Agr., Sportsmen's Bull., no. 1.

Maps:

Akron, Massillion quadrangles.

Map "made under the direction of the

Ohio Canal Commission." Dept. of Public Works.

Brown's Lake Bog. (B4.) 75 acres of deciduous forest, excellent bog, glacial topography, swamp, marsh, lake. In danger of drainage and grazing. $990 \mathrm{ft}$.

Woostert, 8 mi. S. W., Pa. R. R., 2 mi. west, Shreve; Wayne County. $-P . D$. Strausbaugh.

Map: Loudonville quadrangle.

Spellacy Valley Forest $\dagger$.

About 30-40 acres along the narrow valley of Mohican River in Holmes, Know, and Ashland counties. Forest principally of oak, maple, chestnut, and hemlock. Fauna includes foxes; raccoons; gray fox, and red squirrels; ruffed grouse; several otter reported within last 10 years. Stream $50-100 \mathrm{ft}$. wide, pools 5-8 ft. in depth. 900-1300 ft.; sharp.

Loudonville $\ddagger$, $5.2 \mathrm{mi}$. south, Mansfield and Dennison branch, Pa. R. R.; Spellacy**, Holmes County. $-L$. B. Walton.

\section{Map: Loudonville quadrangle.}

Brink Haven State Preserve. (C3.) 1140 acres on west bank of Mohican River one to two mi. north of Brink Haven; leased by state as a game preserve. Forest of oak, maple, chestnut, and other species, with fauna of fox, raccoon, gray fox, and red squirrel, ruffed grouse; introduced Mongolian pheasants; turkey probably in 1922 .

Brink Haven $\ddagger$, C. A. \& C. R. R. (Pa. R. R.); one to two mi. north; Knox County.-L. B. Walton.

\section{Map: Brink Haven quadrangle.}

*Kenyon College Forest. (C4.) About 100 acres of woodland in several tracts, on the lands belonging to Kenyon College. Portions of mixed oak forest, containing original forest trees. Periodically burned over up to 1908; reproduction since 1908. Second growth from 60 to 75 years old in north section. All forest is mixed oak with associates of chestnut, black gum, and several species of hickory. Flat Iron tract of 10 acres clear cut in 1912. Second growth succession of interest. $940-1080 \mathrm{ft}$; rolling.

Gambier $\ddagger$ C. A. \& C. railroad. Knox County.-Edmund Secrest.

\section{Map: Gambier quadrangle.}

Black Hand Gorget. (D5.) Isolated area of scrub and pitch pines; yellow and cherry birches; hemlock on northerly exposures of gorge. Succession of mixed oak-pine forest. Licking River flows through gorge, swift; precipitous slopes of sandstone formation. $780-1100 \mathrm{ft}$.

Newark $\ddagger$, $6 \mathrm{mi}$. east Pennsylvania or B. \& O. railroads, and Ohio Electric Line. B. \& O. R. R. and Electric Line pass through the gorge and stop at local points within one mi. of gorge. Licking County, Ohio.-F. W. Dean.

Maps: Newark and Frazeysburg quadrangles.

*Mt. Pleasant Park, now known as Rising Park. (C4.) 73 acres; a western outlier of the Allegheny Plateau. A pyramidal hill, $200 \mathrm{ft}$. in height, $1.5 \mathrm{mi}$. in circumference, apex 30 by $100 \mathrm{yds}$. Partly forested; deciduous forest on slopes; pine barren summit. City park of Lancaster; it is the intention of the city to keep this as a natural park. 900-1090 ft.

Lancaster $\ddagger$, Fairfield County.

\section{Reference:}

Howe. 1896. Historical Collections of Ohio, I: $590-591$.

Map: Lancaster quadrangle.

The Sugar Grove Region (7 areas). "The Sugar Grove region is a narrow strip of country extending from a few miles north of the town of Sugar Grove in Fairfield County, Ohio, in a southerly direction about twenty miles to the valley of Queer Creek near the southern boundary of Hocking County, . . ." The flora of the region is fairly representative of all of the "hill country" (Allegheny Plateau) of eastern and southeastern Ohio. In this region, many of the plant communities are exceptionally well developed, for its topography is more bold and rugged than that of many other parts of the plateau region. It is particularly interesting because of the mingling, in it, of northern and southern species. It has been a favorite collect- 
ing ground for botanists of Ohio from the time of Sullivant down.

The only railroad station with in the region is Sugar Grove, on the Hocking Valley Railroad. Logan on the east, and Circleville to the west, are other stations from which the region may be approached.

\section{References:}

Bigelow, John M. 1841. Florula Lancastriensis or a catalog of nearly all the flowering and felicoid plants growing naturally within the limits of Fairfield County with notes on such as are medicinal. Proc. Med. Convent of Ohio at Columbus, May, 1841, pp. 49-79.

Griggs, Robert F. 1913. Observations on the geographical composition of the Sugar Grove Flora. Bull. Torr. Bot. Club, 40: 487-499.

Griggs, Robert F. 1914. On the behavior of some species at the edges of their ranges. Ibid., 41: 25-49.

Griggs, Robert F. 1914. A botanical survey of the Sugar Grove Region. Ohio Biol. Survey, Bull. 3.

Maps: Lancaster and Laurelville quadrangles.

*Old Man's Care and the Gulf †. (A4.) Cavern, gorge, waterfalls. Hemlock, birch, and mixed mesophytic forest below, pine and oak forests above. 750$1000 \mathrm{ftt}$.; dissected.

Logant, 12 mi. S.W.; in Section 11, Benton Tsp., Hocking County.

Circleville $\ddagger$, 24 mi. S.E. (a), South Bloomingville; then two mi. east (a, very poor road). $-E$. N. Transeau.

Cantwell Cliffs. (B4.) One sq. mi. of deciduous forest, with cliffs and talus slopes vegetation, ravine. At the western edge of the Allegheny Plateau. Danger of timber cutting. $800-1000 \mathrm{ft}$.; dissected.

Lancaster $\ddagger, 11 \mathrm{mi}$. south, Hocking Valley R. R.; Rock Bridge, 5 mi. S. W.; Hocking County, Ohio.-E.N. Transeau.

Crystal Springs. (D5.) Two sq. mi. of deciduous and conifer borderline forest, talus slopes, ravines and cliffs. Danger of cutting. $800-1000 \mathrm{ft}$.; dissected.

Lancaster $\ddagger$, $7 \mathrm{mi}$. south, Hocking Valley R. R.; Sugar Grove, one mi. west (w) "Crystal Springs" (owner, Mr. Baumgardner, has cottages to rent); Fairfield County. $-E$. N. Transeau, Freda Detmers.

Cedar Falls Forest $\dagger$. (B4.) Narrow canyon-like valley of Queer Creek, extending from Cedar Falls west about one mi. to the mouth of the Gulf.
Abrupt or overhanging high cliffs of massive sandstone with many species of rock-loving ferns, some lycopods and many mosses. Some virgin forest with hemlock, yew, and yellow birch, on the valley floor. One of the very few areas of virgin forest left in this part of the state. Stream small, constant; waterfalls numerous. Of special interest in being located just outside the margin of the glaciated region and having neither till nor outwash gravels present. Fauna includes red fox, raccoon, opossum, skunk, squirrels and many other smaller mammals; birds numerous; insect fauna very abundant. Camp outfit desirable. 740-1010 ft.; abrupt.

Loganł, 15 mi. southwest (a) hilly road, passable in good weather; or

Circleville $\ddagger$, 24 mi. southeast (a) level road, to South Bloomingville, then $4 \mathrm{mi}$. east (w). Hocking County, Ohio.Clara G. Mark.

*Ash Cave Ravine. (B4.) Ravine $\frac{1}{2}$ mi. long of a small tributary of East Fork of Queer Creek. Forested, with large hemlocks and some other species of former forest still standing. Otherwise very similar to Cedar Falls Ravine. A very good fern locality, especially for the species of cliffs and those of moist bottom lands. Stream small, intermittent, with waterfall; $760-1010 \mathrm{ft}$.

Logan $\ddagger$, $18 \mathrm{mi}$. southwest (a) hilly road, passable in good weather; or

Circlevilleł, $28 \mathrm{mi}$. southeast (a) by way of South Bloomingville, first 24 mi. level, last $4 \mathrm{mi}$. rough road but passable in good weather§. No tent needed-camp under great rock shelter. Hocking County, Ohio-Clara G. Mark.

*Kunkle's Hollow Forest and Cliffs $\dagger$.

(D5.) Narrow valley about one mi. long of a small tributary entering Pine Creek from the north at Pine Grove Church (see Laurelville topographic map). Partly second growth forest, partly original forest. High abrupt or overhanging cliffs, seamed and pitted and affording root-hold for various plants. Valley canyon-like, shaded and moist. Flora particularly abundant in mosses, ferns and other rock-loving forms. The cliffs afford dens for foxes and numerous smaller mammals§. Tent not necessary. 760-1100 ft.

Iogan $\ddagger$, $18 \mathrm{mi}$. a little west of southwest (a) very hilly road, passable in good weather, or

Circlevilleł, $20 \mathrm{mi}$. southeast (a) level road to Haynes, then 7 mi. east (a) unimproved valley road. Hocking County, Ohio.-Clara G. Mark.

Crane Hollow'๋. (C2.) A broad valley about 3 miles long and 50 to $100 \mathrm{ft}$. below general level of adjacent land. 
Quite densely forested and with much of primitive forest conditions. Cliffs; a small waterfall; rock strata similar to Cantwell Cliff. Many striking stretches of sheer smooth cliff walls and some narrow caves. $800-1100 \mathrm{ft}$.; abrupt.

Circlevilleł, $16 \mathrm{mi}$. S.E. (a) Laurelville, then $11 \mathrm{mi}$. north and east through South Perry to Gigisonville; south to Crane Hollow. Hocking County.Herbert Osborn.

*Waterloo State Forest. (B3.) 221 acres. Forest areas not contiguous; succession interesting; contains a tract of woodland that has not been recently disturbed by man or fires. The vegetation in places is quite luxuriant, especially the herbaceous flora. The principal trees of the forest are oaks, hickory, chestnut, tulip tree, basswood and gum. Maple and beech occupy the lower slopes along the narrow ravines. Sourwood, red maple, sassafras, dogwood, and laurel are the principal species forming the undergrowth. $700-900 \mathrm{ft}$.; dissected.

Athens $\ddagger, 12 \mathrm{mi}$. west, B. \&. O. R. R.; $1 \frac{1}{2}$ mi. N.E. Mineral, Athens County.H.W. Dean.

Maps: Zaleski and Athens quadrangle.

*Stony Creek State Forest. (D3.) 6000 acres of second growth forest ranging in age from 25 to 75 years; most of the original forest was removed years ago. The young growth is a mixed hardwood type, the various species of oaks preponderating. Principal trees are, in order of abundance: white oak, black oak, chestnut oak, scarlet oak, pignut, shellbark and mockernut hickories, tulip poplar, red maple, red elm, black gum, sassafras and chestnut. The area has been subjected to severe ground fires in the past, and many of the trees carry fire scars. Mammal life consists of cottontail rabbit, squirrels, chipmunk, woodchuck, skunk, and red fox. 600 to $1000 \mathrm{ft}$.; dissected.

Chillicothe $\ddagger$, $10 \mathrm{mi}$. south, on Columbus and Portsmouth Pike (a).-Edmund Secrest.

Map: Waverly quadrangle.
*Mt. Logan State Forest. (D3.) Named after Logan, the Mingo Indian chief. This mountain is the scene of the Great Seal of Ohio. Contains 400 acres, second growth and original forest, mostly regrowth of approximately 60 years of age. Principal trees are white, black, scarlet and chestnut oaks, tulip poplar, red maple, sugar maple, black locust and black gum. Trees have been injured by the recurrence of fires. 700 to $1260 \mathrm{ft}$.; dissected.

Chillicothef, 2 mi. northeast. Base can be reached (a) over gravel roads.Edmund Secrest.

\section{Map: Chillicothe or Camp Sherman quadrangle.}

*Colerain Forest. (D3.) 1200 acres; a part of the school lands of the state. Second growth mixed hardwood forest. Principal trees: white, black, chestnut, scarlet, and red oaks, tulip poplar, hickories, black gum, sassafras, red maple. Forest badly injured by repeated burning. 800 to $1100 \mathrm{ft}$.; dissected; topography varied.

Chillicothef, $10 \mathrm{mi}$. northeast, on gravelled roads (a). Colerain Tshp., Ross County.-Edmund Secrest.

\section{Map: Chillicothe or Camp Sherman quadrangle.}

*Mound City Group. "Ne plus ultra of Mound Builders achievement." The group of 26 mounds is enclosed in an embankment which is nearly square in outline, with rounded corners. The enclosed area is 13 acres, and is included in a park of 57 acres. Land cleared; will be replanted with trees. Level, except for mounds. Under control of Ohio State Archaeological and Historical Society.

Chillicothe $\ddagger, 4 \mathrm{mi}$. north, within Camp Sherman.-Wm. C. Mills.

\section{Map: Chillicothe or Camp Sherman quadrangle.}

Headwaters Pigeon Runt. (C3.) Isolated area of Magnolia tripetala, associated with cherry birch (Betula lenta), hemlock, beech, sugar maple, and sourwood (Oxydendrum arboreum). Magnolia abundant; 4 to 9 in. in diameter. 
Surrounding forests of mixed oak, scrub pine, pitch pine, and shortleaf pine. Probably marks the most northerly limit of Magnolia tripetala in Ohio. Entire area characterized by precipitous outcrops of sandstone in many places extending $100 \mathrm{ft}$. high vertically. $600-950 \mathrm{ft}$.; hilly.

Jackson $\ddagger$, on B. \& $\mathrm{O}$. and Hocking Valley railroads; $7 \mathrm{mi}$. northwest, near Limerick, Liberty Township, Jackson County, Ohio.-F. W. Dean.

Maps: Waverly quadrangle; Jackson quadrangle.

${ }^{*}$ Dean State Forest. (D3.) Comprises 1500 acres. Characterized by broken hills, steep bluffs and sharp ridges. The entire area has been cut over during the flourishing era of the charcoal and iron ore industry in southeastern Ohio. The forest now is composed of second growth stands, consisting principally of mixed hardwoods. The following species are typical of the upper slopes and ridges: white, black, red, scarlet, chestnut, post, and blackjack oaks with scrub, pitch and shortleaf pines occurring in small quantities. On exposures well protected a more mesophytic forest occurs consisting of tulip tree, chestnut and basswood. The principal species forming the undergrowth are sorrel tree, dogwood, red maple, black gum, laurel, and sassafras. ' The entire area has been burned over several times prior to the time it came under the control of the State, and severely culled during the period of charcoal production. 600$1000 \mathrm{ft}$.; dissected.

Ironton $\ddagger$, $15 \mathrm{mi}$. north, Iron R. R.; $1 \frac{1}{2} \mathrm{mi}$. north Steece; Decatur Township, Lawrence County.-F. W. Dean.

Map: Ironton quadrangle.

*Roosevelt Park. (D3.) Tract of 15,000 acres, 5000 acres of which is under the management of the Board of Control of the Ohio Experiment Station, as a state forest, and 10,000 acres are under the Ohio Director of Agriculture. The forests of both tracts are under the management of the State Forester. The forest is second growth, badly in- jured in past years by fire. The area contains a large variety of trees, including a few conifers. Several small streams traverse the tract, some of which maintain their flow the year round. The topography is characterized by sharp ridges or backbones, rising in places into prominent peaks. Succession well illustrated.

Portsmouth $\ddagger, 16 \mathrm{mi}$. west, N. \& W. or B. \& O.; south end of tract is one mi. north of Buena Vista, on the Ohio River; north end of tract $1 \frac{1}{2} \mathrm{mi}$. south of Henley.

Fortsmouth $\ddagger, 16 \mathrm{mi}$. west (a) Cincinnati Pike to Henley; or (a) Buena Vista Highway to south end.-Edmund Secrest, State Forester.

Map: Otway quadrangle.

"Fort Hill" Prehistoric Earthworks, Forest and Stream Gorge. (B3 (b).) About two sq. mi. of original and second growth deciduous forest, including deep ravines and Niagara limestone gorge of the Baker Fork of Brush Creek. The upper levels of the hills are of black slaty shale of the Devonian. Rock cliffs are covered with mosses, ferns, Hepatica, columbines, etc. Stream moderate; shallow. The Fort Hill earthwork covers about 50 acres and the circumference is said to be $1 \frac{1}{2} \mathrm{mi}$. $840-1285 \mathrm{ft}$; sharp to precipitous.

Hillsboro $\ddagger$, on B. \& O. R. R.; east through Marshall and Carmel, and south to Mrs. Matthew's Hotel (R. F. D. 13 , Hillsboro) within the area (a); 18 mi.; or

Peebles $\ddagger$, on N. \& W. R. R.; north on Zanesville road $10 \mathrm{mi}$. to Mrs. Matthew's Hotel (a); Highland County, Ohio.Morten Carlisle.

Reference:

Howe's Historical Collections of Ohio, I: 922 .

Map: Bainbridge quadrangle.

Cedar Fallst. (C3.) Isolated limestone gorge along Cedar Run, one mi. north of Cedar Mills; species predominating on rock cliffs: white cedar (Thuja occidentalis), hemlock, and red cedar, abruptly succeeded by a forest of white, red, and black oaks, hickory, tulip, walnut, basswood, and sugar maple, occupying the surrounding slopes. 
Stream interesting, torrential; flowing through a rugged country. $550-1200 \mathrm{ft}$.; hilly.

Peebles $\ddagger$, on N. \& W. R. R.; $8 \mathrm{mi}$. south; Jefferson Township; Adams County, Ohio. $-F$. W. Dean.

Map: Peebles quadrangle.

\section{Interior Low Plateau}

*Serpent Mound Park. (C3.) 70 acres on the east bank of Brush Creek near the edge of the picturesque hill country of southeastern Ohio. Cliffs of White Dolomite (Niagara) with characteristic rock vegetation; hillsides bordering Brush Creek are wooded (deciduous forest); that part of the park occupied by the Serpent, the smaller mounds, and other relics of the prehistoric people, cleared and park-like. The principal feature is the Serpent effigy, a huge mound in the form of a serpent, $1348 \mathrm{ft}$. long, with an average width of $20 \mathrm{ft}$., and height of 4 to $5 \mathrm{ft}$. $680-780 \mathrm{ft}$.; rolling to precipitous.

Peebles $\ddagger$ (N. \& W. R. R.), 7 mi. N.W. (a).

Hillsboro $\ddagger$ (B. \& O. R. R.), $16 \mathrm{mi}$. S.E. (a). Drive from Hillsboro "of surpassing beauty."

Owned by The Ohio State Archaeological Society, as trustee of the State.

\section{References:}

Cole, W. H. Map and Guide to the Great Serpent Mound, Adams County, Ohio. (Gives historical summary; description of park and of routes to the park.) Ohio State Archaeological Society.

Randall, E. O. The Serpent Mound, Adams County. Published by The Ohio State Archaeological Society.

Howe, Henry. Historical Collections of Ohio, I, 233-234 (1896).

Map: Bainbridge quadrangle.

\section{II1. Lake Section of the Central Lowland Province}

\section{A. Lake Shore Areas}

Mentor Marsh. (B3.) This marsh extends about $6 \mathrm{mi}$. along the Lake Erie shore west of Fairport Harbor, Lake County. The marsh was formerly the river bed of Grand River which now empties into the Lake at Fairport. It is bordered by forests of chestnut, elm, oak, basswood, and maple. The marsh fiora includes cat-tails, marsh grasses, marsh mallows, and pond lilies. The fauna of the marsh includes muskrat, mink, otter, fox squirrel, raccoon, and numerous water birds, especially in the migrating seasons. $580 \mathrm{ft}$.

Cleveland $\ddagger$, $20 \mathrm{mi}$. east Willoughby via New York Central or C. P. \& E. Electric; $7 \mathrm{mi}$. northeast on paved road to Mentor Park where marsh begins.$F$. N. Shankland.

\section{Map: Mentor quadrangle.}

Oak Point. (B4.) Area on Lake Erie at mouth of Beaver Creek. Contains drowned stream swampy flats, three clay hills with swampy and marshy conditions between them, the hills covered with trees, mostly oak; one pond of considerable dimensions formed at time trolley line was put through. Lake encroaching upon shore and swamp rather more rapidly than elsewhere along the shore of this region. Presents many problems for the ecologist. $580 \mathrm{ft}$.; level to rolling.

Lorain $\ddagger$, $5 \mathrm{mi}$. west, Lake Shore Electric, Oakpoint, Lorain County.-Lynds Jones.

\section{Map: Vermilion, Oberlin quadrangles}

Bay Point. (B3.) A narrow peninsula in Lake Erie, with sand dunes, ponds, ridges, low prairie, filled pond forest in the process of succession, sandy shore as well as rocky shore. Next to Cedar Point, the best illustration of dunes, ridges and ponds in process of formation within $60 \mathrm{mi}$. $580 \mathrm{ft}$.

Sandusky $\ddagger$ N.W. across bay. Ottawa County.-Lynds Jones.

Cedar Point. (B3.) A tract of about 70 acres between Beimiller's Cove and Lake Erie includes the best sand dune section on the Point. Typical sand dune and swamp vegetation.

Cedar Pointf, Erie County.-J. $H$. Schaffiner.

\section{Map: Sandusky quadrangle.}

Inscription Rock. A large block of limestone broken off by the glacier from the rock near by. Probably the best example of Indian picture writing in America. 
Kelleys Island, south shore, $\frac{1}{4} \mathrm{mi}$. from steamer dock. $-E$. L. Moseley.

\section{Reference: \\ Howe, Henry. 1896. Historical Col- lections of Ohio, I: $576,588$.}

\section{B. Interior Areas of The Lake Section}

Chagrin Valley Forest. (B3.) About 500 acres along Gully Brook, beginning at Chagrin River and running westward two miles to Deep Valley. Deciduous forest; many rare wild flowers. Valuable for the number and variety of small birds, such as migrating warblers and sparrows, and rare resident species including seven kinds of hawks and three of owls. $600-780 \mathrm{ft}$.; rolling to sharp.

Clevelandf, $19 \mathrm{mi}$. east on Euclid Avenue; Cleveland, Painesville \& Eastern Electric to Stop 35, then $\frac{1}{2} \mathrm{mi}$. south.

Willoughby, Iake County; Ohio.$F$. N. Shankland.

Map: Mentor quadrangle.

*Park Area of Cleveland Metropolitan Park District. The park district includes almost all of Cuyahoga County; some 10,000 acres are included in the contemplated park area, 3600 acres of which have been acquired to date (April, 1923). Cleveland is almost surrounded except on the lake front by a natural park area, which lies 15 to $30 \mathrm{mi}$. distant from the center of the city. It consists of the valley of the Rocky River on the west, the valleys of Tinker's Creek and Chippewa Creek on the south and southeast, and of the valley of the Chagrin River on the east. These streams have cut valleys varying in depth from 100 to $350 \mathrm{ft}$. In places the bottom land has been cleared, but as it is subject to overflow it is of little use as agricultural land. The valley slopes are largely forested. 580 to $1100 \mathrm{ft}$.; dissected, abrupt. The following are separate portions of the park area:

(1) Part of Rocky River Valley. (B3.) A tract of 1000 acres extending up the river from Lake Erie for a distance of $5 \mathrm{mi}$. This is a gorge-like valley some $140 \mathrm{ft}$. deep having steep wooded slopes.

(2) The Chippewa Creek Region. (B3 and D5.) A tract of 1400 acres on the west bank of the Cuyahoga River some $15 \mathrm{mi}$. from Lake Erie. This area is very much dissected and includes Chippewa Creek gorge; it is largely forested. The gorge contains large loose sandstone boulders, some as much as 30 or $35 \mathrm{ft}$. long.

(3) Tinker's Creek Region. (B4.) This tract of 700 acres lies about $15 \mathrm{mi}$. southeast of Cleveland. It is rugged forested region and includes Bedford Glens, a gorge of Tinker's Creek cut to a depth of $150 \mathrm{ft}$.

(4) Whip's Ledge. (D5.) This is an area of 250 acres covering a forested hill slope $350 \mathrm{ft}$. in height and a conglomerate ledge.

Cleveland†.-E. L. Fullmer.

Maps: Cleveland, Berea, Chagrin Falls, Euclid, Mentor.

*Crystal Park. (D5.) Wooded gorge of Black River; 26-30 acres. Botanically interesting; some streamside and swamp vegetation; rock species, etc. Contains Elyria Caves.

Elyriał, Lorain County.-M. $M$. Metcalf.

Map: Oberlin quadrangle.

*Oberlin Arboretum and adjacent refuge area. (H8.) About 60 acres. Open deciduous forest (14 acres); open fields; small stream. Area to be planted; planting limited to Ohio trees and shrubs.

Oberlin $\ddagger$ Lorain County.-M. $M$. Metcalf.

\section{Map: Oberlin quadrangle.}

*Oberlin Municipal Forest. (H8.) About 65 acres. Established for the protection of the potable water supply of the city. Native beech-maple woodland of 20 acres. Of interest from the aspect of succession. About 10 acres of natural regeneration following clear cutting; about 35 acres reforested artificially with hardwood and coniferous species. $850 \mathrm{ft}$.; level.

Oberlinf, 6 mi. west, N. Y. C. R. R.; $1 \frac{1}{2}$ mi. Kipton (w). Lorain County.Edmund Secrest.

Map: New London, Vermilion quadLangles.

Swift's Hollow. (B3, D5.) About 1000 acres; includes an oxbow gorge of Vermilion River, deep narrow gorges of side streams. Contains the most extensive cedar, white pine, and hemlock growths of the whole region. $600-750 \mathrm{ft}$. sharp.

Oberlin $\ddagger, 8 \mathrm{mi}$. N.W.

Birmingham $\ddagger$, 3-4 mi. N. N.E.

Lorain $\neq, 5$ mi. S.E. Lorain County.Lynds Jones.

Map: Vermilion quadrangle. 
Mesophytic Forest, Breeding Place for Great Blue Herons. About 30 acres; deciduous forest; used as nesting place by several hundred great blue herons; about 600 nests, some of the largest trees containing about 25 nests.

Fremont $\ddagger$, 8 mi. west-northwest.

Toledo $\ddagger$, 25 mi. east-southeast; Lake Shore Electric, to Hessville. Heronry about one mi. north from Electric line, and one mi. west of Hessville (a). Sandusky County, Ohio.-E. L. Moseley.

\section{Maps: Elmore and Fremont quad- rangles.}

\section{The Till Plains of the Central Lowland Province}

*Buckeye Lake and Bog†̣. (B4.) This lake is state-owned in its entirety and one of the state parks. It was originally a small lake lying in a swampy swale of land, and artificially increased to its present dimensions in order to furnish water for feeding the Ohio and Erie canal. Reservoir commenced in 1828; completed in 1832; enlarged in 1836. State-owned property- 4000 acres of water and 100 acres of abutting land and islands. Forty species of fish recorded, all but two native.

The part of greatest ecological interest is Cranberry Marsh, a floating island cranberry-sphagnum bog in Buckeye Lake. Topography surrounding the lake is low hills (morainal) and wide shallow valleys. The original lake was a glacial finger lake, a part of Jonathan Creek; waters sluggish, basin $7 \mathrm{mi}$. long, average width $\frac{1}{2}$ mi.; average depth 6-8 ft.; lake is post-glacial and quite young. Bordering the lake to the north is a hardwood grove of about 10 acres. In the lake are numerous islands of which Cranberry Marsh is the largest and ecologically the most interesting. It is a cranberrysphagnum meadow surrounded and invaded by a hardwood tree zone, comprising in its entirety approximately 45 acres. $900 \mathrm{ft}$.

Columbus $\ddagger$, 30 mi. east, Ohio Electric, Hebron, Licking County; two mi. south, Buckeye Lake spur of Ohio Electric, Buckeye Lakeł.-Freda Detmers, E. N. Transeau, Division of Fish and Game, Dept. Agr.

\section{Reference:}

Detmers, Frederica. 1912. An Ecological Study of Buckeye Lake. Proc. Ohio State Acad. Sci., Sp. Paper no. 19.

Maps:

Thurston and Thornville quadrangles.

Map "made under the direction of the Ohio Canal Con:mission", Dept. Public Works.

*Radnor Heronry. (C3.) A small area of wooded swamp (the best part of it probably less than 10 acres) in which thirty or more pairs of the Great Blue Heron are nesting. A mixed growth of large oaks, maples, and poplars, together with smaller trees. Flora very rich and varied. Miscellaneous bird fauna very rich. Swamp very promising for microscopic fauna and flora, but has not been examined. Amount of water and number of mosquitoes make area undesirable for general park purposes; interest essentially scientific. $960 \mathrm{ft}$.; level.

Marion $\ddagger, 17 \mathrm{mi}$. south, or Delaware $8 \mathrm{mi}$. north, Hocking Valley R. R. or C. D. \& M. Electric; $2 \frac{1}{2}$ mi. N.E. (w or a) Radnor (Meredith) Station, Delaware County.-Edward L. Rice.

Map: Delaware quadrangle.

*Indian Lake. (B2.) A state park, formerly known as Lewiston Reservoir. The larger islands were sold under act of the Ohio Legislature. Water acreage 6134, and 200 acres of bulk-heads, islands, and margin; average depth, $8 \mathrm{ft}$.; not polluted. 'Thirty-seven species of fish recorded, all but two native. 1000 ft.; level.

Bellefontaine $\ddagger$, $12 \mathrm{mi}$. N.W. Russels Point or $14 \mathrm{mi}$. N.W. to Lakeview, Ohio Electric or Toledo and Ohio Central R. R.-Division of Fish and Game, Ohio Dept. Agr.

\section{Maps:}

Alger, Bellefontaine quadrangles.

Map "made under the direction of the Supt. of Public Works." 
${ }^{*}$ Lake Loramie Park. (B2.) Formerly Loramie Reservoir. A natural lake augmented by retaining dyke; reservoir completed in 1844 . Acreage in water at weir level is 1800 acres; area of islands and bulk-head 100 acres. Average depth $6 \mathrm{ft}$.; no pollution. Thirty-seven species of fish recorded, all but two native. Similar to Buckeye Lake, but no floating island or cranberry bog. $950 \mathrm{ft}$.

Minister (Western Ohio Electric) $3 \mathrm{mi}$. south, Shelby County.

Versailles, 7.5 mi. E.N.E., C. C. C. \& St. L.; Houston, $8 \mathrm{mi}$. north: one mi. N.E. Loramie.

Osgood (B. \& O.), 6 mi. east; one mi. N.E. Loramie.-Lynds Jones, Division of Fish and Game, Dept. Agr.

\section{Maps:}

Loramie quadrangle.

Map "made under the direction of the Ohio Canal Commission"; Supt. Public Works.

\section{*Lake St. Mary's. (B2.) A state} park; a great artificial lake, about 16,000 acres, in Auglaize and Mercer counties, on the watershed; $9 \mathrm{mi}$. long by 2-4 mi. wide; average depth $8 \mathrm{ft}$. Water acreage 14,248; margins and islands 1500 acres. Reservoir commenced in 1837; completed in 1844. Flooded land was about onehalf prairie and one-half forest, mostly oak. Marshy shores, densely overgrown with aquatic vegetation. Swamp about $15 \mathrm{mi}$. long. Most of the water fowls that pass over Ohio in their migrations may be found here; eagles, hawks, etc.; many fish, 37 species recorded, all but two native. The Division of Fish and Game maintains an inland hatchery on the eastern side of the lake. $880 \mathrm{ft}$.

St. Mary's $\ddagger$, Auglaize County, at east end of lake.

Celina $\ddagger$, Mercer County, at west end of lake.-Charles Dury, Division of Fish and Game, Dept. Agr.

\section{References:}

Howe, Henry. 1896. Historical Collections of Ohio, II: 235 (picture showing condition in 1846); 239-240.
Dury, Charles. 1922. Jour. Clin. Soc. Nat. Hist.

Maps:

Celina, Spencerville, St. Henry quadrangles.

Map "made under the direction of the Ohio Canal Commission"; Dept. Public Works.

Cedar Swampt. (B3.) A strip of swamp land several miles long and averaging $\frac{1}{4} \mathrm{mi}$. wide, bordering Cedar Creek. This little stream has quicksand bottom, flows swiftly, and is cold enough for trout and water cress to thrive. White cedar (Arbor Vitae) grows very thickly in the lowest portions; outlying trees are several species of ash, oak, and maple. Among the herbaceous plants are marsh marigold (Caltha palustris), ladies' slippers (Cypripedium reginae, C. parviflorum), Queen-of-the-Prairie (Filipendula rubra), wild Iris (I. versicolor), skunk cabbage (Symplocarpus foetidus), fringed gentian (Gentiana crinita), partridge berry (Mitchella repens), roundlobed Hepatica (H. triloba). Formerly a large colony of great blue herons had nests in the tallest trees; most of these are now gone. Rattlesnakes are still common. $960 \mathrm{ft}$.; level.

Urbana $\ddagger$ mi. south on Electric to "Woodburns"; one mi. west (w, a); Campaign County.-Florence Murdoch.

Map: St. Paris quadrangle.

*Bryan Forest Park. (B4 and D5.) 500 acres; includes part of the Niagara limestone gorge of the Little Miami River, and one of the most scenic areas of southwestern Ohio. About 200 acres is open field or pasture. Woodland is partly virgin, and is composed of a variety of species, principally chinquapin, white, red and black oaks, white, red and rock elm, honey locust, red cedar, tulip poplar, sycamore, black walnut, butternut, sugar and red maple, and Ailanthus. The area has been grazed, but not severely, and little damage has resulted. The cottontail rabbit, woodchuck, chipmunk, red, gray and fox squirrels, skunk and red fox may be found on the tract. 850 to $1000 \mathrm{ft}$.; rolling except for gorge.

Yellow Springst, two mi. east (a); Xeniał, $10 \mathrm{mi}$. N.W. (a) or traction; Springfield $\ddagger, 10$ mi. south (a) or traction; good gravel roads. Greene County.Edmund Secrest.

Map: Springfield quadrangle, 
Paint Creek Caves and Gorge†. (B3.) Gorge of Rocky Fork of Paint Creek; walls (Niagara limestone) precipitous, in some places more than $100 \mathrm{ft}$. high; covered with mosses, lichens, and ferns. Original forest with most of the native hardwoods; some evergreens-red cedar, arbor vitae, and hemlock. Stream is ideal for game fish, having deep pools of cool water; subject to turbulent drainage, but with cavernous protection.

Bainbridge, Ross County (D. T. \& I. R. R.), 5 mi. west (a, w).

Hillsborof, Highland County (B. \& O.), $13 \mathrm{mi}$. east on Cincinnati and Chillicothe Pike (a).-Louis Kuertz.

\section{Reference:}

Howe, Henry. 1896. Historical Collections of Ohio, I: 920.

Map: Bainbridge quadrangle.

"Hills and Dales" and "Moraine Park." (C4.) State Game Preserve. About 5000 acres of river bottoms, steep ridges of gravel, "kettle hollows," ravines and hillsides. Hilly portions wooded (deciduous forest); arable land; cleared 100 years ago. 760-1000 ft.; rolling.

Dayton $\ddagger$, south on Oakwood car line or Ohio Electric.-William B. Werthner.

Map: Waynesville quadrangle.

"Triangle Park." (C4.) About 145 acres along the Miami and Stillwater rivers; about 30 acres in almost virgin woodland. $780 \mathrm{ft}$.; rolling.

Dayton $\ddagger$, just north of corporation line.-William B. Werthner.

\section{Reference:}

Soil Survey of Montgomery County. U. S. Dept. Agr., Bur. Soils; in coöperation with Ohio Agr. Exp. Sta.

\section{Map: Dayton quadrangle.}

*Fort Ancient. (B4.) The largest prehistoric fortification in the Mississippi Valley. The park contains 310 acres of which about 100 acres are within the walls of the prehistoric fortification. The distance around the enclosure is about $3 \frac{1}{2} \mathrm{mi}$. The steep slopes bordering Randall and Cowen Runs, and the Little Miami River, are wooded. Xero-mesophytic slope forests on sandy and gravelly soil of river bluffs; mesophytic forests on ravine slopes. (Deciduous forests of type seen in Cincinnati Region.) 670-920 ft.; rolling to sharp.
Xeniał, 23 mi. S.W., Pa. R. R.; Ft. Ancient, Warren County.

Loveland $\ddagger$ (B. \&. O. and Pa. R. R.), 18.7 mi. N.E., Pa. R. R.; Ft. Ancient. Morrow $\ddagger 5.2$ mi. N.E., Pa. R. R.; Ft. Ancient.

Owned by the Ohio State Archaeological and Historical Society as trustees of the State.

\section{Reserences:}

Tichenor, W. C. 1916. A guide to Ft. Ancient.

Mills, William C. 1920. Map and guide to $\mathrm{Ft}$. Ancient.

(Both guides include a bibliography of Ft. Ancient.)

\section{Map: Morrow quadrangle.}

The Cincinnati Region (8 areas). The "Cincinnati Region," in which eight of the areas listed are located, includes a section of southwestern Ohio covered by the oldest drift exposed in Ohiothe Illinoian; and a small area covered by the Earlier Wisconsin, which here, however, is not so sharply delimited from the older drift as it is farther east and northeast. The region includes an area of deeply dissected territory adjacent to the Ohio, the Miami and Little Miami Rivers. These major valleys are deeply entrenched, and their valleysides high and steep. (Ault Park Forest, Camp Edgar Friedlander, and Fort Ancient.) Many of the minor tributaries enter through narrow steep-sided ravines, whose sometimes intermittent streams have numerous though low falls. (Typical streams well exhibited in Mt. Airy Forest area.) Farther from the larger streams, the peneplained and drift covered upland is little dissected; the land in consequence is poorly drained. This gives rise to particular soil types with which the very characteristic vegetation is correlated. (Goshen and Bethel Upland Hydrophytic Forest areas.) Intermediate areas of maturely dissected land, and areas on the older and dissected (Illinoian) terraces, where slopes are gentle, are clothed with mesophytic forests of the climax type. (Caldwell Park Forest, and Five-mile Creek Climax Forest.) All parts of the Cincinnati Region 
may be conveniently reached from Cincinnati. None is sufficiently remote from the effects of civilization to harbor any of the large mammals (except possibly a few foxes); the smaller mammals and the birds are abundant; fish of great variety abound in the Little Miami and its principal tributaries, which are among the purest streams of Ohio.

\section{References:}

Aiken, W. H. 1911. Catalogue of the ferns and flowering plants of Cincinnati, Ohio, and vicinity.

Braun, E. Lucy. 1916. The physiographic ecology of the Cincinnati Region. Ohio Biol. Surv. Bull. 7.

Braun, E. Lucy. 1917. The vegetation of conglomerate rocks of the Cincinnati Region. Plant World, 20: 380-392.

Braun, E. Lucy. 1921. Composition and source of the flora of the Cincinnati Region. Ecology, 2: 161-180.

Drake, Daniel. 1815. Natural and statistical view, or picture of Cincinnati and the Miami country, illustrated by maps.

Goodman, A. L., Allen, E. R. and Phillips, S. W. 1917. Soil Survey of Hamilton County, Ohio. U. S. Dept. Agr., Bur. Soils. In coöperation with Ohio Agr. Exp. Sta.

Fenneman, Nevin M. 1916. Geology of Cincinnati and vicinity. Geol. Surv. Ohio, 4th Series, Bull. 19.

Langdon, F. W. 1879. A revised list of Cincinnati birds. Jour. Clin. Soc. Nat. Hist., I, no. 4: 167-193.

\section{Maps:}

Cincinnati (double) or East Cincinnati and West Cincinnati, Hamilton, Mason, Felicity, Batavia.

Goshen Upland Hydrophytic Forest $\dagger$. (1-(B3); 2-(C3).) (1) About 60 acres of original forest on one of the flattest areas of the Illinoian drift (Clermont silt loam type). Intermittent pools. Hydromesophytic deciduous forest; forest openings; lichens and mosses. One of the few areas of virgin forest of this type remaining. Grazed.
(2) About 40 acres of 50 year old second growth forest, pure stand of pin oak, following cutting. Rich undergrowth of characteristic shrubs and herbs. No cutting or grazing; untouched.

Fauna of both areas similar: grey squirrels, birds, frogs, tree-toads, snapping turtles, crayfish. $890 \mathrm{ft}$.; level.

Cincinnatit, 15 mi. N.E., C. M. \& B. Traction, Milford $\ddagger$; mi. east, C. M. \& B., Goshen Station; 100 ft. N.E. (w) first area; $\frac{1}{2} \mathrm{mi}$. west (w) second area; Clermont County, Ohio.-E. L. Braun.

Map: Batavia quadrangle.

Bethel Upland Hydrophytic Forest and Meadowt. (C3 and B4.) About 50 acres of original and second growth hydro-mesophytic forest and meadow. No undergrowth except mosses in denser parts; forest openings with rich and characteristic herbaceous growth. Clermont silt loam soil; almost covered by standing water in spring. $910 \mathrm{ft}$.; level.

Cincinnatił, $28 \mathrm{mi}$. S.E., C. G. \& P. Traction, Bethel ; $1 \frac{1}{2}$ mi. S.E., C. G. \& P., Cordrey's Crossing; $\frac{1}{8} \mathrm{mi}$. S.W. (w). Clermont County, Ohio.-E. L. Braun.

Map: Felicity quadrangle.

*Camp Edgar Friedlander Slope and Flood Plain Forest, and Prairie Openings†. (B4 and A4.) Boy Scout camp site containing 71 acres, about $\frac{2}{5}$ forested. The woods in the Boy Scout grounds "is to be left as a natural forest. We will not permit the cutting down of any of the timber." The title to the ground is permanent. Climax mesophytic forest, xero-mesophytic slope forest, flood plain forest, and prairie openings. Shows complete succession from bare bluff to mature forest. Typical prairie openings on precipitous river bluffs of Illinoian till (Cedar Cliffs). Flora includes bunch grasses and prairie dock, and several species not known elsewhere in Ohio. Fauna includes gray squirrel, chipmunk, cottontail rabbit, woodchuck, water birds and song birds, rich insect fauna. On Little Miami River, one of purest streams in Ohio. 540-700 ft.; rolling, sharp, and precipitous.

Cincinnatił, 20 mi. N.E., Pa. R. R. or auto; $\frac{1}{2}$ mi. east (w, a). Miamiville, Clermont County.-E. L. Braun. 
Map: East Cincinnati quadrangle.

Five-Mile Creek Climax Forest $\dagger$ (A4 and B4.) About 200 acres of virgin forest along upper part of Five-mile creek. Beech forest on flatter areas at ravine head; mixed mesophytic climax forest with characteristic undergrowth on gentle ravine slopes. Occasional steeper slopes forested with oaks. $650-800 \mathrm{ft}$; rolling.

Cincinnatif, $7.3 \mathrm{mi}$. east. C. G. \& P. traction; one mi. S.W. (w) Fruit Hill, Hamilton County.-E. L. Braun.

Map: East Cincinnati quadrangle.

*Cincinnati Water Worlss Forest $\dagger$. (A4 and D5.) About 400 acres; climax deciduous forest, flood plain, swamp, springs, small brook (moderate). Fauna of forest includes gray squirrels, skunks, ground hogs, rabbits, many birds. $500-600 \mathrm{ft}$.; rolling, locally sharp.

In Cincinnatif; C. G. \& P. traction; $\frac{1}{2} \mathrm{mi}$. north California, Cincinnati, Ohio. -E. L. Braun.

Map: East Cincinnati quadrangle.

*Ault Park Forest. (C4.) 205 acres, about half forested; small spring-fed streams. Has a fairly good beech forest; undergrowth considerably destroyed through recreation activities and "park improvements." $540-800 \mathrm{ft}$.; rolling.

In Cincinnati.-E. L. Braun.

Map: East Cincinnati quadrangle.

${ }^{*}$ Caldwell Park Horest. (B3.) 104 acres, about 75 in woodland; mesophytic forest, flood plain forest; clay bluffs. Stream badly polluted. $520-700 \mathrm{ft}$.; rolling to precipitous.

In Cincinnati, Millcreek Valley; $\frac{1}{2} \mathrm{mi}$. west Carthage.-E. L. Braun.

Map: Cincinnati quadrangle.

${ }^{*} M t$. Airy Forest. (B4, D3, H8.) A municipal forest of 1131.43 acres, about 250 acres in woodland; part of this grazed until 1912. Detached woodland areas representing mixed mesophytic forest, slope forests of mesophytic and xeromesophytic types; naturally reforesting areas. Approximately 450 acres have been reforested artificially with native hardwoods and with conifers (including cypress and larch); about 130 acres is tillable, and is used for raising hay and grain; of the remaining 300 acres, part will be left open and a part reforested. Streams small and intermittent but typical of the Cincinnati Region. 500$900 \mathrm{ft}$.; rolling to sharp.

Cincinnatif, $8 \mathrm{mi}$. northwest; within city limits.-Edmund Secrest, C. $H$. Meeds, E. L. Braun.

Map: West Cincinnati quadrangle.

\section{INDIANA}

\section{By Will Scott}

\section{GENERAL CONDITIONS}

\section{Topography}

The southern two-fifths of Indiana was slightly affected by glaciation and the northern three-fifths was covered with the Wisconsin ice sheet. The unglaciated portion is divided into seven physiographic regions whose boundaries run approximately north and south. Beginning with the east the names of these regions and their areas in sq. mi. are: Dearborn upland, 1925; Muscatatuck slope, 1875; Scottsburg lowland, 950; Norman upland, 2075; Mitchell plain, 1125; Crawford upland, 2900; and the Wabash lowland, 4900. Their names indicate the relative elevations; the Dearborn upland is about $1000 \mathrm{ft}$. above sea level; the Wabash lowland is near $500 \mathrm{ft}$. The Mitchell plain is the sink hole region of the state. It together with the eastern part of the Crawford plain, is the cave region containing Wyandotte, Marengo, Shawnee and other less notable caverns.

The Tipton till plain is a ground moraine with little variety in topography. It occupies the southern half of the glaciated area in the morainal and lake region. This consists of a small lacustrine area near Fort Wayne, and the Michigan lacustrine area, the Kankakee lacustrine area, the Valparaiso moraine and the Huron-Erie Saginaw interlobate moraine. The Michigan lacustrine area west of Gary consists of several parallel ridges which mark successive beaches of Lake Michi- 
gan. The Kankakee plain is a complex of outwashed plains, much of it formerly was marsh land. The interlobate moraine extending from the northeast part of the southwest for $100 \mathrm{mi}$. is a lake region of Indiana.

\section{Climate}

The average temperature in the state for January is $28^{\circ}$, southern part is $33^{\circ}$ and the northern part is $25^{\circ}$. The lowest state record is $-33^{\circ}$.

The July average is $75^{\circ}$ for the state, for the southern part is $79^{\circ}$ and for the northern part is $73^{\circ}$. The average maximum for June, July and August is $80^{\circ}$. The highest recorded temperature for the state is $111^{\circ}$. The average diurnal fluctuation is $15^{\circ}$ in winter and $20^{\circ}$ in the summer. The average rainfall for the state is about $40 \mathrm{in}$. In the north half one-tenth of this is snow and in the south half one-twentieth is snow. The rainfall in the north is less than $30 \mathrm{in}$. and in the south more than 40 in. In one small area it reaches 50 in. The average annual evaporation from exposed water surface is about $50 \mathrm{in}$. The state receives an annual average of about 2800 hours of sunshine. The daily average for December is $3 \frac{1}{2}$ hours and for July slightly more than 10 hours. The average growing season is 170 days. The station with the shortest growing season has 150 days and the extreme southwest part of the state has nearly 200 days. (See Visher, 1922. U. S. Weather Bureau summaries of Climatological data Nos. 67 and 68.)

\section{The original biota}

About seven-eighths of Indiana formed a part of the hardwood belt. The other eighth was prairie (Oak Grove Savanna). This occupied the northern part of the west side of the state and was continuous with the prairie region of Illinois (q.v.). The hardwood belt has been described under Ohio (q.v.).

\section{Local biota}

A. Sand area biota. (Lacustrine area south of Lake Michigan.) West of
Gary this is a series of low ridges alternating with long narrow shallow ponds both of which parallel Lake Michigan. "The ridges showed a series of biota: cottonwood, jack pine (of which there were several hundred acres immediately west of Gary), black oak, white oak and red oak. East of the city of Gary dunes began and skirted the Lake into Michigan. The dunes area is characterized by cacti and lizards. (See Shelford, Cowles, 1899, 1901.)

B. The Kankakee Marshes. (The Kankakee lacustrine.) The marshes of this area were among the most extensive in the middle west. It was drained by the Kankakee river which was a stream with great meanders and many broad shallow stretches. The most notable of these was called English lake, originally the largest water body in the state. It formed a great breeding place for aquatic birds and has a rather rich mammalian fauna. (See Butler, 1897; Hahn, 1908.)

C. Caves. The cave region extends from Crawford County on the Ohio River north about $125 \mathrm{mi}$. (See section on topography.) Wyandotte, Marengo, Shawnee, and Mayfields are the best known. A few hundred feet from the entrance of a cave is a habitat of absolute darkness, constant temperature $\left(52^{\circ}\right)$, and high humidity, and dependent upon the inwash from the surface for all basic organic food materials.

The characteristic animals of the cave are totally or partially blind and usually without pigment. The blind fish ( $\mathrm{Am}$ blyopsis spelaeus De Kay), the blind crayfish (Cambarus pellucidus Packard), the beetle (Anophthalmia tenius Horn) and the cave isopod (Caecidotea stygia Packard) are the most typical; in the twilight regions occurs the cave salamander (Eurycea lucifuga); bats in large numbers spend the winter in the caves. Eight species have been taken from Indiana caves (Hahn, 1908). The plankton forms are all epigean species. Almost any of the epigean fauna of the cave region may be taken in the caves except possibly the birds and some 
mammals. Banta recorded 110 species from Mayfield's cave. He classifies them as follows: cave exclusive, 10; permanent residents, 28 ; temporary residents, 24; visitors, 36; strays, 17 . (See Packard, 1888; Eigenmann, 1909; Banta, 1907; McIndoo, 1910; Scott, 1909; Hahn, 1908.)

d. Solution Ponds. The Solution Ponds of the Cave Region. The Solution Ponds of Southern Indiana are formed by the occlusion of the outlets of "sink holes." They are formed suddenly, a pond of some acres being formed sometimes in a few hours. This makes them ideal habitats in which to study the incidence and development of aquatic faunas. The size of the basin in which they lie, its slope, whether it is covered with woodland, grass, or thicket gives them great variety. Some are so large and permanent that they develop the fauna of small lakes, others are seasonal. These characteristics makes them the finest sort of material for the analysis of ecological factors.

e. Lakes. The lakes of Indiana do not differ markedly from others formed in the Pleistocene glaciation. They lie in lower latitudes than the other Pleistocene lakes of America. Many are already extinct. In a small area, lakes exhibiting various stages in the process of extinction may be found. Turkey lake is the largest, area about 5 sq. mi., and Tippecanoe the deepest (37 M.).

Probably twenty of these lakes are large enough to show thermal stratification in the summer. Of those examined about one-third exhaust the oxygen in the hypolimnion during the summer. The lakes are stratified by June first and the autumnal overturn occurs from late September to early November.

There have been more lakes destroyed in Indiana than exist at present. Plant deposition and marl deposits have been the most potent factors in this destruction. Erosion of outlets also has occurred but has played a minute part in the process. Since 1890, drainage has lowered the level of many lakes. This gradual destruction of lakes has resulted in swamps, the bogs of various types. A few examples may be cited. There is a tamarack swamp about $1 \frac{1}{2} \mathrm{mi}$. south of Leesburg. One mile north of North Webster a woodland lakelet almost extinct contains Umbria in enormous quantities. One mile south and a little east of Syracuse is a quaking bog formed in part by swamp loosestrife. Several woodland marshed with interesting odonate faunas are located near Bluffton.

The cypress swamps. The Wabash Lowland originally contained about 20,000 acres of cypress swamps according to Collett, 1874 (quoted by Hahn, 1908; Butler, 1897). They harbored the water hare (Lepus aquaticus) and formed nesting sites for the egret. They have been reduced by drainage and cutting until only a few small remnants remain, one near Vincennes and less than a half dozen in Gibson and Posey counties.

\section{PRESENT BIOTA}

The great till plain of central Indiana has little of the original flora and fauna left. The Kankakee region is rapidly changing. The Lake region has been discussed under the "Original Biota."

The unglaciated part of the state still holds a few patches of undisturbed timber. Much second-growth occurs.

The larger mammals (deer, bear, elk, etc.), the passenger pigeon, paroquet, and wild turkey have disappeared. The ruffed grouse and the pileated woodpecker are rare and limited to the wooded hills of the "knobstone area."

On the other hand, the rodents of the field, the sparrows, meadow lark and quail are more numerous than a century ago, due to the replacing of the forests with cultivated fields.

The Tippecanoe River is the only river in Indiana approximating primitive conditions. Much of its upper course has been unaffected by man except for fishing. Power is being developed in the last $40 \mathrm{mi}$. of its course. The principal southern tributaries of the Wabash have been damaged by the oil field waste. The West Fork of White River has been 
damaged by industrial waste and sewage. The Whitewater River has suffered little from pollution but its basin has been denuded of forests so that it is subject to floods.

The short streams that enter the Ohio between the Whitewater and the Wabash are not polluted and their fauna has not been changed in quality although the number of individuals of some species has been reduced.

\section{AREAS PRESERVED OR OF SPECIAL INTEREST}

Turkey Run State Park $\ddagger$. (A4.) This area is a virgin forest of 466 acres. It is traversed by Sugar Creek. The area is comparatively level except near the creek where it is cut by ravines. Along the ravines there are rocky sandstone ledges up to $80 \mathrm{ft}$. in height. The forest is of the white oak, tulip, sugar maple type. On the ledges of the creek is a fringe of hemlock and yew. Elevation $699 \mathrm{ft}$.

Marshall, Parke Co., C. I. \& W. R. R. Bus line $4 \mathrm{mi}$. North to park.-C. C. Deam.

*McCormick's Creek Canyon State Parkł. (D3.) Area 380 acres. The greater part is woodland, which was cut over many years ago. It is traversed by McCormick's creek, whose bed is 50 to $125 \mathrm{ft}$. below the surrounding country. The area is bounded in part by White River. The woodland is of the white oak-black oak type for the greater part. Elevation $560 \mathrm{ft}$.

Spencer, Owen County, Penna. R. R. Vincennes Div. Bus 3 mi. east to the park.-C.C. Deam.

Clifty Falls State Park. (D3.) Area 300 acres. This is a natural forest along the bluff of the Ohio River. It extends from the river valley to the top of the bluff. It receives its name from Clifty Creek which traverses it. The creek is a small one, but is interesting in that its water at one place falls $90 \mathrm{ft}$. The forest is of the beech-oak type. Elevation $376 \mathrm{ft}$.

North Madison $\ddagger$ or Madison $\ddagger$ Jeffer- son. County, Penna. R. R. Madison Div. (w) or (a) $3 \mathrm{mi}$. west to park.C. C. Deam.

*Clark County State Forest. (D3.) Area 2337 acres. Several hundred acres will be added as soon as the purchases can be validated. The state forest is in the "knob" area. About half of the area lies in the knobs at an elevation of from 800 to 1000 . The area was originally composed of several small farms. There were about 400 acres cleared when purchased, but all of this, except about 50 acres has been planted to forest or has grown up. The whole area was heavily cut over, but for eighteen years there has been no grazing and only one fire, which was of small extent. The forest is of the white oak-black oak type on the lower levels. The summit of the ridges are crowned with scrub pine (Pinus virginiana) and the chestnut oak (Quercus prinus). Beech is frequent in the extreme northwestern part. Elevation $520-1000 \mathrm{ft}$.

Henryville $\ddagger$, Floyd County, Penna. R. R., Louisville Div. or Interstate Traction Line. Walk one mi. north.C. C. Deam.

Vinegar Mills State Park. (D3.) Small park of beech, white oak and black oak along the bluffs of Muscatatuck River between Vernon and North Vernon. Region near park of great physiographic interest and beauty. Elevation $665 \mathrm{it}$.

North Vernon $\ddagger$, B. \& O. S.-W. R. R., Penna. R. R., Madison Div. or Big Four R. R. Greensburg Div.-C. C. Deam.

There is a considerable tract of wild land given to the city of Indianapolis adjacent to one of the city parks, by the late William Watson Woolen to be maintained as a bird preserve. $-W . L$. McAtee.

**Indiana University Farm. (A4.) This area is owned by Indiana University. Area 182 acres. It is a virgin forest of oak and tulip with a few walnut and hickory. Some of the trees are four feet in diameter. It is generally level being a part of the Mitchell plateau. The exceptions to this condition are a 
few sink holes, the gorge below the opening of Shawnee cave, and two places where the roof of the cave has collapsed and exposed the cave stream. The bottom of the gorge at the mouth of Shawnee cave is $105 \mathrm{ft}$. below the road above it. Most of the original flora remains and as a result includes several plants generally regarded as rare in this region. Hahn has discussed the vertebrates of the farm. Flevation $685-570 \mathrm{ft}$.

Mitchell $\ddagger$, B. \& O. S.-W. R. R. and Monon R. R. (a) or (w) to farm $3 \mathrm{mi}$. east.-Will Scott.

Grassy Creek. (D3.) This creek is a drainage line between the Barbee Lakes and Tippecanoe Lake. It is bordered by a narrow marsh that cannot be drained or pastured. Full of marsh plants and aquatics, marsh wrens, red winged black birds, rails, herons, bittern, muskrats and several species of turtles. Not preserved but cannot be damaged much on account of the lakes that it connects. Can be reached by boat from Tippecanoe Lakeł or Kuhn's Landing on Barbee Lakes. Boats may also be obtained at a bridge on a cross road just below Saw-mill Lake which is the lowest one of the Barbee group. Elevation about $800 \mathrm{ft}$.

Leesburg, Big Four R. R. or Winona Traction. (a) to Tippecanoe Lake 4 mi. or Kuhn's Landing $8 \mathrm{mi}$. east.Will Scott.

The Knobstone Area. (D3.) Brown County together with the Eastern part of Monroe and Laurence and the northwest part of Jackson form the most typical and least disturbed part of this area. Much of this region is covered with second growth timber. Different parts are burned over almost every year so that excellent material is furnished for the study of succession. The trailing arbutus and other rather rare plants occur in certain sections of it. Most of the remaining species of mammals and land birds of the state are to be found. Elevation $650-950 \mathrm{ft}$.

Helmsburg, Ill. Cent. R. R. $6 \mathrm{mi}$. (a) to Nashvilleł. Both in Brown County.$W^{r} i l l$ Scott.

The Cave Region. This lies wholly in the Mitchell Limestone and includes parts of the following counties; Munroe, Lawrence, Orange, Washington, Harrison, the Crawford. The following four caves are typical and easily reached.

Mayfields Cave. A small cave $5 \mathrm{mi}$. northeast of Bloomington, $\frac{1}{4} \mathrm{mi}$. in length. Banta, 1907, has described the fauna. A dozen other small caves may be reached from Bloomington.

Bloomington. Ill. Cent. R. R. Monon R. R.

**Shawnee Cave. (Donaldson Cave). (D3.) Located on University Farm described above. Two mi. have been mapped which is about as far as it is possible to go. Canvas boat is necessary for any extended examination. Blind fish, blind crayfish, blind isopods, beetles, spiders, cave salamanders. Part of the fauna has not been worked up. Location same as University Farm.

Marengo Cave. (D3.) This is a "show cave" about $\frac{1}{2} \mathrm{mi}$. long. It is listed because of the ease with which it can be explored.

Marengo, Crawford County. Southern R. R.

Wyandotte Caveł. (D3.) Rivals Mammoth Cave in extent. Three routes. Longest six hours walking. Guides at the cave. These are necessary. The cave has never been mapped and the fauna has never been collected in anything like completeness.

One of the interesting features of the cave region is the solution ponds that form above the underground drainage lines. They exhibit great variety in age, size, depth, surroundings and biota.

Corydon Harrison County, Southern R. R. 12 mi. west (a).-Will Scott.

\section{The vicinity of New Harmony, Indiana} (D3)

This is classic ground, and for that reason if for no other ought to be represented by a suitable reservation. It would, in fact, be my second choice. New Harmony was the residence, and base of activity, of Thomas Say, Le Seure, and other well-known naturalists, and is the type-locality of many species of fishes, turtles, insects and mollusks. The Prince Maximilian von Wied resided there during one entire winter, and published much valuable information on the plants and animals of the vicinity in his celebrated work Reise durch Nordamerika.-Robert Ridgway.

Buzzards Roost. There has been considerable agitation for a Dune Park near Chestertin (North) a state reservation, and this worthy project should be put through so as to preserve for all time some of this unique and interesting area, as a recreational and educational resource for the citizens. A large section of typical cypress swamp near Vincennes 
(S.E.) also should be reserved before it is too late.

\section{BIBLIOGRAPHY}

Banks, N. 1906. A Preliminary List of the Arachnids of Indiana with Keys to the Families and Genera of Spiders. 31st Ann. Rept. Ind. Dept. Geol. and Nat. Res., pp. 715-747.

Banta, A. M. 1907. The Fauna of Mayfield's Cave. Pub. Carn. Inst. Wash. No. 64.

Blatchely, W. S. 1891. A Catalogue of the Butterflies Known to Occur in. Indiana. 17th Rept. Ind Dept. Geol. and Nat. Res., pp. 365-408.

Blatchely, W. S., and Daniels, L. E. 1901. On Some Mollusca Known to Occur in Indiana. A supplementary paper to Call's catalogue. 26th Ann. Rept. Ind. Dept. Geol. and Nat. Res., pp. 577-628.

Blatchely, W. S. 1901. Orthoptera of Indiana. 29th Ann. Rept. Ind. Dept. Geol. and Nat. Res., pp. 123-471.

Blatchely, W.S. 1910. The Coleoptera of Indiana. Ind. Dept. Geol. and Nat. Res. Bull. No. 1.

Bollman, C. H. 1888. A Catalogue of the Myriopoda of Indiana. Proc. U. S. Nat. Mus. Vol. II, pp. 403-410.

Butler, Amos. W. 1897. The Birds of Indiana. Rept. Ind. Dept. Geol. and Nat. Res.

Call, R. E. 1899. A Descriptive Illustrated Catalogue of the Mollusca of Indiana. 24th Ann. Rept. Ind. Dept. Geol. and Nat. Res., pp. 337-535 $+78 \mathrm{pl}$.

Cowles, H. C. 1899. 'The Ecological Relations of the Vegetation on the Sand Dunes of Lake Michigan. Bot. Gaz., Vol. 27, pp. 95-117, 167-202, 281308, 361-391.

Cowles, H. C. 1901. The Plant Societies of the Vicinity of Chicago. Bull. 2, Geog. Soc. Chi.

Deam, Chas. C. 1921. Trees of Indiana. Ind. Dept. Con. Pub. 13.

Evermann, B. W., and Clark, H. W. 1920. Lake Maxinkuckee. Ind. Dept. Cons. Pub. No. 7.

Greene, F. C. 1908. Caves and Cave Formation of the Mitchell Limestone. Proc. Ind. Acad. Sci., 1908.

Hahn, W. L. 1908 . Notes on the Mammals and Coldblooded Vertebrates of the Indiana University Farm, Mitchell Indiana. Proc. Nat. Mus., Vol. 35.

Hahn, W. L. 1908. The Mammals of Indiana. 33rd Ann. Rept. Ind. Dept. Geol. and Nat. Res., pp. 419-654.

Hay, O. P. 1894. The Lampreys and Fishes of Indiana. 19th Ann. Rept.
Ind. Dept. Geol. and Nat. Res., pp. 147-246.

Hay, O. P. 1891. Batrachians and Reptiles of Indiana. 17th Ann. Rept. Ind. Dept. Geol. and Nat. Res., pp. 412-602.

Lyon, M. W., Jr. 1922. Notes on the Mammals of the Dune Region of Porter County, Indiana. Proc. Ind. Acad. Sci., 1922, pp. 209-221.

McIndoo, N. E. 1910. The Biology of the Shawnee Cave Spiders. Biol. Bull., Vol. 19, pp. 303-323.

Mills, W. M. A Physiographic and Ecological Study of the Lake, Eagle (Winona Lake) Region, Indiana. 28th Ann. Rept. Geol. and Nat. Res., pp. 379-396.

Packard, A. S. 1873. On the Cave Fauna of Indiana. 5th Ann. Rept. Trus. Peab. Acad. Sci. Salem, 1872, pp. 93-97.

Scott, Will. 1909. An Ecological Study of the Plankton of Shawnee Cave, with notes on the Cave Environment. Biol. Bull., Vol. 27, pp. 386-406.

Scott, Will. 1910. The Fauna of Solution Pond. Proc. Ind. Acad. Sci., 1910.

Scott, Will. 1916. The Lakes of the Tippecanoe Basin. Ind. Univ. Studies. No. 31.

Shelford, Victor E. 1911. Ecological Succession. III. A Reconnaissance of its Cause in Ponds with Particular Reference to Fish. Biol. Bull., Vol. 22 , pp. 1-39:

Shelford, Victor E. 1911. Ecological Succession. II. Pond Fishes. Biol. Bull., Vol. 21, pp. 127-151.

Sanders, Nell Jackson, and Shelford, V. E. 1922. A Quantitative and Seasonal Study of a Pine Dune Animal Community. Ecology, Vol. 3, pp. 306-320.

Visher, Stephen S. 1922. The Geography of Indiana. Ind. Handbook of Geology, pp. 7-56. Ind. Dept. Cons.

\section{MICHIGAN}

By I. R. Dice, Lynds Jones (Birds), and Helen 'T. Gaige (Reptiles and Amphibians)

\section{TOPOGRAPHY AND CLIMATE}

Most of the topographic features of Michigan are due to the action of the former continental glaciers in forming moraines, drumlins, outwash plains, lakes and other typical glacial features. Subsequent erosion has modified this glacial topography only slightly. The 
relief is in general very moderate, the highest point in the state, in the Porcupine Mountains of Ontonagon County, being only $1421 \mathrm{ft}$. above the level of Lake Superior.

The two peninsulas of which the state is composed are nearly surrounded by the waters of the Great Lakes: Superior, Michigan, Huron and Erie, giving a great length of shore line. At many places along these shores are developed extensive sand dune areas. The presence of the great lakes profoundly modifies the climate of the state. The state is well drained, with numerous rivers and small streams. The drainage of Michigan is all into the St. Lawrence River system, with the possible exception of a few small lakes in the western part of the upper peninsula.

\section{FLORA}

The alternating tracts of clay, of sand, and of gravel soil, and the varying features of hill, bottomland, and of swamp, marsh, or bog, due in general to the effects of the former glaciers, result in much overlapping of the various vegetation types in the state.

Further, the state is, to a considerable extent, the meeting place of the eastern deciduous hardwood forest and of the northern coniferous forest, and a considerable part of the state is occupied by the transition between these two types of vegetation.

On the uplands of Isle Royale in Lake Superior and on the northern part of Keewenaw Peninsula the Canadian coniferous forest is dominant, the most common trees being the balsam fir (Abies balsamea), white spruce (Picea canadensis), and paper birch (Betula alba papyrifera). Isolated patches of this type of forest occur south as far as the northern part of the southern peninsula.

On the uplands with good soil in the northern peninsula the dominant trees are hard maple (Acer saccharum), yellow birch (Betula lutea), and linden (Tilia americana). On lower ground with more moisture the hemlock (Tsuga canaden- sis) becomes common in the hardwood forest, and may on lower slopes form pure stands. The white pine (Pinus strobus) formerly occurred commonly as large isolated trees in the hardwood forest, and sometimes as a pure stand covered considerable areas.

In the central and eastern part of the northern peninsula there are extensive sand areas dominated by pines, mostly jack pine (Pinus banksiana), though much red pine (Pinus resinosa) and some white pine occurred. In general, the pines seem to be successional stages in the development of hardwood forest, which is the climatic climax of the state, and which when established prevents the development of pine seedlings. The jack pine grows on the poorest soil, while white pine is a later stage requiring quite rich soil, and red pine is intermediate between these two in its requirements. On very sandy soil the hardwood forest is extremely slow in replacing the pines, which then persist for a long time.

On protected wet slopes in this peninsula the arbor-vitae (Thuja occidentalis) often formed extensive swamps, and some of the trees reached a very large size. In the lowlands there were very extensive bogs covered by tamarack (Larix laricina), black spruce (Picea mariana), or arbor-vitae. Sphagnum (Sphagnum spp.) and bog sedge (Carex filiformis) are very characteristic of the open parts of these bogs, and a number of characteristic shrubs occur, such as the leather-leaf (Chamaedaphne calyculata), Labrador tea (Ledum groenlandicum), and cranberry (Vaccinium oxycoccus).

The forests of the northern part of the southern peninsula are quite similar to those of the northern peninsula, except that beech (Fagus americana) comes into the hardwood forest as a prominent tree, becoming more common to the southward, while the yellow birch and hemlock tend to drop out to the southward.

In the southern peninsula, particularly in the middle portion, there are very extensive tracts of sand, originally covered mostly by pines. However, 
there were also extensive tracts of hardwood on the richer soil here, and many extensive bogs. The wet lowland forest in this region, as in the upper peninsula, was usually dominated by arbor-vitae, white spruce, tamarack, black spruce, or black ash (Fraxinus nigra).

In the southern part of the southern peninsula the drier upland forests were largely dominated by oaks (especially Quercus rubra and Q. alba) and hickories (especially Carya alba, C. ovata, and C. glabra), while hard maple and beech were confined mostly to the heavy clay soils. The extensive lowland hardwood forests, especially on the flood-plains of rivers and lakes, were dominated largely by such trees as red maple (Acer rubrum), swamp oak (Quercus palustris), white elm (Ulmus americana), linden, black ash, white ash (Fraxinus americana), and butternut (Juglans cinerea). In these forests are found a few representatives of the southern hardwood forest, such as the tulip tree (Liriodendron tulipifera), sycamore (Platanus occidentalis), and gum (Nyssa sylvatica). Numerous tamarack bogs occurred, mostly in the glacial depressions, but on a much less extensive scale than further north. In many places on lake and river shores occurred dense thickets composed of such shrubs as willow (Salix spp.), alder (Alnus incana), buttonbush (Cephalanathus occidentalis), and redosier dogwood (Cornus stolonifera).

Numerous meadows or prairies were originally present in this southern part of the state, some of these being extensions of more extensive prairies in the states to the south and southwest. Some of these prairies were certainly due to frequent fires, while others had apparently developed following the filling up of beaver ponds and of lakes. A characteristic vegetational feature in this part of the state were the "oak openings," which were large or small open tracts covered with scattering oaks (Quercus macrocarpa or Q. velutina), and sometimes having a thick underbrush of hazel (Corylus).

The vegetation of Michigan is now much modified from the primitive. In the southern part of the lower peninsula much of the land is under cultivation and only a few tiny patches of native forest remain. The timber in the woodlots is mostly second growth, and is frequently in bad condition from pasturing and heavy cutting. Many swamps and bogs have been drained. The streams are often badly polluted by sewage and industrial wastes, and the aquatic conditions are therefore much modified.

Forest fires and destructive lumbering have destroyed most of the native forests in the northern part of the state, also, although numerous areas only slightly modified can still be found in the northern peninsula. The pine forests of both peninsulas are now practically all cut or burned. Hundreds of square miles of the sandy plains are now covered with a low growth consisting of such forms as sweet fern (Myrica asplenifolia), blueberries (Vaccinium spp.), bracken fern (Pteris aquilina), and June berry (Amelanchier canadensis). Other extensive areas are covered with sapling forests of aspen (Populus tremuloides and $P$. grandidentata), and some areas have grown up again to small jack pines.

On richer soil in all parts of the state a shrub stage is common following clearings and fires; this includes such forms as red raspberry (Rubus idaeus aculeatissimus), blackberry (Rubus allegheniensis), pin cherry (Prunus pennsylvanica), and sumac (Rhus glabra). Commonly this is followed by a sapling growth of the aspens, and in the north commonly also by the white birch (Betula alba papyrifera).

\section{FAONA}

The animal life of Michigan, like the vegetation, shows a series of transitions from north to south. Contrary to what might be expected, the Straits of Mackinac, between the two peninsulas of which the state is composed, does not appear to act as a very effective barrier to animal or plant distribution. 


\section{Mammals}

The principal native mammals in the Canadian conifer forest of Isle Royale are the marten (Martes americana), Bonaparte weasel (Mustela cicognanii), deer-mouse (Peromyscus maniculatus), red squirrel (Sciurus hudsonicus), snowshoe hare (Lepus americanus), moose (Alces americanus), and rarely caribou (Rangifer caribou).

In the hardwood forests of the mainland of the northern peninsula of Michigan all these forms occur except the caribou, and numerous forms occur which do not occur on the island. The deer-mouse (Peromyscus maniculatus gracilis) and the red squirrel (Sciurus hudsonicus loquax) are slightly different from those occurring on Isle Royale. The bob-tailed shrew (Blarina brevicauda talpoides) is very common in some of the wetter parts of the forests and in swamps. Several bats occur in summer, of which the most common seems to be the little brown bat (Myotis lucifugus). The black bear (Ursus americanus) and the timber wolf (Canis lycaon) are numerous, and so is the red fox (Vulpes fulva). The fisher (Martes pennanti) now is rare, though formerly more common; a few bob-cats (Lynx rufus) occur; and the skunk (Mephitis hudsonica) is common. The Canada lynx (Lynx canadensis) is reported to have formerly been numerous, but it is now practically extinct. The redbacked vole (Evotomys gapperi) is common, while the jumping-mouse (Zapus hudsonius) is less common in the forest than it is in grass and sedge meadows. The porcupine (Erethizon dorsalum) is abundant, but woodchucks (Marmota monax canadensis) are few in the forest. The eastern chipmunk (Tamias striatus lysteri) is numerous, but the western type of chipmunk (Eutamias minimus borealis) prefers the more open brush, and probably was never common in the dense hardwood forests. The northern flying-squirrel (Glaucomys sabrinus macrotis) is fairly common, though not often seen. The
Virginia deer (Odocoileus virginianus borealis) is common, but the moose is rare.

In addition to these forms living in the forest proper, the star-nosed mole (Condylura cristata) occurs principally in marshy places, as do several species of shrews (Sorex personatus, S. richardsonii, and Neosorex palustris). The mink (Mustela vison group) and the otter (Lutra canadensis) occur chiefly along streams and lake shores, as do the muskrat (Ondatra zibethica) and beaver (Castor canadensis michiganensis). The meadow vole (Microtus pennsylianicus) occurs rather rarely in marshes and meadows. Within recent years, with the clearing of the forests, the brush wolf or coyote (Canis latrans) has spread from the westward completely over this peninsula.

In the hardwood forests of the middle and northern portions of the southern peninsula the mammals show slight differences from those of the northern peninsula, although much the same forms are present. The moose, Lake Superior chipmunk, and the northern shrews are absent. The weasel (Mustela noveboracensis) and skunk (Mephitis nigra) are a different species from those of the northern peninsula; and the forest deer-mouse is a more southern form (Peromyscus leucopus noveboracensis); a different subspecies of woodchuck (Marmota monax rufescens) is found; and a southern form of flying squirrel (Glaucomys volans) replaces the one of the northern peninsula. The masked shrew (Sorex personatus), bob-tailed shrew, black bear, timber wolf, red fox, marten, fisher, bob-cat, jumping-mouse, porcupine, eastern chipmunk, red squirrel, snowshoe hare, and Virginia deer, however, all occur in the forest. In addition to these forms, the raccoon (Procyon lotor), gray fox (Urocyon cinereoargenteus), gray squirrel (Sciurus carolinensis leucotis), and elk (Cervus canadensis) were formerly common, and a few cougars (Felis couguar) were found. In swamps and along the shores of lakes and streams the star-nosed mole, mink, otter, muskrat, and beaver were abundant. 
In the northern part of the southern peninsula some of these more southern species overlap the ranges of the more northern forms and in this section we may find, for instance, both forms of the flying squirrel and both forms of the forest deer-mouse.

In the pine forests of the sand plains of the central part of this peninsula, and probably in the sand plains of the northern peninsula, there was originally probably a considerable congregation of animals specially adapted for this situation, such as the marten, fisher, red squirrel, and Virginia deer.

Along the southern border of Michigan, and extending a short distance into the state, a considerable number of still more southerly and prairie forms occur, along with most of the forms living in the central part of the peninsula. Some noteworthy mammals in this section are the opossum (Didelphis virginiana), small shrew (Cryptotis parva), prairie mole (Scalopus aquaticus machrinus), large brown bat (Eptesicus fuscus), red bat (Nycteris borealis), prairie vole, (Microtus ochrogaster), northern pine vole (Microtus pinetorum scalopsoides), southern woodchuck (Marmota monax monax), striped ground-squirrel (Citellus tridecemlineatus), fox squirrel (Sciurus niger rufiventer), cottontail rabbit (Sylvilagus floridanus mearnsii), and bison (Bison bison). The beach mouse (Peromyscus maniculatus bairdii) is common along the open beaches of the larger lake, and in the open fields of the southern part of the state. The bison is now extinct, and with the clearing of the forests the prairie mole, ground squirrel, fox squirrel, and cottontail rabbit have spread northward, some of them reaching the Straits of Mackinac.

It is in the southern part of Michigan that the native mammal fauna has been most modified by civilization, and many species have been exterminated there, such as the deer, bear, and porcupine, which still live in more northern parts of the state; while others, such as the gray squirrel, are much reduced in numbers. On the contrary, numerous species feeding on cultivated crops or living in open fields or brush have become more numerous than ever before, even becoming pests. The Norway rat (Rattus norvegicus) and the house mouse (Mus musculus) have been introduced and are very abundant around houses and even invade the fields.

\section{Birds (L. J.)}

The breeding birds of the swampy and marshy areas are the same as those of Ohio, with the addition of loon, Bonaparte gull, Caspian tern, Forster's tern, Canada goose, Wilson's snipe, alder flycatcher.

Birds breeding along the lake shore on the sand and on islands: The same as those of Ohio and the herring gull.

Birds breeding on the original prairie and in other grassy places: The same as those of Ohio, and Wilson's phalarope, sharp-tailed grouse, short-eared owl, lesser scaup duck, pintail (rarely).

Birds breeding in the deciduous woods: The same as those of Ohio, except summer tanager, and in addition merganser, red-breasted merganser, hooded merganser, black-crowned night heron.

Birds breeding in brushy tangles, flood plains etc.: The same as those of Ohio.

Birds breeding in the evergreen forests: Spruce grouse, ruffed grouse, passenger pigeon, wild turkey, mourning dove, sharp-shinned hawk, Cooper's hawk, goshawk, red-tailed hawk, redshouldered hawk, broad-winged hawk, bald eagle, duck hawk, pigeon hawk, sparrow hawk, osprey, barred owl, sawwhet owl, screech owl, great horned owl, yellow-billed cuckoo, black-billed cuckoo, hairy woodpecker, downy woodpecker, arctic three-toed woodpecker, yellow-bellied sapsucker, northern pileated woodpecker, red-headed woodpecker, northern flicker, whippoorwill, nighthawk, chimney swift, rubythroated hummingbird, kingbird, crested flycatcher, phoebe, olive-sided flycatcher, wood pewee, least flycatcher, blue jay, crow, bronzed grackle, purple finch, red crossbill, goldfinch, pine 
siskin, white-throated sparrow, chipping sparrow, slate-colored junco, song sparrow, towhee, rose-breasted grosbeak, indigo bunting, scarlet tanager, purple martin, cliff swallow, barn swallow, tree swallow, cedar waxwing, migrant shrike, red-eyed vireo, warbling vireo, blueheaded vireo, black and white warbler, Nashville warbler, northern parula warbler, yellow warbler, black-throated blue warbler, myrtle warbler, magnolia warbler, chestnut-sided warbler, Blackburnian warbler, black-throated green warbler, Kirtland's warbler, pine warbler, oven-bird, Connecticut warbler, mourning warbler, northern yellowthroat, Canada warbler, redstart, catbird, brown thrasher, house wren, brown creeper, white-breasted nuthatch, red-breasted nuthatch, black-capped chickadee, golden-crowned kinglet, veery, olive-backed thrush, hermit thrush, robin, bluebird.

Birds breeding in banks, bird houses, etc.: The same as in Ohio.

\section{Reptiles and amphibians (H.T.G.)}

In the Canadian conifer forest on Isle Royale are found the toad (Bufo americanus), the wood-frog (Rana contabrigensis) and the red-bellied snake (Storeria occipitomaculata), while in streams and lakes the mudpuppy ( $\mathrm{NeC}$ turus maculosus) occurs. The spring peeper (Hyla crucifer), and the minkfrog (Rana septentrionalis) chiefly live in swamps and streams, as does the common garter-snake (Thamnophis sirtalis).

In the hardwood forests of the northern peninsula are found the wood-frog, toad, spring peeper, common tree-frog (Hyla versicolor), leopard-frog (Rana pipiens), mink-frog, red-backed salamander (Plethodon cinereus), Jefferson salamander (Ambystoma jeffersonianum), spotted salamander (Ambystoma maculatum), red-bellied snake, fox-snake (Elaphe vulpinus), green-snake (Liopeltis vernalis), and ring-necked snake (Diadophis punctatus edwardsii); chiefly along the streams and in the swamps are found the green-frog (Rana clamitans), newt (Triturus viridescens) 4-toed salamander (Hemidactylium scutatum), water-snake (Natrix sipedon), gartersnake (Thamnophis sirtalis), pond-turtle (Chrysemys bellii bellii), snapper (Chelydra serpentina), and the wood-turtle (Clemmys insculpta).

In the hardwood forests of the southern peninsula occur all the forms listed above except the mink-frog and the pond-turtle. Here also occur the tiger salamander (Ambystoma tigrinum), swamp tree-frog (Pseudacris triseriata), cricket-frog (Acris gryllus), skink (Eumeces fasciatus), brown snake (Storeria dekayi), milk-snake (Lampropeltis triangulum), and racer (Coluber c. constrictor). Chiefly along streams and in swamps are found the pickerel-frog (Rana palustris), bullfrog (Rana catesbeiana), queen-snake (Natrix leberis), garter-snakes (Thamnophis sauritus and T. butleri), and ground rattlesnake (Sistrurus catenatus), soft-shelled turtle (Amyda spinifera), musk-turtle (Sternotherus odoratus), spotted turtle (Clemmys guttata), and map-turtle (Graptemys geographica). The southern pond-turtle (Chrysemys bellii marginata) replaces the form of the northern peninsula. The Fowler toad (Bufo fowleri) and the hog-nosed snake (Heterodon contortrix) are found chiefly in sand dune areas.

A number of southern forms enter the southern part of the state. Among these are the black-snake (Elaphe obsoleta), Kirtland snake (Natrix kirtlandii), Blanding turtle (Emys blandingii), and box-turtle (Terrapene carolina carolina).

\section{NATURAL AREAS}

*Bogardus Tract. 3200 acres. Cutover and burned-over hardwood and pine land, some swamps, and the shores of several large lakes. Now mostly occupied by second-growth forests. An area typical of the conditions in the region. Cheboygan County, $4 \mathrm{mi}$. east of Pellston. Under control of Regents of the University of Michigan.

*The Huron Mountain Club. (B2.) About 10,000 acres typical of the Northern Peninsula of Michigan, including 
hardwoods, coniferous forests, swamps, and bogs. Includes sand ridges, low mountains, medium-sized lakes, small streams, and a considerable stretch of the shore of Lake Superior. Is being preserved in its natural condition. Some shooting in season. Marquette County, $10 \mathrm{mi}$. northwest of Big Bay (station). Owned and controlled by the Huron Mountain Club.

*Warren Dunes. (I8.) 293 acres of dunes along the shore of Lake Michigan, part covered by forest and part by shifting dunes. Includes a considerable strip of lake beach, and several small pools. One mi. north of Sawyer, Berrien County. Preserved in its natural conditions, under management of Edward K. Warren Foundation, Three Oaks.

*Warren Woods. (C4.) About 200 acres, part in native beech-maple forest, with flood-plain forest, and a sluggish, sandy-bottomed stream. About half in cleared fields reverting to wild conditions. One of the few forests of beech and maple still intact near the head of Lake Michigan. $4 \mathrm{mi}$. north of Three Oaks, Berrien County. Preserved in natural conditions, under the Edward K. Warren Foundation, Three Oaks.

${ }^{*}$ Grand Island. (A3.) 14,000 acres, the whole island except about 100 acres in clearing, and the immediate vicinity of the hotel and cottages. In native forest, mostly hardwoods and conifers. Roads and trails have been constructed, and elk and white-tail deer have been introduced, as well as some birds and fish. A small lake in the middle of the island. In Lake Superior (Alger County) one mi. from the nearest mainland, and $3 \frac{1}{2} \mathrm{mi}$. north of Munising. Owned and controlled by the Cleveland-Cliffs Iron Co., Negaunee.-L. R. Dice.

* Emmett County Game Refuge. About 8000 acres, beginning about two $\mathrm{mi}$. southwest of Cecil. Includes sand and gravel shores of Lake Michigan, and sand dunes of varying height. Forest mostly of fir, arbor vitae, and white spruce, all about 40 years old. A little Norway pine and hardwood, few bogs. Tern rookery on an island.
$2 \mathrm{mi}$. S.W. Cecil; automobile. $-L$. R. Dice.

*Fletcher State Park. 160 acres on north branch of Thunder Bay River in Posen Twp., Presque Isle County. Has some virgin hardwood.-L. R. Dice.

*Mackinac Island Park. 1015 acres, consisting of the Military Reservation connected with "Old Fort Mackinac" on Mackinac Island.

Mackinac City, boat.-L. R. Dice.

*Young State Park. About 230 acres on Pine Lake, Charlevoix County. Mostly covered with aspen secondgrowth. Sand and gravel beach.

Boyne City, $3 \mathrm{mi}$. West. (a).-L. $R$. Dice.

*Cedar Hill State Park. 260 acres, in Jackson, Washtenaw, and Lenawee counties. Second-growth timber. Lakes.

Manchester, $7 \mathrm{mi}$. S. (a).-L. R. Dice.

*Burt Lake State Park. Will comprise eventually 500 acres. On south side of Burt Lake, Cheboygan County. Includes shore line. The area consists of cut-over and burned-over land, with at present a jack pine and secondgrowth cover. The location is central for work by boat in any part of the chain of lakes. Boats are available, and camping places are provided. $\frac{1}{4} \mathrm{mi}$. west of Indian River (Michigan Central R. R.).-C.W. Creaser.

*Onaway State Park. 152 acres. Has second-growth hardwood and some arbor-vitae. On foot of Black Lake.

$4 \frac{1}{2} \mathrm{mi}$. N. Onway.-L. R. Dice.

*Interlochen State Park. (C4.) 200 acres in Green Lake Township of Grand Traverse County. Part in virgin white and Norway pine forest nearly in natural condition. Oaks and other hardwoods present on part of tract. Shores of Duck Lake and Green Lake. One mi. south Interlochen (on foot).-W. $G$. Waterman (Mich. Acad. Sci. Rept., 1918).

The following state parks are mainly tourist camps, and in general have little of ecological interest:

Day State Park. 32 acres, Leelanaw County. 
Traverse City State Park. 40 acres, Grand Traverse County.

Harrisville State Park. 6 acres, Alcona County.

Cheboygan State Park. 8 acres, Cheboygan County.

Cadillac State Park. 25 acres, Wexford County.

East Tawas State Park. 16 acres, Iosco County.

Paw Paw State Park. Van Buren County.

Gladwin State Park. 8 acres, Gladwin County.

Harrison State Park. 35 acres, Clare County.

Mears State Park. 12 acres, Oceana County.

Silver Lake State Park. 35 acres, Oceana County.

Grand Haven State Park. 25 acres, Ottawa County.

Otsego Lake State Park. 54 acres, Otsego County.

Manistee State Park. 26 acres, Manistee County.

Muskegon State Park. 37 acres, Muskegon County.

Lyon Lake State Park. 40. acres, Calhoun County.

Benton Harbor State Park. 100 acres, Berrien County.

*Jackson County Sanctuary. 35 acres on Sandstone Creek; ground pitted by old mine shafts and dumps. Vegetation mixed; probably all second-growth.

$4 \frac{1}{2} \mathrm{mi}$. West of Jackson.-L. R. Dice.

*Hanson Military Reservation. About 15,000 acres, including shore of Portage Lake. Jack pine and barrens.

Grayling, 2 mi. W. (a).-L. R. Dice.

*Hillsdale College Preserve. 15 acres. Upland deciduous second-growth forest, and partly wooded swamp.

Hillsdale.-B. A. Barber.

*Michigan National Forest. (See National Forests of the Rocky Mountain District, p. 248.

\section{*State Forests}

More than 40 state forests are estabblished in Michigan, containing thou- sands of acres. They are distributed over all the northern part of the state. Practically all of these have been logged and burned. Young stands of jack pine and aspen are abundant, and many areas are being planted to more valuable lumber trees. The named forests are as follows:

Alcona. 40,640 acres, Alcona and Oscoda County.

Alpena. 14,400 acres, Alpena County. Antrim. 160, acres Antrim County. Arenac. 1200 acres, Arenac County. Au Sable. 51,560 acres, Alcona and Iosco Counties.

Baraga. 80 acres, Baraga County. Benzie. 200 acres, Benzie County. Black Lake. 8000 acres, Cheboygan County.

Cheboygan. 6040 acres, Cheboygan County.

Chippeusa. 8800 acres, Chippewa County.

Drummond Island. 2040 acres, Chippewa County.

F'ife Lake. 10,420 acres, Grand Traverse County.

Garden Island. 1640 acres, Delta County.

Gogebic. 480 acres, Gogebic County. Grayling. 17,120 acres, Crawford County.

Higgins Lake. 18,760 acres, Crawford and Roscommon Counties.

Houghton Lake. 48,080 acres, Roscommon County.

Iosco. 3200 acres, Iosco County.

Kalkaska. 6400 acres, Grand Traverse and Kalkaska Counties.

Manislen. 8160 acres, Kalkaska County.

Lake Michigan. 6080 acres, Emmett County.

Lake Superior. 119,320 acres, Luce County.

Leelanau. 820 acres, Leelanau

County.

Mackinac. 8580 acres, Mackinac County.

Manistee. 1280 acres, Manistee County.

Marquette. 10,400 acres, Marquette County. 
Menominee. 320 acres, Menominee County.

Missaukee. 1800 acres, Missaukee County.

Montmorency. 12,160 acres, Montmorency County.

Muskegon. 800 acres, Muskegon County.

Newaygo. 320 acres, Newaygo

County.

Oceana. 80 acres, Oceana County.

Ogemaw. 6240 acres, Ogemaw

County.

Oscoda. 16,640 acres, Oscoda County.

Otsego. 6880 acres, Otsego County.

Ontonagon. 1920 acres, Ontonagon County.

Pigeon River. 8640 acres, Otsego

County.

Presque Isle. 35,200 acres, Presque Isle County.

Saginaw. 280 acres, Saginaw County.

St. Ignace. 1800 acres, Mackinac County.

* Lighthouse Reservations. A number of Lighthouse Reservations occur around the Great Lakes. Many of these contain situations of ecological interest, especially for shore life. Most are on islands or peninsulars, and special facilities are necessary for reaching most of them. Animals are protected, but some use is made of the timber present. Those in Michigan of most importance are here listed.

Au Sable. 326 acres, Lake Superior.

Beaver Island. 227 acres, Lake Michigan.

Big Sable. 933 acres, Lake Michigan.

Bois Blanc. 640 acres, Lake Huron.

Charity Island. 200 acres, Saginaw Bay.

Detour. 71 acres, at mouth of St. Mary's River.

Devils Island. 320 acres, Lake Superior.

Drummond Island. 56 acres, on Drummond Island, Lake ${ }_{\text {r Huron. }}$

Forty-Mile Point. 27 acres, Lake Huron.

Grand Island Harbor Range. 115 acres, Alger County.

Grand Island. 91 acres, Lake Superior.
Grand Marais Harbor of Refuge. 1014 acres, Lake Superior.

Gull Island. Lake Superior.

La Pointe. 152 acres, Lake Superior.

Manitou Island. 685 acres, Lake Superior.

Michigan Island. 77 acres, Lake Superior.

Mission Point. 142 acres, Lake

Michigan.

Outer Island. 279 acres, Lake

Superior.

Passage Island. 201 acres, Lake

Superior.

Presque Isle. 138 acres, Lake Huron.

Raspberry Island. 288 acres, Lake Superior.

Round Island. 311 acres, Straits of Mackinac.

Sand Island. 111 acres, Lake Superior.

Thunder Bay Island. 161 acres, Lake Huron.

West Huron Island. 42 acres, Lake Superior.

Northern Michigan Forest. (A2.) Large area of deciduous and coniferous forest; with hills, shore, rocky and glacial topography; swamps, pond, lake, river, spring. This is a typical northern Michigan forest; abundant small sphagnum-lined lakes, rich in fish and microfauna; birds abundant. In virgin forest, deer, bear, wolf, and beaver common.

Iron County, $10 \mathrm{mi}$. from Kenton, C. \& N. W. R. R.-A. R. Cahn.

Mason County Forest. (C3.) Tract 10-20 sq. mi. deciduous and eastern coniferous forest, with particularly good. shore and sandy area, swamp, lake, with waterbirds, muskrats, raccoon. Admirably situated for a state park. Contains some of the finest dunes in Michigan. Has little valuable timber, but bits of deciduous and pine forest remain. Has a beautiful interior lake, Lake Hamlin, 6 or $7 \mathrm{mi}$. long, which should be included. None of the land involved is good for tillage. Within the area there is a lighthouse and lifesaving station. Ludington, $5 \mathrm{mi}$.-Geo. D. Fuller.

Benzie County Hardwood. About 600 acres of virgin hardwood on Crystal Lake, south side, about middle of lake. 
Called Old Preemption. On heights sloping to the lake. Includes ravines. Variously owned.

\section{Frankfort.-T. H. Hubbell.}

Grayling Pine. 76 acres, Young stand of white pine, with some Norway pine, hemlock, and hardwood. The last white pine in Michigan.

\section{Grayling.-P. S. Lovejoy.}

Otsego County Hardwood. Several sections of virgin hardwood remain in this county, the last hardwood forests of any adequate area remaining in the southern peninsula. At least 640 acres should be permanently preserved.

Gaylord, 6 mi. W. (a).-L. R. Dice.

Pictured Rocks. (B3.) 10 to 100 sq. mi. along Lake Superior shore in Alger County. Sand dunes, pictured rocks, hardwood and pine forests, cedar swamps, tamarack bogs, small rapid streams, rock exposures, Lake Superior shores. Privately owned. $20 \mathrm{mi}$. north of Seney (wagon), camp.-L. R. Dice.

Porcupine Mountains. (B3.) 10 to 20 sq. mi. in Ontonagon County. Highest-elevation in Michigan. Mountains, rock exposures, hardwood forest, hemlock, pine, bogs, beaver meadows, shrub thickets, small streams and lakes; Lake Superior shore. Privately owned. 24 mi. west of Ontonagon (wagon), camp. - L. R. Dice.

Carpenter Woods. (C4.) About 500 acres in Hope Township, central Barry County. Rolling topography, original hardwood forest; soil of clay and gravel, small stream and swamps. Privately owned. One mi. south Cloverdale (a). -Doreen Potter.

Waterloo Big Marsh. (C4.) About 1200 acres in Waterloo Township, Jackson County, at the headwaters of the Grand River. About one-third in cattails, and a considerable portion in tamarack bog. Much rose shrub and numerous other marsh and swamp habitats; a small creek; one small lake. Sandhill crane breeds; snowshoe hare lingered here until the early nineties. The Grand River drain now under construction will drain most of the area. Privately owned. One mi. northwest Waterloo (w).-Walter Koelz.

Cisco Lake Region. (B2.) Southern Gogebic County. Mostly mixed hardwood deciduous forest in nearly natural conditions, except that the white pine has been removed. Gently rolling topography. Many lakes. Deer abundant. Privately owned. $6 \mathrm{mi}$. east (c), Bent's Resort (State Line, Wisc.). -L. R. Dice.

Little Girl's Point. (A3.) 10 to 20 sq. mi., southeast of Little Girl's Point on Lake Superior, Gogebic County. A high ridge with splendid development of dry sugar maple-linden-yellow birch forest. Numerous black spruce bogs, arbor vitae swamps, hemlock slopes, and stages following burns. A few small patches of white pine. Owned by lumber companies. $14 \mathrm{mi}$. north, (a) Ironwood.-L. R. Dice.

North End Gogebic Lake. (B2.) 10 to 20 sq. mi. west side of Gogebic Lake near north end. Mostly low, wet hardwood forest, numerous extensive black spruce bogs, few beaver meadows, few black ash swamps along Gogebic Lake shore. In nearly natural conditions. Privately owned. $3 \mathrm{mi}$. south (boat), Lake Gogebic Station.-L. R. Dice.

Isle Royale. (A3.) About 200 sq. mi., making up Isle Royale in Lake Superior. Canadian coniferous forest dominant. Hardwood ridges, swamps, bogs, marshes, small streams, lakes, bays, shore of Lake Superior. Moose. Still in nearly natural conditions. Mostly privately owned. $20 \mathrm{mi}$. north of Houghton (c), camp.-L. R. Dice.

\section{SELECTED REFERENCES ON THE ECOLOGY} OF MICHIGAN

Adams, C. C., and others. 1909. An ecological survey of Isle Royale, Lake Superior. Mich. Geol. Survey, Lansing. $\mathrm{xv}, 468 \mathrm{pp}$.

Adams, C. C., and others. 1906. An ecological survey in northern Michigan. Mich. Geol. Surv., Ann. Rept., 1905 , pp. 1-133.

Clayberg, H. D. 1920. Upland societies of Petosky-Walloon Lake region. Bot. Gaz., 69: 28-53.

Cooper, W. S. 1912. The ecological succession of mosses, as illustrated upon Isle Royale, Lake Superior. Plant World, 15: 197-213.

Cooper, W. S. 1913. The climax forest of Isle Royale, Lake Superior, and its development. Bot. Gaz., 55: 1-44, 115-140, 189-235.

Cowles, H. C. 1900. Plant geography of North America. I. The physiographic ecology of northern Michigan. Science, n.s., 12: 708-709.

Dice, L. R., and Sherman, H. B. 1922. Notes on the mammals of Gogebic and Ontonagon counties, Michigan. Univ. Mich., Occ. Papers, Mus. Zool., no. 109.

Dice, L. R. 1920. The mammals of Warren Woods, Berrien County, 
Michigan. Univ. Mich. Occ. Papers Mus. Zool., no. 86.

Gaige, F. M. 1914. Results of the Mershon Expedition to the Charity Islands, Lake Huron. The Formicidae of Charity Island. Univ. Mich., Occ. Papers Mus. Zool., no. 5.

Gaige, Helen T. 1915. The amphibians and reptiles collected by the Bryant Walker Expedition to Schoolcraft County, Michigan. Univ. Mich., Occ. papers Mus. Zool., no. 17.

Gates, Frank C. 1912. The vegetation of the region in the vicinity of Douglas Lake, Cheboygan County, Michigan, 1911. Mich. Acad. Sci., 14th Ann. Rept. 46-106.

Hankinson, T. L. 1908. A biological survey of Walnut Lake, Michigan. Mich. Geol. Surv., Ann. Rept., 1907: 153-288.

Hankinson, T. L. 1916. Results of the Shiras Expeditions to Whitefish Point, Michigan: Fishes. Mich. Geol. and Biol. Surv., publ. no. 20, Biol. Sev., no. 4, pp. 111-170.

Harvey, LeRoy H. 1920. Some phytogeographical observations in Lake County, Michigan, Mich. Acad. Sci., 21st Ann. Rept. 213-217.

Hubbell, Theodore H. 1922. The Dermaptera and Orthoptera of Berrien County, Michigan. Univ. Mich., Occ. papers, Mus. Zool., no. 116.

Hussey, Roland F. 1922. Hemiptera from Berrien County, Michigan. Univ. Mich., Occ. papers Mus. Zool., no. 118.

Leverett, Frank. 1917. Surface geology and agricultural conditions of Michigan, with a chapter on climate by C. F. Schneider. Mich. Geol. and Biol. Surv. Publ. 25, Geol. Ser. 21.

Leverett, Frank, and Taylor, F. B. 1915. The Pleistocene of Indiana and Michigan and the history of the Great Lakes. U. S. Geol. Surv., Monograph., no. 53.

Livingston, B. E. 1905. The relation of soils to natural vegetation in Roscommon and Crawford counties, Michigan. Bot. Gaz., 39: 22.

Livingston, B. E. 1903. The distribution of the upland plant societies of Kent County, Michigan. Bot. Gaz., 35: p. 36.

Nichols, George E. 1922. The Bryophytes of Michigan, with particular reference to the Douglas Lake region. Bryologist, 25: 41-58.

Peet, Max M. 1908. An ecological study of the birds of the Ypsilanti Bayou. Mich. Acad. Sci. 10th Ann. Rept., pp. 162-196.

Reed, H. S., and others. 1902-1911. A botanical survey of the Huron River Valley I-VIII. Bot. Gaz., 34-52.
Ruthven, A. G., and others. 1911. A biological survey of the sand dune region on the south shore of Saginaw Bay, Michigan. Mich. Geol. and Biol. Surv., publ. 4, biol. ser. no. 2.

Transeau, E. N. 1906. The bogs and bog flora of the Huron River Valley. Bot. Gaz., 40: 351-375, 418-448; 41: 17-42.

Waterman, W. G. 1919. Development of root systems under dune conditions. Bot. Gaz., 68: 22-53.

Wenzel, Orrin J. 1912. A collection of mammals from Osceola County, Michigan. Mich. Acad. Sci., 14th Ann. rept., 198-205.

Whitford, H. N. 1901. The genetic development of the forests of northern Michigan, a study in physiographic ecology. Bot. Gaz., 31: 288-325.

Wood, N. A., Smith, Frank, and Gates, Frank C. 1916. The summer birds of the Douglas Lake region, Cheboygan County, Michigan. Univ. Mich., Occ. papers Mus. Zool., no. 27.

Wood, N. A. 1914. Results of the Shiras Expeditions to Whitefish Point, Michigan.-Birds. Michigan. Acad. Sci., 16th Ann. rept., 55-73.

\section{NATIONAL FORESTS OF THE EASTERN DISTRICT}

\section{By E. H. Frothingham}

The eastern National Forests in District 7 cover an aggregate net area of $3,458,638$ acres. About 42 per cent of the area, situated principally in the Arkansas, Ozark, and Florida National Forests, was originally public domain and became National Forest land by presidential proclamation. Most of the remainder was purchased under the act of March 1, 1911 (the Weeks law).

The forests may be conveniently discussed under four geographical divisions: The White Mountain, the Southern Appalachian, the Ozark, and the Florida regions. Of these the Southern Appalachian is the largest and most complicated from an ecological standpoint.

\section{THE WHITE MOUNTAIN REGION}

This region, lying principally within the spruce-balsam-birch-area (Canadian Life Zone) corresponds with the "spruce and northern hardwoods region" recognized in the report of the Committee on 
Research, New England Section of the Society of American Foresters. ${ }^{1}$ Sixteen forest types are found in the region, according to the report. These are characterized by beech, sugar maple, yellow and paper birches (Betula lutea and $B$. papyrifera), spruce, balsam fir (Abies balsamea), northern white cedar (Thuja occidentalis), tamarack (Larix laricina), hemlock. (Tsuga canadensis), and scattering white pine (Pinus strobus). Ten of these types are distinctive, including a northern white cedar swamp type, two fir types, four spruce types, a birch and aspen type, and two mixed types.

\section{THE SOUTHERN APPALACHIAN REGION}

The Southern Appalachian mountain region is commonly regarded as embracing not only the Southern Appalachian ranges included in or connecting the Blue Ridge and Unaka, or Smoky, mountains, but also the Alleghany and Cumberland highlands and the Appalachian valleys, with their interior parallel ridges. The area of the entire region is approximately 93,800 sq. mi. The National Forests are mostly situated in the Appalachian mountains proper, which have an approximate area of $17,700 \mathrm{sq}$. mi. One, the Monongahela National Forest, is in the Alleghany highlands of West Virginia; another, the Shenandoah, covers mountainous country partly in the Alleghany highlands, partly in the Southern Appalachians proper, and partly in the Shenandoah Valley. The total acreage of these National Forests is approximately $2,208,000$ acres, or about one-fifth of the area of the Southern Appalachian mountains.

Between the farthest north (the Monongahela and Shenandoah) and the farthest south (the Alabama) of the National Forests within the region, there is a difference of 5 degrees of latitude and over 9 degrees of longitude. In both the Shenandoah and the Alabama the altitudes extend down to or

1 Revision of a report on a forest region and type classification for New England, by the Committee on Research, New England Section of the Society of American Foresters. Jour. of Forestry, 20: 795$798,1922$. below $1000 \mathrm{ft}$., while at points in North Carolina and Tennessee there are many peaks and ridges exceeding $6000 \mathrm{ft}$. in elevation. Accompanying these variations and a generally steep and broken topography there are pronounced local and general climatic differences and variations in soil, which are responsible, in turn, for a great diversity of vegetational forms.

$\mathrm{Ashe}^{2}$ has listed 12 forest associations in the Southern Appalachians, in which he recognizes 35 forest types, ${ }^{8} 5$ in the Canadian Life Zone, 21 in the Alleghanian area of the Transition, and 9 in the Carolinian area of the upper Austral Zone. For a detailed discussion of these types Ashe's paper above referred to should be consulted. In an article of this length fine distinctions can not be made, and a tentative statement of groups of types prevailing under broadly general environmental conditions is therefore substituted. ${ }^{4}$

\section{Subalpine group 5}

Well-marked subalpine forest types appear in West Virginia-nearly 400 mi. from their nearest extensive occurrence to the north-and extend southward in the mountains at increasing elevations to the Georgia line. Red spruce (Picea rubra) and southern balsam (Abies fraseri), which is abundant in some places, and absent in others, are the most conspicuous members of these types. Yellow birch and fire cherry (Prunus pennsylvanica) are also characteristic. Paper birch (Betula papyrifera cordifolia Fern.) has been found growing sparsely as far south as Mount Mitchell, in North Carolina. Largetooth aspen (Poplus grandidentata) is fairly abundant in these types in West Virginia, and the quaking aspen

\footnotetext{
2 Ashe, W. W. Forest types of the Appalachians and White Mountains. Journal of the Elisha Mitchell Scientific Society, 37: 183-198. 1922.

3 These are based upon composition alone. Using height as a basis in addition to composition, Ashe recognizes 56 types.

${ }^{4} \mathrm{~A}$ more definite statement of types is now being prepared by a committee of the Southern Appalachian Section of the Society of American Foresters. ${ }_{5}^{5}$ This corresponds roughly to the types listed by Ashe as of the Canadian Life Zone.
} 
(P. tremuloides) is also said to occur in certain isolated localities. Beech, buckeye, hawthorns, and some other species enter these types, though they reach better development at lower elevations. The subalpine types occur mostly at altitudes of over $3500 \mathrm{ft}$. in northern West Virginia and over $4500 \mathrm{ft}$. in North Carolina and Tennessee, usually mixing with other types at lower and even sometimes at higher altitudes than those named.

\section{Intermediate group ${ }^{6}$}

Hardwoods make up the great bulk of these types, though hemlocks and pines occur more or less abundantly, often in pure stands. Considered broadly as forest associations or groups of forest types, these aggregates show relatively small geographical as compared with very marked local variations, due to differences in the weight of factors of exposure and altitude. In this broad sense, therefore, these associations may be discussed as though generally un form throughout the region and even north of it, although there are composition differences due to geographical limitations of range of some species within the region.

Upper moist slope types. These types are the highest in altitude of all the Southern Appalachian types below the subalpine types. They are found on high, moist, cool slopes and high ridge crests and are characterized by so called "northern hardwoods"-yellow birch, sugar maple, and beech-and hemlock, with buckeye often abundant, and basswood (Tilia $s p$.), cucumber (Magnolia acuminata), white ash (Fraxinus americana), black cherry (Prunus serotina), red oak (Quercus rubra), and chestnut (Castanea dentata) in varying degrees of mixture. Red oak is important where it appears, as on some high crests. Chestnut similarly comes sparsely into this association from below.

6 These types include approximately those listed by Ashe as of the Alleghanian Area of the Transition Life Zone.
Lower moist slope and cove types. The types occupying the moist situations at lower altitudes than the upper moist slope types are distinguished by chestnut, yellow poplar (Liriodendron tulipifera), red oak, white oak, and hemlock, with a large number of associated species. Among these are red maple (Acer rubrum), chestnut oak (Quercus prinus), hickories, white pine, buckeye, black birch (Betula lenta), black gum (Nyssa sylvatica), basswood, cucumber, white ash, black locust (Robinia pseudacacia), butternut (Juglans cinerea), black walnut ( $J$. nigra), black cherry, dogwood (Cornus florida), hawthorns, and holly (Ilex opaca), with silverbell (Halesia carolina), sourwood (Oxydendrum arboreum), and other species in the southern part of the region. Species intruding from the upper moist slope and dry slope types, are also found. With such a large number of species a great complexity of mixtures is inevitable, and there are several well marked, widely occurring formations, such as those characterized by the dominance respectively of yellow poplar, chestnut, and hemlock (Tsuga canadensis).

Ridge and dry slope types. These occupy the ridges and dry slopes from the Plateau types-at about $2000 \mathrm{ft}$. altitude in the southern part of the region, lower in the north-to the upper moist slope types on exposed aspects. The dry exposure is mainly the southerly one, though this formation may extend around on the west-as is the case in the northern part of the region where the influence of westerly winds is felt-and it may cover thin-soiled easterly exposures. The area occupied is very extensive. As a result of exposure to sun and wind, the light crown cover, and repeated fires, the humus content of the soil and the protecting cover of leaf litter have been largely destroyed or reduced beyond capacity to protect the site from excessive evaporation. The forest reflects the dryness of the site by exclusion of moisture-needing species. The species most characteristic are chestnut, chestnut oak, black oak 
(Quercus velutina), scarlet oak (Q. coccinea), black jack oak (Q. marylandica), white oak $(Q . a l b a)$, locust, sassafras, pitch pine (Pinus rigida), Virginia pine (Pinus virginiana), and table mountain pine ( $P$. pungens). Carolina hemlock (Tsuga caroliniana) has a limited occurrence in the southern part of the region. In the northern part Virginia pine and black jack oak assume a prominence not found in the type farther south.

\section{Plateau group 7}

Upland types. These types include the hardwood and pine formations which characterize the woodlots of the Piedmont Plateau and Appalachian Valley, and extend over the lower hills and ridges skirting the main mountain ranges and spurs into the plateau lands enclosed within the mountain groups. The upper altitude of these types may be stated as approximately $2500 \mathrm{ft}$. in the southern mountains, less in the northern part of the region. In the National Forests of the region they are more largely represented in the south than in the north. There is a wide variety of composition and stand conditions. On ridge and bench lands the characteristic species include principally shortleaf pine (Pinus echinata), southern red oak (Quercus digitata), black oak, post oak (Q. stellata), white oak, hickories, red maple, black gum, Virginia pine, pitch pine, dogwood, and sourwood. In moister situations such as northerly slopes and ravines, red maple, yellow poplar, red gum (Liquidambar styracifua), and scattered ash trees mix with a variety of oaks and hickories.

Lowland and river edge types. These are unimportant, in point of area, in the National Forests. They are almost wholly hardwood, and are confined to narrow strips along streams, valley bottoms, and small swampy areas. Sweet gum, sycamore, (Platanus occidentalis) river birch (Betula nigra), black gum, and black willow (Salix

7 These types include approximately those listed by Ashe as of the Carolinian Area of the Upper Ausaral Life Zone. nigra) are characteristic. Yellow poplar, white oak, and other species intermingle to greater or less extent.

\section{THE OZARK REGION}

The Ozark and Arkansas National Forests are situated in the mountainous portions of Arkansas (Carolinian area of the Upper Austral). The elevation of the forests varies from 500 to 3000 ft. The principal tree species of the uplands include shortleaf pine, white, southern red, post, and black oaks, and shagbark, pignut, and white hickories (Carya ovata, C. glabra, C. alba). Sweet gum, basswood, sycamore, sugar maple, and black walnut are found on the moister soils or along streams.

\section{THE FLORIDA GULF REGION}

The two divisions of the Florida National Forest, in northwestern and north central Florida, respectively, are the areas concerned. This region (lying in the Gulf strip of the Austroriparian area), is characterized by longleaf pine (Pinus palustris), slash pine ( $P$. heterophylla), sand pine ( $P$. clausa), and other pines, scrub oaks, palmetto (Sabal palmetto), and low evergreen shrubs, with cypress (Taxodium distichum), swamp hardwoods, and southern white cedar (Chamaecyparis thyoides) in river and bog swamps. A good place to study the typical "scrub" vegetation of the poorer, drier, sandy lands of Florida, showing all stages of succession from ancient sand dunes to longleaf pine forest. Conditions have been largely modified by fire. Bear, deer, and wild turkeys are to be found.

THE NATIONAL FORESTS

Since the individual National Forests are treated here in alphabetical order, their location by regions, in a general north to south direction, may be of interest.

White Mountain region

White Mountain National Forest 
Southern Appalachian region

Monongahela National Forest

Shenandoah National Forest

Natural Bridge National Forest

Unaka National Forest

Pisgah National Forest

Nantahala National Forest

Cherokee National Forest

Alabama National Forest

Ozark region

Ozark National Forest

Arkansas National Forest

Florida region

Florida National Forest

The National Forests, which are administrative units, are often made up of two or more detached parts, the more important of which are mentioned in the discussion of the individual Forests.

Alabama National Forest (Alabama). Area 97,198 acres, on Walden Ridge, principally in Lawrence and Winston counties. Forests of the plateau types, largely of pine on the upper slopes and deciduous forest, containing considerable valuable white oak and yellow poplar in the hollows.

Supervisor's headquarters at Moultonł.

Arkansas National Forest (Arkansas). Area 652,565 acres in mountainous western Arkansas, mostly in Perry, Saline, Garland, Yell, Logan, Scott, Montgomery, and Polk Counties. Mixed coniferous and deciduous forest with shortleaf pine predominating. Undisturbed areas are to be found.

Supervisor's headquarters at Hot Springs $\ddagger$, $12 \mathrm{mi}$. N. W. (C., R. I. \& P. Ry. and Mo. Pac. R. R.). Other points from which accessible are Womble, 3 mi. N.E. or W.; Eagleton or Rich Mt., one mi.; Bates, $3 \mathrm{mi}$; Waldron, $10 \mathrm{mi}$.; Mansfield, $8 \mathrm{mi}$. S.; Booneville, $9 \mathrm{mi}$. S.; Waveland, 8 mi. S.; and Plainville, $13 \mathrm{mi}$. S.

Cherokee National Forest (Georgia, North Carolina and Tennessee). Area 211,832 acres, mostly in Polk and Monroe Counties, Tenn., Cherokee County, N.. C., and Fannin, Union, Lumpkin, Towns, and White Counties, Ga. Forest types of the Appalachian inter- mediate and plateau groups. A saw timber estimate compiled in 1916 by the Forest Service indicates the following percentages of species: oaks 24, chestnut 21 , yellow pines 14, yellow poplar 13, white pine 13 , hemlock 7 , others 8 . Elevation 1500-5000 ft.

Supervisor's headquarters Athens, Tenn., (L. \& N. R. R. and So. Ry.). Forest most readily reached (a) from Blue Ridge, Ga., (L. \& N. R. R.). Good roads penetrate the Forest.

Florida National Forest (Florida). Area 320,273 acres in two divisions: the Ocala, mostly in Marion County, and the Choctawhatchee, in Santa Rosa, Okaloosa, and Walton Counties, in the extreme northwestern part of the State.

Supervisor's headquarters at Pensacolaf. (L. \& N. R. R.) The Choctawhatchee division is accessible from several points on the L. \& N. R. R. notably Pensacola, Crestview, and De Funiak Springs. The Ocala division may be reached from points near Ocala and Palatka.

Monongahela National Forest (West Virginia). Area 170,377 acres in the Alleghany highlands, mostly in Tucker and Randolph Counties, W. Va. Forest almost entirely cut-over. Subalpine and intermediate types represented, including much of the northern hardwood type. Excellent second-growth of yellow poplar and other species in places.

Supervisor's headquarters at Elkins $\ddagger$ (Western Maryland Ry. and C. \& O. R. R.). Forest also accessible from Parsons, Hendricks, and Durbin.

Nantahala National Forest (Georgia, North Carolina, and South Carolina). Area 221,613 acres, mostly in Macon, Graham, and Clay Counties, N. C., Rabun County, Ga. and Oconee County, S. C. The forest adjoins the Cherokee National Forest and is situated in the Nantahala Mountains on headwaters of the Savannah and Tennessee Rivers. Forest types are of the intermediate group. Forest Service estimate of saw timber indicates following percentage of principal species: oaks 39 (mostly chestnut and red oaks), hemlock 18, 
chestnut 13, yellow poplar 7, basswood 6 , hickories 5 , birch 2 , maple 2 , others 8 . Some fine stands of virgin timber.

Supervisor's headquarters at Franklin, N. C. $\ddagger$ (L. \& N. R. R.). Forest accessible from Tallulah Falls, Ga. (So. Ry.), Murphy, N. C. (So. Ry., 20 mi. (a)), and Lake Toxaway (So. Ry., 12 to $30 \mathrm{mi}$. (a)).

Natural Bridge National Forest (Virginia). Area 143,386 acres in the Blue Ridge Mountains, mostly in Rockbridge, Amherst, Botetourt, and Bedford Counties. Altitudes are between 1000 and $3000 \mathrm{ft}$., with some peaks in the neighborhood of $4000 \mathrm{ft}$. The forest types are of the Appalachian plateau and intermediate groups. There is no subalpine type. The Forest Service saw timber estimate of 1916 indicated the following percentages of important species: chestnut 40 , oaks 36 , yellow pines 4, yellow poplar 3, hickories 2, hemlock 2, white pine 2, others 11 . The chestnut blight (Endothia parasitica) has reached an advanced stage.

Supervisor's headquarters at Lynchburg $\ddagger$ (Southern Ry.; C. \& O. R. R. and N. \& W. R. R.). The Forest may also be reached from Natural Bridge by automobile or on foot.

On the border of the Forest is the Natural Bridge ravine, which was presented by George III to Thomas Jefferson in 1774. (See Harshberger, John W.: "The Forest of the Natural Bridge of Virginia." Forest Leaves, 9: 42-44, June, 1903. See also American Forestry, 2: 238.)

Ozark National Forest (Arkansas). Area 291,526 acres of rolling and mountainous country on the divide of Boston Mountains, north of the Arkansas River. There are three detached tracts, the western in Franklin, Crawford, and Washington Counties, the central mostly in Newton, Pope, and Johnson Counties, and the eastern in Stone and Baxter Counties. The altitudes are between 600 and $1800 \mathrm{ft}$. in the eastern, and 1500 and 2000 in the two others. Undisturbed areas are found in the western division near Cass, the central divi- sion near Simpson, Lurton, and Crowell, and the eastern division, accessible from Sylamore.

Supervisor's headquarters at Russellville $\ddagger$ (Mo. Pac. Ry.). The western division is accessible (h) and probably at times by automobile from Ozark, Ark., 12 mi. N.W. on Mo. Pac. Ry.; or from Combs, on Frisco (St. Paul Branch from Fayetteville) over Cass, Combs, and Eastern Ry., a logging road, carrying passengers to within $1 \frac{1}{2} \mathrm{mi}$. of Cass. The central division may be reached from Russellville, by auto to Lurton, and other points; the Forest Service maintains a 34 mile road through this tract, and connecting links are being completed, making it the most scenic route in the State. The eastern division is accessible from Sylamore (Mo. Pac. Ry.), ferry to W. Sylamore, (regular auto service) $18 \mathrm{mi}$. of government road with $17 \mathrm{mi}$. through forest to $\mathrm{Big}$ Flat or Mountain View.

Pisgah National Forest (North Carolina). Area 269,000 acres. There are four divisions: The Grandfather Mountain (Boone), most of which is in Avery, Caldwell and Burke Counties; the Mount Mitchell, in McDowell, Mitchell, Yancey, and Buncombe Counties; the Pisgah, in Buncombe, Henderson, Transylvania, and Haywood Counties; and the French Broad, in Cocke and Green Counties, Tenn., and Madison County, N. C. The Pisgah division is a national game preserve. The Mount Mitchell division is adjacent to the Mount Mitchell State Park, which occupies the high ridge and peaks of the Black Mountains, including Mt. Mitchell (altitude $6711 \mathrm{ft}$.). Most of the National Forest lies between altitudes of 2000 and 5000 ft., and the prevailing vegetation is that of the intermediate Appalachian types, with intrusion of the plateau types at the lower altitudes. At a few points there are elevations of over $6000 \mathrm{ft}$. The subalpine types occur at altitudes of usually over $4500 \mathrm{ft}$.; spruce and fir are found in small amounts in all four divisions of the Forest.

The prevailing tree species are indi- 
cated by the Forest Service estimate of saw timber compiled in 1916. The percentages of species are: chestnut 45 , hemlock 11, yellow poplar 10, chestnut oak 10 , other oaks 6 , yellow pines 3 , basswood 2, spruce and fir 1, others 12 .

Supervisor's headquarters Ashevilleł (So. Ry.). Pisgah division easily accessible by auto from Asheville or Brevard. A motor road open from spring to fall extends from Black Mountain (and Asheville) to near the top of Mt. Mitchell. The Boone division may be reached from Linville (3 mi. east) or Lenoir (6 mi. west).

Shenandoah National Forest (Virginia and West Virginia). Area 353,544 acres in three main divisions: The Massannutten, on the Blue Ridge, chiefly in Shenandoah, Page, and Rockingham Counties; the Shenandoah, in the Alleghany Front region, in Rockingham, Augusta, Highland, and Bath Counties, Va., and Pendleton County, W. Va.; and the Potomac, just north of the Shenandoah, in Shenandoah and Frederick Counties, Va., and Hardy County, W. Va. The intermediate and plateau groups of types are represented. Timber largely second-growth, with some good bodies of original growth. The Forest Service saw timber estimate of 1916 indicates the following percentage of species: oaks 53 , hemlock 20 , white pine 8 , chestnut 5 , yellow pines 4 , yellow poplar 4, hickories 4 , others 2 . Chestnut, which forms a larger percentage of the second-growth than here indicated for saw timber, is badly infected with the chestnut blight (Endothia parasitica). On the forest and still intact are trench systems of Stonewall Jackson.

Supervisor's headquarters at Harrisonburg, Va.‡ (B. \& O. R. R. and So. $\mathrm{Ry}$.). The Massannutten area is accessible (a) from Harrisonburg, Woodstock, Edinburg and Strasburg, Va.; the Shenandoah from Harrisonburg and Staunton, Va.; and the Potomac from Woodstock, Edinburg, and other points in Virginia.

Unaka National Forest (Virginia, Tennessee, and North Carolina). Area 155.466 acres in two principal divisions: the White Top, in Smyth and Washington Counties, Va., and Sullivan and Johnson Counties, Tenn.; and the Unaka, in Carter and Unicoi Counties, Tenn. The forest is principally of intermediate types, with the subalpine on the highest elevations in or near the National Forest. The 1916 estimate of saw timber indicates the following percentages of species: oaks (principally chestnut and black) 35 , chestnut 28 , hemlock 12, white pine 6 , yellow pines 5, yellow poplar 4, birch 2, others 8. There are two or three undisturbed stands. The remainder is culled, cutover, and largely second-growth forest.

Supervisor's headquarters at Bristol, Tenn. (N. \&. W. R. R. and So. Ry.). The White Top division may be reached (a) or (w) from Damascus, Va., the Unaka from Erwin, Tenn.

White Mountain National Forest (New Hampshire and Maine). Area 440,581 acres in Coos, Grafton, and Carroll Counties, N. H., and Oxford County, Maine. Elevations from 1000 to 6290 ft. The flora varies with forest conditions from nearly natural to badly disturbed by logging and fire. The largest area of virgin timber is the "Great Gulf" immediately below Mt. Washington. This is covered with a mixed stand of red spruce, balsam fir, and paper birch.

Supervisor's headquarters at Gorham, N. H. (B. \& M. Ry. and Grand Trunk R. R.). The whole White Mountain region is easily accessible from the Boston \& Maine, Maine Central, and Grand Trunk Railways, and excellent automobile roads penetrate it. Summer and winter resorts are numerous. 


\section{States with Deciduous Forest, Southeastern Coniferous Forest and Large Swamp Areas}

This section includes the Atlantic Coast and Gulf Coast States and Arkansas. Texas includes large areas of the three types mentioned but since its largest areas are steppe and desert grassland transition, supporting steppe animals, it is placed with the steppe areas. Arkansas includes all three types but its swamps are in no sense coastal as are most of those of the other states except Louisiana.

\section{NEW JERSEY}

\section{By T. C. Nelson}

GENERAL ACCOUNT

Physiographic features and original biota

The state of New Jersey is 8224 sq. mi. in area and exhibits rather diverse conditions. The northwestern portion of the state, which lies above a line running from Seabright to Glassboro to Bridgeton, includes many elevated and rocky districts. Within this area are the Kittatinny Mountains, the lesser ridges of the Newark and Orange Mountains, a group of ridges known as the Highlands, and the Palisades of the Hudson. The ridges are separated by depressions containing swamps and lakes. Nearly all kinds of rock and soil are found in this region. The northern third of the state is covered by glacial drift, giving to the soils of the northern and north middle counties a most varied character.

The southeastern part of the state, lying below the above-mentioned line, presents far greater uniformity in topography and in the nature of its soils. Broad sandy plains rising locally in hills 300 to $400 \mathrm{ft}$. high, with here and there an outcropping of rock, and abundant swamps comprise this area. Much of this region was within comparatively recent times sea bottom, but is much more ancient than the glacial drift to the north.

A third region of the state which forms a belt running along the eastern shore of the southeastern part of the state, and for some distance up the shore of Delaware Bay, comprises about $463 \mathrm{sq}$. mi. of low lying tide marsh and $28 \mathrm{sq}$. mi. of sandy beach. Throughout the southern half of the eastern shore the beach is separated from the mainland by shallow estuaries which communicate with the Atlantic Ocean by several inlets.

The total area of the state was shown by the survey of 1883 to include 7514 sq. mi. of land and $710 \mathrm{sq}$. mi. of water surface. Of the land $7023 \mathrm{sq}$. mi. is upland, as distinct from tide marsh, divided into $3234 \mathrm{sq}$. mi. of forest lands and 3789 sq. mi. of cleared upland. The actual coast line from Jersey City to the head of Delaware Bay is approximately $350 \mathrm{mi}$.

Associated with each of these regions is a distinct biota. Originally the northwestern area was covered with a heavy growth of hardwoods: oak, chestnut, maple, hickory, beech, tulip poplar, ash, birch, gum and elm, with a very few overgreens; white and pitch pine, red cedar, hemlock and occasional black spruce, white cedar, and tamarack (Larix laricina).

The native mammal fauna included the fox squirrel (Sciurus niger neglectus), gray squirrel (Sciurus carolinensis), red squirrel (Sciurus hudsonicus loquax), flying-squirrel (Glaucomys volans), chipmunk (Tamias striatus), woodchuck (Marmota monax), beaver (Castor canadensis), muskrat (Ondatra zibethica macrodon), deer-mouse (Peromyscus leucopus noveboracensis) and other native mice, snowshoe hare (Lepus americanus virginianus), cottontail rabbit (Sylvilagus floridanus mallurus), bobcat (Lynx rufus), red fox (Vulpes fulva), gray fox (Urocyon cinereoargenteus), mink (Mustela vison mink), weasel (Mustela noveborazensis), otter (Lutra canadensis), skunk (Mephitis nigra), raccoon (Procyon lotor), black bear (Ursus america- 
nus), Virginia deer (Odocoileus virginianus), and opossum (Didelphis virginiana).

Common birds were: passenger pigeon, quail, partridge, wild turkey, egret; common reptiles; rattlesnake, copperhead (Agkistrodon mokasen), and spade foot (Scaphiopus $h$. holbrookii), in addition to common frogs, toads and other amphibians.

The southeastern area of the state was covered principally by pitch pine and shortleaf pine (Pinus echinata), with southern white cedar (Chamaecyparis thyoides) in the very numerous cedar swamps which are characteristic of the region. The fauna was much as found in the northwestern area with the exception of copperheads and northern hare, with fewer beaver, bear, and otter, but with deer much more abundant.

Many changes have occured in this state since the coming of the white man. Nearness to large cities and ease of access made it inevitable that the resources of the state should be heavily drawn upon. Ruthless exploitation and many forest fires have removed the virgin vegetation, save for a few small plots, which though much modified still bear virgin trees. Second growth hardwoods, comprising 750,000 acres $\left(\frac{3}{8}\right.$ of the total forest area) are found in the northwestern area, while second growth conifers cover some $1,240,000$ acres of the central southeastern area. Pitch and shortleaf pine occupy nearly onehalf of this region, oak and other hardwoods one-quarter, brush land and burned areas extend over the remaining quarter, with about 4 per cent of the total in southern white cedar swamps.

The original fauna has been greatly reduced by hunters, the inroads of civilization, and by forest fires. In parts of the state, bear and otter still are occasionally seen, while in the southern part deer are plentiful. The snowshoe hare, water hen, wild turkey, passenger pigeon, and lynx have disappeared.

The coastal belt, beginning at the Metedeconk River at the head of Bar- negat Bay, and running south to Cape May and northward along Delaware Bay, contains some areas which are less modified from the original than any other portions of the state. Level salt marshes, flooded during spring tides, border the tidal areas. These are covered with dense growths of sedge grass, Spartina, with here and there patches of Salicornia, and salt grass. The bottoms of the shallow estuaries are for the most part covered by extensive growth of eel grass (Zostera marina); ditch grass (Ruppia maritima) becomes abundant in the mouths of the brackish water streams which enter these bays. Luxuriant growth of numerous marine algae cover much of the bottom and line the shores of the estuaries; these include Ulva, Enteromorpha, Egardhiella, Cystoseira, Porphyra, with many less abundant species. The fauna is that characteristic of muddy bottoms and sandy beaches.

\section{Pollution}

The chief rivers of the state, except the largest, the Mullica River, and the Great Egg Harbor, Tuckahoe Rivers, and the Maurice River, are all grossly polluted. The lower portions of the Passaic, the Hackensack, and the Raritan Rivers, are little better than open sewers. Twenty years ago shad, herring and other fish ascended these streams in quantity, but none are found now. Many of the smaller streams of the state, notably those connected with public water works, are free from pollution and contain trout and other game fish. Barnegat Bay, and most of the estuaries north of Atlantic City, together with the streams entering them are largely unpolluted, and save for first and second cuttings of the southern white cedar in the swamps present in a few spots conditions which are but little modified from the original.

\section{Preserves}

State owned forest preserves, eight in number, comprise about 57,134 acres, with a possible additional 33,000 acres 
which it is hoped may be added to the Kittatinny Mountain Project. Five of these parks are in the southeastern part of the state, the remaining three in the extreme northwestern portion. Three game sanctuaries and fish hatcheries make up 5656 acres while 181,400 acres have been set aside by individuals and corporations for forestry projects or for private parks. With the exception of the state owned parks these areas have been so profoundly modified by selective cutting that none remains in even seminatural condition. Introduction of foreign plants and animals (the Japanese beetle, for example) has caused even further modifications. ${ }^{1}$

\section{NATURAL AREAS}

\section{1. *Bass River State Forest. (C3.)} Burlington County, sand area, 1633 acres of open forest on the Bass River. Second growth pitch pine, shortleaf pine with various oaks, such as white, red, and chestnut oak, mixed in. Area contains several southern white cedar swamps, typical sphagnum bogs with second growth white cedar. River moderate, unpolluted. 10 to $50 \mathrm{ft}$., level. Under state control since 1905-07. Contains some experimental plantations.

Philadelphia, Pa. $\ddagger 2 \frac{1}{2}$ hours on $\mathrm{P}$. R. R. to Tuckerton, N. J. $\ddagger, 6 \mathrm{mi}$. N.W. (a).-T. C. Nelson.

2. *Penn State Forest. (C3.) Burlington County, sand area, 2764 acres on the headwaters of the Wading River. Second growth pitch pine, shortleaf pine, little oak except the true scrub oak mixed in with pine. Several southern white cedar swamps, sphagnum bogs with second growth white cedar. River moderate, unpolluted. Of all the state forests in southern New Jersey this tract shows the most nearly undisturbed conditions. Elevation 50-165 ft., level. Under state control since 1910.

Atlantic City,$+ 2 \frac{1}{2}$ hours on C. R. R.

1 The writer is indebted to the New Jersey Department of Conservation and Development for most of the information contained in descriptions 1 to 8 inclusive, and for important facts contained in other descriptions here listed.) of N. J. to Chatsworth \& (a) 6 mi. S.E.T. C. Nelson.

\section{3. *Lebanon State Forest. (C3.)}

Burlington County, 4812 acres in the typical south Jersey sand area, second growth pitch pine, shortleaf pine, oak southern white cedar. Contains experimental plantations. Under State control since 1908-09. 100-160 ft. level.

Trenton $\ddagger$, 1 hour on P. R. R. to Pemberton $\ddagger$ (a) $9 \mathrm{mi}$. S.E.-T. C. Nelson.

4. *Jackson State Forest. (C4.)

Ocean County, sand and sandy loam, 43 acres of forest 40 years old. Consists of nearly pure pitch pine and shortleaf pine with few oaks. Used for demonstration of practical methods of forestry. $160 \mathrm{ft}$. level. Under state control since 1915.

Lakewood. $\ddagger 10 \mathrm{mi}$. W. to Cassville (w).-T. C. Nelson.

5. *Mount Laurel State Forest. (C4.) Burlington County, 21 acres, upland forest, mixed hardwoods, red, black, and chestnut oaks, red maple, hickory, tulip poplar, white ash, fed gum, black gum, black locust, some scrub pine. 70-175 ft., rolling. Under state control 1908.

Philadelphia $\ddagger$, $\frac{1}{2}$ hour on P. R. R. to Moorestown $\ddagger$ (a) 3 mi. S.E.-T. $C$. Nelson.

6. *Kittatinny Mountain Project. Proposed. (C2.) Sussex County 40,000 acres of hardwoods on Kittatinny mountain, which extends about 36 miles north from the Delaware Water-Gap. It contains 12 small lakes besides many unpolluted streams; 7231 acres of this already preserved in the Stokes Forest (7). As this region embraces some of the most extensive woodlands and least disturbed areas in the State it is desirable that the remaining 33,000 acres be acquired with the least possible delay. 700-1800 ft., rolling.

May be entered as in 7 , or through highways by (a) from New York City in less than 3 hours.-T. C. Nelson.

7. ${ }^{*}$ Stokes State Forest. (C3.) Sussex County, 7231 acres of upland forest in the Kittatinny Range, Blue Mountains. Second growth hardwoods in- 
cluding oaks, chestnut, maple, birch, beech, hickory, ash, with some pitch pine, white pine, hemlock. Streams unpolluted. $700-1600 \mathrm{ft}$., rolling to sharp. Acquired by state 1907-18.

New York City $\ddagger, 3$ hours on Lackawanna R. R. to Branchville \& (a) $3 \mathrm{mi}$. W.-T. C. Nelson.

Swartzwood Lake. (B2.) Sussex County, 560 acres in the foothills of the Blue Mountains; 544 acres of this is water, and about 16 acres of land approaches including a 12 acre hemlock grove. Maintained as recreation area by State.

New York City $\ddagger, 3$ hours on Lackawanna R. R. to Newton $\ddagger$ mi. N. W., or Susquehanna Western R. R. to Swartzwood Sta. $\S$ (a) 2 mi. N. W.T. C. Nelson.

\section{9. * Buckwood Park. (C3.) Game} Preserve, 5000 acres leased for this purpose for 5 years. Lies in Knowlton, Blairstown, and Pahaquarry townships, to S.E. of Kittatinny Mountain Project.

New York City $\ddagger$, 3 hours to Warren, $\ddagger$ (a).-T. C. Nelson.

10. *State Fish Hatchery. (C4.) 119 acres of open deciduous forest and pools used for fish cultural purposes.

Hackettstown $\neq-T$. C. Nelson.

11. *Game Farm. (C4.) Ocean County, 537 acres of sand area on Barnegat Bay sand area. Pines, southern white cedar swamp, along Forked River. Elevation less than $30 \mathrm{ft}$.

Lakewood $\ddagger, 1$ hour C. R. R., to Forked River $\ddagger(\mathrm{w}) .-T$. C. Nelson.

12. Newark City Watershed Preserve. (C4.) Morris and Passaic Counties, about 20,000 acres of mixed hardwoods in rough upland along headwaters of Pequahannock Creek. Stream unpolluted.

Extensive replanting before the war, will probably continue.-T. C. Nelson. 13. White Oak Ridge: East Orange Watershed Preserve. (C4.) Essex County, about 1400 acres of hardwoods, plus 400 acres unforested land. Extensive replanting and conservation of timber practised.-T.C.Nelson.

\section{Private Estates}

14. *New Jersey Zinc County, Preserve. (F6.) About 10,000 acres of hardwoods at Franklin, N. J.

15. *Ringwood Iron County, Preserve.
About 45,000 acres of hardwoods at Ringwood, N. J. $\ddagger$

16. *Wharton Estate. (C3.) Burlington, Camden, and Atlantic Counties. About 100,000 acres in the sand area of pitch pine, shortleaf pine, few oaks. Area centers about Atsion, 2 hrs. from Atlantic City on C. R. R. Headquarters at Hammonton. $\ddagger$

17. * Kinney Estate. (F6.) About 5000 acres of hardwoods, mixed, at Butler, N. J. $\ddagger$

18. *Hartshorne Estate. (F6.) Contains a few acres of virgin hardwoods, have been in estate of family since colonial days. Chestnuts suffering with blight the only trees removed. Highlands, N. J. $\ddagger$

19. ${ }^{*}$ Chrystie Estate. (F6.) Few acres of virgin stand of oak, hickory, ash, maple, beech. High Bridge, N. J. + -T.C. Nelson.

The Worthington Forest and Game Preserve. 2500 acres is on the New Jersey side at the Delaware Water Gap. Shawnee on Del.

Barren or semi-barren areas of interest to the ecologist

20. Pine Barrens. (D4.) Between Bass River Forest and Penn Forest, and between Penn Forest and Lebanon Forest lie about 30,000 acres of stunted pines. These bear seeds when about 3 to $4 \mathrm{ft}$. high, do not grow taller. Many deer, rabbits, quail and other animals found here.

Reached as for any of the above named forests, see $1,2,3 . T$. C. Nelson.

21. Barnegat Sand Area. (A4.) Ocean County, sand spit about $\frac{1}{4}$ to $\frac{1}{2}$ mi. wide and $12 \mathrm{mi}$. long which separates Barnegat Bay from the Atlantic Ocean. Covered with several species of Spartina and other grasses, with occasional clumps of red cedar, and bay bushes. Area includes many sand dunes, ocean beach, salt ponds, salt marshes. Except for occasional Coast Guard Stations region is practically undisturbed. Barnegat Bay practically unpolluted, furnishes excellent region for study of transition from fresh water to marine fauna and flora. Water of Barnegat Bay shows sub-tropical conditions during summer, many broad flats with typical Zostera associations. Alt. 0-40 $\mathrm{ft}$. level.

New York or Philadelphia $₫ 3$ hours on P. R. R., to Seaside Park, 1 mi. S. E.T. C. Nelson.

\section{References:}

For map of forest areas and distribution of species of trees thereon see 
reports of the State Department of Conservation and Development, especially 1919 .

\section{REFERENCES}

Britton, N. L. 1889. A catalogue of the plants of New Jersey. Report of the State Geologist, Vol. II, Pt. 1, p. 27-642. Trenton, N. J.

Harshberger, J. W. 1900. An ecological study of the New Jersey sand flora. Proc. Acad. Nat. Sci. Phila. for 1900, p. 623-671.

Harshberger, J. W. 1910. The vegetation of the Navesink Highlands. Torreya, 10: 1-10.

Harshberger, J. W., and Burns, V. G. 1919. The vegetation of the Hackensack Marsh; a typical American fen. Trans. Wagner Free Inst. Sci., Vol. IX, Pt. 1.

Martin, G. W. 1923. Food of the Oyster. Botanical Gazette, Vol. LXXV, No. 2, p. 143-169. (Contains descriptions of salt marshes and partial list of flora of marshes and adjoining bays.)

Nelson, Julius. 1889. A catalogue of the Vertebrates of New Jersey. Report of the State Geologist, Vol. II, Pt. II, p. 489-824.

New Jersey Department of Conservation and Development. Annual Reports, especially for 1917, 1918.

New Jersey State Museum. Annual Reports.

Noble, G. K. and R. C. 1923. The Anderson tree frog. Zoölogica, Vol. II, No. 18. (Contains important references to biota of pine barrens.)

Stone, W. 1910. The plants of southern New Jersey with especial reference to the flora of the pine barrens. Ann. Rpt. N. J. State Museum for 1910, Part II.

\section{DELAWARE}

\section{By Frank Morton Jones}

\section{General FEATURES AND ORIGINAL BIOTA}

Delaware, with a land area of approximately only 1950 sq. mi., and with the least average elevation above sea level of any of the states, yet includes within its limits a far from uniform physical environment, and naturally possesses a rich and varied fauna and flora. About one-twentieth of its area, in the north, lies within the Piedmont Plateau, with rocky hills reaching a maximum height of $440 \mathrm{ft}$.; the remainder of the state lies on the Atlantic Coastal Plain, and is rolling to flat, usually not exceeding $60 \mathrm{ft}$. above sea level. With the exception of the tidal marshes bordering the Delaware River and Bay, the estuaries of the larger streams, and the sanddune and salt-marsh areas adjacent to the Atlantic Ocean, the state originally was heavily forested. The original forest was principally hardwood,almost exclusively so in the north. At the south-central extremity of the state, a large area, still indicated on the maps as "Cypress Swamp" or "Cedar Swamp," once included within its limits a magnificent growth of cypress.

The once abundant bald cypress (Taxodium distichum), the occurrence of such plant forms as the Muscadine grape (Vitis rotundifolia), the sweet leaf (Symplocos tinctoria), the habitual nesting of the prothonotary warbler (Protonotaria citrea), the yellowthroated warbler (Dendroica d. domin$i c a$ ), the summer tanager (Piranga $r$. rubra), -all point to a marked admixture of southern (Lower Austral) forms in lower Delaware, more marked than is the presence of northern species in the proportionately much smaller Piedmont Plateau region, whose fauna and flora are essentially identical with those of southeastern Pennsylvania. The Swedish records for this region (northern Delaware) include reference to the shipment of the skins of bear, lynx, and beaver, to Sweden and to England; to the abundance and the destructiveness of wolves; and to the use of the wild turkey and the passenger pigeon as food.

\section{PRESENT BIOTIC CONDITION}

In the Piedmont Plateau portion, the hardwood forest has been largely removed, except on the steeper hills and the narrow stream-valleys. On the Coastal Plain, much of the upland swamp area, through clearing and draining, has been converted into agricultural land; dykeing, ditching, and filling have materially modified or destroyed many of the tidal marsh 
areas, which, however, are still extensive; only a remnant of Taxodium remains in the Cypress Swamp, the area and character of which are greatly changed; in the sandier southern portion of the state, stands of pine or of pine and oak have replaced, to a great extent, the hardwood forest, and have also invaded abandoned agricultural lands. No considerable areas of primitive forest remain in the state. About $30 \%$ of the area of the state is forested, the proportion of woodland being greater in the south, and probably not exceeding $15 \%$ in the Piedmont Plateau region. On the Coastal Plain, by the damming of small streams, numerous permanent ponds have been created, and these with their natural margins support an extensive fauna and flora. The sea-beach areas, sand-bar strip, and adjacent salt-marshes bordering the Atlantic are largely state-owned; they have been little modified, and support the limited fauna and flora characteristic of such situations.

In Delaware, the larger mammals, black bear, Virginia deer, and beaver, have been extinct for many years; otter and mink survive; foxes, raccoons, opossums, and smaller mammals are generally distributed; a few pairs of bald eagles still nest within the state; the abundance of game birds and game fish has been affected by human agency; but lying as it does in the path of the annual migrations, and with conditions still favorable to permanent residence, Delaware possesses a rich bird fauna, and of fish-as yet little studied-probably as many species as in the past.

See Maryland for list of birds and mammals.

\section{FISH AND GAME PRESERVES}

Delaware does not contain any national or state Fish and Game Preserves. By a General Order prohibiting all hunting thereon, the state Rifle Range, 300 acres of meadow and marsh land along the Delaware River three miles south of New Castle, has been made a game refuge; and on many privately owned tracts throughout the state, all trapping and hunting are prohibited, and this prohibition is enforced in varying degree.

\section{POLLUTION}

The Delaware River, the lower Christiana, the Brandywine and Red Clay Creeks, are polluted with sewage or with manufacturing waste, though not to the extermination of their normal fauna and flora. In general, the other waters of the state are free from extensive pollution.

\section{NATURAL AREAS}

\section{A. Representative of the Hardwood Forest of the Piedmont Plateau}

The Remains of the Brandywine Forest. (D4.) New Castle County. With some interruptions, bordering the winding course of the Brandywine Creek from within the city limits of Wilmington (Wilmington City Park System) to the Pennsylvania line, about seven miles. The forest strip is of variable width (maximum, about one mi.), occupying the banks of the stream, the steep rocky slopes and the hilltops, and the narrow ravines of small tributary streams; elevation, 25 to $408 \mathrm{ft}$. above sea level. Most of this wooded area has never been completely cleared, little cutting has been done for 50 years or more, and portions of it have been protected against cutting and burning for a longer period, and approximate virgin conditions. The principal trees are oaks, chestnut (largely destroyed by the blight), tulip poplar, beech, hickory, ash, maple, and walnut. The fauna includes foxes, woodchucks, squirrels, raccoons; the vulture occasionally nests among the boulders.

Included areas of special interest or accessibility are:

Alapocus Woods. (D4.) City Park lands, and private owners); about 250 acres, bordering north side of Brandywine Creek between Augustine and Rising Sun bridges, at edge of city; fine protected woodlands, with undisturbed natural herbaceous flora.

Wilmington $\ddagger(w)$.

Rockland Woods. (D4.) Woodlawn Trustees, and private owners); about 150 acres, north side of Brandywine Creek, above Rockland; the Creek Road traverses these woodlands for $\frac{4}{5}$ mi., paralleling the stream; fine unspoiled woodlands with rich flora; steep wooded rocky hills, rising $270 \mathrm{ft}$. in 
$1000 \mathrm{ft}$. , to a maximum elevation of $408 \mathrm{ft}$.

From Wilmington $\ddagger$, $3 \mathrm{mi}$. north to Rockland (a), or Rising Sun trolley to terminus and (w); from Rockland bridge, follow Creek Road $\frac{1}{4}$ mi. north.

Garden of Eden Woods. (D4.) Woodlawn Trustees. ${ }^{1}$ About 135 acres, $4 \mathrm{mi}$. north of Wilmington, between the Concord Turnpike and Brandywine Creek, $\frac{1}{2} \mathrm{mi}$. south of Thompson's Bridge, its southern border separated from Rockland Woods by the Garden of Eden Road; bordering and occupyirg the valley of Rocky Run, to within $1000 \mathrm{ft}$. of its affluence with the Brandywine Greek. Little frequented and unspoiled woodlands, with rich flora, fine boulder masses, and a magnificent natural growth of mountain laurel. $200-400 \mathrm{ft}$.; varied.

From Wilmington $\ddagger, 3 \mathrm{mi}$. north to Rockland (a), thence Creek Road one mi. to Rocky Run bridge.

\section{B. Exceptional and Typical Coastal Plain Areas}

The Heronry near Delaware City. (D4.) Two mi. west of Delaware City, New Castle County, north of the Delaware City-St. Georges road, and occupying a marsh, swamp, and wooded slope bordering Dragon Creek (on the farm of Mr. John Higgins and adjacent properties); for many years a nesting site of the Great Blue Heron; 80 to 100 pairs present annually; the nests are usually grouped within an area of a few acres, though not always in the same trees from year to year; the adjacent marshes, the shores of the Delaware River and Bay, and the banks of the Delaware and Chesapeake canal, form extensive and convenient feeding areas. The birds have received some protection from the owner of the land. Their continued protection, and the permanent reservation of 25 acres of woodland and swamp, would probably ensure the indefinite survival of this interesting colony. $0-40 \mathrm{ft}$.

Delaware City, Delaware $;$; $(w)$ west on St. Georges road $2 \mathrm{mi}$., north across fields to edge of woods.

The Tidal Marshes of Kent County. (B3.) On the shores of Delaware Bay, in Kent County, and extending from the mouth of Smyrna River southward to

1 William P. Bancroft of Wilmington, has deeded to Woodlawn Trustees Inc. about 2000 acres of land lying to the north and east of Brandywine Creek, New Castle County, Delaware, the intent (in part) being to preserve for park purposes the steeper wooded portions bordering the Brandywine and its tributaries, thus safeguarding for the future these remnants of the Brandywine Forest.
Little Creek, is an uninterrupted tidal marsh area about $15 \mathrm{mi}$. in length, with a maximum width of $4 \mathrm{mi}$. Here, 50 sq. mi. of land surface, approximately 30,000 acres, are in more nearly their primitive condition than any other considerable area in the state. The marsh is treeless, and is cut into islands by the tortuous courses of many small creeks; its shores are not embanked and are only slightly above the level of the usual tides; with the exception of a few comparatively small intruded higher areas of farm, woodland, and sandy shore, it is without human inhabitants, and its chief commercial value consists in its production of salt hay, and in the muskrats which are trapped in great numbers. Hundreds of pairs of Black Ducks nest in the marsh.

Title to the marsh area, in general, is vested in a few owners of large tracts. No adequate study of its fauna and flora has been made.

From Dover $\ddagger$, go $5 \mathrm{mi}$. north (a) to Leipsic, at the western edge of the marsh; here motor-boats may be procured.-Major John P. LeFevre, Chief Game \& Fish Warden.

The Ellendale Forest. (C4.) The largest densely-forested areas remaining in Delaware are located in Sussex County. For example, south of Ellendale, and lying on both sides of the duPont Boulevard, with Ellendale midway of its northern boundary, a rectangle $4 \mathrm{mi}$. square (sundry private owners) has less than $20 \%$ of its area cleared, and most of the cleared portions narrowly follow the main roads. This tract of $16 \mathrm{sq}$. mi. includes the height of land between the Delaware and Chesapeake bays, and has a maximum elevation of about $50 \mathrm{ft}$. The forest varies from pine, or mixed pine and oak, to pure hardwood-its trees, in their apparent relative abundance, consisting of pine, oak, maple, in the order named; sweet gum, sour gum, tulip poplar, and holly, are also abundant; and of lesser growth, Magnolia and Aralia; Clethra and Vaccinium form a large part of the prevailing undergrowth.

Over most of this area, cutting has been intermittent and selective, rather than complete, and hardwood trees of 75 to 100 years of age still remain. The forest is penetrated by natural streams and by some artificial drainage ditches, and suggestions for its more thorough drainage and its eventual conversion into agricultural lands, are made from time to time. Sphagnum areas are present, and many of the more interesting herbaceous plants of southern Delaware occur here. Bird and insect 
records from this and adjacent and similar areas indicate an interesting fauna, as yet very inadequately investigated. 38-52 ft.; level.

From Georgetown, Delawareł, go 8 mi. north by P. R. R. to (w) or (a) Ellendale, Delaware.

Delaware Sand-bar Land. (C4.) The state-owned lands of Delaware consist almost exclusively of a narrow strip along the coast, beginning at the mouth of Broadkill River in Broadkill Hundred, Sussex County, and extending southeast and south to the Maryland line, thus including a comparatively short frontage on Delaware Bay, and (with some interruptions, notably at Lewes, Rehoboth, and Bethany Beach) the entire ocean front of the state, from Cape Henlopen southward, a total distance of about $30 \mathrm{mi}$. The width of the strip is variable, from a few hundred yards to $2 \mathrm{mi}$. or more, its western boundaries, over most of its extent, following the shallow waters of Rehoboth, Indian River, and Little Assowoman bays. Included are the sandy beaches, shifting dunes of pure sand, others partially fixed by beach grass (Ammophila arenaria) or clothed with Hudsonia; thickets of Myrica and Baccharis; extensive grassy flats; though many miles of the sand-bar strip are treeless, wherever conditions are favorable, a good stand of loblolly pine maintains itself, and the systematic afforestation of a considerable portion of these state lands has been strongly recommended.

Except in the vicinity of the towns mentioned, the sand-bar strip is almost uninhabited, and has been little changed by human agency. Most of it lies beneath the $20 \mathrm{ft}$. contour line, though at Cape Henlopen one large dune exceeds $70 \mathrm{ft}$. in height.

Lewes $\ddagger$ Rehoboth $\ddagger$; Bethany Beach $\ddagger$ (in summer).

\section{MARYLAND}

\section{By C. C. Hamilton}

\section{GENERAL CONDITIONS}

\section{The topography}

Maryland, although ranking as the eighth smallest state of the Union, is so situated that it offers a wide variety of conditions for the study of plant and animal life out of all proportions to its area. Its greatest length is some 320 mi., measured from the northwest to the southeast, which is nearly at a right angle to the general direction of the Allegheny Mountains. The state is, in effect, a cross-section of the Coastal Plain, the Piedmont Plateau and the Allegheny Ridges. The elevations pass gradually from sea-level to $3342 \mathrm{ft}$. near Table Rock in Garrett County. While the north and south extent of the state is not great $(250 \mathrm{mi}$. at its greatest point), yet it lies between the north and the south and is a meeting ground for plants and animals of northern and southern range. The geological formations range from the most ancient granite and gneiss, through rocks of every age and great mineralogical diversity, down to the coastal deposits of recent times. Overlying these varied rocks and deposits are a diversity of soils, which have been nowhere modified by glacial action, as in the neighboring states to the north. Through the middle of the coastal portion of Maryland stretches the Chesapeake Bay with its great system of estuaries, varying the topography, modifying the climatic conditions and bringing about the constant changes in the distribution of plant communities.

\section{The climate}

Although the climate in general is what is known as continental, it is greatly modified in the eastern portion of the state by the ocean and the Chesapeake Bay, and in the extreme southeast becomes almost oceanic or insular, surrounded as the land is on nearly all sides by water.

Due to the geographical position of Maryland and the increasing altitudes encountered in passing from the coast to the northwestern corner there are considerable differences in temperature, which are of importance in determining the type of vegetation. The average annual mean temperature varies from $47^{\circ}$ to $57^{\circ}$, the average annual mean maximum temperature varies from $58^{\circ}$ to $67^{\circ}$ and the average annual mean minimum temperature varies from $35^{\circ}$ to $48^{\circ}$. There is approximately three 
weeks difference in the appearance of spring between the southern and the northern part of the state and in the higher portions of the Allegheny Mountains this is increased almost two additional weeks.

The average annual rainfall varies from 30 to 55 in., with the larger amounts of rain in the extreme western part of the state (in Garrett County), in the northcentral portion of the state (in Harford and Carroll counties) and in the southcentral part of the eastern shore (in Dorchester and Wicomico counties). The greater part of the state receives an average annual precipitation of 40 to $45 \mathrm{in}$. The precipitation is more or less equally distributed throughout the months, when the means for a long term of years are taken.

\section{The original biota}

Maryland lies in a region in which the dominant vegetation was the deciduous forest, and before settlement by the white man, the state was undoubtedly covered by continuous forests. Only here and there were there restricted areas of marshes, bogs, bare rocks, or sandy areas, in which local conditions were not favorable for tree growth. The forests differed from place to place in their vegetational landscape aspects. Shreve $^{1}$ in his Vegetational Map of the United States, divides the state into four regions. These are, beginning with the southernmost portion of the state and extending north and westward, the Southeastern Mesophytic Evergreen forest, the Deciduous forest, the Northern Mesophytic Evergreen forest, and the Northeastern Evergreen Deciduous Transition forest. These vegetational landscape aspect regions in Maryland correspond-fairly closely-respectively to the Louisianian, Carolinian, and Alleghenian zones of Verrill and to the Lower Austral, Upper Austral and the Transition Life-zones of Merriam.

Since, in the undisturbed condition, Maryland was originally largely covered

1 Shreve, Forrest,Vegetational Map of the United States, Geographical Review, February, 1917. with deciduous and evergreen forests, the animal life must have largely corresponded to that generally found in forests of that type. There was, no doubt, considerable difference in the southeastern and the northwestern parts of the state due to the differences in the climate and the physiography. These differences in the animal and plant biota will be discussed according to the various vegetat onal landscape aspect regions as given by Shreve, Chrysler, Blodgett and Besley. ${ }^{2}$

\section{The Southeastern Mesophytic Forest}

This region includes the area south and eastward from a line extending from the Delaware Bay across the middle of Delaware, through Caroline and Queen Anne counties in Maryland to Baltimore City, from there to the District of Columbia, and thence across the eastern one-third to one-half of Virginia, North Carolina, South Carolina, and southward. This area was largely a forest of evergreen needle-leaved trees with a subordinate admixture of evergreen broad-leaved and deciduous species. Extensive areas in Maryland were pure stands of loblolly pine (Pinus taeda) in open formation, nearly devoid of shrubs and carpeted with grasses and herbaceous plants. Most of this area has but little elevation, only in a few places rising above $150 \mathrm{ft}$. Many swamps, marshes and bogs were common along the low lying shore of the Chesapeake Bay and its tributaries. The marshes of the Eastern Shore aggregate many acres in area and are most extensive in Dorchester and Somerset counties, and have probably changed but little from their original condition. These marshes are of both the salt and the fresh water kind.

The plant life of the salt marshes is limited to those plants which have

2 Shreve, Forrest, Chrysler, M. A., Blodgett, Frederick and Besley, F. W. The Plant Life of Maryland. Maryland Weather Service. Special publication, No. III, 1910. Pp. 533.

This publication is a very valuable piece of work and should be consulted by anyone interested in the ecological plant life of Maryland. It has served as the basis for much of the information regarding plants contained in this report. 
adapted themselves to living in soil or water of high osmotic pressure due to the salt in solution. Salt marsh grass (Spartina glabra) predominates on the outer parts of the salt marshes, while in the inner portions there are associated with it some of the more salt resisting plants, such as Salicornia europaea, Spergularia marina, Atriplex hastata, and Aster tenuifolius.

The vegetation of the fresh water marshes is much more abundant than that of salt marshes, and consists principally of grasses and herbaceous plants. These marshes lie along broad, low streams and are areas above high tide. As one passes up the salt marshes into the fresh water marshes Spartina glabra and Spartina patens soon give way to stands in which one or another of Scirpus americanus, S. olneyi, S. robustus, Spartina cynosuroides, and Zizania aquatica are dominant. Reed (Phragmites communis) and cat-tail (Typha angustifolia) also occur in more or less pure stands. Besides these more or less dominant plants a large variety of other plants will be found.

The vegetation of the dunes and strand along the ocean front is characteristically devoid of trees and made up of a limited number of species of grasses and herbaceous plants of xerophytic character. The fringing bar which forms the ocean front of Maryland is very narrow from the Delaw are line southward to the Chincoteaque Bay, below which it widens, but nowhere exceeds a mile in width. Along its inner side the bar is fringed by fresh or salt marshes and on the outer side is a low series of dunes, everywhere being in a comparative stable condition. The predominant plant of the dunes is sand reed ( $\mathrm{Am}$ mophila arenaria), with which are associated the plants characteristic of dunes throughout the north Atlantic Coast, as American sea rocket (Cakile edentula), beach heather (Hudsonia tomentosa), sea beach sandwort (Arenaria peploides), seaside evening primrose (Oenothera humifusa), cocklebur (Xanthium canadense), saltwort (Salsola kali), knotweed spurge (Euphorbia polygonifolia), and seaside knotweed (Polygonum maritimum).

The animal fauna of the Southeastern Evergreen forest $w^{\circ} \mathrm{s}$, in the original undisturbed condition abundant and probably quite varied. Some of the characteristic mammals ${ }^{3}$ for this region were the Virginia muskrat (Ondatra zibethica macrodon), the rice rat (Oryzomys palustris), Bachman shrew (Sorex longirostris), the little short-tailed shrew (Cryptotis parva) and the fox squirrel (Sciurus niger). This squirrel also extends into the Deciduous forest region.

Other mammals which occurred in this region but also in other regions are the meadow vole (Microtus pennsylvanicus), the gray fox (Urocyon cinereoargenteus), the eastern cotton-tail rabbit (Sylvilagus floridanus mallarus), the beaver (Castor canadensis). The beaver is exterminated except for a few colonies in West Virginia. The otter (Lutra canadensis), raccoon (Procyon lotor), mink (Mustela vison mink), the Virginia deer (Odocoileus virginianus), the black bear (Ursus americanus), the red fox ( Vulpes fulva), the bob-cat (Lynx rufus), the short-tailed shrew (Blarina brevicauda), the star-nosed mole (Condylura cristata) and the common mole (Scalopus aquaticus).

The bird fauna of the Southeastern Mesophytic Evergreen Forest was, and still is, exceedingly rich. The list of birds have been furnished by Dr. A. Wetmore $^{4}$ of the U. S. Biological Survey, Washington, D. C. Some of the species characteristically breeding along the marshes and beaches are as follows: Gull-billed tern, Caspian tern, Forster's tern, least tern, black skimmer, king rail, clapper rail, willet, piping plover, Wilson's plover, sharp-tailed sparrow, and the seaside sparrow.

Some of the migrant species found

3 The list of mammals has been kindly furnished by Dr. H. H. T. Jackson, of the U. S. Biological Survey.

${ }_{4}$ The nomenclature used in the lists of birds follows that of the American Ornithologists Union Checklist, 3rd ed., 1910, with the three supplements issued to date, which are published in the Auk for 1912, pp. 380; 1920, p. 440; and 1923, p. 513. 
usually near the coast are Holbœll's grebe, loon, red-throated loon, dovekie, great black-backed gull, laughing gull, Leach's petrel, Wilson's petrel, gannet, old-squaw duck, American scoter, whitewinged scoter surf scoter, brant, whistling swan, American egret, little blue heron, dowitcher, knot, redbacked sandpiper, sanderling, blackbellied plover, golden plover, semipalmated plover, ruddy turnstone, and oyster-catcher.

Species breeding generally throughout the coastal plain are as follows: fish hawk, chuck-will's-widow, fish crow, boat-tailed grackle, Prothonotary warbler, yellow-throated warbler, longbilled marsh wren, and the brownheaded nuthatch.

The insect fauna of the southeastern mesophytic evergreen forest region has not been studied in relation to the original biota. The number of species of insects is much larger than for the larger forms of life and many insects are limited very much more to distinctly local vegetational conditions. Instead of attempting, therefore, to give a list of species characteristic of this region it will probably serve the purpose much better to name some of the vegetational associations, or types, each of which will have their characteristic local fauna. If the area as a whole was originally a mesophytic evergreen forest the predominating types of insects must have been those of this type of forest. All orders of insects were represented; certain ones, however, more noticeably than others. In the Hymenoptera the Cynipidae and the Tenthridinidae are important while the Cecidomyiidae is one of the important families of the Diptera. The beetles or Coleoptera constitute one of the most important of all orders occurring in forest areas. Of this order the Buprestidae, the Cerambycidae, the Chrysomelidae and the Scolytidae are very important. The Bombyidae and Sesiidae are very important groups of the moths.

A more restricted insect fauna will be found in the salt marshes. In these situations the number of species of plants are limited, due to the salty water, thus limiting the number of species of insects. The fresh water marshes farther back will have a corresponding larger insect fauna, due to the increase in the number of species of plants.

The beaches and sand dunes have an insect life very different from that of the forest but very similar to that of beaches and sand dunes along the Atlantic Coast.

\section{The Deciduous Forest}

This area extends northward and westward from the limits of the Southeastern Mesophytic Evergreen forest and includes all the remaining portion of Maryland except Garrett County in the extreme northwest.

The western portion of this deciduous forest area in Maryland is much rougher and rockier than the eastern portion. It is crossed by four natural belts extending from the north to the south. Three of these belts are hilly or mountainous; the Parr's Ridge belt, the Blue Ridge, including Catoctin Mountain, and the group of ridges westward from North Mountain. The fourth belt lies mainly between the Blue Ridge and North Mountain.

The commonest trees were species of oak (Quercus), hickory (Carya), chestnut (Castanea dentata), beech (Fagus grandifolia), maple (Acer saccharum), walnut (Juglans nigra), tulip tree (Liriodendron tulipifera) and ash (Fraxinus). The vegetation in this area is the least diversified of any of the ecological districts of Maryland. The topography of the lower part is quite uniform and the marshes and swamps are absent. The soil is also more uniform, playing an important rôle in the plant life.

The mammals distinctly characteristic of and more or less limited to the deciduous forest area are few in number. The New England cotton-tail rabbit (Sylvilagus transionalis) is quite characteristic of the deciduous forest area. The gray squirrel (Sciurus carolinensis) is characteristic of this region but also extends into the Northeastern Mesophytic Ever- 
green forest. The elk (Cervus canadensis), which has long been exterminated, was probably characteristic of the deciduous forest area.

In addition to the mammals listed above as typical and distinct for the deciduous forest the following generally distributed mammals occurred: meadow vole, common mole, star-nosed mole, short-tailed shrew, eastern cotton-tail rabbit, gray fox, red fox, beaver, otter, raccoon, mink, bob-cat, Virginia deer and black bear.

The birds characteristically limited to the deciduous forest area for their breeding are quite few. The southern robin is one of these.

Some of the breeding species occurring here but found also on the Coastal Plain or Southeastern Mesophytic Evergreen forest are as follows: red-billed woodpecker, orchard oriole, cardinal, summer tanager, Louisiana waterthrush, Kentucky warbler, hooded warbler, yellow-breasted chat, Carolina wren, tufted titmouse, Carolina chickadee, and blue-gray gnatcatcher.

Species breeding in the deciduous forest area but also found in the Northeastern Evergreen Deciduous Transition forest, are as follows : ruby-throated humming bird, Baltimore oriole, cliff swallow, and the white-breasted nuthatch.

The insect fauna of the Deciduous forest region was probably that typical of deciduous forests in general. There were no marshes, bogs or sand dunes in this area so that the insects found inhabiting such places were absent. Streams, many of them with considerable fall, are numerous. There were probably many small clearings in the forests which would have a fauna different from the solid forest.

\section{Northern Mesophytic Evergreen Forest}

The Northern Mesophytic Evergreen forest area includes within its boundaries all of Garrett County, except a small corner in the extreme northwestern part. This area extends north and south as a narrow belt across the western one-third of Pennsylvania, Garrett
County in Maryland and south across West Virginia, including a small spot in Virginia. This region was characterized throughout by a pure or nearly pure stand of needle-leaved evergreen trees, among which deciduous trees were often present either as minor components of the forest or else as trees of lower stature. In the eastern portion the white pine (Pinus strobus), the hemlock (Tsuga canadensis), the jack pine (Pinus banksiana), and the balsam fir (Abies balsamea) were among the most common. White oak and white pines were formerly present in pure stands.

The mammals characteristic of this region are the smoky shrew (Sorex fumeus), the snowshoe hare (Lepus americanus virginianus), the cloudland deer mouse (Peromyscus maniculatus nubiterrae), the red squirrel (Scuirus hudsonicus loquax), and the hairy-tailed mole (Parascalops breweri).

Other mammals found in this region and also common in the other regions of the state are the meadow vole, eastern cotton-tail rabbit, beaver, otter, raccoon, mink, Virginia deer, black bear, red fox, bob-cat, short-tailed shrew, star-nosed mole, and the common mole.

Among the birds mainly restricted to the Northern Mesophytic Evergreen forest area are two, the Carolina junco, and Cairn's warbler.

Characteristic birds found as migrants throughout the state are the magnolia warbler, Blackburnian warbler, blackthroated green warbler, water-thrush, Canadian warbler, red-breasted nuthatch, brown creeper, and the veery.

\section{Northeastern Evergreen-Deciduous Transition Forest}

This region lies as a narrow belt to the west of the Northern Mesophytic Evergreen forest and is about one-third its width. It includes only a small portion of the extreme northwest corner of Garrett County. It is a region in which the trees of the deciduous forest area to the west and those of the eastern portion of the Northern Mesophytic Evergreen forest were intermingled in nearly equal 
proportions. A very common type of forest in this region was that in which maple (Acer saccharum), beech, and hemlock (Tsuga canadensis) were dominant.

The common muskrat (Ondatra zibethica zibethica) was characteristic of this region. Other mammals found here and common throughout are the meadow vole, common mole, star-nosed mole, short-tailed shrew, eastern cotton-tail rabbit, gray fox, red fox, beaver, otter, raccoon, mink, bob-cat, Virginia deer, and black bear.

The species of birds mainly restricted to this area are the northern raven and the mountain vireo.

The characteristic breeding species of this region found as migrants throughout the state are black-billed cuckoo, yellow-bellied sapsucker, alder flycatcher, prairie horned lark, bobolink, cowbird, rose-breasted grosbeak, goldenwinged warbler, cerulean warbler, chestnut-sided warbler, Wilson's warbler, Bewick's wren, black-capped chickadee, Hermit thrush, and the robin.

\section{Present biota}

The animal and plant life of Maryland has been considerably modified through the clearing of the forests, the cultivation of the land and settlement by man.

The Southeastern Mesophytic Evergreen forest region has many areas which are still in the original or semi-original condition. The marshes, swamps, sandy dunes and beaches have changed but little, and probably has an animal fauna, especially of the smaller forms, somewhat similar to the original. This is particularly true of the insects and many aquatic and semi-aquatic animals. The wooded areas have probably all been cut over once and some several times. While most of the arable land has been cleared, there are still large areas heavily timbered, some of which are pure or nearly pure stands of pines. The larger mammals listed for this region are extinct but most of the smaller ones are still found. The birds are probably very nearly as given in the list for this area.

The eastern and central portion of the deciduous forest area is mostly cleared and tilled. There are, however, many small areas with deciduous forest trees. The western portion of this area is much rougher and has many acres of land in a semi-natural condition. It has all been cut over and much allowed to reforest itself. Most of the larger mammals listed in the original biota for this region, although scarce, are still found. The smaller mammals, and birds are probably all present, although their numbers are not as numerous.

The area included in the Northern Mesophytic Evergreen forest still has several stands of virgin timber. These are listed in the list of natural areas available for study. The topography is rough and rocky with only small valleys under cultivation. The animal and plant life is abundant and offers an excellent opportunity for study.

\section{NATURAL AREAS}

\section{Forest Reserves}

*Herrington Manor State Forest.

In Garrett County, consists of 650 acres, of which about 200 acres are in the original condition of virgin forest, principally of the white oak type. It occupies a plateau of about $2500 \mathrm{ft}$. and is one of the few undisturbed areas in the state. The fauna consists typically of that listed for the Northern Mesophytic Evergreen forest. It is on a state road, has good trails through it and is used as a state play ground with a forest warden in charge.

Oakland, about 4 mi. southeast, B. \& O. R. R. The park can be reached by automobile.-F. W. Besley.

*Swallow Fall Reserve. (C2.) Consisting of 823 acres, *Skipnish Forest Reserve (C2), consisting of 888 acres and *Kindness Forest Reserve (C2), consisting of 206 acres, are in Garrett County situated from 3 to $7 \mathrm{mi}$. from Oakland. The first two named are north of the Herrington Manor Reserve while the 
Kindness Reserve is a short distance south. These three reserves consist principally of deciduous forests cut over previous to 1906 at which time they were acquired by the state. The flora and fauna is similar to that of the Herrington Manor reserve.

Oakland, B. \&. O. R. R. then (a) or wagon.-J. H. Harshberger and C. C. Hamilton.

*Patapsco State Forest Reserve. (C2.) In Howard and Baltimore counties along the Patapsco River. It consists of nearly 1000 acres of state owned land and about 1500 acres of private land, the use of which is given to the state for forest reserve purposes. Some of this area is in its original condition, and it is held in a wild state, with the exception of building of roads and trails to make it accessible to campers. The region consists of a gorge cut through by the Patapsco River, with steep slopes on either side. It has a most interesting flora, including a great variety of tree species and shrubs. The animal fauna consists essentially of the smaller mammals and most of the birds listed for the deciduous forests. These are not abundant due to the nearness to Baltimore. The reserve is about $10 \mathrm{mi}$. from Baltimore and is open to campers and others who may wish to take advantage of outdoor life.

Baltimore, 10 mi. w., B. \& O., Penn., and other R. R. Frequent train service on the old main line of the B. \&. O. R. R. from Relay makes most parts of the reserve easily available.-F. W. Besley.

*Meadow and Negro Mountains Game Preserve. (C2.) Consisting of 4000 acres in Garrett County, privately owned but the use of it is given to the state for game protection, and is maintained in as near a natural condition as is possible. It is a cut-over deciduous forest. The animal fauna is principally an overlapping of that of the Northern Mesophytic Evergreen forest and the western portion of the Deciduous forest. Most forms are present although the larger forms of animals are scarce. Elevation about $2500 \mathrm{ft}$.
Oakland, 10 mi. S.W., B. \&. O. R. R.; two mi. N.E. (a) from Thayersville.F. W. Besley.

*Woodmount Rod and Gun Club.

Have leased in Washington County an area of approximately 1000 acres. This is located on both sides of Sidling Mountain, is principally virgin forest and is kept for game propagation. Wild turkey and quail are more abundant here than elsewhere in the state. About $2500 \mathrm{ft}$. elevation.

Hancock, about 15 mi. east, B. \&. O. R. R. and Western Maryland R. R.; a short distance north (w) from Woodmont Station, Western Maryland R. R.C. C. Hamilton.

*Plummers 1sland Preserve. This consists of an island of 13 acres, located on the Potomac River in Maryland, $5 \mathrm{mi}$. west of the District of Columbia line and 45 acres, flanking the island on the Maryland shore and extending from the bank of the river to the Chesapeake and Ohio Canal. All but 12 acres are thickly covered with deciduous forest growth. The property is well fenced, and visitors are only allowed in company with a member. None of its wild life may be destroyed or removed, unless it is of very objectional character, except for scientific purposes. The island has a cabin for the accommodation of members and guests while studying the fauna and flora of the area. The island is maintained its natural condition, the only introductions being a few rare wild plants around the cabin. On the mainland, any wild plant of the region, not poisonous, or an especially aggressive weed, may be introduced, and colonies of many of these have been established. The property is owned by the Washington Biologists Field Club. Systematic and life-history study of the fauna and flora of the preserve, the most conspicuous of which has been the identification of over 2000 species of beetles from the area and the working out of the lifehistories of a number. A long bibliography of publications relating to the preserve is available and the general features of the preserve are given in 
some detail in the members book published in 1913.-P. L. Ricker.

${ }^{*}$ Gwynnbrook State Game Farm at Gwynnbrook. (B3.) Baltimore County, consisting of 290 acres used to propagate game (at the present time principally quail and pheasants) for distribution to the various counties.

Baltimore, $16 \mathrm{mi}$. north; Gwynnbrook Station, Western Maryland R. R.; or get in touch with the Conservation Commission of Maryland, Munsey Building, Baltimore-C. C. Hamilton.

Zekiah Swamp. (B3.) Is about 6 mi. east of La Plata, the county seat of Charles County, extending for about 13 mi. in a northerly and southerly direction, and is about $\frac{1}{2} \mathrm{mi}$. wide. It is a fresh water swamp which has resulted from seepage and also the silting of Zekiah Creek. The interior of the swamp is in virgin timber, while the margins show successive encroachments of the forest upon adjacent cleared lands. In some places, three parallel lines of ditch banks are evident. These parallel ditches represent three lines of defences thrown up at different periods to protect the adjacent cleared land from becoming water logged. Outside of the first ditch, probably built 75 or 100 years ago, and extending to the second ditch, is a growth of timber of corresponding age. Between the second and third ditches is a later growth, of probably 40 or 50 years. Then outside of the third ditch, the younger forest, grading down to very small trees on the outer edge, has encroached extensively into the open spaces, producing a rather wide swamp in some places.

In the forest may be found opossum, muskrat, squirrels, and other common mammals, and the birds listed for the deciduous forest area. Elevation but little above sea level.

La Plata, $6 \mathrm{mi}$. west of the marsh, is on the P. B. \& W. R. R. and may be reached from Washington, D. C.F. W. Besley.

\section{A peculiar upland swamp. (B4.) 7} mi. northeast of Oakland, near Thayersville, covering some 10 acres on which is found tamarack, black spruce, Canadian yew, cranberry bogs, and vegetation peculiar to this type. So far as I know this is the southernmost native stand of tamarack. There is another swamp somewhat similar near Cranesville, about $10 \mathrm{mi}$. northwest from the one described. About $2500 \mathrm{ft}$.
Oakland, 7 mi. N.E., B. \& O. R. R.; one mi. N.E. from (W) Thayersville, Md.-F. W. Besley.

Swallow Falls. (B4.) On the Youghiogheny River, $7 \mathrm{mi}$. north of Oakland, Garrett County, which has for its setting a 10 acre virgin forest of hemlock, with its undergrowth of rhododendron and other types associated with hemlock. The animals are those common to western Maryland. $2600 \mathrm{ft}$.

Oakland, $7 \mathrm{mi}$. north, B. \& O. R. R. (a) or wagon to the swamp. $-F$. $W$. Besley.

Magnolia Bogs. (C4.) Extending along Indian Creek from Ammendale, Hollywood, Riverdale, Hyattsville, Bladensburg, Reform School and Deanewood, a distance of about $15 \mathrm{mi}$. This is boggy land, due to water from the adjacent hills, which seeps out from a layer of sand between two layers of clay and is intensely cold. The common mammals are present but scarce. See McAtee, W. L.; A sketch of the Natural History of the District of Columbia with an index map. Bulletin of the Biological Society of Washington, No. 1, May, 1918, pages 74-90. Should be preserved.

Washington, D. C. Any of the above mentioned places can be reached to within a short distance by trolley.$J$. W. Harshberger.

*Edgewood Government Reservation. (C2.) Consists of a tract of approximately $16 \mathrm{sq}$. mi. extending along the west bank of the Chesapeake Bay between the Bush and Gunpowder Rivers, a distance of $8 \mathrm{mi}$. The tract extends from the bay back to the Pennsylvania R. R., an average distance of $2 \mathrm{mi}$. It is used for a Government Arsenal. Much of this is low, marshy land and is covered with second growth timber consisting of oak, gum and tulip. Wild life of all kinds abounds here. Geese, ducks of many kinds and the whistling swan are found on the waters; otter, mink, opossums and other animals are found in the woods. The reservation is under military supervision and a permit is necessary to enter the ground. However, it offers exceptional opportunities for studying plant and animal life undisturbed.

Baltimore, about $18 \mathrm{mi}$. southwest of southern part of the reservation; Edgewood Station, Penn. R. R. It would be advisable to write the Commanding Officer, Edgewood Arsenal, Edgewood, Maryland, to make arrangements to investigate the reservation. $-C$. $C$. 
Choptank River Marshes. (A4.) In Caroline County, comprising an area several hundred acres in extent, are of unusual interest. The fauna consists principally of raccoon, muskrat, opossum, otter, mink, weasels and other small mammals. Most of the Maryland marsh birds live and breed here. This is a fresh water marsh.

Easton, 10 mi. east, B. C. \& A. R. R.; Turner station at the marshes on the B. C. \& A. R. R.-J. W. Harshberger.

*Governors Run Oyster Reserve Area in Calvert County. Comprising about 3 sq. mi., $\frac{1}{4} \mathrm{mi}$. from the west bank of Chesapeake Bay, near Port Republic, between a sand bank and the mud bottom. The cultch is a combination of oyster shells, fossil shells and stone. This area has been set aside by the Conservation Commission of Maryland as a breeding ground for oysters.

Prince Frederick, 6 mi. S.E., on the bus line from Annapolis; one mi. east (W) of Port Republic. $-R$. V. Truitt.

* Plum Point Oyster Reserve. Calvert County. Comprises an area of 3 to 4 sq. mi. at Plum Point. It lies about $\frac{1}{4} \mathrm{mi}$. from shore and is of the same nature as the Governors Run Reserve Area, lying about $10 \mathrm{mi}$. north. It may be reached by the bus line from Annapolis. $-R$. V. Truitt.

*St. Jerome's Oyster Reserve Area. St. Mary's County. Consists of $3 \mathrm{sq}$. mi., at St. Jerome, and lying about $\frac{1}{4}$ mi. off the shore. The cultch is similar to that of the Governors Run Reserve Area. To visit any of these oyster areas it would be advisable to get in touch with the Conservation Commission of Maryland, Munsey Building, Baltimore, Md.

Tide Water Bus line from Washington to St. Jerome.-R. V. Truitt.

Annemessex River Flats. (A4.) In Somerset County at the mouth of the Little Annemessex River. This is a salt water area of about 2 sq. mi., averaging about one foot of water. The Chesapeake blue crab abounds here, and it is one of the most favorable places for its molting. This area is being recommended for a preserved area.

Crisfield, 2 mi. S.W., New York, Philadelphia, and Norfolk R. R.; or boat from Baltimore or Annapolis. $-R$. $V$. Truitt.

Susquehanna River Flats. (A4.) Offer very favorable conditions for the breeding of shad. This area consists of about $10 \mathrm{sq}$. mi. adjacent to Havre de Grace in Harford County. Water practically fresh. Depth varies over the area from 1 to $10 \mathrm{ft}$. This area is proposed for preservation.
Havre de Grace, main lines B. \& O. and Pennsylvania Railroads. $-R$. $V$. Truitt.

Sinepuxent Tide Waters. (A4.) In Worcester County between Public Landing and Stockton, a distance of about $12 \mathrm{mi}$., offers ideal conditions for breeding and trapping muskrats. These tide waters include many small islands bordering the shore. The marshes are boggy, soft and have a luxuriant plant growth. Marsh birds are plentifulsage hen, kildeer, plover, gulls, terns, and strikers.

Snow Hill, 5 mi. S., Penna. R. R.R. V. Truitt.

Dorchester County Tide Waters. (A4.) From Taylors Island to Hooper Island, afford many places ideal for the breeding of muskrats and other marsh animals.

These grounds may be reached by boat from Baltimore to Taylors Island, or take the Cambridge bus line from Cambridge direct to some of the marshes at Golden Hill.-R. V. Truitt.

The Calvert County Cliffs. This interesting formation extends from Chesapeake Beach on the north to Cove Point on the south along the Western Shore of Chesapeake Bay. There is but little beach, from which rise abrupt cliffs of from 50 to $100 \mathrm{ft}$. in height composed of clay, sand gravel, marl and diatomaceous earths, containing great masses of fossils. The beach vegetation and the insect life are interesting.

Chesapeake Beach, Chesapeake Beach Railroad from Washington; boats from Baltimore to bay wharves; no boarding house; must be prepared to camp out. -Ernest N. Cory.

Conowingo Barrens. This is an area of unproductive, light yellow to whitish soil, very shallow in most places, derived from serpentine rock that outcrops in ridges throughout the area. Only stunted oaks and pines forest this area. The plant growth is sparse owing to almost total absence of nutrient elements, and the animal life is restricted.

These barrens start about $\frac{1}{2} \mathrm{mi}$. north of Conowingo on the Susquehanna River and extend in a general triangular shaped area to the Pennsylvania line comprising about $10 \mathrm{sq}$. mi. This formation may be found also in limited areas through Harford County.

Conowingo nearest town. May be reached by Columbia and Port Deposit Branch of the Pennsylvania Railroad from Perryville on the south, or by automobile on state road from Elkton through Rising Sun from out of the state, or from Baltimore through Bel Air.-Ernest N. Cory.

Worcester County Sand Dunes. Very 
interesting sand dunes are found along the Atlantic Coast at Ocean City. These dunes occur on the outer edge of a bar fringed along its inner side by fresh or salt Marshes. The predominant plant of the dune is the seasand reed with which are associated the plants characteristic of dunes throughout the North Atlantic Coast, as, American sea rochet, beach heather, sea beach sandwort, seaside evening primrose, American cocklebur, saltwort, knotweed spurge and seaside knotweed.

Ocean City, B. C. \& A. R. R., is in the immediate neighborhood. $-C$. $C$. Hamilton.

\section{Historic and Other Trees Worth Preservation, Maryland}

Tulip trees on St. John's College Campus, Annapolis.

Wye Mills Oak near Easton.

St. Paul's Oak near Chestertown.

\section{VIRGINIA}

\section{By Ivey F. Lewis}

The fauna and flora of Virginia in their geographical affinities include representatives of four of the great forest types: the northern coniferous forest type (the Boreal Canadian), the northern mixed coniferous and hardwood forest type (Transition Alleghenian), the mixed hardwood forest type (Upper Austral Carolinian), and the southern mixed coniferous and hardwood type (Lower Austral-Austroriparian).

The northern coniferous forest (Canadian) fauna and flora is limited to a small area, comprising the higher Alleghenian ridges in the extreme southwestern corner of the State. Into this zone come some of the animals and plants characteristic of more northerly localities, particularly evergreen trees such as red spruce (Picea rubra), hemlock (Tsuga canadensis), and southern balsam (Abies balsamea).

The northern mixed coniferous and hardwood forest (Alleghenian zone) covers the lower ridges and high valleys of the western portion of the state. It stretches in a band about $100 \mathrm{mi}$. wide from the northern to the southern boundary, running northeast by southwest. It includes the Blue Ridge, the
Appalachian Valley (Shenandoah Valley), and the lower of the Appalachian Ridges. Here the

"chestnut, walnut, oaks, hickories (and yellow poplar), of the South meet and overlap the beech, birch, hemlock, and sugar maple of the North; the southern mole and cottontail rabbit meet the northern star-nosed and Brewer moles and varying hare; and the southern bob-white, Baltimore oriole, bluebird, catbird, chewink, brown thrasher and wood thrush live in or near the haunts of the bobolink, solitary vireo, and the hermit and Wilson's thrushes.",

The butternut and hazelnut are also characteristic.

The mixed hardwood forest area (Carolinian zone) occupies the Piedmont Plateau between the "fall line" and the eastern base of the Blue Ridge, as well as the northern portion of the Coastal Plain. It embraces the central part of Virginia and much of the eastern section. Characteristic trees are sassafras, yellow poplar (Liriodendron tulipifera), hackberry (Celtis occidentalis), sycamore (Platanus occidentalis), redbud (Cercis canadensis), persimmon (Diospyros virginiana), shortleaf pine (Pinus echinata), and hickories, with chestnut (Castanea dentata), and walnut (Juglans nigra) common in the western portion, and willow oak (Quercus phellos), sweet gum (Liquidambar styraciflua), and sweetbay (Magnolia virginiana) in the eastern section. Of animals, the opossum (Didelphis virginiana), gray fox (Urocyon cinereoargenteus), fox squirrel (Sciurus niger neglectus), cardinal, Carolina wren, tufted titmouse, gnatcatcher, summer tanager, and yellow-breasted chat are common.

The southern - mixed coniferous and hardwood forest area (Austroriparian zone) occupies the southeastern corner of the state, with its best development seen in the Great Dismal Swamp of

1 Merriam, C. H.: Life zones and crop zones. Bulletin 10, United States Department of Agriculture, 1898. See also Merriam: The Geographic Distribution of Life in North America with special reference to the Mammalia. Proceedings of the Biological Society of Washington, Vol. 7, pp. 1-64. 1892. 
Nansemond and Norfolk counties. The longleaf and loblolly pines (Pinus palustris and $P$. taeda), magnolia (M. virginiana), live oak (Quercus virginiana), bald cypress (Taxodium distichum), black and water gums (Nyssa sylvatica var. biflora and $N$. aquatica), yellow jessamine (Gelsemium sempervirens), cane (Arundinaria macrosperma) and southern white cedar (Chamaecyparis thyoides) are characteristic. The mocking bird, painted bunting, prothonotary warbler, red cockaded woodpecker, and Chuck-will's-widow are said by Merriam to be characteristic birds of this faunal area, but only the first and last named may be considered to represent it in its northernmost extension in Virginia. While many of the plants and animals of this area occur in Virginia, they are, even in the narrow area mentioned above, mixed with many forms of the mixed hardwood area.

\section{GEOGRAPHICAL AREAS}

The geographical areas of Virginia occupy belts running northeast by southwest. The easternmost is the Coastal Plain, which lies between the ocean and the "fall line" through Fredericksburg, Richmond, and Emporia. This area is now approximately two-thirds wooded, though there is not much virgin forest except in the Great Dismal Swamp. The characteristic trees are the loblolly pine, the red, black, and pin oaks (Quercus rubra, Q. velutina, $Q$. palustris) sweet gum, black gum, yellow poplar, hickory, soft maple, holly (Ilex opaca), and in certain restricted localities the southern white cedar (Chamaecyparis thyoides). Animal life is in general abundant, especially along the rivers. Wild turkeys, bobwhite, snipe, and sora are common, while on the larger rivers and along the Chesapeake Bay ducks and geese occur as common migrants. Black bear (Ursus americanus), deer (Odocoileus virginianus) and bob-cat (Lynx rufus) occur in the more remote wooded areas.

West of the Coastal Plain is the broad Piedmont Plateau, a region of shortleaf and Virginia pine (Pinus echinata and $P$. virginiana), white, red, black, southern red, and chestnut oaks (Quercus alba, Q. rubra, Q. velutina, Q. digitata, $Q$. prinus), hickory, yellow poplar, soft maple, and black gum. Less common are loblolly pine, chestnut, ash, black locust (Robinia pseudoacacia), sycamore, river birch (Betula nigra), walnut, cucumber tree (Magnolia acuminata), buckeye (Aesculus octan$d r a)$, elm, willow, cottonwood, and cherry.

There is very little virgin forest in this region, as practically all the forests have been cut and burned over. The second growth timber occupies about two-thirds of the area. Game and native wild animal life is in general less abundant than in the Coastal Plain, though by no means extinct.

The Blue Ridge Region comprises a strip of land on both sides of the crest of the Blue Ridge, varying from $10 \mathrm{mi}$. wide in the northern portion to $40 \mathrm{mi}$. in the southern. This region is mostly wooded, with considerable virgin forest, though fires have caused extensive damage.

In the higher portions of the Blue Ridge Region some of the animals extinct or nearly so in the other regions are not rare. The black bear, Virginia deer, and bobcat occur here not uncommonly, and their presence may be interpreted, as in the Great Dismal Swamp, to indicate a condition in which the native fauna and flora is almost untouched. While the bison, timber wolf, and passenger pigeon are long since extinct here, the survival of the larger feral animals points to the continued existence of considerable areas essentially in their original condition.

The trees are mostly chestnut, red, black, white, and chestnut oaks, yellow poplar, hickory, maple, basswaod, and beech. Shortleaf pine, white pine, and hemlock also occur.

The Appalachian or Shenandoah Valley lies between the Blue Ridge and the Alleghenies, and is 30 to $40 \mathrm{mi}$. wide. 
This is a limestone area, fertile and mostly cleared and under cultivation or devoted to the raising of stock. Wild game is scarce, though the streams afford good fishing; there are fewer sources of pollution from industrial plants than elsewhere in the state. The streams in this region drain north into the Potomac.

The characteristic trees are oaks, yellow poplar, and sugar maple.

The Appalachian Ridges lie between the Valley and the boundaries of Kentucky and West Virginia. Here there is more virgin timber than elsewhere in the state, and the native wild life is not so scarce. In this respect, the same remarks apply here as to the Blue Ridge Region.

The white, red, and chestnut oaks, chestnut, yellow poplar, maple, beech, basswood, hickory, white pine, shortleaf pine (Pinus echinata), and hemlock are common trees.

In this section, and in the Blue Ridge, are the National Forest areas, which afford the best prospects of maintaining undestroyed the native wild life, both plant and animal.

Of the state as a whole, approximately $54 \%$ is wooded. Of the forested areas, $43 \%$ is softwood, $57 \%$ hardwood. The softwoods predominate in the eastern section, hardwoods elsewhere. The dominant softwoods are the pines (loblolly, shortleaf, and Virginia), while among the hardwoods the oaks preponderate, especially the white oak.

The condition of the forests is given in some detail because it furnishes the best indication of the condition of the native wild life. Where there is virgin forest, wild life is abundant and relatively unaltered, but where the forests have been cleared, cut, or burned over the wild life has largely disappeared.

\section{NATURAL AREAS}

Lynchburg City Forest. (C3.) Comprises 7000 acres of land situated northwest of the city on the Blue Ridge. See American Forestry, 2: 238.
Stony Man Mountain Summit. (B3C4.) Comprises 16,500 acres of mountain deciduous forest. It protects the watershed of the Shenandoah River and a portion of that of the Potomac and James Rivers. On the area and still intact are trench systems constructed during the Civil War and under the supervision of Stonewall Jackson. It is preserved by the nation. See Science, October 4, 1918: 342 .

Rockingham, Augusta, Bath and Highland Counties, Va., and Pendleton County, W. Va.-J. W. H.

Natural Bridge Ravine. (C4.) Is a long rocky river; it was presented by George III to Thomas Jefferson in 1774 . See Harshberger, John W.: "The Forest at the Natural Bridge of Virginia. Forest Leaves, IX: 42-44, June, 1903. Natural Bridge (Rockbridge Co.).-J. W. $H$.

\section{Great Dismal Swamp. (A2-B3.)}

Formerly about $1000 \mathrm{mi}$. of coniferous (Chamaecyparis thyoides and Taxodium distichum) and deciduous forest, now being much restricted by drainage and d'eforestation, so that its exact area at the present time cannot be given. It is a large peat bog, the best developed of all the bogs in unglaciated North America. Within its area are hygrophile deciduous forests, swamp or juniper land, and numerous sluggish streams. Near the center is Lake Drummond tapped by a canal (known as the Feeder Canal to the main Dismal Swamp Canal) deep enough for good sized motor boats. The juniper grows in the moister parts where the subsoil is sandy and porous. These areas are held by lumber companies. The hardwoods occur in areas which under drainage make very good farming land. The progressive drainage of this area is threatening the existence of the swamp as a whole. Much of this land is held by the Norfolk County farms and is for sale.

The Great Dismal Swamp is the most important wild life area in the state. Its preservation, at least in part, is the most immediate duty and most vital need in Virginia. Not only are there large stands of virgin forest, but in the tangled thickets and along the sluggish streams are found many of the animals formerly common and now disappearing. 
It is the sort of place generally described as a "sportsman's paradise." See Kearney, Thomas H.: Report on Botanical Survey of the Dismal Swamp Region. Contribution from the U. S. National Herbarium, Vol. V, No. 6, 1901.

The Swamp may be reached from Suffolk by automobile, two mi. to Jericho, thence by boat down a drainage canal, or by boat from Norfolk. The Dismal Swamp Canal runs through the swamp east of Lake Drummond irom Norfolk to Elizabeth City on Albemarle Sound, N. C.

Cape Henry Dune Forest. This comprises about 300 acres of high dunes, sandy shore, and back of the dunes, deciduous forest and loblolly pine. The forest is being gradually destroyed by the encroachment of the dunes. The area was used by the U. S. government during the World War for fortification and proving ground. See Forest Leaves, XV, June, 1916. A similar area in North Carolina is described by Lewis in Economic Papers, N. C. Geological Survey, 1917. The area may be reached from Norfolk (12 mi. east) by trolley.

*Luray Cavern. (B2.) Magnificent galleries and halls with fine stalactites and stalagmites. It has a remarkable cave fauna. As it is in private hands, an admission fee is charged to maintain the cave and electric lights for illuminating purposes. It may be reached from Luray (4 mi.) on the Norfolk and Western Railway.

The Grottoes. This is a cavern somewhat similar to Luray, reached from Staunton by hard road (10 mi.), or from Grottoes on the Norfolk and Western Railway.

Corner's Rock Area. (B2) Contains about 1000 acres, mostly in the Unaka National Forest but partly under the ownership of the "Douglas Land Company," Marion, Va. It is covered by a deciduous and eastern coniferous forest of mixed hardwoods and hemlock on ravines and along creeks. Information may be obtained from the Forest 'Supervisor, H. L. Russell, Bristol, Tenn. 500 acres located at Konnarock, Smyth County, Va., $3 \mathrm{mi}$. from post office. May be reached by (a) from Rural Retreat on the Norfolk and Western Railway.-E. H. Frothingham.

For Natural Bridge National Forest, Shenandoah National Forest, and Unaka National Forest, see "National Forests of the Eastern District."
Shenandoah National Park. (B3.) A committee headed by Hon. H. W. Temple of Pennsylvania has recently recommended to Congress the establishment of a National Park comprising 700 sq. mi. of heavily wooded and ecologically unspoiled territory on the western slope of the Blue Ridge from Albemarle County north and east. This territory is typical of the Blue Ridge Region described above. Its boundaries run close to the celebrated cavern area of the Shenandoah Valley, and besides important historical spots include a wide variety of habitats still virgin.

Yotomac River drainage area. An area of deciduous forest extending along the Virginia side of the Potomac River from Rosslyn to Great Falls, a distance of $16 \mathrm{mi}$. and extending back from the numerous high rocky cliffs along the river bank, a distance ranging from at least $\frac{1}{2}$ to $\frac{3}{4} \mathrm{mi} .-P$. L. Ricker.

\section{NORTH CAROLINA}

\section{By Z. P. Metcalf and B. W. Wells}

\section{GENERAL CONDITION}

North Carolina is one of the most varied states east of the Rockies as far as its ecological features are concerned. The elevation ranges from sea level to the highest peaks east of the Rockies with considerable areas above $6000 \mathrm{ft}$. The state is divided roughly into three main regions, the Coastal Plain, the Piedmont Plateau and the Blue Ridge Mountains.

\section{Coastal Plain}

The Coastal Plain is principally a low plain and extends from sea level to about $500 \mathrm{ft}$. elevation. It is characterized by sandy and sandy loam soils. The lower Coastal Plain is generally flat and the upper Coastal Plain rolling. The characteristic trees are the longleaf (Pinus palustris) and loblolly pines (P. Taeda). Some of the characteristic animals are:

Mammals: Cotton rat (Sigmodon hispidus), Carolina shrew (Blarina brevicauda carolinensis) and little shrew (Cryptotis parva).

Birds: Red-cockaded woodpecker, Chuck-will's-widow. 
Reptiles: Green lizard (Anolis carolinensis), glass snake (Ophisaurus ventralis), whip snake (Coluber flagellum), corn snake (Elaphe guttala), southern green snake (Opheodrys aestivus), ground snake (Carphophis amoena), southern hog-nosed snake (Heterodon simus), red-bellied water snake (Natrix sipedon fasziata).

Amphibians: Ditch eel (Amphiuma means), dwarf salamander (Manculus $q$. quadridigitatus), narrow-mouthed toad (Gastrophryne carolinensis).

For convenience the Coastal Plain may be divided into the following areas: (a) Sand Dunes, (b) Sounds, (c) Bay Lands, (d) Cypress Swamps, (e) Savannas, $(f)$ Pine Flat Woods, ( $g$ ) Sand Ridges, $(h)$ Sand Hills and (i) Upland Pine Forests.

a. Sand dunes. These are mostly small, from 8 to $10 \mathrm{ft}$. high but locally they range upward to $80 \mathrm{ft}$. Usually they form narrow bars called "banks" which separate the sea from the sounds. The northeast facing coast is characterized by the absence of dune cliffs which may be found in the southeast facing coast. The characteristic plants are sea oats (Uniola paniculata), and sea kale (Cakile edentula). Characteristic animals are the ghost crab, sand crabs, salt marsh cicada, Spartina leaf hopper, beach tiger beetle, beach grasshopper, dune fiddler crab.

b. Sounds. The sounds are broad or narrow shallow areas cut off from the sea by the banks. They vary from fresh water at the mouths of the rivers through brackish water to the salt water of the sea. The characteristic plants are, eel grass (Zostera marina) in the salt water, pond weed in the fresh water, Chara spp. and Ruppia maritima. Some of the characteristic animals are the blue crab, and the oyster.

1. The salt marshes are characterized by Juncus roemerianus and salt marsh grass (Spartina glabra). This is the haunt of the salt marsh fiddler crab and the boat-tailed grackle.

2. The fresh water marshes are charac- terized by the broad-leaved cattail (Typha latifolia) and by Scirpus spp. and the river fiddler crab.

c. Bay lands. Large areas of level, poorly drained soil covered with a growth of evergreen shrubbery, characteristic species being inkberry (Ilex glabra), bayberry (Myrica Carolinensis), Leucothoe spp., and pond pine (Pinus serotina). Characteristic animals are, painted bunting, and diamond rattlesnake (Crotalus adamanteus).

d. Cypress swamps. Swamp forest characterized by deep humus soil and the following plants, Nyssa spp., bald cypress (Taxodium distichum), southern white cedar (Chamaecyparis thyoides), and red maple (Acer rubrum). Characteristic animals are marsh rabbit (Sylvilagus palustris), Prothonotory warb. ler, Swainson's warbler, American egret, snowy egret, Louisiana heron, little blue heron, Florida cormorant, cottonmouthed moccasin (Agkistrodon piscivorus) and alligator (Alligator missippiensis).

e. Savanna. Upland sandy bogs which are level and essentially treeless and covered with a vegetation composed of bog xerophytes such as toothache grass (Ctenium aromaticum), trumpets (Sarracenia flava) and Dichromena latifolia.

f. Pine flat woods. Formerly extensive areas of longleaf pine which have been cut and largely replaced by loblolly pine commonly associated with blackjack (Quercus Marylandica), post oak (Q. stellata), water oak (Q. nigra), and Spanish oak (Q. falcata). Characteristic animals are ground rattlesnake (Sistrurus miliarius), glass snake and green lizard.

g. Sand ridges. Local areas in southeastern part of the state with course sandy soil which appears as a layer of glistening sand, with a characteristic vegetation adapted to this habitat in various ways. The prominent plants are turkey oak (Quercus Catesbaei) and wire grass (Aristida stricta).

$h$. Sand hills. Large areas in Hoke, Moore, Cumberland and Montgomery 
counties representing in their characteristic features an advanced stage of the sand ridge. Dominant trees are blackjack, and longleaf pine.

i. Upland pine forests. Undulating areas principally of sandy loam soils now chiefly under cultivation.

\section{Piedmont}

An extensive area in the center of the state of broad, rolling, red clay hills extending from about $500 \mathrm{ft}$. elevation to $2500 \mathrm{ft}$. elevation. This area may be divided into the Lower and Upper Piedmont.

Lower Piedmont. The lower Piedmont areas are characterized by upland pine forests (Pinus Taeda and P. echinata) and valley slopes covered with deciduous forest climax, in which beech, maple and tulip trees (Liriodendron tulipifera) are important trees.

Upper Piedmont. This includes the upper part of the Piedmont and the Asheville Plateau. It is characterized by oak and hickory forest. In certain areas characterized by sterile soils shortleaf and Virginia pine (Pinus echinata and Virginiana) are prominent.

\section{Blue Ridge Mountains}

The mountains generally range from 2500 to $6700 \mathrm{ft}$. in elevation with some considerable areas above $6500 \mathrm{ft}$. For convenience this area may be divided into the Mountain Slopes and the Mountain Summits.

Mountain slopes. This includes the area in the mountains from 2500 to 5500 $\mathrm{ft}$., and is characterized by chestnutoak and hickory forests. Some of the characteristic animals are the red squirrel (Sciurus hudsonicus loquax), woodchuck (Marmota monax), starnosed mole (Condylura cristata), Carolina junco, song sparrow, Baltimore oriole, Canada warbler and ruffed grouse.

Mountain summits. 5500 to $6700 \mathrm{ft}$. Characterized by spruce fir forests (Picea rubra, Abies Fraseri). The following animals, cloudland deer mouse (Peromyscus maniculatus nubiterrae),
Carolina red-backed vole (Evotomys carolinensis), pine siskin, American crossbill, winter wren, brown creeper, red-breasted nuthatch, black-capped chickadee, yellow-bellied sapsucker, Metcalf salamander (Plethodon metcalfi) and redleg salamander (Plethodon shermani).

\section{NATURAL AREAS}

Coastal Plain. The principal points of interest in the dune area are: Roanoke Island, Manteo and the Banks at Nags Head about $40 \mathrm{mi}$. by boat from Elizabeth City, Norfolk-Southern R. R., or about $80 \mathrm{mi}$. by boat from Norfolk, Va., through the inland water ways. Shackleford Bank about $5 \mathrm{mi}$. by motorboat from Beaufort, Norfolk-Southern R. R. Wrightsville Beach about 10 mi. by electric railroad from Wilmington, Atlantic Coast Line and Seaboard Airline Railroads. Fort Fisher about $25 \mathrm{mi}$. (a) from Wilmington. Smith's Island reached by motorboat from Southport which is reached by River Boat from Wilmington.

Salt water sounds may be easily reached at Beaufort, Norfolk-Southern R. R., and at Wrightsville Beach, Electric Line, 10 mi. east from Wilmington. Fresh water sounds, $5 \mathrm{mi}$. east from Moyock, Norfolk-Southern R. R., $25 \mathrm{mi}$. South of Norfolk, Va.

Royal Shoal. (D4.) A small tidal flat in Pamlico Sound. Nesting site for royal, common and least terns, laughing gulls, black skimmer and oyster catchers. Preserved by the Audubon Society. $8 \mathrm{mi}$. from Ocracoke which may be reached (c) from Beaufort. Norfolk Southern Railroad.

Shackleford Bank. (C3.) A narrow bank about $6 \mathrm{mi}$. long containing some of the largest sand dunes along the North Carolina Coast. One mi. from Beaufort, N. C., on the Norfolk Southern Railroad.

Fort Fisher. (B4.) A small area at the mouth of the Cape Fear River. Should be preserved for its historical interest as well as because of its great ecological interest. Large areas of tidal marshes, sand dunes, etc. About $25 \mathrm{mi}$. down the river from Wilmington, Atlantic Coast Line and Seaboard Railroad.

Smith Island. (B3.) Group of seven 
small islands at the mouth of the Cape Fear River. Sand dunes and swamps. Loblolly pine, cedar, palmetto, oaks and wild olive principal trees. Preserved by owners. Southport, reached by steamer from Wilmington, N. C., thence by launch. Atlantic Coast Line and Seaboard Air Line R. R.

Areas of cypress swamp may be easily reached from any of the coastal cities and towns such as Elizabeth City, Edenton, Washington, New Bern, Beaufort, on Norfolk-Southern Railroad; or from Wilmington on the Atlantic Coastline or Seaboard Airline Railroads. Typical savanna localities are found near Burgaw, $25 \mathrm{mi}$. north of Wilmington on the Atlantic Coastline Railroad, or at Havelock, $25 \mathrm{mi}$. southeast of Newbern, on the Norfolk-Southern R. R.

Piedmont. University Forest. (C4.) 500 acres of deciduous and eastern coniferous forest, level plain with hills, sandy and rocky situations, springs and brooks. Preserved by the University of North Carolina. In Orange County, one mile from Chapel Hill, Southern Railway.

*Riverside Park, Rocky Mount.

This is an area of about 5 acres of forest land in a 30 acre park bordering Tar River, one mi. west of Rocky Mount, in Nash County. The Park is owned by the Rocky Mount Mills, Mr. Turner B. Bunn, Secretary. It is to be used perpetually as a public park. The land is rolling and is where the higher Piedmont land breaks off in the lower lands of the coastal plain. The forest is fairly typical, mixed hardwood and pine of the eastern Piedmont and western Coastal Plain regions, containing mature and young trees of shortleaf pine, loblolly pine, southern red oak (Quercus digitata), white oak, sweet gum, and some 25 other species. The remainder of the Park, containing altogether about thirty acres, has been recently thinned in order to obtain the best development for the remaining trees. The preserved area is to be left uncut, and although some cutting has been done in the past, it is left in a seminatural condition. The Park will be visited by hundreds of people from the town of Rocky Mount and the surrounding country, and this area will be valuable as an educational exhibit.
The Atlantic Coast Line Railroad station of Rocky Mount is only two mi. away, a hard-surface road leading to the border of the Park. Well graded automobile roads wing through the Park itself.

Principal points of interest in the mountains are Grandfather Mountain, reached by bus about $25 \mathrm{mi}$. from Lenoir, Carolina-Northwestern R. R.; Black Mountains, reached by motor from Black Mountain, Southern R. R. $15 \mathrm{mi}$. east of Asheville; Pisgah Mountains by motor $15 \mathrm{mi}$. southwest of Asheville; Smoky Mountains $10 \mathrm{mi}$. north of Bryson City, Southern R. R., $50 \mathrm{mi}$. west of Asheville.

Principal mountain summits of interest, Roan Mountains, virgin spruce forest, reached by driving $20 \mathrm{mi}$. from Burnesville, Clinchfield R. R.; Mt. Mitchell, reached (a) $15 \mathrm{mi}$. from Black Mountain, Southern R. R., 15 mi. east of Asheville; Balsam Mountains, reached (w) 6 mi. from Balsam Station, Southern R. R., $35 \mathrm{mi}$. west of Asheville; Smokies, $10 \mathrm{mi}$. from Bryson City west, Southern R. R., $50 \mathrm{mi}$. west of Asheville.

Grandfather Mountain. (C3.) 1000 acres on the summit of the mountain. Covered chiefly by hardwoods. Mostly above $5500 \mathrm{ft}$. two mi. northeast of Linville on the Eastern Tennessee and Western North Carolina Railroad or 30 mi. Northwest of Lenoir on the Carolina and Northwestern Railroad.

Santille Creek Forest. *Large tract of virgin hardwood, one of the best in the southern Appalachians. Tract was recently acquired by the Government. Part of the area under the supervision of the Ashville-Alton. The area is known as the Olmstead tract. Located on the Santille Creek, head waters of the Checoh River. Located in Graham County, 35 to $45 \mathrm{mi}$. from the Southern Railway at Amherst, N. C. $-E$. $H$. Frothingham.

*Pisgah National Game Preserve. (B3.) 90,000 acres upper water shed of the French Broad River. In Transylvania, Haywood, Buncombe and Henderson Counties, N. C. Mostly decidu- 
ous and eastern coniferous forest. Valleys and mountains mostly between 2000 and $4000 \mathrm{ft}$. Few peaks above $5000 \mathrm{ft}$. Land stocked with deer, wild turkey, elk, and bison. Asheville 6 to $20 \mathrm{mi}$. south. Southern R. R. Preserved by the Forest Service.

* Grounds of the Blue Ridge Association. (B2.) 1190 acres on northern slope of the Swannanoa Mountains, Buncombe County, N. C. Mostly deciduous forests. Preserved by the Association. Black Mountain 3 mi. south. Southern R. R.

* Mitchell State Park. (B4.) 1224 acres summit of Mount Mitchell, Buncombe County, N. C. Mostly spruce and balsam forest. Preserved by the State. Black Mountain $6 \mathrm{mi}$. north. Southern R. R.

Summit of Roan Mountain. (B3.) *Mitchell County, N.C., and Carter County, Tenn. This area is included in what has been known as the Cloudland Property, which belonged to General J. T. Wilder of Monterey, Tenn. It is now owned by his family, represented by James A. Maher, a son-in-law of General Wilder, of Kingsport, Tenn. This tract contains some 4500 acres, all of it above $5500 \mathrm{ft}$. in elevation. There are about 700 acres, all of it above $5500 \mathrm{ft}$. in elevation. There are about 700 acres covered by a dense spruce forest. The summit of the mountain is a succession of open areas interspersed with groups of varying size of spruce and balsam trees. On these areas the mountain alder (Alnus crispa) flourishes, one of the few places in this state where it occurs. The area is typical of high mountain summits in the Southern Appalachians. The owners are now planning to develop the property as a health resort, and may be willing to leave certain parts of this property in its native condition.

The Mountain may be reached in a $10 \mathrm{mi}$. walk, or horseback ride, from Roan Mountain Station, Tenn., on a narrow gauge railroad running from Johnson City, Tenn., to Boone, N. C.
It may also be reached from Toecane, a station on the C. C. \& O. Railway, between Johnson City, Tenn., and Marion, N. C., by (h) or (w) some 12 or $14 \mathrm{mi} .-J$. S. Holmes.

National Forests wholly or partly in North Carolina: Cherokee; Nantahala; Pisgah; Unaka. See "National Forests of Eastern District."

Cona, the estate of Mrs. Moses $\mathrm{H}$. Cone, Blowing Rock. 5000 acres containing much primeval forest lands and other native vegetation, destined to be an endowed state park.

\section{BIBLIOGRAPHY}

Ashe, W. W. Loblolly or North Carolina pine. North Carolina Geol. and Econ. Surv. Bull. 24, 1915.

Brimley, C. S. Zoo-Geography. A Study of Life Zones. Journal Elisha Mitchell Scientific Society, xxix: 10-27.

Brown, William H. The Plant Life of Ellis, Great, Little and Long Lakes in North Carolina. Cont. U. S. Nat. Herb. 13: 323-341, 1911.

Harshberger, John W. An Ecologic Study of the Flora of Mountainous North Carolina. Bot. Gaz. 36: 241258, 368-383, 1903.

Lewis, I. F. The Vegetation of Shackleford Bank. North Carolina Geol. and Econ. Surv. Paper 46, 1917.

Kearney, T. H. The Plant Covering of Okracoke Island. A study in the Ecology of the North Carolina Strand Vegetations. Contrib. U. S. Nat. Herb. 5: 261, 1900.

Kearney, T. H. Report on a Botanical Survey of the Dismal Swamp Region. Contrib. U. S. Nat. Herb. 5: 321, 1901.

Metcalf, Z. P. Some Ecological Aspects of the Tidal Zone of the North Carolina Coast. Ecology, Vol. I, 193-197.

Metcalf, Z. P., and Osborn, Herbert. Some observations on Insects of the Between Tide Zone of the North Carolina Coast. Annals of the Entomological Society of America, Vol. XIII: 108-117.

Mohr. Chas. and Roth Filibert. Timber Pines of the Southern United States. U. S. Dept. of Agr. Bull. 13 (Revised Ed.) Division of Forestry, 1897.

Pearson, Brimley and Brimley. The Birds of North Carolina. Volume IV, North Carolina Geological and Economic Survey.

Pinchot, Gifford, and Ashe, W. W. Timber Trees and Forests of North 
Carolina. North Carolina Geol. Surv. Bull. No. 6, 1-224, pls. 1-23, 1897.

Smith, The Fishes of North Carolina. Volume II, North Carolina Geological and Economic Survey.

Wells, B. W. The Major Plant Communities of North Carolina. Tech. Bull. 25 N. C. Agr. Exp. Station, 1924.

\section{SOUTH CAROLINA}

\section{By Philip Luginbill}

\section{GENERAL CONDITIONS}

The state of South Carolina is approximately $31,000 \mathrm{sq}$. mi. in area. In shape the state approaches the form of an isosceles triangle, the apex of which rests upon the summits of the Blue Ridge Mountains. The base borders the Atlantic, while the western and southern boundary are washed by the Savannah River and its tributaries. The geological formations lie parallel to the coast line. For several miles inland the post Pliocene formation rests upon the Eocene. These together with the Miocene and cretaceous formation extend about $100 \mathrm{mi}$. inland or until they touch the crystalline rocks. The line of the crystalline rocks separates the state into two portions well defined geologically, topographically and vegetation and also politically, industrially and even socially. The upper region, the (Piedmont Plateau) is spoken of as the upcountry and the lower (the Coastal Plain), as the low-country. The upcountry is characterized by its growth of shortleaf pine (Pinus echinata) and deciduous oaks, the low-country by its evergreen oaks (Quercus virginiana), draped with long gray moss, (Tillandsia usneoides). Socially the regions are distinctive in customs, manners, ancestry and even in the speech of the people. From the crystalline rocks to the mountains we find various strata, such as limestones, itacolumite, clay talc, mica slates, gneiss and granite. The same parallelism of formations is maintained throughout the mountain region.

\section{Geographical regions and biota}

Geographers ${ }^{1}$ have divided the state of South Carolina into seven regions, (1) Coastal Region, (2) Lower Pine Belt or Savanna Region, (3) Upper Pine Belt, (4) Red Hill Region, and (5) Sand Hill Region, belonging to the Coastal Plain; (6) Piedmont Plateau; (7) Mountain Region. These regions are quite distinctive in types of soil, climate and the biota.

a. Coastal Region. This region occupies a narrow strip of land along the coast rarely extending more than 10 mi. inland. It almost coincides with the pliocene formation. It consists largely of sea islands which at some points along the shore are three and four deep, being separated from the mainland by salt water rivers and inlets of the sea; The salt marshes uncovered at low tide bordering the sea islands are also part of this region. The soil of the sea islands consists largely of fine sandy loam, resting on a subsoil of yellow clay, which gives the soil a yellowish appearance. Besides these soils there are others in the many flats or fresh water swamps and bays, which are composed largely of black vegetable mould of great fertility. These soils are susceptible to drainage. The climate of the sea islands is equable. Extremes of temperatures are greatest in the direction of low temperatures. The rainfall is heavy (mean annual about 50 in.). However the climate is not excessively moist due to the large number of clear days. Fogs are infrequent.

As to the flora of the sea islands; the palmetto, from which the state derived its name "Palmetto State" was formerly very common. Evergreen oaks with long strings of hanging moss were also abundant. Water oaks abounded plentifully while pines, myrtles, vines of various sorts also thrived in abundance.

These islands attain a height of from

1 Hammond's "South Carolina" used as an authority. Some of the material from which this article has been prepared has also been gleaned from that valuable and rare volume. 
10 to $15 \mathrm{ft}$., sometimes of $30 \mathrm{ft}$. above high tide:

The Lower Pine Belt or Savanna Region. This region lying parallel with the coast region has a width of about 50 mi. and attains a maximum elevation of about $130 \mathrm{ft}$. It may be divided into two sections, a region below tide water, formerly including the rice fields of the state and a region above tide water, formerly characterized by terpentine farms and cattle ranges.

The soil of this region is composed of a sandy loam with either a white shady, yellow or clay subsoil. Deposits of accessible marl are found. The drainage is poor. The luxuriant growth of vegetation clogs up the channels scarcely permitting any current to pass. Many swamps and bays are formed in this way.

As to the flora: The most elevated of the swamp lands were cypress ponds containing dense growths of cypress. The bays, contained dense growths of bay, gum, tulip, and undergrowth of vines and bushes. The open savannas of the river bottoms have been the rice lands of the state. The sandy plains were clothed with pines, chiefly longleaf pine, which give to the region its name.

The climate is similar to that of the Coastal Region.

b. The Upper Pine Belt. This region which is sometimes also called the middle country and central cotton belt of Carolina consists of that portion of the state lying between elevations of 130 and $250 \mathrm{ft}$. above sea level. The region is characterized by its large inland bays and rolling pine lands. The drainage is good. The soil is a light sandy loam with a red and yellow clay subsoil. The climate is cooler than that of the Lower Pine Belt. The winters are often dry and cold and the summers hot.

As to the flora: The uplands formerly were covered with longleaf pine and contained a thick undergrowth of hickory and oaks. They are still found in this region but not as abundant as formerly. The evergreen oak does not appear unless planted. This is the northern limit of the gray moss. The swamps contained cypress, white oak, ash, hickory and gum. Cultivated fruits such as plums, pecan nuts, grapes, etc., are successfully grown.

c. The Red Hill Region. The "Red Hills" as they are termed by some geographers may also be called a region although in outline the section is not as distinctive as the others. They give way in some places to the Sand Hills immediately above. They rise 200 to $300 \mathrm{ft}$. above the plain of the Upper Pine Belt in a distance of several miles, this elevation sometimes being attained in traversing several hundred yards. The soil is made up of red clay and sand. Along the Santee River they attain the highest elevation and are known as the "High Hills of the Santee." As this region has an elevation of from 400 to $500 \mathrm{ft}$. above the level of the sea it enjoys a climate that is much drier and more bracing than the region to the south. The nights are cool, with refreshing breezes.

As to the flora: Longleaf pine was formerly quite abundant. The characteristic growth however was oak and hickory of large size. Of the oaks, the southern red oak, appeared to thrive the best. The evergreen oak, wherever planted, does well.

d. The Sand Hill Region. This region is composed of a remarkable chain of sand hills that stretch across the state and has an average width of $10 \mathrm{mi}$. and a maximum width of $30 \mathrm{mi}$. They attain an elevation above sea level of from 600 to $700 \mathrm{ft}$.

The chief constituent of the soil is loose sand. The soil is very poor, lacking in humus but responds readily when properly fertilized. The climate is sunny and dry, and therefore very healthful. Snow does not often occur; sleet is more common but seldom remains long when exposed to the sun for several hours.

As to the flora: This region is characterized by the pine barrens of the state, 
the growth formerly consisting largely of longleaf pine, later supplanted by the shortleaf and scrub pines.

e. Piedmont Plateau. This region consists of that part of the state region spoken of as the up-country. It has a mean elevation of 400 to $800 \mathrm{ft}$. above sea level. Three varieties of soils exist, namely, granite, clay slate and trappean. The rocks of the upper part of this region belong to the Laurentian and Huronian formations; gneiss, granite, mica, talc, and clay slates are also found here.

The Piedmont Plateau has somewhat lower temperatures and shorter seasons than those prevailing in the Coastal Plain regions immediately to the south.

As to the flora: The original growth has disappeared, and is supplanted by the characteristic growth of the shortleaf pine with hickories and large varieties of oaks.

f. The Mountain Region. This region continuing the Blue Ridge of North Carolina, consists of a narrow strip in the extreme northwestern part of the state. It has an elevation from 500 to $3430 \mathrm{ft}$. above sea level. The soils are similar to those in other parts of the state which are formed from the decomposition of gneiss rock. The level uplands consist of sandy loam, the hill sides, of red clay and the bottom lands of dark loam, containing an abundance of lime and potash.

This region has a mean temperature corresponding with that of New Jersey and Kansas, but very different extremes. The mountainous portion, however, has a mean temperature corresponding with the lower lake region. This region is exempt from destructive storms. The annual rainfall is over 60 in. which places this region among those having the heaviest precipitation in the United States.

As to the flora: Shortleaf pine, cucumber tree, mountain laurel, white pine and scrub pine were formerly common. Ginseng (Panax quinquefolea) and snake root (Cimicifuga racemosa) as well as other herbs thrived in abundance.
It is claimed that the Indians in former years earned their living by collecting and disposing of these medicinal herbs.

\section{PRESENT BIOTA}

\section{Flora}

Most of the large timber has been removed throughout the entire state. There are still, however, some large specimens of live oaks with the beautiful festoons of hanging moss, in the coastal region. These oaks are often found in groups, in some cases presumably having been planted by the early settlers.

The palmetto still abounds on the sea islands though not as abundant as formerly. Myrtles and vines of various sorts still thrive in some spots on the islands.

The longleaf pine has been largely supplanted by the shortleaf and loblolly pine. However, even the latter are fast being destroyed by the ax followed often by destructive fires which kills all the undergrowth.

Young forests of longleaf pine are springing up here and there in the sand hills and if protected will in time, replace to some extent, the former magnificent growth of these trees.

Many species of grasses abound in the state. Panicum is especially well represented in the coastal region. About 50 species have been collected in the state. Water millet (Zizaniopsis miliacea) grows to a large size and clumps in marshy places along the coast. Sea oats (Uniola paniculata) is common on the sand dunes on the coast. Bermuda grass (Cynodon Dactylon) and crab grass (Digitaria sanguinalis) thrive well and are largely used for hay. Destructive fires often ravish open woods and uncultivated fields thereby destroying all vegetation.

\section{Fauna}

The beaver and cougar have been extinct for some time. A color variety of the black bear, known as little brown bear, is common in the swamps of the 
southern part of the state. Some specimens attain a fair size. Wolves are rare, almost extinct. Bob-cats and gray and red foxes are common. The deer is abundant in the swamps of the low-country. The opossum, raccoon, skunk, mink, and muskrat are common throughout the state. The alligator is common in the rivers and streams of the coastal region of the state. Ruffed grouse are abundant throughout the state except in the immediate vicinities of the large cities. In the coastal region, the old submerged rice fields afford resting and feeding places to many kinds of migratory birds. Many kinds of fish abound in the streams and bays in the state. Among the common fish are bass, perch, and brim. It is a well known fact, however, that many streams have been "fished dry" owing to the lax laws in the state.

The land and fresh water mollusca of this state are not represented by a large number of species, as compared with other southern states farther west. Of land molluses there are 79 species and varieties distributed among 23 genera, of which Polygyra has 28 species, Gastrodonta 10, Gastrocopta 5, and the others 1 to 4 each. Of the fresh water mollusks there are 107 species divided among 20 genera. There are 60 species of naiades, of which Lampsilis contains 18 and Elliptic 34. Goniobasis, so abundant in Alabama and Georgia, has but 12 species. The fresh water pulmonates, Lymnaea, Planorbis, and Physa are represented by but few species. No attempt has been made by students to study the fauna ecologically. See Maxyck, Contributions from the Charleston Museum, No. 2 for a catalog of the species of South Carolina.-F. C. B.

\section{Pollution}

Several cases of pollution of streams by fertilizer factories and cotton mills have been reported. It is held that the former allow sulphuric acid to contaminate the streams and that the latter permit wastes of various kinds to be dumped into the waters. This is a serious menace to fish and it is pleasing to note that state action is being taken against such practices.

\section{Sea coast and marine conditions}

Oil burning ships along the coast of the state permit oil to run on the water in harbors and bays. This is not only a nuisance but a menace to young fish.

\section{NATURAL AREAS}

The swamps in the low-country of the state are the least modified and many of these would afford suitable areas for preservation.

An area suitable for preservation is the Combahes tract composed of 12,000 acres about half of this amount being in a modified natural state (B2). This tract includes sand areas, swamps, marshes and bays formed from old submerged rice-fields. It is under the influence of the tides. Deciduous trees, evergreen oaks covered with hanging moss, undergrowth of various shrubs and vines abound. The Combahee River is a favorite rendezvous for the alligator. Many kinds of birds abound. The migratory species remain in the marshes for some time to feed. This tract is located 4 mi. east of White Hall, S. C. on the A. C. L. Railway.

\section{Preserves}

1. State Preserves. The State Game Farm, is the only state preserve in the state of South Carolina. It consists of several hundred acres located at Camp Styx, near Columbia. The purpose of this farm is to raise pheasants, wild turkeys, and deer to restock certain areas of the state which have been depleted in game. This farm is maintained by the surplus revenue collected by the State Game Department after paying the schools their portion and the game wardens their salaries and expenses.

2. National Preserves. There are no national preserves except several forest preserves. One National Forest-Manhahala-includes part of Oconee County. 
There is movement under way to set aside about 25,000 acres of land of the Camp Jackson tract at Columbia for a national forest to be known as the Camp Jackson National Forest Preserve. This movement is sponsored by Dr. A. C. Moore, of the University of South Carolina, for many years an ardent worker in the cause of reforestation of South Carolina. To quote Dr. Moore, "The purpose of this preserve is to demonstrate proper forestry methods applicable to the Sand Hill Region of the state. This site lies within the typical Sand Hill Region.

3. Private Preserves. There are a large number of private preserves from several acres to 20,000 acres and over. One of the largest preserves of this kind is the Oketee Club at Ridgeland, S. C. which contains 70,000 acres. These preserves are maintained mainly for sport but in spite of this fact they are not to be utterly condemned as they aid in keeping game from becoming extinct in this state. It is claimed that one may readily observe upon investigation the much greater abundance of game in these preserves as compared to the surrounding country.

\section{GEORGIA}

\section{By Henry Fox}

\section{GENERAL FEATURES AND ORIGINAL} BIOTA

\section{Physiographic regions}

Five physiographic provinces are represented in Georgia. These, beginning at the coast, are (1) Coastal Plain; (2) Piedmont Region; (3) Blue Ridge; (4) Appalachian Valley; and (5) Cumberland Plateau.

1. The Coastal Plain includes practically the entire southern half of the state. Its inland boundary is marked by the Fall Line, which extends in a northeast-southwest direction from Augusta, through Milledgeville and Macon, to Columbus. In general, the region is characterized by low and gentle relief, though in its northern portion, in the vicinity of the Fall Line, it displays considerable hilly and broken topography. In correlation with local differences in soil, altitude and vicissitudes of geologic history, the Coastal Plain exhibits a greater variety of well defined minor physiographic features than do any of the other physiographic provinces. These minor subdivisions are: (a) Sea Islands, a series of long, narrow sandy islands fringing the coast; (b) Tidal Lagoons and Marshes, a confused network of tidal bays, lagoons and channels, with much salt marsh, between the sea-islands and the mainland; (c) Satilla Plain, a strip of nearly level land about 20 to $35 \mathrm{mi}$. wide parallel to the coast, with a general elevation of from 15 to $25 \mathrm{ft}$.; (d) Okefinokee Plain, a higher plain, 20 to 40 mi. wide, roughly parallel to the last, and with a general elevation of 60 to $100 \mathrm{ft}$; (e) Southern Lime-sink Region, a narrow strip of rather rugged topography, parallel to and adjoining the Florida border, and with an elevation of 150 to $275 \mathrm{ft}$.; $(f)$ Altamaha Upland, an elevated tract of country, popularly termed "the wire-grass country," from 40 to $75 \mathrm{mi}$. wide, in the south-central part of the state, with a gently undulating topography and an altitude varying between 125 and $470 \mathrm{ft}$; ( $g$ ) Dougherty Plain, a tract of nearly level country in the southwest corner of the State, a lime-sink region, with an elevation from 125 to $450 \mathrm{ft}$.; (h) Red Hills, a narrow tract of hilly country, a few miles south of and parallel with the Fall Line, characterized by the prevailing red color of its soil, and having an elevation from about 450 to $600 \mathrm{ft}$.; (i) Sand Hills, a very narrow belt of rolling or flattopped hills, composed of pale gray sand or gravel, adjoining the Fall Line, with a maximum elevation of about $700 \mathrm{ft}$.

2. The Piedmont Region forms a wide strip occupying practically the southern two-thirds of the northern half of the state. It is a section of crystalline rocks with a broken or hilly topography. Its elevation varies from about $400 \mathrm{ft}$. along its southern edge to $1200 \mathrm{ft}$. 
along its northern boundary. As a rule, the tops of the hills and ridges in the Piedmont present a level skyline, but locally, dome-like elevations, like Stone Mountain near Atlanta, or Kenesaw Mountain near Marietta, may rise conspicuously above the general level of the country.

3. The Blue Ridge, the highest and most rugged section of the physiographic provinces, occupies the northeastern part of the state. It is a region of bold peaks and high mountain ridges, with narrow intermontane valleys. The country has an altitude of from about 1200 to $5000 \mathrm{ft}$.

4. The Appalachian Valley is a limestone valley situated between the Blue Ridge on the east and the Cumberberland Plateau on the west. It has a width of 40 to $50 \mathrm{mi}$. The topography in general is rolling, but it is traversed by numerous parallel ridges, formed of more resistant rock, which often rise considerably above the general level of the valley itself. The region has a general elevation of 600 to $1000 \mathrm{ft}$.; the ridges, however, may rise to as much as $1800 \mathrm{ft}$.

5. The Cumberland Plateau is formed of a small number of flat-topped mountains or tablelands in the extreme northwest corner of the state. They attain an altitude of 1700 to $2500 \mathrm{ft}$. above sea-level.

\section{Geographic and local plant and animal communities}

There are three principal kinds of forests represented in Georgia: the northern mixed coniferous and hardwood forest, the mixed hardwood forest and the southern mixed coniferous and hardwood forest.

The Northern mixed coniferous and hardwood forest (Transition Zone) in Georgia is typically represented only on the higher elevations of the Blue Ridge province in the northeastern corner of the state, though in a minor degree its influence is shown on the ridges in the Appalachian Valley and on the Cumberland Plateau. In the
Blue Ridge occur such trees, suggestive of more northern regions, as chestnut (Castanea dentata), white pine (Pinus strobus), hemlock (Tsuga canadensis), chestnut oak (Quercus prinus) and maple. Characteristic shrubs are mountain laurel (Kalmia latifolia) and rhododendron ( $R$. maximum). In the valleys of this section there appears to be a strong (Austral) mixed hardwood infusion, southern species meeting and mingling here with typically northern species.

The mixed hardwood forest area (Upper Austral Zone) forms by far the greater part of the northern half of the state. It includes most, if not quite all, of the Piedmont region and practically all of the Appalachian Valley and Camberland Plateau. Under existing conditions this in Georgia is the zone of shortleaf pine (Pinus echinata). Mingled with this tree are the remnants of a once extensive deciduous forest consisting predominantly of a variety of oaks and hickories and dogwood. Most of the country embraced in the mixed hardwood forest area (Upper Austral Zone) is in a state of rather intensive cultivation. As a consequence natural conditions are represented only in places unfavorable for cultivation. The herbaceous flora is predominantly of a weedy type, but in favorable spots the native flora is represented by an assemblage of species typical of rich, deciduous woodlands, such as hepatica, bloodroot, anemones, trilliums, wild geranium, and jack-in-the-pulpit. In general the flora is like that of the Piedmont Region of the Central Atlantic States, with, however, a strong infusion of other forms from the Mississippi Valley. The latter are best represented in the Appalachian Valley and Cumberland Plateau.

The southern mixed coniferous and hardwood forest area (Lower Austral Zone), as limited and defined by Rehn and Hebard, includes the upper twothirds of the Coastal Plain and the lower portion of the Piedmont Region. In this zone the character of the vegeta- 
tion varies considerably according to the prevailing types of soil. In sections where loamy soils prevail the predominant tree, under present conditions, is loblolly pine, but in sandy soils this is very largely replaced by longleaf pine. In the Piedmont portion of this zone mesophytic hardwoods, such as white and black oak and hickories prevail, whereas south of the Fall Line these become relatively infrequent and are largely replaced by more zerophytic species, such as blackjack oak and post oak. Longleaf pine was and, so far as it has not been destroyed, is still the dominant forest tree of the Altamaha Upland-a region which has vegetational features reminiscent of typical pinebarrens. The same species also appears to predominate on the Fall Line Sand Hills. In the Red Hills section it is of more local occurrence, being almost entirely supplanted in this section by loblolly pine. In general, the herbaceous flora north of the Fall Line has closer affinities with that of the adjoining portions of the mixed hardwood forest area (Upper Austral Zone) than to that south of the same line. In the Piedmont Region the soils are prevailing neutral or faintly acid, while south of the Fall Line distinctly acid soils are of rather general occurrence. In the Piedmont, also, swamps and other permanently wet areas are rare and of limited extent, whereas in the Coastal Plain they are common and often of considerable size. These swamps are of two kinds, river swamps and upland swamps. The river swamps border the major streams while the upland swamps form about the headwaters of local streams. The river swamps occupy alluvial flats and support a luxuriant growth of trees of which the more conspicuous and characteristic forms are species of evergreen oaks, as the willow-oak (Quercus phellos) and water-oak ( $Q$. nigra). The upland swamps are of the nature of strongly acid bogs in which such trees predominate as gums (Nyssa), sweet-bay (Magnolia glauca), red maples and pond pines ( $P$. serotina). The most interesting flora of the southern mixed coniferous and hardwood forest (Lower Austral Zone) in Georgia is that found in the Altamaha Upland (the Altamaha Grit Region of Harper), where the conditions approximate those of the typical southern pine barrens.

A Gulf Strip or Palmetto Belt (Sabalian Zone) is recognized by Rehn and Hebard, and is typically represented in the Okefenokee and Satillo plains. As intimated in one of the names, this zone is co-extensive with the range of the cabbage palmetto (Sabal palmetto) which forms the most characteristic tree of the forests. The latter are almost exclusively coniferous in composition, the dominant species being longleaf and slash pine. This is a rich faunal and floral region, with strong affinities to Florida. The alligator is largely limited to this zone, also the diamond-back rattler, and such trees as slash pine and live oak. Cypress is abundant in the swamps, which are often of great extent and tropical luxuriance. Black bears and Virginia deer are reported to exist in this section in considerable numbers. On the immediate coast maritine conditions prevail, the tidal marshes supporting a luxuriant growth of tall reeds in which water-fowl of several kinds find a congenial home, while on the sea-islands the sand dunes show characteristic vegetational features.

\section{PRESENT BIOTIC CONDITIONS}

In Georgia human occupancy and exploitation have for the most part so completely altered natural conditions that it is difficult to form a clear idea of what these conditions were. Georgia, like the other southeastern states, was originally covered with an unbroken forest, but this has been removed on such an extensive scale, especially the more valuable timber trees, that it seems probable that present-day conditions may be misleading. Thus, it is a matter of common knowledge that the dominant forest growth in central 
and north-central Georgia consisted originally of hardwoods, while at present pines predominate. Probably the nearest approach to primitive conditions is to be found in the mountainous northeastern part of the State and in the flat, poorly drained lands of the southeastern part. In the Blue Ridge there are extensive hardwood forests, some of which, according to government reports, have never been lumbered. Certain of these are now included in the Cherokee and Nantahala National Forests. In the southeast the sandy soils support dense stands of longleaf and slash pine, while the extensive swamplands are occupied with a heavy growth of cypress, gums, bays and other trees. In this section is situated the Okefenokee Swamp-a natural wonderland which, it is hoped, may be preserved unchanged for future generations. The Altamaha upland is predominantly a sandy district, at one time covered with a wonderful forest of longleaf pine, which, according to reports from various sources, appears to have been almost completely destroyed. This region has the reputation of being a botanical paradise, similar to, and in many particulars agreeing with, typical pine barrens country. On the coast, according to information furnished by Dr. George R. White, of Savannah, certain of the sea islands (Iittle Tybee, Wassaw, Ossabaw, St. Catharine's, and Black Beard) are said to be almost uninhabited and to have an interesting flora and fauna. With the growing popularity of the seashore resorts there is constant danger of the natural features on these islands being destroyed, and efforts should be made to preserve them before it is too late. There is said to be a private game preserve on one of the islands, but at the present writing particulars are lacking. According to the same informant there is also considerable wild land on the mainland opposite the islands. Between the two are the salt marshes, bays and lagoons in which a typical halophytic flora is developed.

In other parts of Georgia, especially in the Appalachian Valley, Piedmont Region and the upper and western portions of the Coastal Plain the forests are represented only by scattered groves, except locally in the bottomlands where, at least in the Coastal Plain, extensive alluvial forests are frequently represented.

Faunal conditions in Georgia vary according to the character of the country. The larger animals, as deer and black bear, are confined to the more heavily forested sections in the northeast and south. The bob-cat, raccoon, fox, opossum and gray squirrel are said to be rather generally distributed, though becoming scarce in the more thickly settled districts. Snakes are common, especially in the swamps and remote country districts. The rattlesnake and copperhead are of frequent occurrence, and the moccasin abounds in the swamps of the Coastal Plain. Alligators still occur in the Okefenokee and other swamps in the lowlands of the coast. Small birds appear to be abundant, but the larger ones are for the most part scarce. Water-fowl congregate in large numbers in the marshes and tidal lagoons on the coast. Forms closely dependent on forested conditions, as the pileated and ivory-billed woodpeckers, the wood duck, and the wild turkey, have either been exterminated or driven to seek refuge in the wilder and more remote sections.

\section{STREAM POLLUTION}

Very little information appears to be available on this subject. The general impression is that, for the greater part of their course, all the larger and more important rivers of Georgia are contaminated by refuse from the cities and towns of the surrounding country. All the streams which have their sources north of the Fall Line are heavily charged with silt. Typical mountain streams of clear water occur in the mountainous sections in the northeastern part of the state and many of those in the National Forests are protected from pollution. Certain of the 
local towns and tourist resorts derive their supply of water from these sources. In the Coastal Plain, the local streams have a sluggish flow and exhibit the reddish-amber discoloration characteristic of the streams of acid pine lands. All of these streams are more or less contaminated wherever they happen to pass close to human habitations.

\section{NATURAL AREAS}

\section{Possible new localities}

1. Cumberland Island. Owned by Andrew Carnegie, 2nd. Has been a bird and game preserve for nearly forty years. Situated in Camden County. Reached by boat from Brunswick. Area considerable, but exact figures not available at this writing.

2. Ossabaw Island. Owned by Strachan and Co., Savannah. A game preserve of 30,000 acres, containing magnificent colony of herons. Situated in Chatham County. Reached, probably by private arrangement with the owners, from Savannah.

3. St. Catherine Island. Owned by the Rauer's Estate. A game preserve, much like Ossabaw Island. Situated in Liberty County. Not very accessible, could probably be reached by private arrangement with owners from Savannah.

4. Okefenokee Swamp, Charlton County. (C2.) Deciduous swamp forest in midst of southeastern coniferous forest, a region of nearly level country, the greater part permanently wet, but with limited areas of higher dry sandy land as islands within the swamp. Vegetation much like that of the Dismal Swamp of Virginia as described by Kearney. Swamp traversed by sluggish streams, water of a clear amber color. Bears, otters, raccoons, deer, opossum, alligators and snakes reported as common, but scarce in region of settlements, due to incessant gunning. Game laws very poorly enforced, as in most parts of Georgia. Well forested for most part, but the larger and more valuable cypress and longleaf pine now being rapidly removed in lumbering operations. Owned by a lumber company.

Reached most readily from Waycross, Ga. Excellent hotel accommodations at this place. Swamp can be penetrated along line of railroad (Waycross \& Southern) owned and operated by a lumber company. Passage could probably be secured on a log train by application to agent of the company at Way- cross. Train starts from Hebardville, about two miles north of Waycross, and goes far into the Swamp with stops at Hopkins, on its northwestern margin, and Billy's Island about 15 miles further south in the midst of the swamp. Logging camp on this island where sleeping accommodations might be obtained through courtesy of lumber company, also excellent meals at the company's dining hall for its white employees. Extensions of the company's line penetrate far into the swamp. Guides procurable at Billy's Island. Trip from Waycross to Billy's Island takes half a day, to Hopkins about half the time. Parts of the Swamp, especially along its northern and eastern margins can be reached, according to information received at Waycross, by automobile from the latter locality. The Swamp can also be reached from Folkston, Charlton County, but hotel accommodations there not ascertained.

Strong local sentiment at Waycross in favor of preserving the Swamp as a natural game refuge. The lumber company, according to information received from several sources, is willing to surrender its title at cost to either State or National Government.

Information on Okefenokee Swamp based on recent trip with party of Boy Scouts to Billy's Island.

5. Stone Mountain, DeKalb County, Ga. (C4.) A prominent granite dome rising abruptly out of a gently rolling plain in the Piedmont Region. A nearly bare rock mass, with some limited woodland on its flanks near its base. Surrounding country mostly cleared and in high state of cultivation, with scattered groves of mixed deciduous and coniferous trees. Area much modified by human agency. Gently flowing streams at base of mountain bordered by tree growth and harboring interesting flora. The rock dome is the habitat of an interesting species of plant and of a rare saxicolus grasshopper. Extent of area suitable for preservation not determined, but would not include much more than the rock dome. Readily reached on foot from the village of Stone Mountain, about $12 \mathrm{mi}$. east of Atlanta, the terminus of an electric line from Atlanta. Trolley service good. Hotel accommodations in Atlanta excellent. Observed personally on visit to Stone Mountain in April, 1921.

6. Mountain Foot-hills, vicinity of Toccoa, Ga. Observed along route of Southern Railway from car window. Mixed deciduous and coniferous forest, more or less modified by human agency. Country rugged, with deep ravines, at 
headwaters of Savannah River. Hotel accommodations at Toccoa said to be good.

7. Cohutta Mountains, Murray County. Reported as a rugged and heavily wooded mountainous section near Chatsworth, about $20 \mathrm{mi}$. east of Dalton, Whitfield County. Doubtless eastern deciduous forest. A part of the Blue Ridge Section of Georgia. Good hotel accommodations at Dalton. Could be reached by automobile from latter place according to information given, but map shows a railroad (L. \& N.) extending from Cartersville, Ga., north into Tennessee, with station at Chatsworth.

8. Tallulah Falls, Rabun County. (D5.) Eastern deciduous forest, a region of mountains and rocky ravines, with originally beautiful waterfalls, now understood to be partially modified by water power development. A part of the Blue Ridge Mountain section of northeastern Georgia. Extent of area suitable for preservation not known. Not examined in person. Readily reached, according to information supplied by railroads, from the village of Tallulah Falls, which is a station on the Tallulah Falls Branch of the Southern Railway, connecting with the main line (Washington, D. C., to Atlanta, Ga.) at Cornelia. Hotel accommodations good, the locality being a favorite summer resort.

\section{9. *Shorter College Reserve, Rome,} Floyd County. (H8.) Not examined personally, but reported as a tract of open ravine woodland and meadowland along Coosa River. Evidently eastern deciduous forest, probably much modified by artificial "improvement." Apparently in part a pleasure ground. Reported to be about two mi. from Rome. Readily reached by automobile. Hotel accommodations at Rome good.

\section{REFERENCES}

Harper, R. M., A New Method of Mapping Complex Geographical Features, Illustrated by some Maps of Georgia. School Science and Mathematics, xviii (1918), 699-708.

Rehn, J. A. G., and Hebard, Morgan, Studies in the Dermaptera and Orthoptera of the Coastal Plain and Piedmont Region of the Southeastern United States. Proc. Acad. Nat'l. Sci., Phila., ILXVIII (1916), 90-105.

U. S. Geological Survey, Topographic Maps, _Georgia.
Veatch, Otto, and Stephenson, L. W., Geology of the Coastal Plain of Georgia. Ga. Geol. Surv., Bull. 26 (1911).

\section{FLORIDA}

By J. R. WAtson ${ }^{1}$

\section{GENERAL CONDITIONS}

\section{Topography and soil}

Florida is geologically, physiographically, and ecologically young; progressively so from north to south. Its physiographic youth is shown by its generally poor drainage, numerous swamps and shallow lakes, sluggish, ill-defined, crooked streams with low, generally swampy banks.

Much of the northwestern portion is hilly and rolling; a broken north and south ridge divides the drainage of the east and west coasts. The highest elevation above sea level is about 300 ft. Along a considerable part of the west coast and nearly the whole eastern coast extends a line of sandy reefs and narrow islands enclosing narrow shallow bodies of salt water, often called "rivers," viz., "Indian River," "Halifax River," etc.

The underlying rock is largely limestone. The central region is remarkable for its large number of lakes (Lake County alone has 1400)-largely sinkholes due to solution of limestone. The numerous subterranean streams are of similar origin.

\section{Climale}

Owing to its long stretch from north to south and the fact that the southern part is a narrow peninsula with warm seas on both sides, Florida presents a great diversification of plant and animal life. In fact there is much difference beween the vegetation of the northern and the extreme southern portions of

1 The data on orthoptera have been supplied by Prof. T.H. Hubbell, on crane-flies by Prof.J. Speed Rogers, both of the Department of Biology, University of Florida, on reptiles by Prof. Rogers and T. Van Hyning, curator of the State Museum, on birds by Prof. Van Hyning, and on the lepidoptera of south Florida by D.Marston Bates, a student in the University of Florida. Mr. A. H. Howell suggested a number of important changes in the original draft. 
Florida. The extreme southern part of the peninsula is practically tropical. The infrequent frosts are so light that they do not ordinarily penetrate the forest canopy, with the results that tropical plants can grow as undergrowth. This region is, however, very narrow, extending but a few miles from the coast, and gradually changing as it goes north. Probably St. Lucie Inlet should be considered as about the northern limit of the subtropical temperatures. On the west coast it extends up to about Fort Myers.

\section{Soils}

The soils of the state are mostly sandy, and in general progressively lighter from north to south and towards the coasts. Over much of the state, especially the interior, the sand is underlaid at no great depth by strata of clay or limestone. In places along the northern edge of the state, as about Marianna, Tallahassee, Monticello and Madison, a rather sandy red clay outcrops. Many swamps have a layer of muck on the bottom. These, when drained, ultimately make rich trucking lands, consequently there are many drainage projects. The largest of them is the Everglades.

\section{Original biota}

The state's ecological youth is shown by the small proportion in which the native vegetation has reached the climax formation, the magnolia-bayholly forest or even the present hardwood forest or "hammock," which is largely made up of deciduous trees, and by the general small amount of humus in the soil. Ecological succession is slow. The natural deposition of humus is slow, even when not interfered with by man. The high mean temperature causes rapid nitrification and the torrential rains of summer wash the nitrates from the soil into the streams which are dark with organic matter. But fires are very common during the dry season with the result that most pine- and grass-covered lands are burned over every year or two and ecological succession prevented or reversed.

To understand the types of vegetation in Florida it is important that one should bear in mind that there is a marked dry and wet season. The wet season occurs generally during the months from June to September (October on the East Coast); the drier season from November to May, usually reaching its climax in April. This diversification of seasons becomes more marked the farther south one goes in the peninsula. It is the inability to withstand the dry season which retards the spread of the hammocks and limits them to the more moist soils or to those that best retain water. It also explains why many plants such as red maple, ash, hackberry, and blackberries, which grow in mesophytic situations in the north are in Florida confined to swamps or moist soils.

We can divide the vegetation of Florida into five great groups:

1. Grassy Swamps, Savannas, and salt marshes, of which the Everglades would be the largest example,-areas largely under shallow water during the summer, and comparatively dry during the winter and spring and covered with a growth of very tall grasses and sedges, one of the most common being "saw grass," (Cladium effusum), a sedge. On the higher points and islands are occasional patches of forest. Bordering these islands and swamps is often a narrow zone occupied by a more or less dense grove of cabbage palmettoes whose tall, slender, naked trunks, bearing at the top a cluster of large leaves, give to the landscape of much of Florida its tropical appearance. On the other side these savannas merge into the aquatic vegetation of the lakes and swamps (and along the coast salt marshes), such as water lilies, and especially the floating water hyacinth (Piaropus crassipes), which almost cov- 
ers many of the smaller shallow lakes and sluggish streams.

These savannas occupy most of the southern third of the peninsula. In these savannas and swamps nest the Florida duck, the Florida redwing, the boat-tailed grackle, Ward's heron the common little blue heron, whose young are white, the black-crowned night heron, the reddish egret, the snowy heron, the American egret, the king rail, the clapper rail, the Florida gallinule, the purple gallinule, on the Kissimmee prairie, the Florida burrowing owl, and in the cypress trees nest the swallowtailed kite, and the everglade kite. On the beaches various sandpipers (plovers) nest.

This is also the home of the alligator (Alligator mississippiensis), rapidly diminishing in numbers. The marsh rat (Oryzomys palustris) is abundant, the round-tailed muskrat (Neofiber alleni) occurs, also the otter (Lutra canadensis vaga), mink (Mustela vison lutensis), and raccoon (Procyon lotor).

Burrowing in the mud occurs the horn snake (Farancia abacura). Other characteristic snakes of the region are the green water-snake, the banded snake, and the cotton mouth moccasin (Agkistrodon piscivorus). Here also occur the Florida terrapin (Pseudemys floridana), the alligator snapper turtle (Macrochelys temminckii), the common snapper, the soft-shelled turtle ( $A m y d a$ ferox), the banded mud-turtle ( $K i$ nosternon baurii), and in the extreme south the crocodile (Crocodylus acutus). Common amphibians are the Congo eel (Amphiuma means) and the mudeel (Siren lacertina). The curious gopher-frog (Rana aesopus) leaves the gopher holes to breed here.

Characteristic orthoptera are the earwig (Doru davisi), the katydids and the lubberly locust.

Among the butterflies most abundant here are the pearl crescent (Phycodes tharos), $P$. phaon, the white peacock (Anartia jatrophae), Basilarchia floridensis, which breeds on willow, the minute skipper (Ancyloxypha numitor, whose larva feeds on grasses, the little red moth Eulaphe rubicundaria, the pretty little Utetheisa bella, and Apantesis spp.

Some of our largest and most characteristic plant bugs occur here, the large club-legged plant bug (Acanthocephalus femoratus), the southern green stink bug (Nezarra viridula), the leaf-footed plant bug (Leptoglossus phyllopus).

The salt marshes along the coasts form a well marked and distinctive type. The grass Spartina is the dominant plant. Another coarse grass is the sea-oats (Uniola paniculata). In the tidal flats grow two succulent woody plants, one with broad leaves (Scaevola Plumieri) and one with narrow leaves (Tournefortia gnaphaloides. Here also grows the high-water-shrub (Iva imbricaria).

In the extreme south characteristic plants are the sawgrass (Mariscus jamaicensis) and Juncus Roemerianus.

Characteristic orthoptera of the salt marshes are the locusts Orphulella olivacea, and $O$. halophila, and the meadow grasshoppers Conocephalus aigialus, C. nigropluroides, C. spartinæ, and Orchelinum fidicinium. Haplothrips leucanthemi is the characteristic thysanopteran. The great southern white butterfly Pieris monusta is characteristic.

Except during the winter months the salt marsh mosquitoes are extremely abundant. The malaria mosquitoes (Anopheles) are, however, comparatively scarce. In the late spring horse-flies (Tabanus and Chrysops) are extremely abundant.

Characteristic of the salt marshes are the following birds. Some of them nest in the cabbage palmettoes and shrubs along the edges of the swamps and on the islands. The brown pelican, the wood ibis, the Anhinga, the herring gull, and the black skimmer. Characteristic reptiles are the salt-water moccasin (Natrix compressicauda), the loggerhead turtle (Caretta caretta), the 
bastard-turtle (Caretta kempii) and the green-turtle (Chelonia mydas) which nest on the upper beach.

Mangrove Swamp: Much of the low coasts of tropical Florida which are protected from hard frosts, are lined with a dense growth of mangrove, the red mangrove (Rhizophora mangle), and the black mangrove (Avicennia). In these mangroves nests the Florida cormorant and various herons and egrets. Here occurs the katydid, and the crickets Anaxipha scia, Orocharis gryllodes, Nemobius cubensis, and Hygronemobius alleni, and the earwig Euborellia ambigua. The butterfly Phocides batabano breeds on the red mangrove.

2. Flatwoods. a. The so-called "flatwoods," are comparatively level regions, poorly drained, and underlaid at a depth of a few feet with a layer of hardpan that is almost impervious to water. The result is that the soil is very acid although often comparatively well supplied with humus. The vegetation consists of an open forest of longleaved and loblolly pine and, especially in the south, the slash pine and saw palmetto interspersed with gallberries, huckleberries, pitcher plants, sun-dew (Drosera), and other plants characteristic of sour boggy soil, and a good growth of grasses.

Mammals: The cottontail rabbit (Sylvilagus floridanus) and the Florida swamp rabbit (Sylvilagus palustris paludicola) occur here, as does also the raccoon.

Reptiles: An occasional diamondbacked rattle-snake, and ground rattler occur here, as do also the black-snake, the common chicken-snake (Elaphe quatrivittata), the spotted chicken-snake (E. obsoleta confinis), the king-snake (Lampropeltis g. getulus), and the cornsnake (Elaphe guttata). Lizards are comparatively scarce.

Characteristic birds are the bald eagle and the Florida red-tailed hawk, which nests in the tallest pines, and the wood duck.

Insects: The beautiful little pink day flying moth (Utetheisa bella) is especially abundant here. Butterflies characteristic of this region are the southern dogface (Zerene caesonia), the pearl crescent, and Phaon, Hunter's butterfly (Cynthia virginiensis), always abundant about thistles, the nymph Neonympha phocion, the small reddish brown southern metal mark (Lephelisca virginiensis syn. Calephelis), Strymon melinus, and S. cecrops.

Gallberries are often blackened by the sooty mold fungus growing in the honey dew given off by the Florida wax scale (Ceroplastes floridensis). Orthoptera characteristic of this region are the mantids (Stagmomantis floridensis, S. carolina, Oligonyx scudderi, and Thesprotia graminis); the walking sticks (Manomera tenuescens, M. brachypyga, and Anisomorpha buprestoides); the locusts (Radinotatum brevipenne, Mermiria alacris, Gymnoscirtetes pusillus, Aptenopedes sphenarioides. A. aptera, and Melanoplus rotundipennis); the katydids (Odontoxiphidium apterum, Orchelinum militare, Belocephalus subapterus, and $B$. sabalis); and the crickets Falcicula hebardi, and Nemobius ambitiosus. Characteristic crane flies are Tipula sayi, Decranomyia liberta, Rhaphidia domestica, and Gonomyia sulphurella.

During the late spring horseflies and "deerflies" (Tabanus and Chrysops and mosquitoes are very abundant here.

Jassids and cercopids are abundant on the grasses and shrubs, and on the former the black thrips (Haplothrips graminis).

b. Cypress swamps: The shallow depressions in this flatwoods country, which are usually under water but often go dry, are commonly occupied by a dense growth of the pond cypress (Taxodium imbricarium. From the roots of this tree there extend up into the air numerous projections, "knees," which are covered with mosses and ferns. The trunks of the trees frequently bear orchids and other epiphytes (Tillandsia), and from the branches droop long festoons of "Spanish moss," (Dendropogon usneoides). These cypress swamps also 
line most of the streams and swampy lake margins and gradually merge into "low hammock." The largest of these cypress swamps is the "Big Cypress" southwest of Lake Okeechobee in Collier County.

In the larger of these swamps alligators (Alligator mississippiensis), watermoccasins, and water birds abound.

Insects, except mosquitoes, are not especially abundant in the dense shade of the cypress swamps. But craneflies (Geranumyia vanduzeei, Toxorhina magna and Polymera georgiae) are characteristic.

3. Scrub and spruce pine land. On many of the higher ridges in the central part of the peninsula where the sand is deepest and therefore least retentive of moisture, and especially along the sand dunes of the coasts, occurs a dense growth of saw palmettoes (Serenoa serrulata), evergreen oaks (Quercus myrtifolia, Q. geminata), interspersed with a great variety of evergreen shrubs with small leaves and often thick succulent stems. Cacti (Opuntia spp.) are common. It is a typical scrub forest. Some of the more characteristic shrubs are Dahoon holly (Ilex Cassine), Anamomis, Dodonaea Jamaicensis, a heath (Xolisma ferruginea), the hemp vine (Mikenia), golden buttons Actinospermum), Polygonella sp., Thysanelly sp., and Vaccinium Myrsinites. Other characteristic plants are blue curls (Trichostema dichotomum, the carpet weed (Mollugo verticillata), Petalostemon Feayi, Froelichia floridana, the umbrella plant (Eriogonum floridanum) Warea sp. (a crucifer), the dark green and very leafy shrub-Rosemary-the dodderlike parasitic vine (Cassytha americana). South of Mosquito Inlet the major dune plants are the sea grape (Coccolobis uvifera), the cabbage palmetto, the saw palmetto, the cocoa plum (Chrysobalanus pellocarpus), the poison wood (Metopium metopium) and the minor ones the century plants (Agave decipiens and $A$. neglecta), the strangling fig (Ficus aurea), the Spanish bayonet (Yucca aliofolia), Solanum bahamense, Lantana ovatifolia, Ernodea littoralis, the black torch (Erithalis fruticosa), the snow berry (Chiococca racemosa), the marlberry (Icacorea paniculata), Myrsine (Rapanea guinensis).

North of Mosquito Inlet the larger trees, in addition to the oaks mentioned above are the Shore bay (Tamala littoralis), red cedar (Sabina silicicola), cassena (Ilex vomitoria), the wild olive (Desmanthus americanus) Xolisma ferruginea, and the spice tree (Anamomis simpsoni). Smaller shrubs are the French mulberry named from its beautiful magenta colored berries, the Gallberry (Ilex glabra) and the horse sugar (Symplocos tinctoria). On the upper beach the sunflower (Helianthus debilis) and the blue verbena ( $V$. maritima) are conspicuous.

In the older and less dry portions of this area a small pine, Pinus clausa, is the most conspicuous plant. The region has very little grass and therefore does not burn over so readily as the higher pine lands, but occasionally it does burn and the destruction is much more complete. In the higher pine lands, the fire consumes only the grass and shrubs of the forest floor,- " "ground fire," but in the scrub the trees and all are destroyed. There are large areas of this scrub which can be said to be in an almost natural state of preservation as fire runs through them infrequently. The soil is so poor from an agricultural standpoint and the grazing so almost negligible on this land that its commercial development is very slow. The spruce pine is so small as to be valueless for timber except for fire wood, and it does not yield turpentine. The only extensive developments are along the lower parts of the East Coast where the land has been cleared for pineapple fields. This type of vegetation is interspersed to a very marked degree with both flatwoods and high pine land. Animal life is not abundant, the fauna is the poorest of the state, and even insects are not abundant on the coarse 
tough plants, although the locusts (Spharagemon collare wyomingi, Scirtitica marmorata picta, Psinidia fenestralis, and Melanoplus keeleri keeleri) are characteristic. The great southern white butterfly (Pieris monuste) is characteristic, especially in the south.

4. High pine woods. This is usually rolling, well drained country with numerous small lakes and ponds between the hills. The soil is sandy, usually underlaid with clay (sometimes limestone) at no great depth. The typical growth is an extremely open forest of long leaved pine with scattered clumps of saw palmetto. Where not over grazed there is a sparse covering of short grasses, herbs, and a few low bushes such as the "oak-runner" (Quercus pumila). There would doubtless be more shrubs were fires not so frequent. On the higher, drier ridges there is much "scrub oak" including the turkey oak (Q. catesbaei). The lupin (Lupinus sp.) makes large conspicuous green mats with spikes of blue flowers. Ground fires spread rapidly through this region although they do not generate as much heat as in the flatwoods, and a large part is burned over annually, largely purposely by owners of cattle to provide fresh green grass in the spring. In this region the greatest development of citrus has taken place and as a result much of it is cleared. Where underlaid by limestone, particularly in the north central part, the dwarf chinquapin (Castanea nana) is often common, and scattering cedar trees. On the lower East Coast much saw palmetto occurs in the high pine land and the cycad "Coontie" (Zamia floridana) is abundant and characteristic.

Two burrowing animals, the "gopher" and the "salamander," are characteristic of this region. Both animals are sadly misnamed. The "gopher" (Gopherus" polyphemus) is a burrowing turtle, and the "salamander" (Geomys floridanus) a ground rodent, similar to the pocketgopher of the West.

Snakes characteristic of these open woods are crown-snake (Tantilla coronata), the coach whip (Coluber flagellum flagellum), the black-snake, the chickensnake, the corn-snake, the common hognosed snake (Heterodon contortrix), the king-snake and the common gartersnake (Thamnophis s. sirtalis).

Characteristic birds are the bald eagle, the Florida red-tailed hawk, the Florida red-shouldered hawk, the Florida screech owl, the sparrow hawk, the Florida bob-white, the loggerhead shrike, and the Florida wren.

Among the characteristic orthoptera are the locusts (Amblytropidia occidentalis, Melanoplus rotundipennis, and $M$. puer); the katydids (Arethaea phalangium, Orchelimum minor, and Conocephalus saltans); and the cricket (Falcicula hebardi).

Characteristic butterflies which breed here are Papilio philenor on the pipe vine (Aristolochia), the Ajax ( $P$. marcellus), on Asimina, Iole (Nathalis iole), on Cassia, the cloudless sulphur (Catopsilia eubule) on Cassia, Nicippe (Eureme nicippe) on Cassia, the little sulphur (E. lisa) and $E$. delia, on Cassia, the Gulf fritillary. (Dione vanillae) on Passiflora, the Buckeye (Junonia coenia), Danaus berenice on Asclepias tuberosum, Eumaeus atala on Zamia, extremely abundant in the south, Attides halesus, common about blossoms of Chinquapin and Eupatorium serotinum-larva on oaks, Strymon melinus, Hemiargus catalina on Pithecolobium in the south, Goniurus proteus and Epargyreus tityrus on legumes, the larvae rolling up the edges of the leaves, Staphylus hayhustii on Alternanthera, and Hylephila phylaeus on grasses.

5. Hammocks (Hardwood forests). a. Low hammocks: In the low hammocks, which occupy the low wet lands between the high hammocks and the cypress swamps, the dominant trees are sour gums (Tupelo), ash (Fraxinus spp.) red maple (Acer rubrum), hackberry (Celtis mississippiensis), and an undergrowth of blackberries (Rubus $\mathrm{spp}$ )., Andromeda, Virginia willow (Itea vir- 
ginica), laurel-leaved smilax (Smilax laurifolia), trumpet flower (Tecoma radicans), and a host of other shrubs.

"Low hammocks" can be subdivided according to the dominant trees. In the lower, more swampy places where it merges into the cypress ponds the sour gum is often dominant. In other places the cabbage palmetto is the most common plant. In the less swampy parts there is a greater variety of trees, the water oaks (Quercus nigra), and the swamp oak ( $Q$. palustris) are often the common trees. In many wet boggy places at the heads of streams and along their banks the bull bay (Magnolia glauca) is the dominant tree, and with a heavy undergrowth, forms a dense thicket. These are commonly called "bay-heads."

These hammocks are the home of the gray squirrel, Florida opossum (Didelphus virginiana pigra), raccoon, marsh rabbit and an occasional gray fox, and in the larger remoter ones occur the Florida black bear (Ursus floridanus), the Florida wildcat (Lynx rufus floridanus) and deer. Here nest the great horned owl, the Florida barred owl, the black vulture, the turkey vulture, doves, hawks and numerous small birds. The little poisonous coral-snake (Micrurus fulvius) is occasionally seen, and its mimic the scarlet king-snake (Lampropeltis c. elapsoides).

Characteristic butterflies of the low hammocks Papilio glaucus and Enonia portlandia, of moths the Polyphemus (Telea polyphemus), and several species of Catocala. The locust (Melanoplus furcatus) is characteristic. The cricket (Nemobius carolinus) is typically found in the black gum swamps. The following craneflies are characteristic of the low hammocks, Molophilus forcipula M. Hirtipennis, Pilaria recondita, Limnophila macrocera, Bittacomorpha clavipes, Pseudolimnophila luteipennis, P. contempta, Brachypremna dispellans and Epipmagma solatrix: Mosquitoes are very numerous and so are tabanids (Chrysops). b. High hammocks: The high "hammock" occurs in well drained but good moisture holding soils, usually those containing considerable clay or underlaid with limestone. It occupies but a relatively small part of the surface of the land, increasing in amount as one goes north in the state. Where it has reached its apparent climax it is composed largely of broad-leaved evergreen trees of which the dominant ones are magnolias, red bay (Tamala sp.) and holly. Deciduous trees of the types noted below are mixed with them to some degree. Only on the best, moist (but not swampy) soils are these broadleaved evergreen trees dominant. In drier situations, which include the great bulk of the "hammock" the majority of the trees are the deciduous ones, such as blue beeches (Carpinus), hop hornbeam (Ostrya), cork elm (Ulmus alata), basket oak (Quercus Michauxii), bassyood (Tilia sp.), sweet gums, shortleaved pines, live oaks, water oaks (Q. nigra), hickories, which occur to some extent in the climax stands, Spanish oak ( $Q$. falcata), with an undergrowth of wild plums, (Prunus sp.), prickly ash (Aralia spinosa and Fagara Clava-Herculis), red bud, French mulberry, smilax and yellow jasmine (Gelsimium), and on the forest floor, partridge berry (Mitchella repens), sedges and grasses. The high hammock gradually merges into high pine land on the one hand and low hammock on the other. As one approaches the northern part of the state the broad leaved evergreens diminish in numbers, as does also the Spanish moss and other epiphytes, tulip trees (Liriodendron), beeches (Fagus grandifolia), red oak (Quercus rubra) and scarlet oak (Q. coccinea) appear, and the hammock gradually merges into the eastern deciduous forest.

The percentage of evergreens in these hammocks is sufficiently high to keep the forest floor damp and prevent the spread of fire.

In the hammocks are found the usual 
small animals of the forest, most of which like the plants range far north; but some like the "chameleon" (Anolis carolinensis), and some of the butterflies, (viz., Heliconidae) are distinctly southern.

Birds which nest here or in the shrubbery of the forest margin are: ChuckWill's-widow, Florida nighthawk, the fish crow, the cardinal, nests in the dense thickets, and the mockingbird.

Characteristic snakes are the blacksnake, chicken-snake, corn-snake, common hog-nosed snake, king-snake, and the burrowing worm-snake (Carphophis amoena), which looks like a large earth worm.

The lizards are Sceloporus spinosus floridanus, the glass-snake (Ophisaurus ventralis), and the swift (Cnemidophorus sexlineatus).

Insects: Butterflies typical of the high hammocks are: Papilio polydamus, whose larva lives on Aristolochia, $P$. cresphontes, whose larva the "Orange Dog" lives on prickly ash (Fagara).

6. Tropical hammocks. This is a dense jungle of trees, shrubs, llanas, and epiphytes, mostly evergreen but containing a species of hickory. Typical trees are banyans, wild papaya the Gumbo Limbo (Bursera simaruba), Mahogany (Swietenia mahagoni), Rubber Trees (Ficus aurea and F. populina), and Lance Wood Ocotea catesbyana. The butterflies include the big yellow Turnus ( $P$. glaucus), P. troilus iloneus, $P$. palamedes on Persea and Magnolia, Ajax (P. marcellus), the Zebra (Migonitis charithonia) on Passiflora, Buptoieta claudia also on the passion flower, Polygonia interrogationis, Enodia portlandia, the Wood nymph (Megisto sosybius), and the skipper Calpodes ethlius.

Characteristic moths are the Luna (Actias luna dictynna), Polyphemus (Telea polyphemus), the underwings (Catocala spp.), the regal moth (Citheronia regalis), whose larva is the "Hickory Horned Devil," the wasp moth (Cosmosoma myrodora), Dahana atripennis, the moth of the velvet bean caterpillar (Anticarsia gemmatilis), and that of the puss moth (Megalopyge opercularis).

Characteristic hemiptera are the clublegged plant bug, the northern green stink bug (Nezara hilaris), numerous cicadas, membracids, tingids, etc.

For a list of the beetles, see Dozier, 1920.

Many large and beautiful snails are found here.

Characteristic locusta are Melanoplus rotundipennis and $M$. querneus; katydids, Stilpnochlora couloniana, Lea floridensis, Pterophylla camellifolia, Atlanticus gibbosus. The common mantid is Gonatista grisea.

The craneflies are Tipula mingwe, the T. umbrosa group, Dicranomyia liberta, Gnophomyia luctuosa, and Dicranoptycha sobrina.

Typical butterflies are Papilio polydamus, on Aristolochia, the South Florida White (Appias ilaire neumoegenii), Catopsilia agarithe on Cassia, the Zebra, Eunica tatila, Athena peleus on Ficus, Anaena portia.

These tropical hammocks are noted for numerous species of large and beautiful snails.

Fresh waters. Springs in Florida whose waters are practically unpolluted. These are underground water courses in limestone regions which come to the surface in certain places. The largest of these is Silver Springs, six miles east of Ocala. The spring is so powerful that good-sized steamboats regularly navigate the river flowing from it and come up in the spring itself. There are a number of these springs in the state which are but little smaller. As a general thing the more shallow springs and streams although unpolluted as far as pathologenic germs are concerned are so charged with decaying organic matter as to be unpalatable. Most of the streams and many of the lakes are very dark in color as a result of the presence of decaying organic matter. Some of the larger lakes are quite clear and palatable. Lake Weir is one of 
the best examples. In general the streams and lakes of Florida are exceptionally well supplied with fish.

Caves. The limestone region includes a number of caves but none are very extensive. Immense number of bats find refuge in them and the camel cricket (Ceuthophilus latibuli) is a characteristic insect.

Succession. The relation of these different types of vegetation to each other and the ecological succession are indicated in the following diagram:

(14)

$\overline{\text { Evergreen Magnolia Bay Holly Hammock }}$

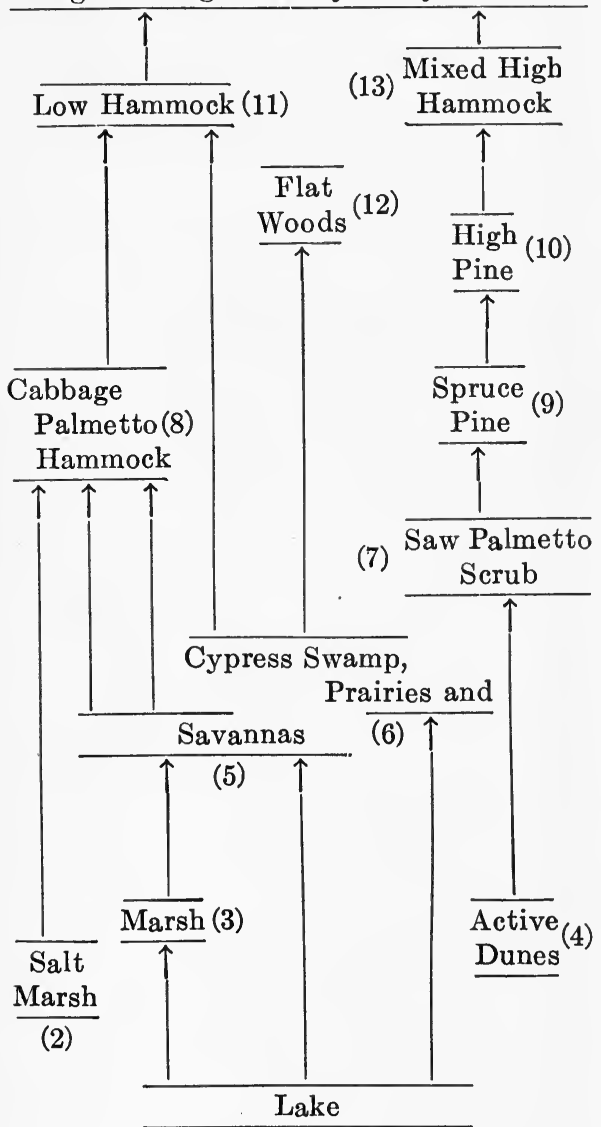

(1)

II. PRESENT Biota

Less than $10 \%$ of the land area of Florida is under cultivation. A large part of the remainder is occupied by open pine forests which have been cut over by lumbermen, turpentined, grazed (by cattle and hogs chiefly), and frequently burned over. The fires are, however, "ground fires" and do not damage mature pines as seriously as a northern forest fire. They do, however, tend to kill out the oaks and other hardwood trees and hence prevent succession.

Both the pine timber and the cypress are being rapidly consumed, and except for two small forest reserves, no attempt is being made at reforestation. Even young pines but a few inches in diameter are being turpentined. Many abandoned fields are growing up in second growth pines, largely loblolly. Some of the hammocks are in a nearly natural condition, there being even a few black bear, deer, and wild turkeys to be found.

The drainage of swamps is also proceeding rapidly as the drained areas make the best trucking soils.

Still there are many areas in nearly a natural state and much of the area of the state offers desirable opportunities to the student and collector. Some of the more desirable areas for such purposes are described in the following pages.

\section{NATURAL AREAS}

\section{a. Extensive natural regions}

The Knox Hill Country and Homes Valley are two very small but rather unique areas in West Florida, constituting cases of rich soil and hardwood forests surrounded by sandy pine regions. A good deal of the area of both has been cultivated and some abandoned, so that some of the forest is second growth. They differ from each other in soil, topography, etc., but on account of their small size the two plant lists are combined. (For additional details about these regions see 6 th Ann. Rep. Fla. Geol., Surv., pp. 217-224.)

Both regions are off the main routes of travel, and Holmes Valley is almost uninhabited. But one can see a good deal of the Knox Hill country in one 
day by walking out from DeFuniak Springs or Ponce de Leon, and the Valley, a railroad crosses it near its eastern end, is reached from Vernon or Chipley.-R. M. Harper.

The West Florida Lake Region is a sandy longleaf pine region, comparatively level except for being pitted with numerous approximately circular depressions containing lakes and ponds. The region is almost uninhabited and uncultivated, but of course the lumber and turpentine men have cut or bled all the longleaf pine they could conveniently reach from the railroads.

Pinus palustris (longleaf pine), Taxodium imbricarium (pond cypress), Magnolia grandiflora (Magnolia), Liriodendron (tulip poplar), Pinus Elliottii (slash pine), $P$. serotina (black pine), Quercus laurifolia occur.

The salamander, Geomys Tuza Mobilensis, is abundant, the dry sandy soil furnishing ideal conditions for it.

Round Lake, near its eastern end, is one of the highest points in Florida, about 300 feet above sea level. $-R . M$. Harper.

The Apalachicola flatwoods is a low flat region near the Gulf coast, with no rock exposures of any kind, and soils classed as fine sand, swamp, loamy fine sand, etc. Less than $5 \%$ is cultivated, but lumbering and turpentining have been going on for a long time. The vegetation is mostly open pine forests with much low shrubby undergrowth, interrupted by many shallow ponds, swamps, and tyty "bays." Oaks are rather scarce. The estuarine swamps of the Apalachicola River belong to this region, but they are much like the Mobile delta, and will be excluded from the following plant list.

Large trees. Pinus palustris (longleaf pine), Taxodium imbricarium (pond cypress), (slash pine), $P$. serotina (black pine), Nyssa biflora (black gum), (sweet gum), (red maple), Pinus Taeda (shortleaf pine), Quercus nigra (water oak), Liriodendron (tulip poplar), Magnolia grandiflora (Magnolia).
The whole region is not very easy to explore, being so flat that there is much standing water, especially in rainy seasons, and roads, railroads, and settlements are rather scarce. April is a pretty good month to visit the region, that being before the rainy season and late enough for many flowers in that latitude, though the number of flowers increases as summer advances. One can get a good view of it though from the railroad running north and west from Apalachicola, or can walk out from that place or Port St. Joe or Wewahitchka (the last being a river landing near the Dead Lakes and remote from railroads).-R. M. Harper.

\section{The Apalachicola River endemics}

There is a colony of Torreya taxifolia, together with a number of other endemic and disjunct species along the bluffs of the Apalachicola River between Chattahoochee and Bristol. Are well drained, but at the same time thoroughly moist, because of the abundant seepage water and the low evaporation rates that prevail. Magnolia occurs among the trees and scrub palmettos in the undergrowth, are plentiful.

Torreya grows all over the slopes of the ravines, from stream-bank to rim, wherever there is any shade. It is mostly an undergrowth tree, seldom reaching a height of more than 20 or $25 \mathrm{ft}$. or a trunk diameter of more than 6 in.-Frank Thone.

Everglades. A portion of the Everglades is still in an almost natural condition. This is particularly true of the region lying southwest of Lake Okeechobee where no drainage operations have been undertaken. The whole region from Lake Okeechobee to the south end of the state can be said to be in a virgin condition. However, roads and drainage ditches are now penetrating it.

The Everglades can be reached (c) up the canals from West Palm Beach, Fort Lauderdale or Miami; by the Atlantic 
Coast Line to Moorehaven. The Tamiami Trail, Tampa to Miami, via Fort Myers and Everglade will be finished in 1926 and cross the lower "glades." Hotels at Moorehaven and Canal Point.-J. R. W.

There are a few bird reservations in Florida. One of these is about Mosquito Inlet south of Daytona.

Ten Thousand Islands. There is a considerable area in the extreme southwestern part of the state along the Gulf Coast parts of which are probably in a nearly natural state. This is adjacent to the big Cypress Swamp. It is a place of alternate mangrove islands and water extending from Marco to Cape Sable. Some settlements have been made on the larger and higher islands. Communication and lodging are such that if one wished to get about he would have to use a house-boat or camp.

A road reaches south to Marco. Boats from Ft. Myer to Everglade several times a week.-J. R. W.

Gulf Hammocks. A region of alternate hammocks, flatwoods, and swamps. The hardwood forests are not suitable for grazing as there is very little grass in them and fire does not go through easily on account of a large part of the vegetation being the large-leaf evergreens, and a consequent absence of a layer of pine needles and grass on the ground. Furthermore, the dense shade keeps the forest floor so moist that fire does not readily run through it. The open pasture lands have been grazed and some of them burned over. The hardwood forests, however, are almost in their natural condition except for the relative scarcity of the larger game. Wild turkeys are common. Deer and bear are still found in the region, but of course they are not as abundant as they originally were. The region is but little settled and developed.

Levy and adjoining counties. Can be reached (a) from Cedar Keys, Bronson, or Old Town.-J. R. W.

Turnbull Hammock. A hammock of considerable area. Except for clear- ings made in this land for orange groves and roads it can be said to be in an almost natural condition except for the absence of big game. The clearing of this land is so expensive that it has delayed development. Some of the immediate seacoast is also in an almost natural state.

East Coast. New Smyrna is in the midst of it. An area still remains south and west of town.-J. R. W.

East Seacoast Regions. Much of the immediate seacoast is still in a natural condition with the exception of the absence of larger game. The soil is so light and poor that it is practically worthless for agricultural purposes, and the vegetation so scattered and of such a nature that fire does not readily run through it. This, however, is true of only a few rods from the seashore, the beach itself, and the more recent of the sand dunes behind it. Except in the immediate neighborhood of resorts the sand dune areas are mostly untouched.-J. R. W.

\section{b. Areas suitable for preservation}

pAllaysatakatchee Flats. (C3.) A large area in St. Lucie County, Florida. A savanna consisting of grassy areas where the principal growth is "saw grass" alternating with "hammocks," or forest patches of cabbage Palmettoes, bays, and similar semi-tropical vegetation usually called in Florida a "low hammock." There are many shallow ponds and swamps. Wild turkeys and deer; few bears occur. A portion should be preserved.

Ft. Pierce I, $12 \mathrm{mi}$. west, or Okeechobee, Fla. East Coast Ry, $10 \mathrm{mi}$. northeast. \& (a) Good roads extend through the tract. $-F . M$. O'Byrne.

pDevil's Mill Hopper. (D5.) This is a large deep "sink" in a limestone region. Several small streams flow into it but the outlet is so large that there is little or no standing pool in the bottom. 180 $\mathrm{ft}$. deep. The steep sides are covered with a dense southeastern climax forest.

Gainesvilleł, A. C. L. Ry. and Seaboard Ry. 7 mi. N.W., or Paradise, A. C. L. Ry. 3 mi. W. (a).

pThe Everglades. (A4.)

This area is being drained. A portion should be preserved in its natural state. Miami $\ddagger$, Moorehaven (a, c) $\ddagger$. 
pUniversity of Florida Grounds. Including typical "high hammock." A portion of the climax forest of the region.

Gainesvillet, Fla. $1.5 \mathrm{mi}$. W.

Streamside Flood-Plain Forest. (C3.) (b). Along Hogtown Creek. A typical flood-plain forest of the region, of ashes, gums, catalpa, tupelo, magnolias, short-leaved pine, dogwood, holly.

Gainesville, \pm 2 mi. W (w) (a).

pGulf Hammock. (D4.) A savanna country occupied by saw grass areas alternating with shallow ponds and dense cypress swamps, and heavy, low hammocks of magnolia. All stages of the succession to the climax forest of the region. The haunts of bear, wild turkey, many birds, etc. Levy County.

Otter Creek, $\ddagger$, on the Seaboard Railway, and Gulf Hammock (a), (h) §.

pPineola Fernery. (B4.) A broadleaved evergreen forest in lime rock region in Citrus County, Fla.

Invernesst; Pineola, $2 \mathrm{mi}$. S., or Istachatta 2 mi. N. Atl. Coast Line Ry. (w), (a).

The Jungle. Miami. (B4.) A tract of Tropical hammock (1200 acres) in Dade County.

Miamit, Fla. East Coast Ry. $3 \mathrm{mi}$. S. (a), (w).

Arboretum of Chas. Deering. A private collection of sub-tropical plants amid native vegetation open for the benefit of students and the public. Miami.

Royal Palm Park‡. (B3.) A state park in Dade County. Belongs to Florida Federation of Women's Clubs. It is on Paradise Key in the Everglades. It has a wonderful growth of Royal Plams and a rich development of "fannick trees," and other sub-tropical vegetation-both forest, savanna and swamp. This is an excellent place to study sub-tropical vegetation and animal life as there is a good lodge on the grounds, and driveways and paths make all parts easily accessible. There is some complaint that it is being "parkified."

Royal Palm Beach I (a).

Torreya and Taxus Floridana Preserve. (B4.)

River Junction $\ddagger$ (w), (h).

pSilver Springs and Rivert. (C2.) At the head of the Silver River, a branch of the Oklawaha. A spring so large and powerful that good sized steamboats come into it regularly. The river is lined by a dense growth of trees, cypress, live- and water-oaks, cabbage palmettoes, bays, etc.

Ocala $\ddagger$, Seaboard and A. C. L. Ry. 6 mi. east, but commonly and best reached by a line of excursion steamers up the
St. Johns and Oklawaha Rivers. (a), (c).

Thousand Islands. (A2.) South of Marco, in Lee, Collier and Munroe Counties (see page 000).

Reached only (c) from Marcoł, Caxambas, Everglade, or Chokuluskee (c) 1 .

pTurnbull Hammock. (C3.) A magnolia hammock in Volusia and Brevard Counties. Vines and epiphytes grow here in profusion. In the tree tops grow ferns as well as air plants in especial abundance.

The Florida East Coast runs through it from New Smyrna to near to Titusville (a) $\ddagger$.

Peace River Hammock. (C3.) In the southwest corner of DeSoto County. Extends along the Peace River.

Ft. Ogdent, on A. C. L., and Charlotte Harbor and Northern Ry. $3 \mathrm{mi}$. west (w), (c).-F. M. O'Byrne.

* Florida National Forest, Ocala Division. A large tract in eastern Marion County has been set aside as a forest reserve. The vegetation is largely spruce pine, high pine, and flat woods.

Ocala 12 mi. east (h) \&. Choctawhatchee Division. See "National Forests of the Eastern District."

\section{REFERENCES}

Stork, Willis

1765 An account of East Florida with Journal kept by John Bartram.

Chapman, A. W.

Flora of the Southern States.

1885 Torreya Tacifolia, Aruatt. A reminiscence. Bot. Gazette (10-251-254).

Bartram, William

1792 Travels.

Blatchley, W. S.

1902 A Nature Wooing at Ormond by the Sea.

1914 Can Ent., pp. 62-63. A brief description of the Kissimmee Region.

1917 Can Ent., p. 137. A brief description of the vicinity of Dunedin.

1918 Jour. N. Y. Ent. Soc. The same. Pp. 155-162.

1920 Orthoptera of N. E. America. (Nature Publishing Co., Indianapolis.)

1920 Can Ent., pp. 42-43. A brief description of the Cape Sable region.

1922 Can Ent., pp. 9-11. A brief description of the vicinity of Ft. Myers and Chokoluskee.

1923 Can Ent., pp. 13-14. A brief description of Moor Haven and Lake Okeeschobee. 
Blatchley (W. S.) and Leng (C. W.)

Rhynchophira or Weevils of N. E. America.

Catesby Mark

1732 Natural History of Carolina, Florida and the Bahama Islands.

1762 Nortus Europae Am. Ericanus 40.

Cory, Chas. B.

The Water Birds of Florida.

Dozier, Herbert L.

An Ecological Study of Hammock and Piney Woods Insect in Florida. Ann. Ent. Soc. of Am., Vol. XIII, No. 4.

Gray, Asa

1875 A Pilgrimage to Terreya. Am. Agriculturist, 34: 266-267.

Harper, Roland M.

1907 Science, Vol. 25, Notes on Distribution of S. E. Salamanders.

1912 Science, Vol. 35, pp. 115-119.

1916 Fern Grottos of Citrus Co., Fla. Am. Fern Jour., September.

Harshberger, John W.

1914 The Vegetation of South Florida. Trans. Wagner Free Inst. Sci., 7: 49-189.

Hebbard, H. G.

1890 Second report of U. S. Ent. Comm.

1894 Insect Guests of the Florida Land Tortoise. Insect Life, Vol. VI, No. 4.

Sargent, C. S.

(Forests of) Florida. Tenth Census U. S., 9: 520-523.

Sellards and Harper

Florida State Geological Reports, III, VII, XIII, contain full descriptions of the floral regions of Florida, peat deposits, etc.

Simpson, Chas. T.

In Lower Florida Wilds. G. P. Putnam Sons.

1923 Out of Doors in Florida. E. B.

Shreve, Forrest Douglas Co., Miami.

Map of the Vegetation of the U. S. Geographical Review, 3 pp. 119, 125. February, 1917.

Small, John K.

1904 Report on Exploration in Tropical Florida. Jour. $N$. $Y$. Bot. Gar., 5: 49-55, 157-164. 1904.

1907 Exploration of Southern Florida. Jour. N. Y. Bot. Gar., 8: 23-28. 1907.

1909 Exploration in the Everglades. Jour. N. Y. Bot. Gar., 10: 48-55. 1909.
1910 Report on Botanical Exploration in Andros, Bahamas. Jour. N. Y. Bot. Gar., 11: 88-101. 1910. (Included on account of relation of flora of Andros to that of Florida.)

1911 Exploration in Southern Florida. Jour. N. Y. Bot. Gar., 12: 147-157. 1911.

1913 Report on Exploration on Tropical Florida. Jour. N. Y. Bot. Gar., 14: 81-86. 1913.

1914 Exploration in the Everglades and on the Florida Keys. Jour. N. Y. Bot. Gar., 15: 69-79. 1914.

1916 Exploration in Southern Florida in 1915. Jour. N.Y. Bot. Gar., 17: 37-45. 1916.

1916 Royal Palm Hammock. Jour. N. Y. Bot. Gar., 17: 165-172. 1916.

1916 A Cruise to the Cape Sable Region of Florida. Jour. $N$. Y. Bot. Gar., 17: 189-202. 1916.

1917 Botanical Exploration in Southern Florida in 1916. Jour. N. Y. Bot. Gar., 18: 98-111. 1917.

1917 The Tree Cacti of the Florida Keys. Jour. N. Y. Bot. Gar., 18: 199-203. 1917.

1918 Collecting Prickly Pears at Apalachicola. Jour. N. $Y$. Bot. Gar., 19: 1-6, 1918.

1918 Ferns of Tropical Florida. Am. Museum Jour., 18: 127-135. 1918.

1918 A Winter Collection Trip in Florida. Jour. $N$. Y. Bot. Gar., 19: 69-77. 1918.

1918 Botanical Explorations in Florida in 1917. Jour. $N . Y$. Bot. Gar., 19: 279-290. 1918.

1919 Narrative of a Cruise to Lake Okeechobee. Am. Museum Jour. 18: 684-700. 1919.

1919 The Prickly Pears of Florida. Jour. N. Y. Bot. Gar., 20: 21-39. 1919.

1919. Coastwise Dunes and Lagoons. Jour. N. Y. Bot. Gar., 20: no. 237. October, 1919.

1920 Of Grottoes and Ancient Dunes. Jour. N. Y. Bot. Gar., 21: 25-38. February and March, 1920.

1920 Cypress and Population in Florida (The Relation of Phytogeography to the Drift of Population as Shown in the Case of Taxodium.) Jour. N. Y. Bot. Gar., 21: 81-86. May, 1920.

1920 The Land of Ferns. Jour. of the Elisha Mitchell Scientific Society, 11: 92-104. June, 1920. 
1920 In Quest of Lost Cacti. Jour. N. Y. Bot. Gard., 21: 161178. September, 1920.

1920 A Botanical Excursion to the Big Cypress. Natural Hist., 20: 488-500. September and October, 1920.

1921 Reminiscences of Alvan Wentworth Chapman. Jour. N.Y. Bot. Gar., 22: 1-12. February, 1921.

1921 Old Trails and New Discoveries. Jour. N. Y. Bot. Gar., 22: 25-40, 49-64. February and March, 1921.

1921 Seminole Bread. Jour. N. Y. Bot. Gar., 22: 121-137.

1921 Historic Trails by Land and by Water. Jour. N. Y. Bot. Gar. 22: 193-222. November and December, 1921.

1922 Wild Pumpkins. Jour. N. Y. Bot. Gar., 23: 19-23. February, 1922.

1922 The Buccaneer Palm. Jour. N. Y. Bot. Gar., 23: 61-70. March, 1922.

1922 Botanical Fountain of Youth. Jour. N. Y. Bot. Gar., 23: 117-133, 139-155. September and October, 1922.

1922 The Blue Stem. Sabal Minor. Jour. N. Y. Bot. Gar., 23: 161-168. November, 1922.

1923 Land of the Question Mark. Jour. N. Y. Bot. Gar., 23: 1-23, 25-43, 62-70. January, February and March, 1923.

1923 The Needle Palm. Jour. N. Y . Bot. Gar., 23: 105-114.

1923 The Cabbage tree Sabal Palmetto.

1923 Ferns of Tropical Florida. Illustrated.

1923 Ferns of Royal Palm Hammock. Illustrated.

1923 Flora of Miami.

1923 Florida Trees.

1923 Flora of the Florida Keys.

1923 Shrubs of Florida.

1923 The Cape Sable Region of Florida.

Smith, Dr. Eugene A.

Vol. 6. Tenth Census Reports. Nat. ural and Agricultural Features of the Cotton Belt.

Torrey, Bradford

1894 A Florida Sketch-book. Houghton, Mifflin \& Co.

Wright and Bishop

1915 A Biological Recognizance of Okefinokee Swamp. II. Snakes. Proc. Acad. of Nat. Sci.

\section{ALABAMA ${ }^{1}$}

By R. M. Harper, M. S. Johnson, and A. H. Howell

\section{Physiographic Features and Original Biota ${ }^{2}$ (M. S. J.) TOPOGRAPHY}

The northern and northeastern portion of Alabama, comprising altogether about two-fifths of the state, is varied, hilly, and in places mountainous; the remainder is comparatively smooth coastal plain, which becomes lower and less hilly toward the south.

Across the north end of the state extends the Cumberland Plateau, more or less interrupted by rivers. Entering from the northeast is the southern end of the Appalachian Valley-known here as the Coosa Valley region, from the principal river which drains it. In general this region consists of parallel ridges running in a northeast-southwest direction, with broad valleys between them; but in detail it is very broken and irregular. In the Blue Ridge, southeast of the Coosa Valley region, is the highest mountain of the state, Cheaha, with an elevation of $2400 \mathrm{ft}$.

The Tennessee River cuts through the Cumberland Plateau, draining part of it in a westerly direction. The Chattahoochee River, forming except in the north the boundary between Alabama and Georgia, drains the region near it. The remainder of the state is drained southwest into Mobile River and Bay by the Tombigbee and Alabama Rivers and their tributaries. In the northern mountainous districts the rivers are swift and the valleys are steep. In the region of the coastal plain the valleys slope more gradually, and in the south the land is so nearly flat that the rivers may be bordered for several miles by

1 Where there was no cooperation between the authors their names are given in the order of receipt of their manuscripts and the parts written by each are indicated in the body of the text. The mammal lists were corrected by A. H. Howell, and the entire paper read by H. P. Loding.

2 I am indebted to R. M. Harper for suggestions and helpful criticism.-M.S.J. 
swamps which are filled with water during flood seasons.

\section{Climate}

Difference in latitude, combined with higher altitudes in the north, give a gradation in temperature from one end of the state to the other; but the range of temperature, either regional or seasonal, is not very great. The mean for the state as a whole is $63^{\circ}$. The winter mean in the north is $41^{\circ}$; the summer mean in the south is $81^{\circ}$. The rainfall throughout the state, except in the immediate vicinity of the coast where it is somewhat greater, is about 52 in. per year. In general the greatest rainfall occurs in summer in regions of pine forest, and in winter in regions of hardwood forest. The distribution of vegetation within the state seems to correspond much more closely to soil than to climate, however.

SOIL

Throughout the greater part of the coastal plain the predominating soil type is sandy loam, usually somewhat intermixed with clay or loam. A considerable part of this region is underlaid by limestone, but the surface soil is often sandy. The black belt (prairie) has rich soil, formed by the weathering of soft limestone, which extends in a band about thirty mi. wide nearly across the state just south of the central part. North of the black belt, the remainder of the coastal plain is mingled clay and sandy loam, generally deficient in lime.

In the hilly country to the north, the soil is less sandy. The soil here has mostly been formed by the weathering of the hard rocks of the region. As streams cut through and expose to weathering agencies the different layers of rock, the soil even of a limited area is necessarily very variable. A brief account of the soils of separate subdivisions will be found in the second part of this report.

Coniferous forests, principally of longleaf and shortleaf pine, occur throughout the state wherever the soil is poorest. Pine forests (especially those of longleaf pine) are subject to fires which, feeding on fallen needles, destroy other vegetation but apparently do not injure the pines. The fires destroy the humus in the soil and keep the soil poor in nitrogen. Regions protected from fire by ravines or forks of streams, even though in a pine forest territory usually develop patches of hardwood forest.

ORIGINAL BIOTA (M. S. J.) (A. H. H.)

\section{Vegetational regions}

Alabama can be divided, very roughly, into a northern deciduous forest and a southern coniferous forest area. Included within the coniferous forest area is a prairie belt, corresponding to the black belt already referred to under the heading "Soil." This division into vegetational regions is somewhat indefinite, though, for a certain proportion of one forest type occurs in the territory of the other; and between the two, and in certain local areas elsewhere, the two types of forest grow mixed together. Besides these principal forest types, which themselves can be further subdivided (as in the second part of this paper), are various other lesser vegetational regions, locally distributed and dependent on local conditions. Animal distribution is influenced by the various factors which affect plant distribution, and by plant distribution itself.

a. Deciduous forest. The deciduous forest of Alabama is primarily oak. White oak, ${ }^{3}$ post oak, red oak, black oak, black-jack oak, chestnut oak, and Spanish oak are most common of the many oaks. Other trees characteristic of deciduous forest are tulip poplar, sweet gum, chestnut, beech, hickory, and dogwood. Even in the deciduous forest areas, though, shortleaf pine is often more abundant than any other one tree.

Animals. Mammals: Virginia opossum (Didelphis virginiana), common,

3 Scientific names of trees are given in the second part of this paper. 
in woods, ravines, etc.; Howell mole (Scalopus aquaticus howelli), burrows, in sandy or loamy soil; Carolina shorttailed shrew (Blarina brevicauda carolinensis), hollow logs and stumps, burrows in moist soil; Florida black bear (Ursus floridanus), probably once everywhere, now limited to the southern swamps; southeastern wolf (Canis floridanus), once everywhere, now only in mountain country; gray fox (Urocyon cinereoargenteus cinereoargenteus), in all sections; cougar (Felis couguar), once occurred here; bob-cat (Lynx rufus floridanus), mountains, swamps, and thickets; New York weasel (Mustela novehoracensis), scarce in mountainous area; deer-mouse (Peromyscus leucopus leucopus) timber tracts, upland woods, hollow logs; cotton-mouse (Peromyscus gossypinus), timbered region of the entire state, both in mountains and swamps; Florida woodrat (Neotoma floridana floridana), common south of Tennessee River in wooded bottoms and swamps; woodchuck or groundhog (Marmota monax monax), northern part of state, burrows under rocks or treeroots on steep wooded slopes; southwestern chipmunk (Tamias striatus), northern two-thirds of state, in brush and fallen timber on forested hillsides and rocky slopes; gray squirrel (Sciurus carolinensis carolinensis), mostly bottomlands, also hillsides, not in pine; Bachman fox squirrel (Sciurus niger texianus), mountain regions, mixed pine-hickory-oak forest, dry uplands; southeastern flying-squirrel (Glaucomys volans saturatus), in all sections, hollow trees and stumps; eastern cottontail rabbit (Sylvilagus floridanus mallurus), common, in open woodland; New England cottontail rabbit (Sylvilagus transitionalis), mountain slopes and foothills; Virginia deer (Odocoileus virginianus virginianus), once common here, now confined to big swamps and rough mountains; large brown bat (Eptesicus fuscus fuscus), moderately common in north, spends winters in caves; red bat (Nycleris borealis borealis), common, migratory, sometimes winters in caves or hollow trees; southeastern pipistrelle bat (Pipistrellus subflavus subflavus), common in north, winters in caves; evening bat (Nycticeius humeralis), abundant, in winter probably hibernates; silver-haired bat (Lasionycteris noctivagans), migrant, resorts to hollow trees in day time; mahogany bat (Nycteris seminola), common in southern half of state, a tree-dwelling species; hoary bat (Nycteris cinerea), rare migrant, rests in hollow trees; LeConte big-eared bat (Corynorhinus macrotis), local, spends day in caves; LeConte free-tailed bat (Tadarida cynocephala) local in southern half, lives about buildings.

Birds (A. H. H.). Ruffed grouse, wild turkey, Cooper's hawk, sharp-shinned hawk, red-tailed hawk, red-shouldered hawk, broad-winged hawk, great horned owl, long-eared owl, hairy woodpecker, downy woodpecker, pileated woodpecker, red-bellied woodpecker, flicker, chuck-will's-widow, whip-poor-will, rubythroated hummingbird, crested flycatcher, wood pewee, blue jay, crow, blue grosbeak, indigo bunting, painted bunting, red-eyed vireo, yellow-throated vireo, black and white warbler, wormeating warbler, parula warbler, cerulean warbler, over-bird, Louisiana waterthrush, Kentucky warbler, hooded warbler, redstart, Carolina wren, whitebreasted nuthatch, tufted titmouse, Carolina chickadee, blue-gray gnatcatcher, wood thrush.

Reptiles. (Only more common and characteristic reptiles are listed.) Chameleon (Anolis carolinensis), in large bushes and small trees; glass snake (Ophisaurus ventralis), burrowing; ground lizard (Leiolopisma laterale), under loose bark of fallen trees; scorpion (Eumeces fasciatus) under loose bark and under logs; red-bellied snake (Storeria occipitomaculata), under loose stones; worm snake (Carphophis amoena), burrowing, or in rotten tree-trunks or vegetation; gray rat snake (Elaphe obsoleta confinis), sometimes in trees; green snake (Opheodrys aestivus), in bushes and low trees; ring-necked snake 
(Diadophis punctatus punctatus), under rocks and loose bark of fallen trees; king snake (Lampropeltis getulus), dry patches of timber; hog-nosed snake (Heterodon contortrix); copperhead snake (Agkistrodon mokasen), poisonous, not found in lowlands; timber rattlesnake (Crotalus horridus), poisonous, in mountains and other inaccessible regions, was once generally distributed.

b. Coniferous forest. The coniferous forest is chiefly pine. In the more typical portions of this region there may be considerable areas of almost pure stand of longleaf pine, growing in open park-like fashion on rather dry sandy soil. Elsewhere, two species of shortleaf pine together with the longleaf pine contribute chiefly to the formation of the coniferous forest. Other evergreen and deciduous trees included in the region of coniferous forest are mostly confined to low wet land or stream borders, and hence cannot be considered a component part of the coniferous forest itself.

Animals. Mammals. Howell mole, sandy or loamy soil; southeastern wolf, once here; gray fox, in all sections; deer mouse, in mixed conifer and deciduous forest; pine mouse (Pitymys pinetorum pinetorum), less common here than in meadows and bottomland; Alabama pocket-gopher (Geomys tuza mobilensis), called "salamander," occurs in southern Alabama east of Tombigbee River, common in sandy pine flats or mixed timber, burrows extensively in poor uncultivated land; Carolina fox squirrel (Sciurus niger niger), limited to dry pine forest, in southeast corner of state; Bachman fox squirrel, intergrades with typical niger and ranges over rest of state; southeastern flying squirrel, in all sections, in hollow trees and stumps; eastern cottontail rabbit, common in thickets; Virginia deer, once here; red bat, common, in trees in summer, sometimes in caves in winter; evening bat, abundant, hibernates in winter.

Birds (A. H. H.). Mourning dove, great horned owl, red-cockaded woodpecker, chuck-will's-widow, blue jay, crow, fish crow, Bachman sparrow, summer tanager, yellow-throated warbler, black-throated green warbler, pine warbler, brown-headed nuthatch.

Reptiles. Chameleon; common swift (Sceloporus undulatus), dry sandy pinelands, or on fallen pines; spiny swift (Sceloporus spinosus floridanus); race runner (Cnemidophorus sexlineatus), common, dry sandy places; scorpion, in dry pine woods; ground lizard; black snake (Coluber constrictor), generally abundant, dry open situations; coachwhip snake (C. flagellum flagellum), habits similar to black snake; gray rat snake; corn snake (Elaphe guttata), found under bark of dead pine trees in spring; DeKay's snake (Storeria dekayi), nocturnal, beneath logs and stones; green snake; ring-necked snake; scarlet king snake (Lampropeltis elapsoides elapsoides), burrowing, or under loose bark of dead pine trees; king snake; hog-nosed snake, dry sandy places; copperhead snake; pigmy rattlesnake (Sistrurus miliarius), dry sandy areas, cut-over pineland; timber rattlesnake.

$C$. Prairie. The prairie belt is a strip 35 to $45 \mathrm{mi}$. wide extending across Alabama just south of the central part (between Sumter and Russell counties). It corresponds with, and is no doubt caused by, the black belt of rich limestone-marl soil which has already been mentioned. The prairie belt contains, besides considerable amounts of prairie or treeless plain, a certain proportion of swamp, canebrake, and even of deciduous and conifer wooded patchesall of which are not unlike corresponding regions elsewhere in the state. The prairie region, being treeless and especially fertile, was most easily available for cultivation. It is mostly prairie animals which are found in cultivated fields, not only in the original prairie belt but in other parts of the state. Land which has been cultivated and later abandoned is more favorable for animal life than land actually under cultivation.

Animals. Mammals. Southeastern wolf, formerly; gray fox; eastern cotton- 
tail rabbit; Florida wood rat, in osageorange hedges; Alabama pocket gopher; swamp rice rat (Oryzomys palustris palustris), in sloughs; cotton rat (Sigmodon hispidus hispidus); harvest-mouse (Reithrodontomys); muskrat (Ondatra zibethica zibethica), in streams; Alleghenian spotted skunk (Spilogale putorius); Virginia deer, formerly.

Birds (A. H. H.). Killdeer, bobwhite, mourning dove, ground dove, nighthawk, meadowlark, lark sparrow, field sparrow, dickcissel, loggerhead shrike, mockingbird.

Reptiles. Box turtle (Terrapene carolina carolina); glass snake; black snake; coachwhip snake; corn snake.

\section{Local areas}

A. Swamp and marsh. By far the most conspicuous and important of the local areas in the state is a series of wet situations which may be designated collectively as swamp. Of these situations the following may be distinguished: moist bottomlands, wooded swamps, canebrake, rivers and streams, and salt marshes. Characteristic trees of moist bottomland are water oak, willow oak, swamp chestnut oak, elm, mulberry, poplar, ironwood, and scaly-bark hickory. Characteristic trees of wooded swamps are white bay, cypress, water oak, black gum, swamp maple, red maple, water hickory, water ash, white cedar, and swamp cottonwood. These trees do not all occur together, however, for certain ones as the bay, swamp maple, and white cedar, grow in peaty swamps bordering small streams, where there is no great fluctuation in water level; and certain other trees, as the red maple, water hickory, water ash, and swamp cottonwood, are found in swamps bordering larger rivers, where they are subject to considerable seasonal fluctuations in the water level. The canebrake is made up of a dense growth of bamboo-like grasses (Arundinaria), which reach a height of 15 to $30 \mathrm{ft}$. Cane is abundant along streams on low land which is submerged a part of the year. Formerly a smaller switch cane occurred extensively over much of the western part of the prairie belt. Trees occurring chiefly along rivers and streams are silver maple, sycamore, birch, willow, cottonwood, and catalpa. In the salt marshes along the coast there are no trees, the dominant vegetation being reed-like grasses and large rushes.

Animals. Mammals. Virginia opossum, swampy bottom lands; Carolina short-tailed shrew, moist or peaty soil, rotten logs; Florida black bear; southeastern wolf, formerly, now exterminated here; gray fox, in all sections; raccoon (Procyon lotor lotor), timbered swamps, river bottoms, salt marshes; mink (Mustela vison mink), swamps, marshes, streams; Alabama weasel (Mustela peninsulae olivacea), scarce throughout the state in timbered swamps and on mountain slopes, dens under roots of trees and in hollow stumps; otter (Lutra canadensis canadensis), sparingly distributed, swamps, streams, ponds; cougar, once here, perhaps some still remain; bob-cat, swamps, brushy thickets, canebrake; cotton mouse, heavy timbered swamps of river bottoms in all parts of state; southern golden mouse (Peromyscus nuttalli aureolus), swampy woodland, canebrake; swamp rice rat, marshy areas in fields, wooded swamps, coastal salt marshes; cotton rat, abundant in marshes; Florida wood rat, wooded bottoms or swamps; pine mouse, sometimes in bottomland timber; muskrat, streams and ponds, except in south of state; Louisiana muskrat (Ondatra rivalicia) marshes near coast, west of Mobile Bay; southwestern chipmunk, most of state, moist bottomland woods, timbered swamps; gray squirrel, moist bottomlands and swamps, nut-bearing trees; bayou gray squirrel (Sciurus carolinensis fuliginosus), confined to shores of bayous and deep cypress swamps; southeastern flying squirrel, hollow trees and stumps; beaver (Castor canadensis carolinensis), formerly in streams throughout state, now very local; eastern cottontail rabbit, occasionally in swampy bottoms; 
swamp rabbit (Sylvilagus aquaticus aquaticus), known as "cane-cutter," abundant over lowlands of state except southeast, found in all river swamps, and ranges up small streams; coast swamp rabbit (Sylvilagus aquaticus littoralis), coast west of Mobile Bay; marsh rabbit (Sylvilagus palustris palustris), south counties, east of Mobile Bay, salt marshes, swamps, ponds, and streams in timber; Virginia deer, common in bigswamps at head of Mobile Bay.

Birds (A. H. H.). Snake-bird, cormorant, hooded merganser, wood duck, least bittern, great blue heron, little blue heron, green heron, black-crowned night heron, yellow-crowned night heron, king rail, Louisiana clapper rail, purple gallinule, Florida gallinule, woodcock, barred owl, kingfisher, Acadian flycatcher, red-winged blackbird, boattailed grackle, Alabama seaside sparrow, white-eyed vireo, prothonotary warbler, Swainson warbler, Bachman warbler, Marian marsh wren.

Reptiles. Common snapping turtle (Chelydra serpentina), inhabits slowrunning muddy rivers and streams, ponds and marshes; common mud turtle (Kinosternon subrubrum); box turtles (Terrapene carolina and T. major); Alabama terrapin (Pseudemys alabamensis), tends to frequent salt marshes; Mobile terrapin (Pseudemys mobilensis); diamond-back terrapin (Malaclemys pileata), requires salt water, found in salt marshes, salt and brackish water; southern soft-shell turtle (Amyda ferox); alligator (Alligator mississippiensis), rivers and swamps of coastal plain; scorpion; ribbon snake (Thamnophis sauritus), borders of streams and lakes in mountainous regions; Ostensacken's snake ( $T$. sackenii); common garter snake ( $T$. sirtalis), along streams and brooks; green water snake (Natrix cyclopion); diamond-back water snake ( $N$. rhombifera); striped water snake $(N$. rigida); banded water snake $(N$. sipedon fasciata); ground snake (Potamophis striatulus); ring-necked snake; king-snake, meadows and cultivated fields; horn snake (Farancia abacura), burrowing, in swampy stretches of timber; water moccasin (Agkistrodon piscivorus), poisonous, called "cottonmouth," abundant in swamps adjoining rivers; diamond-back rattler (Crotalus adamanteus), poisonous, rare.

b. Forest border. Much of the locally distributed animal life yet to be considered can be grouped as belonging to a "forest border" habitat-that is, living where rather narrow regions of shrubs and thickets lie between forest and treeless areas. Even before any land was cleared for agriculture this type of habitat was occasional throughout the state, and quite considerable in the prairie belt.

Animals. Mammals. Alleghenian spotted skunk, borders of brushy swamps and waste land generally, not in wet swamps nor heavy timber; eastern skunk (Mephitis nigra), den in brushy thicket, rock pile, gully, protected location; old-field mouse (Peromyscus polionotus polionotus), weedy hedgerows, neglected fields, edges of open timber, in east part of state; Merriam harvest mouse (Reithrodontomys humulis merriami), brushy borders of cultivated land; cotton rat, weedgrown borders of fields, brushy pastures; deer mouse, borders of cultivated fields, and brushy hedgerows; eastern cottontail rabbit, old fields, brier patches, brushy borders of woodland; least shrew (Cryptotis parva), in grass, fields, and borders of cultivated land.

Birds (A. H. H.). Bob-white, sparrow hawk, screech owl, yellow-billed cuckoo, red-headed woodpecker, nighthawk, kingbird, meadowlark, orchard oriole, Baltimore oriole, goldfinch, chipping sparrow, field sparrow, Bachman sparrow, towhee, cardinal, purple martin, white-eyed vireo, blue-winged warbler, prairie warbler, Maryland yellowthroat, yellow-breasted chat, mockingbird, catbird, brown thrasher, Bewick wren, brown-headed nuthatch, robin, bluebird, barn owl, purple grackle.

Reptiles. Reptiles listed for prairie; also: gray rat snake, green snake, hog-nosed snake, chameleon. 
C. Sandy Beach. Animals. Mammals. Florida skunk (Mephitis elongata), coast region, logs and driftwood on shore; white-fronted beach mouse (Peromyscus polionotus albifrons), abundant among drifting sand dunes, coast of Baldwin County.

Birds (A. H. H.). Least tern, black skimmer, willet, Cuban snowy plover, Wilson plover.

Reptiles. Alabama terrapin; diamond-back terrapin; Clark's water snake (Natrix clarkii).

D. Rocks. Animals. Mammals. Florida wood rat, rocky bluffs or cliffs, south of Tennessee River; Allegheny cliff rat (Neotoma pennsylvanica), cliffs, rock bluffs, caves, north of Tennessee River; deer mouse, rock piles and crevices in cliffs; weasel, erevices in cliffs or rock piles; cotton mouse (Peromyscus gossypinus megacephalus), rocky ledges or bluffs; caves, crevices, rock houses; woodchuck, burrows under boulders or ledges; gray bat (Myotis grisescens), caves along Tennessee River; pipistrelle bat, caves in winter; large brown bat, sometimes caves in winter.

Birds (A. H. H.). Phoebe, raven, cliff swallow, rough-winged swallow.

Reptiles. Worm snake, under rocks; copperhead snake; timber rattlesnake, hibernates in recesses of rocky ledges.

\section{ALABAMA MOLLUSCA (FRANK C. BAKER)}

No state in the Union has a more varied or abundant fauna of mollusks than Alabama. The fresh water fauna may be divided into three divisions, the Tennessee drainage region on the north, the Gulf drainage area on the southeast, and the drainage of the Alabama River which occupies nearly the whole of the state. Of the 533 species of naiades found in America, 411 are to be found in the three drainage areas mentioned, and over 300 are found in Alabama, 91 of which are restricted to the waters of that state. The family Pleuroceridae or river snails number some 500 species, $80 \%$ of which are found in the drainage areas mentioned and a large majority are found in Ala- bama. This state may be said to be the center of distribution for these families. The Amnicolidae are equally well developed, several species, particularly of Somatogyrus, being peculiar to the state. Viviparidae is abundant in both species and individuals. Sphaeriidae, Lymnaea, Planorbis and Ancylidae are less abundant in species than in the north; but Physa, of the fresh water pulmonates, is more largely developed than northward. It is probable that more than a thousand species of fresh water mollusks may be found in the confines of Alabama, this being the largest number from any other state. It is classic ground, giving material for the labors of Say, Lea, Conrad, Tryon, Lewis, Ortmann, Walker, and other students. Many species have doubtless been exterminated by the building of large dams on the Coosa and Tennessee Rivers in recent years.

The state also contains a diversified land snail fauna, though this is not as well developed as is the fresh water fauna. Polygyra, Gastrodonta, Vitrea, Omphalina, Zonitoides, Pyramidula, and Philomycus are well represented; several other genera are represented by one or more species. The development of the snail fauna is greatest in the mountainous districts where there is considerable diversification as regards environmental factors.

\section{Present Biota and Areas Available for Study}

(R. M. H.)

In the following pages the regions numbered 1 to 7 belong to the rocky uplands or hill country, and the remainder to the coastal plain. In regions 1 to 9 , and 11 to 14 the forests are comparatively dense, and the native herbs are relatively inconspicuous and constitute only a small fraction of the total bulk of vegetation. Most of the other regions have open pine forests and an abundant and varied shrubby and herbaceous vegetation, the most abundant species of which will be listed. 
Soil surveys of most of the counties have been published by the United States Bureau of Soils. The United States Geological Survey has published topographic maps of most parts of Alabama north of Montgomery and east of Tuscaloosa (including all the mountains), and some of the later ones indicate woodland by green overprint.

Before listing the dominant plants of each region it will be worth while to point out a few species that are more abundant in Alabama than elsewhere, including a few that are endemic or nearly so:

Small trees: Magnolia macrophylla.

Shrubs: Illicium Floridanum, Hydrangea quercifolia, Neviusia Alabamensis, Croton Alabamensis, Aesculus parviflora.

Herbs: Trichomanes Petersii, Luziola Alabamensis, Carex picta, harperella fluviatilis, Hymenocallis coronaria, Hexaslylis speciosa.

The dominant plants will be divided into large trees (a foot or more in diameter), small trees, shrubs and woody vines, and (vascular) herbs, and arranged as nearly as possible in order of abundance. All bryophytes and thallophytes are omitted. In the case of genera represented by only one species in the eastern United States the specific name is usually omitted.

1. The barrens or Highland Rim is chiefly north of the Tennessee River, and is more extensive in Tennessee. It is a comparatively level region, except in the vicinity of streams, some of which have cut rather deep and narrow valleys. The soil is mainly a grayish or yellowish silt loam of medium fertility, with angular chert fragments scattered

4 The much discussed Muscle Shoals is near the southern edge of this region. There are rocky shoals on the Tennessee River most of the way from Decatur to Florence, but the principal portion is in Lauderdale County, where the river drops $85 \mathrm{ft}$. in $15 \mathrm{mi}$, and is about $1 \mathrm{mi}$. wide and was dotted with wooded islets. The place was doubtless named originally about 100 years ago from the abundance of mussel shells (and the obsolete spelling "muscle" is still used for the shoals by most people), which have been collected there by various conchologists, who however seem to have published no special account of the place. The vegetation has never been studied, and the opportunities for doing so were destroyed by the completion of the Wilson Dam in 1924. Florence and Sheffield, cities of several thousand inhabitants, are close to foot of shoals on opposite sides of river. through it. The upland forests are rather monotonous and uninteresting, and made up of widely distributed species. A few herbs more characteristic of the coastal plain, such as Erianthus strictus, Rynchospora corniculata, Cyperus pseudovegetus, Carex glaucescens, Juncus scirpoides, Eryngium prostratum and Hydrocotyle verticillata, are found in shallow ponds north of Athens, where the pines are most abundant. Near streams, especially on bluffs of flinty limestone, there is a much greater variety, and some very interesting plants, including a large number of spring flowers. A few woody plants chiefly confined to the coastal plain, such as bald cypress (Taxodium distichum), planertree (Planera aquatica), Brunnichia, and swamp privet (Adelia acuminata), extend up the Tennessee River a little way into this region.

The commonest trees are: Large trees: Red oak (Quercus falcata), white oak (Q. alba), loblolly pine (Pinus Taeda), sweet gum (Liquidambar), beech (Fagus), tulip poplar (Liriodendron), post oak (Quercus stellata), hickory (Carya alba), red cedar (Juniperus virginiana), shortleaf pine (Pinus echinata), chestnut (Castanea dentata), black gum (Nyssa sylvatica).

Small trees: Dogwood (Cornus florida), black willow (Salix nigra), ironwood (Carpinus caroliniana).

Tri Cities Park. A few hundred acres on the south side of the Tennessee River is still in excellent condition except for having a few squatters' cabins near its edges, and is a very good example of the original forest. East of Sheffield.

2. The Tennessee Valley proper lies on both sides of the river, and is characterized in its low and level portions by fertile red clayey soils derived from limestone. At the southern and eastern borders of the valley, where it passes into the plateau region, the slopes are composed of nearly pure hard limestone, with very little soil. There are several limestone springs and caves, with more or less interesting fauna. The most noted cave, to zoologists, is Nickajack, at the northeastern corner of the state. (Its entrance is in Tennessee.)

The level red valley lands are mostly under cultivation and have been for a long time, and the present forests in the lowlands are chiefly confined to the poorer and wetter spots. Little Mountain, a sandstone outcrop, and the rough limestone slopes are pretty well wooded, though the best timber, especially red cedar, has been cut out. The following list of trees covers both the red lands 
and the limestone slopes, but not Little Mountain.

Larger trees: Red cedar, red oak, sweet gum, willow oak (Quercus Phellos), scaly-bark hickory (Hicoria ovata), beech, short-life pine (Pinus Faela), mostly second growth, sycamore (Platanus occidentalis), chinquapin oak (Quercus Muhlenbergii), white oak (Quercus alba, Q. Schneckii), post oak (Q. stellata), water oak (Q. Nigra), walnut (Juglans nigra), American elm (Ulmus americana), winged elm ( $U$. alata), hackberry (Celtis occidentalis), tulip poplar, (Linodendron), black gum, white ash (Fraxinus americana).

Small trees: dogwood, black willow, redbud (Cercis canadensis), ironwood, chittamwood or smoketree (Rhus cotinoides, mulberry (Morus rubra).

On the limestone slopes are quite a number of rare and interesting plants, which are likely to remain for a long time, on account of the impossibility of cultivating such areas. Among the many noteworthy plants may be mentioned Leavenworthia, Neviusia, Cotinus, Frasera and Adelia ligustrina. ${ }^{5}$

3. The plateau region, a continuation of the Cumberland plateau of Tennessee, is characterized by horizontal strata of sandstone, and rather poor sandy loam soils. It is several hundred feet higher than most of the neighboring limestone valleys, the highest elevation being about $1850 \mathrm{ft}$. , on Lookout Mountain near the Georgia line. Little Mountain, in the Tennessee Valley, is an outlier of this plateau. The uplands are undulating to moderately hilly, and some of the streams have cut very picturesque gorges, especially near the points where they descend into the limestone valleys. The streams are comparatively clear most of the time. The establishment of a national forest in the western part or this region promises to preserve a considerable portion, and some extensions of it are contemplated.

The plateau section is a mixed pine and oak area in which the following trees are important:

Large trees: Shortleaf pine, white oak, scrub or spruce pine (Pinus virginiana), chestnut, oak (Quercus montana), red oak, Spanish oak (Q. coccinea), post oak, black oak (Quercus velutina), and blackgum.

Small trees: cucumber tree (Magnolia macrophylla), sourwood (Oxydendrum arboreum), holly (Ilex opaca).

5 In the bottoms of the Tennessee River opposite Decatur are a few plants more common in the coastal plain, such as Nyssa uniflora and Decodon verticillatus.
The proportion of evergreens is greatest eastward, where the rocks are more metamorphosed and the summers a little wetter than in the western portion. The upland forests are rather monotonous, but there are some very interesting plants along streams, particularly in rocky places. A surprisingly large number of species chiefly confined to the coastal plain are found in the eastern portion, among them Orontium, Smilax laurifolia, Magnolia glauca, Sarracenia flava (or a variety of it), Polygala nana, Sophronanthe pilosa, Utricularia subulata, Chondrophora virgata. A number of species more or less common here are rare or unknown in other parts of Alabama.

Lookout Mountain Region. The region is thinly settled and not well provided with railroads. Except possibly in midsummer, the naturalist who wishes to explore the remoter parts of it would do well to arrange to have some resident accompany him for protection against moonshiners.

Little River falls and gorge, on Lookout Mountain (Proposed) sandstone cliffs. Noteworthy for number of rare plants along river just above the falls, among them Rhododendron Catawbiense, Sarracenia, flava oreophila, Harperella fluviatilis, Chondrophora virgata, and Helianthus longifolius. Threatened by waterpower projects.

In Cherokee and DeKalb counties, Alabama. See Torreya, 6: 114; 14: 154; Natural History, 10: 200. 9 mi. S.E. Fort Payne (county seat of DeKalb County), $3 \mathrm{mi}$. W. of Blanche, T. A. \& G. R. R., (no hotel accommodations). Noccalula Falls, with a sheer drop of about $90 \mathrm{ft}$., is very accessible, being a few miles north of Gadsden. DeŞoto Falls on Little River, 3 mi. S.E. of Valley Head. 4. The basin region, or Warrior, Cahaba and Coosa coal fields, consists of three distinct areas separated by limestone valleys. It merges into the preceding region (Cumberland Plateau Region), but differs from it principally in being lower and having more shaly rocks, larger and muddier streams, and somewhat richer soils.

The commonest trees are: Loblolly pine, scrub pine, shortleaf pine, longleaf pine ( $P$.palustris), white oak, beech, red oak, sweet gum, red maple (Acer rubrum), poplar, post oak, and chestnut oak. With an understory of small trees: Dogwood, black willow, hop hornbeam (Ostrya virginiana), ironwood, largeleaf magnolia, holly, and southern sugar maple (Acer leucoderme).

Warrior River bluffs. There is a remarkable assemblage of interesting 
plants, some of them commonly regarded as calciphiles, some near their northern or southern limits, and some chiefly confined to Alabama, on bluffs along the Warrior River a few miles above Tuscaloosa. (See Jour. Elisha Mitchell Sci. Soc., 37: 153-160. 1922.) The largest number of species there bloom early in April. On rocky shoals in the river near by were formerly Hymenocallis coronaria and a few other local species, but the shoals have been gradually obliterated by building locks and dams to assist navigation in the last 25 or 30 years, and there are none left now within $50 \mathrm{mi}$. of the fall line at Tuscaloosa. (See Torreya, 14:149-155. 1914.) The molluscan fauna of the shoals was of course practically wiped out at the same time.

Eight Acre Rock, a few miles above Tuscaloosa is another interesting spot in the same county, an outerop of hard white sandstone with several rock-loving plants on it, such as Diamorpha, Talinum teretifolium, Polygala Curtissii, and Crotonopsis linearis, a few miles northeast of Vance.

5. The Coosa Valley region is the southwestern extremity of the great Appalachian Valley, which extends with some modifications all the way to Vermont. It embraces a considerable variety of geology, soil, topography and vegetation, in narrow longitudinal belts. The rocks are mostly limestone, shale, chert and sandstone, the first two usually making valleys and the last two ridges. The soil is above the average in fertility, and a good deal of it has been under cultivation for several generations. Much of the pine, especially longleaf, has been cut out, and a little of it has been turpentined in recent years.

The commonest trees are as follows: Large trees: Loblolly pine, longleaf pine, shortleaf pine, sweet gum, post oak, red oak, black-jack oak (Q. Marylandica) willow oak, tulip poplar, scrub pine, white oak, water oak, red maple, cedar.

Small trees: Dogwood, black willow, sweet bay (Magnolia virginiana), ironwood, and hop hornbeam.

The most interesting plants are found on limestone outcrops, such as Croton Alabamensis near the south end of the valley in Bibb County. There are a few species more characteristic of the coastal plain, such as longleaf pine, (nearly throughout), Nyssa aquatica in Shelby County, and Virginia chain fern (Woodwardia virginica), spikerush (Eleocharis tuberculosa), beak rush (Rynchospora axillaris), pipewort (Ericaulon lineare), oxytria sp. and pitcher plant (Sarracenia flava) in Cherokee County.

6. The Blue Ridge is the southwestern extremity of the Appalachian mountain system, and includes the highest mountain in Alabama, namely, Cheaha (near the junction of Cleburne, Clay and Talladega Counties), $2400 \mathrm{ft}$. above sealevel. Several outlying peaks a little northwest of the main ridge, and surrounded by the Coosa Valley, are treated as part of the Blue Ridge. The rocks are mainly sandstone (as on most other southern mountains), and the topography is quite rugged. Hardly any of the area is cultivated, but lumbermen have cut a great deal of the pine and some of the oaks and chestnut.

Longleaf pine is the commonest tree on sunny slopes, up to nearly $2000 \mathrm{ft}$., which is the highest altitude reached by it anywhere. Next in order are shortleaf pine, black jack oak, black oak, chestnut oak, loblolly pine, scrub pine, red maple, pignut hickory, chestnut, mockernut hickory, and tulip poplar. the small trees are sweet bay, dogwood, sourwood, and Black locust.

From Anniston: A city with good railroad connections, several of the mountains can be reached in a few hours' walk, and others are more accessible from Pyriton. To reach Cheaha, however, it is best to arrange to camp out at least one night.

7. The Piedmont region, which extends northeastward to Pennsylvania, is characterized by granite, gneiss, and other crystalline rocks, moderately hilly topography, and reddish soils, belonging to the texture classes sandy loam, stony loam, slate loam, and clay loam. The forests have been culled for fuel and other domestic purposes.

The commonest trees are longleaf pine, loblolly pine, shortleaf pine, sweet gum, tulip poplar, red maple, red oak, post oak, black-jack oak, mockernut hickory, beech, chestnut oak.

Dogwood, sweet bay, black willow and sourwood.

There is little of special interest in this region, except a few plants more typical of the coastal plain, such as Quercus laurifolia, Illicium, Cyrilla, and Osmanthus, which grow in various places not far from the Coosa River. Hymenocallis coronaria grows on some of the shoals of the Coosa River, but its existence is threatened by the building of large dams for power purposes, one of which was completed in 1914, and another in 1923. The molluscan genus Gyrotoma, confined to this river as far as 
as known, is menaced in the same manner.

8. The central shortleaf pine belt is the innermost division of the coastal plain. It is characterized by noncalcareous clayey and sandy strata of Cretaceous age, moderately hilly topography, with more swamp than in any of the highland regions, and soils classed as fine sandy loam, sandy loam and gravelly sandy loam. Lumbering operations near all the railroads and numerous logging roads have considerably reduced the stand of the various pines.

There is a considerable variety of trees, but most of them are of common and widely distributed species, such as: loblolly pine, shortleaf pine, longleaf pine, sweetgum, tulip poplar, beech, red maple, white oak, water oak, red oak, post oak, black-jack oak, black gum, swamp chestnut oak (Quercus Michauxii), laurel oak, sweet bay, (sometimes a large tree) black willow, dogwood, holly and Mognolia macrophylla.

There is not much of botanical interest in this region, except to one approaching it from farther inland and meeting such coastal plain types as cypress, dwarf palmetto (Sabal glabra), Myrica cerifera and Planera for the first time.

9. The central longleaf pine hills are almost surrounded by the shortleaf pine belt, and might be regarded as an extreme phase of it, with rougher topography and poorer soils. Many of the hills are capped with ferruginous sandstone and their slopes strewn with quartz pebbles. The prevailing soil types are sandy loam, gravelly sandy loam, gravelly loam, loamy sand, and fine sandy loam.

Probably not one-tenth of the area is cultivated, but the longleaf pine, which originally made up something like half the forest, has been pretty thoroughly exploited and some of it turpentined. The trees are about as in the shortleaf pine belt except that the longleaf pine is most abundant, and there are more small oaks (Q. Marylandica, Q. Catesbaei, Q. Margaretta).

The occurrence of chestnut oak so far south is interesting, but more noteworthy is the close resemblance of some parts of this region to the southern pine hills (region 16). In Chilton and Autauga counties there are some sandy bogs, many of them visible from the Mobile \& Ohio R. R., and easily examined in a half-day's walk between stations. These contain a number of pine-barren bog plants.

The "salamander," (Geomys tuza mobilensis), reaches practically its north- ern limit in this region. Its "hills" are nearly always in evidence in the central part of Autauga County. Summer is probably the best time to find plants in bloom.

10. The "black belt," or cane-brake region as it is sometimes called, coincides pretty closely with the area of one of the Cretaceous formations, the Selma Chalk. That is an argillaceous limestone which weathers into very fertile soil, but is covered in many places with sand and clay of later age. The topography is undulating, seldom hilly, and small streams are comparatively scarce, not because of any subterranean drainage, but because the typical soil is so impervious that water runs off soon after a rain. Over half the soil is classed as clay, and next in importance are fine sandy loam and loam. As in the northern part of the state, but unlike most of the coastal plain, winter and spring are the rainy seasons.

The forests chiefly confined to the sandy areas, river-banks, and creekbottoms. The commonest trees at the present time are:

Large trees: loblolly pine (mostly eastward), sweet gum, post oak, shortleaf pine, longleaf pine, red oak, hackberry, willow oak, red cedar, cottonwood (Populus deltoides), winged elm, white ash, scaly-bark hickory, mockernut hickory, sycamore, white oak, water oak, beech, cypress, Taxodium distichum, swamp chestnut oak.

Small trees: black willow, dogwood, black-jack oak, ironwood, mulberry, redbud.

The remnants of natural prairie are small and scattered pretty well over the region; they may be recognized by the presence of such herbs as bluestem (Andropogon furcatus) prairie clover (Petalostemun purpureum), Polytaenia Nuttallii, Asclepiodora viridis, Verbena angustifolia, compass plant, (Silphium laciniatum), purple cone flower (Brauneria pallida), Aster oblongifolius, Rudbeckia amplexicaulis, Lepachys pinnata and Mesadenia tuberosa. Hay fields and pastures often contain some of these same species, together with others known to have been introduced but very characteristic of this region at present, such as Johnson grass (Sorghum Halepense), "primrose" (Hartmannia speciosa), (Monarda citriodora), and Gaillardia pulchella. On bare chalk outcrops there are many red cedars and some interesting shrubs and herbs, such as Arenaria patula, Rosa setigera, Anemone decapetala, Rhamnus Caroliniara, Cornus asperifolia, Houstonia angus $i$ folia, Sabbatia angularis. 
Pecan (Carya illinoensis) and $C$. myristicaeformis are said to be native in a small area near Demopolis (see Mohr's Plant Life of Alabama).

The Southern Railway from Selma to Demopolis passes through the center of the area. The greatest display of prairie flowers is probably in early June.

11. The Chunnennuggee Ridge or blue marl region, confined to Alabama and Georgia, is of nearly the same geological age as the black belt, but less fertile, more sandy, and better watered, perhaps partly on account of having more rain in summer. Some of the creeks and rivers flow in gorges 10 to $50 \mathrm{ft}$. deep, with some interesting plants on their shady walls. The soils are classed as sandy loam, fine sandy loam, sand and clay, and appear to be a little deficient in iron, for quite a number of trees that abound on ferruginous soils in other parts of the state are rather scarce here.

The commonest trees are about the same as those of the "black belt," but fewer species are represented.

There is nothing remarkable here except the occurrence of a few trees rare or unknown farther inland, as the magnolia ( $M$. grandiflora) and tyty (Cyrilla racemiflora), and a few plants of more northerly distribution which have pushed southward along the shady banks of streams.

12. The post-oak flatwoods is a narrow belt confined to Alabama and Mississippi, with flattish topography and stiff grayish clay soil, difficult to cultivate, and not well watered.

Probably nine-tenths of the area is more or less wooded, but lumbering operations have taken the best of the pine. The commonest trees are loblolly pine, shortleaf pine, sweet gum, post oak, red oak, longleaf pine, water oak, willow oak, black willow, ironwood, mulberry, dogwood, and sweet bay.

There is very little of interest in this region. The boundary between it and the black belt is in some places very sharp, the transition being complete within a quarter of a mile or so.

13. The southern red hill belt, shown on the map as extending all the way across the state, can be divided near the middle into an eastern and western portion, which although of about the same age geologically, differ perceptibly in soil, topography, climate, vegetation and population.

The western portion is characterized by rather high ridges for the coastal plain, some of them almost mountainous, with broad valleys between them. The rocks range from limestone to sandstone, and the soils are of moderate fertility. About half the soil is fine sandy loam. There is more rain in early summer than in late summer.

Lumbering has removed a good deal of longleaf pine, and some of the forest is second growth on land formerly cultivated. There is a considerable variety of trees; a few of the commonest are as follows:

Large trees: Loblolly pine, shortleaf pine, longleaf pine, sweet gum, spruce pine (Pinus glabra), magnolia, beech, poplar, white oak, water oak, red oak, black-jack oak.

Small trees: Black willow, sweet bay, dogwood, ironwood, sourwood.

Oaks are relatively scarce here, the most abundant one standing ninth in the list of trees. About $70 \%$ of the trees are evergreen.

There are some very interesting places in this region. The high sandstone ridges, in the western portion, some having an altitude of perhaps 600 ft. and locally known as mountains, make a belt a few miles wide parallel to the edges of the region and passing near Butler and Tunnel Springs. (See map in Special Report No. 11 of the Geological Survey of Alabama, 1920, p. 14.) They are pretty well wooded, and are said to still shelter some of the larger wild animals, such as bear, deer, and wild turkey. On their shaded slopes are quite a number of more northern plants. The mountains are crossed by two or three railroads and the round trip from York, Thomasville, Monroeville, or Selma can be made in one day.

Wilcox County Prairie. In eastern Wilcox County, a few miles east of Snow Hill, where the soil is too thin to plow there is some natural prairie vegetation that is rather unique. (See Ecology, 1: 198-203. 1920.) There ought to be some interesting land shells there, too.

Claiborne Landing. On the Alabama River in Monroe County is one of the most noted lccalities in the world for Eocene fossil shells. There are many other places on both of the large rivers in this region almost as interesting to conchologists.

The eastern division of the red hills is characterized by broad uplands and narrow valleys, and reddish soils below the average in fertility, classed as sandy loam, and fine sandy loam, fine sand and loamy sand. This region has a little more rain in summer and less in winter than sny previously described.

The forest area decreased from about $80 \%$ in 1880 to $50 \%$ in 1920 . Farming is mostly on the smooth uplands, so that the trees of ravines and swamps are 
relatively more abundant now than formerly. The commonest species seem to be as follows:

The trees are mostly those of the western division, with some slight differences in relative abundance. Among the smaller trees, Quercus Catesbaei, $Q$. cinerea, and Osmanthus americana may be mentioned.

Most of the plants are of common and widely distributed species, but there are a few which range mostly southward and eastward, into regions with still sandier soils and wetter summers. A very interesting spot is the "pocosin," a few miles east of Troy (see U. S. soil map of Pike County), an area of practically untouched forest of the sandy hammock type, about $\frac{1}{2} \mathrm{mi}$. in diameter, unlike anything else known in Alabama, but not very different from some of the hammocks of Florida. (See Bull. Torrey Bot. Club, 41: 209-220. 1914.)

The Pea River near Elba flows through a miniature canyon, and on its steep wooded sides are a few plants of interest, such as Adiantum CapillusVeneris, Stenanthium gramineum, Rhapidophyllum Hystrix, Magnolia pyramidata, Ilex vomitoria, and (Kalmia latifolia). Patsaliga Creek and the Conecuh River, near River Falls and Andalusia, have rocky shoals with river weed (Podostemon), but these are likely to be ruined by water-power developments.

Pocosin Sand Area (available). About $3 \mathrm{sq}$. mi. of sandy soil on the east side of Walnut Creek $100 \mathrm{mi}$. north of the Gulf. The so-called pocosin proper consists of about a hundred acres of many-storied climax forest of a type characteristic of the dry sandy soil of the Gulf Coast. The majority of the trees and some of the shrubs are evergreen. Most of these are non-coniferous and of the live oak or magnolia type. The surrounding sand hill country is covered with more sparse vegetation including scrub oaks and pines as the chief outstanding feature. The fauna includes the raccoon, opossum, gray fox, fox squirrel, gray squirrel, and pocket gopher.

Located in Pike County, midway between Troy and Brundidge. The distance between Troy and Brundidge is approximately $10 \mathrm{mi}$. A small station called Banks is midway between the two by rail. Suggested by R. M. Harper. (See Torrey Bull., 41: 209.) Compiled by V. E. S.

14. The lime hills belt is much like the western division of the red hills, except for having more limestone and perhaps more red soils. Probably at least threefourths of it is wooded, and there has not been much damage from logging.
The vegetation of the lime hills in Alabama is not very different from that of the adjacent red hill belt.

Large trees: Longleaf pine, short-leaf pine, sweet gum, red oak, spruce pine (Pinus glabra), red cedar, black-jack oak, magnolia, beech, cypress, post oak, sugar maple (Acer floridanum).

Small trees: Dogwood, redbud, holly, ironwood, and hop hornbeam.

Shrubs and vines: Dwarf palmetto, poison ivy, sparkleberry (Batodendron), virginia creeper, red buckeye (Aesculus Pavia), tyty, and (Aralia spinosa).

The commonest native herb is the epiphytic Spanish moss (Tillandsia usneoides). About the half the trees are evergreen.

Among the noteworthy plants in the lime hills are Asplenium angustifolium, Rhapidophyllum, Dirca, and Campanula Americana.

In the lime hills there are mineral springs of various kinds, some containing salt, some lime, and some sodium carbonate, but their influence on vegetation has never been studied. They are most frequent in the southeastern corner of Choctaw County and the southern part of Clarke, and may be reached in a few hours' walk from Silas and Jackson.

15. The lime-sink region is level to undulating, with many ponds and a few sinks and caves. The soils are prevailingly sandy. Unlike most of the regions previously described, this is characterized by open park-like longleaf pine forests, carpeted with numerous grasses and other narrow leaved herbs. It is swept by fire every year or two, usually in early spring, which is the dry season. (Late summer is the rainy season.) Most of the ponds are pretty well filled with such water-loving trees as cypress (Taxodium imbricarium) black gum and May haw. There are swamps along most of the streams, and dense hardwood forests (hammocks) around the few limestone outcrops.

As the soil responds readily to fertilization, much of the forest has been cleared by farmers. The wooded area decreased from about $95 \%$ in 1880 to $50 \%$ in 1920 . However, there are still some splendid stands of virgin timber, not even turpentined, within a few miles of the sawmill at Lockhart, Ala. (The city of Florala, on the state line, a mile or two away, is a good center for botanical excursions.)

The herbs are a conspicuous part of the vegetation of this and most of the remaining regions. Longleaf pine originally made up at least half of the forest and next in importance are the following.

Large trees: Slash pine (Pinus Elli- 
ottii), pond cypress (Taxodium imbricarium), loblolly pine, black gum, red oak, magnolia, sweet gum, poplar, shortleaf pine, spruce pine, cypress (Taxodium distichum).

Longleaf pine originally made up at least half of the forest; with it were several other pines, cypress, oaks, evergreen magnolia, sweet gum and tulip poplar. As an understory are a large number of smaller trees, of which yaupon (Ilex myrtifolia) and may haw (Crataegus aestivalis) are most characteristic. Shrubs and vines are important; wire grass (Aristida stricta) is the most abundant grass.

16. The southern pine hills $(10 \%$ virgin), or rolling wire grass country as it is often called in Georgia, is a most interesting region, extending with some interruptions from eastern Georgia to Louisiana. Its topography is flat to moderately hilly. Nearly all the streams are bordered by swamps five to ten times the width of the channel, and there are a few shallow ponds. The soils are decidedly non-calcareous, sandy, and below the average in fertility.

The longleaf pine originally made up about two-thirds of the forest. With it were about the same species of trees and shrubs and herbs as in the lime sink region.

Herbs: Aristida stricta (wire grass), Eriogonum tomentosum, Eriocaulon decangulare, Sarracenia Drummondii (pitcher-plant), Rhexia Alifanus, Eupatorium rotundifolium, Sarrancenia flava (pitcher-plant), Pitcheria, Campulosus Kuhnistera pinnata, Pteris aquilina, and hundreds of others.

Among the plants especially characteristic of this region are Chamaecyparis, Myrica inodora, and Cliftonia.

The greater part of the delta is too wet to cultivate and too near sea level to be drained, so that farming is restricted to its edges and upper portions. Much of the cypress and some of the other trees have been removed by lumbermen, but the forests are so dense and the trees grow so rapidly that they are hardly missed.

The upper part of the delta merges gradually into ordinary alluvial swamps, and its most characteristic vegetation is at the lower end, where the following trees prevail:

Black gum (Nyssa biflora) sweet bay, cypress (Taxodium distichum), sweet gum, red maple, tupelo gum, ash, black willow and swamp cottonwood (Populus heterophylla). Buttonbush (Cephalanthus), wax myrtle, bamboo vine, dwarf palmetto, nistletoe, itea, and pepper vine (Ampelopsis arborea), are common shrubs and vines.

There are comparatively few herbs in the swamps proper, but more in the open marshes. The black gum grows larger and more abundantly here than almost anywhere else in Alabama. Populus heterophylla is practically confined to this region as far as Alabama is concerned, but it occurs also in similar situations at the mouth of the Apalachicola River.

These swamps are refuges for certain large animals, such as the bear and alligator. They can be reached in a few miles from any railroad station between Jackson and Mobile, but probably more satisfactorily by hiring a launch at Mobile.

17. The Gulf coast strip includes the islands, dunes, marshes and shell mounds bordering the Gulf of Mexico and other bodies of salt water connected with it. On account of the copious warm summer rains the sand of the dunes is pretty thoroughly leached, and it appears almost as white as snow in many places. Nearly all the woody plants are evergreen.

There are practically all gradations between trees and shrubs, so that the following size grouping is somewhat arbitrary.

Larger trees: Slash pine, loblolly pine, longleaf pine, black gum, live oak (Quercus virginiana), magnolia, sand pine (Pinus clausa), red cedar, hickory, water oak, sweet gum.

Smaller trees: Live oak (Quercus geminata), black jack oak, turkey oak, Cliftonis (tyty), dogwood, holly.

Shrubs and vines: Yaupon, Ilex vomitoria, Myrica cerifera (Quercus myrtifolia), saw-palmetto (Serenoa serrulata), sparkleberry (Batodendron), French mulberry (Callicarpa), Chrysoma pauciflosculosa, bamboo vine, (Smilax auriculata) rosemary (Ceratiola), Conradina canescens.

Herbs: Juncus Roemerianus, sawgrass (Cladium effusum), Spanish moss, Pitcheria, Sagittaria lancifolia, Syngonanthus, and over 100 others.

This region is interesting on account of the large amount of peculiar and almost undisturbed vegetation, and shrubs belonging to families that are mostly herbaceous, or else sparingly represented in the interior, such as Polygonella sp., Ceratiola, Clinopodium coccineum, Conradina, Chrysoma, Baccharis, Iva and Borrichia. But it has no railroads and is rather inaccessible. It is best reached by hiring launches at Bayou la Batre, Mobile, or Pensacola.

The fish and oysters of the adjacent 
waters are of considerable commercial importance, and the usual shore-birds are present.

*Petit Bois Island, a narrow barrierbeach island about ten mi. long, lying largely in Ala. with west end extending into Miss. a few miles off shore in Gulf of Mexico. A bird reservation, with interesting dune and marsh vegetation.

Reached (c) from Bayou la Batre, Ala., or Pascagoula, Miss. The former place is nearest, but latter is larger and has better railroad service.- $R$. $M$. $H$.

\section{BIBLIOGRAPHY}

Harper, R. M. 1913 Economic Botany of Alabama. Part I. Geographical Report on Forests. Geol. Surv. Alabama, Monograph 8.

Howell, A. H. 1921 Biological Survey of Alabama. Part I. Physiography and Life Zones. Part II. The Mammals. North American Fauna, No. 45.

Loding, H. P. 1922 Preliminary Catalogue of Alabama Amphibians and Reptiles. Geol. Surv. Alabama, Museum Paper, No. 5.

Mohr, Charles. 1901 Plant Life of Alabama. Contr. U. S. Nat. Herb., Vol. VI.

\section{MISSISSIPPI}

\section{By Gladys Hoke}

\section{GENERAI CONDITIONS}

The state lies within the coastal plain with the exception of the hills in the northeastern corner. This fact, a difference in minimum and maximum altitude of only $800 \mathrm{ft}$., an average rainfall approximately uniform for all sections, together with the fact that the state lies within a natural forest area would indicate that little diversity would be found either in the soil, the topography or the biota. Although this is necessarily true to a certain extent there are natural distributional features of the biota which are strikingly shown in the northeastern hill section with its many characteristic Appalachian species and in the coastal pine barrens with a biota that resembles that of the bogs of northern glaciated regions.

\section{Climate}

The summers are hot, the winters mild. The mean July temperature is about $80^{\circ}$ with a mean maximum seldom above 93 , though temperatures of $100^{\circ}$ or over occasionally occur. The mean temperature for January is about $47^{\circ}$ with a mean minimum temperature $10^{\circ}$ lower. Temperatures as low as $10^{\circ}$ are uncommon though zero temperatures and lower have been recorded almost throughout the state. The average growing season is seven months. Along the coast it is nine months. Rainfall is heavy in midwinter and midsummer, lighter in October and November. The average annual precipitation is about $50 \mathrm{in}$. except on the coast where it is 60 in. Some snow usually falls every winter though it remains on the ground but a short time.

The sketch map shows the state divided into ten regions based on the topographical and geological and on the floristic regions which conform in a general way.

1. Tennessee River Hills. Topography. This region represents a transition from the Appalachian region to the coastal plain. It is the oldest section of the state and shows outcrops of Paleozoic origin. This area, originally a plateau, is a region of high abrupt hills. Limestone, sandstone and chert are the chief formations.

Original biota. Hardwood forest. This region was covered with a forest of large timber. Common on the hills and slopes were upland oaks, butternut, magnolia, and hickory with such shrubs as deerberry, huckleberry, hazelnut (Corylus americana), and mountain laurel. Some of the herbaceous species were bittercress (Cardamine pennsylvanica), alum root (Heuchera sp.), and violets. Birds once common but now rare or exterminated were: wood duck $\dagger,{ }^{1}$ passenger pigeon*, wild turkey†, Carolina paroquet*, pileated woodpecker $\dagger$, and bald eaglet. The following mam-

1 The symbols * and $\nmid$ indicate extermination and rare, respectively. 
mals were abundant: opossum, cottontail rabbit, southern fox squirrel, gray squirrel, flying-squirrel, bats, whitetailed deer*, bear*, skunk, gray and red fox, wolf*, wild-cat*, and cougar*.

Along the streams and on moist slopes were: white oak, willow oak, water oak, walnuts, maples, hackberry, hop hornbeam, tupelo and black gum, red gum, and cypress. Hydrangeas, trailing arbutus (Epigaea repens), trumpet honeysuckle (Lonicera sempervirens), and liverleaf (Hepatica sp.) flourished. Muskrat and beaver lodges were common and mink and raccoon abounded. Willow (Salix nigra) and alder (Alnus serrulata) formed thickets along wet spring branches. Otters* were not uncommon.

Fish were abundant in the streams. Among the species were: minnows (Notropis umbratilis punctulatus, $N$. bellus and Fundulus notatus), buffalo (Ictiobus urus, cyprinella, bubalus), yellow cat (Ameiurus natalis), channel cat (Ictalurus punctatus), and speck (Ulocentra stigmaea).

2. Pontotoc Ridge. Deciduous hardwood forest. The topography and the biota closely approximated that of the Tennessee River Hills.

3. Northeast Prairie Region. Topography. This gently rolling land resembles the western prairies. The soil is a loamy clay of Cretaceous limestone origin.

Original biota. Some of the characteristic prairie species were: compass plant (Silphium laciniatum), prairie dock (S. terebinthinaceum), milkweed (Asclepias species), Indian plantain (Cacalia tuberosa), prairie clover (Petalostemum candidum), white evening primrose (Oenothera speciosa, O. triloba), blue-eyed grass (Sisyrinchium sp.), black-eyed Susan, and other species of Rudbeckia. Horned toads have been taken but it is probable that they are not indigenous. Sandhill crane, upland plover and partridge were abundant. The bison* was once common but was one of the first species to disappear. This prairie region was almost treeless except for scattered clumps of crabapple, honey locust, and red cedar; and along the streams a heavy growth of lowland oaks, hickory, honey locust, tulip poplar, maples, and ash. Associated with these were: wisteria, papaw, buckeye, blue phlox, cinnamon fern, wild yam-root, common wood violet, and others. The fauna associated with these was characteristic of slightly sluggish stream bottoms. Fish were abundant. They included carp (Opsopoeodus emiliae), minnows, darters (Bolesoma camurum, Etheostoma artesiae, Microperca proeliaris), and yellow and channel cat.

4. Jackson Prairie Belt. Similar conditions obtained in this region though there were marked intrusions from the adjacent sections.

5. Flatwoods Region. Topography. The soil of this strip of undulating land is a heavy clay or fine sand, poor, and usually cold, acid and water-logged. The streams are sluggish and adjacent lands are subject to overflow.

Original biota. Xerophitic mixed forest. The original forest was open and to the north consisted largely of xerophitic oaks on the uplands with a lowland growth very similar to that of the North Central Plateau. Loblolly and yellow pine were dominant over the oaks in the southern portion of the region. The fauna included species of the adjacent regions.

6. North Central Plateau. Topography. The altitude of this maturely eroded plateau varies from about 400 to $700 \mathrm{ft}$. Due to erosion the surface has become gently rolling in the uplands and intricately dissected near the streams. Notwithstanding excellent drainage in the uplands the first bottoms of the streams are often swampy. The eastern and southern half of the region has a clayey or sandy soil which in the western half is overlain by a brown loam.

Original biota. Xerophitic mixed forest. In the original forest on the sandy uplands the shortleaf yellow pine was the dominant type though the forest 
contained many hardwood trees including blackjack, post oak and Spanish oak, hickories, and elm, with a scrubby undergrowth of deerberry, sumac (Rhus glabra and copallina), poison ivy ( $R$. toxicodendron radicans), New Jersey tea (Ceanothus americanus), hydrangeas, muscadine (Vitis rotundifolia), and such herbaceous forms as asters (several upland species), cinquefoil, puccoon (Lithospermum canescens), upland milkweeds, birdfoot violet, and tick trefoil (Desmodium spp.). In the richer loamy soils of the northern and western section pine became rare and the oaks and more mesophytic species were dominant. The upland flora included the species mentioned and plantain (Plantago aristata), crowfoot (Ranunculus fascicularis), day-flower (Commelina virginica), cranesbill (Geranium sp.), dwarf dandelion, everlasting (Antennaria plantaginifolia), may apple, several species of violets, wild yam-root, alum root, spiderwort (Tradescantia virginiana), bracken (Pteris aquilina), and beech fern (Phegopteris hexagonoptera).

The fauna of this region was typical. Insects, crustaceans, millipeds, and centipeds were abundant. Other common species were: toad (Bufo lentiginosus), tree toad (Hyla versicolor), leopard frog, scorpion or blue tailed lizard (Eumeces fasciatus), common lizard (Sceloporus undulatus), garter snake, green snake (Opheodrys aestivus), blue racer (Bascanion constrictor), king snake (Lampropeltis getulus), spreading adder (Heterodon platirhinos), copperhead (Agkistrodon contortrix), and rattlesnake (Crotalus sp.).

The birds and mammals included all the species mentioned in the discussion of the Tennessee River Hills and the prairies.

A heavy forest of hardwoods covered the fertile lowlands. Common trees were: white oak, basket oak, overcup oak, and water oak, red and river maple, sycamore, slippery and white elm, beech, scaly bark (Carya ovata), tulip poplar, redbud, holly (Ilex opaca), river birch, and cypress. . The under- growth consisted of : button bush, holly (I. decidua), bladdernut (Staphylea trifolia), Virginia creeper (Psedera quinquefolia), pepper vine (Cissus arborea), papaw, red haw (Crataegus marshallii), swamp rose ( $R$. carolina), trumpet honeysuckle, muscadine, trumpet creeper (Tecoma radicans), bamboo brier (Smilax rotundifolia), cane (Arundinaria sp.), blue phlox, jack-in-thepulpit, ferns, yellow fringed orchis, and marsh St. John's wort.

In marshes and in the edges of ponds or sluggish waters were boneset (Eupatorium perfoliatum), false dragon head, sedge (Dulichium arundinaceum), arrowhead (Sagittaria engelmanniana), great bulrush (Scirpus validus), swamp rose mallow (Hibiscus moscheutos), deer grass (Rhexia sp.), and water purslane (Ludvigia palustris).

Snails were numerous. Several species of mussels were abundant in the streams. Some of the fish were: shovel bill cat (Polyodon spathula), gar (Lepisosteus sp.), channel cat, mud cat (Leptops olivaris), buffalo, minnow (Hybognathus hayi), and a carp (Opsopoeodus emiliae). Bull frogs, water moccasins (Agkistrodon piscivorus), water snake (Natrix fasciatus), copperhead rattlesnake, soft shelled turtle (Trionyx sp.), Cumberland turtle (Chrysemys elegans), and mud turtle $(C . \mathrm{sp}$.) were abundant in and near the streams and ponds. Essentially all of the species of birds and mammals listed in the Tennessee River Hills and in the prairies occurred in this section.

7. Loess or Bluff Hills Region. Topography. The soil is a fine calcareous silt which has been much eroded forming precipitous hills. This is a transition area both as to topography and biota.

Original biota. Hardwood forest. In the south a gloomy condition of the forest was due to the dense growth of Spanish moss (Tillandsia usneoides) on the trees, and lianes including: fox, river bank and muscadine grapes, Virginia creeper, cross vine (Bignonia capreolata), trumpet creeper, and supple jack. Magnolias and the Cherokee rose $(R$. 
laevigata) were common. The fauna consisted of species of the adjacent regions.

\section{Yazoo-Mississippi Flood Plain.} Topography. This alluvial flood plain is remarkably rich and level. Drainage is poor and much of the land is in a swampy condition. The streams are meandering with numerous bayous, cutoffs, and sloughs. Crescent-shaped lakes, originally old stream beds, are numerous. Levees have been builded along the Mississippi and now overflows from this source are not common. Reclamation of this land will be rapid, the greater portion already being under cultivation.

Original biota. Deciduous hardwood forest. A heavy hardwood forest originally covered this section of the state. The flora was typically hydrophytic and shade loving and the number of species was not great. The swampy areas had a characteristic dense growth of: tupelo and black gum, sweet gum (Liquidamber styraciflua), cypress, lowland oaks, cane (A. macrosperma), palmetto palm (Sabal minor), lizard's tail (Saururus cernus), ditch stonecrop (Penthorum scdoides), frog-fruit (Lippia lanceolata), and day-flower (Commelina hirtella). Less swampy ground had a less dense undergrowth and in addition to the trees mentioned, white oak, white ash, pecans (Carya illineonsis, C. aquatica), hackberry, and magnolia. Willow (Salix nigra) and cottonwood (Populus deltoides) were abundant on the sandy flats near the Mississippi River.

The fauna was typical of such a floral association. Fresh-water molluscs, fresh-water shrimp (in the southern half), and crawfish abounded. The fish included: shovel bill cat, gar, channel cat, mud cat, buffalo, suckers (Catostomus sp.), several species of minnows, shad, little pickerel (Esox vermiculatus), eel, tiny perches, and large mouthed black bass. Snakes and turtles were numerous. They included green snake, copper-head, water moccasin, water snake, and rattlesnake, soft shelled turtle, snapping turtle (Chelydra serpentina), and alligator snapper (Macrochelys lacertina). Alligators were found in the streams and bayous of the southern part of this region. Of the birds that were once abundant the following have been exterminated or are becoming rare: double-crested cormorant $\dagger$, hooded merganser, mallard, wood duck $\dagger$, fresh-water marsh hen, coot, wild turkey $\dagger$, bald eagle $\dagger$, carolina paroquet*, and ivory-billed woodpecker*. All the mammals mentioned in the Tennessee River Hills still occur here. ${ }^{2}$

9. Long Leaf Pine Region. Topography. The surface is rolling, becoming hilly in the western part of the state. The reddish-brown sandy loam soil is rather poor and dry except in the low areas where it is often water-logged and acid.

Original biota. Longleaf pine forest. The biota of this region was characteristic of an almost pure longleaf pine (Pinus palustris) forest. At least ninetenths of the trees were of this species. To the north shortleaf yellow pine crept in while on the west and along the stream bottoms hardwoods from the bluff hills occurred with or replaced the pine. On the sandy well drained uplands in addition to the longleaf pine were dwarf and staghorn sumach, upland oaks, flowering dogwood, wild plum (Prunus americana), sassafras, and sweet gum. Associated with these were: hoary pea (Tephrosia virginiana and spicata), wild bean (Phaseolus pauciflorus), partridge pea (Cassia nictitans and chamaecrista), butterfly pea (Clitoria mariana and Centrosoma virginianum), aster (Aster adnatus, patens, paludosus), black-eyed Susan, milkweed (Asclepias tuberosa), blazing star (Liatris spicata and squarrosa), rosin weed (Silphium sp.), and sundew (Drosera rotundifolia).

Along the streams and swamps where the soil was flooded for several months of the year the chief trees were cypress, ash, sycamore, tupelo gum, and leather wood (Cyrilla racemiflora). In the second bottoms which were better drained

${ }^{2}$ With the exception of the beaver and otter. 
common species were: loblolly and spruce pine, water oak, laurel oak, live oak, magnolias, sweet bay (Magnolia virginiana), fringe tree (Chionanthus virginica), azaleas (Rhododendron nudiflorum and viscosum), river maple, and Smilax laurifolia.

Among the fish of the region were: minnows (Fundulus notatus and Hybognathus hayi), carp (Opsopoeodus emiliae), shiners (Notropis cercostigma), speck, sand darters (Ammocrypta, pellucida, vivax, and beanii) and many of the fresh-water fish mentioned in the next region.

10. Coastal Pine Barrens. Topography. This is a low flat region approaching the Gulf. The occasional ridges about $30 \mathrm{ft}$. above sea level were formerly drifting sand dunes. Between the higher areas are low marshes and swamps which are peaty and acid or brackish. The streams are sluggish and frequently overflow. In summer they are brackish near their mouths.

Original biota. The biota of this region was distinctive. Many species were not found elsewhere in the state, and many on water-logged soil were characteristic of northern bogs. An open growth of pine ( $P$. palustris, taeda, heterophyla) extended over the entire area. In the dry and better drained portions in addition to the pine some of the most characteristic species were: live oak, laurel oak, turkey oak, water oak, upland willow oak, magnolia ( $M$. foetida), leather-wood, sour-wood (Oxydendrum arboreum), and herbaceous species including milkwort (Polygala lutea and nana), deer grass, St. John's wort, butterwort (Pinguicula lutea), sundrops (Oenothera fruticosa), club moss, and pitcher plants (Sarracenia spp.)

On the low wet ground along the streams and swamps in addition to some species mentioned the most typical were: inkberry (Ilex glabra), yaupon (I. vomitoria), sweet bay, red bay (Persea pubescens), tupelo gum, wild olive, dwarf huckleberry (Gaylussacia dumosa), white cedar (Chamaecyparis thyoides), red ti ti tree, white swamp honeysuckle (Rhododendron viscosum), saw palmetto (Serenoa serrulata), pitcher plants (Sarracenia rubra, flava, drummondii), sundew (Drosera filiformis, intermedia, rotundifolia), snake mouth (Pogonia sp.), yellow-eyed grass (Xyris arenicola and other species), star grass (Aletris sp.), and several species of club moss.

Approaching and upon the beaches were: live oaks, pine and wax myrtle (Myria cerifera). Associated with these on the oak and pine flats proper were such characteristic species as sandbur grass (Cenchus sp.), button snakeroot (Eryngium syncihaetum), button weed (Diodia teres), pin weed (Lechea sp.), and partridge pea. On the dunes in addition to the saw palmetto, yaupon holly and wax myrtle already mentioned were: cow berries (Ceratiola ericoides), sea oats (Uniola paniculata), and grass (Panicum sp.). Down on the beaches characteristic forms were: Carolina box thorn (Lycium carolinianum), black mangrove (Avicemnia nitida), salt-marsh fleabane (Pluchea camphorata), marsh elder (Iva oraria), white top (Dichromena colorata), evergreen goldenrod (Solidago sempervirens), salt-marsh aster (A. tenuifolius), bladderwort (Utricularia sp.), and marsh grass (Spartina sp.).

The animals of this region were varied, some coming in from the longleaf pine region on the north and other aquatic species from the Gulf. Snails and mussels, crustaceans and insects were present in great numbers. In the streams some of the commoner fishes were: gars, mud cat, small poison cat (Schilbeodes gyrinus), buffalo (I. cypri. nella), top minnow (Gambusia affinis), crappie (Pomoxis annularis), goggleeye perch (Chaenobryttus gulosus), sunfish (Lepomis sp.), large mouth black bass (Micropterus salmoides), shad (Sigmalosa atchafalayae), mullet (Mugil cephalus), bream (Lagodon rhomboides), spot (Leiostomus xanthurus), croaker (Micropogon undulatus), and goby (Gobiosoma bosci). During the winter and early spring when the water of the lakes and the bayous along the coast was 
fresh or only brackish due to the heavy rains many of these fresh-water species came down the rivers and even into waters that during the summer and the early fall were brackish or salty. During this dry season the fresh-water species were replaced by brackish or salt-water species which extended their range up into the bays and the bayous. They included common mullet, sheeps head (Archosargus probatocephalus), spotted sea-trout (Cynoscion nebulosus), red drum (Sciaenops ocellatus), croaker (Micropogon undulatus), and gulf menhaden (Brevoortia tyrannus patronus).

Starfish, shrimp, crabs including the primitive horseshoe crab (Limulus polyphemus), lobsters, mussels, and oysters were among the common salt-water invertebrates. Toads, tree toads and frogs were abundant as were lizards and turtles. Common turtles were alligator snapping turtle and southern soft shelled (Trionyx ferox), and in the salt marshes the diamond-back terrapin (Malaclemmys centrata concentrica). The gopher turtle (Gopherus polyphemus) was common on the land. Alligators frequented the rivers and the bayous.

The birds of this region were numerous. Many spent a portion of the year here, others were permanent residents. The following were once abundant but are no longer common or are extinct: white pelicans, Wilson's tern, fish ducks, bufflehead, roseate spoonbill*, white $\dagger$ and wood ibis $\dagger$, bittern, white egret*, snowy egret†, Louisiana heron, whooping crane*, and coot.

Note: For detailed accounts of the flora, topography, and geology of the State see:

Plants of Mississippi, Bulletin No. $17 \dagger$. Forest Conditions of Mississippi, Bulletin No. 11; and Mississippi, Its Geology, Soils and Mineral Resources, Bulletin No. 12, by E. N. Lowe, Mississippi State Geological Survey.

\section{NATURAL AREAS}

pCat Island. (A2.) Off the Gulf coast, Gulfport, Harrison County, Mississippi.
Especially desirable as a site for a biological station. Good collecting grounds for insects, salt water fauna and flora, oak, huckleberry, haw, oleander, Ilex, and Salvia. Island uninhabited, one small cabin, seldom visited.

To Gulfportf, Miss., take gasoline boat for trip (about 30 dollars), about 20 mi. south.

Horseshoe Lalve, Tallahatchie River. (B2.) Frequently flooded during winter months. Densely forested-oak, cypress, hickory, and holly. Has been cut-over for big timber and occasionally burned by small fires. Animals: crawfish, fresh water mussels, turtles, terrapins, snakes, fish: cat, trout, perch, eels, gar, etc., opossum, raccoon, mink, skunk, squirrel, rats, gray fox, swamp rabbit, muskrat, rarely beaver*, many birds. (See Louisiana for details of birds.)

I. C. Railway to Oxford $\ddagger$, Miss.

Brush Lake. Very small lake between Mississippi River and present levee. Surrounded by forest, disturbed as little as any in this section. Miss.

Plymouth Bluff and Flat.' (D5.) One of the most northerly points where palmetto is found growing under natural conditions in Mississippi. 50 foot bluff on west side of Tombigbee River. Selma chalk over Eutaw sands. Fossiliferous sharks' teeth, oyster shells, etc. Small ravines. Densely forested-oaks, chestnut, birch, pine. Prairie across river on which palmetto and similar vegetation occur in natural condition. On the bluff slopes semi-xerophytism through mesophytism down to hydrophytism as indicated by the trees:

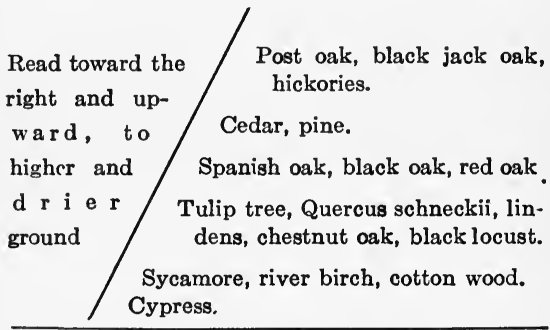

Surface of water

of river.

Southern or M. \& O. Railway to Columbus $\ddagger$ Miss.-C. R. Evans and Gladys Hoke.

\section{BIBLIOGRAPHY}

Apgar, A. C. 1898 Birds of the United States. 
Evermann, Barton W. 1898 A report on investigations by the U. S. Fish Commission in Mississippi, Louisiana and Texas in 1897. Report of the Commissioner of Fisheries.

Gray, Asa. Manual of Botany.

Horniday, W. T. 1913 Our vanishing wild life. New York Zoological Society.

Jordan, D. S., and Evermann, Barton W. 1896 The fishes of North and Middle America. U. S. National Museum, Bull. 47, Vol. 1.

Jordan, D. S. 1899 Manual of the vertebrate animals.

Lowe, E. N. 1913 Forest conditions in Mississippi. Mississippi State Geological Survey, Bull. 11.

Lowe, E. N. 1921 Plants of Mississippi. Mississippi State Geological Survey, Bull. 17.

Townsend, C. H. 1919 Guide to the New York Aquarium. New York Zoological Society.

Small, J. K. Flora of the Southeastern United States.

U. S. Department of Agriculture, Weather Bureau. Climatological data of the United States.

Wailes, B. I. C. 1854 Report on the Agriculture and Geology of Mississippi, embracing a sketch of the Social and Natural History of the State.

Baird, S. F. and Girard, C. 1853 Catalogue of North American Reptiles in the Museum of the Smithsonian Institution, Publication 49.

Hilgard, Eug. W. 1860 Report on the Geology and Agriculture of the State of Mississippi.

\section{LOUISIANA}

By G. W. Goldsmith, Lenthall Wyman AND H. H. KOPMAN

\section{GENERAL FEATURES AND ORIGINAL BIOTA}

\section{Physiographic regions (L.W.)}

While the surface of the state does not vary greatly in elevation, the highest level being about $400 \mathrm{ft}$., there are great differences in soil, general character, and vegetation. The main divisions are: (a) wooded uplands, partly pine, partly hardwood and partly mixed; $(b)$ wooded alluvial bottoms and heavy swamps along large rivers and also wooded coastal plain, entirely cypress and hardwood; (c) level or slightly rolling prairies; (d) coastal and usually tidal flats and marshes; (e) coastal islands. Under (a) the most strongly marked physiographic types are the predominantly pine-bearing lands (longleaf pine hills and pine flats), and the richly wooded but well drained bottoms of small rivers in such regions. Under $(b)$ the strongest types are the slack water cypress and hardwood sloughs in large river basins above tide level, connecting with the main streams only in times of high water or overflow; and the usually submerged and far-spreading tide-level swamps of cypress and hardwood about the so-called lakes of the coastal region. In $(d)$, coastal flats and marshes, the amount of muck, character of vegetation, and degree of salinity of water varies considerably; the surface is greatly diversified by bayous, shallow bays, and lakes.

Highly interesting biotic conditions are presented at the various lines of blending or division of the several physiographic types of the state. Especially notable are the changes from flatwoods or bottomwoods of both small and large rivers to the pine or mixed pine and hardwood hill type; from pine flats to prairies; from pine flats to coastal marshes; from wooded regions of the coastal plains to coastal marshes and from hardwood regions of the coastal plains to pine flats. In other cases the changes are usually more gradual.

\section{Environmental types}

The types of environment, while varying strongly from a physiographic standpoint, are all in a single geographic division: the austroriparian life zone. The principal animal communities peculiar to the several physiographic divisions are as follows:

a. Upland. Plants (L. W.): The uplands are divisible into two distinct forest types, namely, shortleaf pine hills and longleaf pine hills. The shortleaf pine hills, lying in the northwestern part of the state, have fertile sandy loam soils with good drainage. The dominant tree is shortleaf pine (Pinus echinata) which occurs in pure stands on the 
hills, and mixed on the better soils with loblolly pine (Pinus taeda) or with red gum (Liguidambar styraciflua), hickory (Cary alba), and white, post and red oaks (Quercus alba, Q. stellata, Q. falzata). The undergrowth is composed of dogwood (Cornus florida).

The bluff lands are well drained and fertile. They support a dense hardwood growth featured by white, post, overcup and water oaks, beech, hickories, gum, and yellow poplar. Dense undergrowth of haw, dogwood, briers, hornbeam and ilex feature this type. Grasses are missing.

Animals (H. H. K): In uplands with considerable or predominating hardwoods, the opossum (Didelphis virginiana), skunk (Mephitis mesomelas), cottontail rabbit (Sylvilagus floridanus alacer), gray squirrel (Sciurus carolinensis) and occasionally the chipmunk (Tamias striatus venustus), are most characteristic of the mammals, while smaller birds of commoner occurrence than elsewhere are red-headed woodpecker, flicker, towhee, summer tanager, yellow-throated vireo, Louisiana waterthrush, catbird, thrasher, florida whitebreasted nuthatch, tufted titmouse, and wood thrush. It should be noted that consideration is given here and elsewhere only to nesting birds.

In the longleaf pine hills and pine flats regions the most abundant and thriving or more or less peculiar species are the red-headed woodpecker, redcockaded woodpecker, Florida nighthawk, southern meadowlark, chipping sparrow, pine warbler, brown-headed nuthatch and bluebird.

In the river bottoms of the longleaf pine hills the most regular nesting species are yellow-billed cuckoo, redbellied woodpecker, chuck-wills' widow, crested and Acadian flycatchers, summer tanager, red-eyed, yellow-throated, and white-eyed vireos, parula warbler, tufted titmouse, blue-gray gnat catcher, and wood thrush.

b. Hardwood Bottom Lands. Plants (L. W.): The alluvial lands cover onehalf of the state. The hardwood bot- toms support a very luxuriant stand of mixed hardwoods. Several kinds of white oak and water oak, gums, elm, ash, magnolia, sycamore, cottonwood and willow are a few of the species found. The undergrowth is composed of vines, briers, palmetto, yaupon, and hornbeam.

Animals (H. H. K): In the extensive hardwood bottoms, and wooded alluvial coastal plain, the principal haunts of the black bear (Ursus americanus, or perhaps the yellow bear, U. luteolus), cougar (Felis concolor group), bob-cat (Lynx rufus), and deer (Odocoileus virginianus louisianae) are found. The raccoon, mink, swamp-rabbit, and gray squirrel are common. Characteristic birds here are water-turkey, wood duck, wood ibis, little blue heron, yellowcrowned night heron, red-bellied woodpecker, Acadian flycatcher, prothonotary warbler, and sycamore warbler. A peculiar feature of the bird life is that certain species abundant in other physiographic types are plentiful here also, while other species abundantly associated with them in other types are comparatively scarce or absent here. Particularly notable in this last connection are red-headed woodpecker, kingbird, blue jay, cowbird, chipping sparrow, indigo bunting (except in migration), loggerhead shrike, yellowthroated vireo, brown thrasher (except in migration), catbird (except in migration), white-breasted nuthatch and bluebird.

c. Prairies. Plants (L. W.): The prairie region, lying in the southwestern part of the state is a treeless country with few bushes and vines. This belt is marked by good soils bearing excellent stands of grass and sedges.

Animals (H. H. K.): The fauna of the prairies is characterized by a scarcity of mammals. Conspicuous birds are mourning dove, Florida nighthawk, kingbird, and meadowlark.

d. Coastal marshes. Plants (L. W.): The coastal marshes border the Gulf in a strip 10 to $40 \mathrm{mi}$. wide. This is a treeless region which is charac- 
terized by a stand of sedges, grasses, rushes, cattails and reeds. There is a subdivision of this region where freshwater swamps are found. These swamps bear dense stands of cypress (Taxodium distichum) and tupelo gum with little undergrowth where the water stands over 6 in. deep.

Animals (H. H. K.): The prevaling mammal of the marshes is the muskrat (Ondatra rivalicia). While the marshes are favorite resorts of ducks in winter, they are nesting grounds more especially for Louisiana heron, least bittern, king and clapper rails, purple and Florida gallinules, boat-tailed grackle, red-winged blackbird, Louisiana seaside sparrow, Florida yellow throat and long-billed marsh wren.

e. Coastal Islands (L. W. and H. H. $K$.). Coastal islands are the nesting places of the brown pelican, laughing gull, Caspian, royal, Cabot's and Forster's terns, black skimmer and occasional small birds, most notable of which is the Florida nighthawk.

\section{PRESENT BIOTIC CONDITIONS}

(L. W. AND H. H. K.)

Lumbering, hog grazing and fires are responsible for the altering of forest conditions in some regions. The shortleaf pine country is reforesting fairly well but the virgin growth is nearly gone. Many small farms occur in this part of the state. The longleaf pine region has suffered most, and seveneighths of the cutover lands of this type are barren. Few seed trees were left and hogs and fires have prevented natural reproduction. Little farming has been or will be carried on in this belt for many years. Although much longleaf pine timber has been cut the virgin trees will continue to be an important factor for some ten or twelve years. The bluff lands are all in cultivation except where the slopes are too steep. The white oaks and other valuable hardwoods have been cut out. The timber in the alluvial belt is being cleared as fast as levees are built, and cypress and white oak have been culled out already. Practically all of this land will be put into cultivation eventually. The prairie region is practically all used for pasturage or crops. The coastal marshes are still in their original condition and are destined to remain so. The cypress has been removed from many of the swamps and tupelo gum is replacing it.

No species have been seriously reduced in number, although the acreage of longleaf pine will be greatly reduced unless range fires are eliminated and seed trees left on the ground. Cypress seems destined to be largely replaced by tupelo gum.

No original animals existing in Louisiana in modern times appear to have been entirely eliminated, except for the general disappearance of a few species: bison (a few wintered formerly in Louisiana), Eskimo curlew, passenger pigeon, and Carolina paroquet.

III. NATURAL AREAS (G. W. G.)

1. *Louisiana State Wild Life Refuge. (B2.) A tract of 13,000 acres in Vermilion Parish given to the state by Charles W. Ward and E. A. McIlhenny. Deciduous and evergreen savanna and prairie comprise most of the tract together with sandy shore, swamp, marshes, ponds, and bayous. All stages of marsh succession may be found. Alligator, deer, beaver, otter and wild fowl occur.

Abbeville, $30 \mathrm{mi}$. by boat on Bayou Vermilion.-Stanley C. Arthur.

2. *Ward-McIlhenny Wild Life Refuge. (B2.) Comprises 57,000 acres of marsh, bayous, low prairie and sandy shore. Successional stages of marsh vegetation may be found. Alligators, mink, deer, muskrat and water fowl occur. The tract is preserved by the Vermilion Bay Company and is used for very limited hunting.

Abbeville, $20 \mathrm{mi}$. by boat on Bayou Vermillion.-E. A. McIlhenny.

3. *Rockefeller Foundation Wild Life Refuge. (B2.) This consists of 25,000 acres of low plain and prairie with sandy shores and live oaks, marshes, lakes, and 
bayous in Cameron and Vermilion Parishes. Alligator, deer, otter, mink, muskrat, and water fowl abound. Various conditions of marsh succession may be studied.

Abbeville $40 \mathrm{mi}$. by boat on Bayou Vermilion and Inter-Coastal Canal.B. A. McIlhenny and Stanley C. Arthur.

4. ${ }^{*}$ Marsh Island. (B2.) A tract comprising 79,300 acres of marshes, ponds, bayous and sandy shore in Iberia Parish. Successional stages of vegetation may be studied. Alligators, deer, mink, muskrat and water fowl abound. Gift to state by Mrs. Russel Sage.

Abbeville, $30 \mathrm{mi}$. by boat on Bayou Vermilion and Vermilion Bay.-G. W. G.

5. *Shell Keys. (B2.) Marsh and shore conditions. Small islands located off Marsh Island as refuge for water fowl. St. Mary Parish.

Abbeville $60 \mathrm{mi}$. by boat.

6. ${ }^{*}$ Jefferson Island. (B2.) A tract of about 1000 acres in Iberia Parish, composed of deciduous forest, low level plains, swamps and lakes. Swamp succession shown. Mink, muskrat and water fowl.

Abbeville $12 \mathrm{mi}$. by road.-Stanley C. Arthur.

7. ${ }^{*}$ East Timbalier Island. (B2.) A national bird reserve consisting of a few hundred acres of low sandy shore and plain. Located in Terrebonne Parish.

Houma $50 \mathrm{mi}$. by boat.-G. W. G.

8. *Queen Bess Island. (B2.) Baratavia Bay Jefferson Parish. A small island comprising deciduous forest, prairie, swamp and marsh. A refuge for water fowl.

Reached by boats from Grand Island $12 \mathrm{mi}$.-Stanley C. Arthur.

9. ${ }^{*}$ Chandeleur and Breton Islands. This group consists of a low sandy shore and shell keys each of but a few acres extent, the area depending upon the seasonal conditions. They are frequented by water fowl, mink, muskrat, etc. Mangrove swamps occur.

Biloxi, Mississippi $100 \mathrm{mi}$. by boat.Robert Glenk.
10. ${ }^{*}$ Euranium Forest Preserve. (B2.) An area consisting of some 32,000 acres of deciduous forest, eastern coniferous forest, overflow bottom lands, ponds, and lakes. Of this 6240 acres are a game reserve and the remainder should also be so preserved. Bear, deer and raccoon occur together with many forest birds and invertebrates. Winn, LaSalle, and Caldwell Parishes.

Uranea located on reserve.-Robert Glenk.

11. Lands Devoted to Reforestation. (D3.) At Urania, La. Near Urania, La., Mr. Henry E. Hardtner (President of the Urania Lumber Co.), has set aside about thirty thousand acres of cutover land, which he has dedicated to reforestation. The original forests were, for the most part, longleaf pine, and some of the land is reforesting in this same species. To encourage this growth, Mr. Hardtner has fenced off several thousand acres, and is protecting these plots from fire, hogs, etc. These also constitute wild life refuges, as birds, etc., are given absolute protection. The demonstrations of natural reforestation are most interesting.

12. The Kisatchie Wold, or Kisatchie Hills. (B2.) In Natchitoches Parish, La. In central Louisiana, in the southern part of Natchitoches Parish, and extending into Vernon, is a region (referred to in the geology of Louisiana as the Kisatchie Wold), which should be of great value to the Ecological Society. It covers a territory approximately 20 mi. square, and nearly all of it is in either a natural or semi-natural state.

The longleaf pine timber has been removed from about half of this area, which is otherwise in a natural state, save where devastated by fire. The other half is in a primeval state, except where there are small farms, and there are very few of these.

The Kisatchie Wold is a range of sand hills, with an occasional bold outcropping of Grand Gulf sandstone. A part of the country is rolling, but in places the topography may be termed sharp. The elevation is not given in Louisiana Geological Reports, but is probably about $300 \mathrm{ft}$. at the highest point. The streams are swift, clear, and pure; with beds of sandstone and very white sand. It is also a region of excellent springs. 
The hills are covered with almost unbroken forests of the beautiful, but rapidly disappearing, longleaf pine (Pinus palustris); while in the narrow valleys, adjacent to the streams, are splendid growths of magnolia, beech, oak, holly, cypress, etc. In fact, with the exception of two or three, every tree native to Louisiana may be found, and some species attain their maximum size in this locality. Wild flowers grow in profusion, among which are some species that are rare in Louisiana, such as white ageratum and closed gentian. The entire flora of the region is luxuriant, varied and beautiful.

The wild life is highly interesting, deer, fox, wolf, raccoon, opossum, squirrel, rabbit, skunk, and mink being found in abundance; also wild turkeys, woodcock, and other rare birds, as well as all the common species. The streams are well-filled with a variety of fish, such as black bass, striped bass, pike, buffalo, cat and perch.

For two years the Louisiana Federation of Women's Clubs has been agitating the question of a State Park and Wild Life Refuge in this region. The lumbermen of the state have taken it up, and may give about 20 sq. mi., a large part of which will be preserved in a natural state, to Louisiana.

In sand hills of this type, the soil is entirely unfit for agriculture, except in the little valleys along the streams; so, it is highly desirable that these hills be kept growing trees.

The territory described is isolated, and, following heavy rains, almost inaccessible, the only means of travel being by team. In ordinary times, however, it may be reached in an automobile from Natchitoches or Leesville. Both of these towns may be reached by rail from Shreveport or New Orleans. At present the roads are very poor, but a model highway from Natchitoches to Leesville is contemplated, and this will pass through the Kisatchie Hills. The most desirable way to visit this region is to camp, as there are very few places where accommodations are obtainable. - Caroline C. Dormon.

13. Bayou Pierre. (C3.) A fish and mussel stream skirted with swamps, coniferous and deciduous forest. In the parishes of Red River and DeSoto; a 6 mi. strip. $2 \frac{1}{2} \mathrm{mi}$ from Westdale, La.A. D. Howard.

14. Bogalusa tract. (C3.) Location: This area is located in Washington Parish in southeastern Louisiana on the lands of the Great Southern Lumber Company. It lies in Townships 1, 2, 3 and 4 South, Ranges $11,12,13$ and 14 East.
Area: 53,267 acres are included in this tract.

Altitude: Elevations average around $45 \mathrm{ft}$. above sea level.

Conditions: This land is under contract with the State of Louisiana for twenty years. The Great Southern Lumber Company has agreed to protect the land from fires by employing five patrolmen and erecting a $70 \mathrm{ft}$. fire tower. The original timber was longleaf pine but it has been cut clean within the last fifteen years. Very little natural reseeding has taken place. Thirteen thousand acres are under fence, and already several hundred acres have been planted with loblolly pine and slash pine seedlings.

Animals: Raccoon, opossum, mink, rabbit and fox are present on this area, and the birds listed above as occurring in the longleaf pine region probably occur here.

Accessibility: The Bogalusa tract may be easily reached from the city of Bogalusa, as it lies within $6 \mathrm{mi}$. Bogalusa is a city of 15,000 population on the New Orleans and Great Northern R. R. It is about three hours distant from New Orleans. Bogalusa has an excellent hotel.

\section{ARKANSAS}

\section{By JонN T. BuchноLz}

\section{PHYSIOGRAPHIC REGIONS AND GENERAL GEOGRAPHY}

There are two main physiographic regions in Arkansas, the coastal plain lowlands and the mountain or upland country. Most of the uplands belong to the mixed hardwood forest area (Carolinian), while some of the lower hilly lands, their valleys, and all of the lowlands belong to the southern mixed coniferous and hardwood forest area. If one should begin at the northeast corner of the state 8 to $10 \mathrm{mi}$. east of longtitude $91^{\circ}$, and draw a line in a southwestern direction to Little Rock, continuing it nearly to Arkadelphia and thence westward to the Oklahoma boundary, the fraction of the state north and west of this line, considerably more than one-third of its area, is upland, and the remaining southern and eastern part of the state is lowland, a broad coastal plain.

The Arkansas River with its broad valley divides the upland portion of the 
state into two regions. The northern portion consists mainly of a dissected plateau, the Ozark highland, which, beginning at the north bluff of the Arkansas river, rises rapidly to the crest of the Boston Mountains. These mountains mark not only the highest part of the Ozark uplift in this state, but also present the most picturesque and rugged scenery of this entire region. The Ozark National Forest of about 1700 sq. mi. in three tracts is located mostly on the watershed of the Boston Mountains. (See "National Forest of the Eastern District," page 392.) To the north of the Boston Mountains the country continues very rough, but the total relief becomes less as one passes into southern Missouri. In western Missouri and north Arkansas this region of the Ozark Highland is known as the Springfield plateau, while the subdivision to the east of this is the Salem plateau.

South of the Arkansas River the mountains known as the Ouachita Mountains are a part of a folded system. Hard sandstones, slates, and shales form an eroded anticlinorium with the parallel ridges extending principally east and west. The valleys are often broad between these mountains, some of which rise to $2800 \mathrm{ft}$., or about $1750 \mathrm{ft}$. above the surrounding valleys. South of the Ouachita Mountains the Cretaceous deposits give the land a rolling aspect, gradually merging with the Tertiary to the south, where the gently undulating lowlands are a continuation of the yellow-loam region of the Louisiana and Texas coastal plain.

While the Ouachita Mountains consist largely of hard sandstone ridges and broad shale valleys with practically no limestone, the Ozark region north of the Boston Mountains contains much limestone. The sedimentary strata are nearly horizontal and calcareous outcrops are frequently very clearly indicated by marked changes in the character of the flora. Sometimes a good stand of hard maple (Acer saccharum) and many of the elements of a northern maple forest appear in protected ravines having limestone outcrops and a northern exposure, though the more exposed south slopes usually support only the oak savannas or a more xerophytic flora. The dry sandstone ridges of the Ouachita Mountains are covered on the south slopes by a mixture of shortleaf pine (Pinus echinata) with oaks and hickories, and on the north slopes by hardwood forests chiefly of oak and hickory, with hardwoods in the rich bottom lands of the valleys, and pines in the poorer lands. The Arkansas National Forest of approximately 1000 sq. mi. is situated in the Ouachita Mountain region. See "National Forests of Eastern District," page 391.

In eastern Arkansas the broad flat coastal plain region is broken by Crowley's Ridge. This is a long broken hill or ridge of Tertiary deposits varying in width from zero, where streams have cut through it to a dozen or more miles, rising to a height of 100 or $150 \mathrm{ft}$. above the surrounding bottoms. It extends from Helena north and northeast to the northeastern corner of the state. In some of the older reports it was referred to as "Poplar Ridge" from the forest of large yellow poplar (Liriodendron tulipifera) which originally covered it.

Beech is fairly common southward on Crowley's Ridge, especially on its southern part, and many species, as, for example, the white walnut (Juglans cinerea) otherwise rare in the state are found in ravines of this elevated land.

Beech is also found in the hardwood forests of the rich Tertiary alluvial bottoms in the southern counties and formed forests entirely covering some of the lower ridges. Pine forests occupy the sandy soil or poorly drained clay lands, loblolly pine ( $P$. taeda) in the lower bottoms and shortleaf pine $(P$. echinata) on higher ground. Shortleaf pine is the species found in the Ouachita Mountains, a belt of this species originally extending up into north Arkansas as far as southern Missouri, now represented only by several isolated patches in north Arkansas. 
Southern Arkansas still has much valuable pine timber. Cypress swamps are also found in the lowlands of eastern and southern Arkansas along the sluggish streams and bayous.

\section{Prairies}

Grand Prairie should be mentioned as much the largest prairie area in the state. It occupies the greater part of three counties in eastern Arkansas, about 1500 sq. mi., land now largely given over to rice growing. A number of small prairies very similar to Grand Prairie are found in most of the counties of eastern Arkansas.

In the western part of Benton County (the extreme northwest corner) several areas of the Oklahoma prairies extend into the state. Other prairies are found in several scattered areas in the Arkansas river valley, located in the region southeast of Fort Smith overlying the Carboniferous coal beds. Southwestern Arkansas has small patches of the Black Cretaceous Prairie resembling the Cretaceous Prairie regions of Texas. Small prairie openings in glades are scattered throughout the forested hills of the Ozarks.

\section{FLORA AND FAUNA}

As a whole Arkansas offers a very rich and diverse flora and also a varied fauna. The extremes of topography and abundance of forests support a rich fauna of breeding birds, and, being in the heart of the Mississippi valley, it forms a part of the great path of migration. It also affords a winter resort for many water fowl and land birds.

The principal hardwood forests of the uplands are oak savannas. Lumbering is an important industry while farming is very diversified. Fruits of many kinds are successfully grown, such as apples, grapes, peaches, strawberries and other small fruits. The region is also very well adapted to poultry raising and dairying. The northwestern counties of the state grow much wheat, while corn and oats are important farm crops over the entire state. Cotton is grown in some of the valleys of the upland region, on hill land bordering the lowland country, as well as over the entire coastal plain region.

The following species are more or less characteristic of the mixed hardwood forest area (Carolinian): black oak (Quercus velutina), common chestnut oak ( $Q$. muhlenbergii), shingle oak (Q. imbricaria), Ohio buckeye (Aesculus glabra), serviceberry (Amelanchier canadensis), and red cedar (Juniperus virginiana).

Among the mammals of this belt the woodchuck (Marmota monax), Attwater cliff-mouse (Peromyscus boylii attwateri), weasel (Mustela sp.), and spotted skunk (Spilogale sp.) have been listed by Howell. The breeding birds of this zone are Chuck-will's-widow, whippoorwill (rare), phoebe, goldfinch, towhee, oven-bird, brown thrasher, robin, bluegrosbeak, prairie horned lark and scissor-tailed flycatcher.

Other larger mammals of the state include the black bear (Ursus americanus), raccoon (Procyon lotor), wolf (Canis sp.), red fox (Vulpes sp.), gray fox (Urocyon cinereoargenteus), opossum (Didelphis virginiana), fox squirrel (Sciurus niger rufiventer), gray squirrel (Sciurus carolinensis), and flying-squirrel (Glaucomys volans), chipmunk ( $T a$ mias striatus venustus), muskrat (Ondatra zibethica), striped skunk (Spilogale sp.) etc. Virginia deer (Odocoileus virginianus) are still found in the lowlands of the Mississippi and Arkansas river bottoms.

In the Southern mixed coniferous and hardwood area (Lower Austral Zone) of Arkansas cotton and corn are the principle crops, while rice is grown in the Grand Prairie. Lumbering is an important industry, especially in the pine belt of south Arkansas. Important fruits of this Zone are peaches, strawberries, pecans, etc.

Characteristic plants of this area are: black cypress (Taxodium distichum), tupelo gum (Nyssa aquatica), palmetto (Sabal glabra), loblolly pine (Pinus taeda), water oak (Quercus 
nigra), willow oak (Q. phellos), basket oak or cow oak (Q. michauxii), overcup oak (Q. lyrata), Southern red oak (Q. falcata), large cane (Arundinaria macrosperma), red buckeye (Aesculus pavia), pecan (Carya pecan), planer tree (Planera aquatica) hackberry (Celtis mississippiensis), holly (Ilex opaca), and wax myrtle (Myrica cerifera) in the southern counties.

A few of the characteristic mammals of this area have been listed (Howell) as follows: cotton mouse (Peromyscus gossypinus megacephalus), golden mouse (Peromyscus nuttalli aureolus), swamp wood rat (Neotoma floridana subspp.), cotton rat (Sigmodon hispidus), Louisiana pocket gopher (Geomys breviceps), swamp rabbit (Sylvilagus aquaticus), Louisiana skunk (Mephitis mesomelas), evening bat, and Carolina shrew.

Among the characteristic breeding birds of this lowland belt the following have been listed by several ornithologists: water-turkey, Florida barred owl, Florida screech owl, red-cockaded woodpecker, Florida nighthawk, Bachman sparrow, painted bunting, Swainson warbler.

\section{Water pollution}

Waters are polluted in oil fields in southern Arkansas, doing considerable damage to plant and animal life. In the Poteau river near Fr. Smith fish are found to be killed by mine waters charged with iron salts, whose rapid oxidation de-oxygenates the waters and suffocates the fish, or starves them by destroying the algae and their main food supply. Otherwise the pollution occurring from mining, manufacturing and sewage is probably negligible at the present time.

\section{NATURAL AREAS}

*Big Lake. A federal bird and game preserve of 7774 acres, including most of Big Lake, which is a wide place in Little River, a tributary to the St. Francis River. Contains many migrant and winter visitant birds including cranes, many species of ducks such as the mallard, canvas-back, Ringneckedduck, pintails, gadwalls, scaups, mergansers and redheads, wood ducks breed here. Rare wading birds such as the yellow-crowned night heron and many other waders have been observed.

Typical plants are lotus (Nelumbo lutea), cypress, tupelo gum, water hickory (Carya aquatica), overcup oak, cedar elm (Ulmus crassifolia), and to the east of the eastern shore near the Missouri line may be found the rare corkwood (Leitneria floridana). Old maps show the lake much wider than it actually is on the Arkansas side. Blythevilleł on Jonesboro Lake City and Eastern Railway, or Big Lake Station, or Osceola Jct. Also reached from headquarters of warden at Hornersville, Mo.-J. T. B.

*Walker Lake. A federal preserve of 15 acres set aside by executive order. Consists of Mississippi bottom lands shown as a lake in old maps, but practically no lake actually exists in reserved part. Of biological interest because it is a resort and breeding place for rare species of wading birds, particularly the great blue heron, the American egret, the water-turkey, and doublecrested cormorant. The Canada goose occasionally breeds here. Motion picture entitled "Anne's Aigrette" showing breeding colonies of egrets and inhumanity of traffic in plumage was made here by photographers of the Biological Survey, which is available for educational purposes. Blythesvillef on Jonesboro Lake City and Eastern Railway.-J. T. B.

*Big Island. (A3.) An island along Mississippi river in Desha County, formed by Arkansas river on south and west, with White river cut-off $4 \mathrm{mi}$. on west, White river on north and Mississippi river to east. Circumference about $45 \mathrm{mi}$. With the natural protection that it has it would be easy to protect. There are lakes, bayous, and many species of migratory waterfowl, and there is a great quantity of natural cover for game. Contains. Virginia 
deer and black bear. Subject to overflow.-Lee Miles.

Petit Jean Mounlain Park. (C4.) A tract of 1500 acres embracing the most picturesque portion of Petit Jean Mountain, situated along Arkansas River in Conway County, has attracted tourists for its scenic beauty and has been set aside as a state park. Entire mountain is a flat top erosion remnant occupying a synclinal structure. It is capped with sandstone, forming a continuous line of great sandstone boulders where it outcrops on the brow of the hill. Elevation $1100 \mathrm{ft}$. rising from about $320 \mathrm{ft}$. along Arkansas River. Has $100 \mathrm{ft}$. waterfall, "Cedar Falls," which drains mountaintop to the west through canyon several hundred feet deep. More than 50 springs near the summit, some discharging mineral water. Native timber of shortleaf pine, white oak, hickory and a little maple with much of its summit as yet in virgin forest, mainly pine. Mammalian fauna includes wolf, gray and red fox.

Morrilton $\ddagger 9 \mathrm{mi}$. east on good road. Missouri Pacific.-T. W. Hardison.

McNab Wooded Sand Hill and Red River Forest areas. (C3.) One or more small areas of indefinite size (not exceeding several square miles each), west and south of McNab in the wooded sandy hills and bluffs adjacent to the Red River. A region of special botanical interest celebrated for its large number of endemic species. Contains Quercus arkansana, Q. Durandi, Carya myristicaeformis, Castanea alnifolia, Ulmus serotina, Sophora affinis, and many rare species of Crataegus. Abundance of cretaceous fossils.

Fulton $\ddagger$ Ark. on Mo. Pac. Ry., 3 and 5 mi. (a). MeNab-Frisco Ry. one mi. south and two mi. west.J.T. Buchholz.

Harrison Natural Bridge Park. A tract formerly known as the Town Hopper Estate in the heart of the residence district, has been acquired by the City of Harrison as a public playground park. Contains limestone bluff and a natural bridge fronting along on White River with many native trees and other plants characteristic of the Ozark flora. Harrison $\ddagger$, on Mo. North Ark. Ry.J.T.B.

Pigron Pasture. (C4.) Available. A tract approximately 40 acres, known as Pigron's Pasture is noted locally for its bird fauna. It is a nearly level, grazed valley, having a small stream of water, has some meadow and many hawthorns, wild grapes and various kinds of berries aside from sycamores, oaks, walnuts, and other trees. Breeding place for oven-bird, yellow-breasted chat, Kentucky warbler, sycamore warbler, also many more common song birds such as mockingbirds, cat birds, brown thrasher, cardinal, wood pee-wee, field sparrow, gold finch and blue jay. Near Fayetteville on St. L. \& S. F. (Frisco) Railway, two mi. from station, one mi. from Postoffice, east on Elkins-Huntsville Road.-Albert Lano.

Magazine Mountain in Logan County. (B3.) Highest point in Arkansas and one of the highest between Rocky Mountains and Alleghenys, altitude $2823 \mathrm{ft}$. Has very diverse flora and fauna, much of it in undisturbed condition.

Magazine $7 \mathrm{mi}$. east, Blue Mountain 6 mi. N. East on C. R. I. \& Pac. Ry.J.T. B.

*Hot Springs National Park. In Garland County has 44 hot springs, many palatial hotels and bath houses.

Hot Springs $\ddagger$, C. R. I. \& Pac. Ry. and Mo. Pac. Ry.-J. T. B.

Mammoth Spring. (64.) 18 acres in Fulton County, largest spring in western America flowing 300,000 gallons of water per minute, source of Spring River, altitude $580 \mathrm{ft}$.

Mammoth Spring $\ddagger$, Frisco Ry.-J. T. B.

Kessler Mountain. (C4.) Available. One of the Ozark hills which has a maple (Acer saccharinum) forest with northern plants on its northern slopes and in protected ravines otherwise a typical oak savanna of this region. It is probably representative of much of the hill surface of the southern Ozark Mountains. Much of it is still relatively undisturbed. 200 to 1000 acres located in Washington County between Fayetteville and Farmington, $3 \frac{1}{2} \mathrm{mi}$. west from Fayetteville $\ddagger$, or one mi. (w) East from Farmington, Ark., Frisco Ry.-J. T. B. Mt. Nebo. (C4.) A tract of considerable acreage in Yell County. Elevation 330 to $1760 \mathrm{ft}$. Borders along Arkansas River with much of it little disturbed. Has always attracted tourists and should be set aside as state or national park.

Dardanelle, $6 \mathrm{mi}$. west, C. R. I. \& P. Ry. -J. T. B.

Sugar Loaf Mountain. (C4.) In South Sebastian County in Arkansas and Oklahoma boundary. Said to be uninhabited and undisturbed. A beautiful hill typical of the western Ouachita Mountains.

Hartford, several miles, Hartford and Midland Valley Ry.; Rock Island Ry.J.T.B.

Magnet Cove, Arkansas. (F6.) In Hot Springs County, about 4 to 6 sq. mi. should be included in this tract or a 
number of smaller tracts set aside within this area. This region is underlain by igneous rocks and has long been noted for its wonderful display of minerals of which 52 varieties have been reported. It is a relic of an ancient basin of thermal springs. The forest is largely of hardwoods in a region of coniferous forests. It has attracted attention of the early botanists, some of whom reported botanical evidences indicating that the cove was once marshy. Forty-seven native trees have been listed from the region. (See Ark. Geol. Survey Report, Vol. 2, 1890.)

Magnet, reached from Butterfield $4 \mathrm{mi}$. northwest, or Cove Creek $2 \mathrm{mi}$. north on Rock Island Ry.

\section{SELECTED BIBLIOGRAPHY ON ARKANSAS} FAUNA AND FLORA

Buchholz, John T. Notes of Arkansas Pteridophyta. Amer. Fern Jour., 14: 33-38. April-June, 1924.

Buchholz, John T., and Wilbur R. Mattoon. Common forest trees of Arkansas. Bull. Agr. Ext. Div. Univ. of Ark., No. 180. November, 1924. Little Rock.

Harvey, F. L. Arboreal flora of Arkansas. Amer. Jour. Forestry, 1883: 3-20.
Same author in Bot. Gazette, 7: 12; 8: $355 ; 9$ : 195, 196; 10: 279-280; 5: 15; $39, \quad 84 ; \quad 91-93 ; \quad 139-40 ; \quad 6: 189-190$; $213-15 ; 230,273$.

Howell, A. H. Birds of Arkansas. Bulletin No. 38; Biological Survey. U. S. D. S. 1911.

Harper, R. M. Phytogeographical notes on the Coastal Plain of Arkansas. Plant World, 17: 36-48. 1914.

Harper, R. M. Same Undescribed Prairies of Northeastern Arkansas. Plant World, 20: 58-66. 1917.

Palmer, E. J. The forest flora of the Ozark region. Jour. Arnold Arboretum, 2: 216, 232. 1921.

Palmer, E. J. The Red River Forest at Fulton, Arkansas. Jour. Arnold Arboretum, 4: 8-33. 1923.

Palmer, E. J. The ligneous flora of Rich Mountain. Arkansas and Oklahoma. Jour. Arnold Arboretum, 5: 108-134. April, 1924.

Palmer, E. J., Two interesting ferns from Arkansas. Amer. Fern Jour., 14: 39-41. April-June, 1924.

Wheeler, H. E. Birds of Arkansas. (A preliminary report with bibliography by Howell.) Published by State Bureau of Mines, Manuf. and Agr. Little Rock, 1924.

\section{States Chiefly Oak Grove Savanna}

This type of vegetation which is described on page 67 extends from Minnesota to Texas just west of the forest proper. Only those states which are more largely of this than of any other type are included here. Most of Illinois and Iowa, and a large proportion of Missouri and Oklahoma, are covered by oak grove savanna.

\section{ILLINOIS}

By Theodore H. Frison and R. B. Miller

\section{GENERAL CONDITIONS}

\section{Topography}

Illinois is one of the states which form the great Central Plain region of North America. Though essentially a gently rolling or flat plain, the general uniformity of the surface is varied and broken in most parts of the state. Chief among the topographical features responsible for this unevenness are the extensive terminal moraines, the large river systems and their accompanying valleys, the unglaciated areas, and a spur of the conspicously elevated Ozark Highland.

The north-south extent of the state is approximately $5 \frac{1}{2}^{\circ}$ latitude or $385 \mathrm{mi}$., and the east-west extent of the state is approximately $4^{\circ}$ longitude or $216 \mathrm{mi}$. The difference in elevation between the highest and lowest points in the state is less than a thousand feet, the highest point being $1241 \mathrm{ft}$. above sea level in Jo Daviess County and the lowest point $268 \mathrm{ft}$. above sea level at the lower water mark where the Ohio and Mississippi Rivers merge.

\section{Climate}

The climate of Illinois is determined by its location in the interior of the North American continent, the general uniformity of elevation throughout the state, its middle position in respect to 
north latitudes, and its position in regard to moisture bearing winds.

Generally speaking, Illinois is a state with warm summers and cold winters. The average temperature for January, the coldest month, is $26.9^{\circ} \mathrm{F}$. and that of July, the warmest month, is $75.9^{\circ} \mathrm{F}$. Changeableness of weather is a common phenomenon and the changes are often rapid and extreme. Increases and decreases in the temperature of $30^{\circ} \mathrm{F}$. within twenty-four hours are not uncommon, and the temperature has been known to rise $48^{\circ} \mathrm{F}$. within twenty-four hours and to fall $65^{\circ} \mathrm{F}$. within eighteen hours. The average temperature for the state is approximately $52^{\circ} \mathrm{F}$. and the extreme range in temperatures is $147^{\circ} \mathrm{F}$. The difference in annual temperatures between those places having the lowest (Northern Illinois) and highest (Southern Illinois) annual temperatures is a matter of about $10.5^{\circ} \mathrm{F}$. The growing season varies from five months in the northern to seven months in the southern part of the state.

In Illinois the rainfall is well correlated with suitable conditions of temperature for an abundant growth of plant life. The normal precipitation for the state is $36.54 \mathrm{in}$. This precipitation is distributed throughout winter, spring, summer, and fall, respectively, as follows: $6.98,10.33,10.76$, and 8.47 in. The month of May with 4.07 in. of rainfall has the largest average precipitation of the months of the year, and December the smallest with a precipitation of 2.16 in. Nearly $60 \%$ of the normal rainfall therefore falls during the time of year when conditions of temperature are favorable for plant growth.

Though the averages of rainfall are well balanced for the four seasons of the year, there occur many wide departures in local areas from the average. Variations in the amount of monthly precipitation from 0 to 20 in. have been recorded. Such deviations from the average monthly rainfall, together with the distribution of the rainfall within the month or season, are responsible for occasional local or general drouths and flooded conditions in the river and stream valleys.

\section{Original biota}

Illinois is unique among the states in that it contains plant and animal forms representative of the eastern forests, of the western prairies, of the northern bogs, of the southern mountains and the Lake Michigan coastal plain.

\section{a. Deciduous forest}

About $44 \%$ of the state was originally deciduous forest. The northeastern corner and the southern third of the state were almost continuous forest. In the other parts of the state, the forest was confined to the stream margins and to occasional groves away from streams.

The principal trees were white oak (Quercus alba), red oak (Quercus rubra), black oak (Quercus velutina), elm (Ulmus americana), basswood (Tilia americana), soft maple (Acer saccharinum), and especially in the southeastern part some beech (Fagus grandifolia), and sugar maple (Acer saccharum). The larger animals of the deciduous forest included the Virginia white-tailed deer (Odocoileus virginianus), black bear (Ursus americanus), timber wolf (Canis lycaon), red fox (Vulpes fulva), gray fox (Urocyon cinereoargenteus), opossum (Didelphis virginiana), cotton-tail rabbit (Sylvilagus floridanus mearnsii), gray squirrel (Sciurus carolinensis leucotis), deer-mouse (Peromyscus leucopus noveboracensis), timber rattlesnake (Crotalus horridus), ruffed grouse, wild turkey, and the tufted titmouse. Among the smaller animals such forms as the polyphemus moth (Telea polyphemus), the wood cockroach (Parcoblatta pennsylvanica), the katydid ( $M i$ crocentrum laurifolium), the oak-pruner (Elaphidion villosum), the two-spotted bumblebee (Bremus bimaculatus), the white-lipped wood snail (Polygyra albolabris), the striped wood snail (Pyramidula alternata), and a couple of small 
earthworms (Helodrilus tenius) and (Diplocardia singularis) are common to this region.

\section{b. Prairie or Oak-Grove Savanna}

The deciduous forests in central Illinois were scattered in the midst of a rich grassland or prairie. The boundary between the two was composed of shrubs and small trees, such as hawthorn, dogwood (Cornus florida), bladder nut (Staphylea trifolia), raspberry ( $R u$ bus occidentalis), and bitter sweet (Celastrus scandens), which formed a strip about 15 or $20 \mathrm{ft}$. wide. There were thousands of miles of these forest edges in Illinois when the white man first took possession of the land. They were the haunt of the skunk (Mephitis nigra), Franklin ground-squirrel (Citellus franklinii), jumping-mouse (Zapus hudsonius), chipmunk (Tamias striatus), and short-tailed shrew (Blarina brevicauda), and were also the chief nesting places of a host of birds which now inhabit orchards, yards, and hedges. The elk (Cervus canadensis) was fond of the forest edge. Many of the insect pests of fruit-bearing trees and shrubs originally lived in this transitional area of shrubs and small trees.

The prairie proper was a rich grassland composed of such grasses as Andropogon furcatus, Andropogon scoparius, various species of Panicum, etc., together with such herbs as the compass plant (Silphium laciniatum), the prairie dock (Silphium terebinthinaceum), and various species of golden-rod. The great prairie area was astride the Illinois River where its general direction was east and west. The larger portion, south of the river, was about three times as large as the portion north of the river. The entire northern twothirds of the state included prairie areas. The bison (Bison bison), coyote (Canis latrans), badger (Taxidea taxus), striped ground-squirrel (Citellus tridecemlineatus), pocket-gopher (Geomys bursarius), and the prairie rattler (Sistrurus catenatus), were abundant in this region during the period of ex- ploration and early settlement. Here also were found the dickcissel, the prairie lark, the meadow lark, small bee-hive snails (Gastrocapta contracta and Pupoides marginatus), such earthworms as (Diplocardia communis and Helodrilis trapezoides) and many insects which have now become serious pests of cultivated forage crops and grains (cutworms, aphids, white grubs, etc.)

\section{c. Local}

In addition to the dominant biota just described, there were local conditions. Of these the most important were the sand areas, rivers, lakes, and swamps.

The sand areas were associated with Lake Michigan and the glacial drainage courses, namely, the Illinois and Kankakee rivers, and the swamps with the rivers just enumerated, the Mississippi River, the inter-morainal depressions of the prairie area, and the lake district of the northern part of the state. The sand areas have been the subject of various studies of succession. All stages in the development of the forest and prairie occurred on the sand areas. Here grew several kinds of oaks, cottonwood, cacti, Monarda, Diodea, Cassia, Rhus and Stenophyllus, and jack pine in the Lake Michigan Region. The fauna of the sandy areas included such animals as the sand lizard (Cnemidophorus sexlineatus), hog-nose snake (Heterodon contortrix), box turtle (Terrapene carolina), many bembecid and sphecoid wasps, such sand frequenting grasshoppers as (Mermiria neomexicana and Spharagemon wyomingianum), and the cactus feeding syrphid fly (Volucella fasciata).

Swamps were numerous in the central part of the state in the prairie area. They occupied the depressions in the till of the Wisconsin glacier. Prominent among the plants in the swampy areas were cattails (Typha), bulrush (Scirpus), certain willows (Salix), flags (Iris), swamp milkweed (Asclepias incarnata), Sparganium, and Sagittaria. Among the animals were the muskrat (Ondatra 
zibethica), marsh hawk, marsh wrens, red-winged blackbird, dragonflies, and mosquitoes. In the cypress swamps in the southern part of the state occurred the swamp rabbit (Sylvilagus aquaticus). In northeastern Illinois were numerous swamps and a few northern bogs. In the latter grew the tarnarack (Larix laricina), mountain ash (Pyrus americana), pitcher plant (Sarracenia purpurea), cranberry (Vaccinium macrocarpon), and there lived numerous insects with northern affinities such as the tipulids (Nephrotoma sphagnicola and Tipula senega). Swampy areas also occurred in the bottomlands along the water courses and were caused by the overflow during the early spring floods.

The extensiveness of the rivers and lakes, particularly the former, enabled this state to support a varied and abundant aquatic and semi-aquatic biota. The lake district of Illinois was essentially in the northeastern part of the state and here there are about 20 lakes one mi. or more in length. These are of glacial origin. The larger rivers and their tributaries were more evenly distributed throughout the state. Both the rivers and lakes of Illinois were originally well stocked with various kinds of fresh water fish, and aquatic insects and mollusks occurred in abundance. These areas or their margins also supported muskrat and mink, as well as numerous water loving birds.

\section{PRESENT Biota}

The original biota of Illinois is very seriously disturbed. The game, both large and small, has been very largely destroyed, except in the Ozark Highland in the southern part of the state. The bison, black bear, elk, snowshoe hare (Lepus americanus), beaver (Castor canadensis), and gray fox (Urocyon cinereoargenteus), had quite generally disappeared before or about 1850 .

While the area now occupied by most of the plant and animal types just enumerated, and many others necessarily left out, is very much curtailed in contrast with the display of a century and a half ago, there still exist ample examples of every major habitat except the prairie which once was the most representative of them all. Since very few original tracts of prairie now remain, it is of the most urgent importance that some be set aside in perpetuity before it is forever too late.

Extensive drainage has reduced much of the area formerly of swamp and bayous character, while stream pollution has been responsible for the change in the biota of otherwise more permanent habitats - the larger streams and rivers. Notably, the original flora and fauna of the Upper Illinois River is almost exterminated by Chicago sewage.

\section{NATURAL AREAS}

\section{A. CHICAgo DISTRICT}

\section{Prairie}

*Riverside Prairie. (Cook County Preserves.) About 10 acres near the Desplaines River; typical mesophytic prairie; general aspect characteristic of large areas in Illinois oak grove savanna. See Bryant's poem "The Prairies." 630-650 ft. altitude, level. (See frontispiece.)

Chicago, $12 \mathrm{mi}$. west, C. B. \& Q. R. R., or La Grande Electric; $\frac{1}{2} \mathrm{mi}$. N.W. from (W). Riverside, Ill. $-V$. $E$. Shelford.

\section{Deciduous forest of the Cook County district}

${ }^{*}$ Cook County Forest Preserves. Includes deciduous forest, flood plain, ravines, hills, swamps, ponds, rivers, and springs. There are at present 24,806 acres devoted to such purposes which have been acquired since 1913, and according to Chief Forester Ransom H. Kennicott there are 30,000 acres available for reservation as forests. It must be remembered, of course, that not all of this is wooded, but that some is taken up by golf courses, baseball diamonds, tennis courts, and open spaces of various kinds. The Forest Preserve District has also acquired title to more than 260 acres of the 
Skokie marsh so that this entire bit of moorland amounting to over 2000 acres will in time be preserved from drainage projects and kept in its primitive condition.

Cook County's forest preserves are distributed as follows:

\begin{tabular}{|c|c|}
\hline Districts: & Acres \\
\hline Palos. & $6,688.48$ \\
\hline Desplaines... & $5,274.26$ \\
\hline North Branch of Chi- & $2,696.27$ \\
\hline Chicago Heights, Bloom & \\
\hline and Thornton......... & $2,248.76$ \\
\hline Calumet State Line.... & $2,135.82$ \\
\hline $\begin{array}{l}\text { Salt Creek and River- } \\
\text { side } \ldots \ldots \ldots \ldots \ldots \ldots \ldots\end{array}$ & $1,236.66$ \\
\hline Palatine....... & $1,102.08$ \\
\hline Elk Grove..... & $1,273.48$ \\
\hline Orland....... & 734.35 \\
\hline Skokie.......... & 503.90 \\
\hline Lyons.......... & 367.94 \\
\hline Oak Forest.... & 227.20 \\
\hline Beverly Hills. . & 160.13 \\
\hline Schaumburg... & 50.65 \\
\hline Evanston..... & 6.68 \\
\hline & 8 \\
\hline
\end{tabular}

\section{a. Upland areas}

*County Line Preserve. (Cook County Preserves.) A small tract of swampy woods at the margin of the Skokie marsh. Near Braeside Northwestern R. R. $20 \mathrm{mi}$. north of Chicago. $-W$. C. Allee.

p. North Shore Ravines. (C4.) The ravines between Winnetka and Waukegan in Cook and Lake Counties. These ravines contain a rich mesophytic flora in an essentially natural state. These are notable for being almost the only stations for beech (Fagus grandifolia) in northern Illinois. They also contain various plants of northern range. In most of these ravines the public is not particularly welcome. The animals here are those typical of mesophytic woods. The ravine streams are mostly contaminated, so much so that in many cases the resistant water isopod, Asellus communis, is lacking. In others the sensitive May-fly nymphs may be found. The ravines may easily be reached via the N. W. R. R. or Milwaukee Electric which runs near Lake Michigan. Per- sons visiting these ravines may see several in a day. An excellent example is within the military tract at Fort Sheridan. - H. C. Cowles.

*Deer Grove. (B3C3.) (Palatine Preserve, Cook County.) Artifically enlarged, natural lake with practically entire drainage basins of two tributary brooks. About 1200 acres. Open red oak forest with elms along water courses. Some hickory and maple present. Timber is oak-hickory type. Streams small, but permanent. Many temporary and a few permanent ponds. Partly rented for grazing. Prairie Club permanent camp.

Chicago 28 mi. S.E., Chicago and Northwestern $2.5 \mathrm{mi}$. N. (w or a) Palatine, Ill. $-W$. C. Allee.

*Elk Grove Preserve. (B3-C3.) (Cook County.) Two or more mi. south of Arlington Heights on Chicago and Northwestern R. R. Swampy land; contains both banks of Salt Creek for about two mi. The creek is relatively free from contamination at this place.W. C. Allee.

\section{b. Desplaines River Preserves}

Scattered tracts along the Desplaines River taking in much of the river bank from Riverside to the County Line. The river is badly contaminated for most of the distance, but approaches natural conditions near Wheeling where it has been dammed. Large numbers of river mussels occur below Wheeling. Riverside shows some of the best forest.

\section{*Riverside Flood Plain and Savanna} Forest. About 20 acres along the Desplaines River; typical mature flood plain forest of maple, elm, bass wood, walnut and oak. Shows succession from middle age to mature stage. Forest edge with sinuate outlines, outlying groves; grass covered portions, typical mesophytic prairie; general aspect characteristic of large areas in Illinois oak grove savanna. The fauna of the forest edge is especially characteristic; in the forest, raccoons, gray squirrels, 
and many characteristic invertebrates. Stream badly polluted. 630 to $650 \mathrm{ft}$.; level.-V. E. Shelford.

\section{c. North Branch Chicago River Preserves}

*Shermerville Tract. (C4.) (Cook County.) 40 acres of oak-hickory-elm woods a third of which is rustic park and the rest is similar to the other wooded tracts; Claytonia and Trillium grow thickly; wood snails and isopods are plentiful.

$20 \mathrm{mi}$. north of Chicago. C. M. \& St. P. R. R. East of the Station.W. C. Allee.

*Morton Grove Preserve. (B3-C3.) (Cook County.) Oak-hickory forest. On the North Branch of the Chicago river. Relatively uncontaminated water; many crayfishes and fishes.W. C. Allee.

*Edgebrook Preserve. (C4.) (Cook County.) Oak-hickory forest. On North Branch of Chicago River which is here contaminated to a considerable degree. Otherwise the conditions are similar to those above.-W. C. Allee.

\section{d. Southern Upland Preserves}

*Beverly Hills Forest. (Cook County.) 20 acres of deciduous forest and glacial topography, including some swampy brush covered land located in Cook County Forest.

One-half mile northwest from Beverly Hills. C. R. I. \& P. R. R. Chicago, Ill.-V. E. Shelford.

*Glenwood Preserve. (C4.) Oakhickory forest. Thorn Creek is badly contaminated in this region and contains practically no life not found in sewage. Butterfield Creek, which is not reserved, is still uncontaminated and is the best example of a normal brook animal community to be found near Chicago. Johnny darters, Mayfly nymphs, and caddice-fly larvae are abundant.

$20 \mathrm{mi}$. south of Chicago. B. \& $\mathrm{O}$. suburban line, Glenwood.-W. C. Allee.

*Palos Preserve. (C3.) A large tract with widely varying conditions from swampy thickets to open fields. In other places there are wooded ravines. Oaks and elms predominate. In places one finds typical savanna conditions which are in part a result of past farming operations. Conditions are particularly favorable for birds. Moraine ponds are common.

Palos Park, Ill. Wabash R. R.W. C. Allee.

*Chicago Heights Preserve. (C4.) Deciduous forest. Thorn Creek is here unpolluted. Flood plain thickets and open forest growth of oaks and elms give the general features.

$20 \mathrm{mi}$. south of Chicago. C. \& E. I. R. R.-W. C. Allee.

\section{e. Southern Lowland Preserves}

*Burnham and West Hammond Preserves. (C4.) Swampy land in the main, although the West Hammond Preserves have better drainage and support a growth of mixed oaks. The ponds here are largely summer-dry, but in spring there is a heavy frog population. Salamanders (Ambystoma tigrinum) lay eggs here. The fairy shrimp (Eubranchipus vernalis) and an isopod (Asellus communis) are particularly abundant.

Reached by various street car lines from 63rd St., Chicago.-W. C. Allee.

$p W o l f$ Lake or Lake Calumet. Lakes near Chicago containing such snails as Pleurocera and Vivipara commonly, and mussels in abundance. Waterfowl and several varieties of fish are also present. Pond weeds have been regularly removed by ice companies.

Reached by various street car lines from 63 rd Street, Chicago.-W. C. Allee:

\section{f. Streams}

pFox River. (Elgin to Carpentersville Dam.) Good mussel and fish conditions.

Elgin, Ill.-A. D. Howard.

pHickory Creek. (New Lenox to Joliet Park.) One of the few unpolluted streams in northern Illinois. Has varied conditions and fauna. Should be preserved by the state.

New Lenox, Ill. C. R. I. \& P., Joliet 
and Eastern Traction.-A. D. Howard and V. E. Shelford.

\section{B. NORTHEASTERN TIER COUNTIES}

\section{The Shore of Lake Michigan}

pWaukegan Flats. (B3.) One sq. mi. sand area, level plain, with few ridges, ponds, marshes and sluggish streams. Some coniferous trees. A large growth of pine trees of many species grown from seed by the Douglas Nursery. These dunes are displayed chiefly north of Waukegan. Though small in area and miniature in height, the flora is very rich and representative. An attempt has been made to preserve the Waukegan dune area, thus far without success. The tract contains Dead River, a baselevelled stream that opens at times into Lake Michigan and again is closed off by sand. The water is unpolluted, and contains good fauna.

Beach, Illinois, C. \&. N. W. R. R.H. C. Cowles and W. C. Allee.

\section{Inland lakes, swamps and bogs}

pLake County Lakes, Swamps and Bogs. Lake County is notable for its glacial lakes and its innumerable swamps and bogs. The largest and best known of the lakes is Fox Lake. Grass Lake, an arm of Fox Lake, is famous for its bed of lotus (Nelumbo lutea), a rare plant in Illinois except along the Mississippi River. There is a remarkable variety in the fauna and flora of the different lakes. There are about ten true bogs in Lake and the adjoining county of McHenry, representing probably the only stations in the state for certain plants of far northern range, as the tamarack, mountain ash, Andromeda, Chamaedaphne and dwarf birch (Betula pumila). Very abundant here are the sundew (Drosera), pitcher and cranberry plants.

Fox Lake, Ill., C. M. \& St. P. R. R.H. C. Cowles.

Tamarack Swamps. South end of Pistakee Lake, Lake County. About one square mile, including lakes, shrub covered swamp, and three tamarack swamps.

Long Lake, Ill., C. M. \& St. P. R. R., 3 mi. southwest.-V. E. Shelford.

${ }^{*}$ Cedar Swamp of Kane County. Probably nowhere else in Illinois can there be found a swamp of northern white cedar or arbor vitae (Thuja). Fortunately a large part of the swamp area has been acquired by the city of Elgin and is preserved as a natural park, under the auspices of the Elgin Chapter of the Wild Flower Preservation Society. Known as "Trout Park."

City cars run to park.-H. C. Cowles.

C. OUTSIDE THE CHICAGO AND NORTHEASTERN TIER COUNTY DISTRICT

\section{Prairie}

Bondville Prairie. Mesophytic prairie, much of the best of which has recently been destroyed by plowing.

Located in Champaign County. Bondville, Ill., one mi. east, Ill. Traction System.-W. B. McDougall.

\section{Deciduous forests}

pBald Knob Hardwood Forest. (Union County.) This is an upland oak-hickory forest, culminating in Bald Knob, a cleared area, with an elevation of 1025 ft., in the Ozark Highlands of Union County. It would be possible to set aside here for a state forest about 30 sections of wooded area, of which 16,600 acres could be classed as upland timber. (For description, species present and probable yields by types, see "First Report on a Forestry Survey of Illinois," Bulletin of the Illinois Natural History Survey, Vol. XIV, Article VIII, March, 1923.) In the ravines are found beech, tulip tree, white oak, cucumber, mulberry and butternut. As to the fauna, there are the opossum, raccoon, gray fox, skunk, mink, weasel, gray squirrel and cottontail rabbit, and among the snakes, the rattler and the copperhead (Agkistrodon mokasen). Wild turkey were at one time abundant and deer were present not over 15 years ago. Quail are common and an otter was killed by one of the topographic surveyors not over three years ago.

Bald Knob is about $3 \mathrm{mi}$. southwest of Alto Pass, on the Mobile and Ohio Railway (h). Also easily reached from Cobden, main line Illinois Central R. R. (a).-R. B. Miller.

pFountain Bluff. (Jackson County.) This consists of 3297 acres of upland oak forest. In a part of it the best of the merchantable timber has been removed, but portions still contain about 2000 board ft. per acre.

Fountain Bluff is an isolated area of great ruggedness and beauty, separated by many miles of flood plain from the main body of the Ozarks, with which it was once connected. This rock island stands up like a mountain from the flood plain extending on every side, reaching a height of three or four hundred feet 
at its highest point. At the southwest portion the Mississippi River washes its banks and from the top of the bluff the "Father of Waters" forms an impressive feature of the landscape. The bluff is composed of massive sandstone interspersed with peculiar iron layers, except at the south where it is limestone. There is a fine display of hickory, oak and beech and in the spring the flowering display of the serviceberry and dogwood beggars description.

Fountain Bluff is about $\frac{1}{2} \mathrm{mi}$. (w) from Gorham and also on the main highway running from Chicago to Cairo.-Henry C. Cowles.

pFern Cliff. (Johnson County.) This is a tract of only about 36 acres but remarkable for its fern-covered boulders, water-falls framed by high cliffs, sand caves of magnificent proportions, talus slopes with immense fragments broken from the cliffs and perpendicular cliffs $200 \mathrm{ft}$. in height. There is a stream bordered by fine hardwoods, beech, hickory and maple, with fine springs and numerous waterfalls.

Reached (w) from Goreville, $\frac{1}{4} \mathrm{mi}$; Illinois Central, Carbondale to Marion and C. and E. I. R. R. Marion to Goreville. Train connections just right for a day's trip from Carbondale, returning the same night.-R. B. Miller.

Strip Mine Land. (Vermilion County.) About 50 acres of deciduous forest which is slowly being converted into "spoil banks" by the process of strip mining where the surface soil is removed down to several feet in depth by steam shovels, exposing the coal. Where the forests are coming in after "stripping" the land, they are in danger of being partially destroyed by grazing. These lands offer a valuable opportunity to study the re-establishment by succession of the original bottomland forests.

Located two mi. east of Oakwood, on the cement road Champaign to Danville, or take local cars on the Illinois Traction Line; also Peoria Division of the Big Four to Oakwood. $-W$. $B$. McDougall.

Equality Quadrangle Forest. (Pope County.) 720 to 1000 acres of hilly cut-over land lying on the south slope of the Mountains of Hepsidam, with a fair stand of young post oak and other timber which will easily reproduce itself. There lies on these slopes one of the famous springs of Pope County, the Blue Hole Spring. This tract could be connected with a similar tract on the top of Cave Hill, in Saline County, by a road which would give a magnificent view of the country. This tract would make an ideal bird sanctuary, as the mocking bird nests here.

Reached from Route 13 State road with a $3 \mathrm{mi}$. road. Also from Equality, on the L. and N. R. R. between Harrisburg and Shawneetown.-L. W. Gordon.

pBrownfield Woods. (Champaign County.) A tract of about 60 acres of deciduous forest which should be made part of a forest preserve district for the county embracing scattered tracts along a branch of the Salt Fork from Urbana to St. Joseph. It falls in the class of forest running about 4000 board ft. per acre and contains good specimens of red and white oak, sugar maple, elm, hackberry and other bottom-land species. Rich in bird life, some small mammals, numerous mollusca and many insects.

About $3 \mathrm{mi}$. northeast of UrbanaChampaign; (a) or Kankakee-Urbana traction line.-W. B. McDougall.

\section{*University of Illinois Forest Pre-} serve. Thirty or 40 acres of deciduous forest characteristic of the groves of central Illinois; used for scientific purposes. Characteristic mesophytic trees. Some cutting has taken place in recent years removing the walnut and other valuable species. Has been badly damaged by continuous grazing but has recovered rapidly from the harmful effects since it has been under University control.

$3 \frac{1}{2} \mathrm{mi}$. northeast of Urbana. (a) or from Cottonwood Stop, Danville-Champaign branch of Illinois Traction System.-W. B. McDougall.

pTunnell Hill. (Johnson County.) This is a region of much scenic interest and botanists are impressed by the marked differences of its flora from that of any other portion of the state. Nowhere else in the United States have I seen a more varied fern growth, the many shaded cliffs forming veritable fern gardens. Here is the northernmost range of Vaccinium arboreum, V. glaucescens, $V$. tenellum, Sedum pulchellum, Magnolia acuminata, and many other plants.

$10 \mathrm{mi}$. south of Parker, crossing of Illinois Central and C. C. C. \& St. L. Railroads. -T. E. Savage.

*West Woods. (McLean County.) An area of about 40 acres located in McLean County typical of the deciduous forests of the region. A monument in 
the tract states that the area was bequeathed to the county by Mr. West, to be a reserve of original nature dedicated to the interests of nature lovers.

(a) from Leroy, Ill.-I. W. Brown.

Cedar Glen. (Hancock County.) 100 acres deciduous forest, with ravine and bluff, known as Cedar Glen. The glen is in an essentially primeval condition, and the tract should extend over the bottomland to the river.

Located in Hancock County, $3 \mathrm{mi}$. from Warsaw, Ill.-W.K. Hill.

Wild Cat Springs. (Hancock County.) 50 acres deciduous forest, flood plain forest, talus slope, ravine, bluff, shore, lake, river, and spring. This place, known as Wild Cat Springs, includes a ravine into which the water from the Koekuk Power Dam extends for $\frac{1}{2}$ mi. The tract is in a nearly primeval state.

Located in Hancock County, Ill., one mi. from Hamilton.-W. K. Hill.

Sangamon Bottoms. (Piatt County.) 40 acres of flood plain forest, with temporary ponds and a stream with sandy bottom. Shows very well the stages taking place in the flood plain forest.

Located in Piatt County, along the Sangamon River, $1 \frac{1}{2}$ mi. west of White Heath, Ill. White Heath is on a new cement road, Champaign to Springfield; also on the Illinois Central R. R. between Champaign and Clinton.- V. $E$. Shelford.

*Deer Park and Deer Park Canyon. (La Salle County.) One sq. mi. of deciduous forest, with river, canyons, waterfalls and springs. Is maintained by two towns at the present time but should pass into state control and be linked up with Starved Rock Park. The main canyon rivals any of the canyons in Starved Rock Park.

Located near Oglesby, La Salle County.-G. D. Fuller.

*Starved Rock State Park. (La Salle County.) Comprises about 1000 acres on the south bank of the Illinois River, extending along the bluff for about 5 mi. Conditions range from dry rocky bluffs, where the northern white cedar is found, to mesophytic ravines. An extension of the area is planned to include Deer Park Canyon. For further description see Ridgley's Geography of
Illinois, University of Chicago Press, page 327.

Ample hotel accommodations in the park. Reached by C. R. I. \& P. R. R. from Utica, interurban line Utica to La Salle or (a) on Route 7.-R. B. Miller.

Morton Arboretum. An area of about 500 acres or more being developed as a private arboretum by Mr. Morton. To be later endowed for public use.

Located at Morton Grove, about 60 mi. west of Chicago.-H. C. Cowles.

\section{*Matheson Park. (La Salle County.)} Two sq. mi. of deciduous forest with ravines, marshy shore and a portion of the valley of the Little Vermillion River. It is just on the outskirts of the city of La Salle and is named after the owner. It is being used as a pleasure resort to some extent and should be preserved by the city.

La Salle, Ill.-G. D. Fuller.

${ }^{*}$ Winneshiek Bottoms. An extensive area along the Mississippi River bordering four states, namely, Iowa, Illinois, Wisconsin and Minnesota. Congress has authorized the acquisition of this territory as a Federal Reservation for the protection of migratory birds and fish. It is considered that it will be an important factor in contributing to the perpetuation of the migratory wildfowl for which the Mississippi Valley is an especially important highway.W. L. McAtee.

Valley of the East Fork of Fox River. (Richland County.) This area is designated for two reasons: (1) It probably contains a larger proportion of woodland and a greater variety of surface than any other near Olney; and (2) it is contiguous to Bird Haven, a preserve already privately established, though eventually to be for the benefit of the public.

The flood-plain of East Fork, averaging between $\frac{1}{8}$ and $\frac{1}{4} \mathrm{mi}$. wide, is bordered on each side by bluffs elevated about 36 ft. above the stream level, and broken by frequent lateral narrow valleys. Both bottomland and upland are well wooded in many places, and the growth, in certain parts, probably approximates as nearly to the original type as any within the county.

The special interest connected with 
this area consists in the fact that the variety of tree growth probably is not exceeded by that of any section of North America.

The area lies $2 \frac{1}{2} \mathrm{mi}$. north of the center of Olney, and is reached by several good roads.-Robert Ridgway.

The Valley of the Little Wabash River. (Junction of Richland, Clay and Wagner Counties.) Apart from its historical interest, including, as it does, the place where General George Rogers Clark crossed the Little Wabash with his little army undergoing almost insurmountable difficulties during his memorable march from Kaskaskia to Vincennes, this area is an important one from a biological standpoint, on account of the large number of distinctively southern plants which here reach the northern limit of their natural range.

Although the great part, both bottoms and uplands, has been cleared and the remaining woodland for the most part heavily culled, there remain limited a:eas of practically virgin forest, while extensive tracts have grown up with dense young forest.- Robert Ridgway.

The region adjacent to the mouth of White River in Indiana and Illinois. This area is of very special ecological interest, and in my opinion is decidedly the most important of any that I have in mind. The cypress swamps, occupying a considerable portion of "The Neck" immediately above the mouth of White River, represent a "survival pocket" of the flora of the ancient Gulf Embayment. A number of distinctly southern species occur or did occur here that seem to have disappeared from the area lying between White River and the mouth of the Wabash. Here the cypress reached its northern limit in the Mississippi Valley and attained a development comparable to that of the extreme south.

I do not know how much of this remarkable association is left, but I fear a large part of it has disappeared through clearing, drainage, and cultivation. There might still be found a fairly representative remnant.-Robert Ridgway.

"Bird Haven." (Richland County.) "A large variety of trees may be found within the limits of this small native woodland. The plants of "Bird Haven," a tract of 18 acres near Olney, Richland County, have been listed by the owner, Mr. Robert Ridgway, America's noted ornithologist. The list given shows how well the term "mixed hardwood forest" applies even to a small tract of the native forests of the Central States.

"Twenty-two families are represented and in addition, the white mulberry is growing spontaneously as an exotic in Bird Haven; it is thoroughly naturalized in Richland County.

"While Bird Haven is so well supplied with trees growing naturally these do not constitute all the native plant life of this small area. Probably no other forest area of Illinois has had all its vegetation so carefully and accurately listed as Bird Haven. Mr. Ridgway's detailed lists show the great variety of plant life to be found there. Of woody species growing naturally there were 60 trees, 17 shrubs and 12 climbers, a total of 89 native plants. In addition, other woody species native to Illinois have been planted at Bird Haven as follows: 13 trees, 6 shrubs, 3 climbers, or 22 in all making a total of woody plants of 111 species. To this number must be added a list of 227 herbaceous plants, growing naturally, making a grand total of 338 plant species accurately determined."From Ridgley's "The Geography of Illinois."

\section{Coniferous forests}

pUpland Shortleaf Pine Forest. (Union County.) About 200 acres ex. tending in a lengthwise direction along the bluffs facing the Mississippi River, known locally as the "Pine Hills." Elevation in places $800 \mathrm{ft}$. At one time these hills furnished some merchantable pine timber and the pine is likely capable of extension if fires are kept out. Fauna very much the same as that of the upland oak-hickory forests of that region. The wild Azalea is characteristic of these chert hills.

$14 \mathrm{mi}$. south of Gorham, Missouri Pacific or Illinois Central R. R.; $\frac{1}{4}$ mi. east from (w) Wolf Lake Station.R. B. Miller.

pWhite Pine Grove. (Ogle County.) The largest of the remaining native stands of white pine characteristic of the Rock River region, situated on Pine Creek. It has an area of 240 acres which might be extended by thinnings in the hardwoods and by natural regeneration tol 300 acres. Forest conditions are similar to those found in the New England white pine forests. Trees are about 75 years old, many of them being two ft. in diameter at breast height. Natural reproduction is now being prevented by the grazing of cattle. Pine Creek is a beautiful little stream with high bluffs fringed with juniper and its more level lands covered with black walnut.

5 mi. east of Polo (a); on the C. B. \& $\mathrm{Q}$. and the Illinois Central railroads.R. B. Miller. 


\section{Inland sand areas}

pHavana area. Close to Havana in Mason County on the eastern side of the Illinois River lies an extensive sand area. Several reports have been published concerning the biota of this region. The original vegetation was of three types, namely, prairie of the level flats merging into swamps, the sand prairie occupying the more or less pure sand ridges and dunes, and the comparatively recent forest types. The first of these original vegetative areas has now been mostly placed under cultivation by resort to drainage, but much of the two latter types remain almost in their original condition. In this region are still to be found most of the Illinois plants and animals living originally in sandy situations. The plant and insect life exhibits strong western affinities. These areas should be preserved.

Havana, about two mi. east, Devil's Hole.

Havana, about $10 \mathrm{mi}$. northeast, Devil's Neck.-T. H. Frison.

\section{BIBLIOGRAPHY}

Baker, F. C.

1910 The Ecology of the Skokie Marsh Area, with Special Reference to the Mollusca. Bull. Ill. State Lab. Nat. Hist., Vol. VIII, Art. 4.

Cory, C. B.

1909 The Birds of Illinois and Wisconsin. Field Mus. of Nat. Hist., Publ. 131 .

1912 The Mammals of Illinois and Wisconsin. Field Mus. of Nat. Hist., Publ. 153.

Cowles, H. C.

1901 The Plant Societies of Chicago and Vicinity. Bull. Geog. Soc. Chicago, No. 2 (also, Bot. Gaz., Vol. XXXI).

Forbes, S. A.

1913 The Midsummer Bird Life of Illinois; a Statistical Study. Bull. Ill. State Lab. Nat. Hist., Vol. IX, Art. 6.

Forbes, S. A., and Richardson, R. E.

1908 The Fishes of Illinois. Final Report Ill. State Lab. Nat. Hist., Vol. III.

1913 Studies on the Biology of the Upper Illinois River. Bull. Ill. State Lab. Nat. Hist., Vol. IX, No. 10.

Forbes, S. A., and Gross, A. O.

1921 The Orchard Birds of an Illinois Summer. Bull. Ill. State Lab. Nat. Hist., Vol. XIV, Art. 1.
Garman, $\mathrm{H}$.

1892 A Synopsis of the Reptiles and Amphibians of Illinois. Bull. Ill. State Lab. Nat. Hist.,

Gates, F. C. Vol. III, Art. 13.

1912 The Vegetation of the Beach Area in Northeastern Illinois and Southeastern Wisconsin. Bull. Ill. State Lab. Nat. Hist., Vol. IX, Art. 5.

Gleason, H. A.

1910 The Vegetation of the Inland Sand Deposits of Illinois. Bull. Ill. State Lab. Nat. Hist., Vol. IX, Art. 3.

Hall, R. C., and Ingall, O. D.

1911 Forest Conditions in Illinois. Bull. Ill. State Lab. Nat. Hist., Vol. IX, Art. 4.

Hart, C. H., and Gleason, H. A.

1907 On the Biology of the Sand Areas of Illinois. Bull. Ill. State Lab. Nat. Hist., Vol. VII, Art. 7.

Miller, R. A.

1923 First Report on a Forest Survey of Illinois. Bull. Ill. State Lab. Nat. Hist., Vol. XIV, Art. 8.

Mosier, J. G.

1918 The Climate of Illinois. Bull. IIl. Agr. Exp. Station. No. 208.

Ridgley, D. C.

1921 The Geography of Illinois. Univ. of Chicago Press. Chicago.

Ridgway, R.

1889-1895 The Ornithology of Illinois. Final Report Ill. State Lab. Nat. Hist., Vol. I and II.

Sampson, H. C.

1921 An Ecological Survey of the Prairies of Illinois. Bull. Ill. State. Lab. Nat. Hist., Vol. XIII, No. 16.

Shelford, V. E.

1913 Animal Communities in Temperate America, as illustrated in the Chicago region; a study in animal ecology. Univ. of Sherff, E. E. Chicago Press, Chicago.

1913 Vegetation of Skokie Marsh. Bull. Ill. State Lab. Nat.

Vestal, A. G. Hist., Vol. IX, Art. 11.

1913 An Associational Study of Illinois Sand Prairie. Bull. Ill. State Lab. Nat. Hist., Vol. X, Art. 1.

Wood, F. E.

1910 A Study of the Mammals of Champaign County, Illinois. Bull. Ill. State Lab. Nat. Hist., Vol. VIII, Art. 5. 


\section{IOWA}

\section{By L. H. Pammel}

\section{PHYSIOGRAPHIC CONDITIONS AND ORIGINAL BIOTA}

Iowa was originally an oak grove savanna state intersected by streams. The lowlands, bottoms, and adjacent hill slopes were in great part covered with deciduous trees. In order to understand its flora and fauna we must take into account the various drift sheets which covered most of Iowa.

The Kansas drift sheet covered the entire state with the exception of a little portion in northeastern Iowa and Dr. Kay now tells us that even this area did not escape the ice. The typical Kansas topography is well shown in southern Iowa in Henry and Monroe counties. The topography is much dissected, the surface features conforming to the drainage lines. There are large flat areas which before the advent of man were prairies. These areas conform to the original plane before erosion occurred. The soil consists of a blue boulder clay which is often quite compact. A clayey silt, loessial in character, veneers the surface. A second drift sheet, the Iowa, occurs in northeastern Iowa. This in Linn, Buchanan and adjacent counties is characterized by the numerous very large boulders. One of the largest of these in Floyd County near Nashua is perhaps the largest boulder in the Mississippi valley. There are many peat patches and the lakes, if any, are reduced to small ponds. The streams are shallow and the flood plain as well as the adjacent uplands were covered with a deciduous forest. There is little of topographic form. The hills are gentle and rise but little above the flood plain of the strears. There is very little erosion. The soil is a yellow calcareous clay veneered with sand and humus. The Illinoian drift covers only a small part of the state in the region of Burlington. The Wisconsin drift, the most recent of the drift sheets is charac- terized by its rolling hills. It extended into Iowa in the form of a great lobe entering the state in a southeastern direction in the western part on the Iowa Minnesota boundary a little west of the lake region in Osceola County, and on the east, at Clear Lake Cerro Gordo County, in a southwesterly direction to Polk County. This area abounded in lakes. Many of these have been drained. Some 50 of them still remain. Lake Okoboji, Spirit Lake, Storm Lake, Clear Lake, Silver Lake, Twin Lakes and Wall Lake are in the Wisconsin drift sheet. It is in this area that peat bogs are most numerous, some of them covering 300 to 400 acres. In such bogs occur typical northern bog plants like the swamp thistle (Cirsium muticum), bog willow (Salix pedicellaris), and beaked willow ( $S$. rostrata). The state was dissected by the following streams; the Des Moines, Little Sioux, Iowa, Cedar, Oneota and Skunk, all of which have their source in the lake region of the Wisconsin drift. The Little Sioux drains to the Missouri and has its source in the lake region of Dickinson County.

\section{BIOTA}

The greater part of the state was prairie and before extensive drainage began there were many sloughs especially in the Wisconsin drift sheet. In this area there is also much morainic material. On the shores of most of the lakes was a narrow fringe of deciduous trees and shrubs and the red cedar. (Juniperus virginiana). The timbered area around most of these lakes has been much reduced in size.

There are very few evergreens in the state. The red cedar has the widest distribution. This species extends all the way across the state, especially in the north. Not so far west in the south half of the state. White pine (Pinus strobus) occurred originally in small belts and isolated groves. Isolated areas of white pine occurred in Allamakee, Winneshiek, Clayton and Dubuque counties with a few isolated groves 
in Muscatine, Delaware and Hardin counties. The paper birch (Betula papyrifera) has a similar distribution. The cherry or gray birch (Betula lutea) is less abundant but with nearly the same distribution. The balsam fir (Abies balsamea) also occurs; there are a few groves in Allamakee and Winneshiek counties. The dwarf juniper (Juniperus communis) occurs in northeastern Iowa covering limestone rocks, Savin juniper ( $J$. horizontalis) the rarest conifer on a little knoll near Rockford, the Canadian yew (Taxus canadensis) chiefly in northeastern Iowa, to Linn County.

There are no strictly alpine plants in the state though such boreal plants as the white violet (Viola blanda), buck thorn (Rhamnus alnifolia) and aconite (Aconitum noveboracense) are associated with the balsam fir. Southern plants creep up into the state and occur at Muscatine and in Fremont County. Papaw (Asimina triloba), meadow beauty (Rhexia virginica), beech fern (Phegopteris hexagonoptera), redbud (Cercis canadenis) and sassafras are not common, only occurring in southeastern Iowa.

Western Iowa along the Missouri contains the Missouri loess with its typical Nebraskan flora like the western blazing star (Liatris squarrosa), woolly thistle Cirsium caneseus, Aplopappus spinulosus, Yucca glauca and Gaura coccinea. Of the important prairie plants mention may be made of the Iowa thistle (Cirsium iowense), prairie roses (Rosa setigera and $R$. pratincola), prairie clover (Petalostemum), wild licorice (Glycyrrhiza lepidota), Turk's-cap lily (Lilium superbum, L. Farlowii) slough grass (Spartina michauxii), and needle grass (Stipa comata). The alluvial lakes of the Missouri and Mississippi abound with the American lotus ( $\mathrm{Ne}$ lumbo lutea), also an abundance of the white lily (Castalia) and spatter dock (Nymphaea advena). The white lily and spatter dock as well as occasionally the water shield (Brasenia Schreberi) also occur in the inland lakes, the latter rarely as in Little Wall Lake.
The streams of the state as well as the border streams, the Mississippi and Missouri abounded in catfish, pickerel, sunfish and bass. The carp is an invasion and occurs in all of our lakes and streams. The streams for the most part are very much polluted. There are some trout in a few of the streams like the Maquoketa River. Wild geese and ducks of various kinds still abound, the former in migrations becoming rare. Ducks still breed in quantities. At one time wild turkey, prairie chicken, ruffed grouse and quail occurred in great quantities. The prairie chickens are now largely migratory. Red fox is still common in southeastern and northeastern Iowa. There are some wolves, probably mostly coyote. The cotton-tail rabbit was and is common everywhere. The western jack rabbit has moved eastward to central Iowa just as has the western meadowlark. The raccoon, opossum, and several species of squirrel, chipmunk, flying-squirrel and pocket-gopher, are some of the other animals. Virginia deer were once common but have become extinct. There is a naturalized species in Pottawattamie County. Beaver occurred in this state as late as the early seventies but are now exterminated. Elk occurred in all parts of the state but are also now extinct. Bison were once common on the prairies of northwestern Iowa. They were shot as far east as Dallas County as late as 1857 and also at Clear Lake, and in Kossuth County. Fine skulls have been found in Story and Clayton Counties. Black bear also occurred in Iowa at one time. The turtle dove is common and the wild pigeon was common in the late seventies. Vultures are not uncommon in southern Iowa. Many song birds like the meadowlark, eastern and western brown thrasher occur in abundance.

$$
\text { III. NAtURAL AREAS (L. H. P.) }
$$

Gitchie Manito Park. In the area (40 acres) is a pool of clear water known as Jasper Pool. There are a few trees like the green ash, basswood, elm, box elder, and on the Big Sioux river, cot- 
tonwood, almond-leaved willow, black willow, soft maple, rare plants for Iowa like buffalo grass, mesquite, prickly pear, flameflower, common prairie plants as woolly thistle, blazing star, purple flowered onion, asters and goldenrods.

Sioux Falls, $12 \mathrm{mi}$. southwest, C. R. I. \& P. C. M. \& St. P.

*Iowa River. (C3.) The meandering portion of the stream with its islands are a part of the park system of the state. Cottonwood, sycamore, soft maple, swamp white, bur and pin oaks, black, sandbar and almond-leaved willows, green ash, box elder, black walnut, mockernut hickory lower part of stream, American elm, cardinal flower, aster and goldenrod. American lotus, water lilly, spatter dock, wild rice, arrow head, rice cut grass, reed grass.

Iowa City, C. R. I. \& P., Cedar Rapids $\&$ Iowa City Interurban.

*Cedar River. (C3.) The meandering part of the stream a part of the park system. The meandered portion extends to Waterloo; cottonwood, American elm, almond-leaved, black and sandbar willows; green ash, soft maple, black birch, pin oak, swamp white oak, bur oak, honey locust, big or mockernut hickory, cardinal flower, rice cut grass, blue or greater lobelia, monkey flower, asters, goldenrods, etc.

C. \& Gt. W., Ill. Cent. Waterloo, C. R. I. \& P. Iowa City.

*Wapsipinicon River. (C3.) The meandered part of the stream extends into Jones County beyond Anamosa. Cottonwood, almond-leaved, sandbar and black willow, yellow birch, sycamore, pin oak, swamp white, bur and red oaks, American elm, black birch, dogwood, button bush, greater lobelia, cardinal flower, monkey flower, asters, goldenrods, rice cut grass, spanish needles, iris, wild rice, American lotus, spatter dock, Potamogeton, etc.

Anamosa, C. M. \& St. P. Ry., C. \& N. W. Ry.

*Wapsipinicon Park. (B2.) On the Wapsipinicon River; 168 acres adjacent to the City of Anamosa, limestone bluffs, caves and an abundance of fine springs.
Dutch creek flows through the tract; limestone bluffs rising 60 to $100 \mathrm{ft}$. from the flood plain of the stream; Iowan drift sheet. Raccoon, gray squirrel, quail, hawks, brown thrasher, Morning dove, humming bird, etc. Trees; white, black, red and bur oaks, sycamore, sugar maple, soft maple, hickory, blue beech, ironwood, yew, red cedar; Dutchmans breeches, Indian pipe, Virginia creeper, wild grape, poison ivy, bitter sweet, Solomon's seal, bladder fern, maiden hair fern, blood root, etc.

C. M. \& St. P. Ry., Anamosa.

*Iowa Lake. (C4.) Emmet County, native grove, bathing, banks high and well timbered; bur oak, slippery and American elms, basswood, pignut hickory, red osier, shiny leaved willow, red cedar, cottonwood, sand bar, beaked and almond-leaved willows, hepatica, blood root, wild rice, vallisneria, pond weeds (Potamogeton), arrowhead, skull cap, etc. Fishing.

Area 832 acres. Area in Minn. 478 acres, meander 433 ; in Iowa 354 acres, meander 308.

Armstrong C. R. I. \& P. Ry.

Dolliver C. R. I. \& P. Ry. Roads 9-43.

*Medium Lake. (C4.) Palo Alto County, area 991 acres, meander 945 acres.

Narrow fringe of trees, bur oak, green ash, cotton-wood, pignut, sand bar, almond-leaved willow, pond weeds, wild rice, water lily, spatter dock, etc.

Large variety of birds.

Emmetsburg adjacent C. M. \& St. P. Ry.

Highways 17-19.

*Twin Lakes, Calhoun County. (C4.) Two small lakes in Calhoun County, North Twin Lake with an area of 509 acres, meander encloses 569 acres.

Narrow fringe of timber of basswood, American and slippery elm, bur oak, box elder and red haws, acquatic plants like Potamogeton and marsh plants like Carex and Scirpus.

South Twin lake connected with the North Lake, a narrow strip of timber. 
Area of lake 596 acres, meander encloses 600 acres.

Adjacent prairie rich in prairie species, Iowa thistle, blazing star, gentians, goldenrods.

Rockwell City 4 mi. south. Ill. Cent. Ry. C. M. \& St. P. Ry.

*Farmington. (C3.) About 100 acres bank of Des Moines river, $\frac{1}{2} \mathrm{mi}$. south of Farmington.

Natural lake of 40 acres, covered with American lotus. Nearly all native species of oak; post, red, white, black, bur, chestnut, swamp, pin, black jack.

Farmington $\frac{1}{2} \mathrm{mi}$. north, C. B. \& Q. Ry. or C. R. I. \& P.

*Lacey-Keosauqua Park. (C3.). Van Buren County in the great horseshoe bend country of the Des Moines river.

Native wild animals red fox, quail, ruffled grouse, gray squirrel, cedar wax wing, whippoorwill, etc.

Trees; white ash, redbud, quaking aspen, sycamore, red cedar, shellbark hickory, pignut, almond-leaved, black and sand bar willows, red, white, swamp white, chestnut, post, shingle and bur oaks, cottonwood, soft maple, green and white ash, hackberry, basswood, slippery and American elm, red mulberry; shrubs; wild grape, black haws, sumach, bladder nut, dogwoods; of herbaceous plants, purple trilliam, columbine, dutchman's breeches, blood root, hepatica, mandrake, blue cohosh. In prairie opening blazing stars, gentians, goldenrods and asters.

Fine Indian mounds.

Altitude $600 \mathrm{ft}$.

Keosauqua adjacent S. C. R. I. \& P. Ry.

\section{Highway 11.}

*Eldora, Steamboat Rock and Pine Creek Area. (C3.) This area of some 200 acres lies in Hardin County. The most remarkable feature of the region is the peculiar island flora; the plants on the ledges or the talus at the base of the hills are of the boreal type. White pine, paper birch, gray birch, polypody, beech and marginal ferns.

Eldora adjacent, M. \& St. L. Ry., branch of C. \& N. W. Ry.
*Backbone Park. (C3.) Northwestern Delaware County, Richland township, embracing the flood plain of the Maquoketa River and hills adjacent, surrounded by a gentle rolling prairie, but park itself extremely rugged. The Backbone proper is a narrow ridge lying within a hook of the Maquoketa River. Limestone rocks rising 80 to $100 \mathrm{ft}$. above the river. Trees such as commonly found in northeastern Iowa with the exception of the white pine and the sycamore. The fauna is typical for northeastern Iowa. Richmond springs on the spring branch, a trout stream.

Strawberry Point, Clayton County 4 mi. northeast. C. M. \& St. P. Ry.

*Palisades, Linn County. (B2.) Some 140 acres of flood plain of the Cedar River and upland; mesophytic upland woods, vertical cliffs of limestone 30 to $50 \mathrm{ft}$. rising from the Cedar River. Rugged walls border this river for a distance of two mi. in the upper part on the east bank and the lower part on the west bank. Back of the Palisades are gently sloping hills. In places, however deep gullies slope toward the river.

Yellow moccasin flower, showy orchis, polypody, Woodsia, walking leaf fern, narrow leaved spleenwort, cancer root, cliff brake, Indian pipe are common herbaceous plants.

Animals; badger, opossum, raccoon, skunk, mink, fox and wolf, turkey vulture, ruffed grouse, quail, Acadian flycatcher, cardinal, phœbe.

$15 \mathrm{mi}$. southeast of Cedar Rapids, C. \& N. W. Ry. C. R. I. \& P. Ry. Ill. Central. C. M. \& St. P.

Lepley Park. (C4.) Area about 9 acres. Mature flood plain forest.

Station M. \& St. D. Ry. $1 \frac{1}{2} \mathrm{mi}$. north at Union.

Branch of the C. \& N. W. 6 mi. north at Eldora.

*Theodore F. Clark Park. (C4.) 25 acres just above a typical flood plain of Wolf Creek, a tributary of Cedar River, most of it not subject to overflow.

Typical mature mesophytic flora. 
4 mi. northeast of Traer, C. R. I. \& P. Ry.

*Ledges Park, Boone County. (B3.) 644 acres, partly in flood plain of Des Moines River and the adjacent clay uplands. Pease creek flow through the area exposing the Carboniferous sandstone, that rises to a height of 100 to $150 \mathrm{ft}$. Flood plain trees; Reindeer lichen, Juniper moss, pale vetch, pink lady slipper and moosewood.

Boone, 5 mi. east, main line C. \& N. W. Ry. Ft. Dodge Des M. \& So. Interurban Ry.

*Yellow River. (B3.) The whole valley from its source north of Postville has steep bluffs are covered with a mantle of trees. The most interesting are near springs about 80 acres. The plants belong to the boreal type. Balsum fir, white pine, small white violet, highbush cranberry, aconite and beech fern.

\section{Large springs.}

Postville 7 mi. south, C. M. \& St. P. R. R. C. R. I. \& P. Ry.

*Spirit Lake. (B2.) Largest lake in Iowa, in Dickinson County. 20 to 25 ft. deep, area 5660 acres, meander encloses 5884 acres, connects with Marble, Hottes and Little Spirit Lakes. Shores in part covered with bur oak, green ash, cottonwood, basswood, slippery and American elms, beaked, sand bar and almond-leaved willows. Morainic hills; prairie formation of asters, goldenrods, Iowa and woolly thistle, blazing star; in woods hepatica, blood root, prickly gooseberry, prickly ash.

Town of Spirit Lake one mi. south, C. M. \& St. P. Ry.

Orleans adjacent, C. R. I. \& P.

*West Okoboji Lake. (B3.) West Okoboji Lake is situated in Dickinson County. It is the deepest lake in Iowa, 40 to $129 \mathrm{ft}$., glacial origin, drainage to the Missouri river.

3788 acres, meander encloses 3939 acres.

Shores in part covered with trees, in part typical prairie plants. Outline of lake very irregular. Numerous marshes with many aquatic plants and birds. Lakeside Laboratory on Miller's Bay.

Milford 3 mi., C. M. \& St. P. Ry. Arnold's Park adjacent, C. M. \& St. P. Ry.

*East Okoboji Lake. (B2.) Glacial shallow lake, 5 to $12 \mathrm{ft}$. deep, connecting Spirit and West Okoboji, in Dickinson County.

Area 1875 acres.

Narrow fringe of timber; many aquatic plants like Potamogeton, Elodea, Vallisneria, wild rice, and pond lilies; small indentation marshes with Carex, manna grass, rice cut grass, greater lobelia and gentians. Fish hatchery grounds about 11 acres, on north end of lake.

Okoboji on south end of lake, C. M. \& St. P. Ry.

Orleans north end of lake, C. R. I. \& P. Ry.

Spirit Lake, C. M. \& St. P. Ry, C. R. I. \& P. Ry.

*Petersen. (B2.) About 200 acres in Clay County on the north slope of the Little Sioux River, some virgin oaks and black walnut, upland woods with canyons covered with spring beauty, blood root, blue cohosh, practically virgin, not pastured. The wooded slopes open out on the prairie with the usual prairie plants, a glacial valley.

Petersen one mi. north, C. \& N. W. Ry.

Highway No. 10.

*Natural Bridge and Morehead Caves. (B.) One of the interesting wonders of Iowa, in Jackson County. Vertical limestone cliffs 50 to $100 \mathrm{ft}$. high, area 35 acres. The ancient stream has worn a channel through the massive limestone rock leaving a natural bridge covered with white, red and bur oaks. The shady slopes covered with Sullivantia of ferns maiden hair and spleenwort. The Morehead caves can be reached by a path leading from the bridge. The narrow valley extends to the Morehead caves about a mile away to the south. Maquoketa $8 \mathrm{mi}$. southwest, C. M. \& St. P. Ry. C. \& N. W. Ry.

*Pilot Knob. Some 235 acres located 
in Hancock County, forming a part of a low range of hills standing out conspicuously from the surrounding country, an immense glacial moraine, the Altamont.

Knob $300 \mathrm{ft}$. above the valley of Lime Creek.

A small glacial lake near the top of the knob, Dead Man's lake with rare Brasenia.

Trees like the basswood, pignut hickory, black and green ash, bur oak, cottonwood, slippery and white elm, quaking aspen. Of shrubs hazel, wild grape, cornel.

Altitude $1500 \mathrm{ft}$.

Forest City $8 \mathrm{mi}$. west, M. \& St. L. Ry. C. R. I. \& P. Ry.

Garner 8 mi. south, C. M. \& St. P. Ry. C. R. I. \& P. Ry.

\section{MISSOURI}

\section{By A. C. BURrill}

\section{GENERAL FEATURES AND ORIGINAL} BIOTA

The State is divisible into three distinct regions, $(a)$ the northwestern upland plain or prairie region, $(b)$ the Missouri portion of the Ozark uplift, and $(c)$ the southeast lowlands, some $20 \mathrm{mi}$. wide and with an area of over 1000 sq. mi., part of an old flood plain of the Mississippi River and made up of alluvial deposits.

$a$. The prairie region embraces most of the state north of the Missouri River known as Northern Missouri, and a large tongue south of the river on the west side. This was originally covered with rolling plains of mesophytic prairie, with deciduous trees in groves along the countless "branches," creeks and rivers. The large streams have wide valleys, two to $10 \mathrm{mi}$. in breadth, which were originally occupied by rich flood plain forest. The valleys are cut through thick limestone and sandstone in the Missouri River section, and are steepest where the Burlington limestone outcrops-from Clark County in the northeast, south to Lincoln and western
St. Charles counties on the Missouri River and then west to Cooper Countyforming the Missouri River bluffs, then southwest to Polk and Cedar, where it divides southeastward to Taney County and southwest to Jasper and McDonald Counties.

This region originally supported the bison (Bison bison), elk (Cervus canadensis), Virginia and mule deer (Odocoileus virginianus and $O$. hemionus), wolf (Canis sp.), coyote (Canis latrans), prairie chicken, and other species characteristic of such regions in the Mississippi Valley.

$b$. The Ozark region crosses the Missouri northward at the center of the state and again crosses into Illinois below St. Louis in the Cape Girardeau County region. It is characterized by broad smooth valleys, well degraded hills with smooth summits and rough, tree-clad slopes, sharp deep canyons occasionally and rocky knobs in spots. Few localities have an elevation exceeding $1400 \mathrm{ft}$., but abound in water power, rapid mountain streams, rivers and springs clear to the south border, "The Shepherd of the Hills" country. The greater part of the Ozark region was originally forested with oak, hickory, cherry, tupelo black gum, red cedar, walnut, and shortleaf pine; little sugar maple.

Here the black bear (Ursus americanus), bison, Virginia and mule deer, opossum (Didelphis virginiana), raccoon (Procyon lotor), woodchuck (Marmota monax), red fox (Vulpes fulva), gray squirrel (Sciurus carolinensis), fox squirrel (Sciurus niger rufiventer), wolf, and wild turkey were once common.

$c$. The southeast lowlands were once wooded, chiefly, with cottonwood (Populus deltoides), oak, soft maple (Acer saccharinum), cypress (Taxodium distichum), tupelo gum (Nyssa sylvatica) and red or sweet gum (Liquidambar styraciflua). These trees are fast disappearing. Here, also were magnolia (M. virginiana), tulip tree (Liriodendron tulipifera), persimmon (Diospyros virginiana), sassafras (S. variifolium), and 
catalpa (C. speciosa), which overlapped the northern hardwoods.

1. The southeastern swamp regions inhabited by deer, bear, wolf, numerous turtles, frogs, muskrat, herons, and water birds. This is the only water moccasin (Agkistrodon piscivorus) country; fish were once abundant in all rivers and alligators rarely occur.

2. The Mississippi bluffs and bottoms north of this region need special mention; as important for their variety of nut, trees; for big game and fur animals; and for immense locust, willow, ash; sycamore, elm and other trees. Catfish five feet long are still caught in the main rivers and pearl-bearing mussels in clear stream beds, as in upper Mississippi and White Rivers.

\section{PRESENT CONDITIONS}

$a$. The prairie region is now the principal agricultural district and the most important blue grass region of the world. The original prairie vegetation may be seen in many localities along the railroads. Such timber as originally existed has been removed except for very small scattered holdings of black walnut. South and west the prairie broom sedge (Andropogon virginicus), marsh grasses, big and little blue stem (Andropogon furcatus and $A$. scoparius) are most characteristic of a winter landscape not touched by the plow.

The bison, elk, wolf, and deer have long since disappeared from this region. The prairie chicken is found only in a few remote localities where protected, e.g., Linn and Macon Counties. The raccoon, gray squirrel, and many quail still occur.

b. In the Ozark hardwood area, the merchantable timber has been largely removed leaving oak brush and parklike red cedar groves of small stature, but considerable areas of oaks, butternut, hickories, and persimmon remain in a natural state in the remote parts of the Ozarks; and in the southwest, pecans. Deer, wolves, and turkeys still occur. The region least modified is in the south central counties of the Missouri Ozarks where "prairie schooners" are commonly seen along roads and in the big towns, like Neosho. In the streams will be found bass, goggle-eyed perch, redhorse, and other game fish, and in the spring "branches," trout.

c. The southeastern portion of the state has lost most of its original timber and has even lost its recent small industry for dealers in frogs, turtles, water birds, snakes, etc.

$d$. Pollution of the larger streams is inevitable with the large cities along their banks. The Missouri is famed for its turbid water, which permeates the Mississippi some miles below their junction. The Mississippi is clear above the junction, yet the Missouri is said to be better cleared of disease germs by action of the muddy water. Unpolluted waters are Cedar Creek, Flat Creek, Crane Creek, Spring. River, Mt. Vernon Spring Branch, Bennets Spring Branch, Lake Hahatonka, Blue Spring Creek, Paydown Creek, Current River, Merimec Spring, Little Piney, Big Piney, Roaring River, Sugar Creek, Greer Spring Branch, and part of Eleven Point River.

\section{NATURAL AREAS}

\section{Fish and game and bird preserves just starting-1924}

Conservation has been largely at a standstill, but the laws now provide for buying state parks from game Department funds and four will soon open.

$a$. No game preserves are on leased second growth. The St. Louis game park in Taney County, $20 \mathrm{mi}$. south of Forsythe, Mo.; and the Van Cleave Park in Henry County, near Clinton, Mo.

$b$. Fish preserves are set aside at hatcheries in St. Louis, Springfield, and Neosho, Mo.

c. The areas set aside primarily as bird sanctuaries are very limited. There is a prairie chicken reserve in Baker and Locust Creek Townships, Linn County.

\section{Available areas representative of the prairie section (altitude 700 to $1100 \mathrm{ft}$.) of the state}

Prairie chicken prairies. (B4) 2. Several thousand acres of heavily grazed 
prairie, prairie chickens rare, occur on the watershed followed by the Wabash Ry. in Macon and Adair Counties. Grasses are tall red-top, Indian grass, slough-grass and blunt spike grass.

Atlantat, and La Plataf.-W. $T$. Robinson.

(C3 and D4.) Again, Baker and Locust Creek townships in northern Linn County have thousands of prairie chickens due to a twenty-years closeseason experiment. The prairie is mostly Kentucky blue grass and timothy now, the original grasses (Andropogon spp.) being rare.

Brookfield , Linn County, Mo., C. B. \& Q. R. R., Hannibal $\ddagger$ to St. Joseph Div.-W. B. McGregor.

Caldwell County forest and prairie. (A3.) 100 to 200 acres of land including a number of small tracts of original forests of the usual deciduous type of the region. Original prairie now rapidly vanishing. Some flood plain forest 6 to $10 \mathrm{mi}$. southwest of Hamilton, Mo., C. B. \& Q. R. R.-H. M. Fort.

Bottoms and brakes of the Missouri River. (C3.) Bluffs carved with limestone canyons of "branches" running 6 to $10 \mathrm{mi}$. up into the prairie back from the river; and among the rocks, rock lizards, ant-lion pit communities, snakes, quail, etc. Here occur oak, sycamore, bottom willows, ash, ridgeside persimmon and pawpaw.

9 to $10 \mathrm{mi}$. southwest of Columbia, Mo., on M. K. \& T. R. R.-A.C. Burrill.

3. Available areas representative of the hardwoods areas, or Ozarks

Forested north slopes of the Ozarks near Onandaga Cave. Altitude $1100 \mathrm{ft}$. (A2.) Oak hardwoods with red cedar surround this large cave which is reached on the Frisco $\mathrm{Ry}$. in Crawford County to the depot of Bourbon, then $3 \mathrm{mi}$. East; but detrain at Leasburg $\ddagger$ for auto service. Onandaga Park of 10,000 acres has a famous Blue Spring, a Bat Cave and a Cane Bottom where bears abounded.-A. C. Burrill.

pHa-Ha-Tonka Park and Cave. (A3 or C3.) Several thousand acres of forested hill-tops with red cedar on the bluffs. Mountain ravines, lakes, hills, and springs, semi-natural shrubbery along roadsides. Wild turkeys, deer, opossum, gray and fox squirrels, gray and red foxes. Ha-ha-tonka Cave in Camden County is a chief show-place with interesting fauna; lakes, springs, and rivers including bats, crawfish and cavefish. Follow the Big Niangua River in Dallas County from Lebanon or Marshfield on the Frisco Ry.-Altitude 900 to $1000 \mathrm{ft}$.
Versailles C. R. I. \& P. R. R.; go 40 mi. south (a) to it.

Lebanon Frisco Ry.; go $30 \mathrm{mi}$. north (a) to Ha-ha-ton ka\|.

Noel Tract (cave fauna and earliest Indian cave-dwellers). (C3) and (C4) or (D3). Several thousand acres of lightly forested hills and wonderfully carved limestone bluffs with earliest of Indian remains in middle United States, to include the lately discovered and perhaps largest Missouri cavern, Elk Springs Cave. Short leaf pine is common among hardwoods. Various spp. wood molds, cave myriapods and isopods, wasps, etc,. in these small caves.

Noel, Mo. K. C. S. R. R .;(a) or (w) one mi. northwest on Cowskin River.

pSequiota Tract and Cave. (Cave now preserved.) (C4 and D3.) The State Fish Hatchery and a quarry with the famous Sequiota Cave which is entered by wading or in flat boats with flash lights. The cave entrances swarm with mud dauber wasp nests and colonies. Close to the fish hatchery, a sizable stream gradually disappears in sinkholes in the curiously carved river-bed; accompanying fauna and flora interesting, as the many nests and trails of ants (Cremastogaster lineolata and Camponotus spp.). Altitude $1300 \mathrm{ft}$.

Springfield + , Mo., on Frisco and Mo. P. R. R. (Auto service) $9 \mathrm{mi}$. south by daily auto stage to fish hatchery, Green County, a good camping spot all summer.-A.C.Burrill.

Moreau River tract (C3, D4): Terminal moraine remnants. Cole to Morgan Counties. (C3.) (Available.) Several thousand acres of second growth woodlands and remarkably carved steep limestone bluffs along the Moreau River will make an excellent elk, deer and bird preserve, and now has an occasional coyote. The hilltops and river ridge tops are covered many feet deep with wind-blown loess from the Missouri River Valley bottoms many miles away. Excellent bird protection in winter and a prime migration study resort. Altitude 600 to $1100 \mathrm{ft}$.

Still higher elevations of similar formations can be studied to the west in Morgan County, for although the northeast part of the county is natural prairie, the rest to the southwest is natural forest of oak (bur and white), persimmon, pawpaw, and along the streams, sycamores. Skunks and, wolves are becoming numerous. Squirrels, prairie chickens, foxes and fur-bearers are numerous. Boyler's Mill south of Stover, Mo.-F. Dunlap and $H$.K. Welpman.

Jefferson City $\ddagger$ best center, auto 
service, and electric cars to cross the Missouri River bridge: reach by Mo. P. and M. K. \& T. R. R. main lines and C. \& A. branch line.-A. C. Burrill and T. Lueker.

Creve Coeur Lake Area. (A2.) Thousands of red-winged blackbirds, bronzed grackles, and a few rusty blackbirds join every evening in large flocks near Creve Coeur Lake, on sandy land overgrown with scouring rushes (Equisetum hiemale), broken over in autumn into a matted mass under which the redwings spend the coldest, windiest nights in perfect comfort, while the sand absorbs all rains. Altitude $460 \mathrm{ft}$. plus. Interurban from St. Louis or $17 \mathrm{mi}$. on C. R. I. \& P. R. R. to Vigua, Mo.A. C. Burrill and Otto Widman.

Caveland: Stone County Great Marvel and Little Fairy Caves: Lake Taneycomo. (A3 or B2.) (Partly proposed, partly available.) Stone County has two known and very beautiful caves only $2 \mathrm{mi}$. apart, steeply intersected topography.

Some virgin timber yet remains, of cedar, hickory and elm chiefly, but also black walnut, persimmon, pawpaw, hackberry, red-bud, buckbrush, ash, common dogwood, sumac, and black gum, while shortleaf pine occurs near Fairy Cave and mistletoe is rare. Deer, wolf, red and gray foxes, bobcat, opossum, and all fur-bearers occur along this grand White River country; wild turkey, great white heron and egrets, great blue heron, bittern, bald eagle and rarely the Golden eagle.

Great Marvel Cave (C4) is easy of access, charmingly located, and varied in structure; its Auditorium the largest cave room in the world, with the largest unsupported dome and with fine accoustic properties; its Gulf of Doom, awful and forbidding; its battery with a 100,000 bats; its great white throne of mammoth onyx stalagmite $8 \mathrm{ft}$ : high; and the cave fauna of its Mystic River, Lost River, No-Name River, Lake Genevieve and a waterfall $90 \mathrm{ft}$. high - blind fish, spiders, flies and wasps. Entered through a tangle of vines.

Fairy Cave (A2) is a smaller cave, almost as easy of access, but famed for the beautiful scenery in it, a jewel in varied colors and formations, in vaults $125 \mathrm{ft}$. high. Animal life in it is confined to three species of salamander and two or three of bats-one salamander with tiny specks, another dark green with like specks, five inches long, shy, fairly good eyes; and the famous white blind salamander (Typhlotriton spelaeus) are quite common, though found only in this region; the small brown bat, the large white species, and the long-eared species in less numbers. Centipedes, scorpions, an occasional diamond rattler, are reported in this region. Altitude 1000 to $1425 \mathrm{ft}$.-Leulla Owen and Waldo Powell.

Lake Taneycomo (B2, A3) 24 mi. long, formed by big power site dam on the wild White River scenery of rough hillsides and canyons. At the town of Branson on the lake, can be seen the magnificent curves of the beautiful White River walled in by steep cliffs and high bluffs, with kingfishers, spotted sandpipers, and green heron, etc., and all the rarer birds of the Ozarks mentioned under "The Wild Tracts of Pineries of the Current River." Of insectivorous birds, the nighthawk, chimney swift and six kinds of swallows abound; 5 woodpeckers including the red-bellied and six of flycatchers including the greatcrested and Acadian; 10 sparrows including the larkfinch; and in May a great variety of warblers (18), as the sycamore warbler and Louisiana water-thrush. The details of the distribution of the nearly 90 birds to be seen here of a May day are given by Widman (Trans. Acad. Sci. St. Louis, XXIV, no. 8: 70-77). Altitude $750 \mathrm{ft}$. and less.

Reach Fairy Cave on Mo. P. Branch to Reeds' Spring, Stone County, and (a) 5 mi. south to R. Waldo E. Powell Park and farm to cave; Gerber is one depot south of this and (a) or (w) $3 \mathrm{mi}$. S.W.; 2 depots southeast is Branson, Taney County, Mo., and (a) to Forsythe, Mo., at dam.-A.C. Burrill and Waldo Powell.

Roaring River and Chinquapin Formation. (A3 and B2.) River boils out of the base of a mountain and contains bass, and the yellow, blue and channel catfish. The trees include chinquapin oak.

Cassville on Frisco R. R. from Monett $\ddagger$ Mo. Altitude 1300 to $1550 \mathrm{ft}$. pMeramec State Park and virgin timber. (A3.) On the Burlington Escarpment foothills of the northern Ozarks 4700 acres for a park, 4050 being timber, the greater part virgin forest with 12 caves: Bat Cave has bats; Fisher cave; Bear Cave. Altitude 850 to $1100 \mathrm{ft}$.

Sullivan on Frisco R. R., Franklin County, is two hours by rail and three (a) from St. Louis. (W) $2 \frac{1}{2}$ mi. east (hotel; or farm houses in the park). E. T. Grether.

Greer Springs Area. (A3.) Heavily wooded southeast upper slope of Ozarks shows shortleaf pine, oak and much underbrush in mixture; black walnut, and hickories in the bottoms. Here gushes a large spring from the base of a small limestone ledge. Altitude 500 to $900 \mathrm{ft}$. 
Greer, Oregon County, Mo., by auto stage $15 \mathrm{mi}$. south from Winona Jnc., or $20 \mathrm{mi}$. NNE. from Thayer, both on the Frisco R. R., Springfield to Memphis Div. Go one mi. east of Greer. $-H$. A. Buehler.

Wild tracts of Current River. (B3 and B4 and C2.) (Available.) The best and most healthful of Missouri's shortleaf pineries. Many birds and mammals. Altitude 1200 to $600 \mathrm{ft}$.

Eminence $\ddagger$, Shannon County, Mo., on the Salem, Winona \& So. R. R. from Winona Jnc. on the Frisco R. R. (Memphis Div.); or Van Buren, Carter County, on the Frisco; or (a) to Montauk Spgs. $16 \mathrm{mi}$. from Salem on a branch of the Frisco (Springfield-St. Louis Div.) and $4 \mathrm{mi}$. west to cave; or Rolla on main line of Frisco, auto taxi to Licking, and $7 \frac{1}{2} \mathrm{mi}$. southeast to cave. $-D$. L. Bales, S. A. Cunningham and Jasper $N$. Williams.

\section{Available overflow lands; available areas representative of the Southern lowland type}

Overflow lands (C4 and $\mathrm{H} 8$ ) used to teem with ducks attracted to the giantleaved water plant or "Yorkapin," which furnished the ducks a sweetish edible nut. Altitude $290 \mathrm{ft}$.

Hornersvillef on the Deering Southwestern R. R. from Caruthersville (on the Mississippi Div. of the Frisco R.R.) and auto service.

Canada goose feeding grounds. (H8.) (Available.) In the flat overflow lands near Charleston, Mississippi County, there is some major attraction causing great flocks of Canada Geese to halt for weeks in their fall and spring migrations. Miles of willow lowlands and overflow mud flats. Altitude $327 \mathrm{ft}$. and less.

Charleston $\ddagger$, Mo. on Mo. P. branch of Iron Mt. Div.-R. Q. Brown.

Cypress swamps. (G7.) The few remnants of the cypress formation are available.

(A4.) The best is one at Cardwell, 7 mi. W. of Hornersville is on the St. Francois River. Catalpa, American holly and mistletoe on gum trees border cypress formations.

Frisco R. R. from St. Louis to Caruthersvilleł.-C. M. Edwards.

Sand Ridge. (D4.) Two healthful ridges, called East Prairie and West Prairie and Crowley's Ridges, penetrate in a southerly direction the former welter of swamps. Turtles are exceedingly numerous east and west of Dexter in flood bottoms. Numerous vines, sassafras, beetles, and red-backed bill bugs are epidemic in abundance.

Mo. P. and Frisco R. R. from St.
Louis, Charleston, Sikeston, Dexter, and Poplar Bluff.-A.C. Burrill.

Ridge. (D4 and E6.) (Available.) Where the clay ridges left from limestone bluff edges and hills meet the bottoms, a sharp transition often occurs. Cape Girardeau $\ddagger$ on Frisco R. R. $-A$. $C$. Burrill and W. E. Foard.

\section{Available areas in Mississippi bluffs and bottoms}

Mark Twain Cave Tract. (G7 and C3.) Little is left intact in the northern reaches of the Mississippi in Missouri save wooded islands changing with floods. The woods occur on most of the bluff line and become roughest along Cape Girardeau County where the Ozarks cross the river; and vicinity along the river is proposed as near a terminal city, with characteristic bluffs and bluff woods, willow, sycamore, ash, elm and soft maple.

Two mi. south of Hannibal, Marion County, Mo., reached by C. B. \& Q. R. R.-Madison Nelson and A. C. Burrill. Flood Plain Forest. (C3.) Altitude $380 \mathrm{ft}$.

Frisco R. R. Ste. Louis to Perryville Jnc. (Perryville or at Ste. Genevieve, Mo.).-A. C. Burrill.

Red cedar dominant Ozark forest type and in open groves at altitude 700 to 500 ft.; heavier woods are on Negro Fork or Big River.

De Soto, Mo. P. R. R., or auto stage from St. Louis direct to Hillsboro.A. C. Burrill.

Ten-mile Lake. (C3.) (Available.) Above lake 2 by $10 \mathrm{mi}$., is a resort of pelicans, water turkeys, white and blue cranes (herons) many turtles, and a great many species of water plants in the shallows.

The cypress brake once natural cypress lake now largely drained, is near at hand. Altitude $307 \mathrm{ft}$. and less.

Cotton Belt from St. Louis to East Prairie, Mississippi County, Mo.; $4 \mathrm{mi}$. southeast to $10-\mathrm{mi}$. Lake; $14 \mathrm{mi}$. SE. to cypress brake.-Repr. Carl D. Mitchell, E. Prairie, $M o$.

\section{LIST OF REFERENCES}

Daniels, F. P. 1907 The flora of Columbia, Missouri and vicinity. An ecological and systematic study of a local flora. Univ. of Mo. Studies Science Ser. Vol. I and 2, p. 1-319.

Uphof, J. C. Th. 1922 Ecological relations of plants in southeastern Missouri. Amer. Jour. Bot. 9: 1-18.

Robbins, W. J. 1921 Precipitation and the growth of oaks at Columbia. Missouri Univ. of Mo. Agr. Exp. Sta. Res. Bul. 44: 1-21. 
Owen, Leulla. Caves of the Ozarks and Black Hills (Notes on Missouri cave fauna). Out of print.

Widman, O. Ecological relations and distribution of birds (flocks and migrations). Trans. Acad. Sci., St. Louis, xxiv, No. 8, 70-77.

Moore, Geo. T. May, 1923 Missouri Botanical Garden Bulletin, Vol. XI, 5 (gives distribution of the 108 species of Crataegus).

Missouri Forest Trees. Mo. Agr. Exp. Sta. Bul. 98.

\section{OKLAHOMA}

\section{By H. H. LANE}

The state of Oklahoma has an area of 70,470 sq. mi. lying between the Red River on the south (at approximately $34^{\circ}$ north latitude) and the 37 th parallel on the north. The main part of the state, roughly a rectangle, extends from $94^{\circ} 30^{\prime}$ west longitude westward to the 100th meridian; to which the "Panhandle" adds a narrow extension, between latitudes $36^{\circ} 30^{\prime}$ and $37^{\circ}$, westward to the 103rd meridian. The northern boundary is about $470 \mathrm{mi}$. long, while the main portion of the state has a total length of $320 \mathrm{mi}$. and a maximum breadth (eastern boundary) of about $225 \mathrm{mi}$.

\section{TOPOGRAPHY}

The general surface of Oklahoma is a plain sloping gently toward the southeast, with the greatest elevation of a little over $4500 \mathrm{ft}$. near the northwest corner of the Panhandle and a minimum elevation of a little less than $400 \mathrm{ft}$. at the extreme southeastern corner of the state.

Four mountainous uplifts occur wholly or in part within the state, viz., (1) the Ozarks in the northern third of the eastern portion; (2) the Ouachita Mountains to the southeast; (3) the Arbuckle Mountains extending in an east-to-west direction for about $30 \mathrm{mi}$. in the southcentral part; and (4) in the southwest at a d stance of about $30 \mathrm{mi}$. from both the Red River on the south and the Texas line on the west, the Wichita Mountains, which extend southeastward for about $60 \mathrm{mi}$.
The Ozarks are an elevated plain through which the streams have cut deep, narrow V-shaped valleys. The broad, flat-topped hills standing between these valleys are treeless, and for that reason are locally termed "prairies," some of them so extensive as to have been given distinctive names. At the northeastern corner of the Oklahoma Ozarks the ridges attain their greatest elevation, $1150 \mathrm{ft}$. ; while in their southeastern portion they do not rise more than about $400 \mathrm{ft}$. a ove sea level. The individual hills in no case rise more than $400 \mathrm{ft}$. above their bases, and their average height is certainly not over $250 \mathrm{ft}$. The streams are characterized by the clearness of their waters and the rapidity of their flow; their bottoms are gravelly and they carry practicaly no mud. This region was formerly covered with deciduous forests, principally oak, with some pine in the southern part. The large timber has now been practically all cut off, leaving only the scrub, chiefly blackjack and post oak. The region is but sparsely settled.

The Ouachita uplift comprises the roughest surface in the state. Irregular weathering of the rock strata has resulted in the formation of many hills or mountains, of which Rich Mountain is the highest peak, reaching over $3000 \mathrm{ft}$. above sea-level and almost $2000 \mathrm{ft}$. above the streams which skirt its base. The whole Ouachita area is covered with a thick growth of timber, mostly pine and cedar. It is the most sparsely settled portion of the state, and the roads are mere trails, with few bridges over the streams. The majority of the inhabitants outside of the villages are Choctaw Indians. There are no railroads and life there now is as primitive as it was 60 years ago. Though there has been an invasion of lumbermen who have devastated the forests, Congress reserved nearly a million and a half acres of this timber land from allotment, and this portion remains a virgin wilderness and a welcome place of refuge for wild life of all kinds. This region is extremely rugged and along its in- 
numerable mountain streams are numerous cliffs which rise sheer from the water's edge to a height of 200 or 300 $\mathrm{ft}$., forming deep canyons through which the swift streams go dashing and plunging and foaming among the boulders.

The Arbuckle Mountains occupy an area of about $860 \mathrm{sq}$. mi. roughly in the form of a triangle, the base of which is toward the southeast. The surface of this region is in general a plateau sloping from an elevation of $1350 \mathrm{ft}$. in the west to $750 \mathrm{ft}$. in the east. It was originally a group of mountains which must have rivalled the highest of the Rockies in elevation and ruggedness, but weathering and erosion through the ages have worn away the peaks until only their bases are left to form the plateau. This surface in turn has been considerably dissected by erosion so that the streams flow through valleys of considerable depth. The most notable stream of this region is the Washita River which has cut a channel in a north-to-south direction, and in its lower course plunges through a narrow gorge in the limestone hills which rise $300 \mathrm{ft}$. above the water level.' All the streams of this region are clear and rapid, while many of them have numerous beautiful waterfalls. Sink-holes are frequent and some caves have been discovered and explored; none of the latter, however, possess the interest common to limestone caves in other states. The soil in this region is generally thin, sufficing for agriculture only in the valleys, though the hills afford pasture for stock. Transportation facilities are poor; the roads are mere trails and the population is sparse.

The Wichita Mountains extend in two parallel ranges a few miles apart from Fort Sill slightly northwest to Cooperton, a distance of about $60 \mathrm{mi}$. They are composed chiefly of a pink granite, except a rather extensive portion to the southeast which is largely made up of porphyry. Some of the peaks are rugged and rise to a height of 700 to $900 \mathrm{ft}$. above their bases. Their tops an 1 sides are generally washed almost or quite free of soil, though some of their valleys have sufficient soil to be farmed. The lower hill-tops are either bare or support a scant growth of trees. The greater part of this uplift is included in the Wichita National Forest ${ }^{1}$ and Game Reserve, comprising 61,644 acres, including a fenced-in bison range of 9760 acres.

The remainder of the state is rolling country. A strip 15 to $45 \mathrm{mi}$. wide, extending from the southeastern corner westward for about $170 \mathrm{mi}$., is a portion of the Gulf Coastal Plain and comprises all the state lying between the Red River and the Ouachita and Arbuckle Mountains. This is a rich farming area and is mostly under cultivation. The na'ive biota here is distinctly southern in character.

In the east central part of the state is th: Lower Arkansas River Valley Region, a narrow triangular be't with its base at the Arkansas state line and its apex at the eastern end of the Arbuckle Mountains. This is a highland plain through which the streams have cut rather broad; deep valleys, leaving the hill-tops broad and flat. A few isolated peaks rise above this plain to an elevation of $1500 \mathrm{ft}$. or more. Most of the hills are covered with scrubby timber and a good growth of native grass. The greater part of this region is too broken for agriculture, so that grazing and coal mining are the principal industries.

The Prairie Plains Region is a triangular belt running north of the Lower Arkansas River Valley to the west of the Ozarks. In general the 95th parallel forms its western boundary; the Kansas sta'e line its base; while its apex is on Muddy Boggy Creek about $20 \mathrm{mi}$. east of Ada. The surface slopes to the southeast in a series of escarpments with the gentler slopes to the westward. The soils are fairly deep and of moderate fertility, the native grasses furnishing a fine grade hay crop.

The Sandstone Hills Region is an elongated, fairly rectangular area bounded on the south by the Arbuckle

1 "National Forests of the Eastern District." 
Mountains, and extending in a general northerly direction to the Kansas line. Its boundaries are not everywhere sharply defined. The surface of this region is rough and the hill-tops are frequently capped with sandstone ledges some 300 to $400 \mathrm{ft}$. above the lowlands. The slopes are covered by sandstone boulders which render them unfit for farming. The valleys are rich and thickly populated, while the hills are sparsely settled.

The Redbeds Plains Region comprises the greater part of the central portion of the state from the Kansas line to the Red River and extending thence westward to surround entirely the Wichita Mountains. This is in general a slightly rolling plain sloping to the southeast. The streams are of the type common on the plains, where the shallow current flows in a small meandering channel back and forth across the broad shallow valley, deeply choked with sand. During most of the year the larger rivers, like the South Canadian and the Cimarron, are mere creeks with beds of deep and treacherous quicksand, though in early summer after the spring rains and the melting of the snow in the Colorado mountains, they become raging torrents often two miles in width which sweep every obstruction away in the mad rush of the water down-stream. The banks are formed by considerable areas of sanddunes, among which, here and there, occur ox-bow bayous (locally called "lakes") which mark abandoned portions of previous river-beds after the streams have cut new channels across the bends. Over most of this region the surrounding country never reaches an elevation of more than a hundred feet above the water level, and usually much less, wide areas being subject to overflow during times of high water. While over most of the Redbeds Plains timber, principally elm and cottonwood, occurs only along the streams, the extreme eastern portion supports a growth of scrubby blackjack oak. This was the first portion of the state thrown open to settlement, and the population is fairly dense and well established. Railroad facilities are good and the roads, while often mere trails, are in the main well graded and satisfactory for motor travel, especially in pleasant weather.

The Gypsum Hills Region is an irregular area lying to the west of the Redbeds Plains, and extending from the Kansas line to the Red River, including the southwest corner of the state. In general characteristics these two regions are similar. Among the "gyp" hills, however, the streams have generally cut deeper channels which, in the northern portion particularly, have the form of narrow canyons 200 to $400 \mathrm{ft}$. deep. The surface as a whole slopes rather rapidly to the southeast. Numerous ledges of gypsum (calcium sulphate) occur in the hills and the water in the streams is often so impregnated by the "gyp" in solution as to be most unpalatable. These streams, except the Washita, are typical plains streams with sand-choked channels and broad belts of sand dunes along their courses. The Washita carries much less sand and as a rule has steep mud banks. Agriculture depends upon the so-called "dry-farming" method and the kaffirs and other sorghums constitute the chief grain crops. In several localities there are large springs of salt water which emerge from the red rocks below the gypsum ledges, and, especially in the neighborhood of the Cimarron River, several salt plains occur, which in the dry season have the appearance of a heavy fall of snow owing to the whiteness of the salt which covers the surface to the depth of several inches, over 100 sq. mi. of territory.

The Sand Desert Region covers an area of 3000 to $4000 \mathrm{sq}$. mi. in the extreme western part of the state from the Texas line eastward between the Cimarron and South Canadian Rivers. This is region of dry shifting sand and sand dunes almost wholly devoid of trees or other prominent vegetation. It is utterly useless for any sort of agriculture and as barren as the Sahara.

The High Plains Region comprises all the rest of the state, including the 
northwest corner of the main portion and all of the Panhandle. The surface is a sloping plain which descends from an elevation of over $4500 \mathrm{ft}$. in the northwest corner, and has its surface cut here and there by the streams into narrow V-shaped canyons lying between the broad, flat-topped hills. While the soil is sufficiently fertile for excellent farming, the scant rainfall, which averages only 15 in. per year and is often much less, greatly restricts agricultural operations; hence the greater part of the region is in pasture and is but thinly settled. The north side of the Cimarron River in the Panhandle is bounded by the Black Mesa, a bed of volcanic lava, now standing high above the level of surrounding elevations and giving to the landscape a characteristic appearance not found elsewhere in the state.

\section{CLIMATE}

While in general the climate of Oklahoma is regarded as temperate it is characterized by many extremes of weather both of hot and cold, wet and dry. The usual seasonal changes in temperature, like those on the Great Plains in general, are great, ranging from at least $25^{\circ}$ below zero to $116^{\circ}$, or even more, above. Killing frosts may be expected in the northwestern part of the state in the first half of October, while they may be a month later in the southeastern portion. The latest frost in the spring may occur in February in the southern part, or as late as the last of April in the higher western and northern portions; one degree of difference in temperature, where conditions otherwise are the same, may be noted for each $65 \mathrm{ft}$. of difference in elevation. However, the heat of summer is very greatly modified, especially in the southern half of the state, by the influence of the Gulf of Mexico, and the nights are usually comfortably cool even in the hottest summer months. The average annual precipitation varies from 15 in. or less in the Panhandle and the High Plains Region generally to 45 in., or occasionally more, in the southeastern corner of the state. The rainy season includes the months of April to September, though July and August are frequently very dry, and occasionally the fall and winter months are marked by considerable precipitation. Snow-falls of a foot or more on the level sometimes are experienced in the northern sections, while the southern half of the state frequently passes the entire year without the fall of a single snow-flake.

The percentage of actual hours of sunshine out of the number possible averages about 50 in winter and about 65 in summer, while in July, August and September, it is usually 80 to 85 per cent of the possible hours. The prevailing winds are from the south. The tables of the United States Weather Bureau Station at Oklahoma City show, for a period of ten years, "a total of 132 months, that south winds prevailed for 94 months, southeast for 10 months, north for 25 months, northwest 2 months, and northeast 1 month."

A never-to-be-forgotten characteristic of the climate in Oklahoma is the great and sudden drop in temperature which occurs upon the approach of a so-called "norther" in the late fall and winter months. After a period of warm weather when the thermometer registers $80^{\circ}$ or more, say in November, with a light warm south wind, a leaden haze may usually be seen rising gradually above the northern horizon. After several hours the wind changes direction almost instantaneously and comes from the north with a velocity sometimes reaching $60 \mathrm{mi}$. or more per hour, bringing with it a drop in temperature of $50^{\circ}$ to $60^{\circ}$ within a very few hours. In fact, the present writer has seen the mercury drop $60^{\circ}$ in ninety minutes on such occasions, after which a further drop of several degrees may occur but more slowly. Woe unto man or beast caught out unprepared for the "norther!" There is usually little or no snow-fall in connection with these storms, though when such does occur it is apt to be especially severe, and the 
cold wind of high velocity together with the densely falling snow constitues the so-called "blizzard" which brings consternation to the stockmen and the traveller far from shelter. The writer has found stock frozen to death in such a storm within a hundred yards of shelter which it was unable to find through the blinding blizzard.

Destructive tornadoes are frequent in the spring and early summer months, though they may occur at any time of the year, and often appear to "play pranks" that are not usually credited by those who have not experienced their vagaries. In Oklahoma, a "still day" is so unusual as to be remarkable; any breeze that blows less than $10 \mathrm{mi}$. per hour is a "gentle zephyr"; on a "windy day" its velocity may be anything between 20 and $50 \mathrm{mi}$. per hour, while a destructive storm moves at a rate of 60 to $100 \mathrm{mi}$. per hour.

The months of October, November, December and frequently January, have usually the finest weather of the year; the spring months are frequently too wet for comfort; and the summer and early fall months too hot and dusty to be thoroughly enjoyable. Over the Great Plains Region sand-storms and dust-storms are frequent and most annoying during the dry season.

In short, the climate of Oklahoma has the charm of novelty-it is characterized by frequent changes-so that one does not have time to grow weary of a given variety of weather before a change ushers in something different.

\section{THE ORIGINAL BIOTA}

Ecologically speaking, the state of Oklahoma comprises at least four chief zones, to which possibly should be added a fifth to include that portion of the Gulf Coastal Plain that lies along the Red River south of the Arbuckle and Ouachita Mountains. This region is characterized by the presence of southern types of biota not occurring elsewhere in the state. Aside from this there are:

1. The Southern Coniferous Forest
Region of the Ouachita Mountains.

2. The Deciduous Forest Region of the Ozarks and the northeastern part of the state generally.

3. The Oak Grove Savanna Region extending thence westward across the entire state to the Redbeds Plains.

4. The Desert Grassland Region, which comprises the rest of the state. Local variations in these general regions are numerous and some of them of notable interest.

In the Southern Coniferous Forest Region of the Ouachita Mountain ; is to be found most of the still existing virgin forest land of the state. Here the original biota occurs in greatest abundance though several of the larger forms have been reduced by continual (and often illegal) hunting almost or quite to extinction. Among the larger carnivores were the cougar (Felis concolor group), black bear (Ursus americanus), gray wolf (Canis spp.), and bobcat (Lynx spp.). The smaller carnivores, such as the raccoon (Procyon lotor), skunk (Mephitis mesomelas), "civet-cat" (Spilogale interrupta), otter (Lutra canadensis subsp.), mink (Mustela vison subsp.), and weasel (Mustela sp.) were also common, preying upon the still more numerous cottontail and swamp rabbits (Sylvilagus floridanus alacer and $S$. aquaticus), gray and fox squirrels (Sciurus carolinensis and S. niger rufiventer), and various other rodents. Here too the beaver (Castor canadensis) and muskrat (Ondatra zibethica cinnamomina), as well as the otter, were once abundant, as was also the stupid opossum (Didelphis virginiana). The Virginia deer (Odocoileus virginianus subsp.) was probably the only native ungulate found in this region and it occurred in numbers that cannot now be estimated; it is barely possible that the mule-deer (Odocoileus hemionus) and elk (Cervus canadensis) originally included this area within their respective ranges. Among the birds, the wild turkey was present in almost unbelievable numbers, if we may trust the stories of old hunters, and they grew unusually 
large and fat on a diet of mast and grasshoppers. The passenger pigeon and Carolina paroquet are also worthy of special mention, while nearly or quite all the other species which were found in the Mississippi Valley were here either as migrants, or winter or summer residents. The reptilian life included alligator (Alligator mississippiensis which occasionally ascended the Arkansas and Red rivers; alligator-snapper (Macrochelys temminckii) and soft-shelled turtles (Amyda emoryi) which grew to large size and were probably common. Living in the streams with these was the cotton-mouth moccasin (Agkistrodon piscivorus), whose cousins, the copperhead (A. mokasen) and the timber rattler (Crotalus horridus) found suitable habitats among the rock crevices of the mountain sides. Under boulders and fallen logs, the coral snake secured satisfactory retirement and completed the list of venomous forms. Several species of harmless snakes also occurred here on land and in the water, in which also lived the bullfrog (Rana catesbeiana) and leopard-frog (Rana pipiens). Toads hopped over the rough gound and treefrogs sang in the water or from the tree-tops. A few species of ground lizards darted here and there from shelter to shelter or basked in the sunshine on boulder-top or log. In the streams large-mouthed black bass, various catfishes, the spoonbill, the garpike and the alligator-gar pursued their prey in comparative safety. The southern pines and cedar made up most of the timber growth, though there was a liberal sprinkling of oaks and hickories, the former producing the acorns relished by deer and turkey, the latter nuts for the bear, which also found an abundance of service-berries, wild huckleberries, and muscadines (Vitis rotundifolia). In general, the flora was the same as that of southwestern Arkansas.

The Deciduous Forest Region marked the western limits of many species both plant and animal, common in the more eastern sections of the United
States. Here were the sycamore, several species of hickory, the hackberry, several kinds of oaks, ash, papaw, persimmon and dogwood. Less abundant, perhaps, were the crabapple, hazelnut, beech, cucumber tree, smooth alder, chinquapin, water- and willowoaks. More abundant were the serviceberry, redbud and holly, the last of ten reaching extraordinary size. The original fauna included the black bear, the puma or cougar, bob-cat, gray or timber wolf, and the white-tailed and mule deer, as well as the wapiti or elk. Among the smaller forms were the opossum, raccoon, skunk, otter, beaver, woodchuck (Marmota monax), mink, weasel, muskrat, gray fox (Urocyon cinereoargenteus), and red fox (Vulpes sp.). The rodents also comprised the cotton-tail rabbit, flying squirrel (Glaucomys volaus saturatus), fox and gray squirrel and numerous smaller species. Among the birds, besides all the species common inland to the eastward, here was one of the last stands of the now extinct passenger pigeon, and, aside from Florida, this was perhaps the last stronghold abandoned by the Carolina paroquet. The wild turkey and the bob-white were exceedingly abundant, and waterfowl of all kinds were at least migrant visitors to its waters. The golden and bald eagles competed here for a livelihood with a dozen or more species of hawks and owls. Snipe and woodcock were common. The reptiles and fishes were species common to the eastern states and the Mississippi Valley.

The Oak Grove Savanna Region was remarkable largely because in it a few straggling eastern species found their western limits in competition with some western plains forms which had extended their range eastward. Mule deer were more abundant, the whitetail scarcely less so and the elk was not uncommon. The cougar and bob-cat, the gray wolf and the coyote, and the black bear constituted the list of larger carnivores. The smaller carnivores and rodents were as common as to the eastward with 
the striking exception of the woodchuck, which was probably never to be found here, and the flying squirrel was at least less common, occurring only in the larger timber which was confined to the vicinity of the water courses. The bird-life differed little from that of the regions previously noted, except that here the prairie chicken should be added to the list and the paroquet was absent. Wild turkeys and bob-whites were countless in number, hunters reporting that the former could frequently be found in winter covering the ground as thickly as they could stand in flocks acres in extent. Omitting the alligator and other distinctly southern reptiles, the cold-blooded fauna was the same as that in the other regions already discussed. The most characteristic plant form was the scrubby blackjack oak, together with the native grasses and wild flowers.

The Dry Grassland (or Steppe) Region with local exceptions, comprised the remainder of the state, and on account of its extent constituted the most characteristic ecological feature of the area under discussion. Here roamed the bison (Bison bison) in herds that numbered millions of head, moving northward or southward with the season; here too the pronghorn antelope (Antilocapra americana) flashed his signals in numbers too great to be counted, but thought by Nelson and others to have been no fewer than the bison; here also was the elk in many places only less numerous than these other two; while the mule deer probably outnumbered the white-tailed deer, both species were abundant. It seems almost impossible to exaggerate the numbers of all these animals. Indian traders still living maintain that as late as the middle 70's as many as 700 deer were actually counted by one man in the Osage country in less than a week's time! The carnivores were proportionally numerous. The cougar was so common even as late as the early 90 's that as many as two or three might be seen in a half day's drive from Norman to Oklahoma City. This is the exact spot where a century ago Washington Irving enjoyed the bison hunt familiar to readers of his "Tour of the Prairies." The gray wolf and the coyotes, in the poetic language of the native Indian, "were as the leaves of the forest," while the bob-cat constituted a by no means unimportant element of this fauna. The black bear was fully as common, and none of these species confined themselves to regions where cover was abundant; on the contrary they were as apt to be met with on the treeless plains as in the timber along the streams or in the rocky ravines and among the hills. The smaller carnivores, including those already mentioned as occurring in other portions of the state, were present here also, but reinforced by the badger (Taxidea taxus) whose holes punctured every hill-top; by the swift-fox (Vulpes velox), one of the swiftest and most graceful but least cunning of his tribe; and by the blackfooted ferret (Mustela nigripes), a bloodthirsty musteline which restricted itself almost wholly to the neighborhood of prairie-dog villages where it could secure an abundant and easy living. Among the rodents, additional forms worth mentioning include the prairiedog (Cynomys ludovicianus), just referred to, whose extensive villages or cities often covered miles of country, and the blacktailed jackrabbit (Lepus californicus melanotis) still to be reckoned among the conspicuous and characteristic elements of this particular fauna. The pocket-gopher (Geomys lutescens) and the kangaroo-rat (Dipodomys sp.), the woodrat (Neotoma sp.) and the thirteenlined ground-squirrel (Citellus tridecemlineatus ssp.) were other rodents not hitherto noted. Beaver, otter, mink, muskrat, and other fur-bearers were numerous, especially along the streams. The wild turkey, two species of the prairie chicken, and the bob-white occurred in great numbers. Flocks of turkeys numbering fully 3000 each were seen by hunters here as late as 1877, and General Sheridan in 1869 one night visited a turkey roost on the north 
side of the Canadian River in a grove of cottonwoods about three miles long, where thousands of turkeys were in the trees when the hunters arrived. This party killed over 200 and only desisted then because they already had far more than they needed or could take care of! Both the greater and the lesser prairie chickens were present not only in countless numbers, but were so tame that they could literally be "killed with a stick." On many of the "lakes" and streams waterfowl "darkened the sky" as they came and went. Plover and curlew, sandpipers, stilts and avocets were hardly less abundant. Sandhill and whooping cranes, swans, herons and ibises were too numerous to be taken account of. Among the rapacious birds were bald and golden eagles, Cooper's hawk, the sharp-shinned hawk, goshawk, red-shouldered, Swainson's, American rough-legged, ferruginous rough-legged, marsh, sparrow and red-tailed hawks, the Mississippi kite, and a number of owls. Among the latter the most striking species was the burrowing owl, that characteristic dweller in abandoned prairie-dog holes. Flickers of both sorts, including hybrid forms, the mockingbird, meadowlark, and scissortailed flycatcher were abundant. Vultures, both the black and the turkey, fed on every carcass. Crows, jays and ravens were everywhere. The groundloving sparrows and finches, the horned larks and other plains forms swarmed 'over the country, and here the now infamous cowbird undoubtedly adopted its parasitic habit of dropping its eggs in the nests of other birds, in order that, freed from the care of rearing a family, it might accompany the bison on its migrations. The reptiles included an occasional alligator in the Red River or the South Canadian, but the cotton mouth did not go far westward. Rattlesnakes of various kinds were plentiful, notoriously so among the prairie-dog villages. The most characteristic serpent of this region, however, was probably the bullsnake (Pituophis sayi) which grew to large size on the fat of the land. The interesting little horned lizard (Phrynosoma cornutum) shared the ground with the centipedes, scorpions and tarantulas, and feasted on the abundance of insect life, while in the hillier parts of this region the collared lizard (Crotaphytus c. collaris), or "mountain boomer," pursued his way in peace or basked in the sunshine on a rock ledge or boulder. Bullfrogs and leopard frogs vied in chorus with the palustrine treefrogs, while on the dry uplands the cognate toad (Bufo c. cognatus) relied for safety from its foes upon the camouflage afforded by the large splotches of color on its warty back. Tall grasses and weeds filled the river valleys, while the uplands were covered with bunchgrass and other native types; yucca and prickly pear were common, especially in the more arid places. Along the streams the elm with the large conspicuous bunches of mistletoe among its branches competed with the cottonwood and willow, while along the outer margins of the river valleys persimmons and pecans occurred in smaller numbers. The bodarke or Osage orange (Maclura pomifera) was widely distributed and every swale harbored clumps of plum bushes. Wild grapes wound their rope-like stems over bush and tree. In the spring the uplands were a variegated patchwork of prairie flowers, while later dwarf roses, lupines, evening primroses, and many other species too numerous to mention, dotted the landscape in every direction. No less than fifteen hundred species of flowering plants had their home in this region.

Such in brief were the conditions in Oklahoma before its settlement by the whites.

\section{THE PRESENT BIOTA}

But with settlement most of this was changed. In the words of one of the "Sooner" nature lovers, the late Frederick S. Barde:

The opening of Oklahoma to homestead settlement was as though the lightnings of heaven had fallen upon its wild 
life. Fires swept the country in all directions; armies of horsemen penetrated to remote places; wagons rumbled over the hills and down the valleys; there was a tumult of shouting and the roar of guns, and violence reigned, where until that day had been the peace of a primeval solitude. The slaughter had been begun.

Save for three or four small herds in captivity the bison had been exterminated at least fifteen years before "The Run;" the elk had disappeared at about the same time. 'The shameful story of the wanton slaughter of these animals, particularly of the bison, has been told too often and too well to merit repetition here. After 1889, the deer and pronghorn antelope, the black bear and cougar, the beaver and the otter, the wild turkey and the prairie chicken, and many other less conspicuous forms faded away. The last pronghorns were killed in the western part of the state in 1910. In 1917, Cross estimated the number of native wild deer (all whitetails) still in the state at not more than one hundred fifty and these were in the Ouachitas. Today the black bear can be found only in the Ouachita and the Wichita Mountains, and even in the latter may already have vanished. The cougar is now rare even in the mountain refuges, though occasionally one, or even a pair, impelled by hunger or the wanderlust, may revisit other parts of the state, as was the case in Cleveland County in 1917, when a pair of these fine cats spent a season there. The beaver exists now only in one or two private preserves in the western part of the state; the otter is gone; the mink is rare. The gray wolf is no longer common and is doomed to extinction since the farmers and ranchmen wage constant warfare upon him in revenge for the destruction he occasions in their herds and flocks. The coyote is probably holding its own, if not actually increasing in numbers. During the first few years that brought contact with the white settlers, the coyotes became acquainted with cultivated fields, domestic animals, traps, guns and poison bait. Their number decreased until the survivors learned caution and came to understand the ways of man. Now they are frequently considered more cunning than the fox. The present generation is well able to cope with the problems presented by a settled country; are graduates in the mastery of traps and guns; have a nose keen to detect poison; hence, combining boldness with cunning, are now sometimes observed within the environs of even large towns or cities. There is little probability of their eventual extermination. Bob-cats, though rarely seen, are still common in the timber along water courses and in the ravines and canyons oi the more rugged sections. The badger has become rare and will soon disappear forever; raccoons and skunks of several species seem to have adapted themselves fairly well to the new conditions. The opossum, for all its apparent stupidity and helplessness, is still abundant where conditions are favorable, and the writer has counted as many as eighteen in one persimmon tree when that fruit was ripe. The prairiedog, despite constant persecution, or possibly because of it, is extending its range slightly eastward, forming small isolated villages at least as far as Cleveland County. The burrowing owl is following it in this recent extension of its range. The rabbits-cottontail, swamprabbit, and jackrabbit-all seem to survive in plentiful numbers, perhaps partly because of the diminution of the carnivores. Other rodents do not appear to have suffered any loss in population, and some like the pocket gophers and ground squirrels are really serious pests in alfalfa fields.

The larger prairie chicken is probably extinct; while the lesser maintains a precarious hold only in the High Plains Region. Where formerly pelicans could be suen in flocks of 150 (South Canadian River, Cleveland County, 1907), now only occasional stragglers occur; the whooping crane no longer is to be found, and the sandhill crane is rare. Where once flocks of wild geese belonging to 
several species not rarely extended even for miles across the sky, it is now so unusual for the hunter to bag a goose that the event is likely to be chronicled in the local newspaper. Ducks, except on preserves, form only a pitiful remnant of the great flocks that were formerly common, though where given absolute protection, as in the Wichita Reserve, become numerous, tame, and even breed. The wild turkey is still fairly common only in the Ouachitas and a few other of the wilder sections of the state, though in flocks greatly reduced in size. The bob-white fluctuates from year to year, but is certainly gradually growing scarcer. The pileated woodpecker, the most regal bird of its family, is approaching extinction. The woodcock is a sparse denizen of the eastern part of the state, most of them occurring in the Ouachitas. The golden plover still passes through Oklahoma in its long spring flight from Patagonia to the Arctic, though it rarely tarries long enough to be observed. The curlew, once very common, is now rare, or in the case of one species gone altogether. The coot is very common, the loon and grebes rare, while the herons and ibises are only occasionally seen where formerly they were abundant. The robin and the dove are more numerous now than they were fifteen years ago, and the same is true of the brown thrasher, Bewick's wren and the bluebird. The Baltimore and orchard orioles are probably increasing, and the dickcissel vies with the lark sparrow for first place in numbers among the native sparrows. The western meadowlark and both the yellow- and red-shafted flickers are abundant, the latter two hybridizing generally throughout the central part of the state. Yellow-headed blackbirds are common migrants occurring in flocks often of a thousand or more individuals. Red-wings are abundant in river valleys and grackles and cowbirds are numerous enough to be real nuisances in many places. The cardinal and rose-breasted grosbeaks are common winter residents; the bobolink a rare migrant. The mockingbird and scissor-tailed flycatcher are conspicuous summer residents. The road-runner, or ground cuckoo, is a common resident in the western and southern parts of the state as far east as Cleveland County. Whitenecked ravens are residents in the High Plains Region, where in winter the Pinyon jay also occurs. The birds of prey are still to be found, though only a few species, like the marsh hawk, the sparrow hawk and the screech owl, can be called really common. The loggerhead shrike finds a plentiful supply of grasshoppers, sparrows and other smal' birds, and small rodents to impale upon the barbs of wire fences or the thorns of the bodarke or locust, and so is increasing. The vireos and warblers are abundant during the spring migration wherever there is sufficient foliage of trees to conceal them and to furnish a supply of insect food. The whippoor-will gives its mournful cry very commonly in the eastern timbered section of the state, while the western nighthawk, finding the roofs of city buildings safe nesting places, is very numerous on the plains. The chimney swift is increasing as more chimneys become available for nesting purposes, and the ruby-throat hums merrily about the great host of native and cultivated flowers. A bird that deserves especial notice in the leart tern (Sterna antillarum) that is now rarely found inland, being mostly confined to the coasts of the south Atlantic and Gulf states and southern California, yet which nests in Oklahoma upon the Great Salt Plain of Alfalfa County as well as on the Big and Little Salt Plains of the Cimarron.

Reptilian life was never so abundant as that of the mammals and birds, yet proportionately it has suffered just as great a diminution in many cases, except in the wilder portions of the state. Throughout the whole area under cultivation the rattlesnake, once common, has now become exceedingly rare. Harmless species, like the hognosed snake (Heterodon nasicus and $H$. contortrix), often inappropriately termed 
the spreading adder or viper, the bullsnake, the black snake (Coluber c. constrictor), the pilot snake (Elaphe laeta), the coach whip (C. $f$. $f l a-$ gellum), and the kingsnake (Lampropeltis), all suffer from the senseiess fear which leads most people to kill a snake on sight. The most interesting species of snake in the state is one which is rarely seen even by professional zoologists. This is the Texas blind snake (Leptotyphlops dulcis) taken by thewriter at Norman. It is a small worm-like burrowing species much resembling in size and general appearance a large angle-worm. Among the lizards, swifts (Cnemidophorus) and skinks (Lumeces) are common, the horned lizard is abundant, and the so-called "glass-snake" (Ophisaurus ventralis) not rarely seen. The collared lizard, locally called the "mountain boomer" and erroneously considered dangerously venomous, is characteristic of the rocky hills of the western half of the state. The alligator, which rarely ascends the South Canadian as far as Norman, is somewhat more frequently seen in the southeastern part of the state, though always as an occasional straggler. Turtles of a dozen species are common, ranging from the alligatorsnapper that may attain a length of shell of fully $4 \mathrm{ft}$. and a weight of 200 pounds, down to some of the terrapins and boxtortoises only 4 or 5 in. long. Bullfrogs are common and attain a maximum size in Oklahoma waters, which they share with the leopard-frog and treefrogs. In the eastern part of the state the arboreal hyla occurs, while on the plains only the palustrine species are found. The most common toad throughout most of the state is the cognate toad which with its larger size and bigger blotches of color is notably different in appearance from the more common species of the eastern states.

The Fish and Game Warden has recorded the following species of fish from the streams and "lakes" of Oklahoma, but the list is far from complete since almost no systematic search by ichthyol- ogists has yet been made. He names: large-mouth black bass, small-mouth black bass, rock bass, white crappie, black crappie (also known as calico or strawberry bass), pumpkinseed, green sunfish, bluegill, and "between 30 and 40 (sic.) other species or varieties of the sunfishes," yellow cat, black bullhead, brown bullhead, blue cat, big muddy cat, shovel-nose cat or spoonbill, the jacksalmon or pike-perch, the garpike and alligator-gar (the record specimen of the last named species for the state having measured $7 \mathrm{ft} .10$ in. in length with a weight of 196 pounds), and finally various minnows and suckers, not to speak of the introduced German carp.

The Ouachita Mountains are covered largely with longleaf, shortleaf, loblolly, and slash pine, with an occasional sweet gum and Hercules club. The Ozarks carry a growth of oak, hickory, walnut, elm and maple, with an occasional specimen of papaw and witchhazel, while yellow pine occurs on their southern peaks. In the western half of the state along the streams occur cottonwood, elm, hackberry, chinaberry, walnut, willow, dogwood, redbud, soapberry, boxelder and mulberry. In the far western part of the state the thorny mesquite is found both on the prairies and along some of the streams. On the sandhills blackjack, barren- and postoak, hackberry, hickory and sumac are to be found. Barde, writing in the game warden's report for 1912, says :

The flowers of eastern Oklahoma, from the Red River to Kansas, are astonishing in their variety and luxuriance. The violet, columbine, and Dutchman's breeches grow there, and the serviceberry whitens rocky hillsides with its early bloom. The dogwood, linden and redbud expand their dream-like clouds of pink and white from lowland to upland. Here are growths of holly a hundred acres in extent, with their perennial green. Some of these holly trees are of extraordinary size, being $40 \mathrm{ft}$. in height, with trunks as thick as a man's body. The Kiamitia [a portion of the Ouachitas] is an unknown land to the scientifie botanist. [The wild huckleberry] grows everywhere in the Kiamitia; 
the mountain sides are covered with muscadines, the juicy fruit often being as large as a Chickasaw plum.

The plains country throughout the spring, summer and fall, is a constantly changing panorama of flowering forms, too numerous to catalog here. The prairie rose crawls about over the ground; sensitive mimosas with their delicate lavender-pink flowers and finely compound leaves responding quickly to any touch, are attractive and curious: evening primroses, yellow or white, large or small, occur everywhere in season: buffalo beans, purple or yellow, are conspicuously attractive plants. When the wheat fields have been cut, the stubble is soon hidden by a luxuriant growth of coreopsis that makes them beautiful to behold. The tall spikes of the creamy white bell-like flowers of the yucca stand out here and there in the arid regions, while the rosy blossoms of the prickly pear that sprawls ungracefully over the ground are worthy a far better setting. In the fall the composites in all shades and colors and shapes cover the landscape.

The gypsum hills and the margins of the salt plains have each their own peculiar flora. Over most of the state ferns and other low types are conspicuous for their absence, though aquatic algae occur in all bayous and quiet waters.

In short, the observant eye will find much to interest and the imagination much to regret when contemplating the present biota of Oklahoma. Many of the changes have come about as the result of wanton destruction at the hand of civilized man; much with a little foresight could have been preserved, which is now gone forever, but by far the most farreaching changes are due to the inevitable effects of settlement, and could not have been avoided.

\section{NATURAL AREAS}

There are few legal preserves in Oklahoma. The Platt National Park, at Sulphur, has been "developed" as a "health resort," and very little of the natural remains. The Wichita National Forest and Game Reserve is mostly in its pristine condition. About 1,500,000 acres in the Ouachita Mountains was reserved from "allotment" and still remains the wildest and most natural part of the state. Other areas not reserved still comprise portions here and there in their original condition or nearly so.

\section{The Southern Coniferous Forest} Region. †Ouachita Mountains. †Talihina (population less than 1000), on St. Louis and San Francisco R. R., in Le Flore County, is in the midst of this region; go south or east $(\mathrm{h}) \boldsymbol{T}$.

2. The Deciduous Forest Region. Ozark Mountains. ¥Tahlequah (population 2271), on the St. Louis and San Francisco R. R., is in the southwestern part of this region; go east or north (h) or (a) if weather be dry $\uparrow$.

3. The Oak Grove Savannah Region. †Okmulgee (population 17,430 ) is situated within a typical part of this region, on the St. Louis and San Francisco R. R. Go in any direction (a).

4. The Dry Grassland Region. (a) For typical plains: $₫$ Enid (population $16,576)$, on Chicago, Rock Island and Pacific R. R. Go in any direction (a). (b) For †Arbuckle Mountains: go to $\ddagger$ Davis (population 1609), via Oklahoma City, on the Atchison, Topeka and Santa Fe R. R., then (a) about $12 \mathrm{mi}$. southeast to Crusher (village); then east or west (w), (h), or (a) §.

5. †Wichita National Forest and Game Reserve. Go through †Lawton (population 8930) on St. Louis and San Francisco R. R. about $15 \mathrm{mi}$. to Cache; take (a) to Reserve§.

6. Gypsum Hills. Go to $\ddagger$ Weatherford (population 1929), via Oklahoma City, on the Chicago, Rock Island and Pacific R. R., then 5 mi. northwest.

7. Sand Desert. From Kiowa, Kansas, go through $¥$ Woodward (population 3849 ) to Shattuck (population 1365), on the Atchison, Topeka and Santa Fe R. R., then west (a) 10 to 15 mi. .

8. Salt Plains. tGreat Salt Plains on the Cimmarron River: go to $¥$ Alva (population 3913) on the Atchison, Topeka and Santa Fe R. R. from Kiowa, Kansas, then (a) "across country" west by north for about $40 \mathrm{mi}$. I; a smaller salt plain, in Blaine County, is more accessible: go to ¥Watonga (population 1678), on the Chicago, Rock Island and Pacific R. R., from Enid, or Okla- 
homa City via Geary, and drive $5 \mathrm{mi}$. or more (a).

9. Black Mesa. Go to łGuymon (population 1507), in "Panhandle," on the Chicago, Rock Island and Pacific R. R., and then (a) overland nearly 100 mi. northwest $1 .-H$. H. L.

10. Arbuckle Mountains. (B3.) 860 sq. mi., 550,003 acres. A much dissected plateau, showing striking effects of erosion; a pre-Cambrian granite core surrounded by the later formations in series at various angles; prairie ridges and timbered valleys; clear, rapidflowing streams, with many beautiful waterfalls and springs, travertine deposited by algae; artesian wells and springs, charged with minerals. Elevation, 750 to $1350 \mathrm{ft}$. Arbuckle, Murray
County, Santa Fe R. R.-Chas. O. Chambers.

$A$ rendezvous and camp-ground of many geological students from the State University and elsewhere.

11. Kiamichi Mountains. (B3.) In Leflore County. About $100 \mathrm{sq}$. mi. or 64,000 acres, of rugged hills or mountains in the Ouachitas. Deciduous and coniferous iorests, bluffs and rocky situations, full of clear, rapid-flowing streams and wild rugged mountain scenery, very little disturbed by cultivation or lumbering; wild flowers more abundant than in any other part of the state; wild turkey common and wild deer occasionally seen. $500 \mathrm{ft}$. general elevation. Talihina, Frisco R. R. (h) 24 mi. east.-Chas. $O$. Chambers.

\section{E. States Chiefly Grassland or Desert Grassland}

The grassland and great plains area of North America extends from central Saskachewan to southwestern Texas with transitions from grassland to desert reaching westward into New Mexico and southward into Mexico in the valley of the Concias river and in western Chihuahua. Large areas occur in the Canadian provinces of Alberta, Saskachewan and Manitoba. The Dakotas are very largely of this type. It includes a small portion of western Minnesota and of Northwestern Iowa, and large areas in western Nebraska, Kansas, Oklahoma and Texas. Montana, Wyoming and Colorado have large areas of coniferous forest in their central or western parts but since this was largely treated under the various forest districts these states are included here.

\section{TEXAS1}

\section{By Alvin R. Cahn}

\section{GENERAL CONDITIONS}

\section{Topography}

Because of the great area of the state, together with its unique geographical position, Texas presents a region of great

\footnotetext{
1 I wish to express my appreciation to Drs. W. L. Bray, V. Bailey, and D. H. Wright for reading the original manuscript and for many constructive criticisms which have been embodied in the present article; to Dr. V. E. Shelford I am indebted for many suggestions which acted as guide lines in working up a great deal of material.
}

topographic diversity. For the most part there is a general and steady rise from the gulf coast northwestward, a rise which reaches its culmination in the great staked plains region of west Texas, an elevation of $4000 \mathrm{ft}$. A break occurs in this region, represented by the valley of the Pecos River, and the highlands, encircling this valley in the southeastern corner of $\mathrm{New}$ Mexico, reënter the state again as the mountain region of the trans-Pecos country. Here the highest altitude in the state is reached in the Guadaloupe mountains, where Guadaloupe Peak attains a height of $9500 \mathrm{ft}$. The slope is, therefore, from the northwest to the south and southeast. As would be expected in a large region containing such a diversity of elevation, surface conditions are exceedingly varied: Mountains occupy the trans-Pecos region; the Llano Estacado or "staked plains" are high, treeless grassland plains, extending into New Mexico from northwestern Texas; there is a great expanse of central hilly country, great prairie regions ; forest; hot arid desert; low swampy country, such as that along the gulf. Soil conditions vary as well, ranging from pure sand through gray and red clays to the harder limestones and great masses of igneous rock. In the desert and semi-desert country erosion plays and has played a most important rôle, and is responsible 
for much of the topography of the region, while in the sand areas, as the sand dunes of Padre island, the wind is all important, keeping the sands so constantly in motion that vegetation is nearly impossible.

\section{Climate}

As the topography is varied, so is the climate. Over most of the state the climate is mild, healthful and pleasant. The summers are very long, and, near the coast, at least, considerably tempered by the gulf winds. The winters are not severe except in the high northern portions, where the cold becomes intense. Thus at Brownsville, according to Greeley, a light frost (but a serious one!) occurs about once in four years, while at Amarillo, on the Staked Plains, a severe winter brings a biting cold and a drop to the neighborhood of $-20^{\circ}$. The entire state, except the extreme western portion, is affected during the winter months by severe and extremely sudden drops of temperature, known locally as "northers," during which spells a drop of $50^{\circ}$ or more within a very few minutes is common. Rainfall varies greatly, and is of great importance to the distribution of plants and animals, both because of its presence and because of its absence. There is a general decrease in rainfall from the east to the west. Thus the forests of the eastern limits of the state have an annual rainfall exceeding 50 in., while on the staked plains $15 \mathrm{in}$. is about normal. This decreases still more to the southwest, where from 7 to 10 in. is considered a "wet" year. Furthermore, it must be remembered that in some regions this precipitation is periodic, and this periodicity is again of importance. In Kinney County, in southwestern Texas, March, April and May have a total mean precipitation of only $1.1 \mathrm{in}$. out of a total of $23.4 \mathrm{in}$. for the year; Crosby County, in the northwest, has 1.9 in. during December, January, February and March; El Paso, in the extreme southwestern corner, has but 0.9 in. during March, April and May. It can be seen at once that such varied precipitation must have a profound influence on the biota, and we find, therefore, a gradation in the flora and fauna ranging from the southeastern conifer forest type to arid desert.

\section{ORIGINAL BIOTA}

From an ecological viewpoint, Texas, the largest state in the Union, is of primary interest. Within the 265,896 sq. mi. of territory which compose it lie conditions of great diversity. This diversity is due not so much to the size of the state as to its geographical position, its varied climate and diversified topography. Within its boundaries faunistic and floristic elements of east and west, of north and south meet and overlap, producing a biotic complex probably exceeded by no other state. This complexity is further increased by the extension of the major floristic divisions-encroachments one upon another -producing a great variety of local conditions that are certain to confuse the ecologist unless he is aware that such conditions are mere local aspects of a larger unit. Such local conditions are well illustrated in the mesquite semidesert of southern Texas, and in the Rio Grande succulent desert, where local aspects of other larger units are found as extensions up river valleys. Throughout the state there is a beautiful transition from the southeastern coniferous forest with its rainfall of over 50 in. annually to the desert conditions of the trans-Pecos, with an annual rainfall of less than 7 in., and a similar transition from the low marshes of the gulf coast to the mountains of igneous rock in the Guadaloupe range. Due to the fact that Texas has such a large area, coupled with a population that is scattered, there once was much big game within its limits, and a considerable amount still remains, though in constantly decreasing abundance.

In the following discussion an attempt has been made to divide Texas into its natural ecological areas, based on floristic composition as outlined by Shreve and by Bray, and to correlate with these 
areas the animal distribution as outlined by Bailey. This latter part of the task has been particularly difficult, because of the lack of exact and sufficient information as to the limits of distribution of the animal life of the state, but such data do not exist.

\section{Southeastern coniferous forest}

This is an area of some 6000 or more sq. mi. of territory in eastern Texas, which is the western limit of a great band of forest that extends westward into Texas from the Atlantic coastline of South Carolina. In Texas it is separated from the coast by the coastal prairies, which are the western limits of a similar area following eastward through Louisiana along the gulf coast. The western limit of the area is approximately at the Trinity River, while to the north and northwest it blends off into a transition area, the Oak Grove Savanna. It is the region of greatest rainfall in the state, the precipitation exceeding 50 in. annually. Topographically, it is a region of rolling sandy ridges, the Fayette sands, which in itself is an important ecological factor in the floral distribution. The characteristic tree of this forest is the longleaved pine (Pinus palustris), whose deep, penetrating tap root is best suited to such soil. This tree is found in pure stand where abnormal conditions (such as fire and lumbering) have not overthrown the balance. The undisturbed forest is one of open formation with practically no woody undergrowth, carpeted with grass and low herbs, as the conditions are xerophytic for shallow rooted plants. The region is transected by local Bottomland forests (Bray) which follow the wide channels formed by the Sulphur Fork of the Red River, the Sabine, Neches, Trinity and the San Jacinto river systems. It also includes a part of the loblolly pine (Pinus taeda) forest (of Bray) which reaches its climax in the Big Thicket of Hardin County. In the Bottomland forests we find hickories, oaks (white, post, bur, red, Quercus alba, Q. stellata, macrocarpa, rubra) elms, bays, gum, haws, holly and ash, while in the Loblolly forests we find as dominants the loblolly pine, gum, magnolia, with subdominants of holly, waterbeech (Carpinus caroliniana), hornbeam (Ostrya virginiana), dogwood (Cornus florida), witch-hazel (Hamamelis virginiana) and others.

The animal life is typically that of the coniferous forest of the Mississippi valley. Here we find the eastern rattlesnake (Crotalus horridus) at the extreme western edge of its range, and barely extending over the limits of the conifer forest into the transition area to the deciduous forest. Among the squirrels, the western fox squirrel (Sciurus niger rufiventer) and the gray squirrel (Sciurus carolinensis) are here in abundance, overstepping into the aforesaid transition area in eastern Texas as the red and white oak and hickory extend into this area. The same may be said of the Florida flying-squirrel (Glaucomys volans texensis) and the pine-woods deer mouse (Peromyscus gossypinus megacephalus). The Louisiana harvest mouse (Reithrodontomys fulvescens aurantius) covers eastern Texas and is also typical of this region, pushing its range toward the coast, where it enters the coastal prairies, living in the tall grass at the edge of the woods-a local extension of its range. To this region belong also the raccoon (Procyon lotor), Virginia deer (Odocoileus virginianus texanus), black bear (Ursus americanus) and bob-cat (Lynx rufus texensis), these species have a range considerably outside of the conifer forest, due to extensions up the river bottoms where the wooded conditions and the presence of abundant water make these extensions possible.

Local conditions. As local conditions we have within the coniferous forest areas of cane breaks on bottomlands, within which black bears are to be found. The longleaf area is dotted with low patches of hardwoods, known as "hammocks," characterized by holly, etc. 


\section{Temperate deciduous forest}

The deciduous forest, which is characteristic of the Mississippi valley region, extends into Texas from the northeast corner of the state, and continues southwestward in a constantly narrowing band as it grades into the savanna of live and post oak which separates the typical deciduous forest from the mesquite semi-desert region farther to the south. The northeastern half of the deciduous forest must be considered as a transition area between the southeastern coniferous forest and the oak grove savanna. In this transition area the longleaf pine gives place to the shortleaf pine (Pinus echinata) which, however, has been largely cut over, replacement being for the most part by post oak, which extends westward into the pure deciduous forest and oak grove savanna. Throughout the region the pine occurs in conjunction with various species of oak (post, red, white) together with hickory, maple, beech, ash and elm. The rainfall of the region is somewhat less than in the coniferous forest, being between 35 and 45 in., while the soils are essentially extensions of the more eastern lignitic formations, though these soils extend beyond the western limits of the pine, the latter being held down by the deficiency in rainfall.

The animal life is represented by the remnants of the main body of the deciduous forest species to the north and east, this arm of the forest bringing these species down into Texas. Most of the species are, however, represented by more southern varieties of the northern animals. Here we have the Virginia deer, gray fox (Urocyon cinereoargen'teus subsp.), cottontail rabbit (Sylvilagus floridanus alacer) and the opossum (Didelphis virginiana). The region is further populated by the western extension of the range of many of the species common to the coniferous forest, as already mentioned. Thus we get also the red fox (Vulpes fulva) which, though not native to Texas, has been successfully introduced into the conifer forest region and has spread its range into the deciduous forest.

Local conditions. The westward and southwestward extensions of the deciduous forest is broken by oak grove savanna on the sandy soils of the lignitic belt. The uplands of the lignitic belt originally tended to run to short leaf pine, but with its (artificial) removal, place was given to the oak grove savanna.

\section{Oak grove savanna}

The oak grove savanna is, like the deciduous forest, a southern arm of a more extensive northern area, which reaches southward into Texas from the Red River region in a constantly narrowing wedge. (This is true particularly in the case of the upper and lower cross timber; locally, as in Llano County (granite area) broad stretches of oak grove savanna are found.) The region is in reality practically split by the tip end of the deciduous forest projection where soil conditions have rendered the extension of this type of forest possible. Thus we have an area of oak grove savanna lying entirely along the western border of the deciduous forest, and a second area separating the forest from the coast, as the Fayette sands extension of the region. The oak grove savanna must, within Texas at least, be looked upon as a sort of transition area between the deciduous forest and the grassland regions, and is the region in which the various forests of the Atlantic woodland type open out into the steppe country. Again the rainfall is less than in the preceding forest types, being approximately 30 in. in both divisions of the grove. On its western border the oak grove savanna thins out, and much grassland appears within the grove, while on the eastern border it merges with the deciduous forest. The dominant trees are the post oak (Quercus minor), and the black hack (Q. marilandica), with white and black oak (Q. velutina) as sub-dominants. West of approximately the $97 \mathrm{th}$ meridian the areas of grassland increase both in 
number and in proportions, and one finds a good carpet of grass with xerophytic annuals replacing the scrub undergrowth.

This region marks the western limit in Texas of the Virginia deer, but the species is not abundant in the savanna. The prairie spotted skunk (Spilogale interrupta) comes into Texas from the savanna to the north and it is found pushing its way westward into the grasslands where local conditions of country and vegetation permit. Here also ends the range of several cottontail rabbits, the raccoon (following up local aspects of the heavier forest regions) and the squirrels, previously mentioned, of the Atlantic woodlands. One animal can be cited as characteristic of that part of the oak grove savanna which we have mentioned as being cut off by the deciduous forest. In that portion of the savanna lying along the coast we find the gulf spotted skunk (Spilogale indianola) whose range is entirely within the savanna, being cut off and isolated here by the heavy timber to the north and the mesquite semi-desert to the south.

\section{Coastal Prairie}

This is a relatively narrow band of territory projecting southward along the coast of Texas, wedging itself in between the coniferous forest and the Gulf of Mexico. Geologically, it is new land. It is the westward extension of the region of the Mississippi delta, and reaches southwestward into Texas approximately to Matagorda Bay and the mouth of the San Antonio River. It is a region of little drainage and considerable rainfall (from 35 to 50 in.) and is so low that a considerable part of it is practically a brackish water meadow. Along the coastline itself this merges into marsh conditions, which are scattered all along the gulf. The region is practically treeless except for a narrow strip of transition between the prairies and the forest to the north and west, and is characterized by the presence of a rich, grassy vegetation composed of moisture-loving species. This is particularly true over the eastern two-thirds of the area, where the rainfall is in excess of 40 in., while the western third is marked by the dominance of species demanding less moisture as the area pushes southward toward the semi-desert country. The dominant species are the water grasses, broom sedges (Andropogon spp.) panic grasses and emersed aquatic plants. Marsh grass (Spartina sp.) is abundant, as is, locally, the dropseed (Sporobolus sp.).

It is not surprising to find within this isolated and cut off region a number of species of animals whose range does not extend beyond the very limited confines of this highly differentiated area. The Florida opossum (Didelphis virginiana pigra) is typical of the region, and is closely confined to it. It is unknown south of Matagorda Bay, and its range extends north and east following the coastal prairies along the coast. The small mouse (Peromyscus taylorn subater) a very dark race, is confined to the dry coastal prairies north of Matagorda Bay, and is unknown from any other region. Here it lives under the rich carpet of grasses in the open country, with habits that remind one of those of a meadow vole (Microtus). Associated with it is the Louisiana vole (Microtus ludovicianus), also confined to the dry prairies. The rice rat (Oryzomys palustris texensis) is confined to the marshes of the coast region, and is very common throughout the wet areas, as is the swamp woodrat (Neotoma floridana rubida) whose range, however, has an extension northward into the "big thicket" of Hardin County. Closely confined to these marshes one finds also the coast swamp rabbit (Sylvilagus aquaticus littlralis) which extend out only to enter the big thicket where local conditions are similar to those of the coastal marshes. The typical swamp rabbit (S. a. aquaticus) inhabit the bottomlands of all streams of eastern Texas. 


\section{Grassland}

The great plains region, referred to locally as the "cattle country" because it is the great grazing range of the state, is a region of grassland. It is the southern extension of the vast temperate grassland country lying to the north between the Mississippi valley and the eastern slope of the rocky mountains, and occupies a vast area in north central Texas. To the eastward it is met by the diminishing oak grove savanna which merges imperceptibly into it; to the south it meets the Rio Grande succulent desert to which it is bound by the northward extension of the great mesquite country of southern Texas, while its western boundary is the great Llano Estacado. It is a region of perennial sod grassland with a mesquite (Prosopis glandulosa) overgrowth. It is a region of greater elevation than any of the country to the east, rising from approximately $1200 \mathrm{ft}$. to nearly $3000 \mathrm{ft}$. The latter figure is the elevation at the western extremity of the region, from which the semi-desert broken steppe (the staked plains) rise to an elevation of $400 \mathrm{ft}$. The annual rainfall averages about 20 to 25 in., but this rain is periodic: ordinarily a wet spring and early summer, followed by a dry late summer and fall, and a cold, dry winter. Ecologically, the mesquite element is important as it must be regarded as an invasion from the Rio Grande desert, and its extension is followed by floral changes which profoundly alter the typical grassland conditions. The mesquite invasion is followed by conspicuous changes in the grass composition, the so-called "bearded mesquite grass" eventually excluding the plains grasses because of its greater shade tolerance. This is followed by the appearance of other woody species, as the lotebush (Zizyphus) until the open country is covered by a dense growth that proves of serious economic importance. From the faunal viewpoint, the mesquite is also of importance, as we find a number of animals, such as the Baird wood rat (Neotoma micropus) and the Texas diamond rattlesnake (Crotalus a. atrox) extending their range from the typical mesquite semi-desert of the south clear up into the northern portion of the plains region, following very exactly the distribution of the mesquite. Such invasions are confusing until one recognizes the fact that again they simply represent local conditions.

This is the region of the once great herds of bison. Today it is the haunt of the gray wolf (Canis grisseus) or "lobo" of the cattlemen. The kit fox (Vulpes velox) is found here, as is the coyote (Canis spp.). It is the home of the prairie-dog (Cynomys ludovicianus) which formerly inhabited the region in countless millions, but which is now rapidly on the decline. Here they dug their "towns" over great areas of sandy soil. The black-tailed jackrabbit (Lepus californicus subspp.) is abundant over the plains, and is found in local extensions of the grassland on every side. Of particular interest is the distribution of the Richardson kangaroorat (Dipodomys ordii richardsoni) in this region. This species enters Texas from the plains to the north, and in its distribution it completely and exactly encircles the staked plains, and by so doing the species marks very well the western limit of the grassland. It inhabits only sandy country, and extends its range down river valleys when the type of soil is suitable.

\section{Temperate desert grassland}

This is the region known throughout Texas as the Llano Estacado-the staked plains. It is a region of considerable elevation averaging around $3500 \mathrm{ft}$. but reaching $4000 \mathrm{ft}$. in places. It is a high, arid, open steppe, that is characterized at once by the almost total absence of trees. Rainfall is never in excess of 20 in. and often fails to reach 15 in. The conditions are, therefore, much more xerophytic than in any of the series of regions which lead up to the plains from the east. The area lies west of the 101st 
meridian, and is bounded on the east by the extensive grassland country just discussed, while the western boundary is the Rio Grande succulent desert represented by the valley of the Pecos River. This valley pushes up a considerable distance into New Mexico, but eventually the staked plains encompass it on the north and reënter Texas again as a long, slender arc extending into the desert of the trans-Pecos region, then recognized as the trans-Pecos plateau. It is conspicuously a "short grass" country both in reality and from a comparative point of view. Here we find such plants as Bouteloua, Hilaria, Muhlenbergia, Bulbilis, etc. The grasses are dwarfed because of the xerophytic conditions, and are of the type composed of short, narrow leaves which show a marked inclination to curl, due to the excessive transpiration. These grasses are fine as compared to the much coarser grasses of the lower steppes and grasslands and, whereas the latter is so luxuriant as to completely hide grazing cattle (where over-grazing has not been practiced), the grasses of the staked plains are rarely knee high. The landscape is therefore a monotonously rolling one. When this formation reënters Texas in the trans-Pecos region, the same unbroken fields of short grass characterize it. Thus the Davis mountains present a picture of unbroken grass vegetation up to approximately $5000 \mathrm{ft}$., with some xerophytic oak forest in some places above this altitude, with occasional western yellow pine and limber pine, while the upper slopes and summits -especially the upper canyons-must be considered as islands of forests, largely of Rocky mountain type.

The animal life is typically steppe species, and we find here extensions of the prairie dog towns, and the western boundary of the former range of the bison. The Pronghorn antelope (Antilocapra americana) was formerly common here, but is now nearly gone. Several animals show an interesting distribution in this area. A map of the distribution of the pale ground-squirrel (Citellus tridecemlineatus pallidus) shows it to be confined absolutely to the top of the staked plains, and there is no evidence of the species coming down below the general topmost elevation of the region. This is quite different from the distribution of the Richardson kangaroo-rat which is characteristic of a position just intermediate between the staked plains and the grassland at its feet: the species completely encircles the plains, giving a good intermediate contour of the region. Here likewise, closely confined to the dwarf grasses, is the rattlesnake (Crotalus molossus), found only in the Guadaloupe and Davis mountains at the topmost margin of the plains at $6800 \mathrm{ft}$.

\section{Mesquite semi-desert}

This is the region characteristic of the lower Rio Grande valley in southern Texas. To the eastward it extends to the coast, and to the west it follows in a general way the broad valley of the Rio Grande, reaching approximately the mouth of the Devils river, where it encroaches upon the succulent desert of the Pecos and trans-Pecos region. It is a low area, reaching its highest elevation about $1000 \mathrm{ft}$. near the mouth of the Pecos. The rainfall is light over the entire region, being normally about 20 in. Formerly this region was mostly open grassland and mesquite, but now it is overgrown with succulent plants of the prickly pear (Opuntia) type, and the grasses have been largely replaced by shade-enduring species. Where the open grassland prevails we find the plains type of grasses represented by such genera as Bulbilis, Bouteloua, Muhlenbergia and Aristida, with a relatively limited assortment of sand-loving annuals. Throughout the region the dominant tree is the mesquite (Prosopis glandulosa) and associated with it are such typical species as the black persimmon (Brayodendron texanum) hulsache, lechuquilla (Agave lechuguilla) and the creosote bush, though it must be recognized that both the mesquite and the creosote bush extend their range far beyond the limits of the semi-desert. 
The mesquite has a wide range throughout southern Texas, and extends west as well as north beyond the region of typical semi-desert country. The northern extension takes the mesquite a long way into the grassland country, but here it is no longer associated with the other dominant semi-desert species. To the westward, however, the situation is somewhat different. The semi-desert tends to invade the succulent desert for a considerable distance up the valley of the Devils and Pecos rivers, and up the valley of the Rio Grande a short distance beyond the mouths of the Pecos and Devils rivers. Plotting the distribution of the trees above mentioned as associates of the mesquite, together with the mesquite, we find these typical semidesert forms carrying the formation well into the realm of the succulent desert as two arms: one short Rio Grande arm around the mouth of the Pecos River, and a longer arm reaching up the valley of the Pecos. Beyond this they give place to the true succulent desert dominants.

Among the animal forms we find here several reptiles that are typical: the long-tailed holbrookia (Holbrookia propinqua) is confined very closely to this region, and is also an inhabitant of Padre Island, the sand dune region across the tidal flat from the mainland. The horned toad (Phrynosoma cornutum), is abundant here, though this is probably an extension of range from the succulent desert. The western diamond rattler is confined to the region and is typical of it. A map of its distribution shows that it follows out the extensions of the mesquite-persimmoncresote-bush country both northward and up the valley of the Pecos and Rio Grande. The same may be said of the Texas armadillo (Dasypus novemcinctus texanus) though its range exceeds the limits of the region. The Texas opossum (Didelphis marsupialis texensis) likewise is found here, following up the Rio Grande as far as the mouth of the Pecos, but to the north it oversteps the limits of the area. Here also are the Texas grasshopper-mouse (Onychomys leucogaster longipes) and the Texas deer-mouse (Peromyscus leucopus texanus). The ocelot (Felis pardalis ablescens) and the Rio Grande spotted skunk (Spilogale leucoparia) follow very closely the distribution of the mesquite in the region.

\section{Rio Grande (Eastern) Succulent Desert}

This is the real desert region of Texas, a great expanse made up mostly of the valley of the upper Rio Grande, Pecos and Devils rivers. The vegetation is scanty, and occurs most typically not in these valleys but on the arid plateau, the bolson basins and the foothills or the slopes of isolated mountain groups. It is an area of loose sandy soil extending to the base of the mountains, where the debris of erosion is so loose and mobile that anything like a close plant formation is impossible. The vegetation is conspicuously open with no crowding of species nor competition for light and space. The landscape is typically a gray-white color due to the soil cover of eroded limestone. The white glare of this soil as one traverses the region on the Southern Pacific is most trying. The rainfall is very scant, from 7 to 10 in. and often less. During an excessively wet season the grass tends to increase, but never does it approach a grassland formation. The characteristic desert species of plants may be grouped into four gene, al types:

1. The cactus type: represented by approximately 90 species.

2. The yucca-agave type: represented by about 15 species.

3. The dwarf shrub type: represented by approximately 50 species (greasewoods, mimosae, etc.).

4. Miscellaneous: such as the rock ferns, resurrection plant (Selaginella lepidophylla), dry plains grasses (Hechtia) and a number of desert compositae.

- These may be grouped into two classes from the point of view of adaptation:

1. "Those in which a marked development of storage tissue results in unusual 
forms of plants" (Bray). This embraces the cactus-yucca-agave types.

2. The absence of storage (succulent) tissue, and the assumption of a dwarfed condition as a defense against the extreme arid environment.

The animal life of the region is replete with forms typical of the desert, and there are many forms which are closely confined within the limits of the area. Among the reptiles we find the Texas holbrookia (Holbrookia texana) as a very typical desert lizard, its range extending only into the Pecos arm of the mesquite desert. The horned toad ( $P$. cornutum) is abundant in the arid regions, but this species is at the present time showing marked tendencies to extend its distribution northward, exhibiting a wide range of adaptability. In the very arid regions the whip-tailed lizard (Cnemidophorus $t$. tessellatus) is characteristic and abundant. Among the mammals, the gray mule deer (Odocoileus hemionus canus) is closely confined to the area, and the black-tailed deer is common. The Texas antelope squirrel (Ammosperimophilus interpres) shows an interesting distribution, being typical of the succulent desert; the eastern limit of the region marks the limit of the squirrel, and the species does not encroach at all upon the extensions of the mesquite desert. It is confined to the Rio Grande valley and is barred to the eastward by the Pecos. The Pecos River muskrat (Ondatra zibethica ripen$s i s$ ) is found in the local extensions of the mesquite of the semi-desert, while the broad-tailed beaver (Castor canadensis frondator) is found, though not commonly, from the Devils river and the Pecos down the Rio Grande as far as Brownsville. The desert cottontail rabbit (Sylvilagus audubonii subspp.) is a common animal of the open country, and the range of the species extends northward into the grassland and steppe region, where the species frequently uses the holes of the prairie-dog for its habitation. Among the canyons of the Rio Grande and its tributaries an occasional cougar (Felis concolor group) is found, and these animals cause serious loss to stock breeders. The "civet cat" (Bassariscus astutus flavus) is very common over most of the region, and is a characteristic form in the area.

\section{Xerophytic coniferous forest}

This region, the country of the junipers and the pinion, is best represented in the state by a series of "islands" isolated from one another as the tops of the mountains of the trans-Pecos region. Thus we find in the extension of the semidesert broken steppe country that injects itself into the heart of the succulent desert, three distinct areas of semidesert coniferous forest, represented by the Guadaloupe, Davis and Chisos mountains. A comparison of the flora of these three regions shows that, while each has a flora characteristic of itself to a certain extent, there are certain forms that are common to all of them. Of these we can list the following: bull pine (Pinus ponderosa), mountain sugar maple (Acer grandidentatum), Quercus grisea, Prunus (serotina?), Rhamnus purshiana and Symphoricarpos (longiflorus?). Comparing in a similar manner the mammalian fauna of the three regions, we find again certain species in common, namely: the Mexican wood rat (Neotoma mexicana), the mountain cottontail (Sylvilagus robustus) and the black bear (Ursus americanus). Among the birds we can list a dove (Columba fasciata), a woodpecker (Melanerpes formicivorus), a hummingbird (Trochilus alexandri), a vireo (Vireo solitarius), a tanager (Piranga hepatica), and a nuthatch (Sitta carolinensis nelsoni). These species are all co-inhabitants of the regions above $6000 \mathrm{ft}$. at which level the short grasses of the broken steppe give place to the vegetation of the semidesert forest type.

Among the other animal forms that must be considered as characteristic of the region we can call attention to the Sonora deer, which ranges in the mountains at an elevation of 5000 to $9000 \mathrm{ft}$., usually in close association with the oaks and junipers, as the species depends on 
the timber for cover. Therefore the species is isolated within a relatively narrow range. Here also is the bighorn sheep (Ovis mexicana) found locally in the Guadaloupe and Chisos mountains where it is confined to the high altitudes. The gray-footed chipmunk (Eutamias cinereicollis canipes) an inhabitant of the Guadaloupe mountains above 6000 ft., is found ranging upward from this elevation along with the western yellow pine and the Douglas spruce.

\section{PRESENT BIOTA}

The original biota of the state has been profoundly modified by many agencies, many of which are directly due to man, and it is doubtful if any region has entirely escaped this human interference either directly or indirectly. Agricultural development has led to a great modification of both prairie and woodlands. Lumbering in eastern Texas has caused profound changes in the forest aspect, and these changes are all of them bound to increase. Fires have swept the original timberland, and the effects of this on the undergrowth and the natural re-forestation and succession has been profound. Over-grazing has greatly influenced the prairie grassland conditions, and the luxuriant growths of former days is no longer present in many of the regions, leaving practically denuded ranges. These factors and others of a similar nature have greatly altered conditions, and have led to the introduction of vegetation types not native to the region originally. With the advance of civilization has come of course profound changes in the wild animal species of the state. Many species have been exterminated, others have been reduced to a pitiful remnant of once great herds. As would be expected, the big game has suffered most. The great herds of bison are gone; the gray mule deer of the transPecos country is on the decline; the pronghorn antelope still clings uncertainly to isolated regions in the great plains, but is practically gone; the elk, which straggled over the northern region, is gone, and the bighorn sheep is still holding out in regions among the Guadaloupe mountains, but is almost exterminated. The jaguar, once common in east and south Texas, is gone except for a very rare individual; the ocelot clings to the wooded areas of south central Texas, but is nearly gone. Bears of various species are still locally fairly common, but it is a question of time only until they too will be reduced to hopeless remnants. Deer, raccoon, opossum, otter, mink, skunks, and rabbits are still plentiful in their native haunts. Among the birds a similar condition exists. The wild turkey is nearly gone-entirely gone over most of its former range-and the same may be said of the heath hen, roseate spoonbill, egret, cranes, etc. The southern pileated woodpecker is going-along with its native forests, and the ivory-billed woodpecker has preceded it into the past. Quail-both Mexican and bobwhite-are still abundant, but the slaughter of these birds is such that it can only be a question of time before they too are brought to a serious condition.

IV. AREAS AVAILABLE FOR PRESERVATION AND STUDY

As has just been pointed out, man has wrought great changes in Texas, these changes being coincident with the progress of civilization and of course were inevitable. Yet the changes that have occurred are only a beginning, and greater changes still must come. Nothing we can do will bring former conditions back again, but it is in our power to preserve for future study certain typical areas within which the changes have been minimal. All of the regions listed herewith under the heading of Texas are still practically untoucheduntouched except for such changes as must invariably accompany the driving of railroads through the wilderness, etc. Native animals are still present, fine timber still stands if timber was present, and may still be said to be in essentially a primitive condition. These 
areas are, then, still in a natural state, and are likely to remain so for some years to come.

\section{NATURAL AREAS AND STATE PARKS}

\section{a. State parks}

1. Washington Park. (C4). At the old city of Washington on the Brazos River, formerly capital of Texas. This park was established by an act of the Texas legislature in 1916, and with the $\$ 10,000$ that was appropriated, 50 acres of land on the river was purchased. The park commemorates the signing of the Texas Declaration of Independence at Washington on March 2, 1836.

At present the park is inaccessible, but good roads are in project, and will open the park to travelers in the near future. Mr. R. E. Pennington, of Brenham, Texas, will gladly furnish information concerning the park, as Mr. Pennington is one of the commissioners.

2. Goliad State Park. (C4.) Established in memory of the Texas hero James Fannin, and commemorate the massacre of Fannin and some three hundred Anglo-Americans by the Mexicans near Goliad on March 27, 1835.

Information may be obtained from Mr. William Seeligson, Goliad, Texas, one of the park commissioners.

3. San Jacinto Slate Park. Commemorates the battle of San Jacinto on April 21, 1836. It is the largest and best developed park in the State, comprising 275 acres. The roads through the park are in good condition, of shell, and markers point out where different incidents in the course of the battle occurred. Part of the park is on very low ground, sloping to the Chocolate Bayou and San Jacinto River.

Information may be obtained from the keeper, Mr. W. C. Day, at Deer Park, Texas.

4. Gonzales Park. (C4.) Forty acres at Gonzales, Texas. In very fine condition, and is one of the most beautiful spots in Texas.

Mr. J. W. Rainboldt of Gonzales will furnish information.
5. King's Park. (C4.) Is situated just in front of the court house in the historic city of Refugio. It is in beautiful shape. The park commemorates the loss of a party of Texans under Captain King in 1836 at the hands of Mexican soldiers under Unea.

Mr. J. T. Vance, one of the commis. sioners, will furnish any information.

\section{b. Wild life preserves}

1. Laguna Madre Islande. At present Texas has only one wild life preserve, that being a group of islands known as Three Islands, and North and South Bird Island and adjacent flats and reefs in the Laguna Madre on the Texas coast. These islands have been leased for a term not to exceed fifty years to the National Association of Audobon Societies. These islands are the abundant breeding grounds for the following species of birds: laughing gulls; terns: royal, Caspian, Cabot, gull-billed, common, black, least, Forster; black skimmer, Mexican cormorant, brown and white pelicans, reddish egret, Louisiana heron, ward heron, black-crowned night heron, white heron, etc.

\section{c. Available and proposed areas}

1. The Lake Caddo Region. (A2.) An immense swamp association, located in Marion and Harrison counties, on the Texas-Louisiana line. Includes the west half of Lake Caddo, and Cypress Bayou which enters it. About $25 \mathrm{mi}$. long (from east to west) and from 3 to $10 \mathrm{mi}$. wide. A mixture of eastern and western forms. One of the wildest and most natural areas in the entire state. Abundant aquatic life of every description. Reptiles and amphibians abundant; a perfect, natural bird sanctuary, sheltering egrets, wood ducks, ibis, wild turkeys, pileated woodpeckers, and other interesting forms. Contains deer, various cats, and other large mammals. Alligators abundant. May be reached from the City of Jefferson. No one should attempt this region without local assistance, as getting lost in the vast swamp might well be fatal. One of the most ideal game preserves in the United States, and the first region in Texas that should be set aside for a National preserve. Elevation: about $175 \mathrm{ft}$. 
Jefferson, near Caddo Lake. M. K. \& T. Ry. to Jefferson. $-A . R$. $C$.

2. A smaller swamp association that is easily accessible from the City of Palestine. (A2.) Lying in Freestone and Anderson counties. It has a typical swamp flora and fauna; ideal location for avifaund studies. Abundant blackbird colonies and very large crow roost. Elevation: about $500 \mathrm{ft}$.

I. \& G. N. to Palestine.-A. R. C .

3. Big Thicket Swamp Association. A large area of swamp association. A place of considerable interest as it contains fresh water as well as brackish and salt water associations. Land very low, with abundant plant and animal life. An interesting locality for the study of fishes. A wonderful breeding ground for birds and the winter home of hundreds of thousands of ducks and geese that are now subjected to an unmerciful slaughter. Elevation: very little above sea level.

Lies in Chambers County and is accessible from either Liberty or Galveston. Big Thicket, near Liberty. T. \& N. O. Ry. from Houston.

4. Another ideal swamp association, quite similar to No. 3, lying in Brazoria County, just north of the mouth of the Brazos River. If the mouth of the Brazos River be included, then all three types of aquatic environments will be found. A fine location for an ecological study of fish and aquatic insects. The preserve should include the mouth of the Brazos River, and extend some $8 \mathrm{mi}$. northward along the coast, to a depth of about $3 \mathrm{mi}$. At this point the Brazos River forms an impassible barrier to many species. Elevation: little above sea level to $30 \mathrm{ft}$.

Easily accessible from Freeport at the mouth of the river.

5. A coastal region, lying in Nueces and Kleberg counties. (B2.) This region should include, Mustang, Bird, and the northern half of Padre Islands, which form a low, natural breakwater about 6 to $8 \mathrm{mi}$. off the coast. Bird Island, a shell reef, is the breeding ground of hundreds of pairs of brown and white pelicans, thousands of pairs of laughing gulls, great blue herons; royal, caspian, common and black terns, black skimmers, boat-tailed grackles, cormorants, etc. Mustang is similar. Padre Island is a low sand-dune region, whereon is found desert forms of insects and reptiles, as well as thousands of shore birds. Nueces Bay is a paradise for ducks and geese of all species. This region, which is unique, should be preserved at once as a National Park, and wild life sanctuary, and placed under the control of a special warden, as the bird colonies are constantly being raided by fishing crews, so that the species are not holding their own. A wonderful place for the study of shallow water Gulf fishes, as well as the life histories of birds and ecological associations. Padre Island, particularly, is a mixture of Mexican and semi-tropical associations. Elevation: from a few inches to $30 \mathrm{ft}$. above sea level.

Accessible from either Kingsville or Corpus Christi. St. L. B. M. R. R.

6. A typical chaparral association, which is practically unlimited in size. (B2.) Might well contain 200 sq. mi. or more. An ideal locality for the study from an ecological standpoint of life of this type of country typical of Texas. Material for ecological succession is unlimited. Very little water supply. Elevation: about $750 \mathrm{ft}$.

Lies in Zavalla, Frio, Dimmit and La Salle counties, and easily accessible from Hondo, Uvalde and other towns.

8. A high plateau. This is a most interesting region for ecological study, consisting of a very high plateauEdward's Escarpment (A3), which at places reaches $3000 \mathrm{ft}$. and moretogether with much timberland. Interesting floral zonation. Might well contain $50 \mathrm{sq}$. mi. or more. Elevation: about $2000 \mathrm{ft}$.

Reached from Fredericksburg S. A. F. \& N., and lying in the southeast corner of Gillespie County.

9. A region of considerable geologic interest lies in Llano and Burnet counties. (A3.) This marks the line of contact between the lime and granite countries. A very rough, ragged country, known as the Granite Mountains, through which flows the Colorado River. A wide variety of both plant and animal life. Elevation: averages about $1000 \mathrm{ft}$.

Accessible from Kingland and Llano H. T. C. Ry.

10. A sagebrush association. (A3.) Lies in Wilbarger County, on the Red River. A very wild and primitive country, with a typical sagebrush biota. The Red River affords interesting aquatic studies which are in marked contrast with those of the surrounding country. Elevation: about $1200 \mathrm{ft}$.

Accessible from Chillicothe or Vernon.

11. An interesting desert region lies at the northern union of Crosby and Dickens counties. (A3.) The preservable region here would be about $25 \mathrm{sq}$. mi. Interesting more from a botanical point of view, having a good growth of desert flora. Considerable erosion has worn a fair canyon through the region, 
giving interesting contrasts in both fauna and flora. Elevation: about $2500 \mathrm{ft}$.

Reached from Spur, M. K. \& T. R. K.

12. A southern mountain association, lying at the intersection of Jeff Davis, Brewster, Reeves, and Pecos counties. (A2.) This region contains the Davis mountains, and could well contain 250 sq. mi. or more. Very rough and wild country, having a great deal of typical western flora and fauna. Abundant big game. Should be preserved as a national preserve. Most interesting bird and mammal region. Local assistance is almost necessary to anyone going into this country, as it is entirely untouched by civilization. Elevation: about $4000 \mathrm{ft}$.

Can be reached from Fort Davis, but is very inaccessible at present.

13. Another southern mountain association, including the Sierra Vieja mountains. (A2.) A region about as in No. 12 , but even less accessible. These last two regions - 12 and $13-$ will be, probably, the last stand of typical Texas big game, as deer, cats, bear, etc., and either (or better still, both) should be set aside as game preserves in the very near future. Elevation: between 4000 and $5000 \mathrm{ft}$.

Reached from Valentine with difficulty.

14. A small region in the center of Ochiltrep. County, the extreme north end of the Pan-handle (B4), should be set aside at once as a State Park, as it contains the site of an unexcavated Pueblo village of considerable interest. It lies in the heart of a typical Prairie formation, and could include about 20 sq. mi. Elevation: about $3000 \mathrm{ft}$.

Reached from Ochiltree.

15. A small region in central Cameron County is an interesting valley with dominant Mexican type of biota. (A4.) About 20 sq. mi. would cover it and make a most interesting State Park. Elevation: about $200 \mathrm{ft}$. or less.

Reached very easily from Harlington.

16. A tropical association is found on the lower Rio Grande. (A3.) A large game preserve, under national protection (as it is on the Mexican line) should be set aside at once somewhere on the Rio Grande. This is about the most tropical of the associations found in the United States. Both Mexican and more northern biotic forms abound. Deer are still very abundant, as are the larger mammals of other species which characterize the Mexican line. Many birds are found here that are to be found in no other region in the United States. From "an ecological point of view there are simply endless problems to be solved in both plant and animal life. Area: from 200 sq. mi., up. Elevation: less than $200 \mathrm{ft}$., for the most part.

Brownsville St: L. \& B. R. R.

17. A steppe and semi-desert association, that lies in central Randall and Armstrong counties, comprising about 200 sq. mi. Characterized by sand areas, flood plains, waterfalls, ravines, bluffs, gypsum caves, and calcophytes. (A3.) Known as the Paladura canyon, and is typical of a very large region. Canyon walls $850 \mathrm{ft}$. high cut through Triasic, Tertiary and Permean beds. Many fine fossils, mostly reptilian. A bill jointly establishing White Mountain National Park and Paladura National Park has been introduced into Congress several times since 1907, but is not reported back from the committee. Should be preserved by the nation. Elevation: about $3000 \mathrm{ft}$.

Reached from Amarilla.

18. A bay association. (A3.) The coastal region of Calhoun, Jackson and Matagorda counties is one of the largest winter feeding grounds of ducks and geese in Texas, and hundreds of thousands of ducks of many species, together with the Canada goose, brandt, snow goose and blue goose, winter here. Fresh, brackish and salt water. Islands, mostly sand, afford ideal retreats for water fowl. By protecting this region, a big step would be taken in the conservation of our water fowl. Elevation: little above sea level.

Reached from Port Lavaca.

\section{REFERENCES}

Bailey, V. Biological Survey of Texas. N. A. Fauna, 25. 1905.

Bartlett, J. R. Explorations and Incidents in Texas, New Mexico, California, Sonora, and Chihuahua. London, 1854.

Bray, W. L. Distribution and Adaptation of the Vegetation of Texas. Bull. 82 Univ. Texas (Sci. Ser. No. 10). 1906.

Vegetation of the Sotol Country of Texas. Bull. Univ. Texas, No. 60. 1905.

Ecological Relations of the Vegetation of Western Texas. Bot. Gaz., 32: 99-123; 195-217; 262-291. 1901.

Cahn, A. R. Summer Birds in the Vicinity of Lake Caddo, Harrison County, Texas. Wils. Bull., xxxiii, pp. 165176, 1921.

Brown Pelicans at Home. Nat. Hist., xxii, pp. 416-429, 1922.

Louisiana Hevons and Reddish Egrets at Home. Nat. Hist., xxiii, pp.470$489,1923$. 
Coulter, J. M. Botany of West Texas. Contr. U. S. Nat. Herb. 11. 18911894.

Hill, R. T. Physical Geography of the Texas Region. U. S. Geol. Surv. Top. Atlas of the U. S. 1900.

Evermann \& Kendall: The Fishes of Texas. Bull. U. S. Fish Comm. for 1892. Washington, 1894.

Small, J. K. Flora of the Southeastern United States. 1903.

Lewis, I. M. The Trees of Texas. Bull. Univ. Texas No. 22. 1915.

Mearns, E. A. Mammals of the Mexican Boundary of the United States. U. S. Nat. Mus. Bull. 56. 1907.

Winkler, C. H. The Botany of Texas. Bull. Univ. Texas. No. 18. 1915. (Complete bibliography of Texas botany to date.)

Singley, J. A. Texas Mollusca. A Preliminary List of the Land, Fresh Water, and Marine Mollusca of Texas. Geol. Survey Texas, Contributions to the Natural History of Texas, Fourth Ann. Rep., 1892, pp. 299-343.

Strecker, J. K. Reptiles and Amphibians of Texas. Bull. Baylor Univ., Vol. 18, No. 4. 1915.

The Birds of Texas. Bull. Baylor Univ.

\section{KANSAS}

By J. W. McColloch

I. ORIGINAL BIOTA AND GENERAL CONDITIONS

\section{Topography}

Three physiographic regions (fig. 1) are recognized in the state: (1) the Ozark uplift in the extreme southeastern corner, (2) the Prairie plains comprising the eastern one third, and (3) the Great Plains which include the remainder of the state. The transition to the latter is gradual. The entire state is practically an undulating plain which slopes gently from east to west at an average rise of about $7 \mathrm{ft}$. per $\mathrm{mi}$. There is a difference of $3175 \mathrm{ft}$. in the altitude, the lowest being $725 \mathrm{ft}$. in Montgomery County and the highest $3900 \mathrm{ft}$. in Wallace County. The gently rolling prairies are diversified by an endless succession of broad, level plains, isolated hills and ridges and moderate valleys.
Much of the difference in the topography is due to erosion and wind action.

\section{Climate}

The climate of Kansas is typically continental, being characterized by wide extremes of temperature, great variations in the seasonal rainfall, much sunshine, and dry, bracing air, with good wind movement. The temperature of the various sections of the state is fairly uniform, the average temperature ranging from $58^{\circ}$ in the southeastern counties to $51^{\circ}$ in the northwest, with a mean of $54^{\circ}$ for the state as a whole. The highest temperature recorded is $116^{\circ}$ and the lowest $-40^{\circ}$.

The distribution of the rainfall over the state and the time of its occurrence are the chief limiting factors. Precipitation decreases with remarkable regularity from 42 in the southeastern counties to 15 on the Colorado line (fig. 1). From 71 to $78 \%$ of this amount falls during the growing months-April to September. Droughts frequently occur, usually during July and August, due to the high rate of evaporation caused by the excessive amount of sunshine and hot, dry winds.

There is also a great difference in the velocity of the wind in the various parts of the state. In the eastern part the winds are not noticeably higher than those of the states to the east, while the western third of Kansas is one of the windiest inland localities in the country. Excessive evaporation occurs in the western half of the state. At Hays, the evaporation from an open tank during the six growing months was 45 and at Garden City it was nearly 60.

\section{Fauna and flora}

Mammals in the hardwood forests of the valleys in the eastern part of the state were found-such mammals as the opossum (Didelphis virginiana), shorttailed shrew (Blarina brevicauda), Missouri Valley mole (Scalopus aquaticus machrinoides), timber wolf (Canis sp.), coyote (Canis latrans), red fox (Vulpes 
fulva), gray fox (Urocyon cinereoargenteus subsp.), raccoon (Procyon lotor), castern deer-mouse (Peromyscus leucopus moveboracensis), jumping-mouse (Zapus hudsonius campestris), gray squirrel (Sciurus carolinensis), fox squirrel (Sciurus niger rufiventer), flying-squirrel Glaucomys volans), cottontail rabbit (Sylvilagus floridanus mearnsii) and Virginia deer (Odocoileus virginianus macrourus). Along the streams occurred such forms as the muskrat (Ondatra zibethica cinnamomina), beaver (Castor canadensis), mink (Mustela vison letifera), and otter (Lutra canadensis subsp.). Many of these timber and stream forms follow westward in the state for a long distance along the stream valleys. On the grassy prairies of the eastern part of the state occurred such forms as the badger (Taxidea taxus), prairie deermouse (Peromyscus maniculatus bairdii), prairie vole (Microtus ochrogaster), pocket-gopher (Geomys bursarius), striped ground-squirrel (Citellus tridecemlineatus badius), white-tailed jackrabbit (Lepus townsendii campanius), and bison (Bison bison).

On the more arid grassland of the western part of the state some characteristic forms were the prairie wolf (Canis sp.), coyote (Canis nebracensis), swift fox (Vulpes velox), black-footed ferret (Mustela nigripes), badger, pocket-mouse (Perognathus subsp.), kangaroo-rat (Dipodomys subsp.), prairie dog (Cynomys ludovicianus), whitetailed jackrabbit, black-tailed jackrabbit (Lepus californicus melanotis), western cottontail rabbit (Sylvilagus audubonii subsp.), mule deer (Odocoileus hemionus), pronghorn antelope (Antilocarpa americana), and bison.

Entering the southeastern part of the state are a few species characteristic of the southern hardwood forests, such as the rice rat (Oryzomys palustris texensis), and swamp rabbit (Sylvilagus aquaticus).

Likewise several forms characteristic of the southwestern arid lands and deserts are found in the southwestern part of the state, such as the spotted ground-squirrel

(Citellus

spilosoma subsp.).

Kansas had no forests and the principal wooded tracts fringe the rivers and streams. Throughout the eastern part of the state such trees as elm (Ulmus americana), hackberry (Celtis occidentalis), walnut (Juglans nigra), linden (Tilia americana), white ash (Fraxinus americana), oak, sycamore (Platanus occidentalis), and willows thrive. Further west the predominating trees are cottonwood (Populus deltoides), and boxelder (Acer negundo). Sage brush (Artemisia tridentata) is an important shrub in the west.

The original grasses were principally bluestem (Andropogon furcatus), bunch, buffalo (Buchloe dactyloides), and grama (Bouteloua), grasses. Cactus and yucca ( $Y$. glauca) occur abundantly in western Kansas and on sandy areas elsewhere. Sunflowers (Helianthus annuus) abound everywhere and the Russian thistle (Salsola Kali var. tenuifeolia) is fast becoming established. Wild flowers are numerous and varied and form an important part of the flora. The development of large agricultural areas has added numerous cultivated species of plants to the state.

\section{NATURAL AREAS}

*Fort Leavenworth Military Reservation. (A4-C3-F6.) Leavenworth County. River valley hills and native timber have an area of 1900 acres lying along the Missouri river in Leavenworth County, Kansas, which is used as a military reservation. Altitude: 770 to 790. Topography: Varies from river bottom to very hilly deep ravines. There is a large area of native timber, undisturbed.

Two mi. north to Fort Leavenworth. M. P. R. R., K. C. L. \& W. Elec. R. R.

†Wildcat Creek Park. (B4.) Riley County. About 80 acres of woodland, scrub and grassland on western slope of Wildcat Creek. Deciduous woodland along the stream and on the slope, with a strip of scrub above, and the top of the hill covered with grassland. 
Two mi. west from Manhattan, Kansas. U. P. R. R., and C. R. I. \& P.-Lee R. Dice.

$\dagger$ Manhattan Prairie Preserve.

Riley County. Altitude: about 1300 ft. Typical prairie grassland.

Manhattan, Kansas. U. P. R. R. and C. R. I. \& P. R. R.-Lee R. Dice.

*Fort Riley Reservation. (A4-C3.) Riley County. River valley, hills and native prairies has 29 sq. mi. in Riley County (military reservation). Native prairies interspersed with wooded and barren hills. Sand area formations along the Kansas river.

Fort Riley, Kansas. U. P. R. R.

*Fort Hays Branch Experiment Station. (C3-H8.) Ellis County. This is a tract of native prairies, timber and cultivated fields of 3600 acres of the original Fort Hays Military Reservation which was donated to the state by Congress. It consists mainly of high, rolling prairie, with a limited area of rich alluvium bordering on a creek, and is situated on the edge of the semi-arid region. A fair sized stream, Big Creek, flows along the north side.

Hays, Kansas. U. P. R. R.

*Fort Hays Normal School Reservation. (C3-D5-H6.) Ellis County. This is a tract of native prairies and cultivated fields of about 4000 acres of the original Fort Hays Military Reservation which was donated by Congress to the state, similar to the Fort Hays Branch Experiment Station area.

One mi. southwest of Hays. U. P. R. R.

Pawnee Rock State Park. (B4-H8.) Barton County. This is a small tract of only a few acres near Pawnee Rock, Kansas.

One-half mi. north of Pawnee Rock, Kansas. A. T. \& S. F. R. R. Santa Fe Trail.

\section{Areas which should be preserved}

Valley floor, bluffs and hills. Cherokee County. About 100 acres along Spring River (B3-D5-F6), a branch of the Neosho River. Alluvial valley floor, river bluffs, hills, deciduous woodlands of elm, walnut and sycamore, and prairie.
One mi. southeast of Baxter Springs. St. L. and S. F. R. R. Southwest Missouri Electric Line. Jefferson Highway. Kansas.-P. F. Walker.

Sand Hill Park. (A4.) Riley County. About 640 acres of riverside flood plain and sand dunes along the Kansas River. Slightly rolling topography, sand dune area of flood plain formation, with sandy shores, pools, swamp and prairie. The principal trees are cotton wood, willow, and sand plum. The plants and animals are typical of the semi-arid regions lying some 300 to $500 \mathrm{mi}$. to the west. The low vegetation is typical of western Kansas and eastern Colorado, consisting of cacti, yucca, and other semi-arid plants. Of particular interest because of the excellent opportunity afforded near the Kansas state Agricultural College to investigate the plant and animal succession of the plains region of western Kansas, and for the recreational facilities furnished by the tract. Should be reserved by the state.

$4 \mathrm{mi}$. south of Manhattan, Kansas. U. P. R. R. and C. R. I. \& P. R. R. Midland Auto Route. Golden Belt Auto Road. Victory Highway.-J. $W$. McColloch.

Prospect Heights Park. (A4-C4-F6.) Riley County. About 100 acres of rocky upland on Prospect Heights. Rocky heights with southwestern and northwestern exposures and ridge between and a brushy and timbered slope towards the Kansas River Valley. About two mi. southeast of Manhattan, Kansas. U. S. R. R. and C. R. I. \& P. R. R.Lee R. Dice.

Stag Hill Prairie Park. (A4.) Riley County. About 160 acres of prairie with some scrub and woodland on top of Stag Hill with southwestern slope and ravine (in part at least). One of the best native prairie areas of this neighborhood.

About $4 \mathrm{mi}$. west of Manhattan, Kansas. U. P. R. R. and C. R. I. \& P. R. R. Manhattan-Junction City Interurban. -Lee R. Dice.

Upland and flood plain woodland. Riley County. About 20 acres at the "cut-off" of the Kansas River. Several sloughs, hill (or portion of it) to southwest, and edge of river. Level flood plain and bluffs. Deciduous woodland, with scrub and grassland areas. Swamp.

Manhattan, Kansas. U. P. R. R. and C. R. I. \& P. R. R.-Lee R. Dice.

Rock City Park. (A4.) Ottawa County. About 40 acres of sandstone rocks and sandy rolling area. An area about 40 rods wide and $\frac{1}{2} \mathrm{mi}$. long at the edge of the Solomon Valley and about $\frac{1}{2}$ mi. from Salt Creek. 
Minneapolis, Kansas. Union Pacific R. R. Santa Fe R. R.-Jessie G. Adee. Castle Rock Park. (A3.) Gove County. Chalk cliffs and bluffs. Plains or prairie vegetation. Grainfield, Kansas.

Gove, on the Smoky Hill River, about $10 \mathrm{mi}$. distant. Plains Auto Road at Coin to southeast.-Frank U. G. Agrelius.

Low prairie meadow and stream in McPherson County. (A4.) About 40 acres along an unnamed stream. The tract is cut by a tortuous, sluggish stream that is bordered by thickets and marsh grasses. A grove extends along a part of the stream at the southern end of the tract. A typical stand of native Kansas grasses in the virgin condition. Two mi. southeast of McPherson, Kansas.

Atchison, Topeka \& Santa Fe R. R. Chicago, Rock Island Pacific R. R. Missouri Pacific R. R. Union Pacific R. R.-Warren Knaus.

Salt Marsh Area. (A3.) Stafford County. This is an area of about 25 sq. mi. of salt marshes, plains and sand dunes on Rattlesnake Creek in the Northeast part of Stafford County, Kansas. Much of the area is salt and undrained. Consists of marshy alkali flats and stream valleys. There are accumulations of alkali in many places and salt is generally present in the waters of the marshes. Vegetation of coarse grasses.

Ellinwood, Kansas, A. T. \& S. F. R. R. Sante Fe Trail. $10 \mathrm{mi}$. south to salt marshes.

Belvidere Area. (A3.) Kiowa County. An area of bad lands about $10 \mathrm{mi}$. square with the town of Belvidere as the center. It consists of rough broken country (badlands) which has many rock outcrops and deep erosions. Vegetation is a thin growth of buffalo grass.

Belvidere, Kansas. A. T. \& S. F. R. R.

Prairie dog town. Prairie Dog Reservation (A3) in Western Kansas.

Stevens or Morton County. Several prairie dog towns should be preserved in Kansas. The Prairie dog is fast disappearing. The largest town in the state, which occupies about 2000 acres in Morton County, is now being eradicated.

Elkhart, Kansas. A. T. \& S. F. R. R. -F.L. Hisaw.

Areas which do not need to be preserved (Kansas, Finney, Kearny, Hamilton, Morton, Clark, Stafford, and Reno Counties).

Dunes and Areas. (A3.) Sand dunes and hills.
Along the south side of the Arkansas River extending from the KansasColorado line to Garden City, Kansas. This is one of the largest areas in the state. It varies from one to $20 \mathrm{mi}$. in width, being widest at Garden City. Most of this area is devoted to grazing. About 3500 acres of this area in Finney County were ceded to the state by the Federal Government to be used as a game reserve. Garden City, Kansas. A. T. \& S. F. R. R., Santa Fe Trail. Finney, Kearny and Hamilton counties.

Along the Cimarron River in Morton County, Kansas. This is a strip of sand hills averaging about 2 miles in width which extends across the county. Elkhart, Kansas. A. T. \& S. F. R. R.

Along the Cimarron River across the south end of Clark County. This is a strip of sand hills of varying width lying on both sides of the river. Two types of sand occur here-dune and Amarillo sand. Englewood, Kansas. A. T. \& S. F. R. R. 3 mi. southeast of Englewood. Northeast corner of Stafford County, Kansas. This is a large area of sand hills lying adjacent to the Salt Marsh. Ellinwood, Kansas. A. T. \& S. F. R. R. Santa Fe Trail. $10 \mathrm{mi}$. south to sand hills.

Northeast corner of Reno County, Kansas. This is a range of sand hills running parallel to and about $8 \mathrm{mi}$. north of the Arkansas River. Medora, Kansas. C. R. I. \& P. R. R. two mi. southwest to the sand hills.

\section{LITERATURE}

Kansas State Agricultural Experiment Station, Bulletins 1-227.

Useful in tracing the agricultural development. Many bulletins are devoted to the grasses, weeds, mammals, birds, rodents, insects, etc., of the state. Others deal with crops and soils.

Transactions of the Kansas Academy of Science, Volumes I-XXX.

A valuable source of reference. Contains catalogues of the various groups of plants and animals of the state. Many local areas, geological surveys, meteorological summaries and other data pertaining to ecological work.

Kansas State Board of Agriculture, Biennial Reports, Volumes 1-22.

Useful in tracing the agricultural development in the state and the modifications which have resulted. Contain numerous papers relating to the fauna and flora of the state.

U. S. War Department. Pacific Railroads-Explorations and Surveys. Report of Explorations and Surveys. 12 volumes. $1855-1860$. 
Contains a great deal of information of conditions as they occurred at that time. Discusses geology, meteorology, mammals, birds, reptiles, fishes, mollusks, insects and plants.

Kansas University Quarterly, Volumes I-X.

Contain many valuable papers on Kansas animals and plants. State lists of many groups are given and many groups are monographed. Kansas Univ. Geol. Surv. of Kans., Vols. I-IX.

Of geological interest.

Inman, Henry. The Old Santa Fe Trail. Crane \& Co., Topeka, 1899. Also, The Great Salt Lake Trail. Crane \& Co., Topeka, 1899.

Of historical interest. Descriptions are given of many local areas. The habits and distribution of many of the early animals and plants are discussed.

\section{NEBRASKA}

\section{By Robert H. Wolcott}

\section{GENERAL CONDITIONS}

The altitude of Nebraska increases from $810 \mathrm{ft}$. in the southeast corner to $5360 \mathrm{ft}$. at the Wyoming line in Banner County. The state as a whole may be likened to a great inclined plane, rising at the rate of $6 \mathrm{ft}$. per mile for the first hundred miles, and faster and faster as one proceeds westward until for the last $50 \mathrm{mi}$. the rise is 18 to $20 \mathrm{ft}$. to the mile. The mean elevation is $3085 \mathrm{ft}$.

The soils and physiographic features are varied. Three soil regions have been recognized: (1) The loess region, corresponding to the rolling prairies of the eastern portion, includes loess plains and hills, with various types of silt loams, drift hills with drift, clay and sand, alluvial plains, bluffs, canyons, very little stony land, and very few rock outcrops. (2) The sand-hill region, in the central portion, is mostly dune sand with sandy loams in the valleys, which may be dry or wet, with hay flats, marshes or lakes. (3) The high plains in the western portion, the soils of which vary from those of fine texture to those of rough stony land, with frequent rock outcroppings, includes broad pla- teaus, deep and steep-walled canyons, bold escarpments, buttes, and here and there areas of "bad lands."

All of the drainage of the state is into the Missouri River, little directly but through tributaries, such as the $\mathrm{Ni}$ obrara, the Platte, the two Nemahas, and the Blue and Republican by way or the Kansas River.

The climate is a typical inland climate, with hot summers, mild dry winters, and sudden and severe changes. The mean annual temperature varies from over $52^{\circ}$ in the southeast to less than $45^{\circ}$ in the northwest. The nights in summer are generally cool especially in the more elevated western portion. The mean annual rainfall decreases from over 33 in. in the southeast to less than 15 in. in the west; moreover, run-off and evaporation both increase greatly as one goes westward. Seven-tenths of the rainfall comes in the growing season, from April to August, and during the middle of this period the climate of southeastern Nebraska can almost be called humid. The mean annual humidity varies from about 67 to $69 \%$. The mean wind velocity is about $10 \mathrm{mi}$. per hour; being somewhat greater in the west than in the east.

Five biotic regions may be distinguished:

1. The Missouri-river bluff region. Includes the bottomlands and wooded bluffs of the Missouri river and the lower portions of its tributaries. Characterized by broadleaf forest and thicket communities. Conspicuous habitats: the rivers, with their shifting sand-bars; the flood-plain thickets of willow and young cottonwoods and the tall bottomland timber in which cottonwoods are prominent; cut-off ponds, marshes, and swamps; the cool wooded ravines with springs and clear, rapid brooks; the bluffs with more open woodlands in which are oaks, ash, walnut, hickories, linden, and other species of deciduous trees; and steep loess banks, the result of erosion; together with cleared areas and cultivated fields.

2. The prairie region (tall grass 
prairie) of the eastern and southern portions. Includes rolling hills, mostly low, but rising to an extreme height of $100 \mathrm{ft}$. or more and originally covered with a dense sod, the grass cover reaching a height of one to $3 \mathrm{ft}$., and with broad valleys through which meandered creeks and rivers both formerly with sandy or gravelly beds, fringed with timber and shrubbery. Characterized by grass communities in which blue-stems (Andropogon), prairie-grasses (Koeleria) and spear-grasses (Stipa) are prominent. Conspicuous habitats, aside from the prairie itself, are the sand-bedded larger streams with shallow shifting channels and sandbars; and the smaller creeks with their now-muddy banks and fringe of timber and thicket, which may run back into the draws; prairie sloughs, ponds and marshes, with here and there mud flats, sometimes alkaline; weed patches and plum thickets; and the artificial features created by cultivation.

3. The sand-hill region, an area of $18,000 \mathrm{sq}$. mi., in the central portion, to which may be added 2000 sq. mi. in outlying smaller tracts. A very rough area with hills rising $200 \mathrm{ft}$. or more. Characterized by bunch-grass communities with Redfieldia, Calamovilfa, certain blue-stems, and black grama (Bouteloua hirsuta) the dominant grasses. Yucca is a conspicuous plant and there are some cacti. Conspicuous habitats: the open sand-hills, mostly fixed and with a grassy cover, but here and there with "blow-outs" and shifting areas of sand; a little shrubbery in the pockets in the hills, with an occasional hackberry or hackberry thickets; wet valleys, with hay flats, sloughs, marshes or lakes, the latter with sandy, marshy, or boggy shores; and with willow thickets, tree claims, and groves around the ranches. There are few streams and these around the eastern margin, soon entering tongues of prairie which follow back into the hills.

4. The plains region including the western portions of the state and extending eastward along the north- ern boundary and, to a less degree, along the southern. Characterized by short-grass communities, dominated by grama grass, buffalo-grass, and certain grass-like sedges, and with straggling western yellow pines (Pinus scopulorum) scattered over the canyon sides, the buttes, ridges and talus slopes. Conspicuous habitats: the broad slightly uneven, grassy plains; streams running generally in canyons, frequently deep and rock-walled; also dry "sand-draw" canyons carrying water only after rain or from melting snow; irrigating ponds and ditches, rarely with small marshy tracts; rocky escarpments, ridges and buttes with scattering pines; deciduous trees and shrubbery in the bottoms of the canyons, along the streams, or about the ranches; and an increasing amount of cultivated land.

5. The coniferous woodland region, including the Pine ridge in the northwestern part of the state and smaller areas south and east of it, where, on the walls and talus slopes of extensive canyons, rising sometimes to a height of 500 or $600 \mathrm{ft}$., a coniferous woodland has developed. Conspicuous habitats: the pine-clad slopes; deciduous timber and shrubbery at the bottom of the canyons; with springs and cool, clear brooks, and occasional small ponds and marshes, due to the work of beavers.

To these might be added the bad lands, due to excessive erosion, which, because they exist as small scattered areas, we have preferred to reckon as a habitat in the plains region, characterized by their sparse flora and fauna, restricted to only those forms which can withstand the severe conditions.

The boundaries between these areas were more sharply defined before the state was settled, cultivation having tended to obliterate them. In the major areas the vegetation has been but little changed, but the disappearance of the prairie sloughs and marshes and the other changes due to the settling up of the state have led to the disappearance of many animals, especially among the higher vertebrates. 


\section{Original faunal conditions}

Mammals. ${ }^{1}$ Characteristic mammals of the Missouri-river bluff region were the opossum (Didelphis virginiana), spotted skunk (Spilogale interrupta), woodland vole (Microtus nemoralis), woodchuck (Marmota monax), fox squirrel (Sciurus niger rufiventer), and flyingsquirrel (Glaucomys volans). Of these all but the opossum and skunk are practically confined to the Missouri region.

In the prairie region were found originally great herds of bison; while other characteristic forms were probably the coyote, badger, prairie vole (Microtus ochrogaster), pocket-gopher, striped ground-squirrel, Franklin ground-squirrel (Citellus franklinii), and whitetailed jackrabbit.

Among the mammals known to occur natively in the sand hill region are the sand-hill ground-squirrel (Citellus obsoletus), grasshopper-mouse (Onychomys leucogaster arcticeps), deer-mouse, harvest-mouse, Hayden vole (Microtus ochrogaster haydeni), plains pocketgopher (Geomys lutescens), Richardson kangaroo-rat (Dipodomys ordii richardsoni), and Kansas pocket-mouse (Perognathus hispidus paradoxus).

The plains region has as characteristic forms the bison, pronghorn antelope, coyote, black-footed ferret (Mustela nigripes), swift fox, badger, striped ground-squirrel, prairie-dog, Hayden vole, pocket-mouse (Perognathus spp.), and white-tailed jackrabbit.

In the coniferous woodland of the northwestern part of the state are found such species as the yellow-haired porcupine (Erethizon epixanthum), woodrat, wolverine (Gulo luscus), northern plains skunk (Mephitis hudsonica), pale chipmunk (Eutamias pallidus), and red squirrel (Sciurus hudsonicus dakotensis).

\section{Present faunal conditions}

The Missouri River bluffs and prairie regions of the state are characterized by the mammals: the opossum, gray

1 Scientific names of mammals occurring in the South Dakota account do not occur here. squirrel, woodchuck, flying-squirrel, woodland vole, red fox, and spotted skunk, and all but the opossum and skunk are practically confined to the Missouri region. The rest of the state is characterized by the pocket-mouse, kangaroo-rat, prairie-dog, long-tailed weasel, sand-hill ground-squirrel and black-footed ferret, except in the coniferous woodland of the northwest where the long-eared bat, yellow-haired porcupine, mountain rat, northern pocketgopher, wolverine, northern plains skunk, and subarctic deer-mouse are characteristic.

The Missouri region has more than a score of woodland birds which as summer residents and breeders are peculiar to it, including the woodchuck, ruffed grouse, broad-winged hawk, bald eagle, least flycatcher, many warblers, and the brown creeper. There are no birds peculiar to the prairie region, which shares with the Missouri region some 60 savanna and prairie forms, but many of them, as the prairie horned lark, bobolink, lark sparrow, and Bell vireo, find here the most favorable environment. As steppe birds may be mentioned the long-billed curlew, sharptailed grouse, Sennett nighthawk, desert horned lark, several western sparrows, arctic towhee and black-headed grosbeak, with about 16 other species. Conspicuous birds of this region in the state, though not confined to it, are the sharp-tailed grouse, prairie chicken, sparrow hawk, burrowing owl, Arkansas kingbird, and lark bunting. The sand hill lakes harbor a numerous waterbird population, fourteen species being confined to this region during the breeding season. The characteristic birds of the plains are the mountain plover, poor-will, western nighthawk, Say phoebe, magpie, Bullock oriole, Brewer blackbird, chestnut-collared and McCown longspurs, Brewer sparrow, rock wren, and others. Finally, in the coniferous woodland are 25 species peculiar to it as summer residents, including the sharp-shinned and Krider hawks, golden eagle, prairie falcon, 
duck hawk, Lewis woodpecker, whitethroated swift, alder flycatcher, pinion jay, white-winged junco, western tanager, Audubon warbler, Townsend solitaire and mountain bluebird.

Less definite statements can be made in regard to other animal groups, but salient features may be noted. Snakes are in much greater variety in the Missouri region than westward and several species are confined to it. The prairie rattler (Crotalus confluentus) is found in this, the eastern part, the plains rattler only in the west. Two species of sand lizards swarm in the sand hills, but the striped lizard (Cnemidophorus sexlineatus) is common only in the Missouri region. Box turtles (Terrapene ornata) are abundant in the sand hills. A horned toad (Phrynosoma douglassii lemandsi) is rare in the plains region of the southwest. Bufo cognatus is the common toad of the state, $B$. americanus being rare in the Missouri region, and $B$. woodhousii found only in the west. Rana pipiens is found throughout the state; the bullfrog ( $R$. catesbeiana) is rare and, except where artificially introduced, confined to the southeastern portion. Axolotls (Ambystoma tigrinum) are common in the more alkaline sand-hill lakes. The insect faunas of the two ends of the state are decidedly different. In the southern plains region in the west are found solpugids and a large centipede. Terrestrial molluscs are largely confined to the Missouri region. Earthworms are very rare except in the Missouri and prairie regions. The cut-off lakes and bayous in the Missouri region are rich in aquatic forms, and so are the freshest of the sand-hill lakes, but the alkali lakes have a very limited fauna, though at certain seasons the few species present may appear in enormous numbers. The prairie ponds and sloughs have a relatively poor fauna, consisting largely of insects and crustacea, unless spring-fed and permanent, when a rich fauna develops.
II. NATURAL AREAS

\section{Preserves}

1. *Arbor Lodge. (H8.) The former home of J. Sterling Morton, just outside the limits of Nebraska City, which is on the Missouri, $45 \mathrm{mi}$. south of Omaha by the Missouri Pacific Ry. It has been recently deeded to the state and is now being administered as a state park. Represents the southern portion of the Missouri region and consists of about 1000 acres of deciduous forest, open ground, and ravines with springs and small streams. Rich in trees, possessing about 200 species of native and introduced trees. Altitude 905 to $1060 \mathrm{ft}$.

A fine avenue from the town.

2. *Child's Point area. (D3.) About $6 \mathrm{mi}$. from the center of Omaha, consisting of several tracts: 75 acres, held by the Y. W. C. A. as a camp tract; 103 acres given to the Boy Scouts for a camp by Dr. Gifford of Omaha; 700 acres in the Fontenelle Forest, held by Dr. H. Gifford and Mrs. S. Joslyn of Omaha; and about 1600 acres, the Wiley Point Game Preserve, held by Dr. Gifford. The whole forms a continuous tract of nearly 2400 acres, representing every type of habitat in the Missouri region and with a very rich fauna and flora. It is hoped that this will all ultimately become a state park and the natural features preserved. Altituds 960 to $1165 \mathrm{ft}$.

Trolley line from Omaha.

3. *Belmont prairie. (C3.) Two mi. north of Lincoln; 160 acres of virgin prairie, including upland and lowlands. Now used constantly by University classes, but under private control and liable to exploitation. Altitude 1160 to $1240 \mathrm{ft}$.

4. Salt basin and lake. $1 \frac{1}{2} \mathrm{mi}$. west of Lincoln, containing about 700 acres. Should be a city park and game refuge. Now under private control, subject to exploitation, and in part used as an amusement park. Saline lake, artificial 
in origin, saline mud flats, some scattered trees and shrubs, resort of waterbirds in migration. Altitude $1140 \mathrm{ft}$. Street car from Lincoln.

5. ${ }^{*}$ Nebraska National Forest, Loup Division. (C3.) About in the center of the state, and two mi. from Halsey, which is $225 \mathrm{mi}$. from Lincoln on the Chicago Burlington, and Quincy R. R. containing about 90,000 acres of sand hills and lying between the middle Loup and Dismal rivers. No lakes, but some marsh along the streams. Little deciduous timber and shrubbery along Loup and about 7000 acres of planted pine, a small part old enough to have developed forest conditions. A few deer. Altitude 2710 to $2940 \mathrm{ft}$.

Drive out from Halsey. (See page 237, in account of D2 National Forest.)

6. ${ }^{*}$ Nebraska National Forest, Niobrara Division. (C3.) $20 \mathrm{mi}$. from Nenzil, a station $329 \mathrm{mi}$. northwest of Omaha, on the Chicago and Northwestern Ry., containing 126,000 acres of sand-hills, bordering on the Niobrara river. Some deciduous timber and thickets, but mostly sand-hills; few small lakes. Altitude 2700 to $3100 \mathrm{ft}$.

Drive out from Nenzil.

7. *United States Game Preserve. Containing about 16,200 acres, one mi. east of Valentine which is also on the Chicago and Northwestern R. R., 299 mi. from Omaha. Small flood-plain, bluffs, canyons, river, deciduous timber and some thickets. Bison, elk and deer in captivity. Altitude 2480 to $2600 \mathrm{ft}$.

Drive from Valentine.

8. Lake region of Cherry County. (A4.) An area about $8 \mathrm{mi}$. square directly south of Valentine, with a dozen lakes varying from fresh to strongly alkaline, in size from $\frac{1}{2} \mathrm{mi}$. across to $4 \mathrm{mi}$. long and one mi. wide. Should be a state park and contain game preserves. Sand-hills, lakes, with varied shores, marshes, hay flats, blow-outs, shifting sand areas, the center of breeding grounds for water birds. Altitude 2680 to $2785 \mathrm{ft}$.
Drive out from Wood Lake or Valentine, 20 to $25 \mathrm{mi}$.

9. *State Park. (A4.) Dawes County. Containing 640 acres, $8 \mathrm{mi}$. from Chadron, which is in the northwest corner of the State, $447 \mathrm{mi}$. from Omaha and reached by the C. \& N. W. R. R. Under state control. In plains region, representing a portion of the Pine ridge coniferous woodland. Cliffs, talus slopes, canyons, pine, streams with deciduous timber and shrubbery. Altitude 3485 to $3720 \mathrm{ft}$.

Drive from Chadron.

10. ${ }^{*}$ Wood and timber reserve. (A4.) Near Fort Robinson, $29 \mathrm{mi}$. west of Chadron and reached by the C. \& N. W. R. R., and also $426 \mathrm{mi}$. from Lincoln by way of the C. B. \& Q. R. R., containing $12 \frac{1}{2}$ sq. mi. Under national government control. This is part of a tract, $20 \mathrm{mi}$. east and west, 4 north and south, containing about $80 \mathrm{sq}$. mi. and lying along the Pine Ridge, which should be a state park. Rock cliffs, talus slopes, high plains, canyons, valley, bad lands, pine forest, deciduous forest in canyons, springs, streams, valley canyons, sage brush, a few deer, beaver, and all forms referred to previously as in coniferous forest region. Altitude 3735 to $4000 \mathrm{ft}$.

Drive out from Crawford, $10 \mathrm{mi}$,, or Harrison, 4 mi.

11. Scott's Bluff. (A4.) Two mi. from Gering, on the Union Pacific R. R., $426 \mathrm{mi}$. from Omaha, and reached also by the C. B. \& Q. R. R. It contains about 400 acres, in part now deeded. A proposed state park. In plains region. Cliffs, talus slopes, canyons, scattering pine, sage brush, bad lands. Altitude 3880 to $4662 \mathrm{ft}$.

Drive from Gering.

\section{BIBLIOGRAPHY}

Anderson, E. N., and Walker, E. R. An Ecological Study of the Algae of some Sandhill Lakes. Trans. Amer. Mic. Soc., XXXIX, 51-85, pls. IV-XII. 1920.

Bessey, C. E. Plant Migration Studies, Uni. Neb. Studies, V, 1-27. 1905. 
Bruner, L., Wolcott, R. H., and Swenk, M. H. A Preliminary Review of the Birds of Nebraska. Ann. Rept. Neb. State Bd. Agric. for 1903. Also separate. 125 pp. 1904.

Condra, G. F. Geography of Nebraska. 192 pp. Lincoln, 1906.

Petersen, N. F. The Flora of Nebraska. 220 pp. Lincoln, 1912.

Pool, R. J. A Study of the Vegetation of the Sandhills of Nebraska. Minn. Bot. Studies, IV, 189-312, pls. XXVIXL, and map. 1914.

Pool, R. J., Weaver, J. E., and Jean, F. C. Further Studies in the Ecotone between Prairie and Woodland. Uni. Neb. Studies, XVIII, 1-47, figs. 1918.

Pound, R., and Clements, F. C. The Phytogeography of Nebraska. 443 pp., 4 maps. Lincoln, Nebr., 1st ed., 1897; 2 d ed., 1900.

Swenk, M. H. A Preliminary Review of the Mammals of Nebraska. Stud. Zool. Lab. Uni. Neb., No. 89. 88 pp. Lincoln, 1908.

Thornber, J. J. Studies in the Vegetation of the State. I. The Prairiegrass Formation in Region I. Rept. Bot. Surv. Nebr., V, 29-143. 1901.

Weaver, J. E., and Thiel, A. F. Ecological Studies in the Tension Zone between Prairie and Woodland. Bot. Surv. Neb.; N. S., No. 1, 1-59, figs. 1917.

Wolcott, R. H. Biological Conditions in Nebraska. Publ. Neb. Acad. Sci., VIII, 23-34, map. 1906.

Wolcott, R. H. An Analysis of Nebraska's Bird Fauna. Proc. Neb. Orn. Union, IV, 25-55, 6 pls. 1909.

\section{COLORADO}

\section{By Francis Ramaley and W. W. RobBIns}

\section{GENERAL}

Colorado is a state with many different environments. One may travel from the Great Plains of the eastern part of the state or from the warm valleys of the Western Slope to the crest of the Continental divide and pass through as many distinct climates as in journeying from Virginia to arctic Greenland. The lowest point in Colorado has an elevation of $3386 \mathrm{ft}$. and the highest 14,402 ft.; the altitudinal range is therefore $11,016 \mathrm{ft}$., and it is this great variation in altitude which determines the differences in climate.
Topographically the state consists of three main parts: the Great Plains, the mountains, and the western plateau. The principal rivers are the South Platte, Arkansas, Rio Grande, Colorado, Grand, and White. All streams in the densely populated areas are more or less polluted and in periods of active mining may contain objectionable mill tailings which, however, seldom destroy aquatic life.

The Great Plains, comprising the eastern two-fifths of the state, are covered chiefly with short grass. This association is almost uninterrupted except for fringes of cottonwoods and willows along water courses. In a few favored places there is a prairie-grass vegetation. On the divide between the Platte and Republican rivers there are some areas of sand hills with their peculiar plant growth. The two chief grasses of the plains are buffalo grass (Buchloe dactyloides) and grama grass (Bouteloua gracilis). In the early days there were large herds of bison (Bison bison) and prong-horn antelope (Antilocapra americana). The bison is no longer found in the wild state and antelopes are few in number. Of small mammals, mention may be made of the black-tailed prairie-dog (Cynomys ludovicianus), yellow pocket gopher (Geomys lutescens), Richardson kangaroo rat (Dipodomys ordii richardsoni), white-tailed jackrabbit (Lepus townsendii campanius), plains cottontail (Sylvilagus audobonii baileyi), and plains coyote (Canis nebracensis).

The high mountains of Colorado trend north and south, occupying the entire central portion of the state. The eastern slope of the mountains has a chaparral belt between the grassland and the forests of rock pine (Pinus scopulorum) on the foothills. To the north, this narrow interrupted belt of shrubs and small trees is mainly chokecherry and thornapple in the moister places with three-leaved sumac (Rhus trilobata) and mountain mahogany (Cercocarpus parvifolius) in drier situations. In southern Colorado the chaparral 
is chiefly scrub oak. On the Western Slope the sagebrush plains are separated from the foothill forests by a scrub growth of oaks and buckbrush (Symphoricarpos).

The lower foothills of the eastern slope are dominated from an altitude of 6000 to $8000 \mathrm{ft}$. by a more or less open forest of rock pine, with Douglas fir replacing the pine on moist, cool slopes. Along streams in the canyons there is a mixed growth of narrowleaf cottonwood, willow, boxelder, thornapple, wild plum, and chokecherry. The chief mammals of the foothill zone are the white-tailed deer (Odocoileus virginianus macrourus), chipmunk (Eutamias sp.), rock squirrel (Otospermophilus grammurus), yellowhaired porcupine (Erethizon epixanthum), Rocky Mountain cottontail rabbit (Sylvilagus nuttallii pinetis), and mountain coyote (Canis lestes). Birds are numerous here and in the other life zones. (The reader may consult Mrs. Bailey's Handbook of the Birds of the Western United States or Sclater's History of the Birds of Colorado. For an account of the mammals, see Warren's Mammals of Colorado.)

The Montane (Lower Mountain) Zone is next above the Foothill Zone and includes altitudes from about 8000 to $10,000 \mathrm{ft}$. The forest here is either a mixture of pines, spruce, Douglas fir, and aspen or it may be an almost pure stand of lodgepole pine (Pinus murrayana). Mammals present in this zone are the beaver, various squirrels, chipmunks (Eutamias spp.), yellowhaired porcupine, mule deer, mountain coyote, timber wolf, and red fox (Vulpes macroura). The species of birds are almost as numerous here as in the Foothill Zone.

The Subalpine (Upper Mountain) Zone forms the highest timbered belt, extending from the Montane Zone at about $10,000 \mathrm{ft}$. on up to the limit of timber. The principal tree is the Engelmann spruce (Picea engelmanni), with the alpine fir (Abies lasiocarpa), lodgepole pine, and limber pine (Pinus flexilis) as secondary species. Engel- mann spruce is found on all the higher mountain ranges and isolated peaks. In the drier, more windswept localities the spruce is largely replaced by limber pine, lodgepole pine, and the bristlecone pine (Pinus aristata). Mammals present in limited number are the mule deer, Fremont squirrel, mountain pocket-gopher (Thomomys fossor), cougar, Rocky Mountain snowshoe hare (Lepus bairdii), and bighorn sheep (Ovis canadensis).

The average elevation of timber line in Colorado is 11,500 ft.; above this altitude is the Alpine Zone. All of the higher peaks have extensive alpine meadows and boulder fields with their mat and cushion plants so typical of alpine regions. Nearly all the plants are perennials. A common mammal is the pika, or cony (Ochotona saxatilis). The ptarmigan is a well-known bird. Many of the common birds of moderate altitudes are frequent or occasional above timberline, as certain jays, mountain bluebird, western robin, western violet-green swallow, and others.

All of western Colorado is a high plateau broken by mountain ranges and cut into deep gulches and canyons, with high and dry mesas between. Extensive areas are covered by sagebrush (Artemisia tridentata), the most typical sagebrush country being in the northwestern counties. In parts of western Colorado one may travel for miles through sagebrush, then through pinyon pine and cedar, then through sagebrush again; these two plant communities alternating. Common mammals of the sagebrush are the least chipmunk (Eutamias minimus), white-tailed prairie-dog (Cynomys leucurus), Green River pocket gopher (Thomomys ocius), Colorado cottontail rabbit (Sylvilagus audobonii warreni), and mountain coyote. Because of the slight rainfall the growth of timber on south slopes is sparse and there is often a sharp contrast in appearance between north-facing and south-facing mountain sides. In western Colorado the life zones are not clearly and sharply limited. 
The mountain parks of Colorado are elevated valleys clothed chiefly with a dry grassland and surrounded by forestclad hills. The largest are North Park, South Park, Middle Park, and San Luis Park. There are many smaller parks scattered along water courses chiefly in the Foothill and Montane zones of the eastern slope. The Rocky Mountain National Park contains a number of mountain parks of great interest. (See various publications of the National Park Service, U. S. Department of the Interior.)

About one-fifth of the entire area of Colorado is in National Forests. These forests are chiefly protection forests and do not furnish at present any great amount of timber. (See various publications of the U. S. Forest Service, especially those dealing with recreational possibilities.)

The state tree of Colorado is the blue spruce (Picea pungens), occurring locally along streams in the upper foothills. The blue columbine (Aquilegia coerulea) is the state flower. It grows sparingly in the foothills and more abundantly in the Montane and Subalpine zones.

Colorado is well known for its trout. There are native mountain trout in the streams from the foothill country almost to timber line; various species also have been introduced. (For an account of Colorado fishes, see Ellis: "Fishes of Colorado," in University of Colorado Studies, Vol. XI, pp. 1-136, 1914. For reptiles and amphibia see Ellis and Henderson: "Amphibia and Reptilia of Colorado," in University of Colorado Studies, Vol. X, pp. 39-129; Vol. XI, pp. 253-263, 1915.)

Following are some selected titles of papers dealing with vegetation of Colorado.

Cockerell, T. D. A. Alpine Flora of Colorado. American Naturalist, 40: 861-873. 1906.

Cooper, W. S. Alpine Vegetation in the Vicinity of Long's Peak, Colorado. Botanical Gazette, 45: 319-337. 1908.

Ramaley, Francis. Plants of the Floris- sant Region of Colorado. Univ. of Colo. Studies, 3: 178-185. 1906.

Plant Zones in the Rocky Mountains of Colorado. Science, N.S., 26: 642-643. 1907.

Botany of Northeastern Larimer County, Colorado. Univ. of Colo. Studies, 5: 119-131. 1908.

Dry Grassland of a High Mountain Park in Northern Colorado. Plant World, 19: 249-270. 1916.

Xerophytic Grasslands at Different Altitudes in Colorado. Bull. Torr. Bot. Club, 46: 37-52. 1919.

Some Mountain Plant Communities of Sandy Soil. Plant World, 22: 313-328. 1919.

Subalpine Lake-shore Vegetation in North-Central Colorado. Amer. Jour. Bot., 7: 57-74. 1920.

Ramaley, Francis, and Robbins, W. W. Studies in Lake and Streamside Vegetation. Univ. of Colo. Studies, 6: 133-168. 1909.

Robbins, W. W. Climatology and Vegetation in Colorado. Botanical Gazette, 49: 256-280. 1910.

Successions of Vegetation in Boulder Park, Colorado. Botanical Gazette, 65: 493-525. 1918.

Shantz, Homer L. Study of the Vegetation East of Pikes Peak; the Bouteloua formation. Botanical Gazttte, 42: 16-47, 179-207. 1906.

Vestal, Arthur G. Prairie Vegetation of a Mountain-front Area in Colorado. Botanical Gazette, 58: 377-400. 1914.

Foothills Vegetation in the Colorado Front Range. Botanical Gazette, 64: 353-385. 1917.

Although it has not been possible in the space allowed to consider the invertebrate animals of Colorado the reader may wish to know of two papers on invertebrates in which ecological as well as taxonomic matters are considered.

Dodds, Gideon S. Altitudinal Distribution of Entomostraca in Colorado. Proc. U. S. Nat. Mus., 54: 58-87. 1917.

Henderson, Junius. Mollusca of Colorado, Utah, Montana, Idaho, and Wyoming. 'Univ. of Colo. Studies, 13: 65-223. 1924.

\section{NATURAL AREAS}

*Wheeler National Monument. Three hundred acres; of much interest from a geological standpoint, as an example of 
eccentric erosion and extinct volcanic action. Elevation 11,700 to $12,400 \mathrm{ft}$.

It is reached by horseback trail from Wagonwheel Gap or from Creede.Roger W. Toll.

*Mesa Verde National Park. Is located in the southwestern part of Colorado, in Montezuma County. It has an area of $77 \mathrm{sq} . \mathrm{mi}$. The highest elevation is that of Park Point, $8574 \mathrm{ft}$. The average elevation of the mesa is perhaps 500 or $1000 \mathrm{ft}$. less than this.

The nearest railroad point to Mesa Verde National Park is Mancos, on the D. \& R. G. W. It is connected with that point by automobile stage line making daily scheduled trips throughout the summer season. The park is accessible by automobile, but of course most of the ruins are reached either on foot or on horseback.-Roger W. Toll.

\section{Literature:}

Antiquities of Mesa Verde National Park: Spruce Tree House. J. W. Fewkes. Bureau Amer. Ethnology, Bull. 41, 1909.

Antiquities of the Mesa Verde National Park: Cliff Palace. J. W. Fewkes. Bureau Amer. Ethnology, Bull. 51, 1911.

Excavation and Repair of Sun Temple. J. W. Fewkes. Gov. Pr. Office.

\section{*The Colorado National Monument}

The Colorado National Monument $(13,883$ acres $)$ is located in western Colorado, Mesa County. It is a few hundred feet higher than the town of Fruita, whose elevation is $4510 \mathrm{ft}$. Its special characteristics are many lofty monoliths, and it forms a wonderful example of erosion, as well as possessing great scenic beauty and interest.

The entrance to this monument may be reached by automobile from Grand Junction or Fruita, but in order to explore the area one must go on foot.Roger W. Toll.

${ }^{*}$ Estes Park. Few sq. mi. of mountain coniferous and aspen forest, and xerophytic mountain grassland (some Bouteloua), with lakes, springs, and river lying in mountain park topography; beaver present and usual small mam- mals. Small areas along streams and near lakes in the open park have mesophytic vegetation. The park is 7600 ft. altitude, located in the open yellow pine forest area. The Rocky Mountain National Park is but a few mi. to the west but at higher altitude. Estes Park is an important tourist resort with many excellent hotels. For many years there will be plenty of unoccupied land where the natural vegetation can be observed.

Located in Larimer County; village of Estes Park, Colo. Auto stage from Loveland, Longmont, Boulder, or Denver. $-F . R$.

*Rocky Mountain National Park. Many square miles of coniferous mountain forest, alpine and sub-alpine meadow, talus slopes, gravel slides, bogs, mountains, ravines, canyons, marshes, ponds, springs, glaciers; with beaver, bear, deer, and wild mountain sheep. Includes all the climatic and edaphic situations belonging to montane, sub-alpine and alpine life zones of the neighborhood.

For the higher altitudes the distances from hotels are considerable. Automobile roads and government campsites with usual regulations of National Parks. Located in Boulder, Larimer, and Grand Counties, Colo., a few mi. from Estes Park village and postoffice. See account of Estes Park, preceding. May also be reached from Grand Lake, Colo., on the western slope but roads across the Continental Divide open only from mid-July to September 1.-F. $R$.

Tolland Area. Few sq. mi. of mountain coniferous and aspen forest with pine, spruce, fir, and Douglas fir; xerophytic grassland, meadow, flood plain, talus slopes, gravel slides, bogs, waterfalls, ravines, canyons, glacial deposit, swamps, marshes, morainal and rockbasin lakes, swift and meandering streams; deer, beaver, small mammals, many birds. Every kind of association that may be expected from 9000 to 14,000 $\mathrm{ft}$. altitude. Most of the area is in the Colorado National Forest. A summer laboratory was conducted by the Uni- 
versity of Colorado for ten years and numerous publications issued. See Univ. of Colo. Studies, 17: 53-64, 1917, for bibliography.

Located in vicinity of Tolland, Colo., in Gilpin County. Denver \& Salt Lake R. R. passes through Tolland and up over the Continental Divide so that all life zones are easily reached. Hotel accommodations. $-F$. $R$.

Owl Canyon. Few sq. mi. of foothill coniferous forest, with rocky ridges and a very interesting association dominated by Cercocarpus shrubs (Chaparral). See Univ. of Colo. Studies, 5: 119-131, 1908.

Located in Larimer County, $15 \mathrm{mi}$. n.w. from Ft. Collins, Colo., on highway to Cheyenne, Wyo.-F. $R$.

Black Forest of Colorado. Many sq. mi. of coniferous forest (Pinus scopulorum) extending many mi. southeast from Palmer Lake at which point it merges with the mountain forest of the foothills. Very interesting here and even more of interest where it meets the plains near Colorado Springs. The forest extends along a sandstone spur projecting out from the mountains, the ridge gradually becoming submerged in the plains soil of shale origin and the forest disappearing with the changed edaphic conditions. Some Rocky Mountain red cedar (Juniperus scopularum) present in the forest. Chief ecological interest is in the tension between forest and plain as controlled by soil type. The area is covered with claims and private titles but is very little settled and is used chiefly for grazing. There is still plenty of open ground for study.

The southeast part of the forest is reached from Colorado Springs by automobile, distance of about $12 \mathrm{mi}$., or from Monument, $5 \mathrm{mi}$. Both these places and also Palmer Lake are on the D. \& R. G. and Santa Fe Railroads. Hotel accommodations at all three towns. - C. G. Bates.

*Colorado Springs Water Preserve. About 100 sq. mi. of mountain forest comprising most of the typical trees of the eastern Rockies except lodgepole pine, extends from an elevation of 6500 ft. at Manitou to $11,500 \mathrm{ft}$. (timberline) on Pikes Peak. The soil is derived wholly from a coarse-grained granite and shows all ages from loose gravelslides to stable gravelly loams. Points of ecological interest are the several forest types accessible within a short range, and the rather poor development of all forests owing, probably, to severe winter drought. Uniformity of soil type causes marked merging of different associations; decided contrasts resulting from topography and exposure are, however, available.

The area is within the Pike National Forest, largely owned and controlled by the city of Colorado Springs for water-supply purposes. Regulations exclude all stock from the area. Tourists are not encouraged on property owned by the city but scientific workers receive due consideration. The Carnegie Alpine Laboratory (Dr. F. E. Clements, Manitou, Colo., June-August) and the Fremont Forest Experiment Station (C. G. Bates, Box 1068 Colorado Springs) are located within the area of interest. Arrangements might be made in advance by writing either station. Reached from Manitou or Colorado Springs; hotel accommodations year around. A cog railway penetrates the area, starting at Manitou.-C. G. Bates.

*Garden of the Gods and adjacent territory. Few sq. mi. of xerophytic grassland, pinyon-cedar association, and scrub oak thickets (chaparral) lying in the district about Manitou and Colorado Springs. Mesa vegetation described by Shantz in Botanical Gazette, 42: 16-47, 1906.

Electric cars between Colorado Springs and Manitou pass near to the area. $-F . R$.

Florissant Lake Beds. Few sq. mi. of mountain coniferous forest and xerophytic grassland in a chiefly grazing and sparsely populated area. Some aspen forest; mesophytic areas along streams, large lake; general open country, rolling, with few narrow canyons. Remarkable locality for Miocene fossils, both plant and animal. For accounts of geology, botany and paleontology see Univ. of Colo. Studies, 3: 177-185, $1906 . \quad$ Numerous later articles by Prof. T. D. A. Cockerell give descriptions of fossil plants and insects.

Located in Teller County in Florissant, Colorado. Hotel accommodations. 
As to best method of reaching Florissant inquiry should be made at Colorado Springs or at Cripple Creek.

Shawnee Area. Few sq. mi. of mountain coniferous forest, coniferous savanna, xerophytic grassland, streamside mesophytic forest, mountain park topography. A beautiful example of low-altitude mountain park, although not greatly different from others in the vicinity.

On the Platte Canyon line of the C. \& S. R. R. Hotel during summer.-F. $R$.

*Red Rock Lake Area. Many sq. mi. mountain coniferous forest located in the Colorado National Forest; trout streams and sub-alpine lakes; among these is Red Rock Lake which furnishes beautiful illustration of zonation of vegetation at a high elevation $(10,000$ ft. altitude). Beaver, deer, porcupine, small mammals, numerous birds. Opportunities to study effect in the various forest types of timber cutting, fires, landslides, high winds. Vegetation of Red Rock Lake and circum-areas described in Univ. of Colo. Studies, 6: 33-167, 1909.

About $2 \frac{1}{2} \mathrm{mi}$. from Ward, Boulder, County. Hotel at Ward. Reached by auto stage from Boulder.

Boulder Mountain Park. About 4000 acres of foothills including coniferous forests of yellow pine and Douglas fir with aspen groves, excellent examples of canyon forest, rugged topography; beaver, porcupine, and small mammals, such as chipmunks and ground squirrels. Preserved by the city of Boulder as a part of its park system. Includes the usually associated habitats found at altitudes of 5500 to $8500 \mathrm{ft}$. The University of Colorado is located at Boulder. Various publications on the plants and animals of the district, especially A. G. Vestal in Bot. Gazette, 64: 353-385, 1917; also (for lists of animals, especially invertebrates) see Cockerell in Univ. of Colo. Studies, 12: 5-20, 1917, and previous writings; for birds see numerous contributions by Junius Henderson in the various ornithological journals.

The University museum is open throughout the year. Boulder is on the C. \& S. R. R. and Interurban Line
(Kite Route) $30 \mathrm{mi}$. n.w. of Denver. Hotel accommodations.

White Rocks. Few acres of sand steppe with pine-ridge forest poorly developed. It is an outcrop of white sandstone with many plants not found elsewhere in the vicinity. Good examples of plains short grass association. Early vernal flora especially interesting; largely characteristic sand dwelling plants.

In Boulder County, 8 mi. by motor-car (U. P. R. R.) from the city of Boulder. -F. $R$.

Sand Hills of Eastern Colorado. Large areas of sand hill country occur in eastern Colorado especially along the line of the Burlington Railway. Vegetation similar to that of the Nebraska sandhills described by Pool in Minn. Botanical Studies, 4: 189 et seq., 1914.

The sand hills of Colorado may be conveniently reached at Roggen or at Wray on the C. B. \& Q. R. R. east of Denver. $-F$. $R$.

The Colorado Antelope Refuge. Created in 1923, embraces about $100 \mathrm{sq}$. mi. of grazing land in the northeast corner of Larimer County. Toward the western boundary of the Refuge there are a few pines and cedars, otherwise the land is covered chiefly with grass. A few springs and small streams afford suffcient water. Some well-marked buttes and mesas exist but, on the whole, the Refuge may be described as rather level. A few antelope have always been present in the region. Pasturage of domestic animals is not prohibited by the law establishing the Refuge.-F. Ramaley.

\section{WYOMING}

By John W. Scotr

\section{GENERAL FEATURES AND ORIGINAL BIOTA}

Wyoming is especially characterized by its extensive plains, its lofty mountain ranges, and its numerous river valleys. The elevation varies from about $3100 \mathrm{ft}$. at one place on the eastern border to $13,785 \mathrm{ft}$. in the Wind River Mountains. The rainfall varies from less than 6 in., in the Big Horn Valley and in parts of the Red Desert, to 15 to 20 in. in eastern portions of the State: 
the precipitation on some mountain ranges is probably well above 20 to 25 in. Under these conditions the climate is varied, though predominantly cool and mainly arid. The vast treeless plains are level or rolling and are located for the most part in the southern half and in the eastern portions of the state; in the eastern portions the rainfall is sufficient to give the plains the character of grassland steppe, but the plains of the central and western regions are characterized by sagebrush desert which gives place on the foothills and lower mountain slopes to juniper and semidesert coniferous forest. The mountain ranges are found chiefly in the northwest part of the state. Their middle slopes are usually covered with mountain coniferous forest and these merge into the treeless crests and peaks above timberline where alpine conditions prevail. Three great river systems have their sources in the mountains of Wyoming and the heavy snowfall of the mountains helps to make a well watered state, considering prevailing arid conditions.

The life zones in Wyoming as outlined by Cary include the following: (1) A zone occuping the low plains and most of the valleys in which the yucca (Yucca glauca), rabbit brush (Chrysothamnus), salt-bush (Atriplex spp.), juniper, broad leaved cottonwood (Populus occidentalis) and willows are characteristic (Upper Sonoran). (2) A zone, comprising fully half of the state, embracing the high sagebrush and grassy plains, the basal slopes of the mountains and most of the foothills, and characterized by sagebrush (Artemisia tridentata), the narrow-leaved cottonwood (Populus angustifolia), and western yellow pine (Pinus scopulorum) (Transition). (3) A zone covering the middle mountain slopes (Montane Belt) and the highest foothill ranges and characterized by forests of lodgepole pine (Pinus murrayana), aspen (Populus tremuloides), and, higher up, spruce (Prcea engelmanni) and alpine fir (Abies lasiocarpa). A rich fauna and flora is present (Canadian). (4) A compara- tively narrow zone in the timberline region (subalpine), characterized by dwarf Engelmann spruce, alpine fir and white-barked pine (Pinus albicaulis) (Hudsonian). (5) A zone consisting of the mountain peaks and crests above timberline with no trees, but where soil is present and alpine grasses and flowers flourish (Arctic-Alpine). For lists of animals see references below.

\section{PRESENT BIOTIC CONDITIONS}

At one time the large game animals and game birds were very abundant. Countless herds of bison and pronghorn antelope roamed the plains. Now, bison are found only in Yellowstone Park and in one or two private herds. Antelope and elk in spite of protection are being rapidly decimated; bear, deer and bighorn sheep are growing scarce; mountain goats and moose are nearing extinction; hawks, eagles and all kinds of game birds are much less abundant than formerly; prairie-dogs, groundsquirrels, wolves and coyotes are being exterminated by the U. S. Biological Survey. Great flocks of sheep and herds of cattle graze on the plains and in the foothills, and in parts of the National Forests, and many natural areas are being altered by too close grazing. Some areas, principally bordering Yellowstone National Park, are still largely in a primitive condition except for diminishing large game and the introduction of trout. Remote open deserts are also almost untouched. For present distribution of life at various altitudes see Cary's Life Zone Investigations in Wyoming. In nearly all sec. tions, close grazing and in the valleys, agriculture are changing natural conditions. Timber cutting under restricted conditions is allowed in some of the National Forests.

\section{BIRD RESERVATIONS}

Three are known to the writer. The Shoshone Bird Reservation, located in Park County, on the Shoshone River, above the Shoshone dam; water fowl 
here find a refuge. Loch Katrine Bird Reservation, located in the same county with a similar purpose. The Pathfinder Bird Reservation, located in Natrona and Carbon Counties, along the North Platte River above the Pathfinder dam. This is also a refuge for water birds.

\section{POLLUTION}

The mountain streams and in fact, nearly all streams in their upper courses are still unpolluted. In their lower courses, nearly all streams are more or less polluted by sewage from towns, waste from factories or refineries, or by unsanitary conditions of farmyards and ranches on their banks. Water in the desert, arid interior is frequently alkaline and unfit for use.

\section{NATURAL AREAS}

Wyoming State Preserves. There are twelve State game preserves, and two hot springs preserves in the State of Wyoming. The State game preserves embrace a total of about $6,900,000$ acres. The game laws provide that the open season allowed for certain game animals and game birds does not apply within the limits of these game preserves. The game animals receiving this protection include elk, deer, bighorn sheep, Rocky Mountain goats, pronghorn antelope and moose. Elk are also protected outside of the game preserves in Fremont County; this area includes all of Fremont County north of Wind River; the region of the Wind River Mountains between Popo Agie and Bridger State game preserves; and all of Fremont County south of Sweetwater R. and east of Big Sandy Creek. The birds specifically protected include four families, Gallinae, Anatidae, Limicolae and Rallidae (grouse, sage-chickens, ducks, geese, plover, snipe, and coots). The Montane Belt in which a large portion of these preserves is located, is quite uniformly characterized by forests of spruce, fir, lodgepole pine and aspen as well as by a large variety of lower shrubs and plants.

The hot springs preserves are set aside for the treatment and care of disease, for sanitary, recreational and other purposes. Both have points of remarkable interest, but the group of springs at Thermopolis is the larger and more widely known.

Several additional large areas and numerous small ones should be set aside as State preserves. For example:

(1) All of the region drained by the John Day River lying between the crests of the Salt River Range and the Wyoming Range; all lying within the Wyoming National Forest. It is said that no wheeled vehicle has ever travelled over most of this region.

(2) All of the Wind River Range included in what is now "elk protected territory." Besides including the highest mountains in Wyoming and the headwaters of Green River, it embraces a number of large lakes on the western slope of this range. Lies within the Bridger National Forest. (See page 237.)

(3) All of Sweetwater County lying north of the 5th Standard Parallel North and west of $109^{\circ} \mathrm{W}$. Longitude. This area includes the continental divide, the Great Divide Basin, and a part of the Red Desert; here is to be found probably the most barren part of Wyoming.

(4) All of Medicine Bow National Forest in Wyoming, lying east of Range 81 West. Deer, grouse, ptarmigan.

(5) Many other small regions including desert; lakes suitable for migratory birds, mountains, etc., too numerous to mention.

\section{References:}

Cary, M. Life Zones of Wyoming. $\mathrm{Bu}$. of Biol. Survey, North American Fauna No. 42, 1917.

Grave, B. H., and Walker, E. P. Wyoming Birds. University of Wyoming Bulletin, Vol. 12, No. 6, 1913. 
Knight, W. C. The Birds of Wyoming. Bull, No. 55, Wyoming Experiment Station, 1902. (Out of print.) The Yellowstone National Park. The Yellowstone National Park is rapidly becoming our best known park. It was created by act of Congress, March 1,1872 , and is under the supervision of the National Park Service of the Department of the Interior. The Park was established for the preservation of natural features and curiosities and is a sanctuary of wild life of every sort. The Park Service issues each year a bulletin containing descriptive material, information of various kinds, and the rules and regulations governing visitors and tourists in the park.

I. General features: The Yellowstone National Park is about $62 \mathrm{mi}$. long and $54 \mathrm{mi}$. wide; its area is $3348 \mathrm{sq}$. mi., or $2,142,720$ acres. The greater part of the park area, $3114 \mathrm{sq}$. mi., is located in northwestern Wyoming, $198 \mathrm{sq}$. mi. in Montana and $36 \mathrm{sq}$. mi. in Idaho. The elevation varies from near $5300 \mathrm{ft}$. at Gardiner, Montana, the north entrance to $11,155 \mathrm{ft}$. at Electric Peak. The principal area consists of a broad, elevated, volcanic plateau extensively covered with western coniferous forest. This plateau ranges from 7000 to $8500 \mathrm{ft}$. in elevation. The continental divide passes through the southwestern part of the park. On one side are headwaters of the Snake River and on the other the Madison and Yellowstone Rivers. Mention should be made of several large lakes, especially Yellowstone which has over 100 mi. of shore line. The most remarkable natural features are the great number, variety and size of the geysers, the hot springs, the Falls and the vivid coloring of the Grand Canyon of the Yellowstone, the fossil forests, and less evident to the passing tourist, the rich fauna and flora which are here undisturbed.

II. Original biota: The vast area of the park is probably the greatest and most successfully handled wild bird and wild animal preserve in the world. Firearms must be left outside or carried sealed through the park. Dogs must be confined or under leash at all times. Mining, and grazing of live stock, is prohibited. No herds or domestic animals are allowed to run free in the park. No trees are cut down except to make way for roads, trails, or camp sites. Campers must use only dead or fallen timber. The destruction, injury, defacement, or disturbance in any way of trees, flowers, vegetation, rocks, minerals, animal or bird or other life is prohibited. As the park is a sanctuary of wild life of all sorts, hunting, killing, trapping, capturing or frightening any bird or wild animal is prohibited. A few flowers may be picked unless the superintendent decides this is harmful. Fishing with hook and line is permitted. Under these conditions, except for roads, trails, hotels and camps this vast preserve is in a very nearly natural condition. Visitors, as a rule, keep to the beaten road, and with the exception of black bears do not of ten see wild animals which in summer are generally found in the more remote portions of the park. The park contains a great many deer, a good many antelope, a few hundred moose, several thousand elk, and a large herd of bison. Two hundred and five species of birds here live undisturbed lives. Ducks, geese, and other water birds are numerous, and many remain all winter on streams fed by hot springs. Hawks and eagles are common, and swans and pelicans may be seen on Yellowstone Lake. For lists of other birds and numerous other mammals, see bulletins issued by the Park Service.

The extensive, undulating, coniferous forest is characterized by lodgepole pine, Englemann spruce, Douglas fir, and a large variety of boreal shrubs and plants. At the higher altitudes alpine fir and white-bark pine are found near the timberline. At the lower altitudes are sagebrush, narrow-leafed cottonwood, aspen and western red cedar. The open grassy meadows and sagebrush slopes give way higher up to aspen and coniferous forest. 
Bears are seen daily at the garbage dumps of all the hotels and camps. Most of the other wild animals have their summer habitat higher up in the mountains or in more remote regions of the park. Tourists occasionally, but not frequently, see deer, coyotes, antelope, or elk. In winter, elk, antelope, mule deer, white-tailed deer, and bighorn sheep may be seen at the lower levels near Gardiner. Part of the tame herd of bison is kept in summer in an enclosure near Mammoth Hot Springs. Birds are most abundant around the lakes or in open spaces.

III. Present biotic conditions: There is probably no species of animal or plant entirely missing from the original biota. The chief modification of the original biota has been the introduction in the streams of a number of game fishes. A pamphlet by William C. Kendall, entitled "Fishes of the Yellowstone National Park," and published by the United States Bureau of Fisheries, gives information on this subject.

IV. Pollution: With thousands of visitors each year at each camp site, the water in adjacent creeks and streams is not safe to drink. Otherwise the water supply provided is pure and wholesome, and excellent regulations are provided to keep it so. Rules for the disposal of combustible rubbish, garbage and refuse and for providing other sanitary conditions are as strictly enforced as is possible under present management methods.

V. Transportation, lodging, supplies: The park has four entrances. It is reached on the north at Gardiner, Mont., by the Northern Pacific Railroad; on the west at West Yellowstone, Mont., by the Union Pacific Railroad; on the east by auto-stage (55.4 mi.) from Cody, Wyo., connecting with the Chicago, Burlington and Quincy Railroad; and, on the south by daily automobile service (178.7 mi.) from Lander, Wyoming, which connects with the Chicago Northwestern Railroad. Any one of the entrances may be reached by motorists over good automobile roads connecting with some of the main continental automobile highways. A license fee is charged. There are four hotels, five permanent camps, and an automobile transportation line, operated in the park. However, every person may provide his own means of transportation and meals, subject to given regulations. In the free camp grounds pure water is supplied and wood is available. Automobile supplies may be obtained from several authorized places in the park. Various kinds of supplies may be obtained at the general stores. Transportation facilities in the park includes, besides the regular automobiles on the main park highways, saddle-horses, or horses and guides from all hotels and permanent camps.

\section{References:}

(1) Rules and Regulations of Yellowstone National Park. Annual pamphlet of the National Park Service of the Department of the Interior. Gives much useful and interesting information in regard to animals and plants and includes a full bibliography of the park.

(2) Fishes of the Yellowstone National Park. By W. C. Kendall. Bureau of Fisheries Document No. 818, Department of Commerce.

(3) Life Zone Investigation in Wyoming. By Merritt Cary. North American Fauna No. 42, Bureau of Biological Survey, United States Department of Agriculture.

(4) The Birds of Yellowstone National Park. By M. P. Skinner. Roosevelt Wild Life Bull., 1925, Vol. 3, No. 1, pp. 1-192.

(5) The Big Game Animals of Yellowstone National Park. Edmund Heller. Roosevelt Wild Life Bulletin, 1925, Vol. 2, No. 4, pp. 393-455.

$$
-J . W . S \text {. }
$$

\section{National Monuments in Wyoming}

*Devil's Tower National Monument. The Devil's Tower is an almost vertical shaft of igneous rock about $600 \mathrm{ft}$. in 
height. It is one of the most conspicuous features of the Black Hills region, and since it rises above a rounded ridge of sedimentary rocks that is about 600 $\mathrm{ft}$. high, it may be seen in some directions for nearly $100 \mathrm{mi}$. Except near the top and near the base the sides are nearly perpendicular and are strongly fluted by great columns of igneous rock, which are usually five-sided and average about $6 \mathrm{ft}$. in diameter. The top is elliptical in outline, nearly flat, and varies from 60 to $100 \mathrm{ft}$. across. The tower has been scaled by means of special apparatus, but only at considerable risk. The general public can ascend to near the top of the base (a).

Devil's Tower is located in Crook County, Wyo., on the west bank of the Belle Fourche River $9 \mathrm{mi}$. from the Custer Battlefield Highway. The nearest settlement is Tower, which may be reached by stage or auto, $32 \mathrm{mi}$. from Moorcroft, Wyo., a station on the Chicago, Burlington \& Quincy Railway.

*Shoshone Cavern National Monument. The Shoshone Cavern National Monument includes 210 acres of rough mountainous land lying on the north face of Cedar Mountain about $3 \mathrm{mi}$. east of the great Shoshone Dam in Park County, Wyo. The cavern entrance is located at the summit of the reef of rocks at the head of a canyon, about $4 \mathrm{mi}$. southwesterly from Cody, Wyo. The passages are very intricate, so that a trip through the cave should not be undertaken without a competent guide, with a supply of ropes and lamps.

Guides can be employed at Cody, Wyo., a station on the Chicago, Burlington \& Quincy Railway. One may go by automobile or team to the foot of the mountain, about two mi. from Cody, and continue by the same means on a graded road about one-third the way up the mountain; from the end of this road by foot or on horseback to within $100 \mathrm{ft}$. of the entrance to the cave.

\section{Reference:}

General Information regarding the National Monuments. Dept. of the Interior, Washington, D. C.
*Teton State Game Preservet. (A2; A3; B2; B3; C3.) Over 500,000 acres. Part of the Teton National Forest, just south of Yellowstone Park, extending from the crest of Teton Mountains on the west, to the Continental Divide southeast of the Park. Chiefly mountain coniferous forest, including grasslands, sage brush, lakes and streams. Gently rolling to rugged hills and precipitous canyons and mountain sides. Chiefly pine and spruce forests (Canadian zone), but ranging from grassland and sagebrush (Transition) along southern border, to alpine meadows (Arctic Alpine zone) near east and west ends. Elk, deer, moose, bear, otter, game fish and water birds. Altitude, 6500 to $13,700 \mathrm{ft}$.

Jacksonf; $40 \mathrm{mi}$. north to (a) (h) Moran\|, which is located just inside of preserve on Jackson Lake; pack-horse, camp outfit**, for remote portions; (a) and $(w)$ easily accessible regions. Teton County, Wyo.

*Shoshone State Game Preserve†. (A2; A3; B2; B3; C3.) Over 400,000 acres. Part of the Shoshone National Forest, east of the Yellowstone National Park and south of North Fork Shoshone River; otherwise bounded roughly by east edge of Shoshone National Forest, South Fork of Shoshone River, Deer Creek, Absaraka Divide to Yount's Pk., to Hawk's Rest Mountain, south and west edge of Bridger Lake following outlet to Yellowstone River, thence to southern boundary of the Park. Mountain coniferous forest, several ranges, and mountains extending above timber line; sagebrush and grasslands; Bridger Lake, numerous small streams; headwaters of S. fork of Shoshone R. Rolling to sharply rough and precipitous. Chiefly pine and spruce forests (Canadian zone), but considerable areas of subalpine coniferous forest and alpine summits (Hudsonian, and Arctic-Alpine zone); borders on grassland and sagebrush (Transition zone) to the east. 7000 to $13,000 \mathrm{ft}$.

Cody $\ddagger$ is the nearest P. O., $25 \mathrm{mi}$. N.E.; north and east edge by auto or 
central part by pack-horse**; $25 \mathrm{mi}$. S.W. from (a) (h) Cody, Park County, Wyo.

${ }^{*}$ Hoodoo State Game Preserve. (A2; A3; B2; B3; C3.) 200,000 acres. Part of the Shoshone National Forest, east of the Yellowstone National Park and north of the Absaraka Divide. Mountain coniferous forest, some ranges and peaks above timber line; meadows, parks; headwaters of N. fork Shoshone and Lamar Rivers. Rolling to rough, rocky, precipitous situations. Chiefly pine and spruce forests (Canadian Zone), but alpine region (Arctic-Alpine Zone) well represented. Altitude, 7000 to $12,000 \mathrm{ft}$.

Cody $\ddagger$, 50 (?) mi. N.W.; north edge accessible by auto from Cody, the nearest P. O.; wagon, or pack-horse**. Park County, Wyo.

*Carter Mountain State Game Preserve. (A3; B2; B3; C3.) 150,000 acres. Part of the Shoshone National Forest, located east and southeast of the Shoshone State Game Preserve. Mountain coniferous forest, sagebrush, steppe and grassland; bordered by South fork of Shoshone River and includes all of the watershed of Boulder Creek and part of the watershed of the Grey Bull River. Rolling, hilly, mountainous. Chiefly pine and spruce forests (Canadian Zone), bordered in part by grassland and sagebrush (Transition Zone) part of the area extends some distance above timber line. 6000 to $11,000 \mathrm{ft}$.

Cody ; 20 to $60 \mathrm{mi}$. N.E.; $20 \mathrm{mi}$. to nearest P. O., (a) (h) Ishawooa, or $40 \mathrm{mi}$. to (a) (h) Valley, S.W. of Cody. Most of area**. Park County, Wyo.

*Popo Agie State Game Preserve. (A3; B2; B3; C3.) 375,000 acres. Include the southern end of the Washakie National Forest and a small part of the south end of the Bridger National Forest. Embraces the southern end of the Wind River Mountain Range; watersheds of Popo Agie and Sweetwater rivers and of the east fork of Green River. Mountain conifer forest, with frequent open slopes, bordered by dry rolling steppe and arid sage-brush plain; nearly one-third is subalpine coniferous forest (Hudsonian) or alpine meadow (Arctic-Alpine Zone), the remainder is pine and spruce forest (Canadian). 6500 to $12,500 \mathrm{ft}$.

Lander $\ddagger$ is 15 to $30 \mathrm{mi}$. N.E.; for most of area**, nearest P. O. is (a) (h) Lander; for S.E. section, Atlantic City, $30 \mathrm{mi}$., S. of Lander.

*Big Horn State Game Preserve. (A2; B2; B3; C3.) About 900,000 acres. Comprises the whole of the Big Horn National Forest, except a strip $4 \mathrm{mi}$. wide along the eastern border, and a strip $3 \mathrm{mi}$. wide on the western border from the Montana line to a point $14 \mathrm{mi}$. north of the 13th standard parallel. Mountain coniferous forest, rugged hills, open, sage-brush or grassy, slopes. Headwaters of Little Big Horn River and of numerous small streams emptying into Bighorn, Powder and Tongue Rivers. Traversed by the Big Horn Mountains, chiefly in pine-spruce forest belt; crest of range largely in subalpine belt, but considerable area toward southern end above timber line. 6500 to $13,000 \mathrm{ft}$.

Eastern slope reached best from Sheridan $\ddagger$ (20 mi.) or Buffalo $\ddagger$ (15 mi.); western slope reached from Worland $\ddagger$ (35 mi.), Manderson (30 mi.), Greybull (30 mi.), or Kane (18 mi.). Nearest postoffice, Eaton's Ranch, Buffalo, Tensleep, Hyattsville, Shell and Kane. Worland-Buffalo road crosses southern end. Remote regions accessible only by pack-horse**. In Sheridan, Johnson, Big Horn and Washakie counties, Wyo.

*Days River State Game Preserve. (A2; C3.) An irregular tract including 80,000 acres or more; bounded by the Snake River, by the boundary between the Teton and Wyoming National Forests, by the Little John Days and John Days rivers, and by the western boundary of the Wyoming National Forest. All within the Wyoming National Forest. Mountain coniferous forest, sagebrush, grassland; includes 
rugged hills and low mountains, and one side of the Grand Canyon of the Snake River. Embraces types of vegetation from grassland and sagebrush through coniferous forest to timber line. 6000 to $10,000 \mathrm{ft}$.

Afton $\ddagger$, about $40 \mathrm{mi}$. north by packhorse to preserve**. Or, Jackson $\ddagger$, about 25 south by pack-horse**. Lincoln County, Wyo.

(This preserve should be extended about $45 \mathrm{mi}$. southward to include all the drainage basin and watershed of the John Days River; this would add about 380,000 acres, including some lakes; none of this proposed region is suitable for agriculture.)

*Wind River State Game Preserve. (B3; C3.) 2920 acres. Lying chiefly within the Shoshone Indian reservation. This area is $3 \frac{1}{2} \mathrm{mi}$. long, $1 \frac{3}{8}$ to $1 \frac{1}{2} \mathrm{mi}$. wide, and embraces the most important portion of the Wind River Canyon. A narrow gorge, traversed by the Burlington R. R., with semi-desert grassland and sagebrush (Upper Sonoran); the precipices on either side merge into high rolling, arid hills with sagebrush, scattered conifers (Transition). 5000 to $6500 \mathrm{ft}$.

Thermopolis $\ddagger$, the nearest (a) and (w) P. O. is $15 \mathrm{mi}$. north; from nearest R. R. station, (w) Dornick, $\frac{1}{2}$ mi. south.

*Careyhurst State Game Preserve. (B3; C3; D4.) 70,400 acres, embracing all of Converse County in Township $33 \mathrm{~N}$., Range 74, 75, $76 \mathrm{~W}$. together with sections 7 and 18 in Township 33 N., Range $73 \mathrm{~W}$. North border includes flood plain of North Platte River; undulating hills, desert grassland, yucca, sagebrush, rabbit brush; traversed by two small streams which have sources in low mountains farther southwest. Antelope, jackrabbit, prairie-dog, sage-hens. 5000 to $6000 \mathrm{ft}$.

Glenrock $\ddagger$, also Careyhurst, at northern border; C. \& N. W. R. R.; (a) and (h). Converse County, Wyo.

*Bridger State Game Preserve. (A3; B2; B3; C3.) About 98,000 acres, including all of the Bridger National
Forest in Lincoln County; located principally in Townships 37,38 and $39 \mathrm{~N}$. and Ranges 111 and $112 \mathrm{~W}$. Includes slopes from eastern end of Gros Ventre Range and small streams leading into upper Green River. Mountain coniferous forest, sagebrush, grassland; rolling, hilly with mixed forest and open country. All types from sagebrush, through coniferous forest to alpine meadows represented. 7000 to $12,000 \mathrm{ft}$.

Pinedale $\ddagger$ may be reached by auto stage from Rock Springs, $102 \mathrm{mi}$. north; $40 \mathrm{mi}$. N.W. to nearest P. O. (a) Kendall, which is about $5 \mathrm{mi}$. from southern border of preserve**.

*Kendall State Game Preserve. (A4; C3.) About 150,000 acres. Bounded by the north boundary of Township $13 \mathrm{~N}$. by the eastern boundary of Range $105 \mathrm{~W}$., by the Wyoming state line, and by the western boundary of Range 108 W., traversed by the Green River; eastern end includes high hills or mountains that rise to about $9000 \mathrm{ft}$. Yucca, sagebrush, coniferous forest. 5500 to near $9000 \mathrm{ft}$.

May be reached** by wagon or auto (?) from Green River $\ddagger$ or from Rock Springs $\ddagger$, Wyo., 30 to $35 \mathrm{mi}$. north. Sweetwater County, Wyo.

*Splitrock Special Game Animal Preserve. (A3; A4; B3; C3.) $3,800,000$ acres. Bounded by the right of way of the Chicago and N. Western Ry., the North Platte R., the 6th Standard Parallel N., the 12th Guide Meridian West, Beaver Creek and the Popo Agie River. Extensive barren, arid and sandy plains; soil frequently alkaline, desert shrubbery and vegetation; several low ranges of mountains, with barren or sagebrush southern slopes, but with coniferous forest on top and on northern slopes; sagebrush, rabbit brush, yucca, cactus, cottonwood and willow; huge, bare granite domes, or ledges; ravines, canyons. Bordered in part by narrow flood plains of Popo Agie and N. Platte Rivers. Drainage chiefly by small creeks; traversed by Sweetwater River; no perennial streams; large artificial lake above Pathfinder dam in N. Platte 
River, Pathfinder Bird Reservation was located here, favorable to nesting and migratory birds. Should be re-established.

Principal stations accessible on C. \& N. W. R. R. are Casper $\ddagger$, Powder River\|,

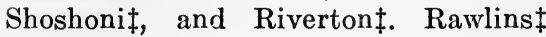
on U. P. R. R., 22 mi. S. Auto roads traverse in part, Casper to Riverton, Rawlins to Casper, Rawlins to Riverton; (a) and (h), camp outfit necessary for remote regions. Fremont, Natrona, Carbon and Sweetwater counties, Wyo.

*Big Horn Hot Springs State Preserve. (B3; B4.) 640 acres. Located just east and adjoining the town of Thermopolis and includes the Big Horn Hot Springs. Under complete control of the State Board of Charities and Reforms. Free bath house and free camping grounds maintained by the state on the Preserve. A part of the water is leased or rented to private bath houses. Good hotels, apartment houses, amusement parks, swimming pools, tennis courts, and dance pavilions are on the grounds. Tourists find this an almost ideal stopping point on the Yellowstone Highway. The town of (w) Thermopolisł also maintains a free camping site. For further information address Superintendent, Big Horn Hot Springs Preserve, Hot Springs, County, Wyo.

*Saratoga Hot Springs Preserve. (B4; C3.) 420 acres, more or less. A tract containing hot medicinal and mineral springs recently purchased by the State of Wyoming and "forever set aside for the treatment and care of diseases and for sanitary, charitable, and such other purposes as shall be from time to time determined by the Board" (of Charities and Reforms).

Near (w) Saratogaf, located on the Saratoga and Encampment R. R., Carbon County, Wyo.

Elk Refuge. An area of 2760 acres in Teton Co. Protects elk in winter, ducks and sage grouse. Fstablished 1915.

Flat Creek Refuge. An area of 40 acres established in 1922 for protection of waterfowl.

Five additional State Refuges have been created in recent years.

\section{MONTANA}

\section{By M. J. Elrod}

\section{GENERAL CONDITIONS}

The state of Montana includes approximately $147,000 \mathrm{sq}$. mi. It may be divided into three general regions; the western or mountainous area; the eastern or plains area, continuous with the Dakotas; and the central and much broken section, containing many small mountain ranges, connecting the plains region with the main range of the Rocky Mountains.

The western part, approximately onethird of the area, contains the most of the forested portion. The eastern part is prairie, except for narrow belts along the water courses, and occasional small areas of scattered coniferous trees in the highlands. No hardwoods occur except a few scattered scrub oak (Quercus macrocarpa) along the Missouri near the Dakota line. Small ash trees occur quite generally along the streams flowing toward the tributaries of the Missouri. The extensive forests are coniferous, with occasional stands of cottonwood, aspen and alder.

The higher summits are in the section adjacent to the Yellowstone National Park. A few summits northward rise slightly above 10,000 ft.; many reach 9000 , and hundreds rise $8000 \mathrm{ft}$. Snow banks and glaciers continue from year to year in the higher ranges throughout the state. Glacier National Park contains the largest number in a rather limited area, many of comparatively easy access. Summits are numerous but generally of small extent. There are exposed, treeless, and generally dry and comparatively lifeless mountain faces and broken talus, slopes.

Included in the state's large area are rivers and creeks both turbulent in the west and slower and muddy in the east. There are few lakes on the plains area, Medicine Lake in the extreme northeast is little but a marsh. Bowdoin lake in Phillips county in the north section is a shallow depression in the plain. Flat- 
head Lake in the northwest covers 190 sq. mi. There are hundreds of mountain lakes covering areas from a few acres to many sq. mi.

\section{ORIGINAL BIOTA}

\section{Forests region}

The Northern Coniferous Forest (Canadian and Hudsonian Zones of Merriam) includes the larger portion of the western forested area.

It is dense on the slopes of the western mountains, the timber line at about 9500 in the south, 6000 to $7000 \mathrm{ft}$. in the north with alpine slopes and meadows, or snow banks, above this elevation. The central portion may be included in the arid Coniferous Forest, the mountain slopes, small ranges, and foothills having dry climate and scant forest.

a. Montane and subalpine forest. The number of species of animals is relatively large in view of the fact that coniferous forests in general have little animal life. One may travel for a day in almost silent dense woods where the sun scarcely reaches the earth.

The montane forests are inhabited by the grizzly bear (Ursus sp.), black bear, marten (Martes americana abietinoides), weasel (Mustela sp.), striped skunk (Mephitis hudsonica), chipmunk (Eutamias sp.), pine squirrel, flying-squirrel (Glaucomys sabrinus subspp.), sagebrush deer-mouse, wood-rat (Neotoma cinerea subspp.), bog-lemming (Phenacomys orophilus), red-backed vole (Evotomys idahoensis), Merriam vole (Microtus $m$. mordax), Rocky Mountain jumpingmouse (Zapus p. princeps), snowshoe hare (Lepus b. bairdii), and deer.L. R. D.

The subalpine forest region is the habitat of the navigator shrew (Neosorex n. navigator), grizzly bear, hoary marmot (Marmota caligata nivaria), Columbian ground-squirrel, chipmunk (Eutamia sp.), sagebrush deer-mouse, red-backed vole, pika (Ochotona princeps subspp.), snowshoe hare, deer, bighorn sheep (Ovis c. canadensis), and Rocky Moun- tain goat (Oreamnos montanus missoulae).-L.R.D.

b. Arid Coniferous Forest. In the yellow pine forests occur the black bear (Ursus americanus), coyote (Canis sp.), cougar (Felis oregonensis hippolestes), yellow-bellied marmot (Marmota flaviventris nosophora), Columbian groundsquirrel, chipmunk (Eutamias sp.), pine squirrel (Sciurus hudsonicus richardsonii), sagebrush deer-mouse, and deer (Odocoileus sp.).-L. R. D.

\section{Alpine tundra}

For list of plants see British Columbia account (page 150).

The alpine summits have apparently few characteristic mammals, but the hoary marmot, pika, deer, bighorn sheep, and Rocky Mountain goat live close to timberline or at times wander above it. $-L$. R. D.

\section{The grassland}

The grassland characteristic of the Great Plains extends far into the state on the east and southeast.

Mammals. In the mixed prairie of eastern Montana are presumed to have occurred originally such mammals as the weasel (Mustela sp.), badger (Taxidea taxus subsp.), coyote (Canis n. nebrascensis), gray wolf (Canis nubilus), striped ground-squirrel (Citellus tridecemlineatus pallidus), prairie dog (Cynomys l. ludovicianus), sage pocket-gopher (Thomomys talpoides bullatus), pocketmouse (Perognathus sp.), Osgood deermouse (Peromyscus maniculatus osgoodi), white-tailed jackrabbit (Lepus townsendii campanius), cottontail rabbits (Sylvilagus nuttallii grangeri and $S$. audubonii baileyi). The bison (Bison b. bison), formerly abundant, is now extinct in the wild state.

The bunchgrass prairies of western Montana are known to be the home of the coyote (Canis lestes), Columbian ground-squirrel (Citellus c. columbianus) brown pocket-gopher (Thomomys fuscus fuscus), sagebrush deer-mouse (Peromyscus maniculatus artemisiae), gray 
vole (Microtus canescens), and whitetailed jackrabbit.

\section{PRESENT BIOTA}

In the National Forests and Parks (see page 214) much of the timber is as yet untouched, except by fire. Plants and animals here live as they have lived for ages past, scarcely influenced by man, except where sought as game or for sport.

The pronghorn antelope, grizzly bear, bighorn sheep, deer, moose, and elk, have been driven to the fastnesses of the hills. The antelope is nearly gone, and may be saved only by heroic efforts. The bison, once roaming the plains in millions, is gone. The National Bison range in the west has some 700 head, fenced in a 20,000 acre range. The grizzly bear and bighorn sheep, seen by Lewis and Clark along the Missouri near Dakota, now live a precarious life among the highest and most difficult mountains. Beaver are to be found in localities near the mountains and in the parks. Wolves are confined to the northern woods. The same thing has happened to game birds. Rapid settlement along the rivers and water courses has depleted their numbers until "rare" may now be written where formerly "abundant" would be applicable. The sage hen and prairie hen are rare. Their range has been turned by the plow, and flax or grain has replaced the sage. In 1900 there were few. English sparrows in the state; now they are in nearly every town. Mississippi river fish ascend the Missouri to the Great Falls, and up the Yellowstone to the falls. Above these are only a few landlocked or introduced species. In the Pacific drainage migration is prohibited by falls in Clark Fork river in Idaho near the Montana line. About a dozen landlocked native species remain in the headwaters.

All of these higher summits support an alpine fauna and flora. On these mountain summits, natural conditions are unaffected by man except where sheep and cattle are grazed. Many are in primitive or natural state.

Precipitation in the state varies exceedingly in different localities, and is, of course, heaviest in the mountains. Here most of the streams have their origin. Little pollution has occurred except in streams below mines and smelters, or as a result of natural wash sediment. The headwaters of the Missouri are generally clear and rushing, the lower portion muddy. The same is true of the Yellowstone which rises in the higher portions of the Yellowstone National Park. The debris from the mines of Butte and the tailings from the smelter at Anaconda have badly polluted the streams of that section, forming part of the headwaters of Clark Fork. The smelter at East Helena on a tributary of the Missouri, and the one at Great Falls, on the bank of the same river, the coal fields of Belt, Stockett, Roundup, and Red Lodge, all turn more or less undesirable material into the streams. A thin population, with no large cities, makes human pollution of the waters much less than that in most states. In general, waters of the main streams are more or less polluted, while the headwaters in the mountains are quite free. None or few of the waters of the National forests are polluted and one may drink freely from any of the thousands of small streams.

\section{NATURAL AREAS}

Eighteen National Forests are included in the state of Montana. In addition to the National Forests and Parks, with their millions of acres and thousand of areas yet in natural condition, a number of additional areas have been set apart or will be permanently preserved.-M. $J . E$.

*Glacier National Park. (A2.) This park is located in the northwestern part of Montana, embracing the main range of the Rocky Mountains, from the Canadian line some $45 \mathrm{mi}$. south and east, including the prairie slopes of the east face and the timbered area of the 
western ridges. Its area of about 1450 sq. mi. embraces 250 lakes of various sizes, 80 glaciers, from a few acres to several sq. mi. in area; the South Fork of Flathead River on the west and the middle Fork on the south, many large creeks and small rushing streams. The elevations are from $3144 \mathrm{ft}$. at Lake McDonald on the west and $4472 \mathrm{ft}$. at St. Mary Lake on the east to the summit of Mt. Cleveland, 10,438 ft. The lakes are from a few feet in depth to 387 , Lake McDonald, and 244, Lake Ellen Wilson. The vegetation includes mountain prairies and coniferous forests, alpine meadows, steppes, deciduous softwood forest, with local communities of swamps, bogs, ponds, lakes, rivers, mountains, ravines and canyons, bluffs, and cliffs, rocks and glacial deposits. A great opportunity will always be offered here for study of a variety of animal and plant communities from hydrophytic to xerophytic, and from plains to alpine mountain summits.

There are both pure and mixed stands of timber: including yellow, western white, lodgepole, white-bark, and timber pines (Pinus ponderosa, P. monticola, P. murrayana, $P$. albiculis, $P$. flexilis) Engelmann spruce (Picea Engelmanni), Douglas fir (Pseudotsuga mucronata), western hemlock (Tsugaheterophylla), Lyall's larch (Larix lyallii), western tamarack (Larix occidentalis), western red cedar (Thuya plicata), cottonwood (Populus trichocarpa) and aspen ( $P$. tremuloides). Nearly a thousand species of flowering plants occur in the Park limits, according to Standley. This systematic study completed, the work of the ecologist is facilitated. The same is true of the mammals and birds. Mrs. Bailey has listed the latter, Mr. Bailey the former. 186 species of birds and 60 of mammals have been recorded. All other fields are open. The mammals include bighorn sheep, goat, moose, elk, white-tailed and mule deer, pine squirrel, flying-squirrel, three species of chipmunks, three of ground squirrels, hoary marmot and brown woodchuck, woodrat, mice, muskrat, beaver, porcupine, two species of pocketgophers, two of rabbits, cougar, Canada lynx, bob-cat, gray wolf, coyote, red fox, otter, mink, fisher, weasels, marten, skunk, badger, brown and grizzly bears, three species of shrews, and four of bats.

Of the mountains, Cleveland, Stimpson, Kintla, Jackson and Siyeh rise above 10,000 ft. Triple Divide Peak is the only mountain on the continent sending water to three oceans. There are many mountains above $9000 \mathrm{ft}$., many even unnamed, and hundreds of square miles of unexplored territory. The Lewis overtrust, extending beyond the Park limits north and south, the chief cause of the Park's scenery, has brought about remarkable geological results which have greatly modified and influenced the biota. Some of the glaciers are quite accessible, affording opportunity for study of adjacent life, and of their effect on growth and distribution.

Trails lead to every section, from which those who know mountains may go to the highest or remotest sections. None of the streams are polluted. In summer, headquarters may be made at the park hotels and chalets, although a camp outfit is quite desirable if not essential for remoter parts.

Belton (the Park Line is just across the river), $2 \frac{1}{2} \mathrm{mi}$. to Lake McDonald (a) or (W) N., $8 \mathrm{mi}$. further to Glacier hotel 11 (boat), $8 \mathrm{mi}$. additional to Sperry glacier (w) or (h) E.; Glacier Park, $10 \mathrm{mi}$. to Two Medicine (a) or (w), $30 \mathrm{mi}$. to St. Mary, (a), $55 \mathrm{mi}$. to Many Glacier (a). Additional chalets "easily accessible."

Indian Reservations. Crow Reservation (B3.), 5475 sq. mi. in Yellowstone and Bighorn Counties. (See reference to Custer Battlefield Military Reservation.)

North Cheyenne Reservation (B3.), 765 sq. mi. in Rosebud and Bighorn counties. This and the preceding include large stretches of the Great Plains of the southeastern portion of the state which are as yet uninfluenced by farming. 
Fort Belknap Reservation (B3.), 840 sq. mi., in Blaine and Phillips counties, between the Milk River and the Little Rockies. See "Isolated Forest." This reservation is in the northern portion, near the Canadian border, and in the prairie and plains country.

Blackfeet Reservation (B3.), occupying large part of Glacier County and small part of Pondera County. It is just east of Glacier National Park, which was formerly a part of the reservation. It covers about $2000 \mathrm{sq}$. mi. and contains many plant and animal, associational regions, water, swamp, prairie, aspen forest, coniferous forest, glacial areas, mountains, and upland. The western border line runs between Upper and Lower St. Mary lakes, and about three-fourths of the Glacier ParkMcDermott Lake road of $55 \mathrm{mi}$. is in this reservation. See Glacier Park.

Fort Keogh Military Reserve. (B3.) Extending for $3 \mathrm{mi}$. from the Yellowstone river to the bluffs, from the Tongue River at Miles City to the fort buildings. About 3 sq. mi., level prairie, partly in hay, mostly unaffected except for grazing. Patches of old cottonwood trees, a fringe of river vegetation, semiarid and alkaline sections with corresponding growth. Typical of the river bottom flora and fauna.

Miles City $\ddagger$, across Tongue River (w), and $3 \mathrm{mi}$. south. $-M . J . E$.

Fort Missoula Military Reservationt. (B3.) Located on the bank of the Bitterroot River. About one sq. mi. of level prairie, with the usual fringe of brush and trees along the river. Vegetation of the reservation is chiefly spring bulbous and root species, with summer grasses. National reservation, fenced. River almost unpolluted, flows about a thousand second feet at low water. $3200 \mathrm{ft}$.

Missoula $\ddagger$, $4 \mathrm{mi}$. southwest, Missoula Electric. $-M . J . E$.

*Bighole Battlefield Monument. (B3.) On the headwaters of the Bighole river. This Monument is a few mi. from Wisdom $\ddagger$, on the western Park to Park highway, and is typical of large conifer- ous areas of the eastern or Gulf drainage near the continental divide.

*Natural Cave. (B2.) Located in the limestone cliffs and hills along the Jefferson river. About 40 acres, with vegetation of limestone cliffs and ravines. Cave with remarkable stalagmites and stalactites, life not studied. Federal preserve.

Whitehall $\ddagger$, 5 mi. east, north side of river (a). $-M$. J. $E$.

${ }^{*}$ Custer Battlefield Military Reservation. (B3.) Located at the top of the bluffs of the Little Bigtıorn river, where the battle was fought in 1876. This square mile of military reservation, besides forming the military cemetery for the dead of this battle, retains untouched and unaffected a small portion of the characteristic flora of the plains region, as well as a few of the mammals and invertebrates. Rolling prairie, $500 \mathrm{ft}$. above the Little Bighorn valley, continuous with the great treeless plains extending into Wyoming.

Crow Agency $\ddagger$, 2 mi. S.E. (a) or (w).$M . J . E$.

*Willow Creek Bird Reservation. (B3.) Near Augusta $\ddagger$ Montana. About one sq. mi., level, grassy, marshy, for protection of shore and marsh birds.M. J.E.

*Pishkun Bird Reservation. (B3.) About half way between Augusta $\ddagger$ and Choteaut, and 5 or $6 \mathrm{mi}$. west of the main road. A few sq. mi. of marshy land on the level border of the Sun river, and on the opposite (north) side of the river from the Willow Creek bird preserve. $-M . J . E$.

*Bird Islands. (B3.) In Flathead Lake. About 10 acres, comprising two small islands, forming the Flathead Lake Bird Reserve. Mountain formation and vegetation, rock shore and ledges with coarse gravel beach. Twenty to 30 species of song birds nest on the island; wild geese formerly nested in large numbers; sandpipers, and golden-eye now present. Scattering western yellow pine, Douglas fir, and cedar comprise the scant forest. Main land half mile away, 20 acre island close 
by. Main lake, to $50 \mathrm{ft}$. depth, all around. Lake fauna same as given for Shore Plain at Biological Station and other places. Lake, $2900 \mathrm{ft}$.; highest island point $50 \mathrm{ft}$. above lake. State preserve, shooting prohibited.

Polson $\ddagger$ $9 \mathrm{mi}$. northeast by boat.M. J.E.

*Montana National Bison Range. (B2.) In western Montana, along the Northern Pacific railroad between Ravalli and Dixon. Nearly 20,000 acres, including several mi. of Post creek, about one mi. of the Jocko river, with a mountain in the center about $2500 \mathrm{ft}$. above the river, or $5000 \mathrm{ft}$. above sea level; open prairie and mountain sides, and thinly timbered areas, with rock slides and cliffs, ravines, wind swept and exposed ridges, and with disappearing small streams heading in springs. Forests of western, yellow pine and Douglas fir, scant undergrowth of shrubbery. Fully described in Senate Report No. 467 and Report American Bison Society, 1908. Range established by Congress in May, 1908. Fenced as a preserve. The 37 bison placed in the range have increased to 460 in 1923 , with 325 elk, several hundred deer, 14 Rocky mountain goats, and several species of game birds. Mesophytic to xerophytic conditions. Jocko river flows about 600 sec. ft., contains several species of fish, and is unpolluted. Post creek heads in the Mission mountains $20 \mathrm{mi}$. distant and is little polluted. The mountains and valleys are greatly modified by glacial action. There are alkaline areas.

Ravallił, $\frac{1}{2}$ mi. N. (w) or (h); Dixon $\ddagger$, one mi. E. (w) or (h). - M. J. E.

*Lake Shore Plain Forest. (B2.) This comprises part of the ground of the University of Montana Biological Station on the east shore of Flathead Lake. About 90 acres with $1 \frac{1}{2}$ mi. of lake shore; glacial and lake gravel floor, with forest of yellow pine, Douglas fir, Engelmann spruce, western tamarack (larch), lowland fir (Abies grandis), birch, alder, and occasional cottonwood and western white pine, with characteristic under- growth and forest floor litter; shows succession of forest, young trees to those some $\mathbf{4 0 0}$ years old. A shore prominence rises $150 \mathrm{ft}$., with young growth. No cuttings, except around Station buildings, have yet been made. Some annuals and perennials, little or no grass. A small swift creek, with hard water, flows through one corner. A large spring flows from an old creek bed. Typical mesophytic forest; general aspect, of large areas of lake bordered forest. The fauna includes the pine squirrel, chipmunk, weasel, flying squirrel, mountain woodrat, bats, mice, with incursions from the adjacent forest of bear, deer, coyote, and others; many song birds, the pheasant and blue grouse, Richardson's grouse, and many species of tree loving birds. The lake here forms Yellow Bay, to depth of $150 \mathrm{ft}$. West of the area the main lake goes down quickly to $290 \mathrm{ft}$. Lake fauna includes the native and introduced fishes, permanent and migrating water birds, and interesting plankton. Beach 50 to 100 ft. wide, sandy to gravelly and rocky. Lake rising 9 to $17 \mathrm{ft}$. during spring high water.

Lake level $2900 \mathrm{ft}$. Lake little polluted. State preserve, shooting prohibited. Polson $\ddagger 16 \mathrm{mi}$. northeast by boat, or $21 \mathrm{mi}$. by automobile; Somersł, $20 \mathrm{mi}$. by boat, or $24 \mathrm{mi}$. (a) southwest.$M . J . E$.

*Open Island Forest. (B2.) On Idlewilde Island in Flathead Lake. 34 acres, belonging to the University of Montana Biological Station. The open woods consist of western yellow pine, Douglas (red) fir, cedar and cottonwood; mesophytic forest, general aspect of large areas of western mountain woods. Shore rocky and coarse gravel. Lake deep to shallow, little polluted. Nearly level, a few feet above lake. State preserve, shooting prohibited. Polson $\ddagger, 6 \mathrm{mi}$. north by boat.-M.J.E.

Open Yellow Pine Forest and Prairie. (B2.) On Wild Horse Island in Flathead Lake. 36 acres on the lake shore, facing north; typical open forest of young to mature trees, with shore border of cedar 
and scattered cottonwood and Douglas fir. Forest merges into grassy mountain slope, typical merging of mesophytic into xerophytic in short distance. General aspect characteristic of forested plain adjacent to treeless mountain side in Montana. Fauna includes pine squirrel, and chipmunk. The lake was wide, coarsely graveled beach. Water rises in May and June from 9 to $17 \mathrm{ft}$., receding in summer to low level in late August. Lake 50$70 \mathrm{ft}$. deep, clear, little polluted. Lake fauna includes a dozen species of fish, entomostraca, protozoa, and other plankton $2900 \mathrm{ft}$., level, rising in three directions. State preserve, shooting prohibited.

Polsonf, $20 \mathrm{mi}$. northwest, auto-stage line to Dayton, and two mi. by boat, or $18 \mathrm{mi}$. by boat from Polson. Somersł, $25 \mathrm{mi}$. southwest, auto-stage line to Dayton, and two mi. by boat, or $20 \mathrm{mi}$. by boat from Somers Montana.-M.J.E.

Flathead River Islands. $\dagger$ (B2.) In the river between Polson and Dixon. Ten islands, comprising about 2000 acres, mostly flood area, largely of deciduous forest, mountainous vegetation, trees mainly cotton wood. These islands and the river adjacent are great resting places for migrant water birds, are the home for many native birds, and exhibit flood-plain development in various stages from early to mature. They should be made a permanent preserve. Flathead river, also called Pend d'Oreille, is the outlet of Flathead Lake, has much beautiful scenery is swift, little polluted, with the fish and invertebrates of the lake. About $2600 \mathrm{ft}$.

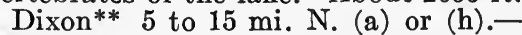
$M . J . E$.

*Isolated Forest**. (B2.) In the Jefferson National Forest, also in the Fort Belknap Indian Reservation. About 60 sq. mi., with deciduous and coniferous forest, mountainous vegetation, and vegetation of talus slopes and gravel slides, glacial topography with mountainous formation, the Little Rocky Mountains. Isolated mountains near the Missouri river, but reached from Malta $\ddagger$, Dodson $\ddagger$, or Harlem $\ddagger$. Valuable as showing tree growth in a semiarid section, removed from other mountain ranges or groups. Springs and creeks. Headquarters may be made at Zortman or Landusky.

Malta $\ddagger$, Harlem $\ddagger$, Dodson $\ddagger$, on the G. N. Ry., 50 to $60 \mathrm{mi}$. S.W. (a).F. A. Cobb.
*Pablo Reservoir Site†. On former Flathead Indian Reservation near Polson, Mont. About 3000 acres, level plain, prairie, partly filled with storage water several $\mathrm{ft}$. deep, from clear and unpolluted streams from the nearby Mission Mountains. Breeding place for water birds, resting place for migrants. Fenced, used only for storage site. About $3200 \mathrm{ft}$. Glacial formation.

Polson $\ddagger$ two mi. south, over and beyond a morainal hill $450 \mathrm{ft}$. above Flathead lake (a) or (h). $-M . J . E$.

Nine-Pipe Reservoir Site. In the former Flathead Indian Reservation near Ronan, Montana. About 2000 acres of former level plain prairie, in part covered with water, a permanent water reservoir, a great resting place for migratory birds and breeding range for water fowl, with aquatic vegetation and natural prairie adjacent to the water. Water several feet deep, from clear mountain streams, filling in spring, lowering in summer. About $3000 \mathrm{ft}$.; level.

Ronan $\ddagger$, about 5 mi. S. (a); Ravallił, past St. Ignatius $6 \mathrm{mi}$., then about 12 mi. N. (a). $-M . J . E$.

Southfork Ranget. (B2.) A short spur from the main range of the Rocky Mountains, containing large glaciers, tremendous cliffs several summits 9500 $\mathrm{ft}$. elevation across the Middlefork river from Glacier National Park. About 300 sq. mi. almost wholly mountains, of the same general character as Glacier Park; glaciers, lakes, waterfalls, cliffs, and general coloring effect as beautiful, striking, and interesting as that of the Park; should be added to the Park. Approach from the west side, from South fork river is through dense forests of untouched coniferous timber with protected stands of large and mature tamarack (western larch) up wooded slopes, and up a $2000 \mathrm{ft}$. talus to narrow summit, or up almost vertical cliffs of $3000 \mathrm{ft}$. Approach from the east, from Great Northern railway and Middlefork river, is past Stanton lake, up a ridge matted with yew, along exposed and arid slopes to extensive snow and ice field with alpine meadows and lakes. There is much glaciated country; talus slopes, canyons, ravines, lakes, and rushing streams are common. Chapman glacier faces north and is a large field. On the 
northeastern face is a long and wide field of snow and ice. Both are unexplored.

As yet there are no trails, hence travel is of exploratory nature, on foot or on horseback, carrying all necessities. Moose, elk, deer, bighorn sheep and, Rocky Mountain goats, black and grizzly bear, beaver, and smaller animals, are common. Both sides of the ranges and all ravines well timbered. Vegetation doubtless similar to that of Glacier Park, of which the region is a continuation. Drainage is entirely into the Pacific. Extremes of elevation, valleys to summits, about $7000 \mathrm{ft}$. All life communities from aquatic to semiarid, from prairie to timber, and lowland to alpine, may be had within short distances. Ideal unexplored and almost unknown country.

Nyack\|, on the Great Northern Railway, back track about $5 \mathrm{mi}$. to first bridge, up ravine to Stanton lake, up southern ridge as far as desired; Coraml|, about 15 mi. south (a), then eastward toward the high summits as one may conjecture.**

*Little St. Joe Game Preserve. In Mineral County, between the Missoula and St. Regis rivers and the Bitter Root mountains. Between 150 and 200 sq. mi., mountainous, with coniferous forests, unpolluted streams, and unmodified. Set aside in 1923 as a state game and bird preserve. Best reached from St. Regis§.-M.J. $E$.

*River Valley and Deciduous Forest. (B2.) Along the Rattlesnake creek. About 25 acres, called Greenough Park, on both sides of the creek; typical of mountain ravine-plains forest of cottonwood, alder, birch, and pine-shows middle age to mature stage, and changing. Forest with characteristic undergrowth, young to mature trees. Normal boulder-strewn swift stream, little polluted, 10 to $20 \mathrm{ft}$. wide, $\frac{1}{2}$ to $5 \mathrm{ft}$. deep, depending on season. The fauna includes pine squirrel, chipmunk, and many species of nesting birds. 3235 ft., level.

Missoula $\ddagger$, $\frac{1}{2}$ mi. N.E (w). $-M . J . E$.

* Spotted Bear Game Preserve. In parts of Powell and Flathead counties, between the Southfork of Flathead river and the main range of the Rockies. Several hundred sq. mi. with Spotted Bear creek as northern boundary; set apart in 1923 as a state game and bird preserve; reached from Missoula§, about $10 \mathrm{mi}$. N.W.; coniferous forests, mountains above 9500 , rushing streams, open prairies.-M. J. E.

Wolf Creek Game Preserve. In Lincoln County. Two townships at the headwaters of Wolf creek, in the Kootenai river drainage; mountains, with forests; reached from Libby $\S$, about 40 or 50 mi. E., or from Jennings $\$$, over the mountains some $20 \mathrm{mi}$; coniferous forests, open glades, rushing streams. Set apart in 1923 as a state game preserve.

*Snow Creek State Game Preserve. In bad lands, or breaks, bordering the Missouri river on south bank, and extending back from 10 to $15 \mathrm{mi}$. About 300 sq. mi., containing deciduous forest, coniferous forest, semi-desert and arid vegetation, with sand areas, talus slopes, gravel slides, ravines, canyons, hills and bluffs, and much glacial soil. Valuable, aside from a game preserve mainly for deer, for its tree growth of coniferous and deciduous forests, in semi-arid section. Eastern limits of Douglas fir. Generally below the prairie level. from 50 to $250 \mathrm{ft}$. Townships 20, 21, 22, Ranges, 34, 35, 36, 37, 38, E. Mont, Merid.

Miles Citył, $92 \mathrm{mi}$. N.W. (a); Jordan 12 to $25 \mathrm{mi}$. N.W. (a). $-F$. B. Cobb.

\section{NORTH DAKOTA}

\section{By J. T. Sarvis and J. E. Switzer}

\section{GENERAL CONDITIONS (J. E. S.)}

North Dakota is located near the center of the North American Continent, in the grass land of the great central lowland between latitudes $45^{\circ}$ $56^{\prime}$ and $49^{\circ} \mathrm{N}$.

\section{Topography}

The state is characterized by the low level Lake Agassiz plain in the eastern part, bordered by a gently rolling prairie belt stretching to the westward which is crossed by occasional morainic belts 
of hills, dotted by many lakes, and gashed by a few deep valleys. Yet farther to the westward the land rises abruptly to the Missouri Plateau, crowned near its eastward margin by the Coteaus of the Missouri. On the northern boundary, about midway of the state, is an old "outlier" of the Plateau, separated from it by the Lake Souris plain, known as the Turtle Mountains. At the base of the western slope of the Coteaus and following their general course is the broad valley of the Missouri. It is joined from the west by the valleys of the Little Missouri, Knife, Heart and Cannon Ball rivers. The general topography west of the Missouri River is a combination of broad valleys, gentle slopes, and abrupt buttes. Along the Little Missouri River, extending from 10 to $15 \mathrm{mi}$. on either side is the well known Bad Lands, but these give way again to the more gentle slope and butte topography before the western boundary of the state is reached.

\section{Climate}

Because of its latitude and continental location the temperatures of North Dakota are very extreme. Summer temperatures of $100^{\circ} \mathrm{F}$. are experienced, and winter temperatures of $-40^{\circ} \mathrm{F}$. may be expected each year. Long periods in which the temperature reaches several degrees below zero each night are common. The summers are characterized by warm days and cool nights. Winter passes quickly into summer with little interim of spring. Rainfall varies from about 12 in. for the mean annual in the western part of the state to slightly more than $20 \mathrm{in}$. in the southeastern part. The precipitation is dominantly of the summer type. During the spring months, the corresponding figures are 6 and 10 in. respectively. The season normally free from frost varies from a little under 110 days to a little more than 120 days. The snowfall reaches about 30 in. and occasionally comes in the form of the disagreeable "Blizzard."

\section{The original biota}

North Dakota lies in the general dry grassland area and has but little diversity in vegetation. However, different areas have more or less distinct characteristics, due chiefly to the unequal distribution of rainfall and to differences in soil and drainage. Timbered areas were confined to narrow margins along the stream courses and the north facing slopes of their valleys, to the slopes bordering Devil's Lake, and to the Turtle Mountains. West of the Missouri River the forests were almost lacking even in the stream valleys. The typical dominants of the woodlands were the elm, oak, ash, maple, and box-elder. The aspen particularly dominated large areas in the Turtle Mountains, and the birch, hackberry, and ironwood grew along the Sheyenne valley. Various shrubs and plants formed a secondary layer under the trees and many herbaceous plants occurred, but disappeared where the trees were removed.

In the mixed prairie type of vegetation of the eastern part of the state the Andropogon grasses dominated. To the westward, with the decrease in moisture the Andropogons surrendered the dominance to the grama grass of the short grass country. In the closed drainage areas, rather extensive in the northeast third of the state, marsh plants found a favorable habitat. Among others, the manna and meadow grasses seem to have been the most abundant.

Wild ducks, geese, and other aquatic birds nested in large numbers in the marsh and lake areas. Prairie chicken and grouse vied with the white-tailed jackrabbit (Lepus townsendii campanius) in populating the uplands and the red squirrel (Sciurus hudsonicus) and cottontail rabbit (Sylvilagus floridanus similis) thrived in the woodlands along the stream courses. Upon all of these the coyote (Canis latrans and C. nebracensis) and red fox (Vulpes regalis) preyed, and the bison (Bison bison) and pronghorn antelope (Antilocapra 
americana) reigned as kings on the prairies. Along the lower Missouri Valley the deer (Odocoileus virginianus subsp. and $O$. hemionus) were found.

\section{Present biota}

The effect of agriculture has been to reduce much of the original prairie to crop land. Yet in the rougher western part of the state, in the Coteaus of the Missouri, and in the lowland areas too wet to cultivate, little change has been made. Timber has been at such a premium that it not only occupies its original area almost entirely, but has had added to it in the eastern part of the state many fine groves as wind breaks about the buildings of the farmers, which tend to break up the monotony of broad expanse of prairie. The area lying east of Devil's Lake and the Turtle Mountains is capable of forestation but the trees have been kept out by the frequency of prairie fires. In the Bad Lands the short grass prairie occurs on the tops of the buttes, but in many valleys little but sagebrush is found.

The wild geese have ceased to nest in the marshes, the coyote and red fox are still seen occasionally in the eastern part of the state but are more numerous to the westward. An open season for deer was granted for ten days in 1921. Sully's Hill National Park, on the southern margin of Devil's Lake, constitutes a preserve for both the plant and animal life of the state. Here a few bison graze as a reminder of the great herds which roamed the plains. The proposed national park in the heart of the Bad Lands near Medora should have the generous encouragement of every one who is interested in the preservation of the native life of the state.

\section{NATURAL AREAS (J. T. S.)}

*Prairie, Missouri River terrace. (C3.) Part of the Ft. Berthold Indian Reservation, site of Indian village called "Fishhook Village;" last occupied by the Mandans in their freedom before being reduced to the status of reserva- tion Indians. Also includes the Indian Scout's Cemetery where are buried men of the Mandan, Hidatsa and Arikara tribes who were enlisted in the United States Army in the 1870's, some of whom served under Custer, and some perished with him in the Battle of the Little Bighorn. A part of this tract is virgin prairie, part is the old village site which is reverting to the native prairie vegetation. About 400 acres should be further preserved by U. S. Government. This place is about $30 \mathrm{mi}$. west of the nearest railway station, Garrison, on Soo R. R.; $18 \mathrm{mi}$. from Elbowoods, McLean County, N. D.-Melvin $R$. Gilmore.

*Prairie. Lies on a terrace (first) of the Missouri River. Site of Military Post of Ft. Rice. (A4.) Mostly native prairie sod; partly planted with cottonwood and box-elder trees. Purchase of State Historical Society of North Dakota as trustee for the State. About $3 \frac{1}{2}$ acres, $3 \mathrm{mi}$. from Ft. Rice, Morton County, N. D. Preserved by the State.-Melvin R. Gilmore.

*Plains Area. (A4.) Prairie.

Mostly short-grass formation. Bouteloua gracilis and Stipa comata, dominate. Part of the area is used for a Coöperative Grazing Experiment by the U. S. Department of Agriculture, Bureau of Plant Industry, Office of Dry-Land Agriculture Investigations and the North Dakota State Experiment Station. Of value to anyone interested in grazing problems as it affords an opportunity to observe the effects of different systems and intensities of grazing upon the native vegetation. $1729 \mathrm{ft}$. ; level: 640 acres, part grazed and part hayland. Preserved by U. S. Department of Agriculture. Anyone wishing to visit this area should first call at the Northern Great Plains Field Station, U. S. Department of Agriculture at this point. Mandan, Morton County, N. D. (1). (a) Field Station, two mi. S.W. Grazing area $3.5 \mathrm{mi}$. S. of Mandan. N. P. R. R.-J.T.S.

Antelope Lake. (F6.) Shore and surrounding hillsides. About $10 \mathrm{sq}$. mi. of 
deciduous forest with flood plains, sand areas, glacial - topography around an alkaline lake, part of which is dry during drought periods. Valuable as containing many tree species growing at or near their range limits. This area also contains two hybrid poplar trees of undetermined parentage, which are hardier than poplars among which they grow when taken to prairie situations. The forest area contains bur oak, green ash, American elm, boxelder, balsam poplar, and trembling aspen-showing advancement from hillside situations to lake shore. Area should be preserved by the State. $1600 \mathrm{ft}$., on north border of the Coteau du Missouri. N. Sec. 6. Twp. 151, R. 73 W.

(a) Harvey, Wells County, N. D., $18 \mathrm{mi}$, N.W. Soo R. R.

(a) Anamoose, McHenry County, N. D., 8 mi., N.E. Soo R.R.-F. E. Cobb.

*Stump Lake Bird Reservation. An island in Stump Lake reserved as a refuge for birds of all kinds. $1500 \mathrm{ft}$. Twp. 161; R 61.

(a) Lakota, Nelson County, N. D., 20 mi., S. G. N. R. R.

*Verendrye National Monument. (A4.) A Federal monument covering a high butte known as Croxhigh Butte overlooking the Missouri River to the west above the Old Crossing of the early voyageurs from Canada, used after 1740. The high butte was the site of an Hidatsa village at one time. The name of the Chief of the village was Crowthat-flies-high. From this the butte has been named Crohigh Butte. A prairie typical to this northern section of the Great Plains. $2000 \mathrm{ft}$.; Twp. 152; R. 92 W. Federal Reserve.

(w) Sanish, Mountrail County, N.D. Soo R. R.-F. E. Cobb and M. R. Gilmore.

*Sully's Hill National Park. (A4.) A Federal Park preserving the site of an early exploring camp on the south shore of Devil's Lake. This area consists of hills, meadows, and forest; forest surrounds a high prairie hill containing practically a museum of the entire flora of the state. The U. S. Biological Survey maintains a preserve for elk, bison, and antelope. $1500 \mathrm{ft}$.; Twp. 162, R. 65. Preserved by the U. S. Government.

Devil's Lake, Ramsey County, 15 mi.,
S. G. N. and Soo. R. R.-F. E. Cobb and $M . R$. Gilmore.

*Chase Lake Bird Reservation. A State Preserve for birds of all kinds. 1400 ft.; Twp. 141, R. 69. Lake in Stutsman County. Preserved by the state.

Steele (1), Kidder County, N. D., 36 mi., N.E. N. P. R. R.

Crystal Springs (1), Kidder County, 12 mi., N. N. P. R. R. -F. E. Cobb.

*Prairie on a High Terrace. (F6.) Situated above the current of the Missouri. Part of the site of an old Indian village site, probably Mandan. Entirely reverted to native vegetation by long passage of time since its last occupation by the Mandans. Purchase by the State Historical Society of North Dakota, as trustee for the State. About $1600 \mathrm{ft}$. 6.15 acres. Preserved by the State.

(a) Huff, Morton County, N. D., two mi. N. P. R. R.

(a) Mandan (1), Morton County, N. D., about $25 \mathrm{mi}$., S.E. N. P. R. R.-M. R. Gilmore.

*Deciduous Forest and Flood Plain. (F6.) Alluvium. Located at confluence of Pembina River with the Red River of the north. Historic site of an old British fur trading post. Except for native trees of the river course and some native shrubs, most of the original vegetation has been exterminated by long human occupation. Gift from the City of Pembina to the State Historical Society as trustee for the State. About $800 \mathrm{ft}$.; about 3 acres. Preserved by the State.

(w) Pembina (1), Pembina County, N. D., $\frac{1}{8}$ mi. N. P. R. R. -M. R. Gilmore.

*Deciduous Forest. (F6.) Steep hillside from margin of Pembina River to the summit of the first terrace of the Pembina Mountain. Natural growth of native forest of the gorge and Pembina Mountainside, deciduous trees and shrubs. Gift to the State Historical Society of North Dakota as trustee for the State. About $950 \mathrm{ft}$. Preserved by the State.

(w) (a) Walhalla (1), Cavalier County, 
N. D., one mi. G. N. R. R. $-M . R$. Gilmore.

*Native Prairie. (A4.) Hillside and valley. This is an excellent specimen of undisturbed and unspoiled native prairie. Gift to the State Historical Society of North Dakota. About 1600 ft.; 5 acres. Preserved by the State.

(a) Jamestown (1), Stutsman County, N. D. 5 mi. N. P. R. R. $-M . R$. Gilmore.

${ }^{*}$ Deciduous Forest and Prairie. (H8.) Flood plain. Alluvium. Site of old Ft. Abercrombie is nearby. Not much trace of original vegetation is left. Gift to the State Historical Society of North Dakota for historical park. $935 \mathrm{ft}$; 6.25 acres. Preserved by the State.

(w) (a) Abercrombie (1), Richland County, one mi. C. M. \& St. P. R. R.-M. R. Gilmore.

Petrified Forest. Area of 25 to 100 sq. mi. Arid grassland on Bad Lands. Many fossil tree stumps. $15 \mathrm{mi}$. northwest of Medora, North Dakota. Inquire Mr. Carl Olsen, Peaceful Valley Ranch, Medora. Reached by wagon.Crystal Thompson.

\section{Reference:}

Bergman, Herbert F. Flora of North Dakota. 1917. 6th Biennial Report, N. D. Soil and Geol. Surv.

\section{SOUTH DAKOTA}

\section{By E. J. Petry and S. S. Visher}

\section{GENERAL CONDITIONS (E. J. P.)}

South Dakota, $400 \mathrm{mi}$. (east and west), is a part of the Great Plains and prairie which stretch from the foothills of the Rocky Mountains almost to the Mississippi River. The state contains lakes, small canyons, buttes, badlands and mountains of great interest to the traveler and scientist. The Missouri River divides the state into two nearly equal eastern and western parts, which differ widely in their soils, geologic and biologic features.

The eastern half, except a small area in the southeast, is underlain by Cretaceous strata, while its soils consist of a fertile dark brown loam of glacial origin, which originally constituted a great prairie, but which is at present almost entirely taken up by farms.

Throughout the northeastern part of this section are found many small lakes surrounded by deciduous groves, while in the southeast, where outcrops of Proterozoic age (Sioux quartzite) occur, there are several streams, notably the Big Sioux River, whose banks are picturesque palisades and cliffs of unexpected height and beauty. From 50 to $75 \mathrm{mi}$. west of the Big Sioux and running parallel with it is the James, or Dakota River, which meanders through an unbroken plain about 1200 ft. above sea-level at the south and 1500 ft. at the north. ${ }^{1}$ Like the Big Sioux, its banks and flood plains are partly wooded.

The western half of the state, beginning at the Missouri River, may be divided conveniently into four general regions. It consists essentially of a dry plain rising gradually from an elevation of about $1400 \mathrm{ft}$. in the east to $3500 \mathrm{ft}$. near the western boundary. This plain is traversed by five nearly parallel rivers which meander eastward and empty into the Missouri River.

$a$. The northwest quarter ${ }^{2}$ of this plain is interspersed with stony buttes several hundred ft. high, and shows rugged outcrops of Tertiary and Cretaceous formations (Laramie and Fox Hills), including clays, lignite, and sandstone of from 200 to $400 \mathrm{ft}$. aggregate thickness.

$b$. The second and largest area is mostly of Cretaceous (Pierre Shale) origin and stretches across the state along the Missouri River, but narrows abruptly toward the west till it occupies the middle third of the plain and finally divides, one arm passing to the north of the Black Hills area, the other to the

1 Darton, N. H. Geology and Underground Waters of South Dakota. U. S. Geol. Surv., Water Supply Paper 227, 1909, 156 pp., 15 plates, incl. maps. 2 Visher, S. S. The Biology of Harding County Northwestern South Dakota. S. D. Geol. Surv., Bull. 6, 126 pp., 1914 . 
southwest. The tough gumbo soils of this arid region are much eroded in some places and support only a small range of plant and animal life. Trees, such as cottonwoods, and hackberries are found chiefly along the streams, most of which often go dry. The higher areas supply pasture only, when sufficient moisture permits.

c. The southern quarter comprises the big Bad Lands of the White River and their southern uplands, the sandy loams and clays of which afford fine pasture-land and many fine agricultural tracts. This region consists mostly of Miocene (Arikaree)-very little Pliocene and Pleistocene-while its greatly eroded northern and northwestern parts, known as the Big Bad Lands of the White River, are exposures, on a grand scale, of Oligocene (Brule and Chadron) ${ }^{3}$ age and support little plant life.

These Bad Lands (Mauvaises Terres), about 50 by $75 \mathrm{mi}$. in extent, are among the most picturesque erosional regions in the world and their many varieties of fossils are world famous. Here are canyons, spires, walls, and many grotesque formations, which yield remains of prehistoric animal life of astonishing variety, some of which are related to modern animals such as turtles, camels, and horses. This area is practically unchanged except where an occasional settlement on the lower flat ground has resulted in cultivation of limited areas.

$d$. The fourth area, the Black Hills, with their partly pine-clad sides, rising above the plain to an altitude of 6000 to $7000 \mathrm{ft}$. above sea level, present the most wonderful part of South Dakota. In certain respects they are unsurpassed in beauty and geologic interest by any other mountainous region in the world. They intercept much moisture and on this account plant 4 and animal life is much more abundant than on the plains. Bear, deer, bison, and antelope (originally wild but now mostly in parks) are

${ }^{3}$ O'Harra, C. C. The White River Bad Lands. S. D. School of Mines. Bull. 13, 181 pp. plus 96 plates, 1920. (This contains a nearly complete bibliography.)

${ }^{4}$ O'Harra, C. C. O'Harra's Handbook of the Black Hills. 159 pp., 1913. among the larger mammals. The plant life partly parallels that of the middle and eastern states, and is largely unchanged except occasionally by lumbering and by fire. This region ( 60 by $120 \mathrm{mi}$.) with its long axis nearly northwest and southeast, presents an ovalshaped uplift of Proterozoic, Palaeozoic, and Mesozoic formations interspersed with valuable metalliferous igneous dykes bearing gold, silver, and other useful metals and minerals. The whole region is interspersed by gorges, deep canyons, parks, and caves of great scientific interest and indescribable beauty.

The rocky formations vary from the red and yellow clays and sandstones to the white limestone and pearly gypsum at the outer borders of the Red Valley, while the more somber colors of schists and ore-bearing strata blend with the pines and wide variety of hardwoods of the interior in a way which one may never forget.

\section{BIотA (Е. J. Р.)}

\section{A. Grassland}

a. Tall grass prairie (True prairie, Clements). The tall grass or Andropogon prairie occupied the eastern part of the state, ${ }^{5}$ except that part in which deciduous forest growth is possiblestream valleys and small lake basins. This is dominated by tall grasses among which the blue stems (Andropogon furcatus and $A$. scoparius), Indian grass (Sorghastrum nutans) and spear or needle grass (Stipa spartea) are important. Many other herbaceous plants bearing beautiful flowers are abundant.

Mammals: In the tall grass prairie of eastern South Dakota are probably found such mammals as the long-tailed weasel (Mustela l. longicauda), Northern Plains skunk (Mephitis hudsonica), badger (Taxidea taxus subsp.), eastern coyote (Canis latrans), gray wolf (Canis nubilus), striped ground-squirrel (Citellus $t$. tridecemlineatus), prairie pocketgopher (Geomys bursarius), Dakota

s Rydberg, P. A. Flora of the Black Hills of South Dakota. Contr. U. S. Nat. Herb., Vol. 3, 1896. (Petry, E.J. Plant Treasures of the Black Hills. Proc. S. D. Hort. Soc. 1924.) 
pocket-gopher (Thomomys talpoides rufescens), Kansas pocket-mouse (Perognathus hispidus paradoxus), harvestmouse (Reithrodontomys megalotis dychei), prairie deer-mouse (Peromyscus maniculatus bairdii), and white-tailed jackrabbit (Lepus townsendii campanius). The bison (Bison b. bison), elk (Cervus c. canadensis) and pronghorn antelope (Antilocapra americana) formerly occured.-L. R. D.

b. Short grass plains or steppe. The dry plains of the western part of the state were covered by a short grass sod in which grama grass (Bouteloua oligostachya) and buffalo grass (Bulbilis dactyloides) are dominant. Many xerophytic herbaceous plants as loco (Aragallus lambertii), Artemisia frigida and Chrysopsis villosa are mingled with the short grass sod. Small remnants of the short grass vegetation persist in the badlands.

The western mixed prairie or steppe is probably the home of the long-tailed weasel, black-footed ferret (Mustelanigripes), badger, swift fox (Vulpes velox), plains coyote (Canis n. nebracensis), prairie-dog (Cynomys l. ludovicianus), striped ground-squirrel (Citellus tridecemlineatus subsp.), sage pocketgopher (Thomomys talpoides bullatus), pocket-mice (Perognathus spp.), kangaroo-rat (Dipodomys ordii subsp.), white-tailed jackrabbit, Wyoming cottontail rabbit (Sylvilagus audubonii baileyi), and others. The gray wolf, bison, mule deer (Odocoileus h.hemionus) and pronghorn antelope formerly occurred, but are now rare or extinct in the region.-L. R. D.

The flora of the Bad Lands and the uplands to the south includes about 200 flowering plants consisting mostly of grasses, sedges, and weeds. Few trees are found in this area. The fauna includes about a score of mammals, of which the largest are the wolf, coyote, fox, porcupine and panther (deer and antelope are rare); while the birds number over 150 species. $^{6}$

- Over, W. H., and Thoms, C. S. Birds of South Dakota. S. D. Geol. and Nat. Hist. Surv., Bull. no. 9, 142 pp., 1921.

\section{B. Partially wooded areas}

a. Fringing forest. Strips of deciduous forest follow all the streams of eastern South Dakota and thin out westwardly until only scattered deciduous trees follow stream courses. Silver maple and box-elder (Acer saccharinum and $A$. negundo), elm (Ulmus americana), white ash (Fraxinus americana), hackberry (Celtis occidentalis), and willows are most important in the fringing forest.

The southeastern wooded river bottoms were likely originally inhabited by the prairie spotted skunk (Spilogale interrupta), striped skunk (Mephitis sp.), red fox (Vulpes fulva), fox squirrel (Sciurus niger rufiventer), eastern chipmunk (Tamias striatus griseus), eastern deer-mouse (Peromyscusleucopus noveboracensis), Nebraska cottontail rabbit (Sylvilagus floridanus similis), blacktailed deer and others. The black bear (Ursus americanus subsp.) probably occurred here natively. $-L . R . D$.

b. Black Hills Forest. The plant life of the Black Hills ${ }^{7}$ is a combination of eastern and western-deciduous trees from the eastern forest and coniferous trees from the west-western yellow pine (Pinus scopulorum) and red cedar (Juniperus scopulorum). Many plants with beautiful flowers and foliage and useful fruits abound.

In the coniferous forests of the Black Hills are found the Black Hills marmot (Marmota flaviventris dacota), a western chipmunk (Eutamias sp.), red squirrel (Sciurus hudsonicus dakotensis), Black Hills pocket-gopher (Thomomys talpoides nebulosus), woodrat (Neotoma cinerea rupicola), Black Hills cottontail rabbit (Sylvilagus nuttallii grangeri), and other species. $-L . R$. D.

III. ANIMAL ECOLOGY OF THE NORTHERN GREAT PLAINS (s. S. v.)

The Northern Great Plains extend from the High Plains of Kansas to central Alberta and from the prairies of

${ }^{7}$ Harvey, L. H. Floral Succession in the Prairiegrass Formation of southeastern South Dakota. Bot. Gaz., 46: 81-108; 277-298. 1908. 
eastern Nebraska, the Dakotas and Manitoba to the foothills of the Rockies. Western South Dakota is rather centrally located in this vast, rather uniform region, and the following account is serviceable for considerable peripheral areas.

Conspicuous animals of the short grass formation of South Dakota

Birds. Among the birds ${ }^{5}$ the only permanent resident represented by many individuals is the desert horned lark. ${ }^{9}$ Longspurs of some species are found in all seasons, the chestnut-collared and McCown's longspurs nesting here abundantly and the Lapland longspur wintering. Two other members of the sparrow family, the lark bunting and the western vesper sparrow are very numerous; the former is quite characteristic, as is also the desert horned lark. Other prominent nesting birds are the Brewer blackbird, burrowing owl, Sennett's nighthawk and upland plover. Formerly the long-billed curlew and the prairie sharp-tailed grouse were common. Several kinds of birds nest in the groves of scattered trees along the streams (considered here under woodland), but often feed along the steppe far from their nests. Examples are: the ferruginous rough-legged Swainson's and sparrow hawks. The cliff and barn swallows, nesting on cliffs or about buildings, are also seen often.

Mammals. No conspicuous species appears to be confined in its range to the steppe of South Dakota, though several varieties are. Of these the plains coyote (Canis nebracensis), pocket-gopher (Geomys bursarius and

'Based on "The Biogeography," Chapt. vi, pp. 80-108, of "The Geography of South Dakota," Bull. 8. S.D. Geol. Surv., Vermillion, S.D. 1918. See also The Biography of the Northern Great Plains, Geogr. Rev., vol. 11, pp. 89-115, August, 1916, The Geography, Geology and Biology of south-central South Dakota, Bull. 5, 1912, and The Biology of Harding County, southwestern South Dakota, Bull 6, cf. the South Dakota Geol. Surv., 1914.

- Scientific names are given in the papers mentioned in the preceding footnote, where plants and environmental conditions are also discussed.
Thomomys spp.), and certain mice and voles may be mentioned. Other mammals abundantly represented on the steppe are the prairie-dog (Cynomys ludovicianus), badger (Taxidea taxus), jackrabbit (Lepus townsendii campanius), striped and spotted skunks (Mephitis hudsonica and Spilogale interrupta), gray wolf (Canis occidentalis), kit-fox (Vulpes velox), long-tailed weasel (Mustela longicauda), striped ground squirrel (Citellus tridecem lineatus subsp.), and formerly the antelope (Antilocapra americana) and bison (Bison bison).

Other animals. The most common snake is the plain bull-snake (Pituophis sayi), with the plains blue racer (Coluber constrictor flaviventris) next and the prairie rattlesnake (Crotalus confluentus) third in most places and seasons. The horned-lizard (Phrynosoma) is numerous in many localities. The common toad (Bufo woodhousii) is seen frequently. The Great Plains toad (Bufo cognatus) is characteristic but not abundant.

Invertebrates aside from the insects are unimportant in this group of associations. It appears that only three of the numerous phyla are represented, the protozoa relatively sparsely, mollusca chiefly by only one species of land snail (Succinea grosvenorii) and the arthropoda by a few spiders and centipedes, and by numerous insects of six of the eight orders: Orthoptera (grasshoppers and locusts), Diptera (gnats, mosquitoes, flies), Lepidoptera (butterflies and moths), Coleoptera (beetles) and Hymenoptera (bees, wasps, ants Ichneumons) and Hemiptera (bugs). The locusts and grasshoppers are the most conspicuous insects and most injurious.

The Hymenoptera of several families (digger wasps, ants, wooly bees) are abundant. Blow flies, bot flies (Gastrophilus equi) and robber flies are plentiful. Lepidoptera are few upon the steppe. The beetles are mostly ground beetles. Bugs are very rare upon the steppe. 


\section{Some "adaptations" of the life of \\ the grassland to geographic conditions (S.S. V.)}

Birds. The birds of the grassland possess two or more of the following characteristics:

1. Nests are necessarily built on the ground.

2. Many kinds sing while on the wing. Examples are the lark bunting, longspur, Sprague's pipit, and frequently the western meadow lark and horned lark.

3 . The songs and calls are loud compared with those of birds of woodland or prairie. Because of the climatic conditions of the grassland, representatives of species in many cases are farther apart than in most other areas. Calls and songs fulfill their chief purpose only when they are heard by other individuals of the species, and therefore need to be relatively loud in the steppe.

4. Social flocking ${ }^{10}$ is less prominent than among the birds of the woods, water, or prairies, where not only do various species migrate in large flocks, but troops wander socially about in other seasons, especially in winter, and several abundant species nest in colonies. The grackle, crow, swift, swallows, night herons, blackbirds, marsh wrens, numerous water-birds, and the bobolink and dickcissel are examples. If the cliff swallow which nests here and there in the badlands, be excepted, none of the abundant birds of the steppe nest in colonies. The scattered distribution of life on the steppe, noted in the preceding paragraph, is exemplified in the distribution of the nests of the steppe birds. The lark bunting and longspurs, and occasionally the Swainson's hawk migrate in flocks which, however, soon break up. Flocking in the winter is largely accidental. Birds gather where food is available, in areas swept by the wind or in patches of taller vegetation which are not snow-covered. Weedy

10 Statements made by Craig, Wallace: "North Dakota Life," Bull. Am. Geog. Soc. XI, pp. 401415,1908 , have led to the erroneous generalization by a few animal ecologists unfamiliar with birds that gregariousness is a characteristic of grassland birds. fields, where seeds are abundant, often are the site of such gatherings.

5. Many have the ability to withstand strong wind. For example, seed-eaters feed during the winter in apparent comfort on wind-swept hills.

6. Females and nestlings are almost all protectively colored. This seems required by the exposure of the nesting sites.

7. Most species are highly migratory. Few individuals remain during winter, and these are of species different from those of summer, except in the case of the desert horned lark. Even this species migrates somewhat. The aridity and the inactivity of other life combine with the cold to encourage the desertion of the steppe during the winter season.

8. Most birds have the ability to withstand the intense heat of the sun. This is especially notable in the nestlings which are often on dark ground.

9. The birds of the grassland of necessity must require but little drinking water. Heavy dews are rare.

10. The power of acute long-range vision appears to be possessed by a much larger number of birds of the steppe than by those inhabiting woodlands. Clearness of atmosphere, slightness of relief over large areas, and the wideiy scattered distribution of life all probably have encouraged the development of acute long-range vision.

Mammals. The mammals of the grassland have all acquired two or more of the following characteristics:

1. Ability to run swiftly. Examples are the antelope (32 mi. an hour), jackrabbit (28 mi. an hour), coyote $(24 \mathrm{mi}$. an hour), kit fox or swift (20 mi. an hour), and gray wolf (20 mi. an hour). ${ }^{11}$

It is possible to run more swiftly upon dry grassy plains than through woods or brush, in marshes or across rugged tracts. For this reason the inhabitants of such plains have come to be the fleetest runners. Long distance running was developed among some of the

11 Velocities are those attained by the normal, healthy adult when pursued by greyhounds, and are quoted from Seton, E. T.: Life Histories of Northern Animals. (New York, 1909.) 
larger mammals, apparently because of the relative scarcity of places of retreat.

2. Ability to burrow. Examples are the pocket-gopher, ground-squirrel, badger, prairie-dog, mice, vole. About $70 \%$ of the species rear their young in burrows and nearly $50 \%$ of the species spend much of their time underground. Burrows are retreats from heat, cold, wind, and some enemies, and for the prairie-dog, at least in some cases, furnish access to the underground water supply.

3. Many have acute long-range vision; the fleet runners all have. This appears to have been developed by the same factors mentioned in the discussion of the vision of birds.

4. A gray or tawny type of coloration which harmonizes well with dead leaves is possessed by nearly all. The skunk, an exception, is less in need of protective coloration than are the other mammals of the plains.

5. Ability to do without much drinking water. Water for physiological activity and for cooling by perspiration is secured mainly from the food eaten. Footprints of most steppe animals are seldom seen in mud about water holes. This is especially true in regard to the rodents, including the jackrabbit.

6. The daily period of activity is chiefly in the early morning, in the evening, and to a lesser degree at night.

Voluntary activity of almost all abundant mammals of the grassland is very limited during the heat of the summer day, when as many as may be are in the shade. Activity generates heat which must be eliminated by perspiration, which in turn requires water, an article which often is precious.

7. Ability to hibernate. The longdistance runners and the carnivorous do not hibernate, but, with the exception of the rabbits, the rodents, the most numerous mammals on the plains, do, and for longer periods than related species in other formations. Hibernation is a response to the unfavorable conditions which prevail during the winter months.
8. The larger herbivores, the bison and antelope, migrated chiefly in response to irregularity of rain and snow. Wolves, which preyed upon them, accompanied them in their wanderings.

9. A few of the mammals of the grissland are gregarious; the bison and antelope congregated probably for protection from wolves and bears, and in response to the lack of numerous places of escape; but also in winter for the heat accumulated in a closely packed herd. Prairiedogs are grouped in towns for protection against coyotes and certain hawks, and possibly by the somewhat restricted soil and ground water conditions which they appear to require.

Reptiles. The reptiles hibernate for nearly half the year, or even longer; can get along without drinking water; and are of small size as compared with related forms in more humid areas. Although the vast majority of reptiles lay eggs, three of the five abundant steppe reptiles (the rattler, plains garter-snake, and horned-lizard) bring forth their young alive. This may be in response to the "hard" conditions imposed by the climate.

Insects. Concerning the insects of the grassland, the following statements may be made:

1. The diurnal period of greatest activity is in the forenoon from 7 to 11 o'clock, after the chill of the early morning is gone but before the heat becomes oppressive. Coition is carried on chiefly between 11 o'clock and one. During the rest of the twenty-four hours most of the insects are quiescent except when disturbed.

2. Seasonal activity is limited nearly to the warmer and more moist three or four months of the year, chiefly June, July and August. There is almost complete inactivity during the colder and drier months of the year. Most species are dormant during ten or eleven months of the year, when many are represented chiefly by eggs.

3. Many forms burrow or occupy mammalian burrows, in so doing having retreats from wind, heat, cold and some enemies. Grassland species in many 
cases burrow to much greater depths than related species of other communities.

4. There is a predominance of hoppers or fast walkers. The development of hopping as a chief mode of progression is not so much discouraged on the grassland as in several other formations by frequent collisions with tall vegetation. The habit of running is favored by bare soil and is more marked among insects of the drier than of the moister parts of the grassland and still more among those of the desert.

\section{Subdivisions of the grassland formation}

1. The Buffalo-grama grass or climax grasslandassociation. Nearly all the birds of the region nest usually or occasionally in this association. The Sprague's Pipit is here characteristic. The bison and the pronghorned antelope appear to have been at home here. The striped gopher is most abundant here, but reptiles and toads are less abundant.

2. The Wheat Grass or Clay Grassland Association. Few birds nest in the wheat grass associations. The relative barrenness of the upland areas and the frequency of flooding of the other portions are doubtless major deterrent influences. The sharp-tailed grouse, however, is more numerous in the floodplain phase of this association than elsewhere, possibly because the taller vegetation affords more protection than the upland associations. Each prairiedog town has one or more broods of burrowing owls. The prairie-dog is the most conspicuous mammal. In parts of this association, notably in Custer and Fall River counties, nearly every low terrace along the valleys is occupied along much of its extent by prairie-dog towns. The danger of being drowned out by the flood waters is greatly decreased by piling up around each hole much of the dirt brought up from below. Many entrances are as much as 12 or 15 in. above the general level of the "flat." This piling up is not accidental, as is shown by the repeated repairing by scraping dirt in from the periphery of the mound, and by the fact that in areas not subject to frequent flooding the detritus brought up from below is scattered widely. The longtailed weasel and the black footed ferret, which prey upon the prairiedog, are numerous, though not often seen. Gophers and other burrowing mammals are lacking in most of the flood-plain areas in the gumbo region, probably because of the floods.

3. Bunch-grass or Dry-soil Steppe Association (sand hills). Most of the animal life of sandy regions is associated with the springs and streams. The areas occupied by the typical sandhill vegetation have a sparse and not distinctive fauna so far as the larger animals are concerned. Of such typical portions, the birds most abundant are the western vesper sparrow, lark bunting and the western meadowlark. Sandy areas within the prairie region of Sanborn County, eastern South Dakota form eastern outliers of the breeding range of the prairie sharp-tailed grouse. The mammals most frequently seen are the jackrabbit, the cottontail rabbit, the plains chipmunk and the pocketgopher (Geomys lutescens). Because of the relative wildness of rough, sandy areas, they form retreats for wide ranging mammals such as wolves and coyotes. Of the reptiles, the most abundant snake is the hog-nosed snake (Heterodon nasicus). The yellow striped swift (Cnemidophorus) is plentiful in the more southern sandhills and another lizard occurs, as does a land turtle (Terrapene ornata). Several insects are abundant in sandy areas, including certain tiger beetles and the ant lion.

4. Buckbush Association. There are no large animals restricted to these patches though there are many nests of birds. In the grassland region, the prairie sharp-tailed grouse, long-billed curlew, upland plover, marsh and Swainson hawks and other large birds, as well as western meadow-larks and Brewer black birds often nest here. Cotton-tail rabbits and ground-squirrel. (Citellus tridecemlineatus, C. franklinii), and the prairie vole (Microtus ochrogaster) are 
at home here. Spiders are especially abundant.

5. Sagebrush Association. The most conspicuous bird characteristic of the sagebrush of this state is the sage hen, which was numerous here until a few years ago. It is being exterminated rapidly.

The most notable insect is the large black and white sage-moth, which is very conspicuous for a few days in July or August. The larvae feed upon sage leaves.

6. Badlands. The badlands, because of their relative inaccessibility, are the home of several carnivores. Gray wolves and coyotes are more frequently met here than elsewhere. Bobcats are plentiful. The puma or mountain lion was formerly not rare. A few antelope still feed on some of the "flats." Bighorn sheep, and mule deer formerly were common and the bighorn may not yet be extinct in the White River Bad Lands. The mammals now most frequently seen in badlands are the striped chipmunk and cottontail rabbit. The porcupine, of nocturnal habit, is also found here. The chief birds are the rock wren, Say's phoebe, cliff swallow, violet-green swallow, western lark sparrow, turkey vulture, and prairie falcon. Rattlesnakes are not lacking, though far from common. The horned-lizards ("toads") are seen occasionally.

The animals are grayish in color with the exception of the bats, swallows and swifts. The crevices and cavelets furnish homes for the chipmunk, bat, bobcat, Say's phoebe, prairie falcon, and rock wren. The cliff swallow and whitethroated swift find cliffs suitable for nesting sites. Several of the larger mammals, notably the bighorn sheep and mule or black-tailed deer, are powerful jumpers.

\section{NATURAL AREAS}

All areas save one "The Dells," noted south of a line from Brookings, South Dakota to Pierre, South Dakota, have been found to be either too artificial (e.g., dams), or too highly modified from the original state (deforested) to be considered in this work.

* Wind Cave National Park. In the Black Hills, the "scene of Custer's first stand, famous for many years for Indian fights and frontier lawlessness." "It is called Wind Cavie because of the strong currents of air which alternate in and out of its mouth. The park is also a game preserve of unusual merit" (From National Parks Portfolio). The strata in which the cave occurs are known as Pahasapa limestone. 10,899 acres; 3700 to $4000 \mathrm{ft}$. 4160 acres set aside for a bison preserve, which encloses deer, elk and antelope.

Hot Springs, $12 \mathrm{mi}$. by bus.-E. J.P. References:

Wind Cave National Park Rules and Regulations, Supt. Documents, Govt. Printing Office.

South Dakota School of Mines, Book of Views, 1920. The Pahasapa Quarterly, June, 1921.

* Crystal Cave. Within the northeast side of the Black Hills National Forest, halfway between Roubaix and Tilford; a most interesting and beautiful spot. This cave differs greatly in formation, crystals etc. from Wind Cave. It is to be reached by road from Piedmont, on the Chicago and Northwestern Railroad, lying about $10 \mathrm{mi}$. northwest of this city, along north side of Elk Creek. Reference:

Pahasapa Quarterly, June, 1921.

* Prairie and Partly Level Plain. In the United States grazing experiment tract, leased for 10 years. About 400 acres near southern edge of Fall River county, South Dakota; partly level plain and prairie. Slightly changed by grazing. Plants characteristic of surrounding areas, showing a few successions. The fauna includes prairie-dog and coyote. Elevation $3565 \mathrm{ft}$; ; slightly undulating.

Ardmore $\ddagger 2 \frac{1}{4}$ mi. N.W., C. B. \& Q. R. R.; about $30 \mathrm{mi}$. S. of Hot Springs, S. D.-E.J.P.

Black Hills National Forest. See U. S. Geol. Surv., 19th Rept. Vol. 5, p. 67, 1898. 
"The Dells." A deep rocky (red Sioux quartzite) gorge lying about $\frac{1}{2} \mathrm{mi}$. to $1 \frac{1}{2}$ mi. southeast of Dell Rapids. The northeast half is within the city limits and protected from spoliation, but the southeast half $\left(\frac{1}{4} \mathrm{mi}\right.$. by $\frac{3}{4} \mathrm{mi}$.) is still in danger of exploitation for building stone, etc. There is plenty of such stone in less scenic areas all about.

The interesting natural flora and part of the fauna are still intact, and the charm of this deep canyon-like gorge (100 to $150 \mathrm{ft}$.) is very surprising and refreshing after the traveler has gazed on hundreds of miles of continuous prairie.

Dell Rapids, on several improved auto trails, and Chi., Mil., \& St. Paul R. R. $-E . J . P$.

Warren's Woods: About 50 acres of upland deciduous forest of oak, elm, linden, and ash, with a score of underbrush, and several hundred herbaceous forms, lies $7 \mathrm{mi}$. northeast of White, South Dakota, and $\frac{1}{2} \mathrm{mi}$. southwest of Lake Hendricks, Minn.

The fauna is much reduced from the original. Soil consists of clays and gravels. Consists largely of a branching ravine, 50 to $75 \mathrm{ft}$. deep, with small stream.

White, by auto east $6 \mathrm{mi}$., north $1 \mathrm{mi}$; Chi., Rock Is. \& Pacific R. R.-E. J. P.

Waubay, Blue Dog, and Pickerel Lakes. A series (8) of marshy lakes, about 40 sq. mi., with some deciduous forest. Breeding haunts of many waterfowl and birds of prey.

Waubay, Chi. Mil. \& St. Paul R. R., thru lower third of area. Auto trails, east, west, north, and south.-E. J.P.
Buffalo Lakes. Similar to Waubay, etc., but about half that area. Very little changed from original condition, hence very good place to study wild plant and animal life. Flora undisturbed and breeding grounds of many animals.

Sisseton, $12 \mathrm{mi}$. west by auto; Chi., Mil. \& St. Paul R. R.

Eden, $5 \mathrm{mi}$. east by auto, Minneap., St. Paul, and Sault Ste. Marie R. R.E. J.P.

The Big Bad Lands of the White River. This wonderland of southern South Dakota has been outlined in part, in a bill (S. 3541) by Senator Norbeck, and by Williamson in 1923 (H. R. 2810) which is to establish Wonderland $\mathrm{Na}$ tional Park. Some eminent authorities think that the area should be continued enough farther westward to nearly double itssize. It would then include the wonderful $^{3}$ area about Scenic, S. D., and the intervening areas to the east and southwest joining the area specified in the bill. The only difficulties to be encountered in this extension, so far as I can learn, are some private claims. Two more townships would add the best areas.

I have not sufficient data to give exact outlines of the area, nor to describe its features better than has been done by the following writers: C. C. O'Hara, Bull. 13, School of Mines, S. D., Rapid City, S. D., 1920.

E. C. Perisho and S. S. Visher, South Dakota State Geological Survey, Bull. 5, 1912.

Chi., Mil. \& St. Paul R. R. passes through the long axis of this area, east and west. $-E$. J.P.

\section{F. States with Coniferous Forest, Semi-desert, and Desert ${ }^{1}$}

Utah, Nevada, Arizona and New Mexico are included here. Idaho, Colorado, and Texas which might be in-

1 This is a group of states classed by the Geological Survey as requiring guides to watering places. The followng publications of the U. S. Geological Survey relate to areas in the United States requiring guides to watering places.

Brown, J. S. Routes to Desert Watering Places in the Salton Sea Region, California. U. S. Geol.

Sur., Water Supply Paper 490-A. 1920.

Thompson, D. G. Routes to Desert Watering

Places in the Mohave Desert Region, California.

U. S. Geol. Surv., Water Supply Paper 490-B. 1921. Ross, C. P. Routes to Desert Watering Places in the Lower Gila Region, Arizona, Ibid, Water Supply cluded are placed elsewhere on account of the small area requiring Guides to Watering Places.

Paper, 490-C. 1922.

Bryan, Kirk. Routes to Desert Watering Places in Papago Country Arizona, Ibid, Water Supply Paper 490-D. 1922.

This series contains detailed maps of excellent character showing roads, other features and a printed guide to the various watering places.

Tre following Water Supply Papers are also of value: Nos. $277,294,320,343,422,423,425,427$ and $450 \mathrm{a}, \mathrm{b}, \mathrm{c}, \mathrm{d}$.

U.' S. Geol. Surv. Bull. 730-B contains a good map and much information on the Papago Country of southwestern Arizona. 


\section{UTAH}

\section{By C. F. Korstian}

Utah is situated near the center of the western United States on the great Intermountain Plateau. The main Wasatch Mountain Range extends north and south practically the entire length of the state; while the Uinta Mountains extend eastward from the Wasatch Range paralleling the Wyoming state line. By far the greater part of the state lies above an elevation of $4000 \mathrm{ft}$. The main summits of the mountains attain altitudes of 10,000 to $13,000 \mathrm{ft}$. A number of isolated mountain masses occur in practically every part of the state. Situated, as it is, in the interior of the continent and to the leeward of the great Sierra Nevada Mountain Range all of the state, with the exception of the higher mountains, has a distinctly arid climate. The annual rainfall varies from 5 to 15 in. throughout the lowerlying portions, while on the mountains the precipitation is 20 to 30 in. per year.

All the country west of the summit of the Wasatch Range drains into the Great Basin. The largest body of water in the state is the Great Salt Lake, the water of which is so salty that a small shrimp is practically the only form of life found in it. This lake is the present day remnant of the ancient Lake Bonneville which formerly occupied an extremely large area in this region. The old shore-line may be traced along the western foothills of the Wasatch Range all the way from Provo to a point some $30 \mathrm{mi}$. north of Ogden.

Practically all of the valleys and the plateau country between the mountain ranges were originally a sagebrush desert, the dominant species being sagebrush (Artemisia tridentata) associated with other small-leafed shrubs. Greasewood (Sarcobatus vermiculatus), and shadscale (Atriplex sp.) are the dominant species on extensive areas of alkali flats in the arid valleys. A distinctly halophytic association of vegetation is found on the salt flats adjacent to the
Great Salt Lake. On the coarser soils of the foothills the junipers (Juniperus utahensis and $J$. monosperma) and, in the southern part of the state, pinyon (Pinus edulis) form open park-like woodlands. (The foregoing types of vegetation fall within the Upper Sonoran Life Zone.)

A small area of extreme desert conditions occurs along the Virgin River in southwestern Utah. This is characterized as a small-leafed shrub desert in which the creosote bush (Covillea tridentata) is the dominant species (Lower Sonoran Life Zone). While no mammals except small burrowing forms occur naturally in this area, reptiles are very abundant.

The mountains were originally clothed with a coniferous forest which is often regarded as a southward extension of the northern evergreen forest. In the southern part of the state western yellow pine (Pinus ponderosa scopulorum) is most abundant. In the central and northern part of the state this species is largely replaced by a brush cover composed of various species of shrubs and small trees (Transition Life Zone). The next higher type altitudinally is that in which Douglas fir (Pseudotsuga taxifolia) and white fir (Abies concolor) are dominant (Canadian Life Zone). In the Uinta Mountains lodgepole pine (Pinus contorta) also forms rather extensive stands. On the higher mountains above $9000 \mathrm{ft}$. Engelmann spruce (Picea engelmanni) and alpine fir (Abies lasiocarpa) are the characteristic species (Hudsonian Life Zone). The forest conditions are described more fully by Baker and Locke in connection with the discussion of the National Forests in the Intermountain Region. ${ }^{1}$ Succulent plants are confined principally to the higher mountain slopes.

The following animals have been reported as inhabiting the sagebrush desert: pronghorn antelope (Antilocapra americana), coyote (Canis spp.),

\footnotetext{
1 This volume, page 224.
} 
prairie-dogs (Cynomys leucurus and $C$. parvidens), badger (Taxidea taxus), jackrabbits (Lepus townsendii and $L$. californicus deserticola), cottontail rabbits (Sylvilagus nuttallii grangeri and S. audubonii warreni), chipmunk (Eutamias sp.), ground-squirrels (Citellus sp.), mice, rattle-snakes, horned toads, and birds as follows: sage sparrows, sage thrashers, sage hens, ravens, herons, western mourning doves, and western meadowlarks. The forest-covered mountains are inhabited by elk (Cervus canadensis), mule deer (Odocoileus hemionus), black bear (Ursus americanus), mink (Mustela vison energumenos), marten (Martes sp.), yellowbellied marmot (Marmota flaviventris subspp.), weasels (Mustela spp.), tree squirrels, ground-squirrels, chipmunk (Eutamias spp.), pocket-gopher (Thomomys spp.), yellow-haired porcupine (Erethizon epixanthum), bob-cat (Lynx sp.), cougar (Felis oregonensis hippolestes), snowshoe hare (Lepus bairdii), and beaver (Castor canadensis subsp.). The latter are confined to a few streams but are now on the increase since they have been under protection. The majority of the other animals often range over two or more life zones. Among the birds found in the forests of Utah the following are worthy of mention: dusky grouse, woodpeckers, sapsuckers, flycatchers, crossbills, junco, nuthatch, kinglet, thrush, bluebird, blue jay, pine siskin, water ouzel, sparrows, grosbeak, creeper, Clark's nutcracker, hawks, owls and the eagle. Many birds that winter farther south nest within the state, some in the coniferous types, others in the deciduous trees and shrubs along the watercourses in the lower mountains, and still others in the sagebrush desert. The lakes and marshes are important to the migratory birds, especially the waterfowl which often alight while migrating.

Following the settlement of Utah the greatest agricultural development has taken place in those parts of the sagebrush desert where it has been possible to irrigate with water from streams rising in the mountains. The desert areas that have not been placed under irrigation have been used as winter range for sheep and cattle which have grazed in the mountain forests in summer. Because of the fact that the pioneer settlements of Utah were very remote from large industrial sources of supply it was necessary for the settlers to utilize the local resources. Therefore, with the continued development of the state, natural conditions in the vicinity of the settlements were materially changed through the denudation of the mountains as a result of unregulated timber cutting, unrestricted grazing, fires and the resultant erosion. Floods and uncontrolable high water became increasingly and alarmingly frequent in many localities, reservoirs and irrigation systems silted up rapidly, washouts were numerous, fields were covered with boulders, debris was brought down from the adjacent mountains, and streams became too muddy during flood periods, and in some cases at all times, for fish to live in them. Since the creation of the National Forests in the mountains, the U. S. Forest Service has inaugurated systems of timber cutting and regulated grazing which favor the ultimate restoration of the forest and the forage plants on the lands under its management. On the other hand in regions remote from the settlements large areas of virgin forest representing virtually natural conditions, except for some grazing, existed when they were incorporated in the National Forests. In the foothills and the valleys adjacent to the settlements, however, due to continued over-grazing and repeated fires the once luxuriant growth of sagebrush has been largely replaced by six-weeks grass (Bromus tectorum).

The bighorn sheep has become rare but is said to be increasing to some extent in the more rugged parts of the Uinta Mountains in the Ashley National Forest. A band of elk has been released 
in the Manti National Forest and another in the Cache National Forest, both of which are increasing. The U. S. Bureau of Fisheries and the U. S. Forest Service have coöperated with the State Game Department in restocking many of the streams with trout; rainbow trout, eastern brook trout and mackinaw trout have been introduced successfully.

The Cache Game Preserve covering 268,501 acres on the Cache National Forest, the Strawberry Game Preserve of 92,160 acres on the Uinta National Forest, the Fish Lake Game Preserve of 307,200 acres on the Fishlake National Forest, the Dixie Game Preserve of 435,200 acres on the Dixie National Forest, the Heaston Game Preserve of 299,200 acres, the Mountain Game Preserve of 19,440 acres, the Ogden Game Preserve of 41,600 acres, the Parowan Game Preserve of 27,520 acres and the Game Preserve of 46,080 acres adjoining Little Zion National Park are State Game Preserves under the control of the State Game Department. The U. S. Biological Survey protects the waterfowl in an 8560 acre Federal Game and Bird Refuge on the Strawberry Valley Project of the U. S. Reclamation Service. Deer and grouse are protected on 76,800 acres in the Zion National Park.

\section{MOLLUSCS OF THE GREAT BASIN}

This area is of great interest on account of its desert conditions and the Quaternary history of its great lakes, Lahontan, of which Great Salt Lake and Sevier Lake are the descendants, and Humboldt, Walker, Pyramid, Carson, and other small lakes which are relics of the great glacial Lake Bonneville. The molluscan fauna of these relic lakes is in some respects peculiar. See the paper by Call, On the Quaternary and Recent Mollusca of the Great Basin, in Bull. 11, U. S. Geol. Surv.

NATURAL AREAS

*Zion National Park. (A2.) The pinyon-juniper type is best developed on the low slopes, while the high mountain tops, which are reached with some difficulty, are covered with western yellow pine. The valley bottom bears a typical growth of cottonwood and other stream-bank species of that region. The fauna consists chiefly of small desert animals. This National Park can be reached from Cedar City very easily by auto stage. The elevation is about $5000 \mathrm{ft}$. in the bottom of the canyon.-F. S. Baker.

*The Dinosaur National Monument. (A3.) This reservation consists almost entirely of exposed beds of sedimentary rocks bearing in the crevices, scattered grasses and herbs, and a few stunted juniper trees characteristic of semiarid woodlands. A typical fauna of small animals is present. Elevation is about $6000 \mathrm{ft}$. Reached from Vernal, Utah (which is $13 \mathrm{mi}$. distance). The village of Jensen is not far from the Dinosaur quarries. $-F$. $S$. Baker.

*Natural Bridges National Monument. (A3.) This area consists chiefly of eroded sandstone rocks with little vegetation. Some juniper, stunted western yellow pine and Fraxinus anomala is present, together with desert herbs. There is a typical desert fauna of small animals. This area is most readily reached from Blanding, Utah, a distance of about $40 \mathrm{mi}$. over rough mountainous country necessitating horse back travel. The country is almost waterless, and services of a guide are necessary in visiting this reservation. -F. S. Baker.

Rainbow Bridge National Monument. Timpanogas Cave National Monument.

*Bryce Canyon National Monument. (B2.) Mountain Coniferous Forest $\dagger$ in the Sevier National Forest. About 4 sq. mi. of talus slopes, mountains and canyons in Bryce Canyon. Semi-desert conditions showing succession from sagebrush to western yellow pine forest. Reserved on account of scenic aspects, dissected eroded topography known as "Temple of the Gods." 6000 to $8000 \mathrm{ft}$. 
Marysvale $\ddagger$, 78 mi. south. D. \& R. G. R. R. daily stage to Panguitch, Utah $\ddagger, 26 \mathrm{mi}$. northwest of areall $\$$.C. F. $K$.

*Timpanogas Area. (B3.) Mountain Coniferous Forest $\dagger$ in the Wasatch National Forest. 10,000 acres of mountains, ravines, canyons, rocks, glaciers, cirques, in Utah County around Mt. Timpanogos. All grazing by domestic livestock has been restricted because of its scenic and ecological interests. Several thousand tourists visit the area each year being attracted by the glacier and mountain scenery. The area possesses great variety of vegetation, very favorable for the study of altitudinal zonation. 5000 to $12,000 \mathrm{ft}$.

Provof, Utah, $15 \mathrm{mi}$. northeast.C. F.K.

*Big Cottonwood Canyon Watershed. (B3.) Mountain Coniferous Forest $\dagger$ in the Wasatch National Forest. About $50 \mathrm{sq}$. mi. including flood plain, talus slopes, waterfalls, springs, swift streams, mountain canyons, on Big Cottonwood Canyon watershed. Protected by Salt Lake City and the U. S. Forest Service, because the city water supply is derived from the creek and also because of its excellent scenic features. The Forest Service has done considerable experimental silvicultural work on this watershed. In the aspen, fir, and spruce types of forest. Fauna includes beaver, bear, deer, muskrat. 5000 to $12,000 \mathrm{ft}$.

Salt Lake City $\ddagger, 25 \mathrm{mi}$. southeast. Brighton $\|$ in head of canyon.-C. F. $K$.

* Bear River Bay. Several thousand acres of shooting preserves in low swampy land near Great Salt Lake. Protected except during shooting season. Especialy good for ground nesting migratory birds. Near Brigham, Utah.-W. C. Allee.

Emigration Canyon. (C3.) Altitude 4500 to $7000 \mathrm{ft}$., typical semi-desert and conifer-covered areas, regular auto service up the canyon in summer from Salt Lake City.-J. M. Aldrich.

The Shore of Great Salt Lake. (B2.) A good place for study of dipterous fauna, take Saltair trains from the city.
Get off when the train turns around.-

J. M. Aldrich.

Salt Lake Beach at Garfield, Utah. (B2.) One sq. mi. lake beach with halophytic vegetation, located in Garfield County, $18 \mathrm{mi}$. west of Salt Lake City, a part of the Great Salt Lake beach at Garfield, Utah.-V.E. Shelford.

Reference:

Barnes, C. T. Mammals of Utah. Utah University Bul., 12 (1922), No. 15, pp. 160, figs. 31 . The author gives descriptions of 121 mammals occurring in Utah, together with accounts of the distribution and the habits of each.

\section{NEVADA}

By C. F. Korstian

Nevada is situated in the western United States on the great Intermountain Plateau and ranks sixth among the states in area.

The greater part of the state is a table land 4000 to $8000 \mathrm{ft}$. above sea level with lower elevations in the extreme southern part, and the tops of the higher mountains reach altitudes in excess of $10,000 \mathrm{ft}$. The state is bounded on the west by the Sierra Nevada Mountains while the Wasatch Range lies to the east just over the line in Utah. It is crossed by a series of parallel mountain ranges having a general northerly and southerly direction. Between the mountains are broad flat valleys presenting true desert conditions.

Practically all of the valleys and the plateau country between the mountain ranges were originally a sagebrush desert, the dominant species being sagebrush (Artemisia tridentata) associated with other small-leafed shrubs. The soil of the sagebrush desert is usually very fertile and yields excellent agricultural crops when watered sufficiently; but the supply of water available for irrigation is decidedly limited. Consequently, there is relatively little land under cultivation in the state except in a few of the better watered valleys, such as the Humboldt. Grease- 
wood (Sarcobatus vermiculatus) and shadscale (Atriplex sp.) are the dominant species on extensive areas of alkali flats in the arid valleys. A distinctly halophytic association of vegetation is found on the salt flats adjacent to many of the salt lakes and on those extensive areas in eastern Nevada which were covered originally by the ancient Lake Bonneville. On the coarser soils of the foothills the junipers (Juniperus utahensis and $J$. monosperma) and in the central and southern part of the state, pinyon (Pinus edulis and P. monophylla) form open park-like woodlands. (These types of vegetation fall within the Upper Sonoran Life Zone.)

An area of extreme desert conditions is found in the southern part of the state, similar to and sometimes considered an extension of the California desert. This is characterized as a small-leafed shrub desert in which the creosote bush (Covillea tridentata) and the sandbur (Franseria dumosa) are common dominant plants over considerable areas, (Lower Sonoran Life Zone). This association contains quite a number of deciduous shrubs and large semisucculents (Yucca brevifolia, Y. arborescens, and Opuntia sp.) are found scattered through it. Grasses and perennial herbs are uncommon, but shortlived annuals are abundant during the spring months. While no mammals except the small burrowing forms occur naturally in this area, reptiles are very abundant.

The higher mountains were originally clothed with a coniferous forest which, with certain modifications, may be regarded as a southward extension of the northern evergreen forest. Western yellow pine (Pinus ponderosa scopulorum) occurs limitedly on the Nevada Mountains and those to the south. In the northern part of the state this species is replaced at similar elevations by either a brush cover composed of various species of shrubs or often by grasslands (Transition Life Zone). The next higher type altitudinally is rather unique in that its composition is quite different from any other common forest type in adjacent states. Aspen (Populus tremuloides) is the commonest tree in the lower part of this type. Occurring to some extent in mixture with aspen and common at the higher elevations limber pine (Pinus flexilis) and alpine fir (Abies lasiocarpa) form forests which have been exploited commercially, notably in the Jarbidge Mountains. Farther south in the $\mathrm{Ne}-$ vada Mountains Engelmann spruce (Picea engelmanni) is found. Succulent plants are confined principally to the forest zone on the higher mountain slopes.

The animals and birds of the various vegetative associations common on the great Intermountain Plateau have been listed in the Utah account. ${ }^{1}$ The writer's knowledge of the fauna of Nevada is not sufficient to warrant an attempt to indicate such minor differences as may occur.

Many of the desert areas have been used as winter range for sheep and cattle which have grazed in the mountain forests of this and other states in summer. The state is much better adapted to the livestock industry than to farming. The grazing of livestock has been practiced almost continuously since the early settlement of the state and has been developed to such an extent that it has resulted in considerable over-grazing. On many of the open ranges in the state the situation is becoming acute. On the other hand, remedial measures to prevent overgrazing are being applied on the National Forests. ${ }^{2}$ Because of the fact that the settlements and mining camps of $\mathrm{Ne}$ vada have, for the most part, been very remote from large industrial sources of supply, it was necessary for the settlers to utilize the local resources. Therefore, with the continued development of the state and the exploitation of the local resources, the natural conditions

\footnotetext{
1 This volume, pages $557-560$.

2 See "Grazing in the National Forests," this volume, pages $33-34$.

The situation in Nevada is also illustrated in figs. 1-3, accompanying "Grazing Practice on the National Forests and Its Effect of Natural Conditions," by C. F. Korstian in, Scientific Monthly, 13: 275-281.
} 1921. 
in the vicinity of these settlements were materially changed through the denudation of the mountains as a result of unregulated timber cutting, unrestricted grazing, fires, and the resultant erosion. Since the creation of the National Forests in the mountains, the U. S. Forest Service has inaugurated systems of timber cutting and regulated grazing which favor the ultimate restoration of the forest and the forage plants on the lands under its management.

None of the major vegetational associations have been destroyed, except locally. Many desert areas, because of the extreme aridity, will doubtless remain in essentially a natural condition. The forest conditions have been described by Baker and Locke $^{3}$ in connection with the discussion of the National Forests. The location of the Forest Supervisor's headquarters is also given.

The Southern Pacific and Los Angeles and Salt Lake Railroads pass through the desert for the entire distance which they traverse the state. Side trips into the heart of the desert can be made from many of the towns along these railroads, the larger of which are Palisade, Elko, Battle Mountain, Winnemucca Reno, Caliente, Modena, and Las Vegas. The Overland Trail and the Lincoln Highway automobile routes from Utah to California cross the state northerly and the Arrowhead Trail crosses the southern tip.

Aside from the National Forests and Indian Reservations no specially reserved areas within Nevada have been brought to the attention of this Committee.

*The Lehman Cave National Monument in Nevada is an area of commonplace pinyon-juniper woodland, similar to thousands of acres elsewhere in Nevada, much more readily reached. This cave has been insufficiently studied for anything to be known regarding the animal life that may be present.F. S. Baker.

This volume, page 224.

\section{ARIZONA}

By G. A. Pearson, E. A. Goldman, Forrest Shreve and Charles T. VORHIES

\section{GENERAL TOPOGRAPHY (F. S.)}

The state is one in which altitude and topographic features are of basic importance in determining the distribution of the widely dissimilar types of biota found within its 113,020 sq. mi. of extent. The conditions of temperature and rainfall are themselves determined by altitude much more than by the $5 \frac{2}{3}^{\circ}$ of difference in latitude between its southern and northern borders.

The most elevated part of Arizona is a broad ridge running from the northwest corner to the center of the eastern boundary, and forming the southern edge of the Colorado Plateau. The broadest part of this ridge, in the northwestern part of the state, has been cut by the Grand Canyon of the Colorado and dissected by other streams. The southeastern end of the ridge, known as the Mogollon Mesa, is narrow, has been less dissected, and culminates near the New Mexican line in the White Mountains, embracing some of the highest elevations in the state. Superposed on the Mogollon Mesa, in the center of the northern half of Arizona, are the volcanic San Francisco Peaks (elevation 12,794 ft.) About $175 \mathrm{mi}$. to the southeast Ord Peak (10,266 ft.) and Escudilla Peak (10,691 ft.) form the summits of an extensive elevated region. On going northeast from any part of the Mogollon Mesa the descent is gradual into the plain drained by the Little Colorado River, lying between 5000 and $6000 \mathrm{ft}$. in elevation. This plain is bordered on the north and east by a plateau 6000 to $8000 \mathrm{ft}$. in elevation and by low mountains. On going southwest from the Mogollon Mesa into the drainage of the Salt and Bill Williams Rivers, the descent is abrupt

1 Where there was no cooperation between the different authors, the names stand in the order of receipt of manuscripts. The committee has arranged the parts and indicated authorship. 
and the most complex topography of the state is encountered.

The southwestern half of Arizona is a vast plain tilted toward the Colorado and Gila Rivers, and studded with numerous hills and mountains. The floor of the plain descends from elevations of 4000 to $5000 \mathrm{ft}$. near the New Mexican boundary to near sea level at Yuma. On the most elevated part of this plain are to be found a number of small and isolated mountains which rise to elevations of 8000 to $10,500 \mathrm{ft}$., including the Pinaleno (Graham), Chiricahua, Huachuca, Santa Rita and Santa Catalina ranges. Throughout the remainder of the plain the mountains are less numerous and not so high.

It is often said in Arizona that a bucket of water thrown out anywhere in the state will flow past Yuma, a remark which is as true with respect to the drainage systems as it is facetious with regard to the commonly prevailing conditions of evaporation.

The differences of altitude in Arizona are accompanied by great differences in temperature conditions. The growing season ranges from 105 days at Flagstaff (elevation $6886 \mathrm{ft}$.) to 310 days at Yuma. The minimum temperatures range from $-20^{\circ}$ at Flagstaff to $27^{\circ}$ at Yuma, and the maximum from $85^{\circ}$ at Flagstaff to $115^{\circ}$ at Yuma. The rainfall increases with altitude from an annual average of 3.36 in. at Yuma to 22.80 in. at Flagstaff, and is greater in the vicinity of large mountains than it is at the same elevation in the open plains.

\section{ORIGINAL BIOTIC REGIONS (F. S.)}

Arizona may be subdivided into the following natural landscape aspect regions: Desert (Lower Sonoran Zone), lying below $3500 \mathrm{ft}$. in the region south of the Mogollon Mesa or below 5000 $\mathrm{ft}$. to the north of it. Desert Grassland (Upper Sonoran Zone in part), lying above $3500 \mathrm{ft}$. and below $6000 \mathrm{ft}$., but not of general occurrence between these altitudes. Xerophytic Forest (Upper Sonoran Zone in part), lying between 5000 and $7000 \mathrm{ft}$., its lower limit being lower on mountain slopes than in open plains. Evergreen Forest (Transition and Canadian Zones), occuring from elevations of 6000 to $7000 \mathrm{ft}$. to the summits of all of the higher mountains except the San Francisco Peaks.

\section{A. Desert biota}

1. Vegetation (F.S.). The conspicuous perennial vegetation of this region consists of a relatively small number of species, although the total flora, including ephemeral herbaceous plants, is large. The animal life is also rich, particularly in small mammals, reptiles, birds, and insects. The most abundant and widely distributed plants are Covillea tridentata, Franseria dumosa, Acacia paucispina, Parkinsonia microphylla, Olneya tesota, Prosopis velutina and numerous types of cacti, chiefly of the genus Opuntia. The level plains are covered with low open stands of Covillea, or else of Franseria, Acacia and Prosopis. The flood-plains bear relatively dense forests of Prosopis velutina or $P$. glandulosa, reaching a maximum height of $30 \mathrm{ft}$., and accompanied by shrubby species of Zizyphus, Celtis and Lycium. On coarse outwash slopes there are open forests of Parkinsonia, Olneya and Prosopis, reaching a maximum height of $20 \mathrm{ft}$. and accompanied by a large number of smallleaved shrubs, such as Acacia, Lycium, Jatropha, Krameria, and Simmondsia, together with a great diversity of cacti, including Carnegiea, Ferocactus, Opuntia and Echinocereus. The vegetation of hills and lower mountain slopes is sometimes heavier and richer than that of the outwash slopes, particularly in the case of hills with highly retentive basaltic clay soil; or in other cases is poor and open, as on hills with soils derived from sandstone or rhyolite.

2. Animals (C. T. V.). The most abundant and conspicuous mammals of this region are the desert jackrabbits, the very interesting antelope jackrabbit (Lepus alleni) (Limited distribution in southern Arizona), Arizona cottontail, small ground squirrels, kangaroo rats, 
wood rat, pocket gohpers, pocket mice, white-footed mice, skunks of the genera (Mephitis, Spilogale, and Conepatus), badger, (Taxidea), and several species of bats, representing the smaller forms. The larger predators are represented by the fox, coyotes, (Canis mearnsi) and others, and the wildcat or "bobcat," (Lynx). Peccaries, once abundant (southern Arizona only) are now scarce, and the mule deer (locally blacktail) are still to be found in the desert. Antelope in times past occurred plentifully, but are now practically wiped out of the desert portion of their former range. The mountain sheep of the desert ranges of the most arid southwest portions of the state also belongs to this fauna.

Turning to the reptiles we find as the most conspicuous or interesting lizards several species of Sceloporus, Cnemidophorus, and Phrynosoma, and the Gila Monster, Heloderma suspectum. While there is a considerable number of species of snakes, many are comparatively seldom seen, the commonest being the racers, Zamenis, the Bull snake, Pituophis, and the Western Diamond Rattlesnake, Crotalus atrox $B$. and $G$. The "side winder" or horned rattlesnake, C. eerastes Hall, occurs in appropriately sandy portions of this zone. Another interest-exciting reptile of this region is the desert tortoise, Gopherus agassizii Cooper.

3. List of mammals and birds (Lower Sonoran Zone). The lower Sonoran Zone is essentially synonymous with the Desert area as described by Shreve. The following is a partial list of the present characteristic mammals and birds of the zone.

a. Mammals ${ }^{2}$ (A. E. G.). Pipistrellus hesperus hesperus, western bat; Antrozous pallidus pallidus, big-eared pale bat; Vulpes macrotis neomexicana, New Mexican desert fox; Citellus tereticaudus arizonae, Arizona ground squir-

2 Among species of mammals excluded are a number such as the coyote, badger, and mountain lion which range in all zones. Some of the species of mammals and birds included occur extensively in two zones as indicated. rel; Ammospermophilus harrisii harrisii, Harris' ground squirrel. Cynomys ludovicianus arizonensis, Arizona prairie dog; Thomomys fulvus toltecus, Toltec pocket gopher; Thomomys perpallidus chrysonotus, yellow-backed pocket gopher; Perognathus intermedius intermedius, intermediate pocket mouse; Perognathus intermedius phasma, Gila pocket mouse; Dipodomys deserti deserti, desert kangaroo rat; Dipodomys spectabilis spectabilis, banner-tailed kangaroo rat (also Upper Sonoran); Dipodomys merriami merriami, Merriam's kangaroo rat; Onychomys torridus torridus, desert grasshopper mouse; Peromyscus eremicus eremicus, desert mouse; Peromyscus maniculatus sonoriensis, Sonora whitefooted mouse (also Upper Sonoran); Sigmodon hispidus eremicus, Colorado Valley cotton rat; Sigmodon hispidus arizonae, Arizona cotton rat; Sigmodon hispidus confinis, Gila cotton rat; Neotoma albigula albigula, whitethroated wood rat (also Upper Sonoran); Lepus californicus eremicus, Arizona jackrabbit; Lepus californicus deserticola, Colorado desert jackrabbit; Sylvilagus audubonii arizonae, Arizona cottontail (also Upper Sonoran); Pecari angulatus sonoriensis, Sonora peccary; Ovis canadensis gailliardi Gailliard's mountain sheep (also Upper Sonoran).

b. Birds (E. A. G., and C. T. V.). Gambel's partridge, white-winged dove, mourning dove, Mexican ground dove, Inca dove, elf owl, western horned owl, road-runner, red-tailed hawk, Texas night hawk, Texan woodpecker, Gila woodpecker, gilded flicker, Arizona crested flycatcher, ash-throated flycatcher, vermilion flycatcher, Sonora redwing, Arizona hooded oriole, Bullock's oriole, house finch, western lark sparrow, desert sparrow, desert song sparrow, Abert's towhee, Arizona cardinal, Arizona pyrrhuloxia, Cooper's tanager, phainopepla, Arizona vireo, Lucy's warbler, Sonora yellow warbler, western mockingbird, cactus wren, verdin, gnatcatcher, Cassin's king bird, Palmer's thrasher, Arizona hooded oriole, canyon towhee. 


\section{B. Temperate semi-desert}

1. Vegetation (F.S.). It is only on relatively level plains or outwash slopes that the sparse type of desert grassland is found, carrying with it numerous representatives of the true desert of lower altitudes. The hills and mountain slopes lying at the same altitude are either desert or Xerophytic Forest. In a few localities between 5000 and $6000 \mathrm{ft}$., on granitic outwash soil, there are grasslands in which there occurs a nearly continuous stand of Bouteloua curtipendula, $B$. oligostachya, Festuca arizonica, Sporobolus cryptandrus and other grasses, with a very scanty representation of such desert forms as Opuntia spinosior, O. whipplei, Ferocactus wislizeni, Acacia greggii, and Momisia pallida.

The principal part of the Desert Grassland of Arizona consists of a very open stand of the above, together with numerous other species of Bouteloua, Eragrostis, Sporobolus, Andropogon, Hilaria, Festuca, Pappophorum and Aristida, together with such conspicuous plants as Yucca elata, Nolina erumpens, Prosopis, Acacia, Celtis and several species of Opuntia. The Desert Grassland is much poorer in shrubs and small trees than the Desert. Yucca elata is usually present in this vegetation and is its most striking plant, being 6 to $12 \mathrm{ft}$. in height and surmounted by flower stalks from 3 to $4 \mathrm{ft}$. in length.

2. Animals (C. T. V.). With respect to the animal life one can not draw much distinction between Desert and Desert Grassland regions without too many specific distinctions for the limits of this article. Of the most conspicuous mammals mentioned for the Desert it may be said that the antelope, mule deer, antelope jackrabbit, banner-tailed kangaroo rat, $D$. spectabilis, and wildcat tend to be more common in the higher regions of the Desert Grassland. For the birds the same may be said of the scaled quail and the cardinal, while the western kingbird supplants the Cassin's.

\section{Xerophytic forest}

1. Vegetation (F.S.). This vegetation lies above the desert slopes of the larger mountains and below the Evergreen Forest, being confined to mountains in southern Arizona, but found on plateaus and plains in central and northern Arizona. The dominant plants are Juniperus pachyphloea, $J$. monosperma or J. Utahensis, and Pinus edulis or $P$. cembroides. With the junipers and pinyons, especially in southern Arizona, occur several species of evergreen oaks, notably Quercus emoryi, $Q$. oblongifolia, and $Q$. arizonica. In the open parklike stand of these trees are found numerous shrubs, as Arctostaphylos, Garrya, Cercocarpus, Rhamus and Fallugia, as well as several types of $A$ gave and $Y u c c a$, and a very large number of root perennials and bunch grasses, the whole forming an extremely diversified and very interesting type of vegetation.

2. Animals (C.T. V.). Here we find a greater change in the more conspicuous faunal elements. In southern Arizona the white tail deer is found, while from the southern rim of the Mogollon plateau northward the deer of this and the montane forest are mule deer, doubtless different forms from the desert mule deer. The small, spotted and roundtailed ground squirrels give way to the larger, bushy tailed species of Citellus, the so-called rock squirrels, while Sciurus spp. now appear. The kit fox gives way to the gray fox. Prairie dog towns form a conspicuous feature of the landscape where normally abundant. The remarkable antelope jack drops out, but the California jack remains, though generally less plentiful than in the lower zone. Peccaries, as now reduced in numbers, are more plentiful here than in the desert, though perhaps not originally so. The basarisk, Bassariscus, the cougar, wolf and occasional jaguar are among the more important new elements in the mammalian fauna. Of the smaller mammals mentioned for the Desert, the changes here are chiefly in 
species or varieties and not in genera, though a Eutamias appears.

Among the birds we find now the Mearn's quail (restricted practically to southern Arizona, however), Stephen's whippoorwill, cuckoo, ashthroated flycatcher, canyon wren, and rock wren.

The collared lizard is rather Upper Sonoran than Lower Sonoran, and the Gila monster occasionally is found here, while new species of lizards of the desert genera mentioned, rather than new genera, mark the changes. The commonest rattlesnake is now $C$. molossus B. and G., in southern Arizona particularly, some confluentus Sag. and others in the northern portion.

D. List of mammals and birds: Semidesert and arid coniferous forest (Upper Sonoran Zone)

1. Mammals (E. A. G.). Otospermophilus variegatus juglans, rock squirrel; Citellus spilosoma macrospilotus, oracle spotted ground squirrel; Citellus spilosoma pratensis, plateau spotted ground squirrel (also Transition); $A m$ mospermophilus leucurus cinnamomeus, cinnamon antelope squirrel; Cynomys gunnisoni zuniensis, Zuni prairie dog (also Transition); Butamias quadrivittatus hopiensis, painted desert chipmunk; Sciurus arizonensis arizonensis, Arizona squirrel; Thomomys latirostris, painted desert pocket gopher; Perognathus flavus bimaculatus, Yavapai pocket mouse; Dipodomys spectablis spectabilis, banner-tailed kangaroo rat (also Lower Sonoran); Dipodomys ordii longipes, painted desert kangaroo rat; Onychomys leucogaster melanophrys, dusky grasshopper mouse; Peromyscus maniculatus sonoriensis, Sonora white-footed mouse (also Lower Sonoran); Peromyscus boylei rowleyi, Rowley's mouse (also Transition); Peromyscus truei truei, True's mouse; Sigmodon minimus minimus, buff-bellied cotton rat; Neotoma albigula albigula, white-throated wood rat (also Lower Sonoran); Neotoma lepida lepida, Thomas' wood rat; Neotoma lepida stephensi, Stephens' wood rat; Neotoma cinerea arizonae, Arizona bushy-tailed wood rat; Lepus californicus texianus, Texas jackrabbit; Sylvilagus audubonii arizonae, Arizona cottontail (also Lower Sonoran); Sylvilagus audubonii warreni, Colorado cottontail; Odocoileus couesi, Coues' white-tailed deer (also Transition and Canadian); Ovis canadensis gailliardi, Gailliard's mountain sheep (also Lower Sonoran).

2. Birds (E. A. G., and C. T. V.). Scaled partridge, Mearns' Massena partridge, Arizona woodpecker, Woodhouse's jay, Arizona jay, pinyon jay, Brewer's blackbird, Scott's sparrow, black-headed Grosbeak (also Transition), desert wren, bridled titmouse, Stephens' whippoorwill, rock wren.

\section{E. Mountain coniferous forest}

The evergreen coniferous forest of Arizona is found almost throughout the portions of the state above $7000 \mathrm{ft}$. in altitude, and in favorable localities it may be found as low as $6000 \mathrm{ft}$. The largest body of forest extends from the vicinity of the San Francisco peaks southeastward to the New Mexican line.

1. Lower Mountain Forest. Vegetation (Transition Zone) ( $F$. S.). At the lower edge of the largest areas or forest and on the small isolated mountain ranges the forest is a relatively open stand of pines (Pinus scopulorum or $P$. arizonica), sometimes with a clear floor, sometimes with an undergrowth of trees and shrubs such as are characteristic of the Xerophytic Forest, or others of higher range. In northern Arizona the commonest undershrubs and small trees are Quereus gambeli, which occurs singly or in large mottes, Robinia neo-mexicana, Arctostaphylos pungens, Cercocarpus parvifolius, Fallugia paradoxa, Rhus trilobata, Ceanothus greggii and Artemisia tridentata, the latter being frequent in extensive close stands. In southern Arizona the commonest undertrees and shrubs are Quercus hypoleuca, Q. reticulata, Arbutus arizonica, Ceanothus fendleri, and Robinia neo-mexicana. Throughout the state 
the pine forests are very rich in suffrutescent or herbaceous perennials, chiefly composites and legumes, while the number of annual species is extremely small.

b. Animals (C. T. V.). In this belt are found Mule Deer (northern Arizona) whitetail deer (south of the Mogollon Rim). Abert, Kaibab and tuft-eared squirrels, Sciurus spp., porcupine, and black bear are the principal conspicuous additions to the fauna. The rodent genera Peromyscus, Sigmodon, Perognathus, and even Citellus drop out wholly or in large part, while Microtus, and Eutamias appear as new elements. Most of the skunk and bat species also disappear.

Merriam's Turkey, the Band-tailed Pigeon, and the Steller Jay are the largest and perhaps best known new elements of the avifauna of this belt. Many warblers and other small birds breed here.

Reptiles are scarce in this belt, though some of the less common species such as Crotalus willardi Meek, and Gerrhonotus kingii have been taken at an altitude above $9000 \mathrm{ft}$. in southern Arizona, and at least one species of Phyrnosoma is commonly found.

2. List of birds and mammals (Transition Zone). a. Mammals (A. E. G.). Mustela arizonensis, Arizona weasel (also Canadian); Callospermophilus lateralis arizonensis, Arizona golden-mantled squirrel (also Canadian); Citellus spilosoma pratensis, plateau spotted ground squirrel (also Upper Sonoran); Cynomys gunnisoni zuniensis, Zuni prairie dog (also Upper Sonoran); Eutamias cinereicollis cinereicollis, San Francisco mountain chipmunk (also Canadian); Eutamias dorsalis dorsalis, Baird's chipmunk; Sciurus fremonti mogollonensis, Mogollon squirrel; Sciurus apache, Apache squirrel; Sciurus aberti aberti, Abert's squirrel; Sciurus kaibabensis, Kaibab squirrel; Thomomys fulvus fulvus, Fulvous pocket gopher (also Canadian); Peromyscus maniculatus rufinus, tawny white-footed mouse (also Canadian); Peromyscus boylii rowleyi, Row- ley's mouse, (also Upper Sonoran); Neotoma mexicana pinetorum, San Francisco mountain wood rat (also Canadian) Microtus montanus arizonensis, Arizona meadow mouse; Microtus mogollonensis, Mogollon meadow mouse; Sylvilagus nuttalli pinetis, Rocky Mountain cottontail; Odocoileus hemionus hemionus, Rocky Mountain mule deer (also Canadian); Odocoileus couesi, Coues' whitetailed deer (also Canadian).

b. Birds (A. E. G., and C. T. V.). Merriam's turkey (also Canadian), band-tailed pigeon (also Canadian), white-breasted woodpecker, broadtailed hummingbird, rufous hummingbird, Coues' flycatcher, Richardson's flycatcher, western evening grosbeak, red-backed junco (also Canadian), chestnut backed junco, spurred towhee (also Canadian), green tailed towhee, black-headed grosbeak (also Upper Sonoran), Louisiana tanager, western tanager, northern violet green swallow, Audubon's warbler (also Canadian), red-faced warbler (also Canadian), MacGillivray's warbler, western house wren (also Canadian), sierra madre creeper (also Canadian), rocky mountain nuthatch (also Canadian), pygmy nuthatch (also Canadian), chestnut-backed bluebird, painted redstart.

\section{F. Upper mountain forest}

1. Vegetation (F.S.). In the elevated parts of the Evergreen Forest the pines that have been mentioned are absent, the genus being represented by the less abundant Pinus flexilis and P. strobiformis. The dominant trees here are Abies concolor, Pseudotsuga taxifolia and Picea engelmannii. The lower limit of this vegetation (Canadian zone) varies according to slope exposure and other conditions from 7500 to $9000 \mathrm{ft}$. In it the trees are large, the stand is heavy and the number of shrubby species is large. The most common deciduous tree is Populus tremuloides, which often covers old burns in extensive pure stands. Along streams and in the more open parts of the forest are to be found 
Alnus oblongifolia, A. tenuifolia, Acer grandidentatum and $A$. brachypterum, as well as the shrubs Symphoricarpos, Ribes, Cornus, Jamesia, Sorbus, and Pachystima. The herbaceous plants are chiefly of northern relationship, with their activity confined to the earliest weeks of the brief growing season.

2. Animals (Canadian Zone) (A. E. G.). a. Mammals. Sorex vagrans monticola, San Francisco mountain shrew; Mustela arizonensis, Arizona weasel (also Transition); Callospermophilus lateralis arizonensis, golden-mantled squirrel (also Transition); Eutamias minimus arizonensis, Arizona chipmunk; Eutamias cinereicollis cinereicollis, San Francisco mountain chipmunk (also Transition); Sciurus fremonti mogollonensis, Mogollon squirrel; Sciurus fremonti grahamensis, Graham mountain's squirrel; Thomomys fulvus fulvus, Fulvous pocket gohper (also Transition); Peromyscus maniculatus rufinus, tawny white-footed mouse (also Transition); Neotoma mexicana pinetorum, San Francisco mountain wood rat (also Transition); Microtus alticola alticola, San Francisco mountain meadow mouse; Microtus alticola leucophaeus, Graham Mountain's meadow mouse; Odocoileus hemionus hemionus, Rocky Mountain mule deer (also Transition); Odocoileus couesi, Coues' white-tailed deer.

b. Birds. Merriam's turkey (also Transition), band-tailed pigeon (also Transition), white-breasted woodpecker, olive-sided flycatcher, Richardson's flycatcher, long-crested jay, Clarke's nutcracker, pine siskin, red-backed junco (also Transition), Arizona junco, spurred towhee (also Transition), greentailed towhee, northern violet green swallow, olive warbler, Audubon's warbler (also Transition), red-faced warbler (also Transition), western house wren (also Transition), Sierra madre creeper (also Transition), Rocky Mountain nuthatch (also Transition), pygmy nuthatch (also Transition), Townsend's solitaire, Rocky Mountain hermit thrush mountain bluebird.

\section{PRESENT BIOTA}

Original conditions with respect to plant life have been modified in varying degree. None of the major vegetational types have been destroyed, however, except on local areas. Cultivation has made very limited inroads. Lumbering and fire have devastated considerable areas of forest, but still larger bodies remain in the virgin state. Very few localities are free from the influence of domestic grazing animals; but substantial areas of all vegetational types are nearly in a natural state.

Wild animal life has been disturbed by the activities of man to a greater extent, perhaps, than plant life. Game laws and game refuges promise to preserve animals subject to extermination, but such artificial restrictions will not restore a natural balance. Among the wild animals still more or less abundant are bear, cougar, bob-cat coyote, deer, pronghor antelope, beaver, black-tailed jackrabbit, Abert squirrel, Kaibab squirrel, horned lark, road-runner, dusky grouse, Arizona jay, piñyon jay, Clarks nutcracker, Merriam's turkey, ducks and geese. Lakes and streams are as a rule artificially stocked with fish. Those which occur in the high mountains are fairly free from pollution.

\section{NATURAL AREAS}

*Grand Canyon National Park. Area 312,290 acres. Altitudes range from 2000 at the bottom of the canyon to over 8000 on the north rim. The higher plateau country bears magnificent forests of virgin yellow pine (Pinus ponderosa scopulorum. In the canyon may be found a great variety of vegetation ranging from extreme desert types to the moisture-loving forms occupying north exposures and water courses. Timber cutting and hunting are prohibited, but cattle grazing is permitted.

Grand Canyon $\ddagger$, A. T. \& S. F. R. R.

Apache Indian Reservation. 1,681,920 acres in east central Arizona. Altitudes range from 4000 to $11,000 \mathrm{ft}$., and vegetational zones from desert-grassland to spruce forest. 
Holbrook $\ddagger$, 75 mi. south, A. T. \& S. F. R. R. White River, Agency Headquarters.

Colorado River Indian Reservation. 272,027 acres in southwestern Arizona. Extreme desert mostly below $1000 \mathrm{ft}$., elevation; mountains, arid mesas and irrigable valley along Colorado River.

Parker $\ddagger$ A. T. \& S. F. R. R.

Gila River Indian Reservation. 371,422 acres in southern Arizona. Desert with mountains, arid mesas, and irrigable valleys. Giant cactus, Parkinsonia, Fouquieria and other desert plants.

Casa Grandeł, $25 \mathrm{mi}$. north, S. P. R. R.; Sacaton, Agency Headquarters.

Gila Bend Indian Reservation. 10,231 acres in southwestern Arizona. Desert, mainly below $2000 \mathrm{ft}$. Typical desert vegetation.

Gila Bendf, S. P. R. R. Agency Headquarters.

Navajo Indian Reservation. 8,783,997 acres in northeastern Arizona. Altitudes range from 4000 to $9000 \mathrm{ft}$., and vegetational zones from semi-desert to coniferous forest. Navajo National Park, area about one square mi., lies within the reservation. It contains petrified forests, a natural bridge and ancient cliff dwellings.

Flagstaff $\ddagger$, $75 \mathrm{mi}$. northeast, A. T. \& S. F. R. R.; Tuba City, Agency Headquarters western division.

Gallupł, N. M., $30 \mathrm{mi}$. northwest, A. T. \& S. F. R. R.; Fort Defiance, Agency Headquarters eastern division.

Hopi (Moqui) Indian Reservation. 2,472,320 acres in northeastern Arizona. Altitudes range from 4000 to $5000 \mathrm{ft}$., and vegetational zones from semidesert to woodland.

Holbrook $\ddagger$, $75 \mathrm{mi}$. north, A. T. \& S. F. R. R.; Keams Canyon, Agency Headquarters.

Hualapai Indian Reservation. 730,940 acres in northwestern Arizona, bordering on the Grand Canyon. Altitudes from 4000 to $5000 \mathrm{ft}$.

Kingman $\ddagger, 30$ mi. northeast, A. T. \& S. F. R. R.; Valentine $\ddagger$, Agency Headquarters.

Kaibab Indian Reservation. Area 138,240 acres, northwestern Arizona. Altitude ranges from 4000 to $5000 \mathrm{ft}$.
Papago Indian Reservation. 2,285,068 acres extending to the southern border of Arizona. The altitude is mainly below $1000 \mathrm{ft}$. This reservation represents the most extreme type of desert.

It can be traversed by automobile starting from Tucson or Casa Grande S. P. R. R., west about $25 \mathrm{mi}$.

Salt River Indian Reservation. 71,691 acres in southern Arizona. Desert, mostly below $3000 \mathrm{ft}$. elevation. Giant cactus and other typical desert vegetation.

Phoenix $\ddagger$ A. T. \& S. F. and A. E. R. R. San Carlos Indian Reservation. $1,834,240$ acres in east-central Arizona. Altitudes range from 4000 to $9000 \mathrm{ft}$. Semi-desert to coniferous forest.

Globeł, S. P. R. R.

Military reservations in Arizona

\begin{tabular}{|c|c|c|c|c|}
\hline NAME & LOCATION & 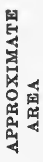 & $\begin{array}{l}\text { NEAREST } \\
\text { TOWN } \ddagger\end{array}$ & RAILROAD \\
\hline & & $\begin{array}{l}s q . \\
\text { mi. }\end{array}$ & & . \\
\hline Buckeye... & Southwest & 3 & Phoenix & A. E. \\
\hline Douglas.... & Southeast & 3 & Douglas & E. P. W. \\
\hline $\begin{array}{l}\text { Ft. Hua- } \\
\text { chuca.... }\end{array}$ & South & 80 & Ft. Hua- & E.P.\& \\
\hline Ft. Apache. & $\begin{array}{l}\text { East-Cen- } \\
\text { tral }\end{array}$ & 15 & $\begin{array}{l}\text { Hol- } \\
\text { brook }\end{array}$ & A. T. \& S. \\
\hline Florence... & South & 20 & Florence & A. E. \\
\hline $\begin{array}{l}\text { Mesa........ } \\
\text { Whipple }\end{array}$ & South & 2 & Mesa & A. E. \\
\hline Barracks. & Central & 5 & Prescott & S.F.P.\&P \\
\hline Wilmot... & South & 5 & Tucson & P. \& S S. W. \\
\hline Yuma. & Southwest & 2 & Yuma & S.P. \\
\hline
\end{tabular}

National monuments

\begin{tabular}{|c|c|c|c|c|}
\hline NAME & LOCATION & 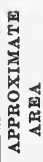 & $\begin{array}{c}\text { NEAREST } \\
\text { TOWN }\end{array}$ & RAILROAD \\
\hline & & $\begin{array}{l}s q \\
m i\end{array}$ & & \\
\hline $\begin{array}{l}\text { Petrified } \\
\text { Forest... }\end{array}$ & East & 50 & Adamana & A. T. \& \\
\hline $\begin{array}{l}\text { Papago } \\
\text { Sahuaro.. }\end{array}$ & Southwest & 5 & Phoenix & S. F.P. P. \& \\
\hline Casa & South & & Florence & Ariz. E. \\
\hline $\begin{array}{l}\text { Walnut } \\
\text { Canyon.. }\end{array}$ & Central & & Flagstaff & $\begin{array}{l}\text { A. T. \& } \\
\text { S. F. }\end{array}$ \\
\hline $\begin{array}{r}\text { Montezuma } \\
\text { Castle.... }\end{array}$ & Central & & Prescott & S. F. P. \& \\
\hline
\end{tabular}




\section{NEW MEXICO}

By A. O. Weese

\section{GENERAL FEATURES AND ORIGINAL BIOTA}

\section{Physiographic regions}

a. Great Plains. Included in this region is approximately the eastern third of the state. The most important subdivision is the valley of the Pecos river which drains southward into the Rio Grande.

b. The Southern Rockies extend into the north central portion of the State from Colorado, and continue as somewhat isolated chains southward into western Texas.

c. The Rio Grande Valley, which cuts through the state from north to south, is generally placed, with a small area in the southwestern corner drained by the Gila and its tributaries, in the "Basin and Range" province.

d. The Colorado Plateau occupies that part of the western half of the state not included above. Mount Taylor, with its associated lava-capped mesas, is the most conspicuous elevation in this region.

\section{Geographic and local plant and animal communities}

The greater part of the state is characterized by a temperate grassland broken by rocks, ravines, high and low mountains, etc. The second largest area is eastern succulent semi-desert in the south central part and Pecos valley. There are also considerable areas of xerophytic coniferous forest and of mountain coniferous forest.

a. Grassland. For plant communities see under Texas (page 507) and Arizona (page 565).

Characteristic animals are the pronghorn antelope, the coyote and the prairie dog. The bison also, at one time, ranged over the greater part of this area. There are many local variations due to mountains and edaphic conditions, such as the presence of streams, playas, saline areas and rock outcroppings.

b. Eastern succulent semi-desert. See under Texas (page 509).

c. Forests. About one-fifth of the state is covered with forest, i.e., in the Southern Rockies and the higher parts of the Colorado Plateau. These forests, except along water-courses, are of the semi-desert coniferous type, becoming increasingly mesophytic with increasing altitude.

For xerophytic coniferous forest see under Arizona (page 565) and for mountain conifer see under Colorado (page 524).

d. Cross section. A typical transect from Rio Grande Valley regions to the top of an adjacent peak of the Rocky Mountains would show a series of communities about as follows:

- (a) River Valley Communities

1. Mud-flat. Tiger beetle ( $\mathrm{C} i$ cindela hirticollis)

2. Cottonwood forest-Juncus meadow savanna. Tiger beetle (Cicindela vulgaris), western meadow lark.

3. Bigelovia association. Blister beetle (Cysteodemus wislizeni).

(b) Semi-desert ("mesa") formation. Pronghorn antelope, coyote, prairie-dog, desert horned lark, beetles (Eleodiini).

(c) Cedar (Juniperus monosperma). Western diamondback rattler (Crotalus a. atrox) and collared lizard (Crotaphytus collaris baileyi).

(d) Pinyon (Pinus edulis) The fence lizard (Sceloporus undulatus), Pinyon jay.

(द) Yellow pine (Pinus ponderosa), Black bear, mule deer, band-tailed pigeon.

(f) Douglas fir (Pseudotsuga mucro. nata). Lynx, dusky grouse, elk.

(g) Engelmann spruce (Picea engelmannii).

(h) Alpine meadow and chaparral associations. Bighorn sheep (also in $\mathrm{g}$ ), white-tailed ptarmigan. 


\section{PRESENT BIOTIC CONDITIONS}

Relatively small areas, except in some of the valleys, have been utilized for agriculture, but grazing has done a great deal to alter former conditions, especially in the short-grass regions, and to a lesser extent in the forests. In many places the original grasses have been almost entirely replaced by such plants as Gutierrezia and Russian thistle (Salsola). Efforts are being made toward the extermination of prairie dogs and other characteristic rodents which interfere with the complete utilization of the land, as well as so-called predatory animals such as the coyote. The bison, which formerly ranged to points west of the Rio Grande, remains only in captivity, and the prong-horn owes its preservation from final extinction to a few interested ranchers. Comparatively little lumbering has been done, and in all of the National Forests (see Pearson's account of D-3 National Forests, page 232) are considerable areas, inaccessible for grazing purposes, practically undisturbed except in so far as the larger animals have been killed off by sportsmen and government hunters of predatory animals. The Arizona elk, which made its last stand in northwestern New Mexico, has entirely disappeared, while individuals of the northern form have been brought back to the state within recent years and are reported to be flourishing. There are a few mountain sheep in the Guadalupe mountains on the southern border. The ranges and numbers of all other large animals have been sharply reduced.

\section{NATURAL AREAS}

The National Forests of New Mexico: (Carson, Santa Fe, Manzano, Lincoln, Datil, and Gila) comprise an area of approximately $9 \frac{1}{2}$ million acres, located mainly in the Rocky Mountain and Colorado Plateau regions of the state. About half of this area is in the pinyon and juniper zones. For further description refer to the section on National Forests.

\section{U. S. Preserves, exclusive of National Forests}

*Bandelier National Monument. See account of Santa Fe National Forest, Jemez division, in National Forests of the Southwestern District (page 000).

*Chaco Canyon National Monument. (B2.) 36 sq. mi. semi-desert with mountain, canyon and rocky situations. Near Putnam, San Juan County. Reached via Gallup (60 mi.) on main line of A. T. \& S. F. Ry.

*Carlsbad Bird Preserve. (B3.) 36 sq. mi. savanna, marsh, pond, river, with land and water birds. Eddy County, two mi. from Lakewood, on Pecos Valley branch of A. T. \& S. F.

\section{Available for preservation}

A. Stinking Lake. (B2.) 8 sq. mi. of swamp and Lake. Rio Arriba County, $4 \mathrm{mi}$. from El Vado. Reached via Chama on D. \& R. G. Ry. Should be made a Bird Preserve, as it is the most important breeding ground for aquatic birds in the state.

B. Areas suggested for reservation in the national forests by G. A. Pearson:

a. Upper desert:

1. Manzano National Forest. Montezuma Ranger Station. Camp pasture, 30 mi. southwest of Mountainair. Go to L. H. Claunch ranch about 25 mi. south of Mountainair, known locally as Pueblo Pardo Ranch. From there, follow dim road 6 to $7 \mathrm{mi}$. west by auto. (Sandy.) Woodland and grassland (Talbot).

2. Jornado Range Reserve. Areas under fence to be selected.

3. Santa Fe National Forest. Abundant material available within forest boundaries or on federal domain nearby. Fencing probably necessary. $-G$. A. $P$. 
b. Woodland:

1. Santa Fe National Forest. City watershed of Las Vegas may be suitable.

2. Carson National Forest. All around Taos Junction. Disadvantage here is poor railroad facilities and hotel accommodations. Most of the accessible areas in northern New Mexico have been cut over and overgrazed for centuries.

3..Fort Bayard Military Reservation. This is all fenced, but stock are grazed inside. -G. A. P.

c. Yellow pine:

1. Lincoln National Forest. In Guadaloupe division is an area of yellow pine and brush which is very rough and little grazed.

2. Datil National Forest. Good areas typical yellow pine are available, but they are difficult of access.G. A. P.

d. Douglas fir:

1. Lincoln National Forest. Cloudcroft Reserve. This contains fine stands of Douglas fir and yellow pine.

2. Santa Fe National Forest. Fir and spruce stands in country between Santa Fe Las Vegas.-G. A. P.

e. Alpine type:

1. Top of Santa Fe Baldy.

2. Top of Jicarilla Peak.

3. Top of Mt. Taylor (probably).-G. A. P.

\section{PLACES TO STOP FOR STUDY}

For the convenience of the ecologist who wishes to make a survey of the most important biotic communities of the state, the following list of favorable points for study is given. As it is probable that most persons desiring such a list will wish to make their observations in the course of a transcon- tinental trip along one of the main lines of travel, it has been arranged with reference to those lines. In all cases hotel accommodations and facilities for excursions into the surrounding country are available.

\section{Santa Fe-Main Line}

This railway enters the state from Colorado through the Raton Tunnel, near which is the highest point on the line. Raton lies just on the southern side of a spur of the Rockies and on the edge of the high plains, over which the road passes until it again approaches the southern end of the Rockies after leaving Las Vegas. A favorable point from which to observe this region is Glorieta (Hotel accommodations must be arranged for in advance; address Valley Ranch), from which excursions may be made into the heart of the mountains. Santa Fe, at the edge of the Rockies on the Rio Grande valley side, is reached by way of a branch line from Lamy. Santa Fe is the center of the archeological interest of the region, and from this point excursions may be arranged covering the entire Rocky Mountain and Rio Grande Valley regions. Bandelier National Monument, within the borders of the Santa Fe National Forest, contains some of the most important of the remains of the prehistoric peoples of New Mexico. Albuquerque is located on the Rio Grande, and the series of communities listed in Section I, 2, of this sketch is to be observed within easy reach. Gallup is an important point of departure for the study of the higher portions of the Colorado Plateau.

The Rio Grande Valley may be traversed by making a detour at Albuquerque via the El Paso line of the Santa Fe, and proceeding by way of the Southern Pacific from El Paso.

\section{Santa Fe-Southern Route}

This line enters the state from Texas, crossing the Pecos Valley, and joining the main line near Albuquerque. Favorable places for study are Clovis, Fort Sumner and Vaughn, all in the 
Great Plains steppe region. The lower Pecos Valley may be reached by way of a branch line from Clovis.

\section{Rock Island-Southern Pacific}

This line enters the state at Tucumcari in the high plains region, crosses the Pecos at Santa Rosa, and approaches the isolated White and Sacramento mountains at Carrizozo and Alamogordo, respectively. To the west of the railway line and between the mountains just mentioned and the San Andreas range, bordering the Rio Grande Valley, lie the Tularosa Plains. Occupying a great part of this basin, which has no drainage outlet, are saline and alkaline marshes and flats, and a great area of about $350 \mathrm{sq}$. mi. of gypsum dunes. A portion of this area was included in the proposed "All-Year National Park," which failed of approval because of some very undesirable features of the bill for its creation. Provision should be made for its preservation without interference with the present policy of the National Park System. This rerion may be best reached from Alan. ordo.

\section{Stinking Lake Bird Reservation (New Mexico)}

10 sq. mi. swamp and lake. Breeding ground for water fowl. $7000 \mathrm{ft}$. Tierra Amarilla, $20 \mathrm{mi}$. west, (a) (h) $4 \mathrm{mi}$. W. (h) El Vado. Should be made State or Federal bird reservation. $-A$. $O$. Weese.

\section{REFERENCES}

de Baca, T. C. 1917 Report of the Game and Fish Warden of New Mexico, 1915-1916. Santa Fe.

Watson, J. R. 1911 A contribution to the study of the ecological distribution of the animal life of north central New Mexico with especial reference to the insects. Rep. Nat. Res. Survey, N. M., 1: 57-117.

1912 Plant geography of north central New Mexico. Bot. Gaz., 54: 194-217.

U. S. Forest Service 1922 The national forests of New Mexico, Dept. Circular 240. U. S. D. A. 1-21.

\footnotetext{
1 Authors not designated.
} 


\section{Section 3. The Tropics North of the Equator}

\section{A. Mexico and Central America}

\section{MEXICO}

\section{By E. W. Nelson and E. A. Goldman}

\section{INTRODUCTION}

The following brief outline is based on information gathered by the authors in the course of field investigations in Mexico, begun in 1892, and continued with short interruptions until 1906. Nearly all of the higher mountain ranges and principal valleys were visited, and field travel extended into every state and territory in the Republic, including an overland journey the entire length of Lower California.

\section{General Features and Native Biota}

\section{A. TOPOGRAPHY}

Mexico, extending from about latitude $14^{\circ}$ to $32^{\circ} 42^{\prime}$ North, and longitude $86^{\circ}$ $40^{\prime}$ to $117^{\circ} 10^{\prime}$ West from Greenwich, presents an extraordinary diversity of physiographic and biologic conditions. It is crossed near the center by the Tropic of Cancer, well to the south of which the land mass culminates on Mount Orizaba (having an elevation of more than $18,000 \mathrm{ft}$., and the highest mountain in North America south of Alaska) in an elevated section including other timberline peaks, one of which, the extinct Volcano of Ixtaccihuatl, bears small receding glaciers on its upper slopes.

All of the 12 or 15 highest mountain peaks of Mexico are of volcanic origin and are grouped about the southern border of the tableland. Orizaba, on the east, fronts the Gulf of Mexico, and the Volcano of Colima looks over the Pacific. Scattered irregularly between these peaks are the other higher mountains, including those about the Valley of Mexico. The Volcano of Colima is still active at intervals and Popocatepetl sends out smoke and steam from small vents in the crater walls.

The salient physical features of the Mexican mainland are simple. The greater part of the area is occupied by what is termed the tableland or great interior plateau. This is an obtusely triangular area having an elevation of from 1500 to $3000 \mathrm{ft}$. in the north and rising from 7000 to 8000 at the apex of the triangle, which forms its southern end, in the region of the Valley of Mexico. The tableland has the form of a rolling plain broken here and there by escarpments and with irregularly scattered mountains rising island-like on its surface, some of them attaining. altitudes from 6000 to $11,000 \mathrm{ft}$. On the west the tableland is bordered by the Sierra Madre Occidental, as the southern extension of the Rocky Mountains from the United States is called, and on the east by the Sierra Madre Oriental.

For most of the distance on the eastern and western flanks of the tableland these mountains slope up so gradually from the tableland that they do not appear as large ranges. On the eastern and western fronts, facing the coasts, the rise from the low base level on the coastal plains is abrupt and often rugged, presenting the contours of strongly developed mountain ranges. Between the low coastal bases of the ranges extend gently sloping coastal plains varying from 25 to more than $100 \mathrm{mi}$. in width, across which flow the rivers draining the mountain slopes. The southern end of the tableland narrows with the general narrowing of the continental area, which brings the mountain ranges together and forms a broken 
mountainous region which occupies most of the State of Oaxaca and is limited to the southeast by the Isthmus of Tehuantepec. This isthmus is a broad trough-shaped pass, with an elevation of only about $800 \mathrm{ft}$. in the highest part, extending across the narrowed eontinent between the Atlantic and Pacific coasts. Beyond this, to the east again rises a broad generally mountainous area reaching an altitude of more than $8000 \mathrm{ft}$., which extends southward as the elevated interior of Guatemala, and thence continues more brokenly into other parts of Central America.

The principal mountain range of Mexico, the Sierra Madre Occidental, as already mentioned, is the southern extension of the Rocky Mountain system. It is broken into sections by passes, each marked by a river canyon and along the Lerma Valley by a broad plain. An offset range located parallel to the coast in Guerrero is known as the Sierra Madre del Sur, which extends southeasterly through Oaxaca to unite with the southern end of the Sierra Madre Oriental. The two great eastern and western mountain systems of Mexico reach their greatest development in the southern extension, between the 18 th and 20th parallels of latitude. There they mark a region of tremendous volcanic activity and the highest peaks, from 15,000 to over $18,000 \mathrm{ft}$. in altitude, stand up boldly, towering high above the surface of the tableland which, about their base, has elevations of from 7000 to $8000 \mathrm{ft}$.

The Peninsula of Lower California has a single, definite mountain range of varying elevation extending near the eastern coast nearly its entire length, to end on the shore of La Paz Bay. This range has an abrupt slope fronting the Gulf of California but descends gently toward the Pacific. The range begins at an elevation of about $4000 \mathrm{ft}$. on the California border as a southern extension of the San Jacinto Mountains of southern California, and about 150 mi. farther south rises to an altitude of more than 10,000 ft. on La Providencia Peak. Near La Paz the mountains are interrupted by a low gap south of which, near the western side of the peninsula, rises the short Sierra de la Victoria, which has an altitude of from 3000 to $6000 \mathrm{ft}$. with occasional peaks rising 1000 or $2000 \mathrm{ft}$. higher.

In addition to the main mountains mentioned above, the land surface of Mexico is here and there diversified by minor ranges.

The long, narrow valley of Toluca in the State of Mexico is the highest in the Republic. It has an altitude of about $8200 \mathrm{ft}$. and is inclosed on three sides by high mountains, the drainage being to the north. The valley floor about 15 mi. broad consists of open sloping, treeless plains with extensive centrally located marshes forming the principal sources of the Rio Lerma, which flows north and westerly into the Pacific and is the longest river wholly within Mexican territory. The valley of Mexico, separated from the valley of Toluca by the Sierra de las Cruces, is much larger and more oval in form, but of similar character. This basin in which is located the City of Mexico, at about $7400 \mathrm{ft}$. altitude, contains lakes Tezcoco, Chalco, Xochimilco, and several of smaller size, together with extensive marsh areas.

Coastal plains form a well defined lowland belt, between the shore line and the basal slopes of mountains, along the entire Pacific littoral of Mexico, both on the mainland and in places on the western side of the peninsula of Lower California. These are interrupted in places where the mountain spurs or ridges extend to the shore line. The seaboard of the Gulf of Mexico has a broader coastal plain which merges into that which covers all the peninsula of Yucatan, including the states of Yucatan, Campeche, and the territory of Quintana Roo, together with the neighboring state of Tabasco, the general area consisting almost wholly of nearly level, or gently rolling tropical lowlands, with slight elevation: 
Owing to the shortness of watersheds and the mountainous character of the more humid portions of Mexico most of the rivers are torrential streams, of which some of the largest on the Gulf side are navigable for small steamers a short distance only from the sea. Aside from the Rio Grande del Norte and the Rio Colorado, both of which are mainly in the United States, the longest river of the Republic is the Rio Lerma or Rio Santiago, as it is termed below Lake Chapala. This river cuts its way from its sources above $9000 \mathrm{ft}$. in the mountains about the valley of Toluca, northwesterly through the Laguna de Chapala to the Pacific in the state of Nayarit. The Rio de las Balsas drains the southern slopes of the lofty group of mountains forming the southern border of the valley of Mexico and the highlands of Puebla and northern Oaxaca and flows through a broad interior valley of arid tropical character. Its general course is westward into the Pacific in Guerrero. The Rio Yaqui flows through great canyons from the high northern part of the western slope of the Sierra Madre Occidental into the Gulf of California. The Rio Mayo, Rio del Fuerte, and many other western slope streams traverse rugged canyons in nearly parallel courses from the highest part of the Sierra Madre to the sea. The rivers of eastern Mexico are short as compared with some western slope streams, owing in part to the more abrupt eastern escarpment of the tableland region. As their watersheds, however, occupy regions of greater precipitation the principal streams of the Gulf slope gather an immense volume of water which form torrents in the mountains and become sluggish floods in traversing the coastal plain where they afford navigation for short distances by small steamers. The Rio Panuco drains the eastern slopes of the tableland region with many ramifications mainly in the states of Vera Cruz, Hidalgo, Queretaro, and San Luis Potosi and enters the Gulf at Tampico. The Rio Papaloapan, with a very short main trunk, combines near its mouth several large streams including the San Juan, flowing from the mountains of northern Oaxaca into the Gulf south of the port of Vera Cruz. Two large rivers, the Rio Grijalva and Rio Usumacinta rise not far apart in the high mountains of southwestern Guatemala and after following widely divergent courses flow through mouths not far apart into the Gulf of Campeche, on the coast of Tabasco. The Rio Nazas, of the northern part of the tableland region carries the drainage of a section of the eastern slope of the Sierra Madre Occidental eastward from Durango to the sink of the Laguna de Meyran, a small body of water with no outlet, in southwestern Coahuila.

Through long continued erosion the drainage channels of several streams flowing into the Pacific have cut through the Sierra Madre Occidental in the states of Chihuahua and Durango and are now draining parts of the eastern slopes of these mountains and adjacent tablelands in both Durango and Chihuahua.

The largest lake in Mexico is the Laguna de Chapala in the state of Jalisco. This lake receives the waters of the Rio Lerma which are discharged from an outlet not far from the mouth of this river. The stream below the lake is known as the Rio Santiago. Other notable depressions are filled by. lakes Cuitzeo and Patzcuaro in Michoacan, and lakes Tezcoco, Chalco, and Xochimilco in the valley of Mexico, all of which are comparatively shallow.

\section{B. CLIMATE}

Climatic conditions in Mexico vary greatly, due not only to differences in latitude between the northern and southern portions, but also in accordance with highly diversified local conditions of elevation, slope exposure, direction of prevailing winds, and other factors. In general the climate of eastern Mexico is most humid in the southern portion."and the region of the higher mountains, the precipitation decreasing rapidly toward the north, 


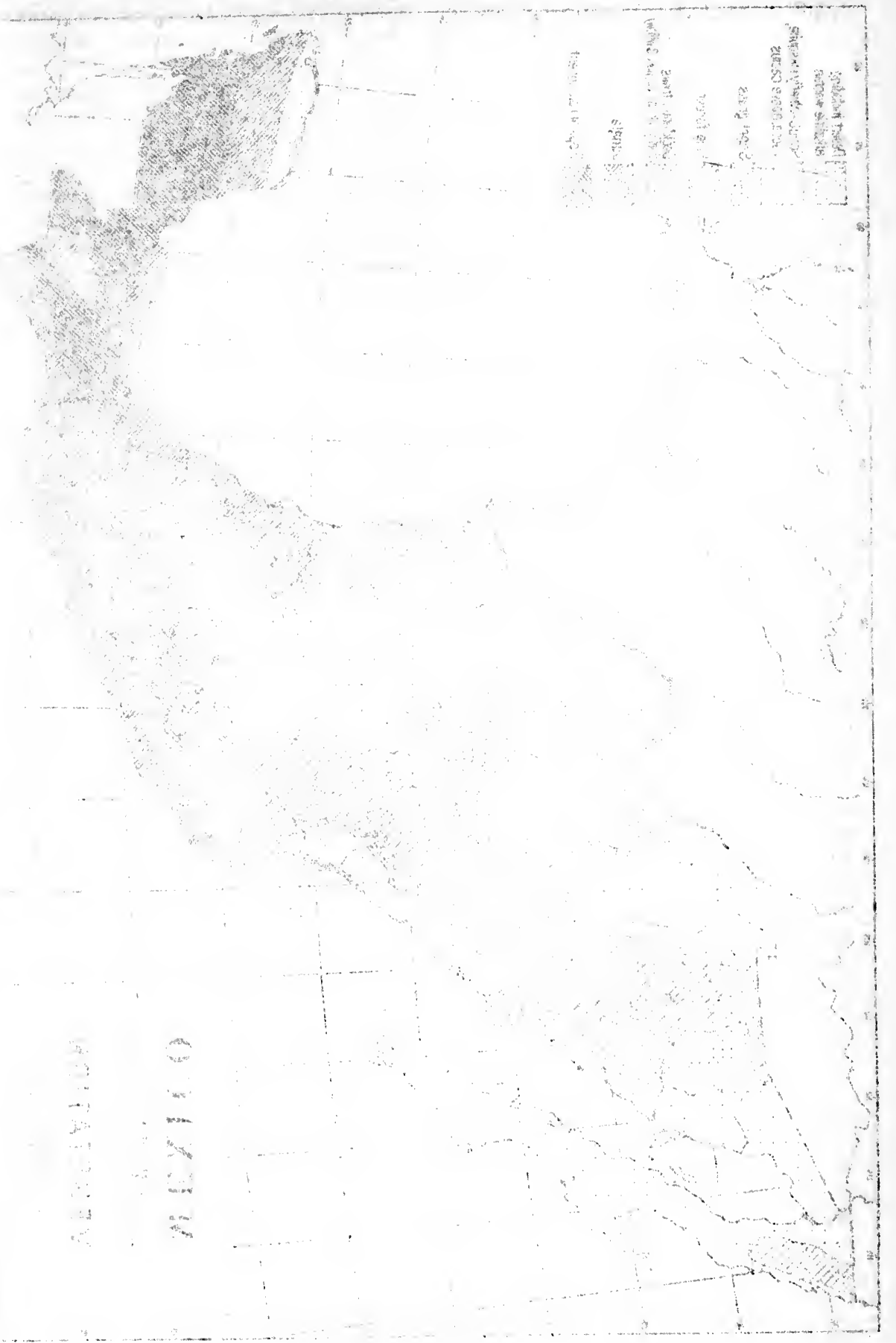




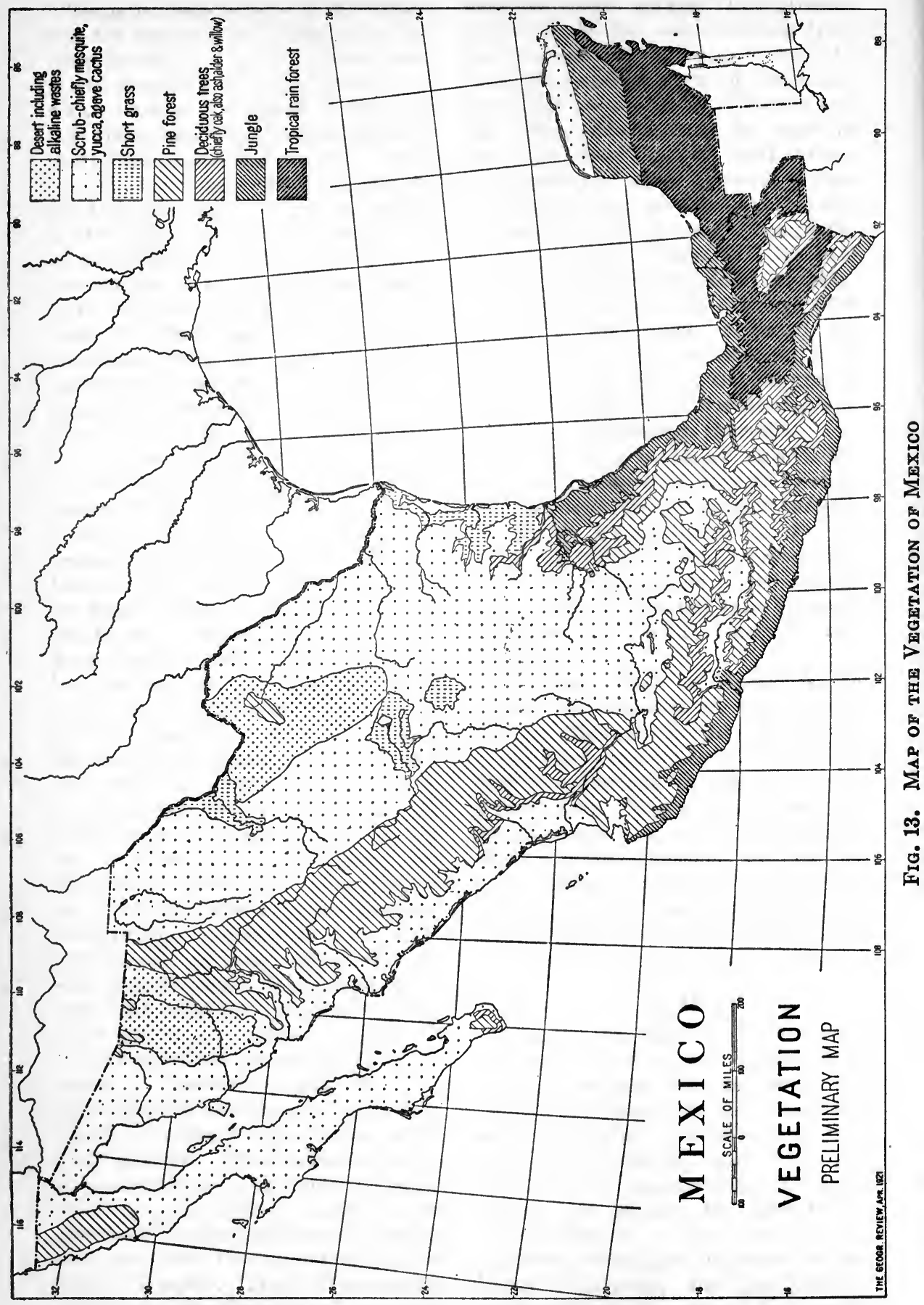


especially in the tableland region where it slopes down to the lower Rio Grande, and in Lower California. Much of the peninsula of Yucatan, however, is comparatively arid as are also some sections of the low Gulf strip in Vera Cruz and the narrow coastal plains bordering the Pacific. The dryest regions of the Republic are the northwestern part of Sonora and the section of Lower California extending from about the thirtieth parallel of latitude to $\mathrm{La} \mathrm{Paz}$.

In these regions, and to a somewhat lesser extent on the plains of northeastern Mexico, the annual precipitation is slight. The aridity of the Pacific coastal plains of southern Mexico is due to the distribution of the rainfall during the year, rather than to any lack of total precipitation. The year is divided into a wet and dry season, and it is to the length of the dry season that the generally arid condition so well reflected in the character of the vegetation is due. The climate of the northern part of the Sierra Madre Occidental in summer is similar to that of the southern part of the Rocky Mountain region in southern Arizona and New Mexico. During this season there are abundant rains, but there is much less snow in winter. Low temperatures due to the elevation of the central plateau and the great height of the mountains of southern Mexico carry Boreal conditions far into tropical latitudes. The rainfall of particular areas is strongly influenced by local conditions, especially variations in altitude, slope exposure, and direction of prevailing winds. As a result sections of "rain forest" may occur on mountain slopes in close proximity to areas of extreme aridity. Comparative measurement data concerning the rainfall of particular areas are not readily available, but field observations without the use of instruments indicate that the wettest regions of the Republic are the Gulf slopes of high mountains in Vera Cruz, Oaxaca, and Chiapas. The rainfall is also excessive on islandlike areas on the Pacific slopes of some of the mountains in Michoacan, Guerrero, Oaxaca, and Chiapas.

\section{NATURAL LIFE AREAS}

Several major North American life zones, or plant and animal associations below the Arctic-alpine belt are easily recognizable in Mexico within which, owing to highly diversified conditions of local environment, a great number of minor associations may be discerned. These minor associations, or plant and animal communities commonly coincide with and are obviously dependent upon changes in landscape aspect such as forests of varying type, grassland, rock formations, sand dunes, lakes, marshes, and streams. Minor ecological groups, closely allied but varying in combination of component parts tend to appear and disappear at irregular intervals throughout the zones. Many animals are not definitely assignable to a particular type of landscape aspect, as for example, they may frequent the grassland for much of their food and retire to the adjoining forest for shelter. Combinations of ecological groups are often conveniently recognizable as floral or faunal regions or districts in which many forms are allied to but often specifically or subspecifically separable from those of neighboring districts in the same major life zone. The major life zones have been incompletely delimited, on the basis of field observation of plant and animal assemblages. Only a mere outline can be presented here. Altitudes are omitted as a rule in this brief treatment as these vary widely in accordance with latitude, slope exposure, base level, and other local climate determining factors.

The Lower and Upper Austral Zones and the Transition Zone are easily traced over the tableland region, including its mountain ranges. Along the southern borders of this area, however, especially where high mountains, directly face tropical lowlands boreal and tropical elements are less widely separated due to peculiar climatic conditions, as a result of which the 
intermediate zones may be obliterated or so intermingled as to become difficult to distinguish. In the high altitudes of this section facing the coast the temperatures are low and suited to the needs of the northern forest and accompanying fauna, while extreme humidity derived from warm cloud formations prevents frost and favors the upward extension of tropical elements. On the higher parts of certain slopes nearly continuous fog or rain has produced a heavy forest cover, with slow rate of evaporation and slight range of variation in temperature throughout the year.

\section{Major life areas}

The names of plant indicators or botanical features are used for convenience in designating most of these areas, which it should be understood are each characterized by a great number of species of both animals and plants.

a. Tropical Zone (including rain forest and arid tropical deciduous forest). This zone as a whole occupies the lowlands and tropical (normally frostless) slopes of the mountains from 5000 to $7000 \mathrm{ft}$. altitude under favorable local conditions in the southern part of the Republic, the upper limit descending to sea level north of Tampico on the Gulf coast, and to low elevations along the west slope of the Sierra Madre Occidental in Sinaloa and southern Lower California. It is divisible into Lower and Upper Tropical sections, and at low elevations into Humid and Arid elements with irregular boundaries, imperfectly known, and impossible to trace in detail in a short account. The Humid Lower Tropical section is fairly uniformly covered with an evergreen forest. The Arid Lower Tropical division includes the coastal plain on the Pacific side north to northern Sinaloa, and parts of the coastal plain in Vera Cruz, Campeche, and Yucatan, together with some of the interior valleys of southern Mexico. Owing to the long dry winter season much of the forest is deciduous. Along the Pacific coast within this arid belt sections of forest alternate with sections of grass-land or savanna somewhat mixed with an irregular growth of Curatella, Coccoloba, Byrsonima, and other trees of non-forest types. The Tropical Zone as a whole, includes the vast fauna and flora which pushes northward from Central America, and is divided into eastern and western branches near the Isthmus of Tehuantepec by the southward thrust of the central highlands.

The habitats of the plants and animals are not well enough known to locate them in plant areas. E.-eastern, largely rain forest; S.--southern, largely rain forest; W.- western, largely arid tropical deciduous forest. See map.

\section{Plants}

Dicranopteris bancroftii, fern. E. Dicranopteris flexuosa, fern. E. Dicranopteris pectinata, fern. E.

Dicranopteris bifida, fern. E.

Dicranopteris palmata, fern. E.

Cyathea princeps, tree fern. E.

Cyathea mexicana, tree fern. S.

Hemitelia costaricensis, tree fern. S

Alsophila quadripinnata, tree fern. S.

Pinus pringlei, Pringle's pine. W.

Pinus oocarpa, ocote. W.

Zamia spartea, cycad. S.E.

Acanthorriza mocinni, palma de escoba. S.

Chamaedorea elegans, palm. E.

Attalea cohune, corozo. S.

Acrocomia mexicana, coyol. W. and S. Agave ixtli, ixtle. S.E.

Ficus padifolia, wild fig. Ranges widely.

Brosium alicastrum, ramon. Ranges widely.

Castilla elastica, rubber tree, hule or arbol del hule. W. and S.

Cecropia mexicana, Guarumo. Ranges widely.

Coccoloba schiedeana, Tamulero. Ranges widely.

Talauma mexicana, flor de corazon. S.

Annona glabra, palo de corcho. Ranges widely.

Persea schiedeana, chinini. E.

Capparis flexuosa, Ranges widely.

Licania arborea, cacahuananche. W. Hirtella americana, cajetillo. W. and S.

Leucaena glauca, lead tree. S.

Lysiloma acapulcensis, tepehuaje. Ranges widely.

Inga spuria, jinicuile. Ranges widely.

Cassia occidentalis, habilla. Ranges widely. 
Hymenaea courbaril, guapinol. Ranges widely.

Bauhinia glabra. S.

Bauhinia latifolia, pata de venado. W. and $\mathrm{S}$.

Haematoxylum campecheanum, logwood, palo de Campeche. S.E.

Haematoxylum brasiletto, logwood, palo de Brasil. W.

Sweetia panamensis, huesillo. W.

Esenbeckia flava, palo amarillo: W.

Elaphrium simaruba, palo mulato, chaca. Ranges widely.

Elaphrium rhoifolium. W.

Swietenia macrophylla, mahogany, caoba. S.E.

Swietcnia humilis, mahogany, Caoba. W.

Cedrela mexicana, Spanish cedar. Ranges widely.

Cedrela yucatana, Spanish cedar. S.E.

Byrsonima crassifolia, nanche. W. and $\mathrm{S}$.

Sapium biloculare, hierba de la flecha. W.

Cyrtocarpa edulis, ciruela. W.

Maytenus phyllanthoides. Ranges widely.

Dodonaea viscosa, switch sorrel. Ranges widely.

Ceiba aesculifolia, pochote. W. and S.

Bombax ellipticum, ceiba, amapola. Ranges widely.

Theobroma cacao, cacao. W. and S.

Guazuma ulmifolia, cuaulote. Ranges widely.

Curatella americana, raspa-viejo. W. and $\mathbf{S}$.

Rhizophora mangle, mangrove. Ranges widely.

Conocarpus erecta. Ranges widely.

\section{Mammals}

Didelphis yucatanensis yucatanensis. Yucatan opossum. S.E.

Marmosa murina mexicana, Mexican murine opossum. S.

Metachirus fuscogriseus pallidus, Orizaba opossum. S.E.

Sorex macrodon, large-toothed shrew. S.E.

Cryptotis nelsoni, Nelson's shrew. S.E.

Notiosorex gigas, giant shrew. S.W.

Saccopteryx bilineata centralis, northern white-lined bat. S.

Balantiopteryx plicata, Peter's pouched bat. S.

Noctilio leporinus mexicanus, Mexican bulldog bat. S.

Chilonycteris rubiginosa mexicana, Mexican dark brown bat. S.

Mormoops megalophylla megalophylla, large-eared bat. $\mathrm{S}$.

Macrotus mexicanus mexicanus, Mexican large-eared bat. $\mathrm{S}$.
Macrotus pygmaeus, pygmy large-eared bat. S.E.

Glossophaga soricina leachii, longtongued bat. S.

Carollia perspicillata azteca, Aztec shorttailed bat. S.

Artibeus phaeotis, Chichen Itza bat. S.E.

Artibeus jamaicensis jamaicensis, Jamaican bat. $\mathrm{S}$.

Desmodus rotundus murinus, Mexican vampire bat. $\mathbf{S}$.

Natalus mexicanus, Santa Anita bat. W.

Dasypterus ega xanthinus, Sierra Laguna bat. W.

Pizonyx vivesi, Cardonal Island bat. W. Canis vigilis, Colima coyote. W.

Urocyon cinereoargenteus fraterculus, Yucatan fox. S.E.

Bassariscus sumichrasti sumichrasti, Sumichrast's bassariscus. S.

Nasua narica molaris, Colima coati, tejon. W.

Potos flavus aztecus, Aztec kinkajou, martica. S.

Mustela tropicalis tropicalis, tropical weasel. S.E.

Tayra barbara senex, gray-headed tayra, cabeza viejo. S.

Felis onca hernandezii, Hernandez' tiger, tigre. W.

Felis onca goldmani, Goldman's tiger. E.

Felis pardalis pardalis, ocelot, tigrillo. $\mathrm{S}$.

Reithrodontomys fulvescens mustelinus, buff-bellied harvest mouse. W.

Reithrodontomys cherriei jalapae, Jalapa harvest mouse. E.

Baiomys musculus musculus, Colima little brown mouse. W.

Peromyscus leucopus mesomelas, Orizaba white-footed mouse. E.

Peromyscus nelsoni, Nelson's mouse. E.

Oryzomys couesi couesi, Coues' rice rat. S.

Sigmodon hispidus toltecus, Toltec cotton rat. E.

Oryzomys chapmani chapmani, Chapman's rice rat. $\mathrm{E}$.

Xenomys nelsoni, Nelson's wood rat. W.

Hodomys alleni, Allen's wood rat. W.

Neotoma tropicalis, tropical wood rat. E.

Neotoma distincta, Vera Cruz wood rat. $\mathrm{E}$.

Ototylomys phyllotis phyllotis, Tunkas rat. S.E.

Heterogeomys torridus, tropical pocket gopher. E.

Heterogeomys hispidus, Jalapa pocket gopher. E.

Platygeomys fumosus, Colima pocket gopher. W. 
Heteromys desmarestianus desmarestianus, Coban spiny pocket mouse. S.

Heteromys gaumeri, Gaumer's spiny pocket mouse. S.E.

Liomys pictus pictus, painted spiny pocket mouse. W.

Dasyprocta mexicana, Mexican agouti. E.

Coendou mexicanum, Mexican porcupine. S.

Citellus annulatus annulatus, bandtailed ground squirrel. W.

Sciurus deppei deppei, Deppe's squirrel. E.

Sciurus yucatanensis yucatanensis, $\mathrm{Yu}-$ catan squirrel. S.E.

Sciurus aureogaster hypopyrrhus, firebellied squirrel. E.

Sciurus socialis cocos, Acapulco squirrel. W.

Lepus flavigularis, Tehuantepec jackrabbit. S.

Sylvilagus gabbi truei, Vera Cruz forest rabbit. E.

Cyclopes didactylus dorsalis, Costa Rican two-toed anteater. S.

Tamandua tetradactyla mexicana, Mexican three-toed anteater. S.

Alouatta palliata mexicana, Mexican howling monkey. S.E.

Ateles neglectus, Mexican spider monkey. S.

Pecari angulatus humeralis, Colima peccary. W.

Pecari angulatus yucatanensis, Yucatan peccary. S.E.

Tayassu pecari ringens, Campeche peccary. S.E.

Odocoileus acapulcensis, Acapulco deer. W.

Mazama pandora, Yucatan forest deer. S.E.

Tapirella dowii, Dow's tapir. S.

\section{Birds}

Oedicnemus bistriatus bistriatus, Mexican thick-knee. S.

Chloroenas rufina pallidicrissa, palevented pigeon. S.E.

Lepidoenas speciosa, scaled pigeon. S.E.

Leptotila gaumeri, Gaumer's dove. S.E.

Coccyzus minor minor, mangrove cuckoo. $\mathrm{E}$.

Piaya mexicana, Mexican squirrelcuckoo. W.

Tapera naevia excellens, northern striped cuckoo. S.E.

Morococcyx erythropygus mexicanus, Mexican rufous-rumped cuckoo. W.

Ara macao, red, blue and yellow macaw. $\mathrm{S}$.

Ara militaris mexicana, Mexican green macaw. W.

Eupsittula astec, Aztec paroquet. S. Brotogeris jugularis, Tovi paroquet. S.W.
Psittacula cyanopygia cyanopygia, Mexican parrotlet. N.W.

Amazona auropalliata, yellow-naped parrot. S.

Amazona autumnalis autumnalis, yellowcheeked parrot. E.

Amazona finschi, Finsch's parrot. W. Amazona albifrons albifrons, whitefronted parrot. W.

Amazona xantholora, yellow-lored parrot. S.E.

Otus hastatus thompsoni, Yucatan screech owl. S.E.

Nyctagreus yucatanicus, Yucatan poorwill. S.E.

Momotus lessonii goldmani, Goldman's motmot. E.

Momotus lessonii exiguus, Yucatan motmot. S.E.

Momotus mexicanus saturatus, coast motmot. W.

Megaceryle torquata torquata, ringed kingfisher. Ranges widely.

Galbula melanogenia, black-chinned jacamar. S.E.

Ramphastos piscivorus piscivorus, keelbilled toucan. S.E.

Pteroglossus torquatus torquatus, collared aracari. E.

Pteroglossus torquatus erythrozonus, Yucatan aracari. S.E.

Aulacorhynchus prasinus prasinus, emerald toucanet. S.E.

Centurus dubius veraecrucis, Vera Cruz woodpecker. S.E.

Centurus rubriventris rubriventris, Swainson's woodpecker. S.E.

Centurus chrysogenys flavinuchus, Acapulco woodpecker. W.

Celeus castaneus, chestnut-colored woodpecker. S.E.

Scapaneus guatemalensis guatemalensis, Guatemalan ivory-bellied woodpecker. S.

Dryobates scalaris parvus, sisal woodpecker. S.E.

Pharomachrus mocinno mocinno, quetzal. S.

Curucujus massena, Massena trogon. S.E.

Trogon melanocephalus melanocephalus, black-headed trogon. E.

Trogon citreolus, citreoline trogon. W. Chrysotrogon caligatus, gartered trogon. S.

Phaethornis longirostris veraecrucis, Vera Cruz hermit. S.E.

Phaethornis longirostris mexicanus, Guerrero hermit. W.

Anthoscenus longirostris pallidiceps, pale-crowned star-throat. $\mathbf{S}$.

Anthoscenus constantii leocadiae, pine star-throat. W.

Campylopterus himileucurus, Delattre's sabre-wing. S.

Amazilia yucatanensis cerviniventris, fawn-breasted hummingbird. E. 
Agyrtria candida, white-bellied emerald. S.E.

Saucerottia beryllina beryllina, berylline hummingbird. E.

Anthracothorax prevostii prevostii, Prevost's mango. E.

Abeillia abeillei, Abeille's hummingbird. S.E.

Chlorostilbon canivettii canivettii, Canivet's emerald. E.

Florisuga mellivora, Jacobin hummingbird. S.E.

Doricha eliza, Mexican shear-tail. S.E.

Lophornis helenae, Princess Helena's coquette. S.E.

Cynanthus doubledayi, Doubleday's hummingbird. S.W.

Chaetura gaumeri, Gaumer's swift. S.E.

Dendrocolaptes sancti-thomae sanctithomae, barred woodhewer. S.E.

$X$ iphocolaptes emigrans sclateri, Sclater's woodhewer. S.E.

Xiphorhynchus flavigaster flavigaster, Swainson's woodhewer. E.

Xiphorhynchus flavigaster yucatanensis, Yucatan woodhewer. S.E.

Xiphorhynchus flavigaster mentalis, Grayson's woodhewer. W.

Lepidocolaptes lineaticeps insignis, northern streaked-headed woodhewer. S.

Sittasomus sylvioides sylvioides, Mexican sittasomus. S.E.

Dendrocincla anabatina anabatina, northern dendrocincla. E.

Dendrocincla anabatina typhla, Yucatan dendrocincla. S.E.

Sclerurus mexicanus mexicanus, Mexican sclerurus. S.E.

Xenops genibarbis mexicanus, Mexican xenops. S.E.

Synallaxis erythrothorax, rufousbreasted synallaxis. S.E.

Xenicopsis variegaticeps, scaly-throated xenicopsis. S.

Automolus cervinigularis cervinigularis, buff-throated automolus. S.E.

Thamnophilus doliatus mexicanus, Mexican antshrike. E.

Thamnophilus doliatus yucatanensis, Yucatan antshrike. S.E.

Microrhopias boucardi boucardi, Boucard's antwren. S.E.

Cercomacra tyrannina crepera, Dusky tyrannine antbird. S.E.

Formicarius moniliger moniliger, Mexican antthrush. E.

Formicarius moniliger pallidus, Yucatan antthrush. S.E.

Grallaria guatimalensis mexicana, Mexican antpitta. S.E.

Cotinga amabilis, lovely cotinga. S.E.

Microtriccus semiflavus, gray-capped tyrannulet. S.

Attila citreopygus salvini, Salvin's attila. E.
Attila citreopygus gaumeri, Gaumer's Attila. S.E.

Attila citreopygus cinnamomeus, Lawrence's attila. W.

Lathria unirufa unirufa, Mexican lathria. S.E.

Pachyrhamphus cinnamomeus, cinnamon becard. S.

Pachyrhamphus major itzensis, Chichen Itza becard. S.E.

Platypsaris aglaiae sumichrasti, Sumichrast's becard. E.

Platypsaris aglaiae yucatanensis, Yucatan becard. S.E.

Erator albitorques, Fraser's erator. S.E.

Tityra semifasciata personata, Mexican tityra. E.

Manacus candei, Cande's manakin. S.

Chiroprion linearis, long-tailed manakin. S.

Pipra mentalis mentalis, yellow-thighed manakin. S.

Onychorhynchus mexicanus mexicanus, Mexican royal flycatcher. $\mathbf{S}$.

Myiarchus yucatanensis, Yucatan flycatcher. S.E.

Oncostoma cinerigulare, bent-billed flycatcher. S.

Todirostrum cinereum finitimum, northern tody-flycatcher. S.

Todirostrum schistaceiceps, slate-colored tody-flycatcher. S.

Platytriccus cancrominus, Mexican spade-billed flycatcher. S.

Craspedoprion brevirostris, short-billed flycatcher. S.

Rhynchocyclus cinereiceps, gray-headed flycatcher. S.

Myiopagis placens placens, placid flycatcher. S.

Elaenia martinica subpagana, northern elaenia. S.

Legatus albicollis, striped flycatcher. S.E.

Myiozetetes texensis texensis, Giraud's flycatcher. S.

Pipromorpha assimilis assimilis, Mexican pipromorpha. S.

Leptopogon pileatus, brown-capped leptopogon. S.

Myiobius xanthopygus sulphureipygius, sulphur-rumped myiobius. S.

Myiochanes brachytarsus, short-legged wood pewee. S.E.

Heleodytes rufinucha, rufous-naped cactus wren. E.

Heleodytes guttatus, Yucatan cactus wren. S.E.

Heleodytes humilis, Sclater's cactus wren. S.W.

Pheugopedius maculipectus maculipectus, spotted-breasted wren. E.

Pheugopedius maculipectus cano-brunneus, Yucatan spotted-breasted wren. E. 
Pheugopedius felix felix, happy wren. S.W.

Thryomanes albinucha, Cabot's wren. S.E.

Henicorhina leucophrys mexicana, Mexican wood wren. S.E.

Nannorchilus leucogaster pacificus, Colima wren. W.

Nannorchilus leucogaster brachyurus, Temax wren. S.E.

Hylorchilus sumichrasti, Sumichrast's wren. S.E.

Catharus melpomene melpomene, nightingale thrush. S.E.

Turdus tristis assimilis, Jalapa thrush. $\mathrm{E}$.

Turdus infuscatus, black thrush. S.E. Turdus flavirostris, Mazatlan robin. W. Myadestes unicolor, slate-colored solitaire. S.E.

Polioptila albiventris, Yucatan gnatcatcher. S.E.

Calocitta formosa formosa, Bullock's magpie-jay. W.

Psilorhinus mexicanus mexicanus, whitetipped brown jay. E.

Psilorhinus mexicanus vociferus, Yucatan brown jay. S.E.

Xanthoura luxuosa luxuosa, green jay. E.

Cissilopha san-blasiana pulchra, Acapulco jay. W.

Cissilopha yucatanica, Yucatan jay. S.E.

Cyanolyca nana, dwarf jay. S.E.

Cyclarhis flaviventris flaviventris, Mexican pepper-shrike. S.

Cyclarhis flaviventris yucatanensis, Yucatan pepper-shrike. S.E.

Vireosylva magister cinerea, Cozumel vireo. S.E.

Neochloe brevipennis, green-winged vireo. E.

Pachysylvia decurtata, gray-headed pachysylvia. S.

Diglossa baritula, Mexican diglossa. S.

Coereba mexicana, Mexican bananaquit. S.

Granatellus venustus, Du Bus' redbreasted chat. W.

Gymnostinops montezuma, Montezuma oropendola. E.

Amblycercus holosericeus, Prevost's cacique. S.E.

Megaquiscalus major obscurus, Colima boat-tail. W.

Dives dives, Sumichrast's blackbird. S.E.

Icterus melanocephalus melanocephalus, black-headed oriole. S.

Chlorophonia occipitalis, Mexican chlorophonia. S.E.

Tanagra hirundinacea, Bonaparte's euphonia. E.

Thraupis abbas, Abbot tanager. E.
Piranga roseo-gularis roseo-gularis, rosethroated tanager. S.E.

Phlogothraupis sanguinolenta, crimsoncollared tanager. S.E.

Phoenicothraupis rubica rubicoides, Mexican ant tanager. E.

Phoenicothraupis rubica affinis, Oaxaca ant tanager. W.

Chlorospingus ophthalmicus, brownheaded chlorospingus. E.

Arremonops rufivirgatus crassirostris, Cordoba sparrow. S.E.

Arremonops superciliosus sumichrasti, Acapulco sparrow. W.

Arremonops verticalis, Schott's sparrow. S.E.

Richmondena cardinalis yucatanica, Yucatan cardinal. S.E.

b. Covillea Association (Lower Austral Zone). With Covillea glutinosa as a convenient plant indicator this zone, also characterized by many other peculiar plants and many animals, occupies much of the northeastern part of the Republic, including the lower portions of the tableland region in the interior, the Rio Grande Valley, the coastal plains of Sonora, and the central section of Lower California from latitude $30^{\circ}$ to near La Paz.

This zone, lying next the Tropical Zone, is separated from the latter by the normal frost line. In it occur representatives of a considerable number of animals and plants of groups mainly tropical in distribution which may be regarded as intrusive, and have become specifically or subspecifically differentiated. It is an area of great aridity and includes the dryest sections of North America. While the zone as a whole is distinguished by the general occurrence of Covillea and other widely ranging ligneous species these are locally very irregularly distributed and interrupted by sections of grassland, especially along the bottoms of broad valleys, by sand dunes, usually of limited extent, and by streams bordered by vegetation with a high moisture requirement. These and other locally varying environmental conditions favor the development of minor plant and animal associations or communities of limited extent. 


\section{Plants}

Ephedra trifurca.

Ephedra aspera, pitamoreal.

Washingtonia sonorae, palm.

Washingtonia filifera, palm.

Yucca schottii.

Yucca australis.

Yucca decipiens.

Nolina affinis.

Celtis pallida, hackberry.

Atriplex linearis.

Atriplex matamorensis.

Prosopis pubescens, screwpod mesquite, tornillo.

Prosopis juliflora velutina, mesquite. Prosopis juliflora glandulosa, mesquite. Acacia greggii, Gregg's acacia.

Acacia wrightii, Wright's acacia.

Pithecolobium brevifolium.

Pithecolobium sonorae, uña de gato. Hoffmanseggia microphylla.

Parkinsonia microphyll, palo verde. Cercidium torreyanum, palo verde.

Cercidium floridum, retama.

Eysenhardtia polystachya, taráy.

Parosela spinosa, indigo bush.

Parosela berlandieri.

Olneya tesota, ironwood, palo de hierro.

Erythrina flabelliformis, colorín.

Covillea glutinosa, creosote \. bush; gobernadora.

Viscainoa geniculata.

Koeberlinia spinosa, corona de cristo.

Elaphrium microphyllum, torote.

Simmondsia californica, jojoba, goat nut.

Fouquieria splendens, ocotillo.

\section{Mammals}

Didelphis marsupialis texensis, Texas opossum.

Cryptotis pergracilis pergracilis, Ocotlan short-tailed shrew.

Mormoops megalophylla senicula, Texas large-eared bat.

Macrotus californicus, California largeeared bat.

Pizonyx vivesi, Cardonal Island bat.

Pipistrellus hesperus hesperus, little western bat.

Antrozous pallidus pallidus, large-eared pale bat.

Canis mearnsi, Mearns' coyote.

Canis microdon, small-toothed coyote.

Bassariscus astutus flavus, tawny bassariscus.

Felis pardalis albescens, Pucheran's ocelot.

Felis pardalis sonoriensis, Sonora ocelot.

Lynx ruffus texensis, Texan wildcat.

Lynx ruffus baileyi, desert wildcat.

Baiomys taylori taylori, Taylor's little brown mouse.

Peromyscus eremicus eremicus, desert mouse.
Peromyscus leucopus texanus, Texas white-footed mouse.

Oryzomys couesi aquaticus, Rio Grande rice rat.

Sigmodon hispidus berlandieri, Berlandier's cotton rat.

Sigmodon hispidus eremicus, western desert cotton rat.

Neotoma albigula melanura, Sonora white-throated 'wood rat.

Neotoma micropus micropus, Baird's wood rat.

Thomomys sinaloae, Sinaloa pocket gopher.

Thomomys bottae russeolus, San Angel pocket gopher.

Geomys personatus tropicalis, Tamaulipas pocket gopher.

Liomys irroratus texensis, Texas spiny pocket mouse.

Perognathus penicillatus pricei, Price's pocket mouse.

Dipodomys platycephalus, Calmalli kangaroo rat.

Dipodomys ordii palmeri, Palmer's kangaroo rat.

Dipodomys agilis peninsularis, peninsula kangaroo rat.

Eutamias merriami meridionalis, Lower California desert chipmunk.

Cynomys mexicanus, Mexican prairie dog.

Citellus tereticaudus, Yuma ground squirrel.

Ammospermophilus harrisii saxicola, Mearns' white-lined ground squirrel.

Lepus californicus eremicus, Arizona jack rabbit.

Lepus californicus merriami, Merriam's jack rabbit.

Sylvilagus bachmani exiguus, Lower California brush rabbit.

Pecari angulatus angulatus, Texas peccary.

Pecari angulatus sonoriensis, Sonora peccary, Jabali.

Odocoileus hemionus eremicus, desert mule deer.

Odocoileus hemionus canus, gray mule deer (also Upper Austral).

Antilocapra americana peninsularis, Lower California antelope.

\section{Birds}

Lophortyx gambelii, Gambel's quail. Callipepla squamata castanogastris, chestnut-bellied scaled partridge.

Psittacula cyanopygia pallida, Sonoran parrotlet.

Amazona viridigenalis, red-crowned parrot.

Amazona albifrons saltuensis, Sonoran parrot.

Otus asio mccallii, Texas screech owl.

Micropallas whitneyi whitneyi, elf owl. 
Colaptes chrysoides mearnsi, Mearns' gilded flicker.

Centurus uropygialis uropygialis, Gila woodpecker.

Dryobates scalaris symplectus, Texas woodpecker.

Platypsaris aglaiae aglaiae, rosethroated becard.

Otocoris alpestris pallida, Sonoran horned lark.

Otocoris alpestris diaphora, Tamaulipas horned lark.

Heleodytes brunneicapillus brunneicapillus, Guaymas cactus wren.

Heleodytes brunneicapillus couesi, Coues' cactus wren.

Thryothorus ludovicianus berlandieri, Berlandier's wren.

Toxostoma longirostris sennetti, Sennett's thrasher.

Toxostoma curvirostre curvirostre, curvebilled thrasher.

Toxostoma curvirostre palmeri, Palmer's thrasher.

Toxostoma lecontei lecontei, Leconte's thrasher.

Mimus polyglottos leucopterus, western mockingbird.

Polioptila plumbea, plumbeous gnatcatcher.

Auriparus flaviceps flaviceps, verdin.

Xanthoura luxuosa glaucescens, Rio Grande green jay.

Dendroica aestiva sonorana, Sonoran yellow warbler.

Megaquiscalus major nelsoni, Sonoran boat-tailed grackle.

Icterus melanocephalus audubonii, Audubon's oriole.

Icterus cucullatus sennetti, Sennett's oriole.

Icterus cucullatus nelsoni, Nelson's oriole.

Amphispiza bilineata deserticola, desert sparrow.

Melospiza melodia fallax, desert song sparrow.

Arremonops rufivirgatus rufivirgatus, Texas sparrow.

Pyrrhuloxia sinuata sinuata, pyrrhuloxia.

Pyrrhuloxia sinuata texana, Texan pyrrhuloxia.

Richmondena cardinalis superba, Arizona cardinal.

Richmondena cardinalis canicauda, graytailed cardinal.

c. Pinyon-Juniper Association (Upper Austral Zone: Pinyon-Juniper Forest). This association or zone occupies an area mainly along the slopes of the mountains above the limits of the Covillea association. It includes most of the oak woods, junipers, and pinyon pines, and may be regarded as a direct extension of the pinyon-juniper association of the southwestern United States. A small, isolated area, assignable to this association, occupies the upper slopes of the mountains of the Cape Region of Lower California, and it occurs in a belt reaching sea level on the Pacific side of the San Pedro Martir Mountains in the northern part of the peninsula. Its greatest extension is along the flanks of the Sierra Madre Occidental.

\section{Plants}

Pinus cembroides, pinyon.

Juniperus californica, juniper.

Juniperus pachyphloea, alligator-barked juniper.

Juniperus flaccida.

Juniperus mexicana, Mexican juniper. Cupressus arizonica, Arizona cypress. Cupressus benthami, Bentham's cypress. Juglans mollis, black walnut.

Hicoria mexicana, Mexican hickory. Quercus reticulata.

Quercus arizonica, Arizona oak.

Quercus emoryi, Emory's oak.

Quercus mexicana, Mexican oak.

Celtis reticulata, hackberry.

Morus microphylla, desert mulberry. Isomeris arborea.

Fallugia parodoxa, apache plume.

Cowania stansburiana.

Cercocarpus paucidentatus, mountain mahogany.

Ceanothus greggii, Gregg's ceanothus. Rhamnus tomentella.

Tilia occidentalis.

Sida neomexicana.

\section{Mammals}

Sorex lagunae, Sierra Laguna shrew. Sorex californicus juncensis, Socorro shrew.

Canis cagottis, Mexican plateau coyote. Mustela frenata frenata, bridled weasel.

Onychomys torridus ramona, Ramona grasshopper mouse.

Peromyscus truei gentilis, Jalisco longeared mouse.

Peromyscus californicus insignis, Dulzura mouse.

Peromyscus truei lagunae, Sierra Laguna mouse.

Oryzomys couesi crinitus, Valley of Mexico rice rat.

Sigmodon minimus, buff-bellied cotton rat.

Neotoma albigula durangae, Durango white-throated wood rat. 
Neotoma fuscipes macrotis, - large-eared wood rat.

Cratogeomys fulvescens, plateau fulvous pocket gopher.

Liomys bulleri, Buller's spiny pocket mouse.

Dipodomys phillipsii, Phillips' kangaroo rat.

Citellus variegatus variegatus, Mexican plateau rock squirrel.

Thomomys bottae nigricans, Stephens' pocket gopher.

Thomomys bottae alticolus, Sierra Laguna pocket gopher.

Sciurus aureogaster frumentor, Perote squirrel.

Lepus gailliardi gailliardi, Gailliard's jack rabbit.

Odocoileus hemionus canus, gray mule deer (also Lower Austral).

\section{Birds}

Chloroenas fasciata vioscae, Viosca's pigeon.

Balanosphyra formicivora bairdi, California woodpecker.

Balanosphyra formicivora angustifrons, narrow-fronted woodpecker.

I)ryobates villosus intermedius, intermediate woodpecker.

Basilinna xantusii, Xantus' hummingbird.

Tachycineta thalassina brachyptera, Lower California violet green swallow.

Thryomanes bewickii charienturus, San Diego wren.

Turdus confinis, San Lucas robin.

Chamaea fasciata henshawi, pallid wrentit.

Baeolophus wollweberi wollweberi, Wollweber's titmouse.

Baeolophus wollweberi annexus, bridled titmouse.

Baeolophus inornatus cineracens, ashy titmouse.

Baeolophus inornatus murinus, San Diego titmouse.

Psaltriparus minimus minimus, bushtit.

Psaltriparus melanotis melanotis, blackeared bush-tit.

Psaltriparus grindae, Grinda's bush-tit.

Sitta carolinensis lagunae, Lower California nuthatch.

Cyanocephalus cyanocephalus, pinyon jay.

A phelocoma cyanotis, blue-cheeked jay. Aphelocoma sumichrasti, Sumichrast's jay.

A phelocoma sieberii wollweberi, Zacatecas jay.

Vireo huttoni cognatus, Frazar's vireo.

Megaquisculus tenuirostris, slenderbilled grackle.

Aimophila ruficeps ruficeps, rufouscrowned sparrow.
Aimophila ruficeps sororia, Laguna sparrow.

Pipilo fuscus potosinus, plateau brown towhee.

Pipilo maculatus magnirostris, mountain towhee.

\section{d. Pine Association (Transition Zone).} An area, commonly characterized by the occurrence of yellow pine, and associated species as plant indicators occupies the upper slopes of the Sierra Madre Occidental, except the summits of the few high peaks, from near the international boundary to the southern part of the Republic where it is represented on the slopes of the higher mountains, and thence northward along the Sierra Madre Oriental largely in the State of Vera Cruz. It also includes most of the upper slopes of the San Pedro Martir Mountains in northern Lower California and of ranges which rise island-like to a sufficient altitude frum the great interior plateau.

\section{Plants}

Pinus ponderosa, western yellow pine. Pinus chihuahuana, Chihuahua pine.

Pinus lumholtzii, Lumholtz' pine.

Pinus arizonica, Arizona pine.

Pinus lambertiana, sugar pine.

Pinus coulteri, Coulter's pine.

Robinia neomexicana, New Mexican locust.

Rhamnus betulaefolia.

\section{Mammals}

Scapanus anthonyi, Anthony's mole. Ursus nelsoni, Nelson's grizzly bear. Ursus machetes, Chihuahua black bear. Ursus americanus eremicus, Coahuila black bear.

Canis mexicanus, Mexican wolf.

Reithrodontomys megalotis zacatecae, Zacatecas harvest mouse.

Peromyscus truei martirensis, San Pedro Martir mouse.

Peromyscus difficilis difficilis, Zacatecas mouse.

Sigmodon leucotis, white-eared cotton rat.

Nelsonia neotomodon, Zacatecas little wood rat.

Neotoma albigula zacatecae, Zacatecas white-throated wood rat.

Neotoma mexicana madrensis, Sierra Madre wood rat.

Microtus mexicanus phaeus, Colima meadow mouse. 
Zygogeomys trichopus, Michoacan pocket gopher.

Eutamias bulleri, Buller's chipmunk. Callospermophilus madrensis, Mexican golden-mantled chipmunk.

Sciurus aberti barberi, Barber's squirrel. Sciurus douglasii mearnsi, Mearns; squirrel.

Sylvilagus floridanus orizabae, Mount Orizaba cottontail.

Odocoileus couesi, Coues' deer.

Odocoileus hemionus californicus, California mule deer.

\section{Birds}

Chloroenas fasciata fasciata, band-tailed pigeon.

Rhychopsitta pachyrhyncha, thick-billed parrot.

Glaucidium gnoma gnoma, pygmy owl.

Campephilus imperialis, Imperial ivorybill.

Colaptes mexicanoides, Guatemalan flicker.

Dryobates villosus icastus, Chihuahua woodpecker.

Leptuas neoxenus, eared trogon.

Trogonurus mexicanus, Mexican trogon.

Basilinna leucotis, white-eared hummingbird (also Canadian).

Colibri thalassinus, Mexican violet-ear.

Cyanolaemus clemenciae, blue-throated hummingbird.

Eugenes fulgens, Rivoli hummingbird (also Canadian).

Selasphorus platycercus, broad-tailed hummingbird (also Canadian).

Cypseloides brunneitorques brunneitorques, chestnut-collared swift.

Lepidocolaptes leucogaster, white-striped woodhewer.

Myiochanes pertinax pallidiventris, Coues' flycatcher.

Empidonax pulverius, Sierra Madre flycatcher.

Empidonax trepidus, Chancol flycatcher.

Ptilogonys cinereus cinereus, Mexican ptilogonys.

Heleodytes megalopterus, Huitzilac cactus wren.

Troglodytes brunneicollis brunneicollis, brown-throated wren (also Canadian).

Troglodytes brunneicollis cahooni, Cahoon's wren.

Catharus occidentalis olivascens, olive nightingale thrush.

Turdus migratorius propinquus, western robin.

Ridgwayia pinicola, Ridgway's thrush.

Sialia mexicana bairdi, chestnut-backed bluebird.

Myadestes townsendi. Townsend's solitaire.

Penthestes sclateri, Mexican chickadee.
Sitta carolinensis aculeata, slender-billed nuthatch.

Sitta carolinensis mexicana, Mexican nuthatch.

Sitta pygmaea pygmaea, pygmy nuthatch.

Sitta pygmaea leuconucha, white-naped nuthatch.

Certhia familiaris albescens, Sierra Madre creeper.

Certhia familiaris alticola, Mexican creeper (also Canadian).

Aphelocoma unicolor coelestis, cerulean jay.

Cyanocitta stelleri diademata, longcrested jay.

Cyanocitta stelleri azteca, Aztec jay (also Canadian).

Oreothlypis superciliosa, Hartlaub's warbler.

Peucedramus olivaceus, olive warbler.

Dendroica auduboni nigrifrons, blackfronted warbler.

Cardellina rubrifrons, red-faced warbler.

Setophaga picta picta, painted redstart.

Ergaticus ruber, red warbler (also Canadian).

Ergaticus versicolor, pink-headed warbler (also Canadian).

Piranga hepatica, hepatic tanager.

Hesperiphona vespertina mexicana, Mexican evening grosbeak.

Spinus pinus macropterus, Mexican pine siskin (also Canadian).

Junco phaeonotus phaeonotus, Mexican junco (also Canadian).

Melospiza melodia goldmani, Goldman's song sparrow.

Pipilo maculatus maculatus, Mexican spotted towhee.

e. Fir-spruce Association (Canadian and Hudsonian Zones). This zone characterized by boreal species of plants and animals occupies the upper slopes to timberline at 13,000 to $13,500 \mathrm{ft}$. of the highest mountains of the Republic. It includes very limited areas on the extreme upper slopes of the San Pedro Martir Mountains in northern Lower California, a few peaks along the crest of the Sierra Madre Occidental, and more extensive belts above about $9000 \mathrm{ft}$. altitude, on the higher mountains of southern Mexico, including those of the state of Chiapas, which form part of the mountain system of Central America. It is doubtful whether Canadian and Hudsonian elements well developed farther north can satisfactorily be separated in Mexico, owing to their limited extent. 


\section{Plants}

Pinus contorta, lodgepole pine.

Pseudotsuga mucronata, Douglas fir (also Transition).

Abies religiosa, pinabete.

Populus tremuloides (also Transition). Alnus firmifolia, alder.

Quercus ghiesbrechtii, Ghiesbrecht's oak.

\section{Mammals}

Sorex orizabae, Mount Orizaba shrew: Cryptotis alticola, Mount Popocatepet shrew.

Bassariscus astutus astutus, Mexican plateau bassariscus.

Reithrodontomys chrysopsis chrysopsis, volcano harvest mouse.

Peromyscus oaxacensis, Oaxaca mouse.

Peromyscus difficils felipensis, Cerro San Felipe mouse.

Sigmodon alticola alticola, Oaxaca cotton rat.

Neotomodon orizabae, Orizaba little wood rat.

Microtus mexicanus mexicanus, Mexican meadow mouse.

Cratogeomys oreocetes, Mount Popocatepetl pocket gopher.

Romerolagus diazi, volcano rabbit.

\section{Birds}

Basilinna leucotis, white-eared hummingbird (also Transition).

Lampornis pringlei, Pringle's hummingbird.

Eugenes fulgens, Rivoli hummingbird (also Transition).

Selasphorus platycercus, broad-tailed hummingbird (also Transition).

Troglodytes brunneicollis brunneicollis, brown-throated wren (also Transition).

Sialia mexicana australis, Nelson's bluebird.

Certhia familiaris albescens, Sierra Madre creeper.

Nucifraga columbiana, Clarke's nutcracker.

Cyanocitta stelleri azteca, Aztec jay (also Transition).

Ergaticus ruber, red warbler (also Transition).

Ergaticus versicolor, pink-headed warbler (also Transition).

Loxia curvirostra stricklandi, Mexican crossbill.

Spinus pinus macropterus, Mexican pine siskin (also Transition).

Spinus atriceps, Guatemalan pine siskin.

Carpodacus cassinii, Cassin's purple finch.

Junco phaeonotus phaeonotus, Mexican junco (also Transition).

\section{Minor life areas}

A few of the numerous regional life areas, into which the major life zones of Mexico are divisible, may briefly be indicated. ${ }^{1}$ No attempt is made to list the total number of species that occur.

a. Cape Lowlands District (Arid Tropical Zone). Lowlands of Cape region of Lower California. Desert plains and low mountains. Flora and fauna derived largely from adjacent mainland of Mexico.

\section{Plants}

Haematoxylum brasiletto, logwood, palo de Brasil.

Esenbeckia flava, palo amarillo.

Elaphrium rhoifolium.

Sapium biloculare, hierba de la flecha. Cyrtocarpa edulis, ciruela.

Maytenus phyllanthoides, mangle dulce. Dodonaea viscosa, switch sorrel.

Rhizophora mangle, mangrove.

Conocarpus erecta.

\section{Mammals}

Oryzomys peninsulae, Lower California rice rat.

Balantiopteryx plicata, Peter's pouched bat.

Natalus mexicanus, Santa Anita bat.

Dasypterus ega xanthinus, Sierra Laguna bat.

Pizonyx vivesi, Cardonal Island bat.

\section{Birds}

Ardea herodias sancti-lucae, San Lucas great blue heron.

Egretta thula brewsteri, Brewster's egret.

Rallus beldingi, Belding's rail.

Crotophaga sulcirostris, groove-billed ani.

Toxostoma cinereum cinereum, San Lucas thrasher.

Dendroica bryanti castaneiceps, mangrove warbler.

Richmondena cardinalis ignea, San Lucas cardinal.

Pyrrhuloxia sinuata peninsulae, San Lucas pyrrhuloxia.

Cyanospiza versicolor, varied bunting.

b. Vizcaino Desert District (Lower Austral Zone). Central Lower California. Desert plains and low, but rugged mountains. A region of extreme

1 For full treatment of floral and faunal districts in Lower California, see Nelson, 1921, pages 117-132. 
aridity, allied in part to the same zone (landscape aspect similar) in southern California and in part to the same zone in Sonora, but many floral and faunal elements differing from both.

\section{Plants}

Covillea glutinosa, creosote bush, gobernadora.

Idria columnaris, cirio.

Fouquieria splendens, ocotillo.

Pachycormus discolor, elephant wood. Simmondsia californica, goat nut.

\section{Mammals}

Odocoileus hemionus eremicus, desert mule deer.

Antilocapra americana peninsularis, Lower California antelope.

Eutamias merriami meridionalis, Lower California desert chipmunk.

Thomomys bottae russeolus, San Angel pocket gopher.

Dipodomys platycephalus, Calmalli kangaroo rat.

Dipodomys agilis peninsularis, peninsula kangaroo rat.

Sylvilagus bachmani exiguus, Lower California brush rabbit.

\section{Birds}

Lophortyx californica vallicola, valley partridge.

Melopelia asiatica mearnsi, western white-winged dove.

Dryobates scalaris eremicus, San Fernando woodpecker.

Centurus uropygialis brewsteri, Brewster's woodpecker.

Colaptes chrysoides brunnescens, San Fernando flicker.

Otocoris alpestris enertera, Santa Rosalia horned lark.

Toxostoma cinereum mearnsi, Mearn's thrasher.

Toxostoma lecontei arenicola, desert thrasher.

Amphispiza belli cinerea, gray sage sparrow.

Pipilo fuscus aripolius, desert towhee.

c. San Diegan District (Upper Austral Zone). Western mainly brush-covered slopes of Sierra Juarez and San Pedro Martir Mountains from sea level to about $5000 \mathrm{ft}$. altitude. The extension of the Upper Austral Zone to sea level is here due to coastal influences. It is interrupted to the southward by Lower Austral plains and low mountains but reappears on the upper slopes of the mountains of extreme southern Lower California as indicated by the allied flora and fauna. Biota mainly an extension of that of southern California.

\section{Plants}

Juniperus californica, California

juniper.

Pinus monophylla, pinyon.

Nolina palmeri, Palmer's nolina.

Quercus agrifolia, California live oak. Quercus, dumosa, California scrub oak. Quercus palmeri, Palmer's oak.

Ribes indecorum, currant.

Adenostoma fasciculatum, chamiso.

Adenostoma sparsifolium, palo amarillo. Heteromeles arbutifolia, California holly. Aesculus parryi, Parry's buckeye.

\section{Mammals}

Sorex californicus juncensis, Socorro shrew.

Onychomys torridus ramona, Ramona grasshopper mouse.

Peromyscus californicus insignis, Dulzura mouse.

Neotoma fuscipes macrotis, large-eared wood rat.

Perognathus femoralis mesopolius, Lower California large-eared pocket mouse.

Thomomys bottae nigricans, Stephens; pocket gopher.

\section{Birds}

Balanosphyra formicivora bairdi, California woodpecker.

Thryomanes bewickii charienturus, San Diego wren.

Chamaea fasciata henshawi, pallid wrentit.

Baeolophus inornatus murinus, San Diego titmouse.

Psaltriparus minimus minimus, bushtit.

Aimophila ruficeps ruficeps, rufouscrowned sparrow.

Pipilo maculatus atratus, San Diego towhee.

\section{d. Cape Mountains District (Upper}

Austral Zone). Mountains of Cape region in extreme southern Lower California. Allied to the San Diegan District of northern Lower California, but separated by hundreds of miles of desert plains and mountains assigned to Lower Austral Zone.

\section{Plants}

Pinus cembroides, pinyon.

Nolina beldingi, Belding's nolina. 
Populus monticola, huirigo.

Quercus devia, encino negro.

Ribes brandegei, Brandegee's gooseberry. Heteromeles arbutifolia, California holly. Arbutus peninsularis, Lower California madroño.

\section{Mammals}

Sorex lagunae, Sierra Laguna shrew. Peromyscus truei lagunae, Sierra Laguna mouse.

Thomomys bottae alticolus, Sierra Laguna pocket gopher.

\section{Birds}

Balanosphyra formicivora angustifrons, narrow-fronted woodpecker.

Basilinna xantusii, Xantus' hummingbird.

Tachycineta thalassina brachyptera, Lower California violet-green swallow. Turdus confinis, San Lucas robin.

Baeolophus inornatus cineraceus, ashy titmouse.

Psaltriparus grindae, Grinda's bush-tit. Sitta carolinensis lagunae, Lower California nuthatch.

Vireo huttoni cognatus, Frazar's vireo. Aimophila ruficeps sororia, Laguna sparrow.

Pipilo maculatus magnirostris, mountain towhee.

e. San Pedro Martir District (Transition and Canadian Zones). Upper slopes (mainly western) of Sierra Juarez and San Pedro Martir Mountains (5000 to $9000 \mathrm{ft}$.) in northern Lower California, an extension, with local modifications, of mountain flora and fauna of southern California. A pine-forested area mainly Transition Zone, but with an infusion of Canadian Zone elements on colder, north slopes of highest peaks.

\section{Plants}

Abies concolor, white fir.

Pinus contorta, lodgepole pine.

Pinus ponderosa jeffreyi, Jeffrey's pine. Pinus coulteri, Coulter's pine.

Pinus lambertiana, sugar pine.

Libocedrus decurrens, incense cedar. Populus trichocarpa, black cottonwood. Populus tremuloides, quaking aspen.

Quercus chrysolepis, canyon live oak. Symphoricarpos parishii.

\section{Mammals}

Scapanus anthonyi, Anthony's mole.

Sciurus douglasii mearnsi, Mearns' squirrel.
Peromyscus truei martirensis, San Pedro martir mouse.

Odocoileus hemionus californicus, California mule deer.

\section{Birds}

Oreortyx picta confinis, San Pedro quail.

Dryobates villosus hyloscopus, Cabanis' woodpecker.

Sialia mexicana anabelae, San Pedro Martir bluebird.

Penthestes gambeli baileyae, Bailey's mountain chickadee.

Sitta carolinensis aculeata, slenderbilled nuthatch.

Sitta pygmaea leuconucha, white-naped nuthatch.

Nucifraga columbiana, Clarke's nutcracker.

Cyanocitta stelleri frontalis, Sierra Nevada jay.

Junco townsendi, Townsend's junco.

f. Vera Cruz Rain Forest District (Humid Tropical Zone, Tropical Rain Forest). Tropical lowlands and mountain slopes from sea level to 6000 to 8000 ft. depending upon local conditions, bearing evergreen forest, receiving moisture in the form of rain or fog at frequent intervals throughout the year. A typical section includes the northeastern seaward slopes of the Volcano of Orizaba and the Cofre de Perote. Divisible at about $3000 \mathrm{ft}$. altitude into upper and lower sections which can not properly be characterized in a short account.

\section{Plants}

Dicranopteris bancroftii, fern.

Cyathea tuerckheimii, tree fern.

Chamaedorea elegans, palm.

Castilla elastica, rubber tree, hule, arbol del hule.

Talauma mexicana, flor de corazon.

\section{Mammals}

Sorex macrodon, large-toothed shrew.

Tayra barbara senex, gray-headed tayra, cabeza viejo.

Sigmodon hispidus toltecus, Toltec cotton rat.

Reithrodontomys cherriei jalapae, Jalapa harvest mouse.

Peromyscus nelsoni, Nelson's mouse. Oryzomys chapmani chapmani, Chapman's rice rat.

Neotoma distincta, Vera Cruz wood rat.

Heterogeomys hispidus, Jalapa pocket gopher. 
Dasyprocta mexicana, Mexican agouti. Sciurus deppei deppei, Deppe's squirrel. Sciurus aureogaster hypopyrrhus, firebellied squirrel.

Tapirella dowii, Dow's tapir.

\section{Birds}

Saucerottia beryllina beryllina, Berylline hummingbird.

Abeillea abeillei, Abeille's hummingbird.

Henicorhina leucophrys mexicana, Mexican wood wren.

Hylorchilus sumichrasti, Sumichrast's wren.

Catharus melpomene melpomene, nightingale thrush.

Turdus tristis assimilis, Jalapa thrush.

Turdus infuscatus, black thrush.

Myadestes unicolor, slate-colored solitaire.

Cyanolyca nana, dwarf jay.

Neochloe brevipennis, green-winged vireo.

Diglosa baritula, Mexican diglossa.

Chlorophonia occipitalis, Mexican chlorophonia.

Phoenicothraupis rubica rubicoides, Mexican ant tanager.

Chlorospingus ophthalmicus, brownheaded chlorospingus.

g. Yucatan Peninsula District (northern and western portions) (Arid Tropical Zone, Arid Tropical Deciduous Forest). Low, gently sloping limestone plains, broken by a few low ridges. A region of moderate rainfall, but long dry season. Vegetation largely deciduous, but foliage retained in the more humid strip along Caribbean coast and across southern Yucatan.

\section{Plants}

Agave ixtli, ixtle.

Coccoloba schiedeana, tamulero.

Brosimum alicastrum, ramon.

Cassia occidentalis.

Bauhinia, glabra.

Haematoxylum campecheanum, logwood, palo de Campeche.

Annona glabra, palo de carcho.

Elaphrium simaruba, chaca.

Cedrela yucatana, Spanish cedar.

Byrsonima crassifolia, nanche.

Ceiba aesculifolia, pochote.

Bombax ellipticum, amapola.

\section{Mammals}

Didelphis yucatanensis yucatanensis, Yucatan opossum.

Cryptotis mayensis, Yucatan shrew.

Macrotus pygmaeus, pygmy large-eared bat.
Artibeus phaeotis, Chichen Itza bat.

Urocyon cineroargenteus fraterculus, $\mathrm{Yu}$ catan fox.

Felix onca goldmani, Goldman's tiger, tigre.

Felix pardalis pardalis, ocelot, tigrillo.

Ototylomys phyllotis phyllotis, Tunkas rat.

Heteromys gaumeri, Gaumer's spiny pocket mouse.

Sciurus yucatensis yucatanensis, $\mathrm{Yu}-$ catan squirrel.

Pecari angulatus yucatanensis, Yucatan peccary.

Mazama pandora, Yucatan forest deer.

Birds

Leptotila gaumeri, Gaumer's dove.

Otus hastatus thompsoni, Yucatan screech owl.

Nyctagreus yucatanicus, Yucatan poorwill.

Momotus lessonii exiguus, Yucatan motmot.

Pteroglossus torquatus erthrozonus, $\mathrm{Yu}$ catan aracari.

Centurus rubriventris rubriventris, Swainson's woodpecker.

Dryobates scalaris parvus, Sisal woodpecker.

Chaetura gaumeri, Gaumer's swift.

$X i p h o r h y n c h u s$ flavigaster yucatanensis, Yucatan woodhewer.

Dendrocincla anabatina typhla, Yucatan dendrocincla.

Thamnophilus doliatus yucatanensis, $\mathrm{Yu}$ catan antshrike.

Formicarius moniliger pallidus, Yucatan antthrush.

Attila citreopygus gaumeri, Gaumer's attila.

Pachyrhamphus major itzensis, Chichen Itza becard.

Platypsaris aglaiae yucatanensis, Yucatan becard.

Myiarchus yucatanensis, Yucatan flycatcher.

Heleodytes guttatus, Yucatan cactus wren.

Pheugopedius maculipectus cano-brunneus, Yucatan spotted-breasted wren.

Thryomanes albinucha, Cabot's wren.

Nannorchilus leucogaster brachyurus, Temax wren.

Polioptila albiventris, Yucatan gnatcatcher.

Psilorhinus mexicanus vociferus, Yucatan brown jay.

Cissolopha yucatanica, Yucatan jay.

Cyclarhis flaviventris yucatanensis, $\mathrm{Yu}$ catan pepper shrike.

Vireosylva magister cinerea, Cozumel vireo.

Piranga roseo-gularis roseo-gularis, rosethroated tanager. 
Arremonops verticalis, Schott's sparrow. Richmondena cardinalis yucatanica, Yucatan cardinal.

\section{h. Guerrero-Colima District (Arid} Tropical Zone, Arid Tropical Deciduous Forest, and Savanna). Coastal plains, and slopes of mountains to about 3000 ft. altitude. A region of moderate rainfall, but long dry season. Trees largely deciduous, except along streams. Forest irregularly interrupted by savanna areas.

\section{Plants}

Coccoloba schiedeana, tamulero. Licania arborea, cacahuananche. Hirtella americana, cajetillo.

Lysiloma acapulcensis, tepehuaje. Cassia occidentalis, habilla.

Bauhinia latifolia, pata de venado.

Bauhinia glabra.

Sweetia panamensis, huesillo.

Swietenia humilis, mahogany, caoba.

Byrsonima crassifolia, nanche.

Bombax ellipticum, ceiba.

Guazuma ulmifolia, cuaulote.

Curatella americana, raspa-viejo.

\section{Mammals}

Canis vigilis, Colima coyote.

Nasua narica molaris, Colima coati, tejon.

Felix onca hernandezii, Hernandez' tiger, tigre.

Felix pardalis nelsoni, ocelot, tigrillo.

Platygeomys fumosus, Colima pocket gopher.

Xenomys nelsoni, Nelson's wood rat.

Hodomys alleni, Allen's wood rat.

Sciurus socialis cocos, Acapulco squirrel.

Citellus annulatus annulatus, bandtailed ground squirrel.

Pecari angulatus humeralis, Colima peccary.

Odocoileus acapulcensis, Acapulco deer.

\section{Birds}

Momotus mexicanus saturatus, Coast motmot.

Centurus chrysogenys flavinuchus, Acapulco woodpecker.

Trogon citreolus, Citreoline hummingbird.

Phaethornis longirostris mexicanus, Guerrero hermit.

Anthoscenus constantii leocadiae, pine star-throat.

Cynanthus doubledayi, Doubleday's hummingbird.

Xiphorhynchus flavigaster mentalis, Grayson's woodhewer.
Attila citreopygus cinnamomeus, Lawrence's attila.

Myiarchus nuttingi inquietus, Guerrero flycatcher.

Heleodytes humilis, Sclater's cactus wren.

Pheugopedius felix felix, happy wren.

Nannorchilus leucogaster pacificus, Colima wren.

Turdus flavirostris, Mazatlan robin.

Cissolopha san-blasiana pulchra, Acapulco jay.

Granatellus venustus, Du Bus' redbreasted chat.

Megaquiscalus major obscurus, Colima boat-tail.

Phoenicothraupis rubica affinis, Oaxaca ant tanager.

Arremonops superciliosus sumichrasti, Acapulco sparrow.

i. Sierra Madre District (Transition Zone). Sierra Madre Occidental of northern part of Republic (Chihuahua, Sonora, Durango). An elevated plateau region (6000 to $8000 \mathrm{ft}$.) with irregular surface, but few high peaks. An extension of the Rocky Mountain region of the United States; deeply cut on the western flank by canyons mainly assignable to lower zones.

\section{Plants}

Pinus ponderosa, western yellow pine. Pinus chihuahuana, Chihuahua pine. Pinus lumholtzii, Lumholtz' pine.

Pinus arizonica, Arizona pine.

Rhamnus betulaefolia.

\section{Mammals}

Ursus nelsoni, Nelson's grizzly bear. Ursus machetes, Chihuahua black bear. Canis mexicanus, Mexican wolf.

Neotoma mexicana madrensis, Sierra Madre wood rat.

Callospermophilus madrensis, Mexican golden-mantled chipmunk.

Sciurus aberti barberi, Barber's squirrel. Odocoileus cousei, Coues' deer.

\section{Birds}

Chloroenas fasciata fasciata, band-tailed pigeon.

Rhynchopsitta pachyrhyncha, thickbilled parrot.

Campephilus imperialis, Imperial ivorybill.

Dryobates villosus icastus, Chihuahua woodpecker.

Leptuas neoxenus, eared trogon.

Empidonax pulverius, Sierra Madre flycatcher. 
Troglodytes brunneicollis cahooni, $\mathrm{Ca}$ hoon's wren.

Catharus occidentalis olivascens, olive nightingale thrush.

Ridgwayia pinicola, Ridgway's thrush.

Sialia mexicana bairdi, chestnut-backed bluebird.

Cyanocitta stelleri diademata, longcrested jay.

Dendroica auduboni nigrifrons, blackfronted warbler.

Junco phaeonotus phaeonotus, Mexican junco.

Melospiza melodia goldmani, Goldman's song sparrow.

j. Sonoran District (Lower Austral Zone). Arid plains and low mountains of Sonora, an extension of the desert region of southwestern Arizona, allied to the Tamaulipan District.

\section{Plants}

Ephedra trifurca.

Washingtonia sonorae, palm.

Yucca schottii.

Celtis pallida, desert hackberry.

Atriplex linearis.

Prosopis pubescens, screwpod mesquite, tornillo.

Prosopis juliflora velutina, mesquite.

Acacia wrightii, catsclaw, uña de gato.

Pithecolobium sonorae, uña de gato.

Hoffmanseggia microphylla.

Cercidium torreyanum, palo verde.

Eysenhardtia polystachya.

Parosela spinosa, indigo-bush.

Olneya tesota, ironwood, palo de hierro.

Erythrina flabelliformis, colorin.

Covillea glutinosa, creosote-bush, Gobernadora.

Koeberlinia spinosa, corona de cristo.

Fouquieria splendens, ocotillo.

\section{Mammals}

Pipistrellus hesperus hesperus, little western bat.

Canis mearnsi, Mearns' coyote.

Felis pardalis sonoriensis, ocelot, tigrillo.

Lynx ruffus baileyi, desert wildcat.

Peromyscus eremicus eremicus, desert mouse.

Sigmodon hispidus eremicus, western desert cotton rat.

Neotoma albigula melanura, Sonoran wood rat.

Thomomys sinaloae, Sinaloa pocket gopher.

Perognathus penicillatus pricei, Price's pocket mouse.

Dipodomys merriami merriami, Merriam's kangaroo rat.
Citellus tereticaudus, Yuma ground squirrel.

Ammospermophilus harrisii saxicola, Mearns' white-lined ground squirrel.

Lepus californicus eremicus, Arizona jack rabbit.

Pecari angulatus sonoriensis, Sonoran peccary.

Odocoileus hemionus eremicus, desert mule deer.

\section{Birds}

Lophortyx gambeii, Gambel's quail. Psittacula cyanopygia pallida, Sonoran parrotlet.

Amazona albifrons saltuensis, Sonoran parrot.

Micropallas whitneyi whitneyi, elf owl.

Colaptes chrysoides mearnsi, Mearns' gilded flicker.

Centurus uropygialis uropygialis, Gila woodpecker.

Otocoris alpestris pallida, pallid horned lark.

Heleodytes brunneicapillus brunneicapillus, Guaymas cactus wren.

Toxostoma curvirostre palmeri, Palmer's thrasher.

Toxostoma lecontei lecontei, Leconte's thrasher.

Polioptila plumbea, plumbeous gnatcatcher.

Dendroica aestiva sonorana, Sonoran yellow warbler.

Megaquiscalus major nelsoni, Sonoran boat-tailed grackle.

Icterus cucullatus nelsoni, Nelson's oriole.

Amphispiza bilineata deserticola, desert sparrow.

Melospiza melodia fallax, desert song sparrow.

Pyrrhuloxia sinuata sinuata, pyrrhuloxia.

Richmondena cardinalis superba, Arizona cardinal.

k. Tamaulipan District (Lower Austral Zone). Lower part of Rio Grande Valley and the plains and low mountains of northeastern Mexico largely in Tamaulipas, but extending into Nuevo Leon and Coahuila, south to a point a short distance north of Tampico. Generally arid in climate, allied to the Sonoran District.

\section{Plants}

Ephedra aspera, pitamoreal.

Yucca australis.

Celtis pallida, desert hackberry.

Atriplex matamorensis.

Prosopis juliflora glandulosa, mesquite. Acacia wrightii, catsclaw, uña de gato. 
Pithecollobium brevifolium, tenaza.

Hoffmanseggia melanosticta.

Cercidium floridum, retama.

Eysenhardtia polystachya, taráy.

Parosela berlandieri.

Covillea glutinosa, creosote bush, Gobernadora.

Koeberlinia spinosa, corona de cristo.

Fouquieria splendens, ocotillo.

\section{Mammals}

Pipistrellus, hesperus hesperus, little western bat.

Canis microdon, small-toothed coyote.

Bassariscus astutus flavus, tawny bassariscus.

Felis pardalis griffthii, ocelot tigrillo.

Lynx ruffus texensis, Texan lynx.

Baiomys taylori taylori, Taylor's little brown mouse.

Peromyscus leucopus texanus, Texas white-footed mouse.

Oryzomys couesi aquaticus, Rio Grande rice rat.

Sigmodon hispidus berlandieri, Berlandier's cotton rat.

Neotoma micropus micropus, Baird's wood rat.

Geomys personatus tropicalis, Tamaulipas pocket gopher.

Liomys irroratus texensis, Texas spiny pocket mouse.

Perognathus merriami, Merriam's pocket mouse.

Dipodomys merriami merriami, Merriam's kangaroo rat.

Citellus mexicanus parvidens, Rio Grande ground squirrel.

Lepus californicus merriami, Merriam's jack rabbit.

Pecari angulatus angulatus, Texas peccary.

Odocoileus hemionus canus, gray mule deer.

\section{Birds}

Callipepla squamata castanogastris, chestnut-bellied scaled partridge.

Amazona viridigenalis, red-crowned parrot.

Otus asio mccallii, Texas screech owl.

Dryobates scalaris symplectus, Texas woodpecker.

Platypsaris aglaiae aglaiae, rosethroated becard.

Otocoris alpestris diaphora, Tamaulipas horned lark.

Heleodytes brunneicapillus couesi, Coues' cactus wren.

Thryothorus ludovicianus berlandieri, Berlandier's wren.

Toxostoma longirostris sennetti, Sennett's thrasher.

Xanthoura luxuosa glaucescens, Rio Grande green jay.
Icterus melanocephalus audubonii, Audubon's oriole.

Icterus cucullatus sennetti, Sennett's oriole.

Arremonops rufivirgatus rufivirgatus, Texas sparrow.

Pyrrhuloxia sinuata texana, Texan pyrrhuloxia.

Richmondena cardinalis canicauda, graytailed cardinal.

\section{MODIFICATION OF ORIGINAL BIOTA}

While much of Mexico remains in essentially primeval condition important changes have been brought about through human occupation, especially near the larger cities. On the higher parts of the Plateau near its southern end many of the more fertile sections of original grassland, or mixed grassland and scrub have been turned into fields of wheat, corn, beans, century plants or magueyes for the production of pulque (a fermented drink), mezcal and tequila (distilled liquors), fiber, and other crops. The grazing of such domestic stock as cattle, horses, burros, sheep, and goats is extensively carried on wherever conditions are suitable throughout the Republic; and this, as elsewhere, has resulted in the overutilization of forage in places, especially in the vicinity of water. Large sections of the northern tier of states remain but little modified owing to extreme sterility and scanty forage production, or to the absence of a permanent water supply for stock.

Within the tropical zone much of the original forest is still intact. Cultivation of the soil here usually involves the clearing of forest for growing a variety of crops including corn, beans, sugarcane, cotton, coffee, cacao, and many kinds of fruit. Coffee is grown on humid tropical mountain slopes to 6000 ft. altitude. A considerable section of northern Yucatan is devoted to the cultivation of a native century plant (Agave $i x t l i$ ) from which is extracted the "ixtle" or "henequen" of commerce. The production of this fiber, extensively used as binding twine, constitutes one of the more important Mexican industries. As a result much of the 
original arid deciduous forest of this part of Yucatan has disappeared.

In some parts of the tropical zone small sections of original forest are cut and cleared by burning during the dry season. With the opening of the rain season these are planted to corn, beans, and other crops which owing to the absence of competing vegetation mature with little or no further attention. The second year some cultivation is required as intrusive non-forest plants are beginning to secure a foothold. The third year the clearing is often abandoned owing to an exuberant growth of herbaceous and shrubby vegetation with which the ordinary native and his primitive tools can not cope. At this stage he often prefers to fell more forest, leaving the cleared area to revert through a succession of dominant plant types leading again after many years to a climax, or near-climax forest. It is evident that in this manner, piece by piece, a very large share of the area covered by the present extensive forests of tropical Mexico has at some time been brought under cultivation by man; and vast areas lost their original forests by clearing many centuries ago.

Fires started by lightning and by human agency have had a profound effect in limiting forest growth, especially along the Sierra Madre Occidental and on the mixed savannas and arid deciduous forested plains along the west coast. While vast bodies of timber remain uncut there has been, aside from general clearing, much destruction of forest through lumbering operations, especially in connection with the development of the vast mining industry of Mexico. The tropical forests of the Atlantic watershed have been exploited for the more valuable timber, such as Spanish cedar, mahogany and logwood until most of the supply within easy reach of navigable streams has been removed. Forest products of the same region include rubber from the rubber tree Castilla elastica, and chicle, the basis of most of the chewing gum of commerce, from Achras zapota. The process of gathering these gums tends to exhaust the trees, causes premature decay and finally their destruction.

Some of the largest marshes including those in the Valley of Mexico and the Laguna de Chapala in Jalisco are reported to have been partially drained within recent years, one result being the obliteration of extensive breeding and feeding grounds for many thousands of migratory and non-migratory waterfowl. This drainage is serious in its effect on water fowl and other aquatic animal life, especially in view of the fact such water areas are very limited in extent in the region under review.

As elsewhere much of the larger game has disappeared over extensive areas due to human occupation of the country. Those especially affected have been the antelope, mule deer, and mountain sheep. The sparse settlement of the country, however, has permitted these game animals to continue their existence in the less frequented sections and efforts are being made by the Mexican government through presidential decrees and recently enacted game laws to protect them. Little organized effort has been made to control predatory animals, but wolves formerly very destructive to domestic stock apparently have been exterminated in the southern part of the high plateau region.

\section{Accessibility of Natural Areas}

The railroad system of Mexico supplemented by stage lines affords, under normal conditions, easy access to many interesting regions, but owing to the rugged character of the country many others can only be reached by undertaking rather long trips with pack outfits. The principal gateways on the north are by rail through Nogales, El Paso, Ciudad Porfirio Diaz, Laredo and Brownsville. The route through Nogales affords access to much of the west coast region, and a connection through Jalisco with the main system of the Republic. A railroad across the Isthmus of Tehuantepec connects the seaports of Coatzacoalcos (now Puerto 
Mexico) and Salina Cruz, and short railroads radiate from the port of Progreso, Yucatan. The principal ports of the east coast, Tampico, Vera Cruz and Progreso, are reached by regular steamers from New York, New Orleans and other cities, and from Tampico and Vera Cruz there is rail connection with the interior. On the west coast there are numerous ports visited by coastwise steamers, some of which have railroad connections. Among the principal ports that may be mentioned are Guaymas, La Paz, Mazatlan, San Blas, Manzanillo, Acapulco, Salina Cruz, and Tapachula.

Visitors to Mexico should be provided with passports. Collectors of birds or mammals, especially, should inform themselves concerning Federal and local laws and regulations affecting shooting and the taking of such material. Letters of introduction to officials and others should be secured whenever possible as they are of great value in preventing misunderstanding. Disturbed political conditions may make certain regions unsafe. Mexican officials are usually very courteous and inclined to be helpful when approached by properly accredited individuals, as are the people in general except the Indians of some remote sections who look with suspicion upon all visitors whose motives they can not readily understand.

\section{BibLIOGRAPHY}

The following bibliography includes the titles of some of the more general works concerning in part the biota of . Mexico, together with those of a few of the more important papers dealing exclusively with the region.

Baker, H. B.

1922. The Mollusca collected by the University of MichiganWalker Expedition in Southern Vera Cruz, Mexico. Occasional Papers, Museum of Zool., Univ. Mich., No. 106. Hernández, Francisco.

1651. Rerum medicarum Novae Hispaniae thesaurus, seu plant- arum animalium, mineralium mexicanorum historia ex Francisco Hernández, novi orbis medici primarii, relationibus in ipsa mexicana urbe conscriptis a Nardo Antonio Reccho collecta ac in ordinem digesta: a Joanne Terrentio, Joanne Fabro et Fabio Columna Lynceis notis et additionibus illustrata. Cui accessere aliquot ex Principis Federici Caesii frontispiciis theatri naturalis phytosophicae tabulae una cum quam plurimis iconibus. $\mathrm{Pp}$. $1-950+1-90$. Ill. Rome, 1651 . (An important early work including much information concerning animals and plants.)

Biologia Centrali-Americana.

1879-1915. An elaborate treatment in 52 volumes by various authors of the mammals, birds, insects, mollusks, and plants of León, Nicolás. Mexico and Central America.

1895. Biblioteca Botánico-Mexicana, Catáloge bibliográphico y crítico de autores $y$ escritos referentes a vegetales de México y sus aplicaciones, desde la Conquista hasta el presente. Mexico, 1895. (Contains an extensive bibliography of Mexican botany.)

Ramírez, José.

1899. La Vegetacion de Mexico, pp. 1-271, with 2 maps. Mexico, 1899. (Describes the general character of the flora.)

Ridgway, Robert.

1901-1919. Birds of North and Middle America: A descriptive catalogue of the higher groups, genera, species, and subspecies of birds known to occur in North America, from the Arctic Lands to the Isthmus of Panama, the West Indies, and other islands of the Caribbean Sea, and the Galapagos Archipelago. Bull. 50, U. S. Nat. Mus., pts. 1-8, each separately paged have been issued (others to follow), covering families in reversed order Fringillidae to Alcidae. Washington: Govt. Printing Office. (The current authoritative systematic account of the birds of the region.)

Ramírez, Jose, and Gabriel V. Alcocer. 1902. Sinonomia Vulgar y Cientifica de las Plantas Mexicanas, 
pp. I-XII, 1-160, Mexico, 1902. (A valuable list of scientific and common names.)

Elliot, Daniel Giraud.

1904. The Land and Sea Mammals of Middle America and the West Indies. Pub. Field Columb. Mus., Zool. Ser., vol. IV, pts. 1-2, pp. 1-850. Chicago, 1904. (Contains list of species with original references, brief descriptions, type localities, and geographic distribution.)

Mearns, Edgar Alexander.

1907. Mammals of the Mexican Boundary of the United States: A Descriptive Catalogue of the Species of Mammals Occurring in that Region; with a General Summary of the Natural History, and a list of trees. Bull. 56, U. S. Nat. Mus., pt. 1 (part 2 unpublished), Families Didelphiidae to Muridae, $\mathrm{pp}$. $1-530$, pls. I-XIII, text figs. 1-126. (An important, but unfortunately uncompleted work on the mammals of the region.)

Miller, Gerrit S., Jr.

1912. List of North American Land Mammals in the United States National Museum, 1911, pp. I-XIV, 1-455, 1912. (An authoritative systematic list of currently recognized North American species at the end of the year 1911, with references to original descriptions; type localities are given and in some instances geographic ranges. It is understood that a new edition of this important work will soon be issued.)

Nelson, Edward W.

1918. Wild Animals of North America. Combining in one volume text and illustrations of two numbers of National Geographic Magazine - that of November, 1916 devoted to the "Larger Mammals of North America, and that of May, 1918 entitled the "Smaller Mammals of North America." (Includes accounts of many Mexican species.)

Pilsbry, Henry A.

Various papers in the Proc. Phil. Acad. Nat. Sci., 1891-1920, on the Mollusca of Mexico, including description of new family and species and ecological notes.
Standley, Paul C.

1920-1923. Trees and Shrubs of Mexico. Contrib. U. S. Nat. Herb., vol. 23, pts. 1-3, pp. $1-848$ (have been issued). Part 1. Gleicheniaceae-Betulaceae (1920). Part 2. Fagaceae-Fabaceas (1922). Part 3. Oxalidaceae-Turneraceae (1923). (A valuable descriptive and distributional list.)

Nelson, Edward W.

1921. Lower California and its Natural Resources. Mem. Nat. Acad. Sci., vol. XVI, pp. 1-194. pls. 1-35. Washington: Govt. Printing Office, 1921. (Includes detailed accounts of life areas.)

\section{GUATEMALA}

\section{By Wilson Popenoe}

In Guatemala, as in Mexico and several other tropical American countries, three climatic zones are popularly recognized. These are the tierra caliente (hot region), in Guatemala extending from sea level to an altitude of about $2000 \mathrm{ft}$.; the tierra templada (temperate region), comprising the territory between 2000 and $6500 \mathrm{ft}$.; and the tierra fria (cold region) which extends from $6500 \mathrm{ft}$. to the upper limit of cultivation, about $10,000 \mathrm{ft}$.

For the purposes of the present work it is more useful to consider Guatemala as comprising the following regions: (1) the Pacific littoral; (2) the volcanic mountains which rise from the northern edge of the coastal plain; (3) the plateau region, known locally as Los Altos, which extends from the volcanic range northward the eastward past the geographic center of the country; (4) the moist mountainous Vera Paz region; (5) the semi-arid valley of the upper Motagua River; and (6) the moist lowlands of the Atlantic Coast, together with the great plain of Petén which comprises about one-third of the whole area of Guatemala.

1. The coastal plain on the Pacific side of Guatemala averages about 50 mi. in width. At the base of the sierra, whence it slopes uniformly to the sea, it has an elevation of 1000 to $2000 \mathrm{ft}$. 
There is a rainy season of several months' duration, followed by a severe dry season, during which vegetation turns brown and many plants lose their leaves. Scattered small trees and scrubby forest occurs throughout, while the entire plain supports a heavy growth of grass during the wet season. Proceeding inland from the coast the trees become gradually larger and more numerous, until the rain forest is reached. The latter occupies a belt along the lower slopes of the volcanoes, extending from levels of 1000 or 1500 up to 5000 or $6000 \mathrm{ft}$.

There are three ports on the Pacific coast, of which two only are important. These are Champerico and San José. Thirty or $40 \mathrm{mi}$. back from the coast are a number of prosperous towns which serve as centers of agricultural activity. From north to south the most important of these are Ayutla, Coatepeque, Retalhuleu, Mazatenango and Escuintla. The plain is generally thinly populated, particularly near the coast. Along the foot of the sierra are numerous coffee plantations and several large sugar estates.

2. The mountain range which rises at the northern edge of the coastal plain forms the main watershed between the Atlantic and Pacific oceans. Its summit is not a well defined crest; it is rounded in places, and elsewhere volcanic cones reach up to great heights. Tacaná (about 13,000 ft.) is the dividing line between Mexico and Guatemala. Almost due east of this peak is Tajumulco, whose elevation is nearly 14,000 $\mathrm{ft}$. Southeastward is Santa Maria at whose northern base lies the city of Quezaltenango. Not far to the east and slightly south of this city is the beautiful lake of Atitlan, surrounded by the volcanoes of S. Pedro, Toliman, and Atitlan. Continuing toward the southeast, the volcanoes Acatenango and Fuego rise from the western side of the valley of Antigua, while on the east is the Volcan de Agua (12,300 ft.). Between this group and the volcano Pacaya is the lake of Amatitlan. Pa- caya is the southernmost peak of consequence, the territory between this point and the Salvadorian frontier being a series of broken hills and ridges, with small valleys here and there. Santa Maria, Fuego and Pacaya have all been in eruption during the past half century.

This mountainous region, gradually becoming lower as it approaches the border of Salvador, is characterized toward the northwestern part of Guatemala by rain forest along the southern slopes, and by oak and pine forests at elevations between 6000 and 10,000 ft. approximately. The Indians long ago cleared the native vegetation from most of the lands suitable for cultivation.

The climate in the inhabited regions of the sierra is cool and practically identical with that of the plateau region which reaches out to the north and east. Rainfall is scanty at the higher elevations, and severe frosts occur at $8000 \mathrm{ft}$. This region is known as tierra fria and is often referred to in literature as having the climate of the Temperate Zone. It should not be inferred, however, that the minimum temperatures experienced in any of the inhabited parts of Guatemala are as low as those of the temperate zone proper. The highest settlements are at elevations scarcely exceeding $10,000 \mathrm{ft}$. It is doubtful if the mercury goes below $20^{\circ}$ F. at such altitudes in Guatemala. Occasionally, it goes as high as $75^{\circ}$.

3. The region known as Los Altos comprises most of the Departments of Huehuetenango, Totonicapan, Chimaltenango, Guatemala, and portions of Quezaltenango, Solola and Suchitepequez. While generally held to be a plateau, it is extremely broken in character, and nowhere are there plains of great extent. Its mean elevation is probably between 6000 and $7000 \mathrm{ft}$. Toward the western side where it approaches the volcanoes, the mean elevation is somewhat greater than toward the east. Throughout all this region, which has been cultivated by the In- 
dians from early times, the best land has been cleared for agricultural purposes, and much of the timber has been cut off for fire wood. It is rare, in fact, to find extensive landscapes in which native vegetation still persists. On the rougher slopes are open forests of oak and pine, while many of the higher regions are covered with grass. Rainfall is scanty and confined to a certain part of the year. Minimum temperatures of 30 to $40^{\circ}$ are experienced and maxima of 80 to $90^{\circ}$. The orange tree can be cultivated up to elevations of $7500 \mathrm{ft}$. The landscape is nearly always characterized by cultivated fields of the Indians, roadways lined with agave plants, and deeply eroded barrancas (occasionally becoming small canyons) in which low scrub forest is found. About Guatemala City, which marks the eastern end of the plateau region, the elevation is only $5000 \mathrm{ft}$.

4. To the average naturalist, there is probably no other portion of Guatemala which possesses so much interest as the Vera Paz. Cobán, the center of this region, lies about $100 \mathrm{mi}$. north of Guatemala City, in a region of low mountains and abundant streams. The southern half of Alta Vera Paz and northern third of Baja Vera Paz are uniform in character; farther south, across the Cachil divide, the country becomes dry and unattractive; while to the north lies Petén, part of the huge plain which extends to the coast of Yucatan.

The mountains of the Vera Paz, few of which reach heights greater than $6000 \mathrm{ft}$., are drained by the Chixoy on the west and the Cahabon and the Polochic rivers on the east. There is practically no level ground in this region; in the small valleys, most of which lie at elevations between 3000 and $5000 \mathrm{ft}$., are Indian villages, as well as coffee plantations which have been developed in recent years by Europeans. The mountains are covered in many places by luxuriant rain forest, and everywhere there are small brooks, clear as crystal. Rains fall upon this region almost daily during the greater part of the year, and there is no well defined dry season, though the inhabitants are wont to consider as such the occasional periods of three or four weeks when the rains cease to an extent which permits the roads to become dry. Toward the southern part of this region, some of the slopes are covered with grass and pine. On the north side of the Polochic valley, however, they are mostly clothed with rain forest. Near San Cristobal and Tactic there are groves of Liquidambar in the open places. The tree dahlia (Dahlia maxonii) brightens with its starry pink flowers many of the hillsides, while beneath the rain forest are to be found tree ferns, dwarf palms of the genus Chamaedorea, orchids, and Bromeliads in abundance.

5. The valley of the Motagua River, from Gualán westward to El Rancho, typifies the arid tropical zone of Guatemala. To the north are the slopes of the Sierra de las Minas, while to the south are low arid hills as far as the frontiers of Honduras and Salvador. Many of the landscapes are typically those of a desert region, with Opuntias and other Cacti, and thorny shrubs of several families, notably Leguminosae. The soil is sandy, and the rainfall only a few inches per annum.

6 . The lower Motagua valley; the region around Lake Izabal; the Golfo Dulce; and the great plain of Petén are to be considered under one head. In all this region the elevation is nowhere above $1000 \mathrm{ft}$. The rainfall is abundant during a large part of the year, and the vegetation is that of the humid tropical zone (Rain Forest). Around Izabal there are great numbers of Attalea palms and forest trees typical of the Central American sea coast. About Puerto Barrios, the land is very low and swampy. Southwest of this point is a small, low range of mountains known as the Sierra del Mico, at whose northern base lies Lake Izabal. Between this and the port of Livingston is the limestone gorge of the Rio Dulce, along 
which is a riot of tropical vegetation famous for its beauty.

The plain of Peten has been more thoroughly explored by archaeologists than by botanists, though its uniformity makes relatively simple the matter of studying either its fauna or its flora. In all this region there are forests and savannahs. During four or five months of the year little rain falls, and travel becomes possible; more than half the time it is extremely difficult to penetrate the interior of this Department, due to the condition of the trails, and the lack of settlements where supplies can be obtained. Only a few thousand people live in Petén, and of these the majority are in the one town of Flores. The great Usumacinta River flows along the western boundary of this Department, and drains the larger part of it.

\section{ROUTES OF TRAVEL}

Guatemala is traversed from the Atlantic to the Pacific by a railroad, which, leaving Puerto Barrios on the Atlantic, passes up the Motagua valley onto the plateau where lies Guatemala City. Thence it descends past Lake Amatitlan and the foot of the Volcan de Agua, to the town of Escuintla, whence it crosses the coastal plain to the port of San José. From Santa Maria Junction, between San José and Escuintla, there is a line which extends up the coastal plain to the Mexican border, with a branch to the port of Champerico.

The railway gives easy access to the humid tropical region of the lower Motagua valley where àre located extensive banana plantations; the desert region about Zacapa and El Rancho; the plateau of Guatemala City; and the entire coastal plain along the Pacific. It also places one within striking distance of other parts of the country.

From such towns as Escuintla, Mazatenango, and Retalhuleu it is easy to reach by horse or mule the rain forest belt on the slopes of the sierra, where are located most of the coffee planta- tions. Quezaltenango and the highland region can also be reached from the railway at Santa Felipe. From Guatemala City there is a stage line to Antigua, which lies in a beautiful and interesting valley, while by horse or mule it is not difficult to visit the entire plateau region (Los Altos) though this requires several days.

The Vera Paz may be reached either from Guatemala by horse or mule, or from Livingston by boat through Lake Izabal to Panzos on the Polochic River, whence there is a railway $28 \mathrm{mi}$. in length to Pancajché, from which place Cobán may be reached by horse or mule in a day and a half. From Cobán there are trails to many parts of the Vera $\mathrm{Paz}$, and one may cross the Chixoy and go through the province of Quiché to Los Altos. The trail from Cobán to Guatemala City passes through Tactic and Salamá, thence over the Chuacús range into the Motagua valley and up to Guatemala City.

The southeastern part of the country may be reached on horseback from Guatemala City. It is not difficult to journey as far as Santa Ana in the neighboring republic of Salvador.

The Petén region is difficult of access, except through British Honduras. The usual route is from Belize up the river to a point near the border of Guatemala, whence there is a trail to Flores.

Overland travel in Guatemala is not difficult, providing one is willing to be satisfied with poor accommodations and food. It is best to carry a few supplies to augment the monotonous round of tortillas, arroz and frijoles. Good riding animals are difficult to secure, unless one has friends in the country.

\section{BIBLIOGRAPHY ${ }^{1}$}

*Brigham, William T. Guatemala: the land of the Quetzal. New York. 1887.

Pepper, Charles M. Guatemala, the country of the future. Washington, D. C. 1906 .

1 Those considered especially valuable are marked with an asterisk. 
*Sapper, Karl T. Grundzüge der physikalischen geographie von Guatemala. Gotha. 1894.

Rodriguez, Juan J. Apuntamientos sobre los estudios de biologia en Guatemala é importancia de estos estudios. . . Guatemala. 1893.

Dearborn, Ned. Catalogue of a collection of birds from Guatemala. Chicago. 1907. (Field Museum of Natural History. Publication 125.)

*Rodriguez, Juan J. Memoria sobre la fauna de Guatemala. Guatemala. 1894.

Blake, Sidney F. Native names and uses of some plants of eastern Guatemala and Honduras. Washington, D. C. 1922. (Contr. Nat. Herb., Vol. 24, pt. 4.)

Blake, Sidney F. New Plants from Guatemala and Honduras. Washington. 1922. (Contr. Nat. Herb., Vol. 24, pt. 1.)

Brigham, William T. The Guatemalan Forests and their Future. Trans. Mass. Hort. Soc. 1884 (pt. 1): 159-173, 1885.

Smith, John Donnell. Enumeratio plantarum Guatemalensium. Oquawka, Ill. 1889-1907.

Rodriguez, Leopold. Note sur la végétation du Guatémala. Bulletin Soc. Bot. France. Vol. 67: 356-360. 1921.

*Sapper, Karl. Die Alta Verapaz (Guatemala). Hamburg, Germany. 1902.

Jáuregui, Antonio Batres. Los Indios, su Historia y su Civilizacion. Guatemala. 1893.

*Recinos, Adrian. Monografia del Departamento de Huehuetenango. Guatemala. 1913.

Popenoe, Wilson. The Avocado in Guatemala. Department of Agriculture, Washington, D. C. Department Bulletin no. 743 .

*Sapper, Karl. Das Nordliche MittelAmerika, Reisen und Studien. 1888-95. 3 vols. Brunswick, 1897.

\section{BRITISH HONDURAS}

\section{By KarL P. SchMid T}

\section{GENERAL CONDITIONS}

\section{Topography}

British Honduras lies at the southeastern corner of the Yucatan Peninsula. The northern part of the country is a part of the typical tertiary limestone area of Yucatan, with its characteristic lakes. To the southeast, the coastal region is a tropical lowland which rises gradually to the west where, on the western border, a plateau level of over $1500 \mathrm{ft}$. is reached. An isolated mountain mass, the Cockscomb Mountains, reaches $3600 \mathrm{ft}$. altitude, the highest in British Honduras.

\section{Climate}

The climate is typically tropical, with a rainy season from May to January. The heat is much relieved by the steady sea breeze along the coast.

\section{ORIGINAL BIOTA}

The tropical rain-forest of the lowlands of British Honduras abounds with the characteristic tropical mammals and birds of Central America, such as tapir, jaguar, brocket deer, curassow and yellow throated toucan. A distinct species of crocodile (Crocodylus moreletii) is found in the swamps near Belize, and manatee is reported to be fairly common in the rivers. The small population and the great extent of forest, from which at most the mahogany has been removed, offers an assurance of easily accessible primitive conditions.

British Honduras offers a number of advantages to the North American biologist, among which are ready accessibility from New Orleans, English speaking natives, and great areas of untouched forest. Twenty-five mi. of railroad lead to an abandoned United Fruit Company plantation, which is surrounded by an uninhabited wilderness. At this plantation, excellent accommodations, and the services of the few remaining workmen are available. The chain of coral cays off the coast offers ready access to coral reef and tide-pool marine life, while their shoreward sides are in many cases a mass of mangrove.

\section{Morris, Daniel.}

1883. The colony of British Honduras, its resources and prospects; with particular reference to its 
indigenous plants and economic productions. London: E. Stafford. $12^{\circ}$, XIII + $152 \mathrm{p}$.

\section{HONDURAS}

\section{By Karl P. SChMidT}

\section{GENERAL ACCOUNT}

\section{Topography}

Honduras includes the mountainous highland which connects the mountains of Guatemala and Nicaragua. This central highland rises to a general level of about $5000 \mathrm{ft}$., above which are higher isolated peaks and ranges, and below which are the deeply cut and often broad valleys of the principal rivers. With the exception of the triangular area which touches the Bay of Fonseca, the drainage is Atlantic. No less than five considerable rivers flow into the Caribbean Sea, besides the Wanks on the Nicaraguan boundary. Of these rivers, the Chamelecon and Ulua to the west are close together and their valleys combine to form the Valle de Sula, which is the most thickly inhabited area in Honduras. The northeast corner of the country is one of the least explored areas in Central America. The mountains are heavily dissected, and many ranges are isolated outliers of the general mass. The northward spur from the highland, which roughly marks the Honduran-Guatemalan border, reaches a height of $6000 \mathrm{ft}$. and approaches within $20 \mathrm{mi}$. of the north coast. The Sierra de Pija is a still more detached range. The Comayagua valley forms a pass, probably below $2000 \mathrm{ft}$., which opens to the north into the valley of the Ulua and to the south into a river flowing into the Bay of Fonseca. A single large interior lake, Lake Yojoa, lies at $2000 \mathrm{ft}$. above sea level, on the northward slope of the central highland.

\section{Climate}

The climate is intensely hot along the coastal plains, much modified by alti- tude in the interior. The Pacific coast is much drier than the north coast, although at the height of the dry season, even this assumes a surprisingly arid appearance. Some of the interior valleys, from which the rains are cut off by mountains, resemble the Pacific coastal plain more than they do the Caribbean, into which their rivers flow. The rainy season begins about June first and extends until November with little interruption. The dry season is, likewise, continuous, producing a strong contrast between the two on the north coast, which becomes much less marked in the interior.

\section{ORIGINAL BIOTA}

The principal floral and faunal subdivisions that suggest themselves are:

1. The tropical coastal-plain forest on the north.

2. An Oak-Pine zone from 1000 to $4000 \mathrm{ft}$. in the outlying mountains to the north.

3. A sub-temperate cloud forest above $4000 \mathrm{ft}$. in mountains to the north. This receives the trade winds.

4. The pine clad mountains of the interior.

5. The semi-arid Pacific slope.

Of these, the first is sharply characterized by the presence of the Cohune Palm, together with common tropical forest trees such as mahogany, fig, and silk-cotton. It is the typical habitat of the strictly tropical mammals among which are the White-faced and howling monkeys, the jaguar and ocelot, the Central American tapir, peccaries, and ant-eaters, armadillos, pacas, etc.

The second is an oak and pine forest, the oaks often hung with Spanish moss. The Cohune palm appears to be absent. The mammals appear to be those of the lowland.

The third offers moisture conditions which give it a rich flora of epiphites and tree-ferns, in a mixed hardwood forest. Several species of dwarf palm are abundant. There is a considerable fauna of tree-frogs and arboreal salamanders confined to it, and many birds, 
notably ant-thrushes and toucans, have species confined to it. The larger mammals, especially deer and peccary, range into it from below.

The fourth subdivision undoubtedly merges into the second, but over great areas it consists of an open growth of pine in a nearly pure stand. There are occasional open meadows in the depressions at high level, but these may not be natural. The pine forest extends to the tops of the mountains. It is through this area that the southward extension of the more characteristically North American forms take place; cougar, coyote, grey fox, and rabbits are among the larger mammals. The appearance of lizards of the genus Sceloporus sets it off rather sharply from the lower districts.

The Pacific area is notable for the considerable cactus and agave element in its flora, the absence of the Cohune palm, and the appearance of other species of palm. Its fauna appears to be largely influenced by that of the mountain area, for Sceloporus variabilis descends at least to $500 \mathrm{ft}$. on this slope.

\section{PRESENT BIOTA}

A large part of the valleys of the Chamelecon and Ulua Rivers is under cultivation for sugar-cane, bananas, or grass-land. In the interior, the chief agricultural industry is cattle-grazing. The original fauna, even in the cleared areas, seems to have been relatively little modified. Deer are remarkably abundant in the neighborhood of San Pedro Sula. Great areas of the country are absolutely primeval.

\section{GUIDE AREAS, EASILY ACCESSIBLE FOR STUDY}

San Pedro Sula, reached by rail from Puerto Cortes, offers an ideal base for field work in Honduras. It is only a five hours' climb from San Pedro, at $200 \mathrm{ft}$., to the cloud forest, on the tops of the mountains to the west, which reach a height of $6000 \mathrm{ft}$., and such a climb carries one through the pine- oak zone. Small lakes on the plain swarm with water birds and are noteworthy for the abundance of crocodiles. By rail and auto, it is possible to reach Lake Yojoa, where hotel accommodations are to be found. The shores of this large lake offer conditions of unusual ecological interest.

Squier, E. G.

1855. Notes on Central America; particularly the states of Honduras and San Salvador: their geography, topography, climate, population, resources, productions, etc., and the proposed Honduras interoceanic railway. New York: Harper and Brothers. 8vo. p. 397 , pl. 11, maps 3 .

\section{THE REPUBLIC OF SALVADOR}

\section{By Paul C. Standley}

Salvador is a small country, having approximately the same area as the State of Vermont. Unlike the other Central American states it has no Atlantic slope, and for that reason its fauna and flora are less diversified than those of the neighboring countries. The seasonal distribution of the rainfall also has an important influence, upon the plant life at least. The rainfall is very moderate for a tropical country, varying in different parts from 58 to 98 in., the average being about 70 in. As elsewhere upon the Pacific slope of Mexico and Central America, the year is divided into two seasons, a wet one, beginning about the middle of April and lasting until the end of October, and a dry one, covering the rest of the year. In the dry season no rain falls, but in the rainy season there may be a period of a week or more without any rainfall, and on the other hand there are occasional temporales, when rain falls almost continuously for one or even two weeks. During the dry season many of the plants wither, some of the trees drop their leaves, and the small herbaceous plants disappear.

Salvador is the most densely populated 
American republic except Haiti and nearly all the arable land, at least in the more productive regions, is under cultivation, so that at middle and high altitudes it is difficult to find localities in which primitive conditions prevail. The principal agricultural product is coffee, and since coffee requires trees for its shade, conditions for animal life are more favorable than might be expected, but they are less satisfactory as regards vegetation.

Broad-leaved forests originally existed over probably the whole country but they are now restricted to the less accessible regions and to those unsuited for agriculture. Eastern Salvador, beyond the Río Lempa, is still mostly in its original state, with heavy monsoon forest along the coast and with thickets and thin forest toward the interior (savanna), interspersed with limited areas of grassland or scrub. The same conditions prevail throughout a narrow belt which extends along the coast and in western Salvador extends inland to the city of Sonsonate, and well up the Río Paz along the Guatemalan frontier. This region is one of low altitude, 1000 ft. or often much less.

At middle elevations the greater part of the forest has disappeared and the land is mostly under cultivation. On all the higher volcanoes there is a dense montane forest, with thick undergrowth and many epiphytes, indicating that the rainfall is heavier here than elsewhere. Much of this forest has been cut away to make room for coffee plantations, but there are still large areas left in the Sierra de Apaneca (in the departments of Ahuachapán and Santa Ana) and upon some of the isolated peaks, such as the Volcano of San Vicente. All these natural forested areas are likely to disappear within the next 25 years, or in even less time.

The vegetation is everywhere tropical and greatly varied, no one species of plant being specially abundant, as a rule. In general appearance the plants are not strikingly different from those of certain parts of temperate North America. Except for the coconut palm, plants of this family are not numerous as to either species or individuals. The most striking and distinctive tree is probably the guarumo (Cecropia mexicana), but certain others such as the madre de cacao (Gliricidia sepium), maquiligua (Tabebuia pentaphylla), and palo mulato (Triplaris americana) are both conspicuous and abundant. Coniferous forests are of only slight extent but there is a small one near Santa Ana and larger areas on the mountains along the Honduran frontier. They are formed by a single species of pine, individuals of which are found in small numbers upon several of the higher volcanoes. The pine forests near Santa Ana consist of widely spaced trees with much undergrowth of shrubs and a thick growth of coarse grasses and other herbaceous plants.

Grassland is of frequent occurrence, particularly in the central departments, and in some parts of the western ones. Near Ahuachapan there is an especially interesting savanna covered almost exclusively with a close sward of a single species of grass, an area quite unlike anything found elsewhere in the country; and on the lower slopes of the volcanoes there are often wide meadows, used for pasture but probably of spontaneous origin. The number of species of grasses is perhaps greater here than in any other Central American area of the same size.

There are several localities in which desert conditions are approached, chiefly because of the nature of the underlying soil. Deserving of mention are several lava flows of known date which are extremely arid but covered with sparse vegetation. A detailed study of them would probably prove to be of great interest. Most of the coastal region is essentially arid, and in some portions, such as the vicinity of Acajutla and the valley of the Río Paz, the plant covering is markedly sparse. Cacti are few in both species and individuals, 
but certain other xerophytic plants are abundant.

The country is rather well supplied with streams, especially in the departments of Ahuachapáan and Sonsonate, and hot springs are found almost everywhere. There are numerous lakes, several of them of large size. That of Maquigüe, near La Unión, possesses a remarkably rich aquatic flora and probably an equally varied fauna.

Nothing is known definitely concerning the animals of Salvador, and no group of them has been thoroughly studied. In spite of the dense population there still persist some of the larger animals such as deer and jaguars, and birds are plentiful, although there do not seem to be as many aquatic birds along the coast as there are in some parts of Mexico, for instance.

About 2000 species of plants are known from Salvador at the present time, but the number actually occurring there is doubtless at least $50 \%$ greater. The flora is similar to that of western Guatemala and closely related to that of the Pacific slope of Mexico, particularly in the State of Oaxaca. It is also very like that of Pacific Nicaragua and of the Nicoya Peninsula of Costa Rica. The flora of western Honduras, however, is decidedly different, at least in its greater part, because of the much greater elevation of the latter country.

Salvador is better provided with transportation facilities than any other part of Central America, and for that reason it is scarcely necessary to mention special routes. Two railroad lines reach from one end to the other, and there are good cart roads to all portions of the country, most of them practicable for automobiles. The higher mountains must be reached by short trips with mules. The Sierra de Apaneca is easily reached thus from Sonsonate, Santa Ana, or Ahuachapán. Provided with letters of introduction, it is easy to obtain lodging at many of the fincas in the high mountains.

\section{NICARAGUA ${ }^{1}$}

\section{By Ludlow Griscom}

\section{GENERAL FEATURES}

Nicaragua is bounded on the north by the republic of Honduras, on the south by the republic of Costa Rica, on the west by the Pacific and on the east by the Caribbean Sea. The northern and southern boundaries are in dispute, but the Rio Coco or Wanx and the Rio San Juan respectively locate these boundaries in any ordinary atlas. The outstanding physiographic features are Lake Nicaragua and Lake Granada, occupying the southern central third of the country. West of these great lakes a relatively level plain stretches to the Pacific. Through this plain from north to south runs a chain of isolated conical volcanoes, three of them now active, rising with great abruptness. Destructive eruptions and earthquakes have frequently occurred, but it is this plain which is the settled part of the country, and the seat of the Indian civilization which the Spanish Conquest destroyed. Just east of these great lakes rise the central highlands. These practically disappear southward; but rise steadily as we proceed northward and spread out both to the east and the west, until just south of the Honduras boundary these highlands occupy more than half the width of the country. The maximum altitude is approximately $5500 \mathrm{ft}$. No definite orographic system exists, the country is exceedingly broken and rugged, and travel is rendered very difficult and tedious. From the east slope of these mountains to the Caribbean stretches a tremendous unbroken rain forest which is practically unexplored and uninhabited, with a very unhealthy climate. Small areas of open savannah are reported in the extreme northeastern section. Their existence requires confirmation.

1 As this country has been but very slightly explored from the naturalist's point of view, this account is very general, and great detail is impossible. No ecological literature exists. 


\section{Geographic and faunal communities}

With the exception of the highest mountains the whole of Nicaragua is in the Tropical Zone, and humidity is consequently the chief factor in causing varying plant and animal communities.

Luxuriant tropical rain forest. The entire Caribbean Slope is one of the most humid areas in the New World. It rains from mid-April to December, and an annual fall of 250 in. is not unusual. Hence the primeval unbroken rain forest, the trees of tremendous height, with the sun never reaching the ground. The flora is unknown, but many valuable timber trees such as mahogany are abundant. The fauna is extraordinarily abundant and varied. Tapirs, jaguars, howling monkeys, sloths, ant-eaters, and many bats and rodents are characteristic. Over 400 species of birds, of neotropical groups, are already recorded.

Arid deciduous forest. The central highlands are apparently a barrier to the moisture-laden trade winds. As a result the Pacific Slope is much drier, the rains are less heavy, and last from mid-May to November. In the dry season the rainfall is rapidly absorbed or evaporated, and semi-arid conditions prevail. Cactus is frequent, and the dominant type of vegetation is a low scrub. Originally a type of open gallery forest is reported, but is now largely destroyed, patches of this forest remaining in a very few places, such as the slopes of the volcanoes El Viejo and Mombacho. We have here a dry Tropical Pacific Slope fauna and flora, quite different from the Caribbean rain forest, and much less abundant and varied. Two associations only can be distinguished, the open scrubby plains and the gallery forest, with markedly different floras and faunas, that of the latter much more varied. Native report has it that this gallery forest was originally the predominating association, but scientific evidence is lacking. There are no rivers, lakes, or marshes.
Very varied ecological and faunal conditions prevail in the central and northern highlands. Most of this region has never been visited by a naturalist, and consequently only a very general account can be given.

Semi-desert. Proceeding due north from Lake Managua to the town of Matagalpa at an altitude of $2200 \mathrm{ft}$., the climate during the long dry season is extremely arid, and the vegetation is distinctly xerophytic, with a total absence of herbaceous plants. The birds are quite different from those of the Pacific Slope. The extent westward of this region is entirely unknown, but its eastern limits are the eastern slopes of the highlands, where the humid Caribbean forest abruptly begins. North of Matagalpa the mountains rise from 4000 to $5500 \mathrm{ft}$. There are at least two high valleys or plateaus known at about $3500 \mathrm{ft}$. Here in addition to the usual dry scrub association is found an oak association, and these districts support many species of birds known nowhere else in the country.

Conditions change abruptly above $3500 \mathrm{ft}$. Between this level and $5000 \mathrm{ft}$. the mountains are covered with a pine forest, with a totally distinct fauna and flora. Many north temperate genera of plants and birds, such as the Sweet Gum, Crossbills, Siskins, Bluebirds, and Flickers, here reach the southern limits of their range. The birds are a beautiful illustration of how favorable ecological conditions have enabled them to adapt themselves to a tropical climate. The altitude is apparently responsible for the great humidity, as it rains in this pine forest belt throughout the year.

Montane forest. Very few of the mountains are known to rise above 5000 $\mathrm{ft}$., but this altitude is sufficient to produce a genuine Subtropical Zone, as defined by Chapman. These summits are covered by an excessively dense, dark cloud forest, characterized by tree-ferns, gigantic begonias, and an astonishing wealth of epiphytes, para- 
sites and hyper-parasites. The bird fauna is scant in individuals but very peculiar. Here is the haunt of the famous quetzal or resplendent Trogon, the remarkable bell-bird, an emerald Paradise Tanager, a gigantic antthrush, and a solitaire. The sun rarely shines, and it rains almost every day in the year. The extent to which this Subtropical Zone occurs is unknown. Hundreds of miles of the northern highlands of Nicaragua have never been visited by a white man.

\section{BIOTA}

From the point of view of the naturalist, Nicaragua is a virtually untouched paradise. Present biotic conditions are apparently primeval in almost every zone, faunal area, and ecological association defined above. Barring a few banana plantations along some of the rivers, and a little crude lumbering, the Caribbean forest is uninhabited and unvisited. The Subtropical Zone and the Pine Forest Region are uninhabited. The balance of the central and northern highlands is very thinly settled, chiefly by pure Indians, who never trap or shoot. Primeval conditions are consequently spoiled only in the immediate vicinity of the few settlements. The thickly settled Pacific Slope is the great exception. While historical and scientific evidence concerning primeval conditions is lacking, it may fairly be presumed that extensive cultivation, the presence of several large cities and a relatively large rural population has profoundly modified original primeval conditions, which now exist in a few remote and isolated localities. Most of this area could not be rated as better than $\mathrm{C} 2$, according to the system of classification adopted in this guide, and much of it would be rated even lower.

\section{NATURAL AREAS}

There are of course no Preserves of any kind in so uncivilized a country.

IV. WATER POLLUTION

The entire absence of factories and industries makes it practically certain that no polluted waters exist.

\section{DIRECTIONS FOR TRAVEL IN NICARAGUA}

The traveling scientist in Nicaragua will be seriously handicapped by the great difficulties in transportation. The east coast can be reached by steamer from New Orleans, and one can disembark either at Cape Gracias or Bluefields where there are small settlements. Greytown, indicated on all maps as lying on the coast at the mouth of the Rio San Juan, no longer exists. From these centers travel or exploration is practically limited to success in hiring a launch or motor boat, and in penetrating up the larger rivers where there are banana plantations or lumber camps, where the traveler is usually received with cordial hospitality. Any side trips into the wilderness require a carefully planned expedition on a large scale, dependent entirely upon man packing in an exceedingly unhealthy and rainy climate, and it is doubtful if a party could average $20 \mathrm{mi}$. a day. On only a few occasions has a traverse of the country to the Pacific Slope been made, and the two regions are entirely out of communication with each other.

Running from Panama to San Francisco the Pacific Mail Steamship Com. pany's steamships stop at San Juan del Sur and Corinto. From Corinto the only railroad in Nicaragua runs to the three big cities, Leon, Managua, and Granada, on Lake Nicaragua. From Granada a steamboat touches at various points along the southern half of the lake, the run terminating at San Juan, where the Rio San Juan runs to the Atlantic, as the outlet of the lake. There are numerous rough roads and trails along the Pacific side of the country but they can be used only by horses, mules, or a primitive type of heavy ox cart with solid wheels. These roads are usually impassable in the rainy season. From Leon a road runs, roughly speaking, northeast to Matagalpa in the central highlands, approxi- 
mately $100 \mathrm{mi}$. away. Under favorable conditions ox teams with machinery have suceeded in reaching Matagalpa. Another trail to the same town starts from Savana Grande on the railroad, a distance of $110 \mathrm{mi}$. This latter is the road used by travelers on horse or mule back. From Matagalpa a trail runs northward over the mountains to Jinotega where it forks, one branch going to San Rafael del Norte and the other to Ocotal. The chlef difficulty for the stranger is in obtaining mules to transport himself and his baggage along the trails mentioned. No one is anxious to hire out his mules, and no native of the lower classes will do any kind of work as guide or muleteer if he can possibly avoid it. One should allow three days on the road to Matagalpa, from Matagalpa to Jinotega one day, from there to San Rafael two days, to Ocotal three days. In addition the traveler must allow an indefinite number of days or weeks at the various starting places to acquire mules. He who reaches Matagalpa from Corinto in less than two weeks will be fortunate. Localities north of Matagalpa he will probably not reach at all in the rainy season.

On the Pacific Slope the volcanoes Viejo, best reached from Chinandega on the railroad, and Mombacho, reached from Granada, are places worthy of careful study. Any section of the Carribean rain forest is worthy of a visit. The fauna and flora around Matagalpa are quite different from those of the lowlands, and at San Rafael del Norte the traveler is in the heart of the pine forest, with the high subtropical rain forest just above that. It is obvious that off the trails mentioned are vast areas of country with diversified climate and topography which still await the exploration of a scientist. Travelers should be warned, however, that to reach any of the more interesting and remote places mentioned is a lengthy and a costly job. Exploration in Nicaragua except on the Pacific Slope could not be done for less than one thousand dollars a month, if new territory were to be investigated.

\section{COSTA RICA ${ }^{1}$}

By LudLow Griscom

I. GENERAL CONDITIONS

\section{Topography}

Costa Rica is bounded on the north by Nicaragua, on the south by Panama, east by the Caribbean Sea, and west by the Pacific Ocean. It has an area of about 18,500 sq. mi., and may be roughly described as a highly mountainous and broken country lying wholly in the tropics.

The chief physiographic feature is the lofty volcanic mountain ranges which follow the general trend of the continent from northwest to southeast. The whole central portion of the country is a broken tableland, lying to the southwest of the main range of the Cordillera, and bounded on the Pacific side by various broken and irregular mountain masses, more or less isolated from each other. As a result the coastal plains on both sides are narrow, varying from almost nothing to 25 or $30 \mathrm{mi}$. in width. The only exception to this statement is the northern and northeastern part of the country, which is comparatively flat and low, draining into Lake Nicaragua or its outlet, the Rio San Juan. The more northerly range rises with great abruptness in the extreme northwest corner of the country from the low level Pacific plain of Nicaragua. Composed at first of a succession of volcanic cones, such as Orosi (5185 ft.), Miravalles (4698), and Tenorio (6800), it changes to a highland, for over 50 mi. without a single volcano. Poas (8895) begins a new series of volcanic peaks culminating in $\operatorname{Irazu}(11,200)$

1 The relatively little thorough exploration of this country, compared with areas of similar size in North America, renders a very general account necessary, and detail is impossible. No ecological literature exists, but the reader is referred to Carriker's Birds of Costa Rica, Annals Carnegie Museum, Vol. VI, No. 4, August, 1910, for a general account of the physiography and faunal distribution, the latter, however, requiring extensive modification. "A Year of Costa Rican Natural History" by P. P. \& A. S. Calvert (MacMillan \& Co., 1917) gives an excellent account of life in the country and there is an extensive bibliography. 
and Turrialba $(10,900)$ in the center of the country. From Irazu, the whole of Costa Rica and both oceans are visible, and its ascent is a profitable and easy excursion for the ambitious tourist. Destructive eruptions have occurred in this section in historical times, and severe earthquakes have destroyed the city of Cartago on two occasions. Slight shocks occur almost annually.

South of Turrialba there is a pronounced break, the continental divide is very narrow, and the sources of the rivers Reventazón and Rio Grande de Tárcoles are within half a mile of each other, flowing to the Caribbean and Pacific respectively in broad, deep valleys. Still further to the southeast is an unbroken expanse of mountains, rivers, and primeval forest, inhabited by wild Indians, and practically unexplored. The so-called Talamanca or Chirrip Mountains rise in this section, culminating in Chirripo Grande (11,485 ft.), Pico Blanco (9645) and Rovalo (7050), the last two placed in Panama on some maps. All altitudes given are uncertain.

The Caribbean coast is monotonous and unbroken. It is covered with heavy forest, numerous rivers descend rapidly from the mountains in narrow valleys, separated by steep ridges, and the climate at low levels is unhealthy and malarial. The Pacific coast, however, is quite different. It is steeper on the whole, and includes two bold promontories or capes. The peninsula of Nicoya is separated from the mainland by the shallow Gulf of Nicoya. The chief port town of Puntarenas is situated about half way up this gulf. In southwestern Costa Rica another bold peninsula is separated from the mainland by the Golfo Dulce. The Cape of Burica is the dividing line between Costa Rica and Panama. It projects straight south into the Pacific and forms the western boundary of David Bay. On the Pacific side are several more or less isolated groups of mountains, rang- ing from 4000 to $8000 \mathrm{ft}$. One of them is directly back of Puntarenas, and another on the Nicoya Peninsula opposite, making the scenery very attractive. As a general rule the rivers are fewer in number but of larger size and rapid current. The Rio Grande de Térraba has a large delta, with several mouths.

The bulk of the population lives in the central plateau, around the four provincial capitals, and at the ports of Puntarenas and Limon on the Caribbean. There is a remarkably high percentage of Spanish blood, compared with other Central American countries, and the negro element is exceedingly small. Indians in a state of complete savagery still exist along the Nicaraguan border and in the Talamanca section. They are inoffensive and are rapidly disappearing.

\section{Climate}

As in Nicaragua, the moisture-laden trade winds from the Caribbean cause a tremendous rain-fall on the Caribbean slope of Costa Rica, sometimes exceeding 200 in. annually. It is fairly continuous throughout the year, but is lightest from January 15 to April 1, which is consequently the pleasantest season of the year. The rainfall decreases with altitude, the only exception being the highest peaks. In the plateau region and the Pacific slope very different conditions prevail. There is a marked rainy season from May 1 to the end of November, light the first and last months, but daily the rest of the time, and often very violent. The remainder of the year is entirely without rain. Altitude divides the country into three distinct climates from the point of view of temperature. It is tropical from sea level to about 4000 ft., cool or subtropical from 4000 to $7500 \mathrm{ft}$., and temperate or cold above that. At San José, the capital, at $4000 \mathrm{ft}$., a light overcoat is welcome at night during the winter months. Frost occurs frequently above $7500 \mathrm{ft}$., and 
snow has been recorded in the ligh mountains. Tree-line is about $10,000 \mathrm{ft}$.

\section{Geographic and faunal communities}

Costa Rica is a naturalist's paradise. The varied topography and climate, combined with favorable geographic position, given it the most varied fauna and flora, for so tiny an area, in the New World. The continent has narrowed down to sixty miles, and in this space occurs an unparalleled diversity. of conditions. Its present fauna and flora has been derived both from the north and the south, and in past geological periods the mountains have been an island, on which peculiar and distinct types have evolved. In birds at least one peculiar family, numerous endemic genera and species, give the Costa Rican highlands rank as a distinct faunal area. The very diversity of conditions and origins, however, makes the delimitation of life zones or ecological associations particularly difficult and complicated, and unfortunately any detailed knowledge of local distribution is entirely lacking. The great rarity of many endemic species, some of general distribution, and others confined to a single mountain peak, affords still further food for speculation. There is, here, a fascinating field in the study of geographic distribution, but only the most generalized account can be given.

Luxuriant tropical rain forest. The Caribbean slope is the easiest to describe. It is covered with a dense tropical rain forest, with an exceedingly humid and unhealthy climate. It is exactly the same as the Caribbean slope of Nicaragua, described in the preceding article. It has a typically rich and varied fauna, all the conspicuous and prevailing neotropical types occurring. There are no less than 400 species of birds recorded. The flora is little known, but the trees are of great size, and the undergrowth of creepers and lianas makes progress difficult, without cutting at every step. At the lowest levels, especially near the rivers, jungles of palm catch the traveller's eye. (For species, see under Nicaragua.)

Arid deciduous forest. On the Pacific side of the country, the difference in rainfall causes a difference in ecological condition, and slight differences in the fauna. The northwestern past, including the Nicoya peninsula is a region by itself, and is exactly the same as the Pacific slope of Nicaragua (which see). It is the extreme southern limit of a fauna which contains such conspicuous forms as the white-winged dove, a cactus wren, a rock wren, several orioles and a long-tailed crested jay (Calocitta). As in Nicaragua an extensive Indian civilization existed at the time of the Spanish Conquest, and much of the original gallery forest has disappeared and is replaced by grassy savanna. Further south the Pacific slope is covered with a dense gallery forest, the fauna of which, at least, is not so distinctly different from the tropical fauna of the Caribbean slope. In extreme southwestern Costa Rica from the Térraba Valley and the Golfo Dulce southward, the heavy gallery forest is again varied by considerable tracts of savanna. Ecologically there would seem to be little or no difference, but the fauna is quite distinct. Numerous endemic species of birds, such as a black and yellow mannakin (Manacus aurantiacus), a snowy cotinga (Carpodectes antoniae), and a hummingbird (Agyrtria boucardi), are found only, here and in the adjacent parts of western Panama. The causes, which have evolved this peculiar fauna, are not understood.

Passing now from the purely tropical zone to higher altitudes, a marked change takes place, when we enter the subtropical or upper tropical zone at about 3500 to $4000 \mathrm{ft}$. There are two distinct ecological divisions. The lower plateau region, while originally forested, is the most settled portion of the country, and has long since been cleared in large part, and used for agriculture and pasture. Such is the country around Cartago and San José. There are 
several broad valleys. There are numerous characteristic plants and animals. Even from the train the casual traveller will notice the absence of palm jungles, and the wayside fields will have flowers, reminding him subtly of a more northern latitude.

Montane Forest. From 5000 to $8000 \mathrm{ft}$. lies what might be called the upper plateau region. It is again forested, the forest exceedingly dense with an abundance of epiphytic vegetation, and tree ferns are noticeable and characteristic. The varied fauna is in part derived from the north, but is composed chiefly of species of tropical origin, which have become adapted to lower temperatures. In the plant world, numerous boreal genera appear (such as Carex) or groups very closely related.

Subalpine evergreen forest. The temperate zone extends from about 8000 ft. to tree-line on the highest summits. It is very humid, the forest is spreading, stunted and gnarled, due to the high winds, and contains oaks and other arboreal species characteristic of a more northern flora. Some of the most remarkable of Costa Rican birds occur in this zone, such as Zeledonia, the type of a distinct family, the beautiful resplendent trogon, or quetzal (Pharomacrus mocinno), the unique peg-billed sparrow (Acanthidops bairdi), and types of clearly northern origin, such as a hairy woodpecker, an ant-eating woodpecker, and a hummingbird (Selasphorus flammula) closely related to species of Mexico and western North America. Above tree-line on the highest volcanoes, living in the scrubby bushes occurs a junco or snow-bird (Junco vulcani).

\section{PRESENT BIOTIC CONDITIONS}

The greater part of Costa Rica is still in a primeval and unspoiled condition. There are three principal exceptions. The lower plateau region, as already mentioned is thickly settled and thoroughly cleared. As it was originally forested, great changes from original biotic conditions must have taken place. In the northwestern section, just as in Nicaragua, the Indian civilization removed most of the original gallery forest, leaving much cleared land, which has turned into grassy savanna. The original biota, here too, must have been profoundly disturbed. The biologist must, however, bear in mind the law of compensation, which clearly applies in such cases. Many of the species now found only in this section of Costa Rica would not occur there at all were it not for the changes which have taken place. The third exception is that part of the Caribbean slope which has been cleared for banana plantations and other types of agriculture chiefly along the railway lines from Puerto Limon to San José. Such cultivation is particularly disturbing in the tropics, where very delicate adjustment to minute variations in conditions can alone explain the numerical abundance of species and the scarcity of individuals. Probably $50 \%$ of the original avifauna, for instance, has disappeared from such cleared areas, never to return, and few indeed are the species which replace them, chiefly certain native ones which were able to adapt themselves to the sudden change in conditions. Cultivation has been steadily spreading and increasing in eastern Costa Rica, but at least $75 \%$ of the tropical rain forest is still a primeval wilderness. There is no satisfactory evidence that a single species of the Costa Rican fauna is as yet in danger of extermination, from causes which could be ascribed wholly to the influence of man. Consequently, while there are no Preserves, none are as yet really needed. No polluted waters of any consequence are known.

\section{POLITICAL RELATIONS, TRANSPORTA- TION AND OPPORTUNITIES FOR RESEARCH}

There is probably no section of the New World tropics which can be reached so conveniently or so cheaply as Costa Rica, or where greater diversity of conditions exist. This is due to the com- 
paratively settled state of the country politically, and to the large concessions of the United Fruit Company on the Caribbean coast, a concern which has expended considerable capital in development. Its comfortable steamers ply regularly to Puerto Limon, and an excellent railroad runs from there to San José, the capital, with branches running to Guapiles and Alajuela. San José is a pleasant city with several excellent hotels and a delightful climate, and this trip is becoming increasingly popular with the tourist, who is given every encouragement. The ride to the capital from Puerto Limon over the continental divide is a fascinating one, and the scenery is magnificent. There are numerous towns and way stations en route, where the biologist can stop, choosing the altitude he desires. The stranger is always hospitably treated, and can often put up at some plantation or hacienda. From Cartago one can ride to the summit of Irazú, and the more energetic traveller can camp at any desired altitude along the way, and study any desired life zone or ecological association.

There is a government railroad running from San José to Puntarenas on the Pacific Coast. There is a tolerable hotel here also, and the steamers of the Pacific Mail Steamship Company call regularly on their way to Panama or San Francisco. They run about every three weeks, but the schedule is irregular, and the boats are often several days late. The traveller must consider several things to save himself annoyance. ile cannot get reliable information in San José about the arrival or departure of these steamers. At Puntarenas he must see the Port Officer and get permission to leave the country. This permit is telegraphed from the Minister of War, and costs five dollars. At least a day must be allowed to secure it. Everything is dutiable in Costa Rica, and your baggage is rated at so much per kilo. Exactly the same thing is true when leaving, the export tax cover- ing all personal effects, at so much per kilo. The scientist, however, with proper letters and credentials, can usually obtain a waiver of import duties, but will have to pay the export duties, unless he remembers to make the necessary arrangements before leaving.

At Puntarenas the biologist can get a glimpse at least of the peculiar fauna of the northwestern section. From there a very fair road runs north to Bagaces, Liberia, and on to Rivas in Nicaragua, Bagaces is in the heart of the savanna country, and a trip to the summit of Miravalles, where many peculiar species are found, is not particularly difficult or expensive. Travel on this road is chiefly by mule or horse, but, animals are not particularly difficult to secure.

Reaching any other section of Costa Rica is increasingly expensive and difficult. The Terraba Valley and the Golfo Dulce region is best reached by securing some small coastwise sailing vessel at Puntarenas. The price will be high, the delay in securing one great, and all supplies must be taken. The little hamlet of Boruca has served as the headquarters of the few collectors who have ever gone there. The interior is unexplored. The whole of northeastern and southeastern Costa Rica is practically unexplored and unvisited. Real results could only be obtained by wellorganized expeditions, prepared for difficult conditions and an unhealthy climate.

Opportunities for research will be limited only by the ignorance or incompetence of the student. In the higher vertebrate groups, few new species remain to be discovered, but many more will be found to occur in the country. In every other phase of biological investigation, the student will have almost a virgin field, and can specialize in any department he sees fit. The foregoing account proves how readily any desired type of climatic or ecological conditions can be reached in this naturalists' paradise. 


\section{PANAMA}

\section{By E. A. Goldman and James Zetek}

\section{INTRODUCTION (E. A. G.)}

The brief account of Panama here presented is largely an abstract from published results (Goldman, 1920) of field investigations by the author in 1911-1912 in connection with the biological survey of the Panama Canal Zone, undertaken by the Smithsonian Institution in coöperation with the Biological Survey and other government departments, and supplemented by information gathered from various sources. The field work was centered largely in the Canal Zone, but extended to extreme eastern Panama.

II. GENERAL FEATURES AND ORIGINAL BIOTA (E. A. G.)

\section{A. Topography}

The narrow intercontinental land mass forming the Republic of Panama extends in a sigmoid curve from east to west between the meridians of $77^{\circ} 15^{\prime}$ and $83^{\circ} 30^{\prime}$ west from Greenwich and parallels $7^{\circ} 10^{\prime}$ to $9^{\circ} 40^{\prime}$ of north latitude. It varies in width from less than $50 \mathrm{mi}$. at the Canal Zone and at the constriction between the mouth of the Rio Chepo and the Bay of San Blas to over $100 \mathrm{mi}$. at the Azuero Peninsula. Except for the Chiriqui Lagoon the northern shore line forms a nearly undented S-shaped curve. The southern coast line, on the contrary, is very irregular. There are numerous inlets or bays, and several peninsulas form prominent salient features. The smaller bays are mainly the tidal estuaries of the numerous rivers, some of which are of large size. The estuary of the Rio Tuyra permits small steamers to ascend to Real de Santa Maria, about half the distance from the outer shore line across to the Atlantic Coast. The most conspicuous projection, the Azuero Peninsula, in broadly extended outline, bounds the Gulf and Bay of Panama on the west. Another prominent feature of the southern coast is the Burica Peninsula, a prolongation of the Serrania de Carones, territory in dispute between Panama and Costa Rica. The largest outlying land area is Coiba Island, of slight elevation, off the southwestern coast. Numerous small islands lie close to the adjacent coast, of which some of the more important are Cebaco, and Leones islands in Montijo Bay, and farther west Insolita, Espartal, Brava, Parida and Sevilla islands. The second largest island is San Miguel, or Rey Island in the Bay of Panama, which with smaller neighboring islands form an archipelago known as the Pearl Islands. These islands are rather low, but rugged in contour, with eroding coast lines like those of parts of the adjacent mainland. Small islands are numerous along the northern coast, but aside from the low, forested archipelago separating the sea from Almirante Bay and the Chiriqui Lagoon, are relatively unimportant.

The general land surface is hilly and irregular, but the only very high mountains are in the extreme western part, where an extension of the highlands of Costa Rica crosses the international boundary about midway between the two oceans and culminates at about $11,500 \mathrm{ft}$. in the volcano of Chiriqui.

The rather ill-defined backbone of the Isthmus is divided by comparatively low passes into several irregular sections in which steep, but not usually precipitous, mountain ranges reach varying elevations, in few places exceeding $5000 \mathrm{ft}$. The Serrania del Brujo, beginning near the Atlantic coast a few miles east of Colon, rises near Porto Bello to 3000 or $4000 \mathrm{ft}$., and partially encircling the Chagres River Valley joins the continental axis near Cerro Azul, a mountain about $3000 \mathrm{ft}$. high on the crest between the Chagres and Pacora river valleys. A short distance east of Cerro Azul are transcontinental gaps probably less than $1000 \mathrm{ft}$. in altitude where the headwaters of the Rio Mamoni interdigitate with those of streams flowing north into the Gulf of San Blas. Farther east the long, narrow curved Isthmian backbone, 


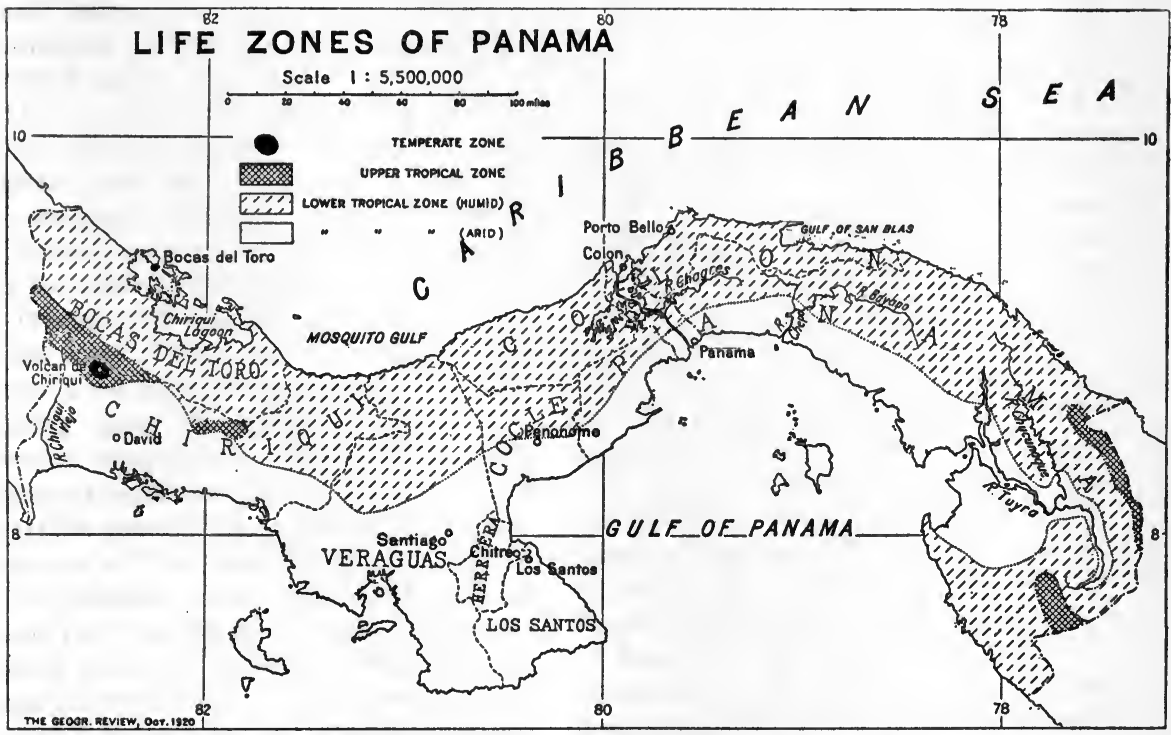

Fig. 14. Map of Barro Colorado Island, Gatun lake, Canal Zone, AND VICINITY

Showing the depth of water but not indicating rivers or contours on the Island. Taken from U. S. Hydrographic Office map No. 5000. (The width of the words "Barro Colorado" equals 3000 yards.) 


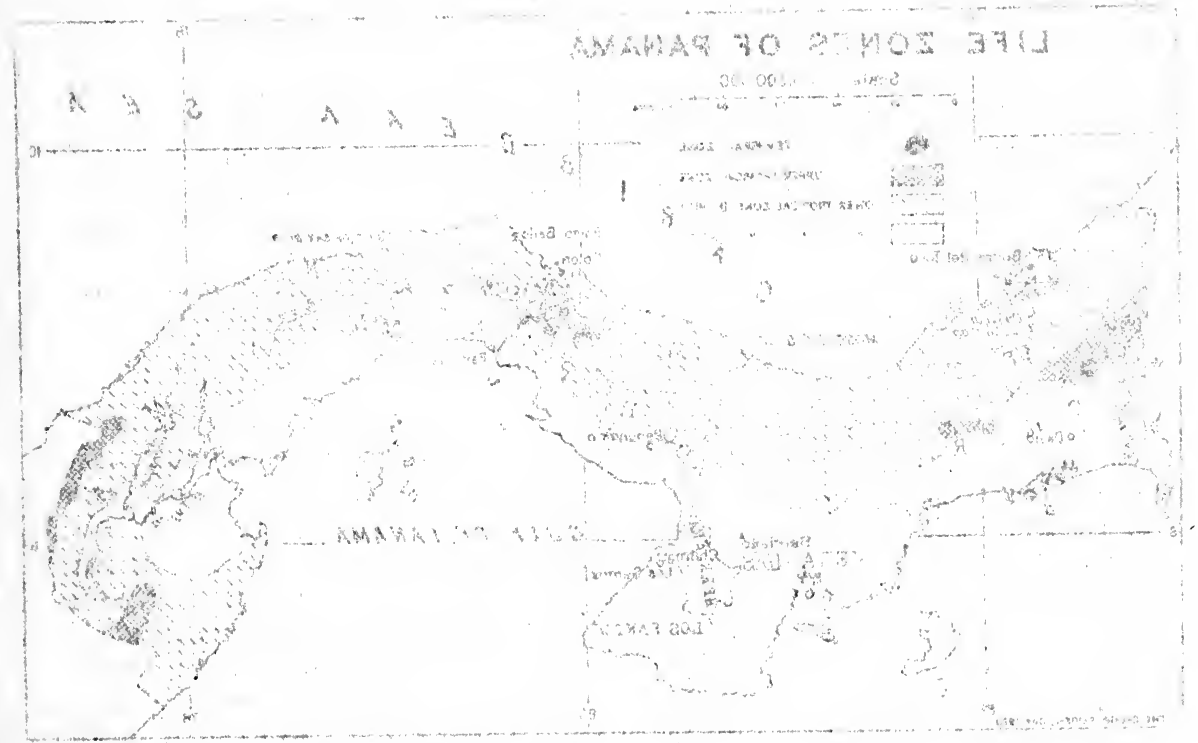

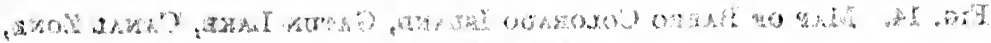
rrytaty thit

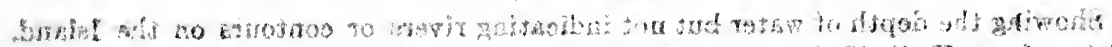

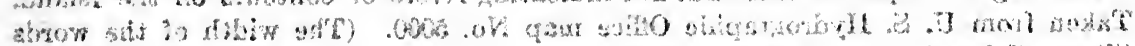

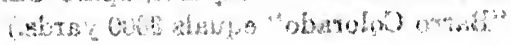


generally known as the Serrania del Darien, reaches in many places an altitude of 3000 to $5000 \mathrm{ft}$., but the crest is interrupted at various points by passes less than $1000 \mathrm{ft}$. high. Mount Pirre is the name applied to a dominant spur, slightly exceeding $5000 \mathrm{ft}$. in altitude and projecting northward into the Tuyra basin in a crescentic curve with the axial trend of the continent along the Panama-Colombian frontier.

Aside from the higher mountain ranges that form the Isthmian backbone, a multitude of rather steep, extensively eroded ridges separating narrow river valleys ramify throughout the greater part of the republic. Extensive and fairly level plains occur at various elevations, however, in the province of Chiriqui, and along the Pacific coast as far east as the Bayano River Valley.

Owing to the narrowness of the Isthmus most of the rivers are short, and from their sources, commonly interdigitating along the opposite sides of the deeply eroded continental divide, flow directly to the sea, but there are several notable exceptions. The greatest river system of the republic is the Tuyra Chucunaque. After draining a large and very humid area, these two rivers unite near the middle of the Isthmus and in combination with several other large streams pour an immense volume of water into the Gulf of San Miguel. The second river of the republic in point of size is the Rio Bayano, which takes a westerly course and joining the Rio Mamoni, a much smaller stream, turns southward and under the name of Rio Chepo enters the Bay of Panama. The most important river of the Atlantic drainage is the Rio Chagres, whose watershed is an interior basin. The general course of the stream is westerly to a point near where it enters the Canal Zone and bends north to the Caribbean Sea. The Chagres, whose waters are now impounded in Gatun Lake, 164 sq. mi. in area, furnishes the water for operating the locks of the Panama Canal, and through the locks at the southern end of Gailliard Cut a part of its flow is diverted into the Pacific Ocean.

\section{B. Climate}

While climatic conditions vary considerably in different parts of Panama, the region as a whole is subject to the influence of two annual seasons, the duration of which are correlated with the direction of the prevailing winds. During the so-called "dry" season the northeast trade wind, blowing daily from about the month of December to the month of May, at times with considerable violence, is accompanied by light, but not infrequent precipitation along most parts of the Atlantic slope. At this season rather light cloud formations discharge their moisture along the northern side of the Isthmus, the rainfall of the coast depending in a measure on the height and proximity of the mountains. At the higher elevations fogs are very prevalent, condensed moisture drips freely from the trees and tropical rain forest conditions prevail. The Pacific coast in marked contrast, at this time has a true dry season, during which little rain falls. During the wet season, beginning usually about the latter part of May and ending about the first of December, southerly winds become dominant and rains are general throughout the Isthmus.

At the Canal Zone, which is a crosssection of the Isthmus about $50 \mathrm{mi}$. in extent, the annual rainfall on the Atlantic coast is nearly double that on the Pacific coast. Official records for 1909 show a total rainfall of 93.06 in. at Balboa, and 183.41 in. at Cristobal; but the average for 13 years at the former station is 71.67 in., and for 40 years at the latter station 130.03 in. This relative difference in humidity of the two sides probably obtains as far west as the Costa Rican frontier, but in eastern Panama the difference is less marked. In much of the Darien region the total rainfall is increased to an annual precipitation of perhaps more 
than 200 in., which renders this area one of the wettest in America.

Clearings are few, and aside from the rather extensive, open, grassy savannas near the Pacific coast, and smaller grass areas in the Chagres Valley, the Isthmus is a practically unbroken expanse of forest.

Under the stimulating influence of frequently recurring showers and continuously moist conditions throughout the year, the Atlantic watershed maintains a much more exuberant growth of vegetation than the Pacific watershed, where long periods of drought check vegetative vigor. At the height of the dry season the trees of the Atlantic forest are clothed with brilliant evergreen foliage, while those of the Pacific forest, truly deciduous for the most part, present bare stems, and the landscape has an autumnal appearance, relieved to some extent along the streams.

\section{Natural life areas}

Three principal life zones are recognizable in the republic, extending at low elevations from sea to sea, and at higher elevations as belts on the slopes, or embracing the tops of mountain ranges. Beginning at sea level these are the Lower Tropical Zone, of which there are well-marked arid and humid divisions; the Upper Tropical or Subtropical Zone, and the Temperate Zone. As elsewhere the major life zones are obviously subdivisible into minor regional faunas and floras, or plant and animal associations of varying rank, most of which are very imperfectly known. A few only of the more characteristic mammals, birds, and plants are mentioned as indicators, and the zonal position of some of these may be subject to revision, when their distribution areas have more completely been delimited.

1. Lower Tropical Zone. An area of high temperature including by far the greater part of the Isthmian land surface from the Atlantic and Pacific shore lines across at low elevations from sea to sea and to about 3000 to $3500 \mathrm{ft}$. in average altitude along the slopes of the higher mountains. Many species of animals and plants range in suitable places throughout the zone; others are restricted to the arid or humid divisions, or reach their greatest development there.

a. Humid Lower Tropical Zone (Lowland rain forest). The Humid Lower Tropical Zone occupies the crests of most of the mountain ranges, and nearly all that part of the Atlantic watershed of Panama lying below about $3000 \mathrm{ft}$. altitude. It is replaced, however, by a strip of Arid Lower Tropical Zone which extends from the Pacific coast across the continental divide in the vicinity of the Panama Canal, but the transition to humid conditions is rapid to the northward of Empire and the bend of the Chagres River. The area is comparatively uniform in character, usually heavily forested, and includes the most luxuriant vegetation on the Isthmus.

Mammals: Marmosa mexicana isthmica (Isthmian marmosa), Marmosa invicta (Black marmosa), Philander laniger derbianus (Derby's opossum), Peramys melanops (Panama peramys), Mazama sartorii reperticea (Canal Zone forest deer), Tapirella bairdii (Baird's tapir), Neacomys pictus (painted bristly mouse), Oryzomys bombycinus bombycinus (silky rice rat), Oryzomys caliginosus idoneus (Panama dusky rice rat), Nectomys alfari efficax (Cana rice rat), Heteromys australis conscius (Cana pocket mouse), Heteromys desmarestianus zonalis (Canal Zone pocket mouse), Dasyprocta punctata isthmica (Isthmian agouti), Microsciurus alfari venustulus (Canal Zone pygmy squirrel), Bassaricyon gabbii gabbii (Costa Rican bushytailed olingo), Sylvilagus gabbi gabbi (Gabb's rabbit).

Birds: Leucopternis ghiesbrechti (Ghiesbrecht's hawk), Odontophorus marmoratus (marbled partridge), Eurypyga major (sun bittern), Leptotila cassini cassini (Cassin's dove), Neomorphus salvini (Salvin's ground cuckoo), 
Capito maculicoronatus maculicoronatus (spotted-crowned barbet), Jacamerops aurea (great jacamar), Hylomanes momotula obscurus (Panama tody-motmot), Electron platyrhynchum minor (lesser broad-billed motmot), Urospatha martii semirufa (greater rufous motmot), Eutoxeres aquila salvini (Salvin's sickle-bill), Pittasoma michleri michleri (Michler's antpitta), Myrmeciza exsul exsul (Sclater's antbird), Gymnocichla nudiceps nudiceps (bare-crowned antbird), Praedo audax (black-billed flycatcher).

Plants: Lycopodium dichotomum, Heliconia wagneriana, Brosimum utile, Cecropia arachnoides (guarumo), Ficus panamensis (Panama wild fig), Ficus pittieri (Pittier's wild fig), Inophleum armatum (Maragua), Swartzia panamensis (cutaro), Sloanea megalophylla, Pachira aquatica, Eschweilera panamensis, Gustavia nana, Gustavia parvifolia, Miconia barbinervis, Sagraea petiolata.

b. Arid Lower Tropical Zone (arid deciduous forest and savanna). The Arid Lower Tropical Zone extends in a belt of varying width, mainly at low elevations, all along the southern side of the Isthmus, excepting the southeastern part, from the Pacific coast line to near the base of the higher mountains, reaching farthest inland along the valley of the Tuyra River, and at the base of the Azuero Peninsula. In the vicinity of the Canal Zone it crosses the continental divide and invades a part of the valley of the Chagres River; islands off the southern coast are also included in its scope.

The total rainfall is by no means scanty, and in the wet season the forested parts of this zone differ comparatively little from Humid Lower Tropical areas, truly arid conditions prevailing only during the dry season when much of the forest, except near water, is leafless and the contrast with the continuously humid areas is very striking.

Two principal associational divisions are recognizable within the Arid Lower Tropical section of the Lower Tropical Zone. These are an arid or semi-arid forest association, and a savanna and savanna border association. The forests are generally continuous along the basal slopes of the mountains and cover irregular contours to near the sea. They also extend as semi-arid belts along the river valleys. Open, grassy plains or savannas, often of wide extent, cover generally level areas along the Pacific slope from near the Costa Rican frontier eastward to the Bayano River. Savannas also occur in the valley of the Chagres River east of the Canal Zone. Many mammals and birds are not definitely assignable to savanna or forest as they find their most congenial habitat along the forest borders where they seek food in the open spaces and retire to the woodland for shelter. No effort is made to differentiate these elements in the brief lists of indicators following:

Mammals: Marmosa mexicana savannarum (savanna marmosa), Philander laniger pallidus (pale woolly opossum), Odocoileus chiriquensis (Chiriqui whitetailed deer), Macrogeomys pansa (Bugaba pocket gopher), Liomys adspersus (Peter's spiny pocket mouse), Sciurus variegatoides helveolus (Canal Zone squirrel), Sylvilagus gabbi consobrinus (savanna rabbit).

Birds: Rupornis ruficauda (rufoustailed hawk), Odontophorus castigatus (Panama partridge), Leptotila rufinucha (rufous-naped dove), Gymnocichla nudiceps erratilis (Costa Rican barecrowned antbird), Myrmeciza exsul occidentalis (Cherrie's antbird), Pheugopedius fasciatoventris melanogaster (black-bellied wren), Anthus parvus (Panama pipit), Basileuterus semicervinus veraguensis (buff-rumped warbler), Sturnella magna inexpectata (Central American meadowlark), Leistes militaris (Cayenne red-breasted blackbird), $A m$ modramus savannarum obscurus (Minatitlan sparrow), Sporophila minuta minuta (minute seedeater).

Plants: Sweetia panamensis, Dalbergia retusa (cocobola), Cedrela mexicana (Spanish cedar), Swietenia macrocarpa (mahogany), Ceiba pentandra, Cavanillesia platanifolia (cuipo), Bromelia pin- 
guin, Roupala complicata, Indigofera pascuarum, Meibomia angustifolia, Phaseolus gracilis, Byrsonima cumingiana (nance), Sloanea quadrivalvis, Guazuma ulmifolia (guacimo), Curatella americana, Duranti plumieri.

2. Upper Tropical Zone (montane rain forest). With the exception of the lofty Volcan de Chiriqui, the Upper Tropical Zone embraces the slopes and crests of mountains above 3000 to 3500 ft. altitude. Its upward extent on the Volcan de Chiriqui has not been accurately determined, but probaby reaches 7000 to $8000 \mathrm{ft}$. varying according to slope exposure. While the zone as a whole is humid, no very definite divisions on the basis of moisture being now recognizable in Panama, variations in humidity due to slope exposure are often marked.

Mammals: Peromyscus pirrensis (Mount Pirre mouse), Peromyscus nudipes (La Carpintera mouse), Rhipidomys scandens (Mount Pirre climbing mouse), Scotinomys teguina apricus (Boquete brown mouse), Oryzomys pirrensis (Mount Pirre rice rat), Rheomys raptor (Panama water mouse), Macrogeomys cavator (Chiriqui pocket gopher), Microsciurus boquetensis (Chiriqui pygmy squirrel), Syntheosciurus brochus (groove-toothed squirrel), Icticyon panamensis (Panama bush dog), Cryptotis merus (Mount Pirre shrew).

Birds : Leurcopternis princeps (barredbellied leucopternis), Odontophorus guttatus (spotted partridge), Aulacorhynchus caeruleogularis cognatus (Darien blue-throated toucanet), Pharomachrus mocinno costaricensis (Costa Rican quetzal), Oreopyga castaneoventris castaneoventris (Chiriqui mountain gem), Goethalsia bella (Goethal's hummingbird), Eriocnemis floccus (wool-tufted hummingbird), Margarornis bellulus (beautiful margarornis), Myadestes coloratus (varied solitaire), Catharus fuscater mirabilis (Darien nightingale thrush), Zeledonia coronata (wren-thrush), Pheucticus tibialis (Irazu grosbeak), Buerremon brunneinuchus (chestnutcapped buerremon).
Plants: Quercus warscewiczii, Quercus bumeliodes, Quercus chiriquensis (Chiriqui oak), Cecropia maxoni (Maxon's guarumo), Prunus occidentalis, Rubus floribundus, Lupinus clarkii, Begonia chiriquina, Psychotria panamensis, Senecio arborescens Lycopodium watsonianum, Piper pseudopropinquum.

3. Temperate Zone (temperate forest). The slopes of the Volcan de Chiriqui, above about 7000 to $8000 \mathrm{ft}$., are assigned to this zone. The mountain has not been visited by me, however, and has been very incompletely explored by others. There seems to be a diminution in moisture above about $8000 \mathrm{ft}$., and temperatures below the freezing point are registered near the summit at about $11,500 \mathrm{ft}$.

Mammals: Reithrodontomys creper (Chiriqui harvest mouse), Scotinomys xerampelinus (Chiriqui brown mouse), Sigmodon austerulus (Chiriqui cotton rat).

Birds: Selasphorus torridus (heliotrope-throated hummingbird), Empidonax atriceps(black-capped flycatcher), Planesticus nigrescens (sooty thrush), Catharus gracilirostris accentor (Chiriqui nightingale thrush), Thryorchilus browni (Brown's wren), Ptilogonys caudatus (Costa Rican ptilogonys), Phainoptila melanoxantha (Salvin's ptilogonys), $B a$ sileuterus melanogenys eximius (Chiriqui warbler), Diglossa plumbea (Costa Rican diglossa), Chlorospingus pileatus (sootycapped chlorospingus), Junco vulcani (volcan junco).

Plants: Lycopodium chiricanum, Lycopodium hippuridium, Dendropthora biserrula, Dendropthora costaricensis, Dendropthora wrightii, Maytenus blepharodes, Arcytophyllum lavarum.

\section{Modification of original biota}

Human occupation of Panama to a degree sufficient to exert a marked effect on the original biota is still restricted largely to particular sections leaving the greater part of the region in a primeval condition. Human agency as a modifying factor is most strikingly exemplified in the construction of the 
Panama Canal. This gigantic undertaking, involving the destruction of formerly unbroken forest and the creation of Gatun Lake, approximately 164 sq. mi. in area, along a transcontinental belt has had a profound effect on the local fauna and flora. Species restricted to the original forest interior are replaced by those of widely different associations which thrive on forest borders or in cleared spaces where grasses, herbaceous vegetation, and a multitude of shrubs and vines of low growth are the first to secure a foothold. In these cleared spaces many birds and certain mammals such as the cotton rats rice rats, and white-tailed deer not found in the depths of the forest find a congenial environment. Along the forest borders marking the edges of the clearings, on the other hand, some forest mammals, especially ground-inhabiting rodents, increase in number owing to the more abundant food supplied by the low growing vegetation.

The impounding of the waters of the Chagres River to form Gatun Lake in an interior basin, and the diversion in this way of Atlantic drainage to the Pacific through the canal has brought about marked changes in water relations on the Isthmus. The rising waters of Gatun Lake destroyed the forest and permitted the extension of many aquatic species into a new area where the development of stable associational relations may be expected to require considerable time. The white-tailed deer (Odocoileus chiriquensis), seems to be absent in the depths of the unbroken forest where it is replaced by the forest deer (Mazama sartorii reperticia), but favors the forest borders or the dense thickets and mixed growth of small trees and shrubby vegetation which have sprung up in the partly cleared spaces. From the partly open country near the Pacific coast of the Isthmus it appears to have followed the Canal route northward nearly to Colon.

Along the southern side of Panama settlements occur at intervals in the savanna and arid deciduous forest type of country and stock raising is carried on to a rather limited extent. On the southern slopes of the lofty Volcan de Chiriqui in western Panama some forest has been cleared and the land devoted to the growing of coffee and other crops. In the vicinity of Bocas del Toro in the northwestern part of the Republic formerly forested areas near the coast have become the seat of a bananagrowing industry.

Considerable sections of the mixed savanna and arid deciduous forest extending along the Pacific coast from the Costa Rican frontier east to the Rio Chepo are swept annually during the dry season by fires which tend to limit the extension of forest growth.

III. ACCESSIBILITY OF NATURAL AREAS (E.A. G.)

The regular steamship routes converge to the Atlantic and Pacific ports at the ends of the Panama Canal. From these ports or stations on the Panama Railroad many points in the vicinity of the Canal Zone embracing a variety of local conditions are easily reached. Barro Island in Gatun Lake has recently been made a station for tropical research by various institutions, and this or other points in the Canal Zone may conveniently be used as headquarters for field operations in many parts of Panama.

Some of the steamers to and from Colon to Port Limon make stops at Bocos del Toro. Small vessels make trips coastwise from Panama, at the Pacific end of the canal west to David from which transportation may be secured to the elevated region about the Volcan de Chiriqui. Small vessels or motor boats also make trips from Panama to the Pearl Islands, to Chepo on the Rio Chepo and to points as far east as Real de Santa Maria near the head of motor navigation on the Rio Tuyra. The Atlantic coast from Portobello eastward is practically uninhabited except by Indians and access to that section is difficult. Although the Isthmian region is narrow the greater part, 
especially the interior of the northern half is difficult of access, owing to the shortness of the navigable streams and the rugged character of the land surface, covered for the most part with an unbroken forest. Because of this inaccessibility the biota of much of the region remains comparatively little known.

Yellow fever, formerly prevalent in the Canal Zone has been controlled, but malarial fever, amoebic dysentery and other diseases of the region should be guarded against in working on the tropical lowlands.

\section{NATURAL AREAS (J. Z.)}

\section{The Rio Pequeni-Boqueron Region, Panama}

The best time of the year to make a trip into this region is during the dry season, i.e., February and March, with the latter the best month. There are two big divides, one close to the Caribbean coast, and the other SouthEast of the Chagres River basin. As a result rainfall is heavy during the rainy season, and the rivers, confined in places to narrow gorges, are impassable.

There are two ways to reach the region. The best is to get into touch with the Manganese Mining Company, Colon R. P., and get by a small boat to Playa de Las Damas at Nombre de Dios. From here they are building a narrow gauge railroad to their two mines. On both sides of this route it is wild. It is possible to go up the Nombre de Dios river in a small cayuca. One could go to Porto Bello and from there by trail to this new road, but this is not advisable on account of the need of guides. It is $17 \mathrm{mi}$. from the coast to the manganese mine No. 2, where a good camp exists. Within this small distance are two fair rest camps. The trip may be made in one day, or in two or three, as is desired. Mine number One is not used at present. Between One and Two, a distance of $12 \mathrm{mi}$., the trail is open and could even be used by horses if need be, though this is not desirable here. At One are good falls, and the river in places along the general route is narrow, with tall, vertical rock walls, with rapids and other exciting features in abundance. Good guides are easily obtainable, and if treated right, well fed and given tobacco (important!) they will prove very satisfactory. A half dollar a day in addition would be ample pay unless the work was heavy due to excessive luggage, when more should be given. The first mine is at Rio Peluca. All along this route one meets no one unless it be a rubber hunter. In a few of the clearings or treeless places, small farms will be met with but their owners, since they planted the seed do not return until it is time to gather in the crop. Nature is a wonderful mother to these natives.

From mine number One to the town of Alejuela, where the Panama Canal has a hydrographic station, it is nine hours in a cayuca with two "palancas," and these cayucas poled by the sturdy natives are as safe as anything can be. In a few places short portage is necessary but the trip is not dangerous. From Alejuela to Gamboa, where the train can be taken to either Cristobal on Panama City, it is a short, uninteresting trip.

There is practically no danger from malaria in this region unless one goes into the Rio Pequeni area, the branch that goes eastward from where the Boqueron joins the main Pequeni. In this particular region it is flat and low, swampy, and the water so muddy that to drink it requires boiling. In the region recommended, very few mosquitoes will be encountered. Instead ticks will be felt, but daily reconnaissance can eliminate them. The screw worm, Dermatobia cyaniventris, which causes a dermal myiasis, is quite common, but not a serious menace if one wears shoes, leggings and clothing. Even if a few larvae should start to develop, the experience is so rare and novel and the danger to health so slight, that they are not objectionable.

The least possible equipment is best. 
Food is of importance, and should be plentiful, concentrated and varied. Definite advice on this can be had from the Survey Division of the Panama Canal or from others who have made such trips. Their advice is essential if the trip is to be a success. Woolen socks are desirable. Tents are not necessary, as they take up too much valuable space which is needed for food. It is best to have a native guide make a thatch palm shelter, which he does rapidly and well. Several rubber covered bags are useful to keep important instruments, papers, matches, etc. protected against rains or accidental turnovers in the rivers. It is usually possible to rent camp equipment from The Panama Canal. Two guides and a cook are ample. The entire trip as outlined, can be made in a week to ten days.

The country about here is typically tropical, of the humid kind. Wild animals are not troublesome. A cougar may be met but as a rule he is not aggresive, though often he will follow one out of curiosity. It is not unusual to find out afterwards that one of these big cats had been following a party all day long. Three kinds of monkeys, the Howler, Red-Spider, and Whitefaced, will be met with, and to the uninitiated the big Howler will cause alarm. If nuts (palm) are abundant, then the wild hog, or jabali, will be met with in large bands, but there is not much danger from them, though they are capable of inflicting very painful wounds.

It is necessary to carry a gun and revolver and plenty of ammunition, in order to get fresh meat each day and for possible protection. Snakes are not plentiful nor unusually serious. Ordinary precautions are all that is necessary.

\section{The Rio Indio-Rio Chagres Region, Panama}

This is another easily accessible virgin region within the Republic of Panama and close to civilization. It is reached from Gamboa by launch to Limon, which is a little above Juan Mina, and then by cayuca to Alejuela, a trip made with ease in one morning. From Alejuela by cayuca to Rio Indio is another half day. Both can be done the same day if arrangements with guides had been made beforehand. At San Juan, the only village of many huts, above Alejuela, on the Pequeni, is a man, called "Old Mexico," a faithful guide who knows every inch of the territory. $\mathrm{He}$ is reached as follows: Old Mexico, San Juan de Pequeni, care of Alejuela Hydrographic Station, via Gamboa, Canal Zone.

The water at Rio Indio is excellent. At Rio Chico and the Chagres is a splendid camp site, on a sand bar. It is only a few minutes from untouched localities. This is a region few men, other than rubber hunters, have entered.

It is easy to get to this region, even to follow the Chagres to its source, and to get back again to the Canal Zone in ten days.

\section{Other regions in the Republic of Panama}

The Chiriqui Province is very interesting because it stretches from sea level to $5000 \mathrm{ft}$. or more. The range is from tropical to temperate climates. A railroad goes from David to Boquete on one side, and to Alanjeon the other side, with the extinct Volcan between the two. While many farms are present, especially in the Boquete region, it is possible to get into virgin territory without difficulty, and to secure good guides and help. Hotels and private houses are plentiful, so that accommodations are not hard to get. The Governor and Alcalde should be seen first, so as to get special letters which will help getting assistance in the interior.

The San Blas region is not suitable for exploration because of the customs of some of the Indians. If treated well and told just what one's mission is, they sometimes prove of great help.

The Darien coast, on the Pacific side, entering through the River Tuyra, which is comparable to the Mississippi, is most interesting as one gets into the 
hilly regions. Here nature is found unmolested and wild, but inaccessible. For an expedition, this territory would prove rich in results.

\section{Barro Colorado Island Laboratory, Gatun Lake, Panama Canal Zone}

The Institute for Research in Tropical America was organized under the auspices of the National Research Council in the spring of 1922. The member institutions are: American Anthropological Association; American Genetic Association; American Museum of Natural History; American Phytopathological Society; American Society of Agronomy; Brooklyn Botanic Garden; California Academy of Sciences; Carnegie Museum; Commercial Museum of Philadelphia; Ecological Society of America; Harvard University; Indiana University; Johns Hopkins University; National Geographic Society; National Research Council; New York Academy of Sciences; New York Zoological Society; University of Michigan; Philadelphia Academy of Sciences; Smithsonian Institution; University of Florida; and Yale University. The Institute was organized to promote research in tropical America. Barro Colorado Island was set aside by the Canal Zone as a reserve and was assigned to the Institute for scientific purposes. The Institute has built a laboratory or field station on the island and provided simple furniture and utensils, so that visiting scientists can camp while carrying on field work in the forest.

Barro Colorado Island is located in Gatun Lake, west of Frijoles, C. Z., and its east side borders the Panama Canal prism. It is approximately 10 mi. from Gatun and Gamboa, and about two mi. west of Frijoles. It is $3 \frac{1}{2} \mathrm{mi}$. long and about $3 \frac{1}{2} \mathrm{mi}$. wide. Its area is about $6 \mathrm{sq}$. mi. It begins with an elevation of $85 \mathrm{ft}$. above sea level, which is the normal level of Gatun Lake, and reaches an elevation of $537 \mathrm{ft}$. It is completely wooded, excepting for a few hectares at one spot of the southern shore which are under cultivation. The vegetation is practically virgin tropical rain forest.

When Gatun Lake was formed, the rising waters slowly inundated all lands below the $85 \mathrm{ft}$. contour. Barro Colorado Island was in the center of an extensive area which the rising waters were covering up. The animals that were able to migrate gradually drained into this island. Thus the island became a refuge to a large host of animals. It has been practically undisturbed and is today the only available large tract of virgin forest in this region.

The number of species of plants on this island, exclusive of cryptogams, is in the neighborhood of 2000 . Vertebrates are well represented. Of the mammals, the following may be mentioned: several species of opossums, sloths, ant eaters, armadillo, peccary, deer, tapir, olingo, several species of rats and similar rodents, tayra, agouti, squirrels, rabbits, raccoon, coati, ocelot, many species of bats, the night monkey, howling monkey, white-throated capuchin monkey, spider monkey, etc., typical of the humid lower tropical zone. The shore fauna and flora are quite varied.

In addition to the island, there are excellent places nearby easily reached by a launch, such as the headwaters of the Trinidad, Sirri and Sirricito Rivers, the Chagres and its tributaries, Rio Gatun, etc., and by cayuca or canoe many of the small streams can be explored.

Brigadier General Jay J. Morrow, Governor of The Panama Canal, under date of April 17, 1923, set aside this island as a Natural Park and prohibited all hunting thereon, in response to a request by Mr. James Zetek.

The Panama Canal is the most accessible region in the world. Steamer service is plentiful and rapid, averaging seven days from New York. Many features are present which should make this island laboratory a popular place for the study of tropical conditions and biota. At Ancon the United States Government maintains a large modern 
hospital. Attached to it is the Board of Health Laboratory, with its departments of bacteriology, pathology and chemistry. The Panama Canal continues the splendid work of sanitation begun by General Gorgas and through which yellow fever and bubonic plague have been eliminated from the isthmus, and malaria and other tropical diseases reduced to a minimum.

In Panama City there is the new Santo Tomas Hospital likewise certain to become a center of medical and sanitary research. Close to it, and coöperating with it, is the new Gorgas Memorial Institute. The establishment of this whole great medical center in Panama City is due to the wise and progressive spirit of Doctor Belisario Porras, President of the Republic of Panama.

The Panama Canal maintains storehouses at Balboa where almost anything can be obtained, and especially in the medical section, where reagents, drugs, glassware, apparatus, etc., are always on hand. Screened, well-ventilated living quarters are also available, averaging $\$ 9$ to $\$ 10$ for bachelors (one room, including janitor service, electricity, and water), to $\$ 20$ to $\$ 30$ per month for "married" quarters. All quarters are equipped with furniture and stoves, but bedding, linen, silverware, chinaware, cooking utensils, etc., must be provided by each occupant. Excellent hotel accommodations are available at Colon, Ancon and Panama City.

Restaurants are operated on the Canal Zones, and good, wholesome food can be obtained at very moderate cost, depending on the wants of the individual. It is possible to live well at these restaurants for $\$ 40$ to $\$ 50$ a month, or less. The commissaries operated by The Panama Canal supply almost everything needed for the home, person and table. In Panama City there are many very reliable stores.

The following excerpt from a letter from the Governor to Dr. David Fairchild of the National Research Council, dated December 14, 1923, is of importance to everyone contemplating a visit to the station for study. It indicates some of the concessions which have been extended to scientists at the Barro Colorado Island laboratory.

To the scientists coming here properly accredited, I shall be glad to extend the privileges you mention-the $\$ 50.00$ rate on Panama Railroad Steamers and right to purchase at our commissaries. We will also give them passes on the Panama Railroad, and will otherwise assist them in any way we can. I am satisfied that the men who will be accredited by your Committee will be of such type, and will have such objects in view, as will fully entitle them to these courtesies.

Scientists who plan to go to the laboratory on Barro Colorado Island must first communicate with the Chairman of the Executive Committee of the Institute for Research in Tropical America, in care of National Research Council, Washington, D. C. They will then receive additional information and will be given the necessary credentials. Candidates will be given preference from institutions which support or "maintain a table" at the Island Laboratory. Exceptions may be made in special cases. Collecting of unduly large series, especially of vertebrates, will not be permitted. The island was set aside first and foremost as a Biological Preserve. Generally speaking the large mammals must not be disturbed.

There are adequate facilities on the island for both study and living. Ordinary native labor can be had for as little as $\$ 1$ per day. There is a distinct advantage in living on the island. No time is lost in getting at once into the jungle. Much important data can be gathered while seated on the veranda of the station building. The island is reached by boat from Frijoles station.

Special apparatus or reagents should be brought by each person, and if these can not be taken along in a trunk as part of the baggage, which is most advisable, but must be sent by freight or express, then such equipment should be sent at least three weeks ahead of time, and the Resident Custodian at Ancon, C. Z., should be notified and 
given all details regarding such shipment, in order to arrange for free entry (exemption from payment of duty). The Resident Custodian should also be notified in advance of the arrival of the scientist in order to have everything in readiness.

Upon arrival at Cristobal, C. Z., the person should take the train to Panama City and go from there to Hotel Tivoli in Ancon. After becoming established at the hotel, he should proceed to Ancon Hospital grounds where the Resident Custodian has his office. The postoffice address of Mr. James Zetek is Box 245, Ancon, C. Z. Mail may be sent in care of Mr. Zetek.

It is not necessary to have a passport or to see any foreign consul when going to the Canal Zone. Once established in the Canal Zone, there is no restriction on entering the Republic of Panama. If steamers of the Panama Railroad Company are used, especially when equipment is sent as freight, a minimum of trouble will be experienced.

President Porras of the Republic of Panama has set aside a very excellent section of land north of the Gorgas Memorial Institute for a Marine Biological Station and Aquarium, and at present writing prospects are very favorable so that within a few years such an institution and aquarium will be built on this land, and thus the fundamental aim of the Barro Colorado Island laboratory will be increased to include marine research.

The library facilities of the Board of Health Laboratory, Ancon Hospital, The Panama Canal Library, and the Gorgas Memorial Institute are available.

\section{v. BIBLIOGRAPHY (E. A. G.)}

The following bibliography includes only the titles of a few of the more important general works bearing upon the biota of Panama. For a bibliography of the mammals see Goldman, 1920.

Wafer, Lionel.

1729. A New Voyage and Description of the Isthmus of America. 3rd edition, London, 1729. Published as pp. 263-460 of the third volume of Dampier's Voyages. The original edition was published separately under the same title in 1699 . (Includes quaint and interesting accounts of the biota based on observations made in eastern Panama in 1681.)

Biologia Centrali-Americana.

1879-1915. An elaborate treatment in 52 volumes by various authors of the mammals, birds, insects, and plants of Mexico and Central America.

Ridgway, Robert.

1901-1919. Birds of North and Middle America. A descriptive catalogue of the higher groups, genera, species, and subspecies of birds known to occur in North America, from the Arctic Lands to the Isthmus of Panama, the West Indies, and other islands of the Caribbean Sea, and the. Galapagos Archipelago. Bull. 50, U. S. Nat. Mus., pts. 1-8, each separately paged have been issued (others to follow), covering families in reversed order Fringillidae to Alcidae. Washington: Govt. Printing Office. (The current authoritative systematic account of the birds of the region.)

Bangs, Outram.

1902. Chiriqui Mammalia. Bull. Mus. Comp. Zool., Vol. 39, pp. 17-51, April, 1902. (An annotated list of 63 species and subspecies mainly from the Volcan de Chiriqui, western Panama. One of the most important single contributions to knowledge of the mammals of Panama.)

Elliot, Daniel Giraud.

1904. The Land and Sea Mammals of Middle America and the West Indies. Pub. Field Columb. Mus., Zool. Ser., Vol. IV, pts. 1-2, pp. 1-850. Chicago, 1904 . (Contains list of species with original references, brief descriptions, type localities, and geographic distribution.)

Goldman, Edward A.

1920. Mammals of Panama. Smith. Misc. Coll., Vol. 69, No. 5, pp. 1-309, pls. 1-39. (An annotated list of species and tentative treatment of life zones.) 


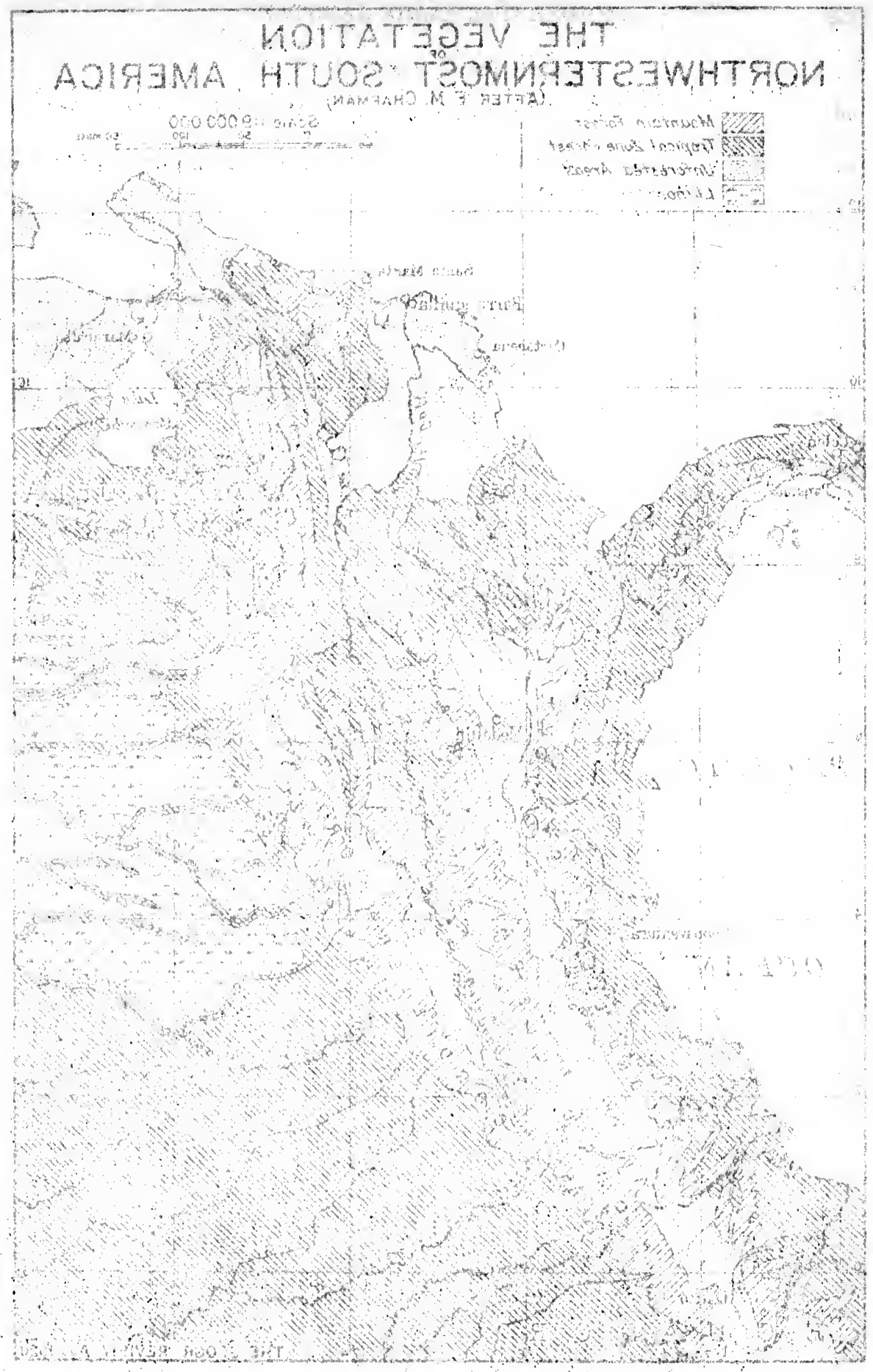






Fia. 15 


\section{B. Northern South America}

\section{COLOMBIA ${ }^{1}$}

\section{By Francis W. Pennell}

The Republic of Colombia, situated in the northwestern corner of the South American continent and adjoining the isthmus of Panamá, occupies a geographic position of extreme interest. Alone among South American countries it touches both the Atlantic and the Pacific oceans, while its mountainsystems and river-systems are the most diversified within the American tropics. The republic lies between latitudes $12^{\circ}$ $24^{\prime} \mathrm{N}$. and $4^{\circ} 17^{\prime} \mathrm{S}$. and between longitudes $66^{\circ} 7^{\prime}$ and $79^{\circ} \mathrm{W}$., occupying an area of about $460,000 \mathrm{sq}$. mi.

\section{TOPOGRAPHY}

\section{A. Mountains}

The Andean uplands dominate the western ralf of Colombia. Entering from Ecuador to the south as a single highland, the system soon divides into three chains or "cordilleras" which trend independently northward and northeastward toward the Caribbean Sea. (a) The Central Cordillera is the highest and maintains without a

1 In this account much topographical and climatological data have been drawn from the comprehensive and detailed "Geografía de Colombia" by Felipe Perez (Bogotá, 1862) and "Nueva Geograf́a de Colombia" by F. J. Vergara y Velasco (Bogotá, 1901), with the latter's maps in the "Atlas Completo de Geografía Colombiana" (Bogotá, 1906). The biological outline of Dr. F. M. Chapman in "The Distribution of Bird-life in Colombia" (Bull. Amer. Mus. Nat. Hist., XXXVI, 1917) is adopted, and from this work is taken special data concerning birds. The information about mammals is quoted from memoranda kindly supplied by Dr. W. H. Osgood of the Field Museum of Natural History. For the Santa Marta region the study of "The Birds of the Santa Marta Region of Colombia" (Ann. Carnegie Mus., XIV, 1922) by Dr. W. E. C. Todd and Mr. M. A. Carriker, and for the Goajira Peninsula a paper entitled "An Account of a Journey through . . . the peninsula of Goajira" by Dr. M. T. Dawe (Bogotá, 1917) have been of assistance. Mr. P. J. Eder's "Colombia" (New York, 1913) and P. .J. Bell's "Colombia" (issued as a bandbook of the U. S. Dept. Commerce, Spec. Agent Ser. 203 , Washington, 1921), give much practical information. The writer has personally spent thirteen months in botanical field-work in Colombia, and has climbed from the warm lowland to the paramo on each of the three cordilleras of the Andes; he has collected plants in the departments of Antioquia, Atlantico, Bolívar, Caldas, El Cauca, Cundinamarca, Huila, Magdalena, Santander, Tolima, and El Valle, and in the intendency of El Meta. break an axis of high peaks from the Ecuador boundary to the Alto de Pereira in Antioquia about $6^{\circ} \mathrm{N}$. These peaks repeatedly rise to snow, from south to north the most important being the group of the Túquerres in Nariño, of the Coconucos (including Puracé) in El Cauca, the mountains Huila and Barragan in El Valle, and the group of the Quindio (including Tolima) in Caldas. Colombia's only active volcanoes are in the southern part of this chain. North of $6^{\circ} \mathrm{N}$. the system is lower and branches widely to form the hilly country of central Antioquia, the axis rising but once again to above timber-line in the Páramo de Santa Inés north of Medellin. (b) The Western Cordillera, leaving the common Andean highland-mass of the Túquerres and containing some of the highest peaks of that mountain-knot, extends north-northeastward parallel to the Central Cordillera and nearly parallel to the Pacific coast. Averaging much the lowest of the three cordilleras, its long axis mostly a range of forested hills, which, however, rises in remote highlands to above timber-line, although never to snow. North of the Río Patía the most considerable uplands are to the north, where occur the more or less isolated "paramos" of Cerro Torrá, Cerro Tatamá, Farallones de Citará, the mountains near Frontino, and the Paramillo. (c) The Eastern Cordillera, leaving the Central Andes at the Coconucos about $2^{\circ} \mathrm{N}$., soon drop into a range of hills trending southeastward, then turning northeastward they form a narrow chain with only occasional higher peaks until $3^{\circ} 48^{\prime} \mathrm{N}$. is reached. Beyond this point the Cordillera widens into a broad upland, with a main axis and a considerable diversity of side chains, so as to form the table-land or plateau of Bogotá. Here was developed the ancient civilization of the Chibcha Indians, many of whose towns as Bogotá, Chiquinquirá and Tunja survive as important Spanish American cities. 
The mountain-chains of this plateau usually rise above timber-line and occasionally, in the peak of Sumapaz and the Sierra de Chita (or Cocuy), receive snow. The axis of the Eastern Cordillera, trending northeast as far as Cocuy, turns thence abruptly northwestward, forming the Pamplona highlands and reaching Ocaña at $8^{\circ} \mathrm{N}$. A low range of hills continues this axis farther to the north, rising to mountains in the Motillones and the Sierra de Perijá, and extending ultimately nearly to the Goajira Peninsula, the most northern point of Colombia. From the Pamplona section of the Eastern Cordillera a mountain-chain diverges abruptly eastward, passing soon into lower hills that form the gap known as the Isthmus of Táchira but then rising again so as to constitute the eastward-trending Andes of Venezuela, the snow-chain of the Sierra Nevada de Merida.

Beside the Andean cordilleras two other mountain-systems must be mentioned. The Sierra Nevada de Santa Marta, southeast of the city of that name and within sight of the Caribbean Sea, forms an irregular mountain-mass rather extensively capped with snow. The system is wholly isolated from the Andes, although separated from the Sierra de Perijá only by a narrow lowland plain. The Serranía de Baudo, skirting the Pacific coast from the Chocó Bay at $4^{\circ} \mathrm{N}$. northward, although chiefly a range of low hills, is also to be carefully distinguished from the Andes. The Andean system terminates wholly in the three cordilleras of Colombia, whereas the Baudo chain is continuous with the highlands of Panamá and forms part of a Central American landmass.

\section{B. River-systems and areas of lowland}

In western Colombia the areas of lowland lie around and between the mountain highlands while in eastern Colombia the whole country consists essentially of one vast plain, the northwestern part of the great interior low- land of South America. Proceeding from the Pacific coast eastward the chief river-systems and areas of lowland are as follows.

$a$. West of the Serrania de Baudo occur only very short streams flowing directly into the Pacific Ocean.

b. Between the Serranía de Baudo and the Western Cordillera is a valley of some $50 \mathrm{mi}$. width, drained northward into the Caribbean Sea by the Río Atrato and southward to the Pacific Ocean by the Rio San Juan. South of Choco Bay the numerous streams from the Western Cordillera flow directly to the Pacific, mostly across an extensive lowland. The whole area from the Gulf of Darien to Tumaco is known as the Chocó.

c. Between the Western Cordillera and the Central Cordillera is the long narrow Cauca Valley, drained northward by the Río Cauca. In El Cauca near Popayán and especially in El Valle the floor of the valley is a plain reaching 20 to 25 miles in width but elsewhere it is much cut into hills and gorges. In Caldas and Antioquia the Río Cauca has cut its way by gorges and deep canyons down from the elevation of the Cauca Plain, 1000 meters, nearly to sea-level. South of Popayán the Río Patía drains the southern extension of this inter-Andean lowland, being the only stream of Colombia to burst through the Western Cordillera to reach the Pacific.

$d$. Between the Central Cordillera and the Eastern Cordillera is the Magdalena Valley, broader and lower than the Cauca Valley. It is drained by the Rio Magdalena, a river which, flowing northward to the Caribbean Sea, forms Colombia's main artery of traffic. Much of the valley floor is a plain, but areas of hills occur in Tolima and Huila. The most considerable plains are about Neiva in Huila, Mariquita in Tolima, and in eastern Antioquia. The Bogotá tableland is drained through the Rio Sogomoso, Río Carare, Río Sumapaz and other streams into the Magdalena.

e. Fronting the Caribbean Sea and 
north of the hills of Antioquia is a plain crossed only occasionally by low ranges of hills. In the western part the Rio Sinú, in the middle part the delta-like courses of the Rios San Jorge, Cauca and Magdalena, all uniting northward to form the single stream of the lower course of the Rio Magdalena, and in the eastern part the Rio Cesar draining the flat valley of Upar southward into the Magdalena, flow across this plain.

$f$. Continuous by a narrow passage with the Valley of Upar, and projecting into the Caribbean Sea so as to form the northernmost point of Colombia and of the South American continent, is the Goajira Peninsula. This lowland embraces plains and low hills, but has only few and inconsequential streams.

$g$. Between the forks of the Eastern Cordillera, and so east of Ocaña and north of Pamplona, is the valley of the Rio Catatumbo, draining northeastward to the Gulf ("Lake") of Maracaibo. Most of the plains of this valley lie in Venezuela, the Colombian portion being chiefly or wholly hilly.

$h$. Eastward from the base of the Eastern Cordillera south of the Pamplona forks stretches the enormous lowland of the interior of South America, of which in Colombia the northern portion drains eastward and northeastward to the Orinoco, the southern portion southeastward to the Amazon. Many streams roughly paralleling each other flow from the Andes or rise in the lowland. To the Orinoco flow the Río Arauca, Río Meta, Río Vichada and Río Guaviare; to the Amazon the Río Uapes, Río Caquetá and Río Putomayo. This area, covering more than half of Colombia's territory, is essentially one continuous plain, although in the Amazonian portion, known as Caquetá, occur a few remote ranges of hills and low mountains.

\section{CLIMATE}

\section{A. Temperature}

Lying within the middle belt of the Tropics Colombia possesses a climate in which the temperature, if we ignore diurnal variation, may be described as practically uniform throughout the year for any given point. Throughout all the lowland areas the climate is continuously hot. The temperature becomes progressively lower as one ascends in elevation, the Cauca Valley near Cali being cooler than the Magdalena Valley at Honda, Popayán near the head of the Cauca Valley cooler than Cali, and Bogotá in the Eastern Cordillera much cooler yet. Higher in the mountains one passes to colder and colder zones until at last on the high peaks snow is reached. Above the snow-line precipitation uniformly occurs as snow, with the result that every mountain reaching so high is capped by a glacier.

\section{B. Rainfall}

Rainfall is distributed very unevenly, depending both upon prevalent winds and upon elevation. In the Caribbean plain the northeast trade winds blow constantly for over half the year, and the land has consequently two long seasons, one wet and one dry. The Goajira Peninsula is arid, but the amount of precipitation increases gradually westward to the Gulf of Darien. In the Choco the west winds from the Pacific produce abundant showers usually throughout the year against the slopes and spurs of the Western Cordillera. On the south eastern slopes of the Eastern Cordillera and on the Amazonian lowland the moisture-bearing winds blow from the east, watering abundantly nearly throughout the year the Andean slopes and the region of Caquetá. On the northern portion of the eastern lowland-the Orinocan portion which is known as Casanarethe rainfall is lighter than further south and is seasonal. On the plains of the middle Magdalena and the hills of Antioquia moderate to heavy rainfall occurs, with a single wet and a single dry season as along the Caribbean. Southward, however, within the troughlike valleys between the Andean cordil- 
leras, the rainfall is distributed in two wet seasons and its amount decreases until portions of the Cauca and upper Magdalena valleys become decidedly arid.

While generally the precipitation increases as the mountains are ascended, this rule is greatly modified locally according to exposure to moisturebringing winds. Thus the plant-life indicative of increased rainfall may obviously be seen to increase upon the western slope of the Central Cordillera when an elevation is attained that overtops the opposing crest of the Western Cordillera. Conversely upon the normally humid slopes of both the western slope of the Western Cordillera and the eastern slope of the Eastern Cordillera occur pocket-like arid valleys caused by the interception of the winds by higher outlying spurs or ridges. At higher levels the rainfall tends to become more constant throughout the year and to occur in lighter individual showers, although the seasons are still evident, and with a time of occurence which may be much altered by local topographic conditions.

\section{NATURAL REGIONS}

Since the wild life of Colombia is so little changed from its primitive state and since no areas whatever have been set apart as preserves, it seems best to modify somewhat the plan of presentment used in this volume for the several states of the United States of North America. We shall consider the different natural regions of life, resultant from topography and climate, and give for each region one or more stations from which it may be studied. In few parts of Colombia and for few groups of plants or animals is the flora or fauna adequately known, so that possibilities of valuable scientific exploration lie within the reach of any who have opportunity to visit this land.

The localities mentioned will be assigned to their political department, so as to facilitate finding upon standard maps. There are few railroads in
Colombia and none that serve to bind together the entire country. Northern Colombia, Antioquia, Tolima and the Bogotá section (Cundinamarca) are interconnected by steamboat travel on the Río Magdalena, with a series of subsidiary railroad lines. Steamboats from Cartagena also ply on the Atrato and lower Sinú. The Cauca Valley and southward should be reached from the Canal Zone by steamer to Buenaventura, connecting with a railroad to Cali. Another approach to Colombia is by steamboat from Ciudad Bolívar on the Orinoco in Venezuela up the Río Meta-an approach which only reaches the eastern "Llanos." Also Cúcuta, with railroad and steamboat connection to Lake Marocaibo in Venezuela, is with difficulty reached from the rest of Colombia. Roads for wheeled vehicles scarcely exist beyond the vicinity of the largest cities, so that much of one's journey into and across Colombia will be over primitive trails, with mules or horses for riding and for pack-loads. While readily traversed in the dry season, most trails become difficult by reason of sloughs and mud-holes in the rainy season. So far as is consistent with the purpose of one's journey one should plan a trip across lowland trails for the dry season. The mountain trails are apt to be none too good at any season, but the months of December to February and June to August are usually the best for travel.

In this discussion we shall consider first the areas of lowland and secondly the mountain regions. All the lowland regions of Colombia, except where arid or, as at Popayán, where, although between the cordilleras, one is above the truly lowland zone of life, are dangerous to health by reason of malaria and other tropical diseases. The upland mountain zones are invigorating and healthful.

\section{A. Rain-forest}

The lowlands of Colombia are covered with evergreen forests wherever rainfall is sufficient in quantity and occurs 
sufficiently distributed throughout the year.

1. Choco Forest. This occupies the area between the Western Cordillera and the Pacific Ocean, including northward the Atrato Valley and the shores about the head of the Gulf of Darien. This region is probably the most humid in the American Tropics and, except for remote arid pockets due to local configuration, is wholly covered with a dense rain-forest. There is a great variety of hardwood trees. Trees of the Rubiaceae are probably most abundant, while those of the Melastomaceae, Lauraceae and other families are common. Very frequent are trees with the tips of the leaves elongated. Palms are prominent, especially along streams. There are many lianas, some woody, some as various Araceae heavy and succulent. Epiphytes, chiefly ferns and Bromeliaceae, occur in moderate number. The floor of the forest supports much underbrush, bushes or stout foliaceous herbs. There may be also ferns, Selaginellas and mosses. Along water-courses and other openings are thickets of bamboo or of broad-leaved succulent wild bananas and like plants. Excepting the gaudy red bracts and yellow pedicels and flowers of these Heliconias, there is little bloom to break the green of the rank vegetation.

Near the coast are wooded swamps, and the Pacific shore is lined probably throughout with mangrove swamps.

Dr. Chapman's "Distribution of the Bird-life of Colombia" reports 150 kinds of birds in the Chocó Forest, of which 100 are restricted thereto. The chief families in order of number of kinds are (1) Tyrannidae, (2) Formicariidae, (3) Dendrocalaptidae, (4) Tanagridae, (5) Trochilidae.

"The mammals are in general related to those of the Amazonian forest, in many cases showing slight subspecific differences. Among them are the jaguar ocelot, sloths, paca, agouti, capuchin monkey, red howling monkey, night monkey, and various opossums including the woolly opossum (Philander) and the water opossum (Chironectes); small rodents and bats of many species are abundant."

Southward and over most of the Chocó Forest heavy rainfall occurs throughout the year, but northward this becomes increasingly seasonally distributed until on the lower Atrato the rains occur from April to December, with January to March nearly or quite rainless.

Only near a few settlements has this forest been cleared.

The middle Choco Forest may be visited most readily from Buenaventura on the coast, and at Cordoba, Santa Rosa and Cisneros, stations on the Buenaventura to Cali railroad. These forest stations are without hotels and in malarial country, but may be visited on day excursions from Buenaventura. From Buenaventura small boats ply north to the Río San Juan, and south to the Río Micay. The northern Chocó Forest may be studied from Quibdo and other points on the Río Atrato reached via steamer from Cartagena.

2. Magdalena-Sinú Forest. This forest occupies the middle Magdalena and lower Cauca valleys from La Dorada in the Río Magdalena and from above Cáceres on the Río Cauca down to their delta-like confluence, thence extending westward over the San Jorge and upper Sinú valleys to the Gulf of Darien. The forest is of moderate density and height, and trees with broad and irregular leaves occur more frequently than in the Chocó Forest. Probably trees of the Rubiaceae and Lauraceae are less frequent than in the Chocó, while Bombacaceae (ceibas) and Lecythidaceae (monkey-pots) are more evident. Along the rivers star-leaved Cecropias are conspicuous. Woody lianas such as various Sapindaceae and Bignoniaceae, are common but huge Araceae are few relative to the Chocó. Epiphytes are not numerous until the foot-hills of the cordilleras are reached where ferns and Bromeliaceae become common. Along the rivers, as may be seen from the Magdalena steamer, occur 
extensive fringes of Heliconias, with areas of large-plumed grasses (Gynerium) and clumps of bamboo.

Near the chief rivers are large areas of swamps and lagoons, from which during seasons of high water are derived the large "rafts" of Pistia (water lettuce) and Piaropus (water hyacinth) which become so conspicuous on the Magdalena itself.

There are 24 kinds of birds known to be restricted to the Magdalena-Sinu Forest, the bird-life of which is mostly shared with the Choc 6 Forest to the west and the Maracaibo and other forests to the east.

"The mammals are much as in the Choco Forest, being those of general distribution in tropical rain forests of all South America. Practically all are derived from the eastward, but some important Amazonian forms are absent, especially among the monkeys."

This region is one of heavy to moderate rainfall, occurring mostly in a rainy season lasting from April to December or with a break in August. From December to May may occur periods of showers or periods without rain.

Only near the chief towns has this forest been cleared.

The Magdalena portion of the Magdalena-Sinú Forest may be readily studied from Puerto Berrio, the most important port of the middle Magdalena, the transfer-point from the steamer to the railroad westward to Medellin. Although in malarial country Puerto Berrio has one of the safest and best hotels in Colombia, being thoroughly screened. Cáceres on the Río Cauca and Ayapel on the Río San Jorge may be reached by steamers from the Magdalena river-port of Magangué. The Sinú portion of this forest may be reached by steamer from Cartagena, the boat running to the town of Monteria (except in the low water of March and April when it stops at Lorica), and from Montería launch or dug-out canoes may be arranged for transportation upstream into the forest.

3. Maracaibo Forest. "Heavy tropi- cal forest" exists in the southern part of the Maracaibo Basin, including the lower valley of the Rio Catatumbo in northeastern Colombia. Beside the statement of Vergara y Velasco that the vegetation is profuse and gigantic, I have seen no description of the Colombian portion of this forest. The region is especially humid.

Rainfall here occurs throughout the year, although most severely from May to October.

The Colombian portion of this forest may be visited from Cúcuta, to be reached by boat from Maracaibo, Venezuela, up the Río Catatumbo and Río. Zulia to Puerto Villamizar, Venezuela, thence by railroad to Cúcuta, Colombia.

4. Caqueta Forest. The great eastern lowland of Colombia from about the course of the Rio Guaviare southward, thus embracing the whole of the Amazonian drainage-area, is covered with a dense "sea" of forest. This is the northwestern portion of the vast Amazonian forest, which, judging by luxuriance as well as extent, may be counted the greatest forest-area of the world. The Colombian portion has been described by Rice and by Miller.

The Caquetá Forest is a heavy rainforest, although the climate is scarcely so humid as that of the Choco Forest of the Pacific coast. The essential composition and aspect of the Caqueta Forest doubtless accords with that of the Choco, but this immense area should be found to be richer throughout in the variety of its forms of life. In looking from any elevation one is impressed with the seemingly infinite variety of tree-outlines and of shades of green. Huge ceibas and other trees raise pyramidal or dome-like crowns above their fellows. Of lesser size trees of the Rubiaceae, Leguminosae and Melastomaceae are common. Palms occur in variety, but chiefly along water-courses. Within the dense forest-shade is an undergrowth of low palms, Carludovicas and other leafy plants. Lianas abound, with numerous Araceae, Sapindaceae 
Bignoniaceae, Apocynaceae, etc. Epiphytes, excepting ferns and mosses, are probably not abundant.

Along the many streams is frequently a lower growth, dense and intricate, made up of such plants as readily survive inundation. This "rebalsa" passes gradually into the neighboring forest.

No summary of the rich bird-life has been included in Dr. Chapman's study. This forest possesses "practically a pure Amazonian mammal fauna, many forms being even subspecifically identical with those from eastern Brazil. A rare rodent (Dinomys) peculiar to the east base of the central Andes has been taken in the region."

In the Caquetá Forest showers occur throughout the year, the rains being nearly continuous from April to September and most heavy in June; the lightest rainfall is in January and February.

Only near a few settlements has this forest been cleared.

The Caquetá Forest is traversed chiefly by the gatherers of rubber. It is everywhere difficult of access. A few trails cross the Eastern Cordillera from the upper Magdalena Valley. One south from Neiva in Huila leads to the small town of Florencia. Another from Bogotá crosses to Villavicencio and south to San Martín; thence one may go southward into the forests along and beyond the Río Guaviare. The lower portion of the Caquetá Forest is best accessible by vessels up the Amazon and tributaries, the Yapura (or Río Caquetá) and the Ica (or Río Putomayo).

\section{B. Grassland and savanna}

The lowlands of Colombia lack evergreen forests wherever the rainfall is deficient in quantity or is distributed so unevenly throughout the year as to permit of a long dry season. Mostly such lowland is covered with a turf oi grasses, although extensive areas of xerophytic bushes and brushy deciduous forest occur. Such unforested lowland areas are termed "llanos"

1. Llanos of Bolivar and Upar. Along the Caribbean coast from the Magdalena delta to beyond the Gulf of Morrosquillo, thence inland across the lower Rio Sinu to the mouth of the Río Cauca and east of the single stream of the lower Río Magdalena so as to include the Valley of Upar drained by the Río Cesar, is an extensive flatland covered originally chiefly by prairie. Except where permanent streams favor the development of ranker types, the prairies were covered by coarse wiry grasses, conspicuous being the species of Andropogon and Aristida. With these occurred doubtless a sparse herbaceous flora of other plants, similar to that of other areas of llanos.

On slopes or low hills, where ridges cross the plain as west of Sincelejo or in the hills between Cartagena and the Rio Magdalena, occur large sections of bushy scrub or of low deciduous forest. This forest is quite like that of the monsoon belt of India, and, in Colombia also, the months of its leafless state are those of most conspicuous bloom. In the alluvial bottom-lands of the Magdalena and Sinú grow huge buttressed trees of Bombax (ceiba) and Anacardium (caracoli), while the meadows may be dotted plentifully with the low spreading corozo palm. In northern Bolívar are extensive low hills covered with dense bushy scrub. Along the coast near Cartagena and southward are open salt marshes covered with coarse low grasses, sedges and rushes, marshes wholly similar to those of the Atlantic seashore of the United States and West Indies.

These Llanos possess the "general mammal fauna of arid lowland tropics, mostly of eastern derivation. This fauna includes the antbear, tamandua anteater, nine-banded armadillo, collared peccary, savanna white-tailed deer, savanna brocket deer, tapir, tayra, hog-nosed skunk, savanna fox, ocelot, and puma."

The region is characterized by one 
long rainy season, from May to November, and an equal dry season from December to April.

These open Llanos have been everywhere long grazed by cattle, and their character changed, at least through central Bolivar, by the widespread introduction of the drought-resistant Guinea and Para grasses. The brushcovered areas and those of deciduous forest remain nearly unchanged from their primitive state.

Corozál and Sincelejo, towns reached by trail westward from Magangué, are in the center of the Llano of Bolivar, but it is doubtful if any remnant of natural prairie can be found near them. The brush hills of northern Bolivar may be studied at Turbaco and Arenál on the railroad from Cartagena to Calamar on the Río Magdalena. The deciduous forest may be visited west of Sincelejo and near Lorica and Montería, towns on the Río Sinú reached by steamboat from Cartagena.

2. Goajira Peninsula. The northernmost prolongation of Colombia is mostly a low arid sandy land, but includes also in the heart of the peninsula proper a considerable district of low hills. It is mostly a land of coarse grasses, brushy scrub and Cactaceae, in aridity exceeding any other part of Colombia. The extensive prairies are said to be covered chiefly with the thin grass, Aristida, and the occasional marshy areas with the sensitive plant, Mimosa, while conspicuous along watercourses is the Anacardium (caracoli).

"The mammals are similar to those of the Caribbean llanos. A small black-naped rabbit (Sylvilagus nigronuchalis) is peculiar to this and the adjoining region in Venezuela."

The rainfall of the Goajira Peninsula is seasonal as on the Llanos of Bolivar and Upar but is much less in quantity, the rains occurring only from May to October.

Some guinea grass has become naturalized in a few areas, but otherwise this land, occupied only by the Goajiro Indians, has scarcely been altered by man.
The Goajira Peninsula may be reached by Indian trails from Río Hacha, a port along the Caribbean coast east of Santa Marta.

3. Llanos of Casanare and San Martin. This region includes the northern portion of the great eastern lowland of Colombia, from the Río Guaviare northward and therefore including nearly all the Orinoco drainage-area. This area may be again divided into a portion north of the Rio Meta forming the true Llanos of Casanare, flat and grasscovered everywhere excepting along some streams, and a portion between the Meta and the Guaviare forming the Llanos of San Martín, slightly rolling and hilly and bearing grassland interspersed with palm-groves and forest. The latter llanos are transitional to the forests of Caquetá, and, inasmuch as they have few distinctive features, will not be further described.

The Llanos of Casanare are the great "Llanos" or prairies of Colombia. They are clothed with a variety of grasses, the leading place being generally held by species of Andropogon, or in moister spots by Paspalum, Panicum and other genera. Among the grasses is found a rich flora of herbs of many families. Some of these belong to genera which in comparable environments have penetrated into the Temperate Zone and are familiar in the Coastal Plain of the southeastern United States. Of such may be mentioned pink-flowered species of Polygala and Meibomia, violet Bradburya, yellow and pink Utricularia, and sedges of the familiar genera Rynchospora and Scleria. Wholly tropical genera of plants are represented by yellow-flowered and pink-flowered Malvaceae and Melastomaceae, various small-flowered bluish or white Menthaceae and Scrophulariaceae, yellow Turneraceae, etc. This little-known prairie flora becomes parched and largely disappears soon after the conclusion of the rainy season.

Along river-courses grow characteristic palms and occur clumps of shrubs and trees. Along the larger rivers are 
considerable narrow forests, which have been best described for the lower course of the Río Meta. Such river-forest includes large trees of Bombax and Ficus, and contrasts with other lowland forests in its considerable number of epiphytes, bromeliads, 'orchids, etc.

"The mammals are not well known, but include the savanna white-tailed deer (Odocoileus), brocket deer ( $M a-$ zama), puma, jaguar, ocelot, tayra, armadillos, and anteaters. The large deer (Odocoileus) is of northern affinities and does not extend to the central Amazonian region as do most of the other mammals."

On the Llanos of Casanare rainfall is seasonal, a wet season lasting from April to October, and a strongly marked dry season from December to March.

The "Llanos" are being increasingly grazed, and it may not be many years before this magnificient pasture-land follows the history of the prairies of the Mississippi Valley and the Pampas of Argentina. It is practically untouched by the plow.

The Llanos may be studied on the plains of the Meta east of Villavicencio, reached by trail ( 5 days) over the Eastern Cordillera from Bogotá. Villavicencio, just at the foot of the cordillera, is in the San Martin type of mixed country, with interspersed belts of forest and prairie. A trail runs southward to the town of San Martín. In order to see the true Llanos of Casanare one should visit some of the plains settlements to be reached by trail over the cordillera from Tunja in Boyacá, a town now accessible by automobile from Bogotá. The country near the lower Río Meta, both river-forest and prairie, may be reached by boat from Ciudad Bolivar on the Orinoco in Venezuela to Orocué, Colombia.

4. Llanos of the upper Magdalena Valley. South from Honda and Mariquita in Tolima the floor of the Magdalena Valley and the lower mountain-slopes to the sides are devoid of evergreen forest, being covered either where flat or rolling or on the exposed foothills with grasses and herbs, or on gorge and canyon sides or in the foothill valleys with brushy thickets and xerophytic forest. The chief open grasslands are in the three small plains, the "Llanuras" of Mariquita and of Purificación in Tolima and the "Llanura" of Neiva in Huila. These prairies are essentially similar to the other lowland llanos of Colombia, but compared with the Llanos of Casanare have a restricted variety of component plants. Andropogon and Bouteloua are characteristic grasses, while Bradburya, Meibomia, Polygala, Sida, Eriosema and Buchnera are familiar herbs. The thickets and low forest become more xerophytic southward, the large species of Cactaceae being increasingly conspicuous. River-banks are lined by groves of palms and growths of bamboos.

"The mammals are generally similar to those of the Caribbean Llanos, those of some groups being differentiated into peculiar subspecies or geographic representatives."

The upper Magdalena Valley has two wet and two dry seasons, the wet seasons being from April to June and from October to December.

The "Llanuras" or prairie portions of the Llanos of the upper Magdalena Valley are extensively grazed, but they have been only locally altered in character by the introduction of foreign grasses or by being broken for agricultural purposes.

The prairie portions may be readily visited at Mariquita and San Lorenzo in Tolima along the railroad from La Dorada to Ambalema, and with more effort at Natagaima in Tolima and Neiva in Huila, towns reached by trail south from Girardot. The hilly portion of the upper Magdalena Valley may be observed at Honda in Tolima, Girardot in Cundinamarca, and shortly above Natagaima.

5. Llanos of the Cauca Valley. The Cauca Valley from western Antioquia southward, and continuous therewith the Patía Valley, constitutes an unforested open or brush-covered lowland 
quite homologous with the similar upper Magdalena Valley. The distribution of grassland or xerophytic scrub follows the same outline. The prairie is most extensively developed in El Valle over the plain stretching from Tulua on the north to Aganche on the south. Smaller areas of level prairie occur near Popayán in El Cauca, and in the Patía Valley in Nariño. Along the streams palms and bamboos occur. A notable feature of the Cauca Valley are the great marshes, occurring east of the river, a section of which is crossed by the railroad between Cali and Palmira. Toward the base of the Central Cordillera, in the subsidiary valley of the Rio La Vieja, is a belt of country apparently originally covered for miles with a solid stand of bamboo.

Through Antioquia and Caldas, in El Cauca from Aganche to near Popayán, and in portions of the Patía Valley, the inter-Andean Cauca-Patía depression is deeply furrowed by canyons or formed into hills. The slopes and canyonsides may be open or covered with low brush or with a low xerophytic forest. Epiphytes, while usually rare in such scrub, may occasionally occur in some abundance, with a fair variety of Orchidaceae and Bromeliaceae.

Thirteen kinds of birds are known only from the Cauca Valley. The mammal life is that of the upper Magdalena.

The Cauca Valley has two wet and two dry seasons, the wet seasons being from March to May and from September to November.

The prairies of the Cauca Valley are intensively grazed and changed by the introduction of drought-resistant grasses, but the rougher surrounding portions have clearly preserved the original flora. The brush-land and low xerophytic forest, except near the chief towns, remain in primitive condition.

The Llano itself,-the true "Valley of the Cauca"-may be visited at Cali, Palmira or Buga, all reached by train from Buenaventura. Just east from Zarzál, reached by river steamer from
Cali, exist xerophytic groves remarkable for epiphytes, and two days by trail eastward, just west of Armenía, one reaches the belt of bamboo. Popayán, accessible by train from Cali to Aganche and thence two days by trail, is in a slightly higher part of the inter-Andean valley.

6. Pocket-like valleys of grassland and scrub. While pocket-like xerophytic areas are doubtless wide-spread through the Colombian mountains and occur at all elevations, it may be worth while to call attention to two that are most readily accessible. On the railroad from Buenaventura to Cali, above the narrow Dagua gorge and within a surprisingly few miles of the wet Choc 6 forest. one passes into an arid grass and brush-covered valley, its slopes sparsely grassy and its floor with a variety of large Cactaceae. Dagua, the only town between Buenaventura and Cali, is in this arid pocket-valley. On the trail over the Eastern Cordillera from Bogotá to Villavicencio one traverses a canyonlike valley with grass-covered slopes and through the midst of its depth roars the Río Negro, a tributary of the Río Meta.

\section{Montane forest}

The middle slopes of all mountainchains in Colombia, whether on the Andean Cordilleras or on the Sierra Nevada de Santa Marta, are clothed in forest. Where the adjacent lowland is forested, as on the western slope of the Western Cordillera and the southern eastern slope of the Eastern Cordillera, the forest is continuous over the mountain-bases. From the Santa Marta mountains the forest also descends to some distance upon the plain. On the slopes toward the inter-cordillera valleys of the Cauca and the Magdalena, forest is only reached at a considerable elevation above the plain.

The Andean mountain-forests are continuous around the sides, and, when not too lofty, over the summits, of the three cordilleras. This continuity and the degree of geographic 
uniformity of the forest makes inadvisable its separate consideration upon each cordillera. However, the wetter conditions prevalent on the western slope of the Western Cordillera and upon the eastern slope of the Eastern Cordillera have produced biotas different from that of the sheltered interAndean slopes. Everywhere, also, have geographic remoteness and especially isolation of upland areas resulted in diversity of the composition of the fauna and flora. The supreme illustration of isolation is the life on the Santa Marta mountains.

Much more important for consideration is the modification of life caused uniformly on all mountain-systems by increasing elevation and resultant cooler temperatures. Thus we may distinguish a forest of the lower and warmer, and a forest of the upper and cooler, mountainslopes-two types of forest that show very important differences in composition.

Subtropical Evergreen Forest. The lower mountain-forest is essentially similar to the evergreen lowland forests already discussed. The hardwood trees belong to the same families, and palms and conspicuous lianas also occur. Even more prominent than in the lowlands is the occurrence of ferns of many types, and tree-ferns here become frequent and characteristic. The trees average lower than in the lowland forest, and their branches spread from shorter trunks. The chief distinguishing feature of the lower mountain-forest is the great abundance and wide variety of epiphytes, constituting a remarkable aerial world of life. Epiphytic ferns and mosses abound, and of the various groups of flowering plants with epiphytic representatives the chief place is held by the two families most highly specialized for this mode of existence, the Bromeliaceae and the Orchidaceae. There is considerable bloom in this forest and consequently, as compared with the lowland, a greater number of pollinating insects and birds. Among the conspicuous flowers are, beside the two families of epiphytes named, terrestrial species of Gesneriaceae (red, yellow, white or violet), Lobeliaceae (red, pink or green) and the Ericaceae (red, white or orange). Significant through both lower and upper mountainforests are the number of tubular red flowers, usually yellow within, doubtless adapted for pollination by hummingbirds, a form of flower shown in many families, e.g., Lobeliaceae, Rubiaceae, Gesneriaceae, Bignoniaceae, Loganiaceae, Ericaceae, Onagraceae, Loranthaceae, and even Orchidaceae.

A wetter phase of the lower mountain-forest, which is developed on slopes especially exposed to moistureladen winds, is remarkable for the extensive and deep growth of mosses, both terrestrial and epiphytic, for the predominance of ferns, Carludovicas and like foliage plants, and for the scarcity of bloom.

A drier phase of the lower mountainforest, which is encountered chiefly where the ascent to forest is made from open arid slopes, contains slight diversity in trees and few if any epiphytes. The growth of trees is open, and the forest will frequently consist of nearly pure groves of the evergreen Humboldt Oak. Between the lowland prairie and such groves is usually a belt of xerophytic bushes.

This lower mountain-forest and the occasional open areas occurring at the same altitude have been denominated the "Subtropical Zone" in Dr. Chapman's study of Colombian birdlife. The chief families of birds are (1) Tanagridae, (2) Tyrannidae, Trochilidae, (4) Dendrocalaptidae, Fringillidae.

This zone "includes most of the larger mammals of the lowland forest and some of the smaller ones or, in many cases, representative subspecies."

Subalpine Evergreen Forest. The upper mountain-forest is yet lower in height than the forest just considered and shows a decidedly greater adaptation to a cool environment. It is less 
luxuriant in aspect. The trees are more uniformly and compactly branched. In its upper stages the trees become strikingly rounded and densely bushy, and frequently occur in park-like formation. More often however the densely massed low trees pass imperceptibly into a zone of shrubs equally dense. The upper mountain-forest, and the plateau savannas and paramo as well, are of peculiar interest because of the double origin of the forms of life that characterize them. There may be here the same types of life seen in the lowland and lower mountain-forests, the same families of trees, of herbs and of epiphytes, but usually or always in special upper-mountain species. With these there are many other types of life not found at all in the lowland and lower forests but which are genera and families which belong characteristically to the cooler parts of the earth, the Temperate zones of the Northern and Southern Hemispheres. Such temperate influence is less marked among trees than among shrubs and herbs, although Colombia has its native species of alder and walnut as well as its various shrubby Hypericums, Gaultherias and Vacciniums, and its many herbaceous buttercups, chickweeds, geraniums and violets. A third series of upper Andean plant and animal types, certainly in its origin assignable to one or the other of these groups but now especially pronounced and interesting, contains the types of life now restricted to or mainly developed upon the Andes, genera often divisible into species pertaining to various elevations and to various isolated portions of the mountain-system. Among flowering plants this series includes Bomarea, Tropaeolum, Monnina, Fuchsia, Calceolaria, Centropogon, Mutisia, and very many others.

The upper mountain-forest is much more broken into isolated portions, due to breaks in the continuity of the Andean mountain-system, than is the forest of the lower slopes. It is continuous throughout the Central Cordil- lera, but in the Western Cordillera becomes isolated upon each of the highlands already mentioned, while in the Eastern Cordillera it covers a large area from Sumapaz to Ocaña, with small areas northeast and southeast of Neiva and again far to the northward in the Motillones and the Sierra de Perijá.

This upper mountain-forest and the open areas occurring at the same altitude have been termed the "Temperate Zone" by Dr. Chapman. 'The chief families of birds are (1) Trochilidae, (2) Tanagridae, (3) Fringillidae, (4) Tyrannidae, (5) Coerebidae.

This cool forest "includes a few mountain forms of mammals derived from tropical relatives, as the mountain paca, the mountain opossum and the mountain brocket deer, also by forms derived from the southern Andes, as the spectacled bear (Tremarctos) and the peculiar marsupial Caenolestes; also by forms of North American affinity as weasels (Mustela), rabbits (Sylvilagus) and shrews (Blarina). It has various peculiar genera of rodents as Thomasomys, Microxus, Chilomys, and Aepeomys."

While on the mountain-slopes seasons are less distinctly marked than on the lowland and because of topography are subject to much modification, the rains tend to occur mostly in two rainy seasons lasting each from an equinox to a solstice. Mid-March to mid-June and mid-September to mid-December are likely to be wet, and mid-June to mid-September and mid-December to mid-March dry or rather dry, at middle elevations of the Andes.

In many parts of Colombia, especially on the western slope of the Eastern Cordillera in Santander and Cundinamarca, on the eastern slope of the Central Cordillera in Antioquia and Tolima and on its western slope in Antioquia, Caldas, EI Valle and El Cauca, the lower mountain-forest has been extensively cleared to make room for plantations of coffee. The upper mountainforest has been considerably cleared for 
agricultural crops on the more densely settled Eastern Cordillera in Boyacá and Cundinamarca, while a boom in cattle is at present causing great and wasteful destruction of this forest in the Quindio and elsewhere in order to create upland pasturage. Still, the mountains of Colombia are today mostly covered with virgin forest, although the traveller along the chief highways may see little of it.

\section{Plateau grassland or savanna}

At several places on the Bogotá Tableland of the Eastern Cordillera, and perhaps occasionally elsewhere on the other cordilleras in the same cool upper mountain-zone of life, occur flat open areas of natural prairies called sabanas. These may contain marshland and enclose small lakes. The two most important of these areas are the Sabana of Bogotá in Cundinamarca and the Sabana of Fuquene near Chiquinquirá in Boyacá. Developed apparently on the flat bottoms of former lakes, both these sabanas are famed for their rich soils and have been intensively cultivated since the days of the Chibcha empire. In the meadows and along the streams of the Bogotá savanna may be seen species of Marsilea, Carex, Juncus, Sisyrinchium, Salix, Alnus, Dichondra, Nierembergia, and Gratiola, genera of plants which mostly pertain to the Temperate zones of the earth. Through much of the Bogotá tableland, and well seen near Bogotá itself, are found slopes partly grassy but usually chiefly covered by growths of bushes or in cañadas of low trees. A varied and rather rich flora is peculiar here, including species of Cerastium, Hypericum, Lupinus, Cestrum, Castilleja, Lamourouxia, Centropogon, and certain Iridaceae, Melastomaceae and Vacciniaceae.

Here the single plant-tuft may be three or four meters in diameter, dark-green and of coralline hardness, showing no impress where one's foot has stepped upon it. Yet inspection shows that the compactly crowded individual stems of Distichia grow upright with the leaves projecting upward so that the human weight has been supported actually upon the tips of the leaves! An interesting array of tiny plants of various families, Ericaceae, Gentianaceae, Scrophulariaceae, Lobeliaceae, etc., grow, dwarfed and protected, within these mats and cushions.

There are yet other plants of the paramo which seem to depend wholly upon some physiologic protection, and the nearly or quite hairless species of Pedicularis, Bartsia, Halenia and like genera grow in the valleys not far below snow. Indeed, the flowering plants that grow closest of all to snow are species of Arabis and Draba, genera of Brassicaceae with but slight or moderate hairy covering but which yet are able to inhabit the bleakest alpine environments throughout the world.

The paramo is the most broken into local isolated areas of the mountain zones of life in Colombia. Its flora varies in composition upon each of the Andean cordilleras and upon isolated tracts of each cordillera. On many of these areas it is still wholly unknown.

There are only 19 kinds of birds characterizing the paramo; of these the largest number (4) belong to the Trochilidae.

The paramo "has no mammal fauna of its own as it is too scattered and too limited in extent. Certain forms from the temperate forest extend into it."

The seasons upon the paramos may occur either at the same time as in the mountain-forest, or else they may more or less reverse the program of lower altitudes. Rains are not heavy on the paramo, but driving misting cold penetrating rain may occur for many days consecutively.

In the Quindio and on the Eastern Cordillera in Cundinamarca and Boyacá the paramos are occasionally pastured. To make better growth of grass they are sometimes burned over. Generally over Colombia, however, no effort has been made to use these remote and bleak highlands. 
(CDE.) Points from which mountain forests, mountain sabanas, and paramos may be advantageously studied. Unless the purpose of an expedition requires otherwise, the ascent of mountain trails should be undertaken during the months of least rain, January and February, July and August.

a. For the Western Cordillera: Frontino in western Antioquia to be reached by trail from Medellin, or via boat from Cartagena up the Río Atrato and Río Sucio to Pabarandocito in the Chocó, thence by trail; Santuario in western Caldas, to be reached by trail from Medellin (5 days), Manizales (two days), or La Virginia (one day), the last accessible by steamboat down the Rio Cauca from Cali; La Cumbre in El Valle, on the railroad from Buenaventura to Cali.

$b$. For the western slope of the Central Cordillera: Pereira and Manizales in Caldas, Pereira to be reached by railroad from Cali and Buenaventura, Manizales to be reached by trails from Medellin (5 days), San Francisco (1 day) and Mariquita (3 days)-from either are trails and paths up into the Quindio; Salento in Caldas on the Old Quindio Trail two days from Cartago on the Rio Cauca and two days from Ibagué in Tolima (probably now best reached from Ibagué by crosstrail from Armenia on the New Quindio Trail)-an excellent point for working in the Quindio; Palmira and Buga in El Valle, reached by railroad from Cali-from whence trails go up into the Cordillera; Popayán in El Cauca, to be reached from Cali by the recently constructed railway ${ }^{\perp}$ from Popayán are trails into and over the Coconucos; Pasto in Nariño, to be reached by trail from Popayán (7 days) or from Quito in Ecuador (7 days)-eastward and southward are trails into and across the Cordillera.

c. For the eastern slope of the Central Cordillera: Mariquita, San Lorenzo, and Ibagué in Tolima, all to be reached by railroad from the Rio Magdalena-

\footnotetext{
${ }_{1}^{1}$ Present activity in construction will soun make many remote places accessible by rail.
}

from these towns are many trails into the Cordillera; from Popayán in El Cauca over the Central Cordillera to its eastern slopes in Huila and Caquetá.

d. For the Eastern Cordillera: Ocaña in Norte de Santander, to be reached by trail from Gamarra on the Rio Magdalena-from Ocaña, just over the divide toward the valley of the Catatumbo, a trail continues to Cúcuta; Bucaramanga in Santander, to be reached by trail from Puerto Wilches on the Rio Magdalena or by boat up the Río Lebrija and thence by trail-the best point for reaching the Pamplona highlands; Bogotá in Cundinamarca! to be reached by railroad from Girardot on the Rio Magdalena-from the capital are railroads across the Sabana de Bogotá north to Zipaquirá and Nemocón, connecting with auto-bus for Tunja in Boyacá, and south to Sibaté, while trails radiate through the highlands of Cundinamarca and Boyacá and cross the eastern Cordillera to Cáqueza on its eastern slope and Villavicencio at its eastern base; Neiva in Huila, to be reached by trail (5 days) from Girardot on the Río Magdalena-from whence are trails into the Cordillera and from slightly to the south across to Florencia in Caquetá.

e. For the Sierra Nevada de Santa Marta: Santa Marta in Magdalenagiving ready access by trails to the lower slopes but only with much difficulty to the upper highlands; Valle de Upar, to be reached by trail from the Caribbean port of Río Hacha, or from $\mathrm{El}$ Banco on the Río Magdalena by steamer (except in dry season) up the Río Cesar to El Paso, thence by trail-giving access by trails up the gentler southeastern slopes of the Sierra to its upper levels and to snow. Also from Valle de Upar the ascent of the Sierra de Perijá (properly a part of the Eastern Cordillera), lying to the southeast, may be made. $-F$. W. $P$.

Santa Marta. An area 60 by $250 \mathrm{mi}$., the altitude ranging from sea level to $19,000 \mathrm{ft}$. Dry savannahs exist on the west, east, and south sides, and rain. 
forest on the north and west slopes. Heath is first encountered at about $10,000 \mathrm{ft}$. and the summits are snow-covered. The mountain range is surrounded by semi-desert. This desert is found around Santa-Marta, the east end of the range, and on the south side, at least between the mountains and Rio Cesar. The forest on the north and west slopes are between 25 and 10,000 ft., except that it comes down to sea level on the north. Tropical rain forest animals include the tapir, armadillo, guano, and bushmaster. In the savannahs are numerous lizards and in the semi-deserts lizards and tortoises. Fine mangrove swamps and bays near the sea shore. The nearest important city is Santa Marta, Colombia, which is reached by the United Fruit Company steamer from New York, and part of the distance from Santa Marta into the region proper may be covered on the United Fruit Company's railroad. It is necessary to outfit in United States. The only item which may well be omitted from the outfit is tents, as travelers can live in the native huts.-A. $G$. Ruthven and A. S. Pearse.

\section{VENEZUELA ${ }^{1}$}

By H. Pittier and H. B. Baker

\section{GENERAL CONDITIONS}

\section{Topography}

Venezuela extends in one direction between the Caribbean Sea to the north and Brazil to the south; in the other direction it is bounded by British Guiana on the east and Colombia on the west. It has an area of $1,043,900 \mathrm{~km}$. (403,067 sq. mi.).

The easternmost ramifications of the Andean orographic system enter Venezuelan territory on the western side, running to the northeast. This is generally known as the Andes of Venezuela (Sierra de Mérida), and reaches an elevation of 5002 meters at Columna

1 Where there was no cooperation between the authors, authorship of the various sections is indicated in the text. The materials were arranged by the committee.
Peak in the state of Mérida; it sends spurs and branches to the north, on both sides of Lake Maracaibo. The Coast Range or Caribbean System, which runs along the seacoast from the Aroa Mountains to the peninsula of Paria, consists of several detached groups, mainly formed by parallel ridges running east and west, and culminating at the Pico de Naiguatá, which is 2765 meters in height.

To the east, the almost unexplored Guiana Mountains divide their intricate system between Venezuela and British Guiana. In like manner, they seem to consist of several parallel chains, running also in an east and west direction, and sending offshoots to the north and south. Their maximum height has not been determined, but seems to be reached in the Maravaca Mountains, between the Caura and Ventuari Rivers. Dr. Jahn supposes it to be of more than 3100 meters. The Sierra Pacaraima, the southernmost member of the system, forms the boundary with Brazil, while the celebrated Roraima (2640 meters) rises on the ridge which separates Venezuela from British Guiana. The western section, bordering on Brazil and Colombia, seems to be covered by rather low hills and mountains, in the middle of which lie valleys drained by the Orinoco and Amazon.

Between the mountains of Guiana and their western extensions on one side, and the Andean and Caribbean systems on the other side, lies the vast Orinoco basin, occupied largely by the so-called llanos. The rivers of this basin drain nearly four-fifths of the whole territory of Venezuela. Comparatively, the plains around Lake Maracaibo, the valleys hidden between the several chains of the Coast Range, and those of the upper reaches of the Rio Negro, occupy but a small area.

\section{Climate}

a. Temperature. Owing to its varied topography, Venezuela, in its several regions, enjoys the whole scale of temperature between the averages of $26^{\circ}$ 
to $28^{\circ} \mathrm{C}$. on the coast and in certain places of the interior, and $0^{\circ} \mathrm{C}$. or less on the summit of the Andes. While there is little variation during the course of the year, the daily range increases with the altitude. As is generally the case all over tropical America, three main belts of temperature are recognized by the Venezuelans: the tierra caliente, the tierra templada and the tierra fría. They correspond more or less to the Basal ( 0 to 1000 meters; mean temperature $28^{\circ}$ to $21^{\circ} \mathrm{C}$.), the Intermediate (1000 to 2800 meters; mean temperature $20^{\circ}$ to $12^{\circ}$ ) and the Upper Belts (2800 to 5000 meters; $12^{\circ}$ to $0^{\circ}$ or less), so designated for biological purposes (the limits and mean temperatures given here being those adapted to Venezuela).

b. Rainfall and humidity. Most of Venezuela is under the influence of the monsoon, which governs the regime of the rainfall. The parts most directly exposed to this wind are either very dry, with less than $800 \mathrm{~mm}$. of annual rain, or moderately humid, with 800 to $1500 \mathrm{~mm}$. They include the coast from Paria to Maracaibo, the Llanos with the lower slopes of the surrounding mountains, and the intermediary ranges of the Caribbean system. In the territory thus defined, the seasonal rhythm is strongly marked, there being as a rule a dry season ("verano") extending from November to April, and a wet season ("invierno") extending from May to October. My experience is that both the annual rhythm and the daily rain offer no comparison as to regularity with that personally observed during fifteen years as Director of the Meteorological Observatory in San José of Costa Rica.

Certain parts of the lowlands present topographic conditions which favor a heavier forest. These are principally the Orinoco Delta, the upper Rio Negro and a limited area south of Lake Maracaibo. In these districts, the mean annual rainfall is probably higher than in most parts of the lowlands. Besides, up to an altitude, that varies with the importance of the mountain masses, the precipitation steadily increases, and culminates in a belt in which rainforests appear, though with characteristics distinct from the lowland forests. Above this, the precipitation decreases anew with the altitude, so that the upper parts of the high mountains constitute another dry belt.

\section{NATURAL BIOTA \\ a. Evergreen forest}

1. Mangrove swamp. The mangrove forests are dependent, not on the precipitation, but upon the ground water. They are found at several points of the littoral regions, especially, though not always, at the estuaries of the large rivers. The five species of trees (Rhizophora Mangle, Laguncularia racemosa, Avicennia tomentosa, A. officinalis and Conocarpus erectus) which form such forests, practically to the exclusion of all others, thrive only in soils permeated with salt or brackish water. Rhizophora grows exclusively on soil permanently covered with sea water; its peculiar adaptations are well known. The other species are found in places alternately dry and inundated, and sometimes in brackish swamps where they are mixed with Acrostichum aureum, Annona glacra and divers Cyperaceae. The principal mangrove forests of Venezuela are situated at the mouth of the Orinoco and the adjacent parts of Golfo Triste, in the Gulf of Cumaná, around Piritú, Unare and Tacarigua Lagoons, at El Carenero near Cape Codera, along the coast of Estados Carabobo and Falcón as far as Chichiriviche and at the entrance to Lake Maracaibo. At the southern end of this body of water, they are replaced by permanently inundated forests, with Inga, Ficus and Cecropia species. This last type of forest forms a striking feature of our flora and is worth more thorough investigation.

2. Luxuriant tropical rain-forest. This represents the optimum of vegetative development in the tropics, but occupies in Venezuela only restricted 
areas, correponding to those of greater atmospheric precipitation. In the lowlands, they attain imposing proportions. The pillar-like trunks of the trees rise to 30 or 40 meters before spreading in a dome of dense foliage, which is in itself a real plant kingdom, such is the wealth of epiphytes, parasites and vines established upon it. Only a very attenuated light passes through the thick foliage but nevertheless, a wonderful storied vegetation fills the space under the larger trees, the lowest tier of which completely hides the rich soil. This is formed by layer upon layer of the decay of past plant generations, and is so soft that the giant trees can maintain their equilibrium only by special adaptations. These are, for instance, plank-buttresses, as in the case of Ceiba pentandra, or adventitious roots such as those of Cecropia and Iriartea.

Great is the variety of vines which form a distinguishing trait of these rain forests. Some originate high up on the branches of the trees and their aerial roots, stretched down into the soil, look taut cordage. Others creep along the tree-trunks, which they partially conceal under their beautiful foliage, while still others climb independently, as they may, helping themselves with aculei, tendrils, twists or other peculiar modifications, until they reach the brilliant sunlight above. We have already mentioned the epiphytes, Aroids, Bromeliads, Orchids and others. Palms, belonging to the genera Jessenia, Euterpe, Martinezia, Manicaria, Astrocaryum and others, found also in the monsoon forests, either fill part of the space under the larger trees, or pierce through the leafy dome.

Among the numerous species of trees which form the tropical forests, the following are either more conspicuous, or better known on account of their economical uses: In the Orinoco Delta and surrounding region, we have forest giants like Dimorphandra excelsa, Nectandra Rodiei, Virola venezuelensis, along with the ever-recurring Ceiba pentandra, several Ficus species, and others of lesser proportions, among which Symphonia globulifera and Carapa guianensis are also worthy of mention. The Upper Orinoco and Rio Negro district, relatively well known, thanks to the explorations of Spruce, are especially rich in species of Licania, Swartzia, Hirtella, Ouratea, Macrolobium and Virola, and certain genera of palms, such as Bactris, Mauritia, Astrocaryum and Lepidocaryum, seem to reach their fullest development in this region. The flora of the rain forest of the Maracaibo basin is no less diversified; besides Copaifera Langsdorffi, found throughout the region, we may cite $C$. fissicuspis, Cariniana pyriformis, Goupia glabra, Dialium divaricatum, Gustavia fustismortui, Labatia parviflora, as well as at least two cow-trees, Couma sapida and $Z$ schokkea edulis. Here, the palms seem to belong principally to the genera Jessenia, Bactris and Attalea.

Floodplain Forest $(H . B . B$.). In the preceding description, Dr. Pittier has mainly described the lowland type of forest in Venezuela, which has been mapped by W. Sievers (1896; Petermanns Mitteilungen, vol. XIII, pl. XV). My own observations lead me to believe that this is not entirely a rain-forest, dependent on the precipitation, but largely an edaphic one, more closely related to the amount of soil water.

Throughout Venezuela, one is impressed by the abundant evidence that the volume of water in the streams must vary greatly with the seasons. Many of the larger rivers, like the Rio Catatumbo throughout its lower course, have, by repeated floods, built up their banks higher than the surrounding country, so that the surface drainage, during the dry season, is away from, or parallel to, the main stream. On these flood plains, the smaller streams, during the dry season, either meander through gravel bars, between high, vertical banks, or disappear in the sand of numerous, anastamosing channels, which may retain long, stagnant pools (caños, or sewers) or lead into large, shallow lakes (cienagas). As a result, 
in those parts of Venezuela where the mountains are some distance back from the coast, the streams flow through wide, almost level flood-plains of alluvial deposit, which, during the wet season, must be largely under water or dissected by innumerable streams. The edaphic influence of this rich soil, containing ground water near the surface, permits the development of large and rich forests, even in the lowlands where the rainfall is not great enough to account for their presence.

Although in some localities, large plantations have been cleared of the smaller trees and brush, the unhealthiness of these lowlands has resulted in a very sparse population. Where large clearings have been made, irrigation is often necessary; when abandoned, such places commonly assume the appearance of rich prairie, and the woodland appears to invade the sun-baked surface with some difficulty. Small clearings become overgrown with remarkably dense growths of Heliconiae and Convolvuli and revert to forest in a few years.

In these lowland forests, tapir (Tapirus americanus), peccaries (Tayassu tajacu), howler-monkeys (Alouata seniculus, etc.), and the chigüire (Hydrochoerus capybara) are especially abundant. The larger parrots (Ara, Conurus, etc.), troupials (Cassicus), and toucans (Ramphastus, etc.) are more conspicuous members of the avifauna, although, as a rule, this appears more monotonous than in the mountains. Where a leaf-humus is developed, the molluscan fauna is very rich; amongst the larger ground forms, Pleurodonte is conspicuous in central Venezuela, but is replaced by Plekocheilus in Estado Táchira. Near streams, the forest mainly consists of palms, which develop very little true humus; in swampy places, almost pure stands of Bactrideae often form dense, impenetrable thickets. In such places, only the arboreal species (Drymaeus, Auris) are represented.

Along the high banks of the larger streams, the soil is often sandy and covered by a dense cane-brush or more rarely by bamboo-thickets; ground lizards (Ameiva) are especially abundant in these places. Although Ampullarius is abundant and freshwater pulmonates occur in the pools and canos (Neoneura is characteristic among the Odonata), the larger streams are remarkably barren, perhaps on account of their frequent scourings; the extreme paucity of Naiades is especially noticeable.

Luxuriant tropical rain-forest $(H . B$. $B$.). In undisturbed portions of the Caribbean System, the arid coastal region passes quite rapidly into the rain-forest, which, in places, reaches down to an altitude of less than a hundred meters. Like most tropical forests, the most noticeable feature is the variety in size of the trees and in the floristic composition; large stands of a single or a few dominant species are conspicuous by their absence. In general, the trees do not attain a very great height, and even the ceibas are less gigantic than in western Venezuela. Epiphytes are quite abundant throughout this type of forest; the bromeliads are especially conspicuous, but the lianas and climbing arums and figs are less conspicuous than in the far more luxuriant Mexican rain-forest or in even that of the eastern foot-hills of the Andes.

Although coffee and cacao plantations encroach considerably on the native forests, in most places on the northfacing slopes these are so rich and evergreen as to discourage any efforts to burn them away. The land is usually cleared by chopping out the brush and leaving the larger trees. Such places return to heavy forest in a few years, and the leaf-humus is often richer and the ground fauna more abundant in "montado" coffee plantations than in the original forest.

Among the larger animals, agouti (Agouti para, Dasyprocta rubratra and prymnolopha), jaguars (Felis onça) and spider monkeys (Ateles) are especially abundant. The bird fauna is one of 
the richest and most variegated that I have ever seen; the smaller birds, such as the flycatchers, parrakeets and hummingbirds, are especially prevalent. The mollusc fauna has more Antillean and Central American elements (such as the Urocoptidae and Pomatiasidae) than does that of the Andes. Arboreal snails (Drymaeus, Auris) are common, while the ground fauna may be exemplified by Poteria and the smaller species of Pleurodonte. From the standpoint of the terrestrial animals, two quite noticeably different types of forest can be distinguished: that with a rich leafhumus, and that with a leached-out root-humus. This difference affects even the arboreal snails, as many of these aestivate on the ground.

The eastern prolongation of the Cordillera Oriental of the Andes is quite markedly different, both geologically and faunisticly, from the Caribbean System, from which it is separated by the semidesert region around Barquisimeto (Cf. Sievers, 1. c.). The appearance of the tropical rain-forest is very similar although larger trees are more prevalent and larger areas are almost completely dominated by tree ferns or palms (root-humus). The scarcity of fan-palm and the rich growth of the similarly leaved Carludovicae among the Heliconiae of the stream borders, are conspicuous differences from the flora of the north-central mountains. In the molluscan fauna the Urocoptidae and Pomatiasidae are absent, in the region studied, and the prevalence of Streptaxidae is notable. The species are closely related to those of central Colombia. The smallest, rocky brooks are often overgrown with Cyclanthaceae and, although poor in specific diversity, contain numerous individuals of Heteragrion and Philogenia (Odonata); Pachychilus (Mollusca) is abundant in the western mountains but absent in the Andes. The creeks of the larger valleys are scoured by the torrential floods of the rainy season, and have a very barren fauna.

3. Montane forest. The temperate rain forests occupy the middle belt of the mountains, not at a fixed altitude, but where the condensation of the water contents of the ascending air masses takes place. During the day, this belt may be easily perceived by the distant observer owing to the broad strip of clouds, which stretch horizontally across it, their base, well defined, ascending or descending with the increase and decrease of temperature. Most of the species which form these forests are hygrophytes. The trees have a weakly developed root-system; their leaves are ample and often provided with dripping points and hydatodes. The epiphytic flora is unusually rich, but the lianes are not so abundant as in the tropical rain forest.

On account of the diversity in their altitude, the flora of these temperate rain forests changes considerably from one place to the other. It would take too much of our limited space to enumerate even the principal species in each case. Generally speaking, the Lauraceae seem to be the dominating family. Typical of their kind are the beautiful forest around Colonia 'Tovar in the Coast Range, the flora of which, though investigated again and again, still seems to be inexhaustible in new species. In this region we note, among many others, Cedrela montana, Guarea mollicoma, G. Ruagea, Eschweilera fendleriana, Weinmannia glabra and Escallonia floribunda, which attain here arboreal dimensions, Protium laxiflorum, $P$. icirariba, Sapium stylare, Styrax macrotrichus, Podocarpus coriaceus, $P$. Harmsianus, etc. Also quite a number of striking species of palms such as Oenocarpus altissimus, Oe.caracasanus, Oe. utilis, Ceroxylon Klopstockia, and at least three Iriarteas. Lesser trees or shrubs are Ilex myricoides, Allophylus excelsus, Guettarda tovarensis and Aegiphila verrucosa. Under these trees, perpetually dripping and shrouded in mist, there grows again a world of ferns and lower Cryptogams, excluded in places by large colonies of the giant grass Planotia nobilis. No less marvel- 
ous is the wealth of Orchids, either epiphytes or terrestrial.

Fauna (H. B. B.). A fairly constant characteristic of this type of forest is the poor development of leaf humus, which is correlated with the scarcity of ground forms. However, Happia guildingi and mediocris were found in the Cumbres, while Rectartemon jessei, Drepanostomella ammonoceras and $H$. mediocris were quite characteristic in Estado Tāchira. The tree snails are more prevalent; Auris euryomphalus and sinuatus appear quite characteristic. The comadreja and huron (Galera barbata and Galictis allamandi) were mainly seen here although they occur at lower levels. In the Sierra de Merida, a kinkajou (Potos flavus meridensis) and a squirrel (Sciurus griseogena meridensis) have been described from an altitude of 2500 meters.

\section{b. Arid deciduous forest}

This type of forest covers about twothirds of the area of Venezuela. It includes a large number of deciduous trees, which assume during the dry season a bare, arid appearance which would place them among the xerophilous formations but for the fact that during the rainy season they are green and luxuriant. These trophophilous forests, however, distinguish themselves from the thorn forest by the relative scarcity of armed trees and ground cacti, the increased frequency of vines and the larger proportions of the trees. From the rain forest, they differ in the great number of deciduous species, and, generally, in the lessened vigor of the vegetation. Also, the underbrush is thinner, so that, but for the districts where square miles of the ground are covered with spiny bromeliads, circulation is everywhere easy.

Specifically, the tree flora of the arid deciduous forest is exceedingly rich. There are no really pure stands and almost each individual tree is distinct from its neighbors. The composition of the forest also suffers marked changes passing from the eastern to the western part of the country, and, of course, in the ascent from the lower to upper levels. In the eastern part, it is characterized mainly by several species of Coumarouna (C. odorata, C. nudipes, etc.) which produce the tonka-beans known in commerce, by rubber-trees, belonging to Hevea and Micrandra (Hevea benthamiana, minor, rigidifolia, $M$. heterophylla), by several balata and chicle yielding Sapotaceae (Achras, Mimusops, Sideroxylon), the well-known Bertholletia excelsa (Brazil-nut tree), Cusparia trifoliata, from the bark of which the Angostura-Bitter is extracted, and many others. Further west, in the states of Carabobo and Yaracuy, the more conspicuous trees are Hura crepitans, found in places closely resembling pure stands, several species of Bombacopsis. Swietenia Candollei (Venezuelan Mahogany), Cedrela mexicana, Cordia alliiodora Toluifera Balsamum, etc. Last but not least, the region surrounding Lake Maracaibo is well known for its wealth in majestic timber-trees, among which it will suffice to name Bulnesia arborea (spurious Lignum Vitae), several species of Tabebuia (T. serratifolia, chrysea, etc.), a Centrolobium probably distinct from the $C$. paraense of the central part of the country, Helietta Pleeana, Copaifera Langsdorffi, several Vitex (V. cymosa, $V$. berteroana), the coffee-wood or brown ebony (Caesalpinia Granadillo), etc. In all these forests are numerous species of palms belonging to Attalea, Oreodoxa, Thrinax, Copernicia, Mauritia and Oenocarpus.

To the monsoon formation we may also join the strips of forest which accompany the rivers of the Llano (GallerieWald of Sievers, 1. c.). They are singled out by the presence of such trees as Copaifera officinalis, Protium heptaphyllum, Hymenaea Courbaril, Andira iner$m i s$ and a few others.

Fauna (H. B. B.). In main the terrestrial species of molluses increase in numbers at the transition between the rain forest and the monsoon forest, although they decrease greatly in the 
drier parts. Strophacheilus oblongus is especially characteristic, although it occurs in the heavier forest. Deer (Odocoileus gymnotis and Mazuma nemorivaga) are more common in the drier forest and "monte" than elsewhere. This type of forest has suffered most from burning and cultivation. In general, the fauna is quite similar to the rain forest although usually much poorer.

1. Deciduous thorn forest. The thorn forests, which extend along the coastal belt from the western boundary to the peninsula of Paria, are also represented inland in some parts where they merge little by little into the savannas. Cactaceae, such as Pereskia Guamacho, Lemaireocereus deficiens, $L$. griseus, Cephalocereus Moritzianus, Acanthocereus pentagonus, Opuntia caracasana, $O$. caribaea and others are typical of this formation, in which grow also several species of Pithecolobium, Bumelia and Jacquinia, Acacia macracantha, A. tortuosa, Caesalpinia Coriaria, Prosopsis juliflora, and other thorny trees and bushes. In the middle of these, larger trees, unarmed, and almost deciduous, appear here and there; they are principally Bursesa Simaruba, Esenbeckia Atata, Aspidosperma Vargasii, $A$. lucentivenium, Amyris balsamifera and A. simplicifolia. Mention should be made also of the several species of Capparis and Croton.

With some variations as to its composition, the same formation is spread throughout the interior of the country, where Mimosa Cabrera is one of prevalent species, along with Caesalpinia Coriaria, and extensive colonies of the palm, Copernicia tectorum, interrupt the low forest here and there.

The appearance of the thorn forest varies according to the degree of prominence of one or the other of the elements of its vegetable covering. In many parts along the coast, on steep hills, and in certain devastated districts, cacti occupy the space to the almost complete exclusion of other species; in other parts, this formation intergrades into the next. Between these arborescent species, the soil is almost bare or has a spare covering of grasses and other herbaceous or fruticose plants. The general impression is always one of excessive aridity.

Fauna (H. B. B.). This practically coincides with the thorn formation of 'Sievers' map. In some places, as indicated above, the prominence of the cacti causes it to assume almost the aspect of a succulent semi-desert. Bulimulus cacticolus is a characteristic snail of these places. A peculiar phase, little studied, occurs on the fossil coral-reefs of some parts of the coast; Sievers includes these, with the usually adjacent sand dunes (Coccoloba uvifera is characteristic) in his "Strand Vegetation." Most collectors, including myself, have neglected this type of country for the richer rain forest. It is very probable that the molluscan fauna will be found richer in Antillean elements, like that of the Dutch Leeward Islands, as there are a number of doubtful records of West Indian genera (Eutrochatella, Cerion, etc.) from northern South America. Brachypodella nidicostata has been described from limestone cliffs near Chichiriviche. The rabbit, Sylvilagus cumanicus, appears fairly characteristic of this type of brushland in eastern Venezuela.

2. Semi-desert. The semi-desert is simply a transition from the thorn forest to the savanna, and perhaps to the Arid Deciduous Forest. Here, the armed trees are in the minority, and among the unarmed ones, many assume considerable dimensions. On the outskirts of the savanna, the semi-desert is formed mainly by stunted trees such as Curatella americana, Bowditchia virgiliodes, Byrsonima crassifolia and $B$. coccolobaefolia. In other parts, the gregarious Bursera gummifera, with its reddish, constantly peeling trunks, is conspicuous, and Gyrocarpus americanus grows in places in almost pure stands. Bursera tomentosa, Ruprechtia sp., etc., also occur frequently in this formation, which may pass almost unnoticed by the layman. 


\section{c. Desert}

To the xerophilous formations belong also the half denuded rocks, met with at all altitudes, exposed to the burning sun and covered with a scant vegetation of shrubs, herbs, mosses and lichens. (The mesa tops, mentioned below, are also practically sandy deserts, with a sparse growth of Curatella americana; Sievers maps the most extensive ones in the northeastern portion of the Orinoco valley-H. B. B.)

\section{d. Grassland}

1. Savanna. Although the Venezuelan savannas attain their greatest development and diversity in the wellknown llanos, they exist on a limited scale almost all over the country, scattered through the forests and on the mountain slopes. A small part of them may have originated in the destruction of the forests by man, but with these exceptions, they are certainly the result of natural processes, and maintain or lose their balance with the wooded parts, either encroaching upon them or giving way to them. They are almost always bordered by a more or less broad belt of low bush, which in certain parts of the llanos is of the true thorn-forest type.

Contrary to the older descriptions, the savannas are anything but uniform, and the often pictured, boundless gi asslands are only approximated away in the south, in the states of Portuguesa and Zamora and beyond the Apure River. These latter are the sábanas de matas (grove savannas) of the natives, which name indicates that even there the continuity of the grass surface is often interrupted by masses of higher vegetation. Here the grass varies from a low sward to the height of a mounted rider. The rivers are barely outlined by a fringe of low bush. In other sections, an older level of the country, divided by the erosion of the rivers, forms the so-called mesas or table-lands, the arid, sandy soil of which is sparsely covered by a scanty, wind-barren vegetation.
Although they are scattered all over the llanos, these mesas belong to a single complex. The rainwater which they receive immediately filters through the sand, to reappear at the foot, giving origin to springs and streams, along which extend by morichales, morasslike areas with slow drainage. Upon this inconsistent soil, extensive groves of the palm (Mauritia flexuosa) rise from a luxuriant tapestry of perennially green vegetation, treacherous on account of the soft substratum.

2. Grassland. The sábanas de pajonales (straw or grass savannas) cover here and there the slopes of the mountains or hide in the middle of the forests. With reference to the specific composition of these distinct types of savannas, we have as yet only very scant information, with the exception, of these pajonales of the coastal system of mountains, which have been repeatedly explored. In their middle belt, around Caracas, the dominating families come in the following order: Graminae (with Paspalum and Andropogon (9 species each), Panicum (6 species), Eragrostis and Sporobolus (4 species each) as principal genera), Leguminosae (Meibomia 11 species, Cassia 9 species, Mimosa and Aeschynomene 4 species each, etc.), Compositae and Cyperaceae. The forestal element is represented by dwarfed specimens of Roupala and Byrsonima, together with a few shrubby Myrtaceae.

3. Fauna (H. B. B.). As Dr. Pittier indicates, the larger portion of the Venezuelan savannas are scattered with groves of trees, in addition to the swampy morichales and, of course, the stream forest. In Venezuela, it is very difficult to judge how much of the apparent aridity is due to climate and how much to deforestation. Most of the northern region appears to become savanna when the trees have been repeatedly burned away, and, outside of the hills, practically none of the smaller streams, even in the original forest, is permanent throughout the year. In this connection, it must be remembered. 
that Venezuela was settled at a very early period in American history, and much of the northern region was extensively cultivated, under control of Europeans, as early as the sixteenth century. In addition, Venezuela lacks native grazing animals, which are now introduced in large numbers.

Although the pajonales or high savannas (Sievers' map) of the coastal ranges are very extensive and, in many places, remarkably barren, I am of the opinion that they, at least, are largely due to the agency of man. The inhabitants have a natural antipathy for forests, and burn them at every opportunity; on account of the prolonged dry season of these valleys, this is easily done. On almost naked, rocky hills near Bejuma, I collected bleached shells of Strophocheilus, etc., that could only have lived in rather heavy forest. In the mountain valleys, little patches of rain forest are bordered by the savanna itself without any transitional dry forest; undisturbed patches give every indication of invasion into the surrounding grassland. For instance, near the barren, grassy summit of Cerro Chiriguara, I found even young tree ferns growing in the open, at some distance from the nearest patch of woods. Climbing bamboos are perhaps the most prominent feature of recently burnt woodlands.

On the whole, these savannas appear to have very little characteristic fauna, while the richer patches of forest have about the same species as similar situations on the heavily forested, north facing slopes of the mountains. However, the richer savanna ponds, which are bordered by a zone of thorn trees and choked by Pistia and sedges, contain the most variegated aquatic molluscan population that I found in Venezuela (Physa,Planorbis, Gundlachia Ampullarius and Homalonyx). In addition, E. B. Williamson pointed out that often the Odonata actually appeared to be more numerous than in the more heavily wooded regions, perhaps because the adults were restricted to the near vicinity of the streams and ponds. A long-tailed flycatcher was commonly associated with the savanna pools, but aquatic birds were rather infrequent. A rabbit (Sylvilagus orinocoi) has been described from the llanos of Maypures, and the otter (Lutra paranensis) is said to be especially prevalent in the streams of this region.

\section{e. Alpine and subalpine formations (Sierra de Merida)}

e. Andine Bushland. The andine brushwood forms a transitory belt between the upper forests and the alpine "paramos." Starting at its lower fringe, the trees become more and more stunted, ending in being so low and spreading that it is at times easier to walk on their tops than on the ground close beneath. They then disappear altogether and are replaced by shrubs and brushwood, often adorned with the most brilliant flowers. Near its upper margin, the woody or fruticose vegetation is more or less interrupted by grassy patches and thickets of undershrubs, which soon take the upper han.' the underbrush being thus superseded by the "páramos." The most conspicuous species of this formation are Myrica arguta, Escallonia floribunda, Bejaria glauca, aestuans, ledifolia, and resinosa (the rhododendrons of the Andes), about a dozen species of Weinmannias, among which are W. glabra, tomentosa and balbisiana and extensive colonies of Arcytophyllum caracasanum.

2. Páramos. These form the uppermost altitudinal belt of vegetation. They are extensively developed in the Andes, while in the Sierra de Merida they exist only on isolated highlands. They are a true xerophytic formation, the result of the combination of intense cold and scarce rainfall, and all of their plants are more or less organized for protection against excess of evaporation and low temperature. These plants are reduced in bulk and height; their roots are thick, the stems usually short, the leaves smallish and either glabrous with 
a thick cuticle or covered with a more or less dense and wooly indument. The flowers are, on the average, exceptionally large and brilliant. Many of the smaller species have naked stems, the leaves being concentrated at the base in the shape of a rosette or cushion. The shrubs are either crowded together or cling tightly to the surface of the rocks and soil.

The inferior and superior limits of the páramos vary greatly with the local conditions. The former is as low as 1700 meters in the Páramo del Morro, Mérida, while the upper line coincides with the extreme superior limit of vegetation, which has not yet been accurately determined. According to Dr. Jahn's collections, the belt of Espeletias extends from 2100 to 4550 meters, and 13 species of other phanerogams and vascular cryptogams are known to grow above 4200 meters. Polylepis sericea, the tree which reaches the highest altitude in the Venezuelan Andes, has been found by the same explorer at 4150 meters.

A legion of interesting plants is scattered over our páramos, so diligently explored by Dr. Jahn. Foremost among them are the above named Espeletias or "frailejones" of which no less than 16 species have been recognized. They are all quite erect plants, varying in size from a few decimeters (herbaceous) to trees several meters high, and all more or less covered with a filmy coat of a white, yellowish or greyish color. Shrubby Ericaceae (Vaccinium, Pernettya, Gaultheria) often form large colonies, while quite a number of genera, such as Gentiana, Geranium, Arenaria, Cerastium, Bartsia, Plantago, Oenothera, Epilobium, etc., appear at first sight familiar to the alpine botanist. The tropical element is represented mainly by several groups of the Melastomaceae (Miconia, Chaetolepis, Monochaetum, Tibouchina).

The flora of the upper belt of the Coast Range though not unlike that of the Andes in its general aspects, is very distinct in specific composition.
Up to the present, only some 30 species of vascular plants have been found to be common to both regions, while nearly 50 (including 10 lichens and 7 mosses), have been only reported from the Coast Range. It is too soon, however, to draw conclusions. Among the species peculiar to the latter system, we cite Eupatoria sillense, Gardoquia discolor, Chusquea Spencei and Pariana inaequalis; the last species is known also from Guiana, and seems to reach its western limit here.

The order of sequence of families, with reference to the number of their species growing above 2000 meters, is found to differ greatly from that noted for the high savannas. The Compositae come first with 82 species, then the Polypodiaceae (45), the Gramineae (41), the Melastomaceae (39), etc.

3. Fauna (H. B. B.). Among the birds, Henicorhina leucophrys, Diva vassourii, and Colaptes rivolii appear to be quite characteristic of the subalpine bushland. From the paramos themselves, the following, among others, have been cited by Ernst: Sarcoramphus condor, Diglosa gloriosa, Conirostrum sitticolor, Eriocnemis vestita, Cinclodes fuscus, Synallaxis gularis, Pseudocolaptes boissoneautii, Margarornis squamigera, Ochthoeca superciliosa, Heliochera rubrocristata, Buarremon schistaceus, Chlorospingus ignobilis, $C$. goeringi and Phrygilus unicolor. An opossum (Marmosa dryas) and a coati (Nasua olivacea meridensis) have been described from an altitude of 4000 meters in the Sierra de Merida, and the bear (Tremarctos ornatus) is said to occur in the Sierra de Merida.

\section{GUIDE AREAS}

\section{General}

New York City (9 days), Red "D" Line (82 Wall Street), direct from Porto Rico to La Guaira. The Dutch line also runs boats between New York and La Guaira. Alternate steamers from Curaçao proceed (one day) to La Guaira, and - (3 days) to Puerto Cabello ( $\ddagger)$, while the others (smaller) to (one day) to Mara- 
caibo ( $\ddagger$ ). Small steamer makes alternate connections from Willemstad.

Practically no customs inspection at Curaçao; small deposit required of second class passengers to insure their deportation. Venezuelan customs officials very strict. Both countries prohibit importation of firearms, but scientists may secure permission through United States Department of State. Passport and vaccination certificate (smallpox) for entrance into Venezuela; be sure to let the officials know where and why you are traveling and they will give you every assistance.

Roads fair throughout the Dutch Leeward Islands. A recently constructed road, across Venezuela from Caracas to San Cristobal, Estado Táchira, is said to be practicable for all cars during the dry season. The road from La Guaira (Caracas) to the Andes is practicable for any kind of motor car as far as Mérida and will be so to the Colombian boundary in a few months. Another very good road goes to $\mathrm{El}$ Sombrero, $300 \mathrm{~km}$. from Caracas, and in the dry season any kind of car can reach San Fernando in a very short time. The beautifful road down the Tuy valley, which is to be continued to Ciudad Bolivar, will be open to traffic soon. Cars are available at larger towns in Venezuela and in Curaçao, Bonaire and Aruba. Fishing sloops also can be hired cheaply in the islands.

Schooner travel: quite good from east to west; slow and uncertain in the opposite direction.

Maps: Venezuelan Government maps of entire country and also of the separate states; the best maps but expensive; complete series of those published in the Acad. Nat. Sci. Philadelphia. U.S. Hydrographic Office: charts 964, 1049, 1290, 2154.-H. B. B.

\section{Orinoco Valley}

La Guaira: monthly government steamer to Cumana, Margarita Island, and Ciudad Bolivar.

La Guaira: (23 km.) R. R. to Caracas $(\ddagger)$, (about $185 \mathrm{~km}$.) to Valencia ( $\ddagger)$, and (about $250 \mathrm{~km}$.) to Puerto Cabello. These arid valleys are very barren collecting grounds.

Valencia: (10 km.) "Ford" or horseback to Lake Tacarigua; (about $45 \mathrm{~km}$.) ditto during dry season to Bejuma ( $\ddagger$ ), and (about $105 \mathrm{~km}$.) to Nirgua ( $\ddagger$ ).H. B. B.

Lake Valencia. A lake 35 by $15 \mathrm{mi}$., an altitude of $1650 \mathrm{ft}$. The vegetation which surrounds it is mostly savanna. The lake is surrounded with beautiful mountains. Fishes are abundant. In the vicinity are deer, caiman, cormorants, herons, frogs, Bufo marinus. This place is reached by the Red D steamship from New York to La Guaira. The nearest important city is Maracay. One could outfit there. May be reached by railroad from La Guaira or Pto. Cabello. Hotels at Maracay and Valencia. Camping outfit is needed, also a guide.A. S. Pearse.

Bejuma: $(2 \mathrm{~km}$.) foot to Laguna de Ramón Coronel, a representative, savanna pond.

\section{North-Central Mountains}

La Guaira: Macuto Electric to Macuto; Rio Macuto valley, a steep, narrow valley, with a narrow border of natural vegetation.

Puerto Cabello: (7 km.), auto or foot to San Esteban (native huts available); Camino Real, foot or horse, to Los Quiguas. Many tributary valleys present natural conditions; avifauna especially rich.

Puerto Cabello: (one night), small steamer to Tucacas ( $\ddagger)$; $(73 \mathrm{~km}$.) R. R. to San Felipe ( $\ddagger$ ) and (about $90 \mathrm{~km}$.) to Aroa ( $\ddagger)$. The immediate region of both of these towns is cleared, but quite undisturbed valleys within walking distance.

During the dry season one can go with any car from Valencia through San Carlos, Acarigua, Barquisimets San Felipe and Pto Cabello. The road is now open from Barquisiments to Coro via Carora, and from here a branch to Puertos de Olta Gracia, in front of Maracaibo, is in construction. 


\section{Cordillera de Merida}

The road to Merida is by steamer to Ea Ceiba, R. R. to Motatan (and soon to Valera) and then by car over Mucuchies Paramo.

Maracaibo: (About 12 hours.) River steamer to San Carlos; R. R. to $\mathrm{El}$ Vigia; road to Merida.

Maracaibo: (About 24 hours.) River steamer to Encontrados on Rio Catatumbo; passes through rich, lowland forests. In the vicinity of the town, the forest has been largely removed, but several swales and ponds are interesting.

Encontrados: $(56 \mathrm{~km}$.) R. R. to E, Guayabo (posada). Rio Zulia, caños, and some uncleared woods. (102 km.) R. R. to La Fría (native huts available), much uncleared, lowland forest: also foot-hills with almost pure stands of tree-ferns (Cerritos de las Brujas), and forest (Quebrada Santa Aguita); Rio La Grita. (115 km.) R. R. to Estación Táchira (terminal; get permission to live in station); a rich locality in the lower mountains; Rio Lobaterita and many tributary brooks.

Estación Táchira: (About $55 \mathrm{~km}$.) good automobile road or horseback to San Cristobal.

Note: Scientists would be very hospitably received at the American oilcamps some of which have penetrated absolutely virgin country in the Motilone region, near the headwaters of the Rio Catatumbo.- - H. B. B.

\section{The Lowlands}

Tucacas: (37 km.) R. R. to Palma Sola (get permission to live in station); rich, lowland forest all around junction; hill forest $3 \mathrm{~km}$. up track towards San Felipe; Rio Aroa and Caño Minapam. (69 km.) R. R. to Boquerón (our party very hospitably received at hacienda maintained by Aroa R. R.); lowland and drier forest; Rio Aroa and numerous brooks, creeks; and caños; a very rich, largely undisturbed region.

Encontrados: See above.

\section{The Coastal Semi-Deserts}

Maracaibo: Everywhere (get in touch with oil-men).

Willemstad: (12 hours.) Biweekly schooner to La Vela; (15 km.) R. R. to Coro ( $\ddagger$ ).

\section{Dutch Leeward Islands}

Willemstad: (About 12 hours.) Weekly mail-schooner (Felipe S. Toledo agency) to Oranjestad, Aruba ( $\ddagger)$. Return trip 36 hours to 2 weeks, dependent on relative strength of wind and current.

Willemstad: (About 12 hours.) Weekly mail-schooner to Kralendijk, Bonaire (rent a house).

Willemstad: Do not get permission from governor of Curaçao and hire a sloop to visit Klein-Curaçao, as that barren island is not worth the trouble.H. B. B.

It would be premature, for this Venezuela, to try to define territories to be kept as reservations. Forest destruction and Nature defacing is the actual program here in Venezuela as everywhere in Spanish America. Traveling through the country is made easier every day, as roads are being built very actively. Of course, it is expensive, unless you have your own car and can handle it yourself. But today, you can go at any time from Caracas to El Sombrero in a few hours, following Humboldt and Bonpland route, and in summer automobiles travel easily to Ciudad Bolivar via Zaraza and to San Fernando de Aguire via Calabozo. Any kind of motorcar will go today from Caracas to Timotes, the high páramo and mountain-pass giving access from Valera to the valley of Merida, and it is expected that in 1925 it will be feasible to reach the town of Mérida itself. An excellent new road from Cumana to Maturin, has just been opened, and another from Barcelona South to Pao. One of the greatest features of progress in Venezuela during the last few years has been the construction of good motor roads on a giantic scale. 


\section{THE GUIANAS}

By William Beebe and H. A. Gleason

\section{Physiography aNd Vegetation}

(W. B.)

In their physiography the three Guianas present certain common characteristics. The principal features are the rivers and their branch streams. In each colony the northern portion of its area consists of a fluviomarine deposit extending inland and gradually rising to a height of 10 to $15 \mathrm{ft}$. above the sea.

Part of the low, coastal land, of these colonies is actually below sealevel. The Atlantic, along shore, is heavy with yellow silt drifted north from the Amazon. This alluvial plain varies in width from 50 to $18 \mathrm{~m}$. and is traversed by ridges of sand and shells, roughly parallel to what is now the coast, indicating the trend of former shore lines. By the draining and diking of these lands the plantations have been developed along the coast and up the rivers. These low lands are attached to a second belt of somewhat higher plateau, which towards the coast is traversed by numerous huge sanddunes and inland by ranges of hills rising in places to as much as $2000 \mathrm{ft}$. The greater part of this belt of country, in which the auriferous districts principally occur, is covered with a dense growth of rain forest, increasing in density and elevation until the magnificent height of two hundred feet is attained. It is in this area that considerable and rich gold and diamond deposits are located. There is the savanna region, isolated outliers of the great Brazilian savannas, occurring irregularly and far in the interior growing only a long wiry grass and poor shrubs. The hinterlands consist of undulating open savannas rising into hills and mountains, some grass-covered, some with dense forests.

The three colonies are sufficiently near alike that detailed description of only one is necessary. Because of the large amount of research which has been done in British Guiana, it is chosen for this purpose.

\section{British Guiana}

\section{TOPOGRAPHY AND CLIMATE}

British Guiana, the westernmost of the three Guianas, has an area of about 90,000 sq. mi., lying between latitude $1^{\circ}$ and $8^{\circ} \mathrm{N}$. and longitude $57^{\circ}$ and $61^{\circ}$ W., with a coast line of $270 \mathrm{mi}$. The coastal lowlands have a width of 10 to $40 \mathrm{mi}$. along the Atlantic, and are composed of marine alluvium scarcely above sea-level. South of this strip lies a belt of low hills of sand and clay, nearly $100 \mathrm{mi}$. wide at the east, but much narrower at the west. The mountain region occupies most of the hinterland and consists largely of plateaus 1000 to $3000 \mathrm{ft}$. in altitude, surmounted with mountain ranges. The mountains are comparatively low in the east and south, and culminate in the Pakaraima range of the southwest, where Mt. Roraima reaches an altitude of about $8600 \mathrm{ft}$.

The Corentyn, Berbice, Demerara, and Essequibo rivers, with their minor tributaries, flow in a generally northerly direction to the Atlantic, which they enter through broad estuaries. The latter receives two large affluents, the Mazaruni and the Cuyuni, which rise on the north slope of the Pakaraima mountains and maintain a generally easterly course. Several rivers of the Northwest district show a strong deviation of their courses to the west, due to the gradual deposition of marine alluvium. All the streams are obstructed by rapids and waterfalls where they pass from one physiographic region to another. Of these Kaieteur is noteworthy for its height of $741 \mathrm{ft}$.

The temperature is continuously hot, the monthly variation on the coast being only $3^{\circ}$, and the annual mean about $80^{\circ}$. Maximum temperatures on the coast seldom reach $90^{\circ}$, but in the savanna region the mean maximum exceeds $90^{\circ}$. The average temperature in the sun exceeds $140^{\circ}$.

There are four seasons, the short dry, February, March, and April; the long wet, May, June and July; the long dry, August, September, October and No- 
vember; and the short wet, December and January. There is considerable variation in these seasons, and occasionally a short season is almost eclipsed. The rains offer no impediment to research. There is no real period of drought and only three-fifths of the rain falls during the two rainy seasons.

The ranfall along the coast increases from east to west from 84 to 100 in., and towards the interior to $150 \mathrm{in}$. along the eastern foothills of the Pakaraima mountains. In the savanna region it is much lower, amounting to about 60 in.

\section{ORIGINAL BIOTA}

\section{The vegetation}

\section{A. General}

Knowledge of the flora and vegetation of British Guiana is still far from complete, and only the merest outline of the leading features of the colony can be given.

The coastal swamps are occupied by the usual mangrove thickets, in which the black mangrove (Rhizophora), the white mangrove (Laguncularia), and the courida (Avicennia) are abundant. These swamps extend up the principal streams to the limit of the influence of salt water.

Fresh-water swamps and marshes parallel the rivers throughout the coastal lowlands, and are generally subject to inundation during the rainy seasons and at every high tide. At the water's edge the tall mucca-mucca (Montrichardia) is abundant, and farther back the wild cacao (Pachira), the pumpwood (Cecropia), and the trysil (Pentaclethra) are characteristic, together with several species of palms of the genera Mauritia, Euterpe, and Manicaria. The whole is bound together by masses of vines, particularly of the dogbane and milkweed families.

Aside from a narrow strip of cultivated land along the coast and the lower courses of some of the rivers, the remainder of the coastal lowlands and the sand and clay belt is covered with rain- forest. It is at present impracticable to distinguish or describe the various plant associations, further than to state that two general types of forest may be distinguished, the one on the clay hills, and the other on the sand ridges (luxuriant tropical rain-forest). The forest-cover is 124 to $150 \mathrm{ft}$. high; the trees are straight and unbranched for 60 to $75 \mathrm{ft}$. A second layer of smaller trees is usually well developed. Lianas are abundant and of large size, while practically every tree is occupied by epiphytic ferns, orchids, and bromeliads. The undergrowth of shrubs and the ground cover of herbaceous plants depends in general on the available light, and is best developed along the stream banks. The great majority of species are woody.

The flora of these forests is extremely rich and much of it is still unknown. Among the hundreds of species of trees, many of the commoner or more important are included in the genera Eperua, Dimorphandra, Inga, $M a-$ chaerium, Caraipa, Lecythis, Nectandra, Licania, Hevea, and Mimusops. The smaller trees and shrubs are largely members of the myrtle, melastome, and madder families. The herbaceous flora includes numerous species of the arrowroot, gesnera, and sedge families, together with numerous ferns and lycopods.

Higher ridges of pure sand are frequently occupied by an open forest of low trees with wide-spreading crowns, in which Dimorphandra is characteristic, and under which there is a luxuriant development of shrubs, herbs, and grasses showing in specific composition relations to the savanna vegetation of the hinterland.

Extensive savannas occupy most of the southern half of the colony, covering the high plateaus and broken only by belts of forest along the streams and on some of the mountain slopes. The vegetation here is composed chiefly of several species of tall grasses and sedges, with numerous herbs and low shrubs as secondary elements, and 
interspersed with thickets and isolated trees of various trees and taller shrubs, among which Byrsonima is especially abundant.

The high mountains of the Pakaraima range maintain a forest similar to that of the low country in general aspect, but with many additional species. In our present state of knowledge, it is impossible to name the most typical genera or species, and endemics are abundant. The same vegetation probably extends westward along these mountains across southern Venezuela as far as the Orinoco.

The highest mountains, Roraima and Kukenaam, have long been known for their remarkable endemism, amounting to about $40 \%$ of the known species, and their flora shows some resemblance to that of the Andean region.

\section{b. One-quarter sq. mi. of jungle at $\operatorname{Kartabo}^{1}$ (W.B.)}

\section{Geographical position}

Kartabo, the site of the Tropical Research Station of the New York Zoological Society, is situated in the north-central part of British Guiana, South America, at the junction of the Mazaruni and Cuyuni Rivers, $6 \mathrm{mi}$. above where these combined streams enter the still larger Essequibo River. Its position on the earth's surface is $58^{\circ} 42^{\prime} \mathrm{W}$. longitude and $6^{\circ} 23^{\prime} \mathrm{N}$. latitude, approximately $400 \mathrm{mi}$. from the equator and $45 \mathrm{mi}$. from the Atlantic Ocean.

Nine-tenths of the general work has been carried on within an area of 2000 by $4000 \mathrm{ft}$. This area is included in the easterly portion of the black area shown on the accompanying map. Unless otherwise stated, the following account of the general ecology of this region, and the various articles which will follow in future numbers of Zoologica, dealing with more definite, intensive researches, refer altogether to this tract of land and water, measuring 2000 by

\footnotetext{
1 This paper presents a few aspects of the general paper on the subject which will appear in "Zoologica," the scientific journal of the New York Zoological Society.
}

$4000 \mathrm{ft}$., at the very point of juncture of the Cuyuni and the Mazaruni Riversan area less than one-quarter the size of Central Park in New York City.

\section{Meteorological conditions}

Accurate records of weather conditions have been taken at the Climatological Station at His Majesty's Penal Settlement, 3 mi. below Kartabo. The statements given here are based upon the published and unpublished records of this Station which extend over a period of twenty years.

Seasons. Four seasons are recognized in Guiana-a short and a long dry, and a short and a long wet season. The following table shows the generally accepted seasonal grouping of months, although slight variations from this table are constantly apparent.

Short dry season: February, March, April.

Long wet season: May, June, July.

Long dry season: August, September, October, November.

Short wet season: December, January.

During the months allotted to the rainy season approximately $58 \%$ of the rains fall, the precipitation amounting to an average of $11.73 \mathrm{in}$. per month. During the dry season $42 \%$ of the yearly rainfall is felt, the monthly average being 6.04 inches.

Rainfall. The average rainfall is $100.53 \mathrm{in}$. per year, the heaviest rainfall being in May (14.00 in.) followed by June (12.44 in.) and July (12.40 in.). March has the lowest rainfall with but 4.94 in. to its credit. The highest records for annual rainfall is 117.75 in. (1918) and the lowest 77.11 (1911). Rain falls on an average of 219 days a year. The highest rainfall for a single month was in May, 1918 (22.34 in.) and the lowest in February $1912(0.03$ in.).

Humidity. The yearly average for humidity is $84.2 \%$. The daily averages are as follows.

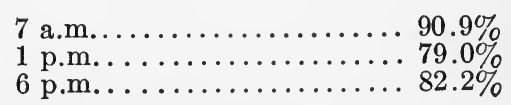


Sunshine. The average daily sunshine is 5.3 hours - the greatest amount being felt in September (6.8 hours) and October (6.7 hours) followed closely by November (6.3 hours) and August (6.2 hours). May (4 hours) followed by March (4.3 hours) have the least sunshine. The maximum amount of sunshine recorded for a single day is $\mathbf{1 1 . 6}$ hours.

Temperature. Seventy-nine and twotenths degrees is the average shade temperature for the year, the highest temperature being in October $\left(81.5^{\circ}\right)$ and September $\left(81.1^{\circ}\right)$, and the lowest in January $\left(77.8^{\circ}\right)$. The maximum and minimum temperatures for the year average as follows:

Maximum........... $83.9^{\circ}$

Minimum........... $74.3^{\circ}$

The following list will show the grouping of the months, the coolest month placed first and the warmest last: January, February, March, June, July, December, April, May, August, November, September, October.

Winds. The winds at Kartabo vary from "gentle" to "fresh" and average $3.5 \mathrm{mi}$. per hour. Because of Kartabo's position the trade winds blow almost steadily throughout the year, while in January, February and March, they continue through much of the night as well.

Meteorology of Kartabo compared with the Coast of Guiana and with the far interior. The following table will show the variation in rainfall, humidity and temperature between the coast as represented by the records taken at Georgetown, and the far interior as represented by the records taken at Dada-nawa, far up on the savannas. The interior station shows a far greater range of temperature and rainfall than do either of the other two places.

\begin{tabular}{|c|c|c|c|}
\hline$\bullet$ & 睡 & 品 & 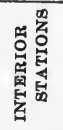 \\
\hline $\begin{array}{l}\text { Rainfall, inches ........... } \\
\text { Humidity, percentage.... } \\
\text { Temperature, Fahrenheit }\end{array}$ & $\begin{array}{l}94.37 \\
78.1 \\
80.5^{\circ}\end{array}$ & $\begin{array}{l}100.53 \\
84.2^{\circ} \\
79.2^{\circ}\end{array}$ & $\begin{array}{l}51.88 \\
86.5 \\
83.1^{\circ}\end{array}$ \\
\hline
\end{tabular}

\section{Physical features}

Land mass. The average height of the land mass at Kartabo is between 40 and $50 \mathrm{ft}$. above the mean high tides. Along the shore of the Mazaruni immediately in front of the Station the land is from 5 to $15 \mathrm{ft}$. above the river. In back of the laboratory the land rises sharply at first, forming a rounded hill about $80 \mathrm{ft}$. in height, which as it continues westward expands laterally until at the western end of the research area it is over $\frac{1}{3} \mathrm{mi}$. in width. This hill forms the beginning of the divide between the Mazaruni and the Cuyuni Rivers. In the northwestern part of the research this hill comes close to the shore of the Cuyuni, while to the north and northeast are swamps and moist lowlands. Southward of the hill rolling lowlands predominate and swamps are fewer in number and less in extent.

Tidal area and shore. The amount of river shore influenced by tide occupies approximately 6000 linear $\mathrm{ft}$., divided as follows:

feet

Rocks................ 300

Sand beaches........... 650

Steep shores with jungle coming to the water's edge, tree roots merging with the tidal area................. 1200

Shallow, mud and sand bottomed flats. . . . . . . . . 3850

The shore is exceedingly diversified as to its physical characteristics, and all conditions of aquatic environments may be found, varying from shores formed of unyielding granite to softest of muddy oozes, and from reeds and mangroves to buttresses of the tallest of jungle trees.

Water. At Kartabo the Cuyuni River is $2500 \mathrm{ft}$. in width. The opposite shore of the Mazaruni is over $6350 \mathrm{ft}$. away from the laboratory.

The tides on these rivers run from one to $3 \mathrm{mi}$. an hour while falling, the fall ranging from 6 to $6 \frac{1}{2} \mathrm{ft}$. At the Station they average about $2 \frac{1}{2}$ hours later than they do at the mouth of the Essequibo, $45 \mathrm{mi}$. away. 
The color of the river water is a pale brown, mainly caused by the stains derived from the leaves of the Wallaba tree (Eperua falcata Aubl.). Lowering a white disk into the water, the color is quite yellowish at the surface, becoming browner farther down and before it disappears it acquires a distinctly orange tone. From eighteen inches downward the color becomes darker and darker and at 25 in. the disk disappears.

Occasionally during heavy rains quantities of brownish yellow mud is brought down in suspension, making the river waters quite opaque.

The temperature of the river water from one $\mathrm{ft}$. below the surface to the bottom averages from $79^{\circ}$ to $80^{\circ} \mathrm{F}$.

Within the research area there are a number of small streams, most of which are drains for the swampy regions. Practically all are densely shaded, narrow in width, meandering at all times through and around the bases of forest trees.

\section{Vegetation}

The flora of Kartabo has been studied by no competent general botanist, and in this resumé I have attempted nothing but an indication of the more conspicuous and abundant growths, particularly those which possess an important relationship with members of the vertebrate fauna, either in the way of food, homes or media of support and progress.

Fluviatile. Blue-green, red and brown algae and diatoms are abundant but no collections have been made of them. Very remarkable purple algae have been found in the stomachs of puffers (Colomesus psittacus) but not observed elsewhere.

Littoral. The littoral fauna is sharply delimited to between tide marks. Where the current is swift near shore, these forms are almost hidden by overhanging vines and lianas, dependent from the high jungle trees which crowd down to the very water. Along sandy and sloping muddy shores they are spread out, but even in such places do not extend more than a few yards from the high tide mark. Specific associations are well marked in the littoral flora-solid cultures of mangroves, sedge, mucka-mucka and others.

Mangroves, Rhizophora mangle, find root-hold in certain definite areas of the gently sloping mud-flats, while back of them on firm mud and sand are the graceful sedges. Two species of sedges are dominant, Eleocharis geniculata $\mathrm{R}$. Br. and Cyperus sp. In spots where the current is not too swift or waves too violent, appear rank upon rank of the aroid lily with the incongruous name of mucka-mucka, Montrichardia arborescens (Linné) Schott. Here and there are small patches of Horse Tails, Equisetum, hinting of epochs long since past. In the last two years, however, these plants have disappeared from the Kartabo shores.

Clustering around the sedge clumps is a low, white-flowered Diodia, creeping along the sand and helping the coarse grasses to cling to the shifting grains. The most conspicuous flower stalks of the fore-shore are the tall shore gentians, Coutoubea spicata Aubl. which hold up their racemes of pinkish-white flowers well above high tide level.

One of the most valuable shore binders is the rush-like herb Xyris tenella Kunth. Hundreds of these little, grassyleaved plants take root beneath the mangroves and their roots mat together. With them occur the straggly, jointed stems with the inconspicuous pea-like flowers of Vandellia difusa Linné.

On beaches of pure sand, fronting disintegrating, soil-covered banks, the plant association is of another character, all uniting to hold fast as much as possible of the granitic talus which now and then slides down in sandy avalanches. Such is the beach directly in front of the laboratory.

Every inch of the precipituous bank which offers foothold is covered with representatives of the clearing faunathe pink and white Mazaruni primroses, Sipanea pratensis Aubl. being the only 
bright color note. At the foot of the bank the tides are felt and the plants are no longer the gentle growth of a summer meadow, but must be virile enough to hold their position against wind and water. As opposed to the mangrove zone, the dominant plants here are grasses. These are of various types, ranging from great, coarse beach grass such as a species of Panicum, to creeping grasses such as Courmelina longicaulis Jacq. A species of Sporobolus is found, with long prostrate stems. In surprisingly exposed places the curious little, clover-like purple-flowered Desmodium stands bravely in low, compact bunches, while Kyllinga with its small white flowers, creeps feebly a few inches from its roots.

Among the mangroves, bromeliads are found in serried rows and clusters, often so abundant as to break down their support. The roots above low water are coated with moss and lichens, while the branches are often put under terrific strain by burdens of heavy vines such as Souroubea guianensis Aubl. and its interesting relatives, several species of Marcgravia. Even the top branches are not free, and epiphytic orchids such as Epidendrum gragrans Sw., Epidendrum nocturnum Jacq. and Diacrium bicornutum (Hooker) Benth. are found in great abundance.

While the actual flora of the tidal area is limited and fixed, yet this zone offers one of the most fertile fields for another phase of botany-the flotsam and jetsam of the river current. Every receding tide leaves a host of stranded seeds and nuts.

Luxuriant tropical rain-forest. Unless artificially altered by man the littoral flora merges directly and abruptly with that of the jungle. At Kartabo some of the river jungle is swampy, with palms as a dominant association, mingled with hard and soft wood trees. On the dry and higher ground we find the typical rain forest of Eastern South America. In the most luxuriant primeval forest, the great trees arise at considerable distances from each other, with trunks straight as plummets, often quite bare of branches for one hundred feet. The undergrowth is scanty and low, and the mid-level is broken only by occasional lianas or aerial rootlets, all of which are as straight as the tree trunks.

Where plantations of the Dutch once existed, or where an Indian has made a clearing for his cassava field, the new growth never regains its maximum development. In these changed conditions, while there are many large, tall trees, yet there is not the unbroken aspect of the roof of the jungle, and the undergrowth instantly reflects this in its more lush character.

In swampy areas Ichnosiphon grows luxuriantly, tall, smooth, reed-like stems, with a burst of leaves at the summit. Comacuballi lianas climb trees and thrust out masses of red berries beloved of birds. Wild ginger, in these places sends its 6 to $12 \mathrm{ft}$. leaves up from compact stumps and Heliconias run riot.

Even in low jungle one can always see through the undergrowth for ten to thirty yards. Thorns are rare, but when they do occur, it is useless to try to force one's way against them. The jungle floor is always covered with a thick carpet of fallen leaves and twigs, from a few inches to a foot or more in depth. In deep jungle herbaceous plants up to $6 \mathrm{ft}$. in height are not uncommon, but inconspicuous. Fallen petals and flowers are abundant, often having dropped $100 \mathrm{ft}$. from some obscure vine. Color in masses is to be found in the tree tops when whole trees burst forth into a solid head of lavender or pink within twenty-four hours. Lichens, fungi and mosses are everywhere. Even in the dry season they flourish in damp places, while during the rains they rival the flowers of the glades in color. As for molds, smuts and rusts, a mycologist who spent four days at the Research Station collected three hundred forms in a few trips along the trails. The importance of this density of vegetable growth 
covering every inch of dry land, cannot be appraised too highly, no matter what form of organic life we chose for intensive study.

The following list gives a few of the larger trees from 60 to $150 \mathrm{ft}$. in height that are found within the research area. Rarely, some of these trees become 200 ft. in height. Unfortunately a great many of the largest trees have remained unidentified and unidentifiable.

Dimorphandra excelsea (Schomb.) Baill., Mora

Nectandra rodiei Schomb., Greenheart

Carapa guianensis Aubl., Crabwood, Guiana Mahogany

Pentaclethra macroloba (Willd.) Kuntze, Trysil

Aspidospermum excelsum Benth., Paddlewood, Yaruru

Rhizophora mangle Linne, Mangrove

Spachea elegans A. Juss., Pigeon-berry

Inga sp., Waikey

Hevea sp., Hatteeballi

Sapium jenmani Hemsl., Wild Rubber

Vochsia tetraphylla DC, Etaballi

Cassia multijuga Rich., Guana

Anacardium rhinocarpus DC., Wild Cashew

Spondias lutea Linné, Wild Plum, Hog Plum, Hoobooballi

Copaifera pubiflora Benth., Purleheart

Piratinera guianensis Aubl., Letterwood

Hymeneae combaril Linné, Locust, Siniri

Hieronyma laxiflora Muell. Arg., Suradanni

Simarupa amara or officinalis, Matchwood Tree, Simarupa

Unidentified, Dalina

Cecropia palmata, Cecropia, Congopump, Pumpwood, Wanasuru

Unidentified, Kurahara

Unidentified, Meerah-wood, Antwood

Unidentified, Hooroowassa

Myristica surinamensis Roland, Dalli

Unidentified, Wareemeah

Nectandra sp., Silverballi

Unidentified, Potchuwee

Tapirira guianensis Aubl.

Unidentified, Arracanduck

Psidium guava, Cockreeeou, Wild Guava

Humirium floribundam Mart., Tauroneero

Tenipa americana Linné, Makreekoonee Rain-forest palms

Astrocaryum tucuma Mart., Cuyuru Palm, Acqueero

Maximilliana regia Mart., Kokerite Palm

Cocos nucifera Linné, Cocoanut Palm

Mauritia flexuosa L. f., Eta Palm

Euterpe edulis Mart., Manicole Palm
Cleared areas. Immediately about the Kartabo laboratory are 25 clumps of bamboos covering a compound of three acres. These are a very tall Javan species, imported by the Dutch from 250 to 300 years ago. West of the laboratory is a clearing of 7 acres which four years ago was in course grass. At the present time it can still be called a clearing, but tall saplings are springing up in all directions and the jungle is creeping in on all sides. This change is a most interesting one and the alteration from jungle offers opportunity for hosts of strange organisms, floral and faunal.

In the clearing every patch of open ground is carpeted with a dense growth of the cheerful little pink Mazaruni primroses, Sipanea pratensis Aubl.-by far the dominant color of the open clearing and with many tiny weevils and other insect hosts. With them are numerous other small, flowering plants, such as Spermacocs verticillata Linné and caerulescens Aubl., and such curious little growths as the Christmas-tree plants, Dupatya. In other parts of the clearing Vervain, Stachytarpheta cayennensis Vahl. and Velvet-Leaf, Sida cordifolia Linné are common, while scattered here and there are patches of Orinoco Boneset Mikania orinocensis H. B. K. Sprouting plants of cashew are common, Anacardium occidentale.

In unexpected places great clumps of ginger lilies, Cruium, spring up. The Pinwheel flower, Tabernaemontana undulata Vahl. shows one of the most amazing floral-fruit transformations. The Tree of Life Bryophyllum pinnatum (Lam.) Kury is as much at home here as in other parts of the world. Sensitive plants Mimosa polydactyla H. \& B., wilt at a touch, and stray bushes of Indigo, Indigofera sp. have handed down their seeds for three hundred years since the Dutch settlers brought them there.

A still larger growth may be defined as saplings, of which the Duka, Tapirira guianensis Aubl., is the most rapid grower. With these, young jungle trees, 
such as Wareemeah, are sprouting from stumps of the old forest. There are also a few lime trees, Citrus medica acida, planted years ago and almost smothered under other growths, but still bearing abundantly. Guavas, Psidium grow here and there.

In many places, both clearing and jungle, Melastomas grow rank, some as trees, others as bushes, shrubs, or even crawling, vine-like, over sandy places. One form called Mesopra by the Bovianders, Bellucia grossularioides Triana, is common about the bungalow, and its coarse rough leaves, woody scaly stems and rounded white blossoms, all form a haven for a whole fauna of insect life.

Along the jungle edge of the clearing the jungle hides its bareness by an abundant growth of vegetation. Among these is torchwood, Icica heptaphyllum Aubl., with its dense foliage, whose wood, when teased out, is used by the Indians as candles, Blood-leaf, Vismia ferruginea H. B. K. and guianensis Pers. with great leathery leaves beloved by a multitude of insects, Trysil trees with the finest of pinnated foliage, Arrancanduck, and Cassia. Here too we find tree Cashews, Clusia, Wild Cocoa and Messopra, with small flowers, and Maibike with its stems lined with lavender bloom.

Along shore the edge of the jungle is varied by many smaller trees and vines. Here grows the Wild Cocoa Pachira aguatica Aubl. flowering twice a year, each blossom one foot across. The close-packed seeds of this plant are delicious, either raw or roasted. Cassia is common here, and Posequeria but vines have the best chance and sometimes ramify for several hundred ft. Especially noticeable are Allamamdas, Bignonias, Petrea and Souroubea guianensis Aubl., the last with its glossy leaves and panicles of stiff, scarlet flowers. Its near relative Marcgravia vies with it in abundance near shore, and sometimes presents a solid front, obscuring the foliage of the remaining trees and bushes behind it.
Another shore plant, which in certain positions becomes almost a vine is the caterpillar flower, Combretum laxum Loefl. with its brilliant yellow and scarlet blossoms.

Spider lilies, Hymenocallis, hold up their drooping, streaming petals from among the sedges and reeds, while in swampy areas grow great clumps of ginger lilies Hedychium coronarium, Konig. In dry clearing edges at the time of the early rains, single plants of scarlet tiger lilies, Hippeastrum, appear.

Although the jungle growth is so luxuriant, yet the soil is very thin, a mere skim of black mold from 6 in. to $2 \mathrm{ft}$. lying on the sand and clay. An Indian cassava field planted in freshly cleared jungle soil will so deplete the ground that a second crop is never attempted on the same field. This is also true of commercial ventures in producing crops on this soil. Three attempts have been made at rearing crops, first sisal hemp, second rubber and third cassava. But all these attempts have failed dismally.

\section{Animal life}

\section{a. Luxuriant rain-forest}

In the rain forest of Kartabo; the mammals range from the mouse opossum to the jaguar and tapir; the birds from the tiniest of humming birds to the harpy eagle; the reptiles and amphibians from the smallest frog to $25 \mathrm{ft}$. boa constrictors; the fish range from half-inch Tomeurus to nine foot catfish. The worms show extremes from minute round worms to earth worms three feet long, and the insects from almost microscopic Coleopters to giant rhinoceros bettles and moon moths with a 12-inch spread of wings.

The forest or jungle is divided into four horizontal zones or strata; the floor of the forest, the lower forest up $20 \mathrm{ft}$., the Mid-Forest as high as seventy and the treetops from 150 to $200 \mathrm{ft}$. above the ground. The floras and faunas of these zones are as distinct as is the abyssmal for the plankton, and 
these in turn from the surface life of the ocean. Finally the air above the jungle had to be taken into consideration as being the principal haunt of many forms of life, just as we have seabirds and flying fish and air-breathing cetaceans in the case of the pelagic simile.

The ground in the jungle was covered with the accumulated debris of centuries, all the immense mass of vegetation which reared itself on high, falling sooner or later, and returning to this globigerina ooze of the dry land.

In the low and mid-heights was found the soft mist of green foliage of the jungle undergrowth, springing from thin, twig-like branches and supported on marvelously slender stems. The level of this undergrowth was between 5 and $70 \mathrm{ft}$., above which the tall, straight trunks of the larger trees were dominant, with no trace of branch of leaf until the luxuriant crowns were reached.

As one walked through the jungle, tinamou and partridges sprang up and whirred away, agoutis and armadillos scuttled from their feeding grounds. Tracks of deer, tapir, paca and various cats showed the movements of these animals during the preceding night. Grisons and, more rarely, small jungle mice and rats were observed. On fallen leaves tiny jungle frogs shrilled, and giant marine toads live their sluggish life. Salamanders and serpents were rare. Once in a while a bushmaster, fer-de-lance, or some harmless snake was seen coiled or slowly slipping over the leaves. Now and then a big yellow turtle ploughed heavily along. All the greater and lesser fry of the underworld whose delight was in decayed wood, who called the mold home, were herestrange grubs and beetles, scorpions, myriapods, peripatus and all wingless, creeping things.

When I raised my eyes to the level of the low jungle-to my own heightan entirely new world appeared. That of two dimensions was left behind and one of three entered. Here began the domain of creatures of moderate flight and of limited climbing ability, which, unlike the tortoise and the tapir were not bound to the ground. Here I was always certain to find manakins of several species, and antbirds of still more. Here the trumpeters and jungle wrens uttered their characteristic calls. At night opossums wandered, while in the twilight of mid-day, morphos-those bits of quintessent pigment-flapped leisurely along, together with their opposites, the skeleton butterflies.

The mid-jungle was the heart of the tropical life. Here I could no longer feel myself on equal terms in height. I had most painfully to crane my neck upward, and to study the inhabitants of this suspended cosmos with glasses or shotgun. Here the big curassows and guans perched and nested, the great pigeons, the motmots, jacamars, trogons, goldbirds, and a host of tanagers and flycatchers and strange tropic forms chirped, sang, fed, courted, and nested. In the mid-heights the big tree-frogs boomed, and the sloths vegetated from birth until the claws of a harpy eagle gripped them. Squirrels were so rare as to appear strange forms, known chiefly from memory; marmosets and coatis usurped their place by day, while kinkajous climbed about by moonlight. Orchids, air-plants and lianas rioted, and unknown growths dropped a myriad plummets, a warp of aerial roots; threads until they reached the ground, then becoming in turn twine, cord, rope and cable. It was the great center of life of the South American jungles, a zone vibrating with a myriad forms suspended half-way between heaven and earth. Still it was a zone with decidedly earthward tendencies. Some of its inhabitants descended to sleep, others to feed or to build their homes. The majority, however, remained throughout their lives as they were born, plankton of the jungle.

Yet another continent of life remains to be discovered, not upon the earth, but 100 to $200 \mathrm{ft}$. above it, extending over thousands of sq. mi. of South 
America. At present we know almost nothing of it. Up to now gravitation and tree-trunks swarming with terrible ants have kept us at bay, and of the tree-top life we have obtained only unconnected facts and specimens. For the most part my glasses showed forms silhouetted in black against the bright sky beyond. I could fire upward and with a heavily loaded choke bore usually bring down the bird I desired. Or I could put my Indians to chopping down some of the great trees, and after hours of labor, if no interfering trees or binding lianas set our work at naught, I could search among the mass of broken, bruised foliage, an almost hopeless task, for casual specimens. And what I found might often have been brushed down from the mid-jungle, or have been disturbed among the very leaves of the ground.

With my shot bird in my hand and my black silhouettes and my scattering of crushed specimens, I was very far from real knowledge of tree-top life. What of the tree-frogs, and butterflies and birds and unknown hosts of creatures which never voluntarily descend to the ground. There awaits a rich harvest for the naturalist who overcomes the obstacles-gravitation, ants, thorns, rotten trunks - and mounts to the summits of the jungle trees. Another year we hope to begin this work, and to sit in hammocks or on platforms swung aloft among the toucans, macaws, parrots and caciques, the umbrella, the calf and the bellbirds whose strange distant notes or whose dead bodies were merely tantalizing invitations to the manifold secrets which intimate observation among the tree-tops is certain to reveal.

To show the stratified activities of a few typical groups of jungle birds and mammals, I have prepared the following rough diagram:

\section{TYPICAL GROUPS}

\section{Ground}

Low forest (0-20 ft.)

Trumpeters

Antbirds

Manakins

Wrens

Thrushes

Mid forest (20-70 ft.)

Curassows

Guans

Pigeons

Hawks

Owls

Motmots

Trogons

Barbets

Jacamars

Puffbirds

Goldbirds

Mourners

Honey-creepers

Tree-tops (70-200 ft.)

Cotingas

Toucans

Macaws

Parrakeets

Parrots

Giant Caciques, etc.

GROUPS FOUND TYPICALLY IN MORE THAN ONE ZONE

\section{Ground}

Goatsuckers . Low forest (0-20 ft.)

Goatsuckers Hummingbirds

Mid-forest (20-70 ft.)

Hummingbirds

Flycatchers

Tanagers

$$
\text { Tree-tops (70-200 ft.) }
$$

Flycatchers

Hummingbirds

Tanagers

Mammals permit a similar mode of representation of altitudinal distribution:

\section{Ground}

Anteaters

Armadillos

Tapirs

Peccaries

Deer

Cats

Dogs

Galictis

Rodents

Low forest

Opossums

Mid-forest

Anteaters

Sloths

Bats

Coatis

Squirrels

Marmosets

Kinkajous

Tree-tops

Red Howlers

Beesa Monkeys

The following mammals occur at the Station: Opossums: Didelphis marsupialis, Marmosa chloe, Marmosa 
cinerea demerarae, Metachirus nudicaudatus, Monodelphis brevicaudata; Threetoed sloth: Bradypus cuculliger; Twotoed sloth: Choloepus didactylus; Great Anteaters: Myrmecophaga tridactyla; Silky Anteater: Cyclopes didactylus; Armadillos: Dasypus novemcinctus, Tatu kappleri; Peccaries: Tayassu pecari beebei, Pecari tajacu macrocephalus; Brockets Deer: Mazama americana tumatumari, Mazama nemorivaga; Capybara: Hydrochoerus hydrochoerus; Agouti:Dasyprocta agutiflavescens; $\mathrm{Paca}$ : Agouti paca. Spiny rats: Proechimys cayennensis. Echimys longirostris; Mice and Rats: Ecomys guianae, Ecomys nitedulus, Ecomys rutilus, Neacomys guianae, Nectomys squamipes melanius, Oryzomys spp.; Squirrel: Guerlinguetus aestuans aestuans; Crab-eating raccoon: Procyon cancrivorus; Kinkajou; Potos flavus; Otter: Lutra mitis; Tayra: Tayra barbara; Coati: Nasua phoocephala; jaguar: Panthera onca; Tiger Cat: Margay tigrina vigens; Yaguarondi: Herpailurus yaguarondi unicolor; Bats: Saccopteryx bilineata, Rhynchiscus naso, Glossophaga soricina, Hemiderma perspicillatum, Mesophylla macconnelli, Phyllostomus hastatus, Vampyrus spectrum, spectrum, Furipterus horrens, Eumops milleri, Mollossus obscurus, Molessus rufus; Monkeys: Saimiri sciureus, Saimiri cassaquiarensis, Alouatta seniculus macconnelli, Pithecia pithecia, Cebus apella apella.

\section{b. Savanna ${ }^{2}$}

In the forests of the Savanna region there are several large carnivorous animals including the black jaguar, puma and spotted jaguar. The spotted jaguar would seem to prefer the open country, where it can hunt deer, and, in these days, cattle. Both the spotted and the black jaguar are known not to despise fish: and it is said that they will lie in wait for turtles coming on to sandbanks, to lay eggs. The ocelot may be found in these woods, also.

2 Extracted from the Rev. Walter G. White's "notes from the Hinterland in Tropical Wild Life" by Beebe, Hartley and Howes.
A savanna fox or maikang occurs. It is audacious, coming into the village in the daytime for fowls or fruit. There is, upon the savannas, a bush, which bears a pretty, red berry, which is called maikang-pimi-u, because the maikang or savanna fox feeds upon it. The maikang makes a hole in which it has its young. A still smaller animal, having a long tail and a pointed snout, is the queer creature called, by the Indians, kuachi. It is the coati, to be found on the low ground about Kwatata Creek.

Uruata Forest is the home of the armadillo and the porcupine and the sloth. In this big forest, droves of peccary trample, making a varied diet of yellow hog-plums, which may be found scattered over the ground, in places, during the season. The Indians name five distinct kinds of peccary, although only two appear to be known to science.

Deer are reported to be diminishing rapidly in the savannas, since the Indians have taken to the buck-gun. The deer are most plentiful about the Napi and upon the Katoka Savanna. Here, again, the Indians differentiate four species of deer: Waiking (Odocoileus virginianus), smaller savanna deer (Mazama simplicicornis) and two bushdeer. The bush-deer are to be found in Uruate Forest.

Not much was seen of opossums, for they keep to the trees, hiding amongst the foliage and in their holes.

Monkeys are common in all the bush. The kwata (Ateles paniscus) has given its name to Kwata-ta, which means Kwata-place (ta being an abbreviation of pata, place), and to the knob of land, Kwata-pubia, or Kwata-head. I have seen a party of a dozen of these animals, making their way from one big bush to another, using, as their highway, the low scrub, which, at that place, fringes the savanna, at the river's edge. They would not cross a long extent of country upon the ground. The red howler (Mycetes seniculus) affords the listener daily and nightly entertainments, in 
these forests. The Sakiwinkie, with its olive and yellowish tints about the head, makes a pretty pet. And the black and fluffy marmoset is also in demand. I have seen both of these monkeys leaping and scrambling amongst the trees, at Uruata, or swarming up the trunks.

Tapir is a splendid diver. It travels long distance by water. I have seen it swimming the Essequibo, where its width is a full mile.

The Indians gave the names of five distinct species of turtle, to be found in the Rapo-nunni and five tortoises, or land-turtles. The warara, which measures $5 \mathrm{ft}$. in length, requires that a man shall be skilled and strong if he desires to turn it. An Indian who brought in one of this size suffered a severe scratching, from the sharp nails, and sustained a rupture. Between January and April turtles' eggs may be found, by the score, in exposed sand-banks. A lay may be discovered by following the turtle's track, easily distinguishable from a boat, and scooping the sand for a depth of 8 inches. Should rain have obliterated the track, eggs may be found by probing where a suspicious indentation of the sand appears. The egg-shells, being of parchment texture, are not easily broken. A smaller turtle, tarekatha, may sometimes be seen by the fifty, or the hundred, together. I counted over fifty emerging from Parishara Pond. Their necks were craned, to enable them to eye our boat, and their whitish throats gave the appearance of a strew of lily-buds, upon the placid surface of the water. Moonlight nights are suitable occasions for watching turtles come forth, to lay. They always return upon the same track, leaving only one mark for the double journey from and to the water. They are able to manage this, because they rotate, when digging the hole for the eggs. It is observable that the bodies of the tortoises are not so flattened as those of the turtle. Tortoises may be found in the Uruata Forest.

The Rapo-nunni teems with alli- gators, and every stream and pond of any size knows them. Their heads, like the ends of gnared logs, may be seen stationary, or almost imperceptibly moving, in mid-stream, or near the bank. Caiman niger mounts guard over every landing, and looks out for unwary dogs, thoughtless children, and careless adults. A foe of the alligator, the iguana, may often be seen upon the bank of the river, sunning itself. Sometimes it lies along the root, or trunk, of a tree, from which its greenish skin is hardly distinguishable.

The pokaru is a good place for studying snakes. In the bush we saw a green labaria; and, crossing a side road, with a frog in its mouth, a black snake, about four feet in length, passed in front of us. The green labaris is known as Lachesis bilineatus. Another green snake, the Corallus caninus, or parrotsnake, lurks in the branches of trees, waiting for unwary birds. The greygreen and chrome rattlesnake is common upon the savanna, although the ordinary person may walk for miles without seeing one. Between the Napi and the Takutu, it is abundant. Upon the Tuka Savanna, one of our Indians was killed by the bite of a rattler. This snake is known to be viviparous.

\section{c. Present biota}

The effect of human occupation has had slight effect on the native fauna except near the coast, and even here only in the vicinity of the sugar plantations.

The Game Laws of British Guiana, both against shooting and trapping, are well planned, exceedingly strict and thoroughly enforced. Data concerning them may be had from Mr. James Rodway, Curator of the Georgetown Museum.

\section{Political Relations, Trans- PORTATION AND OPFORTUNITIES FOR RESEARCH (W. B.)}

The data which I give relating to the conditions at Kartabo, near Georgetown, apply to many localities in the other 
Guianas, Venezuela and Colombia, except for the great advantage of a stable British Government at one's back.

Georgetown, a city of 60,000 , is the capital of British Guiana and is on the coast. It is reached in two weeks from New York by the excellent steamers of the Furness, Withy Line. There are comfortable hotels, rail and automobile roads along the coast, but inland, almost the whole country is unexplored scientifically, and it is possible to penetrate into the interior only by the rivers and waterways, and occasional Indian trails. On the coast the majority of the inhabitants are either negroes or East Indian coolies. In the interior are scattered Indian tribes, and equally isolated hamlets of bovianders of mixed blood-dutch, Indian and negro. The Indians and negroes are the most reliable workers and the former make excellent hunters but poor collectors.

Under the auspices of the New York Zoological Society I have maintained a Tropical Research Station for seven years at Kartabo at the point of juncture of the Mazaruni and Cuyuni Rivers 45 mi. from Georgetown. Here 32 months have been spent, and research carried on by 28 workers from England, France and the United States and 160 contributions have been published, including four bound volumes.

The Station is in the heart of the tropical rain-forest, with large swamps near by, and is at an elevation of only $50 \mathrm{ft}$., yet there has never been any case of malaria or other fevers or illness, nor serious bites from serpents or other creatures. The staff sleep in tents with flaps wide open and no mosquito nets, as these insects are unknown. No siestas are taken and the amount of work and working hours show an increase over those in the north. At the end of a ten months' season, neither men nor women show any ill effects whatever of continuous hard work, although in close proximity to the equator.

Realizing the value of concentrated effort in a limited field, an area of one quarter of a square mile has been marked out and studied, with results which reveal the unbelievable richness of tropical life. These results are now being published in Zoologica, the scientific publication of the New York Zoological Society.

Life History notes have been made on 75 species of mammals, including all the important forms of northern South America. Over 450 species of birds inhabit the district, 108 species of reptiles and amphibians, and over 130 forms of fish. This latter figure represents one-third of the whole fish fauna of the Colony, and was obtained along only a short 200 yards of river.

The coastal and river swamps may be easily studied from Georgetown as a base. For inland work on the biota of the coastal region, Kartabo, the site of the Tropical Research Station, is strongly recommended and may be reached quickly and easily from Georgetown. For study of the sand and clay region, a base may be made at Rockstone on the Essequibo river (one day from Georgetown) or at Tumatumari on the Potaro (two days from Georgetown), at both of which excellent accommodations are available in rest-houses maintained by Sprostons, Ltd., of Georgetown, who also provide regular transportation and mail service. From all other places, an expedition is practically necessary, in the equipment of which Sprostons, Ltd., will be found invaluable. The nearest savannas are on the cattle-trail, 20 to $50 \mathrm{mi}$. southeast of Wismar (one day from Georgetown by steamer), but the typical savanna biota is best seen on the upper Essequibo or Rupununi rivers (about 15 days by boat). The plateau and mountain vegetation are reached with comparative ease, but at considerable expense, along the Potaro river above Kaieteur Falls (5 days from Georgetown), with the assistance of Sprostons, but the Roraima district with its rich endemism is to be attained only by an expensive expedition requiring the packing overland of all supplies. 


\section{REFERENCES}

Anthony, H. E. 1921. Mammals Collected by Wm. Beebe at the British Guiana Tropical Research Station. Zoologica, 3: 265-285.

Beebe, C. William. 1916. Fauna of four square feet of Jungle debris. Zoologica, 2: 107-119.

Beebe, C. William. 1909. Ecology the Hoatzin, Zoologica, 1: 46-66.

Beebe, Hartley and Howes, and White. 1917. Tropical Wild life in British Guiana. New York.

Andre, E. In the Guiana Forest. Rodway, Wm. A Naturalist in the Guianas. London.

\section{ECUADOR}

\section{By Wilson Popenoe and}

H. E. ANThoNy

\section{TOPOGRAPHY (W. P.)}

Ecuador is popularly divided into three regions, the Pacific coast, the Sierra or inter-Andean region, and the Oriente or trans-Andean portion. The coastal region is in the main an alluvial, low-lying plain formed of detritus brought down from the Andes; in the southernmost part of the republic, near the frontier with Peru, it is practically desert in character; about Guayaquil it is swampy during a portion of the year, and extremely dry during another portion; north of this point, as far as Bahia de Caraques, it is somewhat more broken, with several ranges of hills, and has practically the same rainfall as the Guayaquil section; while to the north of Bahia de Caraques it is extremely moist.

The inter-Andean region, though commonly termed a plateau, consists in reality of a number of small basins, lying between the eastern and western ranges of the Andes, and separated by extensions of the latter which are known locally as "nudos" or knots. From north to south the Sierra increases in aridity.

The basins themselves, which usually lie at elevations between 7000 and 9000 ft., possess delightful climates, with abundant rains during a large part of the year (except in the provinces of Tungurahua and Leon, where rainfall is scant), and a rich volcanic soil excellent for agricultural purposes. In these regions were found the principal centers of population and agriculture in preColumbian days.

Within sight of each other, twentytwo snow clad peaks rise from the interAndean plains, presenting one of the most magnificent scenes in the world. Many of these can be scaled without difficulty; others, such as Cayambe and especially Chimborazo, "King of the Andes," are difficult of ascent. Because of their isolation, and the paucity of knowledge concerning them, these peaks are extremely attractive to those interested in geography, geology, and natural history generally. Among modern investigators, Reiss and Steubel (1871-1873) and Edward Whymper (1880) are perhaps the most important. They have obtained the following measurements of altitude:

Eastern Cordillera:

feet

Cayambe (W.)......... 19,186

Sara-Urca (W.) . . . . . . . 15,502

Antisana (W.) .......... 19,335

Sincholahua (R. \& S.)...... 16,365

Rumiñarui (R. \& S.)....... 15,607

Cotopaxi (W.) ............. 19,613

Tungurahua (R. \& S.) . . ... 16,690

Altar (Capac-Urcu) (R.\& S.). 17,730

Sangay (R. \& S.)......... 17,464

Western Cordillera.

Cotocachi (W.) ........... 16,301

Mojanda (R. \& S.)........ 14,088

Pichincha (W.) ........... 15,918

Atacatzo (R. \& S.)......... 14,892

El Corazon (Chamalari) (W.) 15,871

Illiniza (R. \& S.) .......... 17,405

Carihuairazo (W.)........... 16,515

Chimborazo (W.)........ 20,498

The trans-Andine region of Ecuador is similar in character to the neighboring portions of the upper Amazon basin occupied by Colombia, Brazil, and Peru. It is a great forest-covered plain sloping gradually toward the east, and broken on its western margin by short spurs from the Andes as well as by low, isolated ranges which lie between the courses of the larger rivers. It is scarcely inhabited, explored only in 
small part, and offers much of interest to the naturalist.

\section{BIOTA (H. E. A.)}

\section{Luxuriant tropical rain-forest (humid tropical zone)}

a. Esmeraldas district. This district is typical of the coastal forest north of Bahia de Caraques. It extends to Panama. Plant life flourishes and luxuriant vegetation makes an impenetrable canopy. The principal trees of the forest are large and grow to great heights, some of them branching out to form vast canopies of leaves. The names of these trees are legion, but among the most conspicuous are the varieties of wild fig and of the silkcotton or kapok. Others are the socalled cedar, rubber trees, ivory-nut, and many species of palms.

The lower forms of life; countless multitudes of ants work night and day, the long clean-swept paths of the leafcutting ants being seen everywhere, while dense waves of carnivorous ants periodically sweep over large areas. Termites, the so-called white ants, build huge nests on the limbs of trees and riddle dead timber. Brightly colored butterflies, of great size float lazily through the upper regions by day, while more somber-hued, but even more marvelously colored, moths make their appearance at sundown. Frogs frequent every little brook course and damp spot where fallen leaves give them cover, vociferous at night or on overcast days and beautiful in their colors of clear green with markings of yellow or red.

Lizards and snakes while not often, nevertheless lurk in suitable localities and the brilliant coral snake, with bands as precise and conspicuous as if they had been painted on with a brush dipped successively in red, yellow, and black, is a not uncommon sight. A rare snake is the huge anaconda, which may reach a length of as much as 15 to $20 \mathrm{ft}$. and a girth of astonishing dimensions.

Birds are present in great variety, the number of distinct forms being more than 300. Many of them would occasion little comment if seen in northern woods, but there are hosts of others utterly unlike anything in the north. Noisy parrots, gaudy macaws, grotesque toucans, showy hangnests or caciques, and many others are found in the forests of this zone, and are among the most conspicuous denizens. Life and color are added by the flashing plumage of humming birds, trogons, tanagers, and the cotingas.

"The mammals are more secretive and difficult to observe; nevertheless, in time a great many species may be noted. The most prominent mammals are the monkeys, among which first place is given to the large howler (Alouatta aequatorialis), whose reverberating roar is a voice worthy of the jungle, and as characteristic as is the voice of the coyote on our western plains. The sonorous voice of the howling monkey seems fairly to shake the air when heard at close range."

-b. Trans Andine region. See Colombia and the Amazon Valley.

c. Mammals of the Tropical Rainforest. $(\mathrm{E}=$ eastern; $\mathrm{W}=$ western.) Ecuadorian black howling monkey (Alouatta aequatorialis W), red howling monkey (Alouatta seniculus E), night monkey (Aotus gularis E), (Aotus vociferans $\mathrm{E}$ ), spider monkey (Ateles variegatus E), titi monkey (Callicebus cupreus E), marmoset (Callithrix melanura $\mathrm{E}),(\mathrm{C} e-$ buella pygmaea $\mathrm{E}$ ), capuchin monkey (Cebus aequatorialis W), (Cebus albifrons E), woolly monkey (Lagothrix infumata E) Humboldt's woolly monkey (Lagothrix lagotricha $\mathrm{E}$ ), Tamarin monkey (Leontocebus graellsi E), Saki monkey (Pithecia monachus E), squirrel monkey (Saimiri sciureus E), brocket deer (Mazama fuscata), (Mazama zamora), (Mazamagualea), (Mazama tema), (Mazama americana), (Mazama rufina) EW, tapir (Tapirus americanus), whitelipped peccary (Tayassu albirostris), spectacled bear (Tremarctos ornatus majori), black peccary (Pecari niger), ocelot (Felis pardalis aequatorialis), (Felis pardinoides andina), jaguar (Felis 
onca), puma (Felis concolor söderströmi), jaguarondi (Herpailurus yaguarondi), bassaricyon (Bassaricyon alleni), (Bassaricyon gabbii medius), squirrels (several distinct groups) (Sciurus hoffmani) group 2 (Sciurus tricolor) group 1. Microsciurus (pigmy squirrel), cane rat (Dactylomys dactylinus), rabbits (Sylvilagus surdaster, S. daulensis and $S$. kelloggi), sloth (Bradypus spp.), sloth (Choloepus hoffmanni), ant-eater ( $\mathrm{Ta}$ mandua spp.), ant-eater (Cyclopes various races), giant ant-eater (Myrmecophaga jubata), nine-banded armadillo (Dasypus novemcinctus); mouse opossum (Marmosa spp.), large opossums (Didelphys marsupialis group, and $D$. paraguayensis group), coati-mundi ( $\mathrm{Na}$ sua quichua jivaro), grison (Grison vittata brasiliensis), kinkajou (Potos flavus modestus), tayra (Tayra barbara madeirensis and $b$. senilis).

\section{Arid deciduous forest (arid lower tropical zone)}

a. Manta district. Here there is a short rainy season and a long period of extreme drought during which trees lose their leaves. It is a region of intense sunlight and open spaces, a region of little rainfall and of hot, parched plains and hillsides. River valleys open up long vistas from the coast eastward into the interior, where the conditions of this zone prevail.

The mammals include the tapir, white-lipped peccary, jaguar, puma, ocelot, sloth, ant-eater, nine-banded armadillo; coati-mundi, grison, and tayra; capuchin monkey, black howling monkey, opossums, weasels, hares, squirrels, kinkajou, aguit, paca.

\section{Savanna (arid lower tropical zone)}

Below Guayaquil, in the region of Santa Rosa, the broken plains are covered with low scrub interspersed with bits of grassland, dry during part of the year; in the region of Guayaquil, and extending up the valleys of the Guayas and Daule, the land is very low and is covered in places by scrubby forest; elsewhere it is open, with grass in wet season, and arborescent shrubs scattered here and there.

The mammals include the Ecuadorian Fox (Cerdocyon sechurae), nine-banded armadillo, jaguar, ocelot, opossums, squirrels (Sciurus straminens group), ant-eater, rabbit, deer (Odocoileus).

\section{Semi-desert (arid lower tropical zone)}

Vegetation in the extreme southern portion is very scant, essentially desert.

The mammals include the Ecuadorian fox, squirrel (Sciurus stramineus), ninebanded armadillo, bats of many species.

\section{Montane forest (humid subtropical zone)}

It lies between 3000 and $9000 \mathrm{ft}$. in humid regions. "The animal life is quite similar to that of the tropical. For a great many species this is the zone of greatest abundance."

See list tropical rain forest animals. Practically all of the species listed for tropical forest would range, at times at least, up to $9000 \mathrm{ft}$.

\section{Interandine grassland and savanna (arid subtropical zone)}

7000 to $9000 \mathrm{ft}$. The principal hoyos, or inter-Andean basins, of Ecuador, beginning at the Colombian frontier and going southward, are as follows: That of Ibarra, drained by the Rio Mira which flows into the Pacific near Tumaco in Colombia; Quito, drained by the Guaillabamba which is an affluent of the Esmeraldas and also flows into the Pacific; the plains of Latacunga and Riobamba, drained by the River Pastaza, an affluent of the Amazon; the relatively small plains of Chimbo, Alausi, and Cañar, all drained by small streams flowing into the Pacific; Cuenca. These plains are separated by páramo regions and in general lie between the eastern and western ranges of the Andes. Formerly (and still in many places), jaguar, puma, hares, and many small rodents probably occurred. 


\section{Semi-desert}

2000 to 8000 or $9000 \mathrm{ft}$. Low annual rainfall but marked erosion of topography, vegetation very scant and xerophytic in type, made up of cacti, agave, mesquite, etc. These areas are often connected by river valleys with the arid lowland areas. The largest hoyo and one of the most important agriculturally is drained by the River Paute, an affluent of the Marañon, tributary of the Amazon; the relatively unimportant plains of Jubones and Zaruma, are drained by streams flowing into the Pacific; and finally the small butfertile plain of Loja is drained by the Rio Zamora which flows into the Marañon. A large part of southern Ecuador (Loja Province) is extremely arid.

Where aridity is pronounced, mammal life almost nil, bird life very restricted, lizards about the only reptiles seen. Where not so arid, puma, hare, many small rodents occur.

\section{Subalpine evergreen forest (humid temperate zone)}

9000 to $12,000 \mathrm{ft}$. Characterized at upper limits by stunted, gnarled trees. Many mammals of tropical and subtropical forest range up throughout the temperate forest. However the lower temperatures generally are a barrier to the monkeys, and individuals of the other species are not as numerous as lower down. Many small rodents are peculiar to this zone.

\section{Paramillos}

Paramillos at 10,000 to $12,000 \mathrm{ft}$., are often large areas of low scrub and fields of Vaccinium and allied plants.

Andean White-tailed Deer: Odocoileus peruvianus consul, Odocoileus peruvianus

Ecuadorian Guemal: IIippocamelus antisiensis

Pudu: Pudus mephistopheles

Andean Wild Cat: Felis pajeros thomasi

Andean Wolf: Pseudalopex reissii

Spectacled Bear:Tremarctos ornatus majori

Ecuadorian Shrew: Cryptotis aequatoris Shrew: Cryptotis montivaga
Andean Hare: Sylvilagus bandinus and subspecies

American Tapir: Tapirus americanus ?

\section{Andine meadow}

Above the bushland, from 12,000 to $15,000 \mathrm{ft}$., lie the Andine Meadows or páramos. In places these are covered with dense growth of low shrubs, belonging largely to the family Ericaceae, and elsewhere support nothing but bunch grass (Stipa ichu) and frailejon (Espeletia spp.).

The mammals include the Andean white tailed deer, Ecuadorian pudo, Andean wild cat, Andean wolf, hares and small rodents of several genera.

\section{Perpetual snow}

Snow descends to $15,000 \mathrm{ft}$. on the higher slopes of the volcanoes and lies permanently from $16,000 \mathrm{ft}$. upwards.

Flowering plants and low shrubs grow right up to the limits of snow line: the Compositae are well represented. Humming birds follow the flowers.

\section{Local areas}

Water course, etc. Various genera of mice, nameless to the laymen because they have never been given common names, such as various species of $A k o-$ don, running from the lowlands, both arid and humid, up to páramo zone.

Fish-eating Rats: Ichthyomys söderströmi, Anotomys leander, Neusticomys monticolus. Found along the streams from low-lands to High Andes

Water Opossum: Chironectes minimus. Along water courses in lower zones

III. ROUTES OF TRAVEL (W. P.)

\section{Guayaquil}

Guayaquil does not have a severe climate, although nearly on the equator, and in recent years yellow fever has been wiped out. The port is at present a pleasant place in which to stop, and may serve as a base for work on the Ecuadorian littoral as well as in the southern provinces. The hotels are several. The Tivoli is recommended, 
though an even better arrangement is to take a room at the Posada Lacassagne. Living is more expensive than in Quito, though low when compared with the United States or with Colombia and Peru.

Excursions can be made up the river to interesting lowland regions and by land to Milagro and other points on the Quito line. Autos can be hired to take one across the dry plain lying east of town and as far as Santa Elena (see below). Small steamers and launches make trips to points on the coast below Guayaquil, and there is communication every two weeks with Manta, Bahia, and Esmeraldas.

Guayaquil should be avoided, if possible, from January to April, during which period the rains are heavy and constant. The coolest months are June to November, inclusive.

\section{The Ecuadorian Littoral}

Esmeraldas, the northernmost port of the republic, lies at the mouth of the Esmeraldas River, in a region of humid climate and rain forest. Accommodations are fair, and from this point it is possible to penetrate into a littleknown part of Ecuador, using canoes or other shallow draft boats.

Bahia de Caraques, commonly referred to as Bahia, is clean and attractive, offering good supplies of foodstuffs. A railroad extends from this point about $25 \mathrm{~km}$. inland to the settlement of Tosagua. There is an overland route from here to Quito, little used, which passes through Chone and Santo Domingo de los Colorados. The region is less humid than Esmeraldas, rains occurring from January to April, as at Guayaquil. The dry season is long and severe.

Manta, an unattractive settlement perched upon a sand heap, is the port for the town of Monte Cristi. There is a railway from the port to Monte Cristi (13 km.), Portoviejo (40 km.), and Santa Ana $(60 \mathrm{~km}$.). All this section of the country, back to the Andean foothills, is dry and brown during a large portion of the year, being subject to the influence of the Humboldt current.

\section{Guayaquil to Santa Elena Bay}

An excellent opportunity to study life, both animal and plant, in the arid coastal region is offered by the route Guayaquil to Santa Elena Bay, which has as its objective the watering-place known as Salinas. Plans were put on foot to build a railroad connecting the two points, and a route was surveyed and a roadbed graded. Tracks have not been laid up to the present (1925), and the roadbed is used for automobile travel. The $150 \mathrm{~km}$. between Guayaquil and Salinas is usually covered in about five hours. There is no good drinking water available along the road, nor supplies of any sort, excepting a small stock of canned goods at the settlement known as Zapotal.

The first $50 \mathrm{~km}$. are over level country covered with low, scrubby growth, parched and brown during the long dry season, but luxuriant during the rains; the remainder of the journey is mainly over a flat plain covered with a very scanty growth of shrubby vegetation, and in places grass during the wet season.

\section{Southern Ecuador}

A journey through the southern portion of the republic involves a deal of hard travel, but presents opportunities for studying several highly interesting regions. It may be made on horse or mule back, starting either from Huigra, on the Guayaquil to Quito railroad, and proceeding thence through Cañar and Cuenca to Loja, or one may leave Guayaquil by steamer and proceed to Santa Rosa, whence the journey is made on horse or mule through Portovelo (Zaruma) to Loja. It may be found advantageous to enter by one route and leave by the other, and in the following brief notes such a course will be assumed:

A small steamer leaves Guayaquil once a week for the port of Santa Rosa, 
a voyage of about twenty-four hours. Food and a cot or hammock for sleeping can be obtained on board, but no bedding. A light blanket should be taken. It is necessary to arrange in advance for securing riding and pack animals at Santa Rosa, in order that they may be sent from Portovelo or some other point in the interior to meet the steamer.

The journey from Santa Rosa to Portovelo (Zaruma) requires two days, unless the road is in bad condition, when three may be necessary. This trail was at one time notorious as the worst in Ecuador; in recent years it has been improved and it is now passable even in bad weather. The country between Santa Rosa and Portovelo is for the most part thinly populated, and practically no food can be obtained between the two points. Leaving Santa Rosa, the trail crosses a level plain for some distance, and then enters the canyon of the Rio Santa Rosa. Past Limon Playa the canyon becomes narrow, and the trail crosses the shallow stream sixteen times. After a short day's ride, the spot known as La Chonta is reached. Here there are accommodations for several travelers, maintained by the company which operates the mine at Portovelo.

Immediately past La Chonta is a steep ascent known as La Escalera (the staircase); this continues to the crest of the range (6300 ft.), through luxuriant vegetation and typical rain-forest conditions. After following along the side of the mountain for some distance, the range is crossed, and a descent made through the small settlement of Ayapamba (4640 ft.) to the valley of the Rio Calera, which is followed to within an hour's travel of Portovelo (elevation $2100 \mathrm{ft}$.).

The settlement at Portovelo (about two mi. from Zaruma) is American throughout, with modern buildings and equipment. By making arrangements with the company's agent in Guayaquil, properly accredited naturalists can probably secure accommodations from the manager. The country round about is not interesting, but within a few hours' travel excellent collecting ground, of various sorts, can be reached.

From Portovelo, the town of Loja can be reached in two days. The main route is as follows: From Portovelo across the Rio Pindo (bridge), thence a long ascent over the mountain known as El Tablon, thence a long and gradual descent to the village of San Pedro, (one day's ride). From here there is a slight descent into the valley of the Rio Catamayo, and an hour is spent in crossing the dry floor of this valley. The region is arid and very hot, and presents a number of interesting features. Past the settlement of La Toma there is a long ascent over the shoulder of Villonaco Mountain; an elevation of $10,300 \mathrm{ft}$. is reached, and the trail then follows along the side of the mountain at about the same level for some distance, finally descending into the hoyo (basin) of Loja, which it crosses from west to east before the town of Loja (7250 ft.) is reached.

Accommodations are poor in Loja, as in southern Ecuador generally, this section of the country being poverty stricken and not much cultivated. Foodstuffs are difficult to obtain, and the wise traveler will go well-stocked with provisions.

From Loja it is easy to cross the Cordillera de Zamora, an extremely moist region with a highly interesting flora, and descend the valley of the Rio Zamora to the village of the same name. This brings one into the country of the Jíbaro Indians, and onto the Amazonian watershed.

It is easy, also, to make excursions from Loja southward as far as the Peruvian frontier, near which is the huge and arid valley of the Rio Malacatos. There is considerable overland travel between Ecuador and Peru, via the route Loja to Piura. This trail is said to be better than that from Loja to Santa Rosa, and at certain seasons of the year residents of Loja who desire to visit Guayaquil sometimes go southward to Piura, thence by train to the 
Peruvian port of Paita, whence they travel by steamer to their destination. Leaving Loja, one has his choice of two routes for the first portion of the journey; he may proceed either through Gonsanamá and Cariamanga to Macará (on the frontier), or he may go via Catacocha and Celica. From Macará to Piura there is only one road, and that a fairly good one. By either route, the journey from Loja to Piura is made in five or six days.

The trail northward from Loja to Cuenca, and thence to Huigra on the Guayaquil-Quito railroad, is passable throughout the year, though with difficulty during the wet season (January to May), when deep mud will be encountered. The section from Loja to Cuenca is usually made in five or six days. The villages along the road, where one may pass the night, are so situated that it is difficult to make the journey unless in three very long and hard jornadas (days' journeys) or in six short ones. In any event, poor accommodations will be found, and little food, and the traveler who is not forced to depend upon the country for his suplies is indeed fortunate.

Leaving Loja, the trail crosses the plain or basin of the same name and enters the canyon of the Rio Zamora. Las Juntas, a collection of four or five huts, is reached after half a day's riding, and in another five or six hours the village of San Lucas (8200 ft.). Here there is a tambo (inn) where travelers can pass the night. Past this village, the trail leads up around the shoulder of Acacana Mountain, through interesting and attractive country. After reaching $10,200 \mathrm{ft}$., a descent is commenced and continued to the town of Zaraguro (8400 ft.), inhabited by about 2000 Indians. There is a tambo here and limited supplies are available. There is here a change in the character of the country. From Loja thus far there has been abundant rain-forest, with grass in occasional open places; from here northward the mountainsides are dry and barren, with only occasional bits of scrubby forest.
F. Two hours' riding from Zaraguro is Paquishapa (8300 ft.), and a long ascent to the grass-covered paramo. Here there are two tambos, and the region round about is highly cultivated. Another five hours brings one to Cochapata (9000 ft.), a village of perhaps 500 people, in a good agricultural region. About three hours farther on is Nabon $(9100 \mathrm{ft}$.) where there is a tambo, and limited supplies of food, as well as fodder for the animals.

After leaving Nabón, a long ascent is made to the grass-covered páramo, much of which lies at an elevation of about $11,500 \mathrm{ft}$. Ten hours' riding brings one to the settlement of Tarqui $(8750 \mathrm{ft}$.$) , in a pretty agricultural$ region, whence the road follows at the same level onto the floor of the hoyo or basin of Cuenca, and in another four hours the town of Cuenca ( $8500 \mathrm{ft}$.) is reached. Here will be found good accommodations, in one of the most attractive and prosperous towns of Ecuador.

From Cuenca northward to the town of Azogues, the road is sufficiently broad and level to serve for wheeled traffic; from Azogues to Huigra it is suitable only for pack and riding animals. The time from Cuenca to Huigra is two days. The country traversed is more densely populated than that between Cuenca and Loja, and there are better accommodations for travelers. At Azogues there is a small hotel, and another in Cañar; in the village of Tambo de Cañar accommodations can also be obtained, but from this point to Huigra there is practically nothing. In the dry season the trip is usually divided as follows: one day from Cuenca to Cañar, and one from Cañar to Huigra, or vice versa; in the wet season the section between Cañar and Huigra becomes almost impassable, and can not be done in one day.

Leaving Cuenca after a brief ascent into rough country one descends to Azogues (8300 ft.). From this point the road follows the river to Biblian ( $8900 \mathrm{ft}$.), and ascends to the paramo, which it crosses at an elevation of 11,000 to 
$12,000 \mathrm{ft}$. After a short, rocky descent, the town of Cañar $(10,500 \mathrm{ft}$.) is reached; the descent continues, and a stream is crossed. Close by is Tambo de Cañar $(10,000 \mathrm{ft}$.$) , a small village with fields$ of wheat and corn all about. Another ascent to the paramo begins, and several hours are spent crossing the latter, at elevations between 12,000 and 12,500 ft. There is then a long and gradual descent, in part through rain-forest, to the settlement of Huigra.

\section{Guayaquil to Quito}

The only important railroad in Ecuador is that which connects Quito, the capital, with Guayaquil, the chief seaport. This line, $463 \mathrm{~km}$. in length, is owned and operated by an American company. Two days are consumed by the journey from Guayaquil to Quito, or vice versa, all trains stopping at Riobamba for the night. The route is as follows:

Leaving the dock at Guayaquil, passengers proceed by steamer to Eloy Alfaro (Duran on old maps), which lies upon the opposite bank of the River Guayas. Here the railroad starts, trains leaving for Quito daily at 7 a.m. The train proceeds across a level, uncultivated plain to Yaguachi $(22 \mathrm{~km}$.), the first station of importance. From this point to Barraganetal $(69 \mathrm{~km}$.), the plain, which remains level and of low elevation, is cultivated. Beyond Barraganetal a gradual ascent is maintained to Bucay $(87 \mathrm{~km}$., elevation 975 ft.), through country in small part cultivated, covered elsewhere by brush and scrub forest.

Bucay lies at the lower edge of the rain-forest region, and vegetation along the slopes above this point is highly interesting. Here the railway enters the canyon of the Rio Chan Chan, which it ascends toward Huigra (117 km., $4000 \mathrm{ft}$.). This station, headquarters of the railroad company, is the starting point for Cuenca, Loja, and other points in southern Ecuador which are reached by trail only. There is a small but very fair hotel here. Above Huigra the slopes become dry and covered with a scanty growth of leguminous shrubs and other vegetation typical of an arid region. The ascent is rapid through Alausí (143 km., $8553 \mathrm{ft}$.), a town of some importance. The grade is $5.5 \%$ in one place and a switchback is used. At Palmira (166 km., 10,626 ft.), which lies upon a broad rolling plain, a slight descent commences and continues through the small town of Guamote (181 km., 10,000 ft.), whence the line continues at about the same level through Cajabamba $(212 \mathrm{~km}$.), a fairly large and important place, to the station of Luisa (228 km., 10,379 ft.), whence a branch line runs to Riobamba, $15 \mathrm{~km}$. distant. This town, which lies at an elevation of $9020 \mathrm{ft}$., is one of the important centers of agriculture and commerce, and supports a good hotel, at which travelers stop over night before resuming the journey to or from Quito.

From Riobamba the return is made to Luisa, whence the railroad resumes the journey toward Quito. The station of Urbina $\left(275 \mathrm{~km}\right.$. ${ }^{\prime} 11,841 \mathrm{ft}$.) is the highest point on the line. From here the line descends to the fertile, cultivated country about Mocha and Cevallos, two Indian towns of minor importance. Ambato $(317 \mathrm{~km} ., 8435 \mathrm{ft}$.), the most important agricultural center of Ecuador, supports two or three mediocre hotels, and serves as a starting point for the Oriente (eastern Ecuador) via Baños. The country round about is nearly devoid of vegetation, except cultures.

From Ambato the railway proceeds across rolling or broken country, much of it cultivated, past the town of Salcedo to Latacunga (365 km., $9055 \mathrm{ft}$.), a somewhat smaller place than Ambato and Riobamba, and later ascends to the páramo at the base of the volcano Cotopaxi. When the weather is fine, excellent views of the volcano are had. The station of Cotopaxi (405 km., $11,653 \mathrm{ft}$.) is the highest point reached in this section of the line, and from here there is a descent into cultivated country once more. There is now a short ascent. 
through the hills, and the road comes out into a narrow valley whose edge it follows to Quito.

\section{Quito}

The capital of Ecuador is a picturesque and interesting city, lying upon a small plain at the foot of the volcano Pichincha. Due to an elevation of $9450 \mathrm{ft}$., its climate is cool throughout the year. The Hotel Metropolitano is recommended. Naturalists, especially those coming with credentials from the United States Government, should by all means call upon the American Minister before undertaking work in the republic. Through him the coopperation of the Ecuadorian government, which has taken an exceedingly generous attitude toward scientific work of all sorts, can easily be obtained.

As a base for work in the highlands of central and northern Ecuador, Quito is the best spot. Interesting collecting grounds may be found in the immediate vicinity of the city. The slopes of Pichincha have furnished material to naturalists. A few miles distant lies the remarkable Guaillabamba canyon, $4000 \mathrm{ft}$. deep, whose slopes lie within the arid subtropical zone. Several snow-capped volcanos lie within striking distance of Quito and offer excellent opportunities for work at high elevations.

\section{Eastern Ecuador}

From the Ecuadorian highlands the principal routes to the Oriente (as the Amazonian side of Ecuador is popularly called) are four in number. Beginning at the north these are: the Papallacta trail which leads from Quito through the village of Papallacta to Archidona, Tena, and Napo; the Baños route which, starting at Ambato, descends the Rio Pastaza and reaches the ancient settlement of Canelos; the trail from Riobamba to Macas, the largest town in eastern Ecuador; and lastly the trail from Loja across the Cordillera de Zamora to the town of Zamora in the Jibaro country.
The Papallacta trail was one of the first routes from the Ecuadorian highlands to the Amazonian plain. After passing Papallacta it first reaches Baeza, then Archidona (2000 ft.). Sinclair and Wasson report this settlement to consist of four or five white families in as many houses arranged about a public square. Six and one-half $\mathrm{mi}$. from this point is Tena (1700 ft.), the present capital of the Province of Oriente and residence of the Governor. Five or six families comprise the village and there are numerous Indians in the neighboring jungle. A few miles farther is the town of Napo, which lies on the flat north bank of the river of the same name at an elevation of $1850 \mathrm{ft}$. This is a place of about the same size as Tena and lies at the head of canoe navigation.

The most convenient route into the Oriente is that which, leaving Ambato, crosses the plain to Pelileo and descends the river Pastaza. The picturesque and interesting town of Baños (6014 ft.), $30 \mathrm{mi}$. from Ambato, lies immediately at the foot of the volcano Tungurahua and is locally famed for its hot springs. The village offers poor accommodations, but excellent collecting upon the neighboring slopes of Tungurahua and in the valley of the Pastaza. Richard Spruce spent some months here. The ascent of Tungurahua is not difficult and can be accomplished easily in a day and a half. Leaving Baños, where Indian guides can be obtained, one travels on foot or horseback through the settlement of Pondoa and upward to the spot known as El Campamento. The elevation here is about $13,500 \mathrm{ft}$. and a small quantity of water is available. The night can well be passed at this point and the following morning the ascent of the cone begun on foot. Since the last eruption the region above El Campamento has been covered with volcanic scoriae which makes progress slow and laborious. Higher up are vast snow fields which extend almost to the crater. The last few hundred yards are free of snow due to the presence of numerous fumaroles which give off hot 
gases. The crater was inactive for many years but in violent eruption during 1916. In 1925 it still exhibited considerable activity.

About 5 mi. below Baños, the Pastaza passes over the falls of Agoyan, $198 \mathrm{ft}$. high. Sinclair and Wasson, who explored this portion of Ecuador in 1921, state, "Several mi. below Baños we entered the Amazon jungle. We crossed the Rio Verde by bridge, the Machay by a dangerous ford. At Quebrada San Francisco, $42 \mathrm{mi}$. east of Ambato, we noticed sedimentary rocks for the first time. Similar rocks were seen at the Rio Topo, 50 mi. east of Ambato, where a bridge has been built. Shortly beyond the Topo we had to leave our horses, and our journey from there on was on foot. At Mera, $55 \mathrm{mi}$. east of Ambato, at an elevation of $3800 \mathrm{ft}$., the Pastaza emerges from its great canyon. We found the village to consist of a string of about ten houses. It is in the belt of maximum rainfall."

From Mera the trail, which can be negotiated only on foot, passes through Puyo and Indelyama to the village of Canelos (1690 ft.) situated on a beautiful plain overlooking the Rio Bobonaza. Dominican priests are almost the only white residents. It is surrounded by pastures and farms and is said to have few mosquitoes and no malaria. It is the terminus of the trail from Ambato, for here the Bobonaza is navigable by canoe and ten days by water brings one to the Pastaza at Andoas, head of navigation on that stream.

The trail from Riobamba to Macas is of the same character as the two routes above described. Macas, a town of about 500 white people, is the largest in eastern Ecuador. It lies on the south bank of the Upano River at an elevation of $3580 \mathrm{ft}$., according to Sinclair and Wasson.

The trail from Loja to Zamora, far to the south of the others just described, is relatively short and, unlike the others, can be traversed by animals, though during periods of bad weather certain portions must be done on foot. The
Zamora region is mentioned in connection with the discussion of Loja and surrounding country.

\section{Northern Ecuador}

The overland route from Quito northward is much traveled as far as Ibarra, capital of the rich agricultural Province of Imbabura, and to a less extent as far as Pasto in the neighboring republic of Colombia. While not suitable for wheeled vehicles except between Otavalo and Ibarra, the trail is in general of good character and passable for horsemen at nearly all times of the year. Occasionally the section between Ibarra and Tulcán becomes deep in mud and is traversed with difficulty. The region between Quito and the Colombian frontier holds much of interest to the naturalist. The remarkable Guaillabamba Canyon, which lies almost exactly upon the equator $10 \mathrm{mi}$. north of Quito, presents an admirable opportunity to study conditions in the arid subtropical zone. North of this lies the Páramo de Mojanda, where are to be found bits of low forest and the typical shrubby vegetation of the páramo region. Near Otavalo is the Lake of San Pablo, one of the largest bodies of water in the Ecuadorian highlands. Beyond Ibarra is the extremely hot and dry Chota Valley and between this and Tulcán is another interesting paramo region. Off to the east lies the Cordillera de Pimampiro, an extremely moist region in which little collecting has been done.

From Quito to Ibarra there are two principal routes, one going through the town of Pomasqui, thence across the Guaillabamba Canyon up through the village of Malchinguí, across the páramo of Mojanda, and through the prosperous town of Otavalo; the other passes through Carapungo, descends to the Guaillabamba River and passes through the village of the same name, ascends thence to the town of Cayambe, whence it passes to Ibarra. Of the two routes, that through Pomasqui and Otavalo is the shorter and is generally preferred 
by travelers. It is not so good a road in seasons of heavy rainfall; hence the Guaillabamba-Cayambe route, which stays at lower elevations and on sandier soil, is preferred during such periods. By either route it is a two-day ride from Quito to Ibarra. If the PomasquiMalchinguí route is chosen, travelers leave Quito early in the morning, reach Pomasqui, which overlooks the Guaillabamba Canyon, in two and a half hours, descend to the Guaillabamba River which is crossed at an elevation of $6000 \mathrm{ft}$., and then climb by a tortuous, rocky trail to Malchinguí (9600 ft.) which is reached by dark. Here the night may be passed, though the accommodations are poor. Leaving early the following morning, the Páramo de Mojanda is crossed in the forenoon and Otavalo is reached in time for lunch. Three hours more over good road past the foot of the Volcano Imbabura, brings one to Ibarra.

If the Cayambe route is chosen, travelers leave Quito early in the morning, pass Carapungo, a small town overlooking the Guaillabamba Canyon, and descend to the river which is crossed before noon. After a gradual ascent the village of Guaillabamba (7200 ft.) is reached. This lies on a mesa $1000 \mathrm{ft}$. above the river and is notorious for malarial fevers. Ecuadorians usually shrink from the idea of spending the night there, due to the danger of contracting malaria. Continuing by a good trail, Cayambe ( $9450 \mathrm{ft}$.) is reached by nightfall. There is an inn, though accommodations are not good. Leaving early the next morning, Ibarra (7500 ft.) is reached by two or three in the afternoon. Here there are two or three small hotels.

Leaving Ibarra for the north, the trail passes over the shoulder of Yura-cruz Mountain and descends into the arid valley of the Rio Chota, which stream it crosses at a village of the same name $(5000 \mathrm{ft}$.). There is then a long ascent past the village of Mira through a region of barley and wheat cultivation to the town of El Angel (10,000 ft.) where a stop is usually made for the night. The second day takes one over an interesting páramo region to the town of Tulcán on the Colombian frontier.

The journey from Tulcán to Pasto requires another two days. The time consumed in actual travel from Quito to Pasto is therefore six days. Ecuadorians with good riding animals sometimes do it in five, but the traveler dependent on hired animals can expect to make little speed.

From Pasto it is feasible to continue northward through Popayán to Cali, chief city of the magnificent Cauca Valley in western Colombia. It is six or seven days' travel from Pasto to Popayán and two more from Popayán to Cali. From the latter town there is a good railway to the port of Buenaventura, whence steamers sail fortnightly for Panama and Guayaquil, and there is an overland route to Bogotá by the Quindio Pass.

\section{EQUIPMENT}

The naturalist contemplating work in Ecuador will require besides his collecting apparatus the following articles:

Saddle, bridle, and saddle blanket. While the question of a saddle is largely a matter of individual preference, the eleven-inch McClellan will be found one of the most satisfactory obtainable, if not the best of all, for work of the type to be done in Ecuador. A small size is necessary, since the animals obtained in tropical America are rarely as large as North American horses. The bridle should be of small size and provided with a curb bit. For use under the saddle, the best possible thing is a full size O. D. army blanket, which can be folded twice, giving four thicknesses of material.

For the lowlands, khaki clothes are suitable. Heavy shoes and leather puttees are desirable for the highlands as well. In the latter region a warm riding suit of wool should be provided. Commodious saddlebags are essential, as also an aneroid barometer with scale reading to $16,000 \mathrm{ft}$. or better still 20,000 
ft. The watch size barometers are less accurate than those about three inches in diameter. For tropical rains, the rubber poncho made in Latin America is the best possible thing. For the cold drizzles of the highlands, the native woolen poncho is preferable. This can be obtained in any of the highland towns and is a comfortable and altogether excellent thing. For use in the lowlands, a mosquito bar of fine bobbinet should be provided. For sleeping, a light cotton hammock is the best thing if one is accustomed to it. The folding canvas cot is good, but much heavier and more costly to transport. Three or four heavy blankets are required for the highlands.

The best means of carrying funds is in the form of New York drafts, which should be payable to one's self and in denominations of fifty or a hundred dollars. These can be sold in Quito or in Guayaquil and a better rate obtained than for letters of credit and travelers' checks, though the latter are fairly satisfactory.

All equipment should be packed in small trunks (the army locker is best) and canvas sacks so as to be carried on mule back when necessary. Pack saddles are not required, as they are furnished with the pack mules hired in the country.

\section{REFERENCES}

The classic work on Ecuador is Teodoro Wolf's “Geografia y Geologia del Ecuador," published at Leipzig in 1892. Though now out of print, occasional second-hand copies may be secured in Guayaquil and Quito. Wolf spent many years in accumulating the data contained in this book, which is probably the most exhaustive study published. Considering the wide range of subjects he attempted to cover, it is no wonder that occasional inaccuracies are included. The English naturalist, Richard Spruce, traveled in Ecuador during the years 1857 to 1860, after having come up from the Amazonian plain. He had been commissioned by the British government to secure seeds and plants of the various quinineyielding trees-species of Cinchonawhich, due to his efforts, were successfully established in the Asiatic tropics. His "Notes of a Botanist in the Amazon and Andes" (London, 1908) contain much information on Ecuadorian natural history, and make excellent reading. More recently (1909) the Italian naturalist, Enrico Festa, has written a book entitled "Nel Darien e nel Ecuador," which will be found useful, as also Hans Meyer's "In den Hoch-Anden von Ecuador" (Berlin, 1907) and Wilhelm Siever's "Reise in Peru und Ecuador" (Leipzig, 1914). H. E. Anthony, who collected mammals in Ecuador for the American Museum of Natural History in 1921, has published interesting articles in the National Geographic Magazine, October, 1921, and Natural History (Journal of the American Museum of Natural History) for SeptemberOctober, 1921. An excellent account of a journey through the little-known region at the eastern base of the Andes is given by Sinclair and Wasson, under the title "Explorations in Eastern Ecuador," in the Geographical Review for April, 1923. Other data on this region will be found in James Orton's "The Andes and the Amazon" (New York, 1870) and Dr. Hamilton Rice's article, "From Quito to the Amazon via the River Napo," which appeared in the Geographic Journal for 1903. Manual Villavicencio's “Geografia de la Republica del Ecuador" (New York, 1858 ) is also of interest. "The Commercial Travelers' Guide to Latin America," published by the U. S. Department of Commerce (obtainable from the Superintendent of Documents, Government Printing Office, Washington, D. C., price \$1.25), will be found useful.

As to maps, the one published by Wolf in connection with his book is probably the best, but it is scarce and expensive at the present day. Felicisimo Lopez, using the Wolf map, has prepared an excellent and portable 
"Atlas Geografico del Ecuador" (1907) which will be found extremely useful by all who plan to travel in the republic. It can be obtained in second-hand book stores of Guayaquil and Quito. The Flemming map, based upon Villavicencio, Wolf and other sources, is also useful. Large areas of the republic have never been surveyed, hence an altogether satisfactory map is not yet obtainable.

Students interested in the Quichua language, which is spoken by the Indians of the Ecuadorian highlands, will find the subject well set forth in Juan M. Grimm's "La Lengua Quichua," published at Freiburg in 1896. This contains the essentials of Quichua grammar and a vocabulary of words used in Ecuador. It can be obtained in Quito and Guayaquil.

\section{THE AMAZON VALLEY}

\section{By Orland E. White}

\section{GENERAL CONDITIONS}

\section{Topography}

The Amazon valley includes northeastern Bolivia, eastern Peru, eastern Ecuador, southeastern Colombia, portions of southern Venezuela and most of northern Brazil. This huge area, over $2,000,000$ sq. mi. in extent, lies wholly within the tropical zone and consists for the most part of an alluvial gently sloping dished plain, broken in the east by a series of hills and ridges less than a thousand feet in height, which are extensions of the Guiana mountains. This plain with its mountainous borders on the north, south, and west, may be likened in form roughly to a grocer's sugar scoop, lying in an east and west direction parallel to the equator, with its back on the flanks of the Eastern Cordillera and its mouth on the shores of the Atlantic Ocean. The mountainous borders of this basin in the west consist of the wall-like range of the Eastern Cordillera of the Andes, with numerous snow-capped peaks rising to over $20,000 \mathrm{ft}$. and with breaks in the wall through passes often over $15,000 \mathrm{ft}$. high. On the north are the broken ranges of the Orinoco watershed, not so high as the Andes, but in some respects even more difficult of access. Here the greatest break is that through which the Casiquiare river unites the Orinoco and Amazonian waterways. The southern side of the Amazonian "scoop" is largely the high table land of central Brazil with low ranges of mountains, the western extension of which causes the series of rapids known as the Falls of the Madeira. Outlying spurs indicate the proximity of the main ranges, which in the west come very abruptly, for practically the whole area lying in Brazilian territory and comprising the major part of the basin is much less than $1000 \mathrm{ft}$. in altitude. The head of the Madeira river is less than $500 \mathrm{ft}$. and the Amazon river on entering Brazil is about 266 ft. altitude.

The central axis of this area is the Amazon river originating in the small streamlet Lauricocha in the Peruvian Andes, about $100 \mathrm{mi}$. northeast of Lima and at an altitude of about $17,875 \mathrm{ft}$. For a few hundred mi., under various names, its course is north almost to the northern boundary of Peru, where it changes to east, entering and continuing through Brazilian territory as the Solimõens until it unites near Manaos with the Rio Negro, its principal northern affluent, where its course becomes northeast and under its general name of "Amazon," it reaches the Atlantic Ocean, near Para (Belem), after a journey of between 3000 and $4000 \mathrm{mi}$. Its principal southern tributaries are the Madeira, Tapajos, Xingu and Tocantins. High lands, sometimes rolling, sometimes flat lie between the principal tributaries on both sides of the main river and these are referred to as "canpos." The principal northern one lies north of Obydos-the Campos Geraes. At the head waters of the Rio Branco is another such area, while the southern side is plentifully supplied 
with such regions. Between the annual high and low water limits, lie immense flood plain areas of perennially enriched land locally known as "varzias." $\mathrm{Nu}$ merous lakes, natural canals both temporary and permanent dot and intersect this region. The whole basin has been graphically likened to that of a region recently the bottom of a great sea, which, gradually subsiding, leaves ridges of alluvium, cut off lakes, networks of intersecting waterways and small and large areas that have been covered with water only shallowly. The coastal plain of this basin is low, swampy and mangrove embowered.

\section{Climate}

From the standpoint of climate, the area can be divided into at least four regions: the region of perpetual snow, the temperate, the subtropical and the tropical: and two seasons, wet (winter) and dry (summer). The region of perpetual snow (above 17,000 ft., average temperature about $1^{\circ} \mathrm{C}$.) occurs only in connection with the eastern flanks of the high Andes. The temperate lands lie in this same region roughly above $9000 \mathrm{ft}$. with an average annual temperature of about $12^{\circ} \mathrm{C}$. The subtropical comprises such regions as the Yungas valleys of Bolivia, lying at an elevation of between 3000 and $9000 \mathrm{ft}$. (average annual temperature $21^{\circ} \mathrm{C}$.), while the remainder of the area, making up most of the basin, is tropical (average annual temperature about $25^{\circ} \mathrm{C}$.). Each of these regions is characterized by its own faunal and floral types. The seasonal rhythm differs over this area. North of the Amazon the seasons are retarded, while south of it they are advanced. On the north, on the Rio Negro, the rainy season begins in February, reaches its maximum in April, May and June. On the Rio Branco, a tributary of the Rio Negro, the rains begin in April and reach their maximum in June and July and end in August. In the Acre district on the south side, the wet season, or tiempo de agua lasts from September to April, the driest months being June and July. On the Beni and Mamoré rivers, the rains are expected toward the end of November, February and March being the wettest months, with June marking the beginning of the dry season (tiempo de secho). Portions of the main river never have very marked seasonal distinctions. At Pebas, below Iquitos, Peru, the driest month is August, while at Para (Belem) the rains continue throughout the year, September to November being the months of least precipitation. The average annual rainfall at Para is 248.6 $\mathrm{cm}$.; the total average number of rainy days based on 18 years of records, 252, the months of January to June ranging from 22 to 28 days per month. At Manaos (based on 5 years of records) the average annual rainfall was 165.7 cm., rainy days per year, 154.3, the rainiest months by days being December to May ranging from 19.3 to 22.7 days per month. At Porto Velho on the Rio Madeira the average annual precipitation (years 1907 to 1912) was $264.0 \mathrm{~cm}$., ranging from $14.22 \mathrm{~cm}$. in September to $38.68 \mathrm{~cm}$. in December with $1.78 \mathrm{~cm}$. in July, the driest menth. At Para, most of the rain falls in the afternoon, evening or during the night. In the Beni river country, in Bolivia. this also seemed to be the case. The relative annual humidity at Para is 88.3 , maximum 89 , minimum 43 , the highest month being February (93.8), the lowest October with 84.2 At Manaos, the figures are: average 77.6 , maximum 99 , minimum 54. The highest humidity at this station occured at 7 a.m., the lowest at 4 p.m. The average annual temperature at Para (Belem), based on 9 years records, was $25.8^{\circ} \mathrm{C}$., with but slightly over a degree difference between the monthly averages. Another set of observations indicates only $3^{\circ}$ or $4^{\circ}$ difference between the maximum and minimum over a 24 hour day, the highest temperature being recorded about 1 p.m. At Obydos several hundred mi. from Para, essentially the same temperatures are recorded. At Porto Velho, the average recorded temperature was $27.78^{\circ} \mathrm{C}$., maximum 
$36.63^{\circ} \mathrm{C}$., minimum $14.43^{\circ} \mathrm{C}$. (4 years of records) with a difference of only $2.25^{\circ} \mathrm{C}$. between the coldest (June) and the hottest month (September). At Rurrenabaque, Bolivia, on the Beni river and at the base of the last Andean spur, at an altitude of about $1000 \mathrm{ft}$., the average temperature is said to be around $25^{\circ} \mathrm{C}$. Higher up at Huanaco, Peru, altitude $6270 \mathrm{ft}$., the average annual temperature is about $24^{\circ} \mathrm{C}$., while at Iquitos, Peru, lower down, the temperature is higher. The campos regions north of the Amazon are said to be more temperate than the main river valley. The records and opinions of many travellers (among them A. R. Wallace) show the climate of the Amazon valley, for the most part, to be a relatively pleasant one, as far as the temperature is concerned, its chief disagreeable quality being its everlasting, enervating sameness.

In many parts of this region, winds of various kinds modify the temperature markedly. During the dry season, the prevailing winds on the lower Amazon (below Manaos) are from the north and east ("vente geral"), while the "vente de cima" from the west and southwest prevails during the rainy season. At times, particularly in the dry months, a night breeze the "terral" hovers over the river. In the upper river region embracing the country between the Beni and Mamoré on the south and the upper Rio Negro on the north as far east as Manaos, very sudden changes in temperature are caused by the "sur" (Beni) or "friagem" (Purus river region), a strong cold wind that blows spasmodically between March and June from the southwest. A drop of temperature from $33^{\circ}$ to $11^{\circ} \mathrm{C}$. in a few hours at about $520 \mathrm{ft}$. altitude has been recorded from northeastern Bolivia. Accurate detailed climatic data are lacking for many of the areas immediately adjacent to the east Andean ranges. Even during the dry season, there are regions here that are saturated with moisture, such as the Yungas in Bolivia and the tops of many mountain ridges.
In July and September, in such regions, almost everything is moisture-laden and embowered in damp moss and lichens.

\section{ORIGINAL BIOTA}

\section{Vegetation and large animals}

Heavy forests that for unbroken extent and diversity of vegetation types are nowhere equalled in the world, border the main river and its principal tributaries, extending far up the eastern flanks of the Andes, where they are gradually replaced by the shrub or chaparral (ceja) formations which continue the zone of woody plants to about 10,000 to $12,000 \mathrm{ft}$. altitude, the last remnants confining themselves closely to the stream beds, deep down in the canon-like valleys. For 2000 to 4000 ft. above this woody plant limit, the slopes are occupied by herbaceous temperate types. Higher still is a scanty vegetation, largely grasses and alpines, the latter closely appressed to the ground and only occurring in favorable situations, such as sheltered springs. The "campos" regions (pampas, pajonales, savannas) between the main tributaries and in the vicinity of the headwaters of many of the affluents are rather high prairies, of ten monotonously flat with marshy depressions (curiches) through which very sluggish streams act as drainage canals. Some of the "campos" regions are hilly, rolling and comparatively dry, such as the Campos Geraes (Brazilian Guiana), while others such as the Campos Mojos, in northeastern Bolivia, are rather wet even before the rainy season begins. Between the pure prairies and the forests (monte, montana) is a park-like country of prairies sprinkled singly with trees, and with islands of woody vegetation (ihlas de mato) varying in size from a square rod or so up to 5 to 10 acres. Between the forests and the low water line, particularly on the upper Amazon and on most of the southern tributaries, but not on the Rio Negro and other "black water" rivers, there are often areas dominated largely by the huge 
cane grass, caña brava, Gynerium (Rio Beni, Bolivia). These areas sometimes extend back a mile before they meet the forest. On the Rio Negro, the water and the forest meet, as they do on many smaller streams here and there through the basin. Another type of differentiation in the vegetative areas depends on the flood plain-the territory between low and maximum high water recorded over many years (varzias) and the terra firma, land not subject to the annual inundations, except under exceptional circumstances. Wooded portions of the varzias are "ygapos" or "igapos," while those dominated by the great herbaceous stems of the giant arum (Montrichardia arborescens) are "aningas." The greatest differentiation between the different areas is found, generally speaking, on the outer edge of the basin, where the streams begin and the mountains act as barriers and species preservers. In fact these peripheral regions, especially in the west are veritable nurseries for new species, each mountain valley often acting as a specialist for distinct types. As the streams unite and form larger streams and these unite to form still greater arteries, the differentiation between regions becomes less and less until the lower Amazon is in some respects a huge jumble of the animal and vegetable life from all its tributaries, unless special factors of some kind have interfered to prevent a contribution. So the farther away from the delta, in general, the more varied the natural life.

The high altitudes are the home of the semi-domestic llama and alpaca and their wild relatives the vicuna and guanaco. Chinchillas, viscachas and the cavia (guinea pigs) abound in some parts, while in the highest regions the condor makes its home. Plant life in the Andes reaches a height of over 15,000 ft. (4600 m.). Wiry "ichu" grass (Stipa), Festuca and Calamagrostis, rushes, a few hardy and peculiar bromeliads, such as Pourretia, 10 to $12 \mathrm{ft}$. tall with a sentinal-like habit, and mounds of moss- like "yareta," largely Azorellas and Aretiastrums, are characterisic forms. This whole upper region is extremely bleak, barren, stony and full of moors. There are no woody plants, except here and there patches of tola (mostly a composite, Lepidophyllum) which somewhat recall the sagebrush of western North America. Little carpets of starflowered alpines (Gentians, Cerastiums, Perezias) and the dandelion-like Wernerias hug the sheltered slopes, especially near water. Clumps of Opuntia dot the desolation with little thorny domes. Between 11,000 and 12,000 ft., the vanguard of the forest begins to appear as occasional bushes and small trees (Polylepis, Buddleia) and these often abound with parasitic Loranthaceae. Lupines, bushy yellow-flowered Calceolarias, Senecios, Polypodium ferns, lycopodiums (L. robustum), Baccharis, border the high water boundaries of the small streams. Wernerias become plentiful. Between 9000 and $10,000 \mathrm{ft}$., chaparral (ceja) shubbery is present, in quantity and large variety, Rubus, Berberis, Ribes, Calceolaria, Barnadesia, Viburnum, Tibouchina, Fuchsia, and Clematis are common representatives of the woody types, while herbaceous plants are found in such typical forms as Anemone, Tropaeolum, Crotalaria, Bystropogon, Solanum, Gerardia, Liabum, Bomarea, Commelina, Gunnera, Nicotiana, and Tagetes. Among the perchers, or epiphytes, small Tillandsias, climbing Polypodium ferns, various peppers (Peperomias) and orchids (Odontoglossum) are common as forerunners of the great epiphytic plant world, miles away and thousands of feet nearer the sea level. Both purple and yellow dodders $(\mathrm{Cus}$ cuta) furnish evidence of the aggressiveness of the parasitic plants, as they enmesh and wind about their hosts. Climbing composites (Mutisia) and Clematis ramble over the bushes, while above the chaparral area, the grassy slopes are colonized with Bromeliads (Pitcairnia, Puya), red-flowered ground orchids (Epidendrum) and Salvias. Lichens (Usnea, etc.) are prominent on 
shrub and stone. At Pongo de Quime, Bolivia, such a region is in full flower in July, hummingbirds darting from bush to bush and the air is full of springtime scents. Possibly such a district, barring the campos, is the most strikingly floriferous part of the great valley.

From 9000 to $5000 \mathrm{ft}$. (Bolivian Yungas) the country becomes rapidly and progressively more tropical, though both tropical and temperate types are present in strange mixtures, such as Alder (Alnus) trees loaded with epiphytic bromeliads. Palms are still practically unrepresented, except by small thorny undergrowth types. The stumpy-thumb-twigged Cecropias are only occasionally in evidence, while begonias, both giant and dwarf are very conspicuous. This is the elevation where that best of all possible fruits, the Annonaceous cherimoya (Cherimolia), is found wild and matures in perfection under cultivation. Here also all manner of relatives of the potato and tomato swarm, one of the most delicious of which is the "tomati de lima," (Cyphomandra betacea) which in some regions (near Suri, Bolivian Yungas) is grown about the native villages in groves. The mountain tops at this level (in the Andes) are often clothed in Tibouchinas, bushy 6-foot fuchsias loaded with scarlet flowers and shrubby growths plentifully supplied with yellow-spotted perching orchids. The steep mountain slopes (e.g., between Suri and Canamiña, Bolivia) grow coca (Erythroxylon) both cultivated and wild, while the bottoms of the narrow valleys furnish proper climatic conditions for oranges, bananas and coffee. Amaryllids of the large-flowered sort often color the pathway. In certain regions (particularly fine on mountain ridges near Canamiña, and near Covendo, Bolivia) typical rain forest conditions prevail, with dark gloomy forest growth (laurels and slender palms), dripping tree ferns (Cyathea, Alsophila) with mosses and lichens in profusion on stems, leaves, trunks and as ground covering. Small prairies and moors abound with ground orchids, grasses, composites, ferns, thorny Rubus sp., while small streams furnish favorable conditions for Vernonias and other stream-side plants. Wild bean (Phaseolus) vines together with other leguminous types types make tangled masses of vegetation along the trails. Rocky cliffs, several hundred feet high, often furnish marvelous illustrations of the beauty of the bromeliads, while forests of small trees, all but leafless at times during the dry season, present the spectacle of thousands of perching gray-leaved relatives of the pineapple in bloom-a wonderfully effective study in cerise and Corot gray (Espia, near Canamiña; Bolivia). The puma (Felis concolor) and the Andean bear occur in this general region, but monkeys are rare. The llama as a pack animal disappears below this elevation. Cinchona, Chusquea, Calceolaria, Podocarpus, Viburnum, Ceroxylon, Bocconia, Monnina are characteristic genera, while the Melastomaceae and Solanaceae are very profusely represented. The Bolivian Yungas is a characteristic illustration of this level. Travel by train to Eucalyptus, thence by auto to Pongo de Quime, thence by mule to Canamiña.

Below $5000 \mathrm{ft}$. though still mountainous, generally speaking the real tropics begin, where sugar cane, bananas and monkeys flourish. Dry mountain slopes between the river bottoms and the small prairie plateaus support a luxuriant xerophytic covering among which agaves and huge tree cacti (Cereus, Opuntia), are prominent. The tropical plants so commonly associated with the Amazon basin, however, do not appear until an elevation of less than $1000 \mathrm{ft}$. has been reached. Below this level, Para rubber (Hevea sp.), Brazil nuts (Bertholettia), Lecythis sp., wild pineapples (Bromelia), Papaya sp., palms of many kinds (Attalea, Guilielma, Mauritia, Iriartea, Astrocaryum), the cow tree (Mimusops), Vanilla, Cedrela (cigar-box cedar), rosewood, tulip wood, purple-heart (Peltogyne), cassavas (Manihot sp.), cacao 
(Theobroma), balsa (Ochroma), silk cotton (Eriodendron), Bixa, Anacardium, Spondias, Genipa, Tecoma, Panama hat plant (Carludovica), guavas (Psidium) and Victoria regia are widely distributed and common. Families particularly conspicuously represented in tree form other than the palms are the laurels, myrtles, Bignoniaceae, Solanaceae, Sapotaceae, Bombacaceae, Meliaceae and Papilionaceae. The Bignoniaceae are markedly the glory of the American tropics, representatives of them either as vines or trees furnishing the most striking and varied color effects. Other trees or vines producing effective color spots in the monotonous green wall when in bloom are Petrea, Bougainvillea, Erythrina, Triplaris, "aceituna" (Vitex), Calliandra, and numerous Malpighiaceous vines. Typical varzea trees are the cannon-ball tree (Couroupita), Ceiba, Guarea trichilioides, Hura crepitans, Andripetalum. Ficus, Ochroma, Tessaria and Hevea. Cacao, Brazil nut, and various Rubiads are typical of the higher ground. Palms are not a striking element of the river scenery in any portion of the upper basin, i.e., above the entrance of the Madeira, but on the lower river they are very conspicuous, forming great thickets.

The Acanthaceae and Selaginellas often carpet the forest floor for miles, while various species of Heliconia, especially in low, swampy areas, produce vivid tropical effects with their enormous banana-like leaves and bright red and yellow inflorescences. Meibomias also form extensive carpets on the sandy river flats beneath the willowlike Tessaria thickets.

Most of the animal life of the forested region is found close to the streams, much of it living in the huge canebrakes (Gynerium) or just back of them. Various species of monkeys (Mycetes, Ateles, Hopale, Midas, Lagothrix, Nyctipithecus) are common below $3000 \mathrm{ft}$. Other generally distributed Amazonian animals of this level are the tapir (Tapirus), jaguar, ocelot (Felis pardalis), peccary (Dicotyles), Irara or mielero (Galictus), puma (Felis concolor), capybara (Hydrochoerus), coati-mondi (Nasua), opossum, sloth (Bradypus, Cycloturus), paca (Coelogenys paca), agouti (Vasiprosta), deer (Cervus, Coassus), manatee (Manatus), and the vampire bats (Andira and Phyllostoma). Typically widely distributed birds are represented by the "perdis" (Tinamus), parrots, toucans, macaws (Ara), orioles (Icterus, Cassicus), eagles, vultures, hoatzins (Opisthocomus), mutum (Crax), jacanas (Penelope), egrets (Ardea), scarlet ibis (Ibis), anhingas (Plotus), ducks (Cairina and Sterna). The common turtle is Podocnemis. The swamps, sluggish streams and lakes usually contain one or more species of cayman (Caiman). The rivers and lakes present a marvellously diversified fish fauna, among them giant catfish, the pirarucú (Sudis) and species of the blood-thirsty piranha (Serrasalmo) in white, black and red colors. Electric eels (Gymnotus) are not uncommon in certain regions in half covered forest pools. The snakes, relatively speaking, are not numerous, but representatives of both the poison groups occur (Lachesis, Crotalus, Cophias, Elaps). The constrictors (Eunectes, Epicrates) reach huge proportions, anacondas of over $20 \mathrm{ft}$. length not being uncommon. Fresh water dolphins (Steno, Inia) disport themselves in small schools throughout the Brazilian Amazon basin.

The "campos" regions are typically represented by such plant genera as Curatella, Hymenaea, Genipa, Copaifera, Piptadenia, Bauhinia, Zamia, Smilax, Sporobolus and Andropogon. Ground orchids are common (Sobralia, Cyrtopodium). The slow moving streams are covered with floating vegetation (Azolla, Salvinia, Pistia (water lettuce), water lilies and enormous stretches of water hyacinth (Eichornia)). Acres of yellow cannas abound in the marshes between the Rio Beni and the Mamoré rivers. Malvaceae and Gesneraceae are well represented. Palms, cacti, portulaca, bromeliads, epiphytic orchids are 
common as elements of the "ihlas." Typical of the animal life of these prairies are the armadillos (Prionodontes, Tatusia, Lysurus), the banded great ant-eater (Myrmecophaga jubata), the prairie turtle (Cinosternum), deer, the South American stork (Mycteria), the wild $\operatorname{dog}$ (Canis) and the rhea (in certain regions south of the Amazon-Bolivia, east of the Beni from Reyes).

\section{PRESENT BIOTA}

Civilization has only modified the biota slightly through the rubber and brazil nut industries. Agricultural development is insignificant. Game is not plentiful, but for the most part, the country above Manaos-the whole upper basin forming a triangle between the Madeira, the Andes and the Rio Negro-practically remains unchanged.

\section{GUIDE AREAS AVAILABLE FOR STUDY}

1. Rio Uaupés and the Upper Rio Negro. Reached by both regular and-trading company steamers from Manaos. Regular monthly steamer to S. Isabel on the Rio Negro and from there to Rio Uaupés by canoe and launch.

2. The Javary river district. Reached by regular monthly Amazon S. N. Cy. Co. steamer to Remate de Males, 40 mi. up from its mouth.

3. Northeastern Bolivia (El Beni). Reached by several routes. From the east by Booth Line steamer to Manaos, Brazil, regular semi-monthly Amazon River S. N. Cy. steamers to Porto Velho, thence by weekly MadeiraMamoré R. R. train to Bolivian frontier, thence by Bolivian government or trading company steamer to Riberalta. From there passage can be secured on the monthly government launch to within a short distance of Rurrenabaque. From west, see directions for No. 4.

4. Cochabamba River district. Mules and guides from La Paz, Bolivia to Espia, head of navigation on the Bopi river, thence by balsa raft to Covendo Mission. Arrangements should be made several months in advance with the
Franciscans in La Paz for balsas and Indian balseros. December to April or May, transportation is not practicable.

5. Bolivian Yungas, easily accessible from La Paz.

6. Territory tributary to Iquitos, Peru. Regular steamers reach here from Manaos.

For all these regions, camping equipment, special outfits, and certain kinds of canned goods, if desired, should be brought from the United States. Small metal change in quantity, trading articles (knives, salt, large fish hooks) are very desirable in some parts of the Bolivian territory.

\section{BIBLIOGRAPHY}

1. Le Cointe, Paul (Commercial Museum of Para). L'Amazonie brésilienne: Le pays-ses habitants, ses ressources, notes et statistiques jusqu'en 1920 . 2 vols., $528+495$ p. Augustin Challamel: Paris, 1922 probably most useful work cited, deals with climate, physical geography, navigation, (particularly as to river steamship lines, number of sailings per month, distances, etc.), fauna (130 p.) and flora (giving the native as well as the scientific names of many of the species of mammals, birds, fishes, etc., trees, economic plants of local use, etc. with information concerning habits, abundance, habitat, etc. of the animals, the uses and localities of economic plants, etc. A section is devoted to advice to travelers upon hygiene: bibliography of 200 titles.

2. Bates, H. W. Naturalist on the river Amazons. 1st. ed. 1863. To be had in many editions, including one in the Everyman Library Series. This work together with No. 3 are the most useful and authoritative works in English on the natural history of the Amazon valley, although written primarily from the viewpoint of zoology and No. 2 particularly from that of entomology: regions described are: Para and vicinity; the Rio Tocantins; the lower Amazon from the Bay of Maraio to Obydos and from Obydos to Manaos; Santarem and vicinity; Rio Tapajos; the upper Amazons from Manaos to Ega, and Fonte Boa and St. Paulo. 
3. Wallace, A. R. A narrative of travels on the Amazon and Rio Negro, with an account of the native tribes, and observations on the climate, geology and natural history of the Amazon valley. Reeve \& Co.: London, 1853. Natural history of the Rio Negro, Rio Uaupés, etc. The description begins at Para, takes in the Tocantins, and then describes the lower Amazon, the Rio Negro and the Rio Uaupés.

4. Spruce, Richard. Notes of a botanist on the Amazon and Andes. Being records of travel on the Amazon and its tributaries, the Trombetas, Rio Negro, Uaupés, Casiquiari, Pacimoni, Huallaga, and Pastasa: as also to the cataracts of the Orinoco, along the eastern side of the Andes of Peru and Ecuador and the shores of the Pacific during the years 18491864. Ed. by A. R. Wallace. 2 vols. MacMillan \& Co.: London, 1908. Written as a natural history account intelligible and interesting to the layman as well as to the trained scientist, with the primary emphasis on the vegetation aspect (best in English).

5. Whitney, Caspar. The flowing road. Adventuring on the great rivers of South America. Wm. Heinemann: London, 1912. This volume gives a very true picture of the difficulties of South American jungle travel. There are several chapters on the Rio Negro, together with an excellent chapter on "Outfitting for jungle travel."

6. Miller, Leo E. In the wilds of South America. Six years of exploration in Columbia, Venezuela, British Guiana, Peru, Bolivia, Argentina, Paraguay and Brazil. (Under the auspices of the American Museum of Natural History.) Chas. Scribner's Sons: New York, 1918. The author's interests were primarily birds.

7. Orton, James. The Andes and Ama- zon. 3rd. ed. revised and enlarged. Harper \& Bros.: New York, 1876. A much neglected work containing a wealth of information on the whole Amazon valley, written in the language intelligible and interesting to both scientist and layman.

8. Herndon, W. L. and L. Gibbon. Exploration of the valley of the Amazon, made under the direction of Navy Department. 2 vols. 2 vols. of maps. U. S. Govt. Publ.: Washington, 1854 . Much meteorological data are given. Pt. II by the junior author is devoted to explorations on the bolivian tributaries of the Madeira. Most of the report is presented in diary form.

9. Goncalves, Lopes. O Amazonas. Esboco historico, chorographico e estatistico até o anno de 1903. The Amazon. Historical, chorographical and statistical outline up to the year 1903 . In 2 parts, part II being an English translation by Richard Mardock of the Portuguese (part I). Hugo J. Hanf: New York. 1904. This work has chapters devoted to the fauna and flora.

10. Martius, K. F. P. von and A. W. Eichler, I. Urban, Editors. Flora Brasiliensis. 15 vols. 40 pts. with 3811 pl. Munich and Leipzig. 1840-1906.

11. Weberbauer, A. Die Pflanzenwelt der peruanischen Anden. Die Vegetation der Erde. XII. W. Englemann: Leipzig, 1911. Valuable for its geographical and ecological treatment of the plants of the eastern Andean slope.

12. Herzog, Th. Die Pflanzenwelt der bolivischen Anden und ihres östlichen Vorlandes. Die Vegetation der Erde. XV. W. Englemann: Leipzig, 1923. Desirable reference work for its geographical and ecological treatment of the vegetation of the eastern Andean slope and adjacent territory.

\section{Islands in the Atlantic and Adjacent Waters}

\section{BERMUDA}

The islands are located at approximately $32 \mathrm{~N}$. latitude and about 900 mi. east of Charleston, S. C. The area is approximately $50 \mathrm{sq}$. $\mathrm{mi}$. The shores are fringed with mangrove and the greater part of the island was probably covered with species of juniper tree, called Bermuda cedar. Cacti occur in arid spots and sage brush springs on denuded earth. 
For a list of land animals without ecological comments, see Wallace's Island Life.

The island has been the seat of a marine biological station associated with Harvard University. At the present time the station is not open.

\section{REFERENCES}

Heilprin, A. Bermuda Islands. Philadelphia, 1889.

Wallace, A. R. Island Life. London, 1902.

Verrill, A. E., and others. Natural History of the Bermudas, including marine and land forms. Geography and geology. Trans. Conn. Acad. Sci. Arts., Vols. X, XI, XII. 18991907.

\section{BAHAMAS}

The group consists of 29 islands and many rocks southeast of Florida. They were apparently originally covered with scrub and low forest.

\section{REFERENCE .}

G. B. Shattuck. Bahama Islands, Geographic Society of Baltimore, New York, 1905.

\section{CUBA}

\section{By Brother Léon}

Colegio de La Salle. Vedado. Habana

Cuba has an area of 44,164 sq. mi., and lies within the geographical range of $74^{\circ} 7^{\prime}$ to $84^{\circ} 57^{\prime}$ of longitude, $19^{\circ} 48^{\prime}$ and $23^{\circ} 17^{\prime}$ of latitude. Its capital, Havana, is reached in four days from New York, in two days from New Orleans, and from Key West in some hours. The system of railroads extends from one end of the Island to the other, with many branches and roads with motor car service north and south; thus natural areas can be reached easily.

Cuba is rather a subtropical than a hot country. The average temperature in Havana is $26^{\circ} \mathrm{C}$. $\left(27^{\circ}\right.$ in Santiago de Cuba), $28^{\circ}$ in August, $22^{\circ}$ in January. It is rarely over $32^{\circ}$, rarely below $10^{\circ}$. There is a dry season from November to April; the rainy sea- son takes place mainly in May-June and September-October; often July and a part of August are less rainy, or nearly dry.

Climatic data for Havana, Cuba, 1922

\begin{tabular}{|c|c|c|c|c|}
\hline & 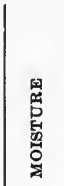 & 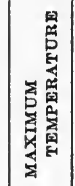 & 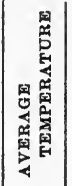 & 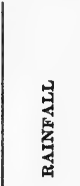 \\
\hline & & ${ }^{\circ} \mathrm{C}$. & ${ }^{\circ} \mathrm{C}$. & inches \\
\hline January. & 71.7 & 28.6 & 22.5 & 1.35 \\
\hline February & 69.7 & 29.8 & 22.8 & 1.00 \\
\hline March. . & 67.4 & 30.9 & 24.6 & 3.70 \\
\hline April. & 67.1 & 31.2 & 25.5 & 0.00 \\
\hline May. & 73.9 & 31.9 & 25.8 & 9.45 \\
\hline June. & 73.4 & 31.1 & 27.0 & 3.84 \\
\hline July. & 70.7 & 32.5 & 27.8 & 1.68 \\
\hline August. & 72.6 & 32.6 & 27.6 & 4.91 \\
\hline September.. & 77.3 & 32.0 & 26.8 & 11.58 \\
\hline October.. & 78.4 & 31.8 & 26.3 & 9.56 \\
\hline November. & 71.0 & 29.9 & 24.8 & 1.12 \\
\hline December......... & 71.8 & 29.5 & 23.7 & 1.31 \\
\hline Year. & 72.1 & 32.6 & 25.4 & \\
\hline
\end{tabular}

Average.....................4.125

Total....................49.50

The Flora of the Island, subtropical in general character, is fairly well known, thanks to the many explorations made under the direction of Dr. N. L. Britton, Director of the New York Botanical Garden and to the intense collecting work made during the last decade by the eminent Swedish botanist Dr. E. L. Ekman, to whom we are obliged for much useful information. But considerable field work is still needed to obtain a satisfactory knowledge of the present and extinct fauna of the Island. This has been proved recently by the fact that many new species of insects have been discovered, in only a few families, by Stephen Bruner and Charles Ballou during the recent exploration of Pico Turquino region.

\section{GEOLOGIC FORMATION}

The condition of Cuba during the different geologic ages is a very complicated matter; besides, "the literature published on the subject is very scanty; 
nevertheless, following the report published in 1901 by Hayes, Vaughan and Spencer, and modifying it after the recent discoveries, we may say that the paleozoic formation is said to exist in Mantua, at the western end of Pinar del Rio province, where quartzite and nearly black clay-slate are found. The same formation is seen in Southern Santa Clara province, in Sierra de Cumanayagua and also in Northern Oriente. During the Paleozoic ages, intrusions of igneous rocks (serpentine, granite, etc.) are supposed to have occurred in sediments now disappeared by erosion.

Of triassic age seems to be the formation of two parallel series of sandstone "Lomas" or rounded hills, north and south of the Jurassic chain, between Guane and San Diego de los Baños.

The jurassic was given as "absent?" in the report referred to above, but its presence has been proved by the discovery of many Ammonites by Vesa, C. de la Torre and later by M. Sanchez Roig, near Viñales, in the chain of dark blue hard limestone which forms the axis of the Organos Range, in Pinar del Rio. A great uplift and erosion must have occurred during that period.

Grey hard limestone of the Cretaceous has been found in all the provinces, with fossils of Radiolites, Barrettia, Requienia, etc. Then occurred a sinking of a large part of the Island.

Sandstone probably of the eocene has been observed south of San Diego de los Baños, in Pinar del Rio. Then, apparently, a large part of the Island was submersed, or at least in Oriente, where fossils of the Eocene have been collected. Volcanic activities of that time caused the formation of alternate beds of volcanic rocks and Eocene sediments.

Radiolarian ground of the Inferior oligocene has been found near Baracoa (Oriente).

Limestone and marls of the Superior oligocene are the most extensive geologic formations of the Island, and occur from Pinar del Rio to Oriente. Then the
Island was all submersed, except some peaks or ridges of North and South Oriente, probably of Southern Santa Clara, and surely of Pinar del Rio, otherwise it would be impossible to explain the actual presence in Western Cuba of the old Microcycas calocoma.

The miocene and the pliocene formations, given as absent or doubtful in 1901 , has been proved to exist, by the discovery of many fossils, in white limestone, near Havana, by Mario Sanchez Roig: Clypeaster lanceolatus, Hemispatagus Hoffmani, etc., teeth of Charcharodon megalodon, Lemna elegans, and of other species of sharks. A general uplift of the Island occurred during the Miocene, followed by a slight sinking and a nearly equal uprising at the beginning of the Pleistocene.

Quaternary formations are rather extensive. Of the post pliocene seems to be the clay-marl bed between Havana and Matanzas. Not far from the last locality have been found five tusks of Hippopotamus.

Pleistocene is represented by a very jaggy limestone, containing recent species, and surrounding most of the coasts, especially the northern one. Then Cuba was united with Isle of Pines.

Of modern times are the alluvions of some plains, as that of Pinar del Rio, where is common an iron-oxid more or less hydrated. Modern formations occurred also between Cardenas and Sagua la Grande, in the Camaguey plain and in Oriente.

Though much work remains to be done in the study and comparison of the faunas and floras of each of the West Indian Islands and of the neighboring continents, something may be said about the geologic relations of Cuba with the adjacent countries.

According to Dr. Ekman, the Flora of Cuba has enough elements in common with Yucatan and Honduras to assume that, probably in Precretaceous ages, it was united with them. With Yucatan through its western end, and with Honduras either through Sierra Maestra and Cayman Islands or indirectly 
through Haiti and Jamaica; but the separation must have occurred also in remote times. As to a supposed union of Cuba with Bahama Islands and indirectly with Florida, it seems to have never occurred; according to N. Taylor and Britton and Millspaugh the Bahama Islands are young geologically, and the species which they have in common with Cuba and Florida have likely been transported from one to another by natural agencies of winds, migratory birds, or oceanic currents.

Cuba itself has floral elements of distinctly heterogeneous origin. The flora of Pinar del Rio is very little like that of Oriente, and since remote times and during a long period, at least up to the Miocene, Western Cuba was surely isolated from Eastern Cuba. Even in the Eastern part of the Island, there are two quite distinct floral elements, that of the Sagua-Baracoa mountains, little like those of neighboring countries, and that of Sierra Maestra. This mountain range has many species in common with Hispaniola, Porto Rico and Jamaica, with which islands it was formerly united. Of these four actual islands, Jamaica has a flora less like those of the other three, and according to Urban must have been separated first; then, according to Arldt came the disjunction of Cuba and Hispaniola through the Windward Passage, probably at the beginning of the Pliocene.

\section{NATURAL REGIONS}

The series of parallel mountain chains which traverse the Island from West to East are covered with semi-deciduous forests; but, according to Dr. Ekman, true tropical rain forest does not exist in Cuba, except, may be, in the Baracoa region, where one tree of the Brazil rain forest is growing, Carapa guianensis.

If we take into account the geological constitution of the different parts of the Island and their corresponding peculiar flora, we may divide Cuba in three main regions: Western, Central and Eastern Cuba. Western Cuba may be divided in three subregions: Pinar del Rio, Isle of Pines, and Havana-Matanzas, younger geologically. Central Cuba has three natural subregions: the flat Colon region, Las Villas, hilly or mountainous, and the Camaguey plain. Eastern Cuba may be also divided into three subregions: the northern flat or hilly portion, and the two more mountainous parts of the Island, the SaguaBaracoa mountains and the Macaca range or Sierra Maestra.

\section{Pinar Del Rio}

Its axis is the Organos Range, of a Jurassic dark limestone including many species of Ammonites: Perisphinctes, Idoceras, Ochetoceras, etc. which have been found near Viñales. Fossils of fishes have also been collected there. This characteristic mountain range with its many vertical escarpments resembles from the distance the pipes of an organ, hence the name "Organos." These peaked hills, or "Mogotes," support a very interesting flora, characterized by the "Palma de Sierra" (Gaussia princeps), Anthurium venosum, Elaphrium Shaferi, Gesneria rupincola with brilliant red flowers, the curious palmlike rutacea Spathelia Britton, and by one of the oldest living plants, the "Palma Corcho" (Microcycas calocoma), which may be found in many "mogotes," near El Sumidero, and also north of Consolación del Sur. The biggest tree of this natural area seems to be Juglans insularis. These "Mogotes" of the Organos range are one of the most notable malacological regions; a great variety of snails: Chondropoma, Choanopoma, Cistula, Megalomastoma, Helix, Helicina, Urocoptis, etc., are found there.

The highest peaks of Organos range are: Pán de Guajaibón, $2500 \mathrm{ft}$., Loma de Miracielo, Loma del Pendejeral, some peaks of Sierra de Viñales, and the Mogote Grande of the Guacamayas Range, little less. The steep and generally nearly inaccessible peaks are undisturbed natural areas or approximately so; in different places they might 
be made into natural reserves, as, for instance, in Rangel region, including the scenic ravine of Santa Cruz river.

The triassic (?) hills to the north and south of this central range are barren pine lands with a low grass vegetation on their tops but with an interesting vegetation along the brooks: Xiphidium xanthorrizon, Pieris cubensis, Xolisma myrtilloides, Clusia menor, Hypericum styphelioides, Alsophila myosuroides, Blechnum serrulatum, and the lovely Lycopodium cernuum; here and there are groves of Quercus virginiana, and in some places the ornamental Befaria cubensis and Purdiaea cubensis are common.

The northern part of Pinar del Rio can be reached easily, either from Guane, the terminus station of the Western Railroad, or from Pinar del Rio City by motor car, through El Sumidero or through Viñales; from Paso Real and San Diego de los Baños, where are famous sulphur baths, and also by the North Coast Steamship Service from Havana. In San Diego de los Baños is found one of the most beautiful birds of Cuba, the "Aparecido de San Diego," (Abelorhina cyanea); Gundlach found it also in Zapata, in Matanzas province and in Oriente.

North of the mountain axis is the narrow north coast area. Bordering on the mangrove, is an interesting shrubby or low forest vegetation, with sometimes very rare plants as Phyllacantha Grisebachiana and Maytenus lineatus, rediscovered recently by Dr. Ekman.

The largest part of Pinar del Rio is a plain extending from the base of the mountains to the south coast. Its extreme southwestern end, the Guanahacabibes, usually named Cabo San Antonio peninsula, said to be about $80 \mathrm{mi}$. long, between Cape Francés and Cape San Antonio, is a coral reef with mangrove swamps on its northern shore, and behind, thickets or low woods, up to the southern high and vertical rocky shore. Between this forest and
Guane to the north, is a very peculiar region with many lagoons of clear water; between them are pine groves and barren savannas with patches of white silicious sand rich in rare and endemic herbs: figworts, pipeworts, grasses, sedges, etc. This natural area has been only slightly disturbed by the exploitation of pines.

The remainder of Pinar del Rio plain, the famous tobacco region of Vuelta Abajo, is formed by sandstone, sandy or swampy savannas and covered either by pine groves or by palms of different species: "Palma barrigona" (Colpothrinax wrightii), "Guano prieto" (Paurotis wrightii), and "Palma Cana" (Sabal florida), the most abundant of all. Only very few plants may have disappeared as a consequence of the planting of Tobacco; patches of the original vegetation may be found in many places: Tabebuia lepidophylla, Coccolobis colomensis, Hyptis shaferi, Vitex divaricata, Tetrazygia bicolor, etc. The chief modification of the savanna region is the extinction of the pines, which, possibly, were growing formerly up to the limit of Havana province. The south coast is, as nearly the entire Carribean sea coast of Cuba, fringed with mangrove swamps two or three mi. in average width.

The deer found in all the Island, is rather abundant in this Western plain; it was introduced by the Spaniards. Wild hogs, escaped long ago from domestication, are common in Pinar del Rio mountains and also in those of Santa Clara and Oriente. A ganoid fish, the "Manjuarí" (Lepidosteus tristoechus), survival of remote geologic ages, is not rare in the rivers of Southern Pinar del Rio. Near the mouth of these rivers, or near the submarine sources of fresh water lives the "Manatí" (Manatus americanus), much more abundant formerly than now. Many interesting birds may be obtrined near the lagoons of this plain, as, for instance, the following, collected in Artemisa: "Pato morisco" (Marila affi- 
nis); "Pato chico" (Nomonya dominicus); "Pato rojo" (Trismatura rubida); "Pato lavanco" (Mareca americana); "Pezcuecilargo" (Dafila acuta); "Guanabá rojo" (Botaurus lentiginosus); "Gallareta azul"' (Ionornyx martinicus); the "Gavilán caracolero" (Rosthramus sociabilis), which lives in lagoons and swamps, feeding on snails especially of the genus Ampullaria. Other species of hawks, as the "Gavilán de monte" (Buteo borealis), are also found in Pinar del Rio. A moth, (Attacus ricinus), is giving silk, but inferior to that of Bombyx mori. The river turtle "Jicotea" (Emys rugosa), is abundant here and in the other provinces.

\section{Isle of Pines}

Isle of Pines is throughout of the same nature as Pinar del Rio. In its northern and northeastern portions are some wooded limestone hills, Sierra de Casas and Sierra de Caballos, about $1000 \mathrm{ft}$. high. The central and western parts are barren pinelands, with an area, between Santa Barbara and Los Indios of the same white sand as that of the Guane-Remates region in Pinar del Rio. The southern part of the Island, the Jorobado peninzula, is a coral reef similar to the Guanahacabibes peninsula. On its southern shore, ragged aeolian rocks alternate with sandy beaches which seem to be the birth place of Thrinax parviflora, the palm of the Cuban coasts. This nearly uninhabited southern part is separated from the rest by the extensive Siguanea and Lanier's swamps. In the little disturbed woods, are found the "Roble de olor" (Macrocatalpa punctata), Schaefferia frutescens, Guayacum sanctum, Metopium toxiferum, Copaifera hymenaefolia, and the beautiful Bauhinia jenningsii; the largest tree of that region is undoubtedly the "Jocuma amarilla" (Sideroxylum foetidissimum). Several marine turtles are fished up in Isle of Pines: the "Tortuga" (Chelonia mydas), the "Caguama" (C. caretta), and the valued "Carey" ( $C$. imbricata).
According to Dr. Ekman, the Jorobado and Guanahacabibes peninsulas (their geological formation and vegetation being much alike) undoubtedly were forming the southcoast of Cuba during the Pleistocene age.

Though the population of Isle of Pines hardly reaches 5000 inhabitants, or perhaps less, good hotels are found in Nueva Gerona, Santa Fé, etc., and in motor car, one may run over the greater part of the Island. A steamship service connects Havana with Isle of Pines through Batabano three times a week.

\section{Habana-Matanzas}

Besides the low limestone hills of the north coast, this region is traversed in its length by two parallel chains of tertiary limestone. Their rocks are less hard than those of the Pinar del Rio mountains and named "diente de perro" (dogtooth) for being eroded by rain into sharp points. The Flora is not so interesting as that of the jurassic mogotes; its predominating elements are, for instance, the three species of "Guara" (Cupania americana, C. macrophylla, C. glabra); the "Víbona" (Dendropanax arboreum); the "Cigua" (Nectandra coriacea); the "Jagua" (Genipa americana); the "Ciguaraya" (Trichi!ia havanensis); Trichilia hirta; Savia sessiliflora; Mappia racemosa; the "Ceibón" (Pachira emarginata); Elaphrium simaruba, Citharexylum fruticosum, Zanthoxulum martinicense, $Z$. elephantipes, etc. Much rarer are the following. Guayacum officinale, Macrocatalpa punctata, Laurocerasus occidentalis, L. myrtifolia, Ficus jacquinifolia, Portlandia daphnoides, and Leptocereus leoni, this usually on steep rocks. Thrinax microcarpa is forming usually extensive patches which conceals the bareness of the rocks; other calcivorous plants abound, among them Philodendron lacerum and $P$. wrightii.

The birds usually found in these Havana wooded hills, are, for instance, several species of hawks: (Circus hud- 
sonius, Falco domingensis), the owl (Glaucidium siju); the "Mariposa" (Passerina cyris); the "Zorzal real" (Mimocichla rubripes); the "Totí" (Dives atroviolaceus). The "Tocororo" (Priotelus temnurus) is found in all the Island and may be approached easily; the same may be said of the "Arriero" (Saurothera merlini). The "Bobito" (Blacicus caribaeus); the "Zunzun" (Riccordia riccordii); the "Pedorrera" (Todus multicolor), the "Judio" (Crotophaga ani), the "Chinchinguaco" (Chalcophanes gundlachii), the "Sinsonte" (Mimus polyglottus), the well known singing bird, are all very common. In the caves which abound in these limestone sierras, are living several species of bats; more than twenty species are found in Cuba. On the shaded rocks, a big inoffensive milliped named "Mancaperro" is so common that one can not avoid crushing a number of them. A great variety of snails may also be collected on these limestone hills. The highest altitude of this Habana-Matanzas range is attained on Pan de Matanzas, about $1300 \mathrm{ft}$. high; the hills of Havana province reach hardly $1000 \mathrm{ft}$.

The flora of the coral reef east of Havana is strongly xerophil, and among the shrubby vegetation of "Guao" (Comocladia platyphylla), "Guao de costa" (Metopium toxiferum), "Manzanillo" (Hippomane mancinella), "Yamaquey" (Belairia spinosa), Pisonia aculeata, Ateleia cubensis, etc., are growing the characteristic Agave legrelliana, $A$. furcroides and at least half a dozen species of Cacti, as the tall Cephalocereus bakeri, Dendrocereus nudiflorus, Leptocereus assurgens, etc. There also is found the very rare and long lost Annona cascarilloides.

The plain of Habana-Matanzas is different from that of Pinar del Rio, not sandy and much more modified by the planting of Sugar cane and other economic plants. The "Palma cana" is less abundant and replaced by the "Palma Real" (Roystonea regia), the most abundant palm of Cuba; the huge
Ceiba pentandra is also seen in many places. As the soil of this plain, out of the serpentinous "Cuabales," is formed chiefly by the decomposition of the limestone sierras, its flora, preserved only in a few places not under cultivation, is partly that of the hills and partly that of the coastal reef, whose chief elements are actually: Eugenia buxifolia, E. axillaris, Ateleia cubensis, Espadaea amaena, Hebestigma cubense, Picramnia pentandra, Dipholis salicifolia, Momisia iguanea, Duranta repens; the so common and appreciated hardwood "Yaití" (Gymnanthes lucida), Cupania glabra, Hybanthus havanensis; the fragrant Guettarda calyptrata, $G$. combsii, G. elliptica, Zanthoxylum fagara, Z. toedosium, Schoepfia chrysophylloides, Helicteres jamaicensis and $H$. semitriloba, Comocladia dentata and C. platyphylla, Erithalis fruticosa, Icthyomethia havanensis, Maba crassinervis, the large drooping flowered Catesbaea spinosa; Colubrina ferruginea and $C$. cubensis, Exostemma caribaeum, the noxious Malpighia cubensis, Citharexylum caudatum and $C$. fruticosum, Casearia sylvestris and C. hirsuta, Opuntia dillenii, Acrostichum excelsum, Hibiscus cruptocarpus and $H$. spiralis; the ornamental Malvaviscus sagraeanus and Rondeletia odorata are common. Among the most abundant vines are Chiococca alba, and the showy flowered Bauhinia heterophylla and Bignonia sagraeana. In the swamps, Malache scabra and Typha angustifolia. On the northern sea shore are Suriana maritima, Borrichia arborescens, Mallotonia gnaphalodes, Rachicallis maritima, Iva cheiranthifolia and I. imbricata, while on the wet south coast are rather seen, in fields of Distichlis spicata, a number of Aster, Crinum americanum, Pluchea foetida, P. purpurascens, Samolus ebracteatus, Acrostichum aureum, Agalinis spiciflora, Mariscus jamaicensis and in places Casuarina equisetifolia naturalized. The Mangrove trees are, of course, the most common on the south coast.

Many birds may be collected on the 
coasts where lagoons or swamps are often near the seashore, as is the case a few mi. west of Havana, where have been collected "Frailecillos" (Aegialitis semipalmatus, Ochthodromius wilsonius); "Zarapicos" (Ereunetes pusillus, Totanus flavipes, Oexychus vociferus); the "Tomeguin de la tierra" (Euethia lepida); Pisobia minutilla, Atitis macularia; many "Bijiritas" (as Dendroica dominica, D. coerulea, Protonotaria citrea, Wilsonia citrina); Zenaida macroura; The "Crequeté" (Chordeites sp.); the "Chamberguito" (Coturniculus paserinus), the "Garzon" (Herodias egretta); the "Aguaita Caimán" (Butorides virescens); the "Sevilla" (Ajaja ajaja); the "Guanabá real" (Nyctanassa violacea); the "Martín pescador" (Ceryle alcyon); the "Golondrina" (Idroprocne bicolor); the "Arriero chico" (Coccyzus americanus). Eastward, in mangroves near Cardenas, Gundlach discovered one of the smallest birds of the World, the "Zunzuncito" (Calypte helenae). A peculiar character of the southern part of this Havana plain, are the subterranean rivers and caves, as those of the vicinity of Alquízar, where blind fishes have been found, as, for instance, Lucifuga subterraneus, likely in communication with the sea by these underground rivers.

Very little vegetation remains undisturbed in this region, even in the "Cuabales" or barren serpentine hills, intruded between the limestone chains; some of them as the Lomas de Coca, del Boticario, de la Pita, near Campo Florido, support a dense growth of trees or shrubs, as the "Cuabas" (Amyris balsamifera and Leucocroton flavicans); Harpalyce cubensis, Hieronyma cubana, Rheedia aristata, Stenostomum lucidum, Rauwolfia cubana, Simplocos strigillosa, Lagetta valenzuelana, Rondeletia brachycarpa; sometimes their vegetation is lower and more open, as in their vicinity of Minas and Guanabacoa, with shrubs as Reynosia mucronata, Eugenia sauvallei, $E$. havanensis, Furcraea cubensis, Brya ebenus, Annona bullata, Hibiscus costatus,
Orbicularia orbicularis; the growth is sometimes chiefly herbaceous, with the ornamental "Palma Jata"' (Copernicia macroglossa), scattered along the rivulets, and Paspalum rupestre carpetting the ground. Vernonia gnaphalifolia is also characteristic of these Cuabales. In holes of the ground are living many big spiders, the "Araña peluda," (Mygale sp.) which the boys catch easily.

The largest of the Cuban lakes, the Ariguanabo, in the Havana plain, not far from San Antonio de los Baños, but more easily reached from Havana, is perhaps the best locality for the study of the Cuban aquatic flora. There, is the large flowered Nelumbo lutea, several Castalia, among which the more common are $C$. odorata and $C$. ampla; Nymphaea advena is very abundant, as well as Nymphaeoides humboldtiana, Utricularia foliosa, Proserpinaca palustris Salvinia auriculata, and, though not so abundant, one of the most beautiful flowers is that of a grass, Luziola spruceana; patches of Salix occidentalis and Cephalanthus occidentalis cover the shallow portions of the lake; Sesbania occidentalis is not rare. Near the shores is the well known Pistia strathiotes, several species of Jussiaea, Persicaria portoricensis, Marsilea polycarpa, and the beautiful water hyacinths (Piaropus crassipes and $P$. azureus). This locality is perhaps better yet for making a collection of aquatic birds: there is found the "Guanana prieta" (Anser albifrons), the "Gallinuelita" (Crybastus gossey), the "Becasina" (Gallinago delicata), the "Gallito" (Jacana spinosa), the "Garcita" (Ixobrychus exilis), the "Gallinuela" (Rallus elegans), the "Gallareta" (Gallinuela galeata), the "Pato negro" (Marila collaris), the "Pato de la Florida" (Querquedula discors), the "Pato cuchareta" (Spatula clypeata).

\section{Colon}

This is a fertile plain, an enormous Sugar Cane district, but so low, that it has been sometimes flooded from coast to coast. On the northern border of 
that plain are the extensive marshes of Bibanasí and Majagüillar, and on its southern the largest swamp of Cuba, the Cienaga de Zapata, covering the southern part of Matanzas province, and extending from the Gulf of Batabano eastwards nearly to the important town of Cienfuegos.

The original vegetation north of Ciénaga de Zapata and south of the northern swamps has nearly disappeared; among the remnants, are found Pithecolobium discolor, Pisonia rotundata; in the savannas are Guettarda elliptica, Melanthera angustifolia, Tabebuia lepidota, Williamia discolor, Guettarda calyptrata, Arundinella deppeana. In the swamps, are found several Aster, several Hyptis, Solidago stricta; and to the south: Lysiloma bahamensis, Pithecolobium tortum, Davilla rugosa, Rheedia brevipes, Banisteriopsis pauciflora, and in places patches of the "Palma Corojo" (Acrocomia crispa).

The Zapata swamps, south of this region, are the home of the Crocodiles, although they are found, in less abundance, in many of the other swamps of the Island. There are two species in Cuba: the most valiant, commonly named "Cocodrilo" (Crocodilus rhombifer), lives in sweet waters, especially in the Zapata swamps; the largest of them, nearly $20 \mathrm{ft}$. long, are in Laguna del Tesoro, the deepest lake of Cuba, in the same Zapata region. The other (Crocodilus americanus), wrongly named "Caimán," lives usually in brackish waters and is more timid, though it attains, like the other species, a length of 15 to $20 \mathrm{ft}$. It is so little feared, that sometimes people are bathing where several of them are roaming.

Zapata is the region of Cuba where the greatest variety of birds may be observed: the "Pato aliverde" (Netion carolinensis); the "Sanjuanera" (Zenaida amabilis); Grus canadensis, Ardea herodias, Audubonia occidentalis, Nyctiardea gardeni, Platalea aja, Tantalus loculator; a number of Pigeons, as Chloroenas inornata; Patagioenas leuco- cephala; other species of the genera Starnoenas, Geotrygon, Chamaepelia, Melopelia, Perissura, Ectopistes, are in the Island. The Flamingo is becoming rare. As to the beautiful "Guacamayo de Cuba" (Ara tricolor), not rare in Zapata in former times, it has surely disappeared. Many species of ducks are also common in those swamps, but hunting in that wet region is not very agreeable, on account of the swarming mosquitoes.

The Zapata swamps are covered with a mostly herbaceous vegetation, as Typha angustifolia, Mariscus jamaicensis and many other sedges, with a patch of Mangrove trees here and there. The vegetation of Zapata peninsula, farther to the south, is a mixture of Mangrove and other forests with many different trees, as "Almácigo" (Elaphrium simaruba), Trema lamarckianum, Krugiodendron ferreum, Fraxinus cubensis, Bauhinia divaricata, Colubrina asiatica, Alvaradoa amorphoides, etc., growing on a jaggy limestone with many sinkholes. In these woods, an interesting rodent, Capromys nana, has been discovered in the recent years; it is much smaller than the other "Jutías" (C. poeyi and C. fournieri), common in the Island; this last species is so easily tamed, that sometimes it is in liberty in the houses as a pet. Near Bahía de Cochinos, are several Indian mounds. This peculiar region is easily reached through the branch connecting Jovellanos with Jaguey Grande, where are hotels, and from there to Bahía de Cochinos through the Australia Sugar Mill Railroad.

\section{Las Villas}

Behind the northern Mangrove swamps or wet savannas of this region, are two chains of limestone mountains; West of Sagua la Grande, the Sierra Morena-Jumagua group of low, rather dry hills, some of them steep, and with a little disturbed vegetation, as that of the Mogotes of Sagua much alike that of Havana coastal limestone hills: Banisteria laurifolia, Hybanthus havanensis, 
Alvaradoa amorphoides, Chascotheca neopeltandra, Argythamnia candicans, Celtis swartzii, Plumiera obtusa, Diospyros halesioides, Tabobuia saxicola. East of Sagua la Grande, in the prolongation of the first chain, is the Sabana Range, reaching an altitude of 1000 to $2000 \mathrm{ft}$. in the Sierras of Bamburanao, Matahambre and Jatibonico, in the caves of which have been found fossils of Megalocnus rodens and Crocodilus sp., by the well known Cuban Naturalist, Dr. Carlos de la Torre. In the Cays of the north coast, may be seen a hawk, feeding on fish, the "Guincho" (Pandion carolinensis). A rare owl, the "Tarabo"" (Asio accipitrinus), has been found near Camajuaní.

The country south of Sierra Morena chain, between Macagua and Santo Domingo is a rather flat or undulated and mostly barren region, of sandy or gravelly savannas and low serpentine hills. Good deer hunting can be had here, and the flora is interesting, showing evident relations to that of Pinar del Rio, especially in the wet savannas of Mordazo and Manacas, where grow several species of Eriocaulon, Xyris, Drosera rotundifolia, Rhexia cubensis. The chief features are the peculiar "Maboa" (Cameraria angustifolia), and the "Jata" palms (Copernicia glabrescens, C. hospita, C. macroglossa); Rondeletia brachycarpa, Pictetia marginata, Chrysobalanus pellocarpus, Tabebuia lepidota. That area has likely been modified and deprived at least of its pine groves. The existence of Pines in Santa Clara province, in former times, is proved by the finding of pine cones, together with the fossils of Megalocnus rodens. This central axis of serpentine is prolonged eastward into the Oriente province.

South of the Central Railroad is the most mountainous part of Las Villas, divided in two ranges. The first and more central is the Cubanacán Range of serpentine formation and denuded appearance; it reaches in Sierra del Escambray and Sierra Alta de Agabama altitudes of $2500 \mathrm{ft}$. or more. Its flora is quite rich in endemic elements. Finally, not far from the coast, and separated by Agabama river, are the two groups of the Guamuhaya Range: the Trinidad mountains and the Sancti Spiritus group. The first is chiefly built up of dolomites and attains an altitude of more than $3500 \mathrm{ft}$., in Potrerillo and Taguayabo peaks. The Sancti Spiritus mountains are formed by serpentines, micaschist and dolomites from north to south in the same order; talc and rock crystal are found in several places. These mountains reach about the same height as the Trinidad Range. As they are sometimes rather inaccessible, there are yet many little modified areas. Most of the highest ridges and peaks are moist from their contact with the fog; many streams flow from those heights and their numerous waterfalls are one of their most interesting features. The damp forest which cover the slopes has chiefly the kind of flora named 'Manacales," characterized by the "Manaca" palm (Calyptrogyne occidentalis); huge trees of Cedrela odorata and Juglans insularis are seen there, as also Citrus vulgaris, Swietenia mahogany, Magnolia cubensis, Ochroma lagopus, Dendropanax arboreum and $D$. cuneifolium, Paritium, tiliaceum, Rondeletia leoni and $R$. bicolor strongly Coumarine scented, Begonia oblicua, Mayepea domingensis, Sapium jamaicense, Ocotea cuneata, Guettarda valenzuelana, Rhamnidium rocanum, Rourea glabra, wonderful specimens of Arthrostylidium urbanii are on river banks; Taonabo obovalis is common; Ilex clementis, and Senecio plumbeus on the ridges, and Machaeonia microphylla on high savannas; but the most interesting botanical feature is the presence of tree ferns up to thirty or forty feet tall, likely the tallest of Cuba. Among the tree ferns are: Cyathea arborea, $C$. cubensis, Alsophila aspera. The floral elements of the Guamuhaya Range are of heterogenous origin, and the percentage of endemic plants usually low.

Flocks of "Cotorras" (Chrysothis leucocephalus) and of "Cateyes" os 
"Periquitos" (Conurus evops) are often seen in these mountains, as also in Oriente and other places. A number of species of hawks are also abundant, making poultry breeding very difficult. The "Caos" (Corvus minutus and C. nasicus) are not rare in those mountains. The "Iguana" (Cyclura carinata), 4 to $5 \mathrm{ft}$. long, is found on the south coast of the Island and in the cays.

The chief fresh water fishes, common also in the other provinces are: the "Viajaca," (Nandopsis tetracanthus), the most common; the "Guabina" (Phylipnus dormitator); the "Dajao" (Dajaus sp.) and the "Joturo" (Joturus. pichardi) which leap over the falls to ascend the rivers; the Anguilla cubensis, and the "Guajacones" of several genera: Gambusia, Girardinus, Limia, Trifarcius, Rivulus.

A number of species of lobsters, some of them of a large size are fished up in the mountain rivers.

The Trinidad mountains are reached from Cienfuegos by motor car; from the Central Railroad by the CumbreTrinidad branch; the Sancti Spiritus mountains by this same line, and better yet by the Zaza del Medio branch through Sancti Spiritus.

\section{Camaguey}

This is a flat country with a longitudinal zone of serpentine savannas in its center. North and south of this zone were, not long ago, extensive forests which have been replaced, in the recent years, by Sugar cane plantations. These forests are much like those of the plains westward, with the well known following elements, which seem to be predominant: Guazuma tomentosa, Bursera simaruba, Pithecolobium arboreum, Chrysophyllum oliviforme, Trichilia hirta the "Yagruma hembra" (Cecropia peltata); the "Yagruma macho" (Didymopanax morototoni); the "Palma Cana" (Sabal florida); and the spiny "Palma Corojo" (Acrocomia crispa).

The large cays of the north coast are flat and mostly with a mangrove vege- tation; the travellers say that wild horses and cattle roam in Cayo Romano. The "Sinsonte prieto" (Mimus gundlachii) has been collected in those cays.

To the south, the country is more swampy. There can be found the rare saurian Anolis fernandinae, as also Anolis equestris which is common throughout the Island.

The central zone of serpentine savannas, as to its flora, resembles closely the same zone of Las Villas, of which it is the prolongation. It is bordered to the north by the limestone Sierra de Cubitas chain, and to the south by the Najasa chain of a similar formation; they reach hardly altitudes of $1000 \mathrm{ft}$. It is said that in that region, near Chorrillo, a good number of yet upright trunks of silicified trees are found; big pieces of them have been brought to Guanabacoa about 40 years ago by the Naruralist Father Pío Galtés, being exhibited in the Escuelas Pías College of that town. The north and south coasts of Camaguey are connected by the Morón-Júcaro branches, through Ciego de Ávila, and by the NuevitasSanta Cruz del Sur branches through Camagüey. The North Coast Railroad connects Morón and Nuevitas.

\section{Northern Oriente}

There, landed Columbus and noted among the mammals of the Island, the "perro mudo" (dumb dog), which the Cuban naturalist Felipe Poey says to be the Procyon lotor or "Mapache" of México, the Racoon of Florida. After the same author, the "Mohuy," of Oviedo (Historia general de las Indias), smaller than the "Jutías," and the most exquisite dish, reserved to the Caciques, could be the "Agutf" (Dasyprocta sp.); the "Cori," our present "Curiel" (Cavia cobaya), and the "Pilori" of French authors, Mus pilorides F. Cuv.; but these indentifications of animals unknown today in Cuba, are rather uncertain.

This region includes one of the three mountain systems of Oriente, the Maniabón Range, a group of rather low, 
but steep and fantastically shaped limestone hills on the north coast, and sterile eruptive hills in the interior; they reach their highest altitude between 1000 and $1300 \mathrm{ft}$., in the barren but botanically interesting serpentine hills near Holguin. Most of the land in this hilly region as well as in the undulated central part of Northern Oriente, including the basin of Cauto river, is planted with Sugar Cane. The Caribbean sea coast is fringed with large swamps, the largest of these, Cienaga de Birama, north of the Cauto mouth, and Ciénaga de Buey south of it. Approaching these are low woods and shrubby savannas, little disturbed and with a great variety of palms.

The two remaining systems of Oriente mountains, the Sagua-Baracoa group and the Sierra Maestra chain are the most important in Cuba.

\section{Sagua-Baracoa}

The Sagua-Baracoa group, between Mayarí, Baracoa and Guantánamo is geologically muich older than Sierra Maestra and perhaps the oldest of Cuba; its flora is, according to Dr. Ekman, distinct from that of all the other regions of Cuba or neighboring islands. This group is drained by the swift Toa river, whose waterfalls, perhaps the biggest of Cuba, are so little accessible that they are nearly unknown. On each side of this river are leagues of forests very little inhabited. Toa river runs likely a larger volume of water than the Cauto (the largest river of Cuba), which gathers the waters from the north slope of Sierra Maestra. These Sagua-Baracoa mountains are usually girdled by lower limestone sierras, which are generally very steep and craggy, as for instance, the famous Yunque de Baracoa. Damp forests, abundant in Manaca palms, alternate with open pinelands or nearly impenetrable thorn forests, the so called "Charrascales." On the top of the highest of these mountains, Sierra de Cristal (4300 ft.), its first and only explorer, Dr. Ekman, found an amazing number of new and strange plants. According to Dr. Ekman, the finest woodpecker of Cuba, the "Carpintero real" (Campephilus bairdii), is abundant on this mountain, though exceedingly rare in other parts of Cuba. Sierra de Moa and Sierra de Nipe are each about $3250 \mathrm{ft}$. high. The last, despite its low altitude, has a flora so marvelously rich in endemic species, that it has yielded over 400 plants new to science in the recent years. The "Sabina" (Juniperus lucayana), the noxious "Palmilla" (Bactris plumieriana), Carapa guianensis, the splendid Spatheliae abound in these mountains and rare ferns, orchids, bromeliads, etc., are met with on every step. The climbing bamboo (Arthrostylidium sarmentosum) is often bordering the tracks in the woods with long garlands hanging from branches, and sometimes the wayside is densely carpeted with the beautifully flowered Begonia Wrightiana. Rich as these mountains are botanically, they are not less interesting to the geologist. If any place, in Cuba, should ever come into consideration for a national reserve, it ought to be this unique mountain, the Sierra de Nipe. In caves of Cape Maisí cliffs, a number of skeletons of Indian "Siboneyes," and also of Caribs who came from the Lesser Antilles, have been found by Dr. C. de la Torre. These "Farallones" (vertical cliffs) are the home of the finest Helix of the world (H. picta), with its hundreds of varieties of different colors. Not far away, near Baracoa, other rare Helices $(H$. imperator), the largest Cuban species and $H$. apollo have been discovered, the first in Mata, the second on top of Yunque de Baracoa. There is also the elusive butterfly Chlosyne perezi; other rare species of this order as Clothilda cubana, Cydimon poeyi may be found north of Guantánamo. South of this town, near Caimanera Naval Station, lives the wading bird Aegialitis nivosa and the rare snail Pleurodonte emarginata. Other rare species of snails, Brachypodellabrooksiana and $B$.turcasiana are in Monte Taurus and Monțe Líbano.neạr 
Guantánamo. Of course, many natural areas of this region remain undisturbed for being inaccessible or nearly so. One of the classic localities in Cuban history of Science, the old Lescaille Mansion, once the headquarters of the great botanist $\mathrm{Ch}$. Wright and of the eminent zoologist Gundlach, lies in the mountains north of Guantánamo, at more than $2000 \mathrm{ft}$. altitude. It is now in ruins and not very easy to find in the woods even with the aid of a guide, but if prepared, it would be an excellent site for a biological station. The rarest of the Cuban mammals, the "Almiquí" (Solenodon cubanus', insect eating, nocturnal and with its nest underground, may be found in the mountains of Sagua-Baracoa. Another mammal, not so rare (Capromys melanurus), seems to be confined also in Oriente province.

The south coast, between Cape Maisí and Caimanera Naval Station, was botanically unexplored in most of its length until 1924. It appeared to be the driest region of Cuba, and consequently, in many places there is an abundant growth of Cacti, as for instance, the "Card6n" (Lemaireocereus hystrix), the most abundant; the "Jijiras" (Cephalocereus spp.); the globose "Melón de costa" (Cactus harlowii), and the "Patana" (Opuntia hystrix), of Imias, whose branches break off and stick to the traveller, even when slightly touched. The valued "Tebenque" (Evolvulus arbuscula), several species of Croton, Thyana, Tabebuia, Plumiera are also abundant. The adjacent region is mountainous and not so dry as the coast. The highest and steepest of those mountains is the Sierra de Imias (4020 ft.), not far from the coast. The huge "Juba" (Dipholis spp.), the "Chote" (Alchornea latifolia), the "Palma boba" or "Palma justa" (Euterpe globosa), are conspicuous elements of the high zone of vegetation named "Monte fresco" (Cool forest). The top of the highest peaks is wooded and of a difficult access, owing to a dense growth of bamboo (Chusquea abietifolia). At the foot of those mountains is plenty of "Mostacillo" (Cap- paris spp.) and of "Guayacán" (Guayacum officinale), as well as a great variety of rare trees.

\section{Sierra Maestra}

The Sierra Maestra Range, the highest of the Island, is divided in three groups with a more or less similar flora. The first lies east of Santiago and culminates in the $4000 \mathrm{ft}$. high Gran Piedra. West of Santiago is the Cobre Group, with its highest peak in Loma del Gato, about $3700 \mathrm{ft}$. Features of its slopes are the groves of "Caney" (Mayepea domingensis), "Palma Justa" (Euterpe globosa), the "Plátano cimarrón"(Helicona bihai), and patches of Myrica cerifera and of Ilex montana on the gravelly hillsides. In the ravines and near the tops are dense forests including here and there some pines (Pinus cubensis), isolated or in small groves. Here, near a place named by the owners "Jardin des fougères," may be observed interesting biotic phenomena, as a palm (Euterpe globosa), $12 \mathrm{ft}$. tall, growing on the trunk of a tree fern; a large inclined Ficus tree, sustained by its former adventitious roots, transformed into several big columns nearly one $\mathrm{ft}$. in diameter. A well fitted place for biological studies is the La Salle Estate, on the crest of Sierra Maestra, very near Loma del Gato, at more than $3000 \mathrm{ft}$. alt.; probably no other house in Cuba is at a higher altitude. A number of habitations and rooms for work are available there during a great part of the year, on application to Colegio Nra. Sra. de la Caridad, Corona Alta 7, Santiago de Cuba. Not far from this city, on the south coast, $5 \mathrm{mi}$. to the East, has been found the extremely beautiful butterfly Papilio Gundlachianus.

The main group of the range, where are the highest altitudes of Cuba, is the Maestra proper, with Pico Turquino $6630 \mathrm{ft}$. high, although before its ascent by Dr. Ekman, it was supposed to be at least 1000 ft. higher. There are also other high peaks, for instance the Bayamesa, south of Bayamo, about $5600 \mathrm{ft}$., and 
Loma Joaquin \& Regino, of about the same height. The vegetation up to $3000 \mathrm{ft}$. is mostly the moist forest of the "Manacales" type, the same which is found in other moist mountains of that altitude; but from $3000 \mathrm{ft}$. up to the highest summits, enveloped most of the time in the fog, this is replaced by another type of vegetation much different from the preceding; instead of "Manaca" palm is "Palma Justa;" trees not seen in lower localities are abundant, as Clethra cubensis, Weinmannia pinnata, Henianthus salicifolius; the biggest trees are the "Barril" ( $C y$ rilla racemiflora), Magnolia cubensis, and species of Dipholis. The "Fangales," as these forests are called are furthermore characterized by a deep cover of dead leaves on the ground, where ferns of the genera Elaphoglossum, Asplenium, etc., are growing in abundance, occasionally replaced by carpets of Sphagnum. In places where the ground is more barren and rocky, and supports only a shrubby growth or low forest, the wind and sun penetrate more freely, keep away the excess of dampness, and there results instead of the "Fangales" vegetation, that of "Montefresco"; this is characterized by Garrya fadyenii, species of Xilosma, Taonabo, Viburnum, etc., together with many Melastomaceae, Lauraceae and Myrtaceae, some Rubus and several showy begonias. In open places are fields of Dicranopteris named "Helechales;" these fern fields, in drier situations of lower mountains of the Island, are usually formed of Pteris caudata and Odontosoria sp. As the high Sierra Maestra is rarely visited by anybody, the vegetation likely will not be disturbed here in a near future. In those high solitudes may be heard the melodious song of the Cuban nightingale (Myiadestes elisabeth). The wild hogs are abundant and rambling up to the highest summits of the Turquino region. Some wild dogs and cats escaped from domestication are also met with sometimes, as well as the Cuban Boa, the "Majá" (Epicrates angulifer); it reaches sometimes twelve or fifteen feet and feeds on "Jutías" and hens, but is not dangerous to man; it is common in all the Island. Among the other snakes are the "Jubos" (the terrestrial ones) as Dromicus angulifer and D. fugitivus, and the aquatic "Cativos" (Tretanorhinus variabilis and Tropidonotus cubanus). In Sierra Maestra, more than anywhere else, the traveller can easily find honey, not only of the common bee, but also the sweeter one of the stingless Cuban bee (Melipona fulvipes).

An interesting locality near the eastern end of Sierra Maestra is Cabo Cruz; here are forests of Pimienta officinalis and of Brosimum alicastrum. The "Rabijunco" (Phaeton americanus), and that very rare and most interesting of cuban reptiles (Criosaura typica) also occur there, as do Helix prominula and Liguus poeyanus.

\section{RE FERENCES}

Hayes, Vaughan and Spencer. Informe sobre un reconocimiento geológico de Cuba. Boletín de Minas. 2. Habana. 1917.

M. Sańchez Roig. La Fauna Jurásica de Viñales. Boletín especial de la Secretaría de Agricultura. Habana. 1920.

M. Sańchez Roig. Escuálidos del Mioceno y Plioceno de La Habana. Boletín de Minas. 6, Habana. 1920.

Roque Allende. Estudio técnico de los yacimientos minerales de Isla de Pinos. Boletín de Minas. 7. Habana. 1923.

Britton and Millspaugh. Bahama Flora. New York. 1920.

Ign. Urban: Symbolae Antillanae. IX. Lipsiae. 1923.

F. Poey. Memorias sobre la Historia Natural de la Isla de Cuba. I. Habana. 1851.

J. Gundlach. Ornitología Cubana. Habana. 1876.

J. Gundlach. Mamalogía Cubana. Habana. 1877.

J. Gundlach. Erpetología Cubana. Habana. 1880.

C. de la Torre. Investigaciones paleontologicas en las Sierras de Viñales y de Jatibonico. Habana. 1910.

C. T. Ramsden. Vida y exploraciones zoológicas del Dr. Juan Gundlach en Cuba. Memorias de la Sociedad Poey. Habana. 1918. 



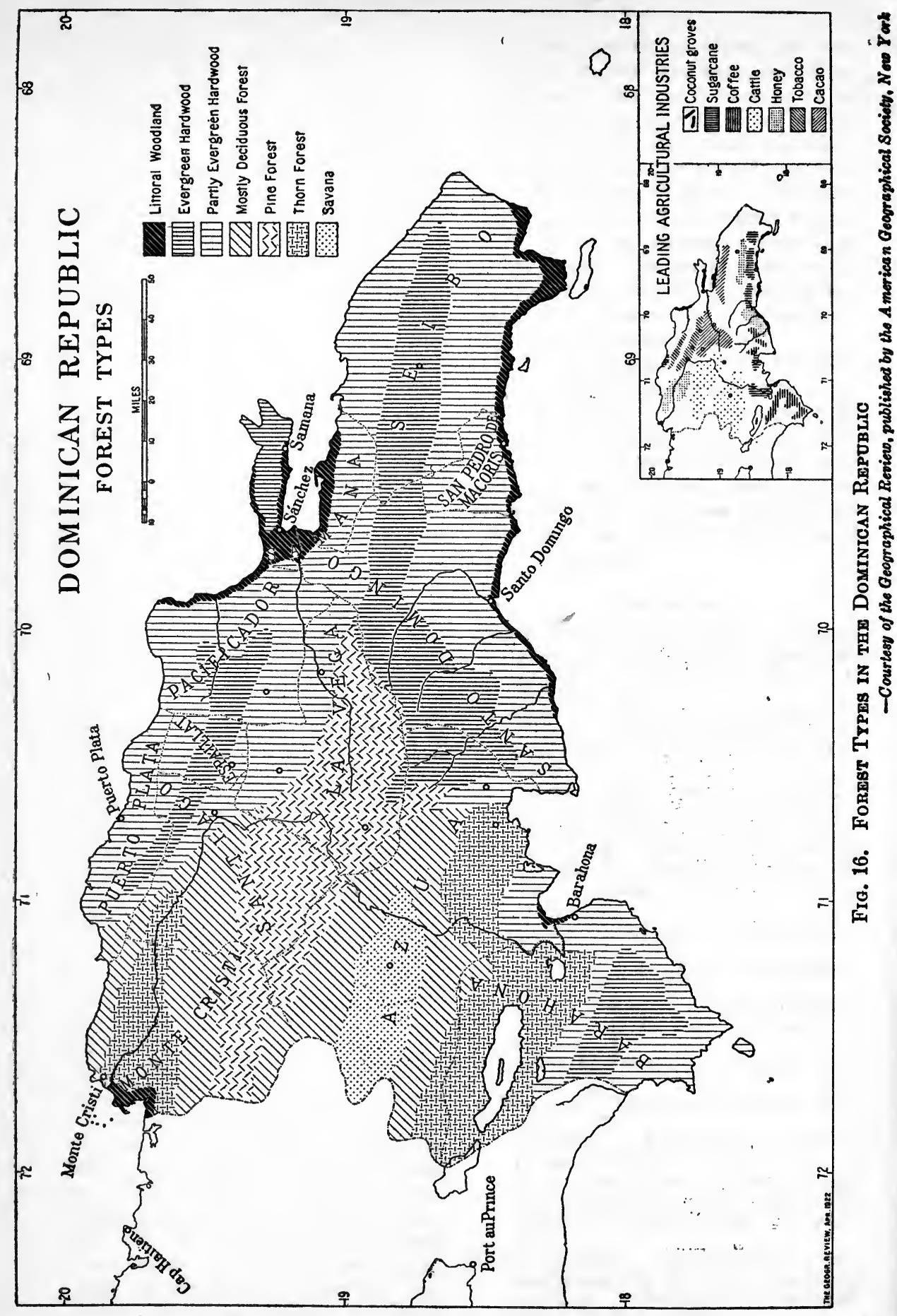




\section{HAITI AND SANTO DOMINGO}

\section{By G. Kingsley Noble}

\section{GENERAL CONDITIONS}

\section{Topography}

The island of Hispaniola is divided by four ranges which run in a general east-west direction. These, by shutting off the trade winds to a greater or less extent, control the rainfall in most of the country. The Monte Cristi range, close to the northern coast, reaches a maximum height of 1400 meters, the high points being near Loma Diego Campo and the easterly Quita Espuela ridge. The central part of the island is a great mass of ranges running in various directions but chiefly east and west. It is here that we find several peaks running up to nearly 3000 meters or over. Naturally, this mountain range catches most of the rain. To the southwest of the central Cordillera there are two additional ranges-or series of ranges-the most northern very dry, the southern wet in part.
The rains falling to a greater or less extent on these.

\section{Rainfall}

The great diversity in vegetation zones is, of course, closely correlated with distribution of the rains. With such a diversity of topography and vegetation zones in Hispaniola we would expect a considerable difference in the precipitation throughout the island. In general it may be said that there are two rainy seasons everywhere on the island. The first is a short one in May and June. Frequently it does not come at all. The second and longer season may occur in September, October or November. Almost every locality has its own rainy season, and as this varies from year to year, it is difficult for the visitor to be sure of his weather before starting for the island. The data in the table given below are compiled in part from statements supplied to me by the former Military Governor of Santo Domingo; they are based in part upon charts in the office of the Chief Engineer of Haiti.

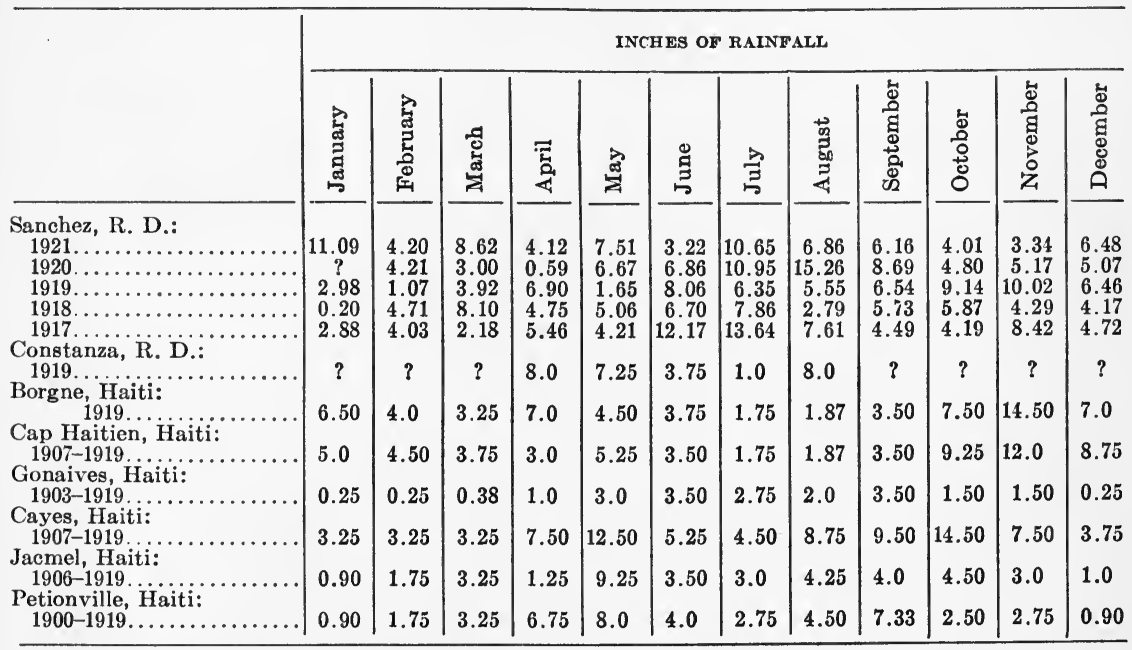

\section{Vegetation areas}

a. North slope of northern coast range is heavily forested in the east, where rain forest occurs sparsely so in the west. Some pines occur on the mountain crests.

$b$. Southern slope of northern range 
is moderately forested. There are some large stands in the east.

c. Cibao valley between northern range and central Cordillera is a broad well-settled plain. Some fine pastures occur here.

$d$. Northern slope of central Cordillera is heavily forested, at least the higher portions. Pine forests cover most of the ridges and some curve down to the lowlands, as for example at La Vega.

$e$. Central plateau is made up of rolling hills covered with grass and broken stands of pine. Dense woods choke the valleys, while thickets of fern occur on the highest peaks.

$f$. Southern slope of the central Cordillera is characterized by bare hills sparsely covered with pine.

$g$. Southeastern coast is mostly scrub country.

$h$. Southwestern mountain range of coast. Some sections (in Santo Domingo) very wet, others (in extreme southwestern Santo Domingo and eastern Haiti) rather dry, a mixture of ecological conditions.

$i$. The southwest north of the Sierra de Bahoruco is very arid; true deserts around the dead sea (Enriquillo) grade into scrub land near Barahona.

$j$. Floristic relations. To the casual observer the trees such as Lignumvitae, Haematoxylon of the lowlands, and the ubiquitous Pinus occidentalis of the hills are of interest. In the southwestern part of Santo Domingo we might expect Opuntia, Cereus, Nopalea, Melocactus, besides several species of Agave and other xerophytic plants.

\section{Animal life (faunistic account)}

The fauna of Hispaniola is of interest to the naturalist because of its peculiar zoögeographic affinities and because of the large number of indigenous forms, the affinities of which have not yet been determined. The island may have been at one time connected with Cuba and at another with Jamaica. The fauna of Porto Rico seems to be merely an extension of that of Santo Domingo.
For example, among the reptiles and amphibians of Hispaniola, Bufo, Gonatodes, Leiocephalus and Amphisbaena are all found in Cuba and most of them in Porto Rico, while not a single one occurs in Jamaica. On the other hand, Aristelliger and Mabuya are found in Hispaniola and Jamaica, the latter in Porto Rico and neither in Cuba. Another illustration of this probable duplex origin of the fauna of Hispaniola is found among the large shiny scaled lizards usually called "Lucia" by the natives of Santo Domingo. There is one species of this genus (Celestus) on Cuba, three on Jamaica, while on Hispaniola there are four, these four representing both Cuban and Jamaican elements. In addition to this Cuban and Jamaican facies to the Hispaniola fauna, there is a touch of Bahaman forms-no less than six species of reptiles and amphibians being common to the two regions.

Mention has already been made of the large number of peculiar forms on the island. The fauna may be summarized as follows:

Mammals. Very few; Solenodon, possibly Capromys and several species of bats.

Birds. A large and varied fauna. Perhaps the most interesting are an enormous piculid, Nesoctites, a peculiar nightjar, several Todys, a crossbill, a Brachyspiza and several birds of very uncertain affinities, such as Microlegia, Phoenicophilus, Calyptophilus, and lastly Dulus, which looks something like a cowbird but builds enormous colonial nests.

Reptiles and amphibians. A large fauna having affinities with other West Indian genera and species; some very spectacular forms among the tree frogs and large iguanids. No poisonous snakes occur on the island.

Fishes. Not well known, mostly West Indian; Lima, a viviparous poeciliid seems to be the dominant group throughout the island occurring in such diverse habitats as mountain brooks and brackish lakes. 
Invertebrates. A large fauna; insect pests not numerous; spectacular forms such as tarantulas, whip scorpions and gaudy land crustacea and molluscs are frequently found.

\section{NATURAL AREAS}

There is very little "virgin country" left in Hispaniola. The Haitians have destroyed practically all of their natural areas, while most of Santo Domingo, except the dense forests, wet valleys, gullies and hilltops, have been burnt over at one time or another. It is very discouraging to the naturalist to roam over the wonderful central Cordillera of the island and to never pass a day without meeting a forest fire. The arrieros make a point of burning these fine forests of the interior in order to make pasture lands they say, but it is really for the fun of seeing the forests burn.

\section{Virgin areas}

As a result of these fires the only areas which retain more or less of their original biota are the rain forests, the wet mountain gullies and the inaccessible deserts. The following wet regions would deserve special study. (1) The Quita Espuela range in the north; (2) the gullies on the north side of the central Cordillera from Paso Bajito north to Jarabacoa; (3) the rain forests of the Samana peninsula; (4) the northeastern parts of Seibo Province; (5) the southern Bahoruco range (near Paradis) and (6) certain parts of the southern peninsula of Haiti. Certain deserts would be of interest to the botanist. The largest desert stretches from just east of Duvergé, north and west to Monte Cristi.

\section{Travel routes}

Travel in Hispaniola is now an easy matter. The Clyde Steamship Company runs the most regular steamship service to the island. At Monte Cristi, the first point of call, one may disembark and hire an auto to take one to most any of the larger towns on the island. This is not the least expensive way to travel. The naturalist will probably prefer hiring two mules and a guide (the whole for about five dollars a day) and striking off from the beaten trail. If one is burdened with much baggage, the Clyde boat will take it to any of the seaports of Santo Domingo. At Sanchez a Scotch railroad runs west to La Vega. One may transfer to San Francisco de Macoris if one intends to investigate the northern mountains. This northern range may also be entered at Puerto Plata where a government railroad running to Santiago has its terminal. Since the United States Marines have entered the island one travels usually by auto from town to town, and then employs mules for ascending the more difficult trails. Travel in the island should not average more than ten dollars a day per person. Lastly, it may be added that the island is now practically free from bandits. Navassa Island, West Indies. Belongs to the United States, which maintains a lighthouse. Reached from Guantanomo, Cuba, by lighthouse tender. Extremely arid conditions prevail, but an unusually rich fauna for the size of the island is preserved. A genus of lizards, Chamaelinorops, is confined to it. K. P. Schmidt.

\section{LITERATURE}

A traveler in Hispaniola should familiarize himself with such authoritative accounts as Vaughan, Cooke, Condit, Ross, Woodring and Calkins on "A Geological Reconnaissance of the Dominican Republic," 1921 (Washington). There is only one map that approaches accuracy. This is a French map (1908, by A. Poujol and H. Thommasset), handled by C. S. Hammond \& Co., New York. The United States Marine Corps have been engaged for some time in a survey of the island, and it will not be long before an accurate map will be available. No ecological account of the island has been published. The various handbooks which have appeared are of little use. 


\section{JAMAICA}

\section{By Forrest Shreve}

The island of Jamaica lies between $17^{\circ}$ and $18^{\circ} \mathrm{N}$. latitude and 76 and $78^{\circ} \mathrm{W}$. longitude, $90 \mathrm{mi}$. south of the eastern end of Cuba and almost equidistant from the nearest portions of the mainland of North, Central, and South America. The extreme length of the island is $144 \mathrm{mi}$., the extreme width $49 \mathrm{mi}$., and the area $4207 \mathrm{sq}$. mi. The axis of the eastern end of the island is formed by the Blue Mountains, which are the youngest and highest range, attaining $7428 \mathrm{ft}$. in Blue Mountain Peak. In the center of the island a limestone peak, Mt. Diablo, reaches an elevation of $2300 \mathrm{ft}$., and just west of it Bull Head is $2885 \mathrm{ft}$. in elevation. In the southwestern part of the island are the Mocho, Carpenter and Santa Cruz Mountains, all less than $2500 \mathrm{ft}$. in elevation. Just north of the center of the island is a region nearly $40 \mathrm{mi}$. long, in which there is an unbroken succession of small limestone hills of nearly uniform height, separated by narrow anastomosing valleys in which lime-sinks are abundant, giving to a portion of the region the name of "Cockpit Country." The remainder of the island is rolling or hilly, with the exception of the extensive alluvial plains in the south-central portion, the swamps in the south-western corner, and the narrow alluvial plain which follows parts of the coast line.

With respect to temperature the climate of Jamaica is that typical of its tropical latitude. The rainfall is greatest in May and October and least in July and August. Its distribution over the island is determined by the prevailing northeast trade wind and by the local topography. At Port Antonio, on the coast north of the Blue Mountains, the total is 130 in., at Kingston, on the coast south of the Blue Mountains the annual total is 37 in. On the summit of the Blue Mountains the total is 168 in., an amount which is probably greatly exceeded at about 4000 to 5000 $\mathrm{ft}$. on the north slopes of the Blue Mountains. The rainfall for other localities in the island ranges from 30 to $100 \mathrm{in}$.

\section{VEGETATION}

The original vegetation of Jamaica has long been destroyed in the plains and valleys devoted to the cultivation of sugar, bananas and coffee, but there still remain in virgin condition extensive areas of forest on the higher mountains and on the relatively arid hills of the south and southwest, as well as in the Cockpit Country. There are also large areas of swamp and savanna and smaller ones of semi-desert that have not been disturbed. Many of these areas which are without economic value, but of the greatest scientific interest, are held in perpetuity as Crown Lands, which assures their continuance in an undisturbed state. In the most frequented portions of Jamaica the character of the vegetation is largely determined by introduced plants, such as the bamboo and royal palm, the mango, tamarind and breadfruit, the grass Arundo donax, and the large leguminous tree Pithecolobium saman.

The vegetation of Jamaica may be very roughly divided into lowland rainforest, montane rain-forest, lowland monsoon-forest, savanna, semi-desert, grass swamps and mangrove swamps.

The lowland rain-forest covered the northeastern corner of the island and higher elevations and windward exposures in the central parishes. Whatever may have been the character of the finest of the original rain-forests, there exist today only suggestions of such forests as may be seen in Vera Cruz or Demarara. The height and density of the canopy are seldom such as to preclude a dense growth of subordinate trees and shrubs, herbaceous plants, lianes and epiphytes. There is, as usual, a large number of species of trees, including the silk cotton (Ceiba pentan$d r a$ ), the Santa Maria tree (Calophyllum 
calaba), the West Indian Cedar (Cedrela odorata), the hog plum (Symphonia globulifera) and one or more species of Eugenia, Nectandra, Solanum, Myrsine, Miconia, Symplocos, Sciadophyllum, Cecropia and Terminalia. The shrubs are numerous in individuals and species, belonging chiefly to the Melastomaceae, Rubiaceae and Piperaceae. Two small palms enter the forest and species of Heliconia, as well as tree ferns, and other large terrestrial, epiphytic and climbing ferns.

The montane rain-forest lies above $4500 \mathrm{ft}$. It is not so tall as the lowland forest, has a more open canopy, is frequently broken by thickets of ferns such as Gleichenia and Davallia or by the slender bamboo Chusquea. The composition of the forest is simpler than on the lowlands, the dominant trees being species of Clethra, Vaccinium, Podocarpus, Ilex, Cyrilla, and Cleyera. The undergrowth is dominated by ferns and Piperaceae, members of both alliances showing a great diversity of size and habit. Tree-ferns are abundant, and the terrestrial and climbing ferns and epiphytic ferns and mosses are more numerous than the flowering plants.

The lowland monsoon-forest is best developed in the south-eastern parishes, in the lee of the Blue Mountains, but it merges into the lowland rain-forest in the central portion of the island. Extensive cultivated areas were probably covered with this type of forest under their original condition. The stature of the forest varies greatly from place to place, but the canopy is always relatively open. Lianes are frequent and also climbing aroids, while the epiphytic vegetation is almost confined to Bromelia, several species of Tillandsia, and a few orchids and large ferns. Among the commonest trees in the monsoonforest are Bursera simaruba, Haematoxylon campechianum, Guiacum officinale, Ardisia tinifolia and Bucida buceras.

The savannas of Jamaica have likewise been very largely brought under cultivation, and have yielded much of the sugar and banana land in the southern parishes. They occupied alluvial or very gently rolling areas, and were characterized by a rainfall of 35 to 50 in. The formation consisted of a covering of coarse grasses and scattered shrubs, with a very open stand of trees, mostly either possessing very small leaflets or having the drought-deciduous habit. Characteristic trees are the cashew (Prosopis juliflora), the logwood (Haematoxylon campechianum), and Pithecolobium unguis-cacti. In the vicinity of Kingston large areas of former savanna and monsoon forest are now occupied by open groves of the introduced guango tree (Pithecolobium saman), in the shade of which is grown guinea grass (Panicum maximum), the principal forage plant of the island.

The semi-desert areas lie along the south coast, chiefly on limestone in the vicinity of the Healthshire Hills and on Portland Point. The vegetation is chiefly shrubs and small trees, growing in open formation or more frequently in closed thickets from 4 to $12 \mathrm{ft}$. in height. The commonest shrubs are several species of Acacia, Cassia, Inga, and other leguminous forms, together with Ardisia, Croton, and a number of compositae. With them, and often in considerable abundance, grow several types of cacti, including the tall columnar "dildoe" (Cephalocereus swartzii), the slender Harrisia gracilis and the massive turks head (Cactus melocactus).

The principal swamp areas are in the parish of St. Elizabeth, with smaller areas in Clarendon and Westmoreland. These are formed chiefly of grasses and coarse sedges and ferns, and are wholly unlike the arborescent swamps of mangrove (Rhizophora mangle and Avicennia nitida) which skirt the coast of the island at many localities.

\section{Areas}

The lowland rain-forest may best be seen by driving up the Rio Grande from St. Margaret's Bay or up the Buff Bay 
River from Buff Bay, and by making short excursions from the road into the adjacent valleys. Less accessible but more interesting examples can be seen in Cunhacunha Pass, between the Blue Mountain Peak and the John Crow Mts., reached by road from Bath. More accessible lowland forest of the type covering the central limestone areas may be easily visited on Mt. Diablo, reached by train to Ewarton, driving road to a point between there and Moneague, and by saddle or on foot to Hollymount, a plantation near the summit. The Cockpit Country is best seen by taking a train to Balaclava, and driving thence to Troy.

The Montane rain-forest may be reached in the saddle from Gordon Town, using Cinchona as a base. Morces Gap and New Haven Gap, on the main ridge, can be easily reached within 2 hours from Cinchona, either locality affording typical virgin conditions.

A few typical remnants of the monsoon forest may be found along the coast east of Kingston, between the mouth of Hope River and the mouth of the Yallahs, being easily accessible by driving road, supplemented by excursions on foot.

Typical remnants of the savanna may be seen at a number of localities near the railway between Kingston and May Pen.

The semi-desert is most easily seen by driving to Port Henderson, at the mouth of Kingston Harbor, from Spanish Town.

The grassy swamps are most accessible along the Black River, by driving from Appleton or Ipswich, on the Montego Bay Branch of the railway. The mangrove swamps are well developed around the western end of Kingston Harbor, near the railway station of Gregory Park.

\section{REFERENCES}

Goose, Philip Henry. Naturalist's Sojourn in Jamaica.

Shreve, Forrest. A Montane RainForest. Pub'n 199. Carnegie Inst. Wash.

\section{PORTO RICO AND THE VIRGIN ISLANDS ${ }^{1}$}

\section{By N. L. Britton and Geo. N. Wolcott}

\section{General Conditions}

\section{A. GENERAL GEOGRAPHY AND GEOLOGY}

Porto Rico and the Virgin Islands, forming the eastern part of the northern axis of the West Indies, constitute a geographical, geological and biological province with many natural features in common. The region with a total land area somewhat less than that of the State of Connecticut, lies within the geographical area of west longitude $67^{\circ} 56^{\prime}$ (Mona Island) to west longitude $64^{\circ} 16^{\prime}$ (Anegada Island) north latitude $17^{\circ} 40^{\prime}$ (St. Croix); $18^{\circ} 33^{\prime}$ (Northern coast of Porto Rico) and $18^{\circ} 43^{\prime}$ (Anegada).

Porto Rico is traversed from west to east by a mountain chain, composed of highly tilted stratified rocks of cretaceous age and of great variety, largely of volcanic ashes (tuffs) shales and some hard, sparingly fossiliferous limestones, with many intrusions of eruptive igneous rocks also of many kinds. These mountains reach altitudes of some $4200 \mathrm{ft}$. in the Cordillera Central in the central and western parts and of about $3500 \mathrm{ft}$.

1 It has been quite accurately studied during the scientific survey of the region by the New York Academy of Sciences, still in progress, in cooperation with the insular government of Porto Rico, the United States Naval government of the Virgin Islands, the American Museum of Natural History, the New York Botanical Garden, the geological and anthropological departments of Columbia University and other cooperating institutions and individuals. The publication and preparation of the results of this survey, as of July 1, 1925, may be reported as follows:

Vol. I, Geology of Porto Rico, complete in four parts, with maps and illustrations, pp. 384. Vol. II, Geology of Porto Rico, parts 1 and 2, published, with maps and illustrations; parts 3 and 4 in preparation. Vol. III, Palaeontology of Porto Rico, parts 1 and 2 , published, with illustrations of Tertiary Mollusca; other parts in preparation; Vol. IV, Geology and Palaeontology of the Virgin Islands, nearly completed for publication. Vol. V, Botany of Porto Rico and the Virgin Islands, Spermatophyta, complete in four parts, pp. 626; Vol. VI, Botany of Porto Rico and the Virgin Islands, part 1, Spermatophyta, published; part 2, Spermatophyta, in press; parts 3 and 4, Pteridophyta, Bryophyta, nearly complete for publication; Vols. VII and VIII, Botany of Porto Rico and the Virgin Islands, Bryophyta, Thallophyta, partly completed for publication; Vol. IX, Zoology of Porto Rico, parts 1 and 2, Mammalia, with illustrations, in press; parts 3 and 4; Aves, Reptilia, Amphibia, in preparation; Vols. $\mathrm{X}$-XII, reserved for Pisces and Invertebrata.N. L. B. 
in the Sierra de Luquillo in the eastern portion; this cretaceous mountain axis, broken and reaching much lower elevations, forms the Virgin Islands to the east, the crown of St. Thomas being about $1500 \mathrm{ft}$. altitude, the hills of St. Jan about $1300 \mathrm{ft}$. Tortola about 1600 ft.; Virgin Gorda perhaps 1400. St. Croix reaches about $1250 \mathrm{ft}$. on the summit of Mt. Eagle.

East of the Virgin Passage the islands of St. Thomas; St. Jan; Tortola and Virgin Gorda have many dependent bays and islets forming altogether the most beautiful archipelago within the American tropics; the marine views from the hills are wonderfully attractive and the climate is most enjoyable. Anegada, the most eastern of the archipelago, is a low aeolian limestone and sand island, with considerable differences from all the others in its plant and animal population. St. Croix lies some miles south of the rest of the archipelago and is also somewhat differentiated biologically.

Lying unconformably on the upturned edges of these cretaceous strata on the northern and southern sides of Porto Rico, except eastward, are Tertiary shales and limestones locally heavily fossiliferous, often cavernous, only slightly tilted, deeply eroded into characteristic peaked hills and mountains, with many vertical escarpments; these limestones attain great thickness in western Porto Rico, thinning out eastward and seen only as isolated hills and finally disappearing toward the eastern end of that island and not represented at all in the Virgin Islands from Culebra eastward; on St. Croix, however, these Tertiary strata underlie large areas.

The distribution of rainfall is widely unequal in different parts of the province, and especially in Porto Rico, and is the most potent factor in the natural distribution of plants. It is greatest in the northeastern mountains of the Sierra de Luquillo and in the Cordillera Central, and least in the southwestern parts of Porto Rico, where desert conditions obtain, characterized locally by the abundant growth of several species of cacti and numerous other xerophytic types.

\section{B. POLITICAL RELATIONS AND COMMUNICATION}

Porto Rico; St. Croix (Santa Cruz); St. Thomas and St. Jan are United States Islands. Tortola, Virgin Gorda and Anegada are British.

Porto Rico includes politically the island dependencies Mona and Desecheo to the west in the Mona Passage; Cayo Muertos off the southern coast; Vieques (Crab Island); Icacos; Culebra (Snake Island); Culebrita and some other islets to the east.

Porto Rico is reached by steamships from New York in from three and onehalf to five days; St. Thomas and St. Croix by steamers from New York in five or six days, and there is regular weekly interinsular steamship communication between Porto Rico, St. Thomas and St. Croix. Excellent hotel and boarding house accommodations are to be had in all three of these islands. The other islands of the archipelago are reached only by motor-boats or sail boats and accommodations for visitors are meagre, and in order to study some of them living on boats or camping is necessary. $-N$. L. B.

\section{Present Biotic Conditions}

\section{(N. L. B. AND G. N. W.)}

The littoral halophytic flora and fauna of the province remains in its pristine condition; it contains but few species not found widely distributed on the coasts of the other West Indies and of continental tropical America. Except locally, the original vegetation of most of the area has been profoundly modified, and many of the species have become either very rare, or eliminated.

Portions of the southwestern dry districts are essentially in natural 
conditions; natural rain forests are now restricted to limited areas at high elevations not very easily accessible. Extensive reforestation is an acute need for water conservation and for firewood and other forest products; it has been commenced in Porto Rico, with good prospects of extension (but not in the Virgin Islands).

All accessible agricultural areas in Porto Rico, and many that elsewhere would not be considered agricultural, have been exploited to their maximum because of the density of human population. There are not now and never were any large wild mammals in Porto Rico. Native lizards and bats, the mongoose, intentionally, and rats, accidentally introduced, probably constitute nine-tenths of the vertebrate life. The Agouti, armadillo, boa, giant turtle and several lizards are practically extinct. There are no unpolluted streams of any size in Porto Rico, as one or two sugar-mills (Centrals) use water from and drain into each one. The largest unpolluted stream is Rio Guajataca near Quebradillas (poor hotels at Camuy and Isabela) with smaller ones near Rio Grande and Mameyes.G.N.W.

The Rio Blanco, a stream of fair size formed from several rivers draining the greater portion of the south slopes of the Luquillo Mountain Range is unpolluted except for the few miles of its lower course through the municipality of Naguabo.-E. M. Bruner.

Porto Rico does not offer the opportunity for studying natural areas in the tropics that the comparatively little exploited island of Hispaniola, especially the part which is Santo Domingo, Republica Domonicana, does. $-G . N . W$.

\section{Travel and Areas Available FOR STUDY}

Porto Rico has a splendid system of motor-car roads, paralleling the coasts and crossing the mountains at several points at elevations from about 2000 $\mathrm{ft}$. to about $2800 \mathrm{ft}$. and there are numerous vecinal roads reaching out in all directions usually possible to Fords in dry weather. A railroad extends nearly all around the island.-N. L. B.

\section{AVAILABLE AREAS}

\section{Lagoons, Limon or La Plata (B2)}

Of interest because of wild fowl congregating there. Considerable bodies of water at times, at others not much more than mud flats. Reached afoot (one or two mi.) from the mentioned R. R. stations, which are merely stations and not towns, or by bus and horseback from Yauco (hotels), or automobiles (through cane roads) from Ensenada.G. N.W.

\section{Lagunas, San Jose, Torrecilla, Pinones}

Salt water lakes connecting with San Juan Bay at Martin Peña Bridge in Santurce and also directly with the Ocean at Cangrejos some 8 or $10 \mathrm{mi}$. east of Santurce. The three lakes are connected by canals and can be navigated at all times by small motor boats. They are almost entirely surrounded by mangrove forests which are included in the Insular Forest system. Fish and water fowl abound. The waters present unusually vivid displays of phorphoresence at night.-E.M. Bruner.

\section{Laguna Tortuguero Sand Areas}

Highly characteristic natural area of white silicious sand occurs on the northern coastal plain of Porto Rico, especially about Laguna Tortuguero, a large freshwater lake.

Reached by foot from stop "Algarroba" on the American R. R. and by vecinal road from the vicinity of Vega Baja or Manati; somewhat disturbed; worthy of being made a nature reservation. $-N$. L. B.

Chaparral of Dry Deciduous Forest (B4)

"Ballena" near Yauco and "Vertera" near Boqueron. Rough rocky areas receiving too little rainfall and with too little soil to be cultivated.-G. N.W.

\section{Tropical Rain Forest or Moist Deciduous Forest (C4)}

"Indiera," area unknown, altitude about $2500 \mathrm{ft}$., consisting mostly of an 
abandoned coffee plantation now returning to original conditions, with an abundance of tree fern, orchids, etc. Will doubtless soon have tree ferns, etc., so cut as to be of little interest. 25 meters along the road now theoretically protected by law. Of greatest value at present because it can be reached so easily, and in climbing the mountain from Yauco all gradations of rainfall received can be noted.

Reached by auto from Yauco, $23 \mathrm{~km}$. on the new road to Lares and from Lares.-G. N.W.

\section{Steep Rocky Hills}

Considerable area of dry deciduous forest, that except for having some of the larger trees cut and being grazed by goats and cattle, will probably remain unchanged. Between Yauco and Ponce, readily accessible by $R$. R., auto road, or by foot, from either city.G. N.W.

\section{EXISTING AND PROPOSED INSULAR} FORESTS

\section{Luquillo National Forest (A3)}

See in Eastern Forest District.

\section{*Maricao Insular Forest}

Contains approximately 5000 acres. Is situated in the mountainous region embracing the headwaters of several important streams within the municipalities of Maricao, San German, and Sabana Grande. About 2000 acres are deforested lands upon which very interesting reforestation projects are being conducted. More than half of the total area consists of one body of typical tropical rain forest which has been but slightly disturbed from its original condition. It is quite similar in general characteristics to the Luquillo National Forest and is the second largest area of orignal or virgin forest growth in the island, the Luquillo Forest being by far the largest virgin forest area.E. M. Bruner.

\section{*Guanica Harbor Forest}

An area of some 5000 acres covering low ridges along the south coast immediately east of Guanica Harbor. Exceedingly rocky, thin-soiled land and characterized by semi-arid climate. Original forest practically destroyed. Accessible to the towns of Guanica and Yauco. There are numerous trails making the entire area accessible. A few guinea may still be found. One of the few places in Porto Rico where lignum vitae still occurs.-E. M. Bruner.

\section{*Point Barraco Forest}

Contains about 500 acres covering a narrow rocky ridge protruding into the Carribean at the west side of Guayanilla Bay. Is in every respect similar to the Guanica Harbor Forest from the eastern end of which it is separated only by a narrow strip of land. Is easily accessible from the Sugar Central of Lluveras Hermanos between the towns of Guayanilla and Yauco.-E. M. Bruner.

\section{Mona Island Forest}

Situated in Mona Passage, midway between Porto Rico and Santo Domingo, and belonging to the former. The conditions of climate and vegetation are in many ways unique, representing an extreme of aridity and of development of the cactus flora on nearly bare limestones. Except for the relatively small amount of coastal plain, which has already been more or less cleared of its original forest growth, the entire Island of Mona will be preserved in a natural condition. The few trails on the island are nothing more than dim paths which can be followed only by one thoroughly familiar with them. The forest growth of the elevated land hardly attains tree size at all but is merely a brush forest over the greater portion of the area, though tree sizes may be attained by a few species in some small scattered spots having a comparatively fair depth of soil. Over most of the area the scrubby forest cover is quite dense and is made 
up of both woody and herbaceous plants. Many species of cacti, varying from the creeping and low or ground forms to the true tree cactus, abound and add greatly to the discomforts and difficulty of travel. The occurrence of the large lizard, Cyclura stejnegeri, and of a West Indian boa, Epicrates monensis, in considerable numbers is notable. The Cyclura is extinct in Porto Rico, the boa nearly so.

$35 \mathrm{mi}$. slightly southwest of the city of Mayaguez. Reached by the motor boat or sail boat of the Light House Service which maintains a more or less regular service between Mayaguez and the Light House situated on Mona Island. There are usually about two sailings per week. Small parties can find accommodations at the light house, though food and army cots should be carried. From 6 to 24 hours are required for the trip either way between Mayaguez and the lighthouse.-G.N.W. E. M. B., and K. P. Schmidt.

\section{*Insular Mangrove Forests}

These consist of numerous parcels of tidal swamp lands supporting mangrove forests with an aggregate area of about 15,000 acres. They occur on the north, east, south and west coasts and in no less than 20 different localities. In addition to the true mangrove, Rhizophora mangle, three other species and sometimes four are found. All five species are locally called mangrove (mangle in Spanish).-E. M. Bruner.

\section{*Porto Rico's Small Islands}

Desecheo in the Mona Passage, is already a bird preserve; it is xerophytic, its rocks cretaceous, and it exhibits highly interesting elevated beaches similar to those at points on the coast of Porto Ilico. Cayo Muertos is also limestone, with natural scrub vegetation of great density. Vieques is a long narrow island, largely occupied by sugar-cane fields but with some unmodified areas, partly underlain by creta- ceous rock partly by Tertiary limestones. Icacos consists of a pure white soft limestone, with highly interesting natural low vegetation. Culebra and Culebrita are xerophytic and but little modified, their rocks cretaceous. $-N$. L. B.

\section{Luquillo National Forest (Porto Rico)}

Area 12,443 acres. Is typical tropical rain-forest comprising large variety of hardwood species, some of which in the more favored locations attain great size. On the headwaters of the Mameyes River trees of Dacryodes excelsa, locally called tabonuco, reach heights of approximately $100 \mathrm{ft}$. and diameters up to 60 in., and occur in fair sized stands. On the higher mountain tops, and particularly on the crest of El Yunque Mountain forests occur as extremely dense stands of dwarfed trees from 6 to $10 \mathrm{ft}$. in height and 2 to 4 in. in diameter, and made up for the most part of the same species which attain fair sizes at lower altitudes and on more favorable locations. These dwarf forests are characterized by the presence of mosses almost completeiy enveloping the trunks and branches of the trees and hanging from the crowns in short thick bunches. Because of the high humidity and excessive rainfall these mosses are at all times throughout the year completely saturated with moisture and dripping water. The Luquillo is essentially a protective forest because of its excessive rainfall which averages about 140 in. per year, the exceedingly rugged topography of the Luquillo Range, and on account of the necessity of stream-flow protection for the benefit of the surrounding rich agricultural lands. A complete forest cover will be preserved and over most of the area this will be kept in its original condition. El Yunque, the highest peak, is $3483 \mathrm{ft}$. Other high and well known peaks are El Cacique, El Duque and El Toro.

Of particular interest are the series of falls and cascades of the four main 
tributaries of the Rio Blanco (White River), viz, Rio Hicaco, Rio Camuy, Rio Prieto and Rio Sabana. These streams which drain the greater portion of the south slope of the Luquillo Range fall some $2000 \mathrm{ft}$. in a horizontal distance of about two mi., and form the Rio Blanco by their confluence just above the Preston Ranch which is situated about $5 \mathrm{mi}$. from Naguabo and from which it is accessible by automobile.

Some $30 \mathrm{mi}$. of bridle trail have recently been built through and about the Forest, the one from Hacienda Catalina to the peak of El Yunque being surfaced by loose broken stone and laid out on a very easy grade.

Supervisor's headquarters at Rio Piedrasł. Forest may be reached by auto from San Juan to Mameyes Hacienda Santa Catalina (one hr.) thence afoot by trail to summit of the peaks. A public shelter just below El Yunque; nearest hotel at Rio Grande.-E. $M$. Bruner.

\section{REFERENCES (N. L. B.)}

Bello y Espinosa, Domingo. Apuntes para la Flora de Puerto-Rico. Ann. Soc. Española Hist. Nat., Vol. 10, pp. 231-304 (1881); Vol. 12, pp. 103130 (1883).

Britton, N. L. The Vegetation of Mona Island. Mem. Missouri Bot. Gard., Vol. 2, pp. 33-55, pl. 1 (1915).

Britton, N. L. and Wilson, Percy. Botany of Porto Rico and the Virgin Islands.-Spermatophyta, Sci. Sur. Porto Rico and Virg. Ids., Vol. 5; Vol. 6, parts 1 and 2 (1923-1925) New York Academy of Sciences.

Cook, O. F. and Collins, G. N. Economic Plants of Porto Rico. Contr. U. S. Nat. Herb., Vol. 8, pp. 57-269, plates 13-55, 1903.

Howe, Marshall A. Report on a visit to Porto Rico for collecting Marine Algae. Bull. N. Y. Bot. Gard., Vol. 16, pp. 219-225 (1915).

Stahl, Agustin. Estudios sobre la Flora de Puerto-Rico. Published in six parts, 1883-1888.

Stevenson, John A. A Check List of Porto Rican Fungi and a Host Index. Journ. Dep. Agric. Porto Rico, Vol. 2, pp. 125-264 (1918).

Urban, Ign. Flora Portoricensis. Symbolae Antillanae, Vol. 4, pp. 771, 1903-1911.
Wilson, Percy. The Vegetation of Vieques Island. Bull. N. Y. Bot. Gard., Vol. 8, pp. 379-410 (1917).

\section{REFERENCES (G. N. W.)}

Allen, G. M. Mammals of the West Indies. Bull. Museum Comp. Zool., Vol. 54, July, 1911, pp. 175-263.

Anthony, H. E. Indigenous Land Mammals of Porto Rico, Living and Extinct. Memoirs, American Museum of Natural History, N. S., Vol. 2 , pt. 2.

Gundlach, Juan. Fauna PuertoRiqueña. In Ann. Soc. Española Hist. Nat. (Vol. 16-22, May, 1887January, 1894. Insects.) Madrid.

Investigation of the Aquatic Resource Fisheries of Porto Rico. On the U. S. Fish Commission Steamer Fish Hawk in 1899. Bull. U. S. Fish Commission, Vol. 20, pt. 102, 1900 (1902), pp. 1416.

Murphy, Louis S. Forests of Porto Rico, Past, Present and Future. U. S. Dept. Agr. Bull. No. 354, October 20, 1916.

Schmidt, K. P. Contributions to the Herpetology of Porto Rico. Annals of the New York Academy of Sciences, Vol. 28, pp. 167-200, September 8, 1920.

Stejneger, Leonhard. Herpetology of Porto Rico. Report U. S. National Museum, 1902, pp. 549-724. (No. 129,1904 .)

Wetmore, Alex. Birds of Porto Rico. U. S. Dept. Agr. Bull. No. 326.

Wolcott, G. N. Insectae Portoricensis. Jour. Dept. Agr. P. R., Vol. 7, No. 1, January, 1923 (to be issued about February, 1924.) Insular Experiment Station, Rio Piedras, P. R.

\section{Virgin IsLands (N. L. B.)}

ST, CROIX (SANTA CRUZ)

Lying isolated in the sea about 40 mi. south of the Virgin Passage, with one contiguous islet, St. Croix is visible in clear weather from the hills of Porto Rico and St. Thomas. There is a range of hills and low mountains of stratified and eruptive cretaceous rocks along its highly picturesque north-western coast, and a few hundred acres of forest exist here at higher elevations; otherwise this island has been deforested; these hills cause a moderate rainfall in the central and western districts; they should be 
reforested, at least, in part. Eastward the land is low undulating locally hilly and nearly level, underlain by the cretaceous strata, the rainfall less and xerophytic conditions evidenced by abundant cacti and Agaves, obtain over large areas. South of the northwestern hills, extending eastward into the central districts, slightly tilted, heavily fossiliferous Tertiary limestones overlie the older strata, which locally appear as erosion areas in isolated hills. There are numerous water-courses on St. Croix, which may for the most part run dry in periods of drought; along these, locally, and along the coasts, areas of natural vegetation are found. Most of the arable soil of the island is occupied by sugar-cane plantations. St. Croix has an excellent system of roads, except in its dry eastern parts, which are not easily accessible.

\section{ST. THOMAS}

Forming the eastern coast of the Virgin Passage, the rocky cretaceous hills of St. Thomas rise abruptly; there is very little level land and steep slopes preponderate. Except for a few hundred acres in detached areas at the higher elevations, the original forests disappeared long ago; the denuded steep hillsides do not retain much of the moderate rainfall, the run-off being very rapid. Considerable areas at lower elevations are rather densely covered with scrub vegetation, among which occasional larger trees exist, but truly undisturbed natural conditions are scarcely to be found, except locally, along and near the coasts. As would be expected, many species recorded by early authors as found on St. Thomas, have not been observed there in recent times; a few of these are endemic, not known from elsewhere, and have probably been exterminated.

There is a limited amount of good driving road on St. Thomas, most parts of the island being reached only on foot or by horse; the irregular coast line is indented with many beautiful bays and coves, accessible by boats, sailing in these waters and eastward through the rest of the archipelago being highly enjoyable.

\section{ST. JAN}

St. Jan or St. John, lies immedately east of St. Thomas and forms the eastern frontier of the United States in the West Indies. Like St. Thomas, it is almost wholly hilly, its rocks similar; its coast line is less indented, but there are bays at both the west end and the east. This island presents a more luxuriant appearance, however, on account of its forests of the bay tree or bay-rum tree, covering extensive areas, and yielding by distillation oil of bay of superior quality; these forests or groves are carefully maintained nearly pure, by cutting out other trees and shrubs, but there are also some small areas of mixed natural forest, one of them near the western end of the island protecting a ravine of great beauty, with a mossy brook.

To study St. Jan the visitor must proceed on foot, by horse and boat; there are no driving roads.

\section{TORTOLA}

Separated from St. Jan by a narrow strait, Tortola much resembles St. Thomas in its hilly topography, and its irregular rocky coast line. It is a little higher, however, and one gets the impression that its slopes, on the whole, are scarcely as steep. A few hundred acres of the highest hill are still in forests, known as "High Bush" and at the time of my visit in 1913 were essentially undisturbed and made up of characteristic West Indian tree species, wholly suitable for a nature reservation, and as a nucleus for reforestation. Here, as on contiguous islands, littledisturbed areas occur in places along the coasts, most conveniently reached by water. Tortola has several island dependencies of considerable area, rather heavily wooded, or at least so appearing. 


\section{VIRGIN GORDA}

The cretaceous mountain axis terminates eastward in the hills of Virgin Gorda. This island lies a few miles east of Tortola and is but sparsely inhabited. The hills along its northern coast are similar to those of Tortola, St. Jan and St. Thomas and they are more forested and less disturbed. The lower part of Virgin Gorda is largely composed of great masses of coarse granite rocks, forming rectangular blocks as large as houses, giving one the impression from the sea of a ruined city; a contiguous islet of the same structure is known indeed as "Broken Jerusalem." This physiographic feature is very striking and unusual.

\section{ANEGADA}

Anegada is about ten mi. long and a little over two mi. wide at about the middle. It rises only a few feet above the sea; the eastern and central parts are a nearly level plain of aeolian limestone; the western part is a plain of sand, with saline areas and salt ponds. Its vegetation includes a number of species not known to grow on other Virgin Islands.

\section{REFERENCES (N. L. B.)}

Borgesen, F. The Marine Algae of the Danish West Indies. Vol. 1, pp. 226, fig. 1-170 (Copenhagen, 1913, 1914); Vol. 2, pp. 498, fig. 1-435 (Copenhagen, 1915-1920).

Borgesen, F., and Paulsen, Ove. Om Vegetationen paa de Dansk-Vestindiske Oer. Bot. Tidsskr., Vol. 22, pp. 1-114 (1898).

Britton, N. L. The Flora of the American Virgin Islands. Mem. Brooklyn Bot. Gard., Vol. 1, pp. 19-117 (1918).

Britton, N. L. The Vegetation of Anegada. Mem. N. Y. Bot. Gard., Vol. 6 , pp. 565-580 (1916).

Eggers, H. F. A. Flora of St. Croix and the Virgin Islands, West Indies. Bull. U. S. Nat. Mus., No. 13, pp. 133 (1879).

Millspaugh, C. F. Flora of the Island of St. Croix. Field Mus. Bot. Vol. 1, pp. 441-546 (1902).

Seaver, Fred J. The Fungous Flora of St. Thomas. Mycologia, Vol. 16, pp. 1-15. 1924.

Seaver, Fred J. The Fungous Flora of St. Croix. Mycologia, Vol. 17, pp. 1-18. 1925.

\section{DUTCH WEST INDIES}

By H. Burrington Baker

I. GENERAL CONDITIONS

Topography

The five islands of this group, Curaçao, Klein-Curaçao, Bonaire, Klein-Bonaire, and Aruba lie just off the north coast of Venezuela, but all of them except the last are separated from the mainland by great depths (1400 meters) of water. Physiographically, these islands are very similar to the coastal strip of Venezuela, although the soil is more calcareous, due to the large exposures of coral-reef limestone.

Superficially, each of these islands is a canoe-anticline, with the thick, late Tertiary, coral-formations at the surface. Erosion has removed the crest of the fold, so that the central region exposes the older, metamorphic and igneous rocks, while the narrowed limestone rim is broken into bold, triangular monadnocks, often separated from each other by narrow-mouthed bays (sunken stream valleys), and with precipitous escarpments on their eastern sides.

\section{Climate}

These islands are very arid; the mean annual precipitation at Willemstad, Curaçao, is $561 \mathrm{~mm}$.; at Oranjestad, Aruba, 435 mm.; at Kralendijk, Bonaire, $516 \mathrm{~mm}$. The driest month is May with a mean precipitation, at Willemstad, of $11 \mathrm{~mm}$., while the wettest is November, with a mean of $118 \mathrm{~mm}$. However, the rainfall is very variable; a rainy month may record precipitation much greater than that of a dry year, and a goodly proportion arrives in a few, torrential storms. The eastern sides of the islands are more arid than the western ones; the desiccating trades, where they first touch land, produce a landscape that resembles that of mountain peaks, at and above timberline, but with occasional dunes of dazzingly white, coral sand. The temperature (mean annual (1903-1921) at Willemstad, $27^{\circ} \mathrm{C}$.; extremes $20^{\circ}$ to $33^{\circ}$ ) and the wind 
direction (85.7 per cent from the east) are as constant as the rainfall is variable. The mean daily variation in temperature $\left(24.9^{\circ}\right.$ to $\left.29.5^{\circ}\right)$, although small, is twice that of the mean monthly records $\left(25.9^{\circ}\right.$, January to March, to $28.3^{\circ}$, September).

\section{II. ВIOTA}

The flora is characterized by the abundance of Croton. Commonly the omnipresent thorn-trees are dwarfed and distorted by the trade winds; the foliage of the dividivi usually consists of a flat, matted fan, which only spreads out to the leeward of the trunk. The giant, organpipe cacti are among the most conspicuous features of the vegetation, while the flat-jointed cacti (Opuntia) are almost everywhere, and the large "niggerheads" of Melocactus and the spiked rosettes of Agave may be about the only plant life near the summits of the larger, limestone monadnocks. Nowhere can the vegetation truly be called a forest, although, in protected places, especially on the leeward slopes of the higher hills, larger trees (Bursera, Casearia, Bumelia, Machaonia, Guaiacum, etc.) do form small, or even quite extensive, open groves. Quite a few of the trees and shrubs shed their leaves during the driest portion of the year, although evergreen plants are also prevalent. On the leeward slopes of the highest peaklets (Sint Christoffelberg; 372.4 meters), are the most heavily wooded valleys in the islands; especially conspicuous are the large mats of Bromelia lasiantha, while a few epiphytes (Tillandsia, Ficus, etc.) somewhat increase the luxuriance of the arboreal foliage.

These islands are naturally without large mammals, although deer have been introduced on Curaçao; the monotonous avifauna is especially characterized by the gray mockingbirds and shrikes, although parrakeets lend a touch of color in the more protected cliffs. A large, nesting colony of flamingos lives among the salt-pans of southern Bonaire.
Ground lizards (Cnemidophorus) are very abundant everywhere and the cliffs are often infested by large iguanas. Terrestrial molluses are almost lacking in the central region, but the limestone rim, although poor in generic diversity, support an individual abundance, of such genera as Cerion and Tudora, that I have never seen surpassed. Due to the isolation of the islands, practically all of the native species (also the genera Stoastomops and Cistulops) are endemic, and the frequent breaks in the limestone rim are coincident with a remarkable diversity of closely related species, subspecies and local races. The affinities of this molIuscan population are with that of the northern Antilles, rather than with that known from the adjacent mainland, but, as already indicated, the coastal fauna of Venezuela has been little studied.

Although the larger trees are cut for charcoal, and the aloes fields of Aruba have replaced the natural vegetation of some of the limestone plains, the aridity of these islands, and of the coastal strip of Venezuela, has safeguarded the preservation of natural conditions throughout these semideserts. However, thriving coco-plantations are maintained wherever the ground water is near the surface or irrigation is possible. A few springs comprise most of the freshwater in the islands, although sink-holes in the limestone commonly form natural wells with varying degrees of salinity. Despite the dry climate, protected embayments are usually lined by mangrovethickets, both on the islands and along the mainland; these are infested by an abundance of large, burrowing crabs. Another peculiar phenomenon of this region is presented by the large armies of "soldasjis" (hermit-crabs) which march down from the highlands, during the rains, to "wash their eggs" in the ocean.

\section{GUIDE AREAS}

Included in account of Venezuela. 
IV. BIBLIOGRAPHY

Baker, H. Burrington. 1924. Occ. Papers Mus. Zool. Univ. Mich., No. 152. Land and Freshwater Molluses of the Dutch Leeward Islands. Notes on topography and climate, with brief descriptions of most portions of the limestone rims of all of the islands. Small maps and photographs.

Bcldingh, I. 1914. The Flora of Curaçao, Aruba and Bonaire. Leiden. Detailed account, with notes on formations, regions, and topography. Bibliography.

Lorié, J. 1887-9. Samml. Geol. Reichs- mus. Leiden, 2 se., Bd. I., pp. 111149. Geology.

Martin, K. 1887-8. Bericht über eine Reise nach Niederländisch West Indien; vols. I and II. Leiden. Very detailed account, copiously illustrated, of topography, geology and history. Geological maps, rather indefinite.

Ruthven, A. G. 1923. Occ. Papers Mus. Zool. Univ. Mich., no. 143. Reptiles of the Dutch Leeward Islands.

N.B.: Large scale, accurate, contourmaps of Curaçao, Aruba, and Bonaire and Klein-Bonaire can be obtained from Government Secretaries, Willemstad, Curaçao.

\section{Pacific Islands}

\section{GALAPAGOS ISLANDS}

They consist of 5 larger and 10 smaller islands about $600 \mathrm{mi}$. west of the coast of Ecuador. The largest island has an area of 1560 sq. mi., and an extreme elevation of $5000 \mathrm{ft}$. The area of the entire group is 2870 sq. mi.

As a rule the shore and lower elevations are parched and rocky presenting only a few thickets of Peruvian cactus and stunted shrubs, up to an elevation of $800 \mathrm{ft}$. Above this height and occasionally coming down to the shore, are trees with deep green bushes covered with orchids and trailing moss. The shores of the larger island are fringed in some parts with a dense growth of mangrove.

There were probably 15 species of giant land tortoise at the time of the discovery of the island. Seven of these are known to science and each is confined to its particular island. A peculiar genus of lizard has one shore species and one distinctly land species (extracted from Encyclopaedia Britannica).

\section{REFERENCES}

Dall, W. H. 1896. Insular Landshell Faunas, especially as illustrated by the data obtained by Dr. G. Baur in the Galapagos Islands. Proc. Phil. Acad. Nat. Sci., 1896, pp. 395-459.

Beebe, William. 1924. Galapagos: World's End. G. P. Putnam's Sons.

\section{PHILIPPINE ISLANDS}

MOUNT MAKILING AS A STATION FOR BIOLOGICAL STUDY

\section{Br F. T. McLean}

One of the most accessible areas of natural tropical forest near Manila is about $40 \mathrm{mi}$. (70 km.) southeast, on the slopes of Mount Makiling, an extinct volcanic cone about 3500 ft. (1143 meters) high and $2 \frac{1}{2} \mathrm{mi}$. from the town of Los Baños. This mountain, covering an area of 10,000 acres, and its immediate surroundings provide examples of nearly all of the principal types of natural habitats common in the Philippine Islands; Los Baños borders on Lake Bay, the largest body of fresh water in the archipelago, and near the town may be found shallow lake and shore vegetation, fresh water swamps, and both hot and cool saline bogs surrounding the mineral springs, which give to the town its Spanish name of "The Baths." Between the lake and the mountain are some cultivated and some abandoned fields in almost all stages of reforestation-first the mixed growth of weeds, then rank growths of tall grasses, constituting the "Congonales," and scrub growths of short-lived trees. On the lower slopes of the mountains, and to the east extending out onto comparatively flat lands, are areas of High Forest 
quite typical of those parts of the Philippine lowlands with a seasonal distribution of rainfall. Beween 1500 ft. (500 meters) and $2700 \mathrm{ft}$. (900 meters) elevation the forest is classed as rain forest, and is quite similar in appearance and composition to that of the northern and eastern slopes of the Islands generally, where the rainfall is non-seasonal. The elevations above $2700 \mathrm{ft}$. to the summit are mainly covered with extremely moist forest, called the mossy forest, on account of the heavy coating of moss on most of the tree trunks. Interspersed in openings and exposed areas of shallow soil within this region are patches of rank growths of grassesMiscanthus, Saccharum and Imperata (Cogon). Thus all of the principal types of habitats, except the mangrove swamps, strand forests, and subalpine scrub, are represented in the Mount Makiling area.

Because of its accessibility from Manila from which it may be reached by train or auto in about two hours, or by boat, the wild life has been more thoroughly studied on this mountain than on many other areas of similar diversity in the tropics. Extensive collections have been made here of the insects, reptiles, birds and plants particularly. Further, the Colleges of Agriculture and Veterinary Science and the Forest School of the University of the Philippines are located at the foot of Mount Makiling, and the mountain has been set aside as a natural botanic garden. It has been opened up by a system of trails constructed and maintained by the Forest School, and all forms of wild life are protected. The facilities of the school laboratories and the assistance of capable student assistants have always been available for visiting scientists.

\section{FRESH WATER LAKE}

The lake and swamp vegetation bordering on Lake Bay at Los Baños have been studied by Gates, ${ }^{1}$ and his

1 Gates, C. F. Swamp vegetation in hot springs area in Los Baños, Laguna, P. I. Phil. Jour. Sci., 9:
495-516. 1914. paper has been consulted with reference to them. The lake is shallow for the most part, and in many places supports a growth of eel grass, Vallisneria gigantea Graebn.; inata, Ceratophyllum demersum L.; and pondweed, Potamogeton malainus Miq. attached to the bottom. Floating aquatics, such as quiapo, Pistia stratiotes L. lia, Lemna sp. and the introduced water hyacinth, Eichhornia crassipes Solms, are abundant. A number of migratory aquatic and shore birds are found on and around the lake during the winter. Fish of many species occur in the lake, notwithstanding the fact that the natives get a large part of their subsistence from lake fishing, and some of these fish are curious in that they are normally salt water forms, which have wandered in from Manila Bay and have apparently become accustomed to the fresh water habitat. Small clams are also found in the lake and some of the tributary streams.

\section{FRESH WATER MARSH}

In the shallow water along the eastern shore of the lake, particularly, are large areas of lotus, Nelumbium speciosus Willd; in a similar location near Los Baños the white water lily, Castalia sellata (Willd.) Blume occurs. In shallower water and in wet marsh occur Typha angustifolia L. var. javanica Schnizl. and the equally cosmopolitan Pragmites vulgaris Trin. On the saturated soils bordering these, and occasionally flooded occur the blue flowered Monochoria spp.; Polygonum spp. and Ipomea; a sedge, Fimbristylis miliacea (L.) Vahl. There appear to be no indigenous shore birds characteristic of this area, though there are many migrants. As in all open ground areas of the Philippines, life forms of wide distribution predominate here, the only important exception being among the frogs, of which the common species such as Rana Vettigera Wiegmann are indigenous to the Philippines.

SALINE MARSHES NEAR THE HOT SPRINGS

In the salty waters flowing from the hot mineral springs there are in the 
notter parts a number of interesting algae and bacteria, some of them occurring at temperatures as high as $60^{\circ} \mathrm{C}$. In the areas saturated with the cooled salt water are plants usually associated with the seashore swamps, such as the large, coarse fern, Achrostichum aureum L. The salty areas are too restricted to support characteristic salt water animal life.

\section{BEACH}

The pioneer vegetation of the drier, more sandy lake shores is dominated by two cosmopolitan species of vines, the pataning dagat or "Sea bean," Canavalia lineata (Thunb.) DC, and Ipomea pes caprae L. Both of these are widely distributed on exposed shore lines throughout the tropics.

\section{GRASSLANDS AND OPEN BRUSH}

The vegetation of the abandoned fields of the lowlands consists largely of introduced forms and species of very wide distribution throughout the tropics. This area, extending from the lake to well into the foothills of Mount Makiling, is therefore primarily of interest to students of plant succession, for many of the steps from the cultivated fields to high forest may be seen here. The first growth immediately after an area is abandoned is composed of herbs, herbaceous vines and grasses: Ageratum conyzoides L., Corchorus acutangulus Lam., Amaranthus spp., Mimosa pudica, L., Synedrella nodiflora (L.) Gaertn.; Paspalum conjugatum Berg., Cynodon dactylon (L.) Pers. and Eleusine indica (L.) Gaertn., are some of the commonest forms. These and most of the grassland species are either introduced or widely distributed species, there being comparatively few endemic forms. A few low shrubs also appear early in the revegetation of cleared areas; notably Blumea balsamifera (L.) DC., Sida retusa L, Urena lobata L. and Desmodium spp.

A second step is the conversion of the weed areas into more nearly pure grass, by the entry and spread of such rank grasses as Cogon, Impereta cylindrica (L.) Beauv., talahib, Saccharum spontaneum L., etc. These are usually accompanied by such shrubs as Flemingia strobilfera (L.) R. Br., Mallotus muricatus, Mussaenda phillipica L. C. Rich, with its conspicuous white leaflike floral bracts and Tabernaemontana pandacaqui Poir., an endemic species with clusters of conspicuous white, jasminelike flowers and brilliant red and yellow seed pods. Among these are the forerunners of the arborescent flora; several introduced forms, such as aroma, Acacia farnesiana (L.) Willd., Psidium guajava, Linn., Averrhoa bilimbi, L., A carambola, L., and Laucaena glauca (L.) Benth., all of American origin; Bauhinia malabarica Roxb., Leea manillensis Walp. and Laportea spp., the giant stinging nettles.

These grasslands or "Congonales" are of great extent in the Philippines, and indeed through the entire Indomalayan region. They are a result of a system of temporary and shifting cultivation by the Malays, who with their primitive implements are poorly equipped to combat in their fields such vigorous grasses as the cogon, Imperata cylindrica (L.) Beuv. These abandoned cogonales would quickly grow up to trees, as such areas are doing around the college lands, if it were not for frequent fires, which destroy all but the more resistant trees, such as the aroma, Acacia Farnesiana (L.) Willd., the binayuyu, Antidesma ghaesembilla Gaertn., and the alibangbang, Bauhinia malabarica Roxb., and even these are stunted by the frequent burning, as the natives usually fire these patches three or four times a year.

The next development in the succession is the brush forest or "Parang," composed of numerous species of small, rapid-growing trees, such as Macaranga spp., Mallotus spp., labayo, Melochia umbellata Stapf., Premna spp., Ficus nota Merr. (tibig), Ficus hauili Blanco (Hauili), Ficus ulmifolia Lam. (isis), Ficus pseudopalma Blanco, and bayagusa Voacanga globosa Merr. Among 
these occur a few species of larger stature; anilao. Columbia serratifolia Merr., anabion, Trema orientalis Blume, alim, Mallotus moluccanus Muell.Arg., Duhat, Eugenia cumini (Linn.) Merr., anubing, Actocarpus cumingiana Trec., and many others. Beneath these the first evidences of shade-loving undergrowth appear; such herbs as pungapung, Amorphophalus companulatus (Roxb.) Blume, with its huge, illsmelling flowers with purple and yellow spathes in May, Sida humilis Willd. and Syndrella nodiflora (L.) Gaertn., alpinia spp., Donax cannaeformis, K. Shum., Flagellaria indica, Linn., Nephrolepis hirsutula (Forst.) Pr., and Kolowratia elegans Presl. Many vines are also in evidence; Lygodium circinnatum Sw., with twining fronds 15 or more $\mathrm{ft}$. long, and with occasional branches from the axils of the pinnae nearly as long as the main rachis; Aristolochia tagala Cham., Bridelia stipularis (L.) Blume, a trim, hemispherical shrub in youth and later developing into a scrambling vine; several species of Convolvulaceae, of the genera Hewittia and Merrimia, and species of Piper, close relatives of the betel and black peper and Scheffera spp., which is more properly an epiphytic shrub, with its roots finally extending to the ground; also species of rootclimbing aroids of the genus Raphidophora, and the climbing bamboo, Schizostachium diffusum Merr. The Philippine mistletoe, Loranthus philippinensis, Cham and Schlecht, which is abundant on a number of the parange trees, is of special interest, because it in turn is frequently parasitized by another member of the Loranthaceae, a species of Viscum, which is likewise a greenleaved hemiparasite. The structural and physiological relations of these two parasites to one another would be an interesting study.

The animal life in these lowland grass and brush lands is, like the plant life, largely made up of cosmopolitan or widely distributed species. Of the larger mammals, most of the common forms are abundant here, though they are largely nocturnal and are infrequently seen. The Philippine deer, Rusa philippinus Smith, wild pigs, Sus philippinensis Nehring, and monkeys, Macacus cymologus var. cummingii Gray are so abundant in the areas bordering on the forest as to become a nuisance. The alemoose or civet cat, Viverra tangalunga Gray, is a frequent nocturnal marauder of the hen roost. Fruit bats of all sizes are also common, the larger ones being very destructive of bananas, while some of the smaller ones seem to specially relish the wild figs, Ficus nota, etc., and have the unpleasant habit of bringing their feasts to dwellings and scattering bits of fig on one's floor. Among the common birds of the grassland and parang are the guava bulbul, Pycnonotus goivieri Scopali, the brilliant yellow and black, harsh-voiced oriole, Oriolus acrorhynchus Vigors, a large black cuckoo, Centropus viridis Scopali, which has a long tail, iridescent feathers and a low, chuckling call; kingfishers, Halcyon gularis $\mathrm{Kuhl}$, H. chloris Bodd. and Alcedo bengalensis Briss. are frequent. Swifts, Tachornis pallidior McGregor, and species of Collocali are conspicuous at dusk, and later the nightjar, Caprimulgus manillensis Walden, emerges from the thickets. Its curious call, resembling the whip-poor-will, gives it its native name of "Tucaroc." The brown rice bird, or weaver finch, Munia jagori Martens, congregates in flocks and creates havoc in the maturing rice fields. In dense thickets and bamboo clumps are found a small migratory green dove, Calcophaps indica L., two black and white birds, a thrush, Copsychus mindanensis Boddaert and a flycatcher, Rhidipura nigritorquis Vigors, and a beautiful blue flycatcher, Hypothymis occipialis Vigors. The imported Chinese quail and the Philippine red and black wild jungle-fowl, Gallus gallus L., are also found commonly in the grassland during the dry season.

Insect life is abundant and varied, as elsewhere in the tropies. Locusts, cicadas, katydids, crickets, mole crick- 
ets, beetles, moths and butterflies are both abundant and varied. Perhaps the most conspicuous forms are the ants and termites. Ants of many sorts seem omnipresent. They and the termites are the chief scavengers of the tropics. The ants gather up all waste food around the houses, carry away dead insects, and frequently remove planted seeds from the seedbeds. It is necessary to protect all food and nursery beds from these pests. There are also many sorts of termites, and they are such efficient wood destroyers that one seldom sees dead trees either standing or fallen in the forest, they are so promptly consumed by the termites. A common mound-building termite is Termes philippinensis Oshima. This insect is wood-destroying, and builds large clay mounds, filled with tunnels made of a sort of papier maché. These tunnels are damp and on them grows a fungus mycelium, of a species not found anywhere else except on termite mounds. The young termites appear to feed on the little white buttons produced by this fungus, and it is thought by some that the fungus is planted and cared for by the termites. At all events, the fungus is found on all of the nests of this species of termite. The caste system is possibly even better developed among the termites than among the ants, there frequently being among the soldiers alone two distinct forms. The winged adult males and females migrate in large swarms at the beginning of the rainy season, in May, such flights often starting at about seven in the evening and continuing for an hour or more, often interrupting the dinner hour by completely covering table and food with a writhing mass of insects shedding their long wings. Associated with the termites in their mounds are frequently several other insects: a red ant, Solenopsis geminata Fabr., which is destructive to the termites, and several species of beetles or earwigs, cockroaches, springtails and myriopods, which serve as scavengers to the ter- mites. They avoid the light, traveling in tunnels inside timbers or in earthern tunnels built over the surface of bark, rocks, etc. ${ }^{2}$ This is but one of several species of termites in the Philippines, as the order Isoptera is highly developed there. At least forty species have been reported from the Islands, and Los Baños is the type locality of five of these. These are in addition to the above mentioned form, Termes Copelandi Oshima, one of the common earth mound building forms, its mounds being low and broad; Eutermes luzonicus Oshima; Microtermes los-banosensis Oshima, which builds hard nests at the bases of trees, bamboos, etc., and extends earthern tunnels over them; and Coptotermes flavicephalus. All of these appear to require contact with the earth to secure sufficient moisture, and may be kept out of houses by careful guarding of the foundations. The situation is quite different with the small, beetlelike bucbuc, which are classed by Light ${ }^{3}$ as "House termites," and placed in the genera Cryptotermes and Planocryptotermes. These work in cured timber and bamboo, without any connection with the ground. One species of termite, Leucotermes philippinensis, has been reported as attacking sugar cane plants as well as wood.

Another group of insects of interest are the fig-pollinating insects, Blastophagus, of which there appears to be a distinct species of insect for each of the seventy or more species of Ficus found wild on Mount Makiling. Probably more extensive and complete collections of insects have been made on and around Mount Makiling than in any other similar area in the tropics. This has been due largely to the activities of Dean C. F. Baker and the students of the Philippine College of Agriculture. Vast numbers of new species of tropical insects have been described from Baker's

2 See Uichanco, Leopoldo. General facts in the biology of Philippine mound building termites. Phil. Jour. Sci., 15: 59.

Light, S. F. Notes on Philippine Termites. Phil. Jour. Sci., 19: p. 41 (1921). 
collections, published in the Philippine Journal of Science and elsewhere. Extensive studies of the parasitic insects of this region have also been made by $\mathrm{F}$. Muir and other members of the scientific staff of the Hawaiian Sugar Planters' Association.

Among the reptiles, the largest now found in this locality is the iguana-like biauac, a large terrestrial lizard living near the water courses, the crocodile having been exterminated in this thickly populated district. The large house lizard or Gecko gecko L., naturally arboreal and common in broken bamboos, is apparently nocturnal, and makes the night hideous with his raucous call of "Gecko, Geck-ko, Geck-ko-ko-ko." This common species is possibly introduced, though there are many native species. There is also a small, brown, house lizard, more numerous and much less timid. The skinks are less frequent in the houses, but common in moist thickets and forest.

Common lizards at low elevations around Mount Makiling are according to Taylor:4 Sphenormorphus curtirostris Taylor; S. steerei Stejneger, a small species. Other species found there are Leilopasma pulchellum Gray, Tropidophorus Gravi Günther, etc.

Competing with the larger lizards in the capture of mice and insects are numerous species of snakes; pythons and cobras, of which the king cobra is the largest and probably the most poisonous. $\mathrm{He}$ is frequently found in the grasslands, but less often frequents dwellings than do the pythons and larger snakes.

In the mountain streams are found several species of frogs: Rana magna Stejneger, which is one of the largest forms and much prized for food; Rana woodworthi Taylor, which is described from Los Baños material; and Rana similis Günther.

4 Taylor, Edward H. Additions to the herpetological fauna of the Philippine Islands. I-Phil. Jour. Sci., 21: 161-206; II-Phil. Jour. Sci., 21: 257303; III-Phil. Jour. Sci., 22: 515-555.

See also for further herpetological data: Philippine Amphibia, Phil. Jour. Sci. 16: 213; Snakes of the Philippine Islands, 1922.

\section{HIGH FOREST}

The assertion has frequently been made that the Philippines were originally a practically unbroken forest, and this assumption is made the more probable by the fact that most of the endemic forms of both plant and animal life are either confined to or closely associated with the natural, dense forest. Fortunately the lumbering on Mount Makiling has not been sufficiently intensive to destroy the natural forest cover. Therefore all, or nearly all, of the original species of plants and animals have persisted here, though the proportion of some of the tree species in particular has been greatly modified by the selective cutting of the more valuable woods, rattans, etc.

Whereas we have seen that the grasslands and parang contained many introduced species, in the forest introduced species are exceptional and have gained little foothold. Thus the traveler seeking distinctively Philippine wild life may well neglect the open country and immediately go into the dense forest areas.

The High Forest, which forms a zone around the base of Mount Makiling up to an elevation of about 500 meters, is characterized by its dominant canopy of very tall, large trees, beneath which are successive layers of shorter trees and finally shrubs, each layer containing its own particular group of species. This makes up the so-called "three-story forest" of the eastern tropics. The general contour is not unlike the hardwood forests of the eastern United States, where the dominant trees may consist of large oaks, etc., while in the more open places are trees of smaller stature, such as sassafras, and below these in turn are the dogwoods, and then the large shrubs. But in the Philippine forests the composition is much more complex, consisting of scores of species, on a single acre, and the number of distinct layers or "stories" of vegetation is greater.

Among the top story trees, the most 
conspicuous and largest are members of the family Dipterocarpaceae: Bagtican lauan Parashorea malaanonan Merr., the trunk of which like many of the large tropical trees, is often heavily buttressed; White lauan, Pentacme contorta M. and R., which like the last yields a soft, easily worked but perishable wood; guijo, Shorea guiso (Blanco) Blume, which has been much cut for use in construction and is less abundant; and several trees of other families as Malaikmo, Celtis philippinensis Blanco, the fruits of which are flavored like the serviceberry, but are larger; (pili) Canarium luzonicum A. Gray, which yields the pili nut of commerce and a valuable resin. Several species of strangling fig also attain to the top story of this forest.

About 70 species of figs occur on Makiling; of these 15 have the strangling habit. The strangling fig, or balite, starts as an epiphyte in the top of a tall tree.' Its root system descends to the ground and spreads laterally, forming a network about the trunk of its host. The roots that reach the ground perform the ordinary functions of roots. After the network enveloping the host has coalesced, the strangling fig becomes self-supporting by its trunk which completely surrounds and strangles or crushes the tree upon which it started. The genus Ficus is one of the largest in this region. In the Makiling flora there are about seventy species of Ficus, including nearly half of the total number known in the Philippines. ${ }^{5}$

The tallest trees in the top story of the Makiling High Forest are about 50 meters tall, and have a diameter of about $1 \frac{1}{3}$ meters.

The second story is composed of a larger number of species than occur in the first or top story, and they are in general shorter, having a height of from 15 to 25 meters. One of the most numerous of these is the balobo, Diplodiscus paniculatus Turcz. Several species of Aglaia and Palaquium also are common, as well as the bulala, Nephelium mutabile Blume; and the catmon, Dillenia phil-

\footnotetext{
5 Trelease, S. F. and McLean, F. T. Mount Makiling as a station for botanical research. Philippine Agriculturist, 8: 6-16, 1919.
}

ippinensis Rolfe, which produces acrid spherical green edible fruits, with spirally twisted segments, enclosed in thick flesh scales, also edible. Other interesting trees are the camagon, Diospyros discolor Willd., an ebony with mottled black and light colored wood; the calingag, Cinnamomum mercadoi Vid.; and tangisang biauac, Ficus variegata Blume, with conspicuous smooth scurfy cinnamon-colored bark. Palms are also frequent, the fan palm or anahau, Livistona sp., being particularly abundant toward the upper limits of this zone; also the pugahan or fishtail palm, Caryota cummingii Lodd.; Pinanga insignis Becc. and Orania palindan. Arenga pinnata Merr., the sugar palm or cabo negro is one of the few introduced species to find a place in this forest.

Trees and tall shrubs which attain a height of 10 to 15 meters or less are considered as constituting a third story. In this class belong Thea lanceolata (Blume) Poir; species of Leea; Oreocnide trinervis Miq.; Aglaia spp. Underneath these are shrubs Callicarpa spp.; Ixora longistipula Merr.; Melastoma fusca Merr., with its pink flowers reminding one of a wild rose in size and color; and Strobilanthes pluriformis C. B. Clarke, which occurs at all elevations in the forests of Mount Makiling. Ferns and herbs are few on the floor of the forest, specially at low altitude, and the earth is characteristically bare of litter.

Climbers are a conspicuous element in the vegetation, among the most prominent being the rattans or climbing palms, species of Calamus and Daemonorops, which usually have thorny leaf petioles and long slender trailing flagellae with stout, recurved spines, which make progress through rattan thickets both awkward and painful. Climbing bamboos Schizostachyum diffusum (Blume) Merr. are also abundant.

Together with the strangling figs, these climbing monocotyledonous plants seem the most characteristic members of the general vegetation to one who is 
unacquainted with tropical forests. Climbing aroids also attract attention. Several species of Rhaphidophora, with large, often deeply-lobed leaves, are among the most remarkable of these. Pothoidium and Pothos are aroids which cling to the trunks of trees by means of horizontal adventitious roots. They have linear leaves that stand at right angles to the stem; the leaf is joined near the middle, the distal portion being the blade and the proximal portion an expanded leaf base, having the photosynthetic function. Large climbing ferns of the genus Stenochlaena are also conspicuous on exposed tree trunks. Dicotyledonous vines form a very prominent part of the vegetation. They attain great lengths, and hang suspended like long ropes from the branches of the high trees. These vines resemble somewhat the grapevines of the woods of the eastern United States, but differ in their greater size and abundance and in the fact that many of them are twiners. A number of stems will often be twisted tightly together, forming a spirallytwisted, rope-like mass. Among the most characteristic of the larger vines are Symphorema luzonicum (Blanco) F. Vill. belonging to the Verbenaceae, and several species of the genus Mucuna, of the family Leguminosae, including vines that bear purple or white evil-smelling flowers, whose calyxes and young pods are covered with extremely irritating spines. Strongylodon macrobotrys A. Gray, also of the Leguminosae, which has greenish-blue flowers on large panicles one meter long, is frequently found in moist places. Among the other vines that may be mentioned are several species of Tetrastigma and Cisus of the Vitaceae, Bauhinia cumingiana (Benth.) F. Vill. of the Leguminosae, Uvaria scandens C. B. Rob, and other species of Uvaria of the Anonaceae, and Merremia nymphaeifolia (Blume) Hallier of the Convolvulaceae.

Epiphytes are not so prominent in the High Forest as in the other two zones. But a number of kinds may be seen on the horizontal branches and in the forks of the trees. Among these epiphytes are several species of ferns; probably the most numerous are Drynaria quercifolia L. Sm. and Asplenium nidus L., the bird's nest fern. The former has leaves of two sorts; one is the ordinary foliage leaf, and the other is a scale that collects decaying leaves. Roots penetrate this mass of decaying matter and apparently absorb water and other substances from it. Orchids of many species occur as epiphytes in this forest; but they are relatively scarce, and most of them do not have either conspicuous or beautiful flowers. The orchid with showy flowers that is most frequently collected is Phalaenopsis amabilis Blume, the butterfly orchid, which has green leaves and large white flowers.

A grotesque member of the flora of Mount Makiling is Rafflesia manillana Teschem. This is found usually in the transition zone, in passing from the High Forest into the Rain Forest, although it also occurs in the High Forest. The mature plant of Rafflesia consists principally of a reddish-brown flower, from fifteen to twenty centimeters in diameter, found growing as a parasite on the root of Cissus, a vine. The morphology of Rafflesia manillana Tesche M. has been carefully studied by Brown. ${ }^{6}$ The root of Cissus upon which the plant grows often bears a number of young buds in addition to a series of mature, open flowers. Five or six specimens may sometimes be found growing near the surface of the soil in a very small area. There is usually no difficulty in locating specimens of Rafflesia, some being found within a meter of the trail.

Another strange plant is Taeniophyllum, an epiphytic orchid that has flat, green roots, about $3 \mathrm{~mm}$. wide and 30 cm. long. The stem and leaves of this orchid are very much reduced, and the photosynthetic process takes place in the root. This is a case of an extreme modification of the root. A number of orchids, of course, contain chlorophyll in long cylindrical roots; but this orchid performs all of its photosynthetic work in these long, flat, leaf-like roots.

The mammals of the High Forest are for the most part also found in the grassland and parang occasionally, and have already been mentioned-the Philippine deer, Rusa philippinus Smith; wild pigs, Sus philippinensis Nehring; monkeys, Macacus cymologus var. cummingii Gray and the alemoose or civet cat, Viverra tangalunga Gray. There are several conspicuous birds found in this and in the rain forest, which seldom if ever leave the dense forest cover. The noisy great hornbill or calao, Hydrocorax hydrocorax L., with its red head and bill, and black and brown plumage, noisy flight and raucous call of "Au, calao, au, au" demands attention, as does its

- Brown, W. H. The relation of Rafflesia manillana to its host. Philippine Journ. Sci., Sec. C, 7: 209-226. pls. 10. 1912. 
smaller relative, the tarictic, Penelopides manillae Boddaert. The balud or imperial pigeon, Muscadivores chalybura Bonaparte, and the smaller Phapitreron leucotis Temminck are not uncommon. The little black and yellow titmouse, Pardaliparus elegans Lesson, often breaks the stillness of the forest with his chickadee song. These are but a few of the birds to be met with. Mount Makiling is neither high nor extensive enough to harbor the truly high mountain birds; all of the forest forms may be found more or less abundant throughout the mountain in all types of vegetation, so far as their food supplies occur. The snakes appear less prominent in the forest than in the brush and grassland. Insects are undoubtedly as abundant, but are apt to be in the foliage high over head, except for the ants and termites, which appear as active here as elsewhere. Conspicuous in the dense forest is the great variety of snails, some of them quite large. Leaches of a number of sorts are abundant as they are unpleasant, and attach themselves to man or beast indiscriminately. The leaches demand moist conditions and are not troublesome in the High Forest of Mount Makiling during the dry season, in April or early May.

\section{RAIN FOREST}

The transition from the High Forest to the Rain or Midmountain Forest is a gradual one, occasioned by the greater rainfall and more uniform seasonal distribution of moisture at higher elevations. Toward the upper part of the High Forest, ferns and herbaceous plants become more abundant on the forest floor, the heights of the trees become less, and epiphytes become more abundant and varied in character. The trees characteristic of the top story of the High Forest gradually drop out of the composition, and the tree canopy thus becomes a two storied one, with a heavy undergrowth.

Ferns are such a conspicuous element in the Rain Forest that they are deserving of special conșideration, Tree ferns of the genus Cyathea are prominent. Species of Selaginella are found both in the moist soil and as epiphytes in the tree tops. Other common terrestrial ferns are Tectaria irregularis (Pr.) Copel., which also occurs abundantly in the moister parts of the High Forest, Dennstaettia elmeri Copel., a giant fern with finely dissected fronds occupying the opener locations, and mingled with species of Dryopteris, Pteridium aquilina (L.) Kuhn., etc. On open cliffs and rock ledges occur the giant Marratia and species of Gleichenia. Among the numerous epiphytes, ferns are also prominent; several species of Nephrolepis, some of them with very large fronds; a number of forms of the Asplenium nidus group; Aglaomorpha Meyeniana, with its huge, coarse pinnate fronds; Odontosoria chinensis $\mathrm{J}$. Sm. and the pale green Davallodes hirsutum. Among the smaller, curious forms are Polypodium sinuosum Wallich., with channeled, ant-harboring rhizomes and the diminutive grass-like Monogramma trichoidea J. Sm. Near the upper limits of the Rain Forest, and in moist ravines, where the humidity approaches that of the Mossy Forest, are found the graceful, pendant epiphytic Lycopodium carinatum Desv., and several species of Hymenophyllaceae.

The trees of the Rain Forest may be considered as forming two stories instead of three, as in the High Forest. These stories correspond approximately in height to the second and third stories found in the High Forest. The top story trees in the Rain Forest have a height of from 15 to 20 meters. Among the trees in this story may be mentioned Astronia spp., Eugenia spp. (which are here top story trees instead of second story trees as in the High Forest), Quercus spp., Weinmannia luzonensis Vid., Palaquium spp., Cratoxylon celebicum Bl., Dillenia reifferscheidia F. Vill. and $D$. philippinensis Rolfe. Strangling figs are rather prominent members of the tallest trees in this forest. The lower story in the Rain Forest is composed of trees and shrubs, reaching a height of about eight meters. Among these may be mentioned Neolitsea villosa Merr., Thea lanceolata (Blume) Poir., Saurauia spp., Oreocnide trinervis Miq. 
Tree ferns belonging to the genus Cyathea are conspicuous in the Rain Forest, and these become more numerous as the summit is approached. Tree erns require a very moist environment, and their presence serves as the most obvious indication of the transition from the High to the rain-forest vegetation on this mountain. A tall palm with divided leaves, Pinanga insignis Becc., and a species with slender stems, Pinanga barnesii Becc., and fan leaf palms, called by the natives "Anahao," Livistona $s p$., form prominent components of the vegetation in this zone.

Among the vines the climbing pandans (Freycinetia spp.) are very conspicuous in many parts of this forest; also rattans (Calamus spp. and Daemonorops spp., bejuco or uway), climbing bamboos (Schizostachyum spp.), and aroids especially a large-leaved Rhaphidophora. Long, rope-like, dicotyledonous climbers, which occur so abundantly in the High Forest, are less numerous in the Rain Forest, though they form a noticeable component. Begonia aequata A. Gray, a dainty little creeping vine, with pink flowers, is quite common.

The floor of the forest is covered with various herbs, especially Elatostema $s p p$., and shrubby plants, of which Hedyotis and Strobilanthes pluriformis C. B. Clarke are prominent; and rattans and ferns also occur abundantly in the ground cover. Along the ridges, the rattans form an extremely dense growth at a height of from one to two meters above the ground. They have leaves that bear long, whip-like structures covered with recurved spines; these make it difficult to walk through the forest.

Epiphytes seem to be more numerous in the Rain Forest than in the High Forest. Among those found abundantly are epiphytic vines, orchids and ferns. The showy, pin-flowered Medinilla magnifica Lindl. is found here and also in the Mossy Forest, though not in the High Forest. Specimens of Nepenthes, the pitcher plant, may also be found growing here, though they are scarce along the trail. It is interesting to note that epiphytic Bromeliacea, which are prominent in tropical America, do not occur in the Indo-Malayan region.

\section{MOSSY FOREST}

The trees and large shrubs that form the canopy of the Mossy Forest may be regarded as forming a single story. The larger specimens of trees have a height of about 12 meters; but in many places the forest, is considerably lower than this. Among the prominent trees are Clethra lancifolia Turcz., Itea maesaefolia Elm., Symplocos sp., Rapanea philippinensis Mez., Dillenia reifferscheidia F. Vill., Neolitsea villosa Merr., Homolanthus, and Eurya japonica. Amone the common shrubby plants may be mentioned Strobilanthus pluriformis C. B. Clarke; Melastoma polyanthum Bl., Medinilla myriantha, Vaccinium spp. and Rubus fraxinifolius Poir. Large specimens of tree ferns, Cyathea spp., are conspicuous in the Mossy Forest.

Vines are in this zone but do not appear to be so numerous as in the Rain Forest and in the High Forest. One of the conspicuous vines is Hoya odorata Schlt., which has waxy white flowers that are very fragrant. Medinilla magnifica Lindl. is abundant in the lower part of this forest. It is an epiphytic shrubby vine with broad shining leaves and pendulous pyramidal clusters of rose-pink flowers. Other vines that occur are Trichosporum philippinensis $\mathrm{O}$. Ktze., Conocephalus sp., Dichrotrichum chorisepalum Clarke, Medinilla myrtiformis Triana., Alyxia monilifera Vid., and the fern, Oleandra colubrina, Copel. Two large sprawling ferns, Gleichenia and Pteridium are rather common. Ficus repens, common in moist places at lower elevations, is also found here. Epiphytic mosses and liverworts, which form dense growths on the trunks of most of the trees, aid in distinguishing this forest from the two at lower altitudes.

Many forms of mosses, liverworts and lichens cover the smaller branches of the trees, and several kinds of these plants grow on the surfaces of the leaves. About 15 species of filmy ferns, Hymenophyllaceae, are found growing in fair abundance on the trunks of trees; these also occur in the upper part of the rain-forest, but more sparingly; their leaves are often covered with moisture. Nepenthes, the pitcher plant is found as an epiphyte in the Mossy Forest as well as in the rain-forest. Several species of $B e g o n i a$ are found here; among these are Begonia aequata A. Gray, Begonia lagunensis Elm. and Begonia oxysperma with large clusters of coral-red flowers. Epiphytic species of Rhododendron also occur here. The soil in the Mossy Forest is covered principally with various species of dicotyledonous herbs, including Coleus multiflorus Benth. and species of Elatostema, and Hedyotis. Hymenophyllaceae and several other kinds of ferns, Selaginella, Lycopodium, and a few species of beautiful orchids also occur.

Among the most striking members of 
this forest are the large epiphytic ferns, Aglaomorpha, Leucostegia, Nephrolepis, and Davallia. Another curious epiphytic fern is the ant-harboring Lecanopteris, with its large channeled base. Other ant-harboring plants are Hydnophytum and Myrmecodia belonging to the Rubiaceae.

The forest of Mount Makiling is recommended for study, because both its flora and fauna have been studied more in detail than has any other natural forest area in the Philippines. There are more than 1800 species of vascular plants known in the Makiling flora, a few of them being confined to this single mountain. Extensive collections have also been made here of the fungi, mosses and liverworts, insects, reptiles and birds. According to Muir, ${ }^{7}$ 55 of the 68 species of derbids found in Luzon have been taken on Mount Makiling and the neighboring locality of Los Baños.

Mount Banajao, nearly $7500 \mathrm{ft}$. high (2300 meters) is an easy journey from Los Baños, and has a much wetter climate as well as a greater height. The vegetation at its foot is accordingly essentially rain forest. The transition to mossy forest is more gradual than on Mount Makiling, and there is a distinct type, of coniferous forest, of nearly pure Podocarpus imbricatus $\mathrm{Bl}$. and $P$. costalis C. Presl. at its summit. Associated with these are a number of truly alpine forms. The flora is much richer in ferns and mosses than is Mount Makiling, but the animal life seems less abundant.

\section{REFERENCES}

Brown, W. H. The vegetation of Philippine Mountains. Phil. Bur. Sci., Manila, 1919. This gives a detailed account of the climate and forest vegetation of Mount Makiling

\footnotetext{
${ }^{7}$ Muir, F. The Derbidae of the Philippine Islands. 'Phil. Jour. Sci., D., 12: 50-52, 1917. Makiling as a biological station. Phil. Agr., 8: 17-18. 1919.
}

and a brief account of Mount Banajao.

Brown, Wm. H., and Mathews, Donald M. Philippine dipterocarp forests, Phil. Jour. Sci., 9: 413-561. 1914.

Gates, Frank C. Swamp vegetation in hot springs area at Los Baños, Laguna, P. I. Phil. Jour. Sci. C, 9: 495-516. 1914.

Muir, F. The Derbidae of the Philippine Islands. Phil. Jour. Sci. D, 12: 50-52. 1917.

Muir, F. Makiling as a biological station. Phil. Agric. 8: 17-18. 1919.

Trelease. Sam F., and McLean, Forman T. Mount Makiling as a station for botanical research. Phil. Agric. 8: 6-16. 1919.

McGregor, R. C. Some features of the Philippine ornis. Phil. Jour. Sci., 16: 361-437. 1920.

Taylor, E. H. Additions to the herpitological fauna of the Philippine Islands. I-Phil. Jour. Sci., 21: 161-206. 1922: II-ibid., 21: 257303. 1922; III-ibid., 22: 515-557. 1923.

Taylor, E. H. Amphibians and turtles of the Philippine Islands. Philippine Bureau of Science. 1922.

Taylor, E. H. Lizards of the Philippine Islands. Philippine Bureau of Science. 1922.

Taylor, E. H. Snakes of the Philippine Islands. Philippine Bureau of Science. 1922.

Hollister, Ned. A list of the mammals of the Philippine Islands, exclusive of the Cetacea. Phil. Jour. Sci., 7: 1-64. 1912.

Light, S. F. Notes on Philippine termites. I-Phil. Jour. Sci., 18: 243257. 1921; II-ibid., 19:23-63. 1921.

Copeland, E. B. The Polypodiacea of the Philippine Islands. Manila. 1905.

Uichanco, L. General facts in the biology of the Philippine moundbuilding termites. Phil. Jour. Sci., 15: 59.

Merrili, E. D. Flora of Manila. Philippine Bureau of Science, Manila, 1912; also, numerous papers by Merrill on classification of Philippine plants.

Foxworthy, F. W. Philippine gymnosperms. Phil. Jour. Sci., 6: 149-177. 1911.

Foxworthy, F. W. Philippine Dipterocarpaceae. I-Phil. Jour. Sci., 6: 231-287. 1911; II-ibid., 8: 163-199. 1918. 



\section{LIST OF ORGANIZATIONS INTER- ESTED IN THE PRESERVATION OF NATURAL CONDITIONS}





\title{
A. LIST OF STATE AND TERRITORIAL REPRESENTATIVES
}

\author{
By W. G. Waterman
}

In the lists of state, provincial, and extra-territorial representatives are included the names of Ecological Society representatives and in a few cases the names of actively interested state bureau officials. The latter are in parentheses. The plan contemplates having both a botanist and a zoologist in each territory.

Abbreviations, etc.: Chmn., chairman of committee on the conservation of natural conditions; *, negotiations not completed, or no recent reply; $Z$, primarily interested in animals; $B$, primarily interested in plants; $G$, primarily interested in geography.

\section{United States}

\section{A. FOREST DISTRICTS}

District 1: J. A. Larsen, United States Forest Service, Missoula, Mont.

District 2: Director, Fremont Forest Experiment Station, ColoradoSprings, Colo.

District 3:G.A. Pearson, Southwestern Forest Experiment Station, Flagstaff, Ariz.

District 4: F. S. Baker, United States Forest Service, Ogden, Utah.

District 5: E. N. Munns, United States Forest Service, San Francisco, Calif.

District 6: Director Wind River Forest Experiment Station, Stabler, Wash.

District 7: E. H. Frothingham, Appalachian Forest Experiment Station, Asheville, N. C.

District 8: District Forester, Juneau, Alaska.

\section{B. STATES}

\section{Alabama}

Prof. R. M. Harper, (G), University, Ala.

Peter A. Brannon, Curator, Department of Archives and History, Montgomery, Ala.

\section{Alaska}

R. F. Griggs, National Geographic Society, Washington, D. C.

\section{Arizona}

Prof. G. A. Pearson, (B), United States Forest Service, Flagstaff, Ariz.

\section{Arkansas}

Prof. John T. Buchholz, (B), Department of Botany, University of Arkansas, Fayetteville, Ark.

\section{California}

Prof. H. C. Bryant, (B), University Museum, Berkeley, Calif.

Prof. T. I. Storer, (Z), University Farm, Davis, Calif.

\section{Colorado}

Prof. F. Ramaley, (B), University of Colorado, Boulder, Colo.

\section{Connecticut}

Prof. G. E. Nichols, (B), Yale University, New Haven, Conn.

Connecticut State Park and Forest Commissioner, A. M. Turner, Drawer 1402, Hartford, Conn.

\section{Delaware}

Frank Morton Jones, 2000 Riverview Avenue, Wilmington, Del.

Mrs. Arthur W. Spruance, 2502 Willard Street, Wilmington, Del.

\section{Florida}

Prof. J. R. Watson, (Z), University of Florida, Gainesville, Fla.

\section{Georgia}

Dr. Henry Fox, (Z), Department of Biology, Mercer University, Macon, Ga.

J. M. Reade, (B), University of Georgia, Athens, Ga. 


\section{Idaho}

Prof. R. A. Muttkowski, Department of Zoology and Entomology, University of Idaho, Moscow, Idaho.

A. S. Piper, (G), Bureau of Mines, Moscow, Idaho.

\section{Illinois}

Prof. H. C. Cowles, (B), University of Chicago, Chicago, Ill.

Prof. W. C. Allee, (Z), University of Chicago, Chicago, Ill.

\section{Indiana}

Prof. Will Scott, (Z), University of Indiana, Bloomington, Ind.

C. C. Deam, (B), State Forester, State House, Indianapolis, Ind.

\section{Iowa}

Prof. L. H. Pammell, (B), Department of Botany, Ames, Iowa.

Dr. T. C. Stephens, (Z), Morningside, College, Sioux City, Iowa.

\section{Kansas}

Prof. James W. McColloch, (Z), Agricultural College, Manhattan, Kan.

Prof. F. U. G. Agrelius, (B), Kansas State Teachers College, Emporia, Kan.

\section{Kentucky}

Dr. Austin R. Middleton, (Z), University of Louisville, Louisville, $\mathrm{Ky}$.

\section{Louisiana}

Hine, Willard R., 323 Custom House, New Orleans, La.

Kopman, H. H., (Z), Louisiana Department of Conservation, New Orleans, La.

\section{Maine}

Prof. A. O. Gross, (Z), Bowdoin College, Brunswick, Me.

\section{Maryland}

Prof. C. C. Hamilton, (Z), Maryland State College, College Park, Md.

\section{Massachusetts}

Dr. Anna Starr, (B), Mt. Holyoke College, South Hadley, Mass.

\section{Michigan}

Dr. Lee R. Dice, (Z), Museum of Zoology, University of Michigan, Ann Arbor, Mich.

\section{Minnesota}

Prof. C. O. Rosendahl, (B), University of Minnesota, Minneapolis, Minn.

\section{Mississippi}

*Prof. Harrison R. Hunt, (Z), Biology Department, University of Mississippi.

\section{Missouri}

Prof. K. C. Sullivan, (Z), University of Missouri, Columbia, Mo.

\section{Montana}

Prof. M. J. Elrod, (Z), University of Montana, Missoula, Mont.

\section{Nebraska}

Prof. R. H. Wolcott, (Z), University of Nebraska, Lincoln, Nebr.

\section{Nevada}

Dr. F. S. Baker, (B), United States Forest Service, Ogden, Utah.

C. W. Glover, State Fish and Game Warden, Carson City, Nevada.

\section{New Hampshire}

Prof. K. W. Woodward, (B), State Forester, University of New Hampshire, Durham, N. H.

Prof. C. F. Jackson, (Z), University of New Hampshire, Durham, N. H.

\section{New Jersey}

Prof. T. C. Nelson, (Z), Rutgers College, New Brunswick, N. J.

Charles P. Wilber, (B), State Forester, State House, Trenton, N. J., Department of Conservation and Development.

\section{New Mexico}

John Woodgate, Jemez Springs, New Mexico.

\section{New York}

Prof. W. L. Bray, (B), Syracuse University, Syracuse, N. Y.

\section{North Carolina}

Prof. Z. P. Metcalf, (Z), Raleigh, N. C. Prof. B. W. Wells, (B), State College Station, N. C.

\section{North Dakota}

Prof. J. T. Sarvis, (B), Field Station, Mandan, N. D.

* Not yet accepted. 


\section{Ohio}

Dr. E. Lucy Braun, (B), Department of Botany, University of Cincinnati, Cincinnati, Ohio.

\section{Oklahoma}

Prof. C. O. Chambers, (B), Department of Botany, Oklahoma Agricultural and Mechanical College, Stillwater, Okla.

\section{Oregon}

Dr. Thornton T. Munger, (B), United States Forest Service, Portland, Ore. Wm. N. Finley, Jennings Lodge, Ore.

\section{Pennsylvania}

Prof. J. W. Harshberger, (B), 4839 Walton Avenue, Philadelphia, $\mathrm{Pa}$.

\section{Rhode Island}

Dr. Marion D. Weston, (B), Rhode Island College of Education, Providence, Rhode Ișland.

Henry E. Childs, 864 Broadway, East Providence, R. I.

\section{South Carolina}

Dr. Philip Luginbill, United States Entomological Station, Columbia, S. C.

Prof. A. C. Moore, Department of Biology, University of South Carolina, Columbia, S. C.

\section{South Dakota}

Prof. E. J. Petry, (B), South Dakota State College, Brookings, S. D.

\section{Tennessee}

*Prof. Edwin B. Powers, (Z), University of Tenn., Knoxville, Tenn.

\section{Texas}

Prof. A. R. Cahn, (Z), 117 West Nevada Street, Urbana, Ill.

\section{Utah}

F. S. Baker, (B), United States Forest Service, Ogden, Utah.

\section{Vermont}

Prof. Geo. F. Burns, (B), University of Vermont, Burlington, Vt.

\section{Virginia}

Dr. I. F. Lewis, (B), Department of Biology, University of Virginia, University, Va.

\section{Washington}

Prof. G. B. Rigg, (B), University of Washington, Seattle, Wash.

Prof. Horace Gunthrop, (Z), University of Washington, Seattle, Wash.

\section{West Virginia}

Prof. W. E. Rumsey, (Z), Experiment Station, Morgantown, W. Va.

\section{Wisconsin}

Clyde B. Terrell, (Z), Oshkosh, Wis.

Dr. Huron Smith, (B), Milwaukee Public Museum, Milwaukee, Wis.

\section{Wyoming}

Prof. John W. Scott, (Z), University of Wyoming, Laramie, Wyo.

Dr. E. B. Payson, (B), University of Wyoming, Laramie, Wyo.

\section{Canada}

\section{ALBERTA}

Miss Annie Norrington, (B), University of Alberta, Edmonton, Alberta.

Dr. Wm. Rowan, (Z), University of Alberta, Edmonton, Alberta.

\section{BRITISH COLUMBIA}

Prof. John Davidson, (B), University of British Columbia, Vancouver, B. C.

\section{MANITOBA}

Prof. C. H. O'Donoghue, (Z), University of Manitoba, Winnipeg, Manitoba.

*Prof. V. W. Jackson, University of Manitoba, Winnipeg, Manitoba.

NEW BRUNSWICK

John D. Tothill, Fredericton, N. B.

Wm. McIntosh, Museum of Natural History, Saint John, N. B.

NEW FOUNDLAND

Arthur Mews, Deputy Colonial Secretary, Saint John, New Foundland.

*Mr. George E. Turner, I. S. O., Saint Johns, New Foundland. 
NOVA SCOTIA

A. H. Mackay, (B), 61 Queen Street, Dartmouth, Nova Scotia.

\section{ONTARIO}

Dr. C. D. Howe, (B), Dean of Forestry, University, Toronto, Ont.

J. R. Dymond, (Z), Department of Biology, Toronto University, Toronto, Ont.

James B. Harkin, (Dominion Parks Branch), Ottawa, Ont.

QUEBEC

Mr. Edward Wilson, Grand Mere, Quebec.

Mr. C. G. Piche, Department of Lands and Forests, Quebec.

\section{SASKATCHEWAN}

Dr. A. E. Cameron, (Z), University of Saskatchewan, Saskatoon, Sask.
Prof. W. P. Thompson, Biology Department, University of Saskatchewan, Saskatoon, Sask.

\section{Extra Territorial}

HAWAII

C. S. Judd, Superintendent of Forestry, Honolulu.

PANAMA

Dr. James Zetek, (Z), Ancon, Canal Zone.

$$
\text { PORTO RICO }
$$

Prof. D. E. Durland, College of Agricultural and Mechanical Arts.

PHILIPPINE ISLANDS

Wm. H. Brown, Bureau of Science, Manila, Philippine Islands. 


\title{
B. LOCAL ORGANIZATIONS
}

\author{
By W. G. Waterman
}

The following is a list of local or state organizations interested in various forms of conservation.

\section{United States}

ALABAMA

Alabama Anthropological Society, Montgomery, Ala.

Alabama State Department Archives and History, Montgomery, Ala.

Baldwin County Historical Society, Fairhope, Ala.

*Bartram Natural History Society, Montgomery, Ala.

Charles Mohr Society, H. P. Loding, Gem Floral Garden, Mobile, Ala.

Moundville Historical Society, Moundville, Ala.

*Russell County Historical Society, Scale, Ala.

Tennessee Valley Historical Society, Tuscumbia, Ala.

\section{ARIZONA}

Arizona Natural History Society, University Station, Tucson, Ariz.

Arizona State Forestry Association, University of Arizona, Tucson, Ariz.

Fort Valley Forest Experiment Station, Flagstaff, Ariz.

\section{ARKANSAS}

Arkansas Federation of Women's Clubs, Mrs. Edwin Bevens, Helena, Ark.

Department of Zoology, University of Arkansas, Prof. S. C. Dellinger, University of Arkansas, Fayetteville, Ark.

State Forestry, Fish, and Game Association, Hamp Williams, President, Hot Springs, L. L. Kimball, Secretary, Russelville, Ark.

\section{CALIFORNIA}

American Society for the Advancement of Science, in care of California Academy of Sciences, San Francisco, Calif.

* Written but letters returned.
Audubon Association of the Pacific, A. S. Kibbe, 1534 Grove Street, Berkeley, Calif.

California Academy of Sciences, Golden Gate Park, San Francisco, Calif.

California Alpine Club, Helen Wild, 1645 Hyde Street, San Francisco, Calif.

California Audubon Society, Mrs. Harriet W. Myers, 311 No. Normandie, Los Angeles, Calif.

California Fish and Game Commission, Postal Telegraph Building, San Francisco, Calif.

California Nature Study League, Mr. C. M. Goethe, Capital National Bank Building, Sacramento, Calif.

California Wild Flower Protective Society, Mrs. Bertha Rice, President, Saratoga, Calif.

California Wild Life Defenders, Box 15, Capitola, Calif.

Cooper Ornithological Club, Museum of Vertebrate Zoology, Berkeley, Calif.

Forest, Fish and Game Protective Society, Mr. J. B. Hauer, President, 338, Pine Street, San Francisco, Calif.

San Diego Natural History Museum, Balboa Park, San Diego, Calif.

Sierra Club, (North Chapter), San Francisco, Calif.

Sierra Club, (South Chapter), Los Angeles, Calif.

Southwest Museum, Marmion Way and Avenue, 46 Los Angeles, Calif.

State Forester, Sacramento, Calif.

Western Society of Naturalists, Occidental College, Los Angeles, Calif.

\section{CONNECTICUT}

Connecticut Botanical Society, Miss Annie Lorens, Secretary, 96 Garden Street, Hartford, Conn. 
Connecticut Forestry Association, P. L. Butterick, Secretary, Yale Forest School, New Haven, Conn.

\section{COLORADO}

Colorado Academy of Sciences, State Museum, Denver, Colo.

Colorado Mountain Club, 202 Chamber of Commerce Building, Denver, Colo.

Colorado Society of Economic Biology, in care of Professor of Zoology, Colorado Agriculture College, Fort Collins, Colo.

History and Natural History Society, State Museum, Denver, Colo.

Rocky Mountain Climbers Club, Boulder, Colo.

\section{DELAWARE}

Garden Club of Wilmington, Delaware, Wilmington, Del.

New Century Club (Committee on Conservation), Wilmington, Del.

Society of Natural History of Delaware, Wilmington, Del.

\section{DISTRICT OF COLUMBIA}

American Civic Association, Washington, D. C.

Audubon Society of the District of Columbia, Miss Helen Childs, Secretary, Chevy Chase, Md.

Biological Society of Washington, Washington, D. C.

*Botanical Society of Washington, Washington, D. C.

National Geographic Society, Washington, D. C.

Wild Flower Preservation Society (Chapter), 3740 Oliver Street, Washington, D. C.

\section{FLORIDA}

Audubon Society, Mrs. Katherine A. Tibbets, Secretary, The Belmont, Saint Petersburg, Fla.

Florida Federation of Women's Clubs, Mrs. N. F. Blackman, Orlando, Fla.

The Florida Entomological Society.

\section{GEORGIA}

Biological Department, Mercer University, Macon, Ga.
Georgia Academy of Science, Henry Fox, Secretary, Mercer University, Macon, Ga.

\section{HAWAII}

Hawaiian Trail and Mountain Club, Honolulu, Hawaii.

\section{IDAHO}

Benewah County Rod and Gun Club, Saint Maries, Idaho.

Clark County Rod and Gun Club, Dubois, Idaho.

Fremont County Rod and Gun Club, J. B. Quayle, Secretary, Saint Anthony, Idaho.

Gooding Rod and Gun Club, Gooding, Idaho.

Latah County Rod and Gun Club, Moscow, Idaho.

Minnidoka County Fish and Game Association, H. V. Cresson, Rupert, Idaho.

Pocatello Rod and Gun Club, C. G. Summer, President, Pocatello, Idaho.

Preston Rod and Gun Club, Milo A. Wheeler, Preston, Idaho.

Soda Springs Rod and Gun Club, S. E. Mathews, Soda Springs, Idaho.

Washington County Rod and Gun Club, F. D. Stover, Secretary, Weiser, Idaho.

\section{ILLINOIS}

Chicago Academy of Sciences, Lincoln Park, Chicago, Ill.

Chicago Geographic Society, Field Museum, Chicago, Ill.

Forestry Department Chicago Women's Clubs, Mrs. Russell Opdike, Chairman, 902 Oakwood Blvd., Chicago, Ill.

Friends of Our Native Landscape, Mr. Edison Wheeler, Secretary, 215 West Huron Street, Chicago, Ill.

Illinois Audubon Society, O. M. Schantz, President, 1649 Otis Building, Chicago, Ill.

Illinois State Academy of Sciences, C. F. Phipps, Secretary, State Teachers College, Dekalb, Ill.

Illinois Federation of Women's Clubs, Conservation Committee and Committees of 333 Districts, Mrs. Theron Colton, 936 E. 46th Street, Chicago, IIl. 
llinois Forestry Association, Mr. E. F. Dodge, Secretary, Box 8, 69 West Jackson Blvd., Chicago, Ill.

Illinois Natural History Survey, Dr. S. A. Forbes, Chief Natural History Building, Urbana, Ill.

Izaak Walton League, Chicago Chapter, Frank K. Reilly, President, 1006 S. Michigan Avenue, Chicago, Ill.

Kenilworth Garden Club, Miss Margaret Harris, Secretary, Kenilworth, Ill.

League of Cook County Women's Clubs, Mrs. J. M. Lazarski, Secretary, 11340 Prairie Avenue, Chicago, Ill.

Municipal Art League, Mrs. H. A. Tyler, Secretary, 909 Leland Avenue, Chicago, Ill.

North Shore Garden Club, Mrs. Bertrand J. Cahn, President, Lake Forest, Ill.

Oak Park and River Forest Garden Club, Miss Jane Porter, President, Oak Park, Ill.

Prairie Club, Miss A. E. Hathaway, Secretary, 537 First National Building, Chicago, Ill.

Riverside Wild Flower Preservation Society, C. M. McIntyre, Secretary, Riverside, Ill.

Public Affairs Committee, Union League Club, A. C. Crane, Secretary, 69 W. Jackson Boulevard, Chicago, Ill.

Wild Flower Preservation Society, Illinois Chapter, Mrs. Chas. Eaton, Secretary, 5744 Kimbark Avenue, Chicago. Ill.

Woodlawn Woman's Club, Mrs. DeWitt Foster, Chairman, 1653 E. 67th Street, Chicago, Ill.

\section{INDIANA}

Archeological Society, Eli Lilly, Indianapolis, Ind.

Audubon Society, Samuel Perkins III, Indianapolis, Ind.

Department of Conservation of the State of Indiana, R. Lieber, Indianapolis, Ind.

Indiana Academy of Science, Flora Anderson, Bloomington, Ind.

Indiana Historical Society, Logan Esary, Bloomington, Ind.
National Dunes Park Association, Mrs. F. J. Sheehan, Gary, Ind.

Nature Study Club of Indiana, Samuel Perkins III, Indianapolis, Ind.

Pottawatomie Chapter, D. A. R., Hazel W. Leary, Secretary, Gary, Ind.

IOWA

Botanical Seminar, State College, Ames, Iowa, C. M. King, Secretary.

Davenport Academy of Science, Davenport, Iowa.

Iowa Academy of Science, J. H. Lees, Secretary, Des Moines, Iowa.

Iowa Conservation Association, G. B. MacDonald, Secretary, Ames, Iowa.

Iowa State Horticultural Society, R. S.

Herrick, Secretary, Des Moines, Iowa.

Iowa Ornithologists' Union, W. M.

Rosen, President, Ogden, Iowa.

Sioux City Academy of Science, Sioux City, Iowa.

KANSAS

Kansas Academy of Sciences, in care of Univerity of Kansas, Lawrence, Kan. McPherson Science Club, Prof. Chas. Morris, Secretary, College Hill, McPherson, Kan.

\section{KENTUCKY}

Kentucky Academy of Sciences, A. M. Peter, Kentucky Agricultural Experiment Station, Lexington, Ky.

Wild Flower Preservation Society (Chapter), Miss Ada Crosweller, Secretary, Covington, $\mathrm{Ky}$.

\section{LOUISIANA}

Baton Rouge Park Association.

Biological Club, Louisiana State University, Dr. E. H. Behre, Biology Department, Louisiana State University, Baton Rouge, La.

Louisiana State Parks Association, Harold Neal, Audubon Park, New Orleans, La.

New Orleans Academy of Sciences, H. E. Buchanan, Tulane University, New Orleans, La.

Rapides Park Association, Mrs. L. J. Hackenjos, Alexandria, La. 
MAINE

Portland Society of Natural History, A. H. Norton, Curator, Elm Street, Portland, Me.

Jocelyn Botanical Society, Elm Street, Portland, Me.

Knox County Natural History Society, Belfast, Me.

\section{MARYLAND}

Maryland Academy of Science, $105 \mathrm{~W}$. Franklin Street, Baltimore, Md.

Maryland Conservation Commission, Munsey Building, Baltimore, Md.

Maryland Forestry Association, Calvert Building, Baltimore, Md.

Maryland State Board of Forestry, F. W. Besley, Forester, Calvert Building, Baltimore, Md.

Maryland State Game and Fish Protective Association, $\mathrm{Mr}$. Wm. H. Fisher, Secretary, 210 E. Redwood Street, Baltimore, Md.

Wild Flower Preservation Society (Chapter), 100 Club Road, Baltimore, Md.

\section{MASSACHUSETTS}

Appalachian Mountain Club, Harlan P. Kelsey, Tremont Building, 1050 Tremont Street, Boston, Mass.

Boston Society of Natural History, 234 Berkeley Street, Boston, Mass.

Massachusetts Audubon Society, 66 Newbury Street, Boston, Mass., Winthrop Packard, Secretary.

Massachusetts Daughters of American Revolution, Mrs. James C. Peabody, 21 Allston Street, Boston, Mass.

Massachusetts Forestry Association, Harris A. Reynolds, Secretary, 4 Joy Street, Boston, Mass.

Massachusetts State Federation of Women's Clubs, Mrs. Frederick G. Bauer, clerk, Pleasant Street, South Weymouth, Mass.

New England Botanical Club, 246 Devonshire Street, Boston, Mass., Robert A. Ware, Secretary.

Society for the Protection of Native New England Plants, Horticultural Hall, 300 Massachusetts Avenue, Boston, Mass.

Trustees of Public Reservations, 14 Beacon Street, Boston, Mass.
MICHIGAN

Civic League (Saginaw), May Turner, 1702 Court Street, Saginaw, Mich.

Detroit Audubon Society, Ralph Beebe, 2920 Hillgen Avenue, Detroit, Mich.

*Detroit Bird Protecting Club, Agnes Sherman, 572 Lavin Avenue, Detroit, Mich.

Detroit Zoological Society, Richard E. Follett, Dime Bank Building, Detroit, Mich.

Michigan Academy of Science, Arts and Letters, L. R. Dice, University of Michigan, Ann Arbor, Mich.

Michigan Audubon Society, Geneva Smithe, 106 Summit Street, Ypsilanti, Mich.

South Haven Bird Club, Florence T. Gregory, South Haven, Mich.

\section{MINNESOTA}

Minnesota Academy of Science, Prof. O. W. Oestlund, Secretary, University of Minnesota, Minn.

Minnesota Chapter of Wild Flower Preservation Society, Mrs. Erroll K. Naftalin, Maryland Hotel, Minneapolis, Minn.

* Minnesota Game Protective League, Room 18, Court House Building, Minneapolis, Minn.

State Forestry Board, W. T. Cox, State Capital, St. Paul, Minn.

State Game and Fish Department, J. F. Gould, Commissioner, Old Capital Building, St. Paul, Minn.

Ten Thousand Lakes of Minnesota Association, Ryan Building, St. Paul, Minn.

\section{MISSISSIPPI}

No representative.

\section{MISSOURI}

Wild Flower Preservation Society, Miss Mary Gilmer, Secretary, 2415 Independence Avenue, Kansas City, Mo.

\section{MONTANA}

Montana Experiment Station, Bozeman, Mont.

Montana State Sportsmen's Association, Headquarters, Missoula, Mont.

State Fish and Game Commission, Helena, Mont. 
United States Forest Service, District

No. 1, Missoula, Mont.

Missoula Bird Club, Missoula, Mont.

\section{NEBRASKA}

Bruner Bird Club, Mrs. G. A. Loveland, 1130 S. 20th Street, Lincoln, Nebr.

Fontenelle Forest Reserve Association, Roy Towl, 524 Peters Trust Building, Omaha, Nebr.

Nebraska Academy of Science, Miss Virginia Zimmer, University of $\mathrm{Ne}$ braska, Lincoln, Nebr.

Nebraska Audubon Society, Mrs. Margaret Hamilton, 592 N. 40th Street, Omaha, Nebr.

Nebraska Ornithologists' Union, Prof. Myron H. Swenk, Agricultural College University of Nebraska, Lincoln, Nebr. State Federation, of Women's Clubs, Miss Harriet Summers, Beatrice, Nebr.

\section{NEVADA}

Nevada Science Club, University of Nevada, Reno, Nev. Dr. L. W. Hartman, President, Miss Margaret E. Mack, Secretary.

\section{NEW HAMPSHIRE}

Society for the Protection of New Hampshire Forests, P. W. Ayres, Forester, 4 Joy Street, Boston, Mass.

The New Hampshire Academy of Sciences, W. C. O'Kane, Secretary, Durham, N. H.

The New England Section of the Society of American Foresters, H. O. Cook, Secretary, State House, Boston, Mass.

\section{NEW JERSEY}

*Apgar Club, Trenton, N. J.

Department of Conservation and Development, State House, Trenton, N. J.

Haddonfield Natural Science Club, Haddonfield, N. J.

Moorestown Natural History Society, Moorestown, N. J.

Newark Entomological Society, Free Public Library, Newark, N. J.

New Jersey Audubon Society, 164 Market Street, Newark, N. J.

*Salem Naturalists Field Club, Salem, N. J.
State Fish and Game Commission, Trenton, N. J.

The Montclair Bird Club, R. H. Howland, Montclair, N. J.

The Paterson Ramblers, Mr. F. Ward, Secretary, 225 Marion St., Paterson, N. J.

The New Jersey Geography Teachers, Miss Helen Steele, Passaic High School, Passaic, N. J.

Woodstown Naturalists' Field Club, Woodstown, N. J.

\section{NEW MEXICO}

New Mexico Game Protective Association, Albuquerque, N. M.

Southwest Section Society of American Foresters, Albuquerque, N. M.

\section{NEW YORK}

Adirondack Camp and Trail Club, T. M. Longstreth, Lake Placid Club, New York City.

Adirondack Mountain Club, T. M. Longstreth, Lake Placid Club, New York. (Publicity of Adirondack Company resources.)

The American Geographical Society of New York, Isaiah Bowman, Director, 156 Broadway, New York City.

*Appalachian Mountain Clubs, New York City.

Buffalo Academy of Science, Frank W. Johnson, Chairman, Botanical Section, Buffalo, N. Y.

Explorers Club, New York City.

*Fresh Air Club, New York City.

New York Academy of Science, Ralph

W. Tower, Secretary, American Museum of Natural History, N. Y.

New York Conservation Commission,

H. F. Prescott, Secretary, Albany, N. Y.

New York State Forestry Association, J. R. Simmons, Secretary, Albany, N. Y.

Rochester Academy of Science, Rochester, N. Y.

Torrey Botanical Club, Marshall A. Howe, Secretary, N. Y. Botanical Garden, Bronx Park, N. Y.

Victory Mountain Park Committee, John H. Finley, Chairman, in care of N. Y. Times, New York City. 
Wild Flower Preservation Society of New York, Mrs. Elizabeth G. Britton, Secretary, New York Botanical Garden, Bronx Park, N. Y.

\section{NORTH CAROLINA}

Elisha Mitchell Scientific Society, University of North Carolina, Chapel Hill, N. C.

North Carolina Academy of Sciences, Bert Cunningham, Secretary, Trinity College, Durham, N. C.

North Carolina Forestry Association, I. S. Holmes, State Forester, Raleigh, N. C.

\section{NORTH DAKOTA}

State Game and Fish Commission, Commissioner, Bismarck, N. Dak.

State Historial Society, Curator, Bismarck, N. Dak.

State Park Board, Chairman, Bismarck, N. Dak.

OHIO

Audubon Society, Miss Lucy B. Stone, Secretary, Columbus, Ohio.

Blue Hydra Society, University of Cincinnati, Cincinnati, Ohio.

Cincinnati Society of Natural History, 312 Broadway, Cincinnati, Ohio.

Cleveland Museum of Natural History, 2717 Euclid Avenue, Cleveland, Ohio.

Ohio Academy of Sciences, Wm. Alexander, Secretary, Weather Bureau, Columbus, Ohio.

Ohio State Archaeological and Historical Society, Wm. C. Mills, Ohio State University, Columbus, Ohio.

Wild Flower Preservation Society, Cincinnati Chapter, Morton Carlisle, 71 E. Hollister Street, Cincinnati, Ohjo.

OKLAHOMA

Oklahoma Academy of Science, L. B. Nice, Norman, Okla.

\section{OREGON}

Angora Hiking Club, Astoria, Ore.

Audubon Society, in care of Central Library, Portland, Ore.

Isaak Walton League, in care of W. S. Raker, Northwestern Bank Building, Portland, Ore.
Nature Study Club, in care of Mrs. A.

L. Stevenson, Corvallis, Ore.

Oregon State Game Commission, Pittock Block, Portland, Ore.

Society of American Foresters, Pacific Northwest Section, 403 Post Office Building, Portland, Ore.

The Mazamas, Chamber of Commerce Building, Portland, Ore.

The Oregon State Board of Forestry, State Forester, Salem, Ore.

The Oregon Historical Society, Court

House, Portland, Ore.

The Trails Club, Portland, Ore.

Western Naturalists, in care of Prof. $H$. P. Torrey, University of Oregon, Eugene, Ore.

Wiyeast Club, in care of C. E. Graves, Hood River, Ore.

\section{PENNSYLVANIA}

*American Alpine Club, Philadelphia, $\mathrm{Pa}$.

Biological Club of the Philadelphia Schools, 13th and Spring Garden Streets, Philadelphia, Pa.

Botanical Society of Pennsylvania, University of Pennsylvania, Philadelphia, Pa.

Botanical Society of Western Pennsylvania, O. E. Jennings, Carnegie $\mathrm{Mu}$ seum, Pittsburgh, Pa.

*Bucks County Natural Science Club, Doylestown, $\mathrm{Pa}$.

Delaware Valley Naturalists Union, 124 North 18th Street, Philadelphia, $\mathrm{Pa}$.

Doylestown Nature Club, Doylestown, $\mathrm{Pa}$.

Everhart Museum, Scranton, Pa.

Geographical Society of Philadelphia, Witherspoon Building, Philadelphia, Pa.

Harrisburg Natural History Society, Harrisburg, $\mathrm{Pa}$.

Historical Society of Frankfort, Frankfort, Philadelphia, Pa.

Lansdowne Natural History Club, Lansdowne, Delaware County, Pa.

*Manoa Natural History Society, Manoa, Delaware County, Pa.

Naturalists Field Club, University of Pennsylvania, Philadelphia, $\mathrm{Pa}$. 
Natural History Club of the Germantown High School, Germantown, Philadelphia, $\mathrm{Pa}$.

Natural History Society of Philadelphia, Wagner Institute, 17th and Montgomery Avenue, Philadelphia, $\mathrm{Pa}$.

Pennsylvania Forestry Association, 130 S. 15th Street, Philadelphia, Pa.

Philadelphia Academy of Sciences, Philadelphia, $\mathrm{Pa}$.

Philadelphia New Century Club, 124 S. 12th Street, Philadelphia, $\mathrm{Pa}$.

Science Club, Lebanon Valley College, Annville, $\mathrm{Pa}$.

*State Federation of Pennsylvania Women, Committee of Forestry and Horticulture, Philadelphia, Pa.

The Audubon Societies, Academy of Natural Science, 19th and Pace Streets, Philadelphia, $\mathrm{Pa}$.

The Delaware County Institute, Media, $\mathrm{Pa}$.

The Pennsylvania Alpine Club, H. W. Shoemaker, 71 Broadway, New York City.

The Pennsylvania State Conservation Council, 315 Commonwealth Building, Harrisburg, $\mathrm{Pa}$.

The Wild Flower Preservation Society of America, 4B Gunter Apartments, 41st and Baltimore Avenue, West Philadelphia, $\mathrm{Pa}$.

\section{RHODE ISLAND}

Appalachian Club (Narragansett Branch) Edward C. Parkhurst, 148 Melrose Street, Providence, R. I.

Civic Improvement and Park Association, John H. Cady, 127 Power Street, Providence, R. I.

Rhode Island Botanical Club, Prof. Walter Snell, Department of Botany, Brown University, Providence, R. I.

Rhode Island Entomological Society, Martin Bowe, 27 Gladstone Street, Providence, R. I.

Rhode Island Field Naturalists Club, Inc., Miss Ida Arnold, 17 Lake View Road, Meschanticut, R. I.

Rhode Island Horticultural Society, Ernest K. Thomas, R. I. Hospital Trust Company, Providence, R. I.

\section{SOUTH CAROLINA}

Conservation Society of South Carolina, James Henry Rice, Secretary, Hotel Jerome, Colombia, S. C.

\section{SOUTH DAKOTA}

South Dakota Academy of Science, Secretary, Prof. A. L. Haines, University of South Dakota, Vermillion, S. D. South Dakota Federation of Women's Clubs, Dept. of Conservation of Natural Resources, Mrs. A. D. Clift, Secretary, Rapid City, S. D.

South Dakota Horticultural Society, Dr. N. E. Hansen, Secretary, South Dakota State College, Brookings, S. D.

\section{TENNESSEE}

East Tennessee Audubon Society (Knoxville), Mrs. Walter Barton, President, 701 11th Street, Knoxville, Tenn.

East Tennessee Ornithological Society (Knoxville), H. P. Ijams, President, R. D. No. 9, Knoxville, Tenn., S. A. Agden, Secretary, Fountain City, Tenn.

Humane Society of Chattanooga, Mrs. Richard Hardy, President, Chattanooga, Tenn.

Smoky Mountain Conservation Association, W. P. Davis, Chairman, 40017 th Street, Knoxville, Tenn.

Smoky Mountain Hiking Club, Bruce A. Rodgers, Secretary, Y. M. C. A., Knoxville, Tenn.

Tennessee Academy of Science, Scott C. Lyon, President, Southwestern University, Clarksville, Tennessee; Rosco Nunn, Secretary, United States Weather Bureau, Nashville, Tenn.

Tennessee Ornithological Society (Nashville), Albert F. Gainer, President, 2507 Ashwood Ave., Nashville, Tenn.

\section{TEXAS}

Outdoor Nature Club, Department of Zoology, University of Texas, Austin, Tex.

Hollands Magazine, Dallas, Tex.

Texas Fish Game and Oyster Commission, Austin, Tex. 
UTAF

Utah Academy of Science, C. Arthur Smith, Secretary, East High School, Salt Lake City, Utah.

Utah Mountain Club, J. E. Broaddus, 312 Walker Boulevard, Salt Lake City, Utah.

\section{VERMONT}

Green Mountain Club, Rutland, Vt.

Vermont Botanical Club, Burlington, Vt.

Vermont Bird Club, Burlington, Vt.

Vermont Forestry Association, Montpelier, Vt.

Vermont Fish and Game League, Montpelier, Vt.

\section{VIRGINIA}

Agricultural Experiment Station, Blacksburg, Va.

Miller School of Biology, University of Virginia, Charlottesville, Va.

Office of the State Forester, University of Virginia, Charlottesville, Va.

The Biological Society in care of Prof. W. D. Hoyt, Washington and Lee University, Lexington, Va.

The Biological Club, in care of Prof. $\mathrm{H}$. E. Hayden, Jr., University of Richmond, Richmond, Va.

The Grimes Natural History Club, in care of Prof. Donald W. Davis, College of William and Mary, Williamsburg, Va.

The State Department of Game and Fisheries, Hon. W. MacDonald Lee, Commissioner, Richmond, Va.

Virginia Academy of Science, I. F. Lewis, President, Dr. E. C. L. Miller, Secretary, Medical College of Virginia, Richmond, Va.

\section{WASHINGTON (STATE)}

Cascadians, Clarence True, Yakima, Wash.

Klahhane Club, Port Angeles, Wash.

Mountaineers, Seattle, Tacoma, Bremerton, and Everett, Wash.

Natural Parks Association of Washington, 4102 Arcade Building, Seattle, Wash.

Pacific Northwest Bird and Mammal Society, State Museum, University of Washington, Seattle, Wash.
Sagebrush and Pine Club, J. H. Wright, Yakima, Wash.

Spokane Mountain Club, A. Glasgow, N. 1221 Monroe Street, Spokane, Wash.

\section{WEST VIRGINIA}

Agricultural Experiment Station, H. G. Knight, Director, Morgantown, W. Va.

West Virginia Geological Survey, I. C. White, Geologist, Morgantown, W. Va.

West Virginia Scientific Society, Secretary, Morgantown, West Va.

West Virginia Wild Life League, Howard H. Cleaves, 727 Goff Building, Clarksburg, West Va.

\section{WISCONSIN}

Friends of our Native Landscape, F. A. Aust, University of Wisconsin, Madison, Wis.

Isaak Walton League, State Capitol, Madison, Wis.

*Milwaukee Garden Club, Milwaukee, Wis.

*Milwaukee Mushroom Club, Milwaukee, Wis.

Outdoor Section of City Club, Milwaukee, Wis.

Wauwatosa Garden Club, Wauwatosa, Wis.

Wild Life Protective Society, Mrs. Nelson M. Black, Secretary Public Museum, Milwaukee, Wis.

Wisconsin Academy of Science, Arts and Letters, Chauncey Juday, 35 Lathrop Streets, Madison, Wis.

Wisconsin Archaeological Society, Chas. E. Brown, Secretary, Historical Museum, Madison, Wis.

Wisconsin Conservation Commission, State Capitol, Madison, Wis.

Wisconsin Federation of Women's Clubs, Madison, Wis.

Wild Flower Preservation Society, Mrs. Wm. Finger, President, 177-34th Street, Milwaukee, Wis.

\section{Canada}

ALBERTA

Northern Alberta Game and Fish Protective League, W. F. H. Mason, Court House, Edmonton, Alberta. 


\section{BRITISH COLUMBIA}

Alpine Club of Canada, Vancouver and Victoria sections in care of Mrs. S. H. Mitchell, Secretary-Treasurer, Sydney, B. C.

British Columbia Mountaineering Club, J. H. Speer, 2426 Seventh Avenue, W., Vancouver, B. C.

British Columbia Ornithologists Union, in care of Provincial Museum, Victoria, B. C.

Cowichan Field Naturalists Club, Duncan, B. C.

The Vancouver Natural History Society, in care of University of British Columbia, British Columbia, Vancouver, B. C.

British Columbia Ornithologists Union, J. W. Winson, Huntingdon, B. C.

Natural History Society of British Columbia, H. T. Nation, in care of C. C. Pemberton 323 Sayward Building, Victoria, B. C.

\section{MANITOBA}

Federation of Women's Clubs, Mrs. Lennox, 90 Kenora St., Winnipeg, Man.

Fish and Game Conservation League of Manitoba, W. G. Scott, Box 577, Winnipeg, Man.

Manitoba Game Protective Association, J. P. Turaner, 403 Merchant Bank Building, Winnipeg, Man.

Manitoba Game Protection League, H. J. Merkeley, 706 Somerset Block, Winnipeg, Man.

Natural History Society of Manitoba, A. M. Davidson, M. D., 6. Medical Arts Building, Winnipeg, Man.

NEW BRUNSWICK

Fredericton Science Club, Secretary, Entomological Laboratory, Fredericton, New Brunswick.

Miramichi Natural History Society, Secretary, Chatham, New Brunswick.

Natural History Society of New Brunswick, Mr. Wm. MacIntosh, in care of Natural History Museum, Saint John, New Brunswick.

\section{ONTARIO}

Clandeboye Bird and Game Protective Association, Eslie Carter, R. R. I., Clandeboye, Ont.
Clyde N. Leavitt, Forester, Railway Commission, Ottawa, Ont.

Commission of the Dominions Park Branch, J. B. Harkin, Ottawa, Ont.

Ontario Entomological Society, A. W. Baker, Ontario Agricultural College, Guelph, Ont.

Ontario Forest, Fish and Game Protective Association, Lieut. Col. A. Kelley Evan, Toronto Club, Toronto, Ont.

Ontario Women's Institute, G. A. Putman, Parliament Building, Toronto, Ont.

Ontario Sportsmen's Game and Fish Protective Association, Sam Harris, 113 Sterling Road, Toronto, Ont.

Ottawa Field Naturalists Club, Dr. J. Frank Wright, Victoria Memorial Museum, Ottawa, Ont.

Royal Canadian Institute, Prof. J. C. Fields, President, 198 College Street, Toronto, Ont.

\section{QUEBEC}

Laurentian Club, Lac la Peche, via Shawinegan Falls, P. Q.

Province of Quebec Society for the Protection of Birds, W. S. Hart, P. O. Box 1185, Montreal, P. Q.

Province of Quebec Association for the Protection of Fish and Game, J. R. Innes, 286 Saint James Street, Imperial Bank Building, Montreal, Que.

Sportsmen's Fish and Game Protective Association of the Province of Quebec, Chas. Fremont, K. C., 81 Saint Peter Street, Quebec, P. Q.

\section{SASKATCHEWAN}

Saskatchewan Game Protective Association, W. M. Van Valkenburg, Regina, Sask.

NOVA SCOTIA

Nova Scotia Institute of Science, Halifax, N. S.

Nova Scotia Inland Game and Fishery Protection Association.

PRINCE EDWARD ISLAND

Prince Edward Island Game and Fish Protective Association, A. R. B. Duck, Charlottetown, P. E. I. 


\title{
C. NATIONAL ORGANIZATIONS
}

\author{
By C. F. JACKSON
}

The following is a list of national organizations interested in various forms of conservation. Where information was available the name of the organization is followed by the name and address of the secretary, the phase of conservation in which the organization is most interested and the approximate total membership.

American Association for the Advancement of Science, Burton E. Livingston, Smithsonian Institution, Washington, D. C. Preservation wild life and national parks.

American Association of Museums, L. V. Coleman, American Association of Museums, Smithsonian Institution, Washington, D. C. Museum work.

American Institute of Park Executives, Will O. Doolittle, Secretary-Treasurer, Rockford, Ill.

American Society of Mammalogists, Hartley H. T. Jackson, United States Biological Survey, Washington, D. C. Conservation of mammals. 600 .

American Ornithologists' Union, J. S. Palmer, 1939 Biltmore Street, N. W., Washington, D. C. Birds. 1900.

American Phytopathological Society, R. J. Haskell, Bureau Plant Industry, Washington, D. C. Conservation plants and crops. 635 .

American Society of Naturalists, A. Franklin Shull, University of Michigan, Ann Arbor, Mich. Fundamental and general biology; natural history. 420.

American Anthropological Association, The, A. V. Kidder, Andover, Mass., American Indian life. 550.

Archeological Institute of America, David M. Robinson, John Hopkins University, Baltimore, Md. Indian mounds.

American Society of Zoologists, W. C. Allee, University of Chicago, Chicago, Ill. Wild life in general.

Association of American Geographers, Richard E. Dodge, Storrs, Conn. Scenic America.
American Fern Society, Charles S. Lewis, 835 Edgewood Avenue, TrenF ton, N. J. Ferns.

American Nature-Study Society, Mrs. Anna B. Comstock, 123 Roberts Place, Ithaca, N. Y. Wild life.

American Association of Economic Entomologists, C. W. Collins, Melrose Highlands, Mass., Control of noxious insects protection and increase beneficial insects. 773 .

American Geographical Society, Isaiah Bowman, Broadway at 156th Street, New York. Geography and scenic assets of America. 4000.

Alberta Natural History Society, Mrs. S. Pamely, Red Deer, Canada. Protection birds and game.

American Civic Association, Harlean James, 905-907 Union Trust Building, Washington, D. C., National parks, forests and scenic assets of America. 1500.

American Museum of Natural History, Percy R. Pyne, Museum 77th Street and Central Park West, New York. Forestry and wild life. 7325.

American Forestry Association, O. M. Butler, The Lenox Building, $1523 \mathrm{~L}$ Street N. W., Washington, D. C. All phases pertaining to natural resources. 14,000 .

American Scenic and Historic Preservation Society, Edward Hagaman Hall, Old Tribune Building, 154 Nassau Street, New York. Scenic and historic places and forests. 500 .

Alpine Club of Canada, S. H. Mitchell, Sidney, Vancouver Island, B. C., Canada. Exploration, education as to scenic value, national playgrounds, 
preservation of scenic beauties. 659.

American Alpine Club, Walter D. Wilcox, 1526 New Hampshire Avenue, Washington, D. C. Scenic beauty. 128.

American Nature Association, P. S. Ridsdale, 1214-16th Street N.W., Washington, D. C. Scenic beauty and wild life.

Associated Mountaineering Clubs of North America, LeRoy Jeffers, 65 Central Park West, New York City. Scenic beauty.

American Game Protective Association, J. B. Burnham, 233 Broadway, New York. Wild life.

Alpine Club of Canada, S. H. Mitchell, Sidney, B. C. Scenic beauty and natural condition.

Boone and Crockett Club, Kermit Roosevelt, 44 Beaver Street, New York. Big game. 164 .

Botanical Society of America, I. F. Lewis, University, Va. Undisturbed plant conditions.

Botanists of the Central States, Edward A. Burt, Missouri Botanical Garden, St. Louis, Mo. Undisturbed plant conditions.

British Columbia Ornithologists Union, J. W. Winson, Huntingdon, B. C. Protection of birds and game.

British Columbia Mountaineering Club, J. H. Speer, 2426 Seventh Avenue, W., Vancouver, B. C., Canada.

Canadian Society for the Protection of Birds, Inc. Miss Laura B. Durand, McLean Building, 153 University Avenue, Toronto, Ont., Canada. Conservation birds.

Camp Director Association of America, F. L. Bryant, 466 E. 17th Street, Brooklyn, N. Y. Scenic and wild life conservation.

Canadian National Parks, J. B. Harkin, 178 Queen Street, Ottawa, Canada. National parks.

Co-operative Campers, Margaret Bliss, 45-47 Brooklyn Avenue, Seattle, Wash. Scenic conditions, parks and wild life. Council on National Parks, Forests, and Wild Life, G. B. Grinnell, 238 E. 15th
Street, New York City. Parks, forests, and wild life.

Dominion Parks Branch, F. H. Williamson, 178 Queen Street, Ottawa, Ontario. National parks.

Entomological Society of America, C. L. Metcalf, University of Illinois, Urbana, Ill. Preservation of natural areas. 650.

Ecological Society of America, A. O. Weese, James Millikin University, Decatur, Ill. Preservation of natural areas.

Explorer's Club of Mexico, Otis McAllister, Apartado Postal 1908, Mexico, D. F. Scenic conditions in Mexico.

Essex Wild Life Conservation Association, Edward R. Kerr, Walkerville, Ontario, Canada. Protection birds and game.

Forest and Stream Society, T. H. Mearns, 231 West 57 Street, New York City. Preservation of forests, streams, and wild life 14,000.

Field and Forests Club, F. M. Brooks, 12 Pemberton Square, Boston, Mass. Wild life and forests.

Fresh Air Club, Mortimer Bishop, 88 Nassau Street, New York City. Outdoor America.

Forest Service, W. B. Greeley, 930 F Street N.W., Washington, D. C.

Geological Society of America, Charles P. Berkey, Columbia University, New York City, N. Y. Unwasteful production of coal and useful metal resources in North America. 507.

Hawaiian Trail and Mountain Club, Miss Zarel Jones, 418 Hawaiian Trust Building, Honolulu, Hawaii. Forests and scenic beauty.

Hamilton Bird Protection Society, Ruby R. Mills, Public Library, Hamilton, Ontario, Canada. Conservation of birds.

Isaak Walton League of America, M. S. Heiss, 536 Lake Shore Drive, Chicago, Ill. Forests and wild life. 100,000.

McIlwraith Ornithological Club, C. G. Watson, 201 Ridout Street, South, London, Ontario, Canada. Protection birds and game.

Manitoba Game Protection League, 
H. J. Merkeley, 706 Somerset Block, Winnipeg, Man., Canada. Conservation birds and game.

Manitoba Game Protective Association, J. P. Turaner, 403 Merchant Bank Building, Winnipeg, Canada. Conservation birds and game.

Mineralogical Society of America, Frank R. Van Horn, Case School Applied Science, Cleveland, Ohio. Natural resources. 280.

National Association of Audubon Societies, T. Gilbert Pearson, 1974 Broadway, New York City, N. Y. Protection wild birds and animals. 150 associated clubs and organizations. 7500 members.

Natural History of New Brunswick, St. John, N.B. Protection birds and game.

Natural History Society of British Columbia, H. T. Nation, in care of C. C. Pemberton, 323 Sayward Building, Victoria, B.C. Protection birds and game.

Natural History Society of Manitoba, A. M. Davidson, M.D., 6 Medical Arts Building, Winnipeg, Man. Conservation birds and game.

Northern Alberta Game and Fish Protective League, W. F. H. Mason, Court House, Edmonton, Alta, Canada. Protection birds and game.

New York Zoological Society, Madison Grant, 111 Broadway, New York City. Conservation of forests and wild life in America, South Africa and Australia. 2725.

National Parks Association, Robert Sterling Yard, 1512 H Street, N.W., Washington, D. C. Conservation National Parks vs. inimical legislation; preservation parks for scientific observation and to promote their use for education. 2000.

National Academy of Sciences, David White, United States Geological Survey, Washington, D. C. Forests and wild life. 249.

National Parks Association of Canada, A. C. Wheeler, Sidney, Brițish Columbia, Canada.
National Park Service, S. T. Mather, National Park Service, Washington, D.C. National parks.

Ontario Entomological Society, A. W. Baker, Ontario Agricultural College, Guelph, Ont. Canada. Protection birds and game.

Ontario Sportsmen's Game and Fish Protective Association, Sam Harris, 113 Sterling Road, Toronto, Ont., Canada. Protection of fish and game.

Ottawa Field Naturalists' Club, Dr. J. Frank Wright, Victoria Memorial Museum, Ottawa, Canada.

Ontario Forest, Fish and Game Protective Association, Lieut. Col. A. Kelley Evan, Toronto Club, Toronto, Ont. Canada. Game and birds.

Permanent Wild Life Foundation, W. T. Hornaday, New York City.

Province of Quebec Society for the Protection of Birds. W. S. Hart, P. O. Box 1185, Montreal, P. Q. Protection birds.

Province of Quebec Association for the Protection of Fish and Game, J. R. Innes, 286 Saint James Street, Imperial Bank Building, Montreal. Fish and game.

Prince Edward Island Game and Fish Protective Association, A. R. B. Duck, Charlottetown, P. E. I. Protection fish and game.

Paleontological Society, R. Bassler, United States National Museum, Washington, D.C. Conservation natural resources.

Save the Redwoods League, N. B. Drury, 298 Monadnock Block, San Francisco, Calif. Redwood forests.

Societe Provancher d'Historie Naturelle du Canada, Jos. Matte, 18 Masionneuve Avenue, Quebec, P. Q. Birds and game.

Saskatchewan Game Protective Association, W. M. Van Valkenburg, Regina, Sask. Fish and game.

Sportsmen's Fish and Game Protective Association of the Province of Quebec, Chas. Fremont, K. C. 81 Saint Peter Street, Quebec, P. Q. Protection game. 
Sullivan Moss Society, Edward B. Utah Mountain Club, J. E. Broadlus, 312 Chamberlain, 18 West 89th Street, Walker Bank Building, Salt Lake City, New York City. Hepatics, mosses, lichens. 150.

Sierra Club, William Colby, Mills Building, San Francisco, Calif. National parks and forests. 2500 .

Tramp and Trail Club, G. L. Bickel, 756 Park Avenue, Portland, Ore. Mountains and forests.

Travel Club of America, F. StraithMiller, 114 Grand Central Palace, New York City. Scenic beauty, parks, and forests.

Utah. Mountains and forests.

Vancouver Natural History Society, C. F. Connor, M.A., 3529 W. Second Avenue, Vancouver, B. C. Conservation of wild life.

Wilson Ornithological Club, Gordan Wilson, 1434 Chestnut Street, Bowling Green, Ky. 650.

Wild Flower Preservation Society. P. L. Ricker, President, 3740 Oliver Street, Washington, D. C. 

VI. INDICES 



\section{LIST OF BIRD NAMES}

Giving the common and scientific names of the birds of the United States according to the Check List of the American Ornithological Union.

Albatross, Black-footed, Diomedea nigripes

Albatross, Laysan, Diomedea immutabilis

Albatross, Short-tailed, Diomedea albatrus

Albatross, Sooty, Phobetria palpebrata auduboni

Albatross, Yellow-nosed, Thalassogeron culminatus

Ani, Crotophaga ani

Ani, Groove-billed, Crotophaga sulcirostris

Auk, Great, Plautus impennis

Auk, Razor-billed, Alca torda

Auklet, Cassin's, Ptychoramphus aleuticus

Auklet, Crested, Ethia cristatella

Auklet, Least, Ethia pusilla

Auklet, Paroquet, Phaleris psittacula

Auklet, Rhinoceros, Cerorhinca monocerata

Auklet, Whiskered, Ethia pygmæa

Avocet, Recurvirostra americana

Baldpate, Mareca americana

Becard, Xantus's, Platypsaris aglaiæ albiventris

Bittern, Botaurus lentiginosus

Bittern, Least, Ixobrychus exilis

Blackbird, Brewer's, Euphagus cyanocephalus

Blackbird, Red-winged, Agelaius phoniceus phoniceus

Blackbird, Rusty, Euphagus carolinus

Blackbird, Yellow-headed, Xanthocephalus xanthocephalus

Bluebird, Sialia sialis sialis

Bluebird, Azure, Sialia sialis fulva

Bluebird, Chestnut-backed, Sialia mexicana bairdi

Bluebird, Mountain, Sialia currucoides

Bluebird, San Pedro, Sialia mexicana anabela

Bluebird, Western, Sialia mexicana occidentalis

Blue-throat, Siberian Red-spotted, Cyanosylvia suecica robusta

Bobolink, Dolichonyx oryzivorus

Bob-white, Colinus virginianus virginianus

Bob-white, Florida, Colinus virginianus floridanus

Bob-white, Masked, Colinus ridgwayi
Bob-white, Texas, Colinus virginianus texanus

Booby, Sula leucogastra

Booby, Blue-faced, Sula dactylatra

Booby, Blue-footed, Sula nebouxi

Booby, Brewster's, Sula brewsteri

Booby, Red-footed, Sula piscator

Brant, Black, Branta nigricans

Buffle-head, Charitonetta albeola

Bullfinch, Cassin's, Pyrrhula cassini

Bunting, Beautiful, Passerina versicolor pulchra

Bunting, Indigo, Passerina cyanea

Bunting, Lark, Calamospiza melanocorys

Bunting, Lazuli, Passerina amæna

Bunting, McKay's Snow, Plectrophenax hyperboreus

Bunting, Painted, Passerina ciris

Bunting, Pribilof Snow, Plectrophenax nivalis townsendi

Bunting, Snow, Plectrophenax nivalis nivalis

Bunting, Varied, Passerina versicolor versicolor

Bush-Tit, Psaltriparus minimus minimus

Bush-Tit, California, Psaltriparus minimus californicus

Bush-Tit, Grinda's, Psaltriparus minimus grindo

Bush-Tit, Lead-colored, Psaltriparus plumbeus

Bush-Tit, Lloyd's, Psaltriparus meianotis lloydi

Canvas-back, Marila valisineria

Caracara, Audubon's, Polyborus cheriway

Caracara, Guadalupe, Polyborus lutosus

Cardinal, Cardinalis cardinalis cardinalis

Cardinal, Arizona, Cardinalis cardinalis superbus

Cardinal, Florida, Cardinalis cardinalis floridanus

Cardinal, Gray-tailed, Cardinalis cardinalis canicaudus

Cardinal, San Lucas, Cardinalis cardinalis igneus

Catbird, Dumetella carolinensis

Chachalaca, Ortalis vetula mccalli

Chat, Long-tailed, Icteria virens longicauda 
Chat, Yellow-breasted, Icteria virens virens

Chickadee, Penthestes atricapillus atricapillus

Chickadee, Acadian, Penthestes hudsonicus littoralis

Chickadee, Alaska, Penthestes cinctus alascensis

Chickadee, Bailey's Mountain, Penthestes gambeli baileyæ

Chickadee, Barlow's, Penthestes rufescens barlowi

Chickadee, California, Penthestes rufescens neglectus

Chickadee, Carolina, Penthestes carolinensis carolinensis

Chickadee, Chestnut-backed, Penthestes rufescens rufescens

Chickadee, Florida, Penthestes carolinensis impiger

Chickadee, Hudsonian, Penthestes hudsonicus hudsonicus

Chickadee, Long-tailed, Penthestes atricapillus septentrionalis

Chickadee, Mexican, Penthestes sclateri

Chickadee, Mountain, Penthestes gambeli gambeli

Chickadee, Oregon, Penthestes atricapillus occidentalis

Chickadee, Plumbeous, Penthestes carolinensis agilis

Chickadee, Valdez, Chestnut-backed, Penthestes rufescens vivax

Chickadee, Yukon, Penthestes atricapillus turneri

Chicken, Attwater's Prairie, Tympanuchus americanus attwateri

Chicken, Lesser Prairie, Tympanuchus pallidicinctus

Chicken, Prairie, Tympanuchus americanus americanus

Chuck-will's widow, Anstrostomus carolinensis

Coot, Fulica americana

Coot, European, Fulica atra

Cormorant, Phalacrocorax carbo

Cormorant, Baird's, Phalacrocorax pelagicus resplendens

Cormorant, Brandt's, Phalacrocorax penicillatus

Cormorant, Double-crested, Phalacrocorax auritus auritus

Cormorant, Farallon, Phalacrocorax auritus albociliatus

Cormorant, Florida, Phalacrocorax auritus floridanus

Cormorant, Mexican, Phalacrocorax vigua mexicanus

Cormorant, Pelagic, Phalacrocorax pelagicus pelagicus

Cormorant, Red-faced, Phalacrocorax urile

Cormorant, Violet-green, Phalacrocorax pelagicus robustus

Cormorant, White-crested, Phalacrocorax auritus cincinatus
Cowbird, Molothrus ater ater

Cowbird, Bronzed, Tangavius æneus coneus

Cowbird, Dwarf, Molothrus ater obscurus

Cowbird, Red-eyed, Tangavius æneus involucratus

Crake, Corn, Crex crex

Crake, Spotted, Porzana porzana

Crane, Little Brown, Grus canadensis

Crane, Sandhill, Grus mexicana

Crane, Whooping, Grus americana

Creeper, Bahama Honey, Cæreba bahamensis

Creeper, Brown, Certhia familiaris americana

Creeper, California, Certhia familiaris occidentalis

Creeper, Mexican, Certhia familiaris albescens

Creeper, Rocky Mountain, Certhia familiaris montana

Creeper, Sierra, Certhia familiaris zelotes

Crossbill, Loxia curvirostra minor

Crossbill, Mexican, Loxis curvirostra stricklandi

Crossbill, Newfoundland, Loxia curvirostra perena

Crossbill, White-winged, Loxia leucoptera

Crow, Corvus brachyrhynchos brachyrhynchos

Crow, Fish, Corvus ossifragus

Crow, Florida, Corvus brachyrhynchos pascuus

Crow, Hooded, Corvus cornix

Crow, Northwestern, Corvus brachyrhynchos caurinus

Crow, Southern, Corvus brachyrhynchos paulus

Crow, Western, Corvus brachyrhynchos hesperis

Cuckoo, Black-billed, Coccyzus erythrophthalmus

Cuckoo, California, Coccyzus americanus occidentalis

Cuckoo, Kamchatka, Cuculus canorus telephonus

Cuckoo, Maynard's, Coccyzus minor maynardi

Cuckoo, Yellow-billed, Coccyzus americanus americanus

Curlew, Bristle-thighed, Numenius tahitiensis

Curlew, Eskimo, Numenius borealis

Curlew, Hudsonian, Numenius hudsonicus

Curlew, Long-billed, Numenius americanus

Dickcissel, Spiza americana

Dipper, Cinclus mexicanus unicolor

Dotterel, Eudromias morinellus

Dovekie, Alle alle

Dove, Bermuda Ground, Chœmepelia passerina bermudiana 
Dove, Dusky Mourning, Zenaidura macrouva caurina

Dove, Ground, Chœmepelia passerina passerina

Dove, Inca, Scardafella inca

Dove, Mexican Ground, Chœmepelia passerina pallescens

Dove, Mourning, Zenaidura macroura carolinensis

Dove, Western Mourning, Zenaidura macroura marginella

Dove, West Indian White-winged, Melopelia asiatica asiatica

Dove, White-fronted, Leptotila fulviventris brachyptera

Dove, White-winged, Melopelia asiatica trudeaui

Dove, Zenaida, Zenaida zenaida

Dowitcher, Limnidromus griseus griseus

Dowitcher, Long-billed, Limnidromus griseus scolopaceus

Duck, Black, Anas rubripes

Duck, Florida, Anas fulvigula fulvigula

Duck, Harlequin, Histrionicus histrionicus

Duck, Labrador, Camptorhynchus labradorius

Duck, Lesser Scapu, Marila affinis

Duck, Masked, Nomonyx dominicus

Duck, Mottled, Anas fulvigula maculosa

Duck, Ring-necked, Marila collaris

Duck, Ruddy, Erismatura jamaicensis

Duck, Rufous-crested, Netta rufina

Duck, Scaup, Marila marila

Duck, Western Harlequin, Histrionicus histrionicus pacifiens

Duck, Wood, Aix sponsa

Dunlin, Pelidna alpina alpina

Eagle, Bald, Haliœetus leucocephalus leucocephalus

Eagle, Gray Sea, Haliœetus albicilla

Eagle, Golden, Aquila chrysaëtos

Eagle, Northern Bald, Halioetus leucocephalus alascanus

Egret, Casmerodius egretta

Egret, Brewster's, Egretta candidissima brewsteri

Egret, Reddish, Dichromanassa rufescens

Egret, Snowy, Egretta candidissima candidissima

Eider, Somateria mollissima dresseri

Eider, King, Somateria spectabilis

Eider, Northern, Somateria mollissima borealis

Eider, Pacific, Somateria v-nigra

Eider, Spectacled, Arctonetta fischeri

Eider, Steller's, Polysticta stelleri

Falcon, Aplomado, Falco fusco-cærulescens

Falcon, Peale's, Falco peregrinus pealei

Falcon, Peregrine, Falco peregrinus peregrinus

Falcon, Prairie, Falco mexicanus
Finch, Aleutian Rosy, Leucosticte griseonucha

Finch, Black Rosy, Leucosticte atrata

Finch, Brown-capped Rosy, Leucostricte australis

Finch, California Purple, Carpodacus purpureus californicus

Finch, Cassin's Purple, Carpodacus cassini

Finch, Gray-crowned Rosy, Leucosticte tephrocotis tephrocotis

Finch, Guadalupe House, Carpodacus amplus

Finch, Hepburn's Rosy, Leucosticte tephrocotis littoralis

Finch, House, Carpodacus mexicanus frontalis

Finch, McGregor's House, Carpodacus mcgregori

Finch, Purple, Carpodacus purpureus purpureus

Finch, San Clemente House, Carpodacus mexicanus clementis

Finch, San Lucas House, Carpodacus mexicanus ruberrimus

Finch, Sierra Nevada Rosy, Leucosticte tephrocotis dawsoni

Flamingo, Phænicopterus ruber

Flicker, Boreal, Colaptes auratus borsalis

Flicker, Colaptes auratus auratus

Flicker, Gilded, Colaptes chrysoides chrysoides

Flicker, Guadalupe, Colaptes rufipileus

Flicker, Mearns, Colaptes chrysoides mearns $i$

Flicker, Northern, Colaptes auratus luteus

Flicker, Northwestern, Colaptes cafer cafer

Flicker, Red-shafted, Colaptes cafer collaris

Flicker, San Fernando, Colaptes chrysoides brunnescens

Flycatcher, Acadian, Empidonax virescens

Flycatcher, Alder, Empidonax trailli alnorum

Flycatcher, Arizona Crested, Myiarchus magister magister

Flycatcher, Ash-throated, Myiarchus cinerascens cinerascens

Flycatcher, Beardless, Camptostoma imberbe

Flycatcher, Buff-breasted, Empidonax fulvifrons pygmæus

Flycatcher, Coues's, Myiochanes pertinax pallidiventris

Flycatcher, Crested, Myiarchus crinitus

Flycatcher, Derby, Pitangus sulphuratus derbianus

Flycatcher, Fork-tailed, Muscivora tyrannus

Flycatcher, Gray, Empidonax griseus

Flycatcher, Hammond's, Empidonax hammondi 
Flycatcher, Least, Empidonax minimus Flycatcher, Mexican Crested, Myiarchus magister nelsoni

Flycatcher, Lower California, Myiarchus cinerascens pertinax

Flycatcher, Olivaceous, Myiarchus lawrencei olivascens

Flycatcher, Olive-sided, Nuttallornis borealis

Flycatcher, San Lucas, Empidonax difficilis cineritius

Flycatcher, Scissor-tailed, Muscivora forficata

Flycatcher, Sulphur-bellied, Myiodynastes luteiventris

Flycatcher, Traill's, Empidonax trailli trailli

Flycatcher, Vermilion, Pyrocephalus rubinus mexicanus

Flycatcher, Western, Empidonax difficilis difficilis

Flycatcher, Wright's, Empidonax wrighti

Flycatcher, Yellow-bellied, Empidonax flaviventris

Fulmar, Fulmarus glacialis glacialis

Fulmar, Giant, Macronectes giganteus

Fulmar, Pacific, Fulmarus glacialis glupischa

Fulmar, Rodgers's, Fulmarus rodgersi

Fulmar, Slender-billed, Priocella antarctica

Gadwall, Chaulelasmus streperus

Gallinule, Florida, Gallinula chloropus cachinnans

Gallinule, Purple, Ionornis martinicus

Gannet, Moris bassana

Gnatcatcher, Black-tailed, Polioptila californica

Gnatcatcher, Blue-gray, Polioptila cærulea cærulea

Gnatcatcher, Plumbeous, Polioptila plumbea

Gnatcatcher, Western, Polioptila cræulea obscura

Godwit, Black-tailed, Limosa limosa

Godwit, Hudsonian, Limosa hæmastica

Godwit, Marbled, Limosa fedoa

Godwit, Pacific, Limosa lapponica baueri

Golden-eye, Glaucionetta clangula americana

Golden-eye, Barrow's, Glancionetta islandica

Goldfinch, Astragalinus tristis tristis

Goldfinch, Arkansas, Astragalinus psaltria psaltria

Goldfinch, Black-headed, Spinus notatus

Goldfinch, Green-backed, Astragalinus psaltria hesperophilus

Goldfinch, Lawrence's, Astragalinus lawrencei

Goldfinch, Pale, Astragalinus tristis pallidus

Goldfinch, Willow, Astragalinus tristis salicamans
Goose, Barnacle, Branta leucopsis

Goose, Bean, Anser fabalis

Goose, Blue, Chen cærulescens

Goose, Cackling, Branta canadensis minima

Goose, Canada, Branta canadensis canadensis

Goose, Emperor, Philacte canagica

Goose, European White-fronted, Anser albifrons albifrons

Goose, Hutchins's, Branta canadensis hutchinsi

Goose, Pink-footed, Anser brachyrhynchus

Goose, Ross's, Chen rossi

Goose, Snow, Chen hyperboreus hyperboreus

Goose, White-cheeked, Branta canadensis occidentalis

Goose, White-fronted, Anser albifrons gambeli

Goshawk, Astur atricapillus atricapillus

Goshawk, Mexican Asturina plagiata

Goshawk, Western, Astur atricapillus striatulus

Grackle, Boat-tailed, Megaquiscalus major major

Grackle, Bronzed, Quiscalus quiscula æneus

Grackle, Florida, Quiscalus quiscula aglæus

Grackle, Great-tailed, Megaquiscalus major macrourus

Grackle, Purple, Quiscalus quiscula quiscula

Grassquit, Tiaris bicolor

Grassquit, Melodious, Tiaris canora

Grebe, Eared, Colymbus nigricollis californicus

Grebe, Holbœll's, Colymbus holbælli

Grebe, Horned, Colymbus auritus

Grebe, Mexican, Colymbus dominicus brachypterus

Grebe, Pied-billed, Podilymbus podiceps

Grebe, Western, Achmophorus occidentalis

Green-shank, Glottis nebularia

Grosbeak, Alaska Pine, Pinicola enucleator alascensis

Grosbeak, Black-headed, Hedymeles melanocephata

Grosbeak, Blue, Guiraca cærulea cærulea

Grosbeak, California Pine, Pinicola enucleator californica

Grosbeak, Evening, Hesperiphona vespertina vespestina

Grosbeak, Kadiak Pine, Pinicola enucleator flammula

Grosbeak, Newfoundland Pine, Pinicola enucleator eschatosus

Grosbeak, Pine, Pinicola enucleator leucura

Grosbeak, Rocky Mountain Pine, Pinicola enucleator montana

Grosbeak, Rose-breasted, Hedymeles ludoviciana 
Grosbeak, Western Blue, Guiraca cærulea lazula

Grosbeak, Western Evening, Hesperiphona vespertina montana

Grouse, Canada Ruffed, Bonasa umbellus togata

Grouse, Columbian Sharp-tailed, Pedixcetes phasianellus columbianus

Grouse, Dusky, Dendragapus obscurus obscurus

Grouse, Fleming's Dendragapus, obscurus flemingi

Grouse, Franklin's, Canachites franklini

Grouse, Gray Ruffed, Bonasa umbellus umbelloides

Grouse, Oregon Ruffed, Bonasa umbellus sabini

Grouse, Nova Scotia Ruffed, Bonasa umbellus thayeri

Grouse, Prairie Sharp-tailed, Pediacetes phasianellus campestris

Grouse, Richardson's, Dendragapus obscurus richardsoni

Grouse, Ruffed, Bonasa umbellus umbellus

Grouse, Sharp-tailed, Pediccetes phasianellus phasianellus

Grouse, Sierra, Dendragapus obscurus sierræ

Grouse, Sooty, Dendragapus obscurus fuliginosus

Grouse, Yukon Ruffed, Bonasa umbellus yukonensis

Guillemot, Black, Cepphus grylle

Guillemot, Mandt's, Cepphus mandti

Guillemot, Pigeon, Cepphus columba

Gull, Bonaparte's, Larus philadelphia

Gull, California, Larus californicus

Gull, Franklin's, Larus franklini

Gull, Glaucous, Larus hyperboreus

Gull, Glaucous-winged, Larus glaucescens

Gull, Great Black-backed, Larus marinus

Gull, Heermann's, Larus heermanni

Gull, Herring, Larus argentatus

Gull, Iceland, Larus leucopterus

Gull, Ivory, Pagophila alba

Gull, Kumlien's, Larus kumlieni

Gull, Laughing, Larus, atricilla

Gull, Little, Larus minutus

Gull, Mew, Larus canus

Gull, Nelson's, Larus nelsoni

Gull, Ring-billed, Larus delawarensis

Gull, Ross's, Rhodostethia rosea

Gull, Sabine's, Xemia sabini

Gull, Short-billed, Larus brachyrhynchus

Gull, Siberian, Larus affinis

Gull, Slaty-backed, Larus schistisagus

Gull, Vega, Larus vegæ

Gull, Western, Larus occidentalis

Gyrfalcon, Falco rusticolus gyrfalco

Gyrfalcon, Black, Falco rusticolus obsoletus

Gyrfalcon, Gray, Falco rusticolus rusticolus
Gyrfalcon, White, Falco islandus

Hawk, Black Pigeon, Falco columbarius suckleyi

Hawk, Broad-winged, Buteo platypterus

Hawk, Cooper's, Accipiter cooperi

Hawk, Cuban Sparrow, Cerchneis sparveroides

Hawk, Desert Sparrow, Cerchneis sparverius phalæna

Hawk, Duck, Falco peregrinus anatum

Hawk, Florida Red-shouldered, Buteo lineatus alleni

Hawk, Harlan's, Buteo borealis harlani

Hawk, Harris's, Parabuteo unicinctus harrisi

Hawk, Krider's, Buteo borealis krideri

Hawk, Little Sparrow, Cerchneis sparverius paulus

Hawk, Marsh, Circus hudsonius

Hawk, Mexican Black, Urubitinga anthracina

Hawk, Pigeon, Falco columbarius columbarius

Hawk, Red-bellied, Buteo lineatus elegans

Hawk, Red-shouldered, Buteo lineatus lineatus

Hawk, Red-tailed, Buteo borealis borealis

Hawk, Richardson's Pigeon, Falco columbarius richardsoni

Hawk, Rough-legged, Archibuteo lagopus sancti-johannis

Hawk, San Lucas Sparrow, Cerchneis sparverius peninsularis

Hawk, Sennett's White-tailed, Buteo albicaudatus sennetti

Hawk, Sharp-shinned, Accipiter velox

Hawk, Short-tailed, Buteo brachyurus

Hawk, Sparrow, Cerchneis sparverius sparverius

Hawk, Swainson's, Buteo swainsoni

Hawk, Texas, Red-shouldered, Buteo lineatus texanus

Hawk, Zone-tailed, Buteo abbreviatus

Hen, Heath, Tympanuchus cupido

Hen, Sage, Centrocercus urophasianus

Heron, Anthony's Green, Butorides virescens anthonyi

Heron, Black-crowned Night, Nycticorax nycticorax nævius

Heron, California, Ardea herodias hyperonca

Heron, Espiritu Santo, Ardea herodias sanctilucas

Heron, European, Ardea cinerea

Heron, Frazar's Green, Butorides virescens frazari

Heron, Great Blue, Ardea herodias herodias

Heron, Great White, Ardea occidentalis

Heron, Green, Butorides virescens virescens

Heron, Little Blue, Florida cærulea

Heron, Louisiana, Hydranassa tricolor ruficollis 
Heron, Northwestern, Coast Ardea herodias fannini

Heron, Treganza's, Ardea herodias treganzai

Heron, Ward's, Ardea herodias wardi

Heron, Yellow-crowned Night, Nyctanassa violacea

Hummingbird, Allen's, Selasphorus alleni

Hummingbird, Anna's, Calypte anna

Hummingbird, Black-chinned, Archilochus alexandri

Hummingbird, Blue-throated, Cyanolæmus clemenciæ

Hummingbird, Broad-billed, Cynanthus latirostris

Hummingbird, Broad-tailed, Selasphorus platycercus

Hummingbird, Buff-bellied, Amizilis cerviniventris chalconota

Hummingbird, Calliope, Stellula calliope

Hummingbird, Costa's, Calypte costæ

Hummingbird, Lucifer, Calothorax lucifer

Hummingbird, Marcom's, Atthis morcomi

Hummingbird, Rieffer's, Amizilis tzacatl

Hummingbird, Rivoli's, Eugenes fulgens

Hummingbird, Ruby-throated, Archilochus colubris

Hummingbird, Rufous, Selasphorus rufus

Hummingbird, Salvin's Amizilia salvini

Hummingbird, White-eared, Basilinna leucotis

Hummingbird, Xantus's, Basilinna xantusi

Ibis, Glossy, Plegadis autumnalis

Ibis, Scarlet, Guara rubra

Ibis, White, Guara alba

Ibis, White-faced Glossy, Plegadis guarauna

Ibis, Wood, Mycteria americana

Jabiru, Jabiru mycteria

Jacana, Mexican, Jacana spinosa

Jaeger, Long-tailed, Stercorarius longicaudus

Jaeger, Parasitic, Stercorarius parasiticus

Jaeger, Pomarine, Stercorarius pomarinus

Jay, Alaska, Perisoreus canadensis fumifrons

Jay, Arizona, Aphelocoma sieberi arizonæ

Jay, Belding's, Aphelocoma californica obscura

Jay, Black-headed, Cyanocitta stelleri annectens

Jay, Blue, Cyanocitta cristata cristata

Jay, Blue-eared, Aphelocoma cyanotis

Jay, Blue-fronted, Cyanocitta stelleri frontalis
Jay, California, Aphelocoma californica californica

Jay, Canada, Perisoreus canadensis canadensis

Jay, Coast, Cyanocitta stelleri carbonacea Jay, Couch's, A phelocoma sieberi couchi Jay, Florida, Aphelocoma cyanea

Jay, Florida Blue, Cyanocitta cristata florincola

Jay, Gray, Perisoreus obscurus griseus

Jay, Green, Xanthoura luxuosa glaucescens

Jay, Labrador, Perisoreus canadensis nigricapillus

Jay, Long-crested, Cyanocitta stelleri diademata

Jay, Newfoundland, Perisoreus canadensis sanfordi

Jay, Oregon, Perisoreus obscurus obscurus

Jay, Piñon, Cyanocephalus cyanocephalus Jay, Queen Charlotte, Cyanocitta stelleri carlottæ

Jay, Rocky Mountain, Perisoreus canadensis capitalis

Jay, Santa Cruz, Aphelocoma insularis

Jay, Steller's, Cyanocitta stelleri stelleri

Jay, Texas, A phelocoma texana

Jay, Woodhouse's, Aphelocoma woodhousei

Jay, Xantus's, Aphelocoma californica hypoleuca

Junco, Arizona, Junco phæonotus palliatus

Junco, Baird's, Junco bairdi

Junco, Carolina, Junco hyemalis carolinensis

Junco, Gray-headed, Junco phronotus caniceps

Junco, Guadalupe, Junco insularis

Junco, Montana, Junco hyemalis montanus

Junco, Oregon, Junco hyemalis oreganus

Junco, Pink-sided, Junco hyemalis mearnsi

Junco, Point Pinos, Junco hyemalis pinosus.

Junco, Red-backed, Junco phæonotus dorsalis

Junco, Ridgway's, Junco hyemalis annectens

Junco, Slate-colored, Junco hyemalis hyemalis

Junco, Shufeldt's, Junco hyemalis connectens

Junco, Thurber's, Junco hyemalis thurberi

Junco, Townsend's, Junco hyemalis townsendi

Junco, White-winged, Junco aikeni

Kestrel, Cerchneis tinnunculus

Killdeer, Oxyechus vociferus

Kingbird, Tyrannus tyrannus

Kingbird, Arkansas, Tyrannus verticalis

Kingbird, Cassin's, Tyrannus vociferans 
Kingbird, Couch's, Tyrannus melancholicus couchi

Kingbird, Gray, Tyrannus dominicensis Kingfisher, Belted, Ceryle alcyon alcyon Kingfisher, Northwestern Belted, Ceryle alcyon caurina

Kingfisher, Ringed, Ceryle torquata

Kingfisher, Texas, Chloroceryle americana septentrionalis

Kinglet, Dusky, Regulus calendula obscurus

Kinglet, Golden-crowned, Regulus satrapa satrapa

Kinglet, Ruby-crowned, Regulus calendula calendula

Kinglet, Sitka, Regulus calendula grinnelli

Kinglet, Western Golden-crowned Regulus satrapa olivaceus

Kite, Everglade, Rostrhamus sociabilis

Kite, Mississippi, Ictinia mississippiensis

Kite, Swallow-tailed, Elanoides forficatus

Kite, White-tailed, Elanus leucurus

Kittiwake, Rissa tridactyla tridactyla

Kittiwake, Pacific, Rissa tridactyla pollicaris

Kittiwake, Red-legged, Rissa brevirostris

Knot, Calidris canutus

Lapwing, Vanellus vanellus

Lark, California Horned, Otocoris alpestris adusta

Lark, Desert Horned, Otocoris alpestris leucoløma

Lark, Dusky Horned, Otocoris alpestris merrilli

Lark, Horned, Otocoris alpestris alpestris

Lark, Hoyt's Horned, Otocoris alpestris hoyti

Lark, Island Horned, Otocoris alpestris insularis

Lark, Montezuma Horned, Otocoris alpestris occidentalis

Lark, Pallid Horned, Otocoris alpestris arcticola

Lark, Prairie Horned, Otocoris alpestris praticola

Lark, Ruddy Horned, Otocoris alpestris rubea

Lark, Scorched Horned, Otocoris alpestris adusta

Lark, Sonora Horned, Otocoris alpestris pallida

Lark, Streaked Horned, Otocoris alpestris strigata

Lark, Texas Horned, Otocoris alpestris giraudi

Limpkin, Aramus vociferus

Longspur, Alaska, Calcarius lapponicus alascensis

Longspur, Chestnut-collared, Calcarius ornatus

Longspur, Lapland, Calcarius lapponicus lapponicus
Longspur, McCown's, Rhynchophanes mccowni

Longspur, Smith's, Calcarius pictus

Loon, Gavia immer

Loon, Black-throated, Gavia arctica

Loon, Pacific, Gavia pacifica

Loon, Red-throated, Gavia stellata

Loon, Yellow-billed, Gavia adamsi

Magpie, Pica pica hudsonia

Magpie, Yellow-billed, Pica nuttalli

Mallard, Anas platyrhynchos

Man-o'war-bird, Fregata aquila

Martin, Cuban, Progne cryptoleuca

Martin, European, Chelidonaria urbica

Martin, Gray-breasted, Progne chalybea

Martin, Purple, Progne subis subis

Martin, Western, Progne subis hesperia

Meadowlark, Sturnella magna magna

Meadowlark, Rio Grande, Sturnella magna hoopesi

Meadowlark, Southern, Sturnella magna argutula

Meadowlark, Western, Sturnella neglecta

Merganser, Mergus americanus

Merganser, Hooded, Lophodytes cucullatus

Merganser, Red-breasted, Mergus serrator

Merlin, Falco asalon

Mockingbird, Mimus polyglottos polyglottos

Mockingbird, Western, Mimus polyglottos leucopterus

Murre, Uria troille troille

Murre, Brünnich's, Uria lomvia lomvia

Murre, California, Uria troille californica

Murre, Pallas's, Uria lomvia arra

Murrelet, Ancient, Synthliboramphus antiquus

Murrelet, Craveri's, Brachyramphus craverii

Murrelet, Kittlitz's, Brachyramphus brevirostris

Murrelet, Marbled, Brachyramphus marmoratus

Murrelet, Xantus's, Brachyramphus hypoleucus

Nighthawk, Chordeiles virginianus virginianus

Nighthawk, Florida, Chordeiles virginianus chapmani

Nighthawk, Pacific, Chordeiles virginianus hesperis

Nighthawk, San Lucas, Chordeiles acutipennis inferior

Nighthawk, Sennett's, Chordeiles virginianus sennetti

Nighthawk, Texas, Chordeiles acutipennis texensis

Nighthawk, Western, Chordeiles virginianus henryi

Noddy, Anoüs stolidus 
Nutcracker, Clarke's, Nucifraga columbiana

Nuthatch, Brown-headed, Sitta pusilla

Nuthatch, Florida White-breasted, Sitta carolinensis atkinsi

Nuthatch, Pygmy, Sitta pygmæa pygmoa

Nuthatch, Red-breasted, Sitta canadensis

Nuthatch, Rocky Mountain, Sitta carolinensis, nelsoni

Nuthatch, Slender-billed, Sitta carolinensis aculeata

Nuthatch, San Lucas, Sitta carolinensis lagunæ

Nuthatch, White-breasted, Sitta carolinensis carolinensis

Nuthatch, White-naped, Sitta pygmæa leuconucha

Old-squaw, Clangula hyemalis

Oriole, Arizona Hooded, Icterus cucullatus nelsoni

Oriole, Audubon's, Icterus melanocephalus auduboni

Oriole, Baltimore, Icterus galbula

Oriole, Bullock's, Icterus bullocki

Oriole, Orchard, Icterus spurius

Oriole, Scott's, Icterus parisorum

Oriole, Sennett's, Icterus cucullatus sennetti

Osprey, Pandion haliaētus carolinensis

Oven-bird, Seiurus aurocapillus

Owl, Aiken's Screech, Otus asio aikeni

Owl, Arctic Horned, Bubo virginianus subarcticus

Owl, American Barn, Tyto pratincola

Owl, Arizona Spotted, Strix occidentalis lucida

Owl, Barred, Strix varia varia

Owl, Brewster's Screech, Otus asio brewsteri

Owl, Burrowing, Speotyto cunicularia hypogæa

Owl, California Pygmy, Glaucidium gnoma californicum

Owl, California Screech, Otus asio bendirei

Owl, Coast Horned, Bubo virginianus icleus

Owl, Coast Pygmy, Glaucidium gnoma grinnelli

Owl, Dusky Horned, Bubo virginianus saturatus

Owl, Dwarf Horned, Bubo virginianus elachistus

Owl, Elf, Micropallas whitneyi

Owl, European Hawk, Surnia ulula ulula

Owl, Ferruginous Pygmy, Glaucidium phalcenoides

Owl, Flammulated Screech, Otus flammeolus

Owl, Florida Barred, Strix varia alleni

Owl, Florida Burrowing, Speotyto floridana
Owl, Florida Screech, Otus asio floridanus

Owl, Great Gray, Scotiaptex nebulosa nebulosa

Owl, Great Horned, Bubo virginianus virginianus

Owl, Hasbrouk's Screech, Otus asio hasbrouki

Owl, Hawk, Surnia ulula caparoch

Owl, Hoskins's Pygmy, Glaucidium hoskinsi

Owl, Island Saw-whet, Cryptoglaux acadica brooksi

Owl, Kennicott's Screech, Otus asio kennicotti

Owl, Labrador Horned, Bubo virginianus heterocnemis

Owl, Lapp, Scotiaptex nebulosa lapponica

Owl, Long-eared, Asio wilsonianus

Owl, MacFarlane's Screech, Otus asio macfarlanei

Owl, Mexican Screech, Otus asio cineraceus

Owl, Newfoundland Horned, Bubo virginianus neochorus

Owl, Northwestern Horned, Bubo virginianus lagophonus

Owl, Pacific Horned, Bubo virginianus pacificus

Owl, Pasadena Screech, Otus asio quercinus

Owl, Pale Horned, Bubo virginianus occidentalis

Owl, Pygmy, Glaucidium gnoma pinicola

Owl, Richardson's, Cryptoglaux funerea richardsoni

Owl, Rocky Mountain Screech, Otus asio maxwellix

Owl, Sahuaro Screech, Otus asio gilmani

Owl, Saint Michael Horned, Bubo virginianus algistus

Owl, Sanford's Elf, Micropallas whituei sanfordi

Owl, Saw-whet, Cryptoglaux acadica acadica

Owl, Screech, Otus asio asio

Owl, Short-eared, Asio flammeus

Owl, Snowy, Nyctea nyctea

Owl, Spotted, Strix occidentalis occidentalis

Owl, Spotted Screech, Otus trichopsis

Owl, Texas Barred, Strix varia nelucola

Owl, Texas Screech, Otus asio mccalli

Owl, Vancouver Pygmy, Glaucidium gnoma swarthi

Owl, Western Horned, Bubo virginianus pallescens

Owl, Xantus's Screech, Otus xantusi

Oyster-catcher, Hæmatopus palliatus

Oyster-catcher, Black, Hæmatopus bachmani

Oyster-catcher, European, Hæmatopus ostralegus

Oyster-catcher, Frazar's, Hæmatopus frazari 
Parauque, Merrill's, Nyctidromus albicollis merrilli

Paroquet, Carolina, Conuropsis carolinensis

Parrot, Thick-billed, Rhynchopsitta pachyrhyncha

Patridge, Alaska Spruce, Canachites canadensis osgoodi

Partridge, Canada Spruce, Canachites canadensis canace

Partridge, Hudsonian Spruce, Canachites canadensis canadensis

Pelican, Brown, Pelecanus occidentalis

Pelican, California Brown, Pelecanus californicus

Pelican, White, Pelecanus erythrorhynchos

Petrel, Ashy, Oceanodroma homochroa

Petrel, Black, Oceanodroma melania

Petrel, Black-capped, Pterodroma hasitata

Petrel, Bulwer's, Bulweria bulweri

Petrel, Forked-tailed, Oceanodroma furcata

Petrel, Guadalupe, Oceanodroma macrodactyla

Petrel, Hawaiian, Oceanodroma castro

Petrel, Leach's, Oceanodroma leucorhoa

Petrel, Least, Halocyptena microsoma

Petrel, Kaeding's, Oceanodroma leucorhoa kaedingi

Petrel, Pintado, Daption capense

Petrel, Scaled, Pterodroma scalaris

Petrel, Socorro, Oceanodroma socorroensis

Petrel, Storm, Hydrobates, pelagicus

Petrel, White-bellied, Fregetta grallaria

Petrel, White-faced, Pelagodroma marina

Petrel, Wilson's, Oceanites oceanicus

Pewee, Large-billed Wood, Myiochanes richardsoni peninsulæ

Pewee, Western Wood, Myiochanes richardsoni richardsoni

Pewee, Wood, Myiochanes virens

Phainopepla, Phainopepla nitens

Phalarope, Northern, Lobipes lobatus

Phalarope, Red, Phalaropus fulicarius

Phalarope, Wilson's, Steganopus tricolor

Phœbe, Sayornis phobe

Phœbe, Black, Sayornis nigricans

Phœbe, Say's, Sayornis sayus

Pigeon, Band-tailed, Columbia fasciata fasciata

Pigeon, Passenger, Ectopistes migratorius

Pigeon, Red-billed, Columba flavirostris

Pigeon, Scaled, Columba squamosa

Pigeon, Viosca's, Columba fasciata vioscæ

Pigeon, White-crowned, Columba leucocephala

Pintail, Dafila acuta tzitzihoa

Pipit, Anthus rubescens

Pipit, Meadow, Anthus pratensis

Pipit, Red-throated, Anthus cervinus

Pipit, Sprague's, Anthus spraguei
Plover, Black-bellied, Squatarola squatarola cynosurae

Plover, European Golden, Pluvialis apricaria

Plover, Golden, Pluvialis dominica dominica

Plover, Little Ringed, Charadrius dubius

Plover, Mongolian, Charadrius mongolus

Plover, Mountain, Podasocys montanus

Plover, Pacific Golden, Pluvialis dominica fulva

Plover, Piping, Charadrius melodus

Plover, Ringed, Charadrius hiaticulus

Plover, Semipalmated, Charadrius semipalmatus

Plover, Snowy, Charadrius nivosus

Plover, Upland, Bartramia longicauda

Plover, Wilson's, Pagolla wilsonia wilsonia

Poor-will, Phalænoptilus nuttalli nuttalli

Poor-will, Dusky, Phalænoptilus nuttalli californicus

Poor-will, Frosted, Phalænoptilus nuttalli nitidus

Ptarmigan, Adak, Lagopus rupestris chamberlaini

Ptarmigan, Alexander's, Lagopus lagopus alexandræ

Ptarmigan, Allen's, Lagopus lagopus alleni

Ptarmigan, Dixon's, Lagopus rupestris dixoni

Ptarmigan, Evermann's, Lagopus evermanni

Ptarmigan, Kenai White-tailed, Lagopus leucurus peninsularis

Ptarmigan, Nelson's, Lagopus rupestris nelsoni

Ptarmigan, Reinhardt's, Lagopus rupestris reinhardi

Ptarmigan, Rock, Lagopus rupestris rupestris

Ptarmigan, Southern White-tailed, Lagopus leucurus altipetens

Ptarmigan, Townsend's, Lagopus rupestris townsendi

Ptarmigan, Turner's, Lagopus rupestris atkensis

Ptarmigan, Ungara, Lagopus lagopus ungavus

Ptarmigan, Welch's, Lagopus welchi

Ptarmigan, White-tailed, Lagopus leucurus leucurus

Ptarmigan, Willow, Lagopus lagopus lagopus

Puffin, Fratercula arctica arctica

Puffin, Horned, Fratercula corniculata

Puffin, Large-billed, Fratercula arctica naumanni

Puffin, Tufted, Lunda, cirrhata

Pyrrhuloxia, Arizona, Pyrrhuloxia sinuata sinuata

Pyrrhuloxia, San Lucas, Pyrrhuloxia sinuata peninsula 
Pyrrhuloxia, Texas, Pyrrhuloxia sinuata texana

Quail, California, Lophortyx californica californica

Quail, Chestnut-bellied Scaled, Callipepla squamata castanogastris

Quail, Gambel's, Lophortyx gambeli

Quail, Colorado Gambel's, Lophortyx gambeli sanus

Quail, Mearns's, Cyrtonyx montezumce mearnsi

Quail, Mountain, Oreortyx picta picta

Quail, Plumed, Oreortyx picta plumifera

Quail, San Pedro, Oreortyx picta confinis

Quail, Arizona Scaled, Callipepla squamata pallida

Quail, Valley, Lophortyx californica vallicola

Quail-dove, Blue-headed, Starnænas cyanocephala

Quail-Dove, Key West, Oreopelia chrysia

Quail-Dove, Ruddy, Oreopelia montana

Rail, Belding's, Rallus beldingi

Rail, Black, Creciscus jamaicensis

Rail,. California Clapper, Rallus obsoletus

Rail, Caribbean Clapper, Rallus longirostris caribous

Rail, Clapper, Rallus crepitans crepitans

Rail, Farallon, Creciscus coturniculus

Rail, Florida Clapper, Rallus crepitans scotti

Rail, King, Rallus elegans

Rail, Louisiana Clapper, Rallus crepitans saturatus

Rail, Light-footed, Rallus levipes

-Rail, Virginia, Rallus virginianus

Rail, Wayne's Clapper, Rallus crepitans waynei

Rail, Yellow, Coturnicops noveboracensis

Raven, Corvus corax sinuatus

Raven, Northern, Corvus corax principalis

Raven, White-necked, Corvus cryptoleucus

Redhead, Marila americana

Redpoll, Acanthis linaria linaria

Redpoll, Greenland, Acanthis hornemanni hornemanni

Redpoll, Greater, Acanthis linaria rostrata

Redpoll, Hoary, Acanthis hornemanni exilipes

Redpoll, Holböll's, Acanthis linaria holboclli

Redstart, Setophaga ruticilla

Redstart, Painted, Setophaga picta

Red-tail, Alaska, Buteo borealis alascensis

Red-tail, Western, Buteo borealis calurus

Red-wing, Bahama, Agelaius phœniceus bryanti

Red-wing, Bicolored, Agelaius gubernator californicus
Red-wing, Florida, Agelaius phoniceus floridanus

Red-wing, Kern, Agelaius phoniceus aciculatus

Red-wing, Nevada, Agelaius phoniceus nevadensis

Red-wing, Northwestern, Agelaius phoniceus caurinus

Red-wing, San Diego, Agelaius phoniceus neutralis

Red-wing, Sonora, Agelaius phcniceus sonoriensis

Red-wing, Thick-billed, Agelaius phoniceus fortis

Red-wing, Tricolored, Agelaius tricolor

Red-wing, Vera Cruz, Agelaius phoniceus richmondi

Road-runner, Geococcyx californianus

Robin, Planesticus migratoriusmigratorius

Robin, San Lucas, Planesticus confinis

Robin, Southern, Planesticus migratorius achrusterus

Robin, Western, Planesticus migratorius propinquus

Rook, Corvus frugilegus

Rough-leg, Ferruginous, Archibuteo ferrugineus

Ruff, Philomachus pugnax

Sanderling, Crocethia alba

Sandpiper, Aleutian, Arquatella maritima couesi

Sandpiper, Baird's, Pisobia bairdi

Sandpiper, Buff-breasted, Tryngites subruficollis

Sandpiper, Curlew, Erolia ferruginea

Sandpiper, Green, Tringa, ocropha

Sandpiper, Least, Pisobia minutilla

Sandpiper, Pectoral, Pisobia maculata

Sandpiper, Pribilof, Arquatella maritima ptilocnemis

Sandpiper, Purple, Arquatella maritima maritima

Sandpiper, Red-backed, Pelidna alpina sakhalina

Sandpiper, Semipalmated, Ereunetes pusillus

Sandpiper, Sharp-tailed, Pisobia acuminata

Sandpiper, Solitary, Tringa solitaria solitaria

Sandpiper, Spoon-bill, Eurynorhynchus pygmeus

Sandpiper, Spotted, Actitis macularius

Sandpiper, Stilt, Micropalama himantopus

Sandpiper, Weatern, Ereunetes mauri

Sandpiper, Western Solitary, Tringa solitaria cinnamomea

Sandpiper, White-rumped, Pisobia fuscicollis

Sandpiper, Wood, Rhyacophilus glareola

Sapsucker, Northern Red-breasted, Sphyrapicus ruber notkensis

Sapsucker, Red-breasted, Sphyrapicus ruber ruber 
Sapsucker, Red-naped, Sphyrapicus varius nuchalis

Sapsucker, Williamson's, Sphyrapicus thyroideus

Sapsucker, Yellow-bellied, Sphyrapicus varius varius

Scoter, Oidemia americana

Scoter, Surf, Oidemia perspicillata

Scoter, Velvet, Oidemia fusca

Scoter, White-winged, Oidemia deglandi deglandi

Seedeater, Sharpe's, Sporophila morelleti sharpei

Shearwater, Allied, Puffinus assimilis

Shearwater, Audubon's, Puffinus lherminieri

Shearwater, Black-tailed, Priofinus cinereus

Shearwater, Black-vented, Puffinus opisthomelas

Shearwater, Cory's, Puffinus borealis

Shearwater, Greater, Puffinus gravis

Shearwater, Manx, Puffinus puffinus

Shearwater, New Zealand, Puffinus bulleri

Shearwater, Pink-footed, Puffinus creatopus

Shearwater, Slender-billed, Puffinus tenuirostris

Shearwater, Sooty, Puffinus griseus

Shearwater, Townsend's, Puffinus auricularis

Shearwater, Wedge-tailed, Puffinus cuneatus

Sheldrake, Ruddy, Casarca ferruginea

Shoveller, Spatula clypeata

Shrike, California, Lanius ludovicianus gambeli

Shrike, Island, Lanius ludovicianus anthonyi

Shrike, Loggerhead, Lanius ludovicianus ludovicianus

Shrike, Migrant, Lanius ludovicianus migrans

Shrike, Northern, Lanius borealis

Shrike, White-rumped, Lanius ludovicianus excubitorides

Siskin, Pine, Spinus pinus

Skimmer, Black, Rynchops nigra

Skua, Catharacta skua

Skylark, Alauda arvensis

Smew, Mergellus albellus

Snipe, European, Gallinago gallinago

Snipe, Great, Gallinago media

Snipe, Wilson's, Gallinago delicata

Solitaire, Townsend's, Myadestes towmsendi

Sora, Porzna carolina

Sparrow, Acadian Sharp-tailed, Passerherbulus nelsoni subvirgatus

Sparrow, Alameda Song, Melospiza melodia pusillula

Sparrow, Aleutian Savannah, Passerculus sandwichensis sandwichensis

Sparrow, Aleutian Song, Melospiza melodia sanaka
Sparrow, Bachman's, Peucæa æstivalis bachmani

Sparrow, Baird's, Ammodramus bairdi

Sparrow, Belding's, Passerculus beldingi

Sparrow, Bell's, Amphispiza belli

Sparrow, Bischoff's, Song, Melospiza melodia insignis

Sparrow, Black-chinned, Spizalla atrogularis

Sparrow, Black-throated, Amphispiza bilineata bilineata

Sparrow, Botteri's, Peucæa botterii

Sparrow, Brewer's, Spizella breweri

Sparrow, Brown's Song, Melospiza melodia rivularis

Sparrow, Bryant's, Passerculus sandwichensis bryanti

Sparrow, California Sage, Amphispiza nevadensis canescens

Sparrow, Cassin's, Peucæa cassini

Sparrow, Chipping, Spizella passerina passerina

Sparrow, Clay-colored, Spizella pallida

Sparrow, Dakota Song, Melospiza melodia juddi

Sparrow, Desert, Amphispiza bilineata deserticola

Sparrow, Desert Song, Melospiza melodia fallax

Sparrow, Dusky Seaside, Passerherbulus nigrescens

Sparrow, Field, Spizella pusilla pusilla

Sparrow, Florida Grasshopper, Ammodramus savannarum floridanus

Sparrow, Forbush's, Melospiza lincolni striata

Sparrow, Fox, Passerella iliaca iliaca

Sparrow, Gambel's, Zonotrichia leucophrys gambeli

Sparrow, Golden-crowned, Zonotrichia coronata

Sparrow, Grasshopper; Ammodramus savannarum australis

Sparrow, Gray Sage, Amphispiza nevadensis cinerea

Sparrow, Harris's, Zonotrichia querula

Sparrow, Heermann's Song, Melospiza melodia heermanni

Sparrow, Henslow's, Passerherbulus henslowi henslowi

Sparrow, Ipswich, Passerculus princeps

Sparrow, Kadiak Fox, Passerella iliaca insularis

Sparrow, Kenai Song, Melospiza melodia kenaiensis

Sparrow, Laguna, Aimophila ruficeps sororia

Sparrow, Large-billed, Passerculus rostratus rostratus

Sparrow, Lark, Chondestes grammacus grammacus

Sparrow, Leconte's, Passerherbulus lecontei

Sparrow, Lincoln's, Melospiza lincolni lincolni 
Sparrow, Louisiana Seaside, Passerherbulus maritimus fisheri

Sparrow, Macgillivray's Seaside, Passerherbulus maritimus macgillivraii

Sparrow, Mendocino Song, Melospiza melodia cleonensis

Sparrow, Merrill's Song, Melospiza melodia merrilli

Sparrow, Mountain Song, Melospiza melodia montana

Sparrow, Nelson's, Passerherbulus nelsoni nelsoni

Sparrow, Nevada Savanna, Passerculus sandwichensis nevadensis

Sparrow, Nuttall's, Zonotrichia leucophrys nuttali

Sparrow, Oregon Vesper, Poocetes gramineus affinis

Sparrow, Pine-woods, Peucæa æstivalis astivalis

Sparrow, Rock, Aimophila ruficeps eremoeca

Sparrow, Rufous-crowned, Aimophila ruficeps ruficeps

Sparrow, Rufous-winged, Aimophila carpalis

Sparrow, Rusty Song, Melospiza melodia morphna

Sparrow, Sage, Amphispiza nevadensis nevadensis

Sparrow, Samuels's Song, Melospiza melodia samuelis

Sparrow, San Benito, Passerculus rostratus sanctorum

Sparrow, San Diego Song, Melospiza melodia cooperi

Sparrow, San Clemente Song, Melospiza melodia clemantæ

Sparrow, San Lucas, Passerculus rostratus guttatus

Sparrow, Santa Barbara Song, Melospiza melodia graminea

Sparrow, Savannah, Passerculus sandwichensis savanna

Sparrow, Scott's, Aimophila ruficeps scotti

Sparrow, Scott's Seaside, Passerherbulus maritimus peninsulæ

Sparrow, Seaside, Passerherbulus maritimus maritimus

Sparrow, Sharp-tailed, Passerherbulus caudacutus

Sparrow, Shumagin Fox, Passerella iliaca unalaschcensis

Sparrow, Slate-colored Fox, Passerella iliaca schistacea

Sparrow, Song, Melospiza melodia melodia

Sparrow, Sooty Fox, Passerella iliaca fuliginosa

Sparrow, Sooty Song, Melospiza melodia rufina

Sparrow, Stephens's Fox, Passerella iliaca stephensi

Sparrow, Suisun Song, Melospiza melodia maxillaris
Sparrow, Swamp, Melospiza georgiana

Sparrow, Texas, Arremonops rufivirgatus

Sparrow, Texas Seaside, Passerherbulus maritimus sennetti

Sparrow, Thick-billed Fox, Passerella iliaca megarhyncha

Sparrow, Townsend's Fox, Passerella iliaca townsendi

Sparrow, Tree, Spizella monticola monticola

Sparrow, Vesper, Poccetes gramineus gramineus

Sparrow, Western Chipping, Spizella passerina arizonæ

Sparrow, Western Field, Spizella pusilla arenacea

Sparrow, Western Grasshopper, Ammodramus savannarum bimaculatus

Sparrow, Western Henslow's, Passerherbulus henslowi occidentalis

Sparrow, Western Lark, Chondestes grammacus strigatus

Sparrow, Western Savannah, Passerculus sandwichensis alaudinus

Sparrow, Western Tree, Spizella monticola ochracea

Sparrow, Western Vesper, Poxcetes gramineus confinis

Sparrow, White-crowned, Zonotrichia leucophrys leucophrys

Sparrow, White-throated, Zonotrichia albicollis

Sparrow, Worthen's, Spizella wortheni

Sparrow, Yakutat Song, Melospiza melodia caurina

Spoonbill, Roseate, Ajaia ajaja

Starling, Sturnus vulgaris

Stilt, Black-necked, Himantopus mexicanus

Stint, Long-toed, Pisobia damacensis

Surf-bird, Aphriza virgata

Swallow, Bahama, Callichelidon cyaneoviridis

Swallow, Bank, Riparia riparia

Swallow, Barn, Hirundo erythrogastra

Swallow, Cliff, Petrochelidon lunifrons lunifrons

Swallow, Coahuila Cliff, Petrochclidon fulva pallida

Swallow, Cuban Cliff, Petrochelidon fulva

Swallow, European, Hirundo rustica

Swallow, Lesser Cliff, Petrochelidon lunifrons tachina

Swallow, Mexican Cliff, Petrochelidon lunifrons melanogastra

Swallow, Northern Violet-green, Tachycineta thalassina lepida

Swallow, Rough-winged, Stelgidopteryx serripennis

Swallow, San Lucas, Tachycine tathalassina brachyptera

Swallow, Tree, Iridoprocne bicolor

Swan, Trumpeter, Cygnus buccinator

Swan, Whistling, Cygnus columbianus

Swan, Whooper, Cygnus cygnus

Swift, Black, Cypseloides niger borealis 
Swift, Chimney, Chætura pelagica

Swift, Vaux's, Chætura vauxi

Swift, White-throated, Aëronautes melanoleucus

Tanager, Cooper's, Piranga rubra cooperi Tanager, Hepatic, Piranga hepatica

Tanager, Scarlet, Piranga erythromelas

Tanager, Summer, Piranga rubra rubra

Tanager, Western, Piranga ludoviciana

Tattler, Wandering, Heteroscelus incanus

Teal, Blue-winged, Querquedula discors

Teal, Cinnamon, Querquedula cyanoptera

Teal, European, Nettion crecca

Teal, Green-winged, Nettion carolinense

Tern, Aleutian, Sterna aleutica

Tern, Arctic, Sterna paradisæa

Tern, Black, Clidonias nigra surinamensis

Tern, Bridled, Sterna anætheta recognita

Tern, Cabot's, Sterna sandvicensis acuflavida

Tern, Caspian, Sterna caspiaimperator

Tern, Common, Sterna hirundo

Tern, Elegant, Sterna elegans

Tern, Forster's, Sterna forsteri

Tern, Gull-billed, Gelochelidon nilotica aranea

Tern, Least, Sterna antillarum

Tern, Roseate, Sterna dougalli

Tern, Royal, Sterna maxima

Tern, Sooty, Sterna fuscata

Tern, Trudeau's, Sterna trudeaui

Tern, White-winged Black, Clidonias leucoptera

Thrasher, Bendire's, Toxostoma bendirei

Thrasher, Brown, Toxostoma rufum

Thrasher, California, Toxostoma redivivum

Thrasher, Crissal, Toxostoma crissale

Thrasher, Curve-billed, Toxostoma curvirostre curvirostre

Thrasher, Desert, Toxostoma lecontei arenicola

Thrasher, Leconte's, Toxostoma lecontei lecontei

Thrasher, Mearns's, Toxostoma cinereum mearnsi

Thrasher, Palmer's, Toxostoma curvirostre palmeri

Thrasher, Sage, Oreoscoptes montanus

Thrasher, San Lucas, Toxostoma cinereum cinereum

Thrasher, Sennett's, Toxostoma longirostre sennetti

Thrush, Alaska Hermit, Hylocichla guttata guttata

Thrush, Audubon's Hermit, Hylocichla guttata auduboni

Thrush, Bicknell's, Hylocichla aliciæ bicknelli

Thrush, Dwarf Hermit, Hylocich!a guttata nana

Thrush, Gray-cheeked, Hylocichla aliciæ alicix
Thrush, Hermit, Hylocichla guttata pallasi

Thrush, Monterey Hermit, Hylocichla guttata slevini

Thrush, Northern Varied, Ixoreus nœvius meruloides

Thrush, Olive-backed, Hylocichla ustulata swainsoni

Thrush, Red-winged, Turdus musicus

Thrush, Russet-backed, Hylocichla ustulata ustulata

Thrush, Sierra Hermit, Hylocichla guttata sequoiensis

Thrush, Varied, Ixoreus novius nœvius

Thrush, Willow, Hylocichla fuscescens salicicola

Thrush, Wood, Hylocichla mustelina

Titmouse, Ashy, Bæolophus inornatus cineraceus

Titmouse, Black-crested, Bæolophus atricristatus atricristatus

Titmouse, Bridled, Bæolophus wollweberi

Titmouse; Gray, Bæolophus inornatus griseus

Titmouse, Plain, Bæolophus inornatus inornatus

Titmouse, Sennett's, Bæolophus atricristatus sennetti

Titmouse, Tufted, Bæolophus bicolor

Towhee, Pipilo erythrophthalmus erythrophthalmus

Towhee, Abert's, Pipilo aberti

Towhee, Alabama, Pipilo erythrophthalmus canaster

Towhee, Anthony's, Pipilo crissalis senicula

Towhee, Arctic, Pipilo maculatus arcticus

Towhee, California, Pipilo crissalis crissalis

Towhee, Cañon, Pipilo fuscus mesoleucus

Towhee, Green-tailed, Oberholseria

Towhee, Guadalupe, Pipilo consobrinus

Towhee, Large-billed, Pipilo maculatus magnirostris

Towhee, Nevada, Pipilo maculatus curtatus

Towhee, Oregon, Pipilo maculatus oregonus

Towhee, Sacramento, Pipilo maculatus falcinellus

Towhee, San Clemente, Pipilo maculatus clementoe

Towhee, San Diego, Pipilo maculatus megalonyx

Towhee, San Francisco, Pipilo maculatus falcifer

Towhee, San Lucas, Pipilo fuscus albigula

Towhee, Spurred, Pipilo maculatus montanus

Towhee, White-eyed, Pipilo erythrophthalmus alleni 
Tree-duck, Black-bellied, Dendrocygna autumnalis

Tree-duck, Fulvous, Dendrocygna bicolor

Trogon, Coppery-tailed, Trogon ambiguus

Tropic-bird, Red-billed, Phaëthon othereus

Tropic-bird, Red-tailed, Phaëthon rubricaudus

Tropic-bird, Yellow-billed, Phaēthon americanus

Turkey, Florida, Meleagris gallopavo osceola

Turkey, Merriam's, Meleagris gallopavo merriami

Turkey, Rio Grande, Meleagris gallapavo intermedia

Turkey, Wild, Meleagris gallopavo silvestris

Turnstone, Arenaria interpres interpres

Turnstone, Black, Arenaria melanocephala

Turnstone, Ruddy, Arenaria interpres morinella

Veery, Hylocichla fuscescens fuscescens

Verdin, Auriparus flaviceps flaviceps

Verdin, Cape, Auriparus flaviceps lamprocephalus

Vireo, Anthony's, Vireo huttoni obscurus

Vireo, Bell's, Vireo belli belli

Vireo, Black-capped, Vireo atricapillus

Vireo, Black-whiskered, Vireosylva calidris barbatula

Vireo, Blue-headed, Lanivireo solitarius solitarius

Vireo, Bermuda, Vireo griseus bermudianus

Vireo, Cassin's, Lanivireo solitarius cassini

Vireo, Frazar's, Vireo huttoni cognatus

Vireo, Gray, Vireo vicinior

Vireo, Hutton's, Vireo huttoni huttoni

Vireo, Key West, Vireo griseus maynardi

Vireo, Least, Vireo belli pusillus

Vireo, Mountain, Lanivireo solitarius alticola

Vireo, Philadelphia, Vireosylva philadelphia

Vireo, Plumbeous, Lanivireo solitarius plumbeus

Vireo, Red-eyed, Vireosylva olivacea

Vireo, San Lucas, Lanivireo solitarius lucasanus

Vireo, Small White-eyed, Vireo griseus micrus

Vireo, Stephens's, Vireo huttoni stephensi

Vireo, Texas, Vireo belli medius

Vireo, Warbling, Vireosylva gilva gilva

Vireo, Western Warbling, Vireosylva gilva swainsoni

Vireo, White-eyed, Vireo griseus griseus

Vireo, Yellow-green, Vireosylva flavoviridis
Vireo, Yellow-throated, Lanivireo flavifrons

Vulture, Black, Coragyps urubu urubu

Vulture, California, Gymnogyps californianus

Vulture, Turkey, Cathartes aura septentrionalis

Wagtail, Alaska Yellow, Budytes flavus alascensis

Wagtail, Swinhoe's, Matacilla ocularis

Wagtail, White, Motacilla alba

Warbler, Alaska Yellow, Dendroica cestiva rubiginosa

Warbler, Audubon's, Dendroica auduboni auduboni

Warbler, Bachman's, Vermivora bachmani

Warbler, Bay-breasted, Dendroica castanea

Warbler, Black and White, Mniotilta varia

Warbler, Blackburnian, Dendroica fusca

Warbler, Black-fronted, Dendroica auduboni nigrifrons

Warbler, Black-poll, Dendroica striata

Warbler, Black-throated Blue, Dendroica cærulescens cærulescens

Warbler, Black-throated Gray, Dendroica nigrescens

Warbler, Black-throated Green, Dendroica virens

Warbler, Blue-winged, Vermivora pinus

Warbler, Cairns's, Dendroica corulescens cairnsi

Warbler, Calaveras, Vermivora ruficapilla gutturalis

Warbler, California Yellow, Dendroica cestiva brewsteri

Warbler, Canada, Wilsonia canadensis

Warbler, Cape May, Dendroica tigrina

Warbler, Cerulean, Dendroica cerulea

Warbler, Chestnut-sided, Dendroica pensylvanica

Warbler, Connecticut, Oporornis agilis

Warbler, Dusky, Vermivora celata sordida

Warbler, Golden-cheeked, Dendroica chrysoparia

Warbler, Golden Pileolated, Wilsonia pusilla chryseola

Warbler, Golden-winged, Vermivora chrysoptera

Warbler, Grace's, Dendroica gracice

Warbler, Hermit, Dendroica occidentalis

Warbler, Hooded, Wilsonia citrina

Warbler, Hoover's, Dendroica coronata hooveri

Warbler, Kennicott's Willow, Acanthopneuste borealis

Warbler, Kentucky, Oporornis formosus

Warbler, Kirtland's, Dendroica kirtlandi

Warbler, Lucy's, Vermivora lucia

Warbler, Lutescent, Vermivora celata lutescens

Warbler, Macgillivray's, Oporornis tolmiei 
Warbler, Magnolia, Dendroica magnolia

Warbler, Mangrove, Dendroica bryanti casteneiceps

Warbler, Mourning, Oporornis philadelphia

Warbler, Myrtle, Dendroica caronata

Warbler, Nashville, Vermivora ruficapilla ruficapilla

Warbler, Northern Parula, Compsothlypis americana pusilla

Warbler, Olive, Peucedramus olivaceus

Warbler, Orange-crowned, Vermivora celata celata

Warbler, Palm, Dendroica palmarum palmarum

Warbler, Parula, Compsothlypis americana americana

Warbler, Pileolated, Wilsonia pusilla pileolata

Warbler, Pine, Dendroica vigorsi

Warbler, Prairie, Dendroica discolor

Warbler, Prothonotary, Protonotaria citrea

Warbler, Red-faced, Cardellina rubrifrons

Warbler, Sennett's, Compsothlypis pitiayumi nigrilora

Warbler, Sonora Yellow, Dendroica cestiva sonorana

Warbler, Swainson's, Limniothlypis swainsoni

Warbler, Sycamore, Dendroica dominica albilora

Warber, Tennessee, Vermivora peregrina

Warbler, Townsend's, Dendroica townsendi

Warbler, Virginia's, Vermivora virginice

Warbler, Wilson's, Wilsonia pusilla pusilla

Warbler, Worm-eating, Helmitheros vermivorus

Warbler, Yellow, Dendroica œestiva æestiva

Warbler, Yellow Palm, Dendroica palmarum hypochrysea

Warbler, Yellow-throated, Dendroica dominica dominica

Water-Thrush, Seiurus noveboracensis noveboracensis

Water-Thrush, Grinnell's, Seiurus noveboracensis notabilis

Water-Thrush, Louisiana, Seiurus motacilla

Water-Turkey, Anhinga anhinga

Waxwing, Bohemian, Bombycilla garrula

Waxwing, Cedar, Bombycilla cedrorum

Wheatear, Oenanthe ananthe ananthe

Wheatear, Greenland, Oenanthe ananthe leucorhoa

Whimbrel, Numenius phøopus

Whip-poor-will, Antrostomus vociferus vociferus

Whip-poor-will, Stephens's, Antrostomus vociferus macromystax

Widgeon, European, Mareca penelope
Willet, Catoptrophorus semipalmatus semipalmatus

Willet, Western, Catoptrophorus semipalmatus inornatus

Woodcock, Rubicola minor

Woodcock, European, Scolopax rusticola

Woodpecker, Alaska-Three-toed, Picoides americanus fasciatus

Woodpecker, Alpine Three-toed, Picoides americanus dorsalis

Woodpecker, Arctic Three-toed, Picoides arcticus

Woodpecker, Arizona, Dryobates arizonœ

Woodpecker, Ant-eating, Melanerpes formicivorus formicivorus

Woodpecker, Batchelder's, Dryobates pubescens homorus

Woodpecker, Cabanis's, Dryobates villosus hyloscopus

Woodpecker, Cactus, Dryobates scalaris cactophilus

Woodpecker, California, Melanerpes formicivorus bairdi

Woodpecker, Chihuahua, Dryobates villosus icastus

Woodpecker, Downy, Dryobates pubescens medianus

Woodpecker, Florida Pileated, Phloonomus pileatus floridanus

Woodpecker, Gairdner's, Dryobates pubescens gairdneri

Woodpecker, Gila, Centurus uropygialis

Woodpecker, Golden-fronted, Centurus aurifrons

Woodpecker, Hairy, Dryobates villosus villosus

Woodpecker, Harris's, Dryobates villosus harrisi

Woodpecker, Ivory-billed, Campephilus principalis

Woodpecker, Narrow-fronted, Melanerpes formicivorus angustifrons

Woodpecker, Lewis's, Asyndesmus lewisi

Woodpecker, Nelson's Downy, Dryobates pubescens nelsoni

Woodpecker, Newfoundland, Dryobates villosus terrænovæ

Woodpecker, Newfoundland Downy, Dryobates pubescens microleucus

Woodpecker, Northern Hairy, Dryobates vilosus leucomelas

Woodpecker, Northern Pileated, Phøotomus pileatus abieticola

Woodpecker, Nuttall's, Dryobates nuttalli

Woodpecker, Pileated, Phlootomus pileatus pileatus

Woodpecker, Queen Charlotte, Dryobates villosus picoideus

Woodpecker, Red-bellied, Centurus carolinus

Woodpecker, Red-cockaded, Dryobates borealis

Woodpecker, Red-headed, Melanerpes erthrocephalus

Woodpecker, Rocky Mountain Hairy, Dryobates villosus monticola 
Woodpecker, San Fernando, Dryobates scalaris eremicus

Woodpecker, San Lucas, Dryobates scalaris lucasanus

Woodpecker, Sierra, Dryobates villosus orius

Woodpecker, Sitka Hairy, Dryobates villosus sitkensis

Woodpecker, Southern Downy, Dryobates pubescens pubescens

Woodpecker, Southern Hairy, Dryobates villosus auduboni

Woodpecker, Southern White-headed, Xenopicus albolarvatus gravirostris

Woodpecker, Texas, Dryobates scalaris symplectus

Woodpecker, Western Pileated, Phlœotomus pileatus picinus

Woodpecker, Three-toed, Picoides americanus americanus

Woodpecker, Valdez, Dryobates $p u$ bescens glacialis

Woodpecker, White-breasted, Dryobates villosus leucothorictis

Woodpecker, White-headed, Xenopicus albolarvatus albolarvatus

Woodpecker, Willow, Dryobates pubescens turati

Wren, Alaska, Nannus alascensis

Wren, Aleutian, Nannus meliger

Wren, Baird's, Thryomanes bewicki bairdi

Wren, Bewick's, Thryomanes bewicki bewicki

Wren, Bryant's Cactus, Heleodytes brunneicapillus bryanti

Wren, Cactus, Heleodytes brunneicapillus couesi

Wren, Cañon, Catherpes mexicanus conspersus

Wren, Carolina, Thryothorus ludovicianus ludovicianus

Wren, Dotted Cañon, Catherpes mexicanus punctulatus

Wren, Florida, Thryothorus ludovicianus miamensis

Wren, Guadalupe, Thryomanes brevicauda

Wren, Guadalupe Rock, Salpinctes guadeloupensis

Wren, House, Troglodytes aēdon aēdon

Wren, Kodiak Winter, Nannus hiemalis helleri

Wren, Lomita, Thryothorus ludovicianus lomitensis

Wren, Long-billed Marsh, Telmatodytes palustris palustris

Wren, Marian's Marsh, Telmatodytes palustris marianx

Wren, Prairie Marsh, Telmatodytes palustris iliacus
Wren, Rock, Salpinctes obsoletus obsoletus

Wren, San Clemente, Thryomanes leucophrys

Wren, San Diego, Thryomanes bewicki charienturus

Wren, San Lucas Cactus, Heleodytes brunneicapillus affinis

Wren, San Martin Rock, Salpinctes obsoletus proximus

Wren, Seattle, Thryomanes bewicki calophonus

Wren, San Nicolas Rock, Salpinctes obsoletus pulverius

Wren, Short-billed Marsh, Cistothorus stellaris

Wren, Texas, Thryomanes bewicki cryptus

Wren, Tule, Telmatodytes palustris paludicola

Wren, Vigors's, Thryomanes bewicki spilurus

Wren, Western House, Troglodytes aëdon parkmani.

Wren, Western Marsh, Telmatodytes palustris plesius

Wren, Western Winter, Nannus hiemalis pacificus

Wren, White-throated, Catherpes mexicanus albifrons

Wren, Winter, Nannus hiemalis hiemalis

Wren, Worthington's Marsh, Telmatodytes palustris griseus

Wren-Tit, Chamœa fasciata fasciata

Wren-Tit, Coast, Chamoea fasciata phoea

Wren-Tit, Pallid, Chamæa fasciata henshawi

Wren-Tit, Ruddy, Chamæa fasciata rufula

Yellow-legs, Totanus flavipes

Yellow-legs, Greater, Totanus melanoleucus

Yellow-throat, Belding's, Geothlypis beldingi

Yellow-throat, Florida, Geothlypis trichas ignota

Yellow-throat, Maryland, Geothlypis trichas trichas

Yellow-throat, Northern, Geothlypis trichas brachydactila

Yellow-throat, Pacific, Geothlypis trichas arizela

Yellow-throat, Rio Grande, Chamæthlypis poliocephala

Yellow-throat, Salt Marsh, Geothlypis trichas sinuosa

Yellow-throat, Tule, Geothlypis trichas scirpicola

Yellow-throat, Western, Geothlypis trichas occidentalis 


\section{INDEX TO AUTHORS AND LOCALITIES}

Adams, C. C., 45

Administration of Wild Life, 45

Agriculture, Importance to, 13

Alabama, 440

Alaska, 141

Alaskan National Forests, 147

Alberta, 253

Amazon Valley, 674

Anderson, W. A., Jr., 349

Anthony, H. E., 662

Aquatic Preserves, 11

Arctic Islands, 98, 115

Arizona, 562

Arkansas, 464

Art, Value to, 7

Ashe, W. W., 10

Bahamas, 682

Baker, F. C., 27, 38

Baker, F. S., 224

Baker, H. B., 637, 707

Bates, C. G., 237

Beebe, W., 649

Bermuda, 681

Bibliography, 81

Biology, Importance to, 13

Biota, Descriptive List, 60

Biota of Middle America, 77

Biota of the Americas, 57

Birds, Relation to Vegetation, 31

Braun, E. Lucy, 20, 354

Bray, W. E., 332

British Columbia, 150

British Honduras, 600

Britton, N. L., 700

Bryant, H. C., 193

Buchholz, J. T., 464

Burns, G. P., 316

Burill, A. C., 485

Cahn, A. R., 502

California, 193

Caverhill, P. Z., 150

Claridge, B. E., 299

Colombia, 623

Colorado, 524
Connecticut, 326

Connell, A. B., 253, 263

Conservation, Duty to, 52

Costa Rica, 607

Cuba, 682

Davidson, J., 150

Delaware, 398

Dexter, J. S., 258

Dice, L. R., 60, 168, 377

Dutch West Indies, 707

Dymond, J. R., 288

Ecuador, 662

Ekblaw, W. E., 87, 90, 98, 102, 111

Elrod, M. J., 537

Fires, Relation to Biota, 34

Florida, 427

Forest Laws, 15

Fox, H., 422

Frison, T. H., 469

Frothingham, E. H., 387

Fuller, G. D., 293

Gaige, Helen T., 168, 377

Galapagos Islands, 709

Game Refuges of Pennsylvania, 28

Geography, Importance to, 12

Georgia, 422

Gleason, H. A., 649

Goldman, E. A., 562, 574, 612

Goldsmith, G. W., 460

Graves, H. S., 52

Greenland, Danish, 90

Greenland, Northwest, 87

Griscom, L., 604, 607

Gross, A. O., 305

Guatemala, 596

Guiana, 649

Gunthorp, H., 168

Guthrie, J. D., 147

Haiti, 695

Hamilton, C. C., 401

Harper, R. M., 440 
Harshberger, J. W., 338

Hofmann, J. V., 202

Hoke, Gladys, 454

Honduras, 601

Howe, C. D., 288

Howell, A. H., 440

Hudson Bay, 115

Hutchinson, A. H., 150

Idaho, 249

Illinois, 469

Indiana, 372

Iowa, 480

Jackson, C. F., 314

Jamaica, 698

Jillson, W. R., 349

Johnson, M. S., 440

Jones, F. M., 398

Jones, G. T., 75

Jones, E., 60, 354, 377

Kansas, 515

Kentucky, 349

Kopman, H. H., 460

Korstian, C. F., 17, 19, 33, 557, 560

Labrador, 102

Landscape Architecture, 8

Landscape Aspects, 80

Lane, H. H., 490

Larsen, J. A., 208

Lawrence, W. E., 181

Leon, Brother, 682

Lewis, I. F., 410

Life Zones, 75, 80

Literature, Value to, 7

Locke, S. B., 224

Louisiana, 460

Luginbill, P., 418

McColloch, J. W., 515

McFarland, F. T., 349

McLean, F. T., 709

Mackay, A. H., 303

Mackenzie Watershed, 115

Maddox, R. S., 347

Maine, 305

Makiling, Mt., 709

Management of Natural Areas, 42

Manitoba, 263

Marie-Victorin, Brother, 293

Maryland, 401
Massachusetts, 318

Metcalf, Z. P., 413

Mexico, 574

Michigan, 377

Middleton, A. R., 349

Miller, R. B., 14, 469

Minnesota, 267

Mississippi, 454

Missouri, 485

Montana, 537

Munger, T. T., 181

Munns, E. N., 216

Museums and Nature, 27

Muttkowski, R. A., 249

National Forests:

Alaska, 147

California, 216

Eastern District, 387

Grazing in, 33

Intermountain District, 224

Northern District, 208

North Pacific District, 202

Rocky Mountain District, 237

Southwestern District, 232

National Monuments, 20

National Parks, 20, 45

National Regions, 83, 87

Nebraska, 519

Nelson, E. W., 574

Nelson, T. C., 394

Nevada, 560

New Brunswick, 299

Newfoundland, 111

New Hampshire, 314

New Jersey, 394

New Mexico, 570

New York, 332

Nicaragua, 604

Nichols, G. E., 326

Noble, G. K., 695

North Carolina, 413

North Dakota, 544

Norton, A. H., 305

Nova Scotia, 303

Ohio, 354

Oklahoma, 490

Ontario, 288

Oregon, 181

Organizations, List of, 727

Osgood, W. H., 141 
Pammel, L. H., 480

Panama, 612

Pearse, A. S., 11, 284

Pearson, G. A., 232, 562

Pennell, F. W., 623

Pennsylvania, 338

Petry, E. J., 548

Philippine Islands, 709

Phillips, J. M., 28

Pittier, H., 637

Pollution, on Animal Life, 38

Popenoe, W., 596, 662

Porto Rico, 700

Preble, E. A., 115, 150

Preservation in National Forests, 17

Prince Edward Island, 302

Quebec, 293

Ramaley, F., 524

Representatives, List of, 723

Rhode Island, 330

Rigg, G. B., 168

Robbins, W. W., 524

Rosendahl, C. O., 267

Rumsey, W. E., 341

Salvador, 602

Sample Plots in Forests, 19

Santo Domingo, 695

Sarvis, J. T., 544

Saskatchewan, 258

Schmidt, K. P., 600, 601

Scott, J. W., 529

Scott, W., 372

Shelford, V. E., 13, 42, 57, 60, 75, 77, 81, 85

Shreve, Forrest, 77, 562, $69 \mathrm{~S}$

Silviculture of Reserves, 10

Smith, F., 31
South Carolina, 418

South Dakota, 548

Standley, P. C., 602

Starr, Anna M., 318

Switzer, J. E., 544

Tennessee, 347

Texas, 502

Ungava, 102

Utah, 557

Venezuela, 637

Vermont, 316

Virginia, 410

Virgin Islands, 700

Visher, S. S., 12, 548

Vorhies, C. T., 562

Washington, 168

Watson, J. R., 427

Weese, A. O., 570

Wells, B. W., 413

Weston, M. D., 330

West Virginia, 341

Whitcomb, S. L., 7

White, O. E., 674

White, S., 8

Wight, H. M., 181 .

Wisconsin, 284

Wolcott, G. N., 700

Wolcott, R. H., 34, 519

Woodward, K. W., 314

Wyman, L., 460

Wyoming, 529

Yukon Region, 115

Zetek, J., 612 


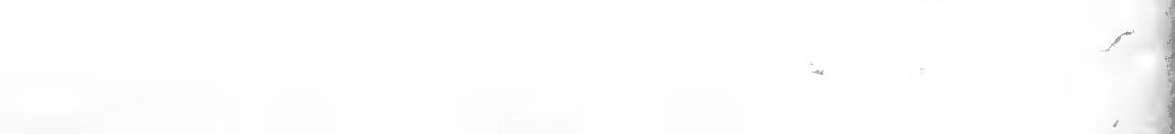




\section{Sans Tache}

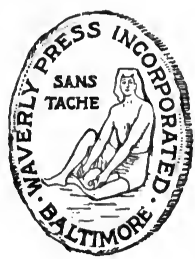




\section{Sans Tache}

T N THE "elder days of art" each artist or craftsman enjoyed the privilege of independent creation. He carried through a process of manufacture from beginning to end. The scribe of the days before the printing press was such a craftsman. So was the printer in the days before the machine process. He stood or fell, as a craftsman, by the merit or demerit of his finished product.

Modern machine production has added much to the worker's productivity and to his material welfare; but it has deprived him of the old creative distinctiveness. His work is merged in the work of the team, and lost sight of as something representing him and his personality.

Many hands and minds contribute to the manufacture of a book, in this day of specialization. There are seven distinct major processes in the making of a book: The type must first be set; by the monotype method, there are two processes, the "keyboarding" of the MS and the casting of the type from the perforated paper rolls thus produced. Formulas and other intricate work must be hand-set; then the whole brought together ("composed") in its true order, made into pages and forms. The results must be checked by proof reading at each stage. Then comes the "make-ready" and press-run and finally the binding into volumes.

All of these processes, except that of binding into cloth or leather covers, are carried on under our roof.

The motto of The Williams \& Wilkins Company is Sans Tache. Our ideal is to publish books "without blemish"-worthy books, worthily printed, with worthy typography-books to which we shall be proud to attach our imprint, made by craftsmen who are willing to accept open responsibility for their work, and who are entitled to credit for creditable performance.

The printing craftsman of today is quite as much a craftsman as his predecessor. There is quite as much discrimination between poor work and good. We are of the opinion that the individuality of the worker should not be wholly lost. The members of our staff who have contributed their skill of hand and brain to this volume are:

Composing Room: Roland Stultz, Andrew Rassa, William Koch, Harry La Motte, John Flanagan, William Fite, Steve Simmons, Ernest Salgado, James Jackson, Harry Harmeyer, Austin Uhland, Edgar Simmons, George Behr, John Crabill, 
Nathan Miller, Charles Shultz, William Sanders, Henry Shea, Edward Rice, George Moss, Theodore Nilson, Frank Witt, Ray Kauffman, James Armiger, Joseph Abrams, Herbert Leitch, Richard King, Anthony Wagner.

Keyboard: Minnie Foard, Harry Susemihl, Helen Twardowicz, Hannah Scott, Katherine Kocent, Anna Kelly, Eleanor Luecke, Vera Taylor.

Proof Room: Sarah Katzin, Alice Reuter, Mary Reed, Ruth Trieschman, Ethel Strasinger, Lucille Bull, Angeline Eifert, Audrey Tanner, Edna Clark, Dorothy Strasinger, Lillian Gilland, Arthur Baker, Geraldine Browne.

Casters: Kenneth Brown, Ernest Wann, Mahlon Robinson, Charles Aher, George Smith, Frank Malanosky, Martin Griffen, Henry Lee, Frederick Wall.

Press: Raymond Bauer, August Hildebrand, Robert Gallagher, Leo Ledlich, Fred Lucker, William Harrison, Jr.

Folder: Laurence Krug. 


\section{WORTH WHILE BOOKS}

METEORS By Charles P. Olivier, Ph.D.

"This is a timely book," says the Journal of the Franklin Institute; "it is the first general treatment of meteoric astronomy since 1871 . . . . The story is completely and succinctly told in an inviting and charming manner. The arrangement permits one to read the non-technical part of the book and omit, without a sense of incompleteness, the well told chapters that contain the mathematical treatment . . . The author has perhaps contributed more to meteoric astronomy than any other living American." $6 \times 9$. Striking cover design. $\$ 6.00$.

\section{DICTIONARY OF BOTANICAL EQUIVALENTS}

By Ernst Artschwager and Edwina M. Smiley

The second edition, revised and enlarged. Now includes French-English, German-English, Dutch-English, Italian-English. Designed for every student and investigator who reads foreign botanical literature. A practical reference volume. Blank pages at the end of each section for addenda. Price $\$ 3.25$.

TREE ANCESTORS By Edward Wilber Berry, Ph.D.

This is a glimpse into the past of our familiar tree stocks. "The reader need not be a botanist nor a biologist to appreciate this treatise," says the Mercury, "but after reading it, he will be a better student and a more enthusiastic disciple of Nature." $6 \times 9.270$ pages. Forty-eight illustrations. Price $\$ 3.00$.

\section{WEATHER PROVERBS AND PARADOXES}

By William J. Humphreys, Ph.D.

"This handbook on weather proverbs and paradoxes by one of the foremost experts on meteorology is invaluable and should be on the library table of every well-read scholar," says Science and Invention. "Get it. Study it and you'll discover an appreciation of Nature in her 'visible forms' that you have never felt before," is the comment of the Mercury. Illustrated. Price $\$ 1.50$.

\section{THE WILLIAMS \& WILKINS COMPANY} Publishers of Scientific Books and Periodicals BALTIMORE, U. S. A. 




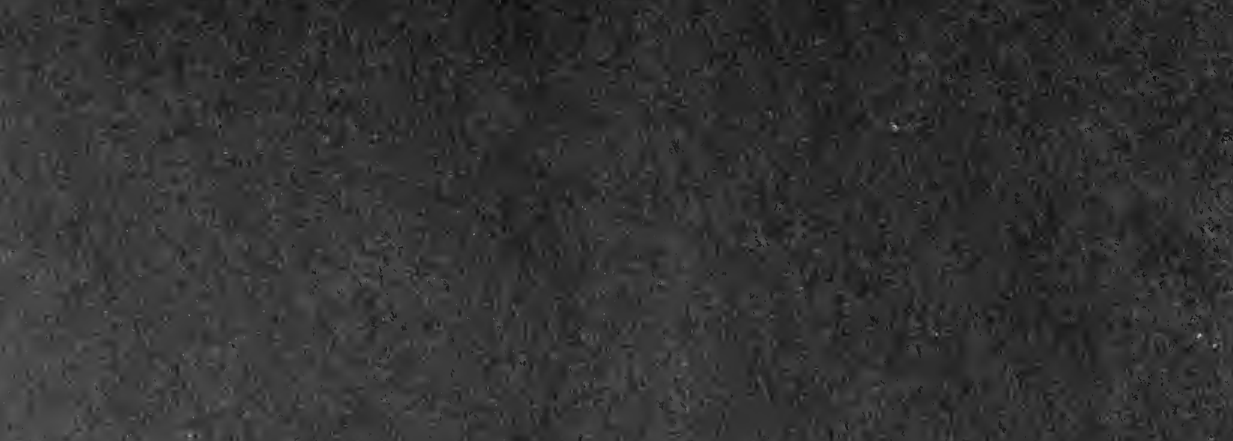

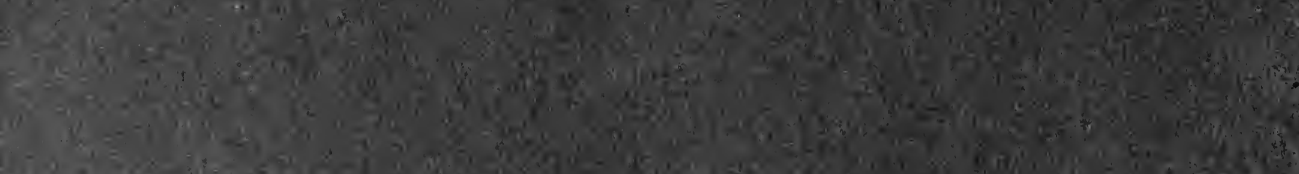

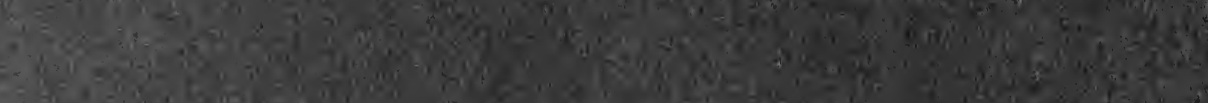

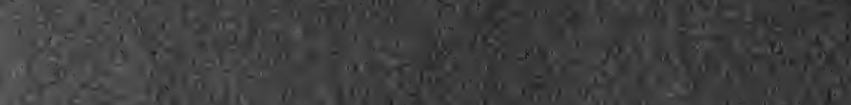
4. $x^{2}+x+2 x$

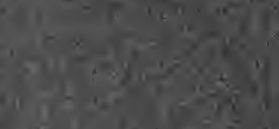

4..

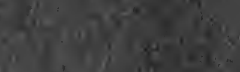

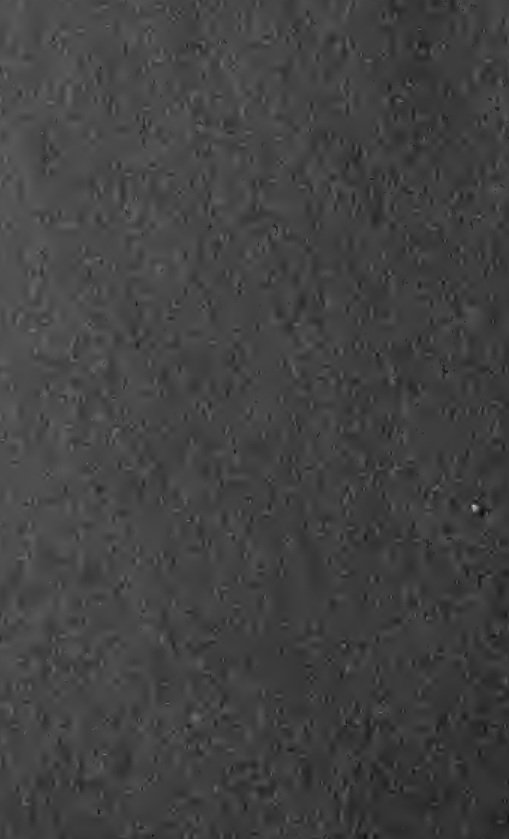

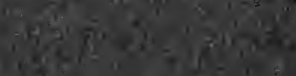




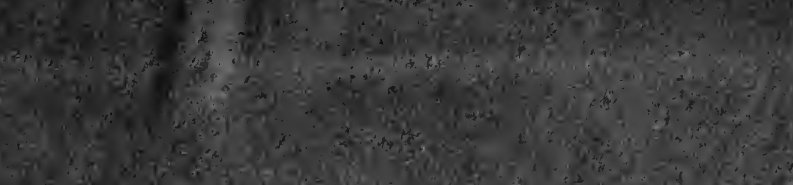

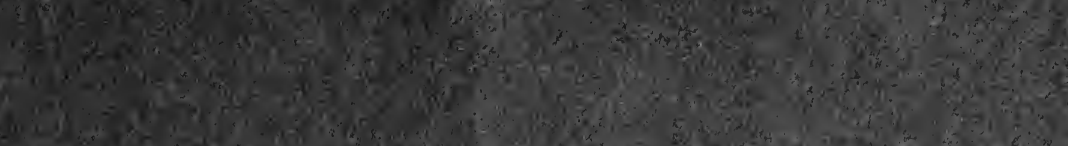
When



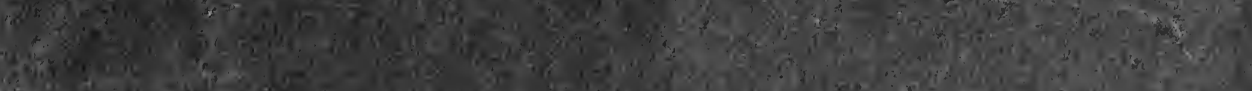

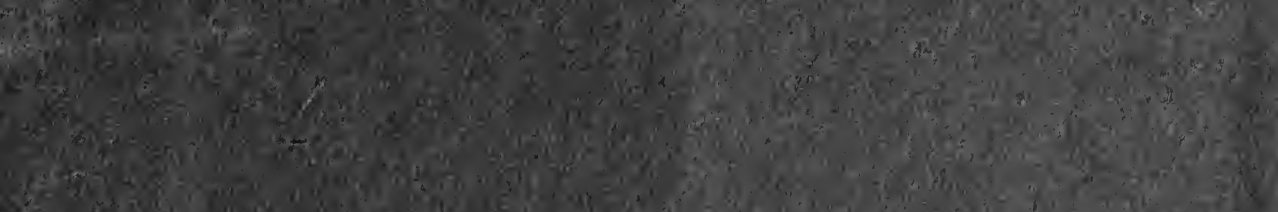

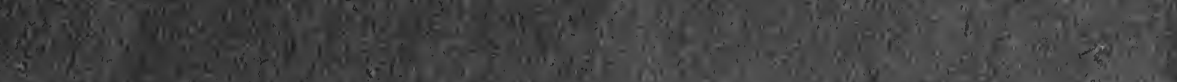
20.

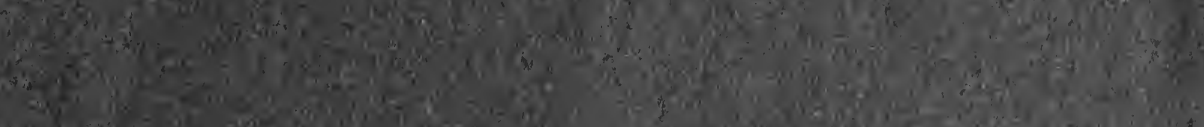

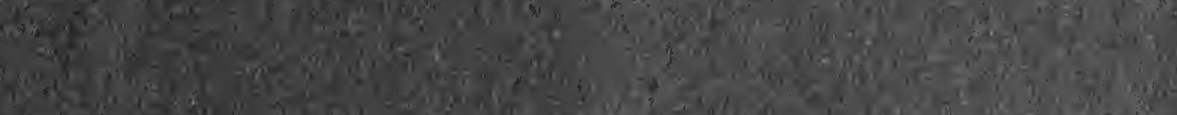
(1) ifiliti

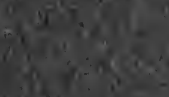

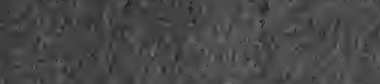
Sin an. if $+8,28$ 7.Ning 1.2. 21

$\tan 2=$

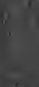
ing:

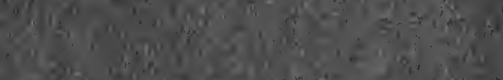
H.

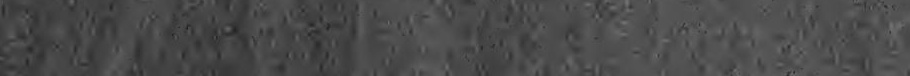

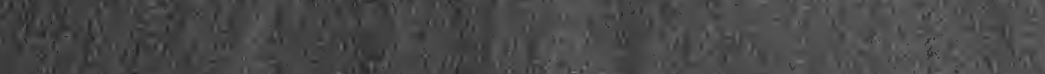

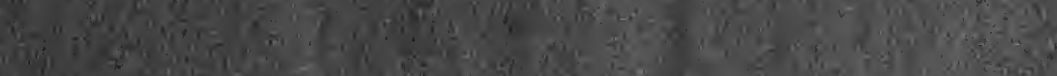
4.

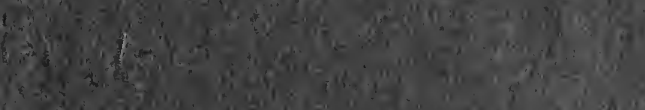

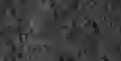
ind $y(x)=$ (5) (c)

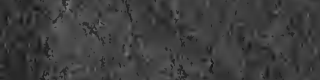
(6)

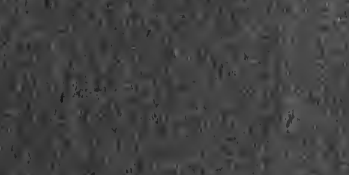

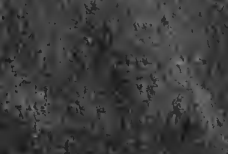




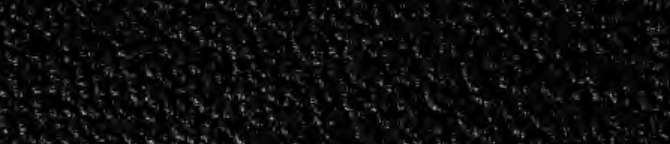

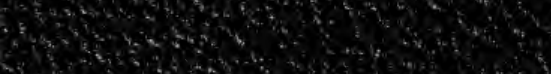

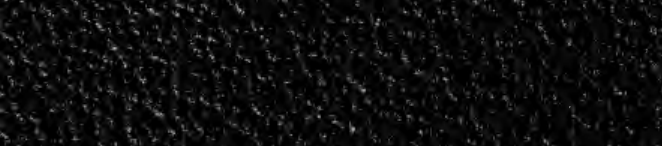

$2 x+3,2+2$

(1)

(5)

(1)

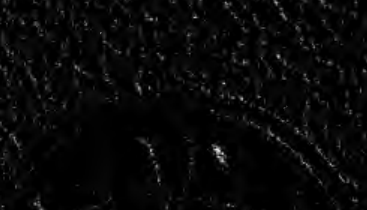

(3)

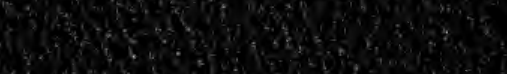

7.n.

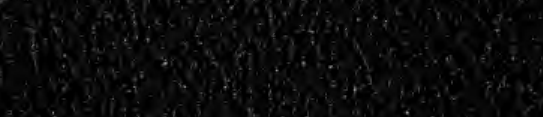

and

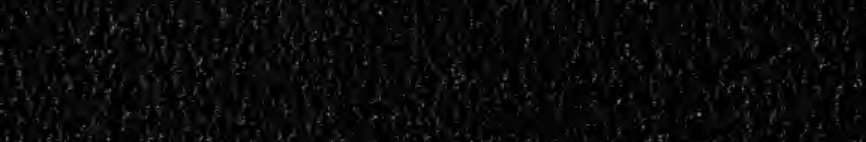

A.

- 